Fall 1998

\title{
1998 Miracle Yearbook
}

Cedarville College

Follow this and additional works at: https://digitalcommons.cedarville.edu/yearbooks

Part of the Higher Education Commons, Organizational Communication Commons, and the Public Relations and Advertising Commons

\section{Recommended Citation}

Cedarville College, "1998 Miracle Yearbook" (1998). Yearbooks. 27.

https://digitalcommons.cedarville.edu/yearbooks/27

This Book is brought to you for free and open access by DigitalCommons@Cedarville, a service of the Centennial Library. It has been accepted for inclusion in Yearbooks by an authorized administrator of DigitalCommons@Cedarville. For more information, please contact digitalcommons@cedarville.edu. 


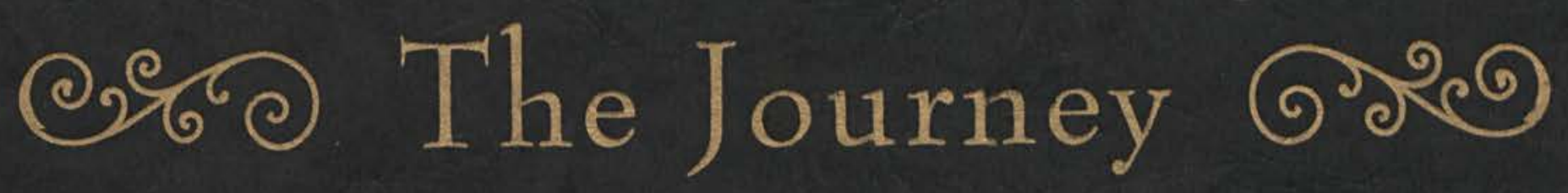

Miracle 1997 


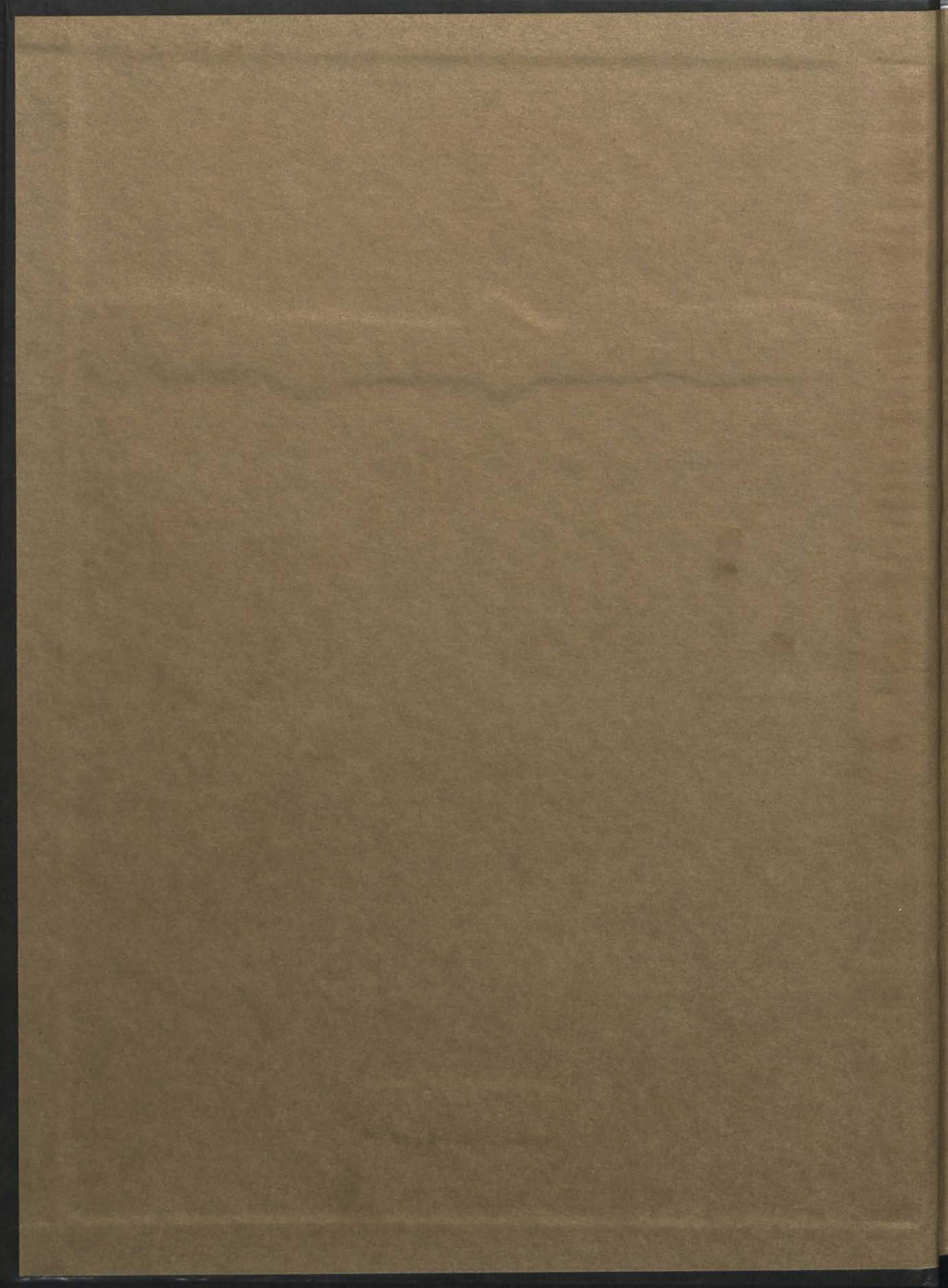





\section{1 is not the practical activities that are the strength of this Bible Training College--its entire strength}

lies in the fact that here you are immersed in the truths of God to soak in them before Him.

You have no idea of where or how God is going to engineer your future circumstances, and no knowledge of what stress and strain is going to be placed on you either at home or abroad. And if you waste your time in overactivity, instead of being immersed in the great fundamental truths of God's redemption, then you will snap when the stress and strain do come. But if this time of soaking before God is being spent in getting rooted and grounded in Him, which may appear to be impractical, then you will remain true to Him whatever happens.

-Oswald Chambers, $M_{y} U_{\text {tmost for }} H_{\text {is }} H_{\text {ighest }}$ 


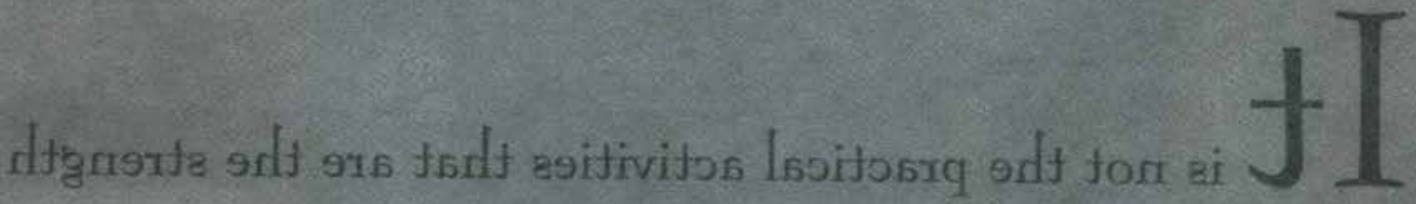

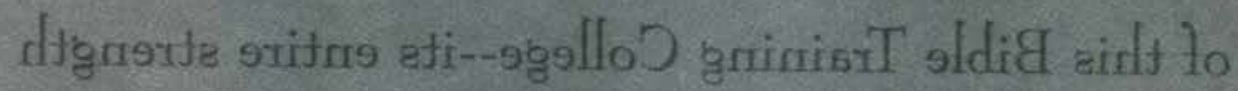

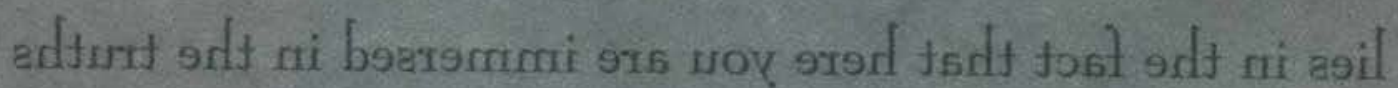
.miH srotod monts ri stsoz of boD to

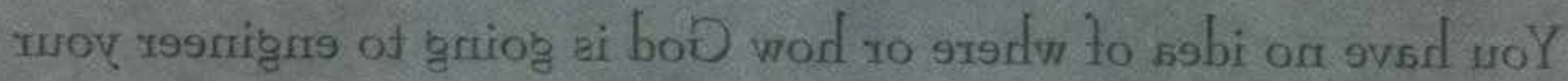

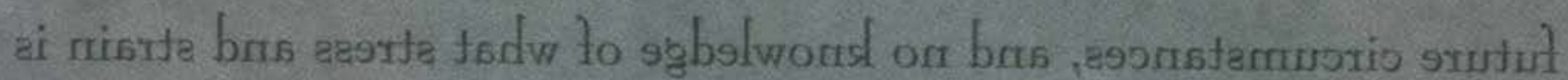
stasw woy ti bra bsords ro gmorl ts renlfis woy no basslq ad of griog

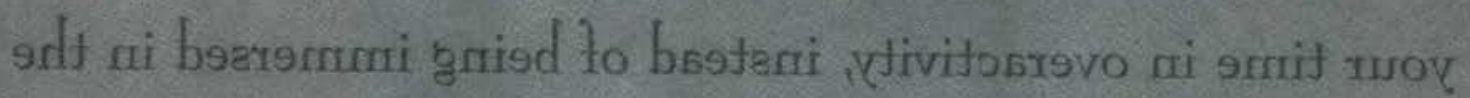

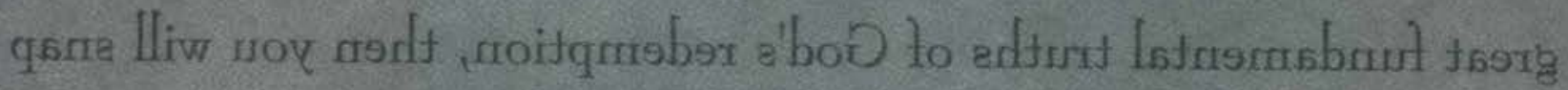

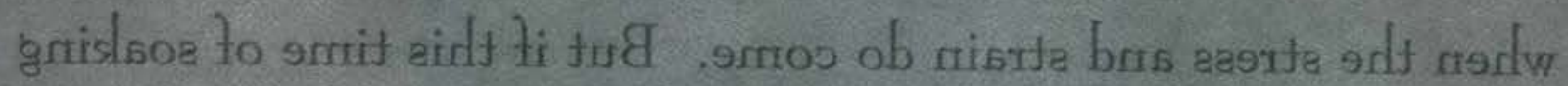

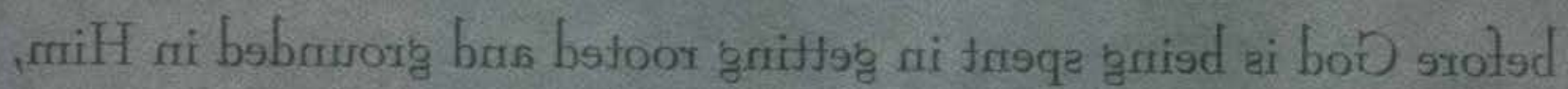

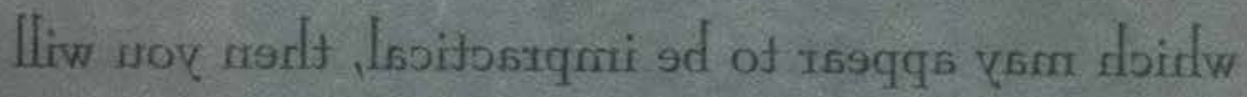

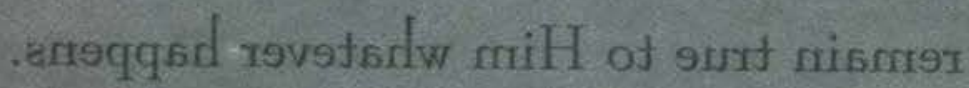

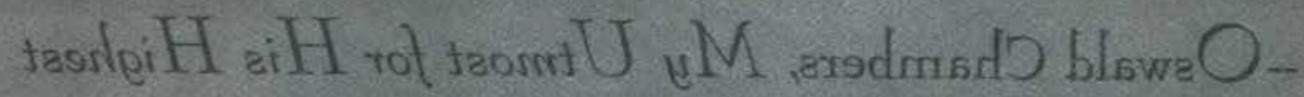




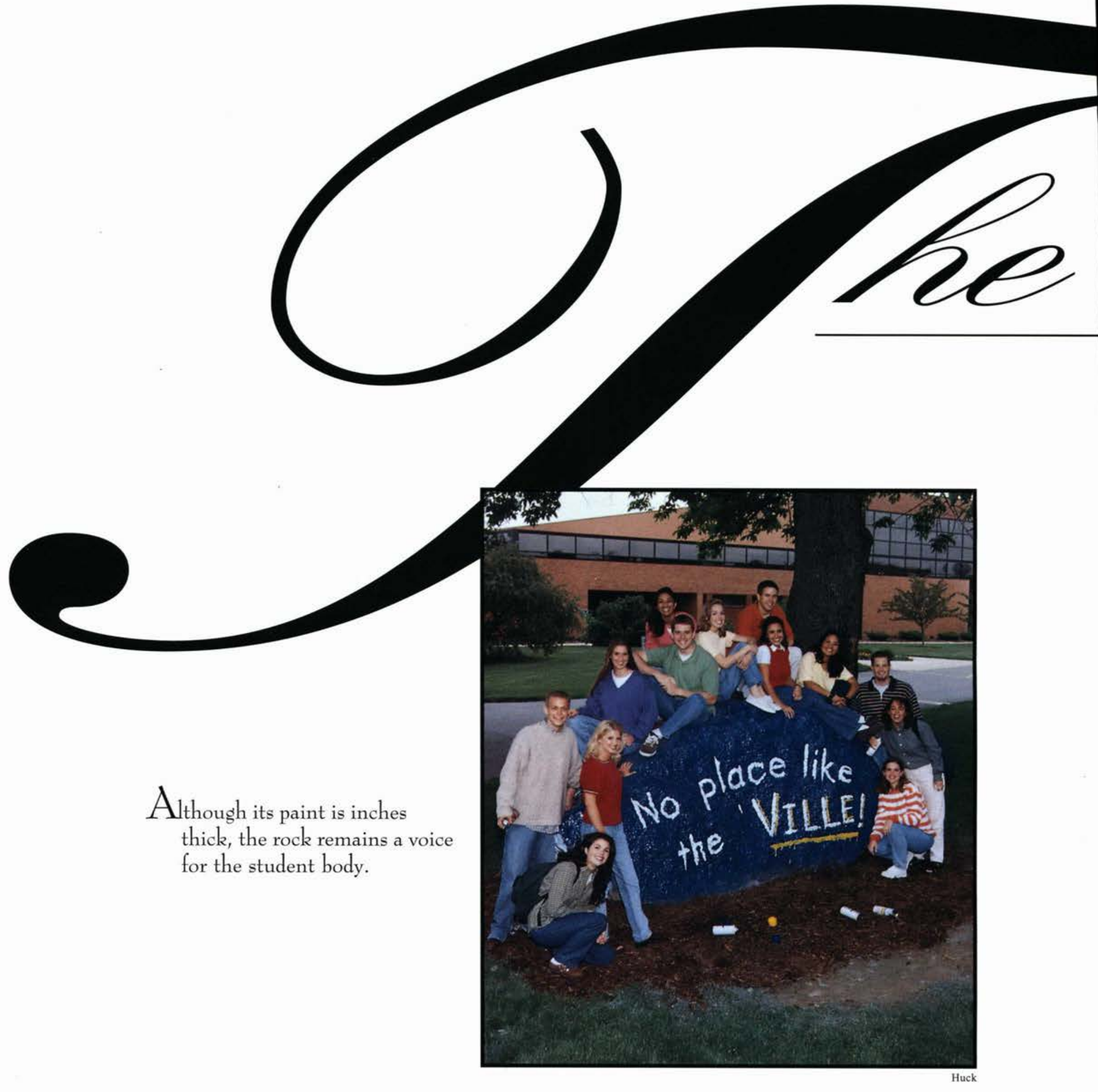

Cedarville College 251 N. Main

Cedarville, OH 45314 



\section{The 19.98}

\section{Cedarville College}

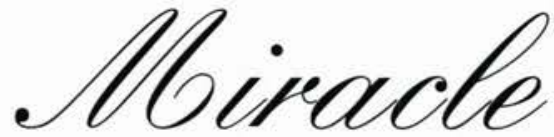

Pilgrim's Progress is an allegory of a venturous journey-a journey as true for us today as it was in 1678 , when John Bunyon dipped his fountain pen to inscribe the tale. The path was and is narrow. The circumstances were and are burdensome. God's Holy Word was and is consistent. And, the destination remains the same: the CelestialCity.

This school year was part of that journey. Whether you were a freshman welcomed by a fuzzy bee, or a senior who walked across the graduation platform, the memories God gave will be sure to encourage you. I trust that through the pages of this book, you will bereminded of this timeless truth-you are on a journey, and in the end you will hear "Well done, good and faithful servant. Enterinto the joy of the Lord." May God bless you.

Chris R. Ashcraft Editor In Chief

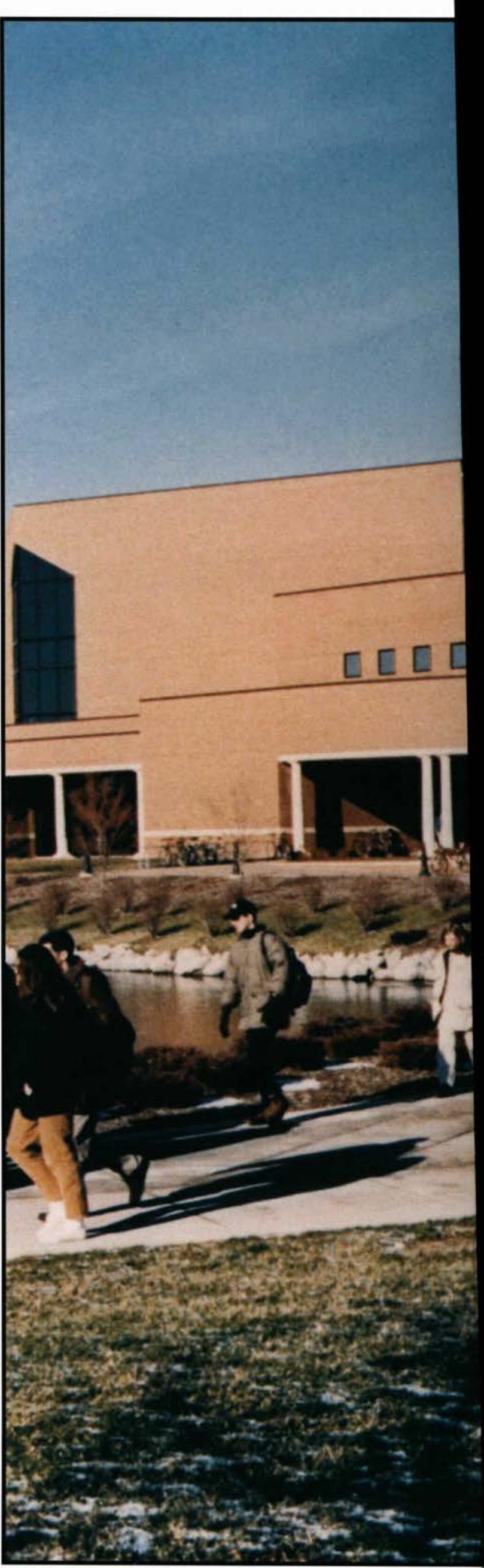




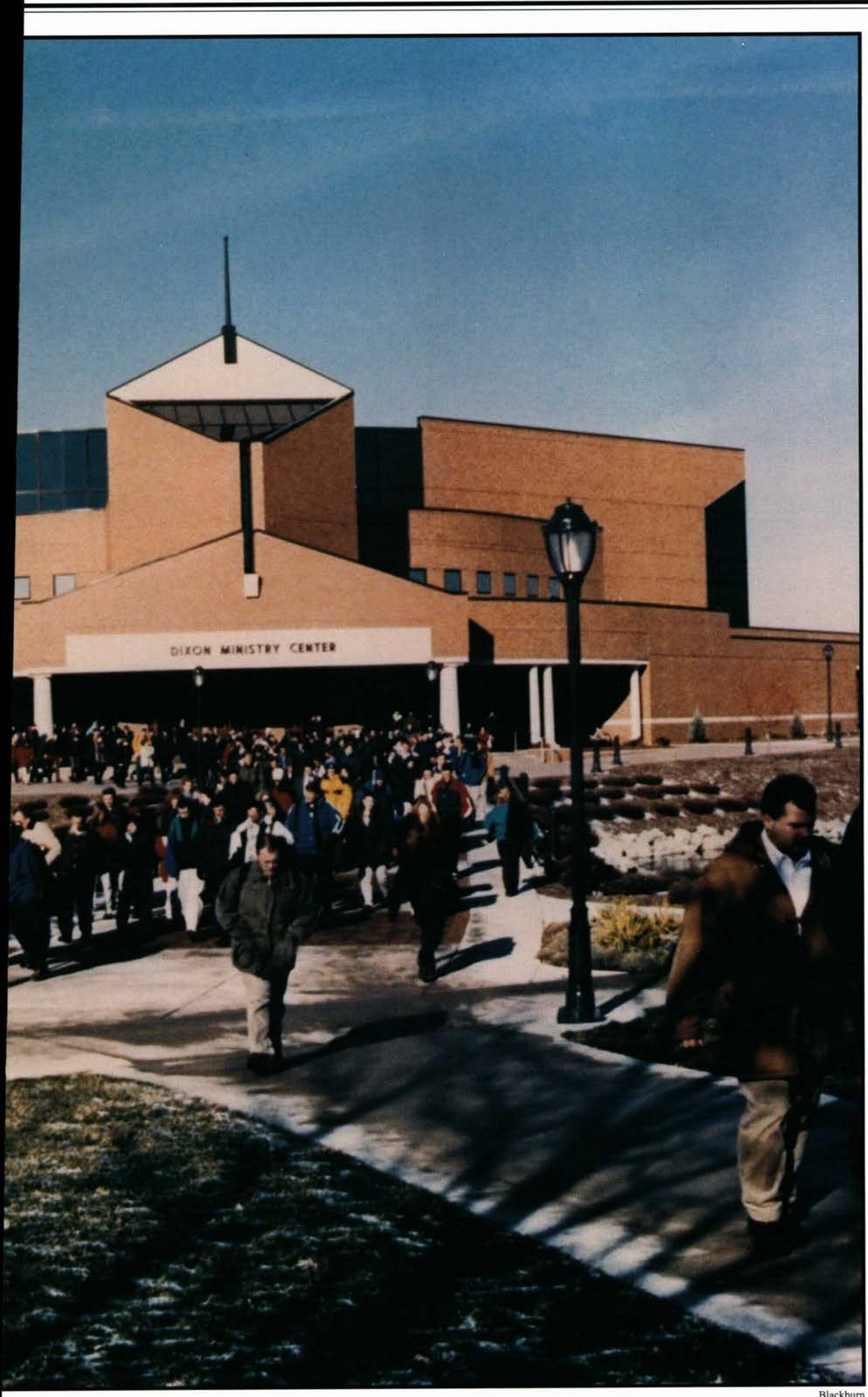

Cedarville College students receive Biblical training on a daily basis through the use of the Jeremiah Chapel. This training is one of many aspects of the College, which prepare students for the Journey. 


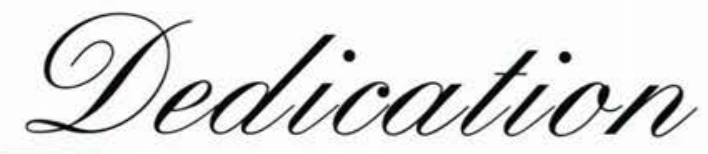

A life of service: Dr. David Drullinger

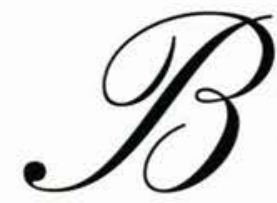

ut as for me, it is good to be near God. Psalm 73:28a (NIV) Known as an avid San Francisco 49ers' fan and a friend of the students, Dr. Drullinger is a familiar face around campus. Described as a man of conviction, Dr. Drullinger exemplifies his life verse Ps. 73:28a in his ministry at Cedarville. This verse is his guiding principle, a "North Star" for his life. It guided him to Cedarville in 1989 , to pursue a ministry in teaching and equipping young men and women to be all they can in Christ as they prepared to go out in their various fields and vocations.

A graduate of Western Baptist College, Dr. Drullinger pursued his Masters Degree at Golden Gate Baptist Seminary and received his Doctor of Ministry Degree from Western Baptist Conservatory in 1980. Before arriving to Cedarville, he taught at Western Baptist College for seven years, served on their board of trustees, and pastored a church in Keizer, OR for seven and a half years.

Dr. Drullinger's arrival at Cedarville shows how God guides people where He wants them to be. Dr. Drullinger had taken a year off the pastorate and felt called back to teaching. He and his wife were in a cabin without the modern conveniences when he received a letter from Cedarville College. He didn't apply for a job, but agreed to visit and has been here ever since.

His ministry at Cedarville has been varied. Teaching is the fo- investment in the future, for he sees each student's "world changing potential." His goal is to help the students have a dynamic relationship with God based on the internal, and his affinity for liberal arts helps him train the students for the future and the ministry they will have in their different areas. He loves

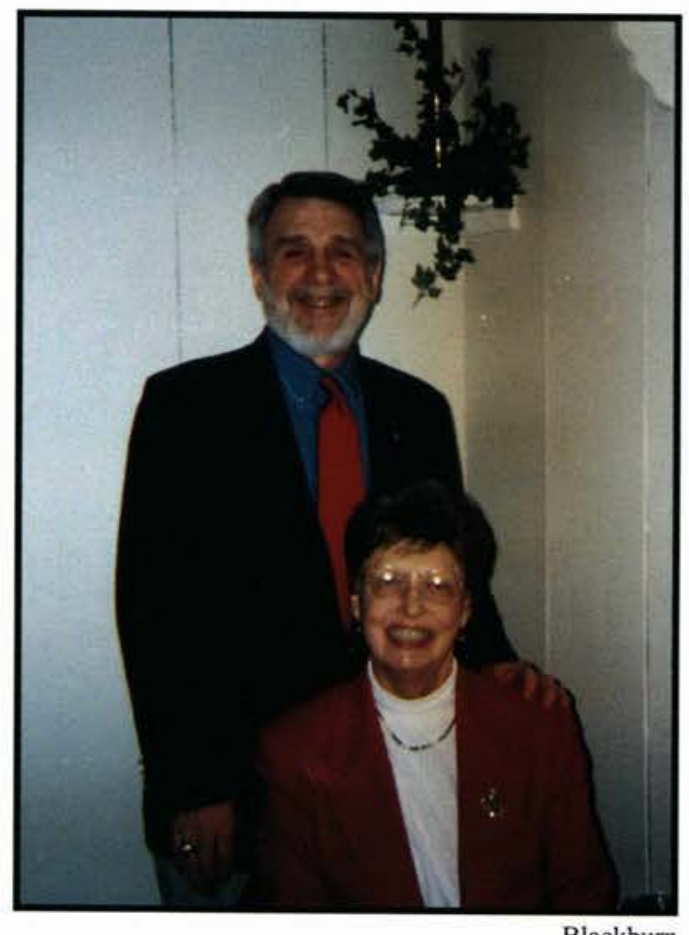

Qr. David Drullinger and his wife, Mrs. Helen Drullinger.

the interaction with the students for they have enthusiasm. He is also a writer of Sunday School curriculum for Radio Bible Press, the spiritual advisor for $\mathrm{CAB}$, pastor at Washington Heights, and conference and chapel organist. In the past year, he has written and recorded a daily program, Minute for the Church, which has been broadcast on eighty radio stations in the United States. He is a friend the lay person and addresses the ch: lenges of living out your faith in $\mathrm{Chr}$ through involvement in the loc church. The program has faithf listeners and has received positi comments from pastors, counselor and even prison inmates.

Dr. Drullinger is described by st dents and faculty as an excelle teacher, one who challenges studen to think and is concerned about st dent needs. His peers describe him a godly man, a man of conviction, y willing to listen. His love for peop is seen around campus. Dr. Jac Riggs, Chairman of the Bible depar ment, says "Dr. Drullinger often use the word 'wonderful' with a sense o emotion and awe to describe some thing. To use his word, I conside him to be a wonderful man of God, a a devoted husband and father, faith ful teacher of truth, and a truste friend."

No article about Dr. Drullinger ca be written without mentioning hi helpmeet. Throughout their 36 yea marriage, Mrs. Drullinger has sup ported Dr. Drullinger's ministry, and has contributed in her own way. During her recent bout with cancer, thein realization of the fragility of life has increased their oneness. It has also strengthened the message of Ps. $73: 28 \mathrm{a}$. In context, some things will not matter, but other things will. As they begin their tenth year of service here in Cedarville, there is nowhere else they would rather be. "We thank God [literally] everyday for bringing us to Cedarville College." 


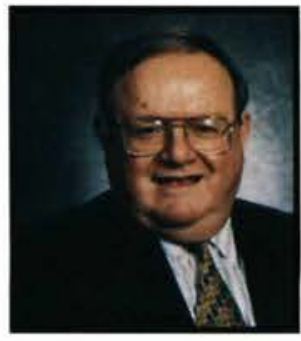

Eugene Apple

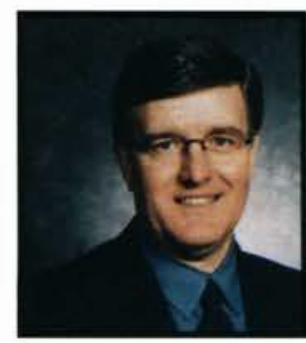

William Bernhard

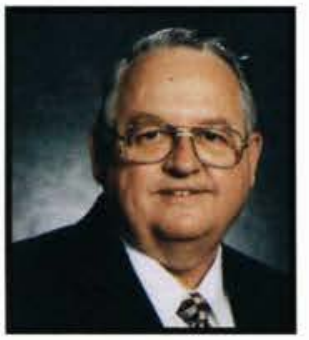

James Carraher

Gilbert Brueckner

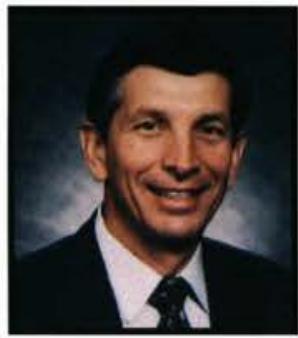

James Engelmann

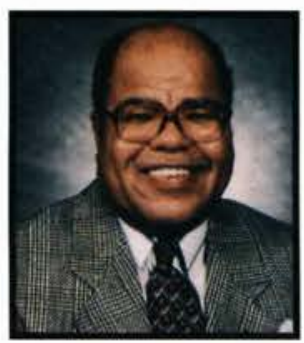

E.L. Hawkins

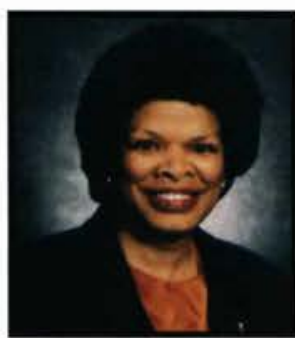

Deforia Lane

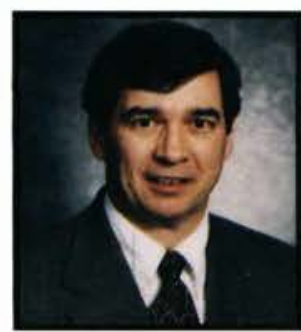

William Rudd

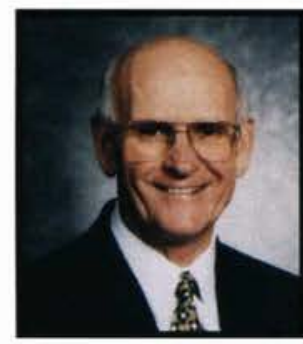

Joseph Godwin

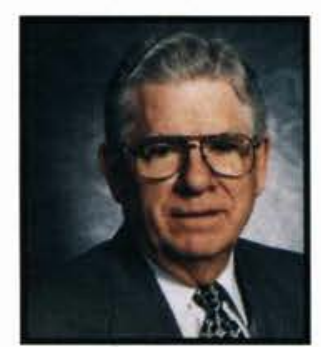

Jack Jacobs

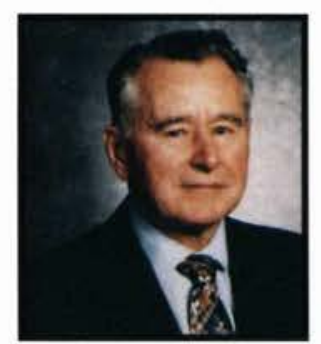

C. Eugene Miller

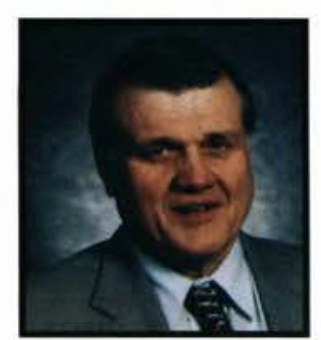

Lorne Scharnberg

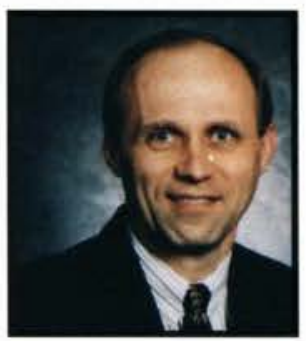

John Blodgett

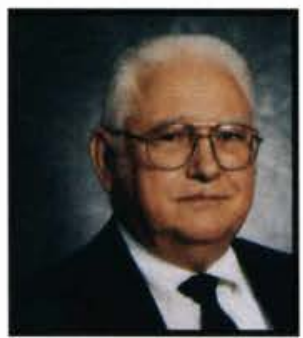

Jack Cline
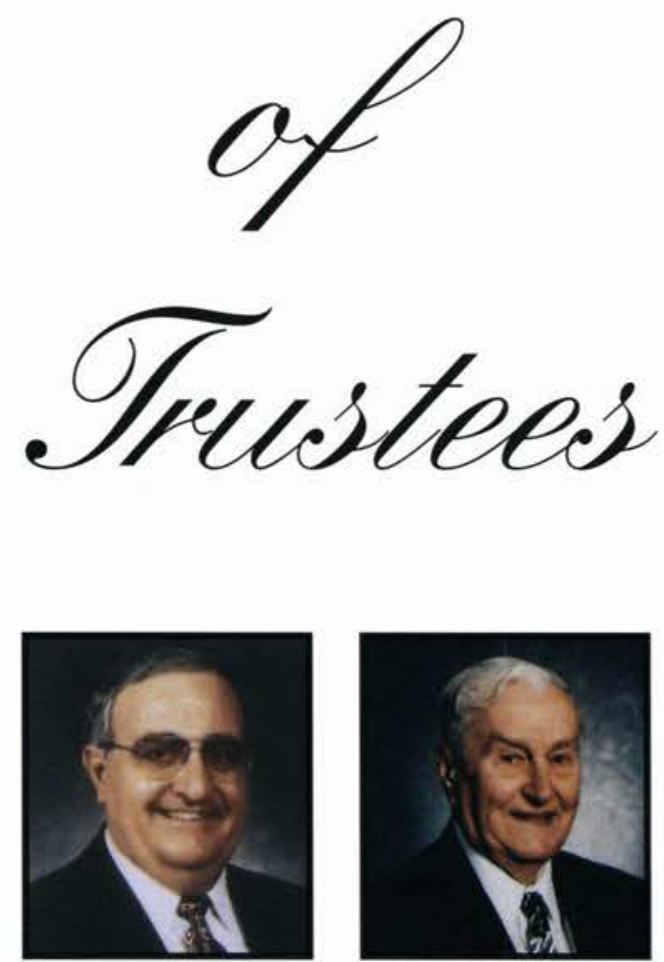

James Misirian

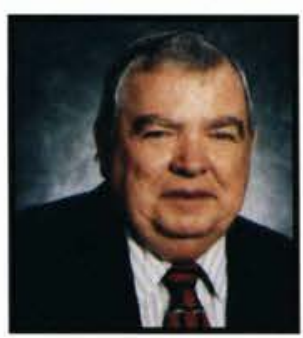

Bill Smith

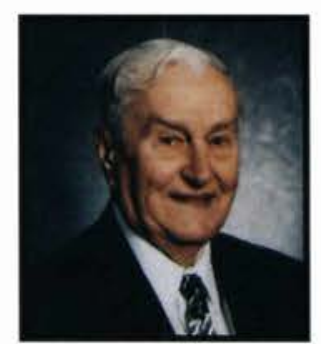

J. Dale Murphy

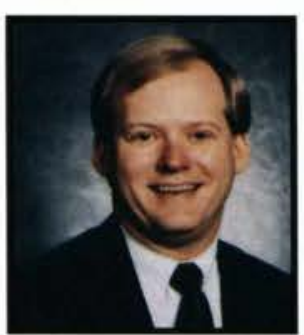

Bruce Sparks

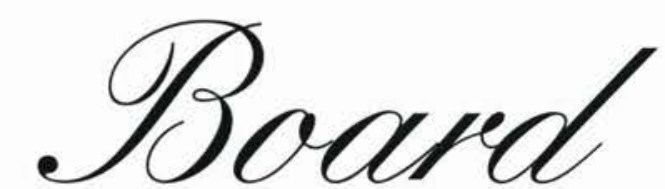

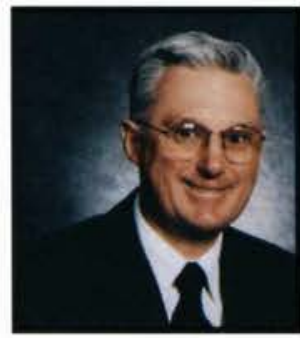

William Bolthouse

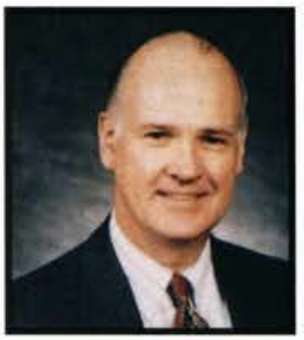

William Commons

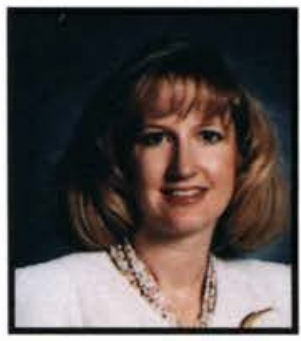

Sherry Bouquet

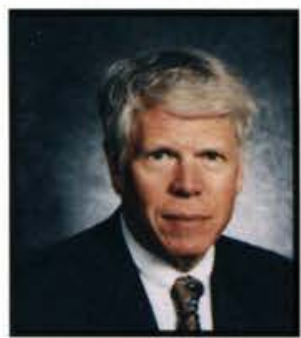

James DeVries

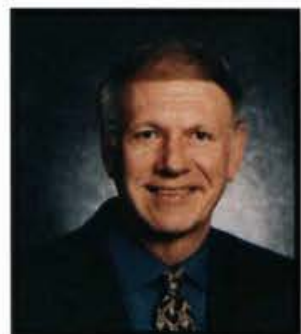

David Graham

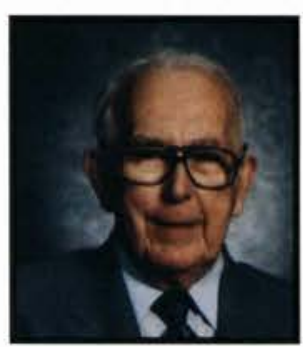

James Jeremiah

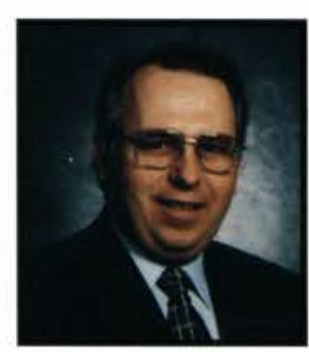

Randy Patten

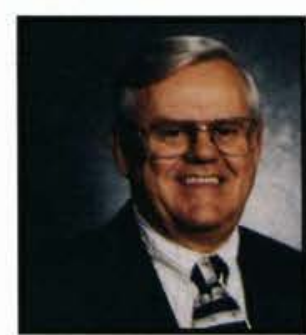

Albert Stevens

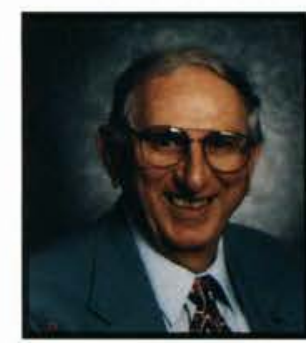

Francis Bresson

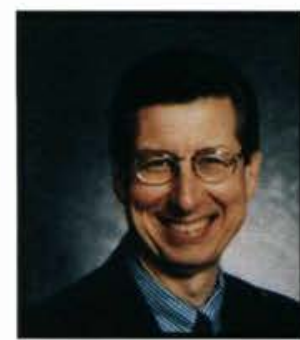

Daryle Doden

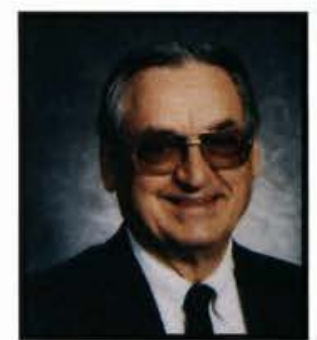

Roy Guenin

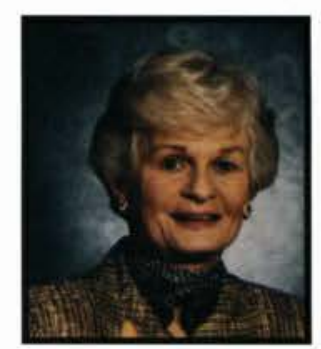

Ruth Kempton

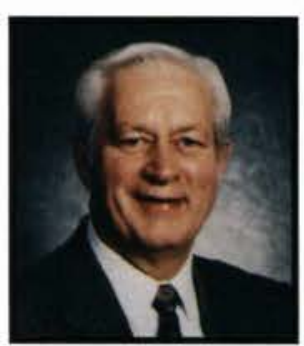

Lynn Rogers

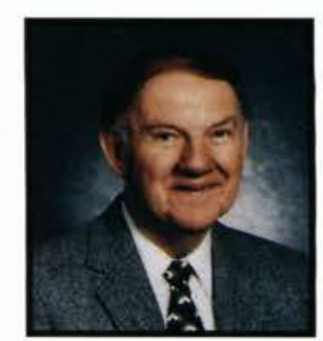

Donald Tyler 

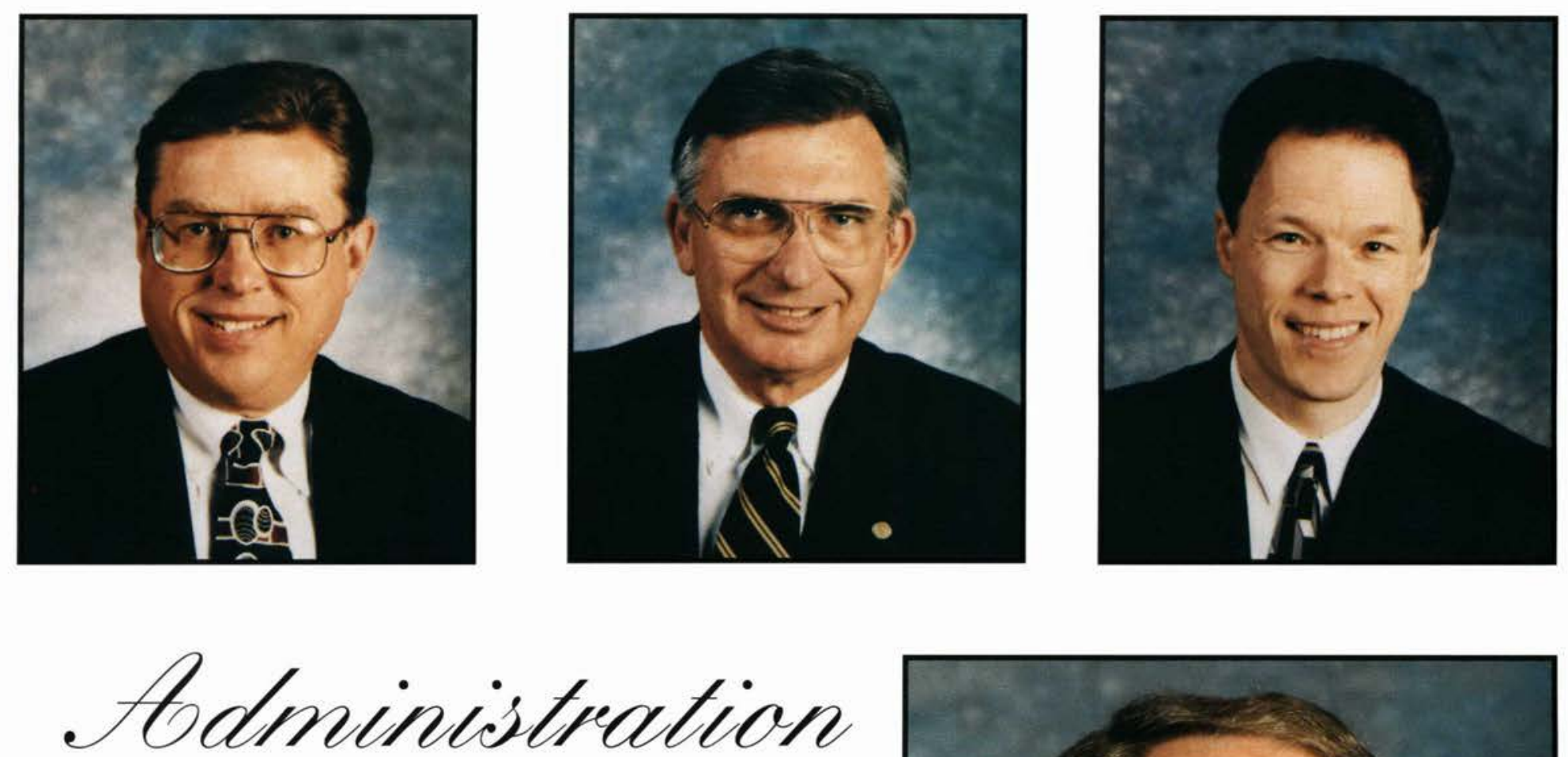

Top (L to R): Mr. John C. Anglea

Vice President for Business

Dr. Martin E. Clark

Vice President for Development

Mr. David M. Ormsbee

Vice President for Enrollment Management.

Middle: $\quad$ Dr. Paul H. Dixon

President

Bottom: $\quad$ Mr. Donald W. Rickard

Vice President for Student Services

Mr. Robert K. Rohm

Vice President for Christian Ministries

Dr. Duane R. Wood

Academic Vice President
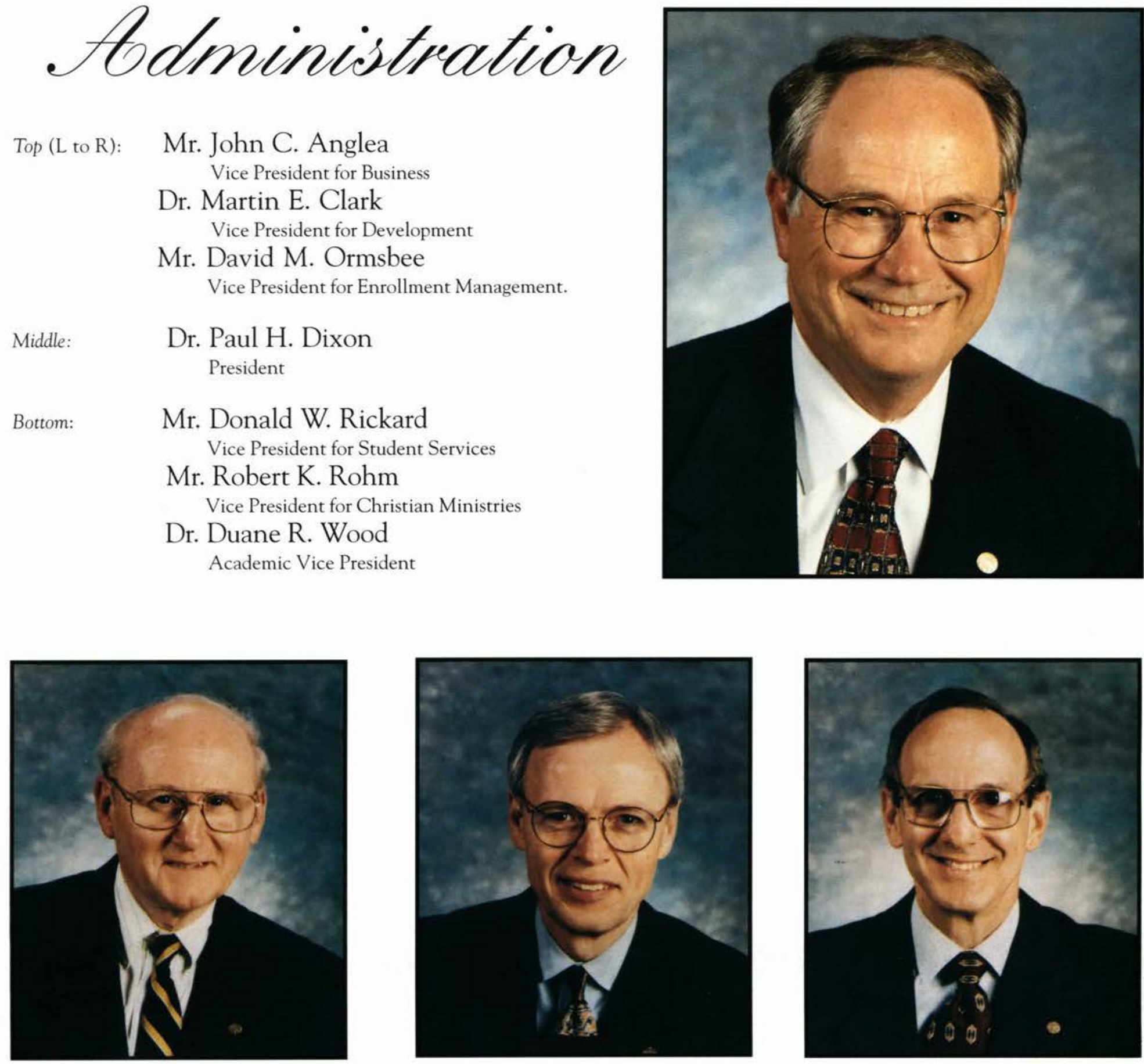
STUDENT

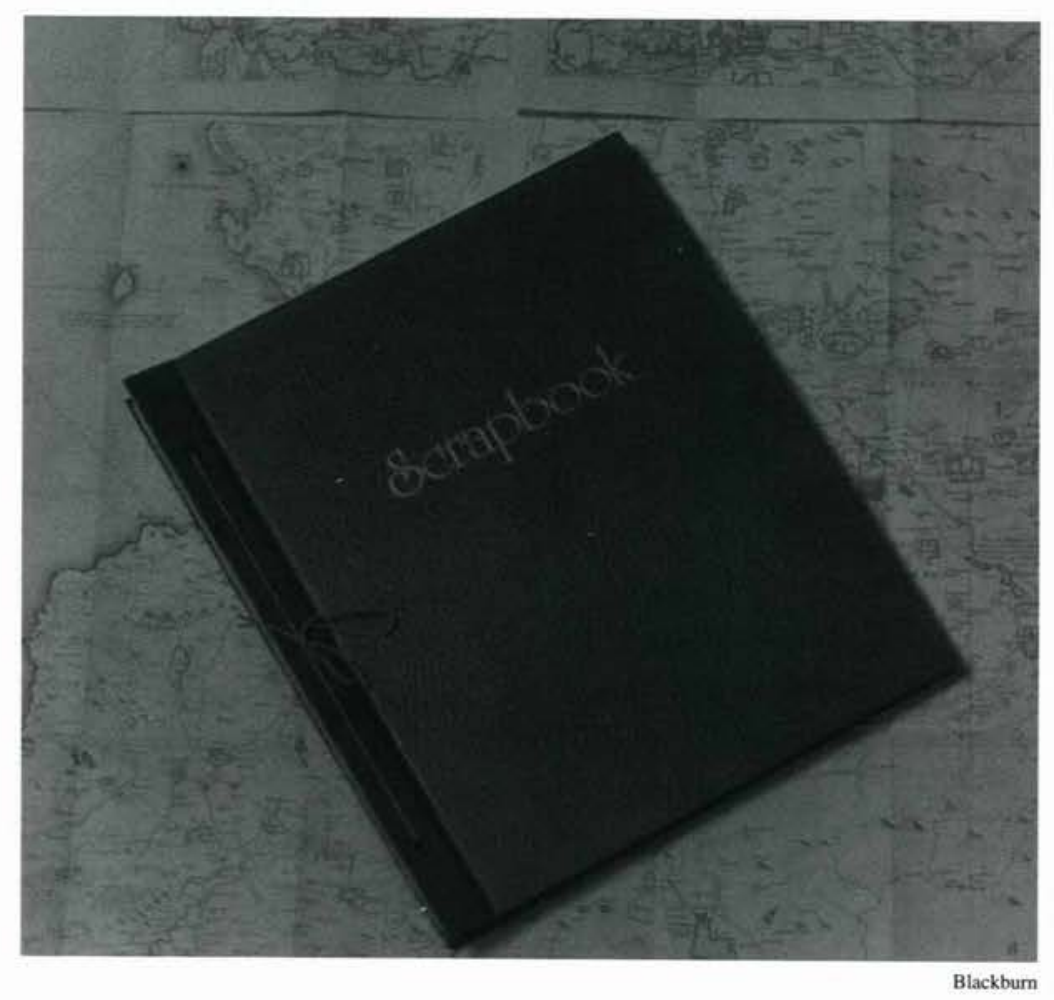

LIFE 


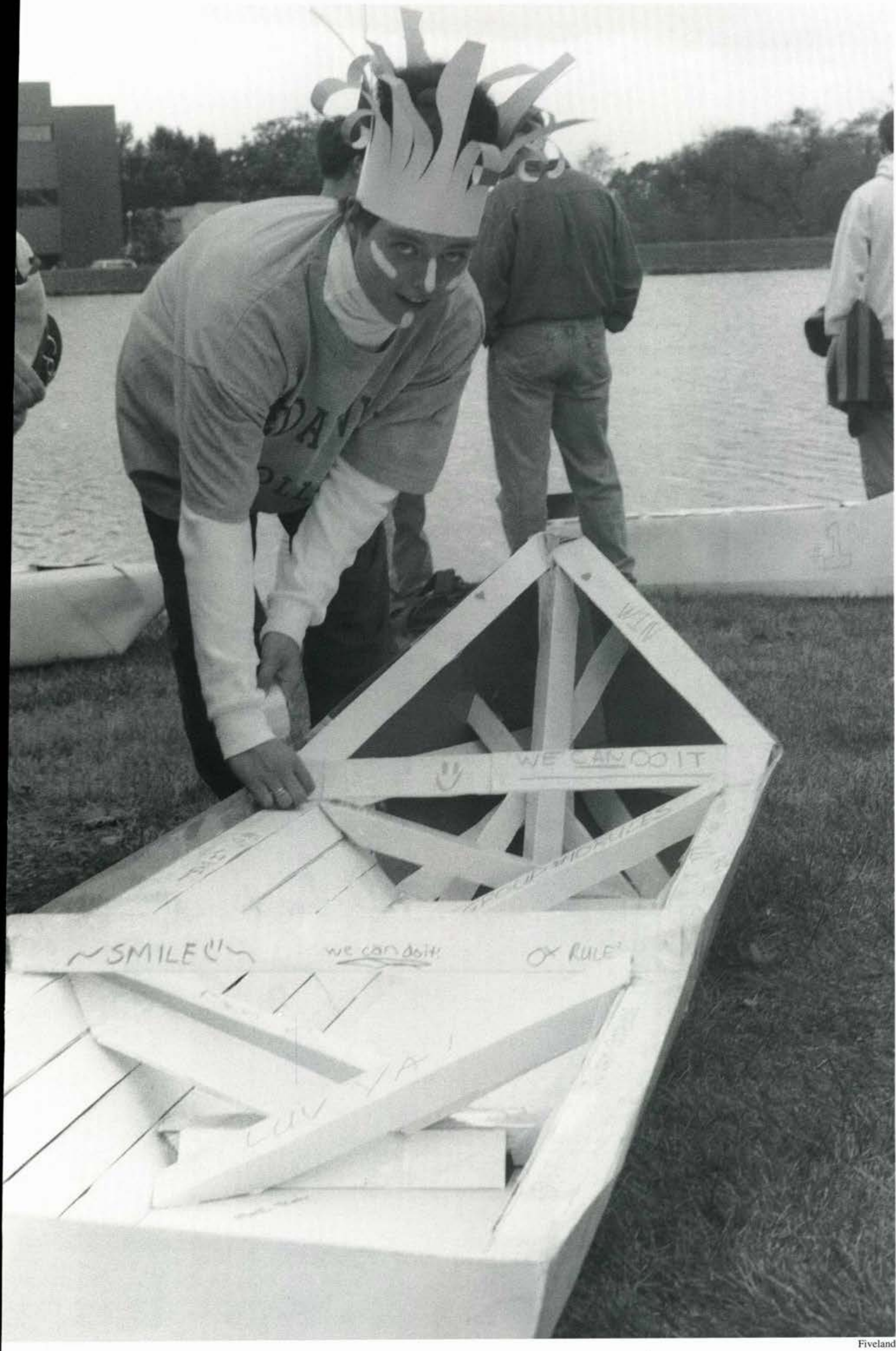

$\square_{\text {ngineering }}$ students like Joy Hester compete in the annual cardboard canoe race--one of the many aspects of student life at Cedarville. 


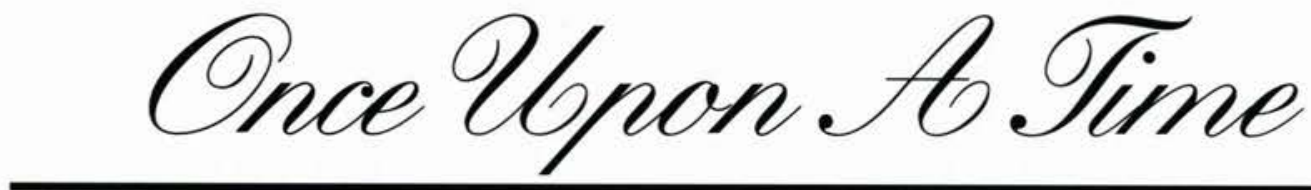

$\mathrm{H}$ o m e c o m i $\mathrm{n}$ g $\mathrm{P}$ a $\mathrm{r}$ a $\mathrm{d}$ e

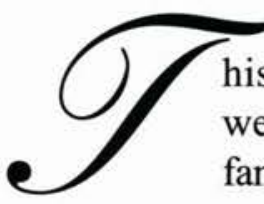

his was a special weekend of seeing familiarfaces andremembering the old times. "OnceUpona Time" wasthe theme for this year's Homecoming festivities; and what an appropriate themeitwas.

Dr. Dixon started the weekend with The State of the College Address. In the Address, he talked aboutCedarville's growthandplans for future development.

The music faculty presented The PRISM concert and reflected on how the Cedarville music department has grown in the many years since its establishment. Thepresentation, narrated by Dr. David Matson, related the musicians' "attempt to serve Jesus Christ with [their] talents." The brass choir opened the evening with "Fanfare for the Common Man." The Concert Chorale, Men's Glee Club, and Symphonic Band followed the

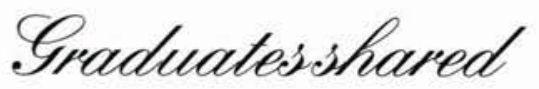

afdmentories and

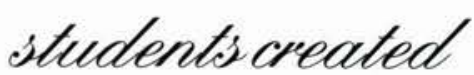

new memorier...

brass choir's numbers. The CedarvilleCollegeOrchestraclosed the evening with a patriotic "AmericanSalute."

In addition to groups of student musicians, the faculty also contrib- uted their musical gifts. DiCuirci, Dr. James Colman, Pagnard, Dr. John Mortensen, Dr. Charles Clevenger, and Mr. Mark Spencer displayed their marvelous talents.

The Saturday morning parade continued with the "Once Upon a Time" theme. Asmanypeoplelined the streets, they saw floats representing castles, nursery rhymes, and even a more recent past, the hippie era. The afternoon's activities gave the alumni a chance to interact with one another and to reminisce about their memories at Cedarville. The graduates shared oldmemories and presentstudents creatednew memories. Both the graduates and present students will carry these memories with them happily everafter.
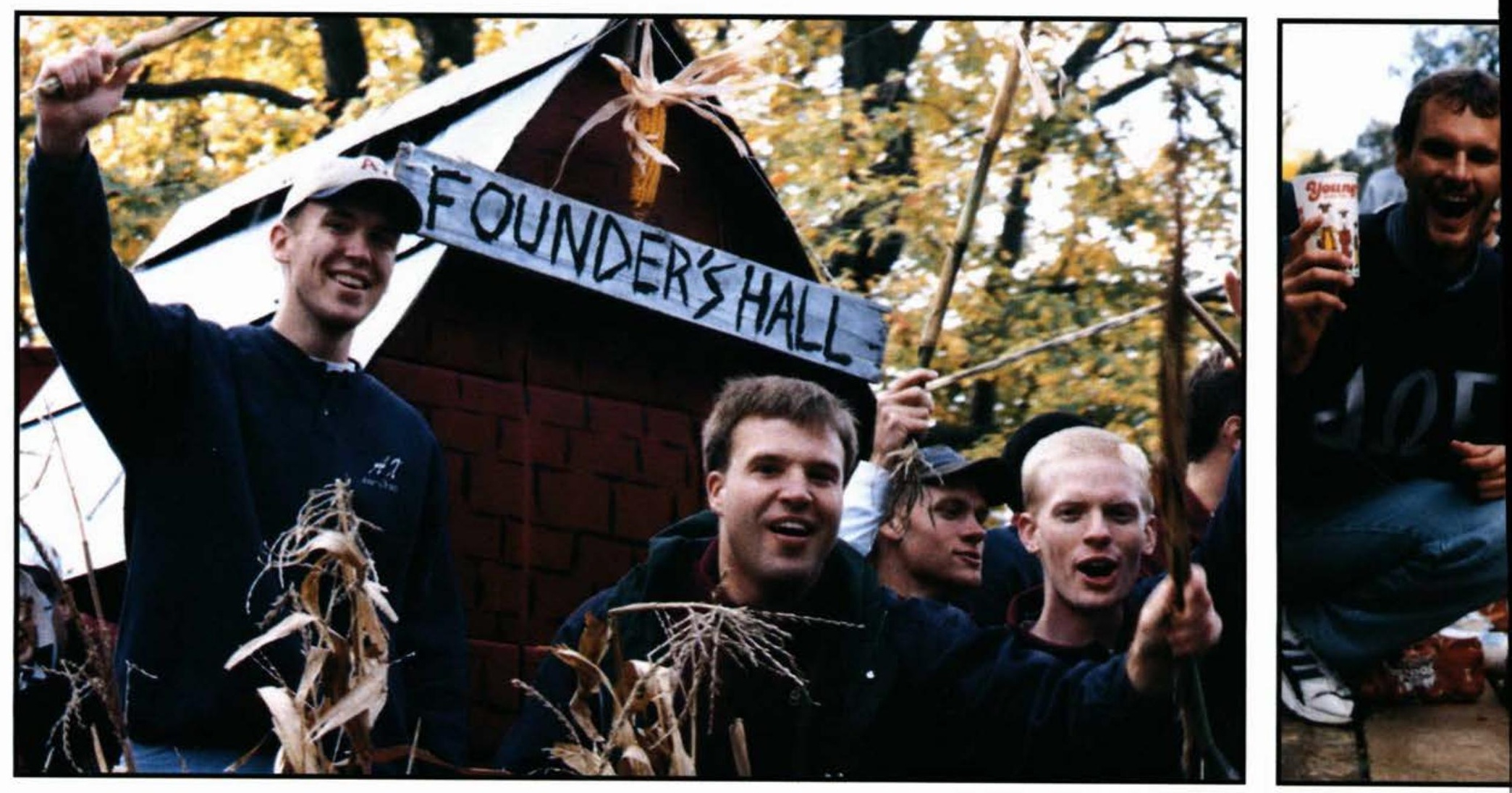


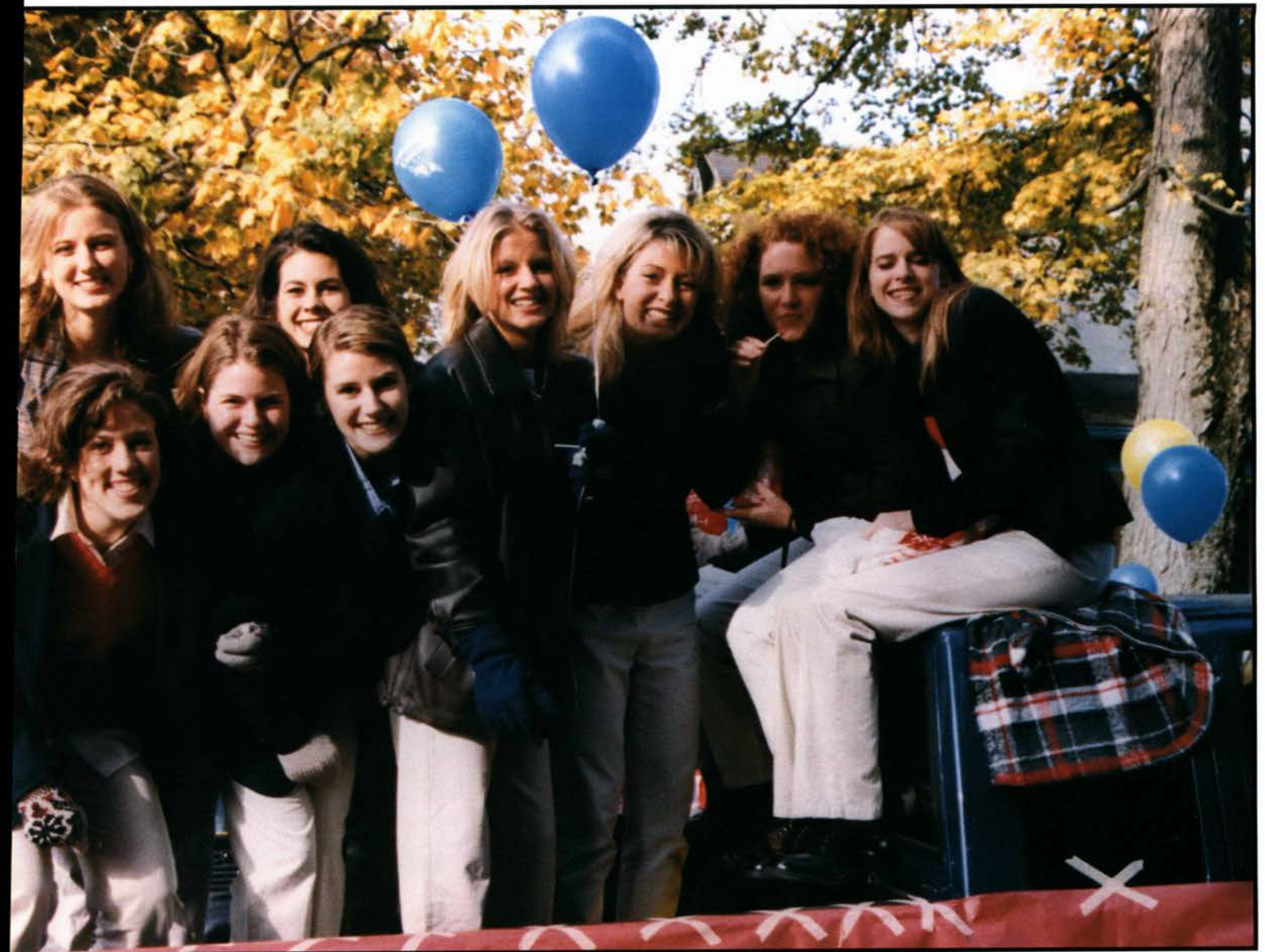

Blackbum

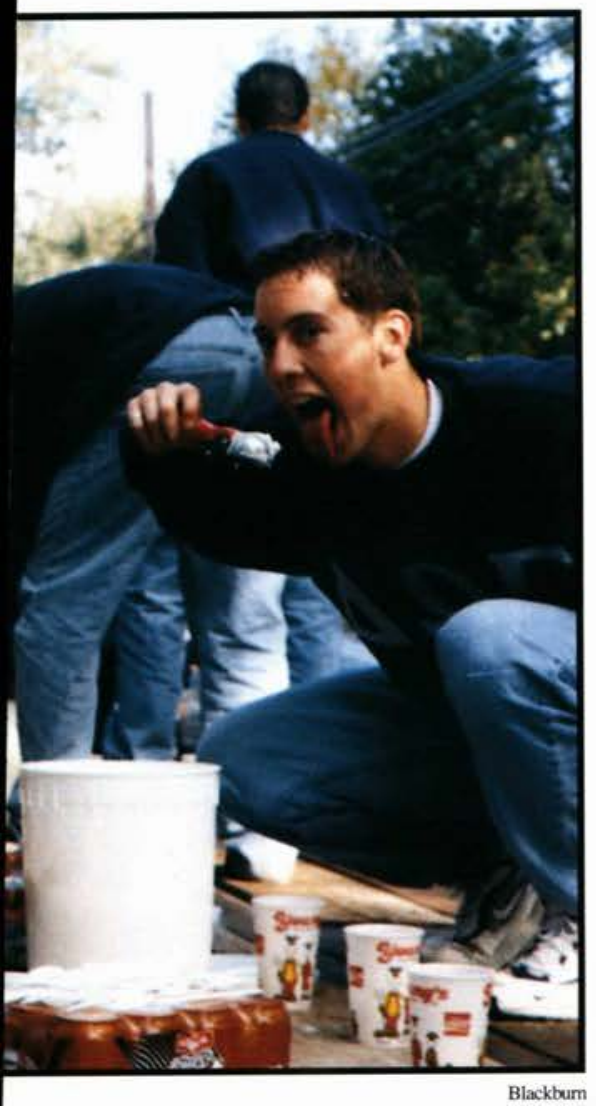

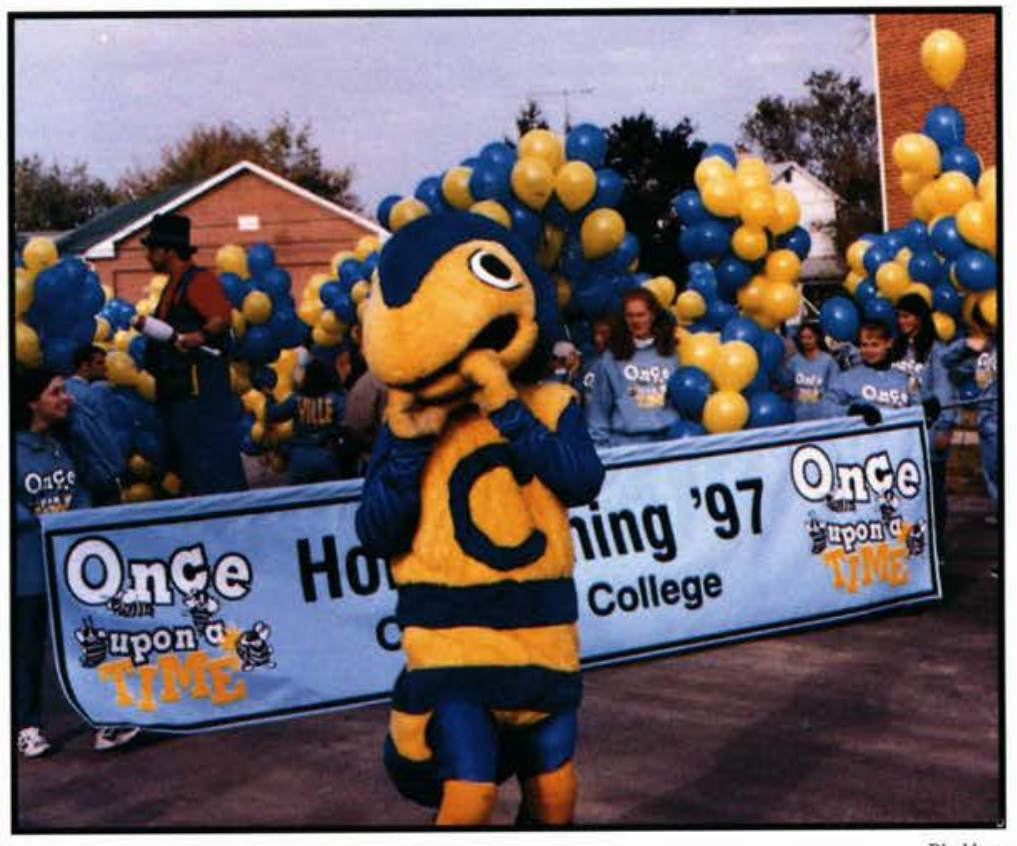

Paul DiCuirci and Dave Fourman assist in making root beer

floats from a homecoming float.

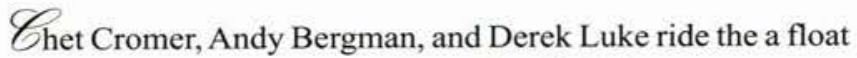
representing the old Founder's Hall--pictured on far left.
Qembers from

Delta Pi Sigma enjoy the parade and activities.

The Cedarville bee, along with students, gets the Once Upon A Time parade off to a good start. 
Prenda Trion

Homecoming Queen

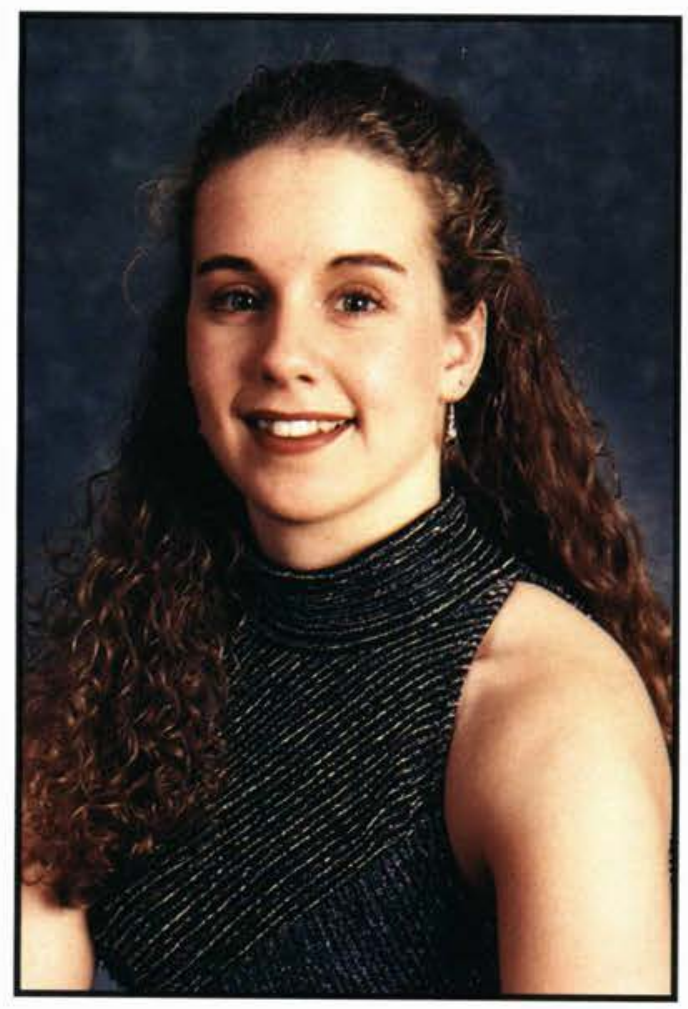

Sara Bathricte

Senior. Attendant

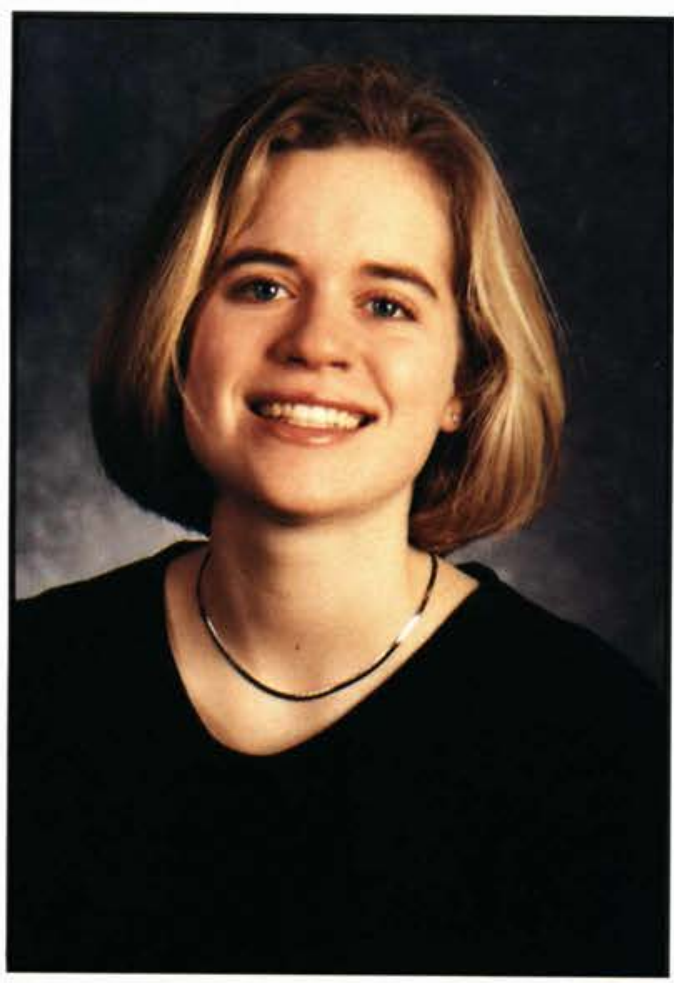

Melissa Heatherington Frestiman. Allendant

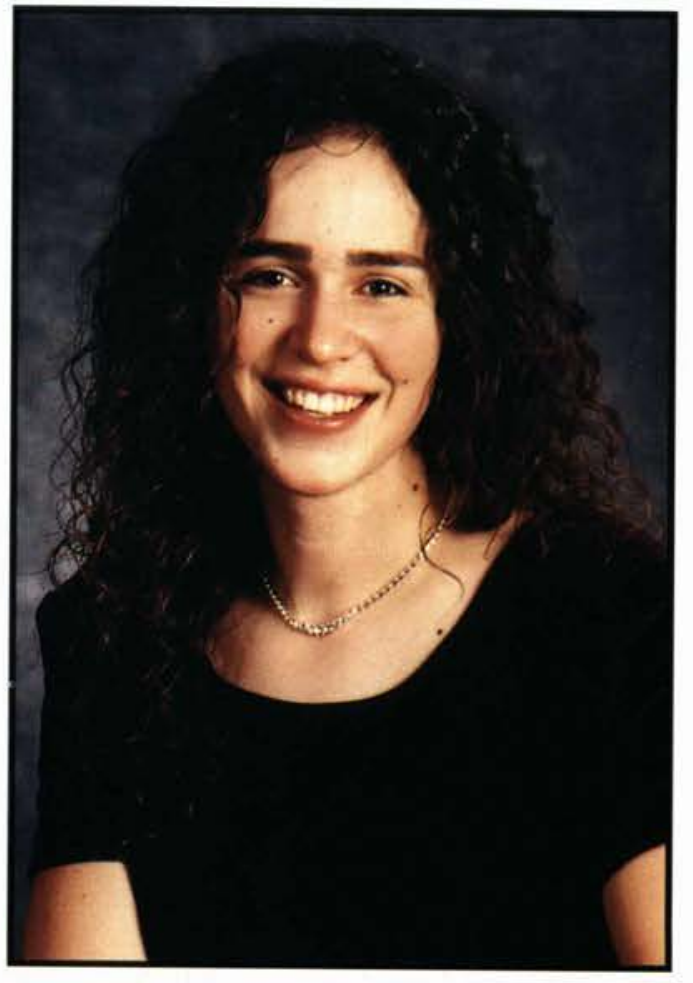

Seneva Roberls

Sophimore. Ablendunt

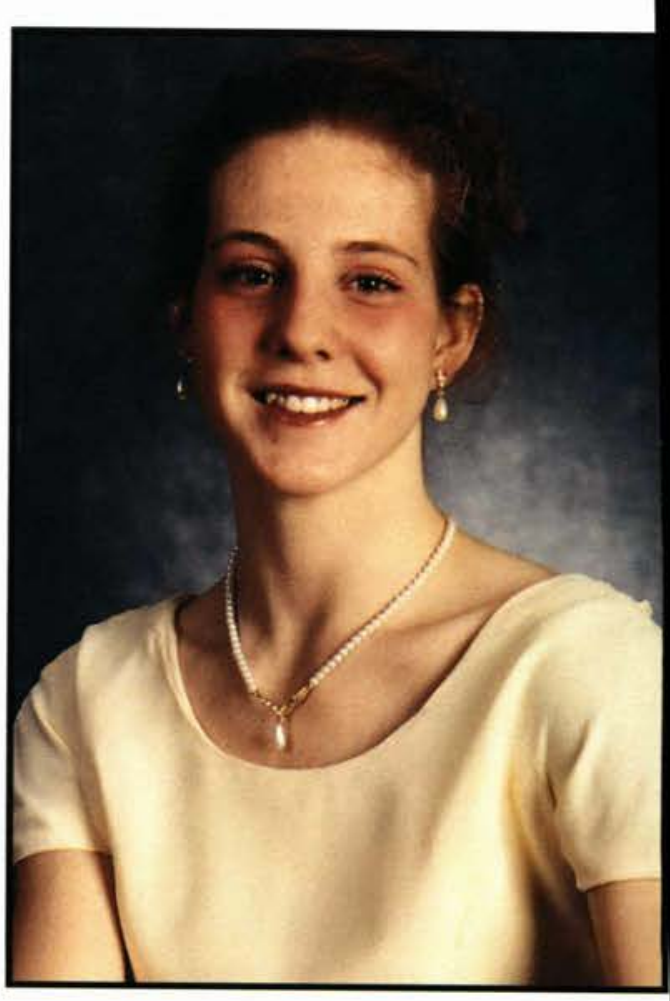

Sara Whitney Funior Avtendant 


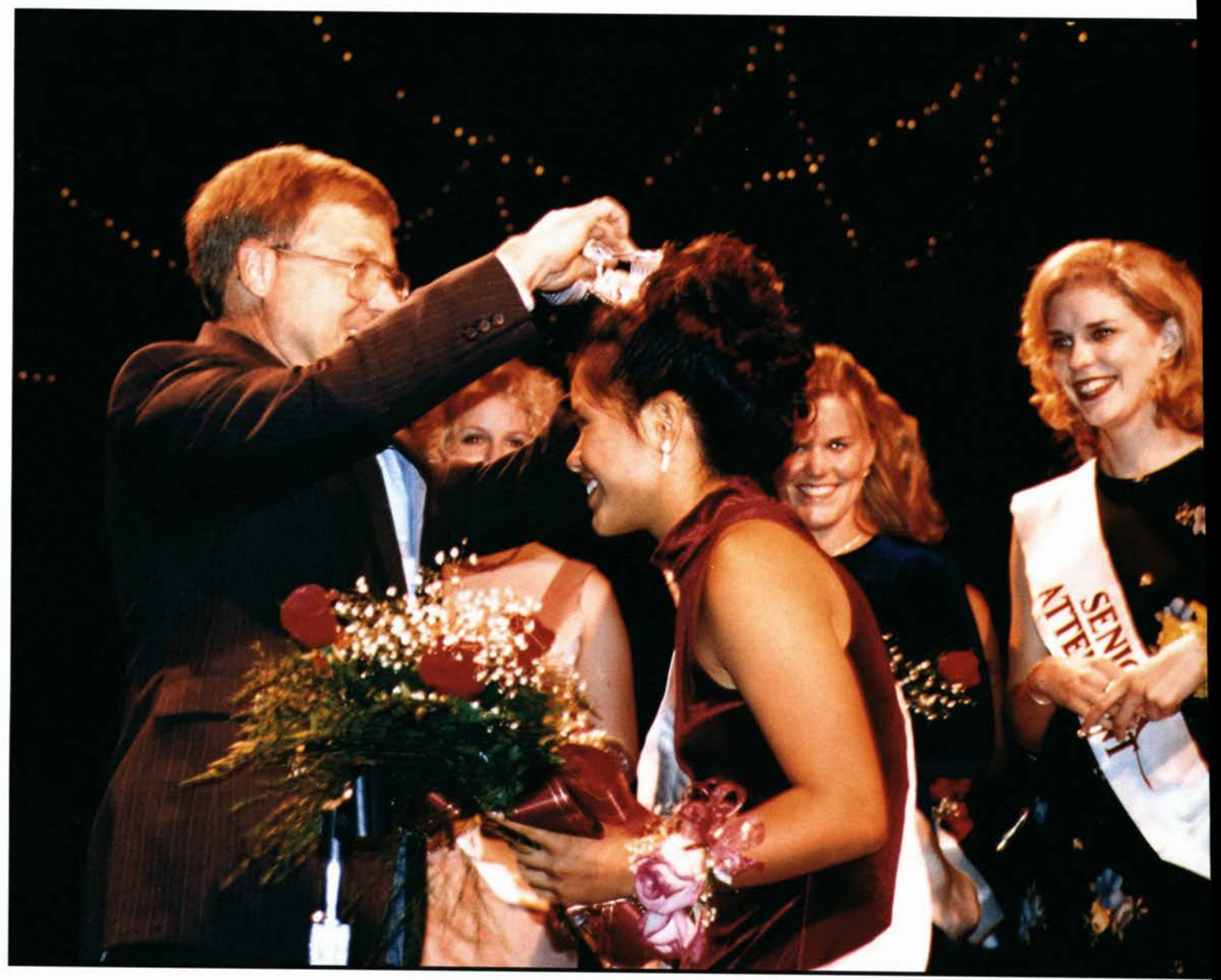

- fter the banquet, Michael W. Smith entertained Cedarville students, singing songs such as "No Place In This World" and "Friends."
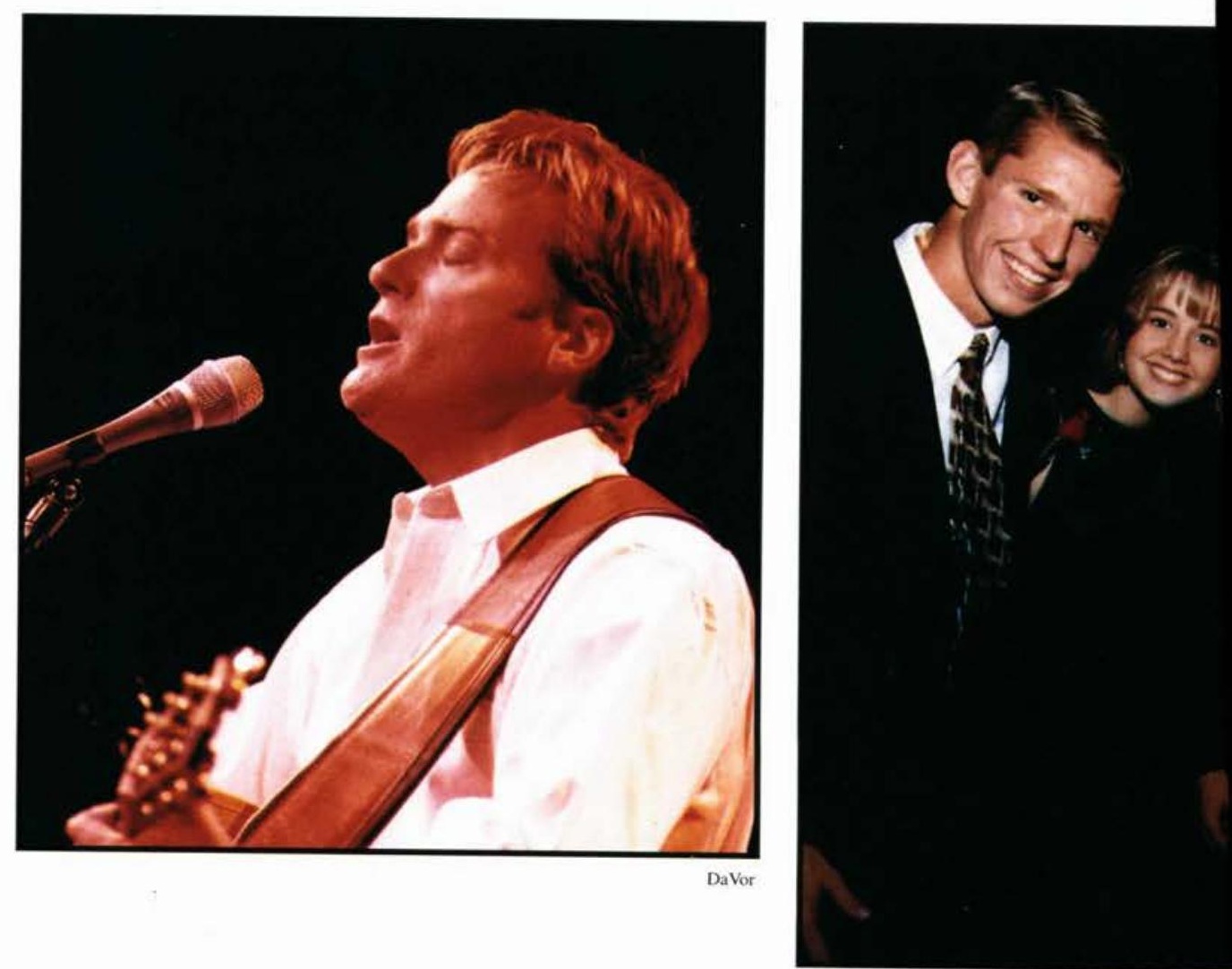
Prenda Inion is crowned this year's

homecoming queen at the homecoming banquet.

Chris Ashcraft, Jennifer Hangosky,

Suzanne King, and Geoff Hillman enjoy their last

homecoming banquet together.
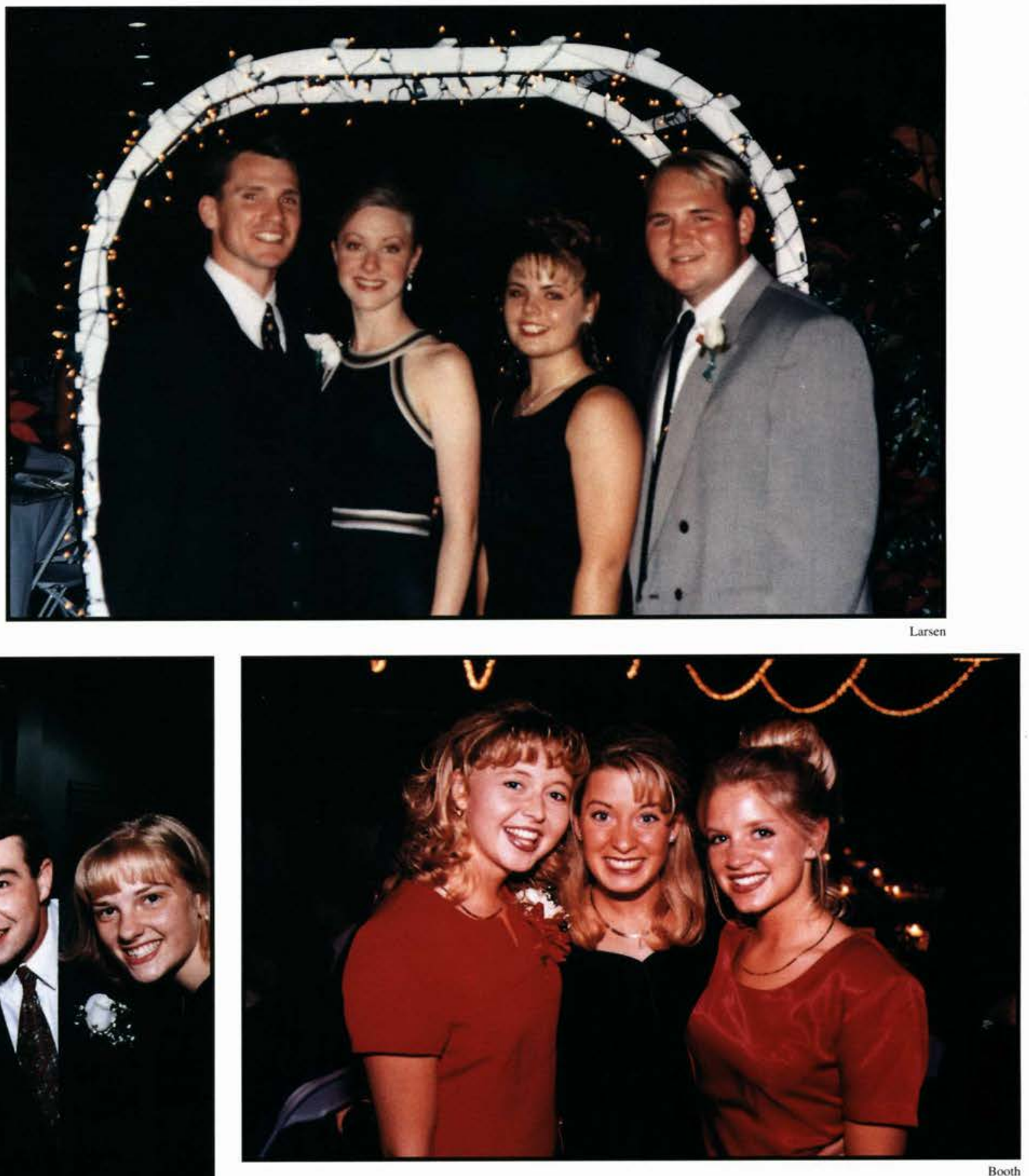

Sate Patterson, Amanda Sage, Jud Neer, Alika Holley, Ben Kaminsky, and Laura Rausch enjoy the banquet together.

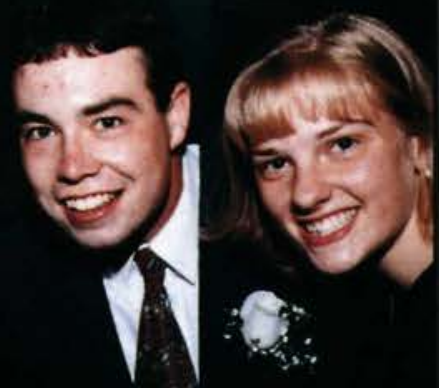




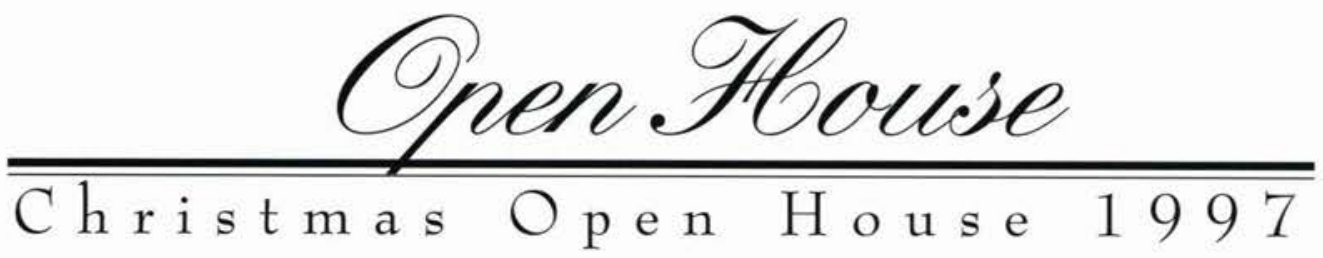

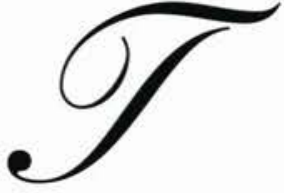

welve Smurfs race down a McChesneyhall with Gar-gamel

chasing. It's no secret what time of yearitisagain. The 'Villeishopping with decorations and outrageous costumes for Open House, all in hope of winning firstprize - apizza party and dinner at the Olive Garden.

This year was especially crazy with the ladies opening their halls and units the day after students arrived back to campus from Thanksgiving break. Even with little time to prepare, they did an excellent job. Visitorsexperiencedeverythingfrom Heaven to a New York Christmis.
The guys showed their creativity by decorating their halls as Sherwood Forrest, a Haunted Christmas, the

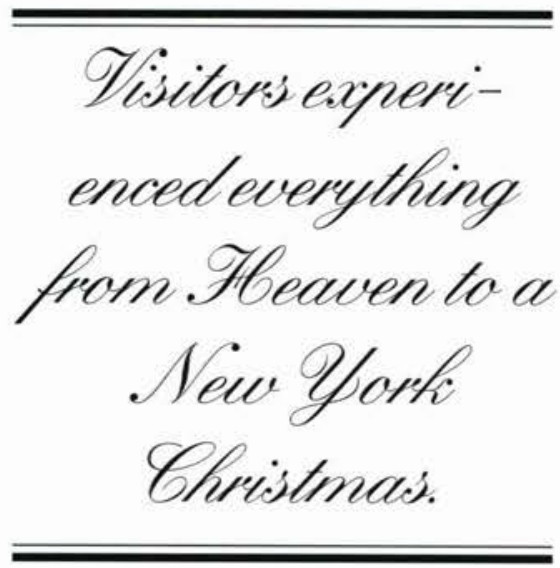

Dating Service, and a Caribbean Christmas complete with the sea.

This year the units and halls were judged separately. Maddox 8's time machine and Lawlor 14's haunted house were the unit winners, and Willetts New York City Christmas and McChesney's SherwoodForrest were the hall winners.

For the first time, Open House was splitinto twonights toallow Dr. Dixon and all the students to visit more unitsandhalls. Dr. Dixon said heenjoysmaking ittoeverystudent's room, and that he "look[s] forward to the open houses every year. It is a great time to be with the students in their 'home away from home.' The atmosphere reminds me of why Iremain excited about being a part ofCedarvilleCollege."

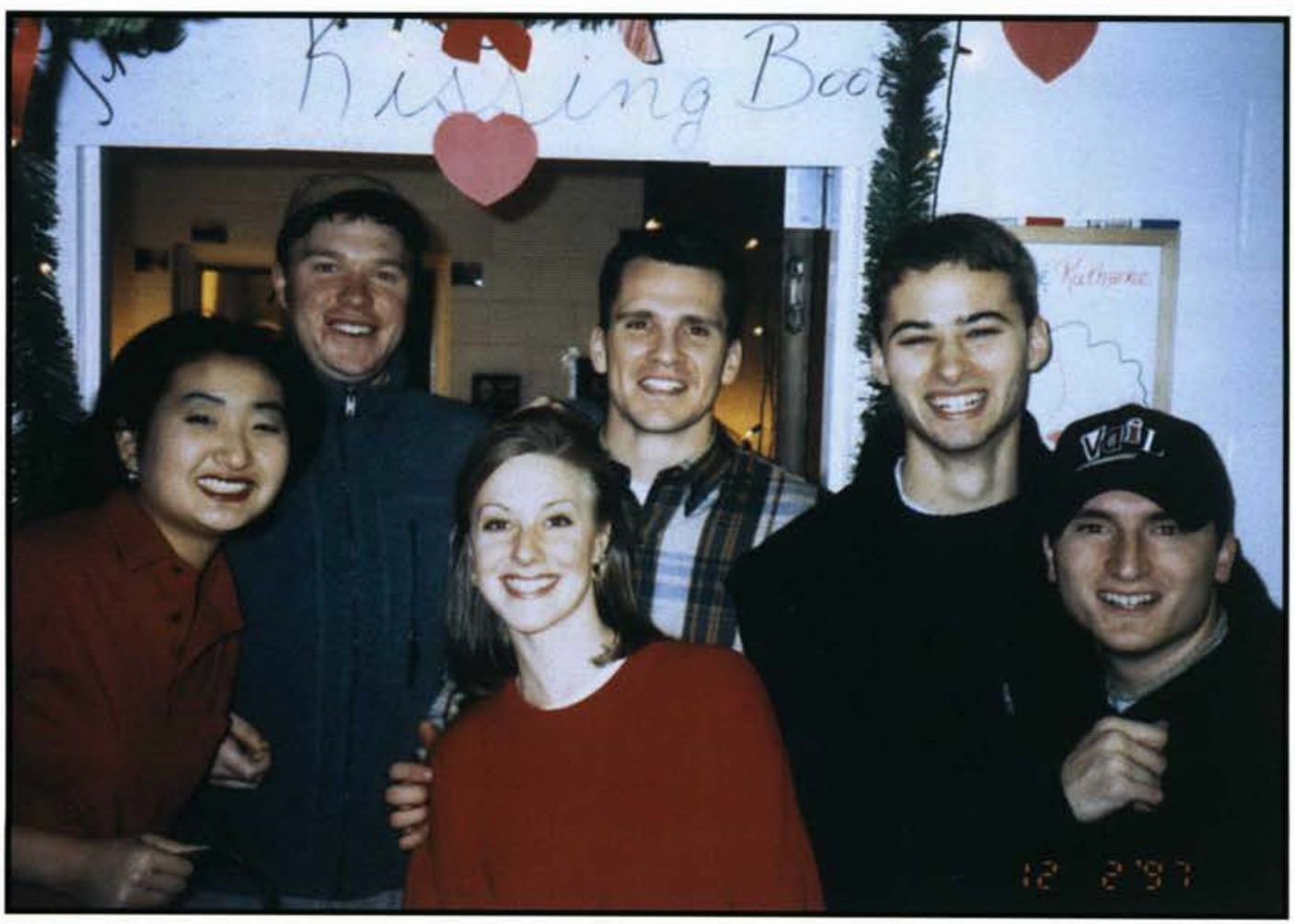

Ruthanne Pierson, Loren Peirson, Jen Hangosky, Chris Ashcraft, Kevin Meadows, and Jessie Deconto enjoy the festivities.

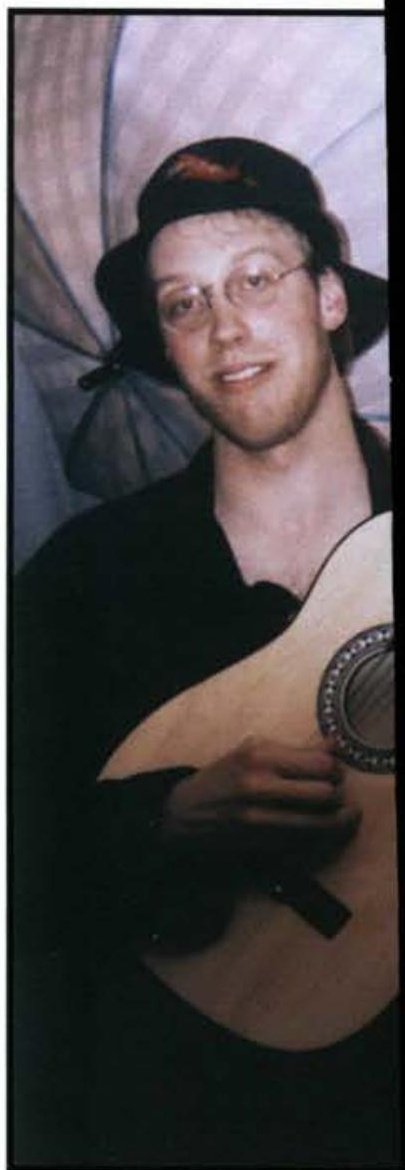



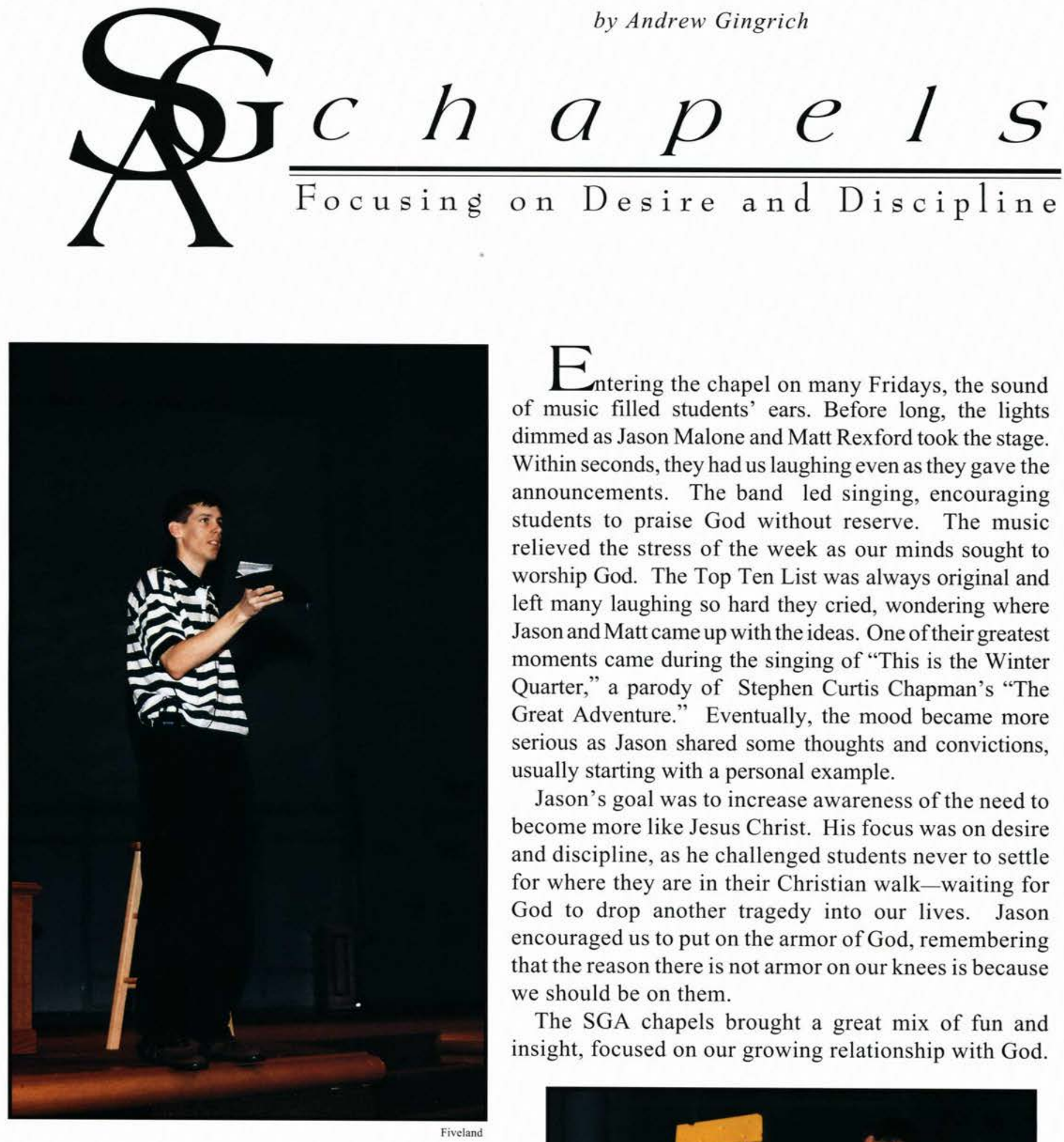

ntering the chapel on many Fridays, the sound of music filled students' ears. Before long, the lights dimmed as Jason Malone and Matt Rexford took the stage. Within seconds, they had us laughing even as they gave the announcements. The band led singing, encouraging students to praise God without reserve. The music relieved the stress of the week as our minds sought to worship God. The Top Ten List was always original and left many laughing so hard they cried, wondering where Jason and Matt came up with the ideas. One of their greatest moments came during the singing of "This is the Winter Quarter," a parody of Stephen Curtis Chapman's "The Great Adventure." Eventually, the mood became more serious as Jason shared some thoughts and convictions, usually starting with a personal example.

Jason's goal was to increase awareness of the need to become more like Jesus Christ. His focus was on desire and discipline, as he challenged students never to settle for where they are in their Christian walk-waiting for God to drop another tragedy into our lives. Jason encouraged us to put on the armor of God, remembering that the reason there is not armor on our knees is because we should be on them.

The SGA chapels brought a great mix of fun and insight, focused on our growing relationship with God.

Jason Malone was this year's SGA chaplain. He challenged the student body to become more Christlike through his messages on desire and discipline. (above)

Scott Moody assists Jason in a sermon on the armor of God. This may have been the first time the helmet of salvation was represented with cheese. (right)

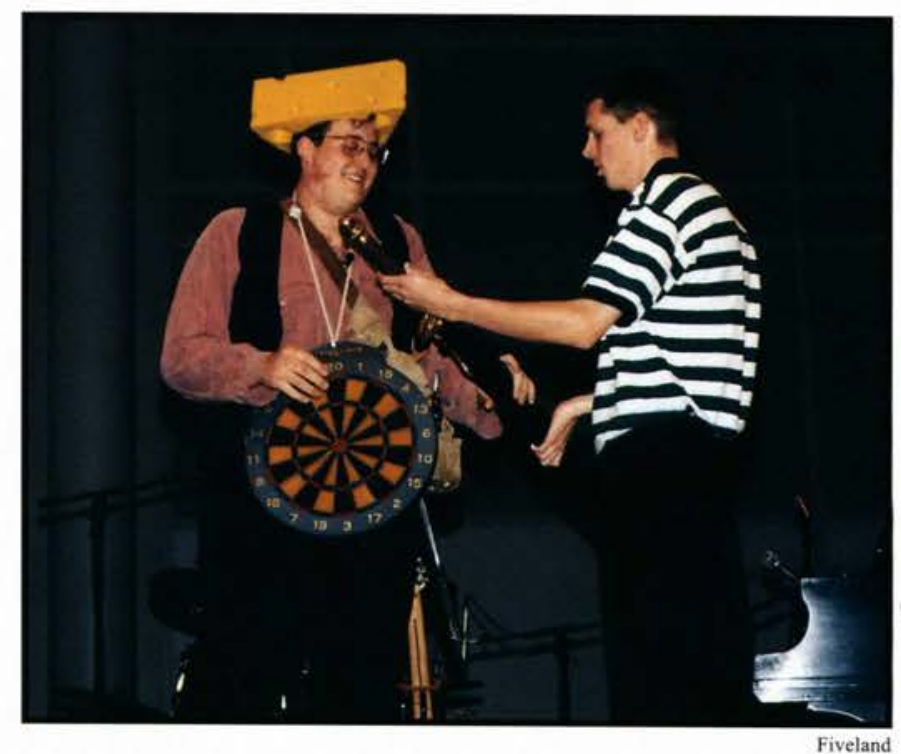


Leading the student body in worship, the SGA band opens the chapel service.

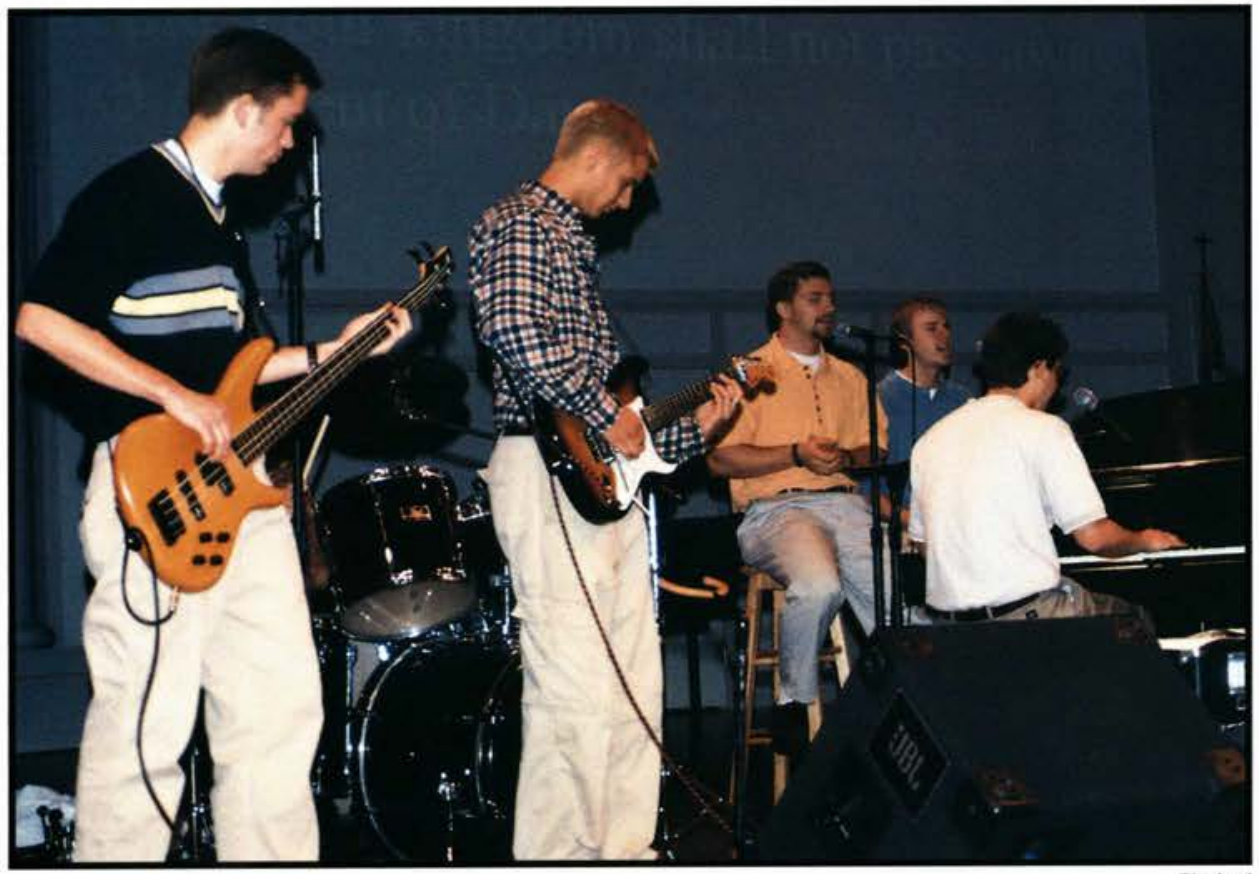

Fiveland

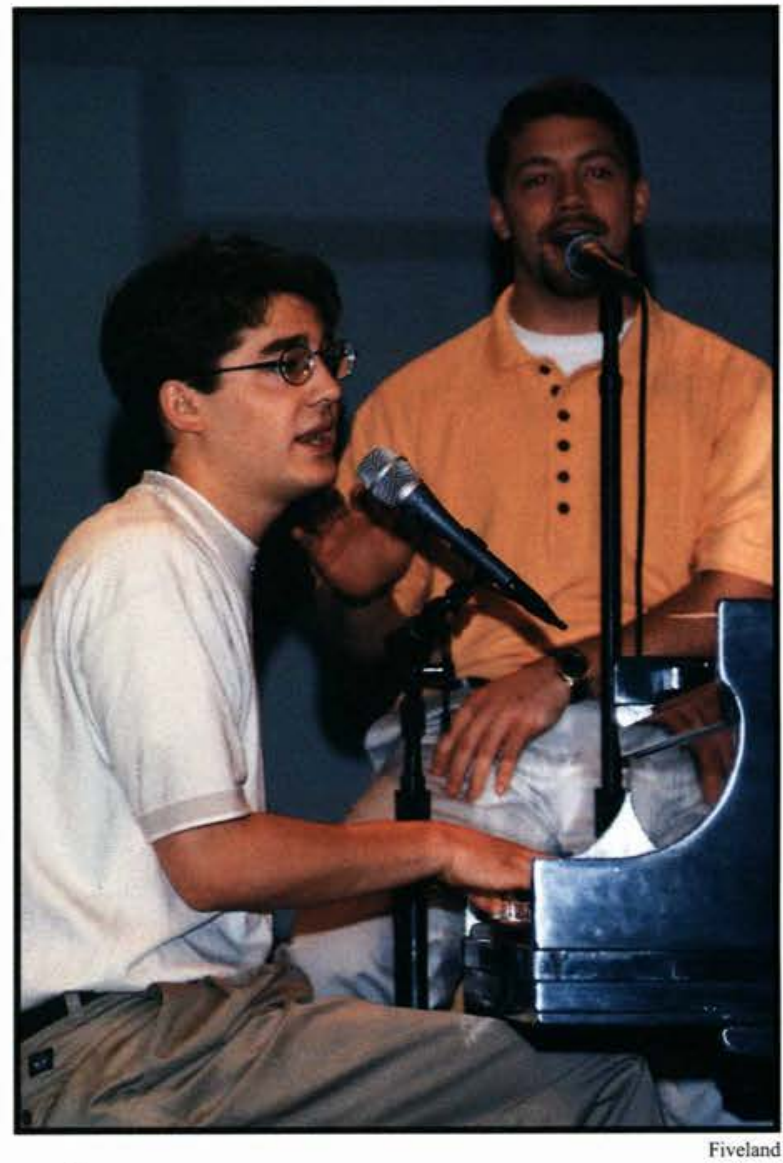

Jason Malone not only prepared a message for each service, but also had a top ten list to share. (left)

Matt Rexford and Dan Forness share their talents in the SGA band. (above) same. Jason Malone proves this by wearing a bunny suit.

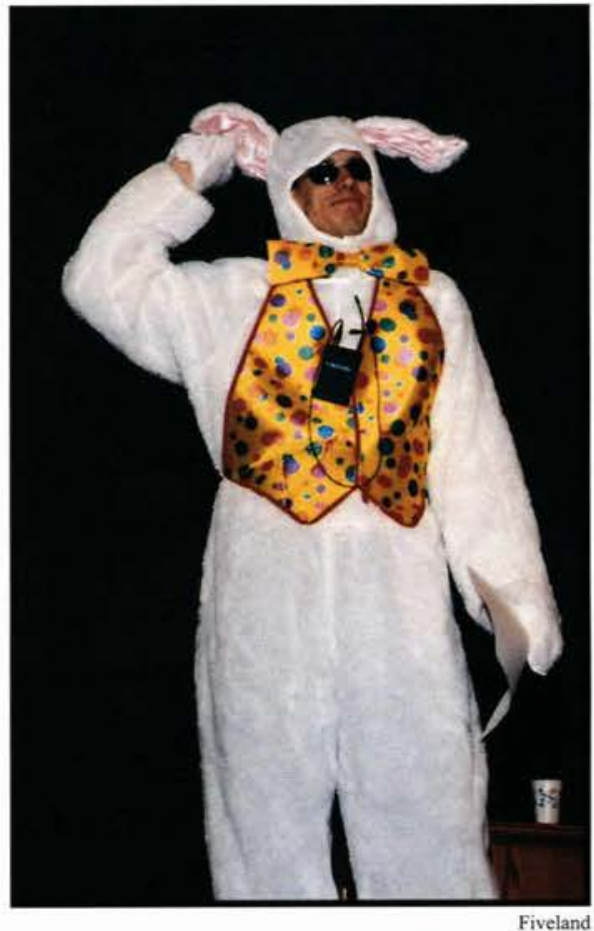

eland

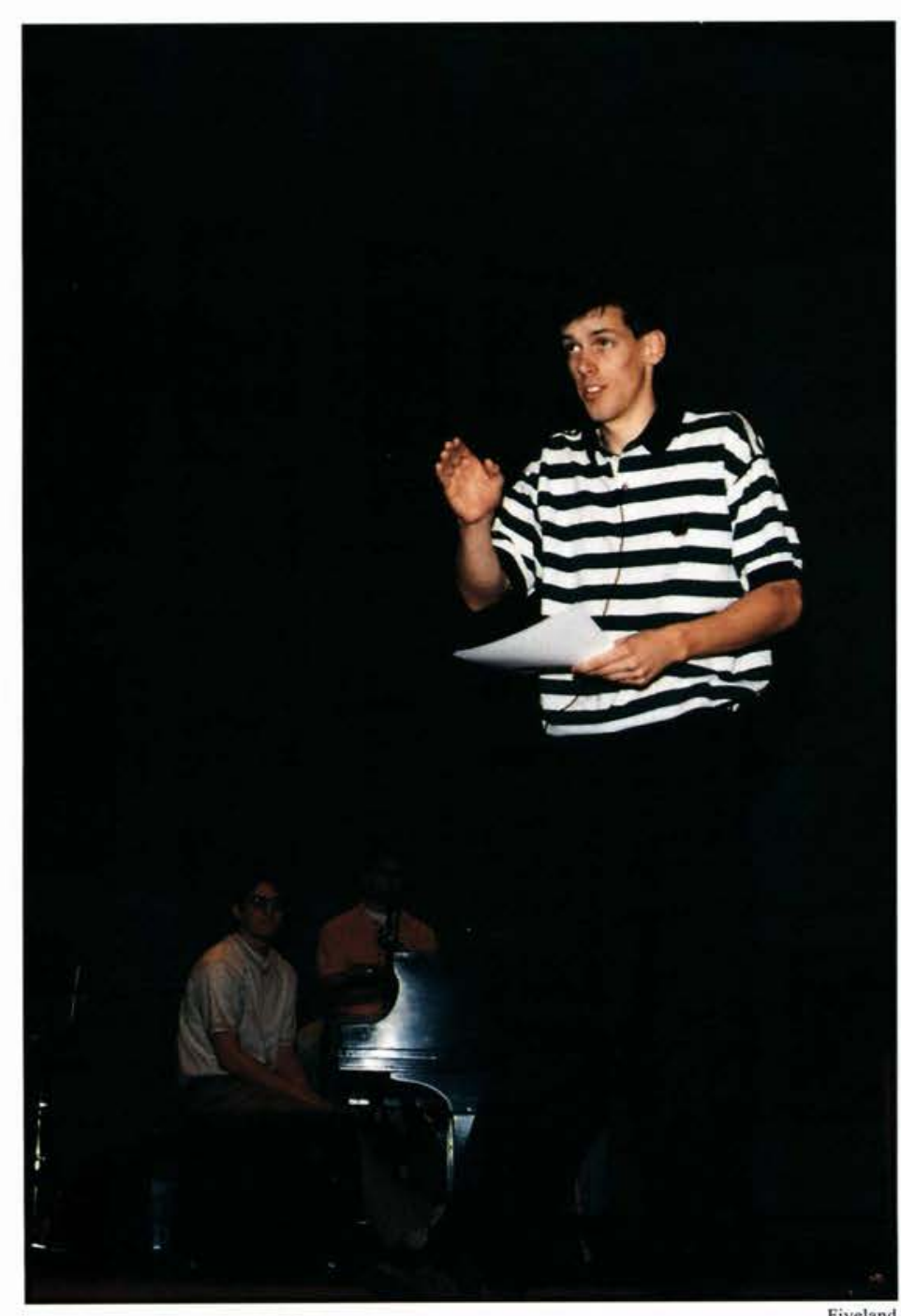




\section{CATALOGS ADMISSIONS}
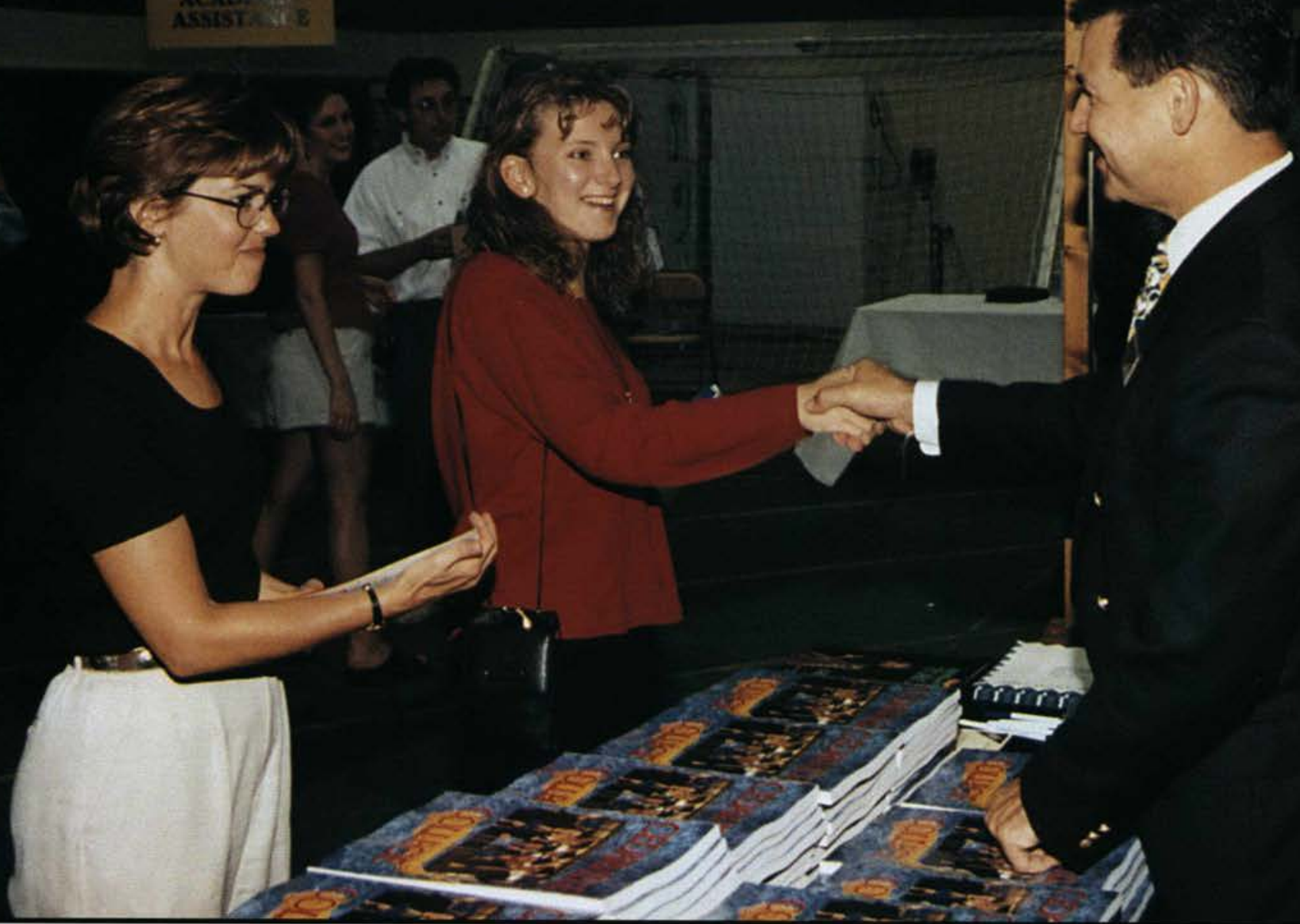

$\mathscr{E}_{\text {katerina Kochetova }}$ is one Cedarville's new international students from

St. Petersburg, Russia. Also pictured are Stewart Zeharick from Admissions, and Ekaterina's host mother.

Sick Chou and Greg GregFlory assist new students as they move in during the Getting Started weekend.

Oeremy Pierre works hard to unload his belongings from his van to his new dorm room.
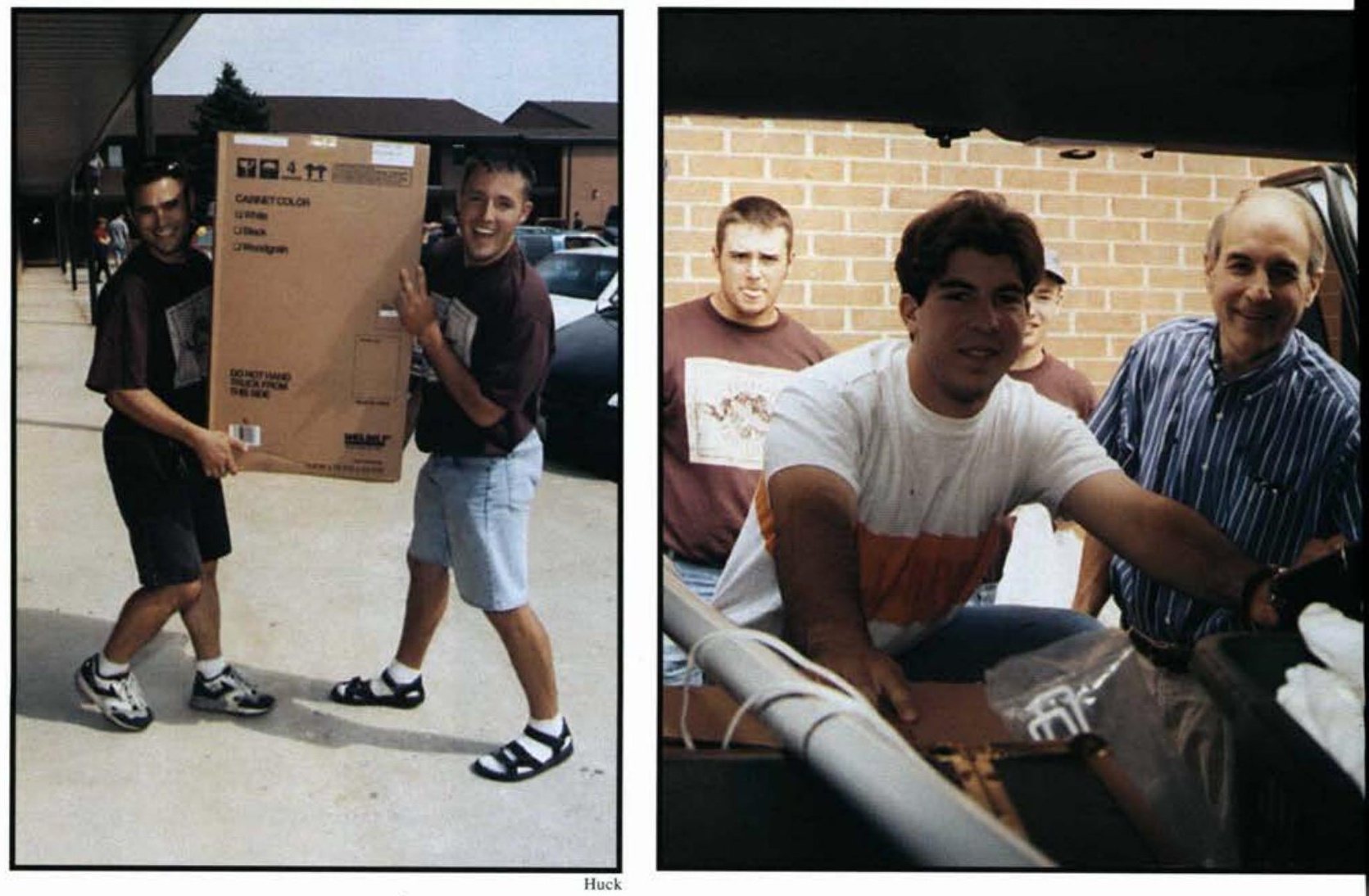

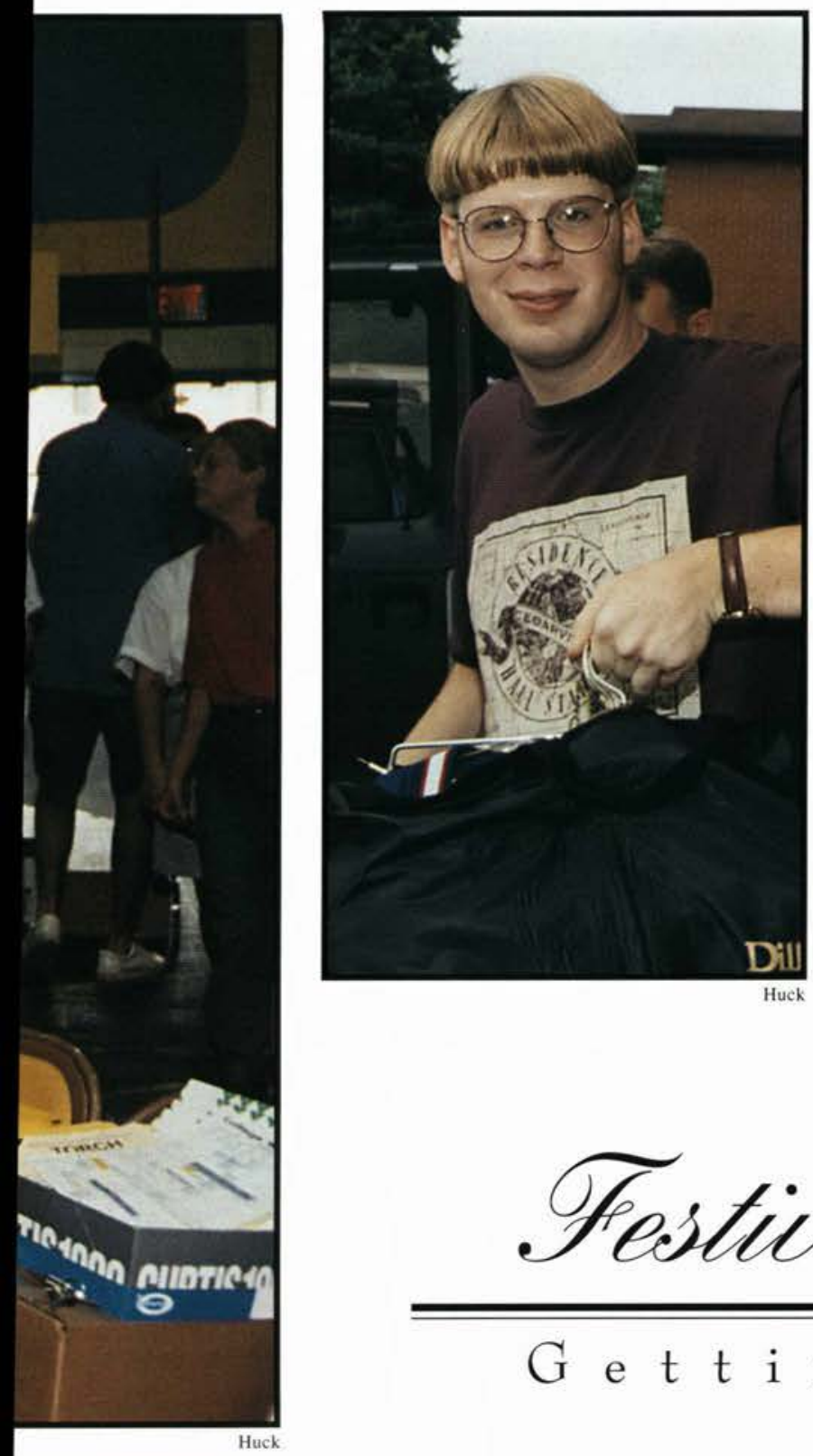

Ra Kevin Boblitt assists students as they move into their dorms.
Tim Miller and his parents pose for the traditional welcome photo with the Cedarville bee.

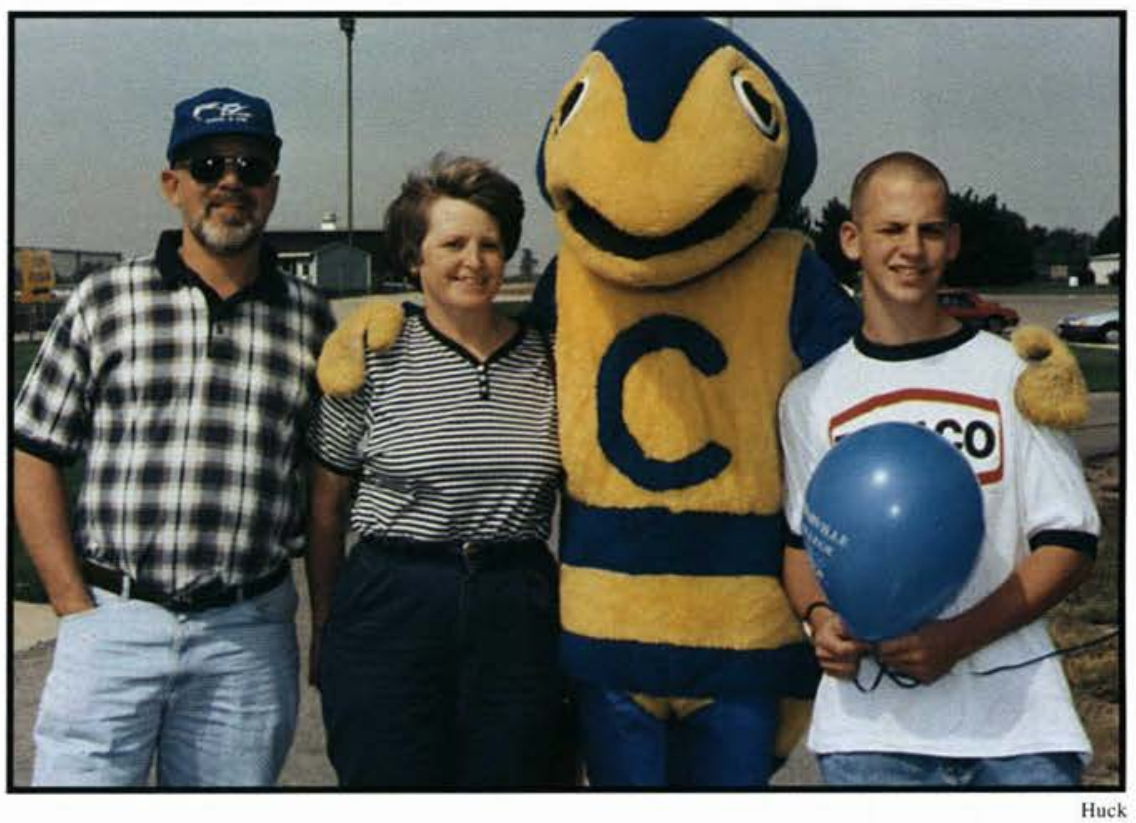

by Nancy Houck

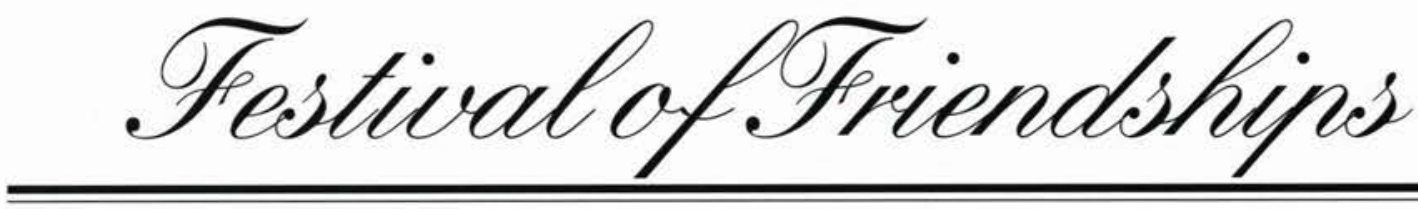

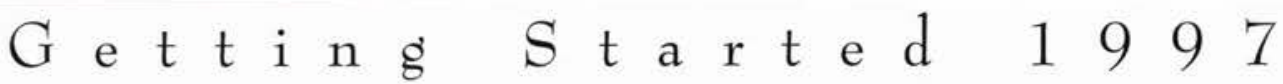

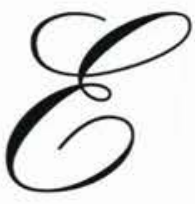

ight hundred and thirty ofCedarville's newest students experienced Getting Started '97's "Festival of Friendships." Getting Started provided Cedarville's largest class of incoming students with the opportunity to meetnew friends and getacclimated to college life.

Small groups served as an integral part of the process. The 641 freshmenwere dividedinto 56 small groups, and the 121 transfers formed their own small groups. Each group of ten to twelve students had two or three upperclassmen leaders.

Friday morning new students be- gan to arrive for housing registration and a day packed with orientation activities. The Getting Started staff and RAs assisted students as the moved into their resi-

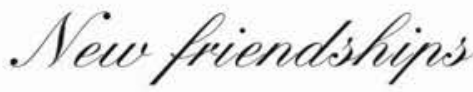
start off the college life at Gedarvilte... dence halls.

That evening, the Athletic Center housed the annual Early Arrival Party. Orientation events continued on Saturday. "Calling Home," a drama depicting the changing par- ent/child relationship was a highlight. The traditional "New Student Picture" was shot from the top of the Centennial Library Saturday night.

The Getting Started Program followed, kicking offin the DixonMinistry Center. New students met their small groups and then headed over to the Athletic Center for games. Sunday was a day of worship with Morning Worship in the $\mathrm{DMC}$ and an evening praise time with John G. Elliot.

When the Fall BibleConference started on Monday morning, everyonehad metnew friends, settled into their dorms, and had a taste of what their time at the "Ville would be like--busy. 


\section{Guest Arrista Perform at the 'Tille}

he year began with a special visit from GLAD during Homecoming weekend. This group of men sang both traditional hymns and popular contemporary Christian songs for an evening the audience would remember. The goal of their concert was that everyone involved would get a glimpse of Christ, and the college family experienced true worship at the concert.

After the Royalty Banquet for the Homecoming Court in October, the college family benefitted from the musical talents of Michael W. Smith.

In November, Wes King, Sarah Hart, and Scott Kripayne brought a concert to the Dixon Ministry Center from their
"Room Full of Stories" tour. King began the concert with "I Believe," a song that made him popular among Christian music lovers and Hart and Kripayne performed a couple of their fresh, new songs. Students, faculty, and friends of the college family stood, clapped, and sang along as King and his fellow artists lifted up praise to the Lord.

Cedarville was also blessed with the ministry of Steve Green during the Fall Quarter.

When the winter quarter began in January, students were awaiting the Point of Grace concert scheduled for the first Friday night of the quarter. Although the concert had a rough start due to technologi- cal and sound difficulties, it culminated a glorious ending with a blending of voic from both the audience and the artists in $t$ familiar song "Circle of Friends." Throug out the concert, Point of Grace made evident that all the glory goes to God.

Steve Camp visited Cedarville in $\mathrm{Fe}$ ruary to give a concert and speak in chap During his concert, Camp accompani himself at the piano and presented son from his latest project, Mercy in the W derness. Cedarville's Jubilate choir join him on seven different numbers includir "The Beauty of Holiness" and "We Star In Grace." At the end of his concert, Can challenged his audience to be more lil Christ-perfectly righteous.
16 embers of GLAD take the stage during Homecoming Weekend.

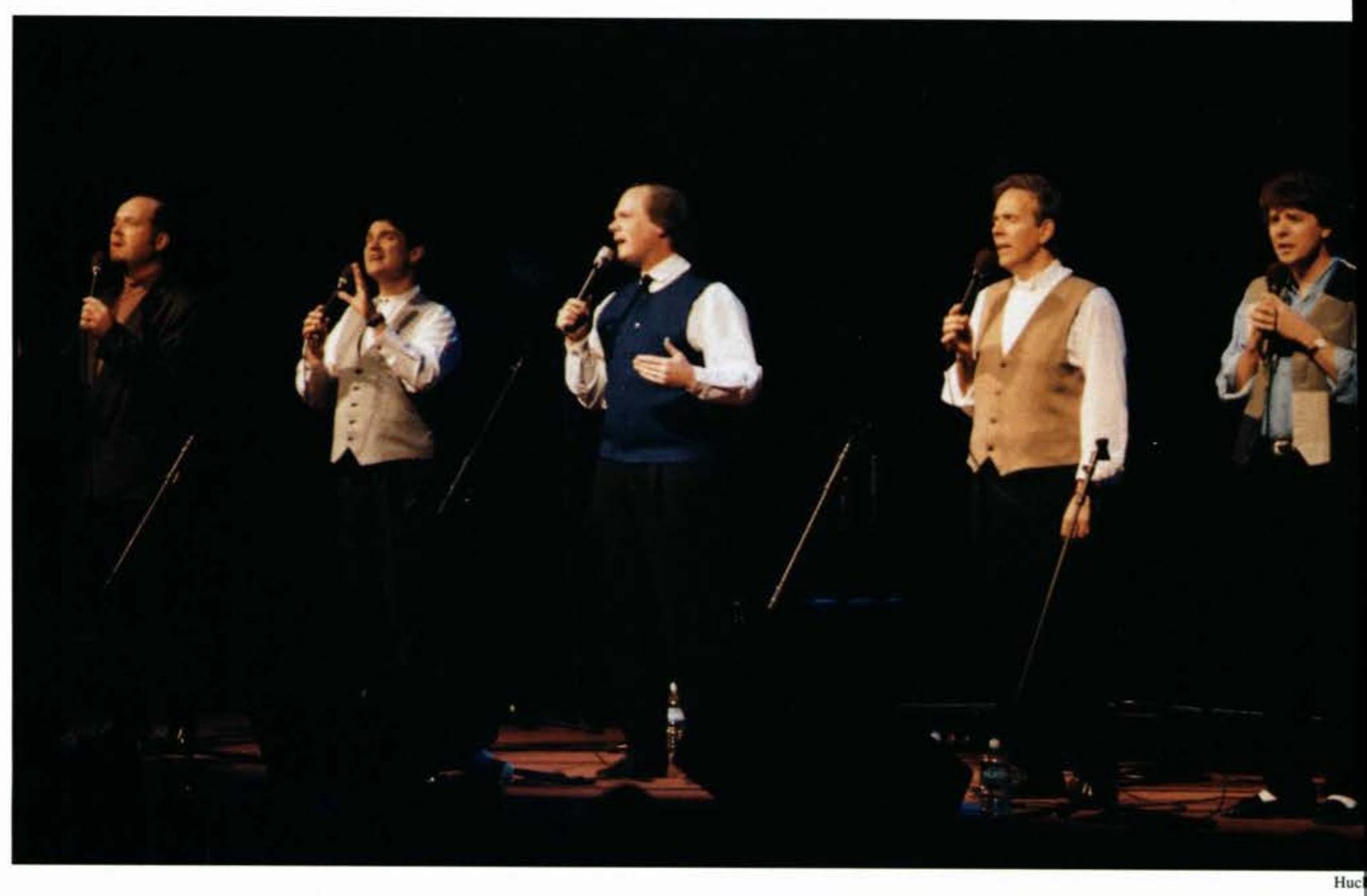




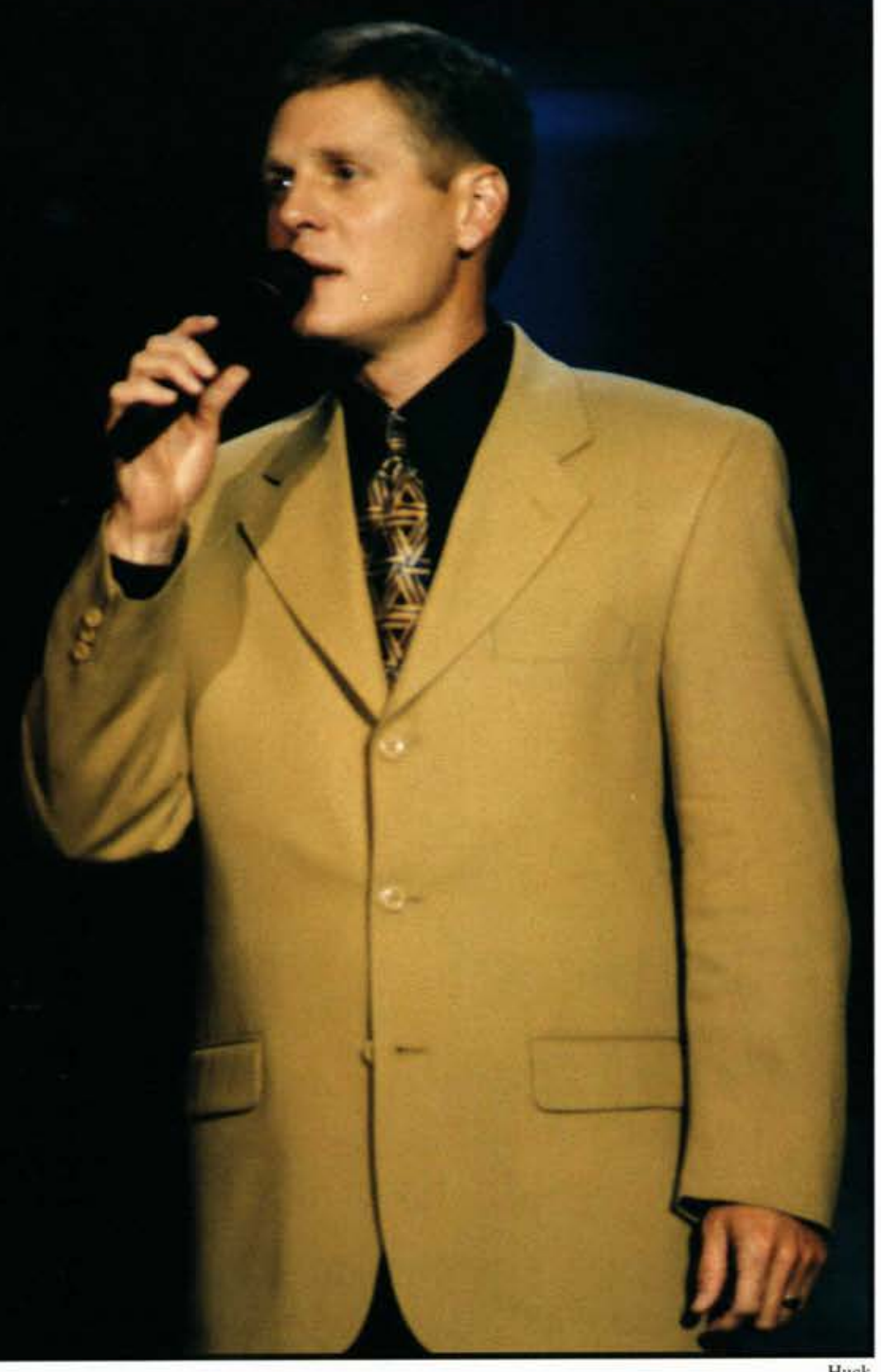

teve Green

appeared in a special

concert for Dayton

Christian Schools

(left).
- $\mathrm{n}$ energetic Michael w. Smith entertains in a concert after the Homecoming banquet (below).
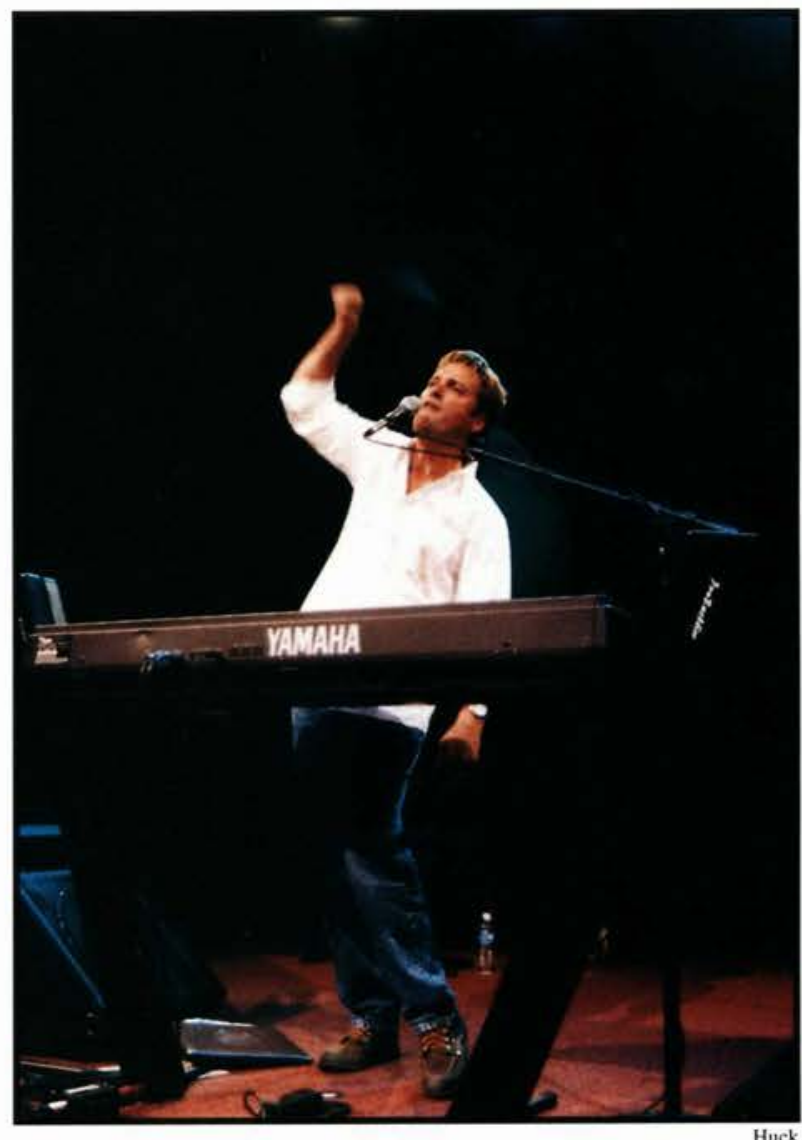
Grace.

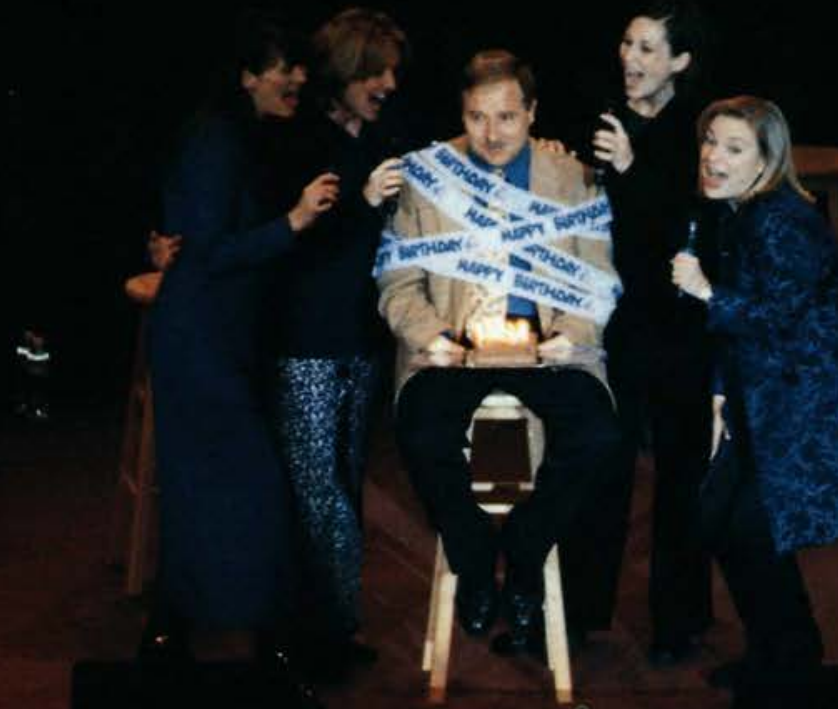



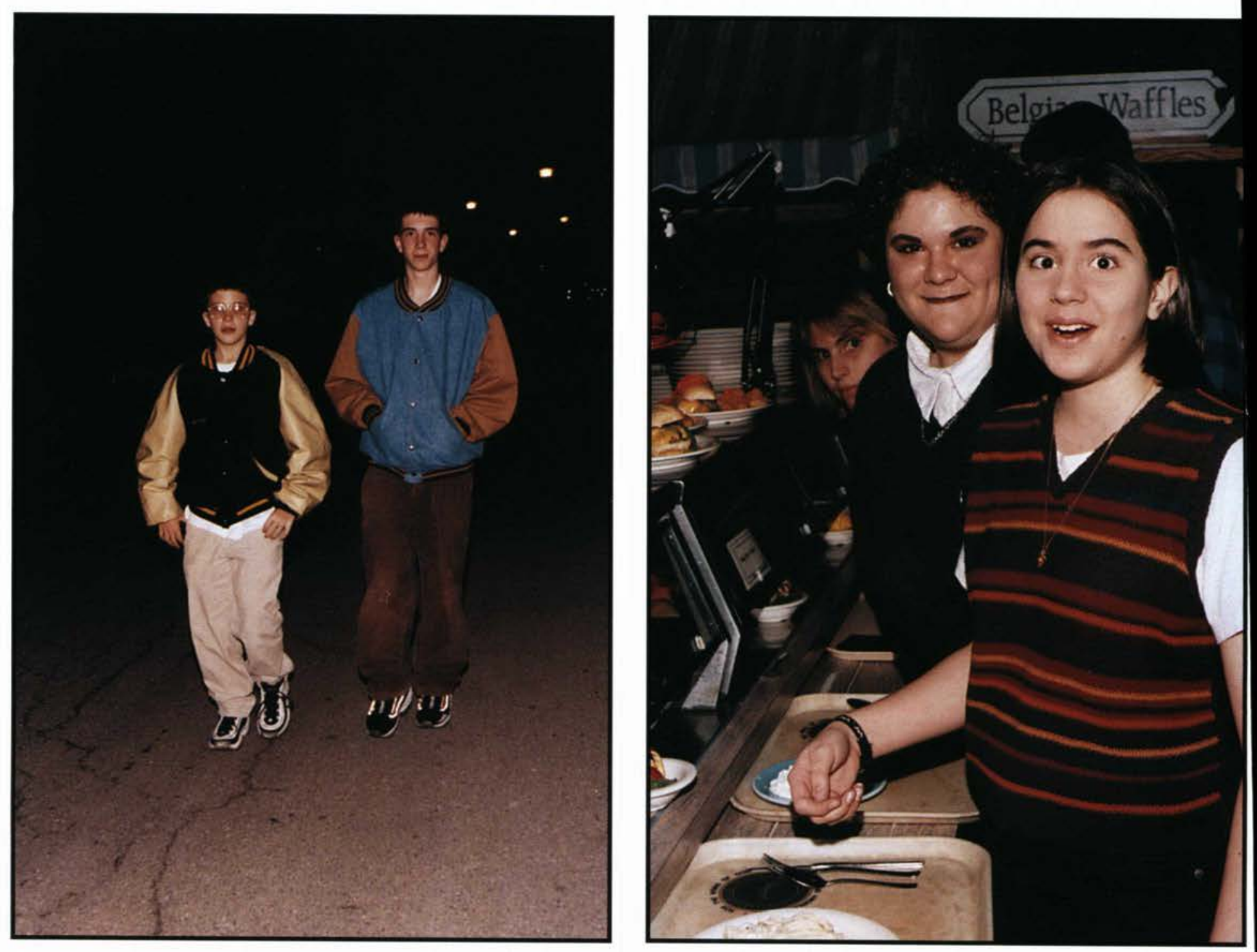

- dam Ballah and his lil sib take a walk to Mom and Dad's. (above left)

Oosalyn Jones surprises her lil sib with some shepherds pie. (above right)

Fill Townsend challenges her lil sib to a game of pool in the $3 \mathrm{M}$ building (the Mitre Center).

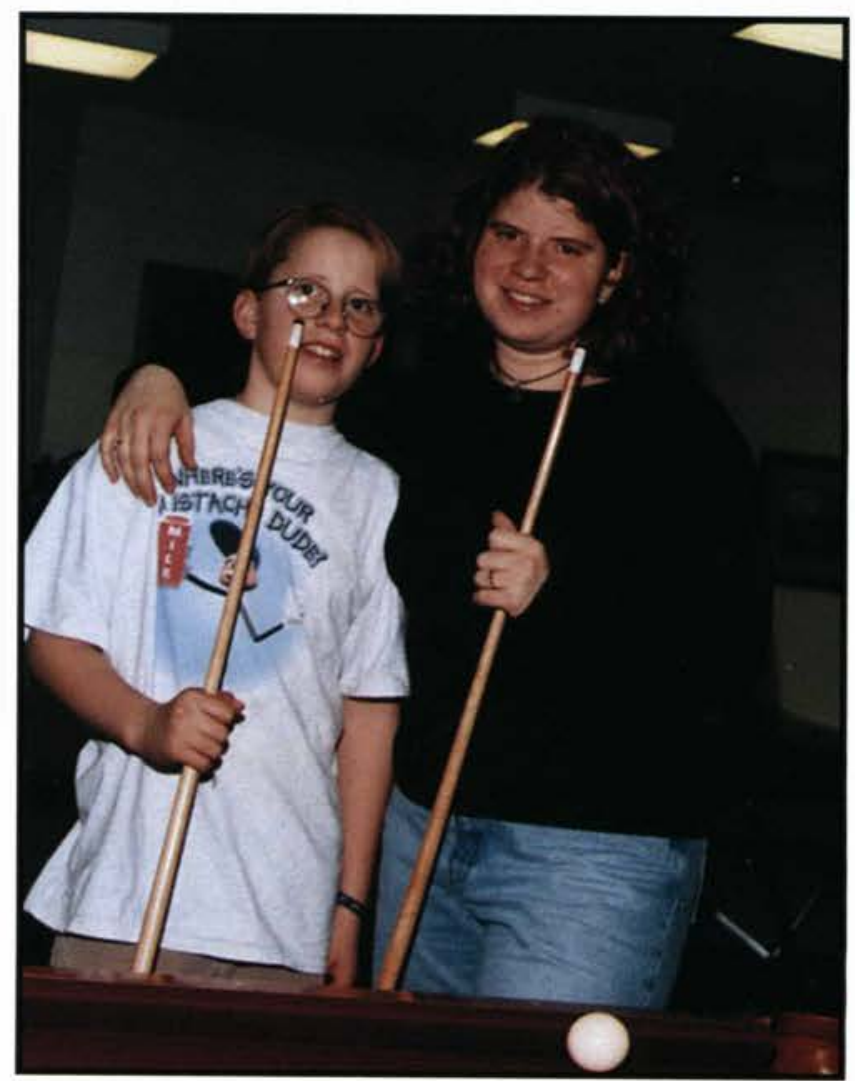




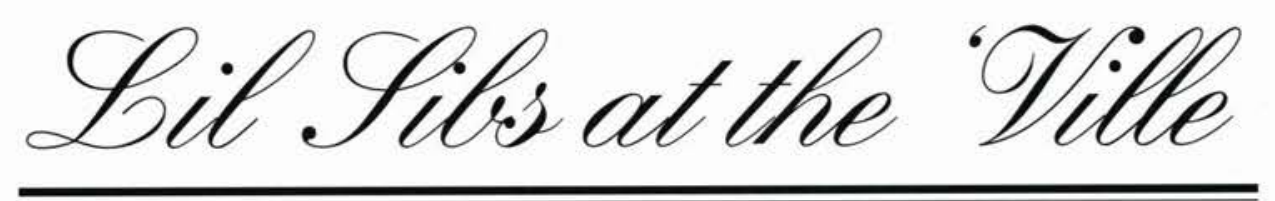

\section{A $F$ a $m$ i 1 y $G$ a $t h$ e $r$ i $n g$}

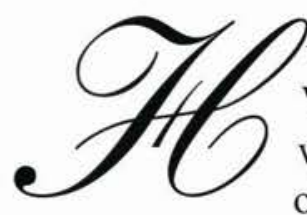

undreds of kids and teenagers invaded Cedarville February 13-15 for Li'l Sibs Weekend. This weekend provided siblings with the opportunity to explore our world. Boys followed their older brother's lead around campus, and girls mirrored their older sister's relations with people. Siblings, cousins, and younger friends alike absorbed the atmosphere of Cedarville College.

Li'l Sibs Weekend offered several opportunities for visitors to see their college sibs in action. The weekend exploded with the Winter Games in the AC. Coordinated by CAB, students and visitors had a variety of events in which to compete. Pitching contests, mountain climbing, velcro-suit obstacle challenge and a bungi run. In between contests, sibs had personal caricatures drawn or participated in karoki. Siblings used these games as warm-up for late night activities. This year, late night skate and late night bowling were highlights at the midnight hour. In addition to these activities, the Lab Band presented a free concert in the Jeremiah chapel to accommodate those jazz loving visitors, or those without energy for the Games.

A baseball card show was held Saturday afternoon. Then Saturday evening, Cedarville Jackets were the highlight. Next generation Cedarville fans grooved with the pep band and cheered on the players with "we back the Jackets all the way!" After the game, students and sibs moved up to the Second Floor for ADO/DOE's annual Cupid's Bash.

Helping kids with their trays at Chuck's, being cautious on sidewalks when rushing to class, and enthralling them with dorm life is a welcomed treat for Cedarville students.

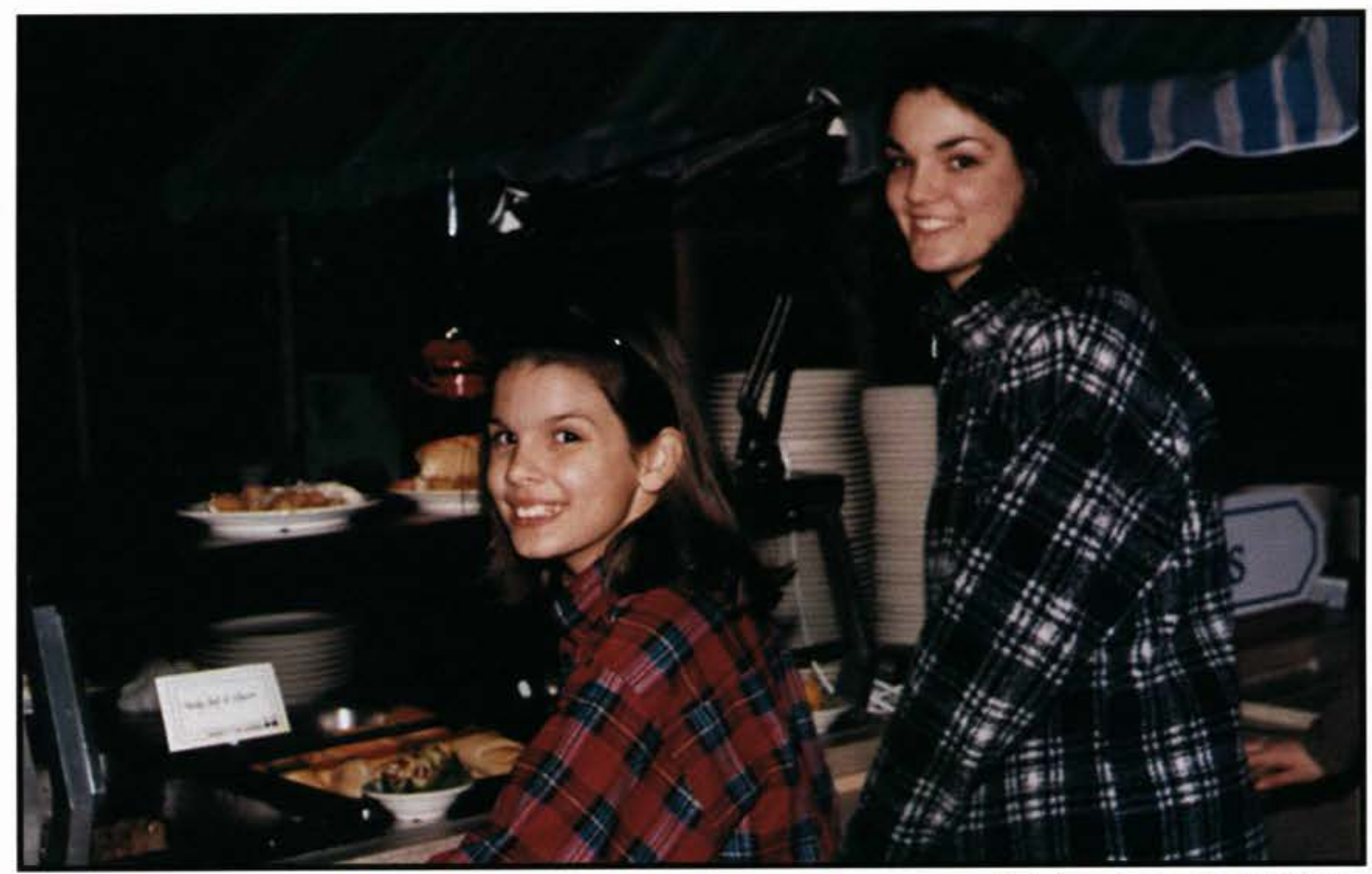

all photos submitted by Blackburn Caren Meyers takes her lil sib to meet Chuck McKinney and to taste some college cafeteria entrees. 


\section{Career Linfis:}

\section{Recruiting for Jobs, Internships, and Graduate Studies}

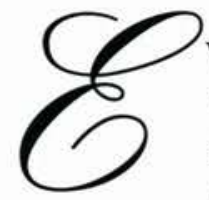

very quarter the Career Services Office invites businesses, colleges, and various other employers to come to Cedarville's Career Link Days to recruit college students for jobs, internships, or graduate studies. These days make employers more accessible to students and give employers a chance to recruit some of their best future employees.

CareerServices had a great turnout at the Business andCommunications CareerLink Day. Twenty-eight companies visited the college to recruit fresh talent on this day. Students attended the job fair and spoke to representatives of companies such as AirTouch Cellular, Aerotek, State Farm Insurance Companies, Mycom, and Sherwin-Williams Company.

Career Services also held a Career Link Dayfeaturingseminariesandgraduateschools

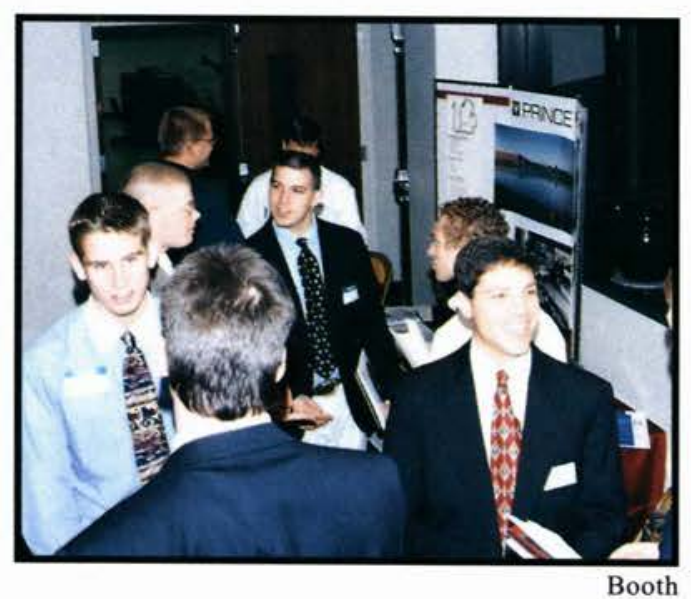

from many states. The seminaries and postgraduateinstitutionssetuptheirdisplaybooths inside the Dixon Ministry Center. Baptist BibleSeminary, Masters Theological Seminary, Trinity Seminary, GrandRapids Baptist Seminary,Biblical TheologicalSeminary, and ColumbiaBiblicalSeminaryallattended the conferencetointerview prospectivestudents. CareerServiceshostedaCareerLinksdayfor
Engineering,Science, andMathintheEngineer Nursing,andScienceBuilding. Thiseventbrou representativesfrom theU.S.Navy,LucentTe nologies,BetaLaserMike,LincolnElectron PrinceCorporation, OhioElectronicEngrav andotherstocampus.

In January, Career Services hosted Social Services Day. Among the organi tions present were Shepherds Home, Te Ranch, Lifeway for Youth and Toward dependence. Students had the opportun to interact with employers they norma might not have been able to meet.

Career Services also brought in car recruiters, Christian Schools, healthcare ganizations, and international businesses career days throughout 1998.

Although Career Days are primarily activity forseniors, manyjuniorsparticipated theevents. Thisdemonstratestheinitiativea drivethatcharacterizesCedarvillestudents

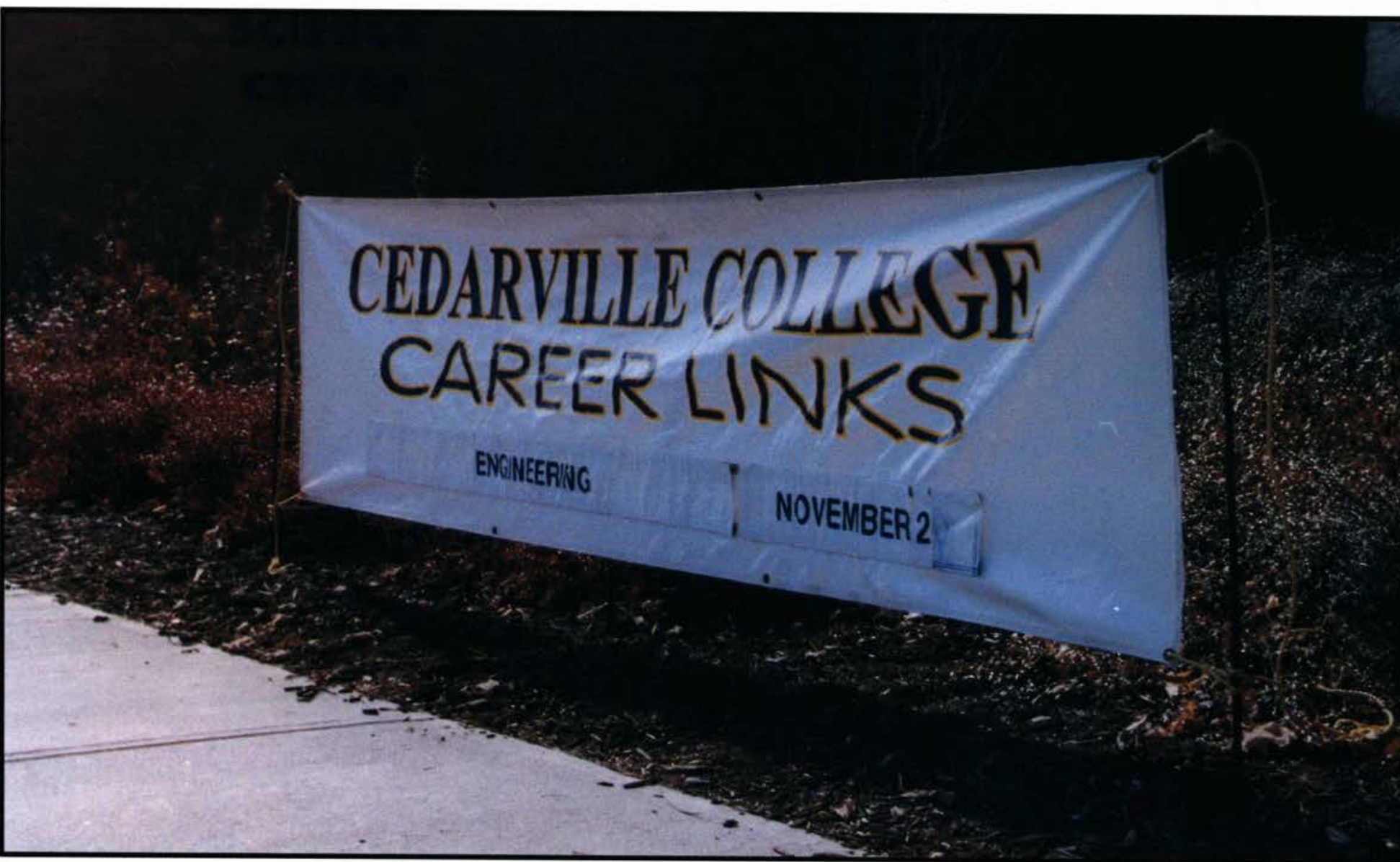




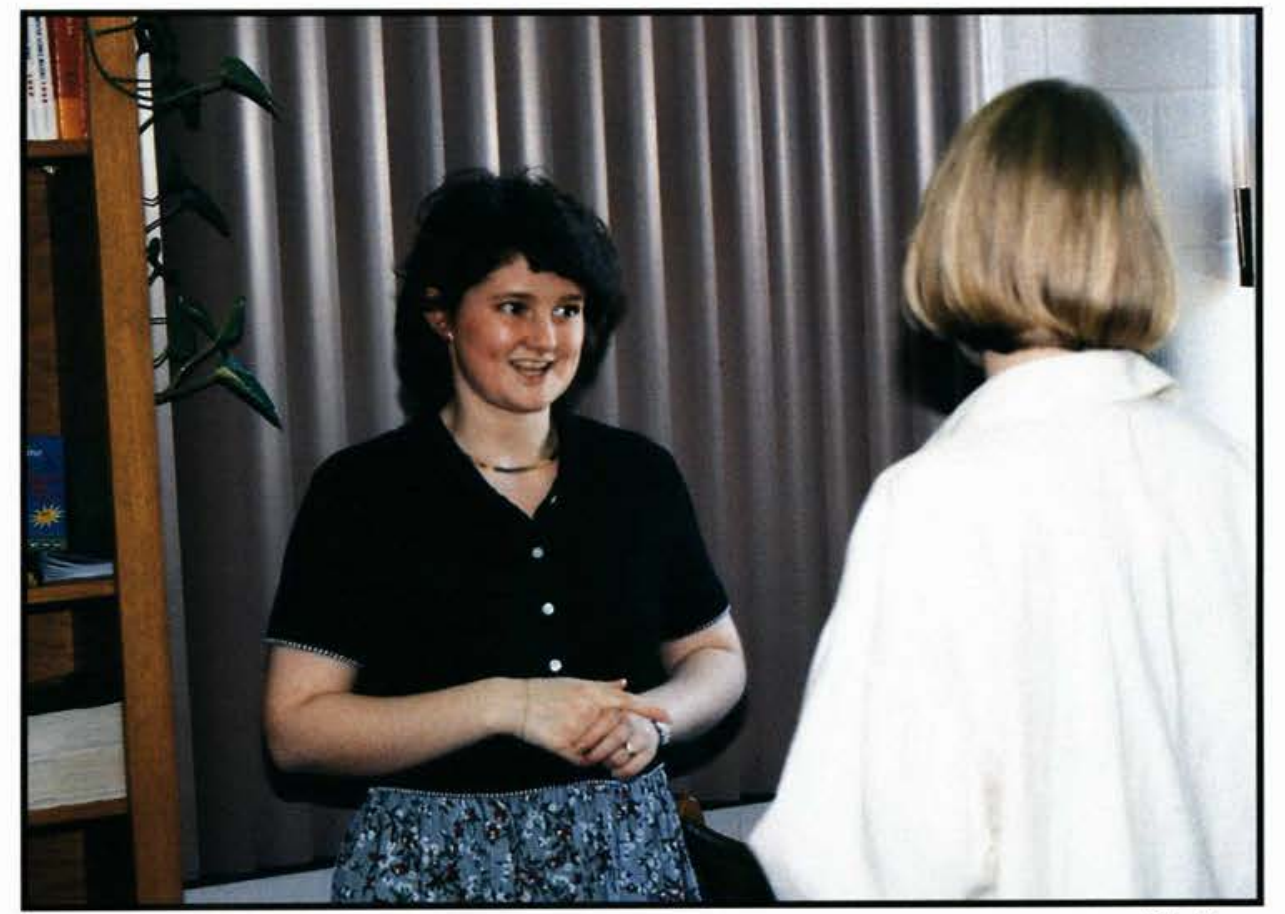

Blackburn
Deborah Campbell (left) is one of the many helpful staff members in Career Services.

Rob Bouwens (below), a mechanical engineering major, gathers vocational informa-tion in that field.

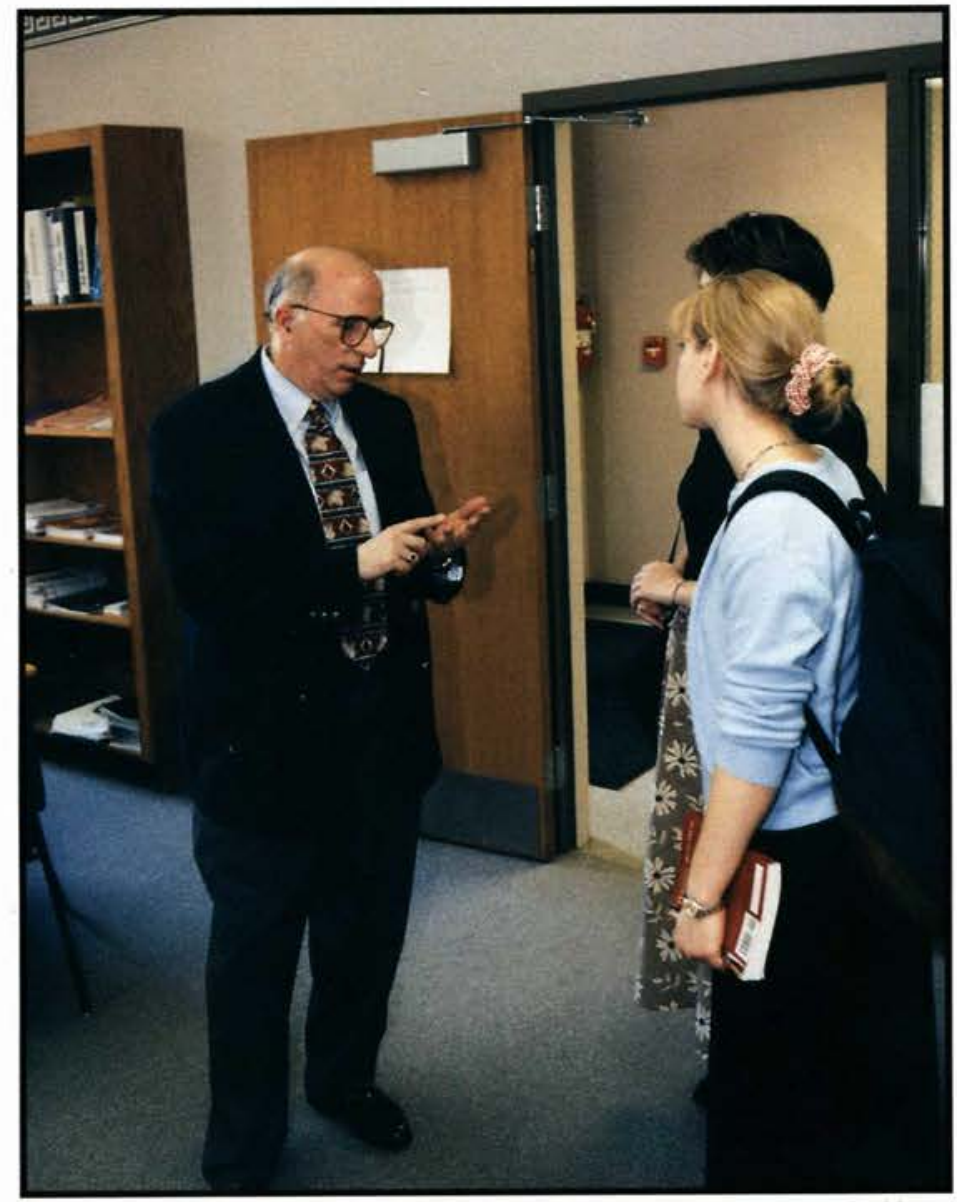

Blackburn

Lew Gibbs, director of Career Services, has brought 31 years of experience from IBM to Cedarville College.

$T_{\text {he Career Services' banner stands at the engineering }}$ career links day, one of the seven career links events.
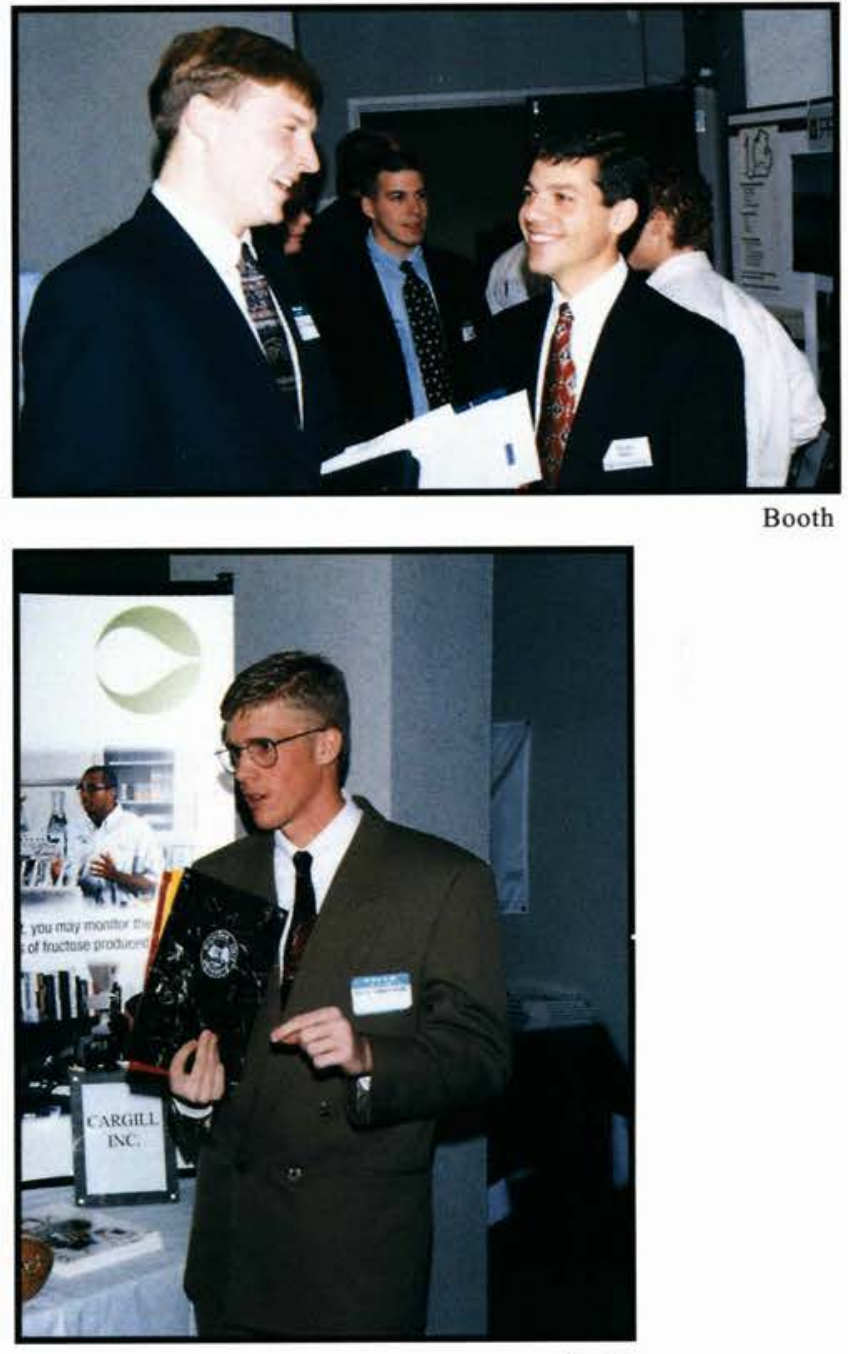

Booth

Eric Steenwyk searches for information about Cargill, Inc., a chemistryrelated company. 


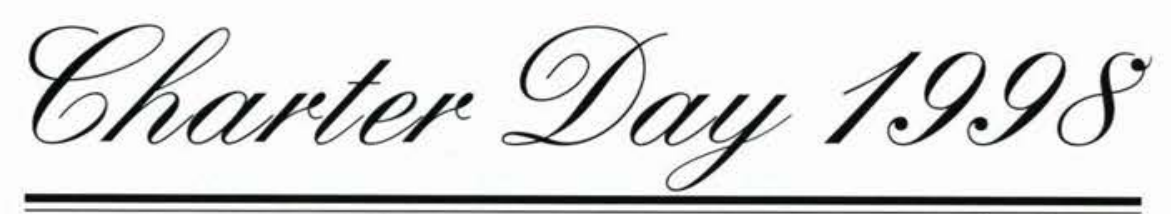

Cedarville's 101 st Birthday

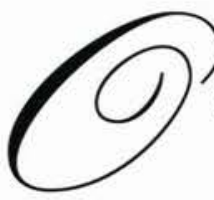

n January 26, 1998, Cedarville College celebrated its 101 st birthday since the building of Founder's Hall in 1897. Symphonic Bandand Jubilate helped to lead the festivities during the Charter Day chapel through special music. Symphonic band played a rousing rendition of Cedarville's alma mater.

The guest chapel speaker was Dr. Timothy George, senior editor for Christianity Today. Dr. George gave an inspirational message on faith and assurance of salvation. He told of Martin Luther's search for a gracious God and his journey to find the Lord and have an intimate relationship with Him. His last words were, "The body they maykill, theKingdomabideth still." This promise was especially important on Charter Day as we examined the past, present, and future of Cedarville College.

Some have said that there are three ingredients for Cedarville's success: a strong constituency, strong leadership, and strong community support. The College has been richly blessed because of its foundation and God-honoring priorities of devotion to Christ, an academically strong, God-honor- ing education, and service to the community. From two graduates in 1898 to 410 in 1997 , God's blessings of growth and strong leadership are extremely evident. Our past presidents have left a legacy of dedication to God and a desire for college growth, and this legacy is being carried on by our current president, Dr. Dixon. If we continue to look to our Savior and our godly heritage for guidance, the 21 st century will also be marked by a superb quality of education and a never-ending devotion to Jesus Christ our Lord.
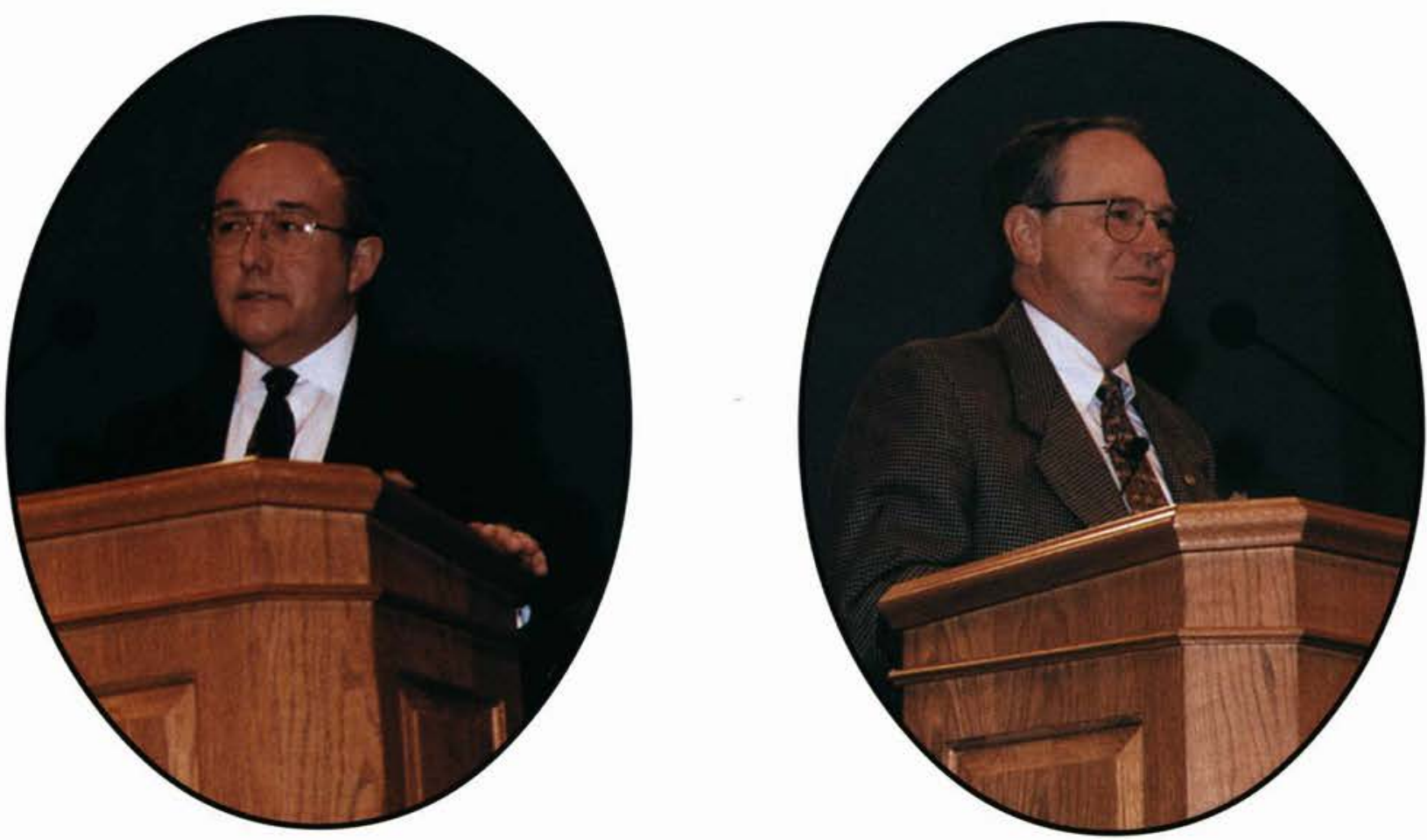

Pictured above are History Professor, Dr. J. Murray Murdoch (left), and Cedarville College President, Dr. Paul Dixon (right). both photos by David Blackburn 


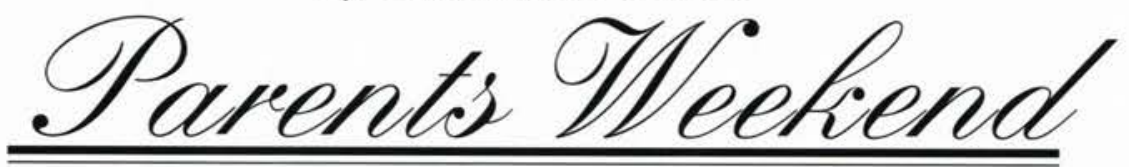

$\mathrm{Parents}$ We e ke nd 1998

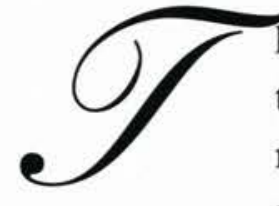

he smell of fresh cut grass, the decorative floral arrangements, and the mobs of parents again signals to the student body that parent's weekend has arrived. Many parents came to the chapel service Friday to witness their sons and daughters receive awards in the Honors Day chapel. Others streamed in from all over the country to visit with their students and share in their Cedarville experience.

Many students panic at the thought of entertaining their family for a weekend, but the college provided a plethora of activities and concerts for families to enjoy. The spring play, The Heiress, ran for its second week while the old radio show On the Air, ran at the historic Opera House. In-between shows, parents and students could enjoy complimentary hotdogs, sandwiches, and horse-drawn carriage rides. The weekend concerts were again the Pops Concert, featuring the Symphonic Band, Chorale, Men's Glee Club, Brass Choir, and Lab Band. Dick and Mel Tunney provided the entertainment for the Saturday night Artist

2. ick Tunney smiles as he entertains the crowd. (top)

A dina Andrews and her parents head out for the evening after the Artist Series. (center)

Goncert Chorale joins Mel Tunney as part of the Artist Series. (below)
Series. Unfortunately, the fire alarm added a bit of extra percussion to the performance, yet the audiences still enjoyed the music and ministry of the Tunneys.

Although showers filled the weekend, periods of sunshine persisted, which gave parents an accurate perception of Cedarville's weather. Parents' weekend provides a unique opportunity for students to share with their families the professors, classes, and friends they have at Cedarville and the work Christ is doing in each of us.
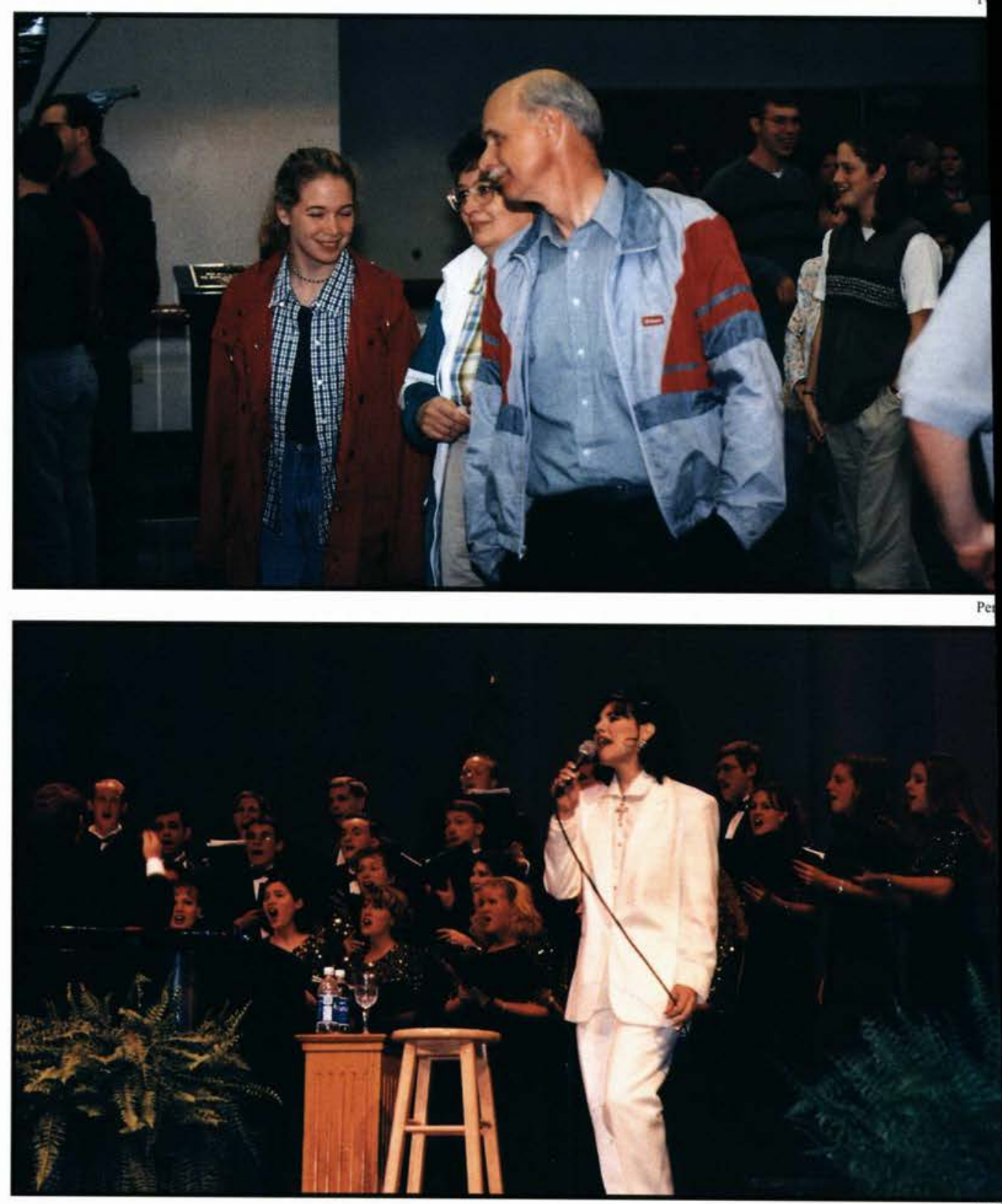


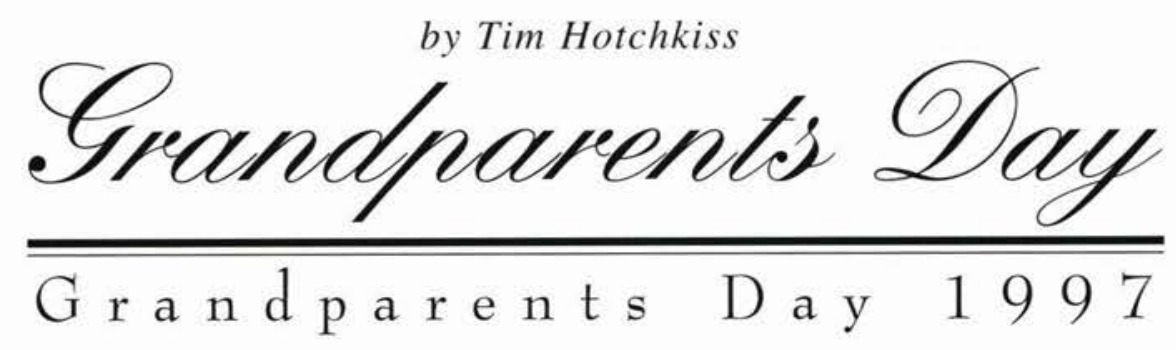

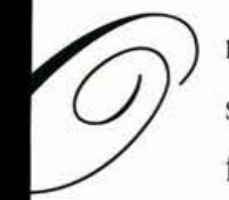

n Friday, November 14th, six hundred grandparents filed into the chapel for the tenth annual Grandents Day chapel. Grandparents day is elebration of families, and many gentions of families were able to come ether at Cedarville and enjoy fellow$p$ with each other this year.

The Friday morning chapel hour was ely dedicated to the grandparents. Durchapel, each grandparent received a sage or a boutonniere from their reective grandchild. The Campus Acities Office helped hand out the flow-

Performing on stage that morning re the Symphonic Band, the Concert orale, and the Lifeline Players. A video aired on the big screen with students talking about what grandparents meant in their lives and why they were important. Senior communication arts major Alissa Whitten and junior finance and accounting major Matt Hamer emceed the events.

Included in the chapel hour were special giveaways called "Get to Know the Grandparents," and the members of Campus Activities helped out by running up and down the stairs with the roving microphone. Some of the categories were the grandparent that traveled the furthest, the oldest, the youngest, the grandparents with the most grandchildren, and the grandparents who had been married the longest. The results were surprising. Many grandparents have celebrated the golden anniversary, and one set had been married for 62 years. One set of grandparents was very pround of their 23 grandchildren.

During their stay, each grandparent received a free lunch pass for a meal on Friday, a coupon for the bookstore, and an invitation to a reception held by Dr. and Mrs. Dixon in the Dixon Ministry Center Friday afternoon. Both Dr. Dixon and Mrs. Dixon greeted them as they arrived to this reception. Many grandparents also attended the play, Marvin's Room, during the weekend and an exciting basketball game on Saturday night.

No doubt, all of the grandparents felt very honored to be recognized, and they enjoyed spending time with their grandchildren.

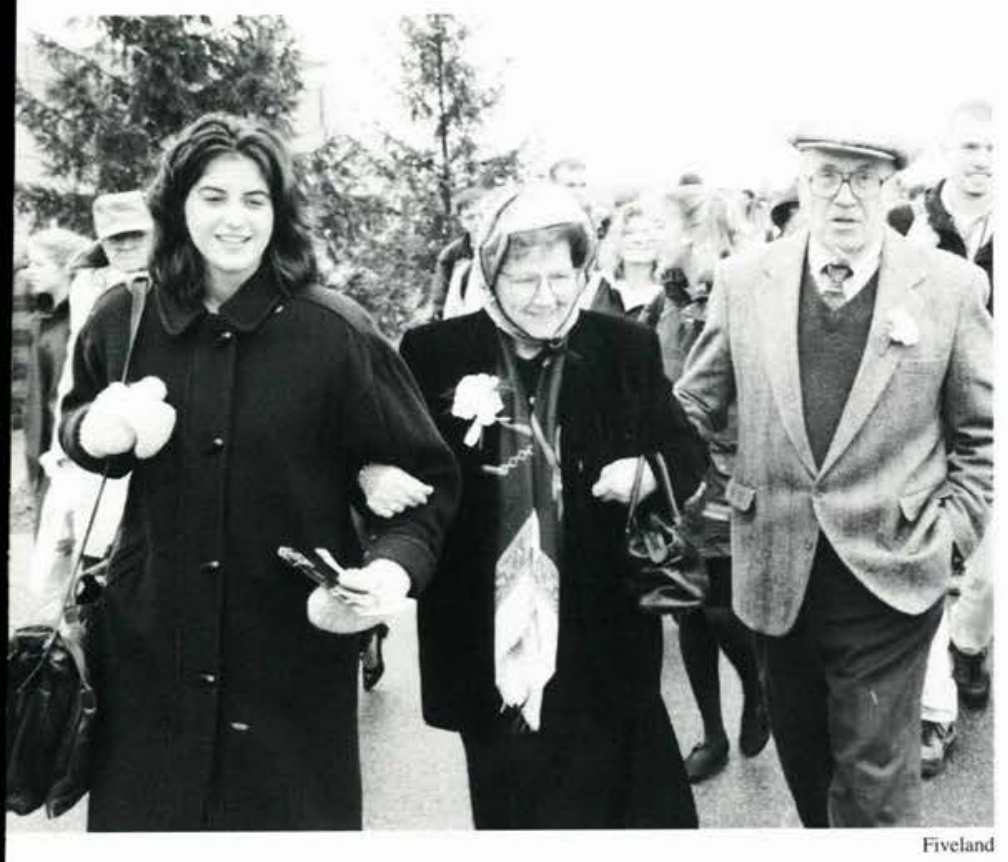

Carrie Mansfield and her grandparents lead the way on the walk from chapel.

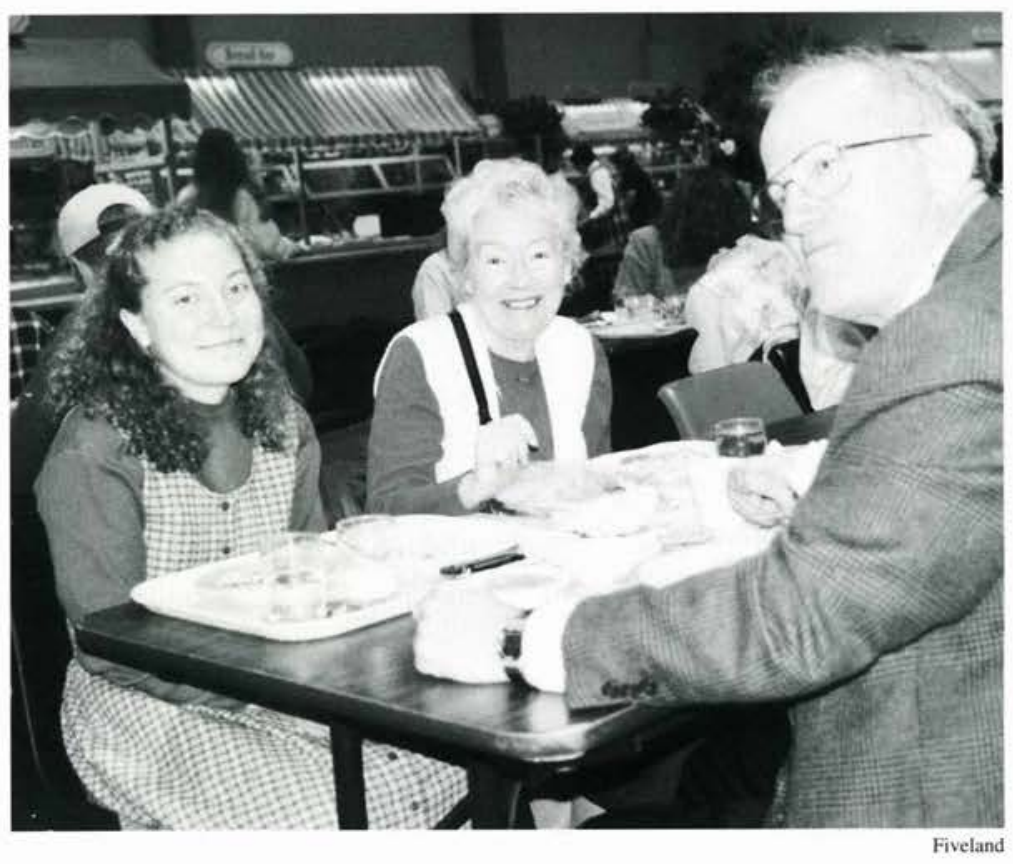

Celanie Lehman's grandparents enjoy a meal with her at Chuck's. 
ACADEMIC

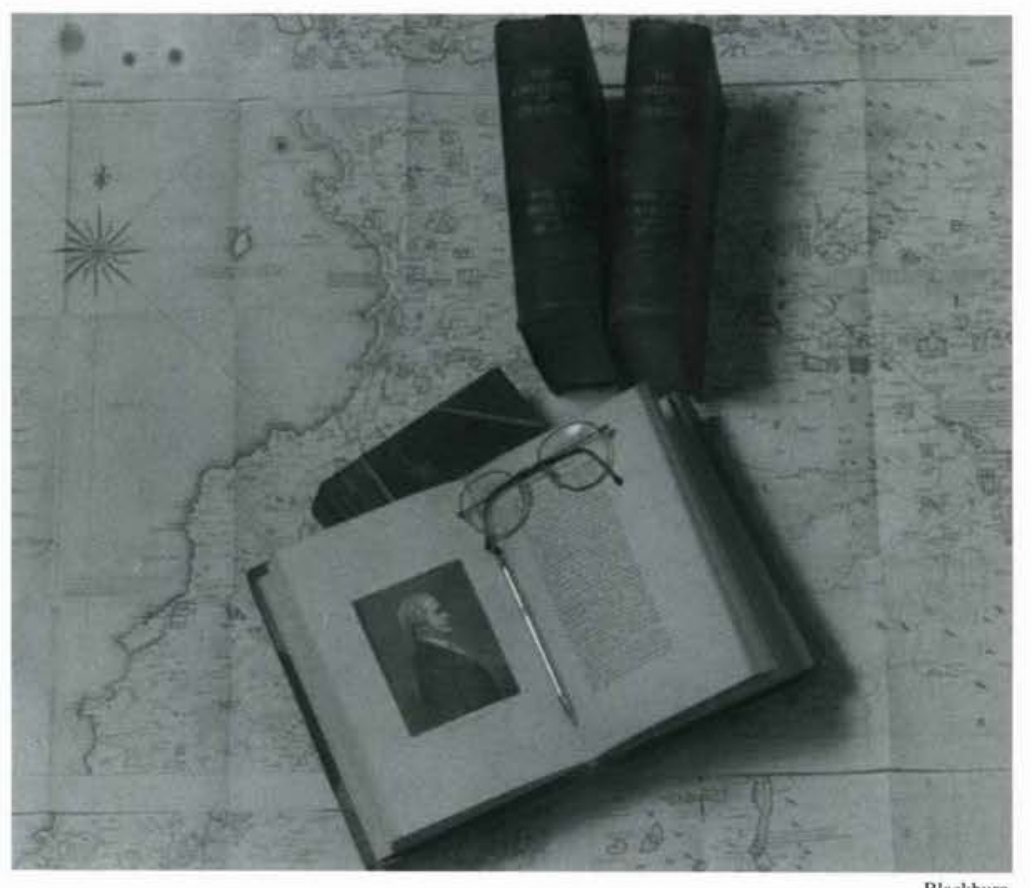

LIFE 



\section{Gedarville Gollege. Facully}

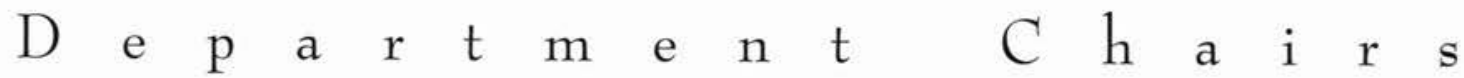

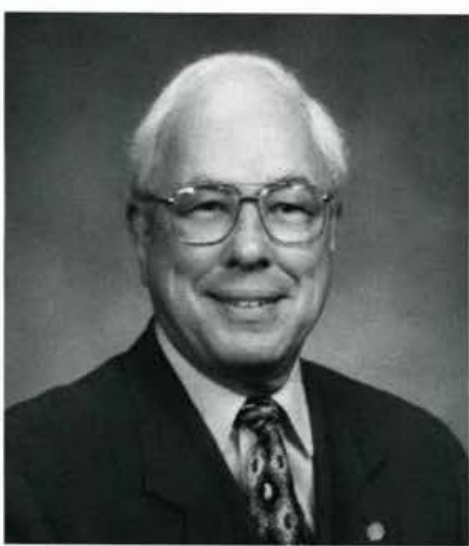

Fack Roiggs. Th. 2 .

Biblical Education

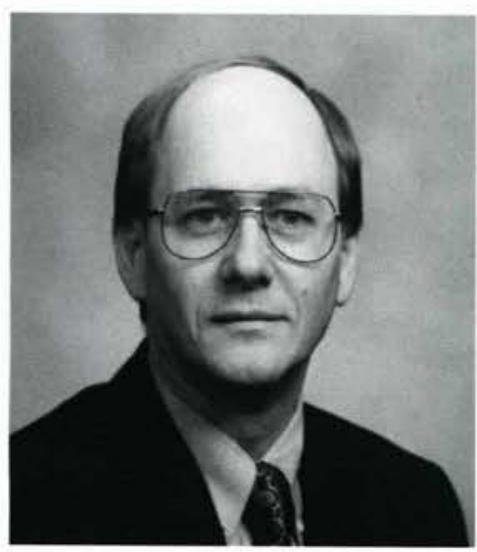

Saurvence Eavodney, $\mathscr{P} / . \mathscr{Q}$.

Engineering

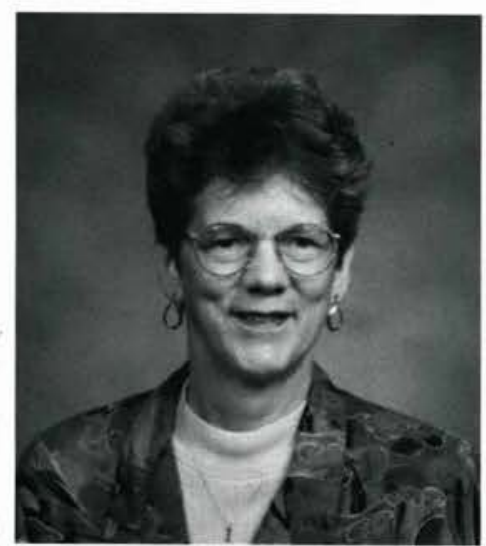

Trene Allym. Ph:

Nursing

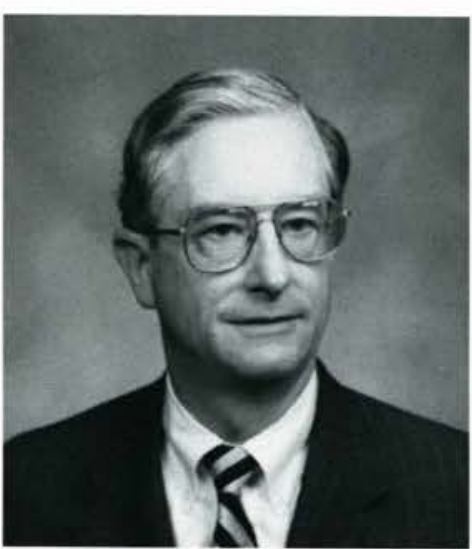

Marimus, Hasen. NG. S. t.

Business Administration

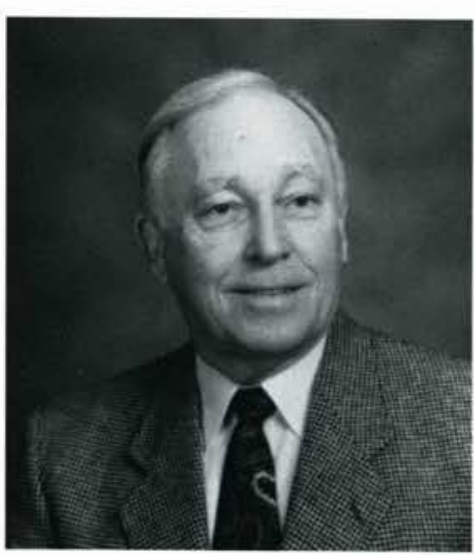

Tonald Gallan. Ph. D.

Health and Physical Education

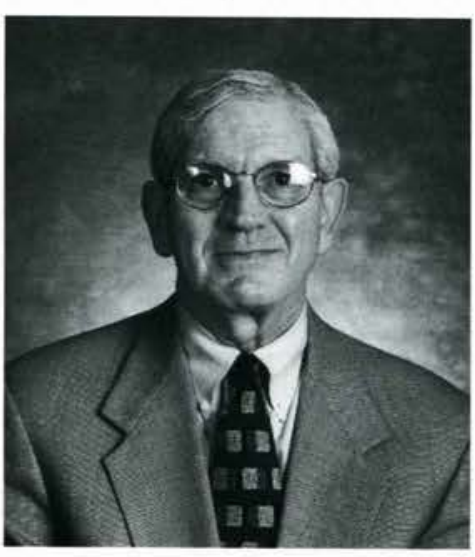

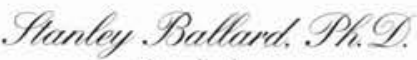
Psychology

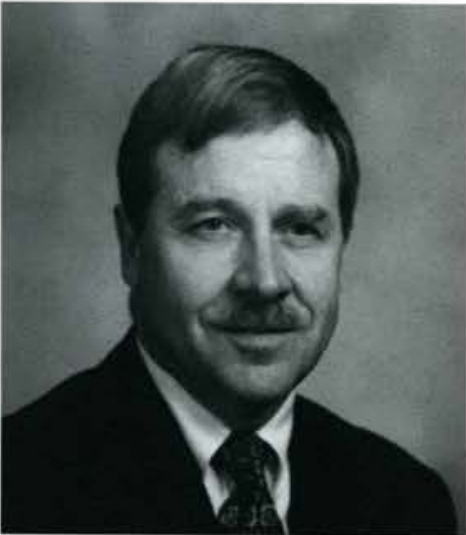

Tames Phippis:Ph:D.

Communication Arts

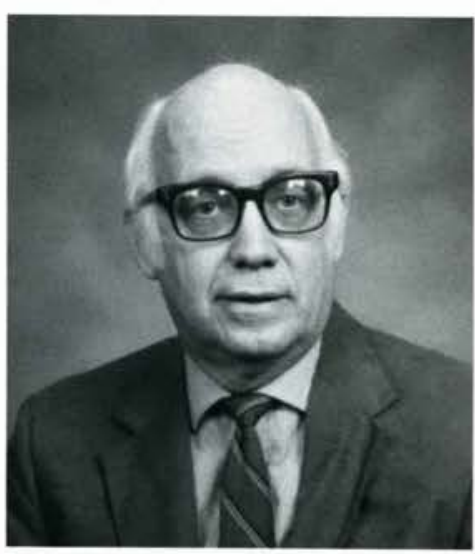

Ray, Rartholomeut $\mathscr{P} / \mathscr{D}$.

Language and Literature

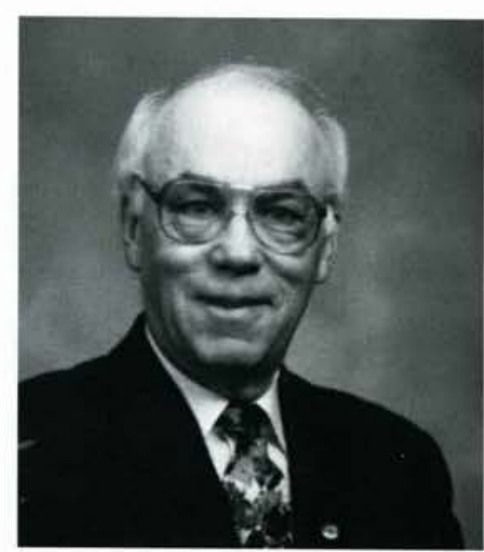

Daniel Wesed. PP. D.

Science and Mathmatics

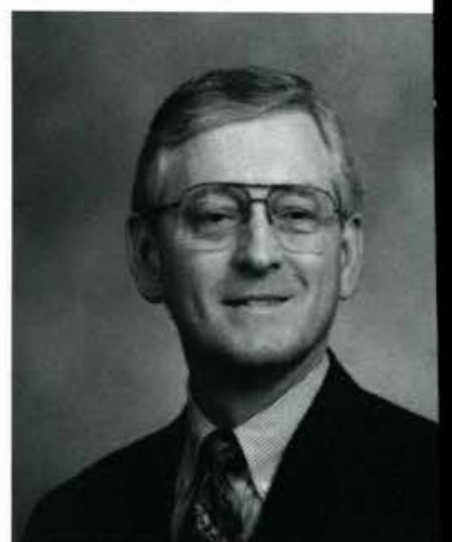

Merlim togen: Ph: $\mathscr{D}$. Education

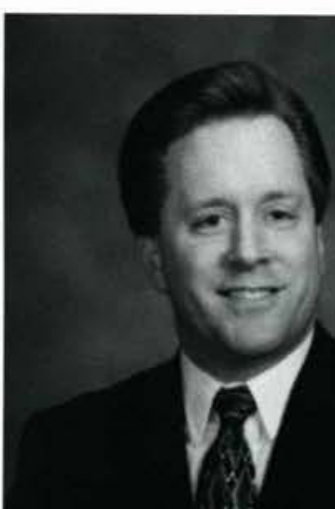

Tames Colman. Ph:QD. Music

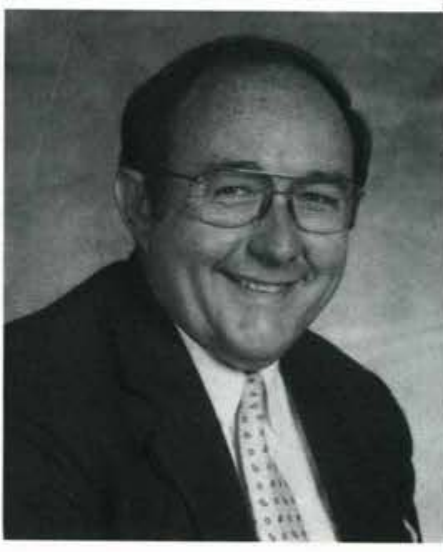

Mburray, Mburdoch, Ph: Social Science and History 


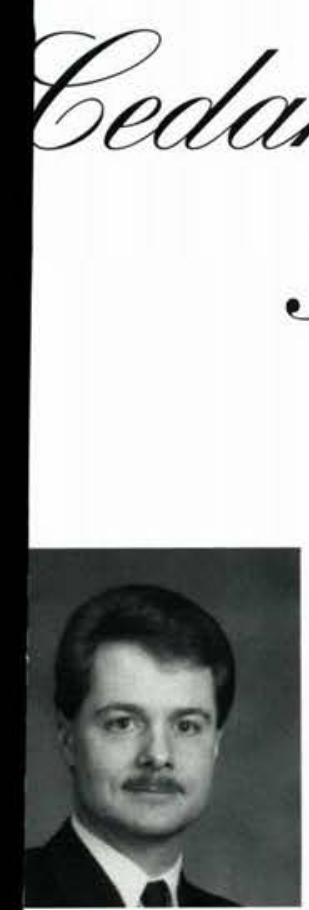

\section{Gart Buby} P/LY.

Associate Dean

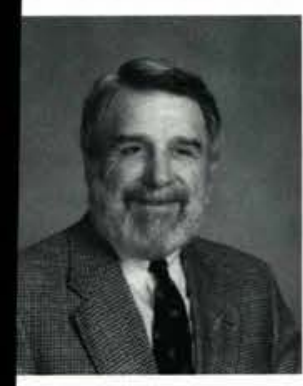

\section{Iravid Irullinger 2. Tlim.}

Biblical Education

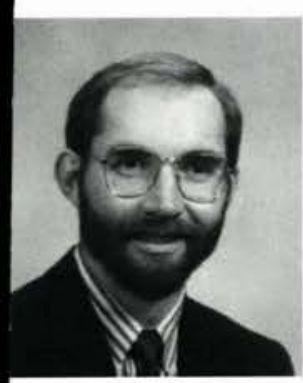

Chisis lbitler PhY

Biblical Education

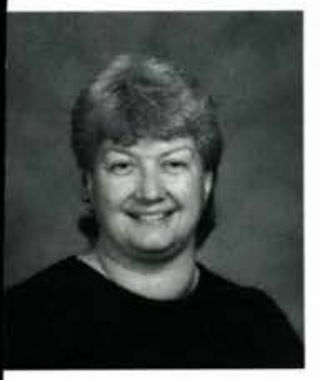

Mearthe Folinison ll.t.

Business Administration

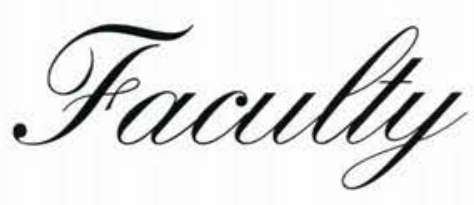

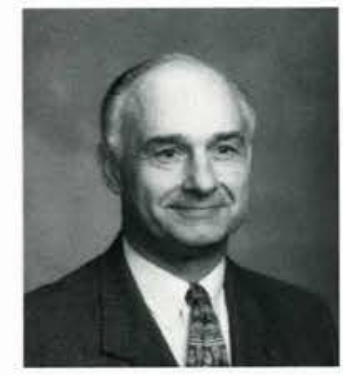

Charkis. Ellport

Assistant to the Academic VP

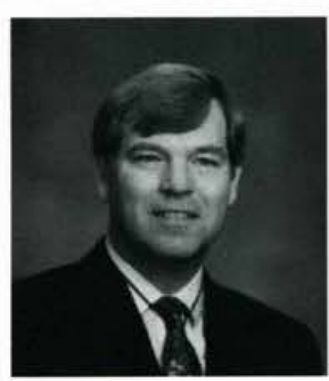

Floyd Elmene

Biblical Education

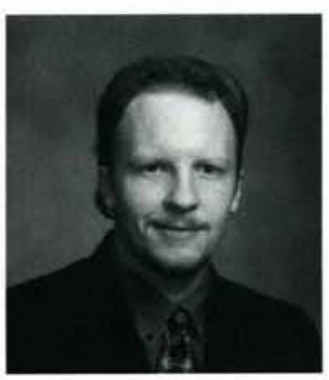

Surid. llills

Biblical Education

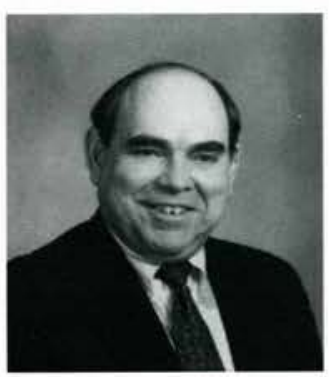

Sharon Fohmion V.S.T.

Business Administration

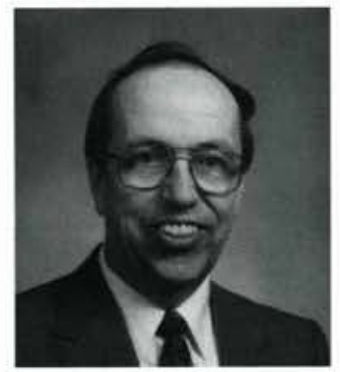

Iavid Rotman

Director of Computer Services

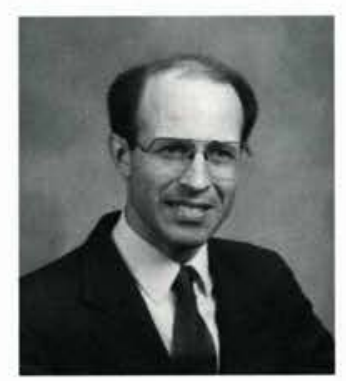

Ianid Gides

Biblical Education

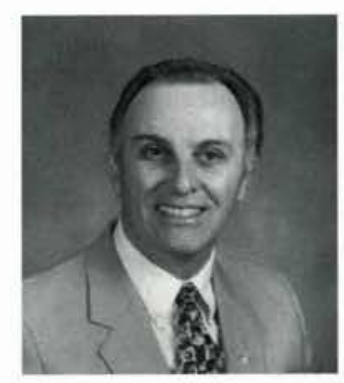

Inevid Wiarren

Biblical Education

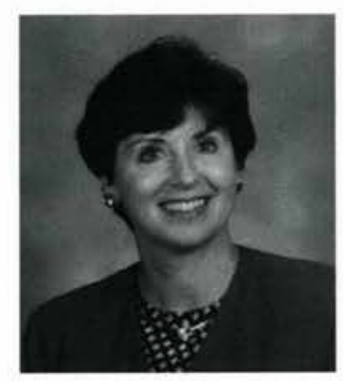

Bolly Come Il..

Business Administration

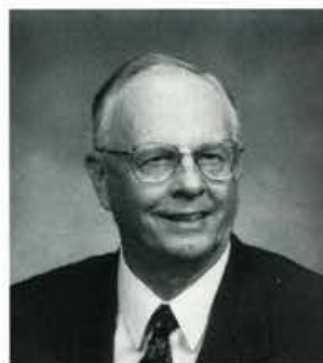

Eliffered Folumion Q. CD.

Assistant to the President

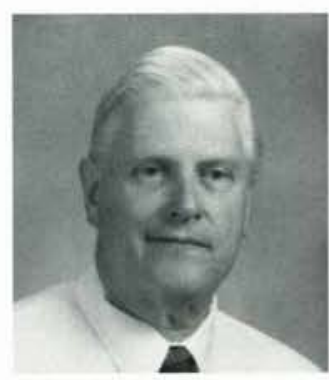

Fames Rirmsiad

Biblical Education

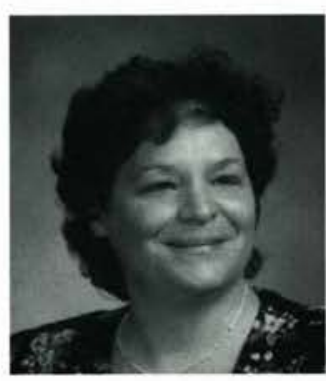

Eheryl Fourcell

Biblical Education

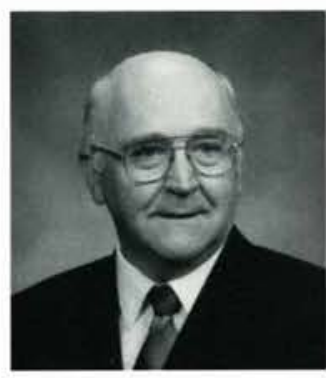

Brichard Batdurin

Business Administration

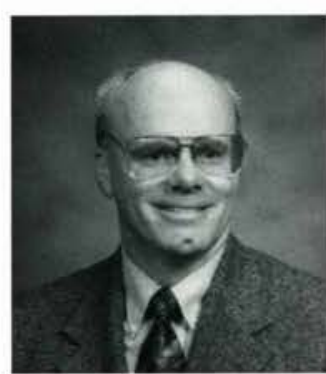

William Ragle $\mathscr{P} / 2$.

Business Administration

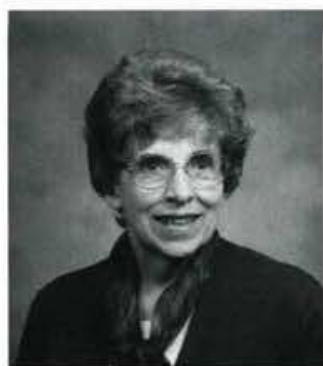

Tendera Enener Ib.T.

Director of Counseling Services

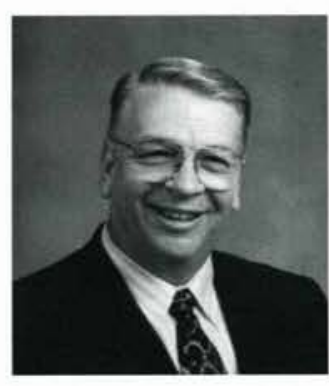

Richand Blumenilod

Q. Ibim.

Biblical Education

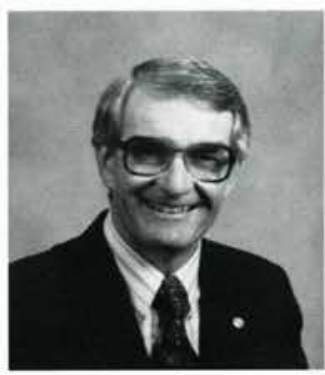

Ratien Siromacki Th.

Biblical Education

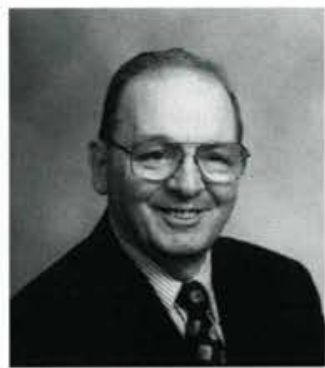

Elifferd. Foured

Business Administration

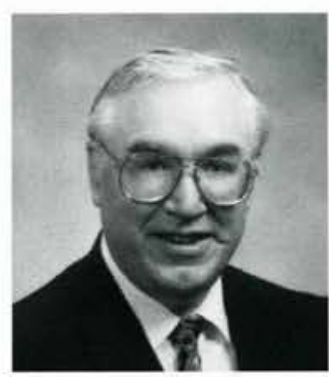
Solem Srmith
Il..S.

Business Administration

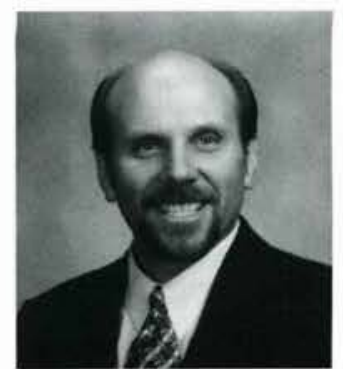

Fenathan Prirpite $11.6 \%$

Associate Dean

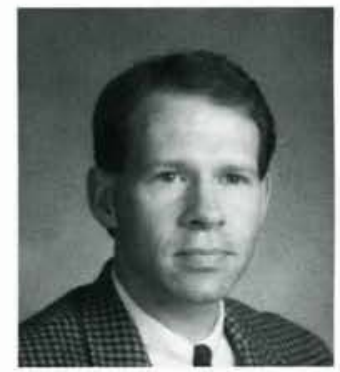

Sregory Gouser

Biblical Education

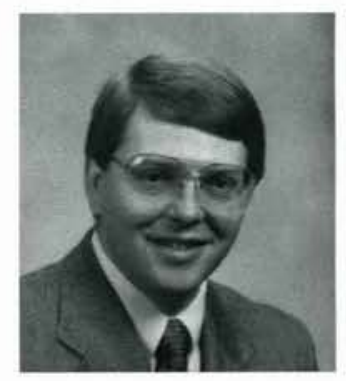

Thomes; Hutclision . Min:

Biblical Education

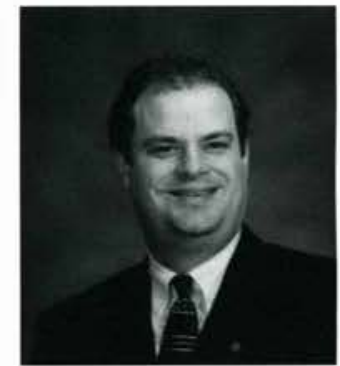

Foffrey Foucell

Business Administration

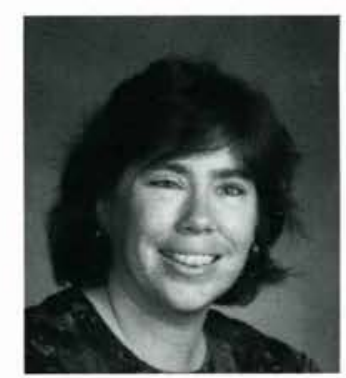

Sarratis Smith PhI.

Business Administration 


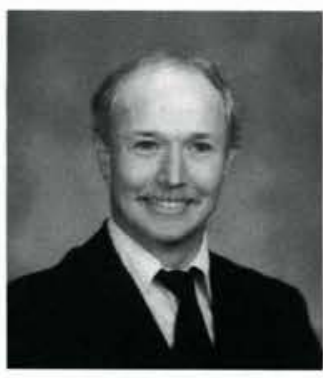

Heitey Sureelisen . I6.Y.

Business Administration

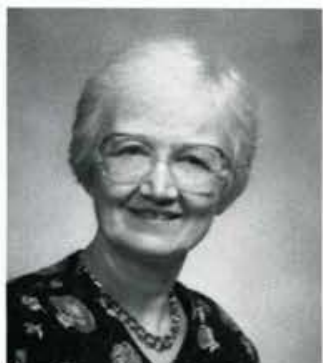

Siee. Batien

Ed.

Education

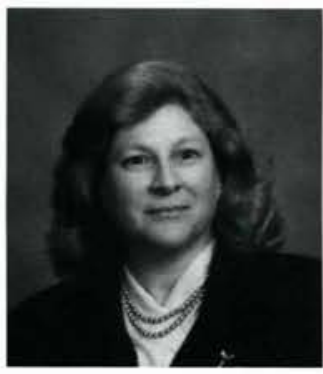

Carat Eils; 16. 7

Education

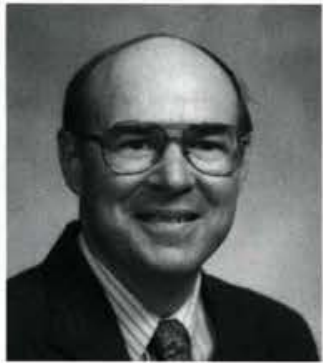

Harroned. Hegne Ph.
Ensineering

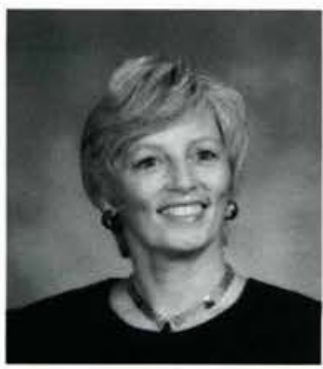

Teresen Elark Il. 1

Health and Physical Education

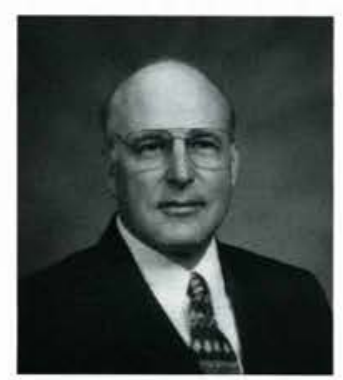

Romald Writher Q.R.t.

Business Administration

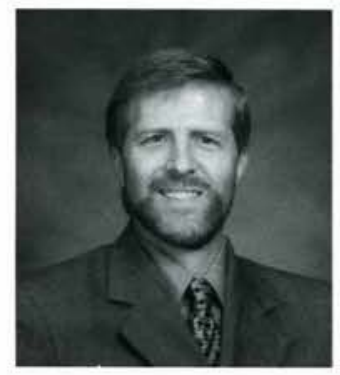

Philipe. Sowisedl

Education

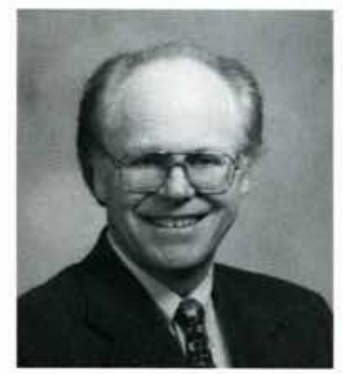

Deveryene. Frvent

Ed.

Education

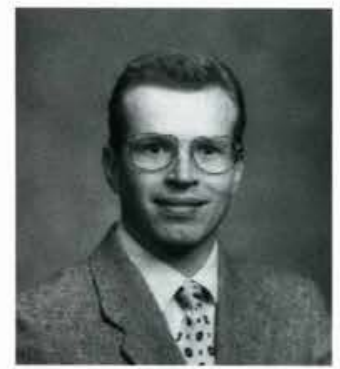

Elinem. Folil P/. $\mathrm{Y}$.

Engineering

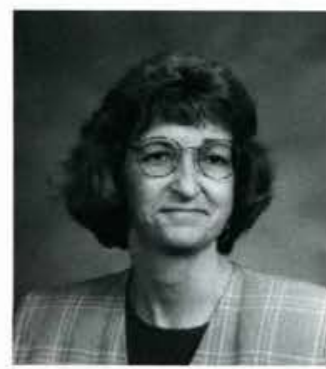

Fialletren Frovir

II. .1

Health and Physical Education

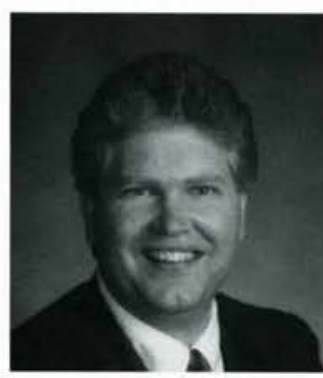

Fomes. Kromgel

.ll. I.

Communication Arts

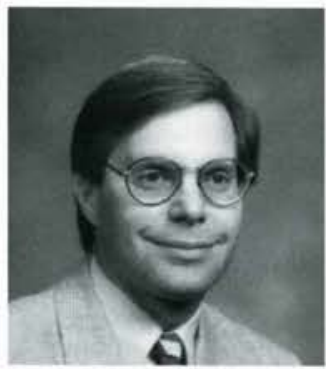

Edelin. Bermenam

P/. Y.

Education

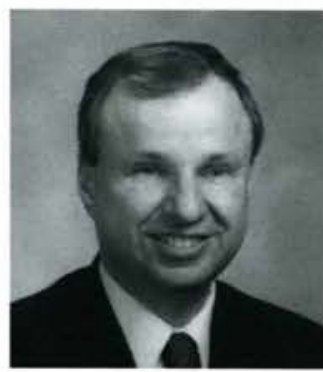

Tiruntriy Henlon

Education

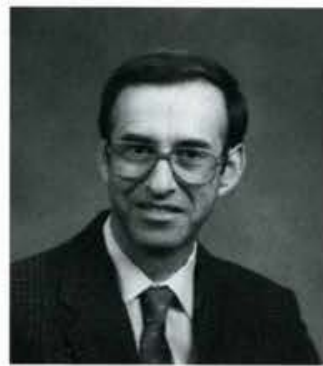

Ralied Larmenere II..Y.

Engineering

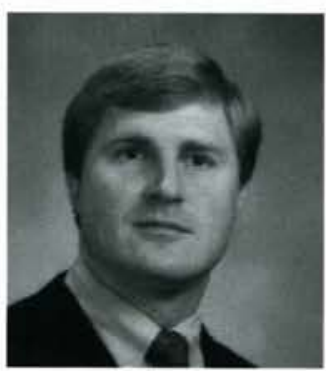

Eneme. Hellevid

P/.

Health and Physical Education

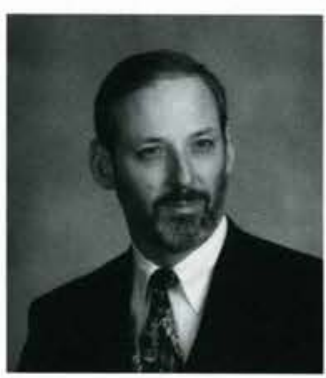

7. Mlidiand Lopies

PII.

Communication Arts

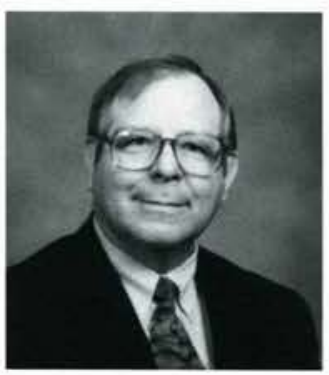

Cener Penentierger

Y.Ed.

Education

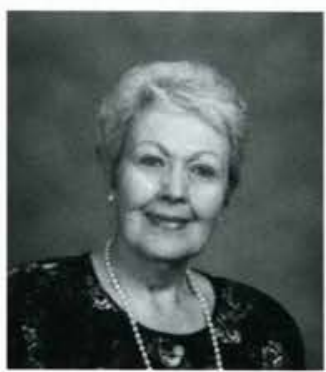

trumer Reulli. Mille

II.. 0.

Education

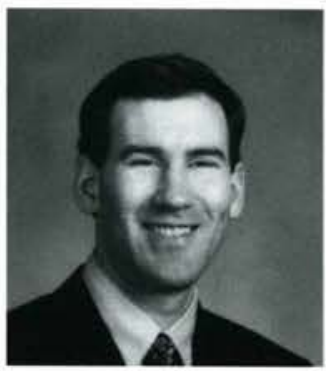

Simued Sren.Serogery

Engineering

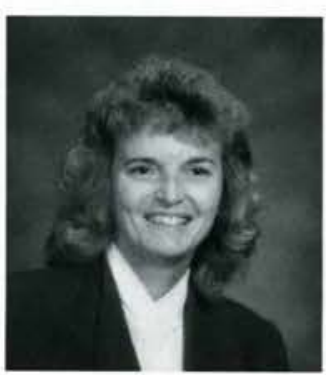

Premeles Jolinsione

P/. Y.

Health and Physical Education

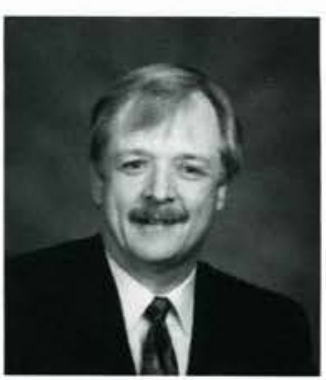

Hiert. Itometernet

ll. .

Communication Arts

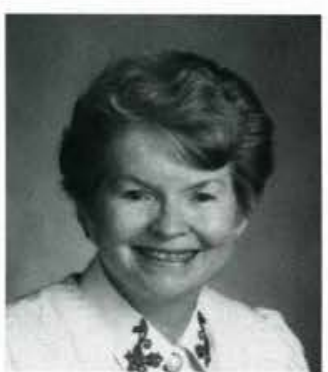

Sally, Caidle

Ed.

Education

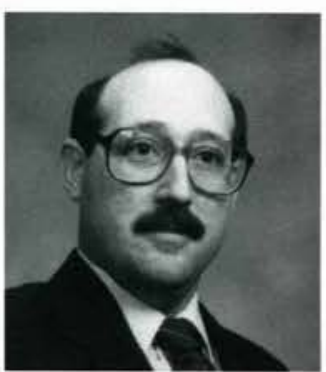

Redeerl Chomenes.

P/. L.

Enģineerin

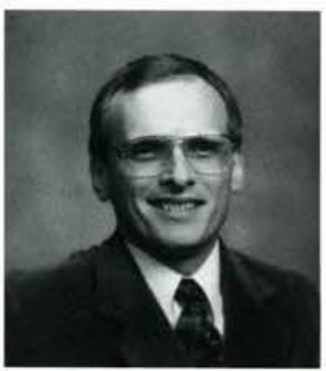

Peffrey . Nliodll

Engineering

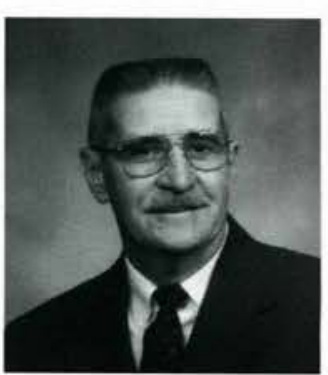

Elevin Riving

II. Ed

Health and Physical Education

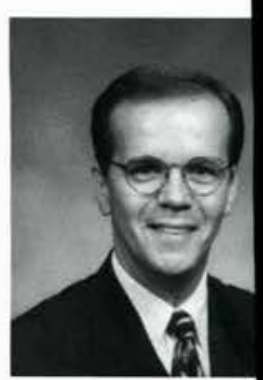

Survel Boliey

P/. L.

Communication A

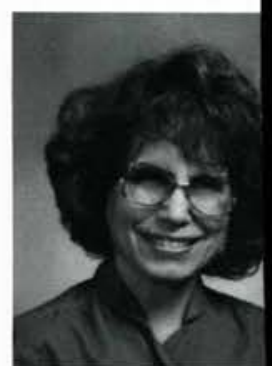

Hearnen Eimen: Ed.

Education

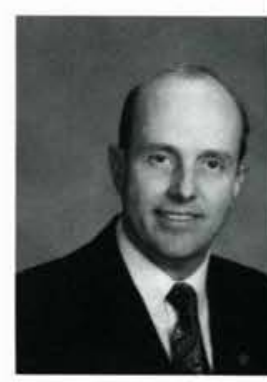

Kith Franei:

II.S.E.

Ensineerin

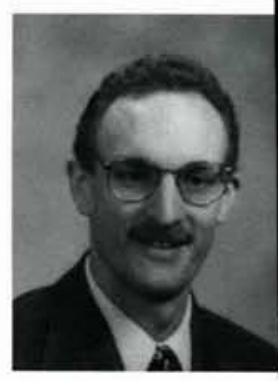

Themens Trempison I/. 2.

Engineering

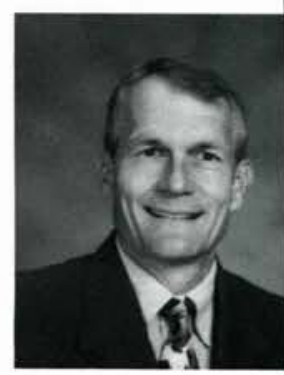

Folin Mllo Silliement 16.\%.

Health and Physical Educa 


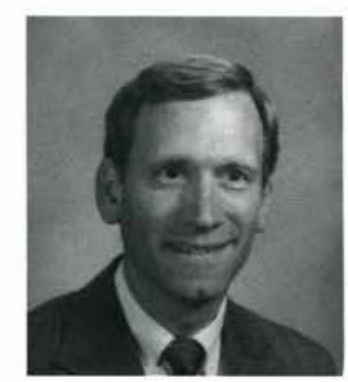

Mbark Krlimets IL.S.S.

Nursing

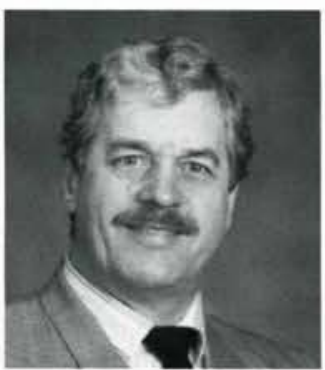

Leroy Gimen: $\mathscr{P}$.

Science and Mathematics

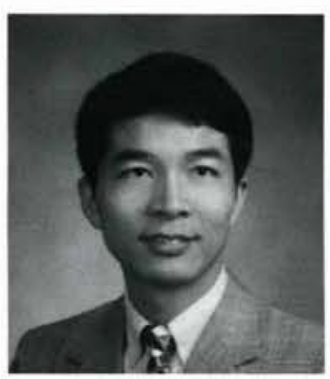

Dati Luo

$\mathscr{P} / \mathscr{L}$.

Science and Mathematics

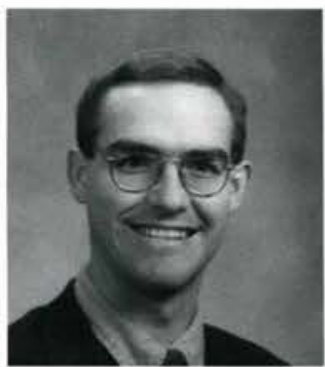

Tames Gellens $\mathscr{P H S}$

Science and Mathematics

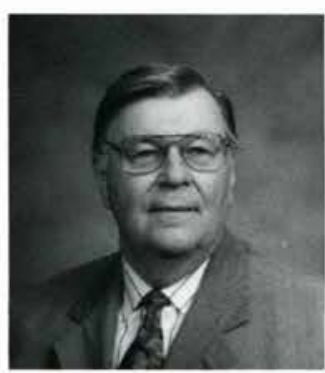

Allen lbonone

P/L

Social Science and History

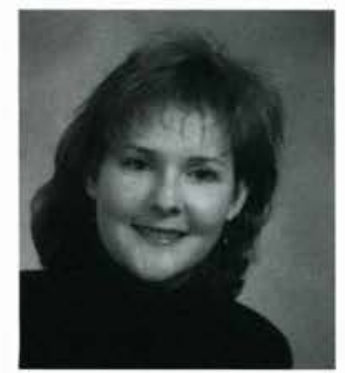

Sandra Prall

IL.Y.

Nursing

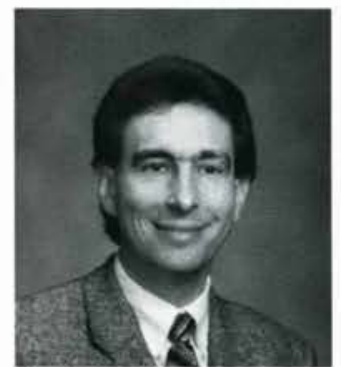

Demnis. Flenlge

$P / 1$.

Science and Mathematics

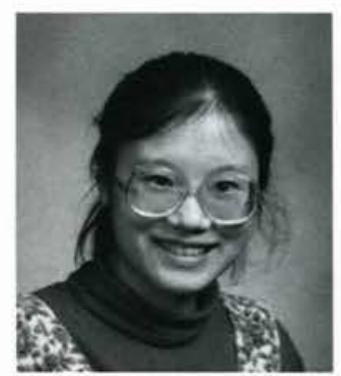

Sing S.in Sue

Science and Mathematics

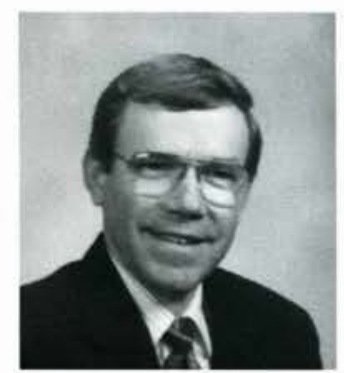

Fohn Siluiess

PH.

Science and Mathematics

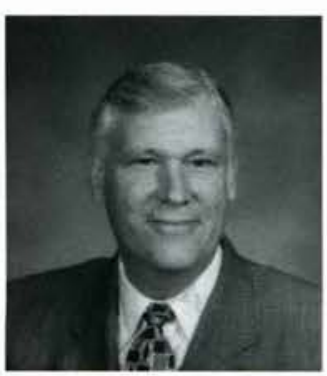

Ratient Parr

$\mathscr{P} / \mathscr{V}$

Social Science and History

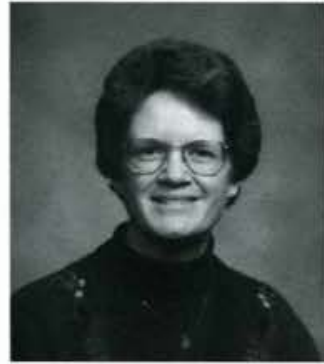

Sheron Scatillly,

P/. D.

Nursing

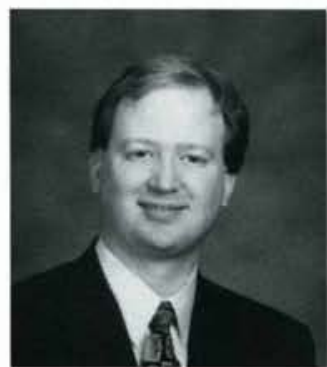

Qurrin. Frey

$\mathscr{P} / \mathscr{D}$

Science and Mathematics

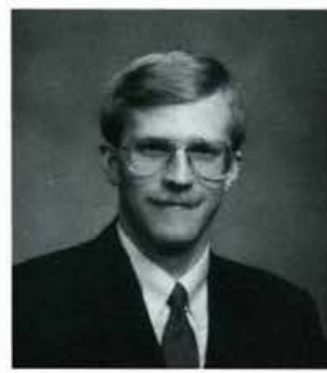

Ibark Ibo Clain

Ph⿻

Science and Mathematics

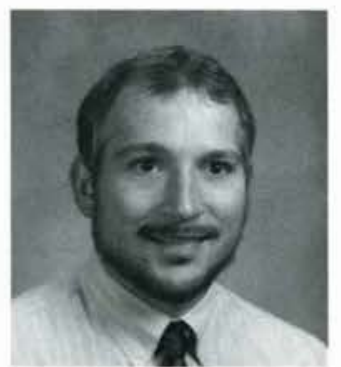

Gohn Whitmore

Science and Mathematics

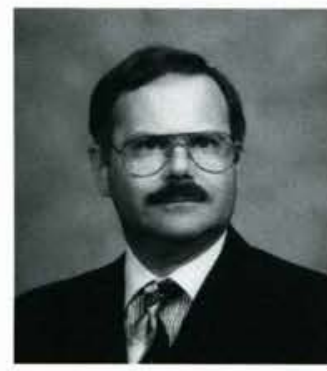

Fevin Fims

PhO

Social Science and History

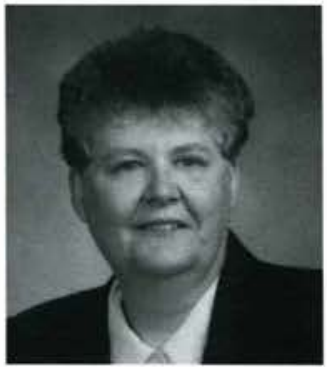

Dudith . Mrrubsole

16.T.

Nursing

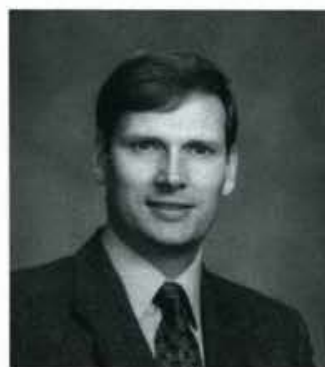

Heven Sollemer PhQ

Science and Mathematics

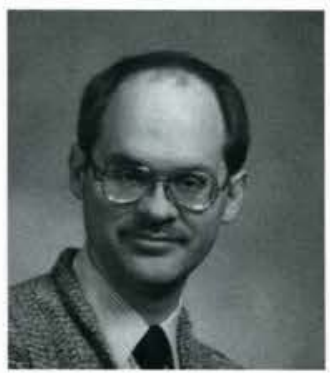

Souglas Hbiller

P/. D.

Science and Mathematics

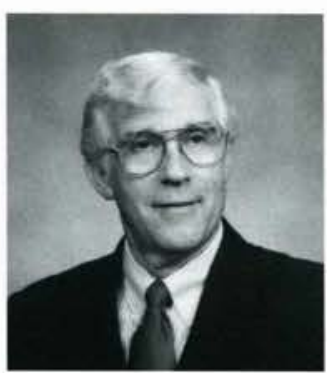

Tosenh Habey

Social Science and History

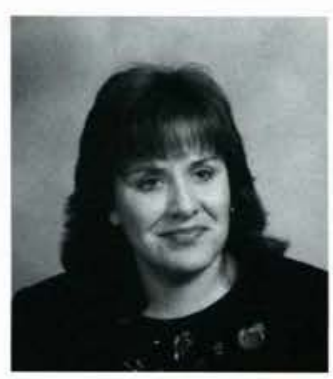

Gynthic Suller- Thed Il.S.Y.

Social Science and History

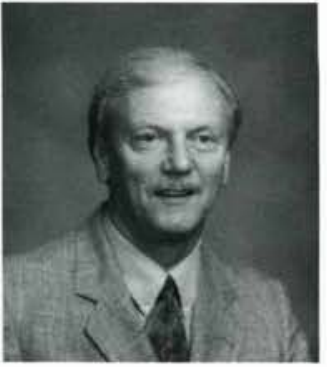

Robient. Thlines:

$\mathscr{P} / \mathscr{Y}$.

Psychology

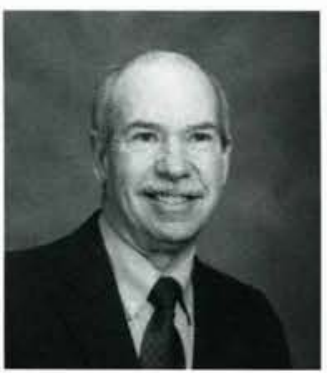

Larry. Helmich

Science and Mathematics

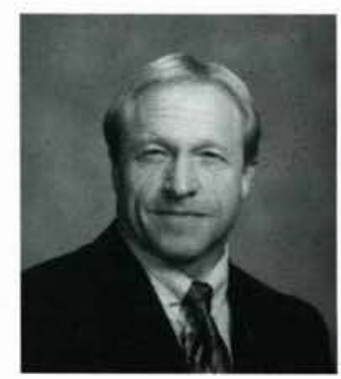

Terry Phippis

Science and Mathematics

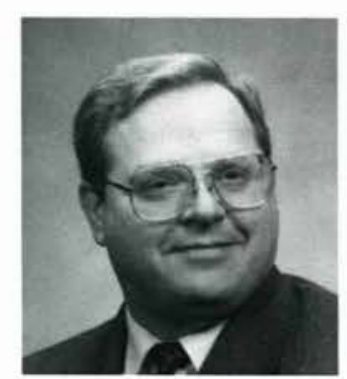

Nebon Herning $\mathscr{P} / \mathscr{P}$.

Social Science and History

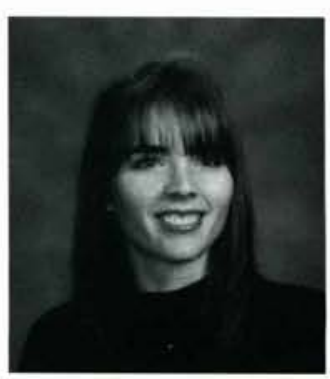

Seanna Throop UL.Y.X. Social Science and History

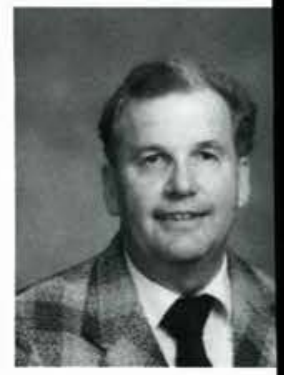

Edurin Amenitherest Ph.

Science and Mathemat:

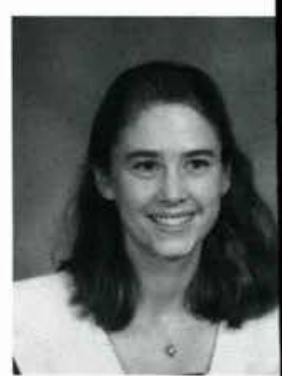

Heather Furnevil $\mathscr{P} / \mathrm{D}$

Science and Mathemati

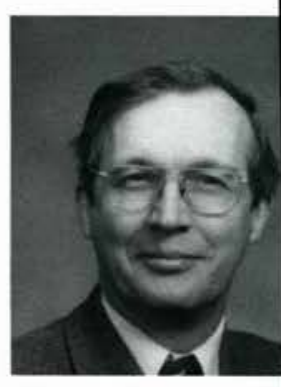

Rotient Schumache Science and Mathemati

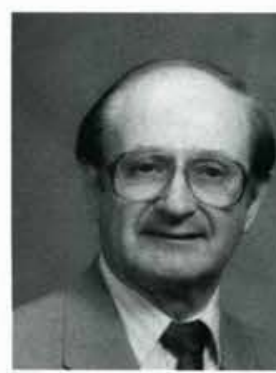

Fames 160 Soldric Ph.

Social Science and Histon

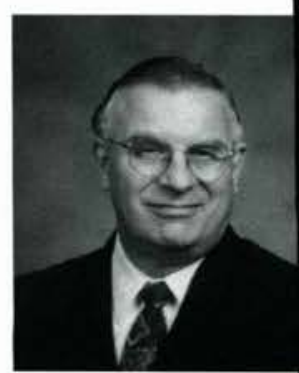

Robert Wiggins $\mathscr{P} / \mathrm{D}$. Social Science and Histor 


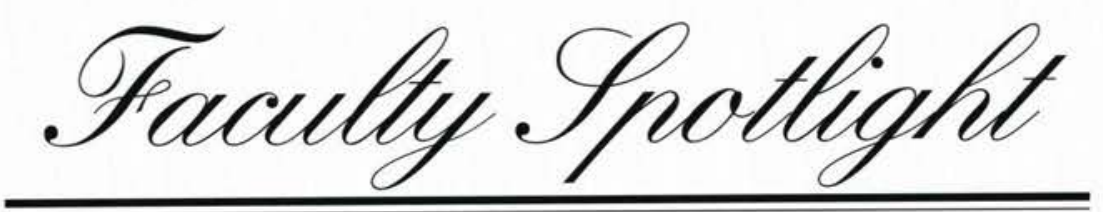

$M r . \quad E d$ w a $r d \quad S$ p e $n$ c e $r$

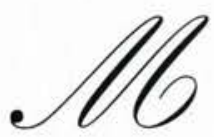

r. Spencer is probably best remembered by his students for call-
Ph.D work at Bowling Green University.

During his years here, he has served as department chair, yearbook ading them, "My dear ones." visor, advisor for Delta Chi
His longevity at this col-
(when it was a literary orHis longevity at this college and his ministry in the English Department allows him to do what he believed the Lord called him to do, and that is teach.

Mr. Spencer received his undergraduate training at Ashland College in Ashland, $\mathrm{OH}$, and received his theology degree at Faith Theological Seminary in Wilmington, DE. He completed his Master of Arts at the University of Dayton and did

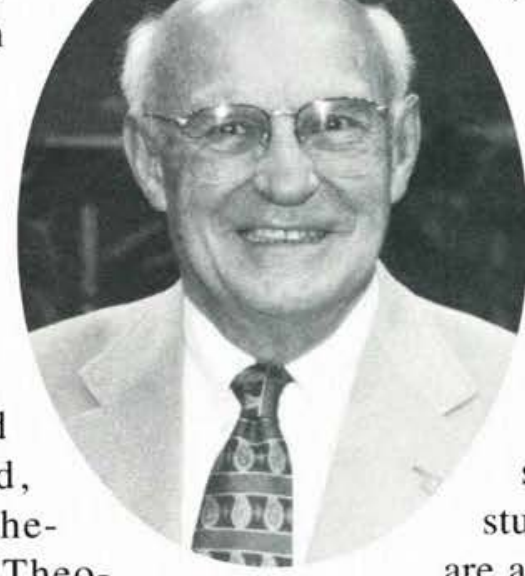

ganization) and is now on the tenure, student life, educational policies and department chair committees, and is the coordinator for freshman composition.

Through his teaching, he seeks to reproduce in student's lives things that are an important part of him, not just impart information. He tries to relate to students that people are the most important part of life.

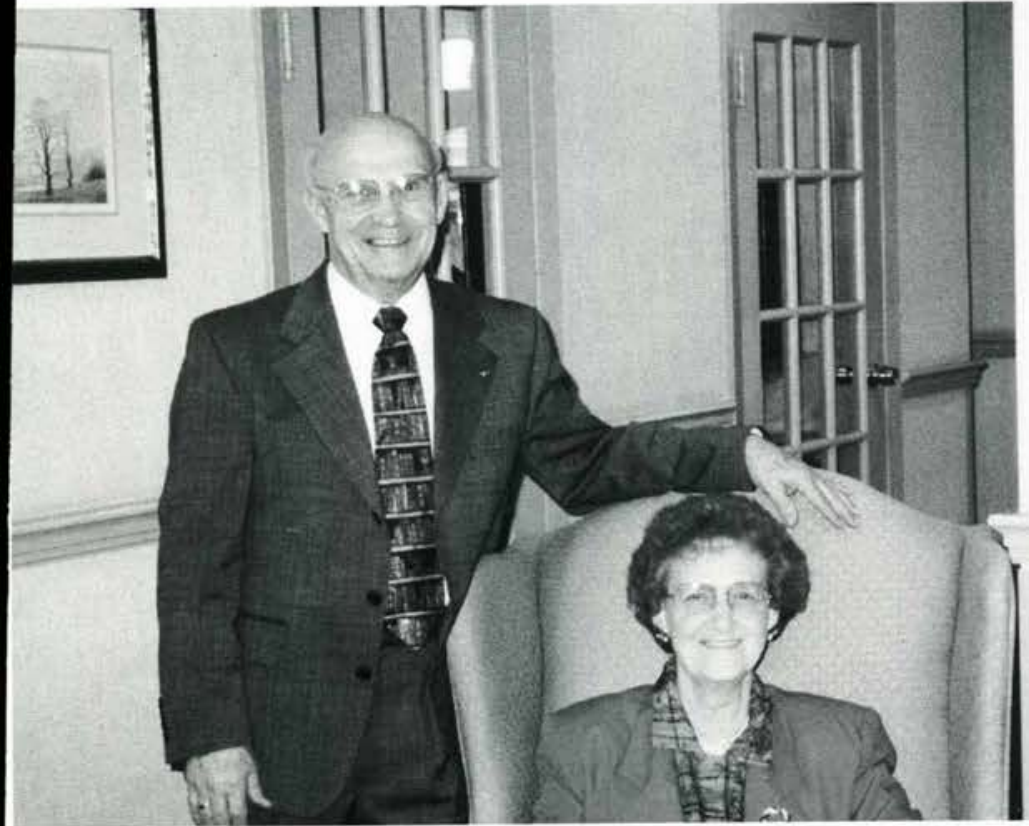

Wr. Spencer and his wife Dorothy model for the students what a loving relationship should be like. This year they celebrated their 52nd Wedding anniversary.

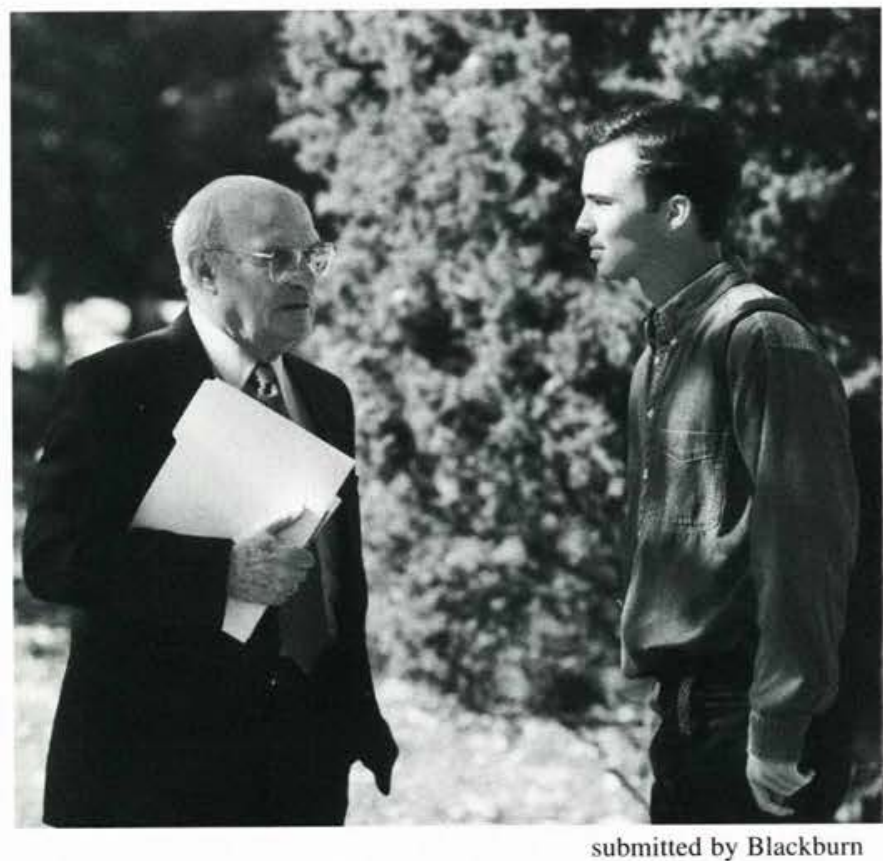

Or. Spencer is probably best remembered by his students for calling them, "My dear ones." Here Mr. Spencer is pictured with Cedarville student Mark Wood. 


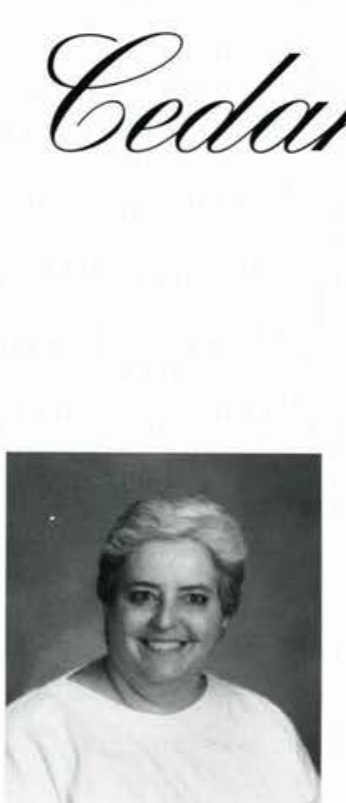

Slaff

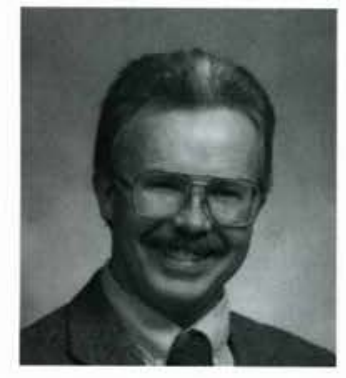

Ilichal. Buder

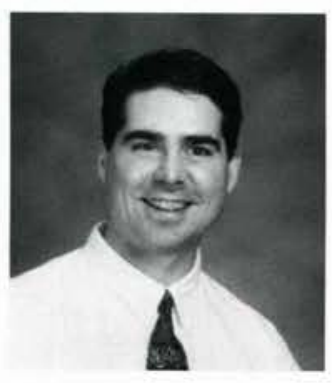

Feffery Brite

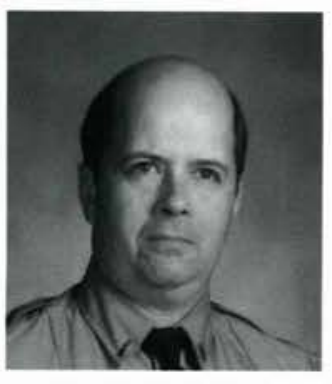

Fomes Bowersor

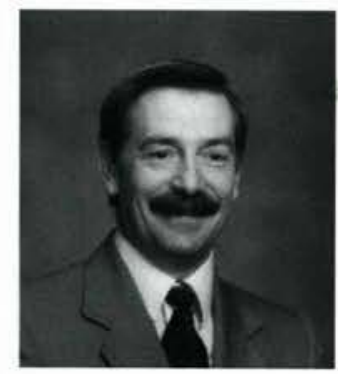

Fack Gampladt

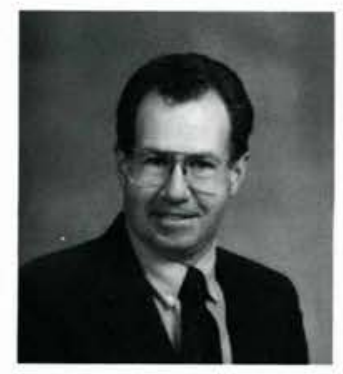

Farne: Elurk
Rinnald Buder

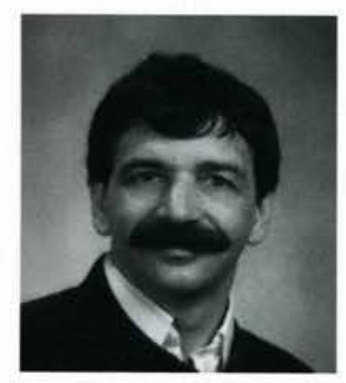

Roluert Binlek

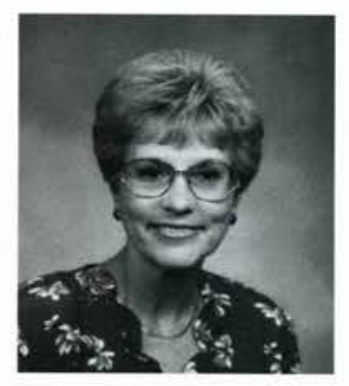

Enomie. Prodels:

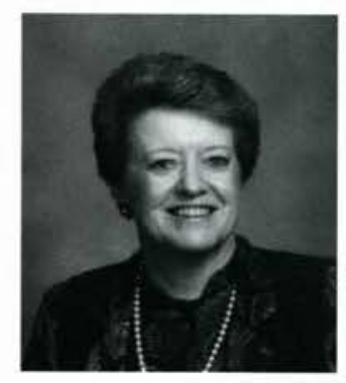

Frren Campitell

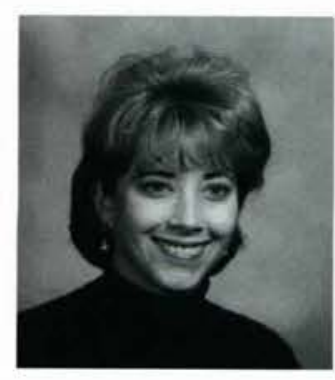

Livar Cole

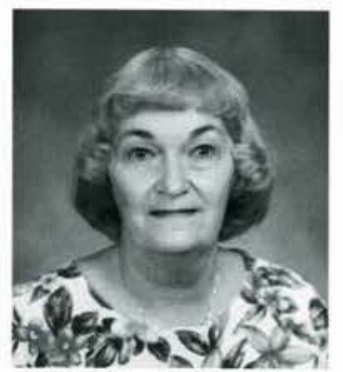

Bartiara. Baise

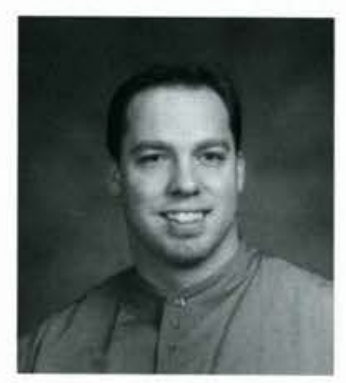

Ibichuel. Bieniets

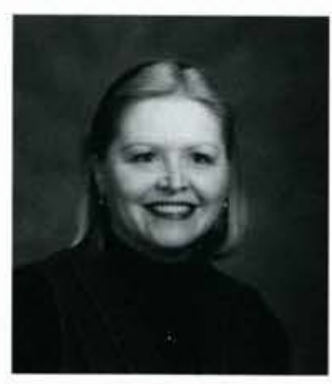

Parnele Bromer

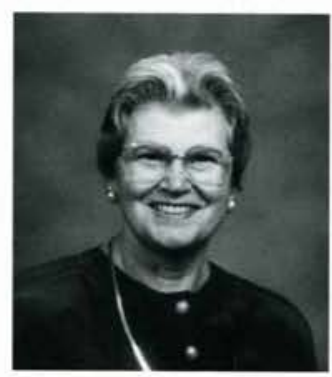

Mlierla Carr

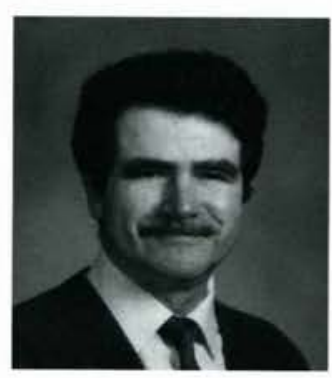

Ponatel Coy

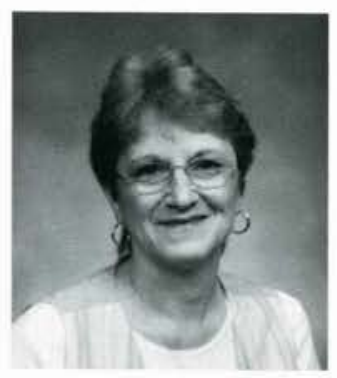

Rirlli. Lyer

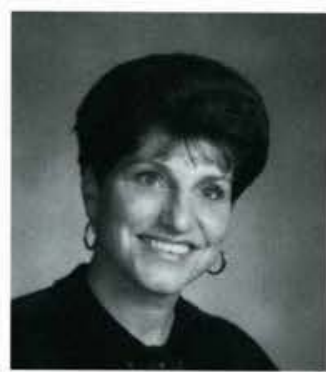

Soumm Boripe

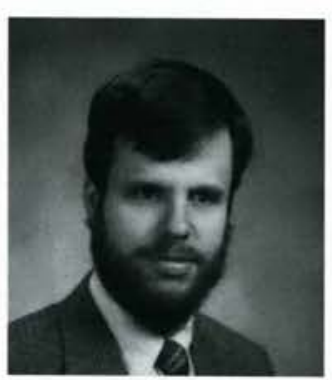

Prian Blair

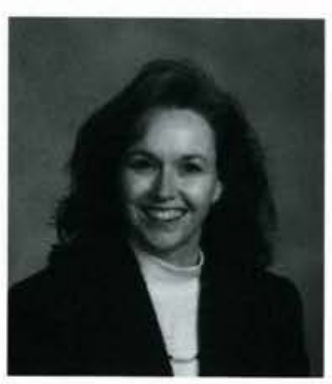

Elivatielli. Buctilem

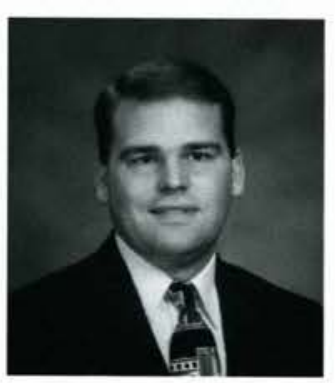

Gary Garler

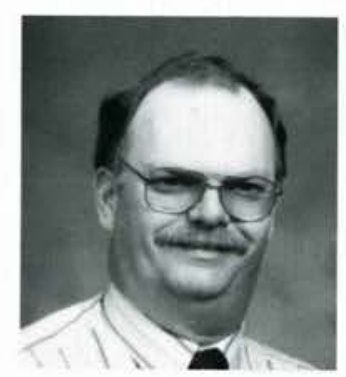

Peffery Cernoningham

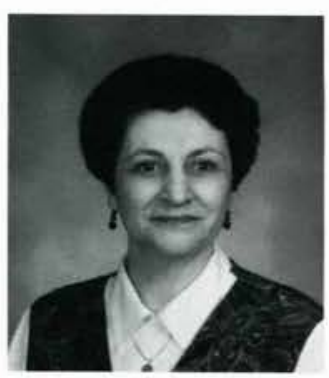

Frrmens. tudreus;

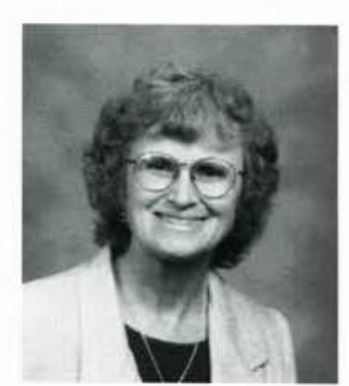

Utarllie. Solderin

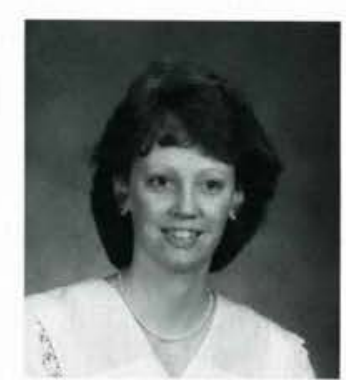

Garat. Blis;

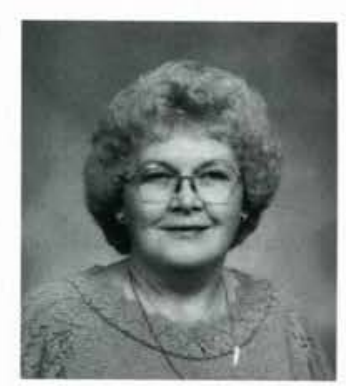

llargard Burricleter

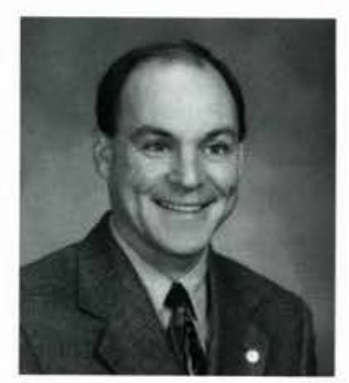

Fremes Calo

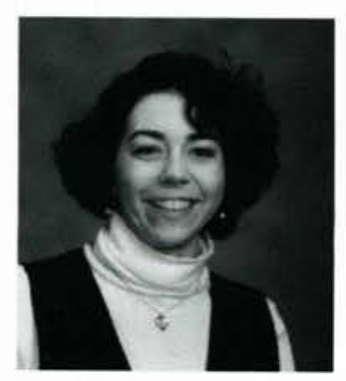

- llodody Ciurlis

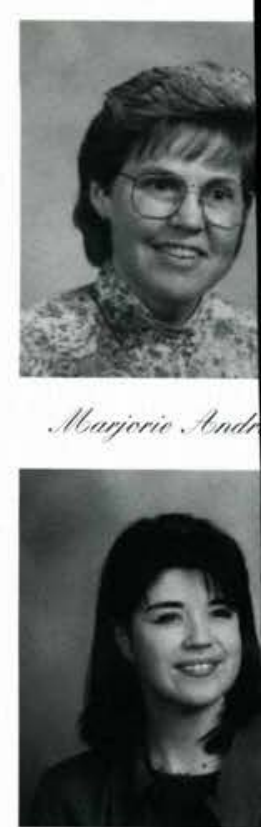

Petricier Bollive

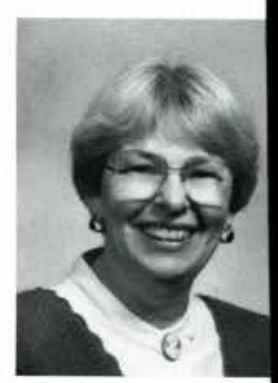

Heten Blemmenils

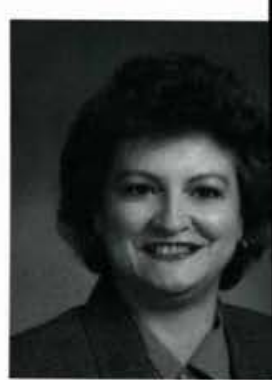

Inderat, Gagurin
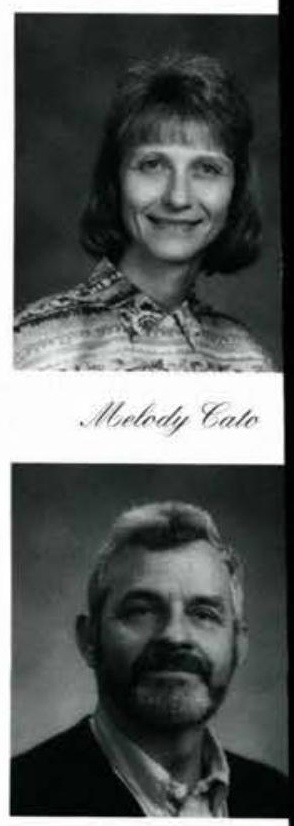

Savid Senlinger 

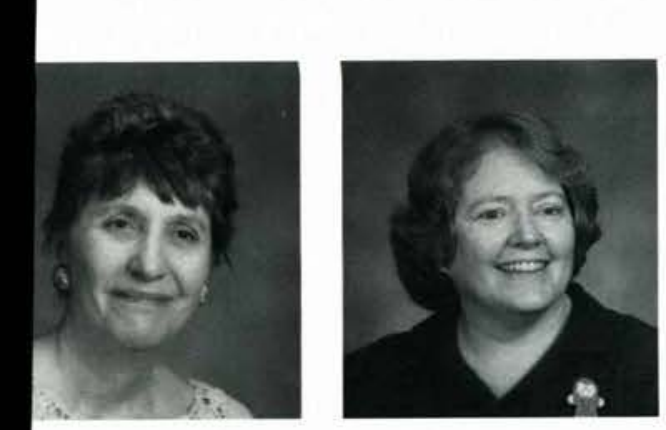

InJime Sirkey

Gremen Lerrundo

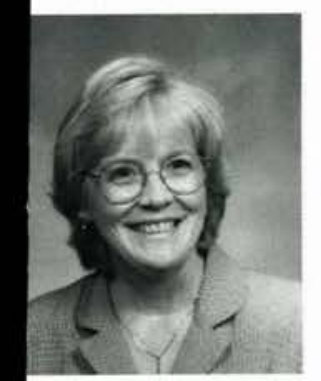

Ponnela Elmome

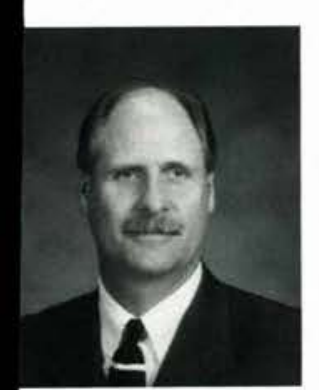

Surid Soffuer
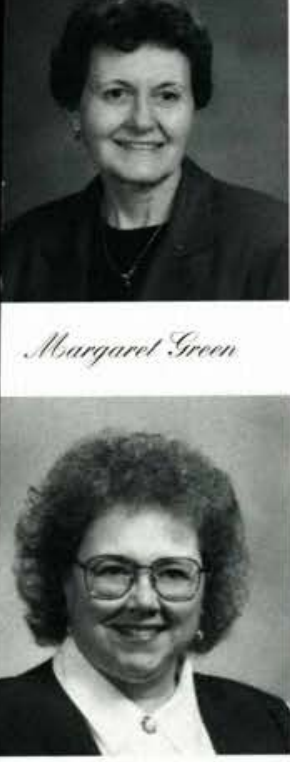

Ganalyn. Hadism

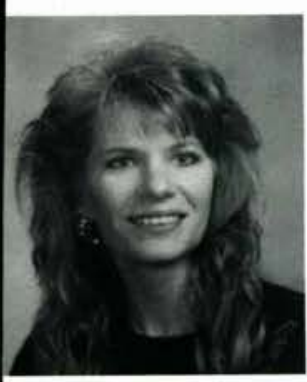

Surburam Hount

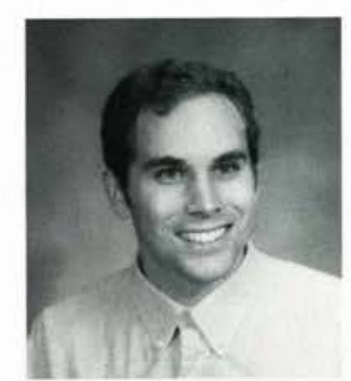

Tirrm Eisles;

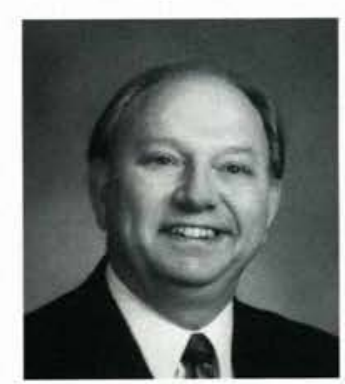

Prinl Sollinney

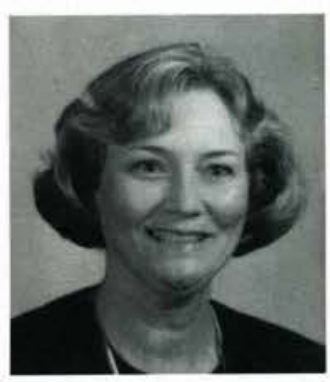

Fernime Grenemennel

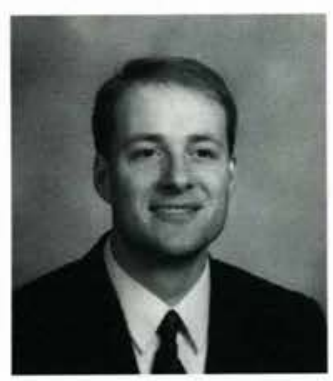

Surid Hoeche

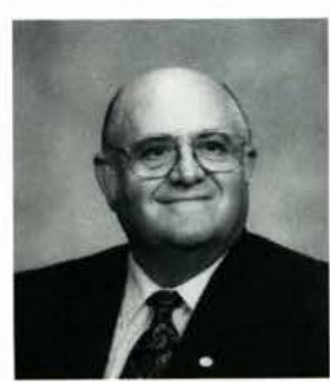

Enigh Hunl

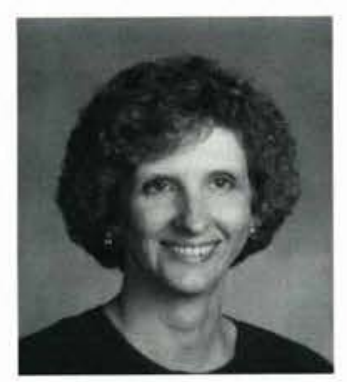

Ulorgared Dillon

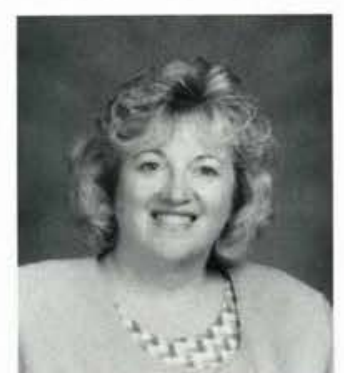

Doyer. Frorlewe

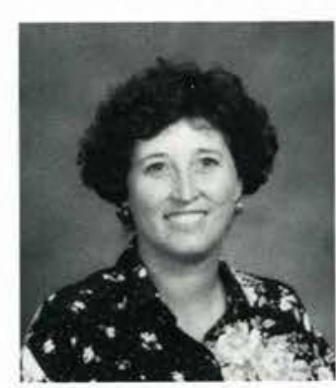

Card Senorge

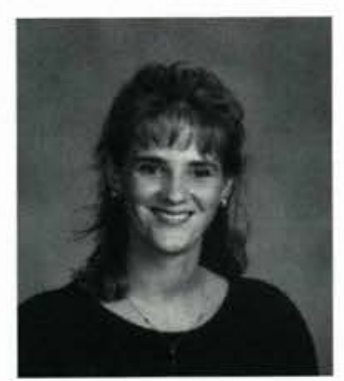

Risisly Griffill

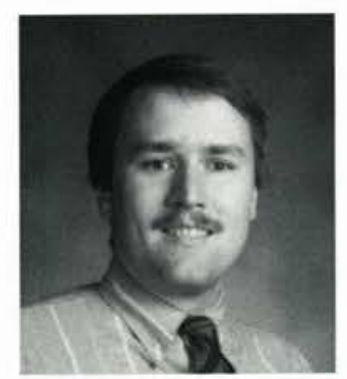

Mente. Hender

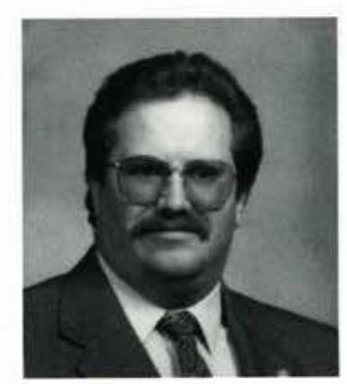

Roliert. Hunl
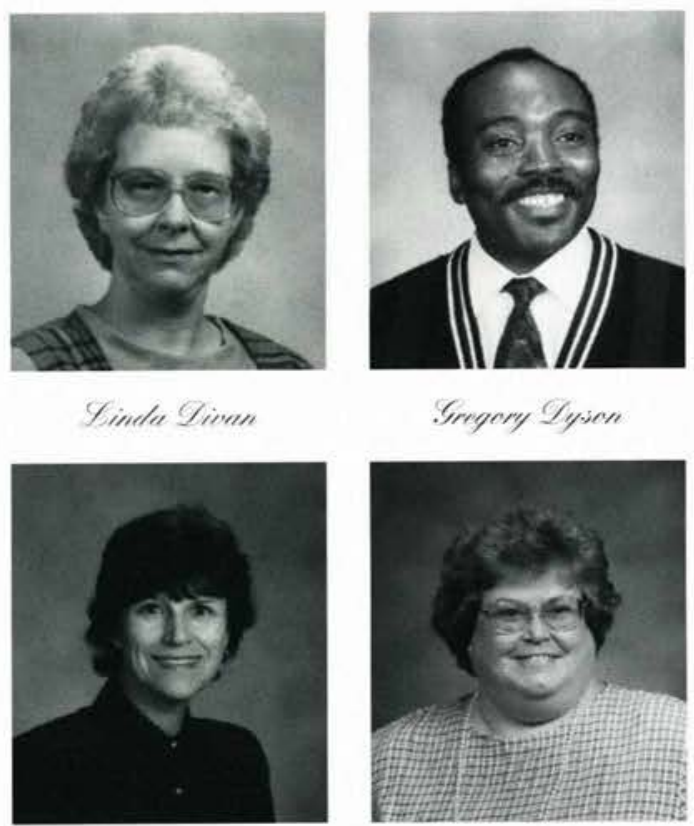

Serogary Yyson

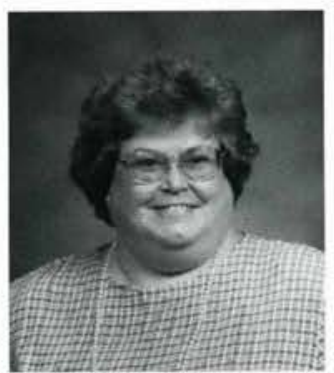

Susane. Ferrllimer

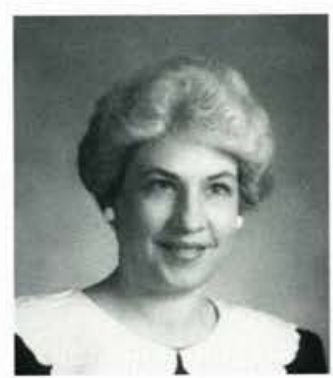

$$
\text { Simmen Sellumblis }
$$

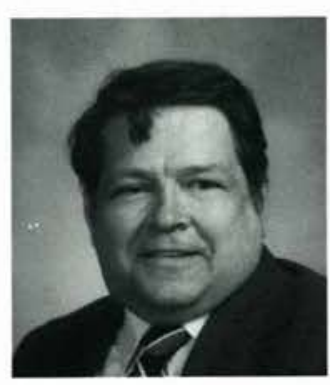

Kiritl, Hague

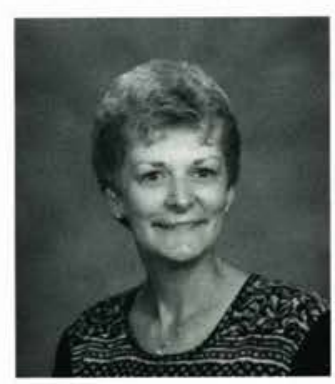

Potricin Helleer

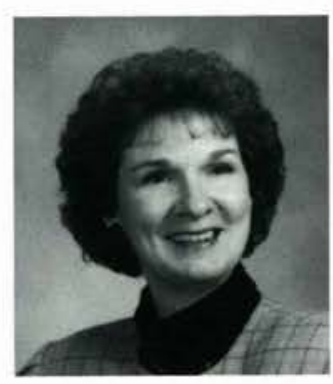

Shirloy Fotinion

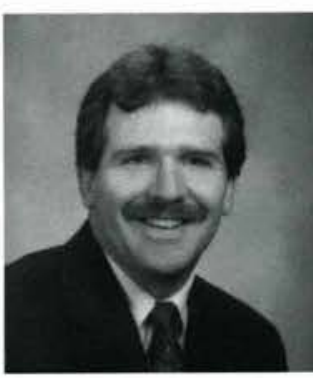

Pliitip Serofion

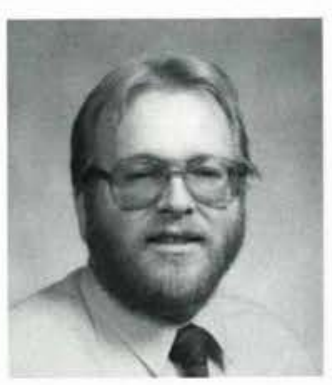

Timalliny Hanidl

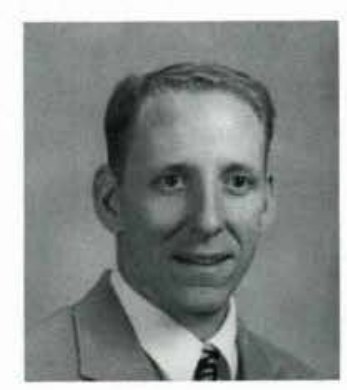

Hcall Huck

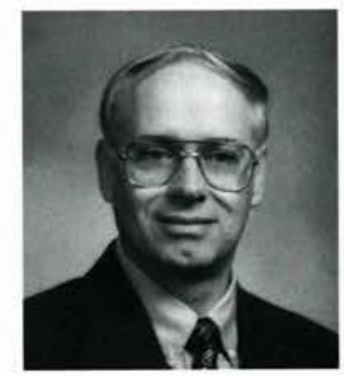

Timalluy Gotinion

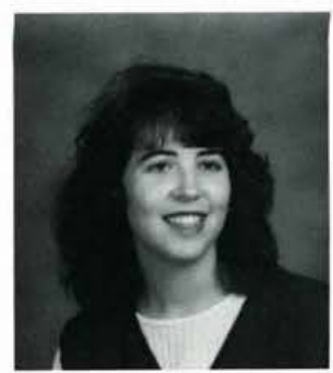

Mremen Echistrin

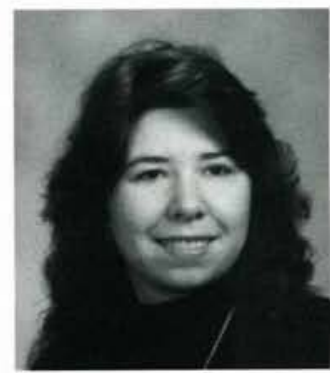

Iara. Fratery

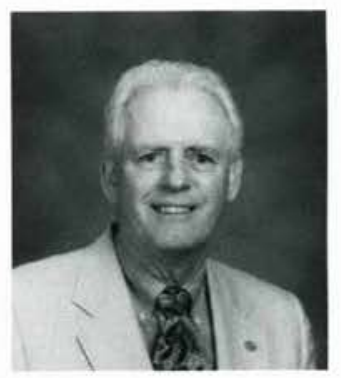

Harnld Srem

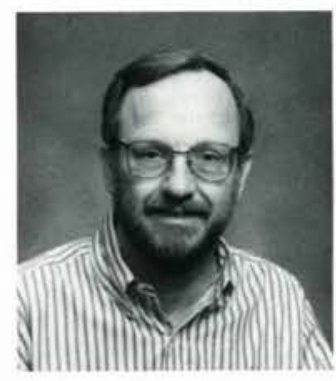

Iate. Helmult:

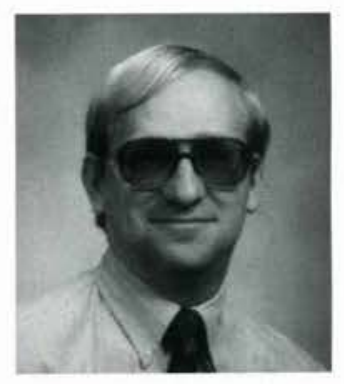

Sury Hull

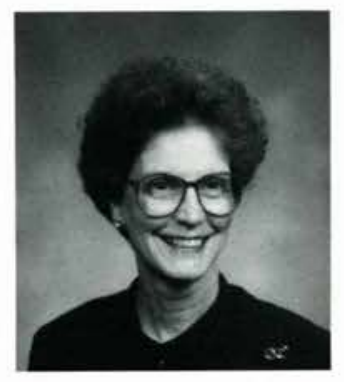

Meertiax Framber 


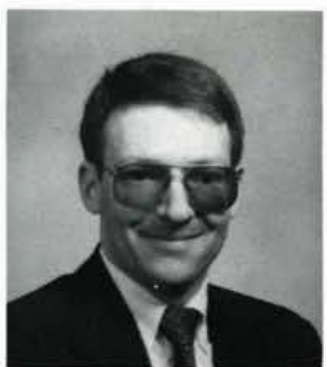

Savid Krammeyer

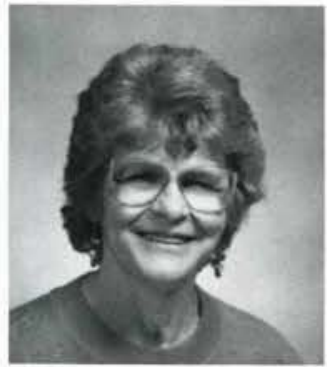

Mancy. Kinauff

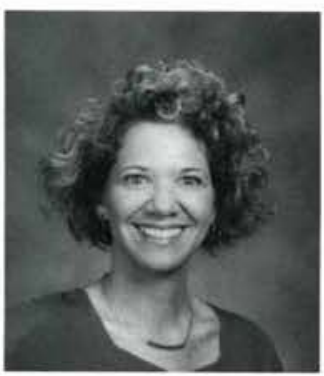

Foilh Lim

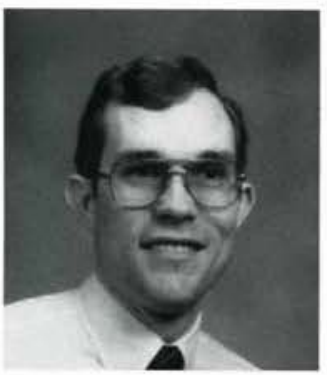

Glan. Ibe Cain

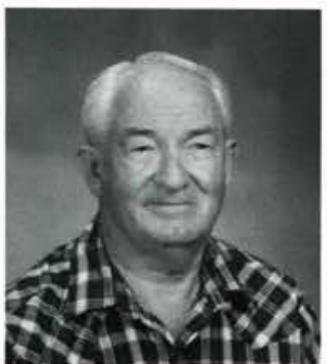

Gavern Mlusidelman

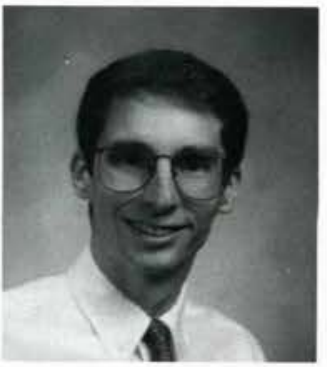

Inugles: Phillipi:

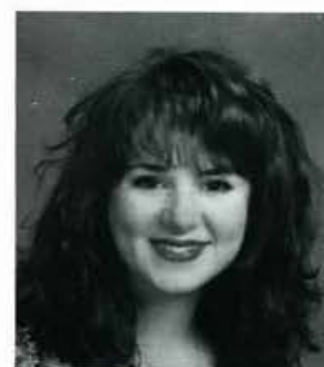

Lari. Keirn

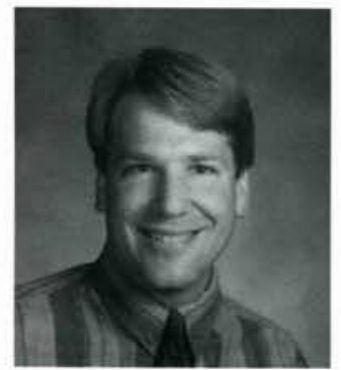

lbark Kandir

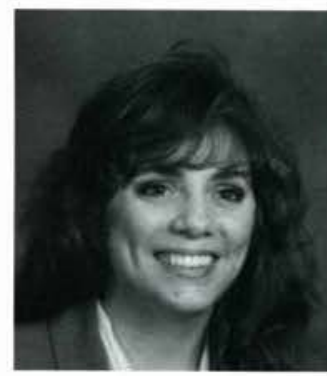

Fimberly Longe

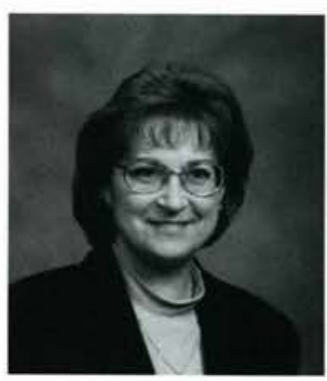

Selira. Ito Innoted

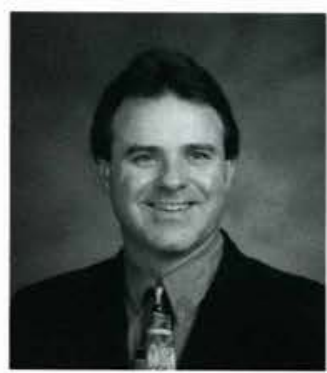

Brimn Meiler

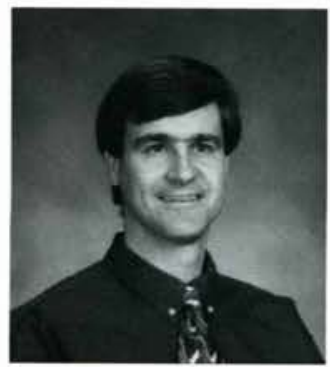

Folin Poller

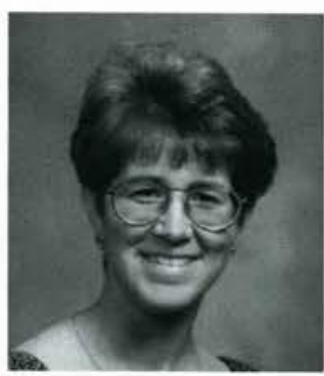

Elnime. Forlle

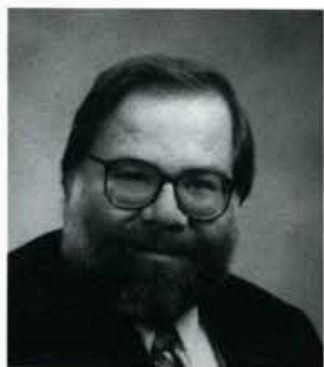

Sirepory Rien:

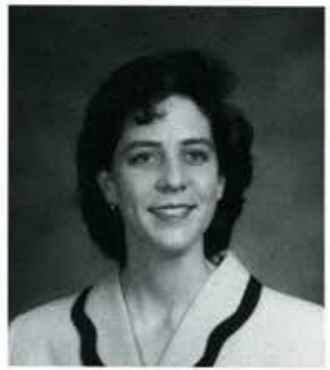

Kelly lloris

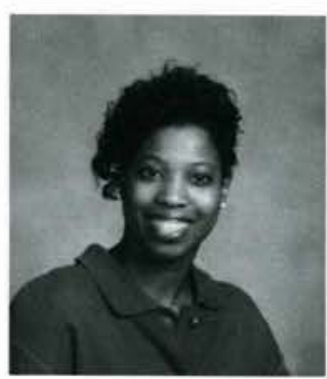

Krevin. Ilon. Mint

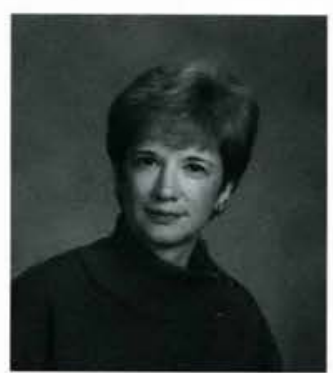

Guann Nichato:

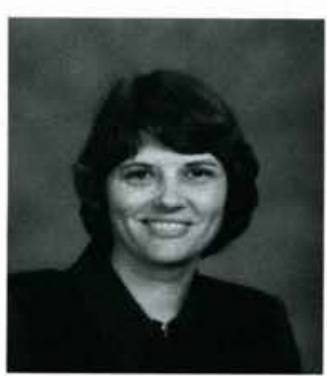

Rulle Pruegh

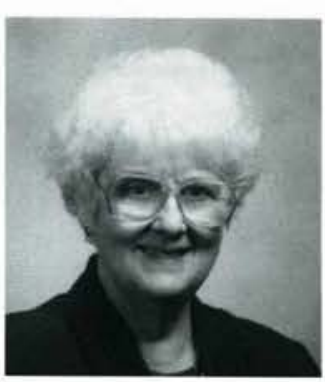

Demene. Kienelelt

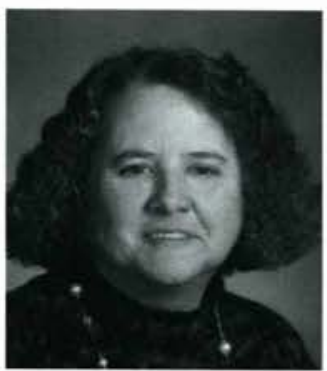

Corimne Lake:

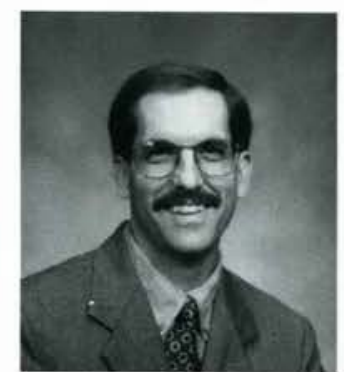

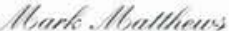

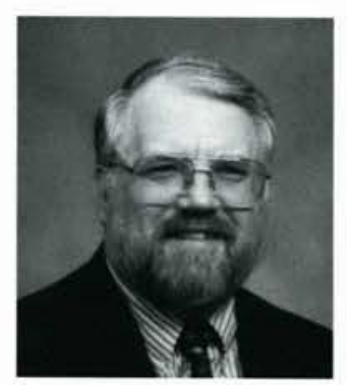

Fred Iberrill

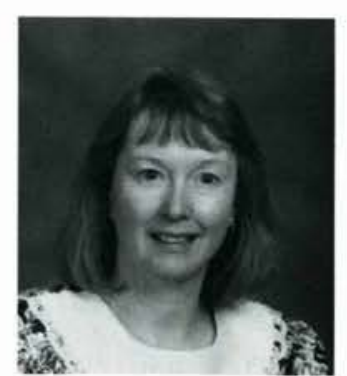

Kentherine Porr

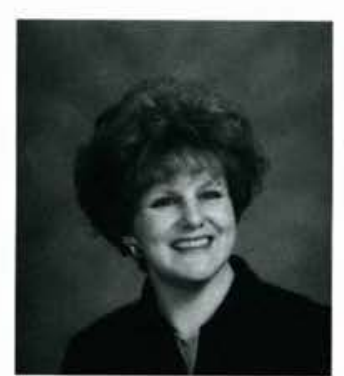

Ienna Purple

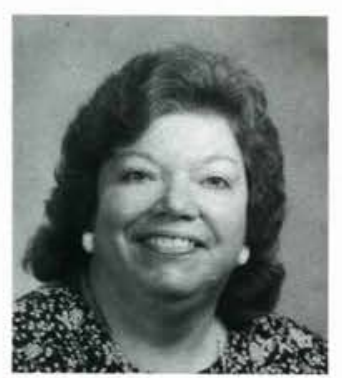

Toi. King

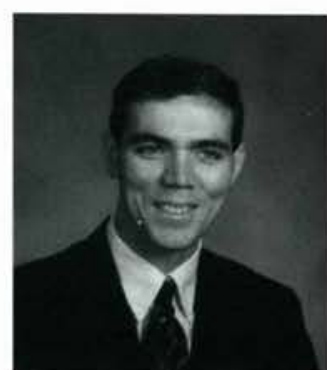

Cliad Sarr

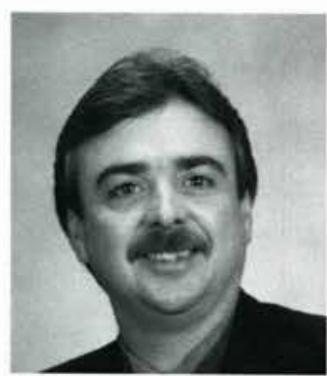

Tripme Iberie

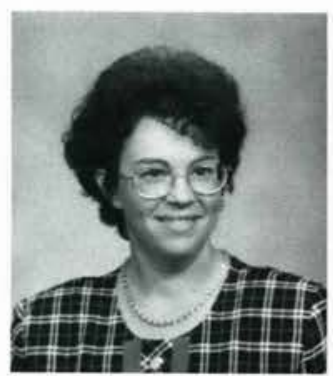

Cheryt. Hibler

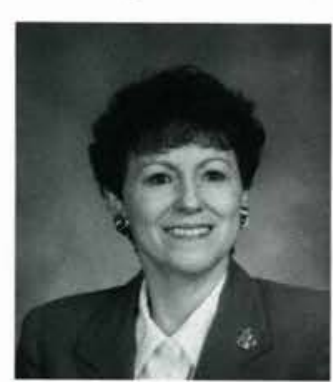

Rove Payne

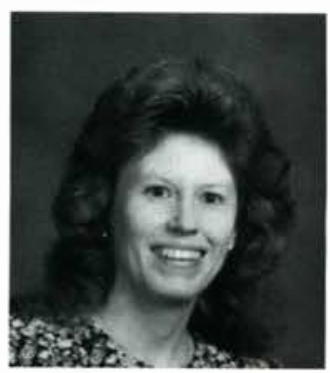

Sancy Ranger
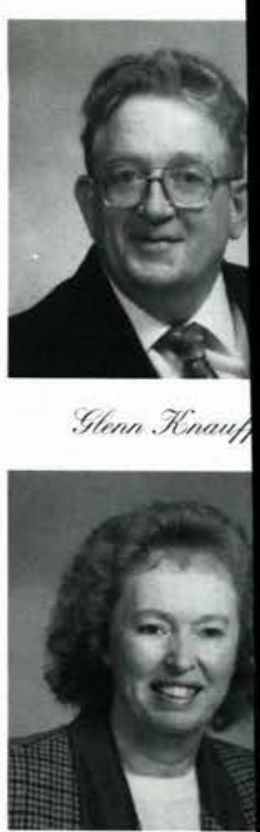

Palricin See

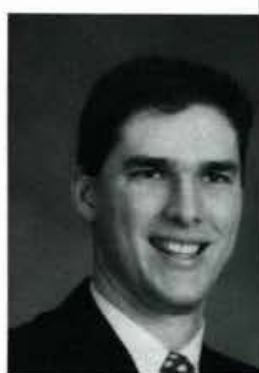

- lbark llasdir

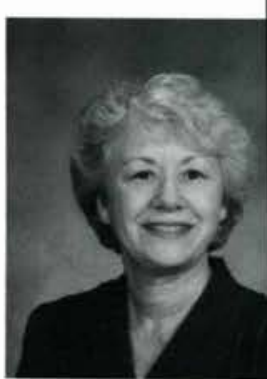

Pliyllis Iborris

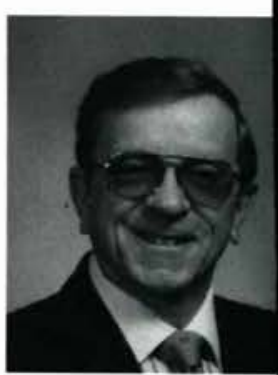

Edmond Pliellipin.

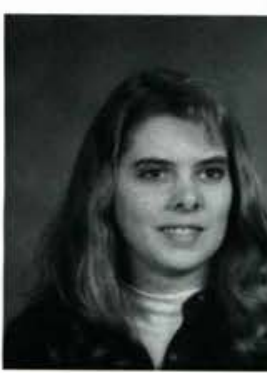

Tamara Ravey 


\section{Freshmen}

Jennifer Abbey

Timothy Abbott

Jessica Acker

Michelle Ackerman

Elizabeth Adamowich

Shannon Adams

Stephanie Aittama

Rebecca Allen

Sara Allen

Shawn Allen

Jewel Alley

Melissa Alt

Cara Anderson

Adina Andrews

Daniel Angelone

Jared Applegate

Jacqueline Ayette

Ruth Back

Jack Bailey

Janelle Baker

Ryan Balding

Benita Banks

Kelly Barron

Julie Bartlett

Christopher Bean

Joshua Bean

Robbie Beat

Abigail Beck

Deborah Beck

Amanda Begley

Karen Belknap

Eric Bender

David Bennett

Adam Beres

Diane Bielo

Nycole Bills

Kristina Bilodeau

Robert Bischoff

Sarah Bishop

Stephen Black

Daniel Blair

Elizabeth Blaquiere

Daniel Blosser

Jason Boggs

Ahlam Boland

Bradley Bonn

Kenneth Borror

Angela Borsos

Jeremy Brantham

Jennifer Brayer

James Brentlinger

Christine Brittin

Jami Broman

Bethany Brooks

Heather Brown

Julie Brown
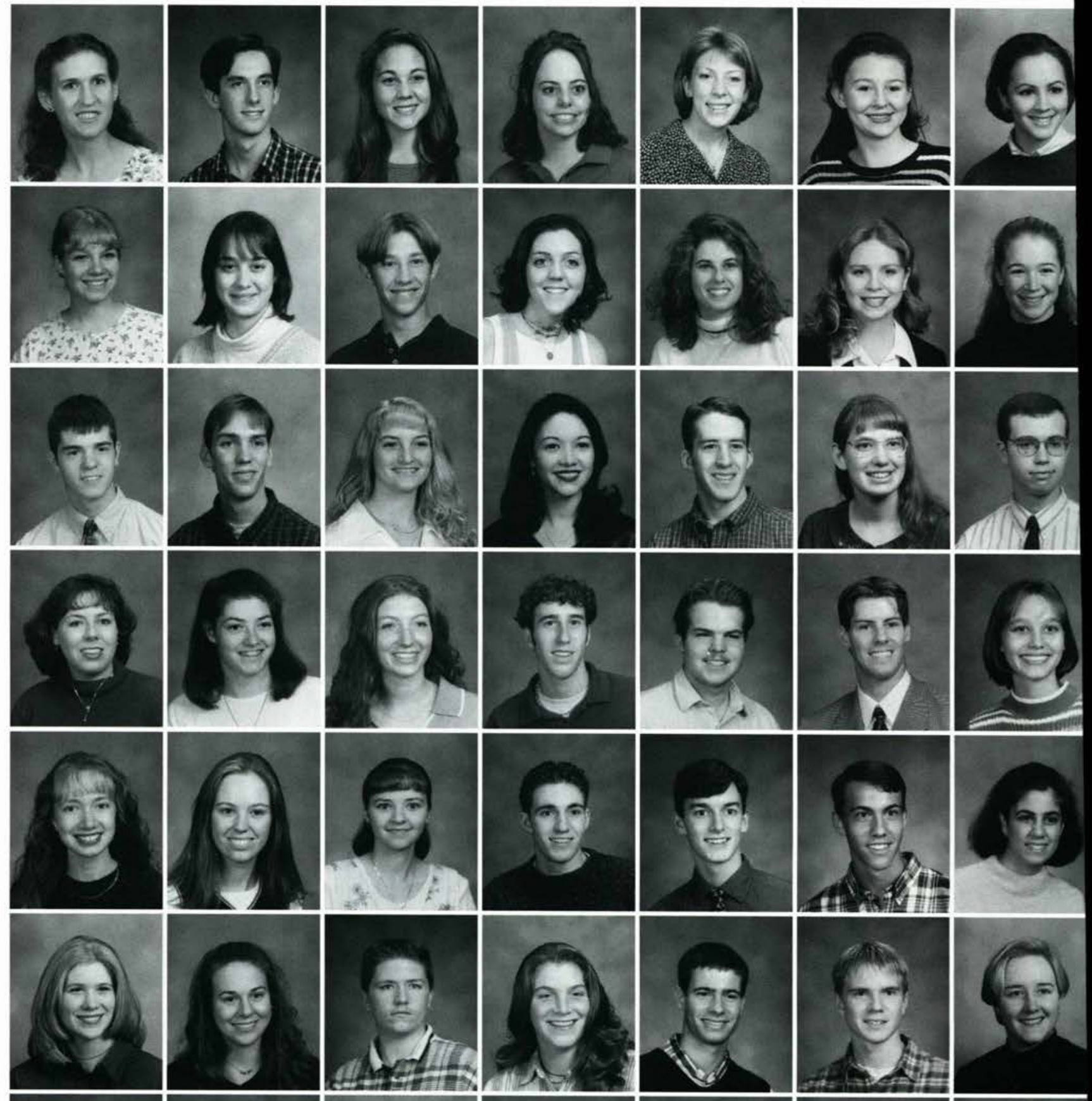

19.
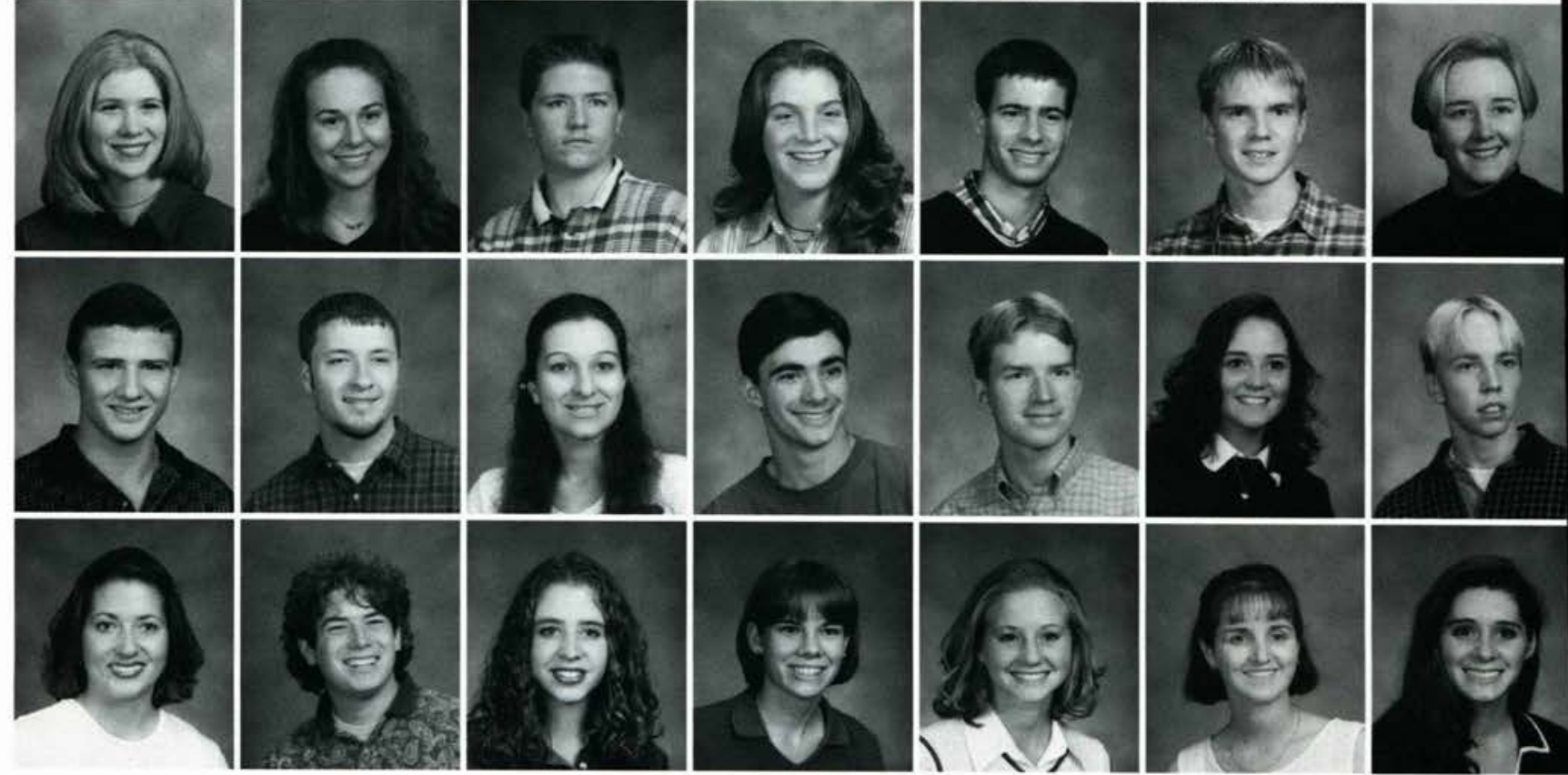
Jennifer Drexel

Sarah Duda

Robyn Duff

Andrea Du Four

James Dunbar

Matthew Dunn

Sarah Dunn

Justin Dyer

Joshua Eckburg

Jason Edem

Codi Edgington

Ryan Elam

Julia Farlow

Jonathan Faulkner

Holly Favorite
Julia Fawcett

Fernanda Fernandes

Michael Ferrigno

Karl Feucht

Eric Fisher

Carrie Fleck

Sarah Flenar

Marisa Flory

Chad Foerch

Christopher Fonte

Brian Foote

Melissa Foote

Kellie Forbes

Jenelle Forward

Daniel Foster

Lorraine Foser

Rebekah Foster

Anglea Fraley

Sarah Fraser

Leah Frazee

Heather French

Katie Futrell

Rebecca Garber

Miriam Gardner

Brian Garver

Belinda Geesaman

Christina Gideon

Samuel Gilbert

Vanessa Gilliam

Andrew Gingrich

Richard Girth

Kelly Gleason

Ryan Goble

Meredith Gombis

Alicia Good

Amy Gordin

Jennifer Gordon

Brian Gornick

Elizabeth Gosztyla

Heather Graff

Kyra Gray

Robert Graybill

Rebekah Green

Jennifer Griffith

Corrie Grigorenko

Jennifer Grubert

Stephen Gryn

Esther Haffey
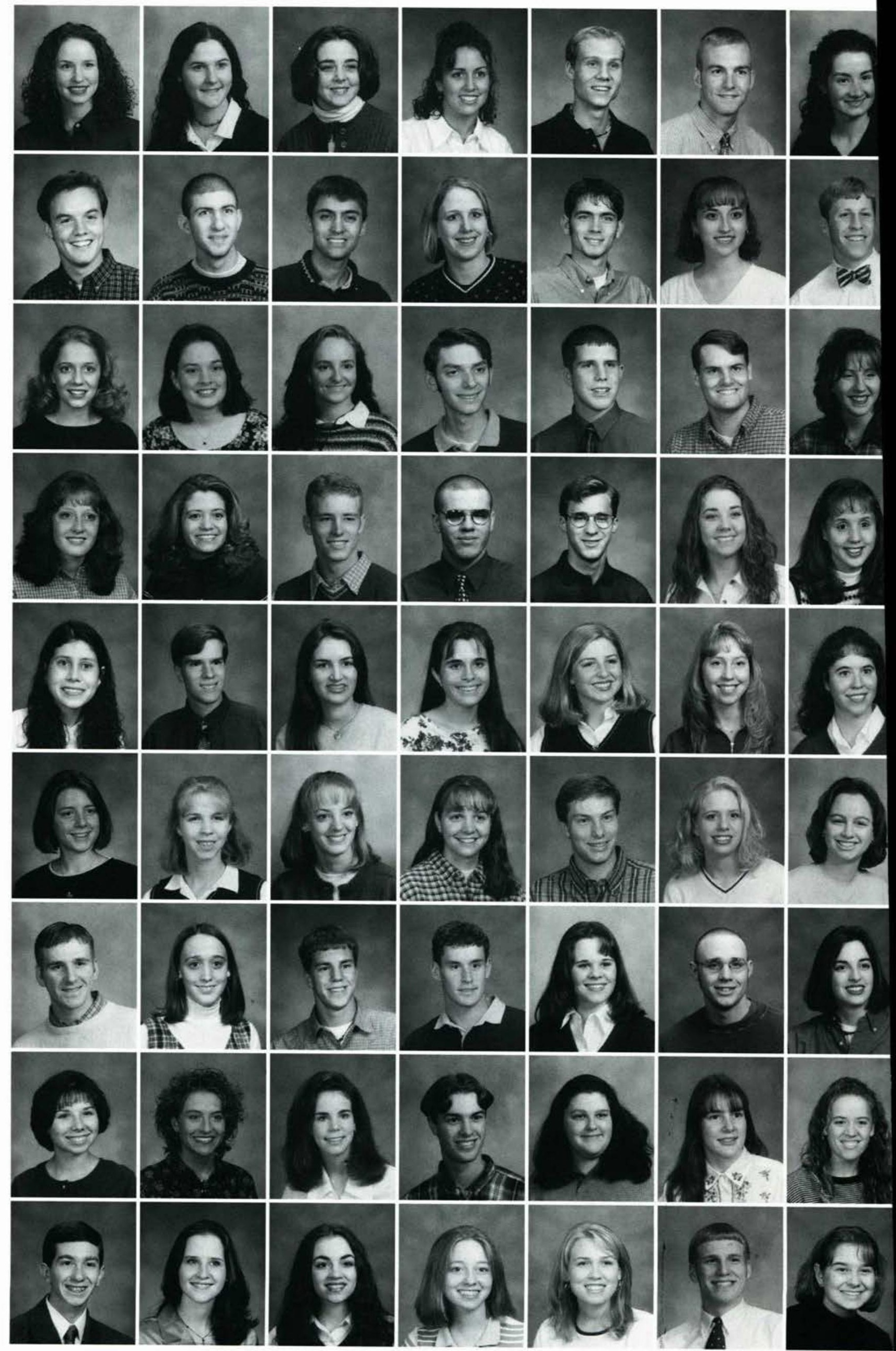
Heidi Kinniburgh Erika Kipp

Jonathan Kleis

Phillip Koch

Robert Kocher

Ekaterina Kochetova

Katie Koeppen

Lynn Koetsier

Jennifer Kranenburg

Brent Krumdiack

Stephanie Kurowickis

Ellen Laber

Seth Lacy

Jennifer Larson

Nathan Lasso

Thomas Lawson

Jonathan Leach

Kerry Lecklider

Erin Lee

Karen Leininger

Sarah Leisure

Daniel Leone

Edward Letts

Nelson Lewis

Kenneth Loescher

Samuel Logan

Esther Loh

Tricia Lottf

Michael Lowstetter John Lucas

Courtney Ludema

Jennifer Lutes

Robert Lutz

Jonathan Lyttle

Jennifer Maass

Jennifer Madsen

Rebekah Mann

Paul Manson

Joel Manwarren

Amanda Mariage

Matthew Marshall

Jessica Mathias

Stephen Mattick

Janice Maurizi

Jenna Mc Callister

Sally Mc Cann

Phillip Mc Cubbin

Kelly Mc Kay

Dave Mc Kenzie

Elizabeth Mc Kinney

Stephen Mc Murray

Andrea Mc Neal

Kimberly Meadows

Melissa Meckstroth

Deborah Meitzler

Cary Mesnard

Maren Meyers

Mindy Middleswart

Haley Miller

Nicholas Miller

Timothy Miller

Todd Mitchell

Jeremy Mix
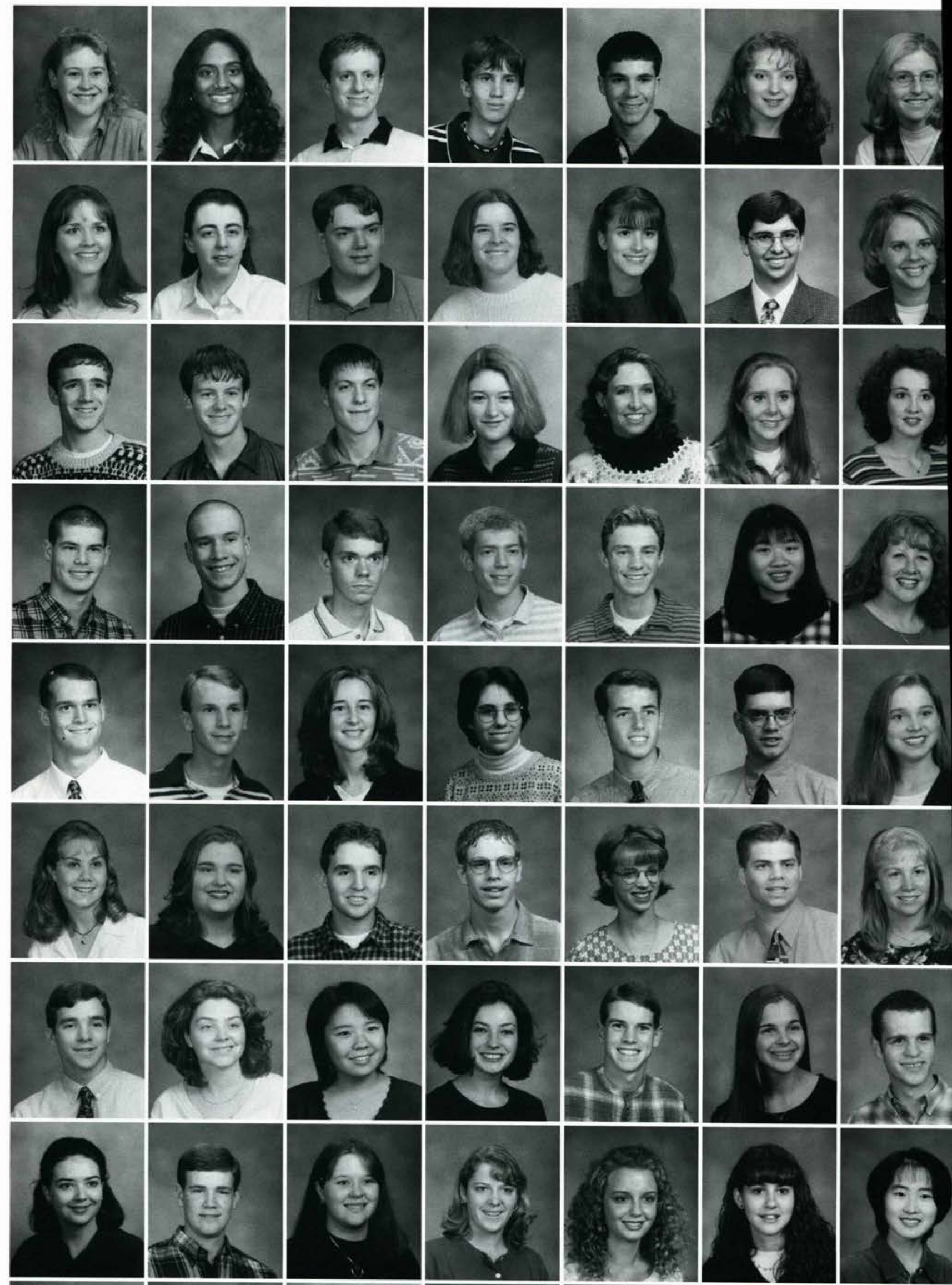

6.
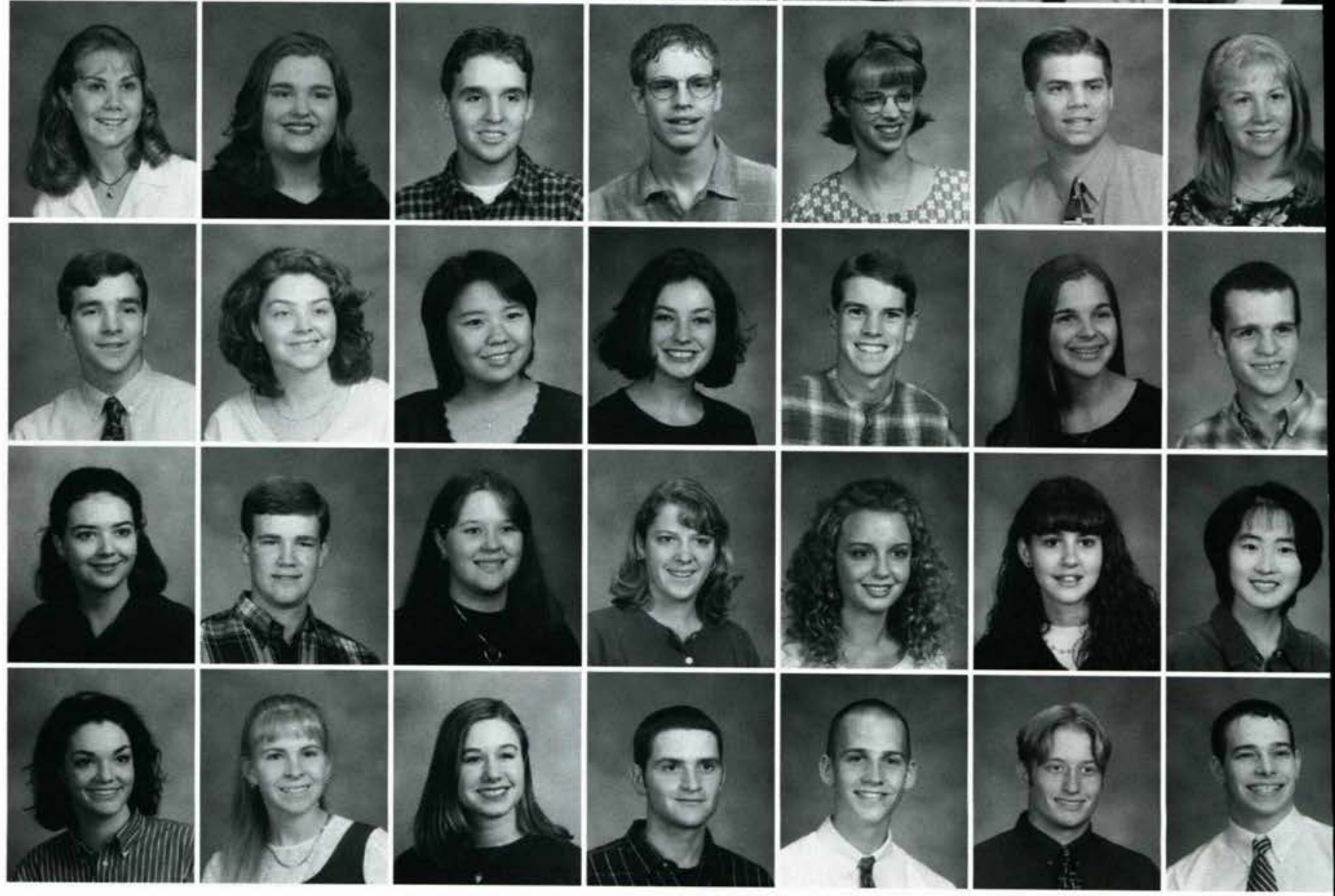


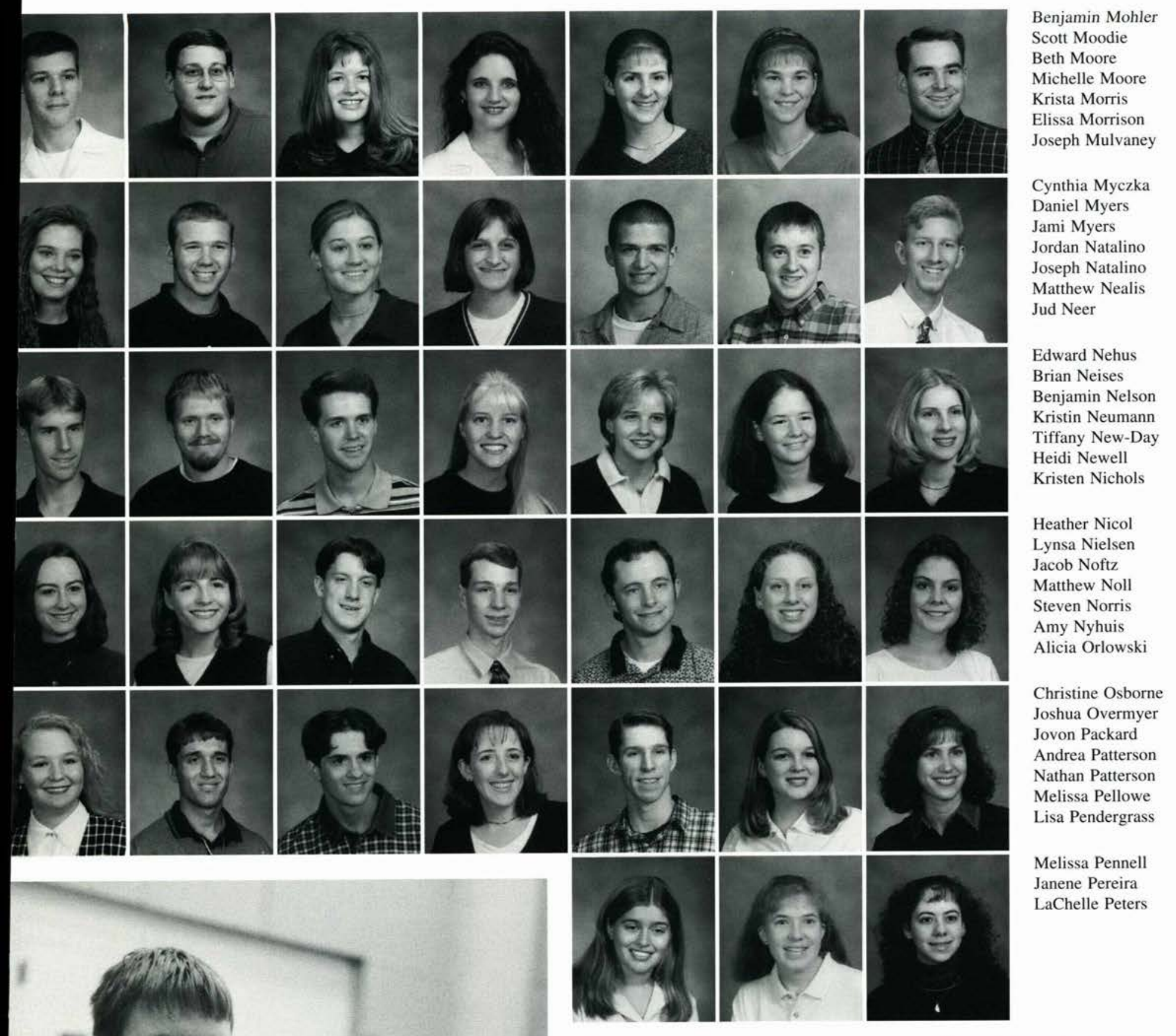


Lani Peterson

Jason Pfeiffe

Spencer Phelps

Amber Philyaw

Jeremy Pierre

Jason Pierson

Jennifer Ploeg

Amie Poelman

Lindsay Pohlman

Vanessa Policani

Emily Poling

Sarah Pollock

Sarah Pomerleau

Amanda Porter

Daniel Potter

Karie Potter

Nicholas Powell

Matthew Powers

Christina Powley

Jennifer Pressdee

Ruth Price

Kristen Prince

Timothy Prusha

Rebekah Pugno

Natalie Reed

Amy Reno

Karen Reynolds

Zacharie Rhodes

Timothy Rickert Charisa Ripma

Misty Roberts

Jasmine Robinson

Joanna Robinson

Janelle Rocke

Roberta Roe

Melissa Roesch

Sarah Ronczkowski

Timothy Ropp

Brandon Ross

Sherri Ross

Tabitha Rowe

Amber Rumphol

Alan Sage

Amanda Sage

Brian Sampsel

Tina Samuels

Timothy Sastic

Jaclyn Schaafsma

Stephanie Schanher

Kristin Schierloh

Brady Schlesener

Sarah Schilcher

Amanda Schmuck

Emily Schuck

Brett Scott

Curt Scott

Nicole Scott

Jennifer Secor

David Shaffer

Eric Sheldon

Rebecca Shellenbarger

Abigail Sherwood

Brian Shook
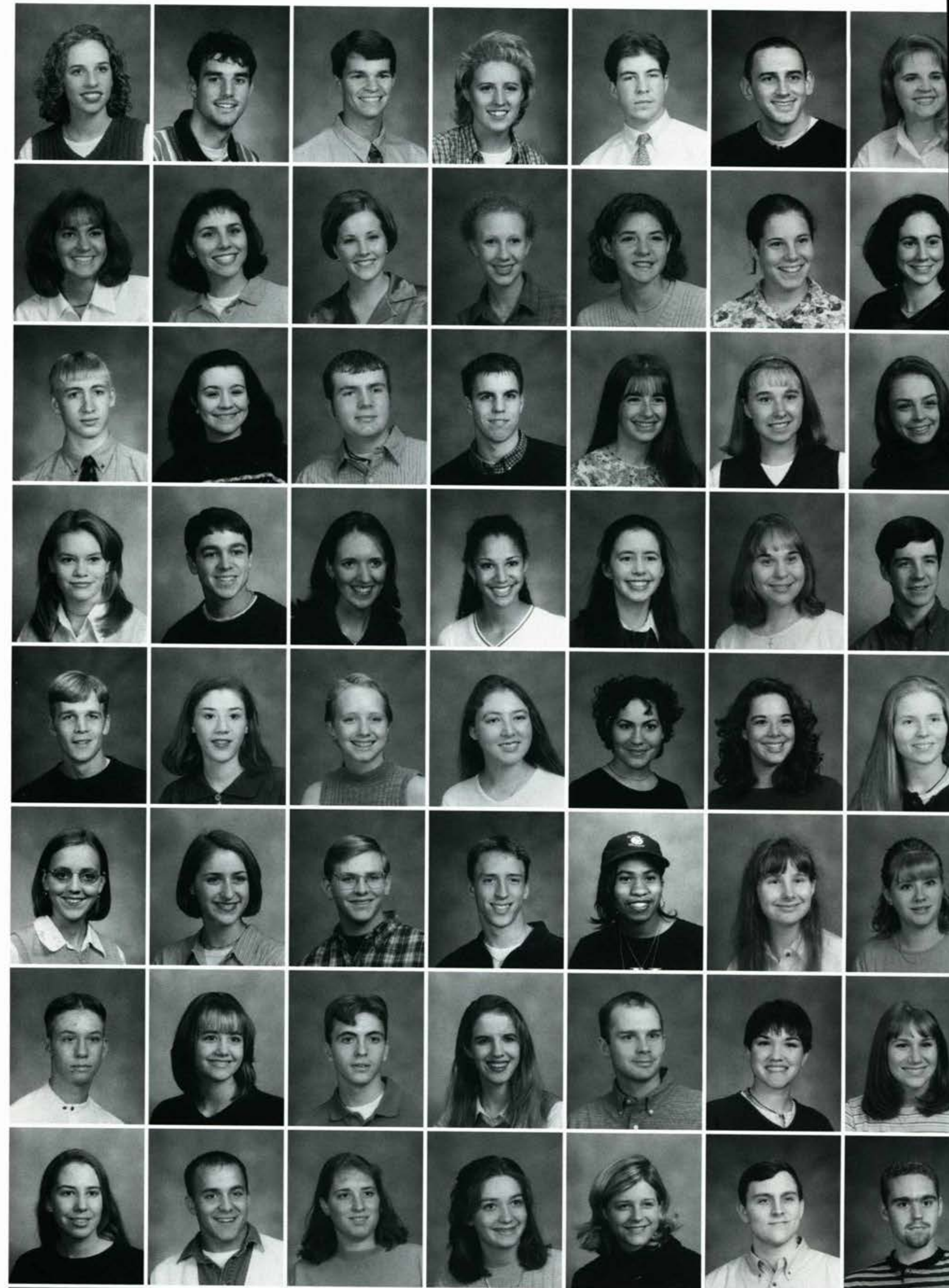

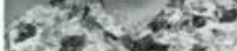
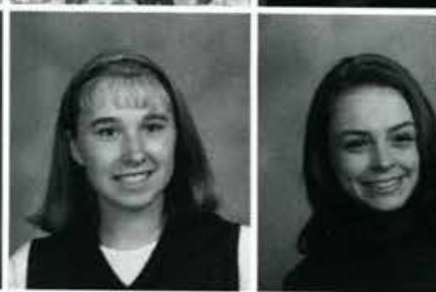

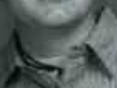
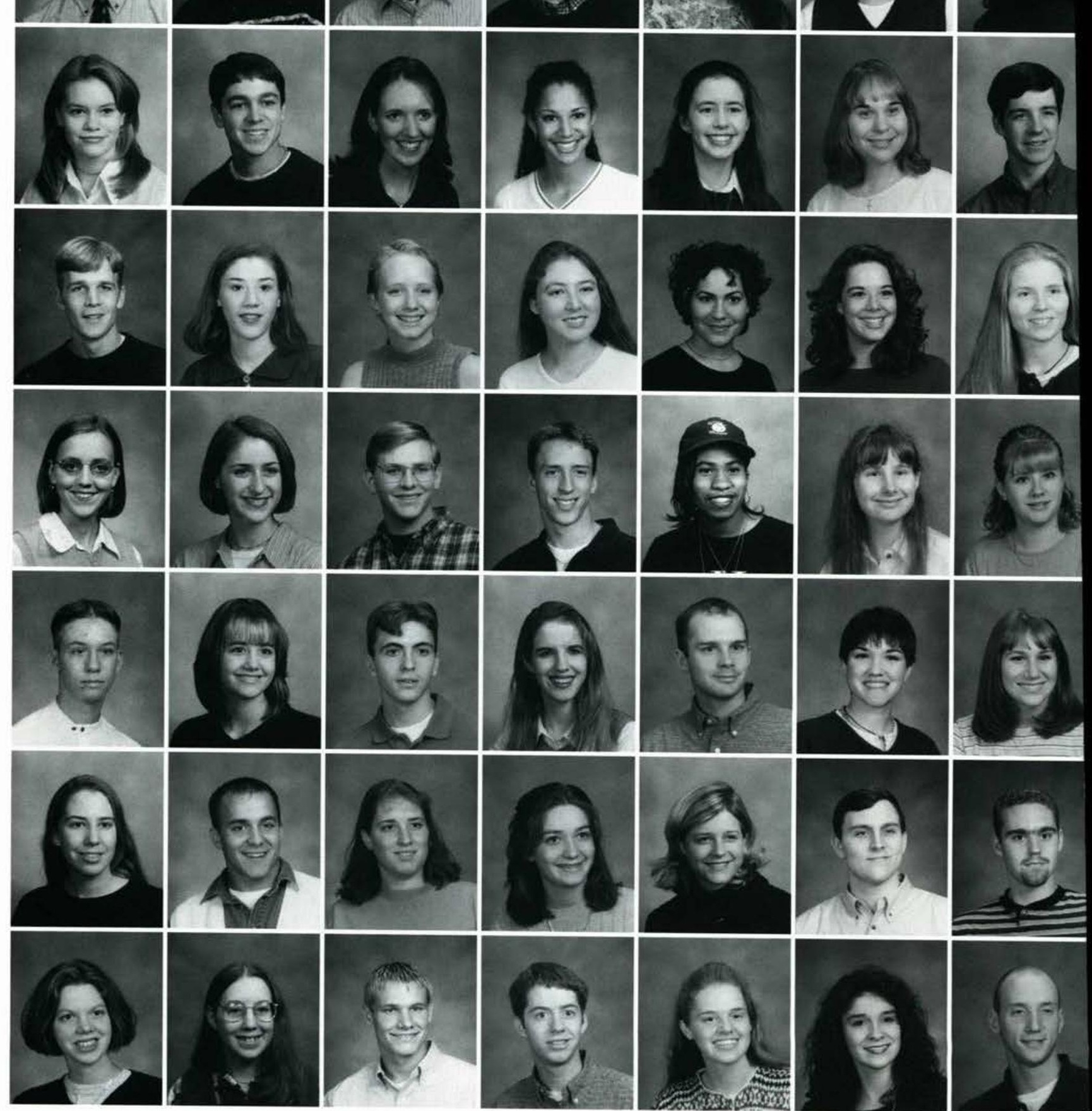
Andrea Weber Stacie Weinert Kristil Wendler Eric Wentz

Nathan Weygand Christina Wheatley

Amanda Wheeler

Lisa Whitely Heather Whitlock

Julie Wilkins

Amy Williams

Joshua Williams

Jennifer Willis

Roderick Willis

Julie Winar

Megan Winburn

Adrienne Wita

David Wolf

Terra Wood

Amy Wooten

Tami Wortman

Jaime Wyrtzen

Shelley Yahara

Kenneth Yoder

Lissa Young

Jason Zaugg

Troy Ziel

Tia Gyurik

James Rossignol, Jr.
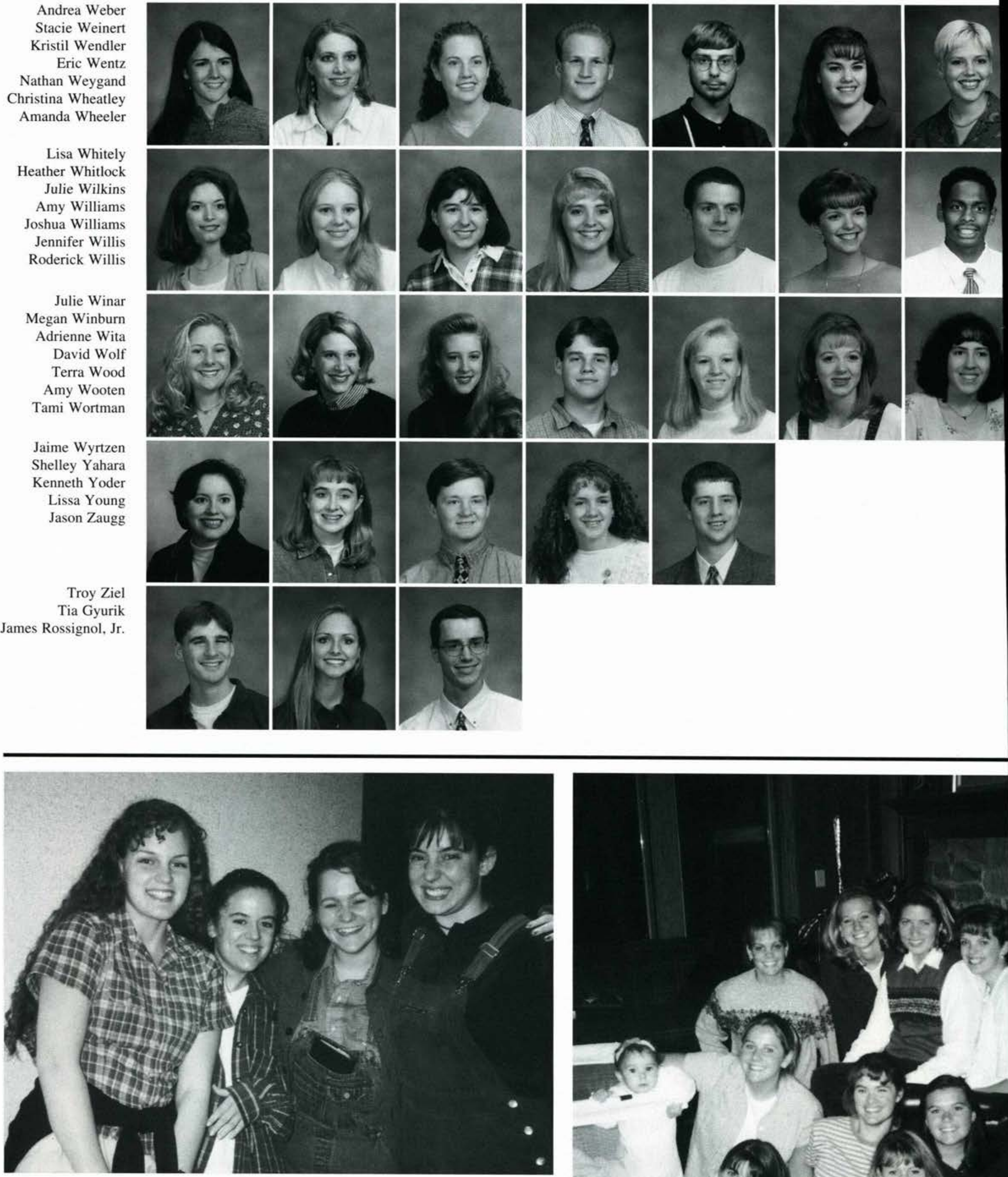

Elizabeth Barker, Kyra

Gray, Rene Rosencrantz, and Erin Jopson spend some time together after Fellowship.
Susan Stout, Bethany Brooks, Jennifer Brayer, Jennifer Willis, Julie Winar, Ellen Laber, Christina Wheatley, Amanda Byrd, and Sherry Christiansen spend the weekend relaxing at Julie's house.

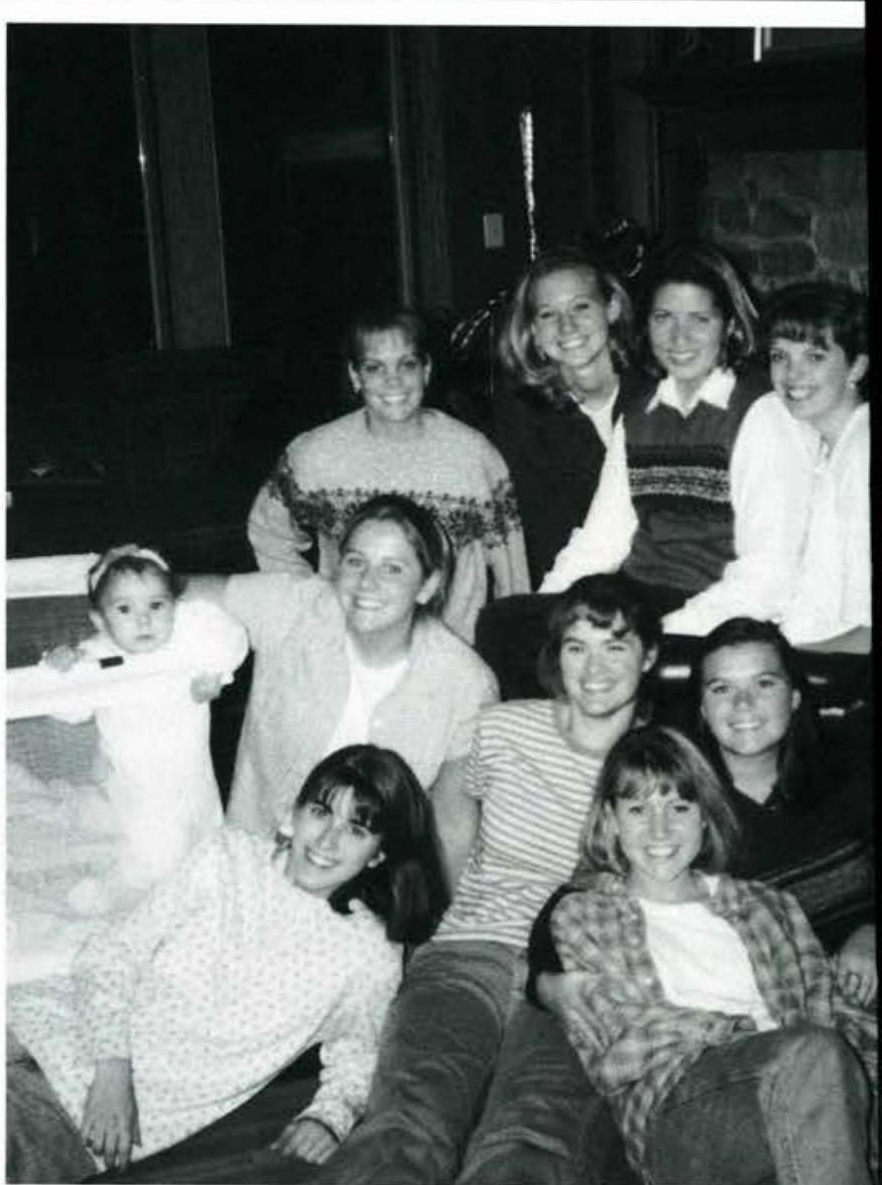



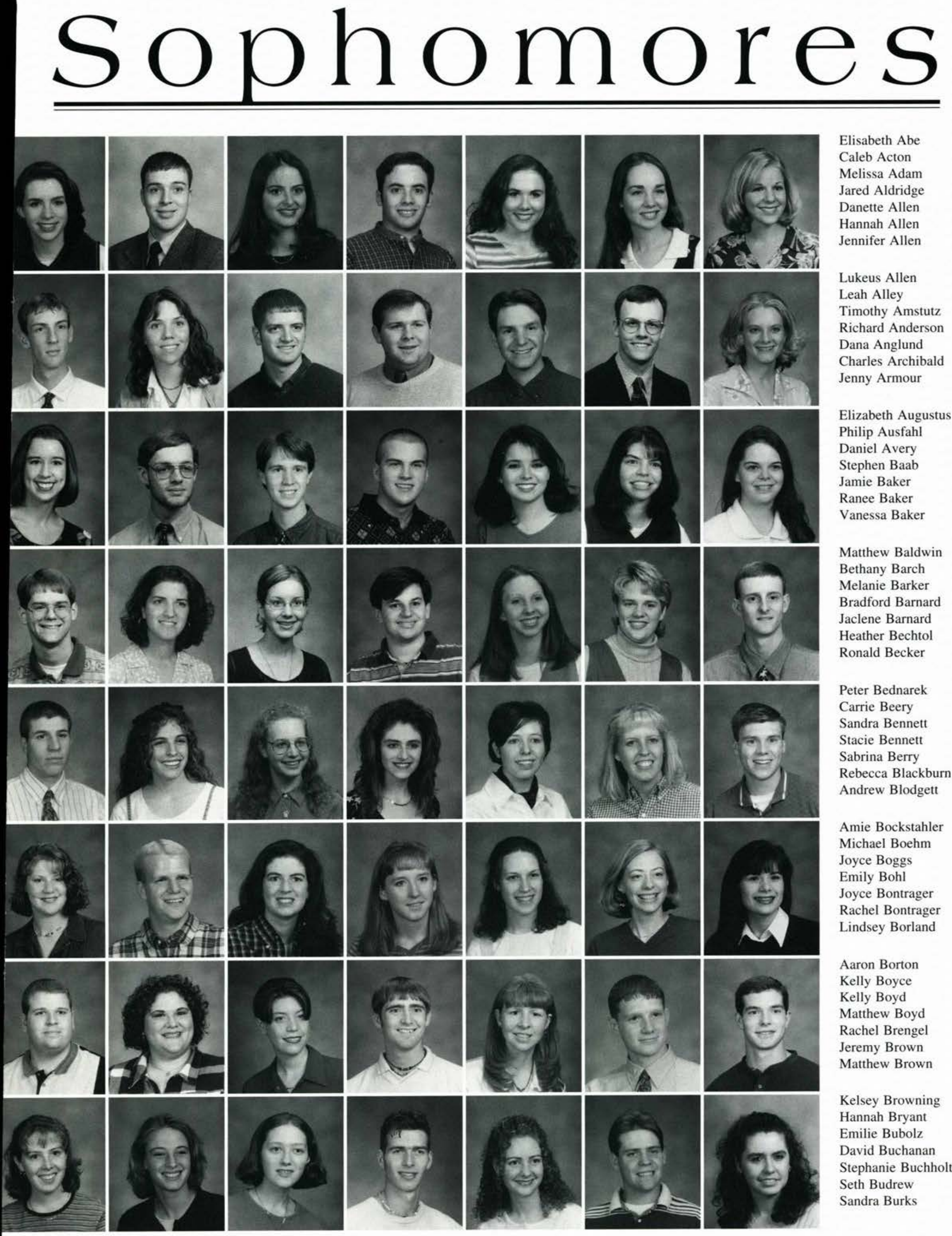

Elisabeth Abe

Caleb Acton

Melissa Adam

Jared Aldridge

Danette Allen

Hannah Allen

Jennifer Allen

Lukeus Allen

Leah Alley

Timothy Amstutz

Richard Anderson

Dana Anglund

Charles Archibald

Jenny Armour

Elizabeth Augustus

Philip Ausfahl

Daniel Avery

Stephen Baab

Jamie Baker

Ranee Baker

Vanessa Baker

Matthew Baldwin

Bethany Barch

Melanie Barker

Bradford Barnard

Jaclene Barnard

Heather Bechtol

Ronald Becker

Peter Bednarek

Carrie Beery

Sandra Bennett

Stacie Bennett

Sabrina Berry

Rebecca Blackburn

Andrew Blodgett

Amie Bockstahler

Michael Boehm

Joyce Boggs

Emily Bohl

Joyce Bontrager

Rachel Bontrager

Lindsey Borland

Aaron Borton

Kelly Boyce

Kelly Boyd

Matthew Boyd

Rachel Brengel

Jeremy Brown

Matthew Brown

Kelsey Browning

Hannah Bryant

Emilie Bubolz

David Buchanan

Stephanie Buchholtz

Seth Budrew

Sandra Burks 


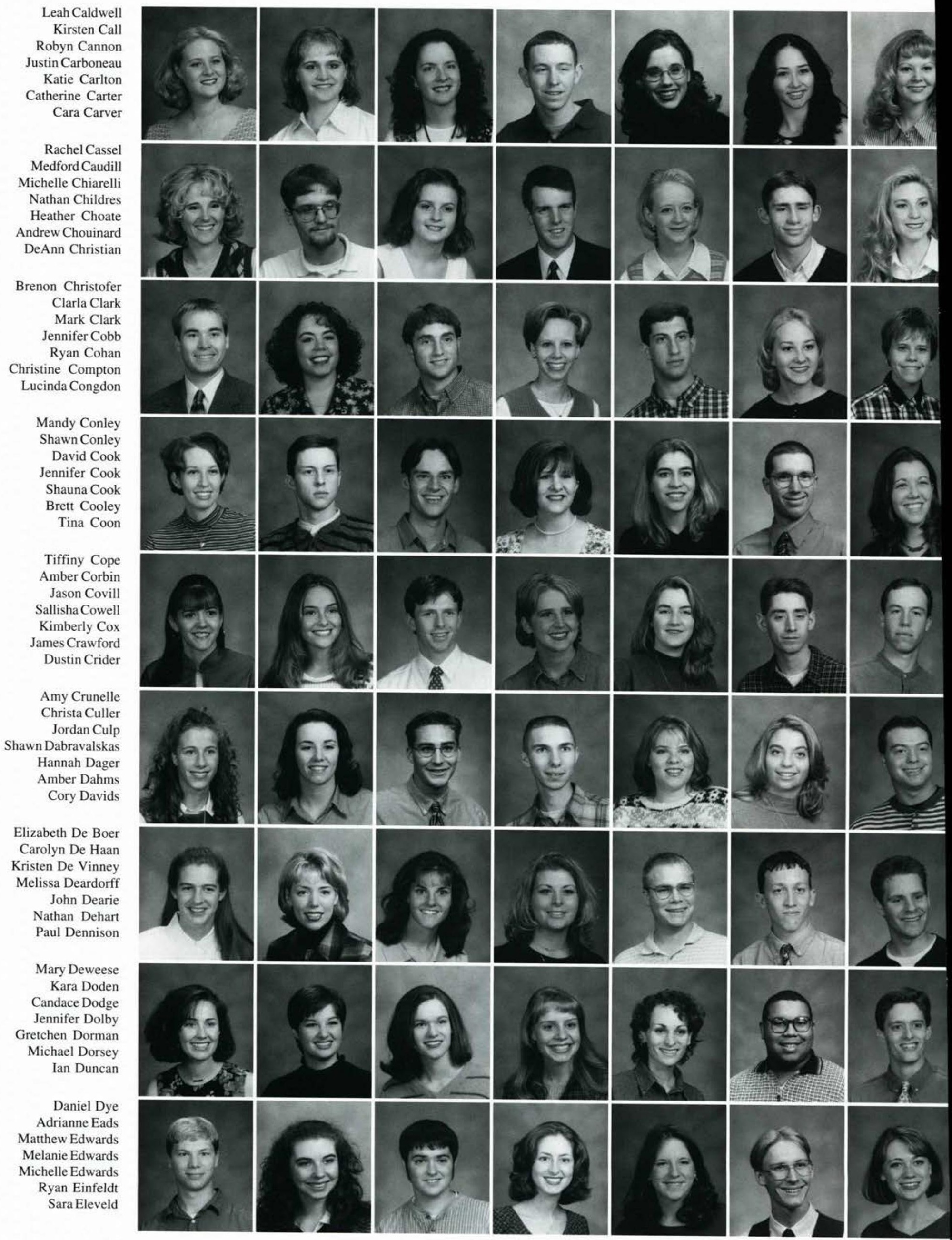




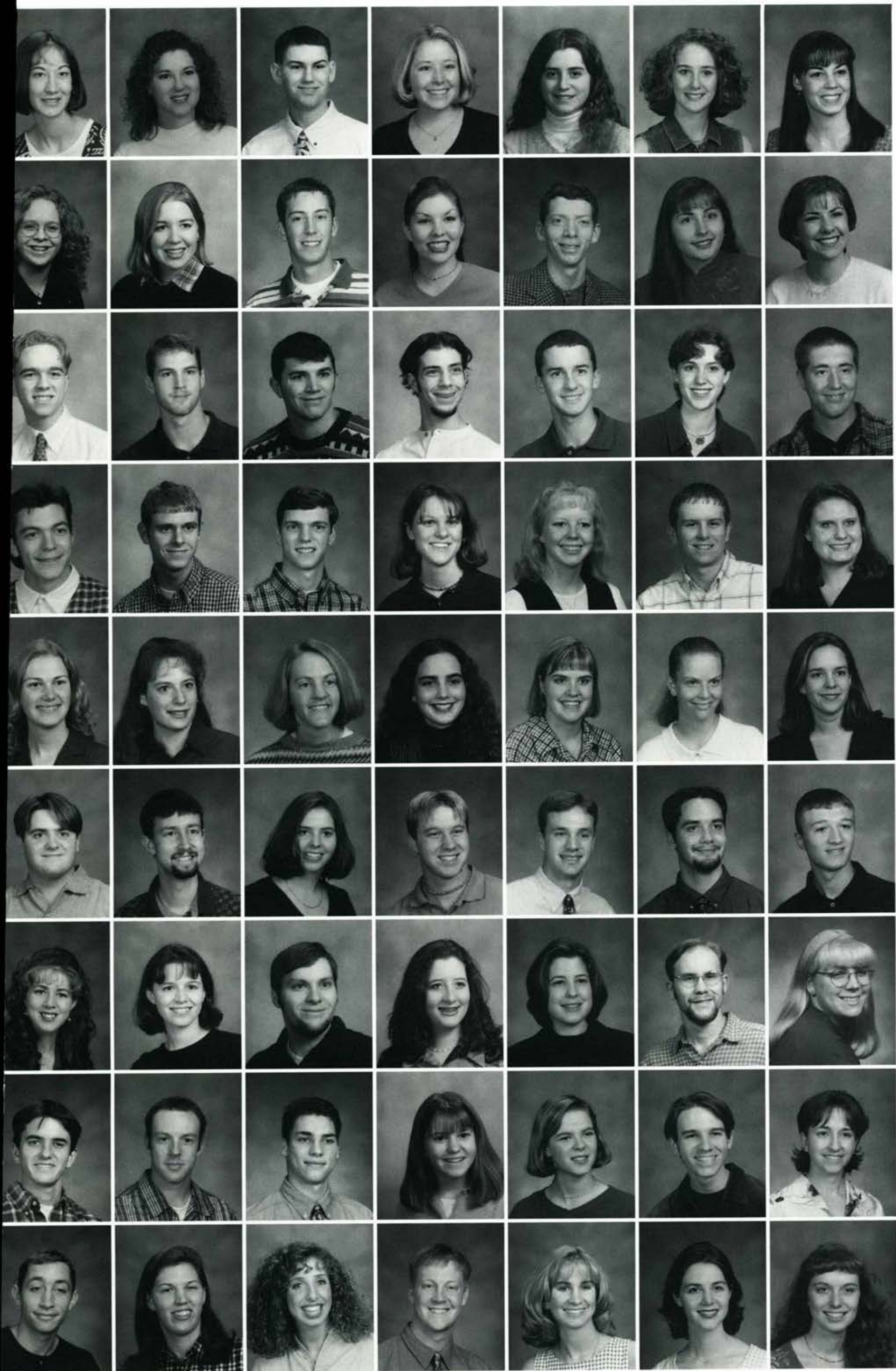

Jennifer Elliott

Andrea Endicott

Michael Essington

Carrie Fabian

Siobhan Fagan

Karyn Farkus

Jennifer Ferguson

Summer Fielder

Julie Finnigan

David Fourman

Rebekah Fox

Steven Fox

Alison Fraley

Loree Fraley

Jeremy Frank

David Freeman

John Freese

Matthew Freitag

David Fretz

Summer Friend

Daniel Fries, Jr.

Joshua Fronduti

Thomas Fry

Jonathan Fuge

Christina Fullerton

Caren Furst

Kyle Gantz

Melinda Gates

Sara Gedraitis

Dawn Geib

Jessica Gerber

LaVonna Getz

Sarah Gilchris

Allison Gillett

Stephenie Gleason

Justin Goehring

Matthew Goetz

JeriAnn Goodbar

Justin Goodrich

Shawn Graves

Don Gray

Daniel Greco

\section{Julie Gregory}

Joy Griffith

Christopher Grigson

Kelly Grindall

Meredith Gross

Stephen Guenther, Jr.

Karen Guikema

James Hall

Jason Hall

Jonathan Hallsten

Amy Hamilton

Jillianne Hancock

Timothy Hardin

RoseAnn Hassell

Mark Hayner

Leanne Heath

Molly Heaton

Andrew Hedges

Robyn Heffner

Christina Heflin

Karri Heldreth 
Amy Herb

Christopher Herman

Aubrey Hess

Paul Hickernel

Sarah High

Sarah Hills

Robert Hirschelman

Karl Hjembo

Amanda Hlad

Kristine Hofstetter

Jessica Hooper

Kristin Hoovler

Joanna Houck

Melissa House

Jennifer Howard

Casey Huebner

James Hulbert

Pamela Huls

Jennifer Hutfless

Heather Jackson

Erica Jenkins

Amanda Johns

Gregory Johnson

James Johnson

Katherine Johnson

Kathryn Johnson

Britney Jones

Jocelyn Jones

Keith Jones

Jeffrey Jordan

Lisa Katz

Denise Kear

Andrew Kempe

Heather Kennelly

Kimberly Ketterer

Kyle Kickbusch

Andrea King

Karen King

Heidi Kinsey

Robert Kirby

Kimberly Kleiman

Michael Koerbel

Vianna Kreuder-Crowell

Andrew Krum

Kristin Kuhn

Barbi Kuvshinikov

Amy Kuyper

Daniel Kwas

Timothy Kwast

Mark La Fleur

Julie Lamborn

Michael Lampton

Jennifer Larson

Rebecca Leatherman

Shanna Lenhart

Cheyenne Leslie

William Leukhardt

Kimberly Leverson

Stephen Light

Tiffany Linden

Betsy Linnell

Jennifer Linton

Katie Little
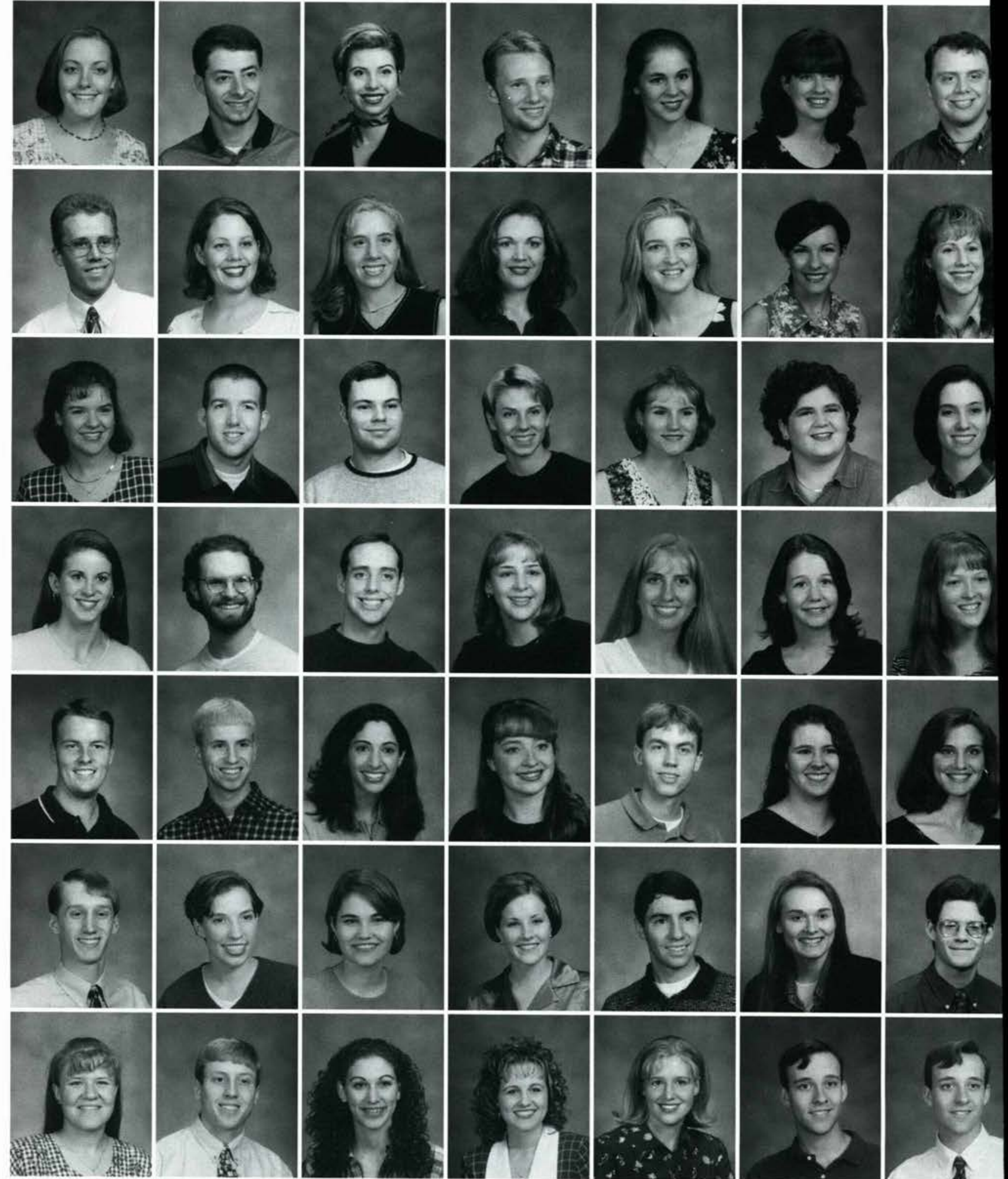

githet
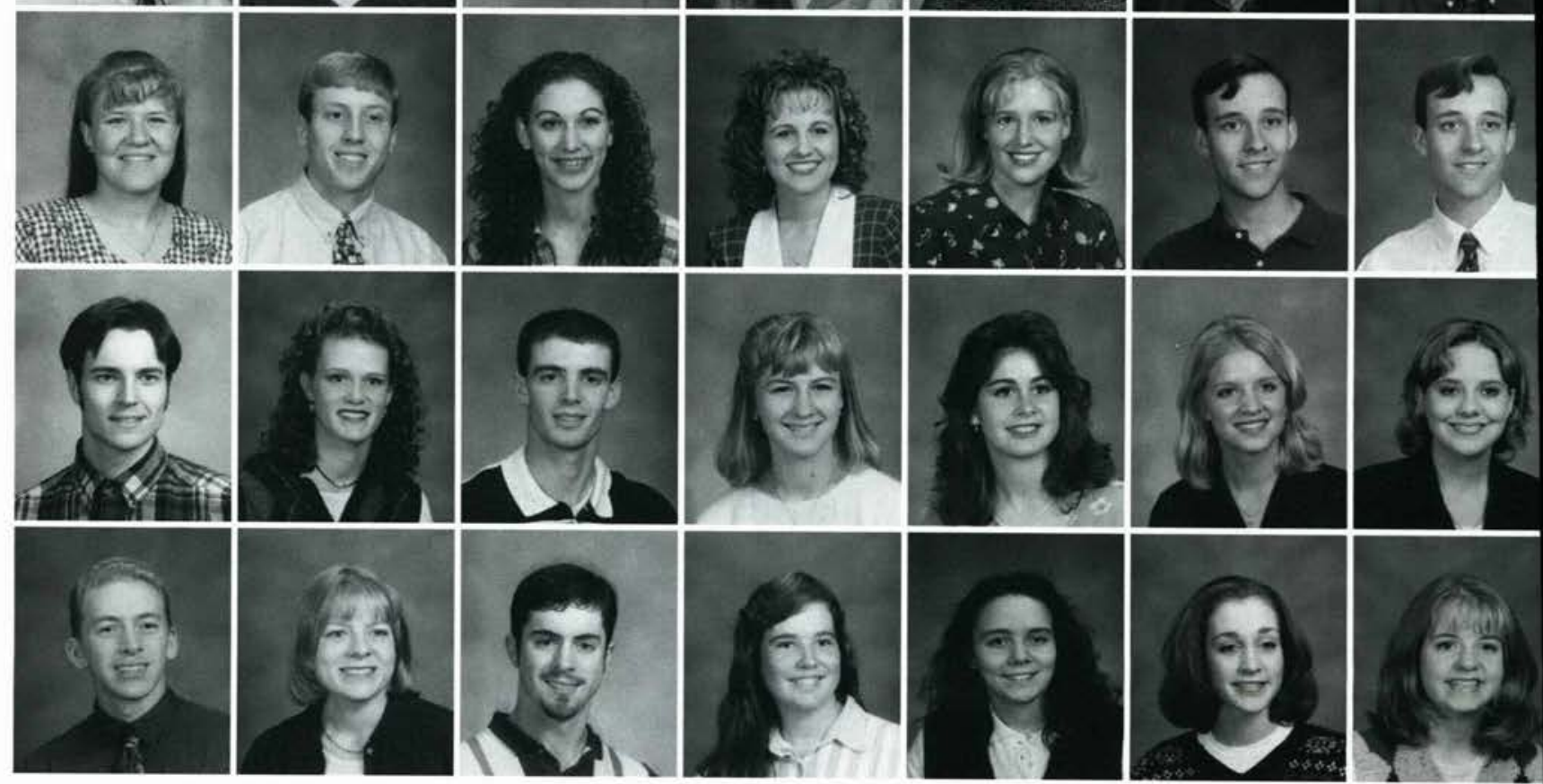


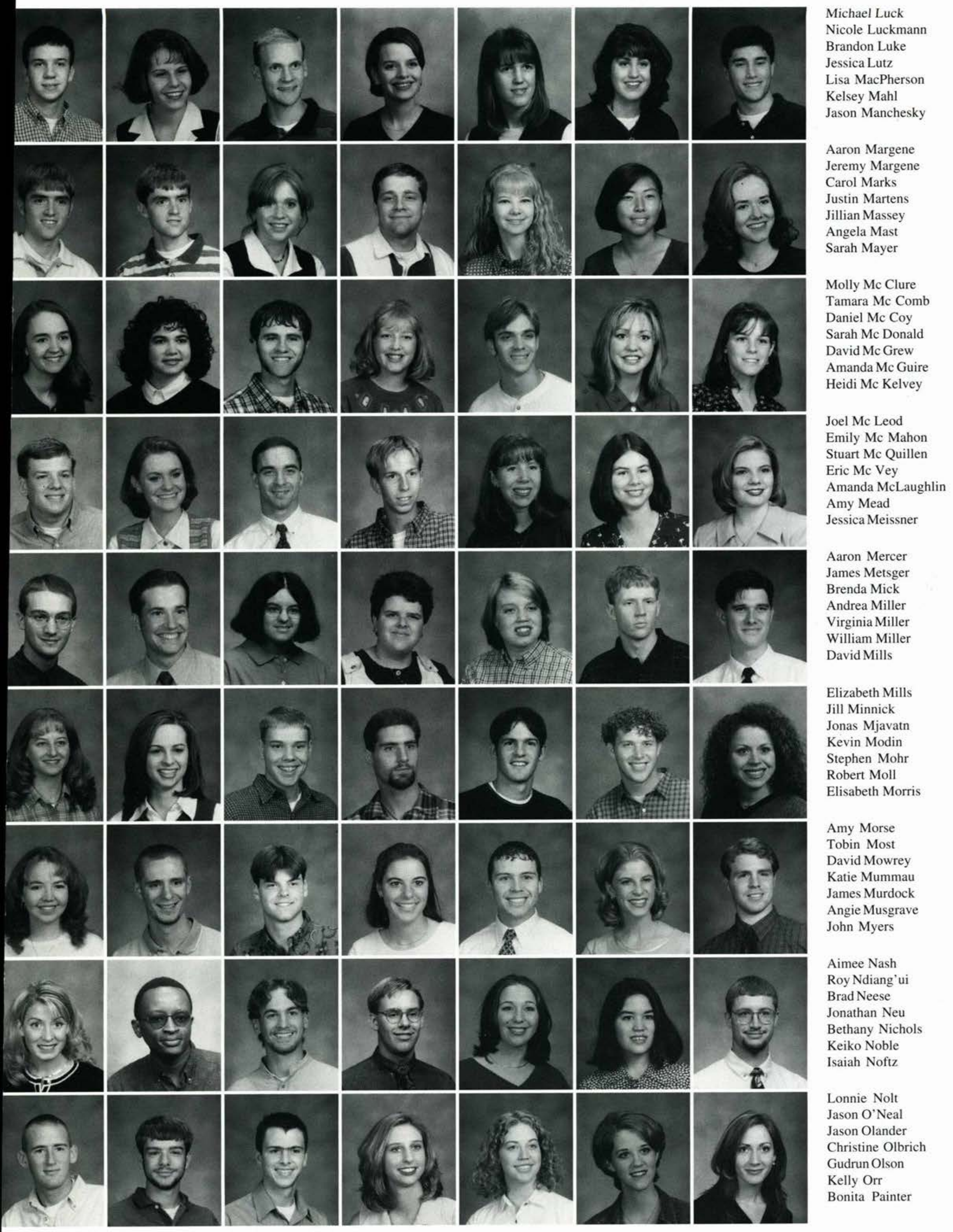


Rachelle Paquin Danielle Parker Kristina Parr Jordan Patrick Eric Pauling Matthew Pedersen Grady Peeler III

Jessica Pennington

Miriam Perez

Amy Peterson

Tiffany Peterson

Troy Pfeiffer

Jaya Philip

Krista Pierce

Amy Pitstick

Matthew Plaatje Casey Platt

Susan Plummer

Amy Pollard

Lina Ponder

Michelle Prado

Christa Preston

Angela Primo

Marlena Proper

Rachel Puckett

Jodi Quint

Jesse Racine

Daniel Rainsberger

Allison Ramsey

Amanda Ratliff

Jonathan Rauch

Briar Redfern

Naomi Redinton

David Reisenbigler

Kelly Reitz

Rachel Reno

Christina Riley

Sarah Rittgers

Jamie Ritzer

Hannah Rives

Adam Rizer

Geneva Roberts

Mindy Robinson

Stacey Romeyn

Todd Romin

Adam Rorex

Joel Rose

Brian Rosseau

Maranatha Ruberg

Casey Ruffin

Scott Ruhlman

Megan Ruoss

Rachel Ryan

Kimberly Sanderson

Gretchen Savage

Joel Schenk

Christina Schield

Christine Schmidt

Crystal Schulman

Rebekah Schuring

Lisa Scott

Stephanie Selin

Aaron Shaw
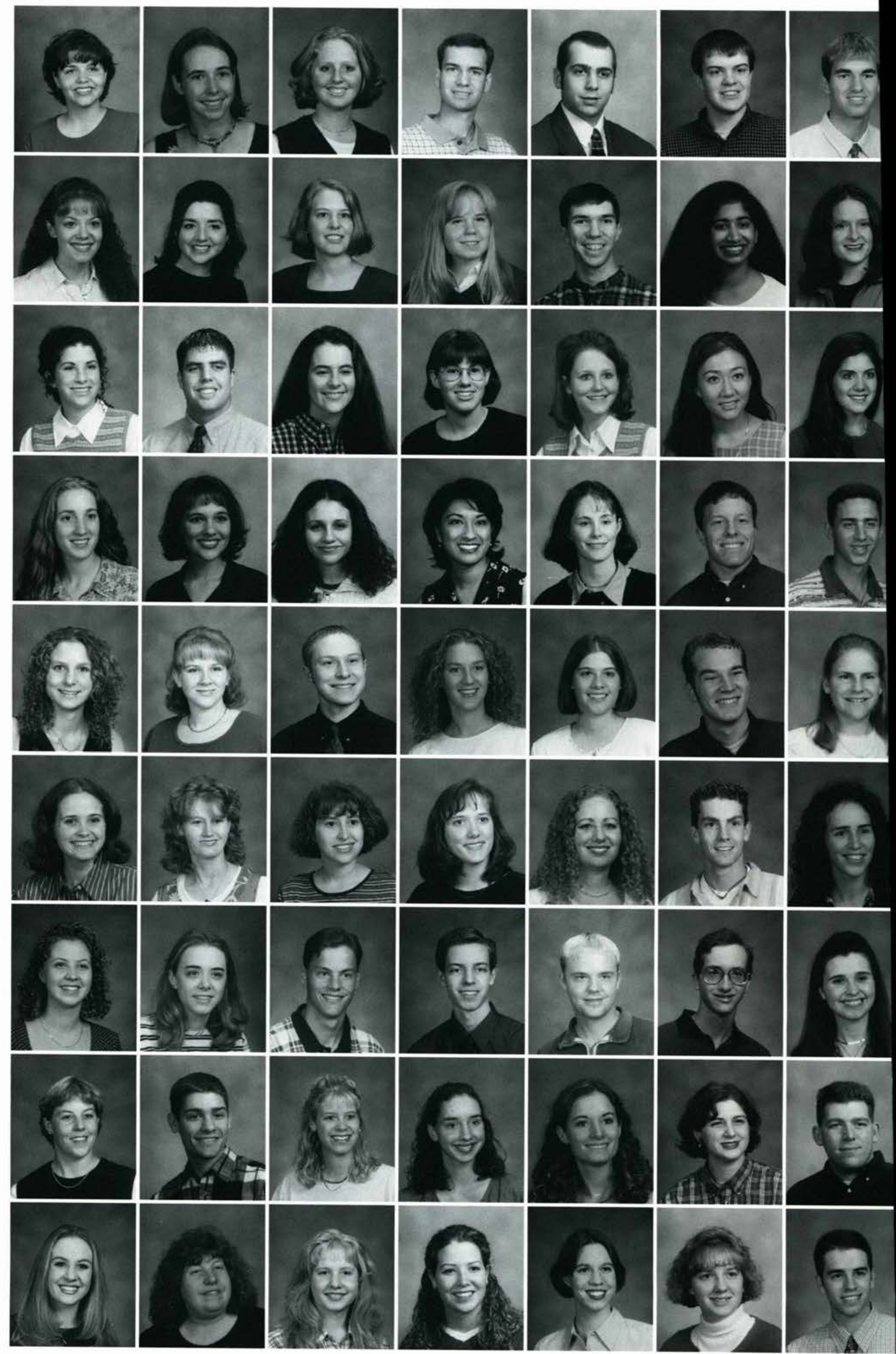


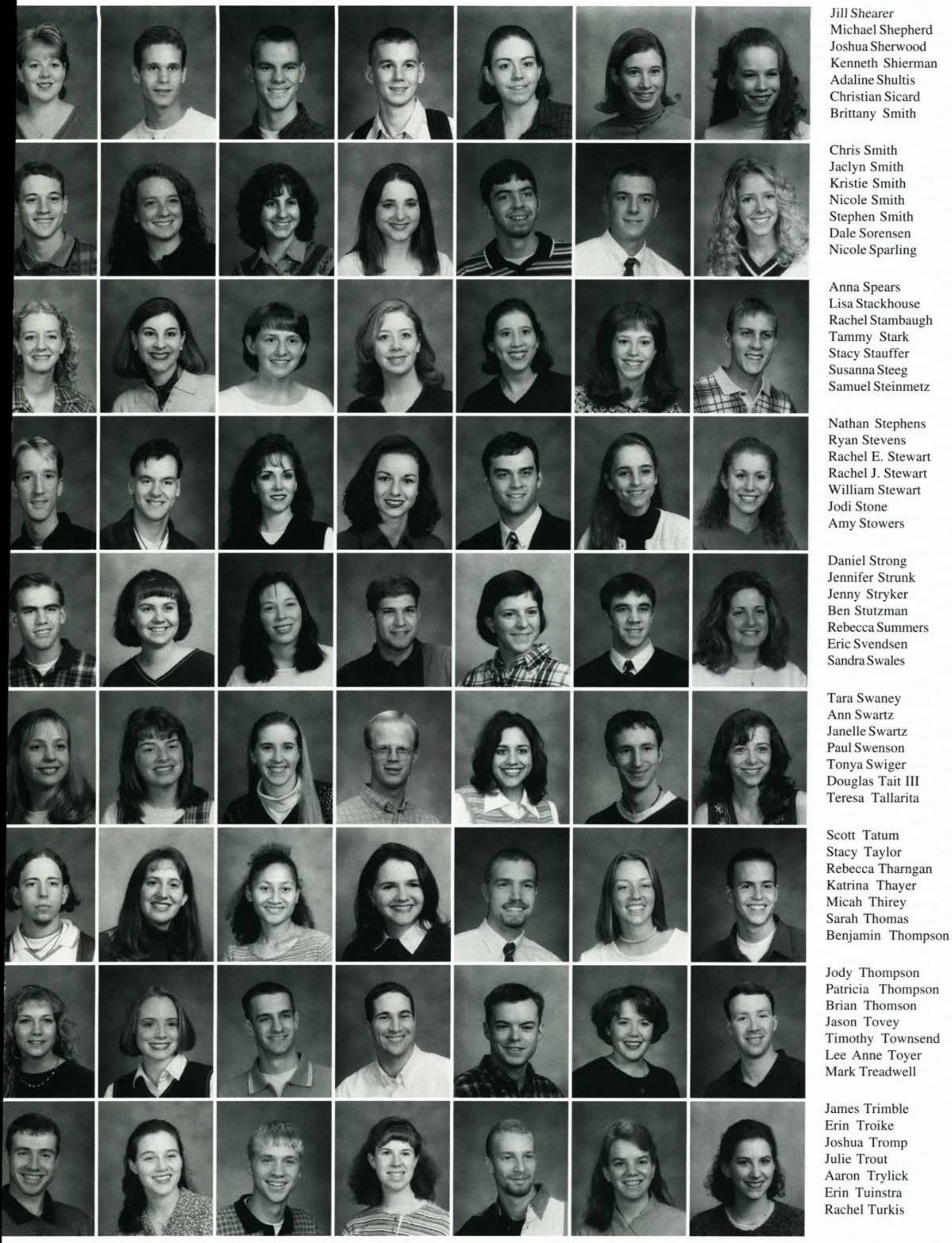


Esther Twigg

Angela Tyson

Heather Tyson

Megan Valade

Tracy Valiknac

Heather Van Gorp

Michele Vanlier

Neil Vitali

Rachel Volpe

Ty Waardenburg

Michael Wade, Jr.

Melanie Wadlington

Jessica Wagne

Lindsay Wagner

Scott Walker

Sarah Walkley

Piyawath Warinsee

Melissa Warner

Adam Warnken

Aaron Warriner

Emily Watkins

Megan Wawro

Emily Weidler

Jennifer West

Lorraine Wheeler

Danielle Whygle

Sharon Wickholm

Sara Wiersma

Jackie Williams

Mark Williamson

Loring Wilmer

David Wilson

Margueritte Winkels

Jamie Wishar

Jennifer Wishart

Neil Witherell

Bethany Withers

Elizabeth Wolfe

Miranda Woller

Krista Word

Susanna Workman

Mark Wyse

Katie Zwar
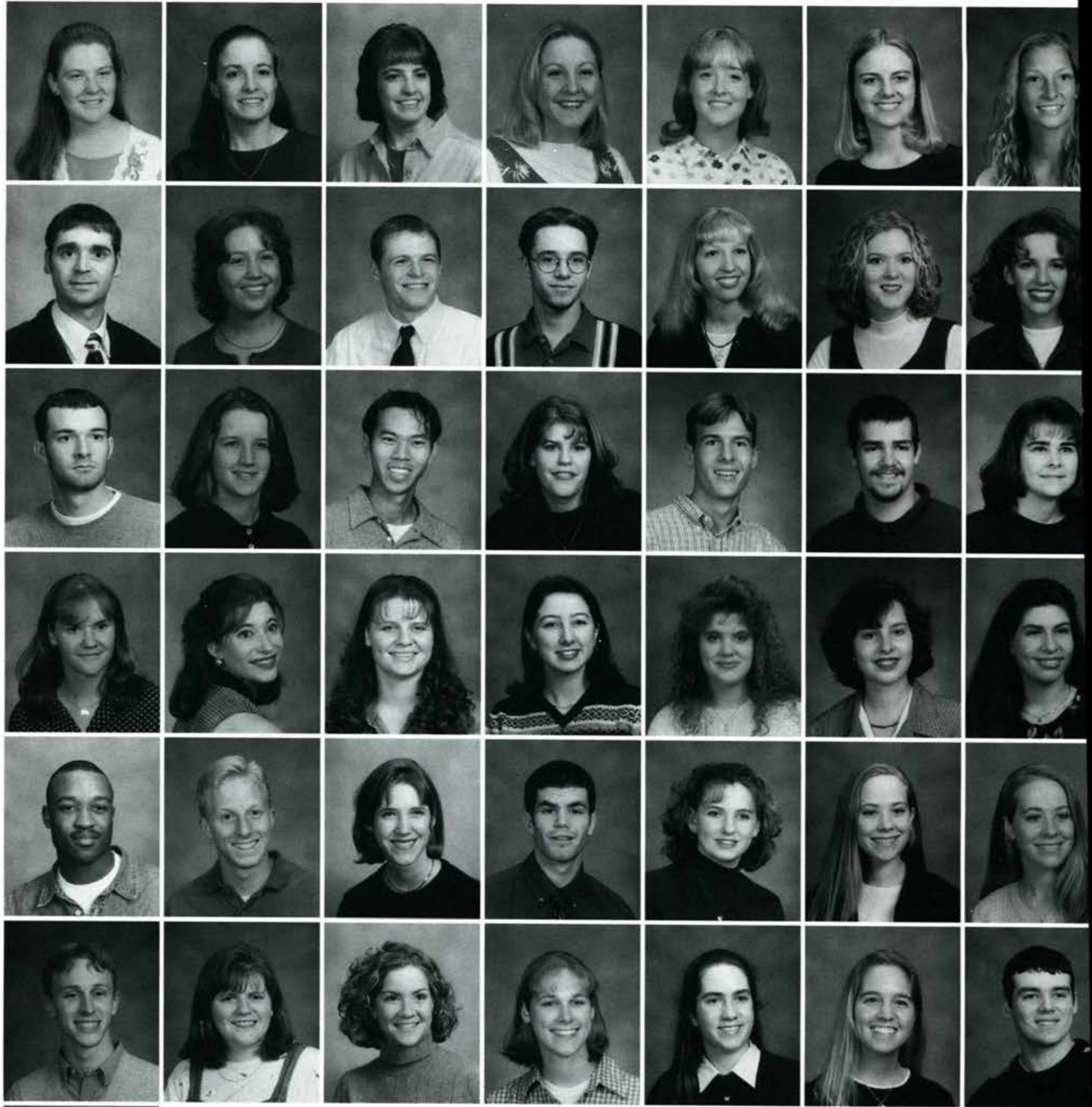

Jim Johnson and

Matt Noll take some time

off to relax during a

Concert Chorale reherasal.

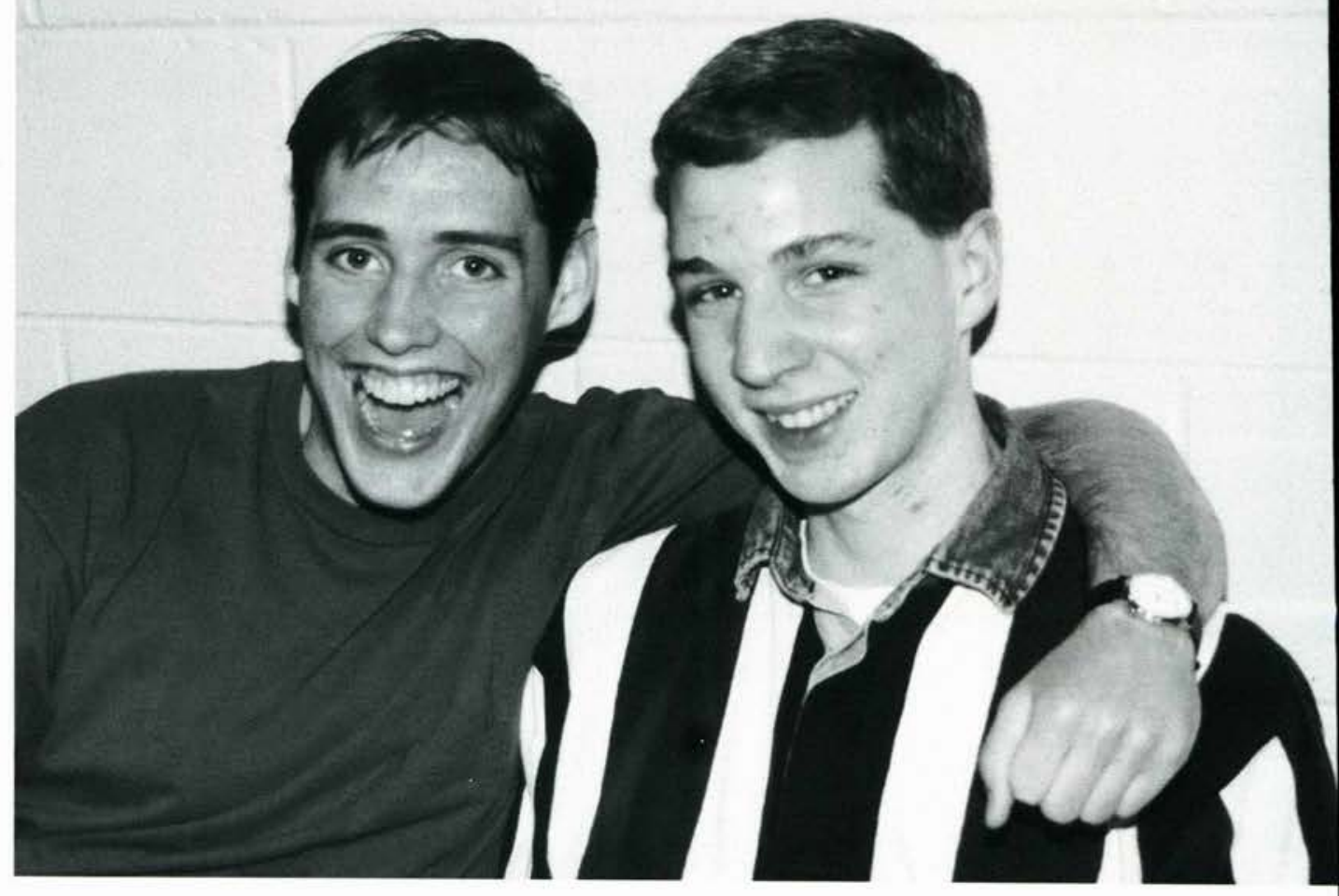


Laura Brown
Jill Bruin

Faith Buchanan

Deborah Buck

Sheryl Buckley

Aaron Burak

Tiffany Burgett

Kelly Burggraf

Ginger Butler

Krista Byler

Raenell Bylsma

Daniel Byrne

Brian Caldwell

Shannah Campbell

Nicole Carlson

Amy Carpenter

John Carr

Sarah Carr

Jamie Cartwright

Daniel Castellini, Jr.

Allison Caylor

Andrea Caylor

Nicole Chakalis

Derek Chandler

Donald Chapin

Robert Chapman

Jerami Cheatwood

John Chesnes III

Peter Chevere

Emma Chmura

Nicholas Chou

Diana Christensen

Heidi Christman

Elizabeth Clark

Michelle Clark

Andrew Clary

Pamela Claus

Nancy Clawson

Amy Clutz

Gregory Coates

Jenny Coble

Daniel Cochrane

Kelly Cochrell

Johannah Conant

Jeffrey Connors

Aaron Cook

Laura Cook

Matthew Cook

Lonny Cooper

Naomi Cooper

Aimee Copeland

Kelly Cordts

Joanna Cormany

Jeremy Couture

Nathan Crain

Kathleen Cramer

Melissa Crawford

Sarah Crawford

Cheston Cromer

Rebekah Crosson

Rhonda Culp

William Cunningham

Jennifer Dake
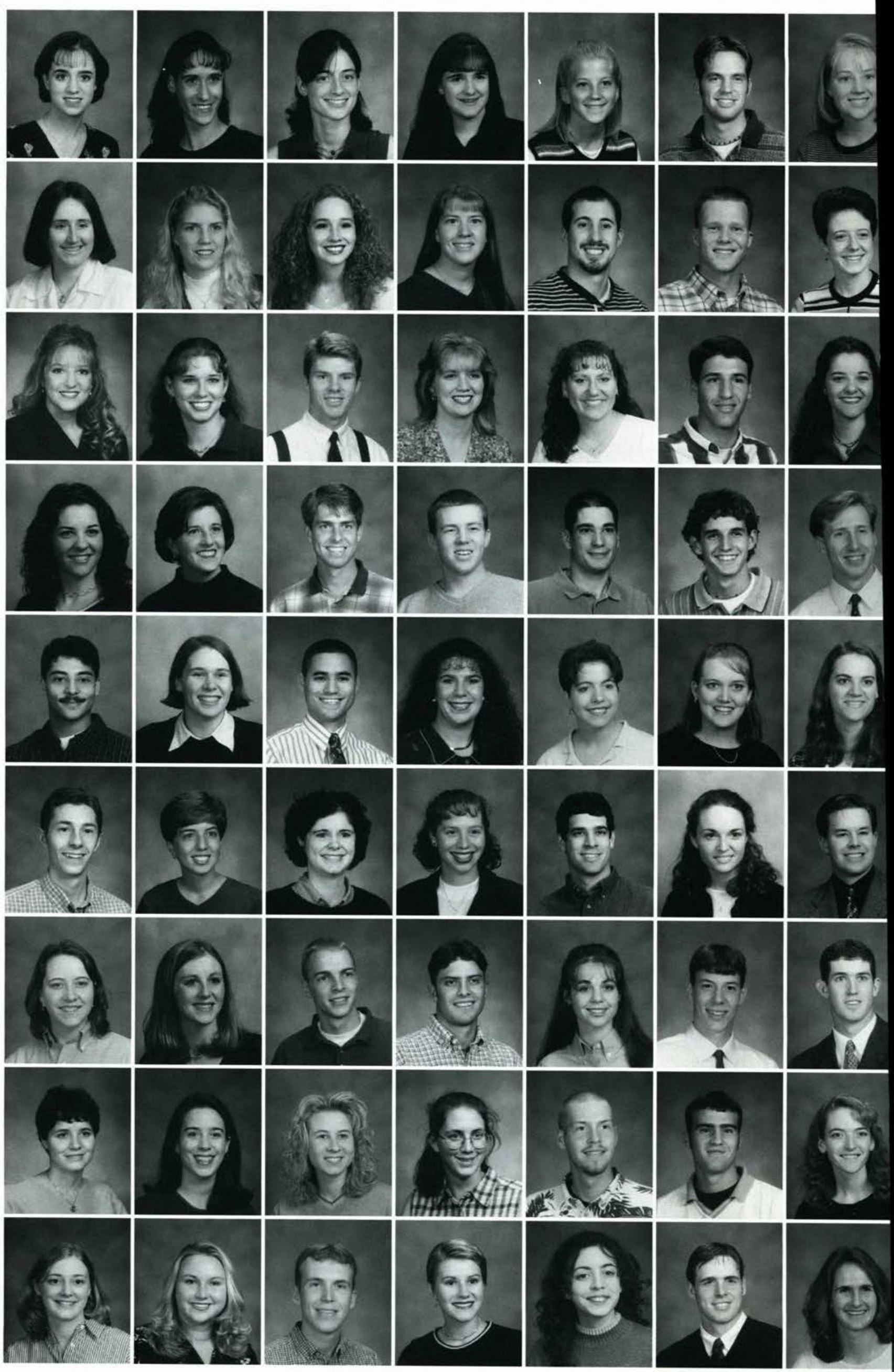
Amber George

Timothy George

Andrea Gersema

David Gillespie

Shelly Gillet

Janae Gerrish

Jana Glessner

Sarah Glupker

Erin Goehring

Stephen Goldsworth

Gilliam Gombis

Thomas Goodrow

Barry Gorsuch

Berney Gorsuch

Kelly Grady

Jason Grahame

Edith Granillo

Sarah Grapentine

Monique Gras

Kevin Greer

Michael Gregg

Rachel Griffin

Lesley Grow

Michael Grubbs

Paul Gwilt

Lara Gyurik

Kevin Haisch

Matthew Hamer

Duane Hammond

Jonathan Hammond

Stephen Handel

Dustin Hansen

Lance Harkleroad

Rachel Har

David Hassenzahl

Karen Hayes

Jeffrey Haynes

April Heineman

Jared Henniger

Elizabeth Hennis

Timothy Hewitt, Jr.

Andrew Heyd

Michele High

Christa Hil

McArthur Hill, Jr.

Cara Hines

Todd Hintz

Jamie Hof

Jennifer Hoffman

Marc Hollins

James Holz

Julia Horne

Shannon House

Jeremy Howard

Timothy Howard

Angela Howe

Jennifer Howell

R. Brent Hughes

Alison Huizinga

Krsiten Hunter

Matthew Hus

Amy Hutchison

Jeanette Irish
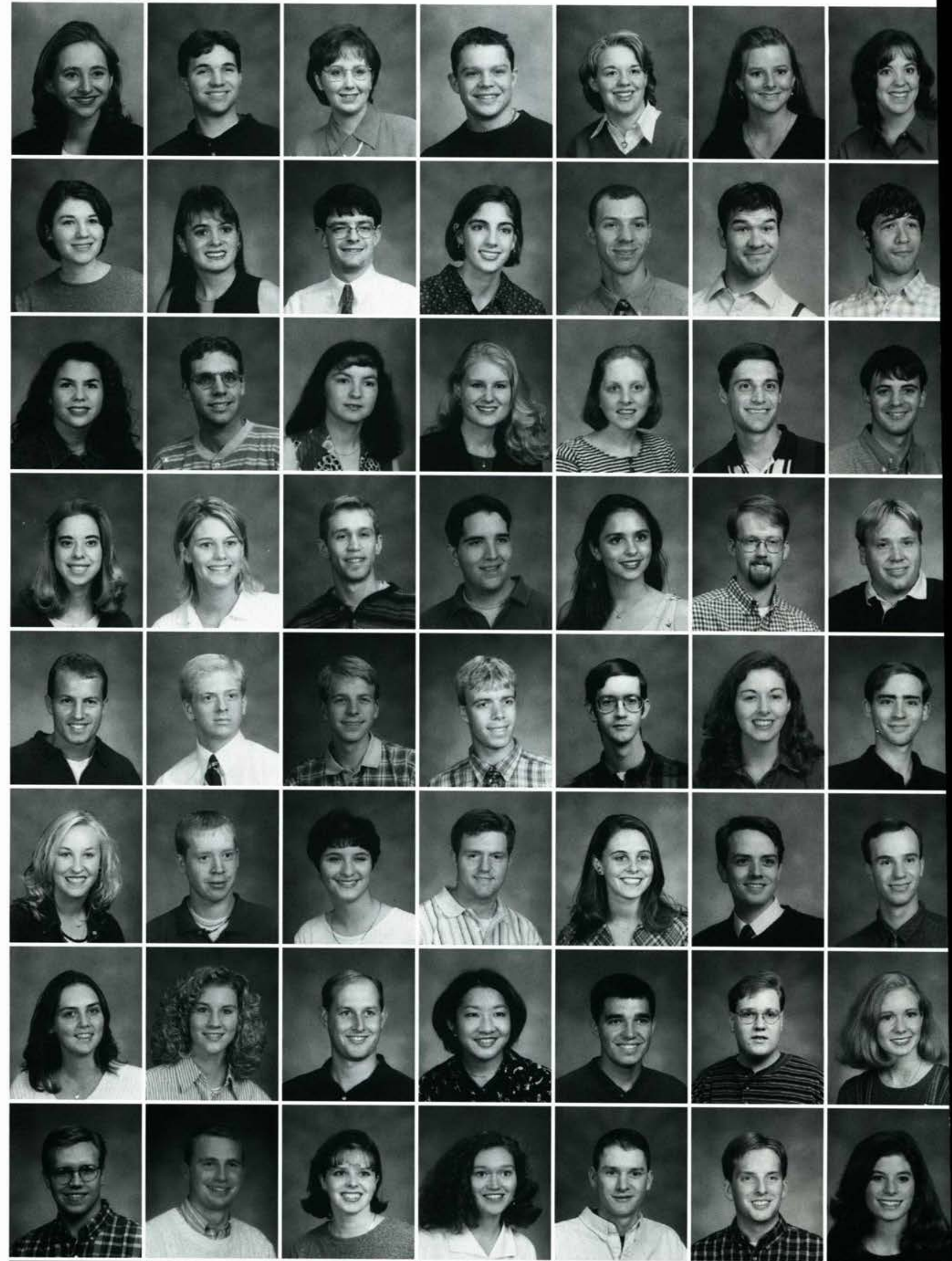

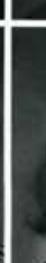
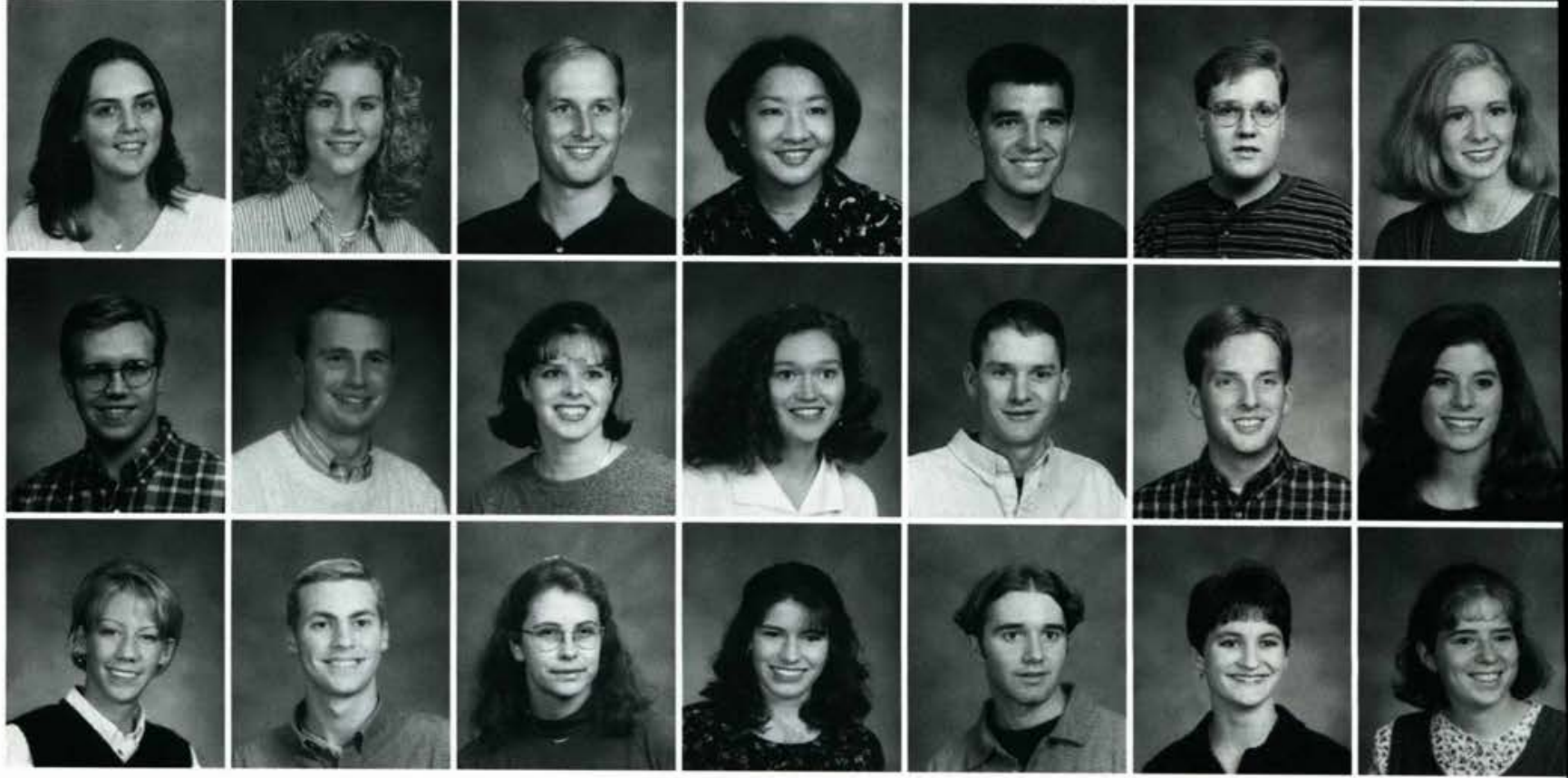
Stephanie Mace Joan Mallman Carrie Mansfield Samuel Mantravadi Andrew Manwiller

Ghena Marchetti

Abigail Mariage

Rosemarie Marotta Chirsty Marr

Kristin Marshall Sarah Martin Jennifer Mason Michael Maurice Heather Maybury

Kathleen Mayer Christopher Mc Auley John Mc Caw

Eileen Mc Coskey

Michael Mc Cubbin Elizabeth Mc Donald

Cynthia Mc Fadden

Kathy Mc Farland Kimberly Mc Kenzie Erin Mc Larty Philip Mc Vey

Meredith McGahan

Amanda Melcher

Joseph Mellish

Kristina Mencarini Jason Merritt Ross Meyers Joshua Michael

Mark Milec

Carrie Miller Jeff Miller

Kristie Miller Shawn Miller Lindsey Milne Jared Mitchell Lindsey Mitchell Anastasia Mobley

Alison Modock

Chris Moles Kelly Montague John Moodie

Michael Moran Kelley Morgan Rachel Morris Jeffrey Motter

Heidi Mountz Jeanne Moynihan Amanda Mullen Thomas Mullins III

Jonathan Murphy Todd Musser Jennifer Myers

Sundi Myers Jeffrey Nafziger Jason Naill

Beth Nelson

Meredith Newfeld

Christopher Nolt

Andrew Nyveldt
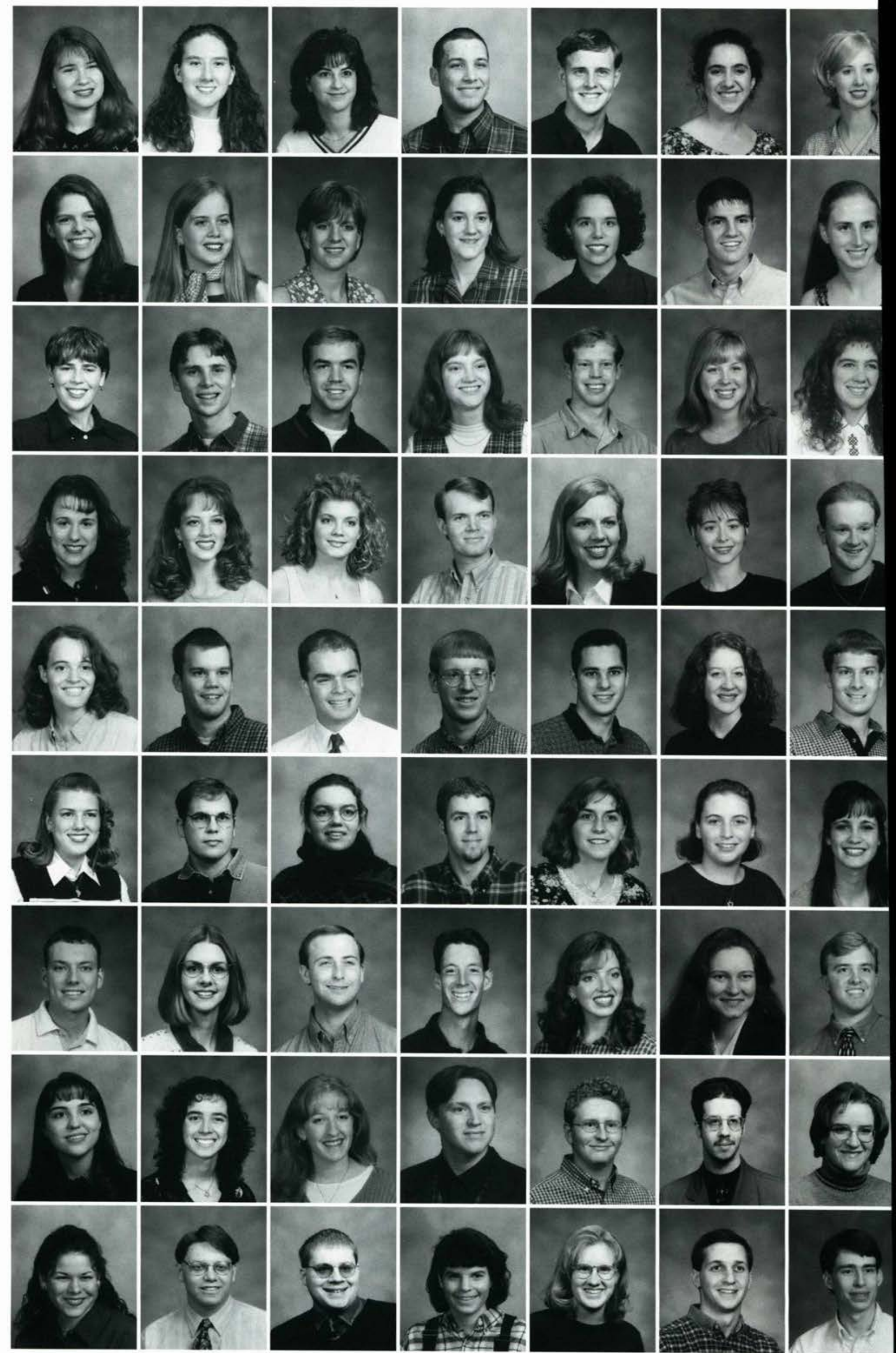


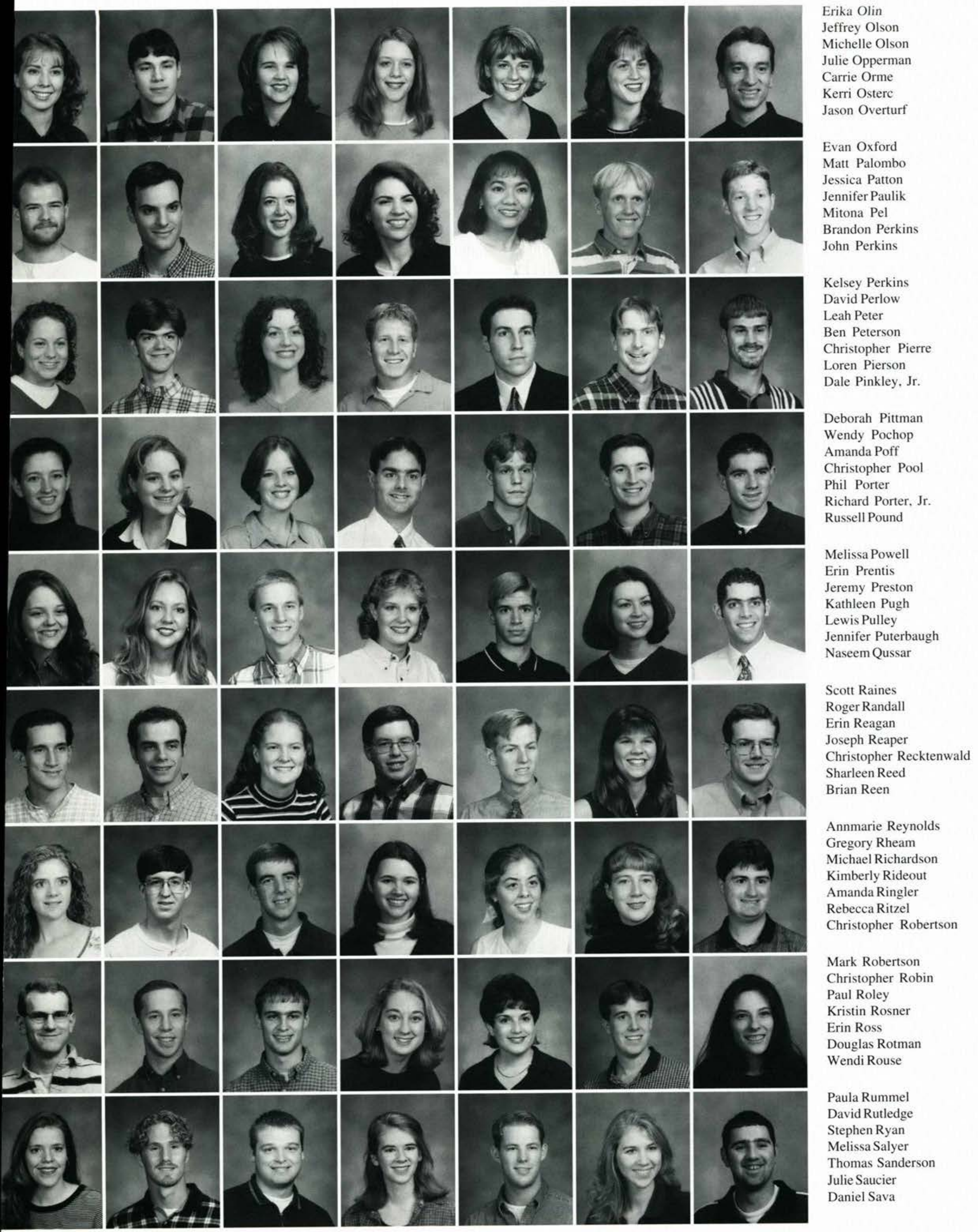


Bonnie Schaefer

Rachel Schafer

James Scheid

Lindsay Schneider

Dean Schuler

Jeffrey Schumacher

Constance Schwartz

Christopher Scott

Kimberly Scott

Jessica Seeley

Jamie Sell

Bethany Seyfang

Tara Seyfert

Craig Shank

Paul Sheldon

Rebecca Shelford

Hannah Sherwood

Erick Shumaker

Jared Skillings

Jedediah Smith

Michelle Smith

Valerie Smith

Amy Smutylo

Joshua Snyder

Aaron Sokoll

Holly Sorensen

Valerie Sorg

Alicea Stachler

Michael Stark

Erin Steelman

Steven Strong

Joshua Strychalski

Erin Stuenzi

Melissa Stumbo

Joshua Tackett

Jay Talladay

Christy Taylor Jennifer Tegtmeier

Nicole Thomas

Adam Thompson

Benjamin Thompson

Lisa Thomson

Jennifer Tiel

Erin Timco

Jill Townsend

Christopher Troupos

Jonathan Turner

Carrie Tyson

Ryan Urbassik

Rebecca Upham

Rebecca Vanderground

Beth Vencill

Jared Voigt

Brandley Voumard

Melissa Wabeke

Laura Waddell

Holly Waechter

Catherine Walcott

Bethany Walker

Lisa Walker

Timothy Walker

John Ward

Krista Warder
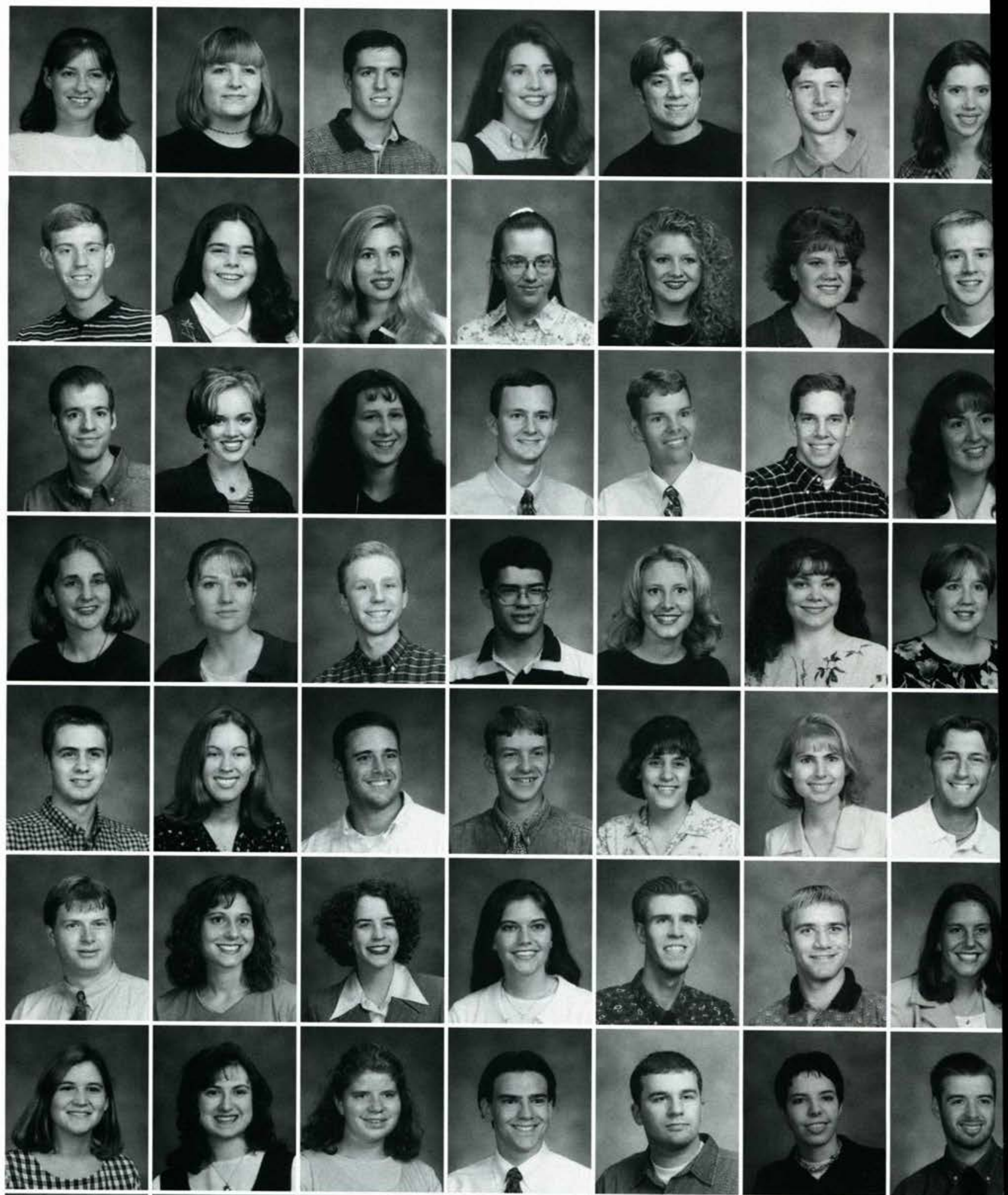

.
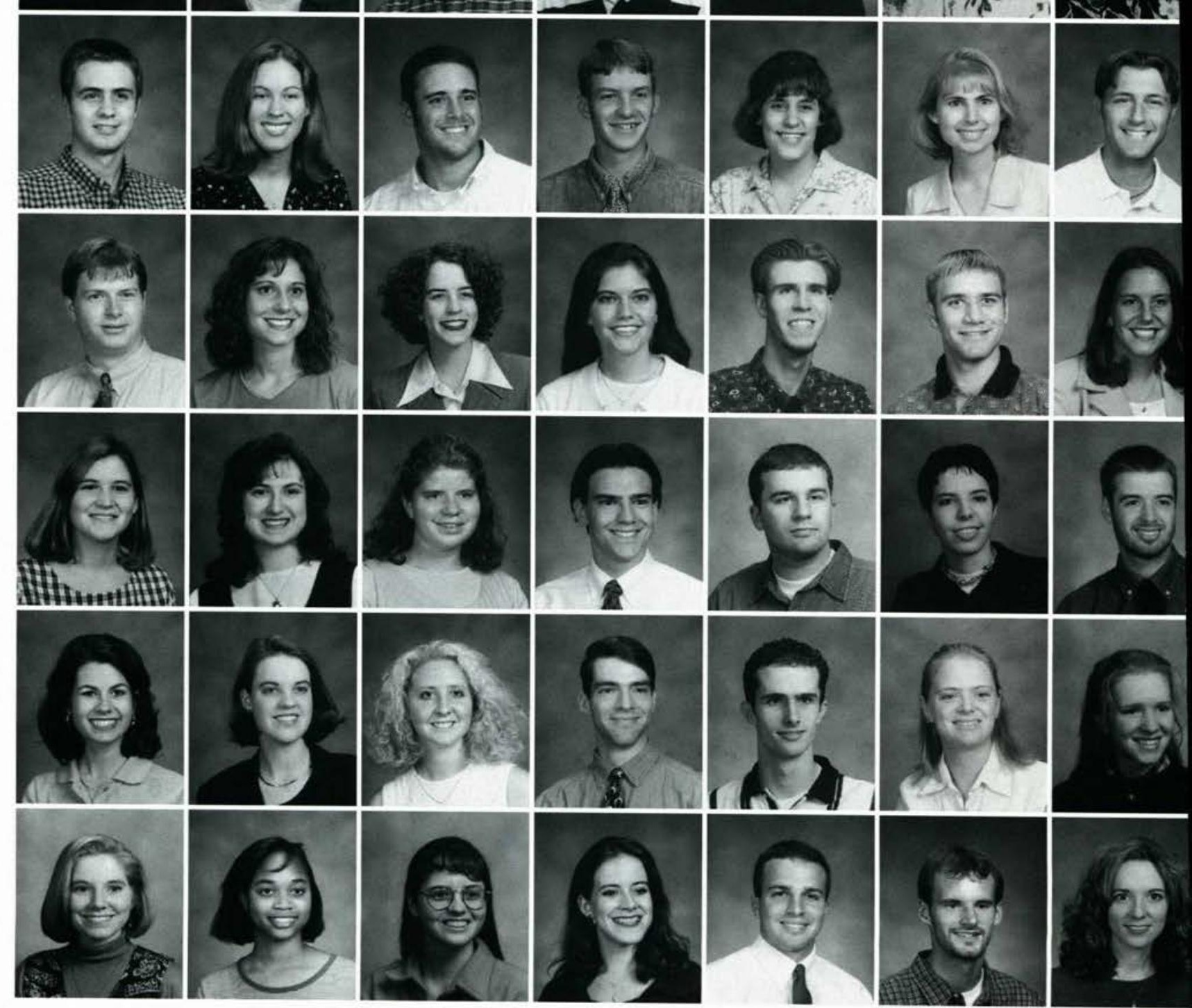


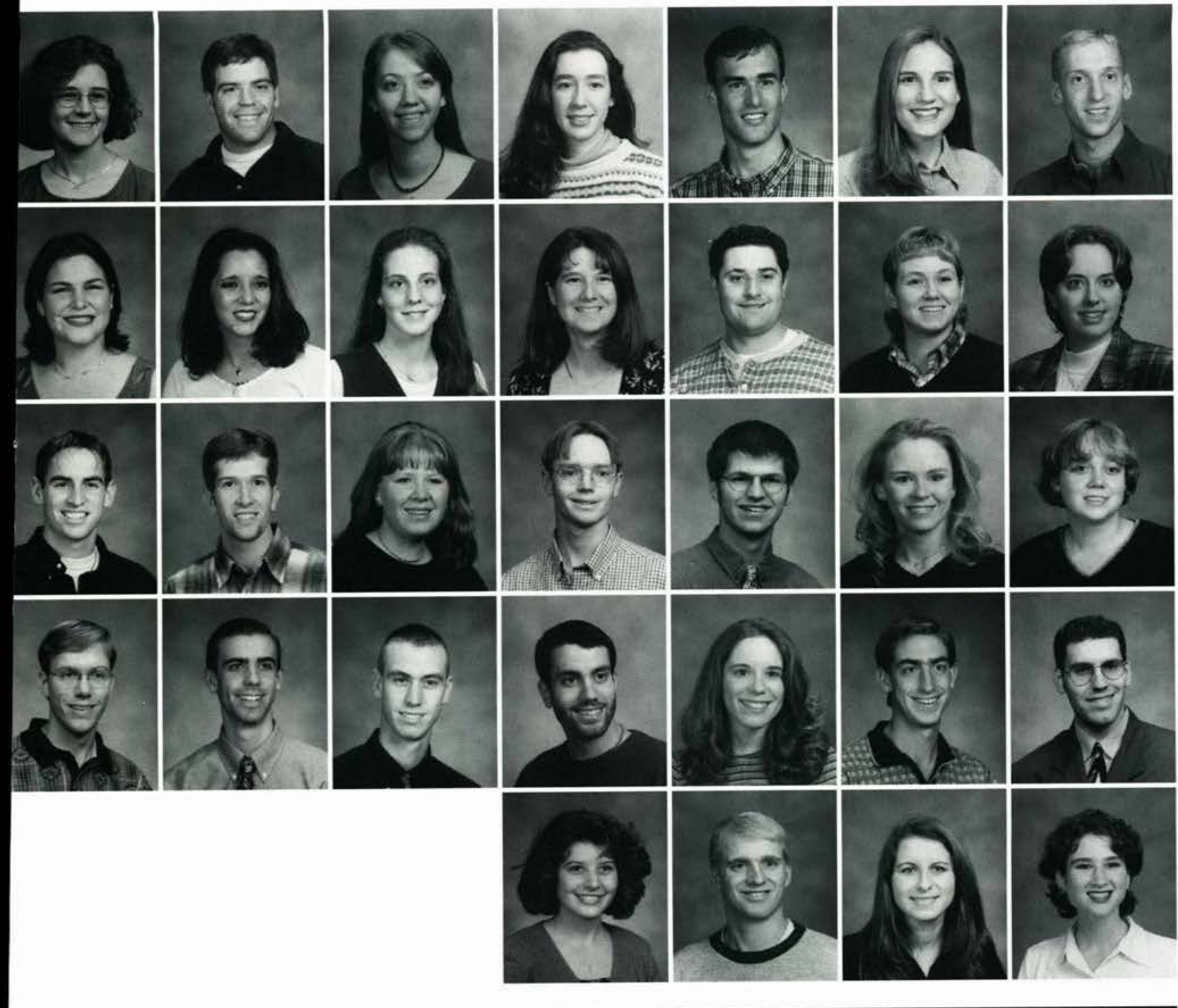

Emily Weber

Jason Weber

Tami Weber

Ann Weeks

Carl Weise

Christine Wiesert

Michael Wenger

Carrie White

Alisa Whitt

Sarah Whitney

Kendra Whitson

Justin Wilder

Alissa Williams

Stephanie Wilson

Jason Wing

Braden Wingert

Katherine Wolf

Aaron Wolfe

William Woods

Cindy Wren

Jana Wright

Nathan Wright

Thomas Wright

Kevin Yankovich

Randy Yinger

Laurie Yingling

Michael Yoder

Kevin Young

Kristy Young

Jamie Zehr

Angela Zinz

Tiffany Zirke

Jill Townsend and

Dave Jouwstra prepare to

go on stage to perform in a

Symphonic Band Concert.

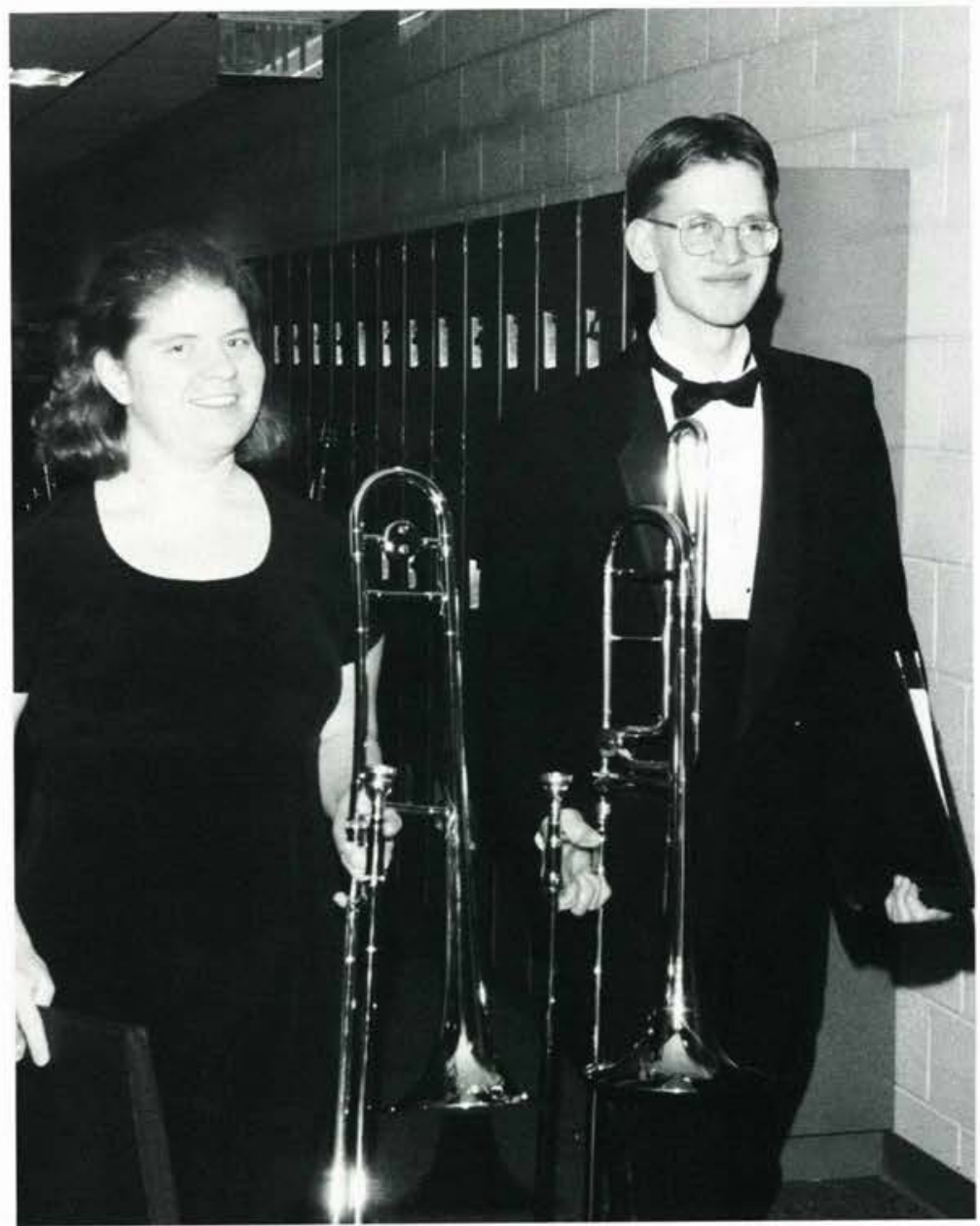




\section{Academic}

\section{Honors Day}

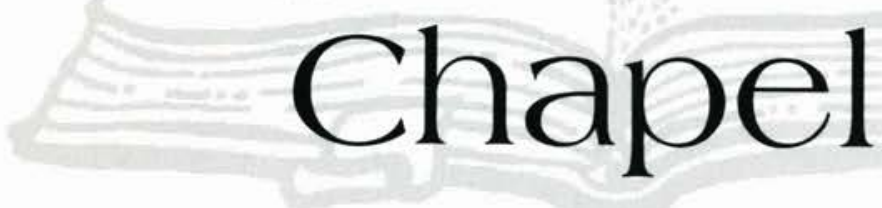

by Ruthanne Pierson

$\mathrm{E}$ very year the faculty, administration, students, and parents gather to honor those students who have achieved academic excellence throughout their college career. The annual chapel always falls on the Friday of Parents Weekend so parents can also participate in the ceremonies and honors given to the achieving students. The Alumni Association awards an annual scholarship to a student from every discipline. Additional awards and scholarships are given based on grades, extracurricular activities, leadership, and Christian service.

Companies and organizations also recognize students who have displayed propensity and achievement in vested fields. Such individuals included Andrew Litteral, a junior mechanical engineering major, whom the American Society of Mechanical Engineers selected to receive

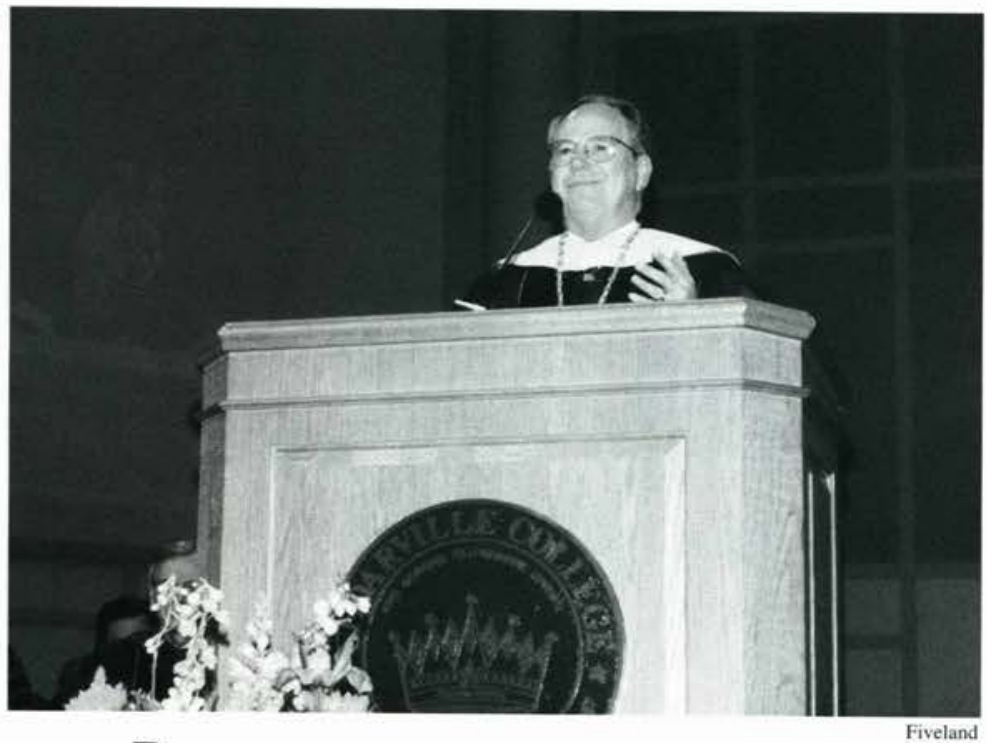

Dr. Paul Dixon speaks to the many parents, students, faculty, and staff present at the annual Honor's Day Chapel. (above) one of two scholarships in the United States and Canada Additional award categories included the Cedarville College Christian Ministries Award given to Tiffany Hamilton and Josh Halulko. The Ruby Jeremiah Scholarship, awarded to a married student involved in Christian ministry and academic involvement, was given to Virginia Opperman McDole.

Not only does the college recognize outstanding students, but the faculty and staff of the year are also awarded during this chapel. The 1998 staff of the year was Leigh Hunt, Director of New Construction, while the faculty of the year award was given to Mrs. Deborah Haffey, Associate Professor of Communications. Although Cedarville has numerous students and faculty who have achieved academic excellence, this chapel honors just a few who have set a standard of discipline and continue to challenge their peers and themselves.

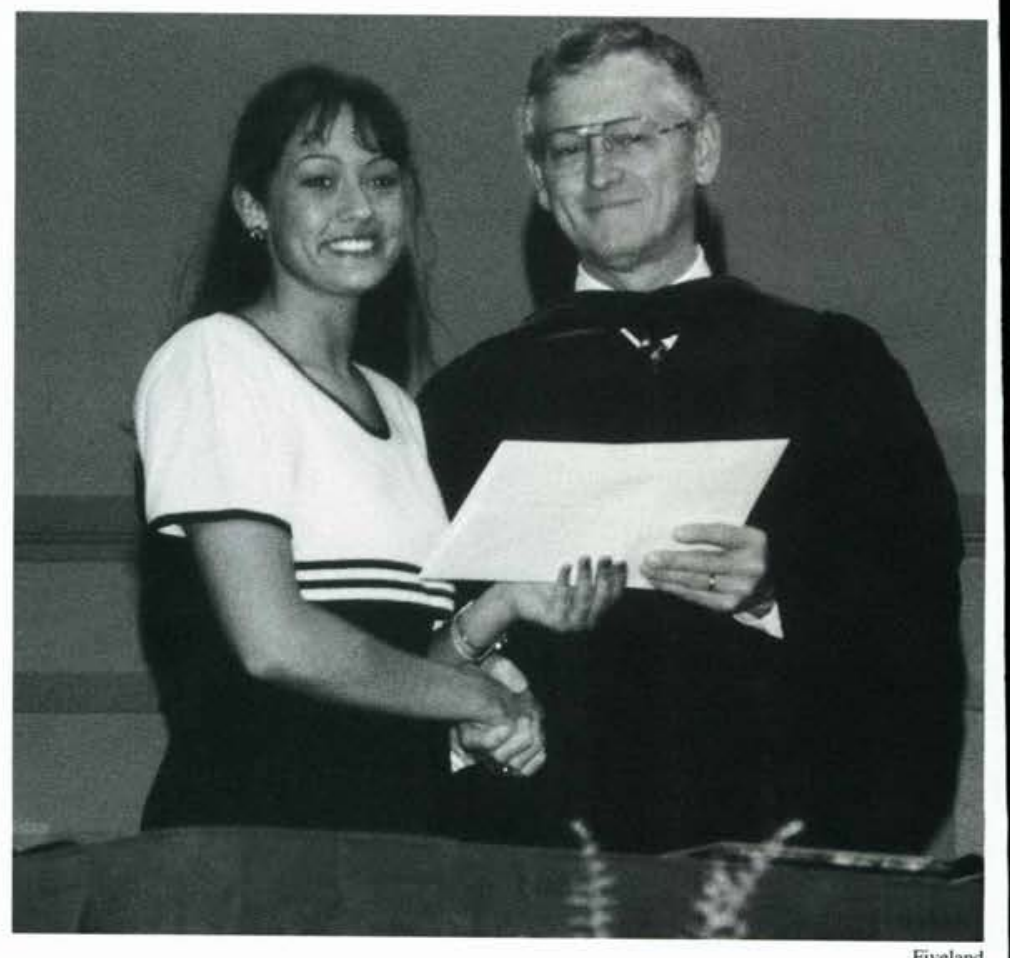

Dr. Merlin Ager, Chair of the Department of education presents junior, Lori Brown, with the Arline Littleton Autio Award. (right) 
Department of Biblical Education

$\begin{array}{lr}\text { The Alumni Scholarship Award in Biblical Education } & \text { Paul Rummel } \\ \text { The David G. Canine Award } & \text { Laurie Web }\end{array}$

The David G. Canine Award

The George M. Lawlor Greek Award

The Oxford University Press Awards

Joseph Preston

The Hugh T. Hall Memorial Scholarship

The Marlin Rayburn Award

CE.Youth Award

Laurie Weber \&e Gordon Boyd

Ernest Clark

StevenBurchett

Christopher Strychalski

Department of Business Administration

The Alumni Scholarship Award in Business

The Amstutz Management Sales Award

The Boyd Accounting Award

The Business Faculty Senior Scholar Award

The Wall Street Journal Award

Emiy A/t

Emily $A / t$

Michael Lewis

Erin Johns \& Emily Dizer

Brian Klakring

The Department of Communication Arts

The Alumni Scholarship Award in Communication Arts

Shannah Campbell

Ghena Marchetti

Sara Romang

The Rietveld Fine Arts Award

Gillian Gombis

Abigail Howe

Aaron Ponzani

Shannon Snow

Lori Brown

The Arline Littleton Audio Award

The Elmer W. Engstrom Department of Engineering

The Alumni Scholarship Award in Engineering

The SAE Outstanding Student Award

The IEEE Dayton Section Award

The ASME Scholarship

The Nehemiah Engineering Award

Shawn Lundvall Seth Valentine Nathan Wright Andrew Litteral Robert Bouwens

The Department of Health and Physical Education

The Alumni Scholarship Award in Physical Education

The Dr. And Mrs. Duane R. Wood Award

Rusty King Memorial Scholarship

Lindsey Mitchell Rebecca Jordan \& Car/ Weise Rebecca Jordan \&ै Craig Shank

The Department of Language and Literature

The Alumni Scholarship Award in Language and Literature Jonathan Head

The Andersho Family Scholarship

The Edith Hart Milner Award

Kathy McFarland

Angela Justic

The MYCOM Professional Writing Award

Sponsored by: Allan and Patti Massey

Lisa Walker

The Department of Music

The Alumni Scholarship Award in Music

The John E. Kohl Music Award

The Faculty Music Award

The Love Pedagogy Scholarship

Music Contribution Award

Outstanding Future Music Teacher Award

The Rietveld Fine Arts Award

Kristi Lynn Walborn Award

Jason Naill

Amy Clutz

Ryan Einfeldt

Jennifer Stuenzi

Rueben Vawter

LeaAnne Churgovich

Amy Clutz

Alisa Whitt

The Department of Nursing

The Alumni Scholarship Award in Nursing

The Pat Yoder Amstutz Nursing Award

The Kimberly Kerr Memorial Scholarship
The Lillian Kresge Memorial Scholarship

The Dorothy Hilma Leinger Nursing Award

Samatha Polgardy

Sarah Martin

Rebecca Jordan

The Taylor Scholarship Award

Jessica Secley

The Department of Psychology

The Alumni Scholarship Award in Psychology

The Alton R. Brown Psychology Awards

Nicholas Chou \& Jared Skillings

The Department of Science and Mathematics

The Alumni Scholarship Award in Schience and Mathematics Craig Shank

The AuSable Fellowship

The Austin Elmore Award in Plant Biology

Benjamin Stutzman

Melanie Lehman

The CRC Press Chemistry Award

Edward Nehus

The Creation Research Awards

Biology

Chemistry

Mathematics

The Patterson College Chemistry Award

Organic Chemistry Award

Coriann Kooy

Joseph Cantor

Melody Brickel

Amber Wilson

Craig Shank

The Department of Social Sciences and History

The Alumni Scholarship Award in Social Sciences \& HIstory Tiffany Peterson

Edmund Burke Award

Christina Farris

SGA Award

Christopher M. Brown

Cedarville College Christian Ministries Awards

Ryan Dyer, Joshua Halulko, \& Tiffany Hamilton

The John W. Bickett Heritage Scholarships

David Beary Eric Crauford, \& Jeanne Carlton

The Ruby Jeremiah Scholarship

Virginia McDole

Staff Member of the Year

Mr. Leigh Hunt

Faculty Member of the Year

Mrs. Deborah Hafey

\section{This chapel honors just a few who have set a standard of discipline and continue to challenge their peers and themselves.}




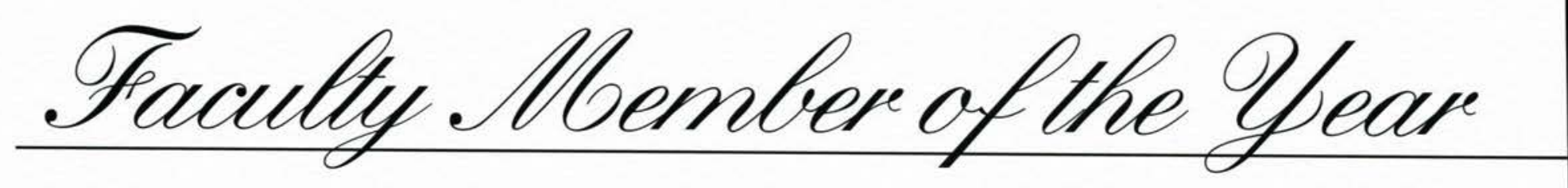

by Ruthanne Pierson

\section{Communications Associate Professor Deborah Haffey}

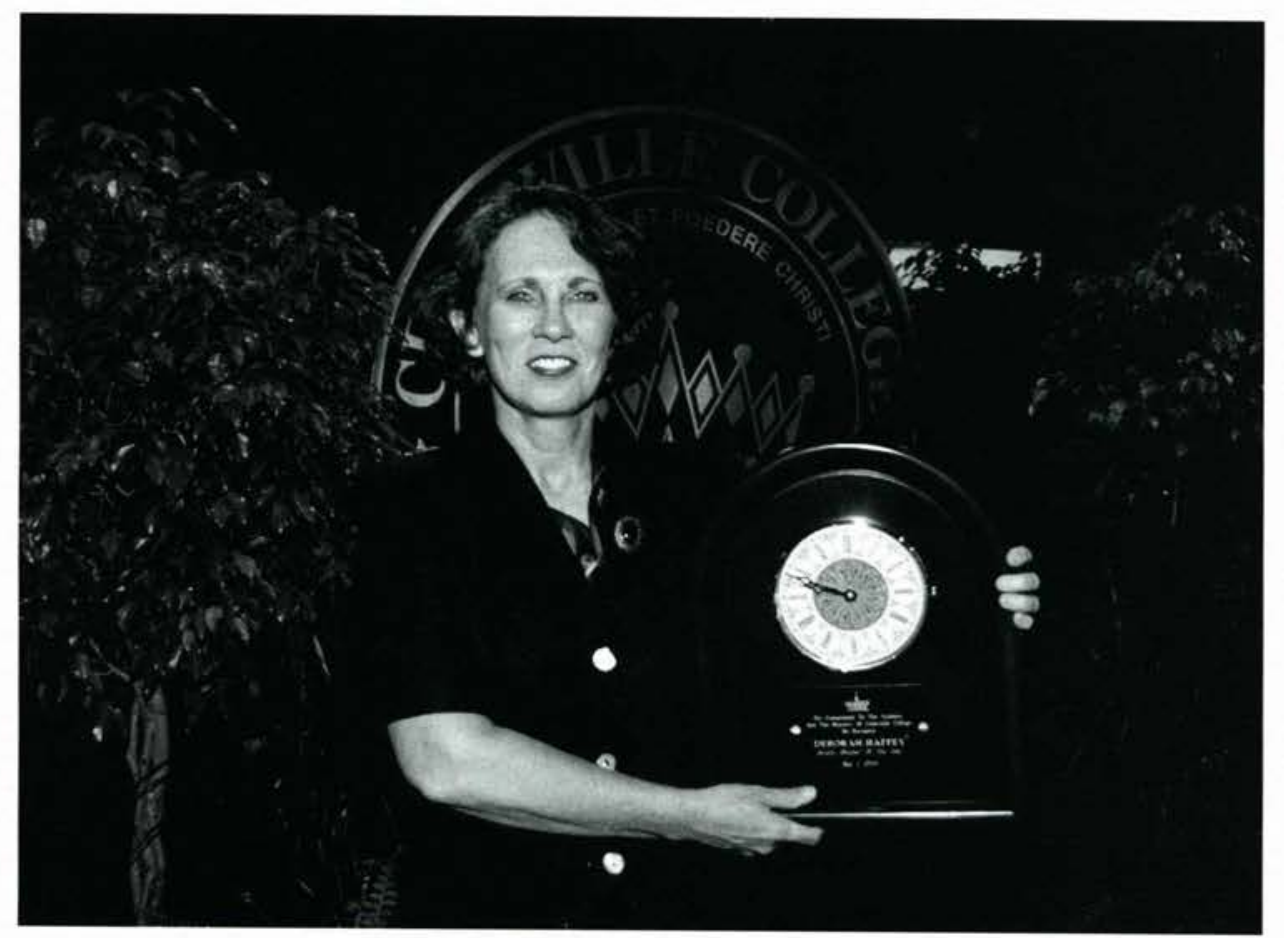

Huck ne of the greatest honors a pr
sor can receive is when the students reco
his or her dedication and excellence i
classroom. Cedarville is committed to a
standard of quality education not only
students, but also its faculty. Thus, the fa
of the year award, voted on by the student
administration, is probably one of the gre
achievements any professor can obtain.
yearthe students selected Mrs. Deborah Ha
Associate Professor of Communication
to receive the 1998 Faculty of the Year Ay
Mrs. Haffey, a ' 68 Cedarville grad
continued with her Master's in Speech
munication at The Ohio State University
ishing her degree just one year later. For
years, she taught high school and then
back to Cedarville and taught adjunctly
1974 to 1985 . Shortly thereafter, she be a full-time faculty member in 1987. She is currently pursuing her Ph.D. in Speech Communication at The Ohio State Unive as well as teaching full-time at the college. Not only is Mrs. Haffey a dedicated professor, but she also coaches the college de team, an additional challenge she began in 1987 and presently directs today. Her family is also active in the college as her husb David Haffey, serves as a legal consultant for the college and all three of her children have or currently attend the college.

Mrs. Haffey began a hesitant return to Cedarville when her husband relocated to the area due to work. Yet, she has fo it be an interesting and fulfilling decision. She continues to teach at Cedarville, because, "First, the students are so motiv and bright, above the national average." Her second reason links back to Aristotle, the father of rhetoric. She expla "Aristotle would only teach a student rhetoric who had a well-developed moral character-he wouldn't give such a powe tool to a person who didn't have a sense of ethics."

When asked why she has stayed with the field of Speech Communication she reasons that rhetoric is an exemplar of the liberal arts. reasons, "The field demands that one must know about many things and people in order to communicate-I am never bored.

In addition to this award, some of Mrs. Haffey's professional highlights have been gaining tenure, working with the Ho Program, and participating in the faculty integration program headed by Dr. Estes. Her personal highlights, she hone replies are, "going to the classroom." She loves teaching.

Mrs. Haffey's students have been supportive and mindful of her family commitments throughout her years of teaching. recalls their graciousness and understanding of her flex-time. She also describes them as being honest, lovingly confron when necessary, and spiritually challenging.

When asked what kind of legacy she would like to leave, she candidly answered, "For a student to come and take my place do a better job." She also shared, "I want to give to students a holistic experience, to live life wholly with the ability to bring everyth together, not just a good life spiritually, but a complete life and a good sense of the work around us. I want them to critique it, ana it and capitalize on it, informed of what we know of God." As her students will testify, she is steadily working toward that g 74 academics 


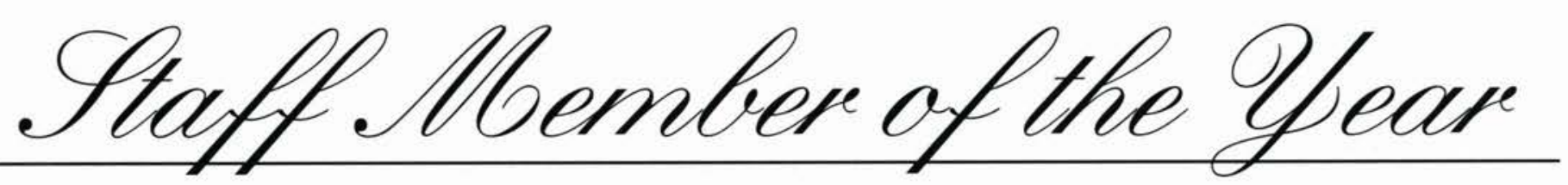

by Dave Perry

Director of New Construction Leigh Hunt

Otudents, fac-

ulty, staff and visitors often take the buildings on campus for granted. But for Mr. Leigh Hunt, these buildings represent his work as Director of New Construction. Hunt helps plan the new buildings, coordinate with the administration and contractors, architects, and workers, inspect the work being done, and pay the bills. In his fifteen years at Cedarville, he has helped with the building of the Centennial Library, the renovation of the Business Administration building, the

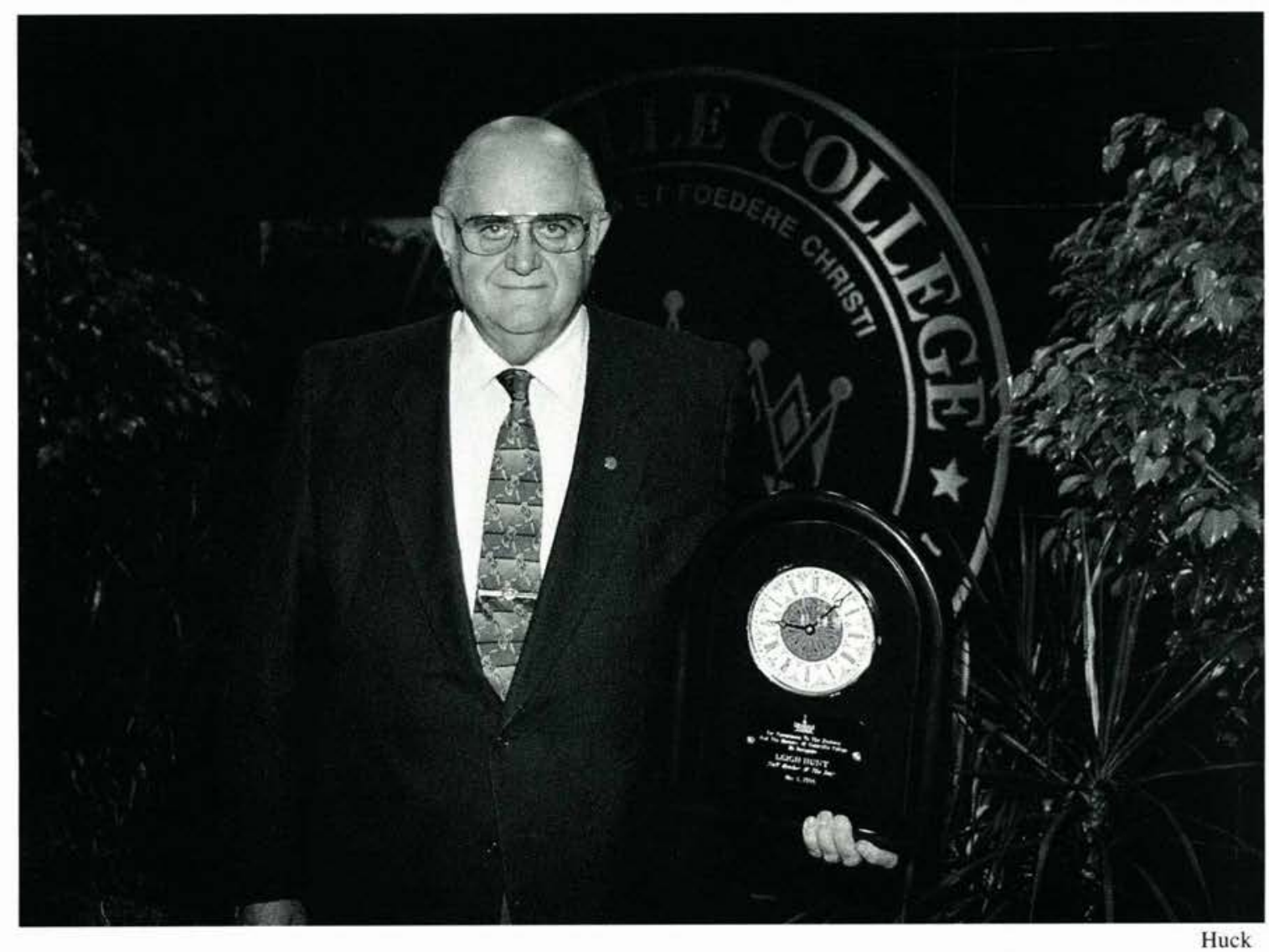
building of Alford Annex, Brock, the Willetts wings, the Three M Dorm, the Dixon Ministry Center. Currently, he is working on the renovation of Cedar Hall to the future Technology Center and plans for a Student Union.

Hunt started his education at the Baptist Bible College of Cleveland. In his senior year, the Baptist Bible College became Cedarville College and he was in the first class of Cedarville graduates. After his schooling, he stayed in the area and started construction work. When there was an opening at Cedarville in the physical plant department, he applied and has been here ever since.

His ministry is not only in his position as Director of New Construction, but in befriending students and inviting them to his house. He and his wife love getting to know students, and keep close contact with many of them though the years.

Mr. Hunt has enjoyed his years at Cedarville. He likes working with the staff and the administration and does not see his work as a job, but a ministry where the Lord has placed him. Hunt, given the opportunity to leave words of wisdom, said, "I encourage people to appreciate what we have at Cedarville-students, faculty and staff alike." 


\section{Candids}
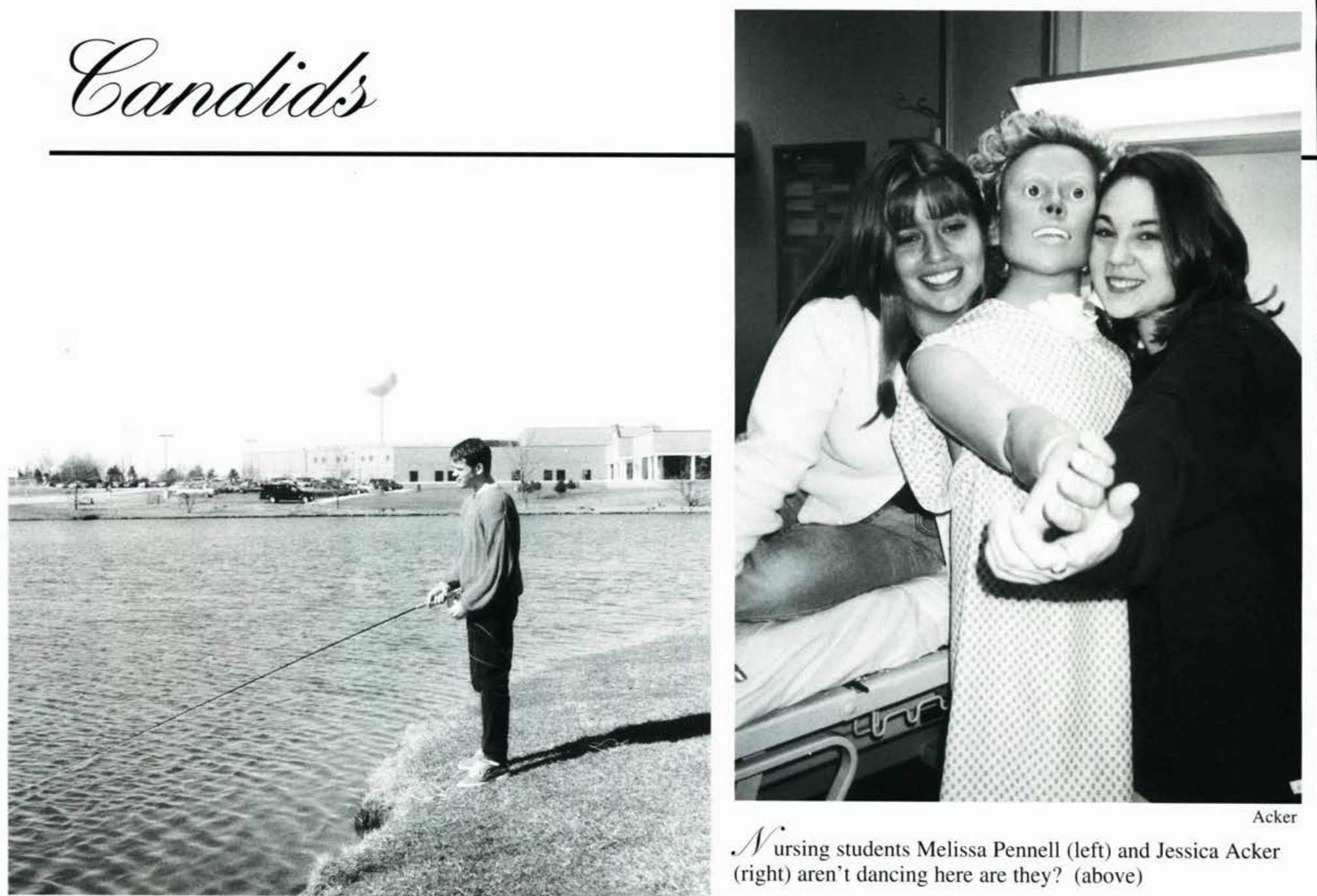

$\mathscr{N}$ ursing students Melissa Pennell (left) and Jessica Acker (right) aren't dancing here are they? (above)

$\mathscr{T}$ enior Bible major Steve Gerber finds time to balance his academic load with some fishing at Cedar Lake. (above)

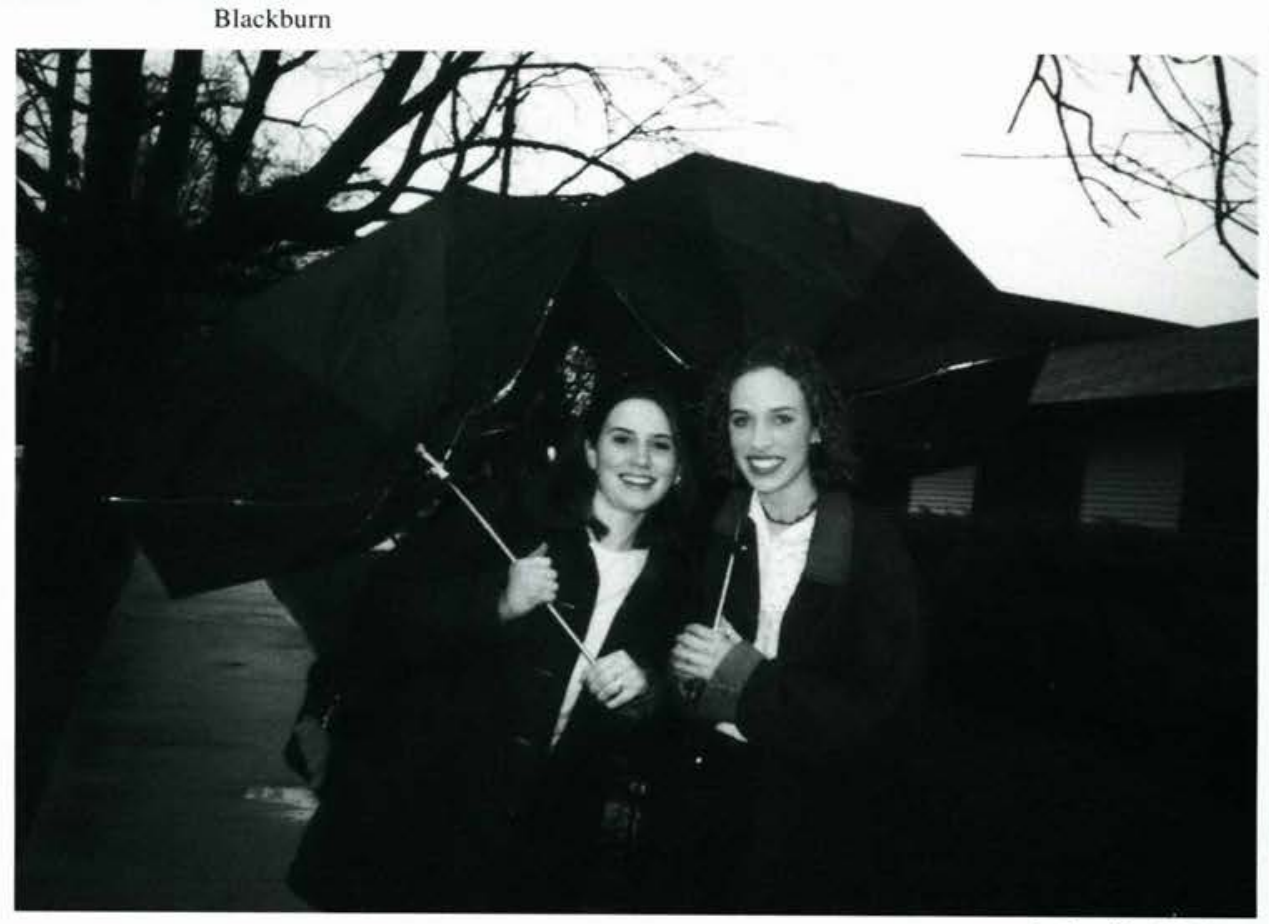

submitted by Walberg

Cook out Chicago, Cedarville just may take your nickname; however, political morals has nothing to do with it. Pictured here are Karissa Walberg (left) and Lani Peterson (right). (above) 

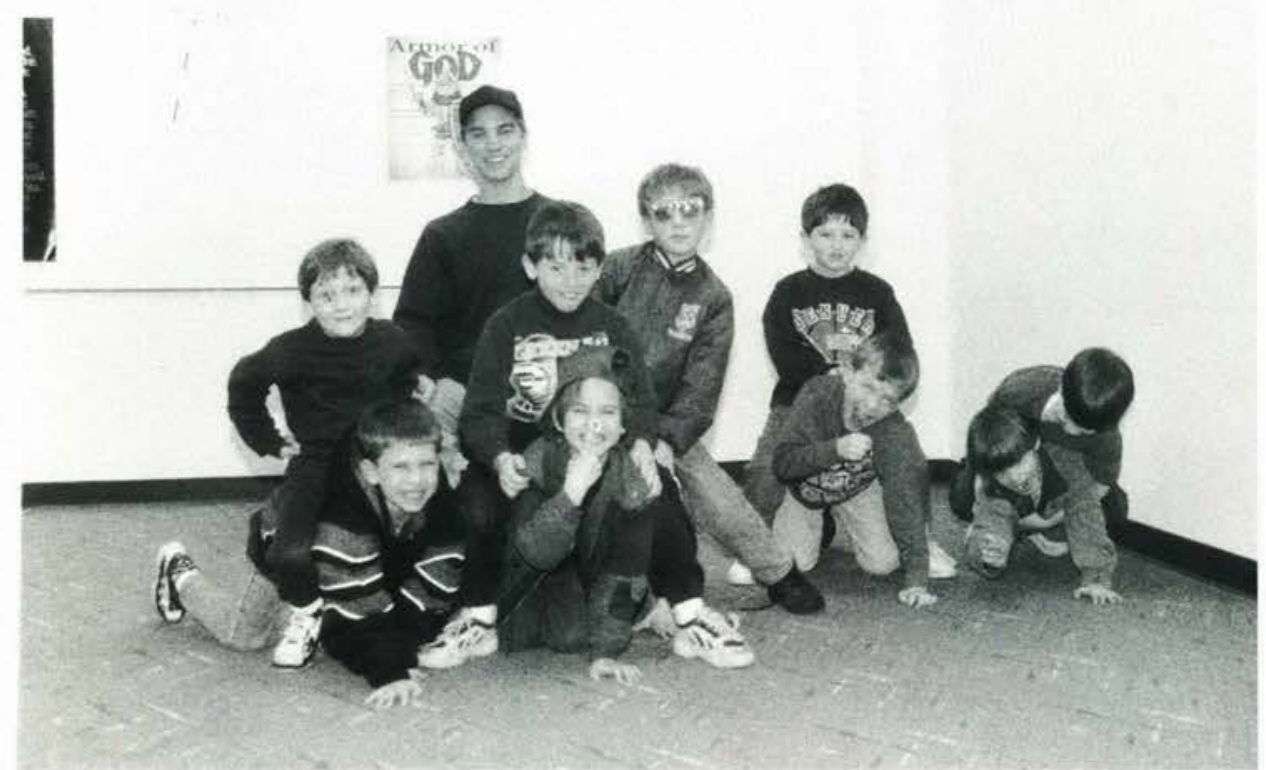

Blackburn

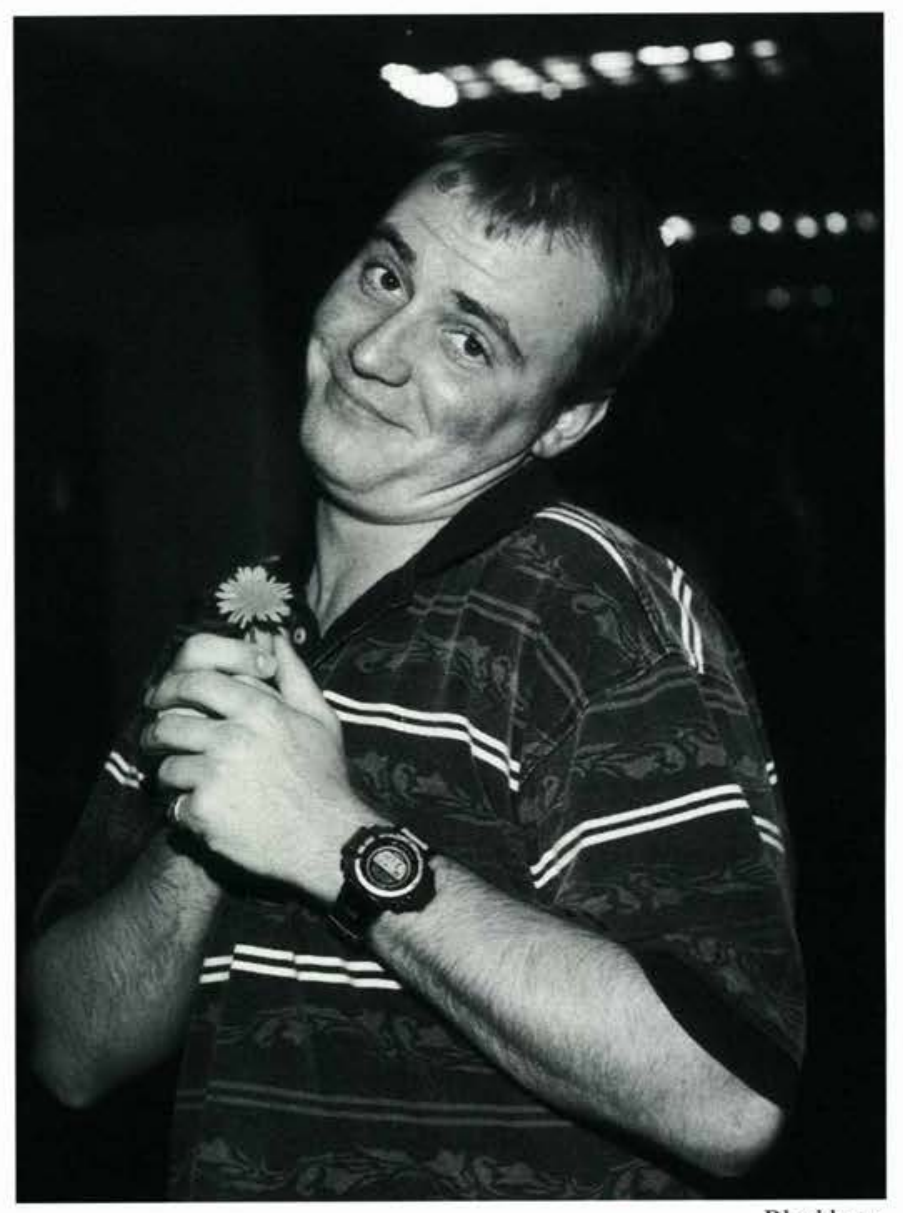

Blackburn

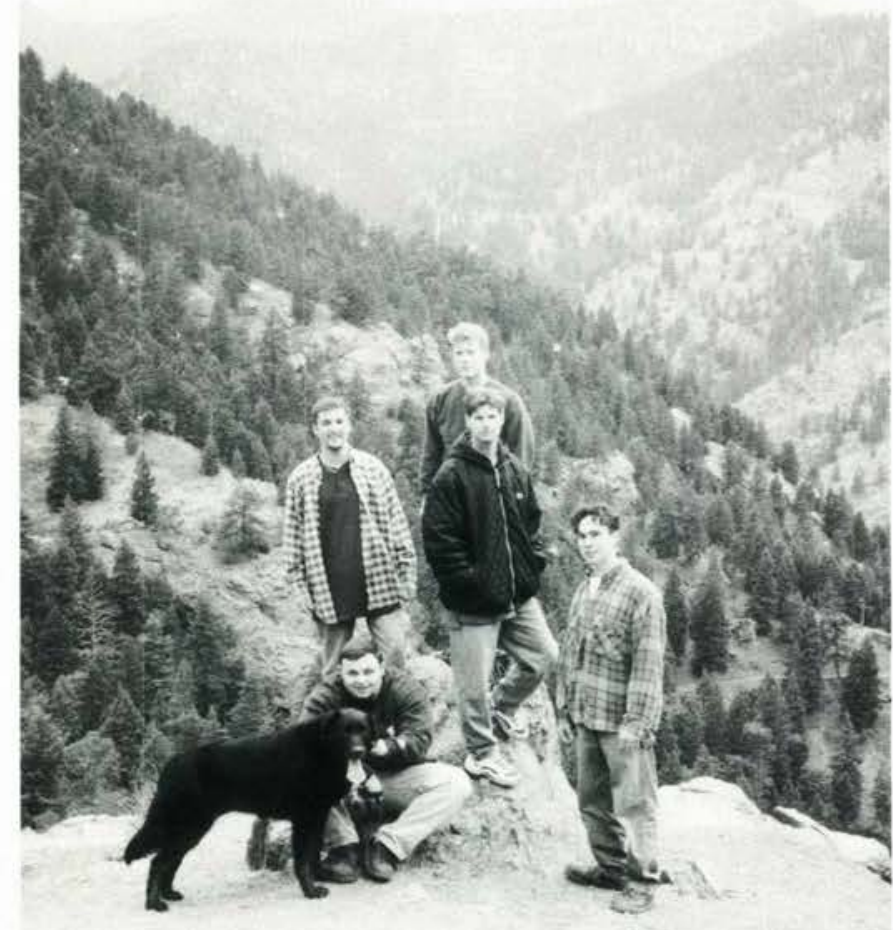

Klakring

Seniors (1-r) Brian Klakring, Joel Foerch, Eric Bedillion,

Dan Grazier, and Dave Hoskins enjoy their spring break

together in Colorado Springs, Colorado. (above left)

Unior Psychology major Chad Jensen has found a beautiful dandelion for Dr. Dixon. (below right)
Cenior Broadcasting major Mark Allen shares time ministering to a handfull of future Cedarville students. (left) 


\section{Class Officers}

\section{Freshmen}

\section{Sophomores}

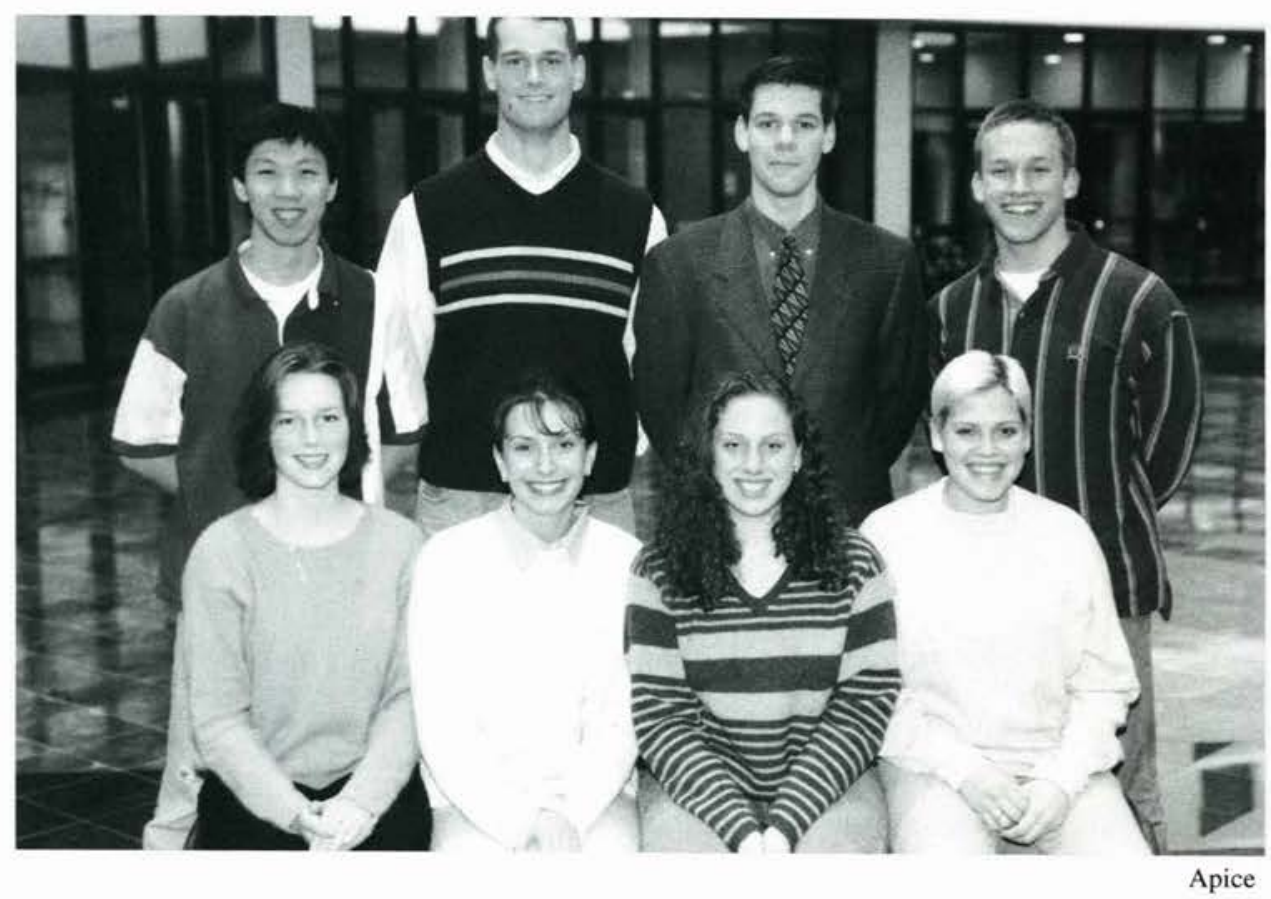

Front: (l to r) Christine Howe, Shawn Stephns, Amy Ny, Amanda Wheeler Back: (l to r) John Stedge, Mike Lowstetter, Ben Mohler, Joel Holins

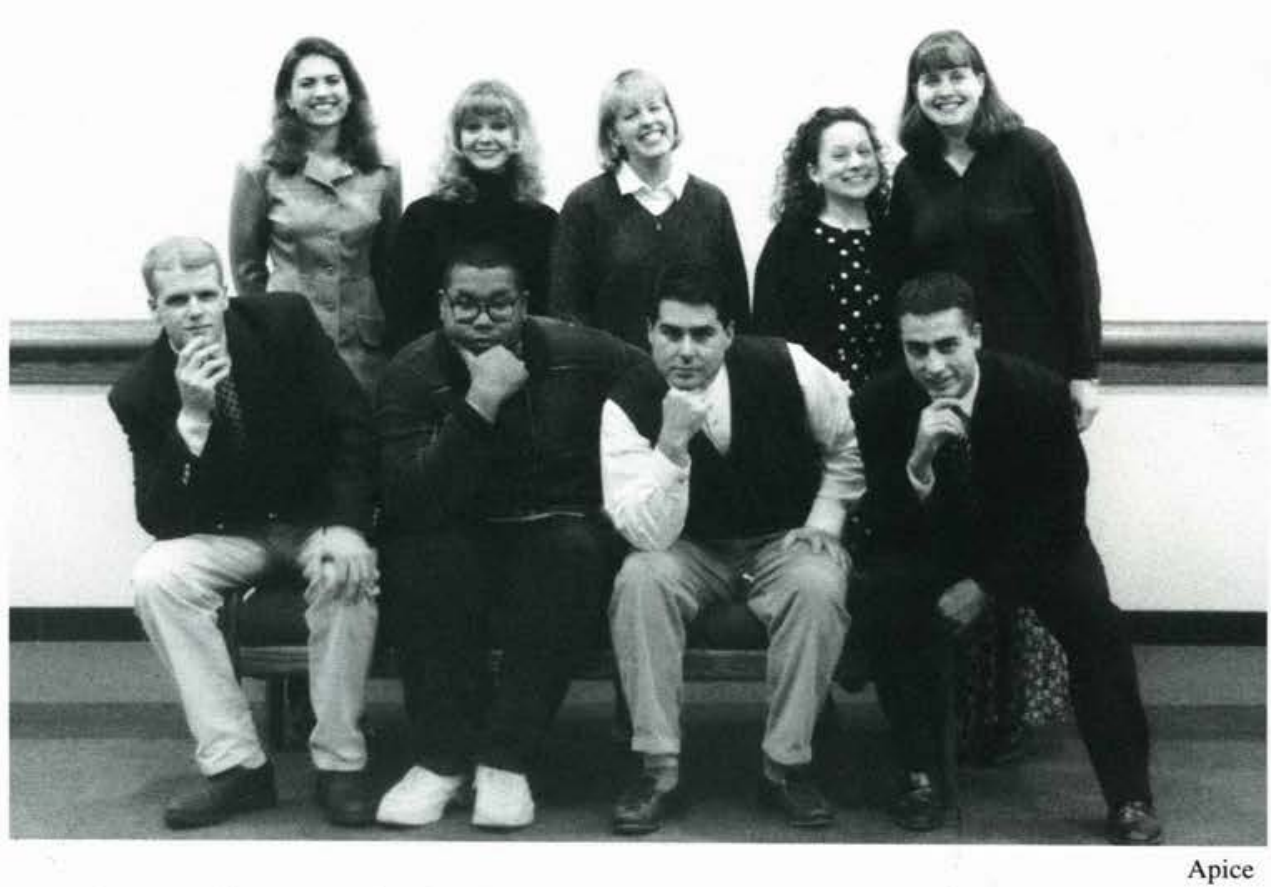

Front: (l to r) Michael Bahm, Mike Dorsey, Jeff Beste (Advisor), Scott Lehr Back: (l to r) Jen Pollock, Cara Carver, Kelsey Perkins 


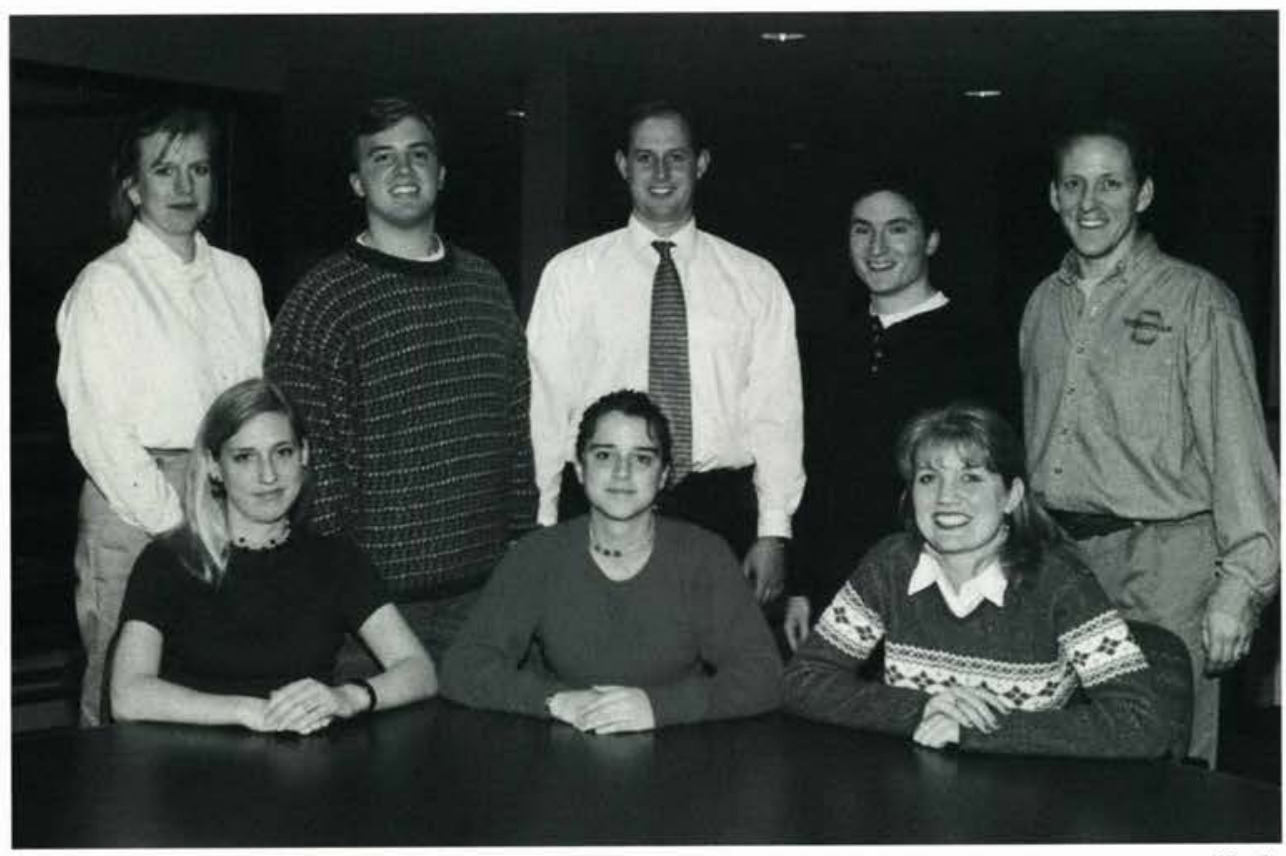

\section{Juniors}

Front: Sarah Carr, Rebecca Blackwood, Julie Mobley

Back: (l to r) Kristen Marshall, Jeff Motter, McArthur Hill, Jesse Deconto, Scott Huck (Advisor)

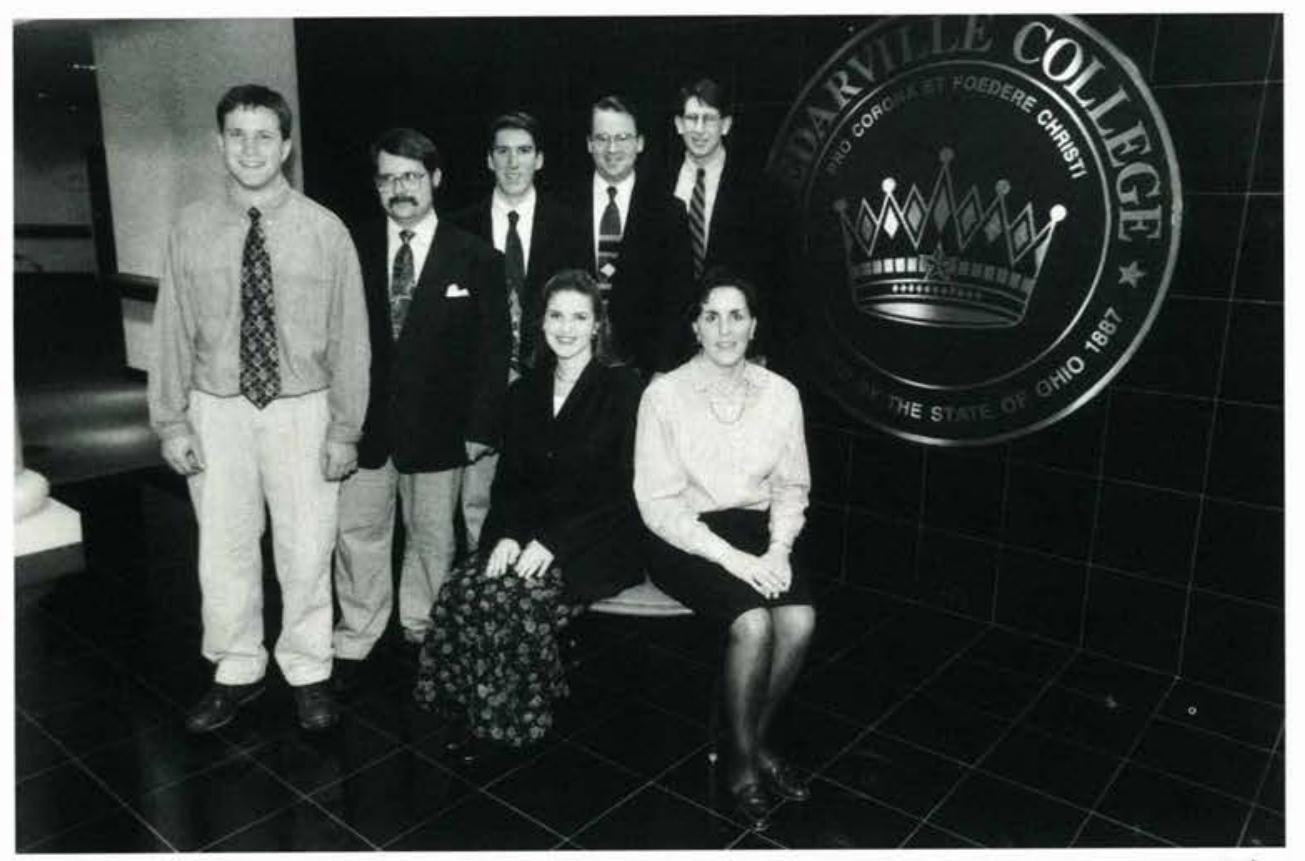

\section{Seniors}

Front: Chrisi Chamberlain, Kirsten Gibbs (Advisor)

Apice

Back: (l to r) Mark Warren, Aaron Hutchinson, Matt Murphy, Rob Malvaney, Ben Haffey 

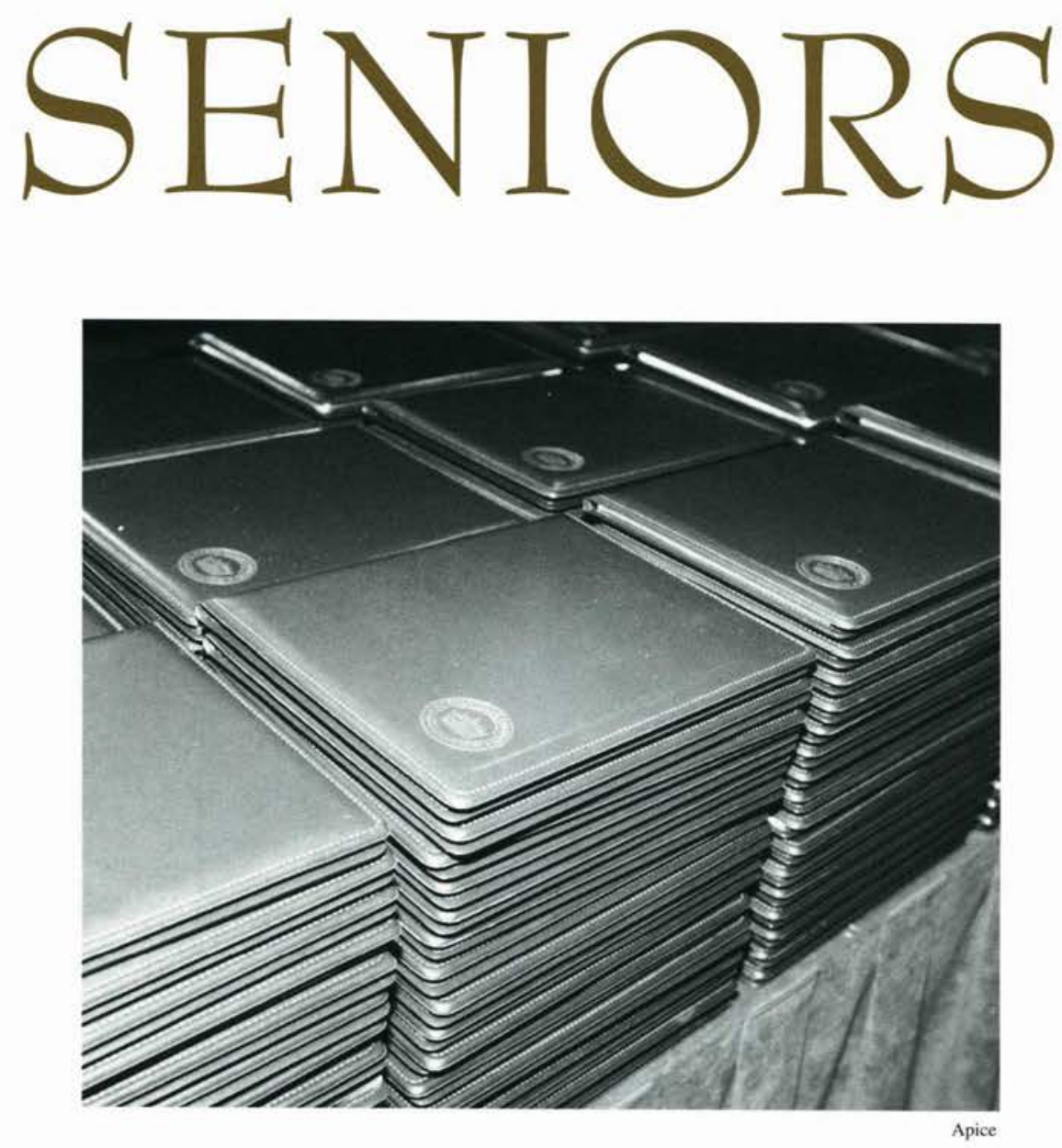


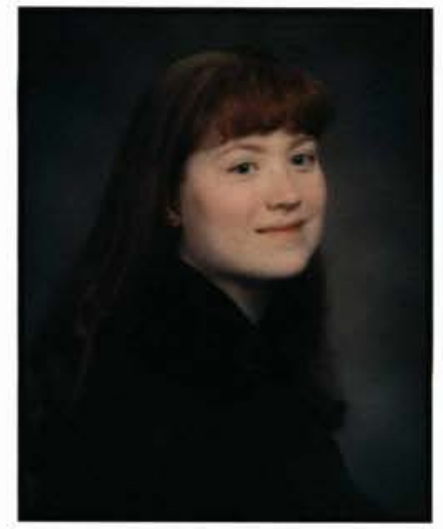

Delanie Abel

Business Education

Columbus, $\mathrm{OH}$

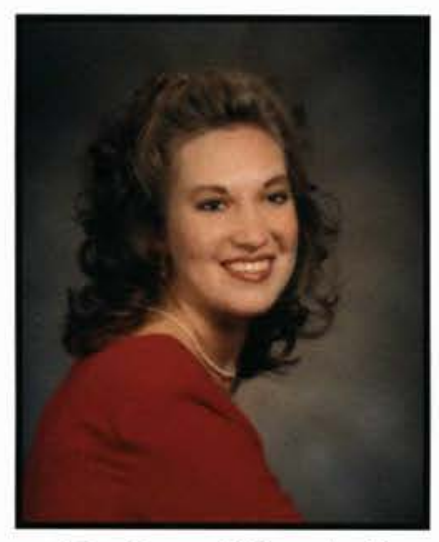

Deborah E. Atten

English Education

Glen Mills, PA

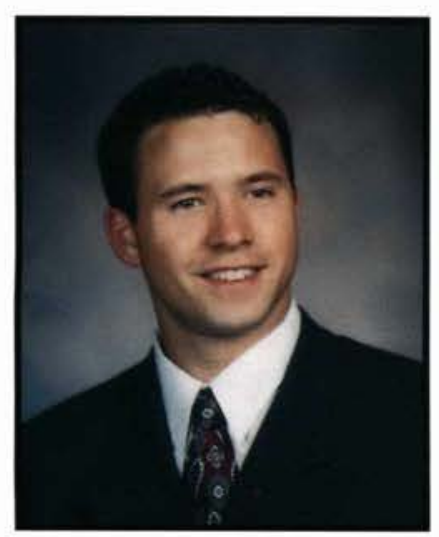

Foshua E. Amo:

Communication Arts

Lancaster, $\mathrm{OH}$

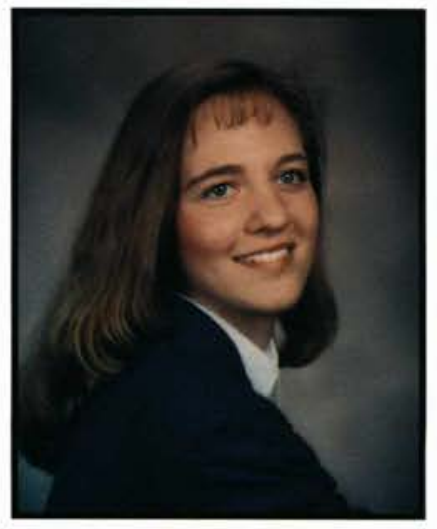

Sifli: Anderion

Elementary Education

Colorado Springs, CO
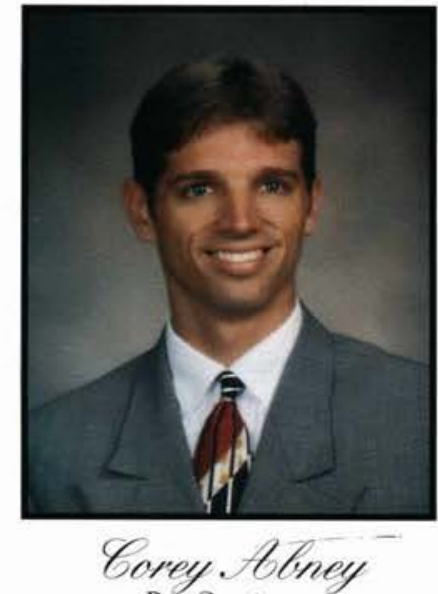

Pre-Seminary

Huber Heights, $\mathrm{OH}$

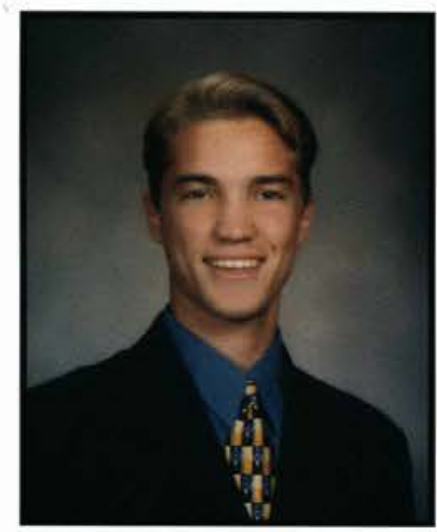

Mark. P. Alten

Broadcasting

Glen Mills, PA

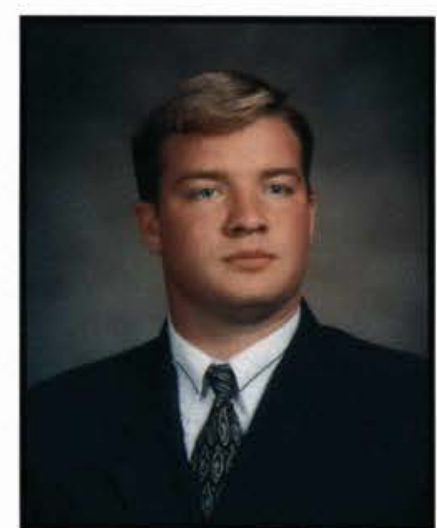

Pame: R. Amilula

Athletic Training

Cherry Hill, N]

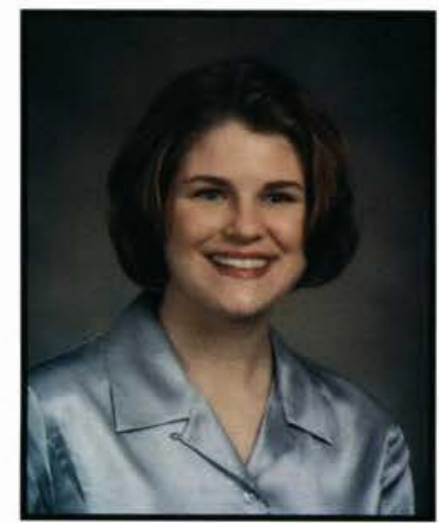

Fexica Olb. Angelone

Elementary Education

West Chester, OH

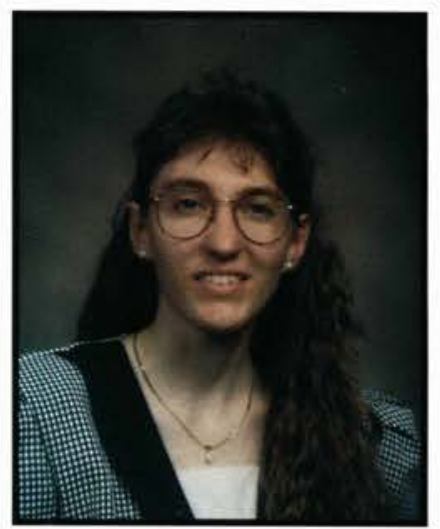

Slenda. R. Thersinoeto

Nursing

Newaygo, Ml

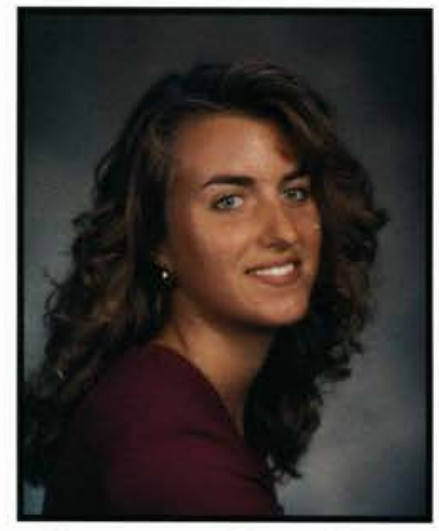

Weredith.R. Allgrim Biology

Almond, NY

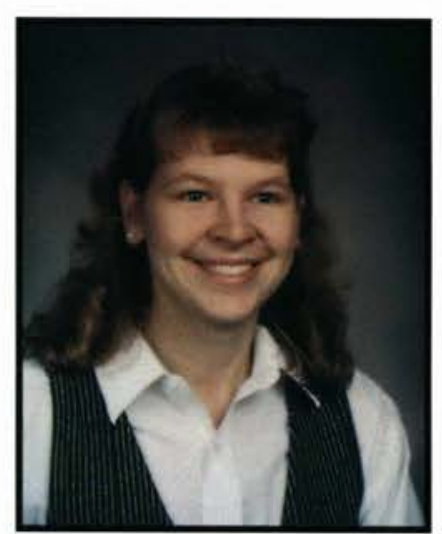

Heather. S. Amundion

Elementary Education Cedarville, $\mathrm{OH}$

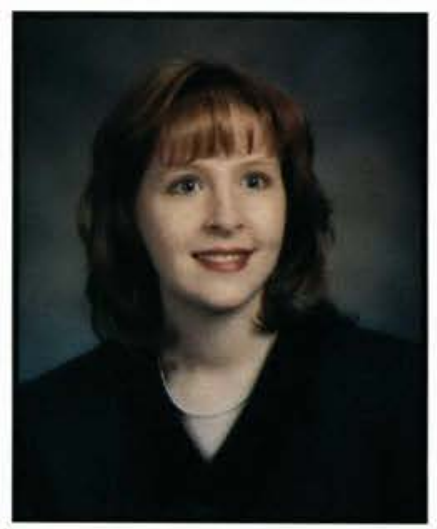

Saurie. Ib. Anna

Management

Pennellville, NY

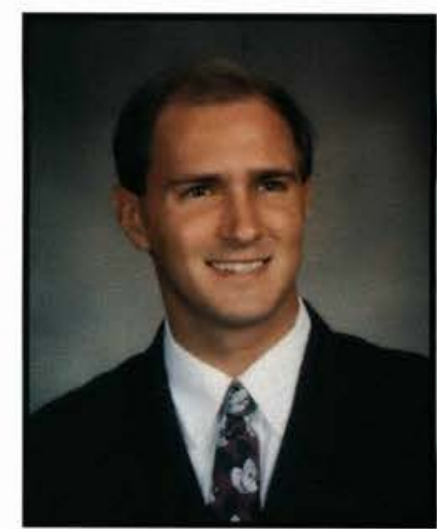

Glayton W. Atten Math

Cambridge City, IN

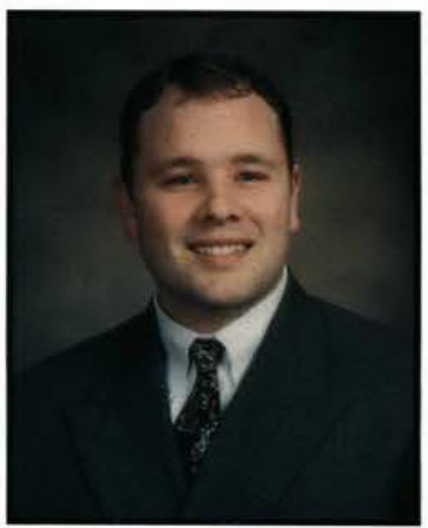

Robert.S. Ament Marketing

Murrysville, PA

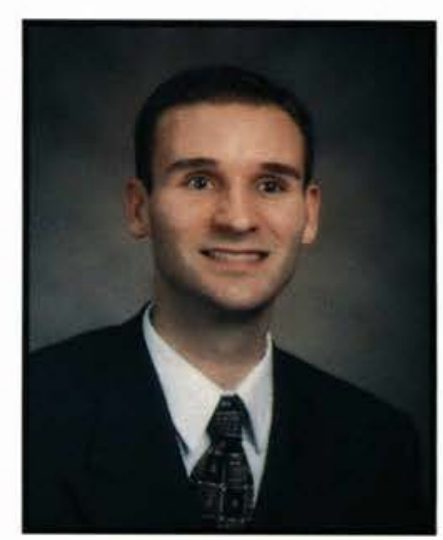

Ryan R. Anderion

Accounting/Finance

Des Moines, IA

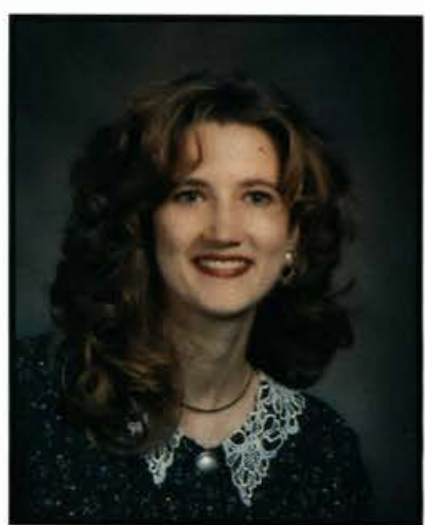

Gulie. A. Armour

Mechanical Engineering

Rochester, NY 


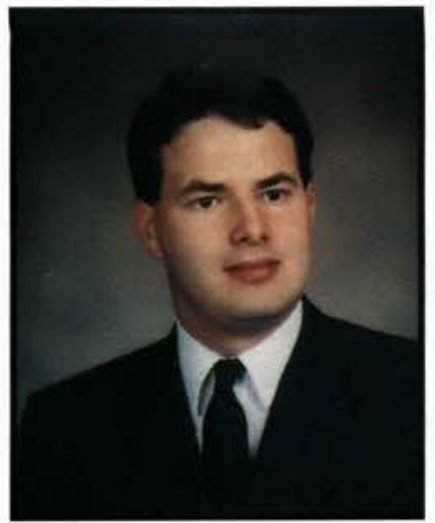

Revin. Fomitrong

History/Political Science

Wooster, $\mathrm{OH}$

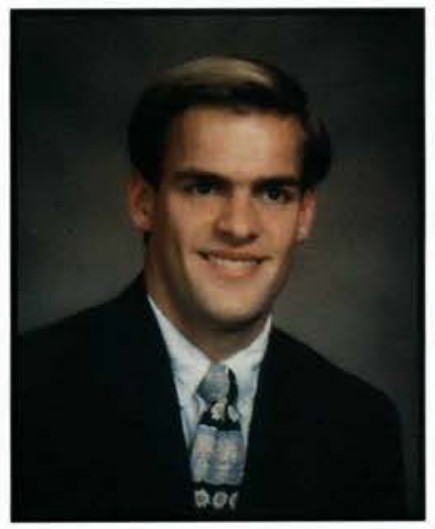

Foinua D. Huifatil

Bible Comprehensive

Peoria, IL

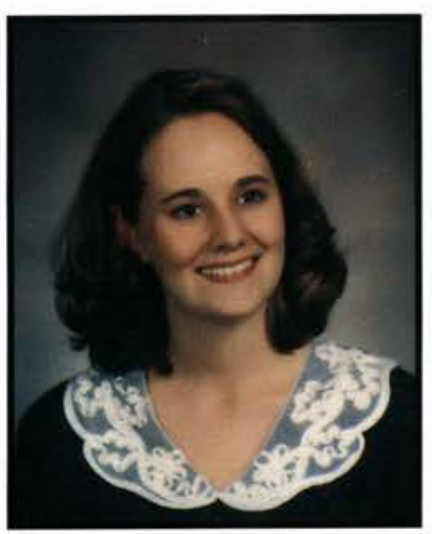

Erin R. Bartier Marketing

Lebanon, $\mathrm{OH}$

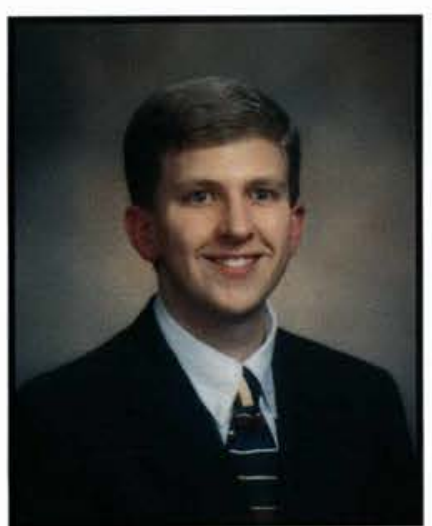

Bradley D. Barlledl Professional Writing Cedarville, $\mathrm{OH}$

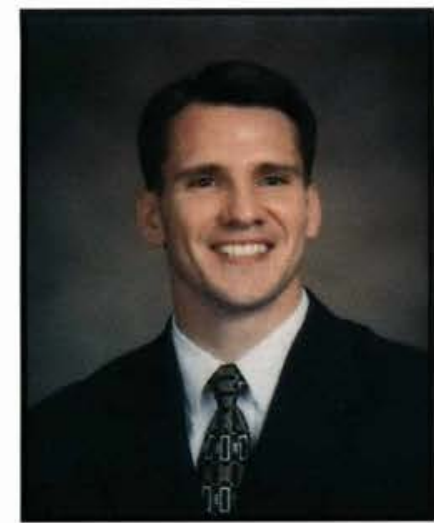

Ghris. R. Asharaft

Professional Writing

Utica, $\mathrm{OH}$

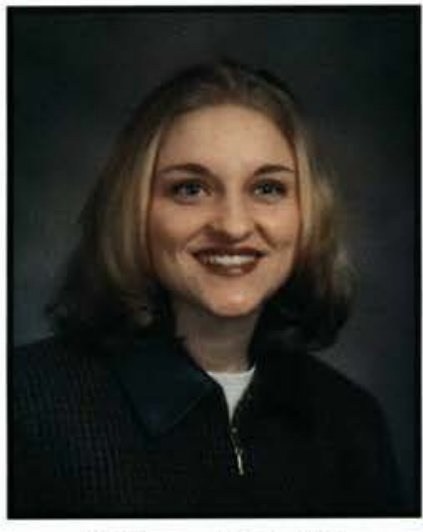

Abllison L. Baer

Nursing

Akron, NY

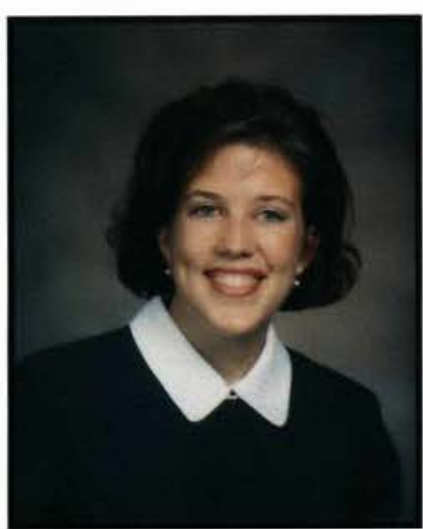

Gill.KS. Barnes

Elementary Education

Southampton, PA

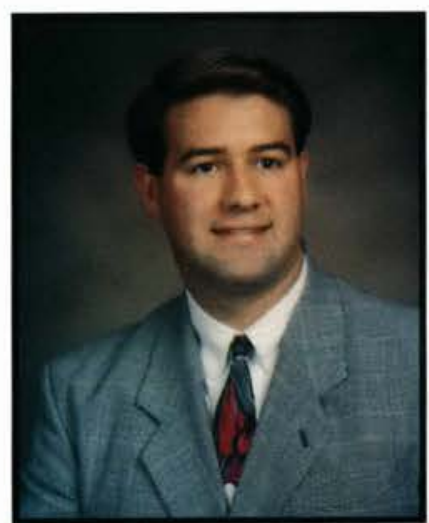

Fonathan Il. Basner

Bible Comprehensive

Voorhees, NJ

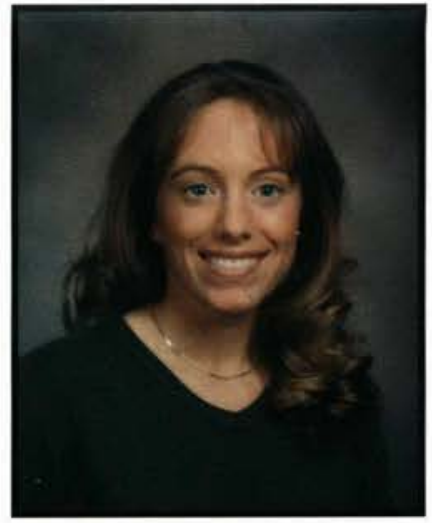

Dena Mb. Arid

Comprehensive Physical Education Brookpark, $\mathrm{OH}$

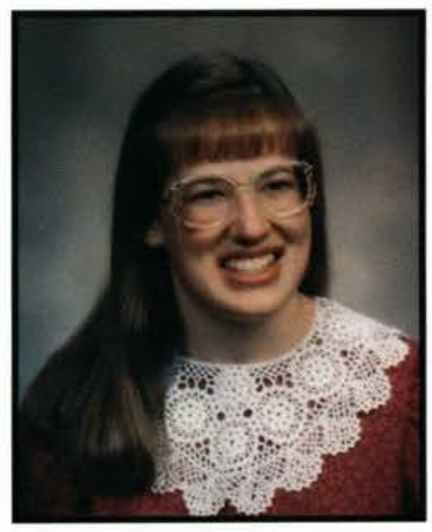

Ganelle L. Batier Nursing

Cardington, $\mathrm{OH}$

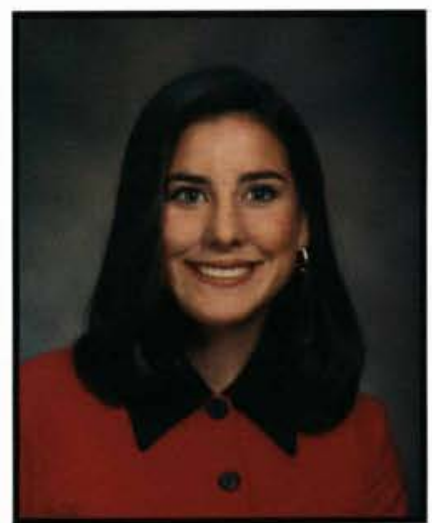

Hoolly F. Barnell

Elementary Education

Goodrich, MI

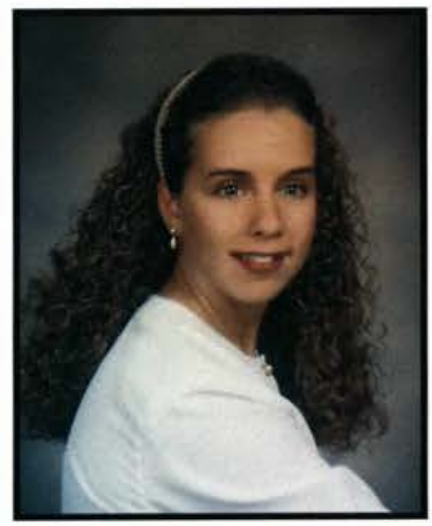

Sara E. Bathrich Nursing

Muskegon, MI

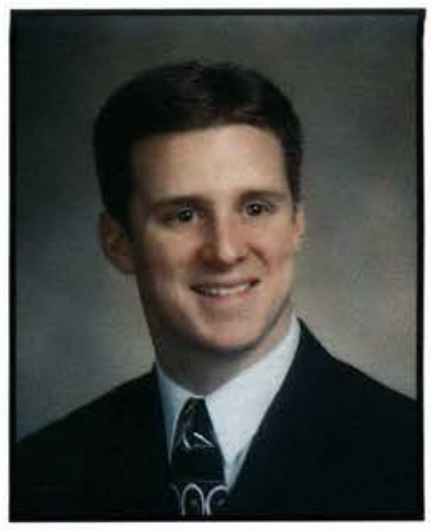

Paion. Aluell

Communication Arts

Aberdeen, MD

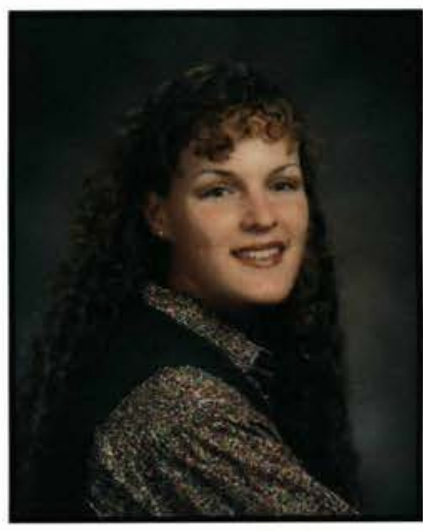

Elizabeth. Bartier

Professional Writing

Waterford, CT

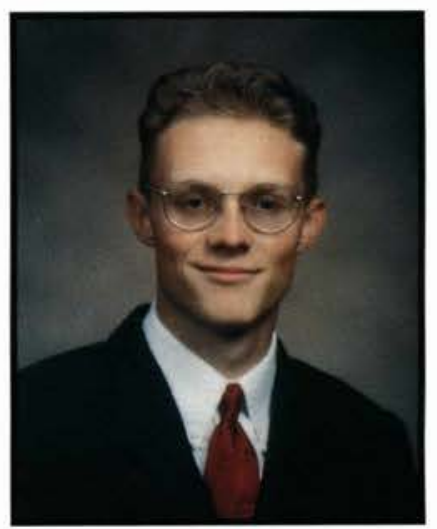

Tisrael B. Barr

American Studies

Jamestown, $\mathrm{OH}$

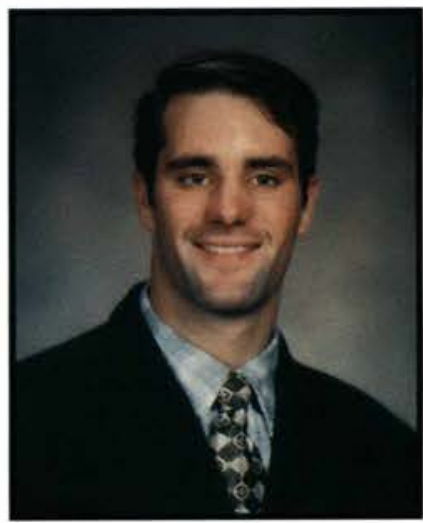

Mather. Of. Beck

Bible Comprehensive

Caldwell, ID 


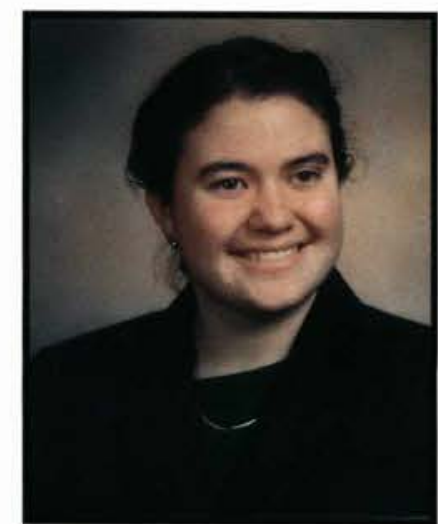

Taime L. Bedford Biology

Strongsville, $\mathrm{OH}$

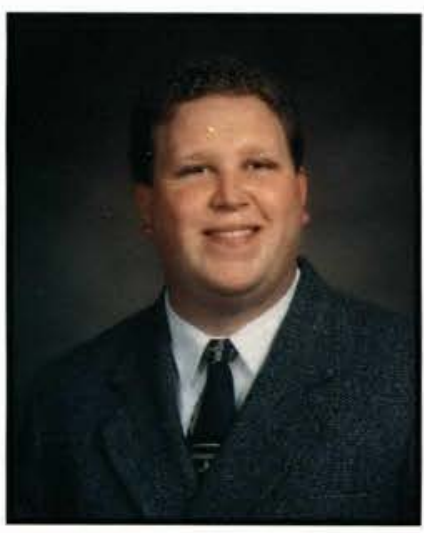

Eric. Mb. Bickel

Broadcasting

Warren, IN

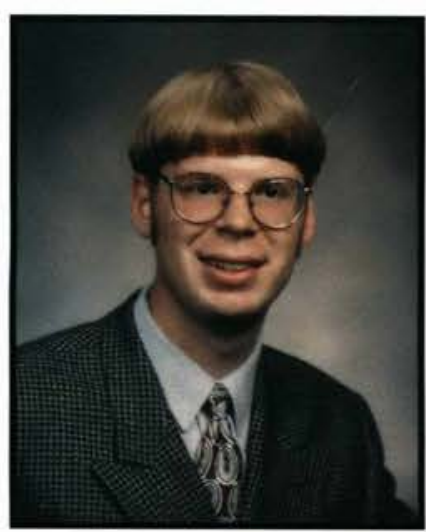

Tevin L. Boblith

Applied Psychology

Mt. Blanchard, $\mathrm{OH}$

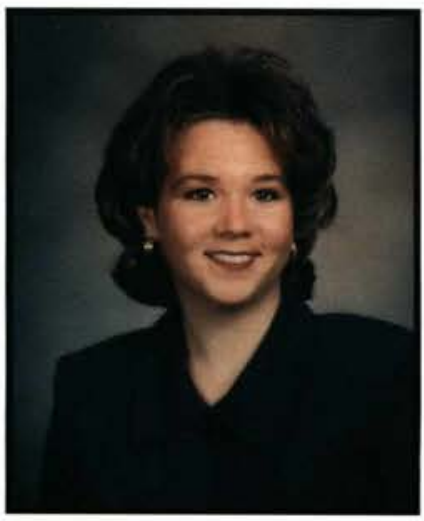

Fill. A. Bollman

Professional Writing

Fort Wayne, IN

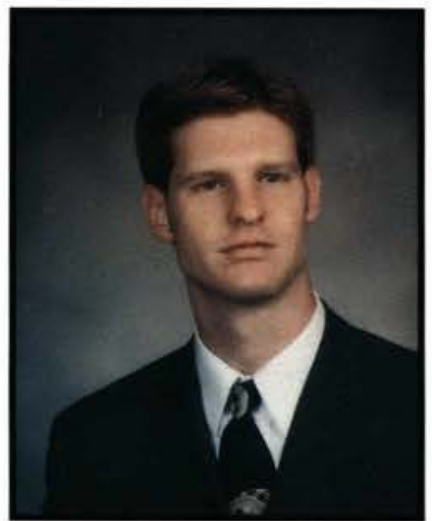

Eric. Bedittion

Mechanical Engineering

Lansdale, PA

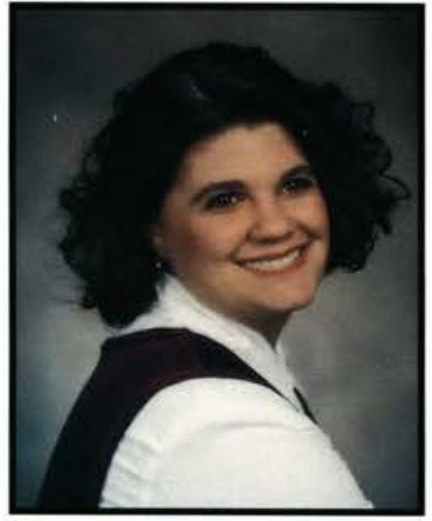

Allyison L. Biela

Elementary Education

Lakeside Park, KY

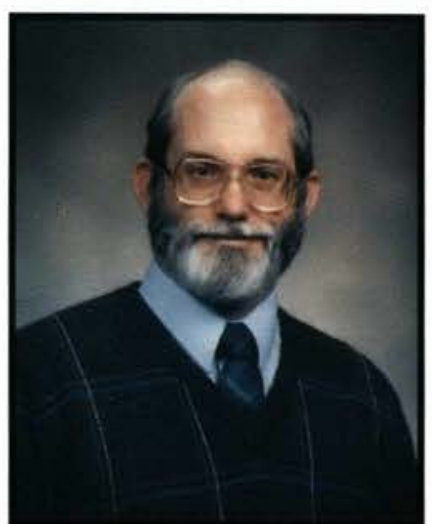

Teff.'. Boddy

Electrical Engineering

Springfield, $\mathrm{OH}$

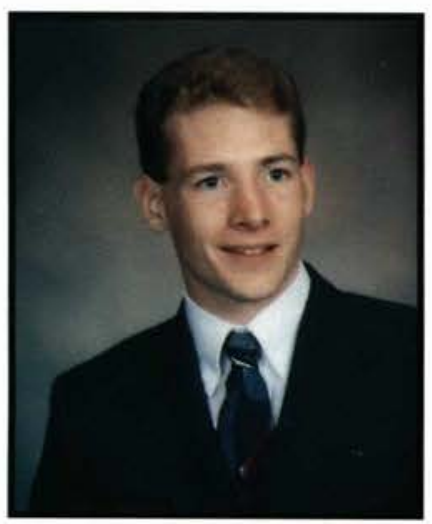

Michael. A. Bonner

Nursing

Saginaw, MI

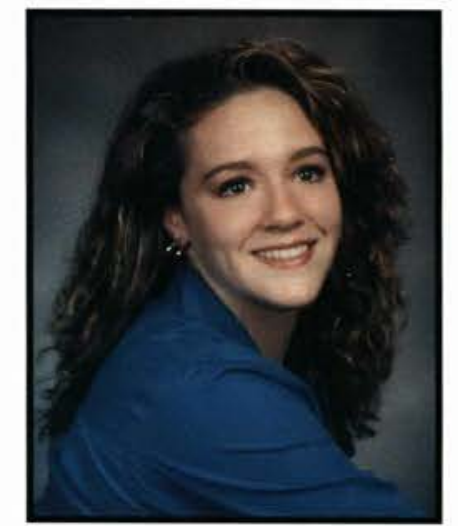

Summer $\mathscr{L}$. Benninglon

Comprehensive Physical Education

Lynchburg, VA

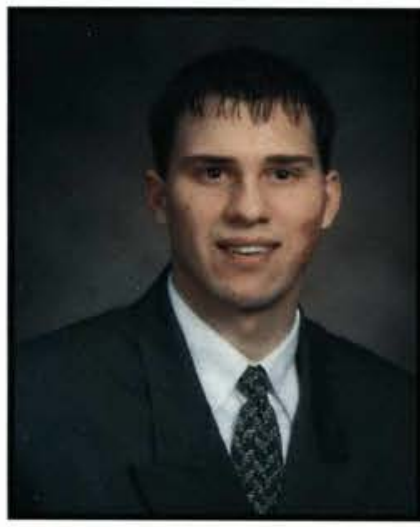

Ryan B. Bigelow

Finance

Juneau, AK
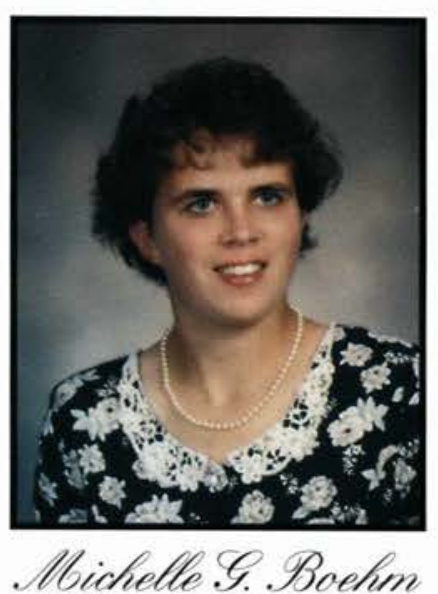

Elementary Education Dunkirk, $\mathrm{OH}$

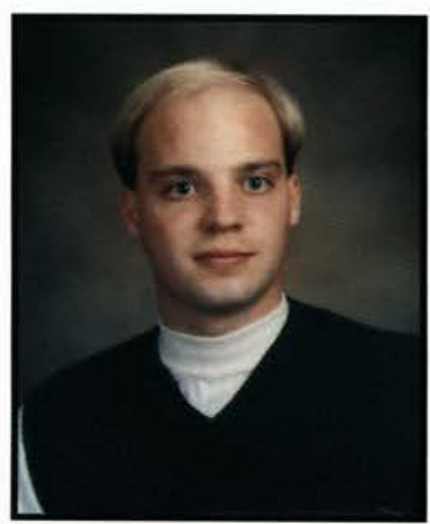

Benjamin R. Boolie Psychology

Ionia, MI

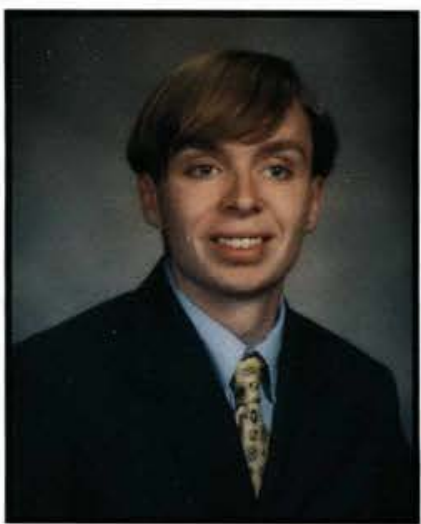

Garon 2. Berning

Elementary Education

Sidney, $\mathrm{OH}$

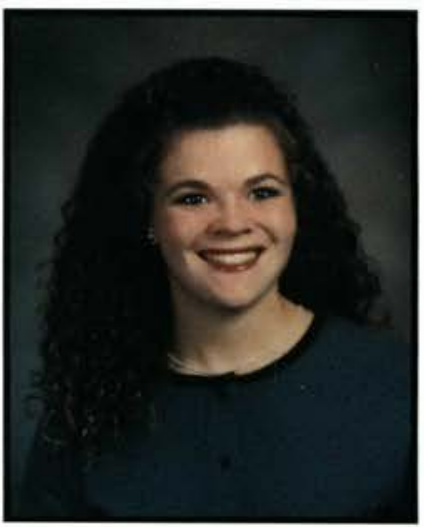

Sacey L. Billing

Nursing

Springfield, $\mathrm{OH}$

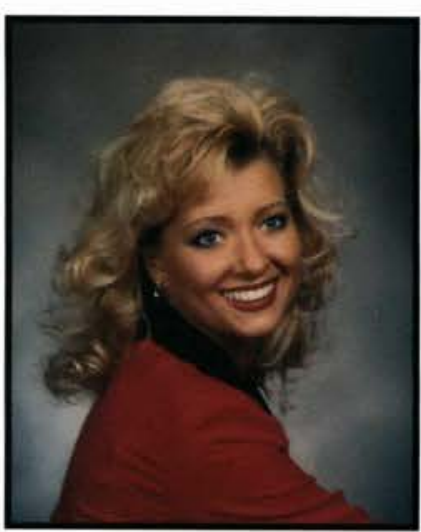

Tulia A. Boerlie Elementary Education Lima, $\mathrm{OH}$

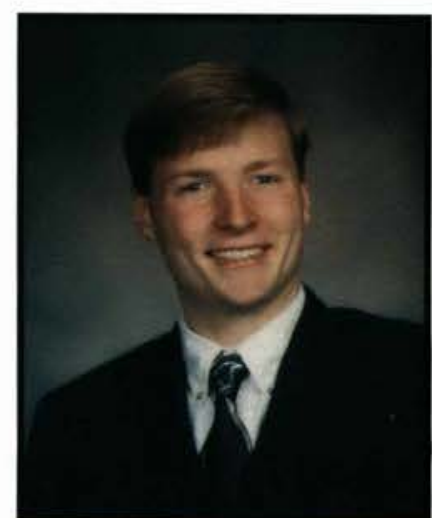

Bobert F. Bowwen:

Mechanical Engineering

Wayland, MI 


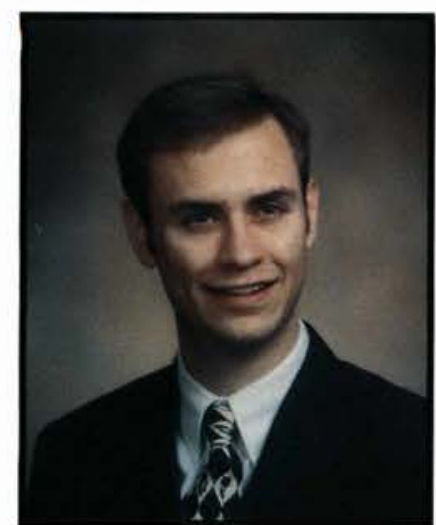

Gordon 2. Royd

Pre-Seminary

North Salem, IN

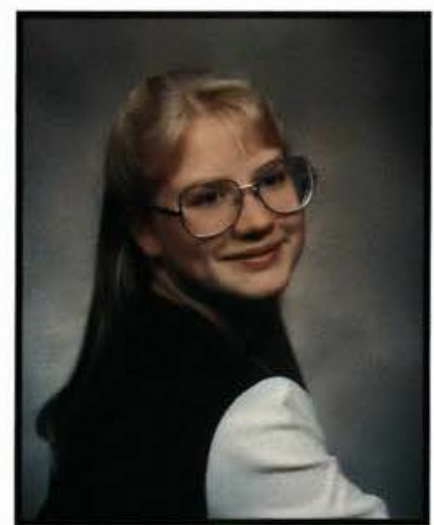

Melody O. Brickel

Lewisburg, $\mathrm{OH}$

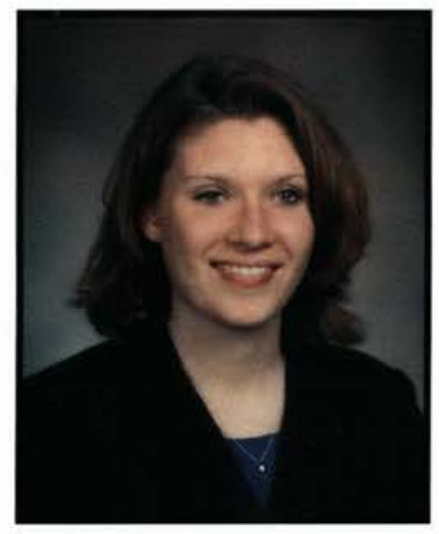

Nifici: Bb. Broughton

Elementary Education

Cedarville, $\mathrm{OH}$

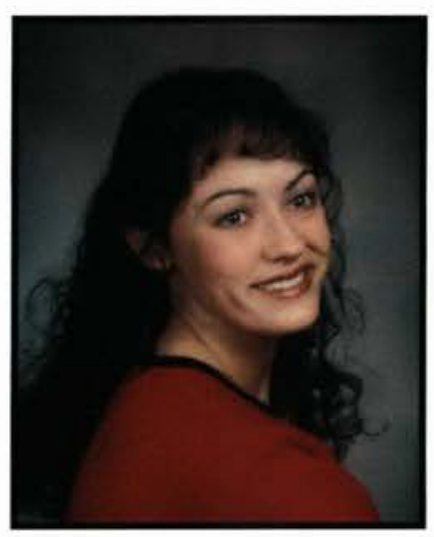

Bori. Ro. Broun

Elementary Education

$\mathrm{Xenia}, \mathrm{OH}$

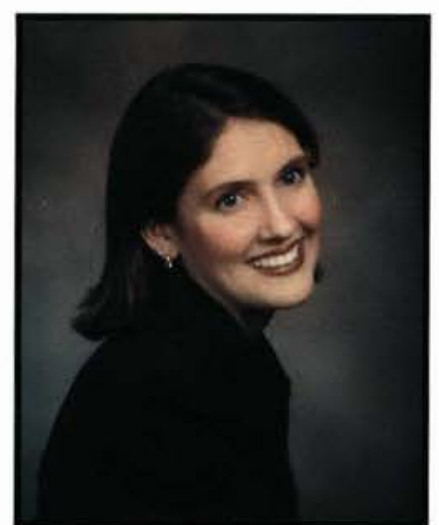

Lisa.S. Pranon

Music Education

Grand Rapids, MI

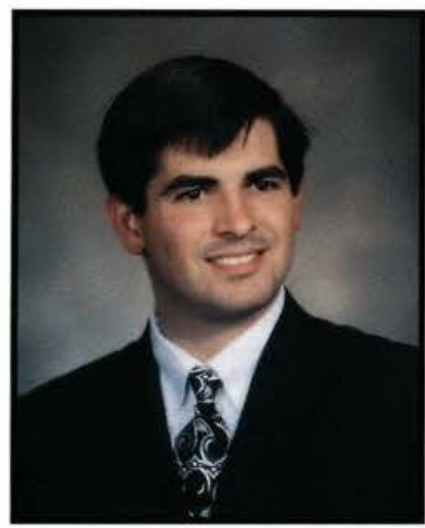

Ooseph C. Prinfley

Granville, $\mathrm{OH}$

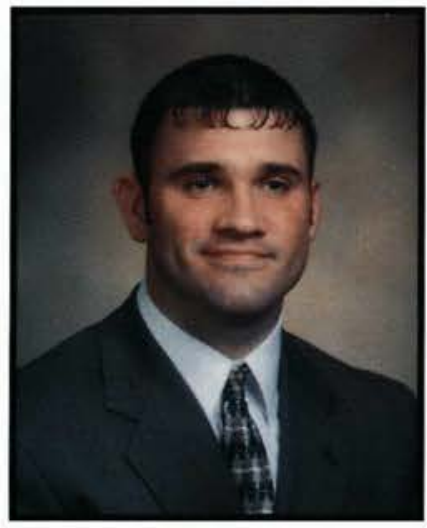

Abaron Prown

Criminal Justice

Constantine, MI

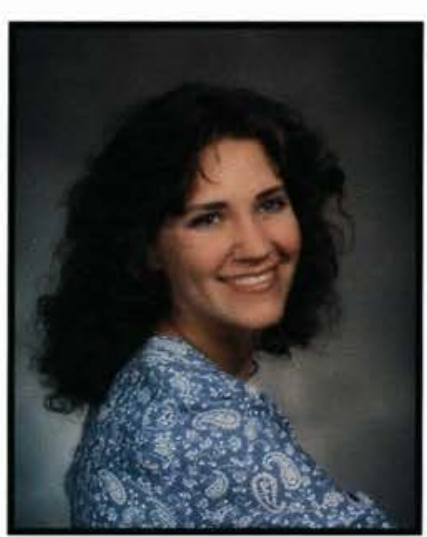

Armanda L D. Bructiner Music

Elkhart, IN

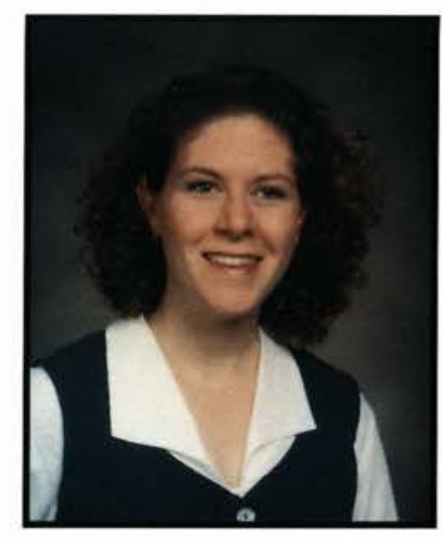

Beth. A. Rrentlinger Biology

Seville, $\mathrm{OH}$

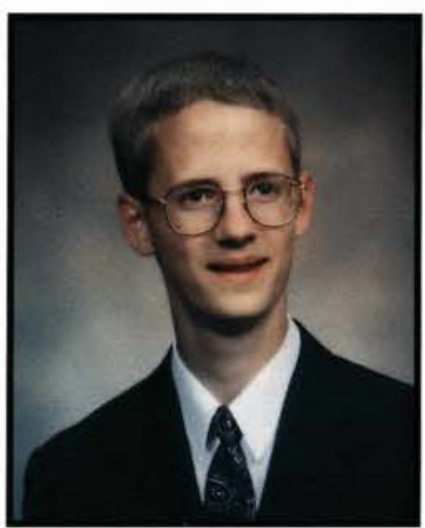

Deref. D. Brintimeier Math

Lena, IL

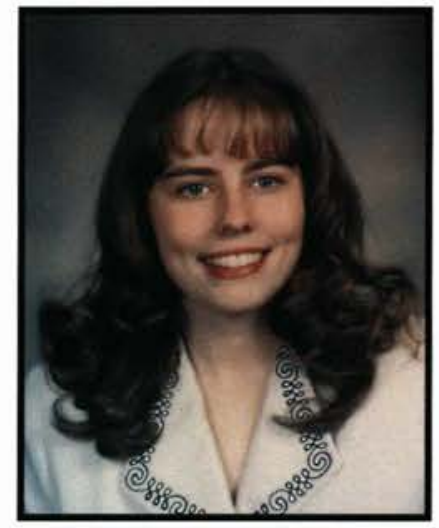

Evelyn A. Brown

English Education

Ellwood City, PA

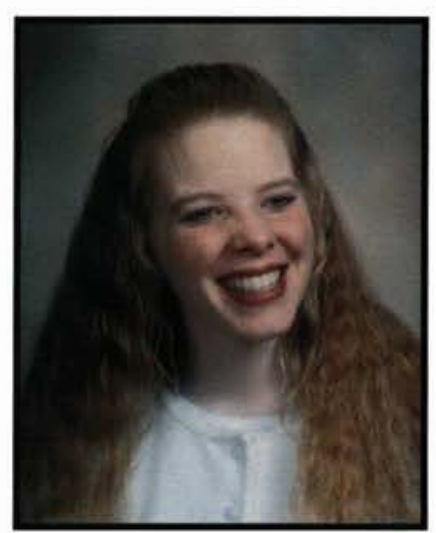

Armanda Ml . Bryion

Elementary Education

Cincinnati, $\mathrm{OH}$

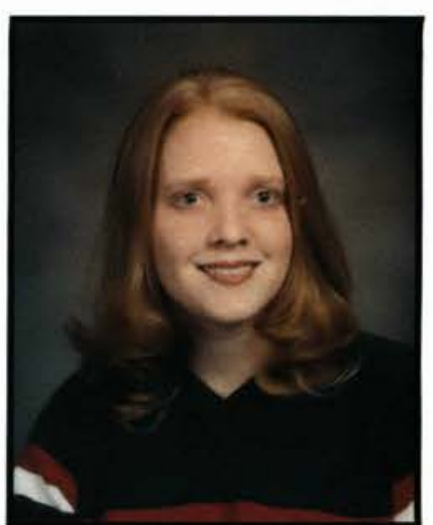

Slacy $\mathscr{L}$. Rrewer Nursing Jenison, MI

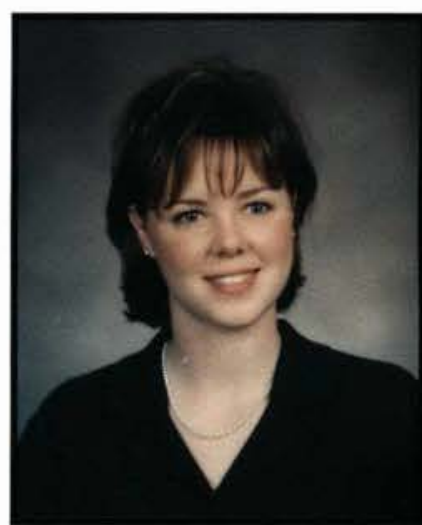

Heather A. Brodic

Psychology

Northville, MI

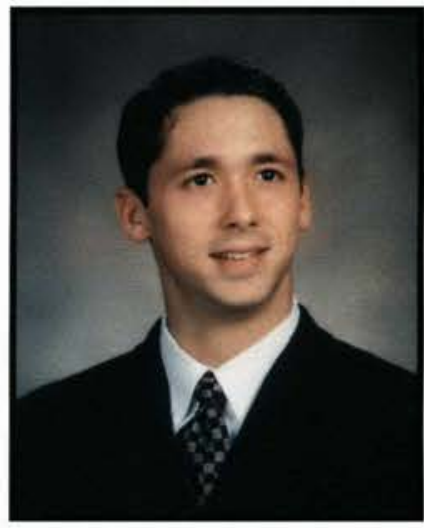

Tason D. Prown

Communication Arts

Peoria, IL

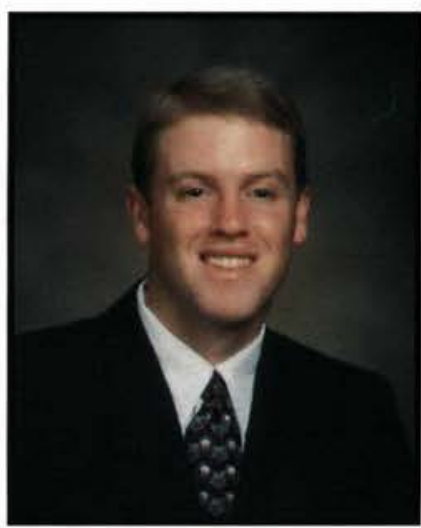

Sleven F. Burchell

Pre-Seminary

Morral, $\mathrm{OH}$ 


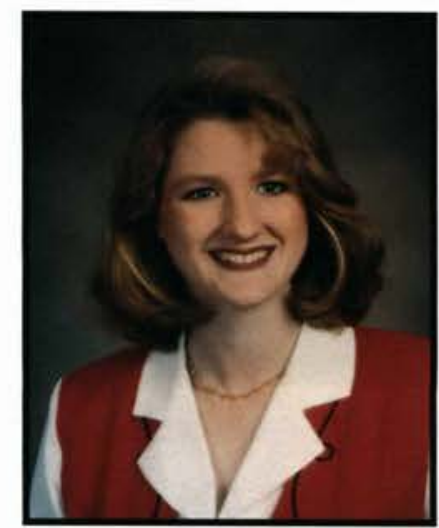

Marqarel D. Burgess:

Elementary Education

Mayfield Heights, $\mathrm{OH}$

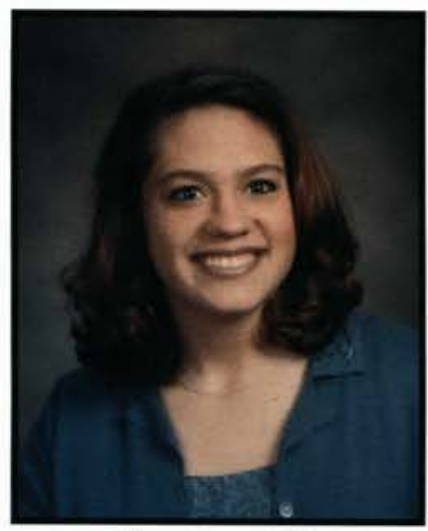

Andrea Buls

American Studies

La Rue, $\mathrm{OH}$

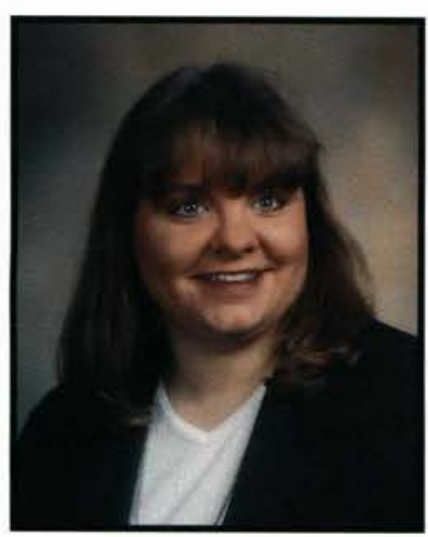

- bprit of. Garter

International Studies

Canton, $\mathrm{OH}$

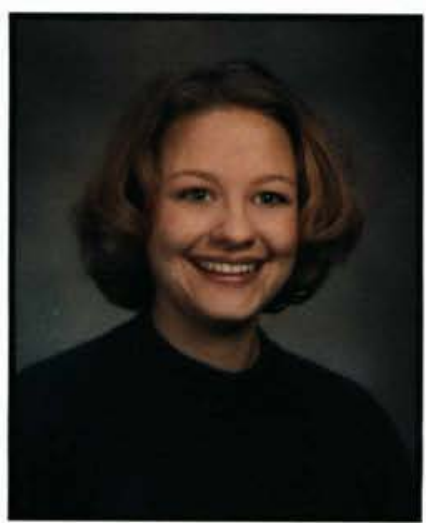

Bea. Gnne Ghurgovich

Music Education/Music

Medina, $\mathrm{OH}$

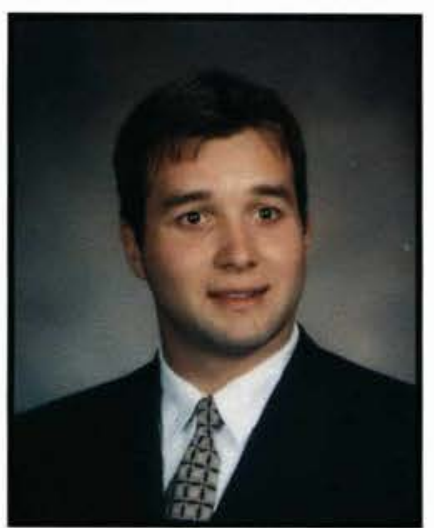

David. A. Surlie

Communication Arts

Ontario, Canada

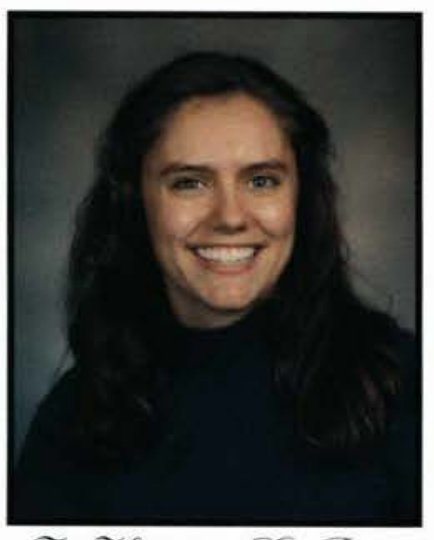

Fo. Hanna C. Rypres Social Work

Morgantown, WV

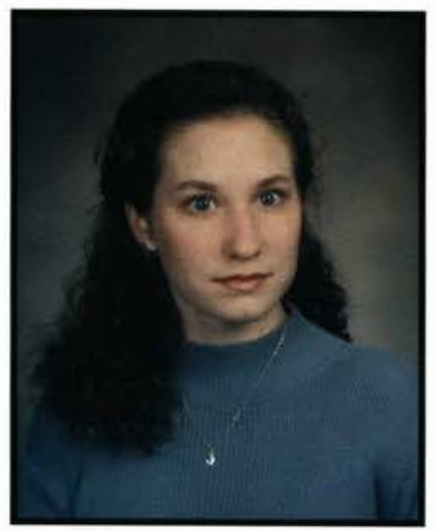

Foristyn A. Barter Elementary Education

Sylvania, $\mathrm{OH}$

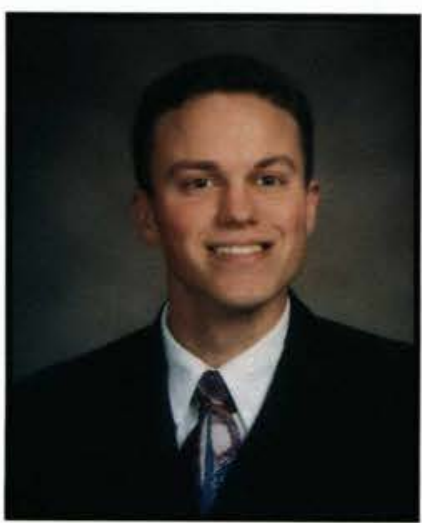

Paion to. Girone

History/SocialScience

Rhinebeck, NY

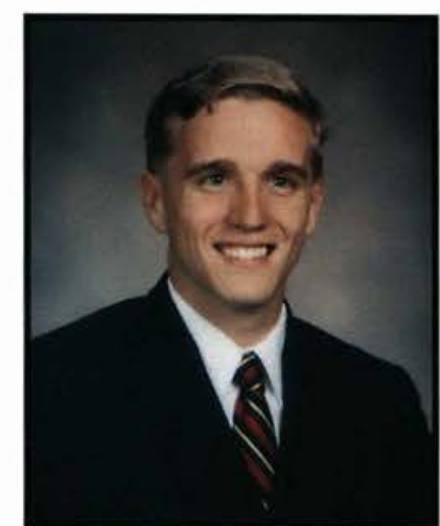

Ryan. A. Rurlichard

MechanicalEngineering Dayton, $\mathrm{OH}$

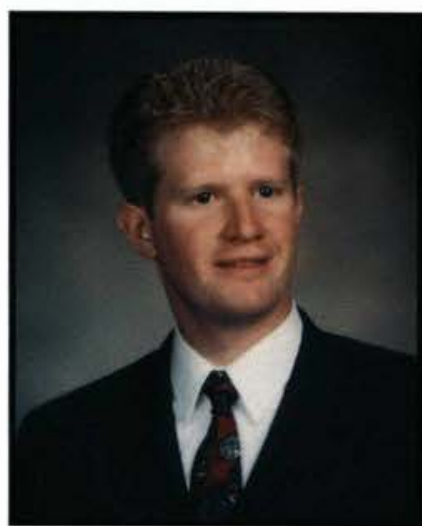

Foseph Ilb. Bantor Chemistry/Biology El Cajon, CA

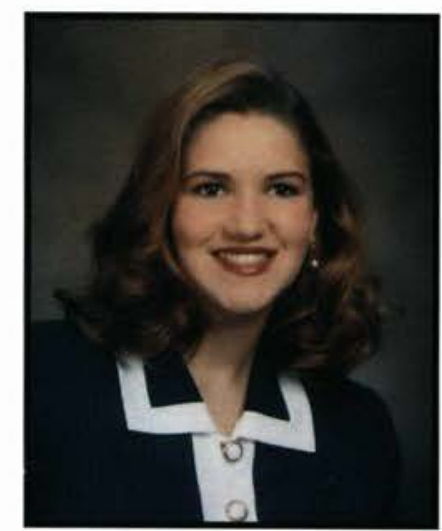

Fristine D. Chamberlin Elementary Education Cincinnati, $\mathrm{OH}$

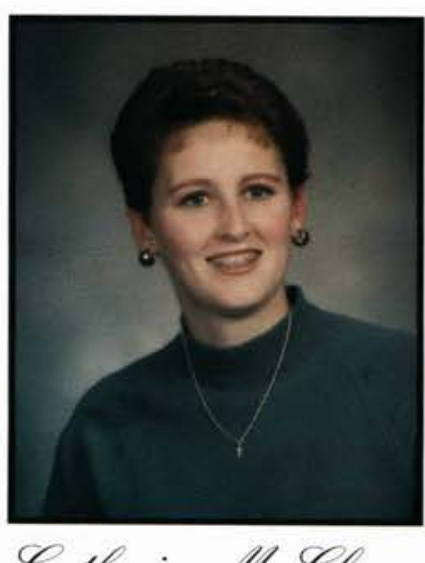

Gatherine. Ilb. Blaggg

Nursing

Sanger, CA

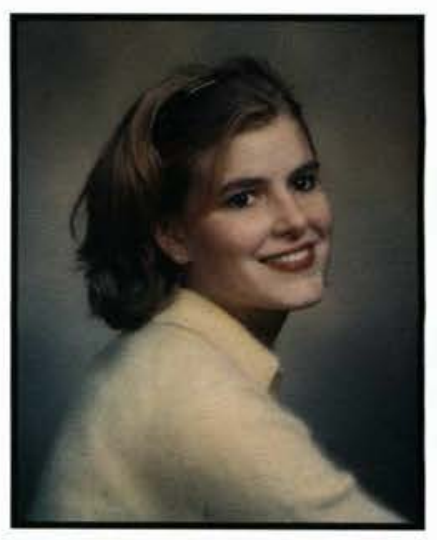

Tennifer D. Ruller

Elementary Education London, $\mathrm{OH}$

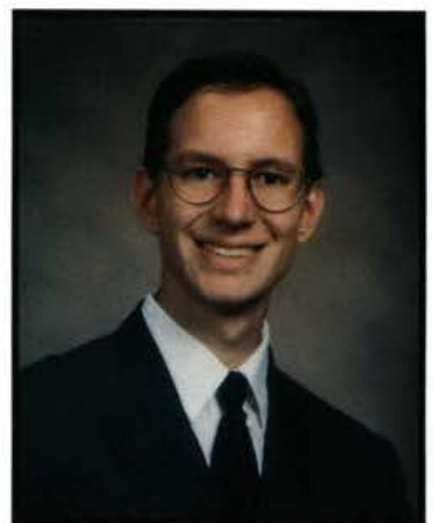

David L. Garl Math

Lakewood, NJ

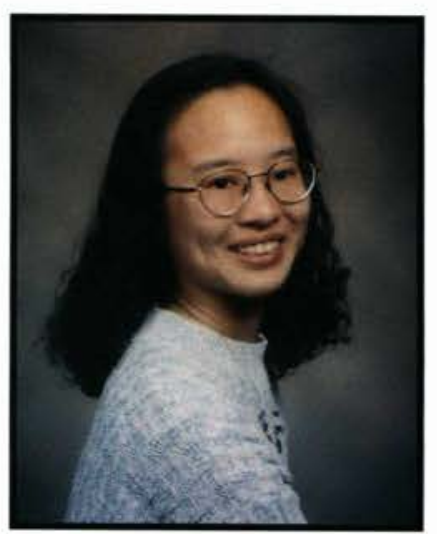

Erica WT. Chung English Education/Music

Woodland, CA

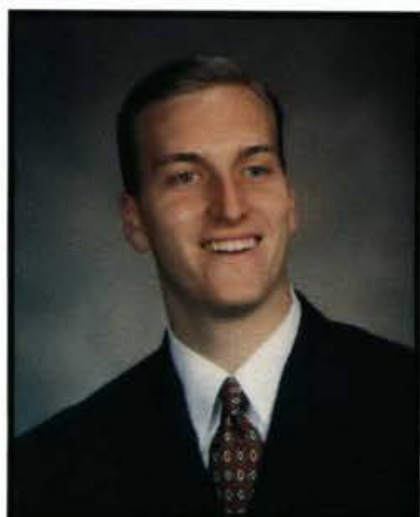

Ernest:P. Glarts Op:

Bible Comprehensive Roanoke, VA 


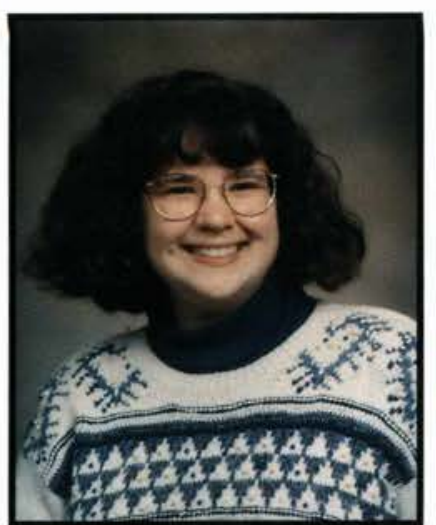

Ghristy L. Cleaver

Professional Writing

Kellogg, IA

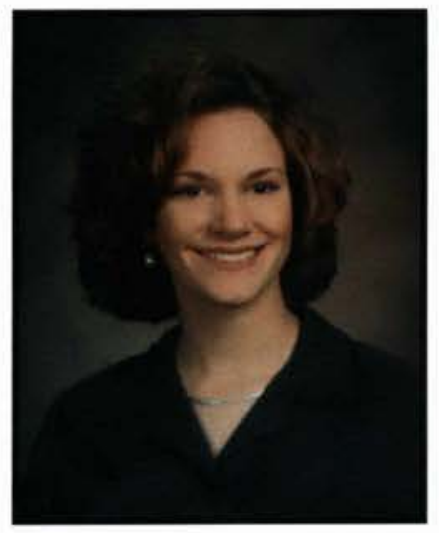

Bebeca E. Comfort Social Work

Cumberland, MD

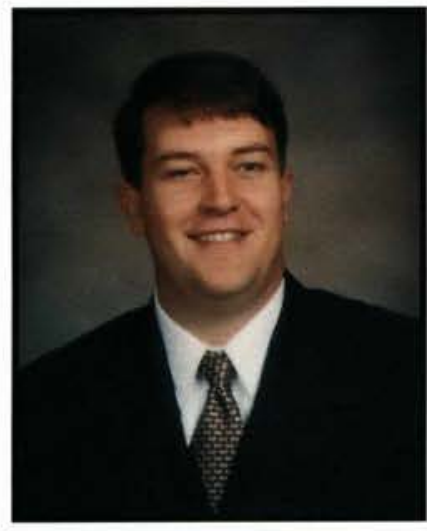

Andrew. Ko. Gousens Athletic Training/Physical Ed

Warrington, $\mathrm{PA}$

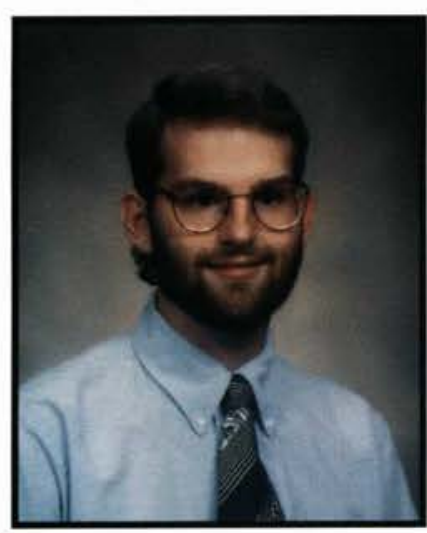

Thoma: L. Gulberion

Nursing

Rosamond, IL

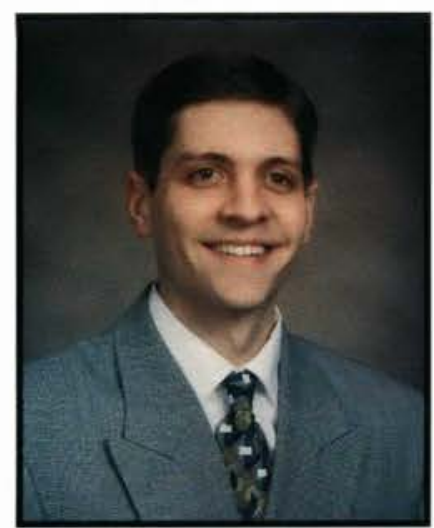

Pautblicts

Communication Arts

Clinton, MI

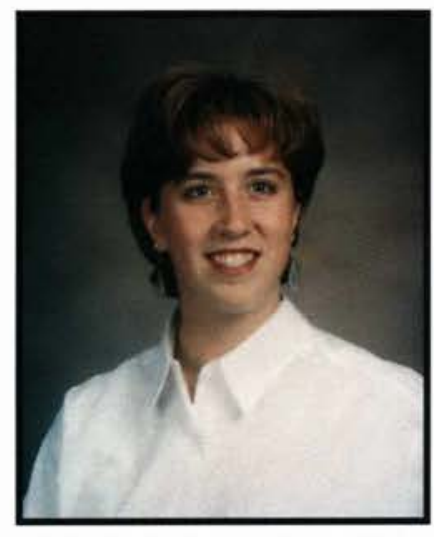

Disa. llb. Gook

Claremont, $\mathrm{NH}$

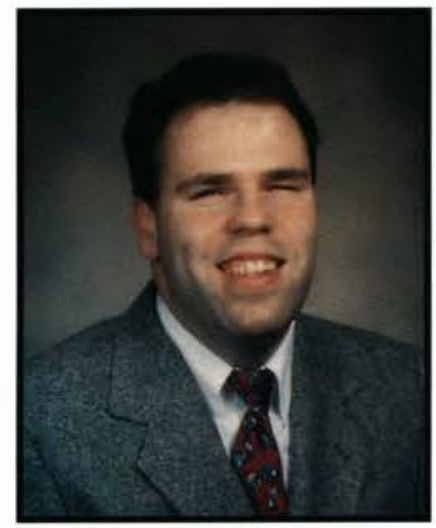

Ryan Mb. Coverdell

Broadcasting

Amanda, $\mathrm{OH}$

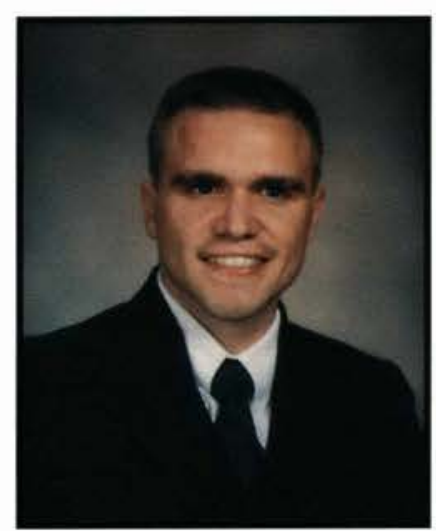

Gabe OD. Custer

CIS/Management Cable, $\mathrm{OH}$

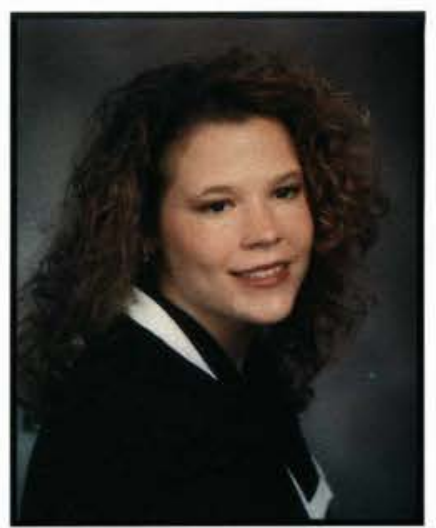

Danielle. Coler

Elementary Education

South Charleston, $\mathrm{OH}$

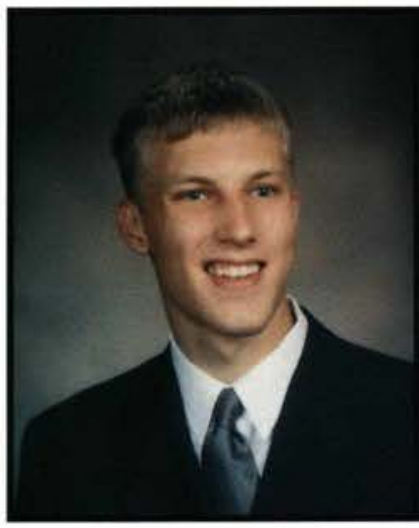

- tondrew R. Cooper Computer Information Systems Granby, CT

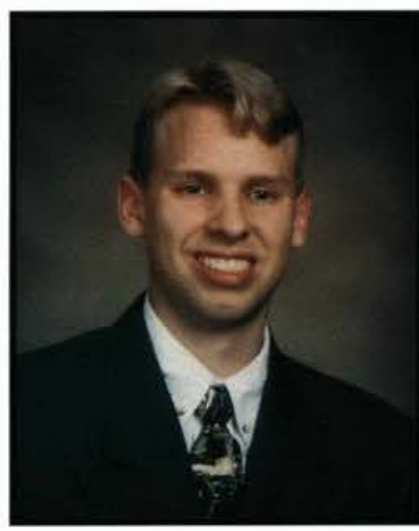

Wichael D. Grauford Computer Information Systems Perrysburg, $\mathrm{OH}$

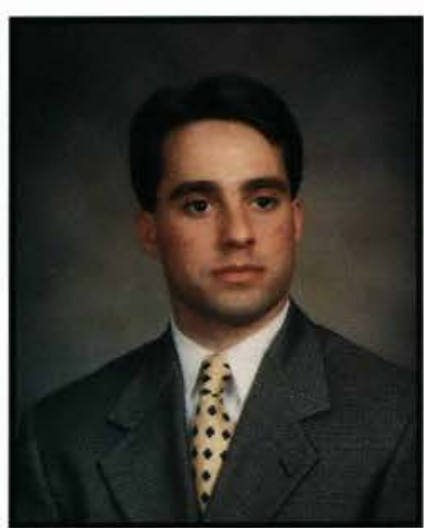

Tamie. t. Dato Management/Marketing Derry, $\mathrm{NH}$

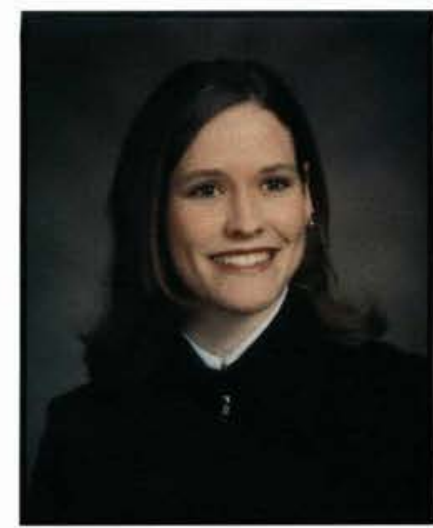

Rethany O. Gomer Nursing

Grand Rapids, MI

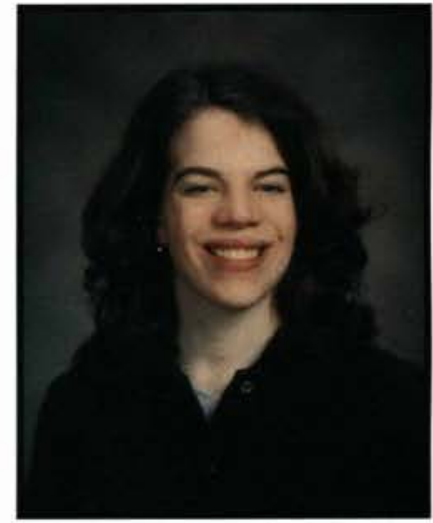

Elizabeth. A. Gooper Social Work

Convent Station, NJ

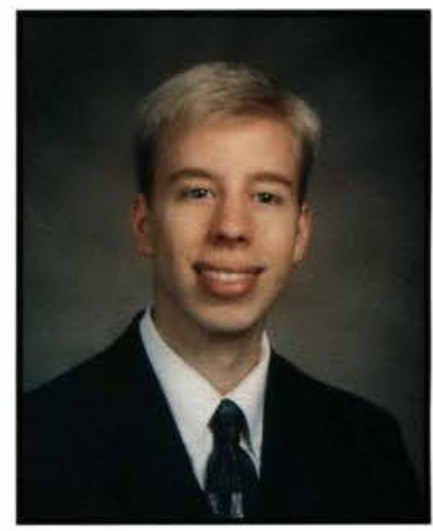

Games. Gresuell Computer Information Systems Dayton, $\mathrm{OH}$

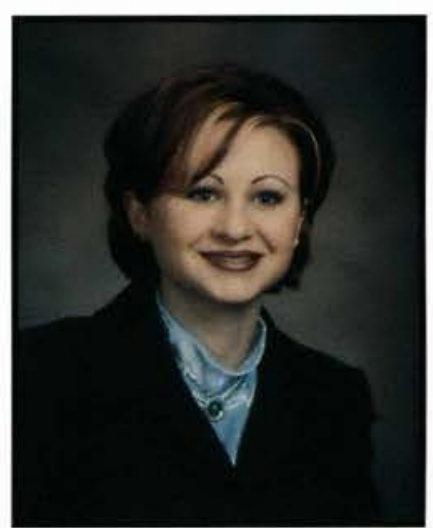

Sina Davidion Marketing Lakewood, CA 


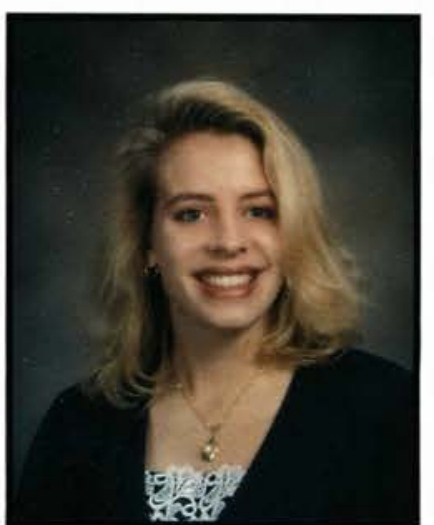

Anne E. Davis

Computer Information Systems

Seward, PA

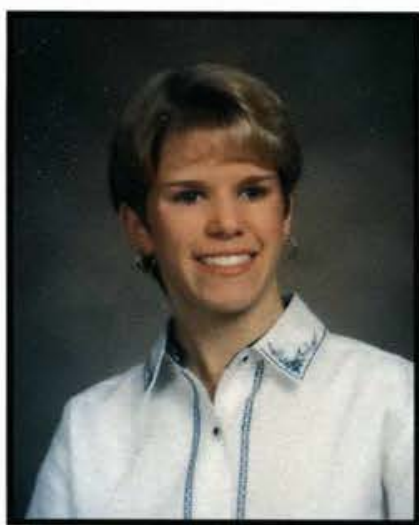

Garale. De. Fock

Elementary Education

Hudsonville, MI

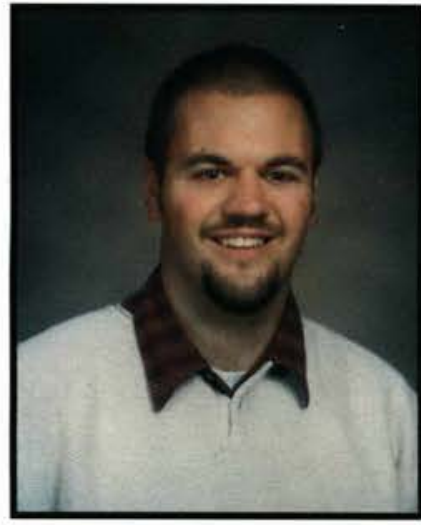

Dame: R. Deurald

Bible Comprehensive

Libby, MT

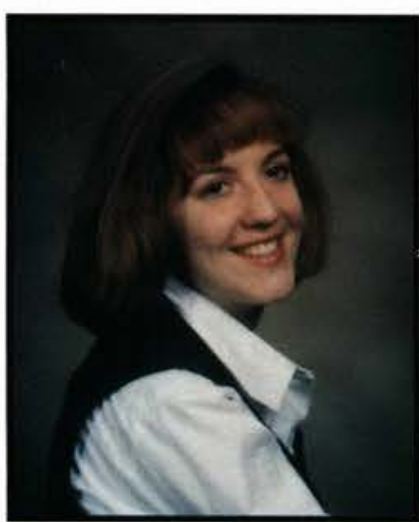

Gheri L. Dougla:

Social Work

Norwood, $\mathrm{OH}$

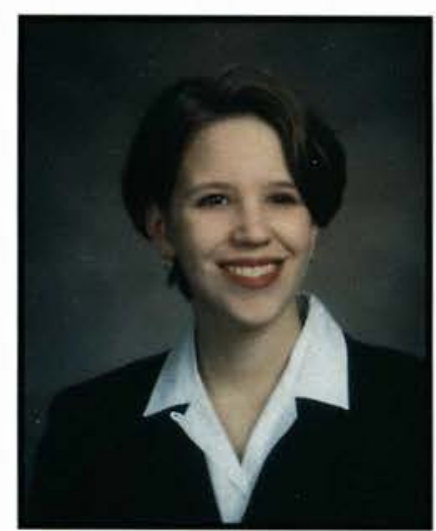

Garrie L. Davis

Elementary Education Cedarville, $\mathrm{OH}$

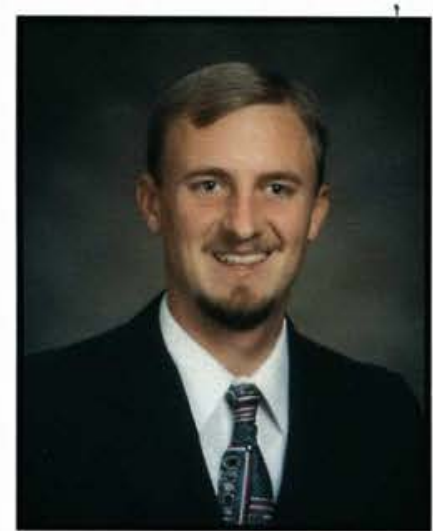

Paul.T. De Kruyter

Mechanical Engineering

Kalamazoo, MI

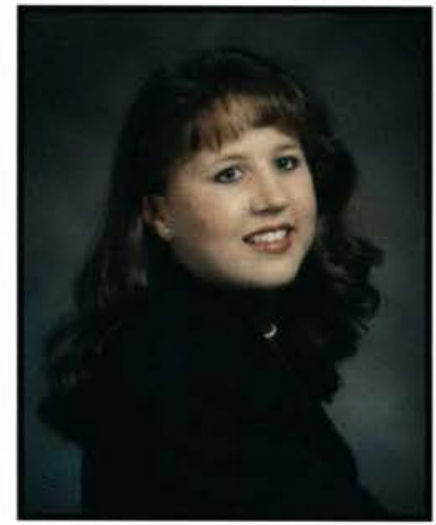

Stephanie Ab. Dicherion Nursing

Daleville, VA

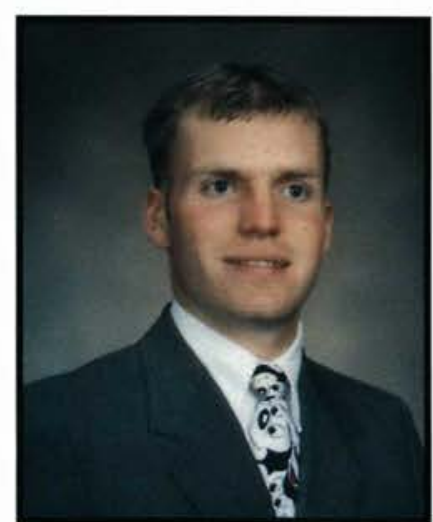

F. Aaron Dunham

Computer Information Systems Springfield, $\mathrm{OH}$

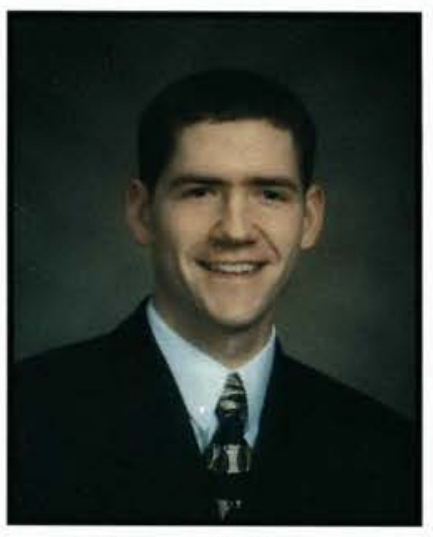

Glay. A. Davis

Marketing

Cedarville, $\mathrm{OH}$

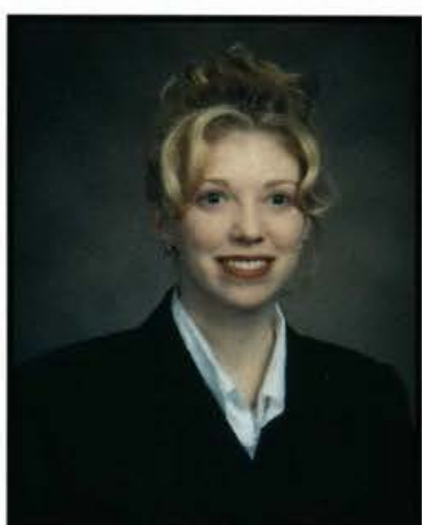

Tennifer L. Decker

Nursing

Marion, NY

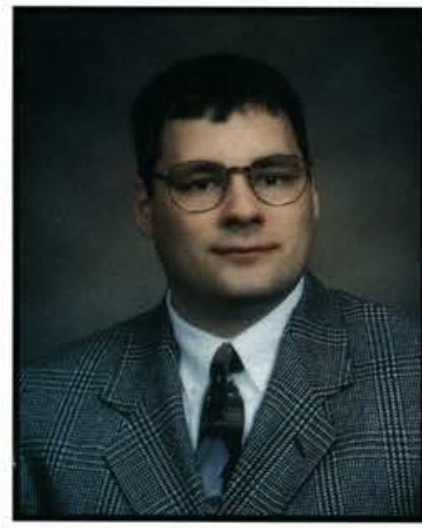

Benjamin F. Diller

Marketing

Bluffton, $\mathrm{OH}$

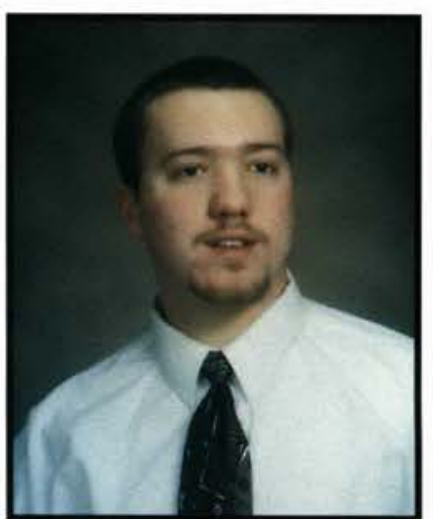

Brian Dye

Elementary Education

Chicago, IL

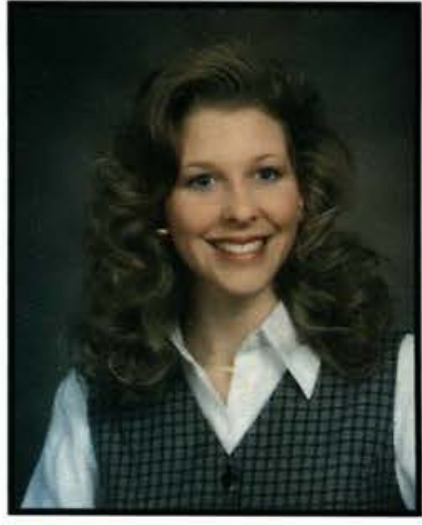

Rachel. P. Davis Nursing

Columbus, $\mathrm{OH}$
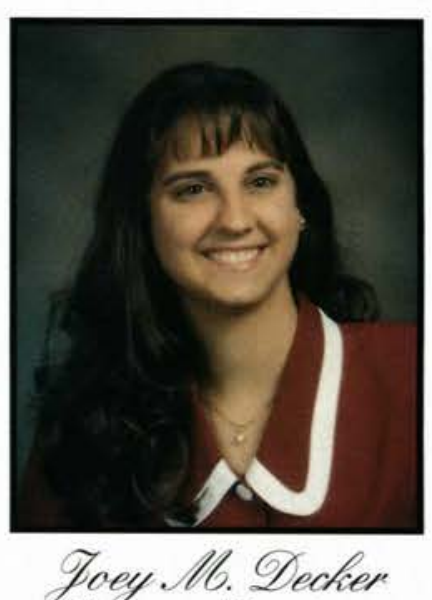

Elementary Education Hagerstown, MD

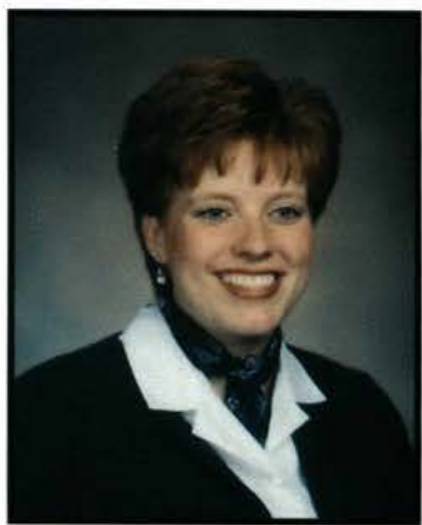

Tamie L. Dodion Nursing

Danville, IN

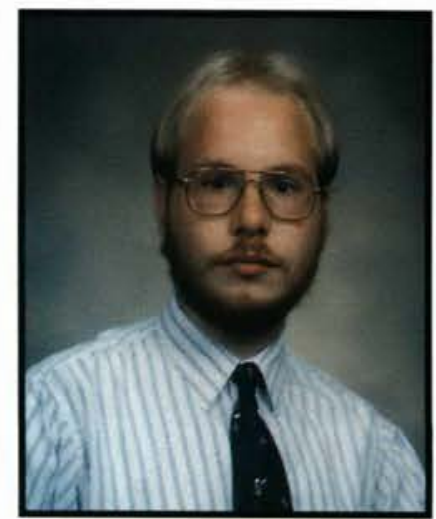

Tames. D. Quer

Music/Bible Comprehensive West Warwick, RI 


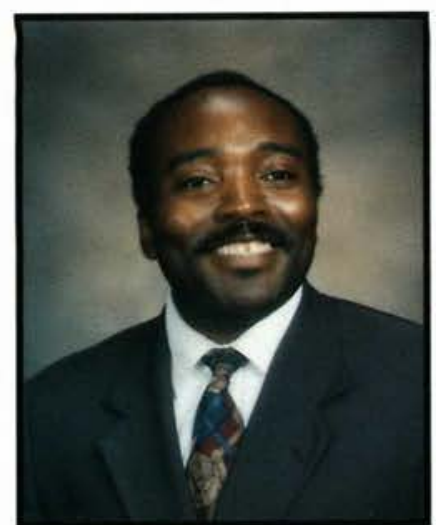

Srequry. S. Dyion

Bible Comprehensive Cedarville, $\mathrm{OH}$

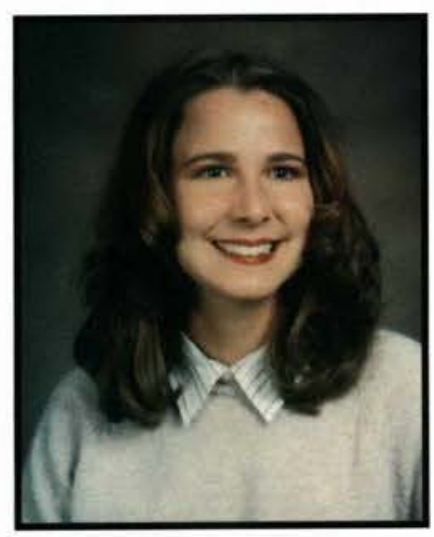

Bachelle. H. Elder

Math

Gilman, WI

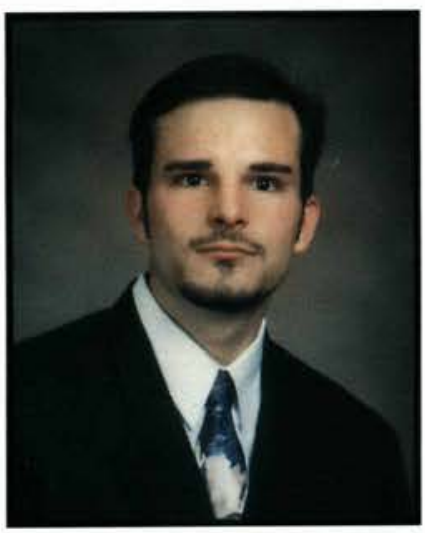

Robert E. Emery

Applied Psychology

Cedarville, $\mathrm{OH}$

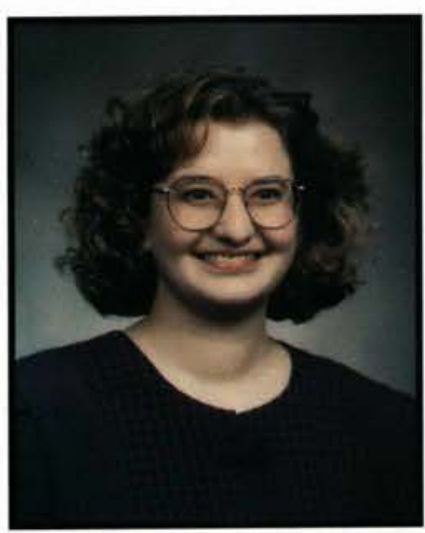

Martha Mb. Failor

Elementary Ed/English Ed Nevada, $\mathrm{OH}$

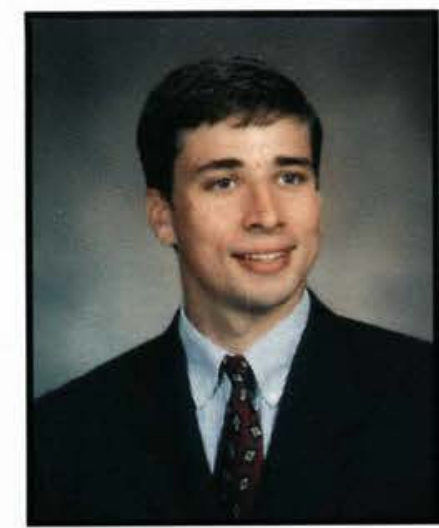

Foel. A. Eaby

Athletic Training

Marietta, PA
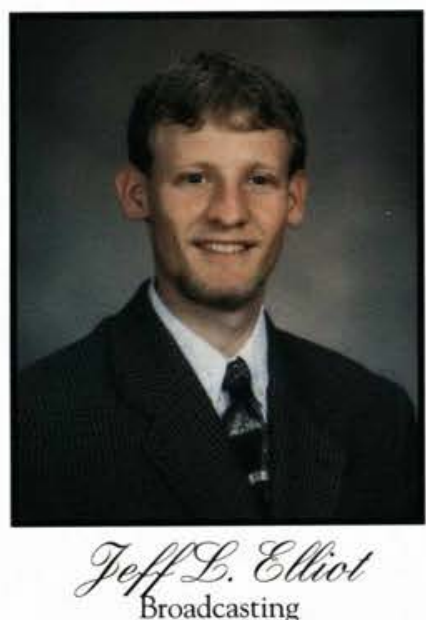

Brownsburg, IN

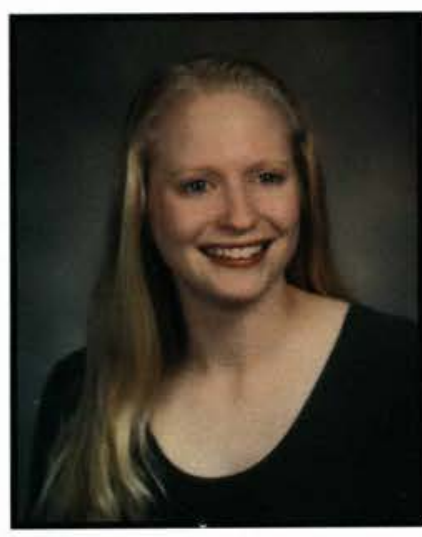

Saranne E. Emery

Applied Psychology

Cedarville, $\mathrm{OH}$

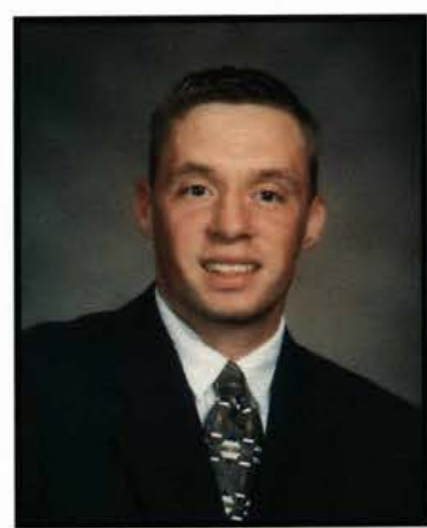

Rryan R. Falle

Accounting

Monterey, IN

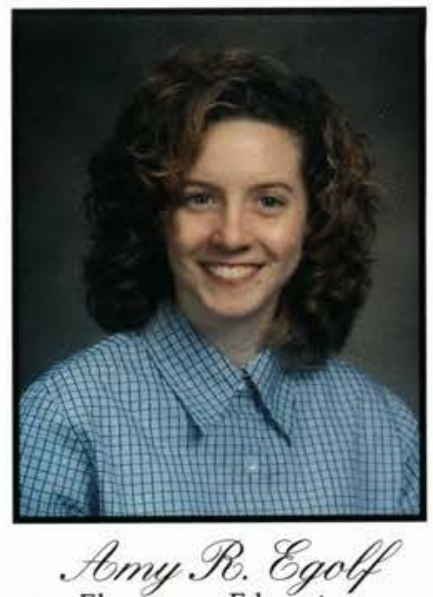

Elementary Education

Columbus, $\mathrm{OH}$

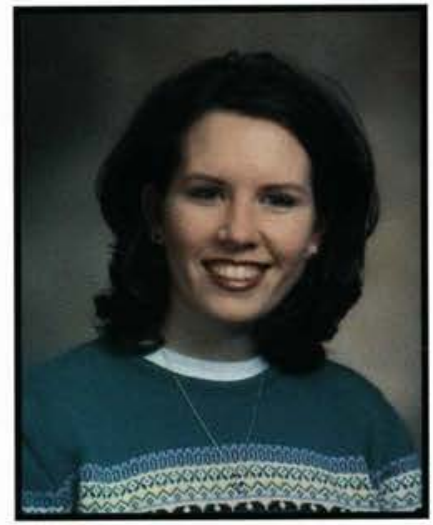

Gody G. Ellioll

Nursing

Dayton, $\mathrm{OH}$

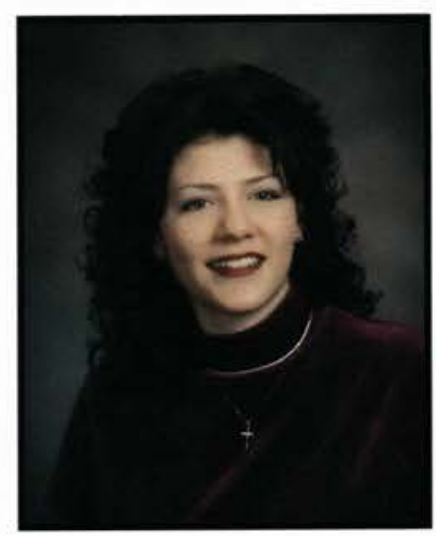

Focelynn. S.Endisley

Communication Arts

Coshocton, $\mathrm{OH}$

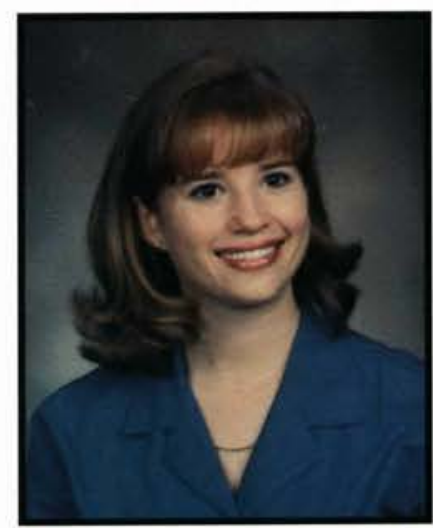

Ghristina L. Farris Political Science

Purcellville, VA

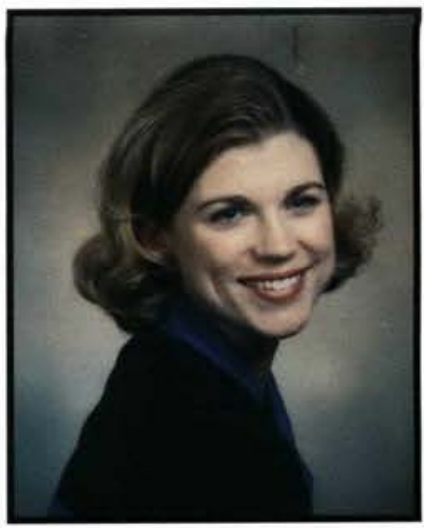

Stacie A. Eldeen

Elementary Education

Tucson, AZ

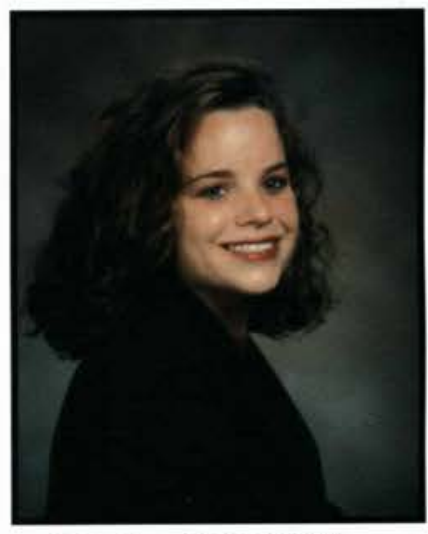

Debra K. Ellison Math

Lonsdale, MN

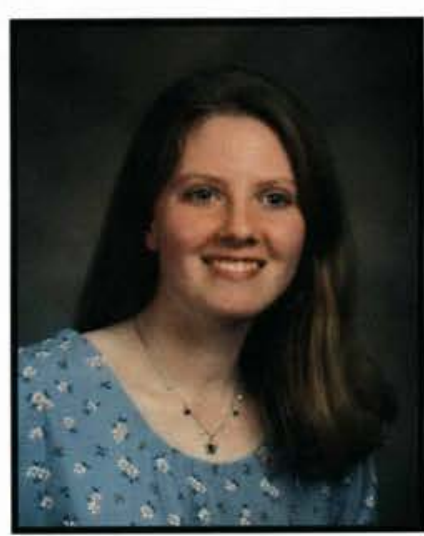

Tean E. Erte:

Biology

Columbus, $\mathrm{OH}$

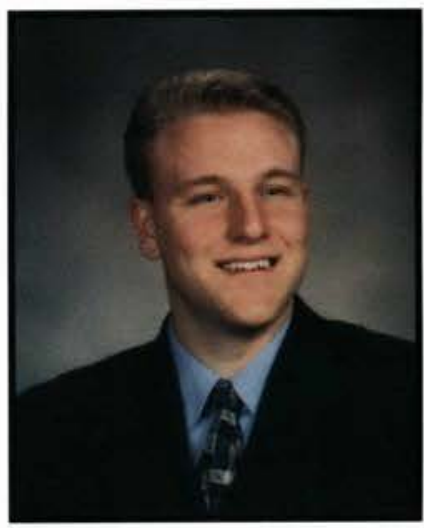

Thoma: N. Faultiner Math

Indianapolis, IN 


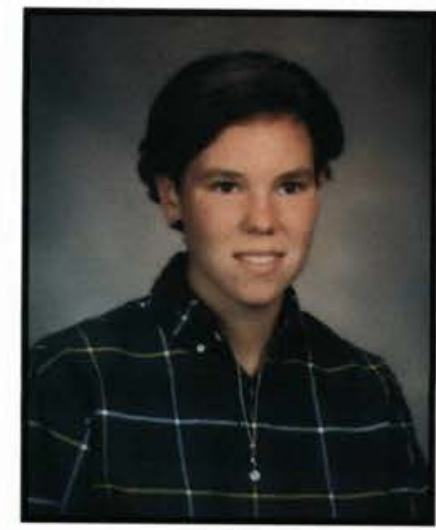

Zennifer L. Fisher

Elementary Education

Buellton, CA

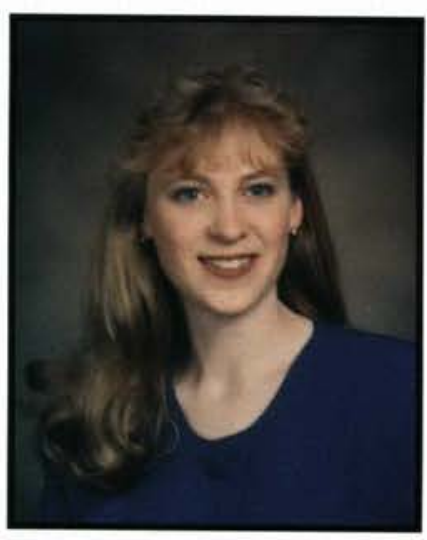

Armanda L. Foole

Chemistry/Biology

Issaquah, WA

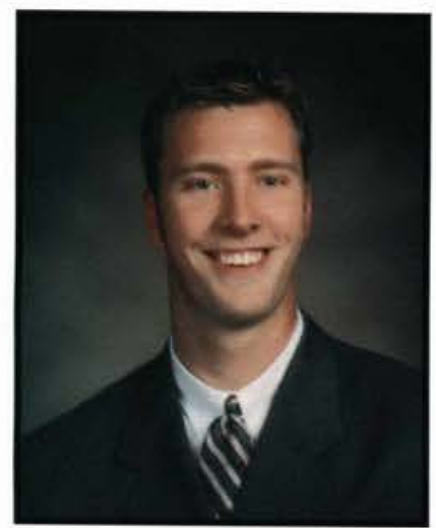

Mattheu. Mb. Fourman

Biology

Greenville, $\mathrm{OH}$

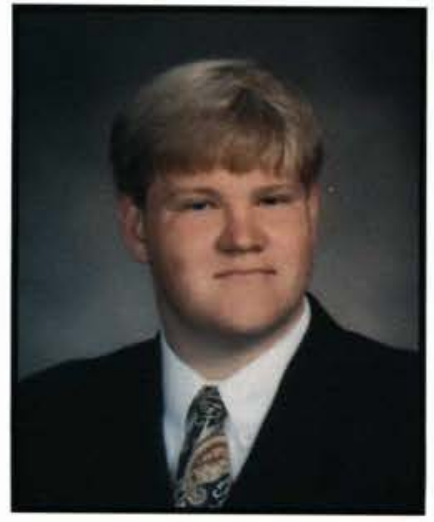

Ryan L. Freed

Broadcasting

London, $\mathrm{OH}$

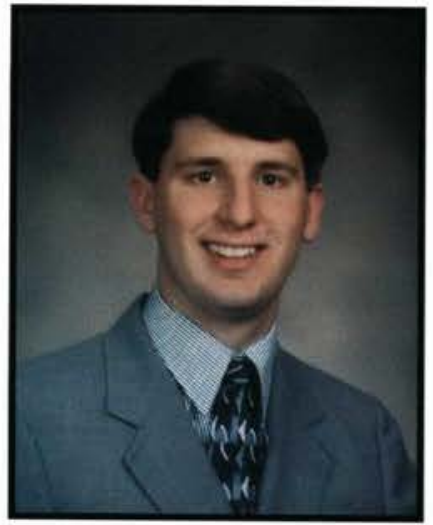

Timothy. R. Flowers Math

Newport News, VA

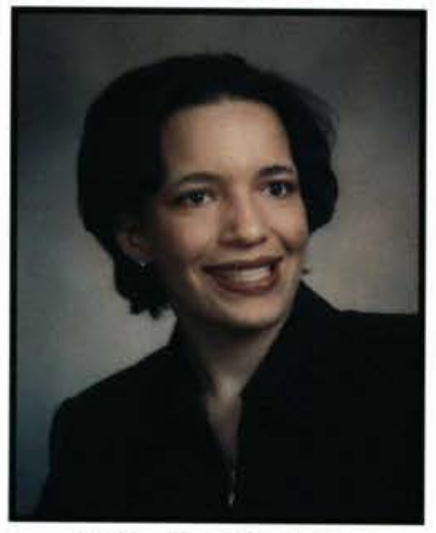

Kelly L. Ford

Professional Writing

Burlington, NJ

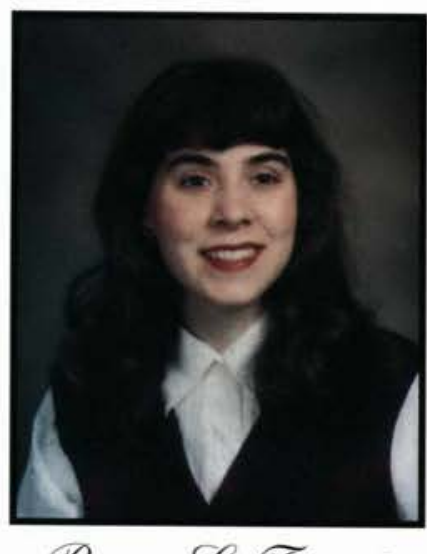

Renee L. Francis

Nursing

Lambertville, MI

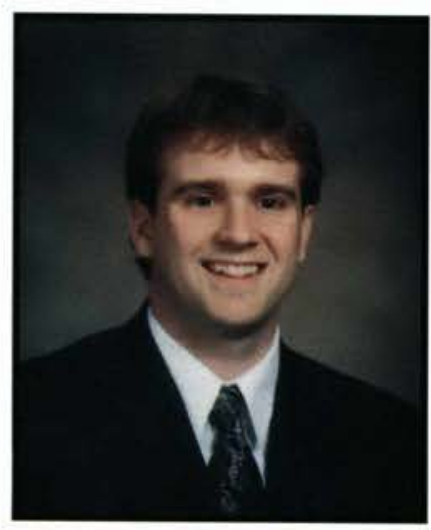

DanielE. Freeman

Computer Information Systems

West Buxton, ME
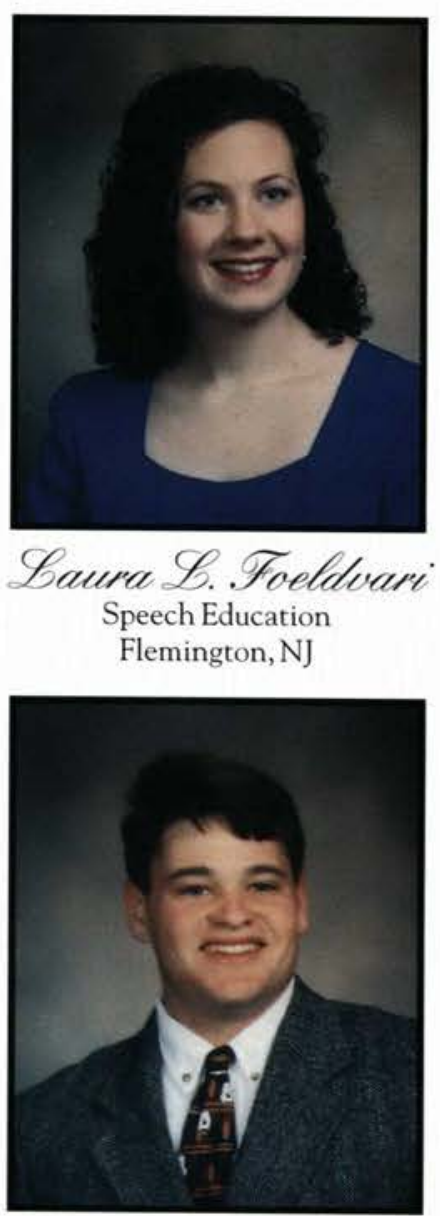

Kevin. T.Fountain

Physical Education

Castile, NY

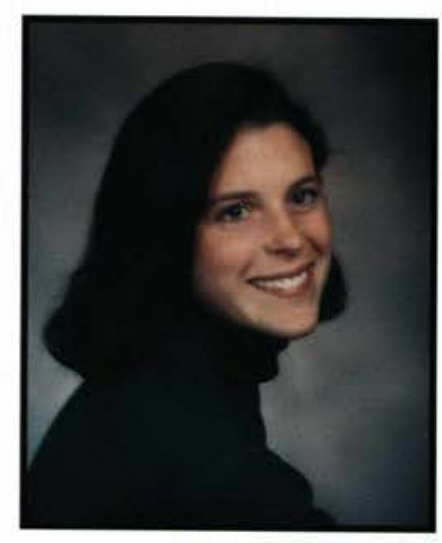

Tristen Tr. Frederich Nursing

Worthington, $\mathrm{OH}$

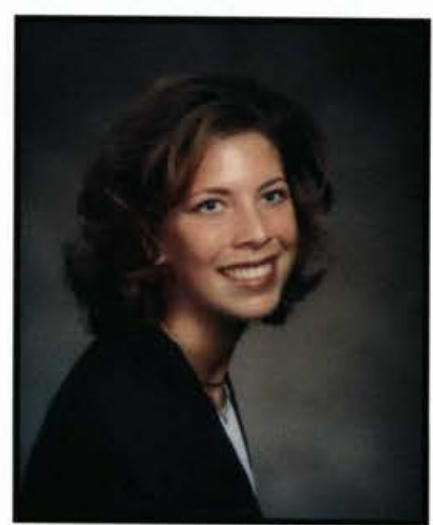

Bethany F. Gaffreer English Education Cedarville, $\mathrm{OH}$

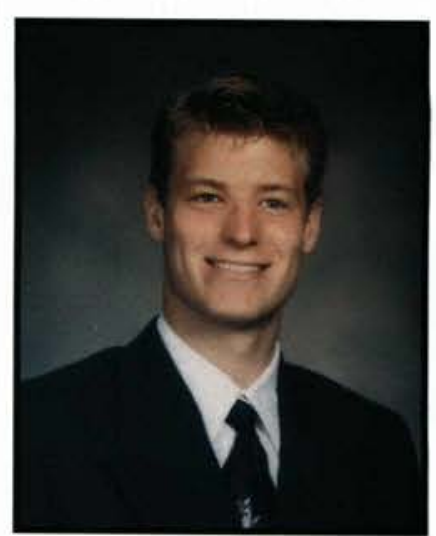

Foel.R. Foerch

Mechanical Engineering

Williamston, MI

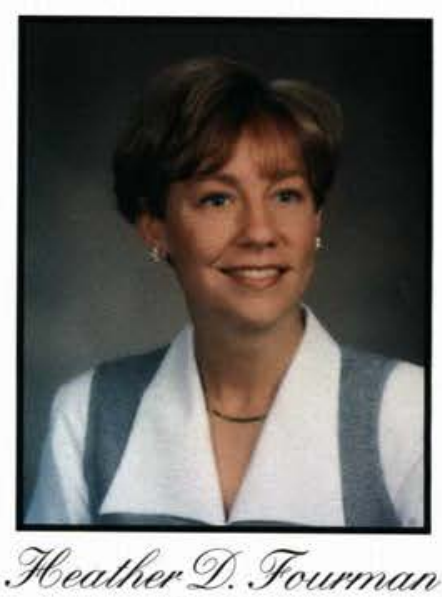
English

Greenville, $\mathrm{OH}$

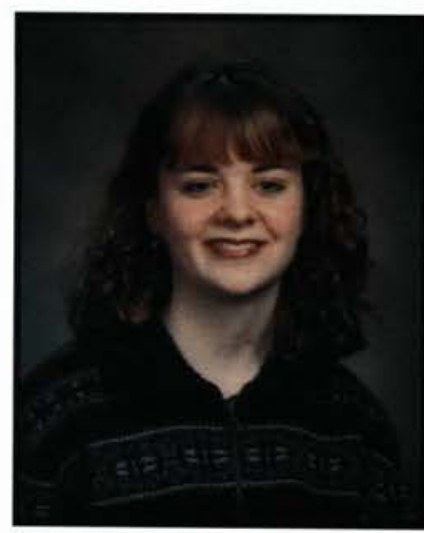

Tictoria. Ml. Frederichison Communication Arts

Manchester, CT

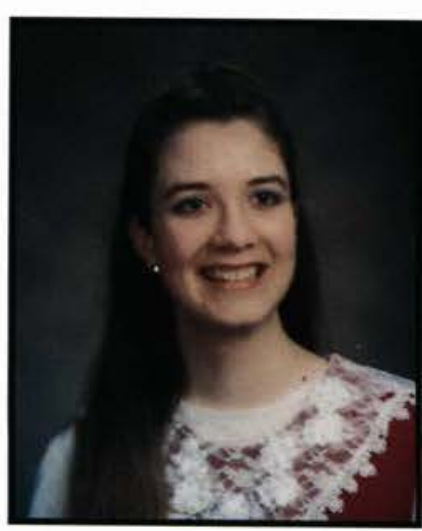

Christiana L. Gain

Music

Xenia, $\mathrm{OH}$ 


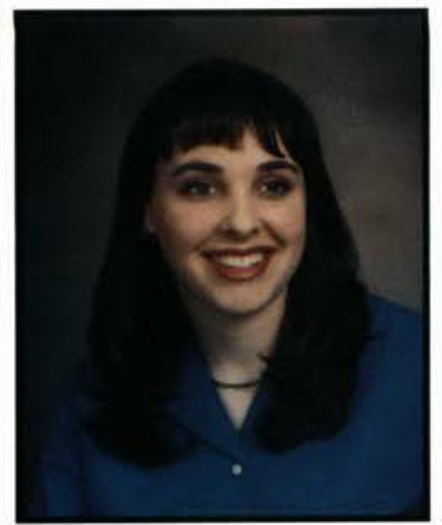

Elisabeth. Ko. Galovits English Education

Sussex, WI

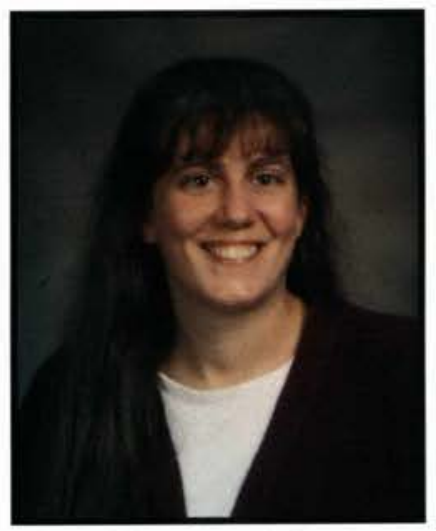

Bethany Seiger

Elementary Education

New Carlisle, $\mathrm{OH}$

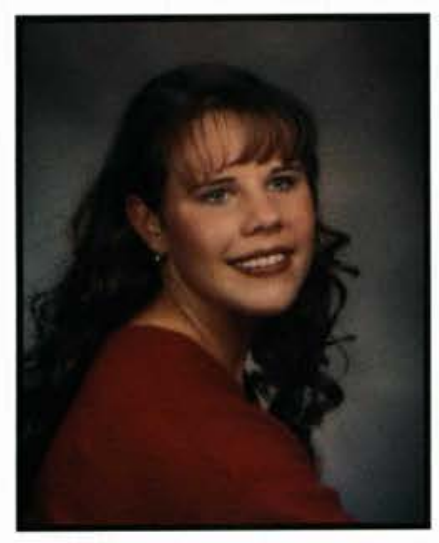

Kristi. S. Sleaion

Business Communication Technology Erie, PA

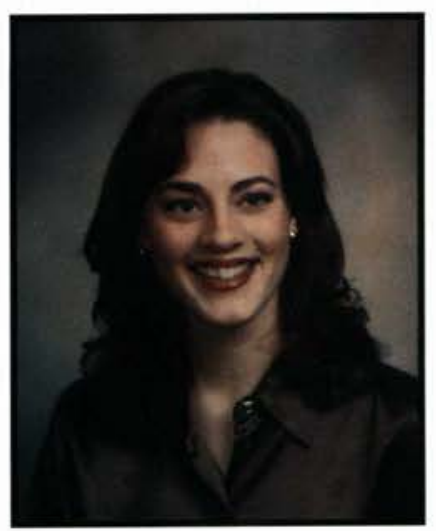

Tanna Golluals

Bible Comprehensive Cedarville, $\mathrm{OH}$

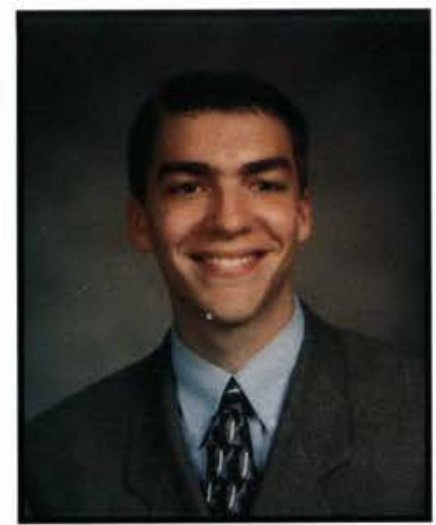

Sephen E. Sarcia

Broadcasting

Roselle, NJ

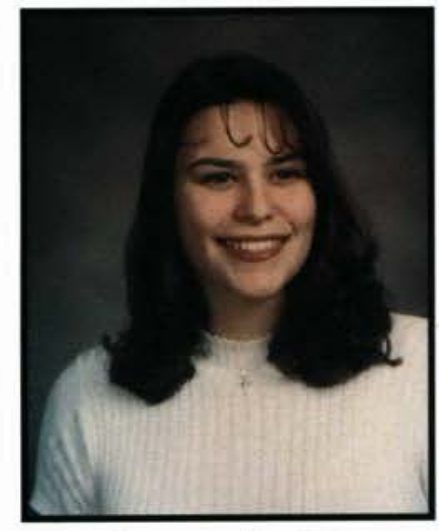

Rebeca M. Senovia

Nursing

Auburn, CA

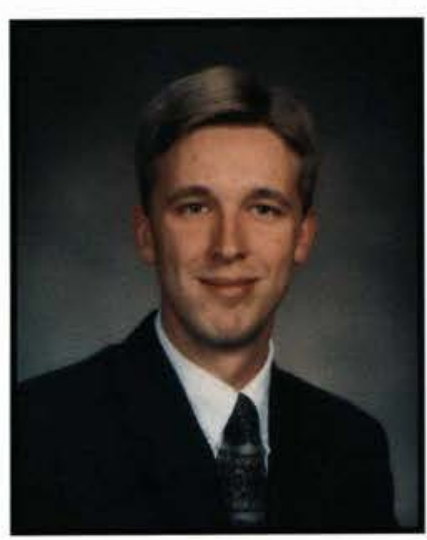

Fohn G. Slich

History

Jenera, $\mathrm{OH}$

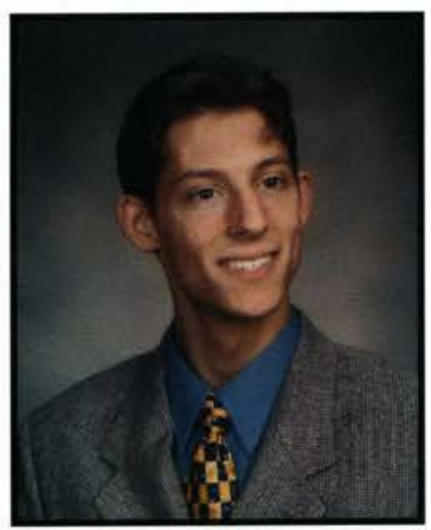

Blatie@. Gouldte

Professional Writing

Guilford, ME

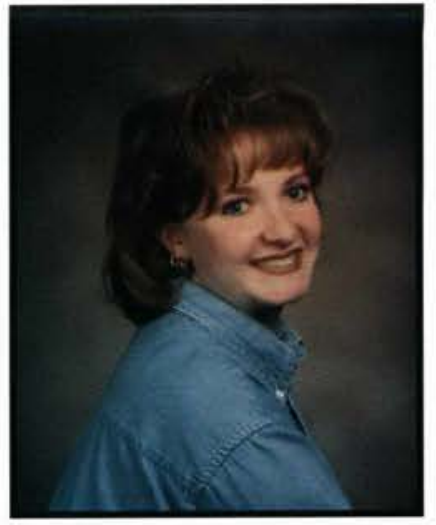

Tristen G. Gault

Business Communication Technology Perkasie, PA

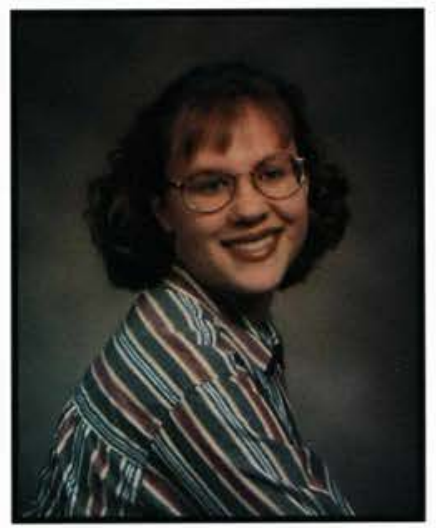

Gillisa R. Gerber

Elementary Education Pella, IA

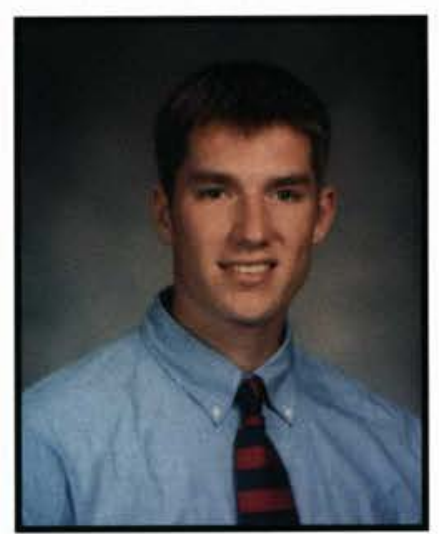

Ghristopher. P. Slupher Biology

Grandville, MI

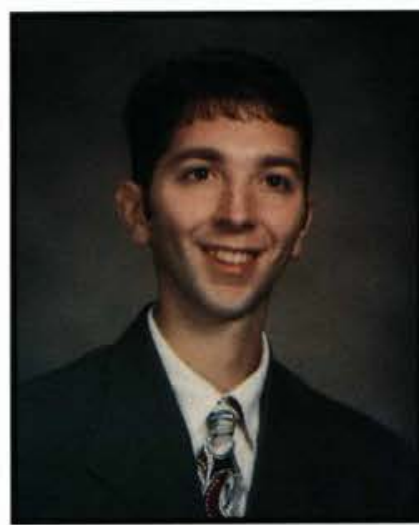

Michael F. Sraybill Bible Comprehensive Cedarville, $\mathrm{OH}$

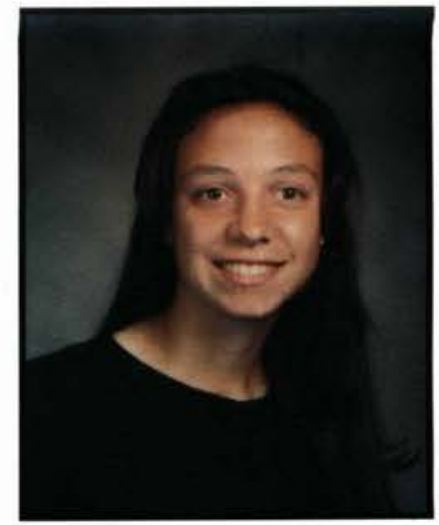

Melody L. Glur

West Paterson, NJ

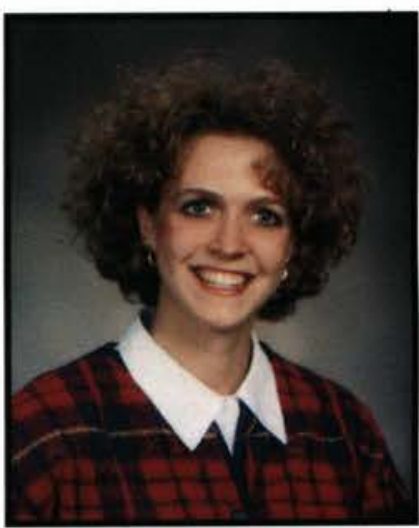

Sinda D. Gilbert

Elementary Education

Haddon Heights, N]

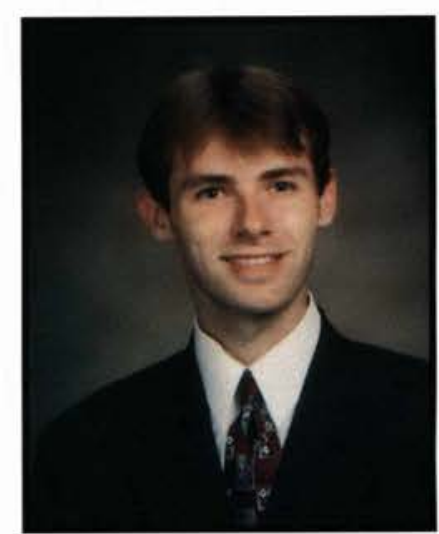

Eric F. Goiman

Bible Comprehensive Madison, IN

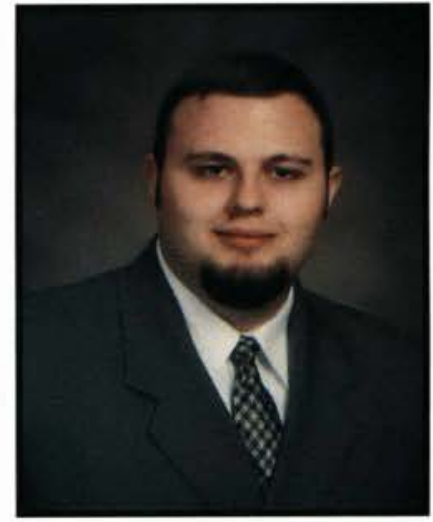

Daniel\%. Srazier Electrical Engineering Beavercreek, $\mathrm{OH}$ 


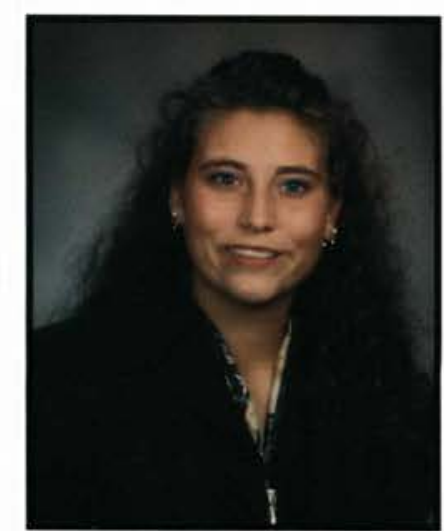

Himee R. Greenuood

Marketing

Springfield, $\mathrm{OH}$

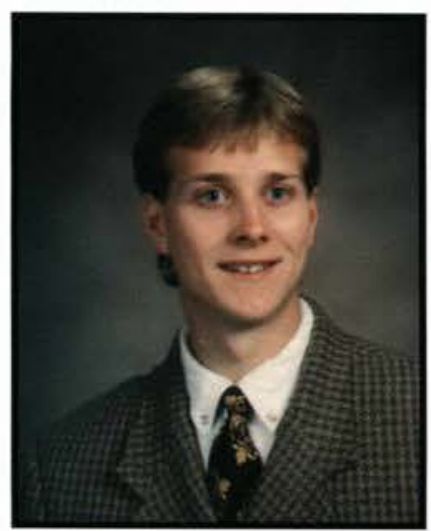

Gohn Grued

Management

Cedarville, $\mathrm{OH}$

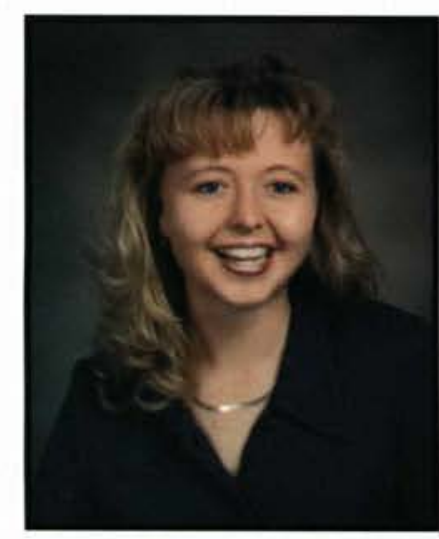

Fodie D. Tbager

Nursing

Bidwell, $\mathrm{OH}$

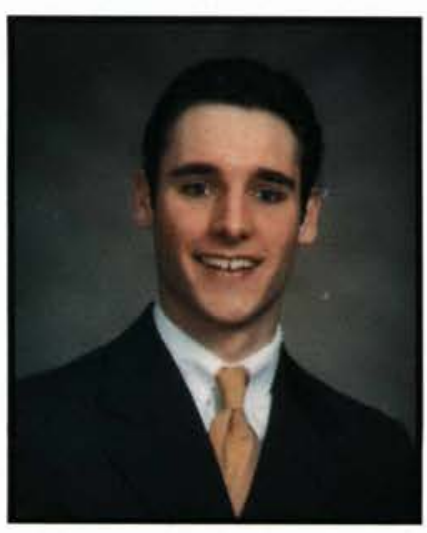

M. Ansion Hanbury Communication Arts

Jacksonville, FL
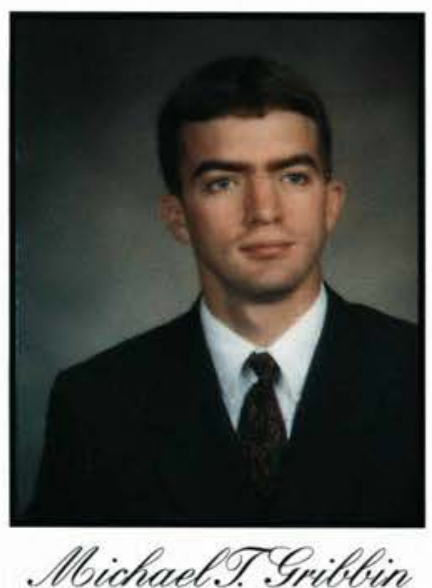

Communication Arts

McKean, PA

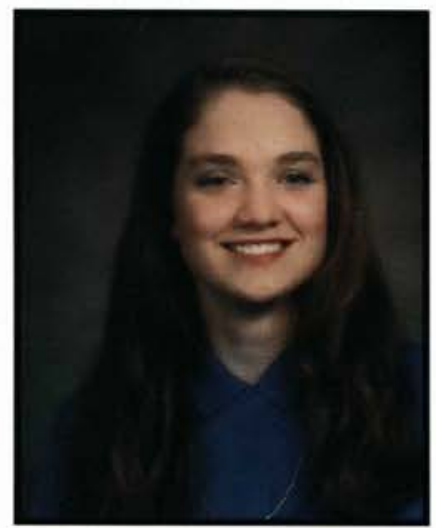

Garolyn. Mb. Suerette Music

North Bath, ME

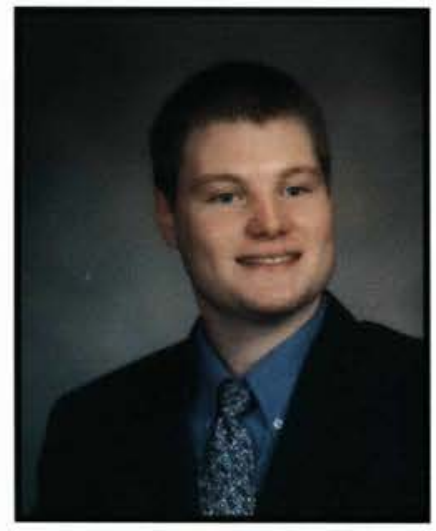

Toshua D. Tbalutha Elementary Education

Ravenna, $\mathrm{OH}$

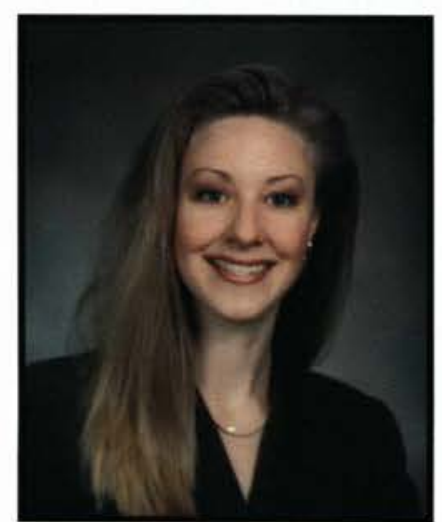

Gennifer L. Hangoily Finance

Chesterland, $\mathrm{OH}$

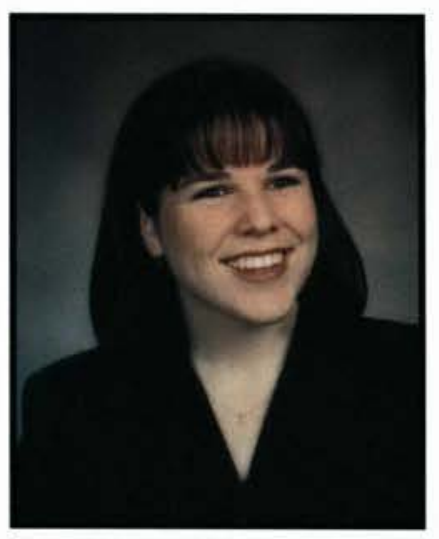

Sara to. Gromtio

Nursing

North Andover, MA
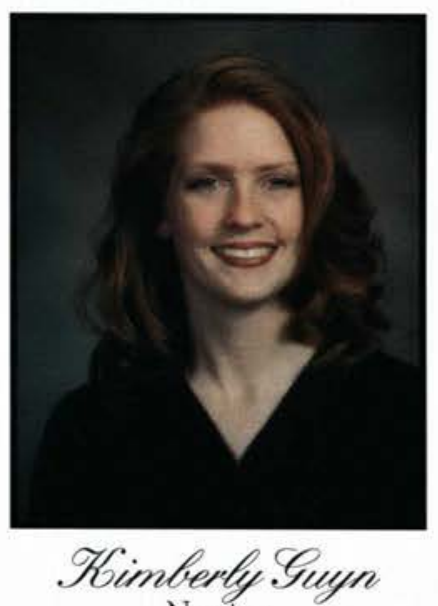

Nursing

Cedarville, $\mathrm{OH}$

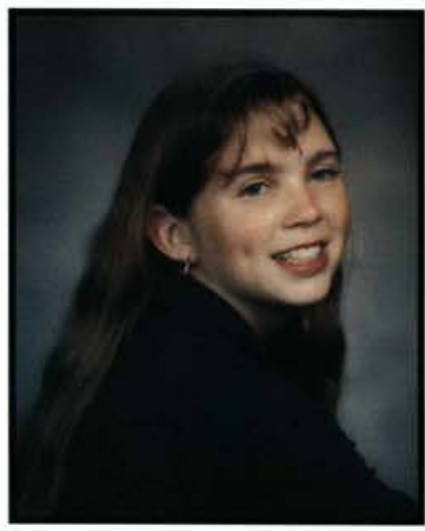

Lori: A. Hamilton

Elementary Education

Winfield, IL

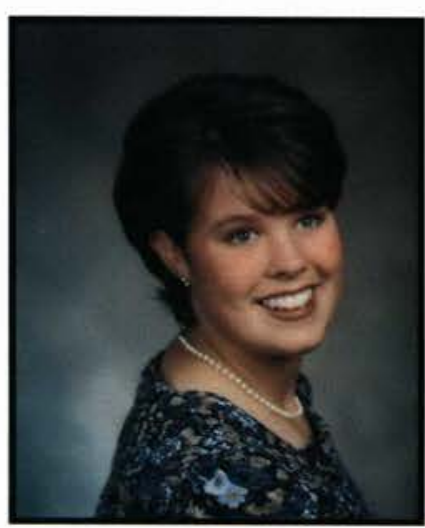

Gara L. Harju

Social Work

Hudsonville, MI

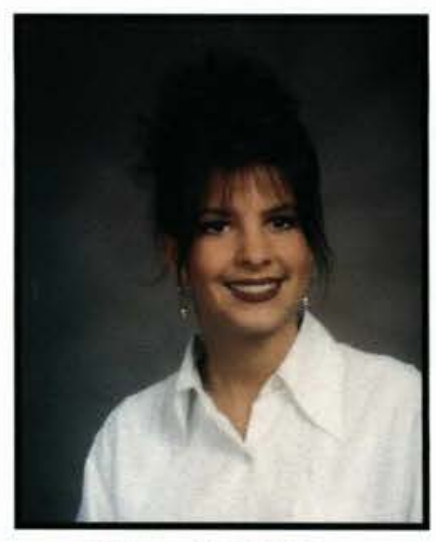

Sarah E. Grov: Nursing

Harrisburg, PA

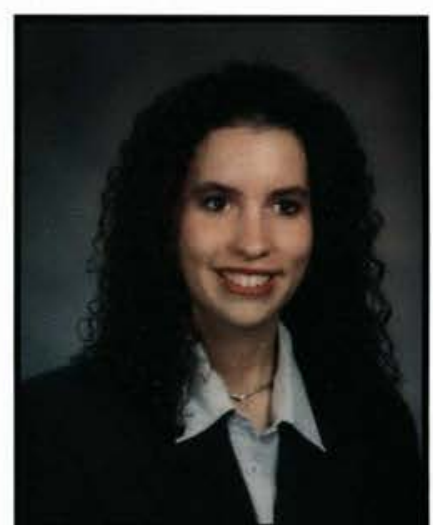

Garrie to. Surilt Biology

Omaha, NE

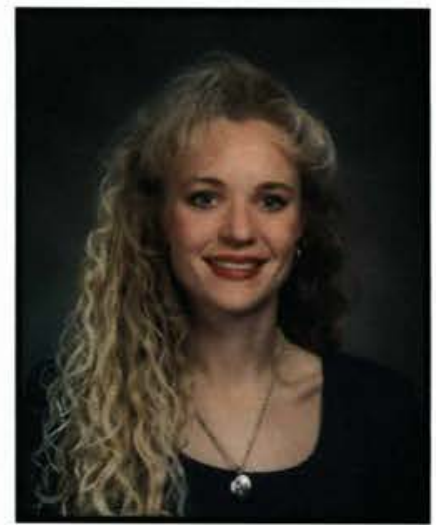

Tiffany A. Tbamilion Elementary Education

Niceville, FL

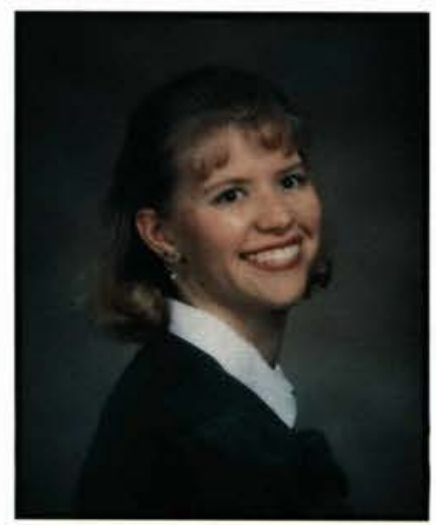

Anna Mb. Hbarlan

Nursing

Wilton, CA 


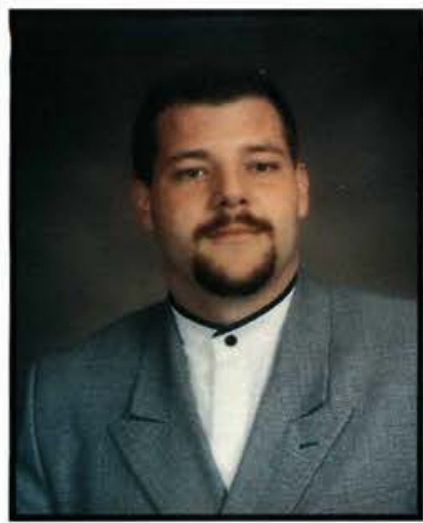

MichaelW. Harsh Computer Information Systems Lakehead, CA

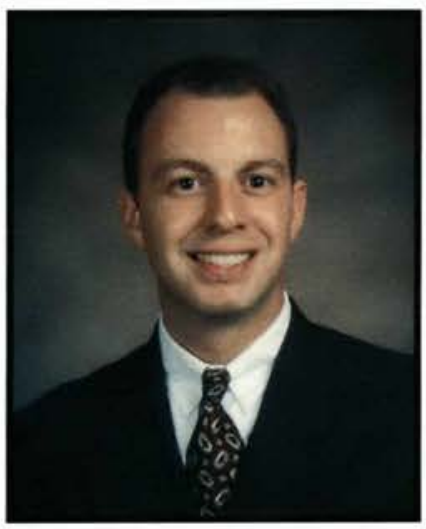

Daniel W. Thich:s

Mechanical Engineering

Cedarville, $\mathrm{OH}$

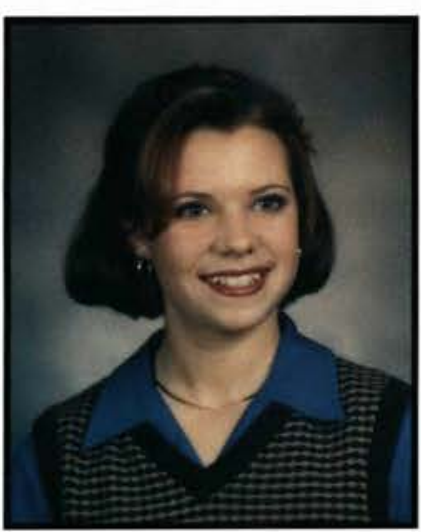

Alicia llb. Tbill

Nursing

New Castle, PA

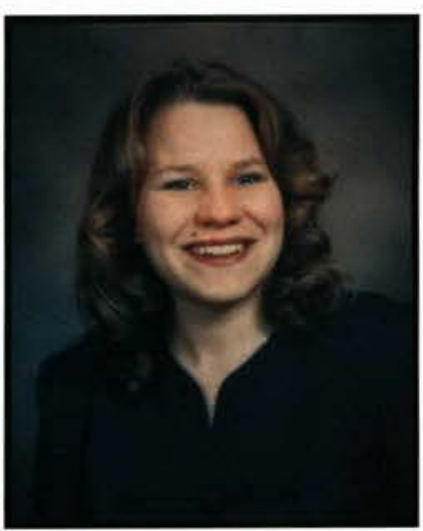

Melis:a L. Hints

Nursing

Delaware, $\mathrm{OH}$
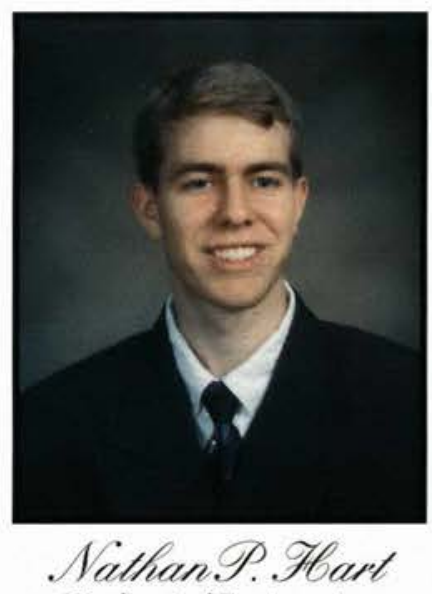

Mechanical Engineering

Lubbock, TX

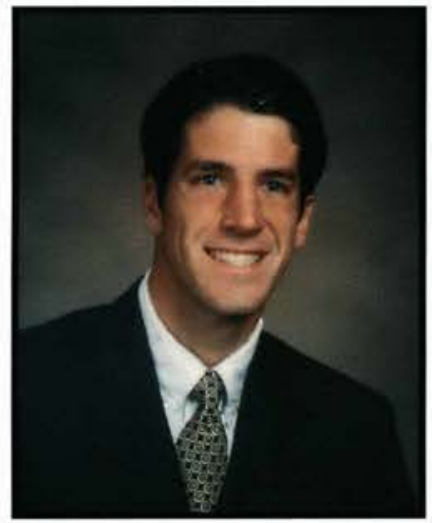

Michael F. Hidalgo Communication Arts

Grand Rapids, MI

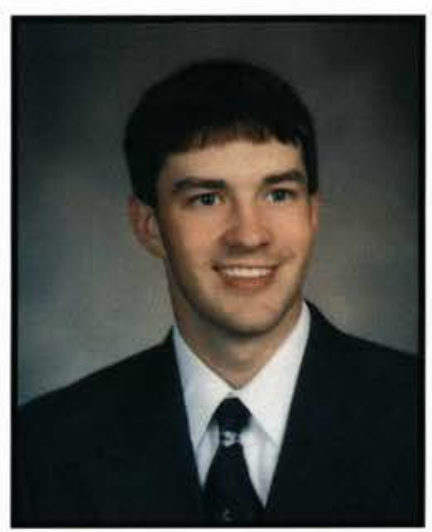

Dustin M. Hbill

Marketing

Cedarville, $\mathrm{OH}$

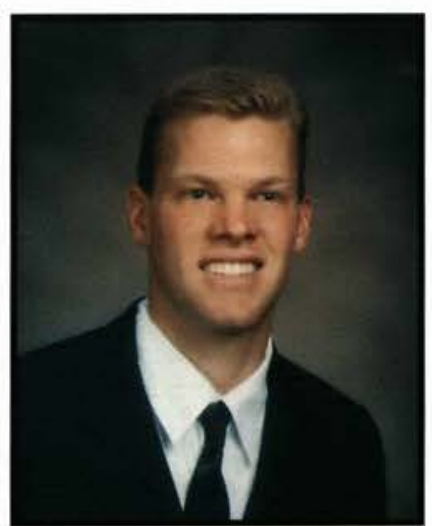

David. F. Hofert

Broadcasting

Apex, NC
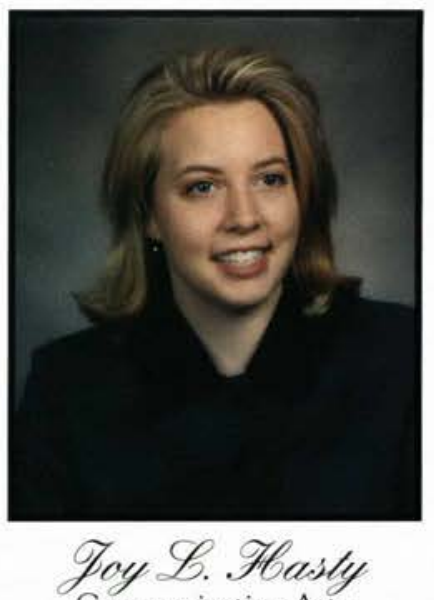

Communication Arts

Shelby, Ml

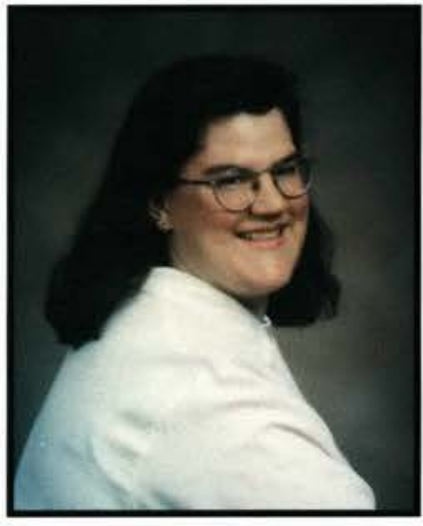

Brooke T. Higqin:

Elementary Education

Wooster, $\mathrm{OH}$

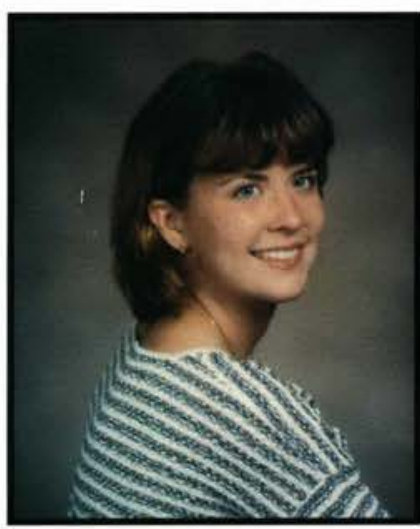

Leqan P. Hbill

English Education

Cedarville, $\mathrm{OH}$

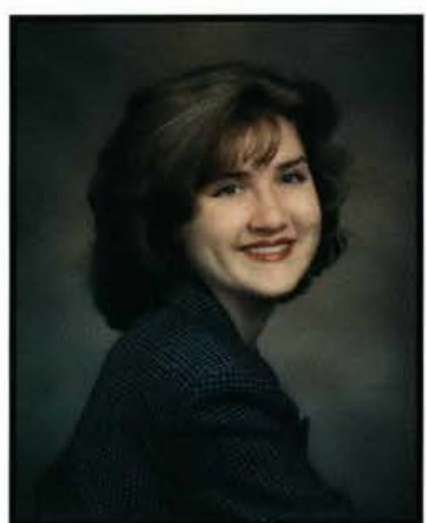

Tulie Tboffman
Psychology

Haddonfield, NJ

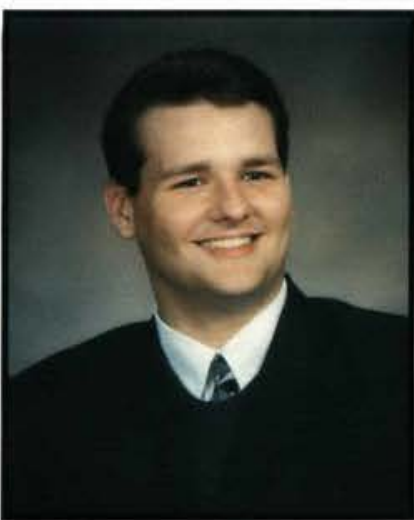

David.F. Helton

Pre-Seminary

Kokomo, IN

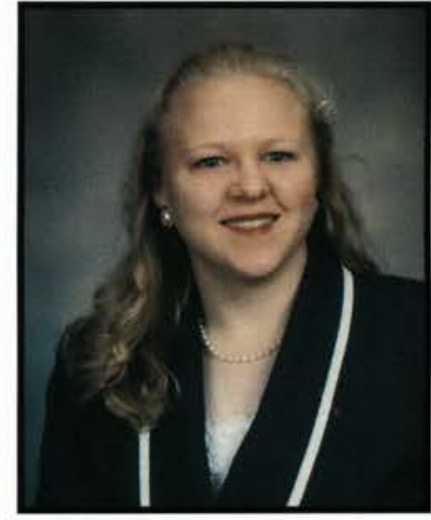

Michelle. H. Higgin: Nursing

East Corinth, ME

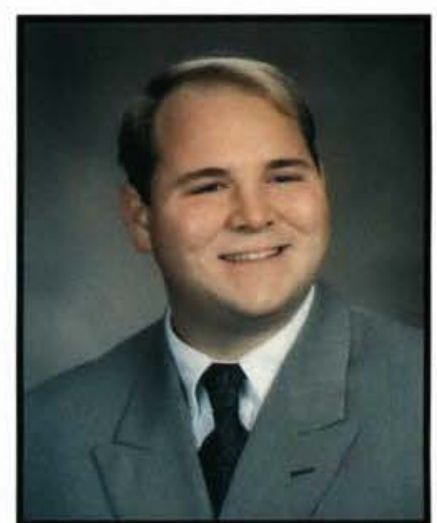

Geoffrey, Ab. Hoiltman Fr.

Accouting/Finance

Ashland, $\mathrm{OH}$

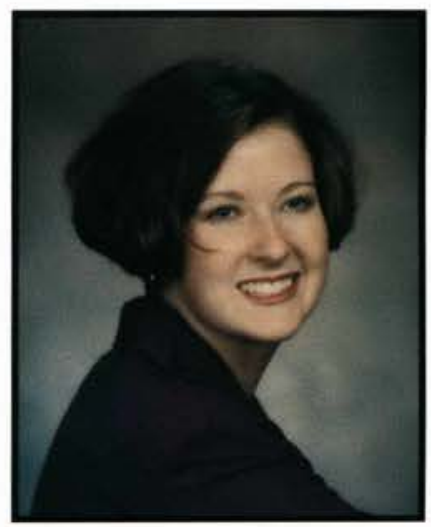

Ghrisly R. Hoover

Elementary Education

Sterlin Heights, MI 


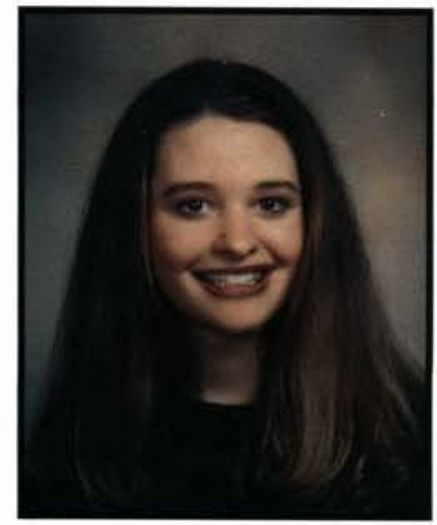

Kelly Ulb. Hopne

Applied Psychology

Muskegon, MI

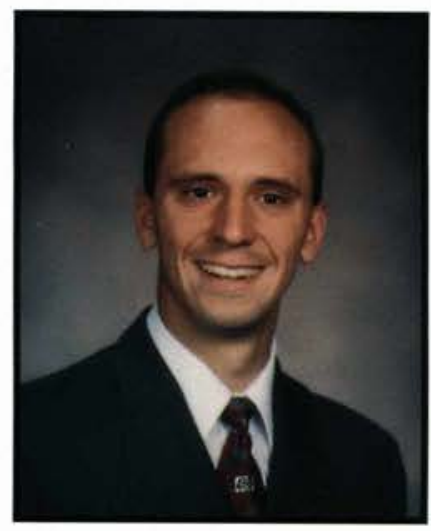

Nathan A. Hout

Mechanical Engineering

Homeworth, $\mathrm{OH}$

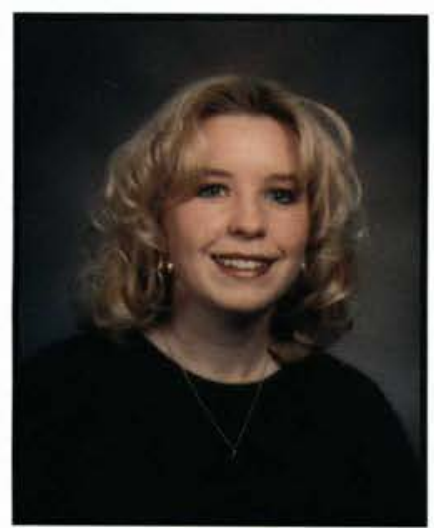

Patricia A. Tbubbard Nursing

Batavia, IL

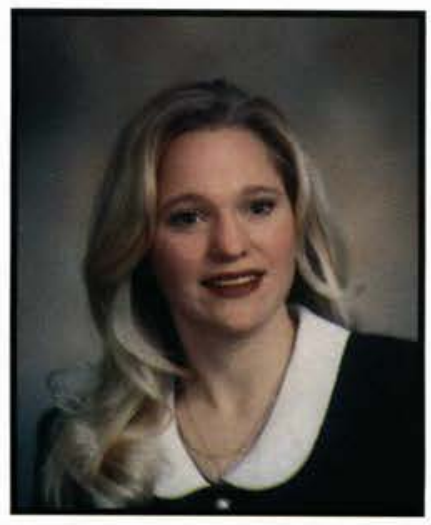

Amy B. Hourel

Nursing

Painesville, $\mathrm{OH}$
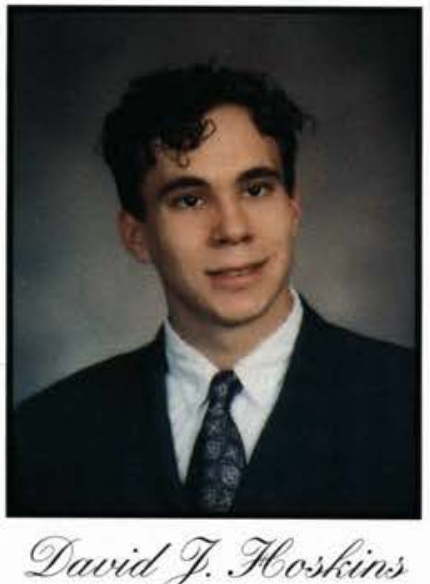

Marketing

Payson, IL
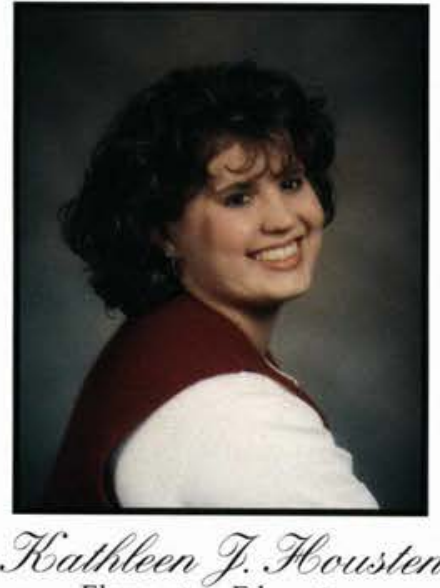

Elementary Education

Bound Brook, NJ

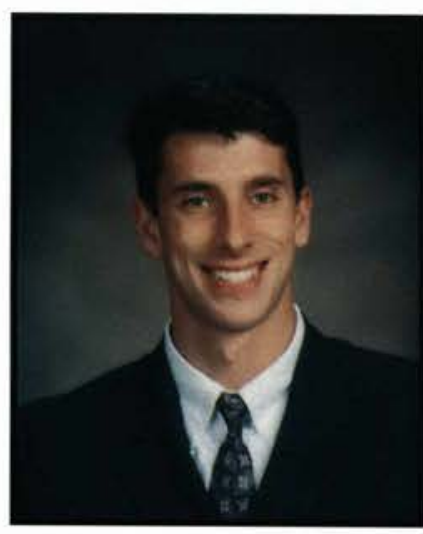

Daniel F. Houdion

Biology

Rudyard, MI

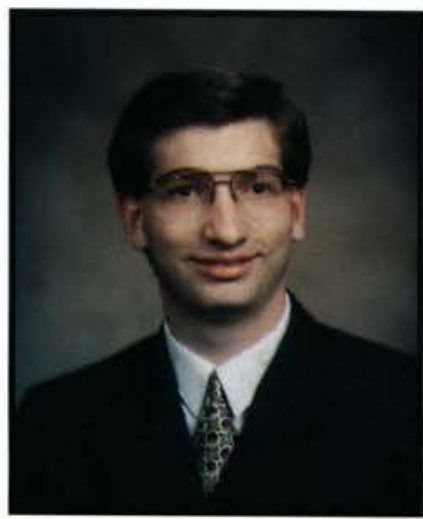

Fooll R. Hbustrand Management

Greensburg, PA

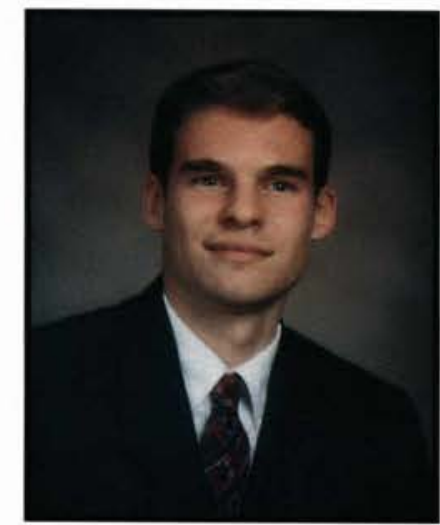

Timothy L. Hodchliciss

Professional Writing

Northfield, $\mathrm{OH}$

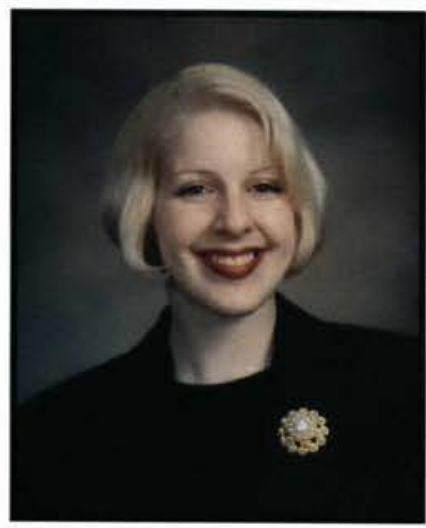

Fody. 1. Hovis Music

Goodrich, MI

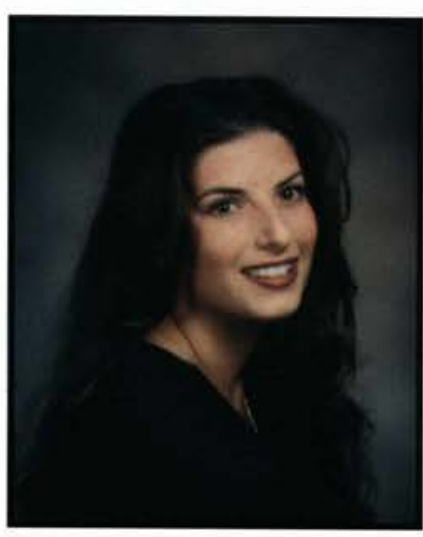

Taterie Tbuggter

Elementary Education

Otisville, MI

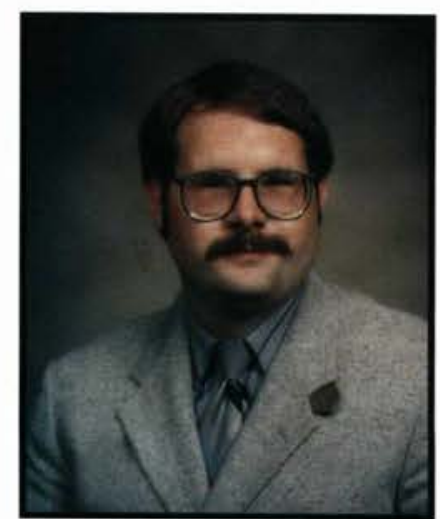

Garon R. Hutchicon Chemistry

Albany, $\mathrm{OH}$
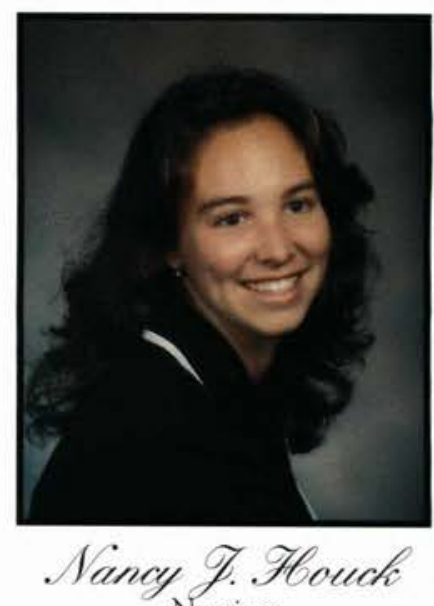

Cortland, $\mathrm{OH}$

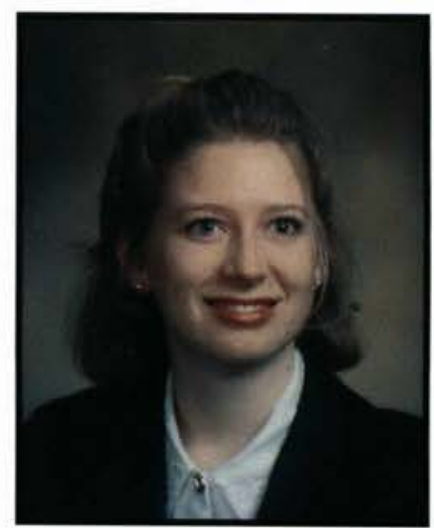

Abigail. R. Howe

Elementary Education

Indianapolis, IN
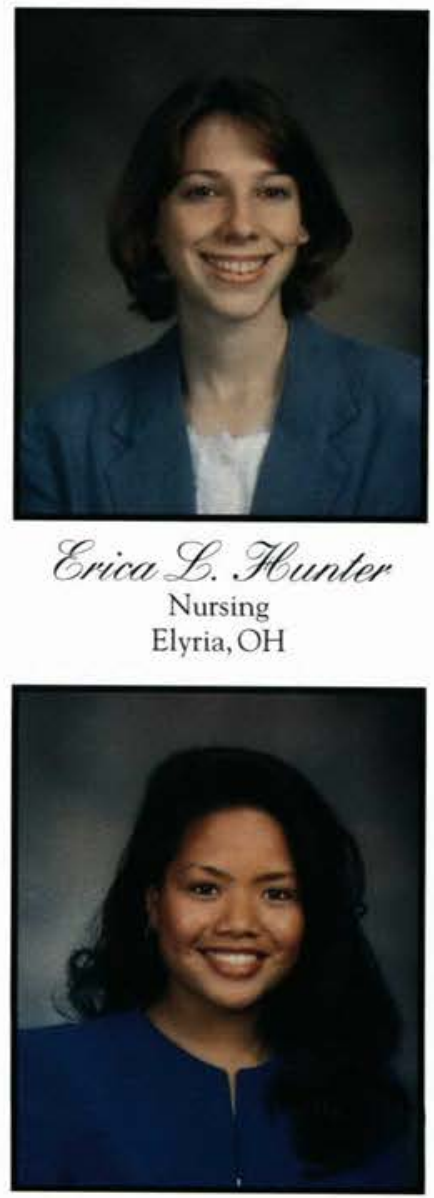

Prenda G. Tnion

Nursing

West Chester, PA 


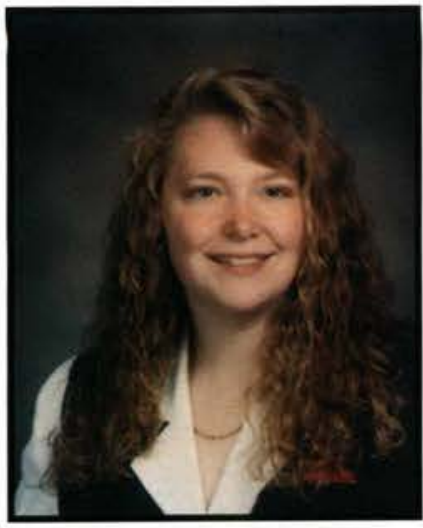

Becky Mb. Twey

Nursing/Chemistry

Bartlett, IL

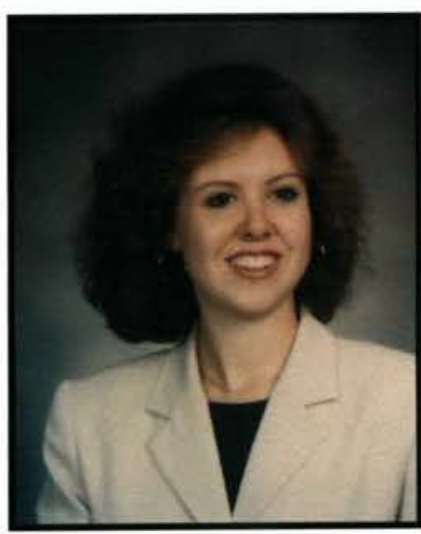

Erin R. Fohn:

CIS/Accounting

Phillipsburg,NJ
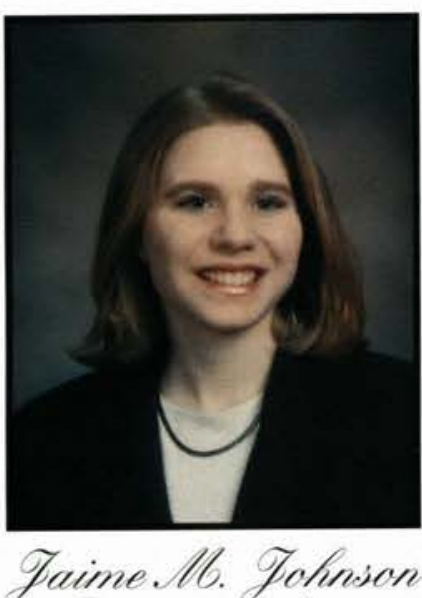

Communication Arts

Barre, VT

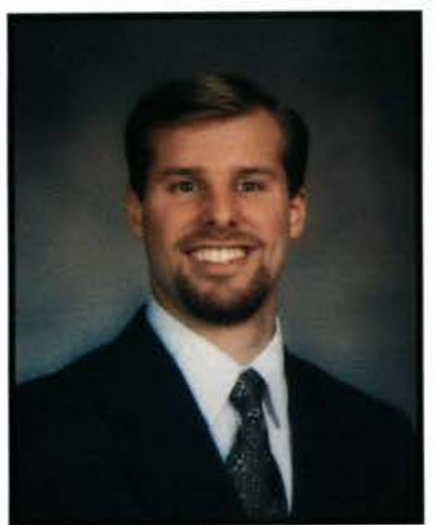

David. A. Fone:

Accounting/Finance

Reading, PA

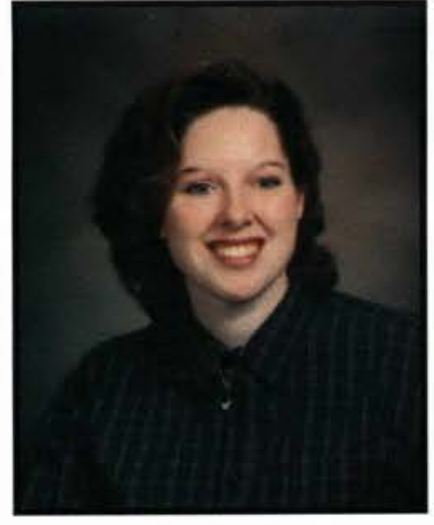

Ruth. A. Fachion

Elementary Education

Monmouth Junction, NJ

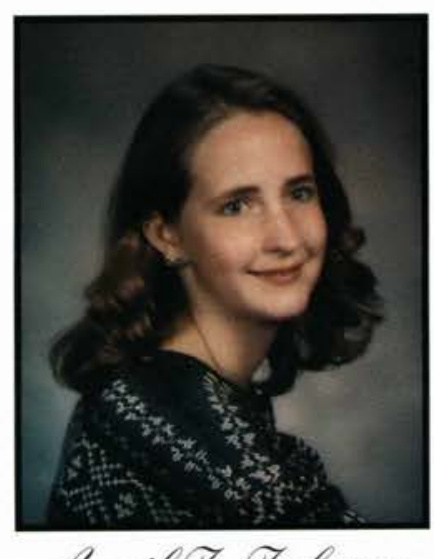

April Jiolohyion

Biology

Wheaton, IL
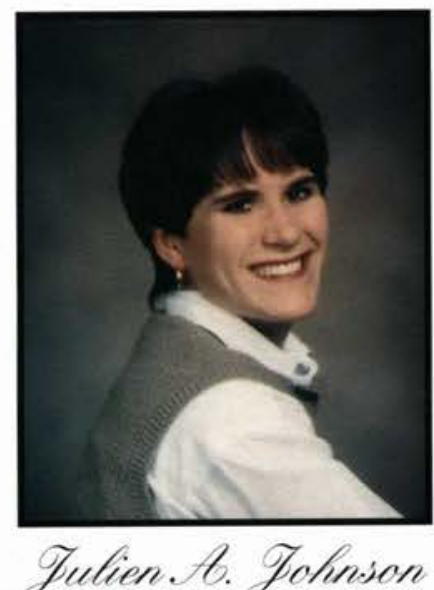

Comprehensive Physical Education McClure, $\mathrm{OH}$

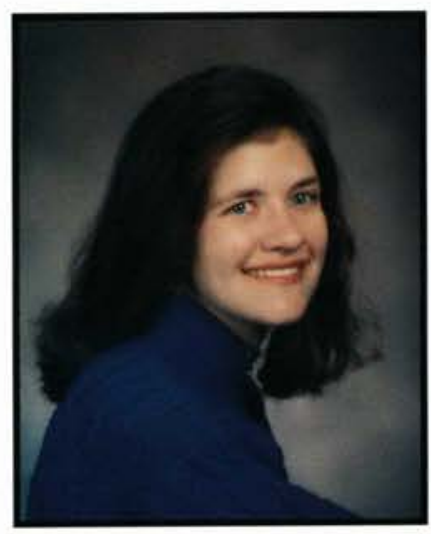

Futic. A. Fonesstra

Accounting/Finance

North Royalton, $\mathrm{OH}$

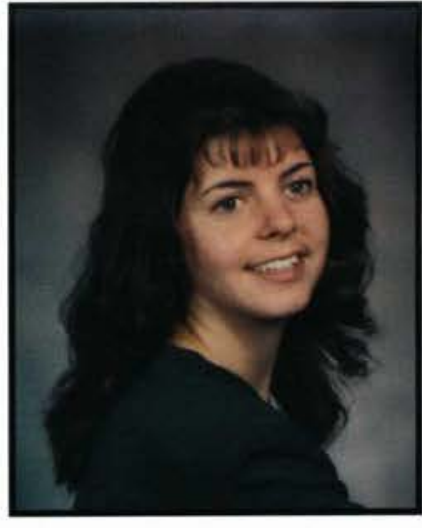

Rebecar F. Fentis

Bible Comprehensive

Danville, VT
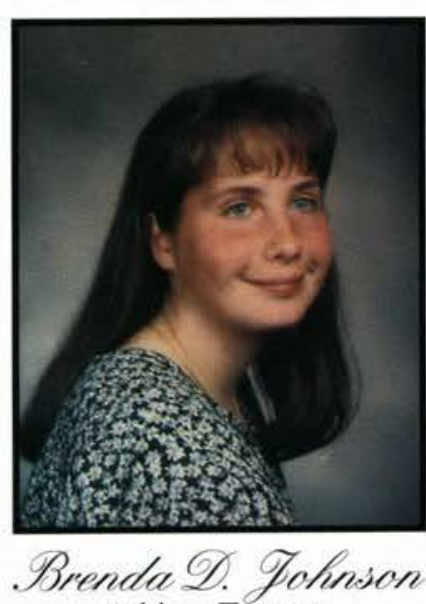

Athletic Training

Greenville, PA

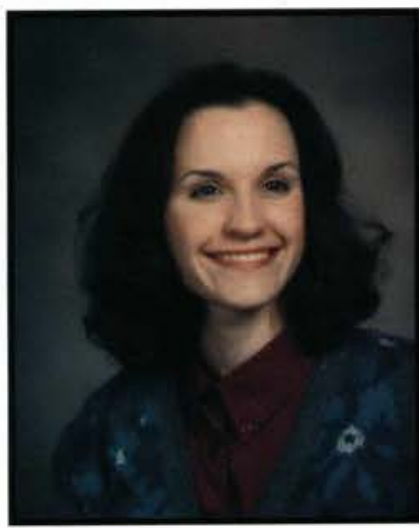

Bebeca F. Fohnion Social Work

Centerville, VA

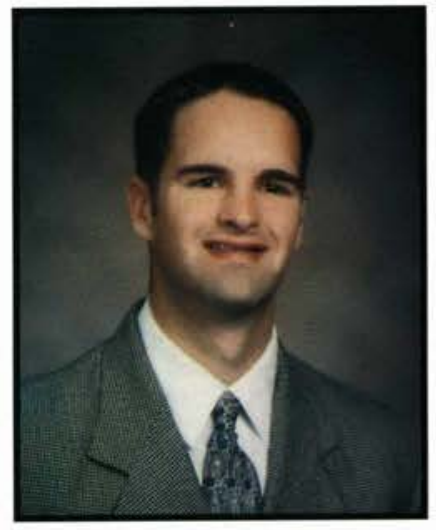

Daniel. Kaynor

Finance/Accounting Waterloo, IA

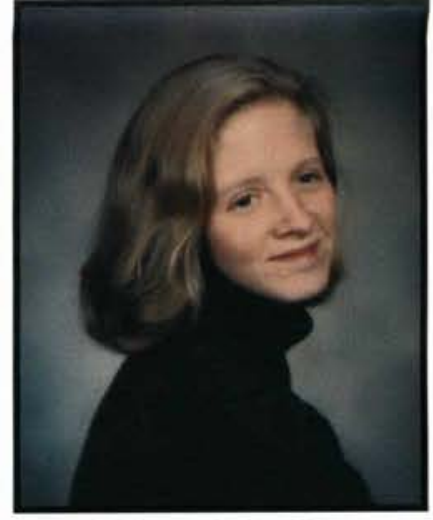

Haxy L. Fex

Elementary Education

North Berwick, ME

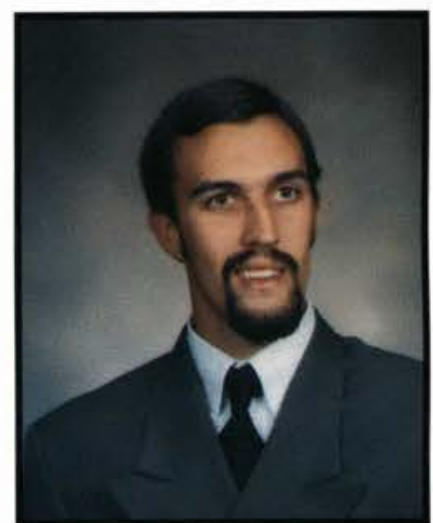

Gregory llb. Gohnion Elementary Education Lapeer, MI

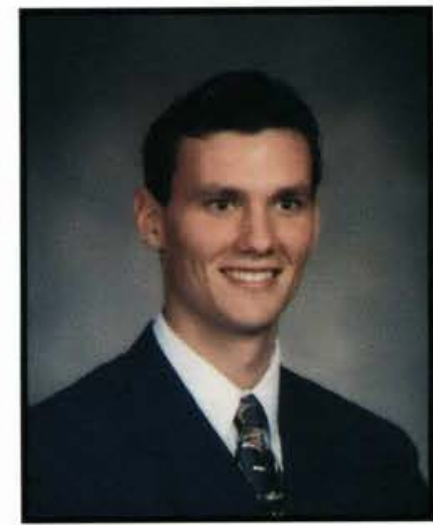

Fodd D. Fohnion Chemistry

Dennison, $\mathrm{OH}$

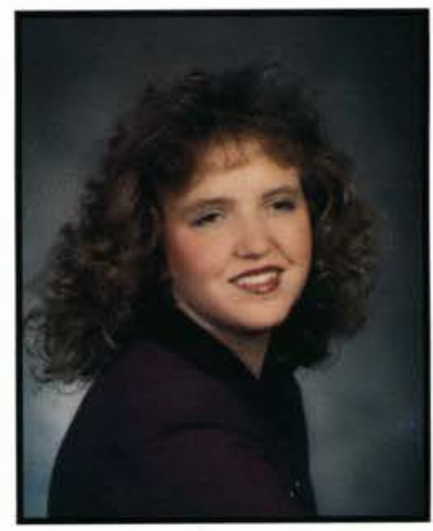

Cori: A. Kenny

Marketing

Cedarville, $\mathrm{OH}$ 


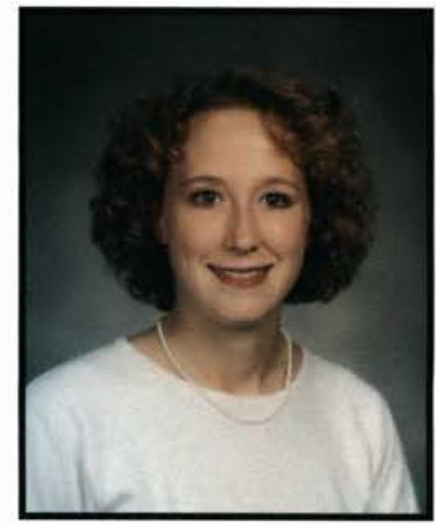

Tennifer R. Kerr Social Work

Burton, MI

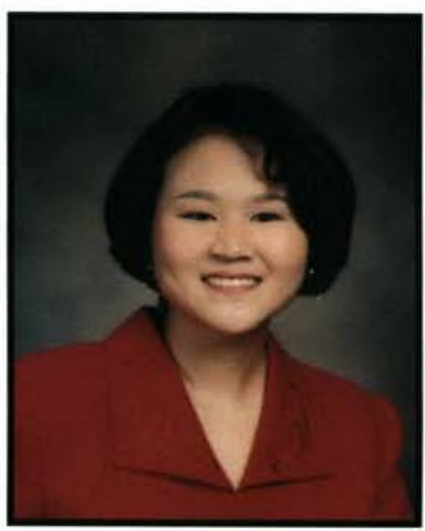

Bachel KF. Finight

Political Science

Bay City, MI

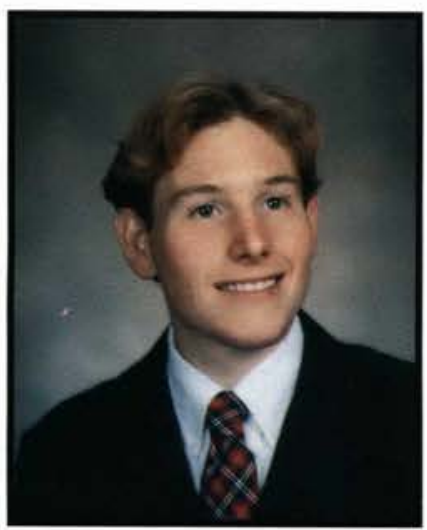

Scoll Ml. Troxial

Electrical Engineering Adel, IA

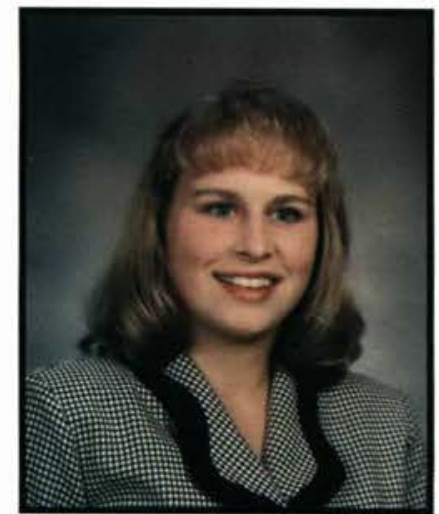

Gena M. Samoreaux Nursing

Greenwich, $\mathrm{OH}$
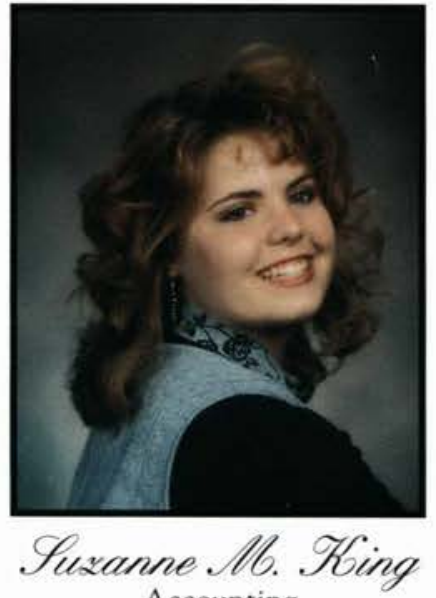

Accounting

Cable, $\mathrm{OH}$

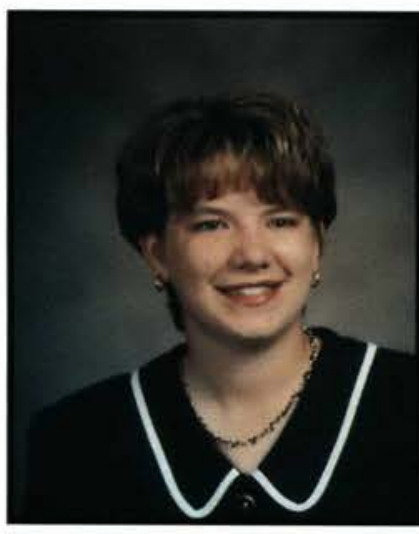

Ann Mlb. Kobliela

Nursing

Garrett, IN

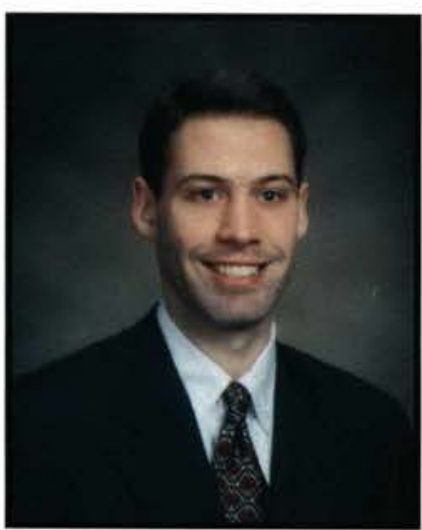

Godam Wade Krampe

Mechanical Engineering

Grand Rapids, MI

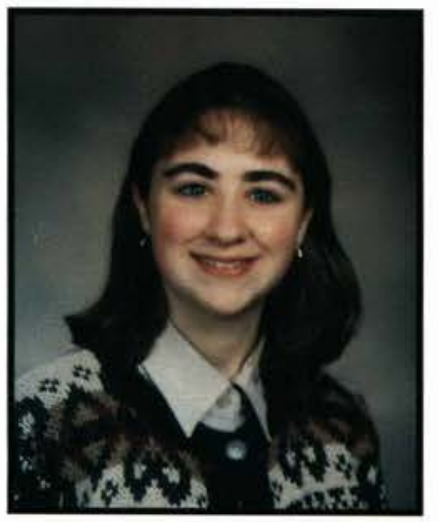

Anna R. Lanthorst

English Education

Concord, $\mathrm{NH}$

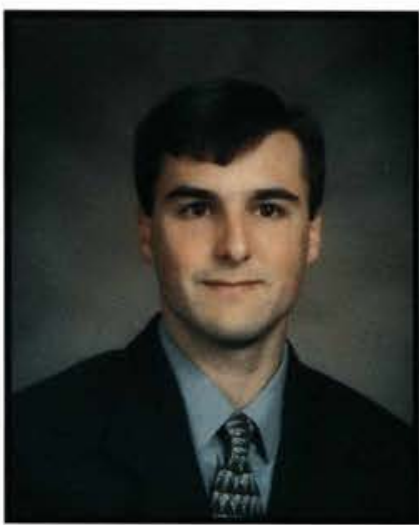

Brian S. Kolatring

Finance/Accouting/Marketing

Annapolis, MD

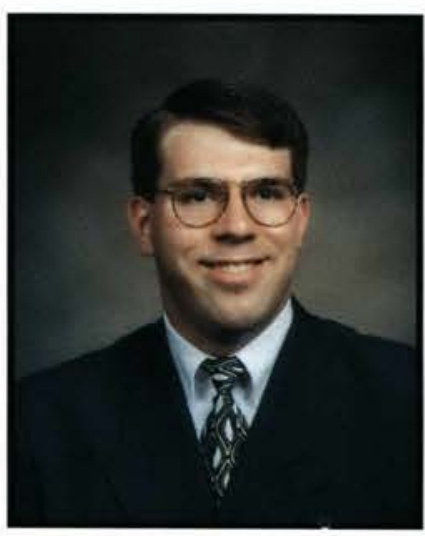

Paul G. Koopp

Accounting

Clark Summit, PA

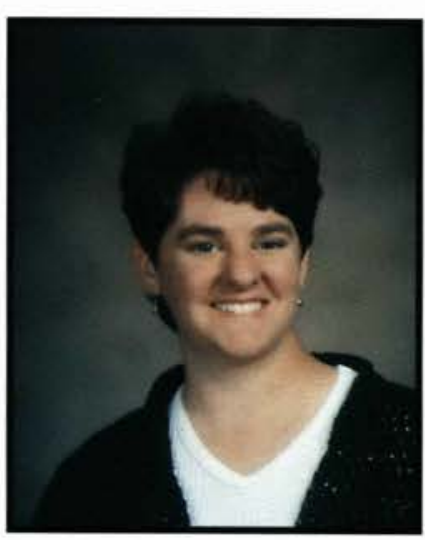

Michelle.R. Labos.

English Education Laurel, DE

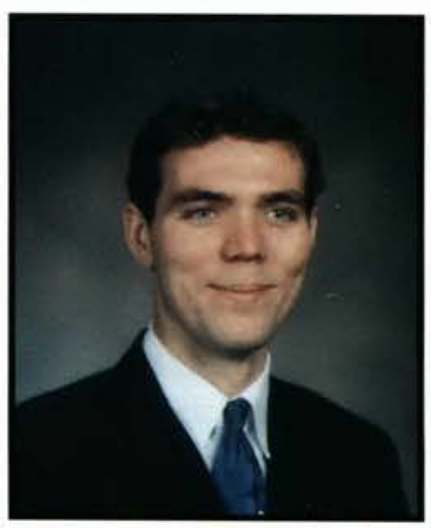

Chad E. Larr

Criminal Justice

Springfield, $\mathrm{OH}$

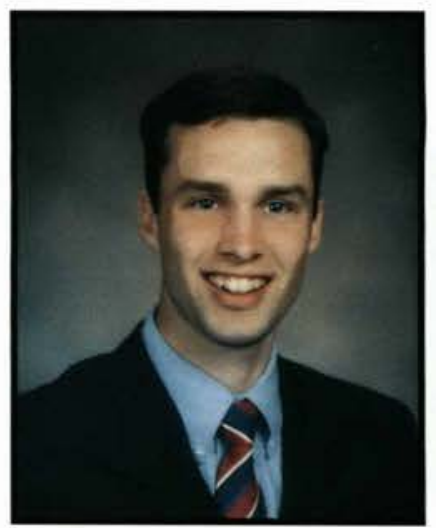

Stephen E. Koline

Elementary Education

Danville, VA

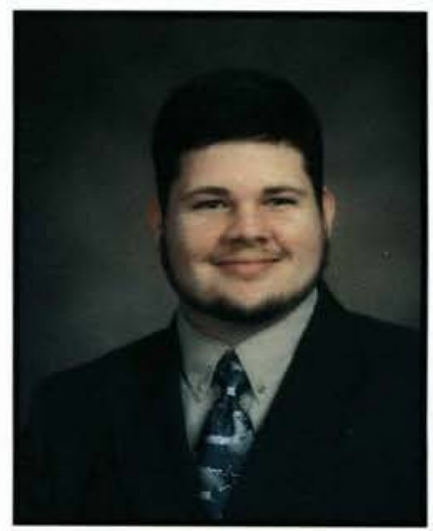

Bobert A. Kouba

Broadcasting

Stow, $\mathrm{OH}$

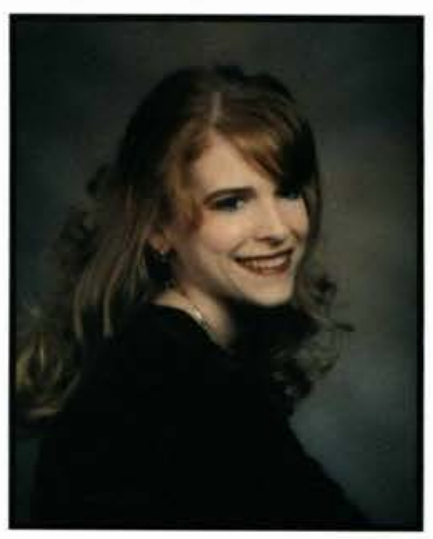

Bebecca L. Laties

Music/Music Education Springfield, $\mathrm{OH}$

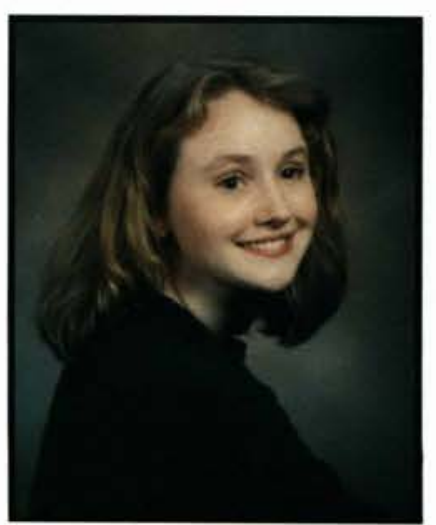

Daime R. Larion Nursing

Burke, VA 

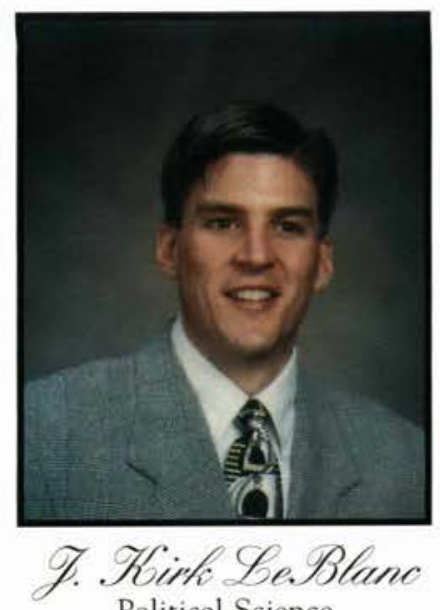

Political Science

Jamestown, $\mathrm{OH}$

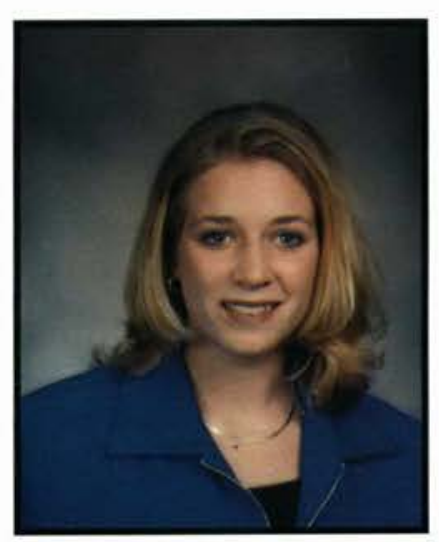

- bngela R. Bentiart

Professional Writing

Grand Blanc, MI

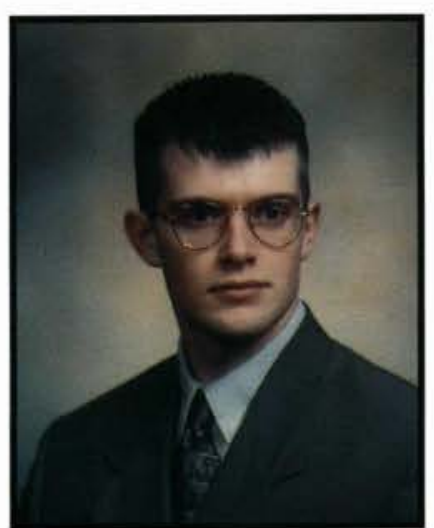

David E. Sinn

Marketing

North Canton, $\mathrm{OH}$

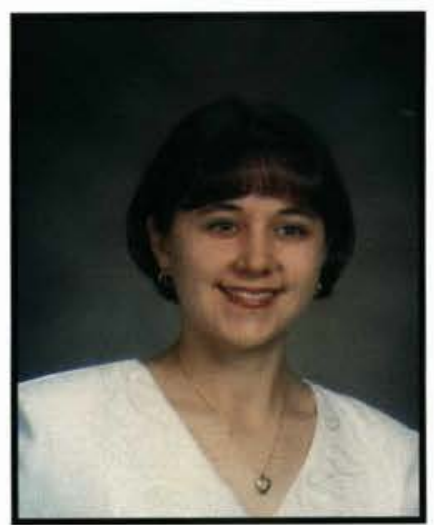

Sarah Ab. Lutie

Nursing

Algonquin, IL

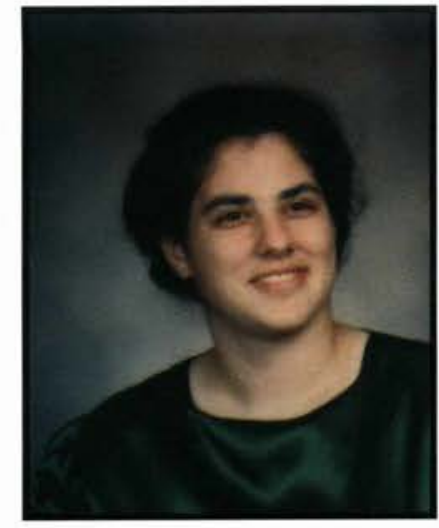

- lbina D. Letiman Social Work

Arcanum, $\mathrm{OH}$

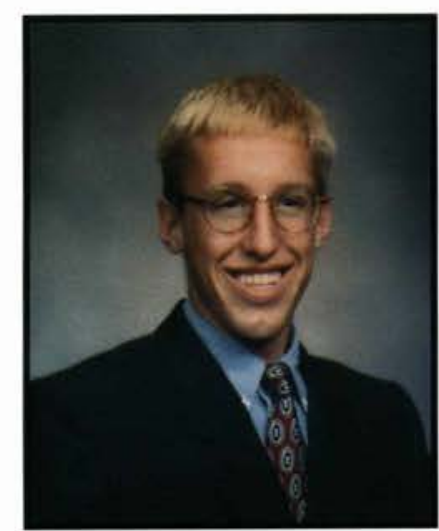

Ghristopher. P. Geverette Elementary Education Dayton, $\mathrm{OH}$

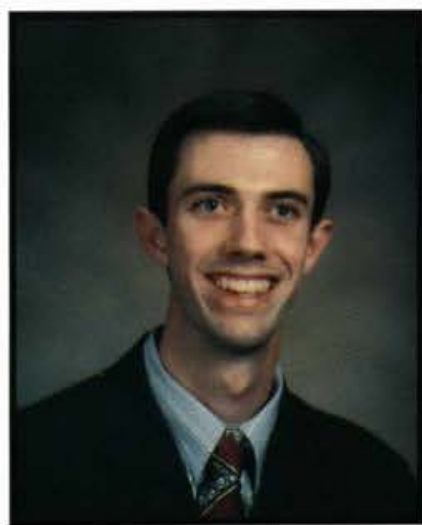

Foseph. A. Lloyd

Pre-Seminary

Elkhart, IN

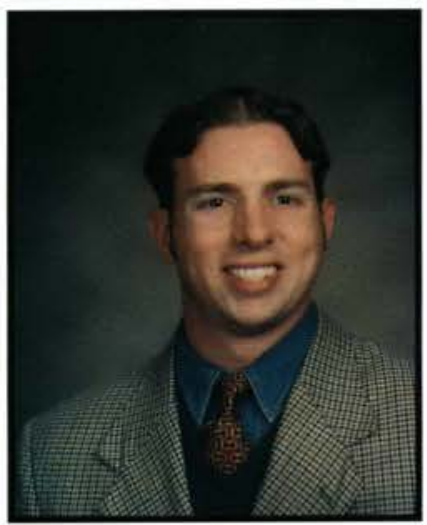

Toshua R. Lunney Math Clio, MI

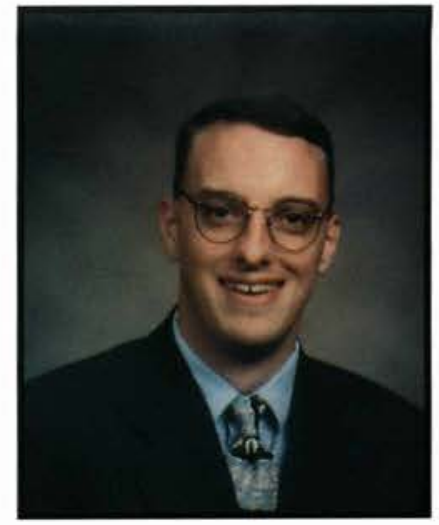

Thomas; Deightentreimer Bible Comprehensive

Cedarville, $\mathrm{OH}$

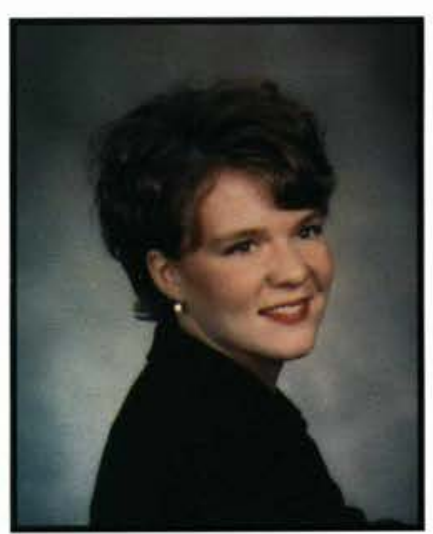

Surah Il. Sightly

Music/Bible Comprehensive

Blooming Prairie, MN

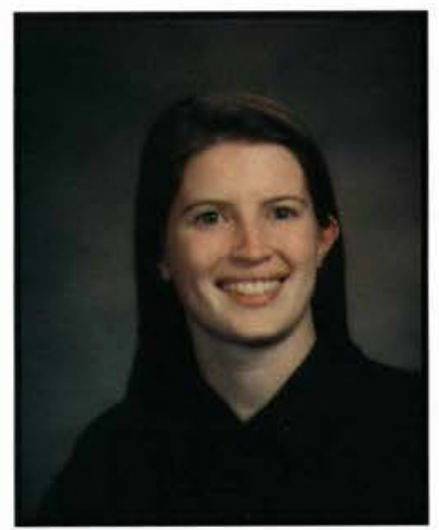

Melisisa. S. Dorinovich

Elementary Education

Montpelier, VT

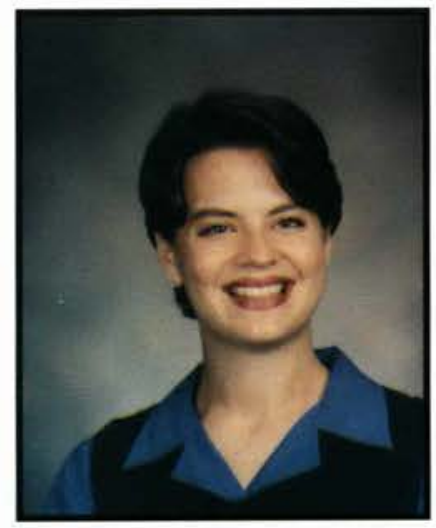

Fennifer OF. Lulz

Communication Arts

Orlando, FL

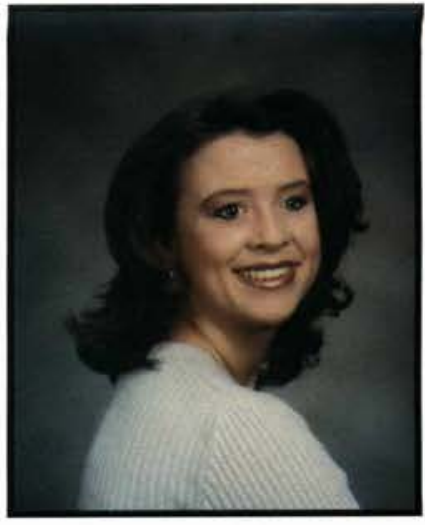

Todi: B. Leinbach Nursing

Indianapolis, IN

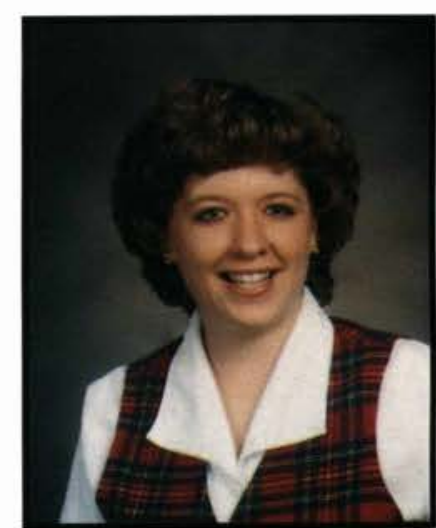

Karrisa R. Linafelter

Management

Fairbault, MN

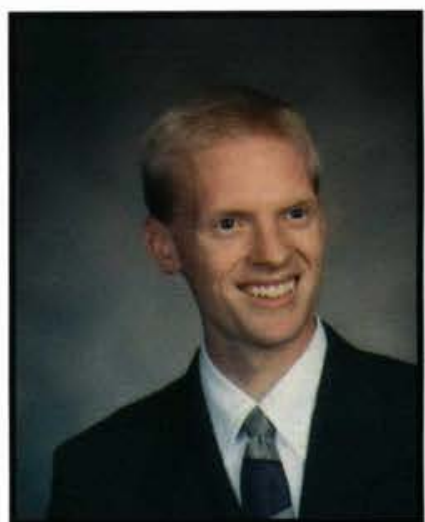

Derel WT. Duke

Criminal Justice

Algonquin, IL

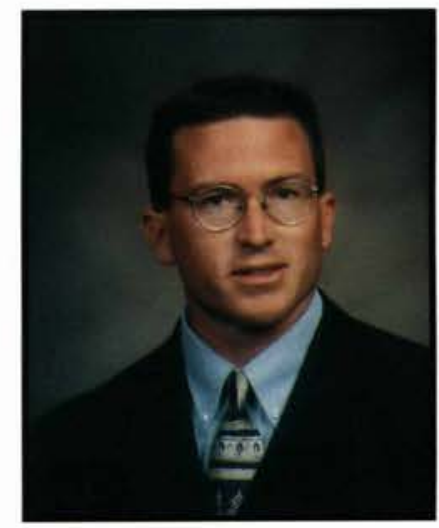

Garon Mb. Gynn History/Social Science Springfield, $\mathrm{OH}$ 


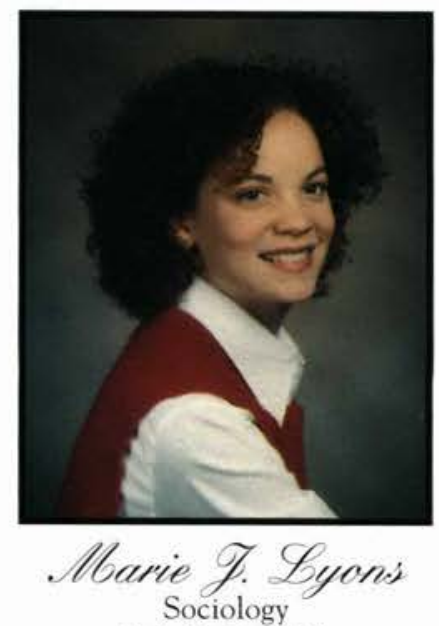

Palo Cedro, CA

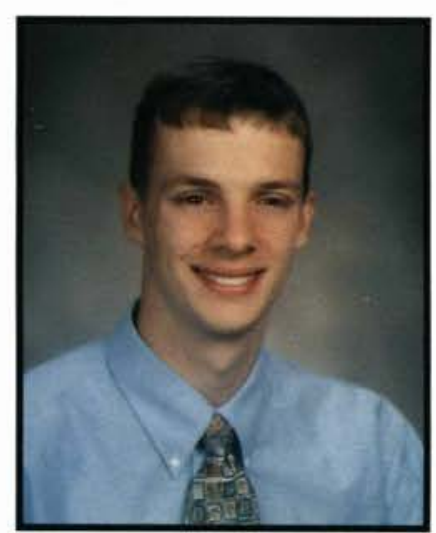

Michael. S. Lann

Mechanical Engineering

Kalamazoo, MI

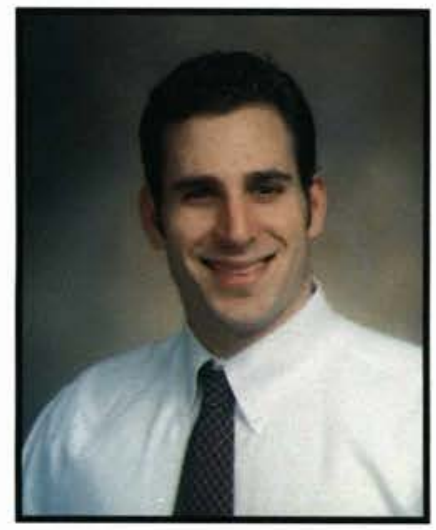

Neil F. Masiai

Elementary Education

Vernon, CT

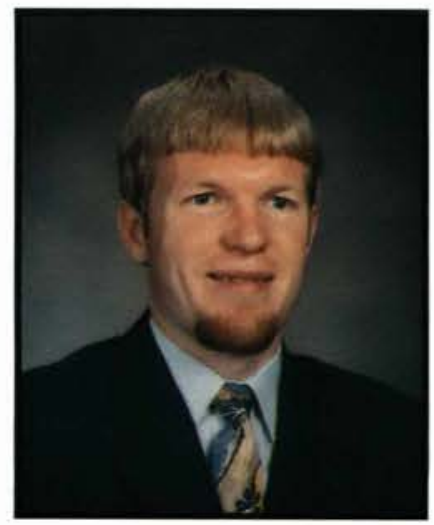

Date Nb. Nbobrory

Multimedia Technology

Palos Hills, IL

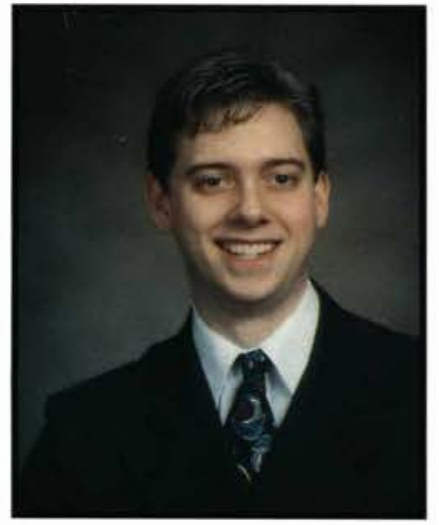

Graig Nb. Magrum

Broadcasting

Oregon, $\mathrm{OH}$

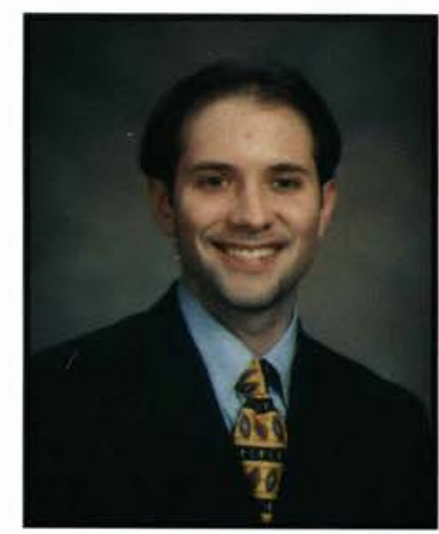

Nicholas. A. Mariana II

Elementary Education

Oregon, $\mathrm{OH}$

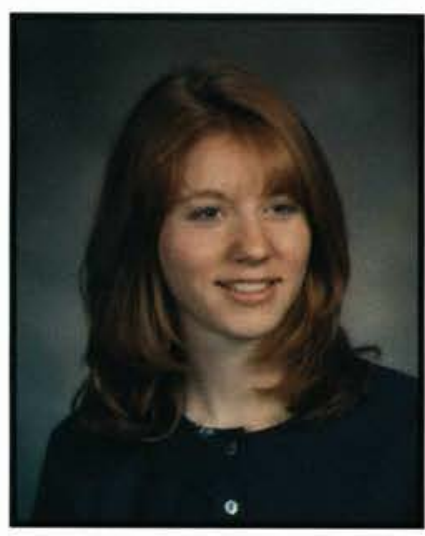

Tamara L. Matula

Elementary Education

Lagrange, ME

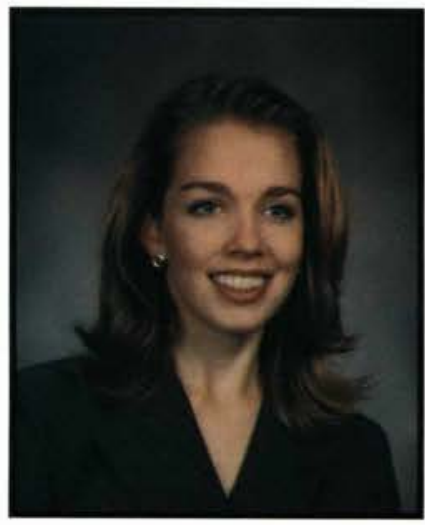

Moel. ll. WoDermill

Communication Arts

Olney, MD

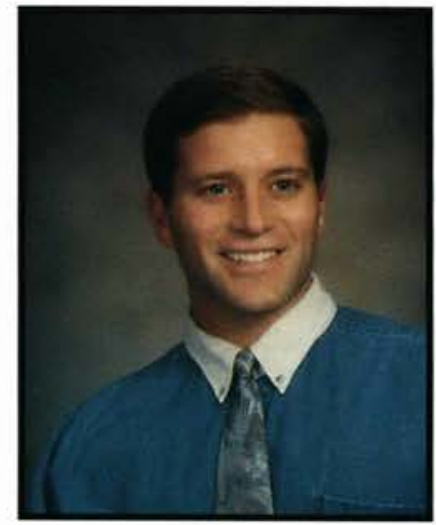

- tondrew L. Matone Elementary Education

Spring Valley, MN

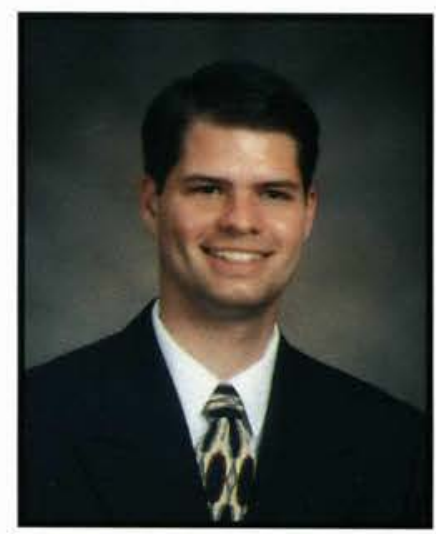

Andrem.T. Darshall Psychology

Center Point, IN

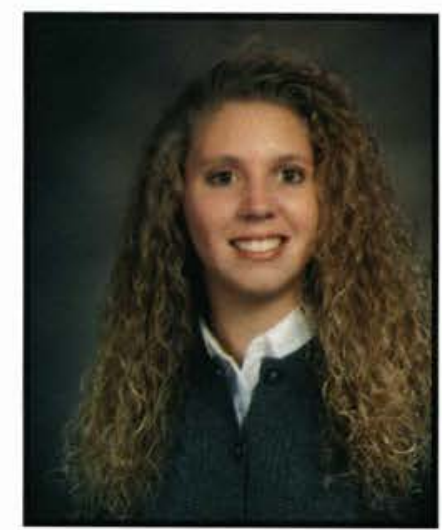

Kimberly t. Maunard

Biology

Phoenix, AZ

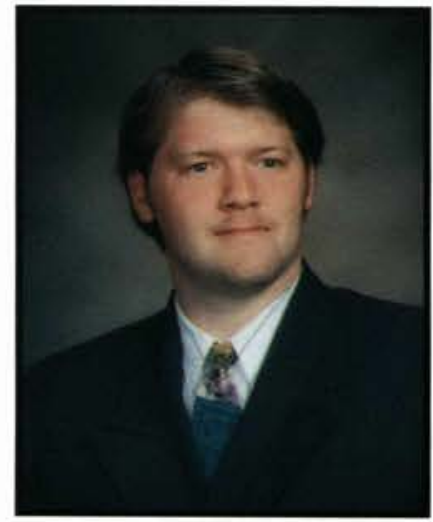

Roberl.T. NocDale

Pre-Seminary

Cedarville, $\mathrm{OH}$

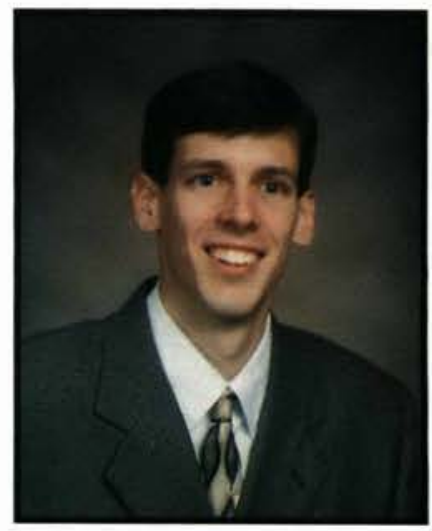

Taion. A. Walone

Bible Comprehensive

Spartanburg, SC

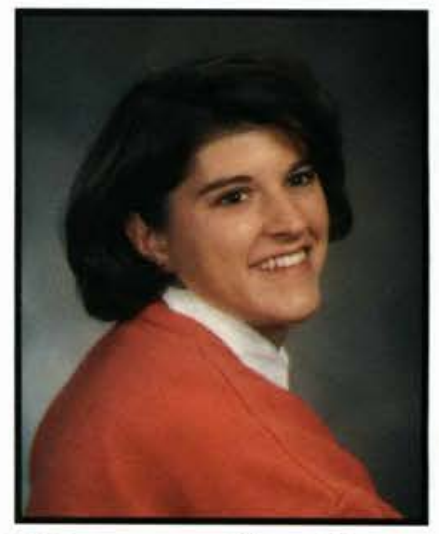

Ghristine Nb. Martin

Elementary Education Mill Hall, PA

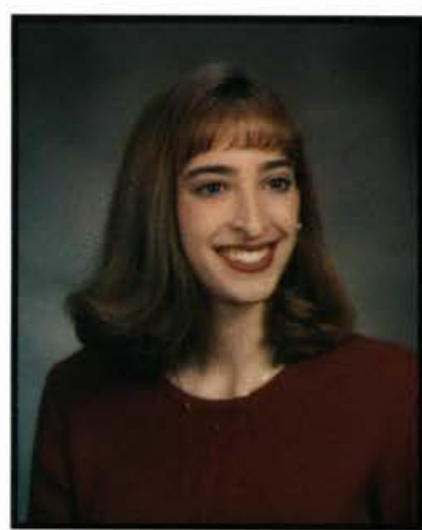

Tulie L. Lboboy

Elementary Education Clarkston, $\mathrm{Ml}$

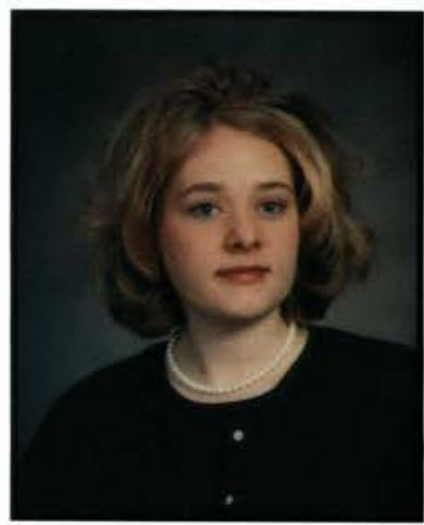

Tirginia R. MoWole Spanish

Cedarville, $\mathrm{OH}$ 


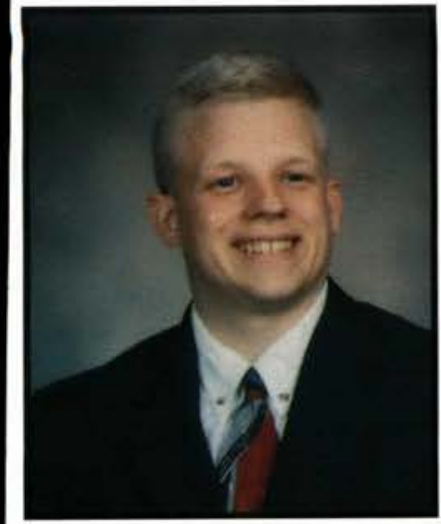

Peter WT. Ma Leod Broadcasting

Harrisburg, PA

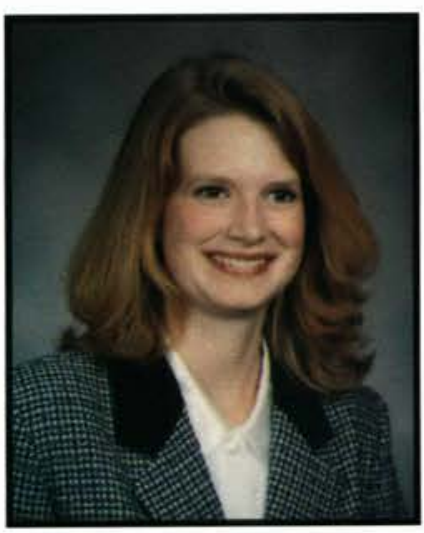

Emily O. Weetis:

Trotwood, $\mathrm{OH}$

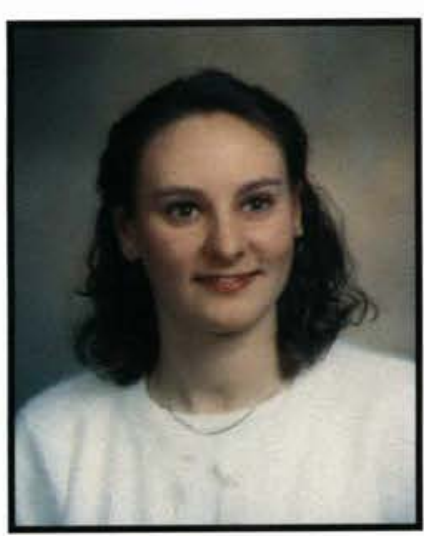

Tammy Mb. Michaels

Elementary Education McHenry, IL

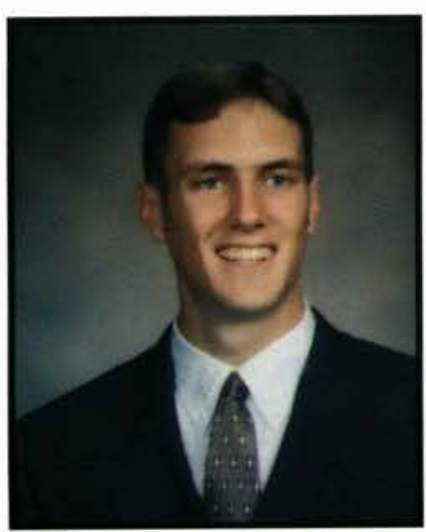

Brent D. Willer

Pre-Seminary/History

Canton, MI

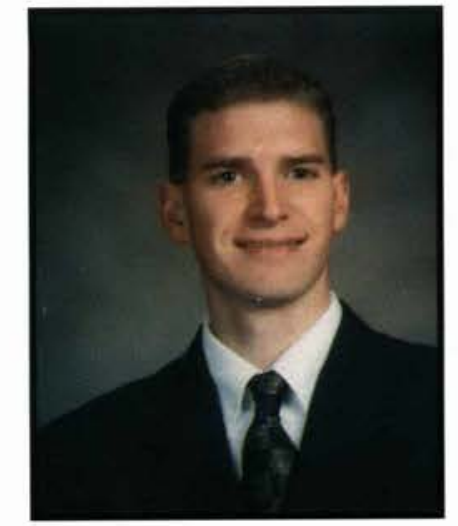

David. A. MaPhersion Criminal Justice

Oroville, CA

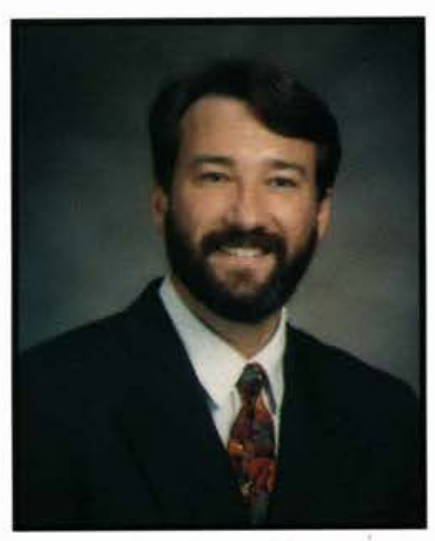

Steven P. Merchant

Bible Comprehensive

Centerville, $\mathrm{OH}$

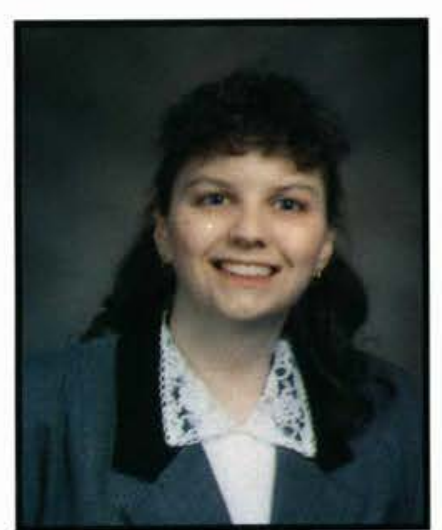

Garin E. Michatestivi

Elementary Education

Hagerstown, MD

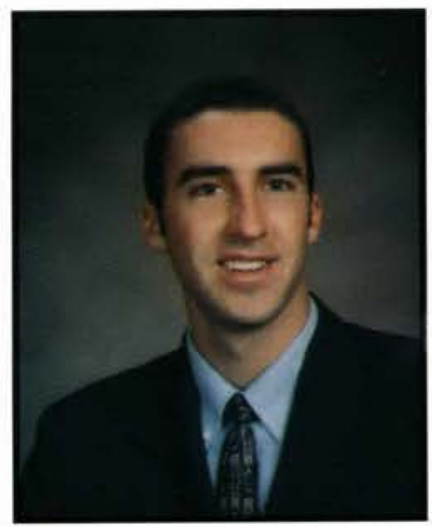

Pryan G. Diller Bible Comprehensive

Sioux Falls, SD

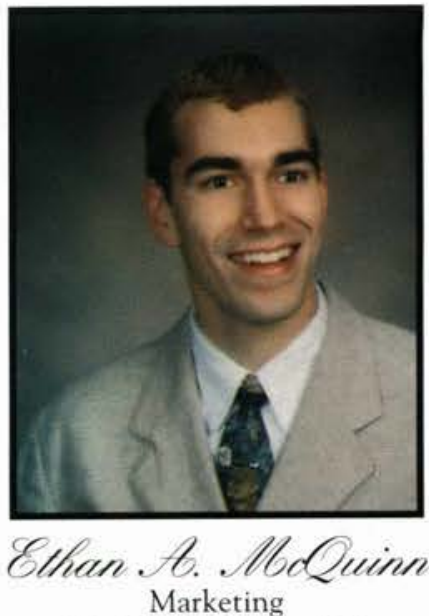

Highlands Ranch, CO

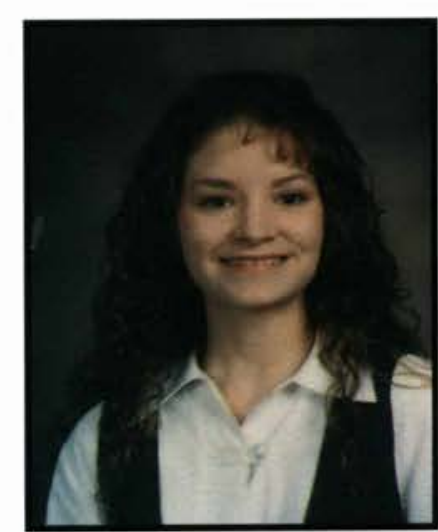

Angela A. Meredith

Elementary Education

Snover, MI

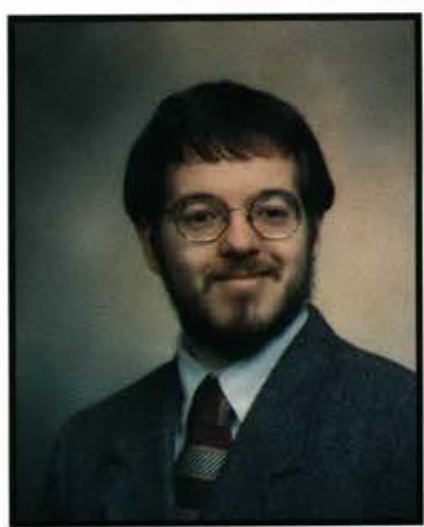

Teffrey S. Wick

Computer Information Systems

Cedarville, $\mathrm{OH}$

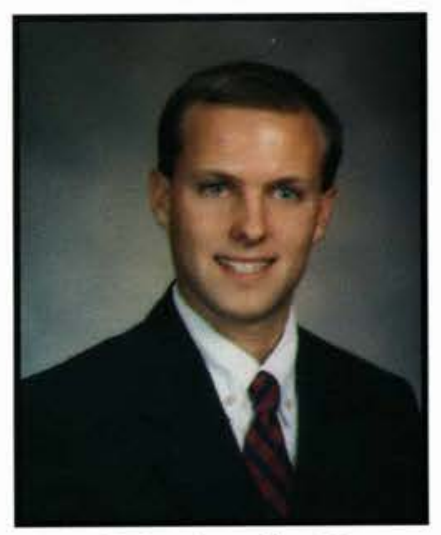

Toyle Wbiller

Management

Cedarville, $\mathrm{OH}$

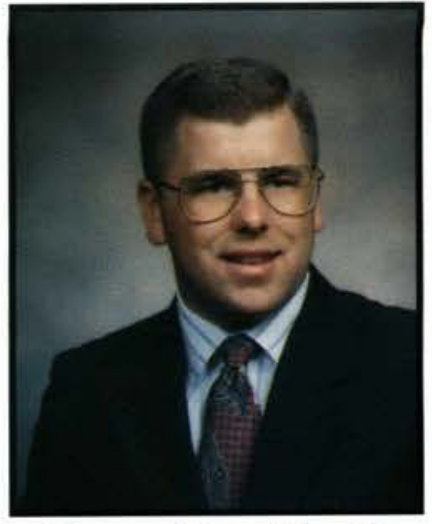

David E. Wbectley

Political Science

Clayton, MI

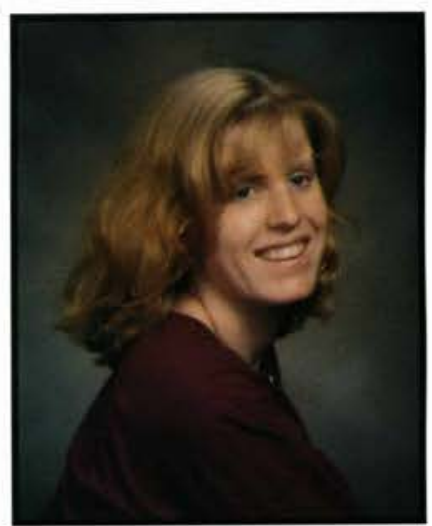

Angela F. Leyer:

Elementary Education

Belding, Ml

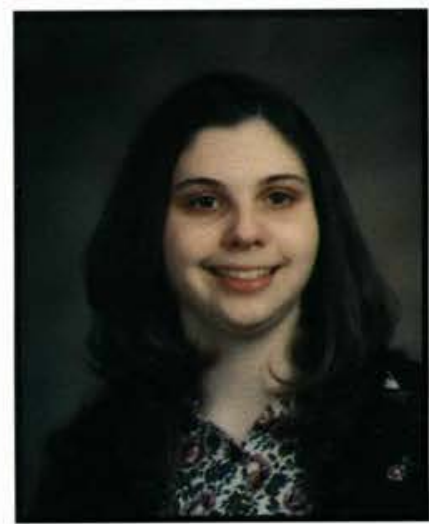

Nellie Rae Mick

Elementary Education

Cedarville, $\mathrm{OH}$

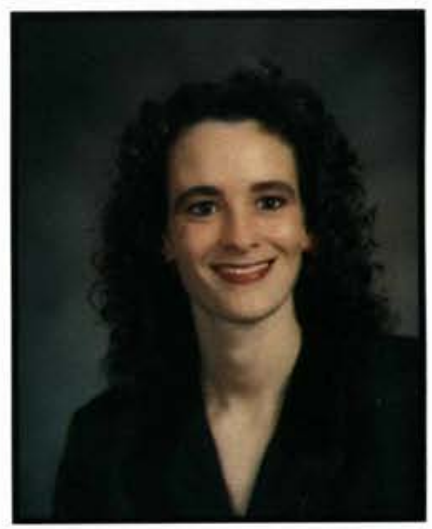

Mindy L. Miller

Elementary Education Lima, $\mathrm{OH}$ 


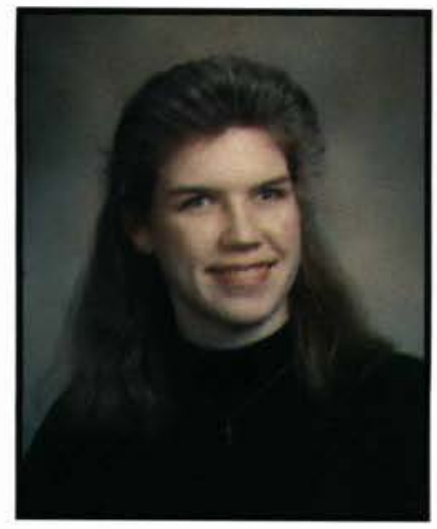

Sara. A. Nbiller Broadcasting

Mokena, IL

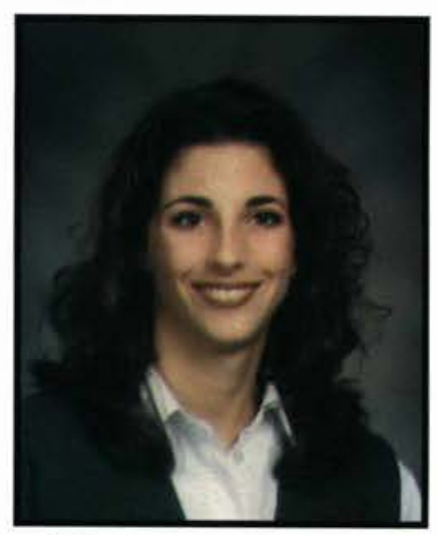

Tathryn T. Lboore

Physical Education

Beavercreek, $\mathrm{OH}$

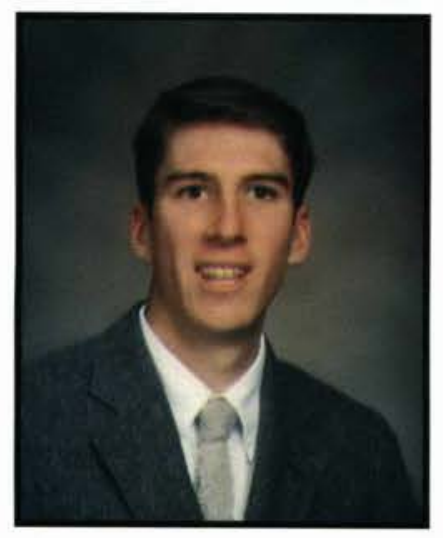

Mbathew R. Mburlyny

Management/Marketing Burdett, NY

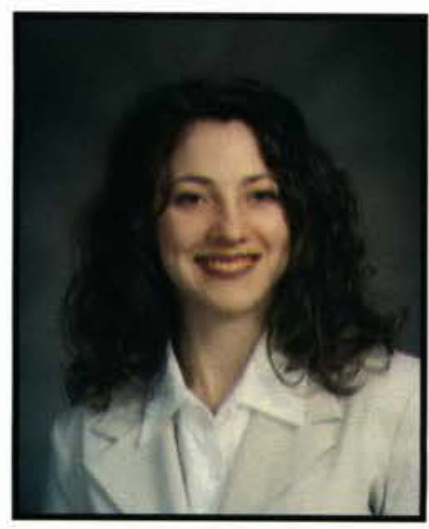

Gatherine E. Nebon

Nursing

Xenia, $\mathrm{OH}$

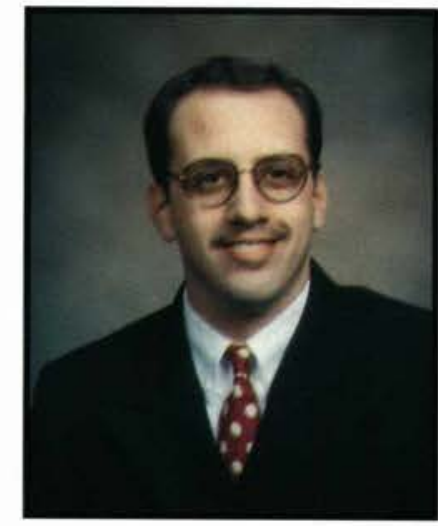

Toel. A. Misirian

Criminal Justice

Union Grove, WI

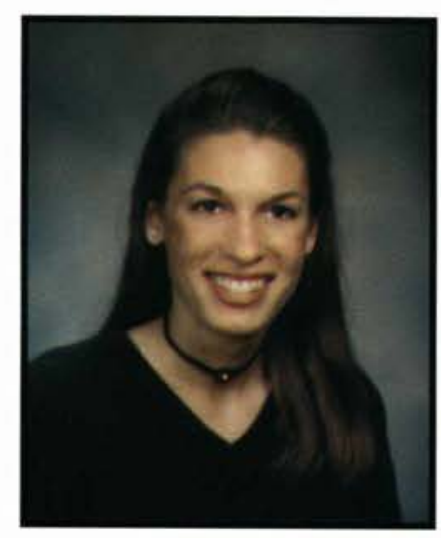

Christine Ml. Mollin Bible Comprehensive Johnstown, PA
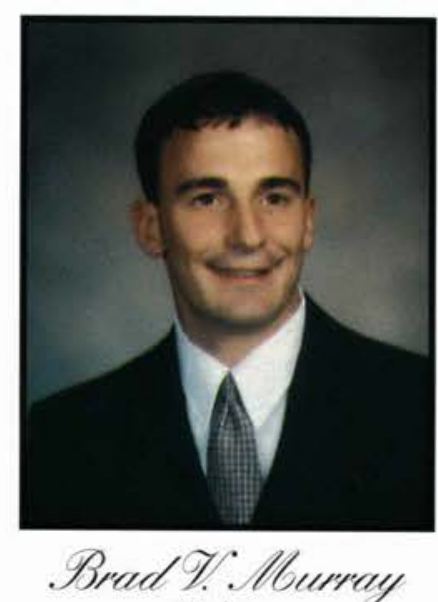
Biology

Mt. Pleasant, PA

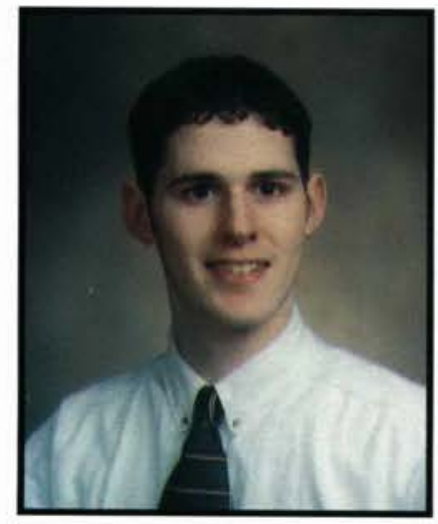

Teffrey S. Necuman

Baldwinsville, NY

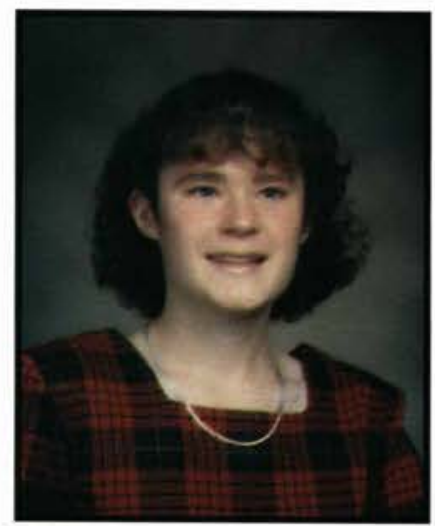

Slephanie T. Nlboody

Nursing

Lincoln, ME

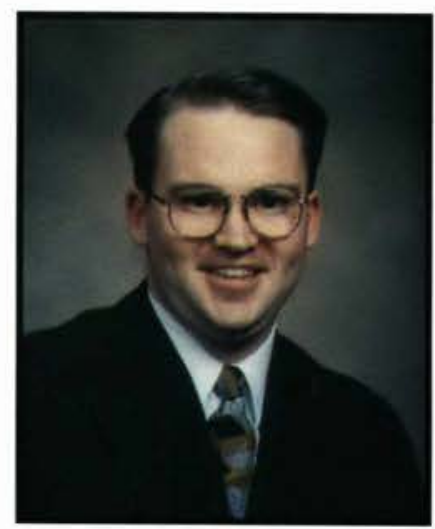

Robert. Ib. Nbutwaney Political Science/Finance Tucson, AZ

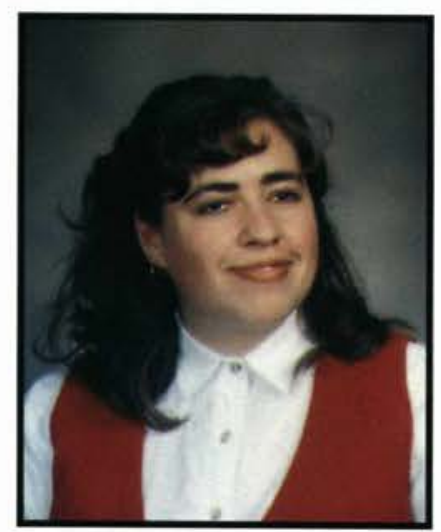

Michacla KC. Mburray

Elementary Education Cincinnati, $\mathrm{OH}$

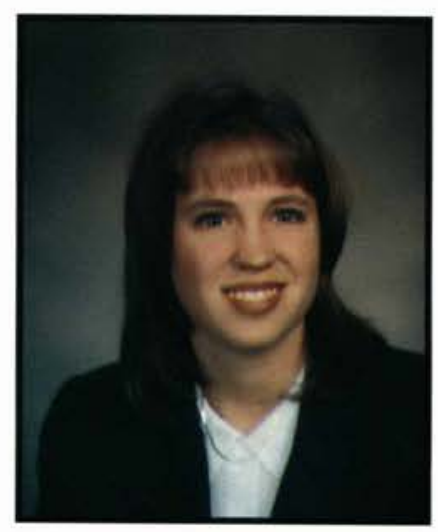

Heidi C. Neumain Accounting Englewood, FL

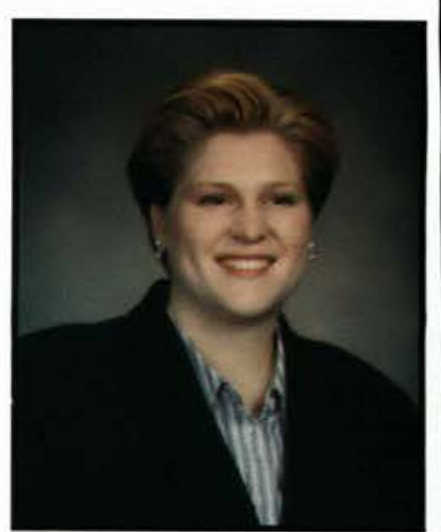

Tratie F. Mloon

English Education

Akron, $\mathrm{OH}$

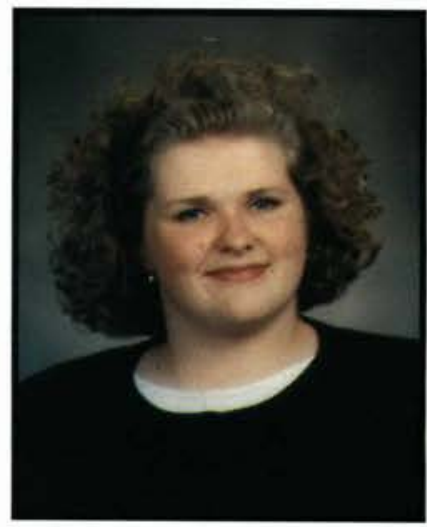

Heather E. Dburdoch Social Work

Kenmore, NY

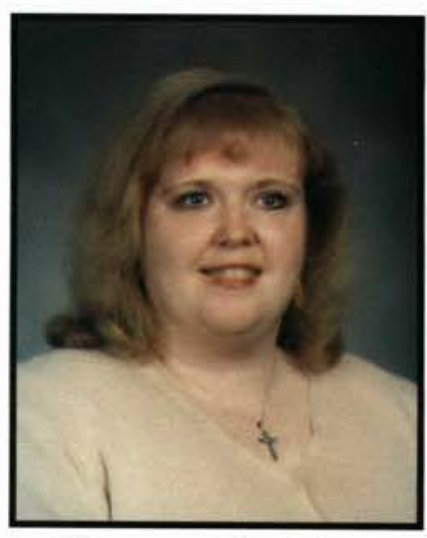

Sandra G. Neeley

History

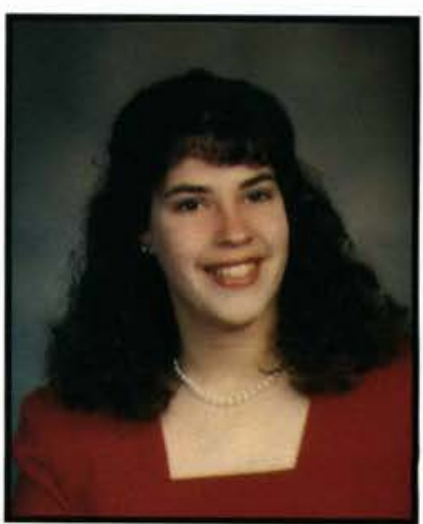

Amy KT. Nichole Elementary Education Meshoppen, PA 


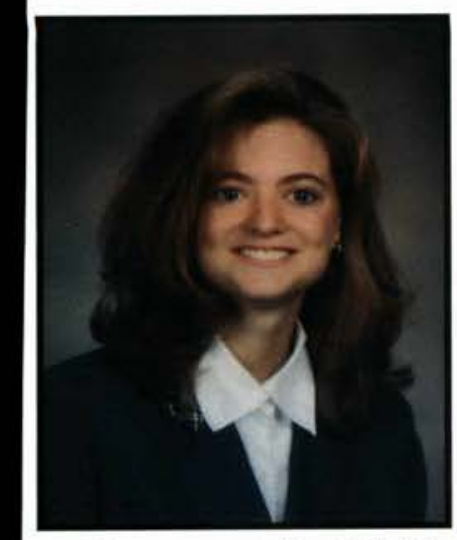

Patricia L. Noble

Broadcasting

Westwood, NJ

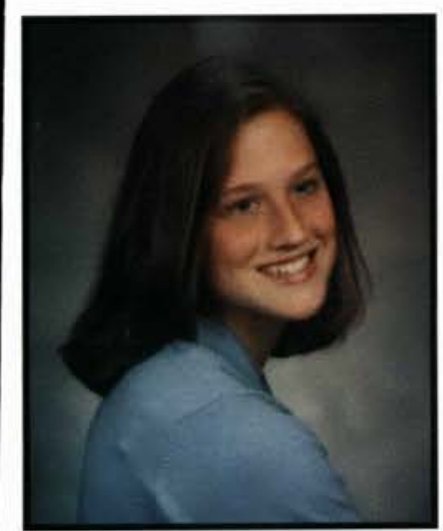

Andrea L. Qsterc

Math

Wappingers Falls, NY

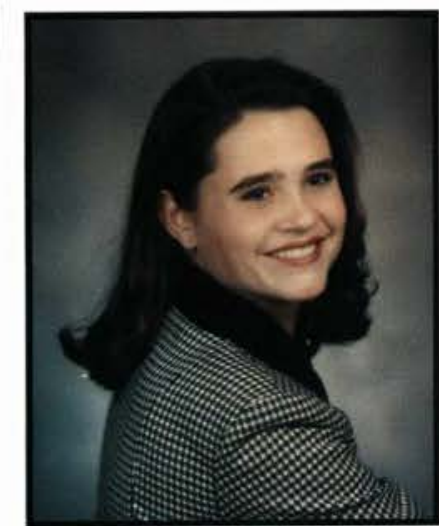

Gutie. Ko. Palmer

Elementary Education Lima, $\mathrm{OH}$

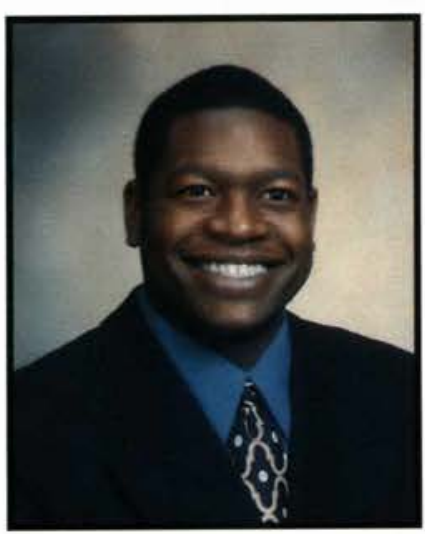

Mathan Mb. Payne Nursing

Oxon Hill, MD

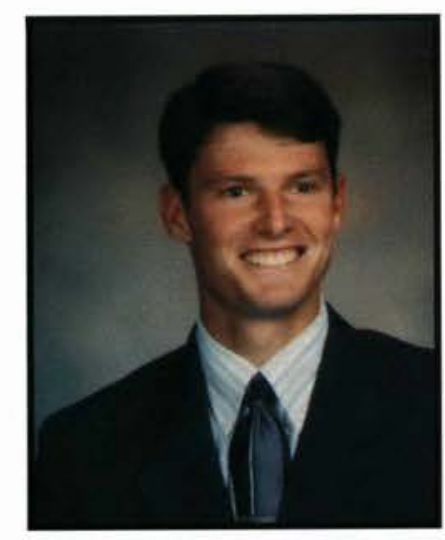

Renjamin P. Nordacis

Elementary Education Waseca, MN
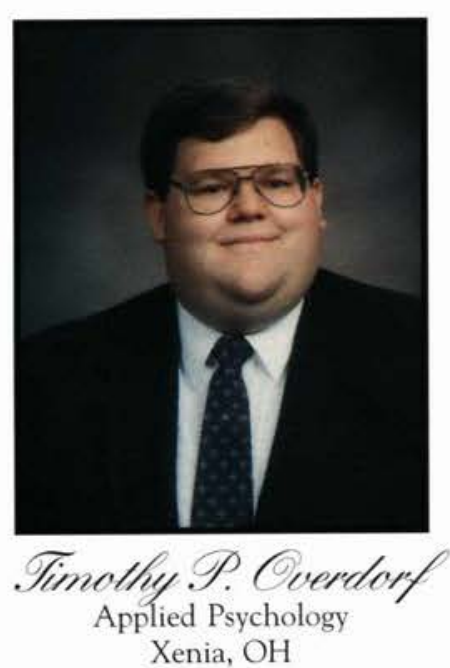

Xenia, $\mathrm{OH}$

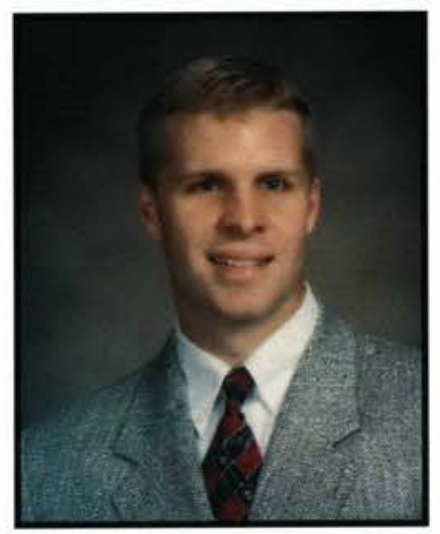

2. Daniel Parlin Marketing

Astatula, FL

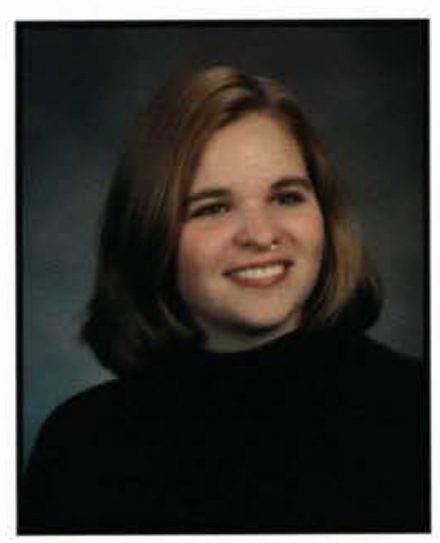

Lisa A. Peary

Business Communication Technology Londonderry, NH

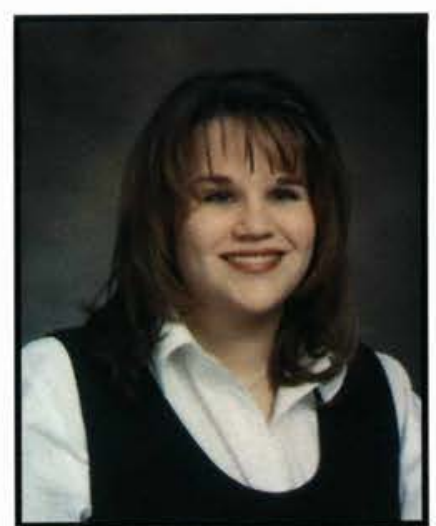

Sarra L. Ober:

Communication Arts

Des Moines, IA

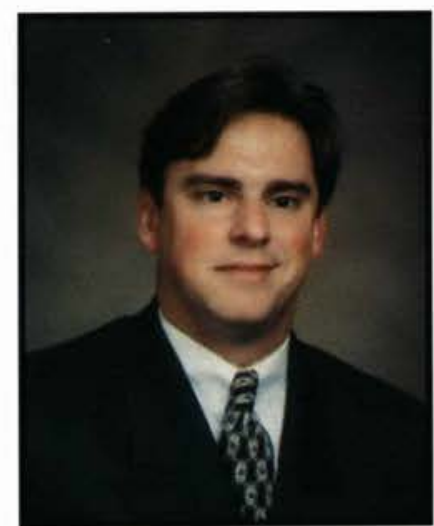

Foshura. Overholl

Accounting/Finance

Parkertown, NJ

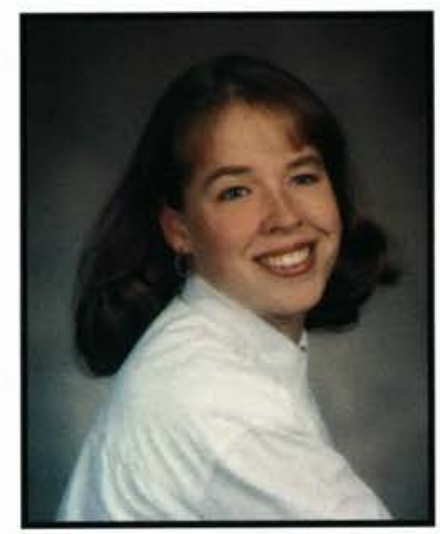

Wendy. KC. Passineau

Pre-Law

Mason, MI

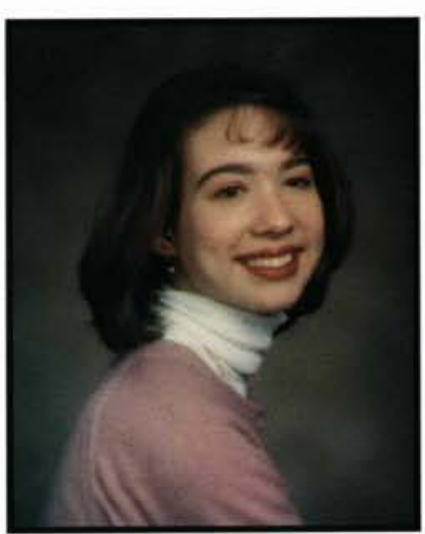

Charis L. Perez

Computer Information Systems Patrick Springs, VA

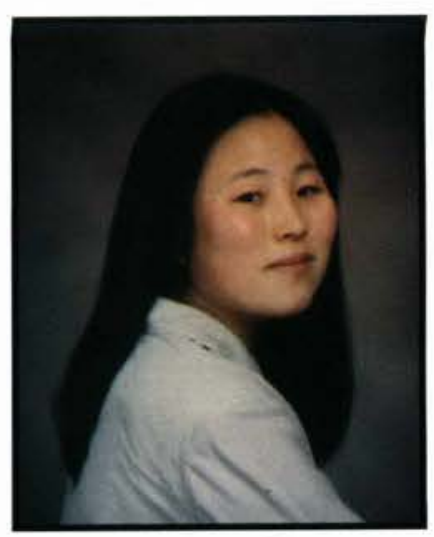

Glisula Ohature

Communication Arts Hokkaido, Japan

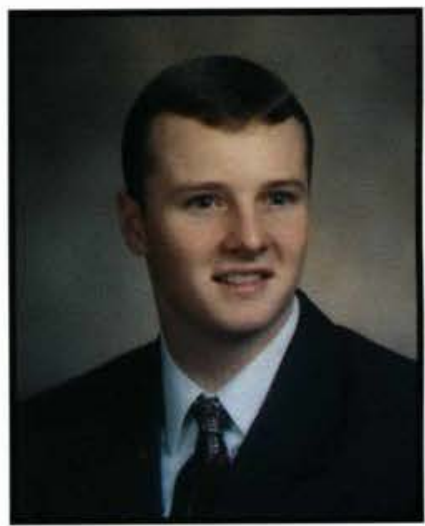

Troy A. Page

Management

Terre Haute, IN

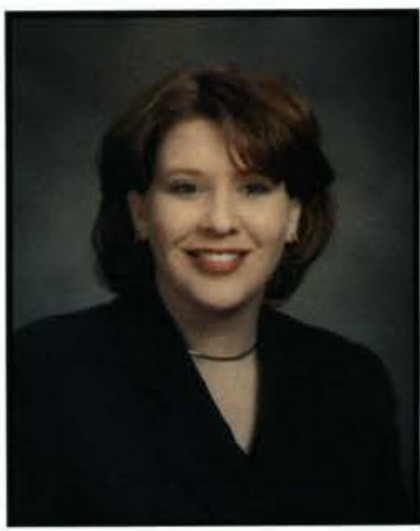

Pelieca D. Patten

Elementary Education Fishers, IN

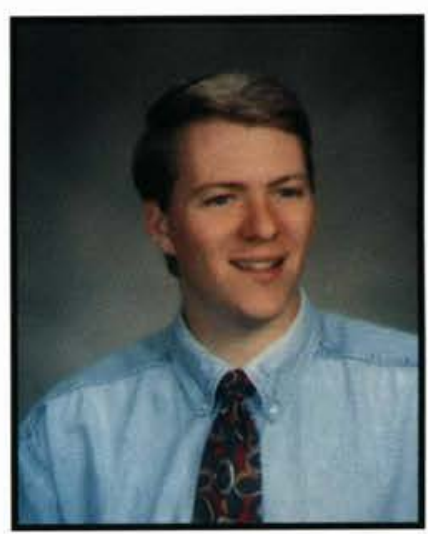

Ghistopher $\mathscr{D}$. Perry

Political Science

Waynesville, $\mathrm{OH}$ 


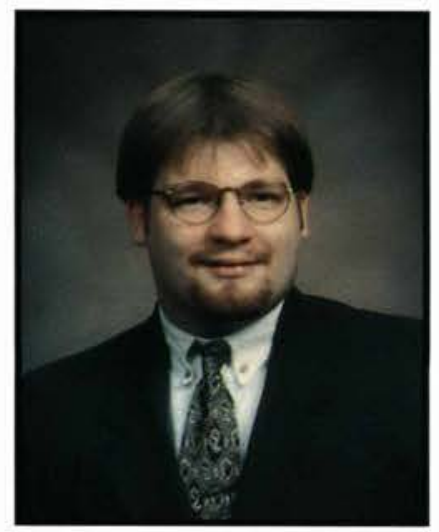

David C. Perry

English

Sheffield, MA

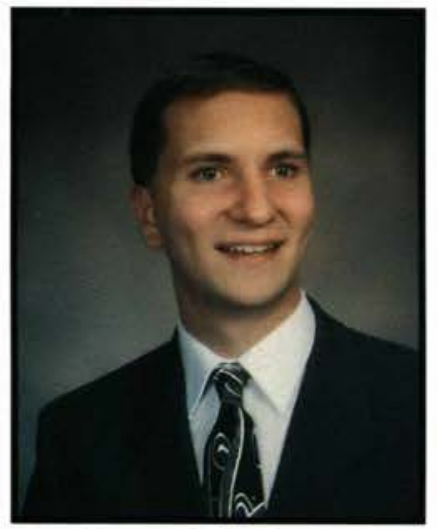

Brell E. Pfeiffer

Nursing

Grandville, MI

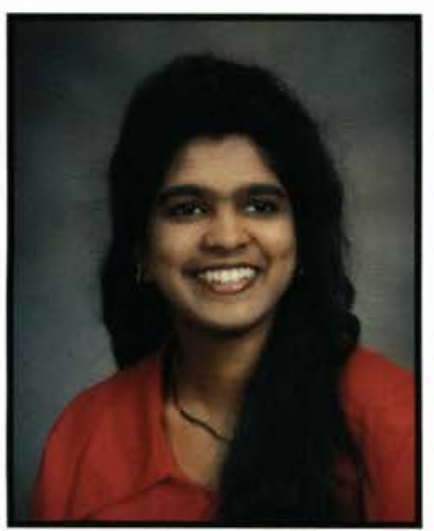

Dovothy.T.Pivesan

Nursing

Cedarville, $\mathrm{OH}$

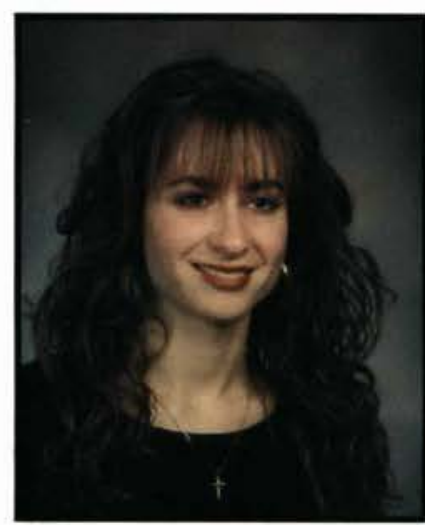

Samantha O. Polgardy Nursing

Phillipsburg, NJ
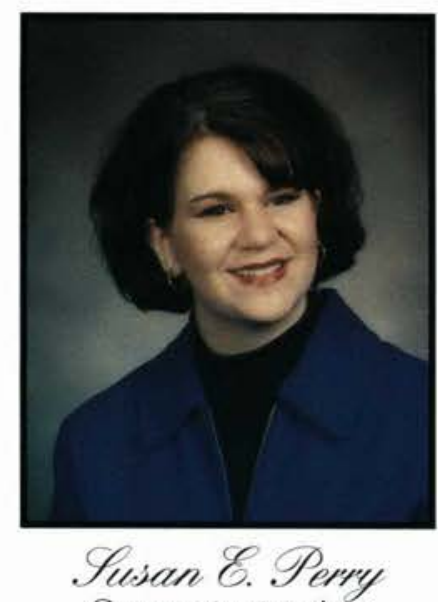

Communication Arts Cedarville, $\mathrm{OH}$

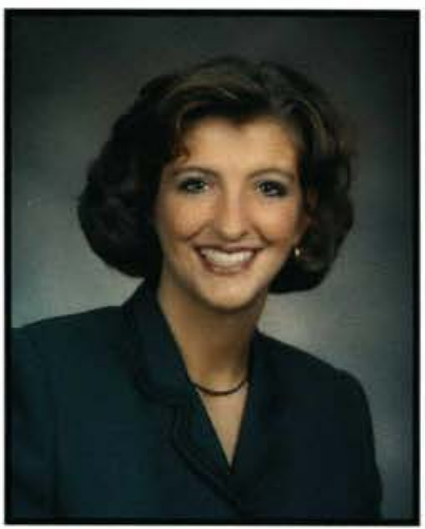

Melinda OP. Pichell Social Science/History

Birmingham, AL

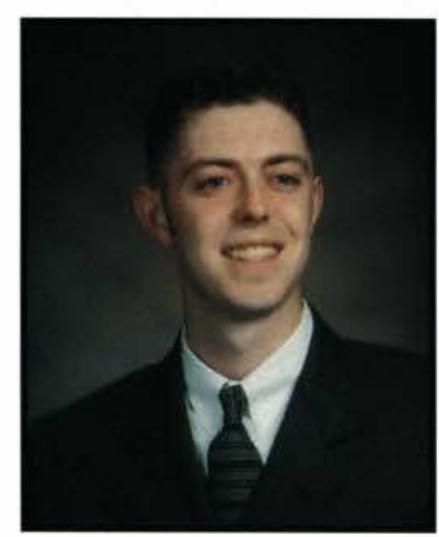

Ghristopher D. Pittenturf

Computer Information Systems Oxford, MI

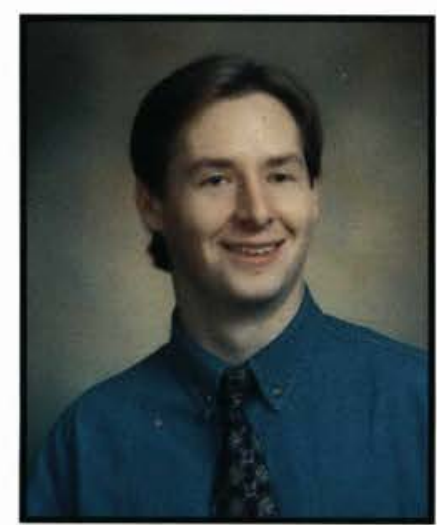

Garon P. Ponzani English Education

Galloway, $\mathrm{OH}$
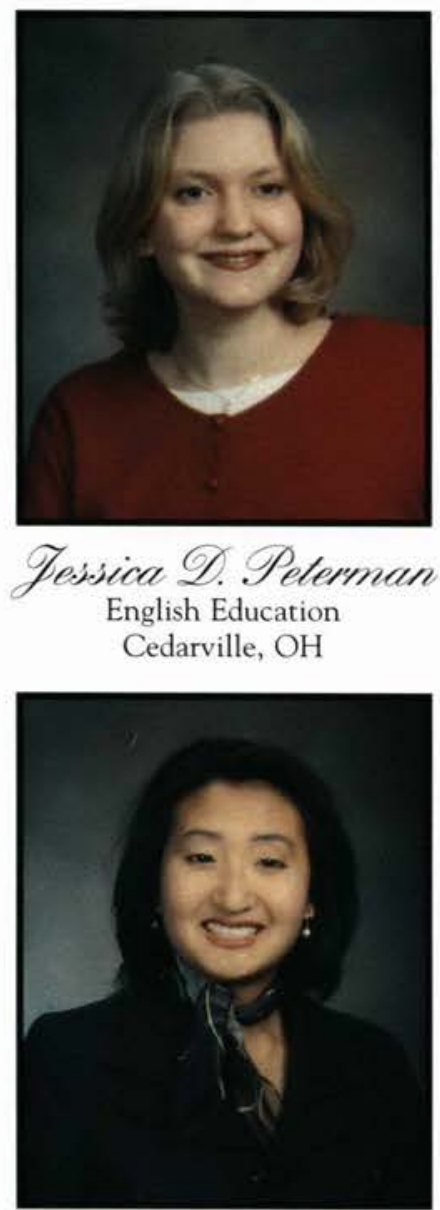

Puthanne. P. Pierson Communication Arts

Puyallup, WA

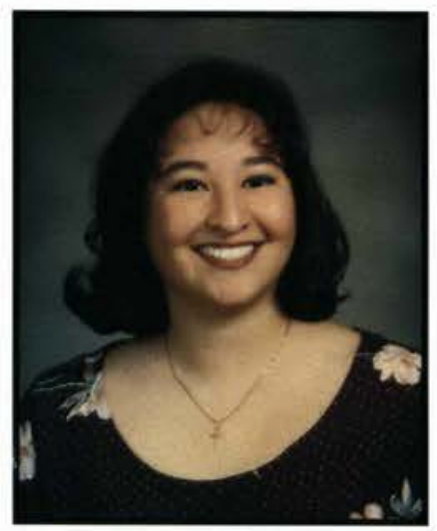

Qvelte Pizana

Bible Comprehensive Castroville, TX

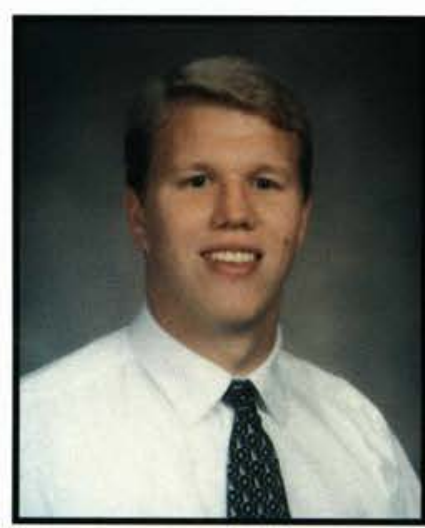

Tacob D. Porter:

Electrical Engineering

Xenia, $\mathrm{OH}$

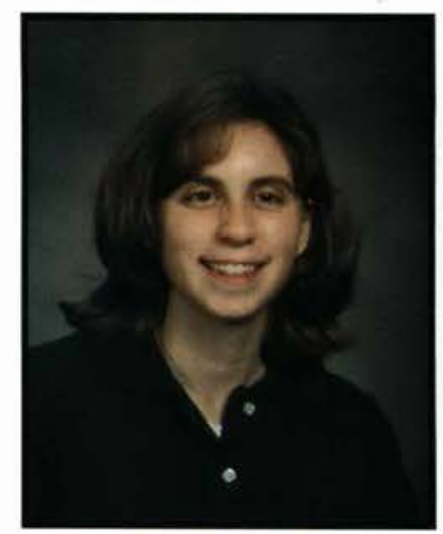

Holly. B. Peterion

Bible Comprehensive

Owatonna, MN

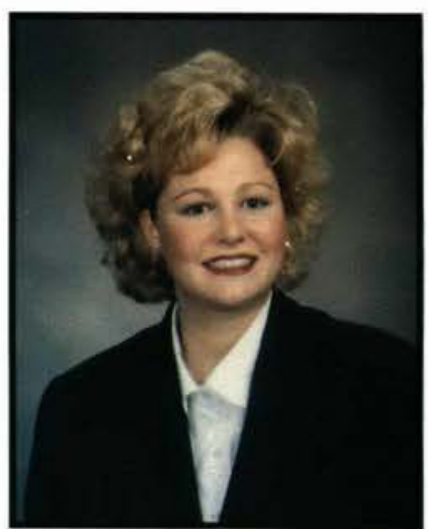

Hilary L. Pifer

Communication Arts

Lapeer, MI

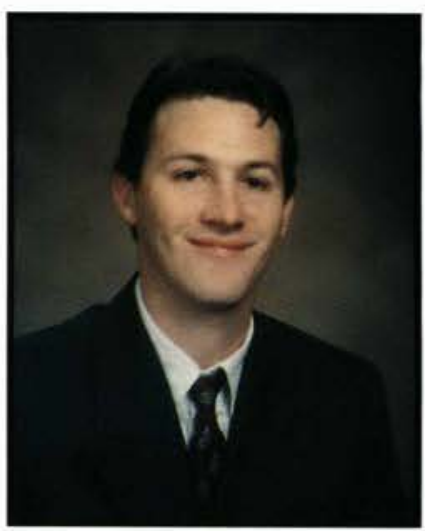

Tustin TPPoe

Criminal Justice

Fairborn, $\mathrm{OH}$

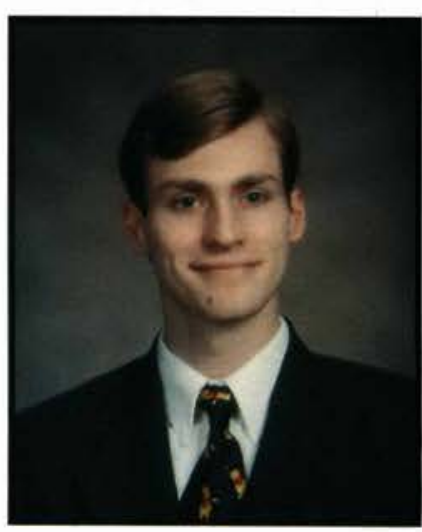

Bichard WH. Porler

English Education

West Jefferson, $\mathrm{OH}$ 


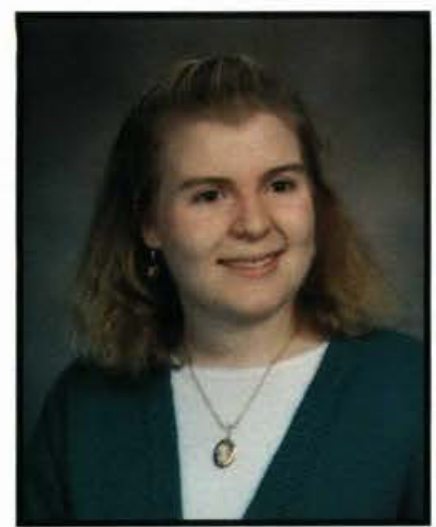

Gynthic L. Polter

Elementary Education

Nashville, MI

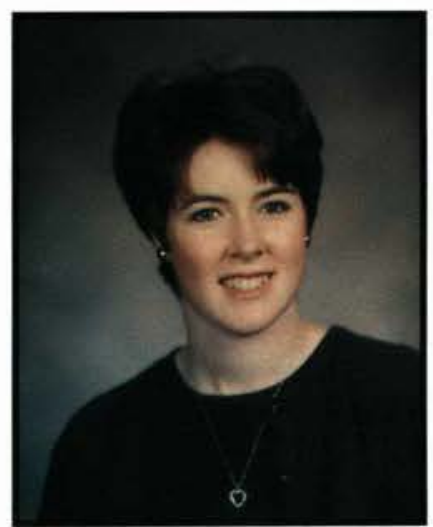

Kelly. A. Purdy

Broadcasting

Marietta, GA

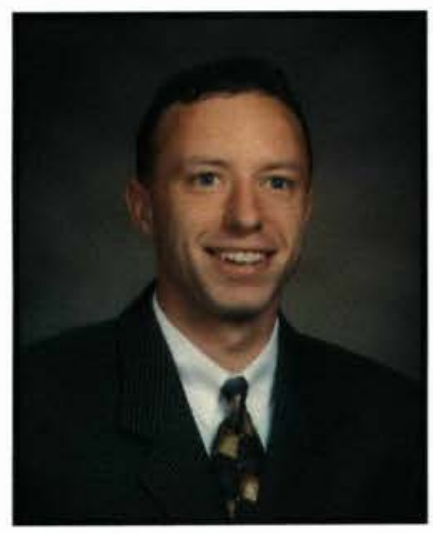

David NG. Rea

Mechanical Engineering

Clarkston, WA

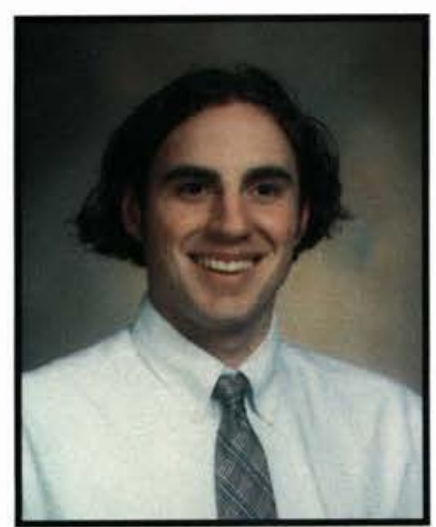

Tesse Beibson

Psychology

Cedarville, $\mathrm{OH}$

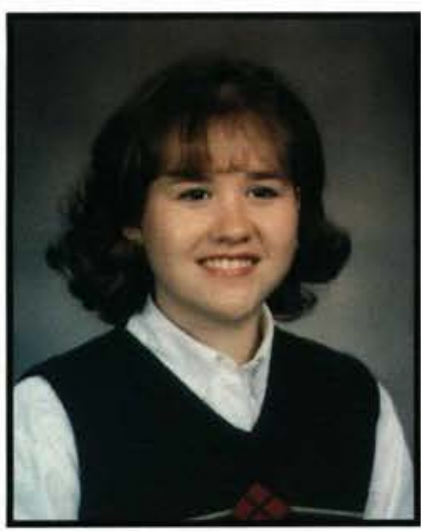

Mary E. Powell

English Education

Greenville, SC

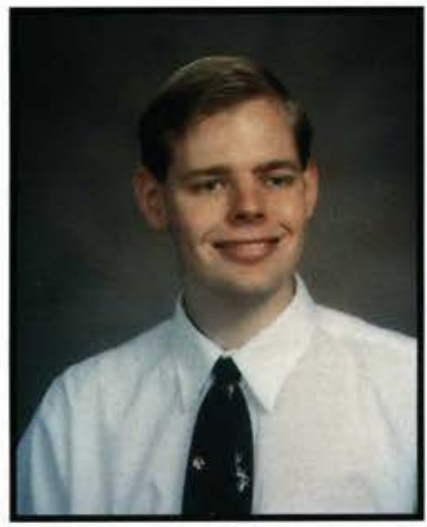

Nathan Mb. Badford

Communication Arts

Cross Lanes, WV

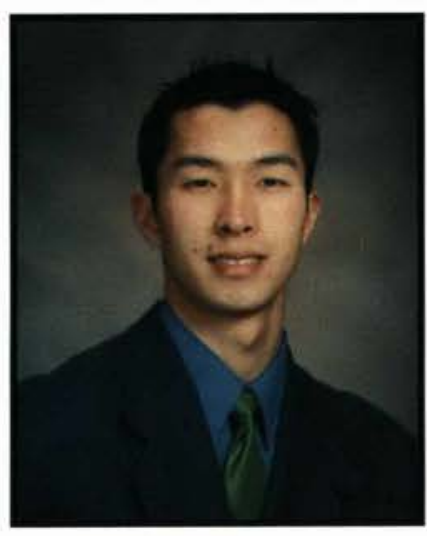

Tamin Reda

Biology

Wrentham, MA

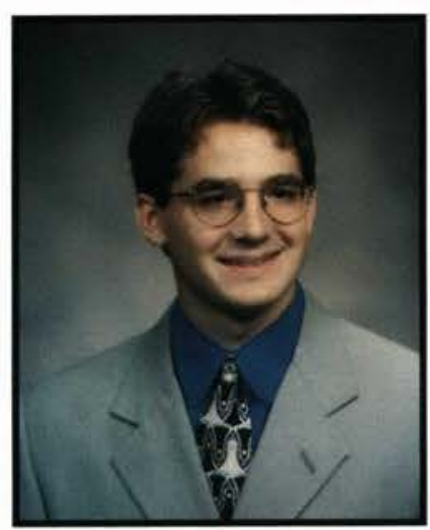

Matthew C. Rexford Church Music Ministry Mauldin, SC

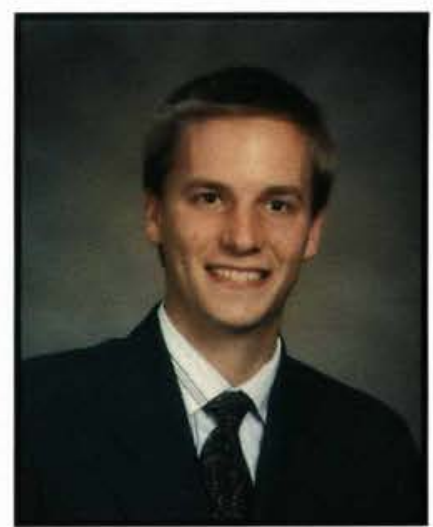

Tosieph. Il. Preston

Pre-Seminary

Cranesville, PA

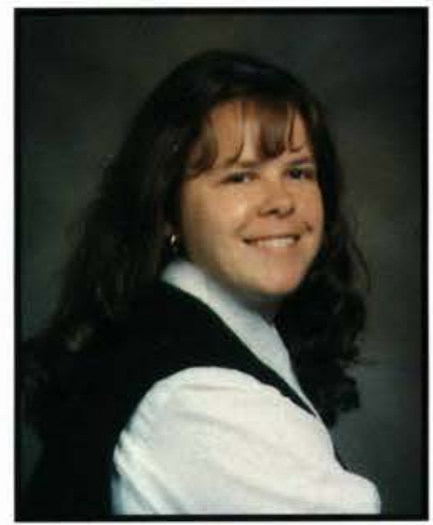

Patricia L. Rains

Elementary Education

Fairfield, $\mathrm{OH}$

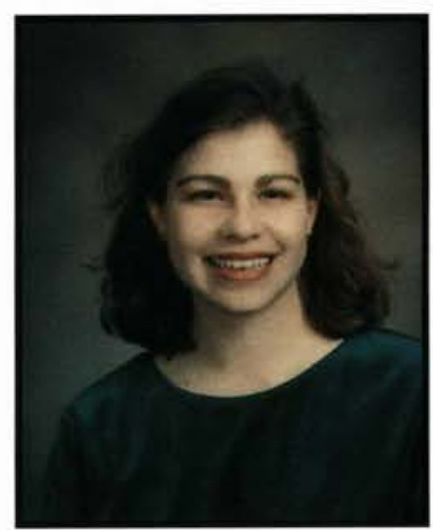

Gennifer. S. Reed Biology

Reading, PA

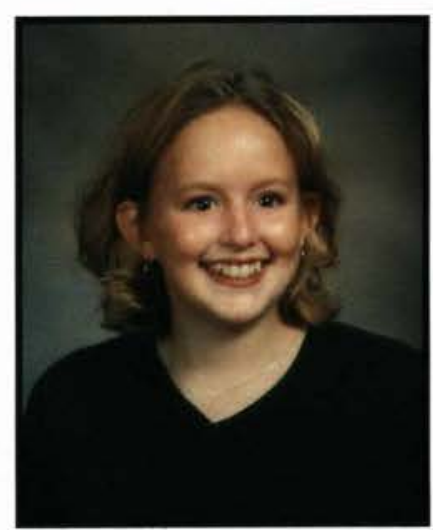

Rebecca S. Ribeiro Nursing

Wilmington, DE

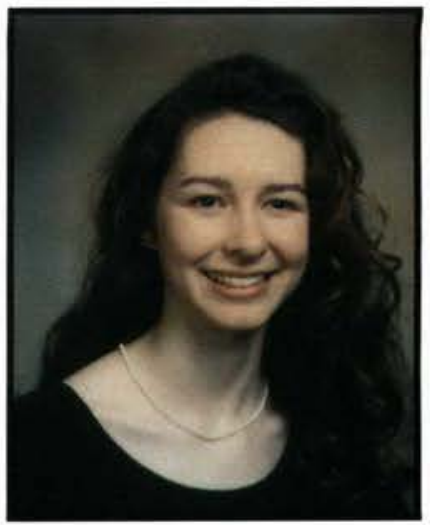

Marry E. Price

Marketing

Tipp City, OH

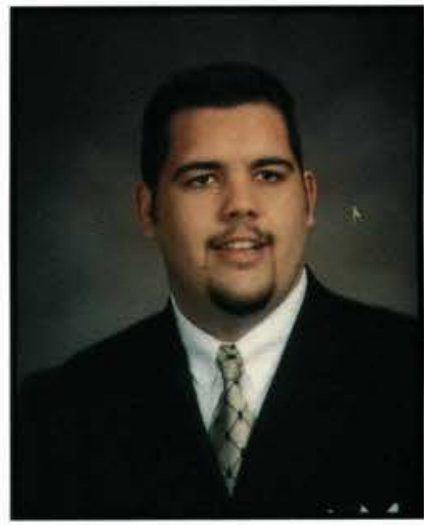

Facol D. Ramba

History/Political Science

Elk Grove, CA

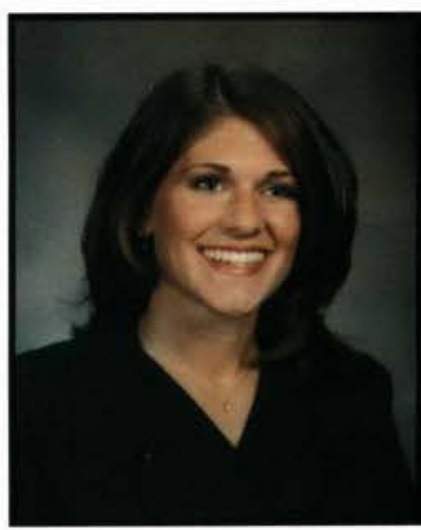

Laura Il. Refior

Elementary Education Warsaw, IN

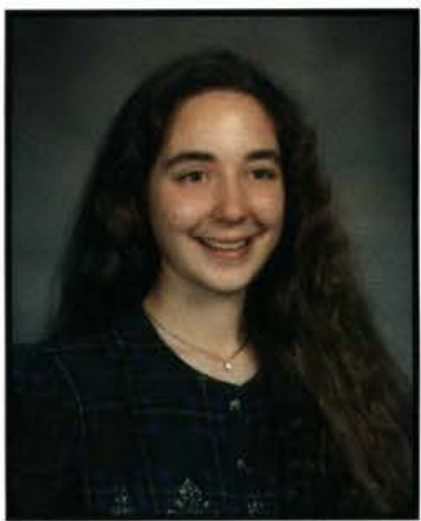

Patricia E. Rice

Nursing

Rockville, MD 


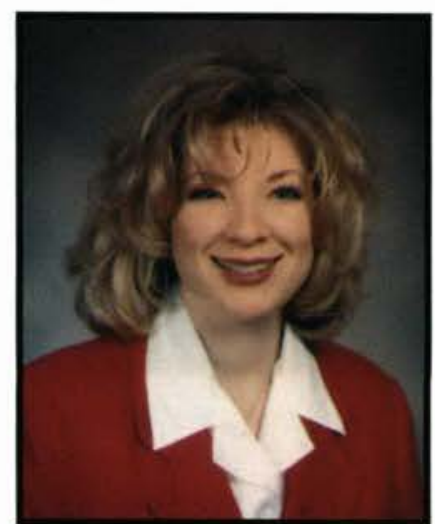

Amy S. Bigg

Communication Arts

Hillsboro, $\mathrm{OH}$

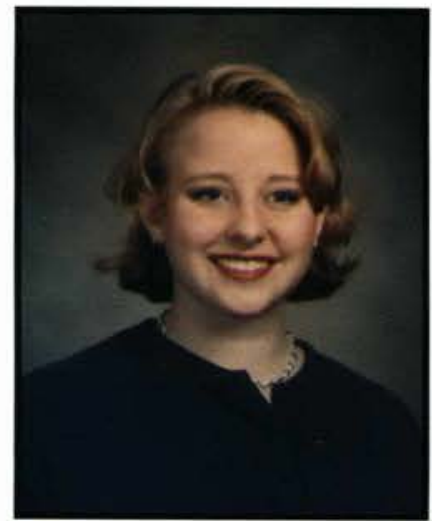

Shauna Poberts

Communication Arts

Cincinnati, $\mathrm{OH}$

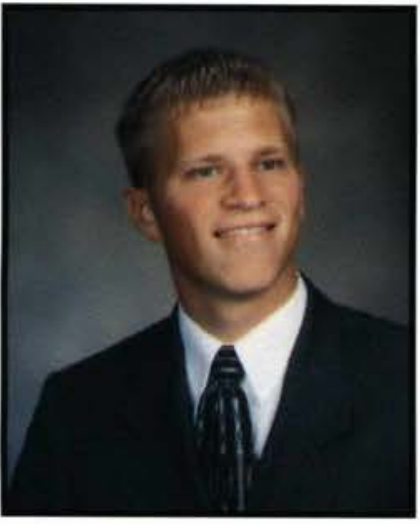

David. A. Rooke

Marketing

Bakersfield, CA

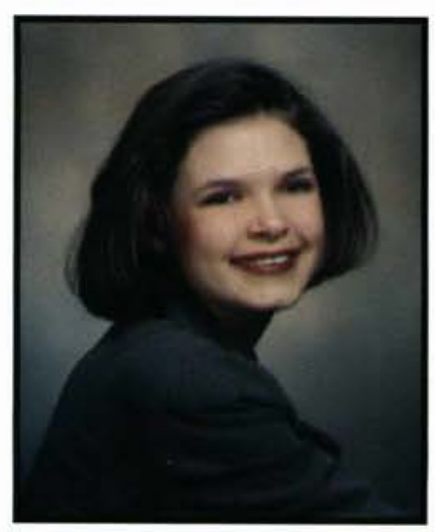

Ghrystie. Mb. Ruba

Elementary Education

Philadelphia, PA

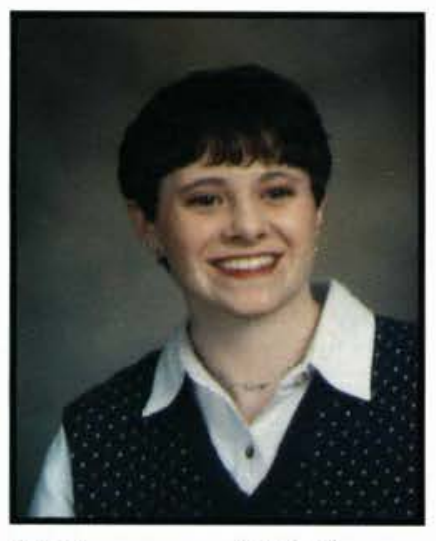

Ghristina M. Rising

Applied Psychology

Vestal, NY

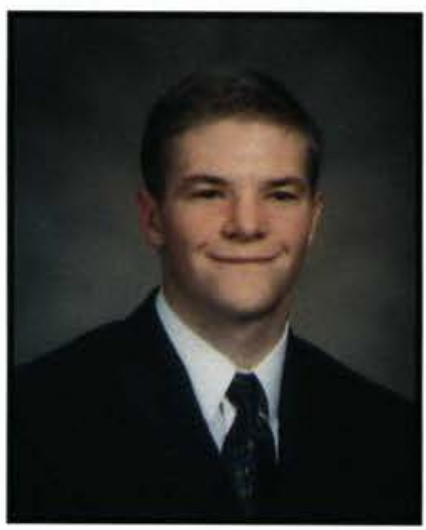

Gharle: Of. Rolinion

Global Economics/International Business

Santiago

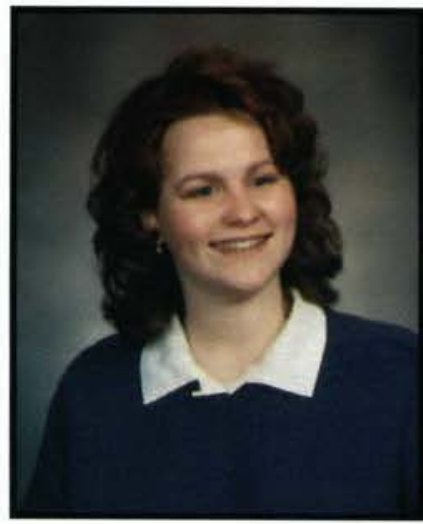

Bene. A. Basencranta English

Flushing, MI

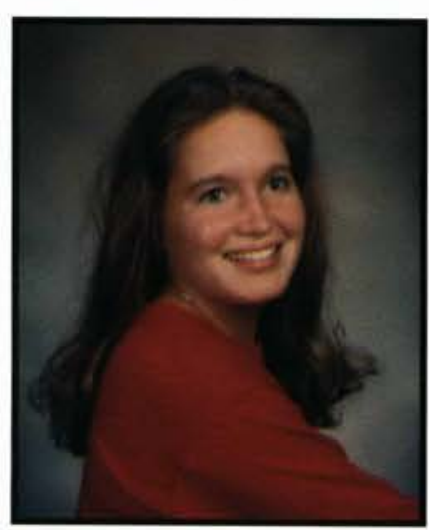

Ann R. Ruequegger

Elementary Education

Centerville, $\mathrm{OH}$

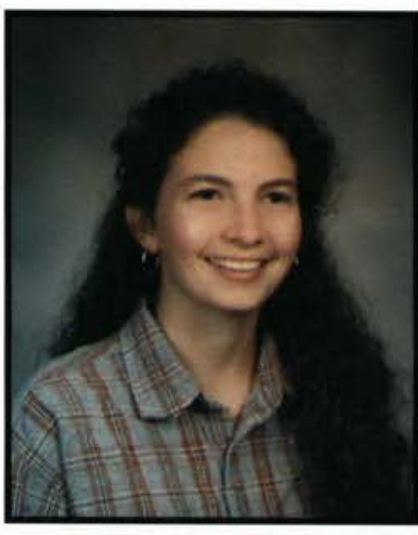

Gharily Hb. Bixer

English Education

Virginia Beach, VA
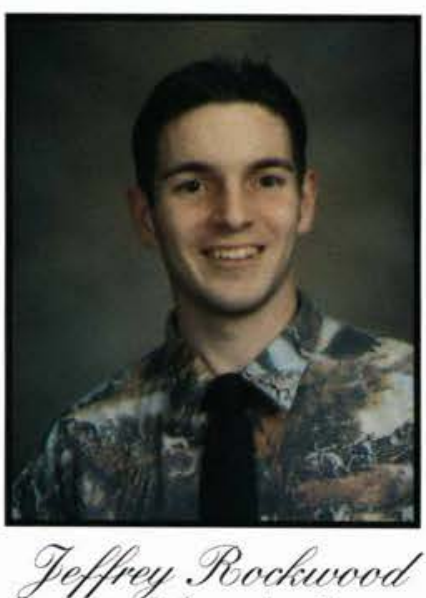

Computer Information Systems

Silver Lake, $\mathrm{OH}$

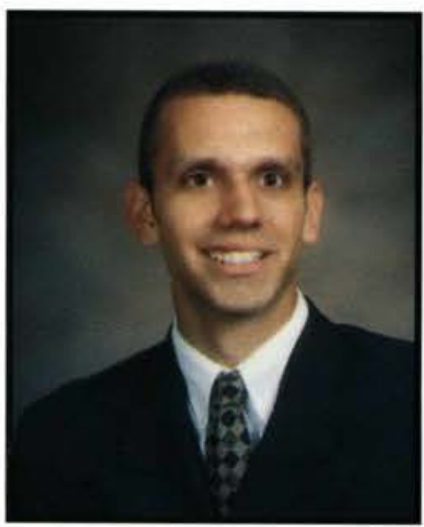

Darin T. Basenvald Bible Comprehensive

Wadsworth, $\mathrm{OH}$

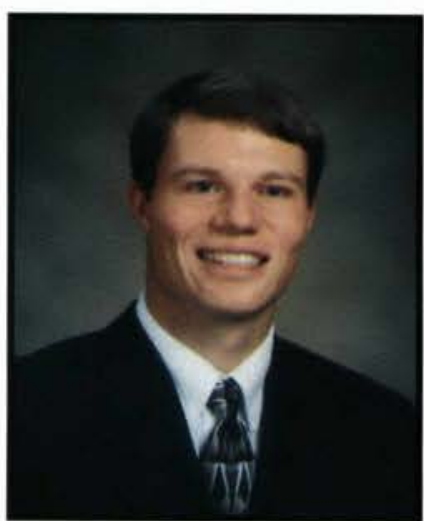

R. Tach Buffin

Elecrical Engineering

Grand Lake, CO

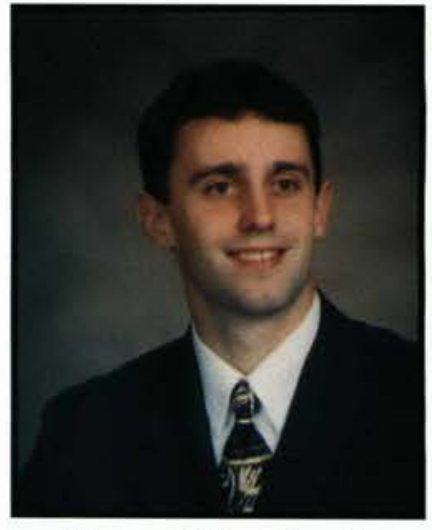

Micah E. Roberts

Mechanical Engineering Milton, VT

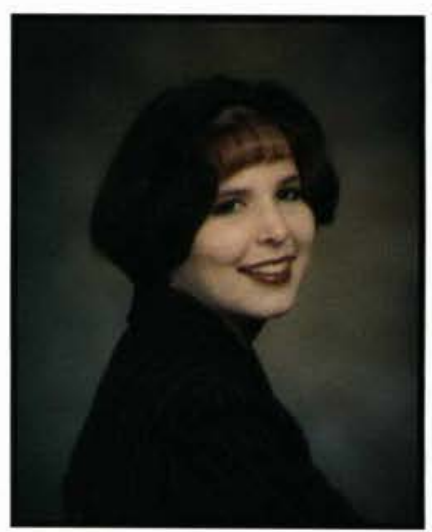

Sara Ll. Romang

Communication Arts/Special Education Prairie Village, KS

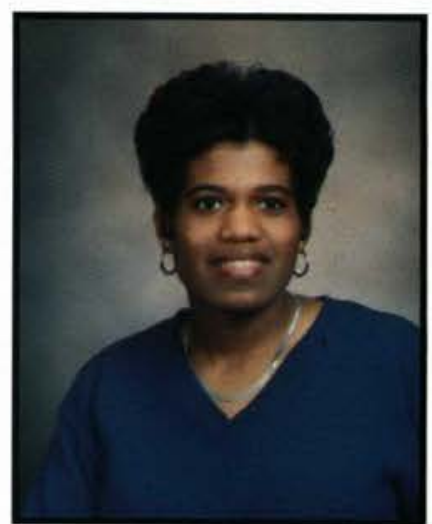

Tulie Rosis

Applied Psychology

East Providence, RI

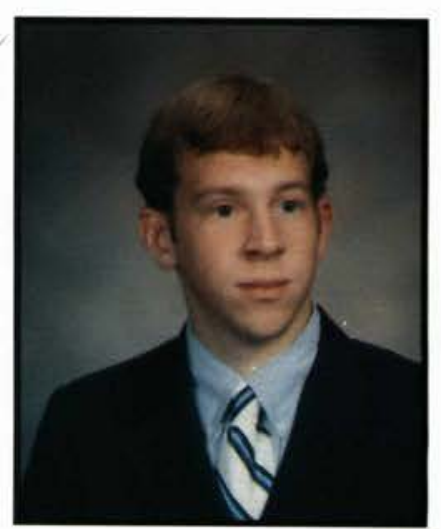

Fason. R. Rumnion-Sray

Professional Writing Waldwick, N] 


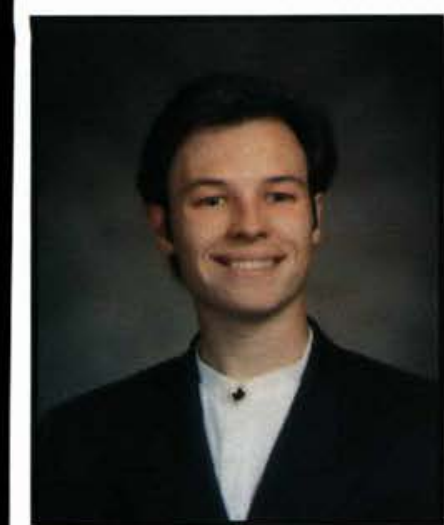

Toshuma h. Rourn

Church Music Ministry

Archbold, $\mathrm{OH}$

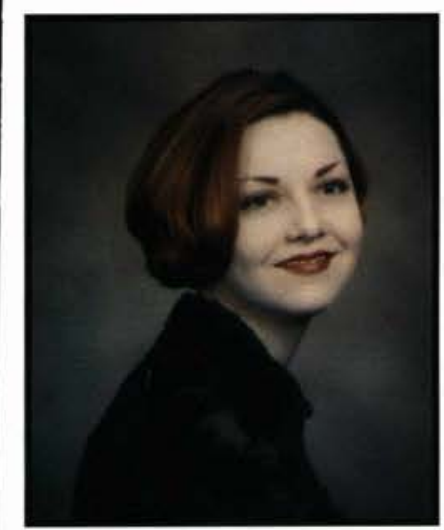

Stacy Ob. Saville

Communication Arts

Lanham, MD

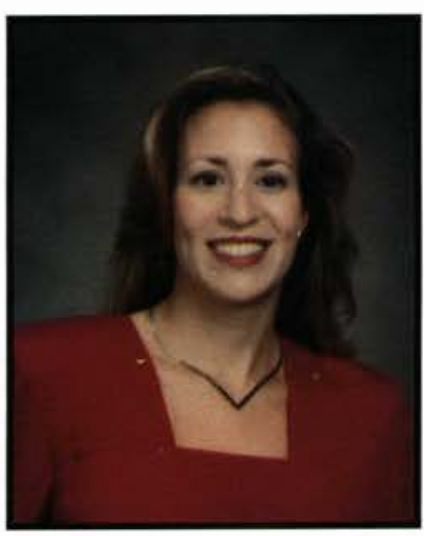

Bethany O. Achloegel

Clarks Summit, PA

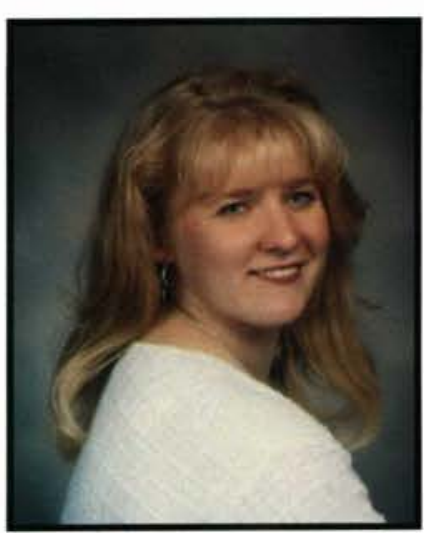

Gana F. Fchurinn

Sheboygan, WI

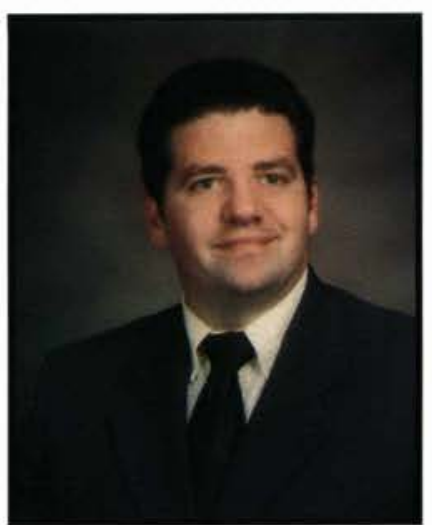

Ted R. Rusidell

Pre-Seminary

Sidney, $\mathrm{OH}$

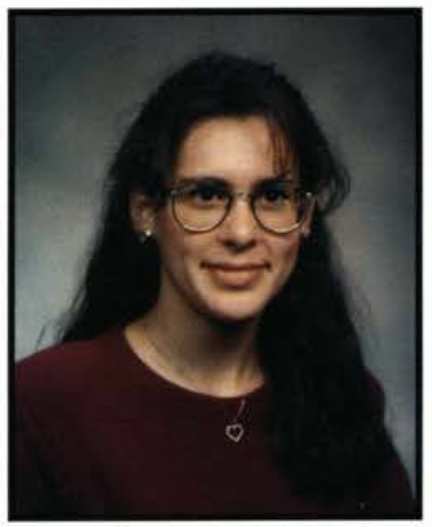

Dichete Schafer

Elementary Education

Ionia, MI

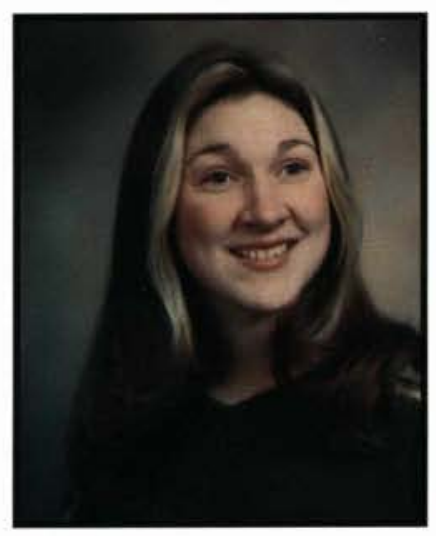

Heather A. Schuler Applied Psychology Horseheads, NY

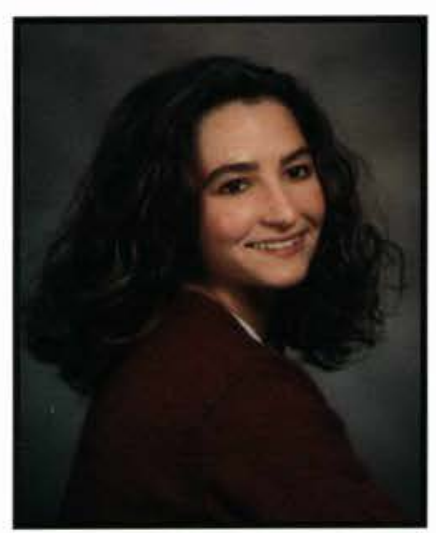

Dana L. Scoll

Nursing

Canton, MI

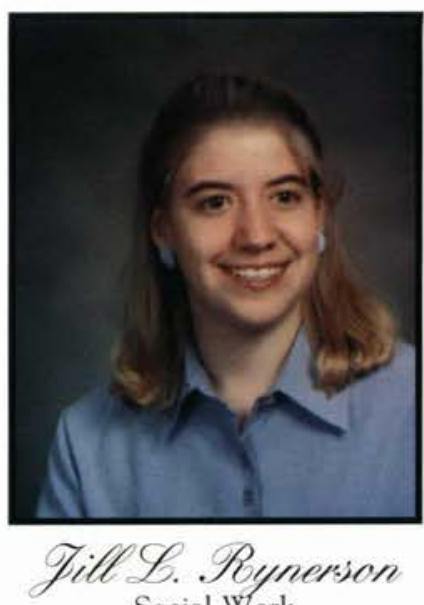

Social Work

Prior Lake, MN

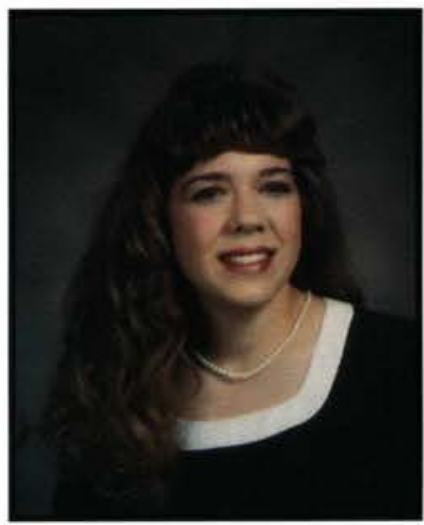

Summer Ko. Schafer Communication Arts

Basom, NY

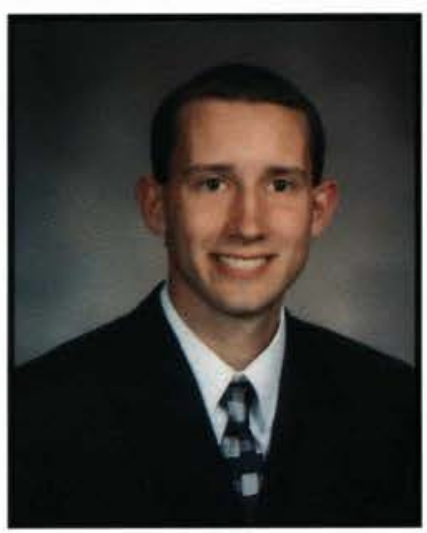

Fonathan 2. Schults Math

Bartlett, TN

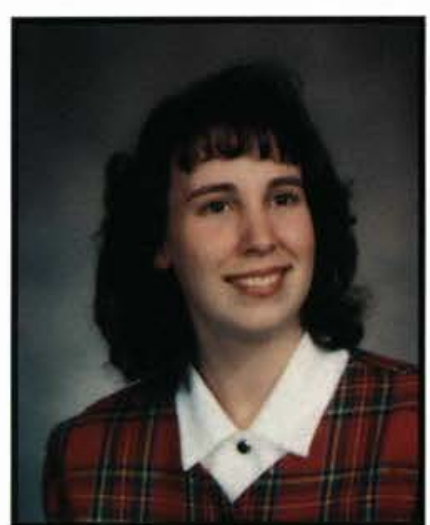

Tamara F. See English Education Camdenton, $\mathrm{MO}$

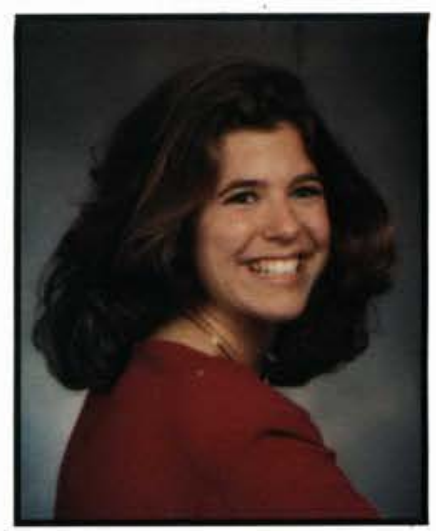

Carla Mb. Salvaggia Elementary Education Randolph, NY

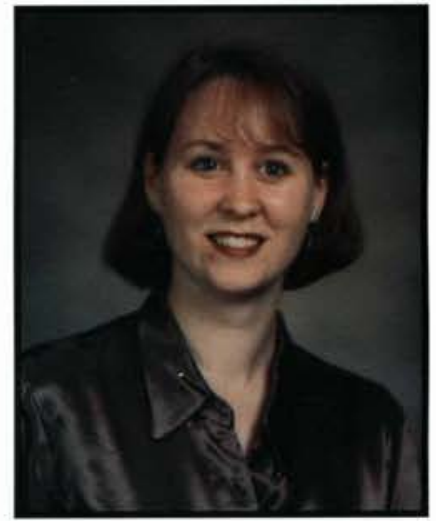

- Legan Achier

Communication Arts

Dundee, IL

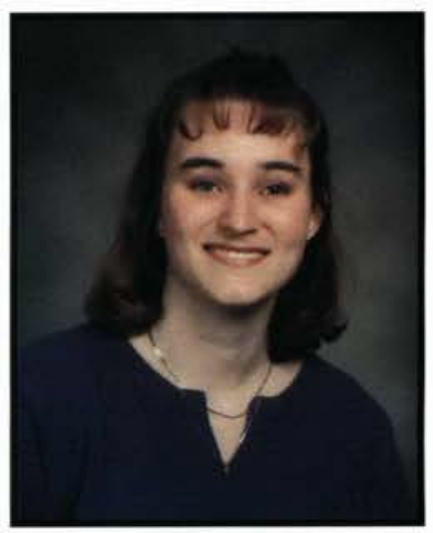

Laura KS. Schula Accounting

Menomonee Falls, WI

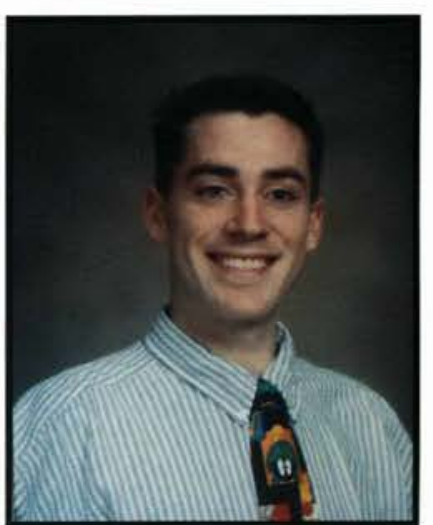

Denver Seelly

Electrical Engineering Hilliard, $\mathrm{OH}$ 


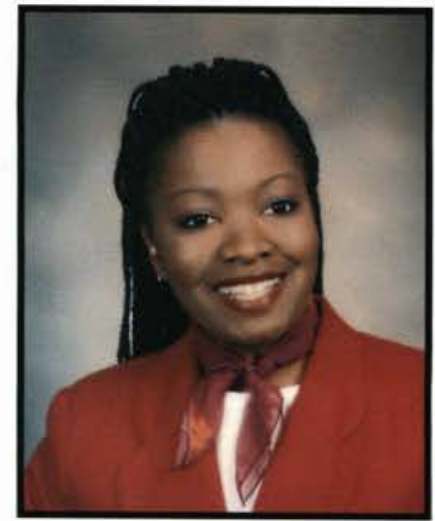

Armanda. A. Senior

Elementary Education

Mahwah, NJ

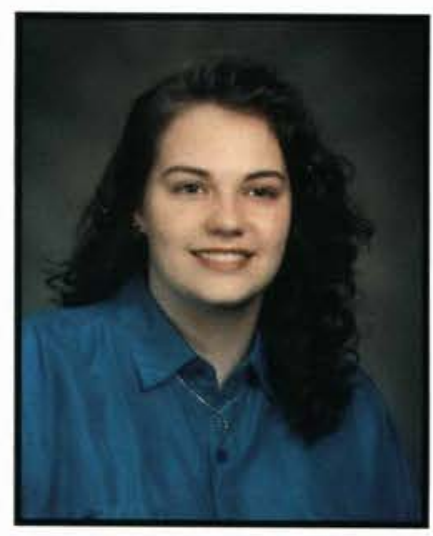

Karin O. Shilling

Elementary Education

Wooster, $\mathrm{OH}$

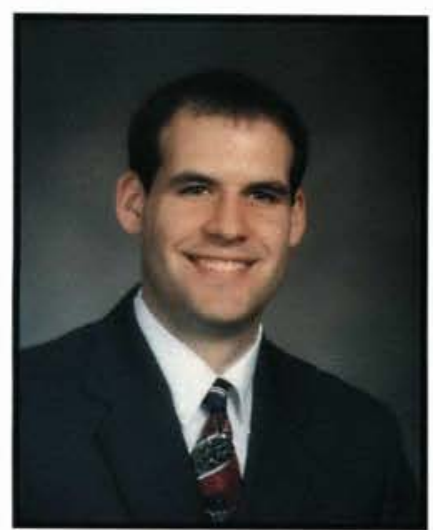

Fon Mrubiale

jlobal Economics/International Business Cedarville, $\mathrm{OH}$

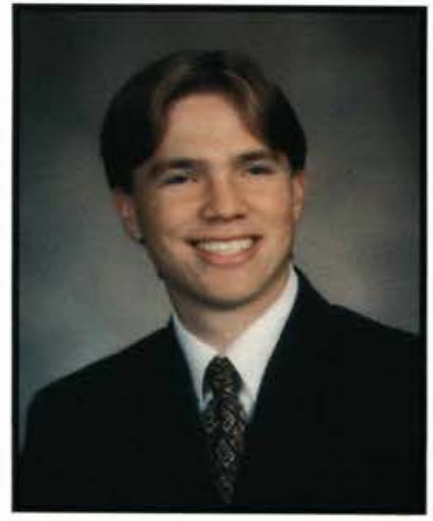

Stephen S. Hates

Elementary Education

Portage, MI

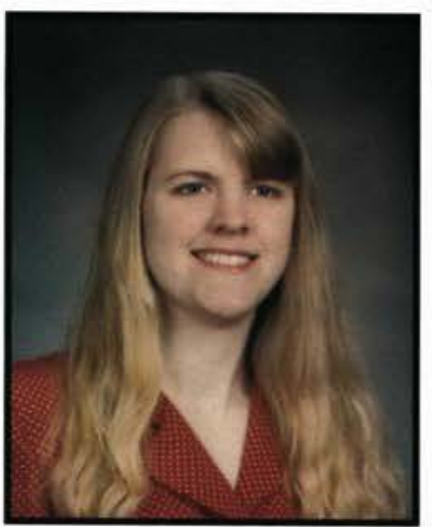

Rachel. A. Sharp

Finance

Cedarville, $\mathrm{OH}$

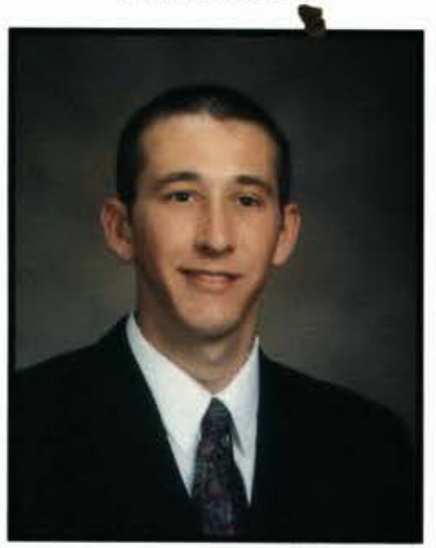

Shawn A. Shipp

Elementary Education

Greenville, $\mathrm{OH}$
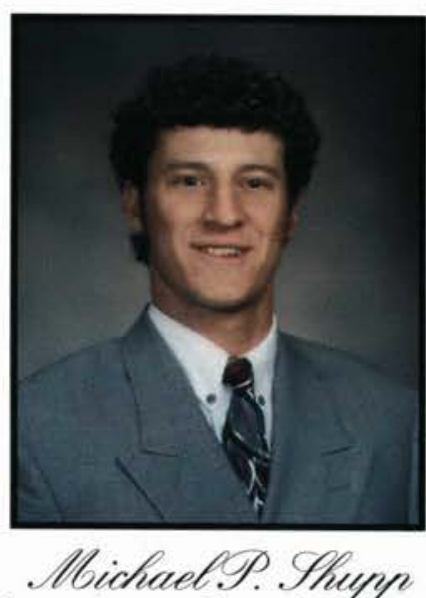

Comprehensive Physical Education Pataskala, $\mathrm{OH}$

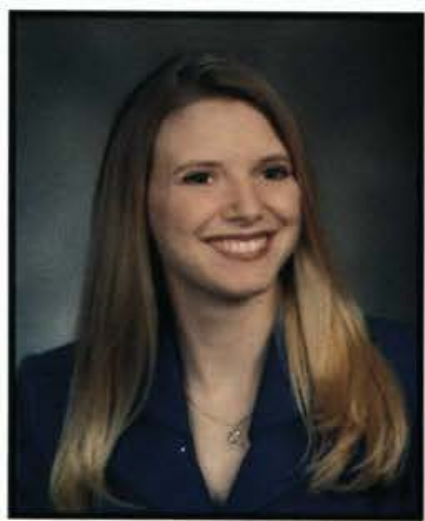

- bltyion Mb. Smith Communication Arts

Canal Fulton, $\mathrm{OH}$

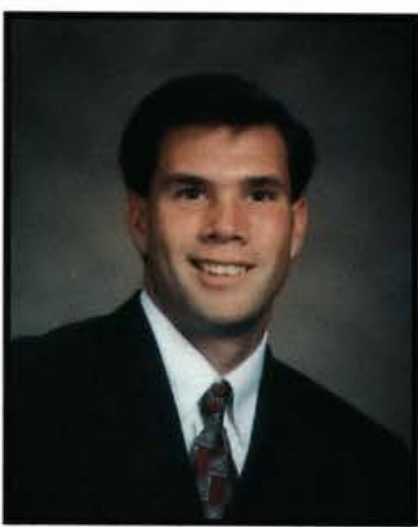

Andrew H. Shaw

Finance

Chambersburg, PA

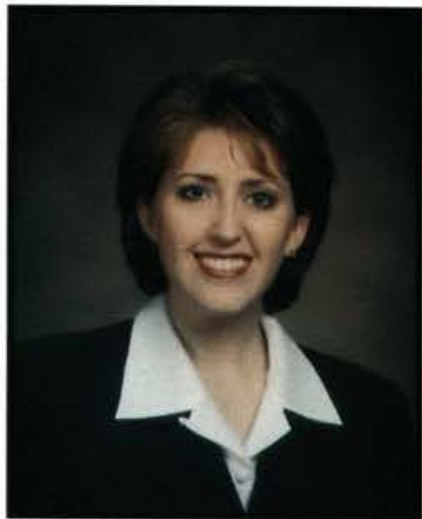

Gourlenay R. Shoaff Communication Arts

Leesburg, VA

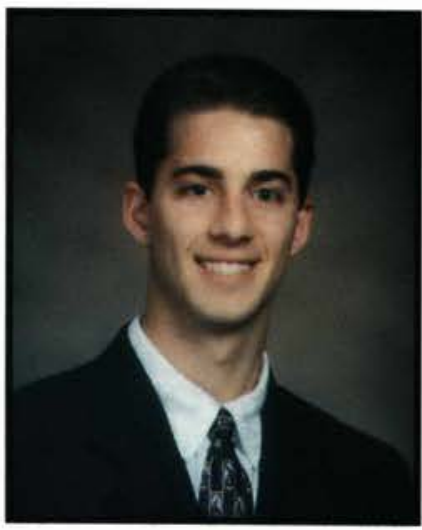

Timathy A. Simon

Criminal Justice

Canton, MI

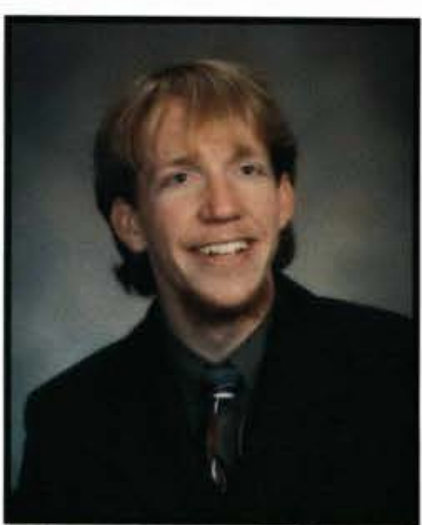

Darrin C. Smith Biology

Gosport, IN

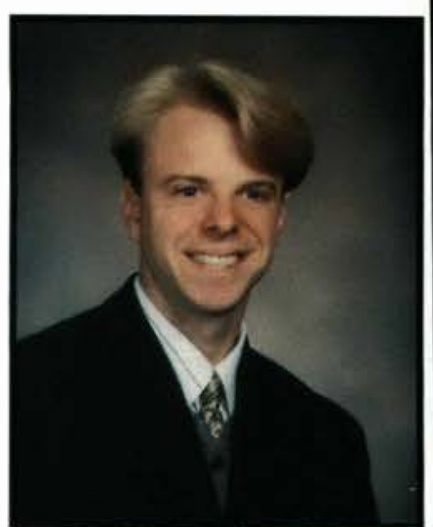

Scoll D. Sham

Church Music Ministry

Canal Winchester, $\mathrm{OH}$

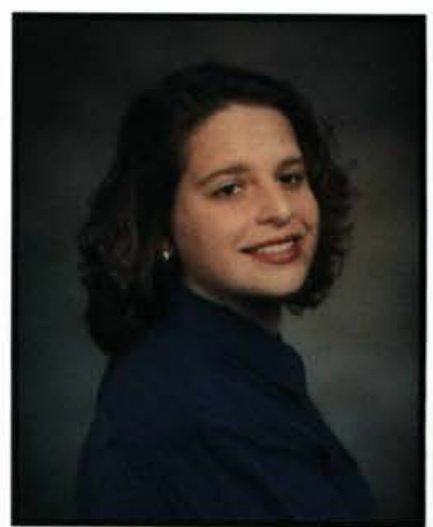

Lestey Mb. Shover Nursing

Duncannon, PA

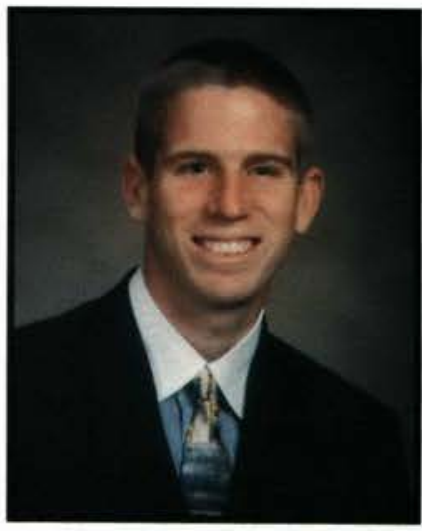

Daniel. Ab. Shurdal Mechanical Engineering Bel Air, MD

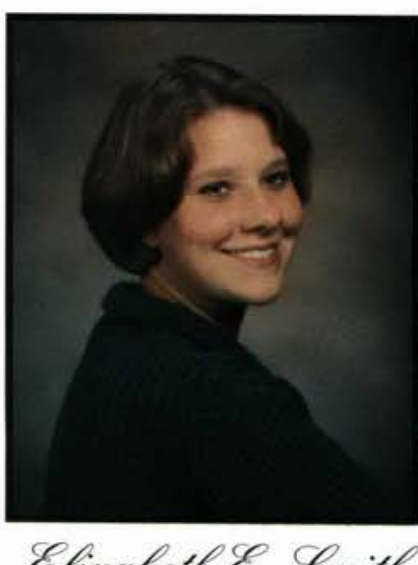

Applied Psychology Hurricane, WV 

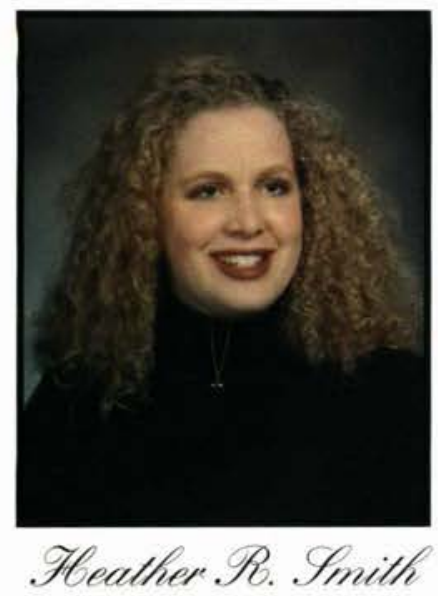

Public Administration

Neshanic, N]

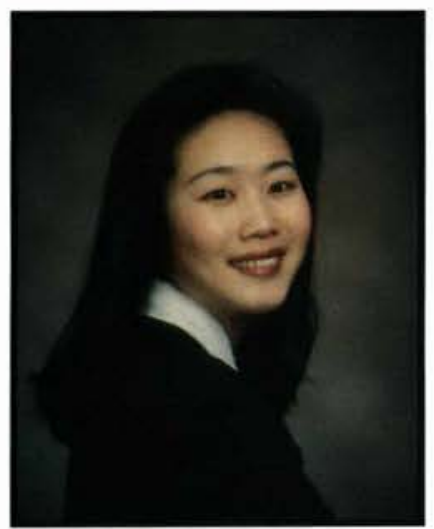

Kaathy Solm

Nursing

Chicago, IL

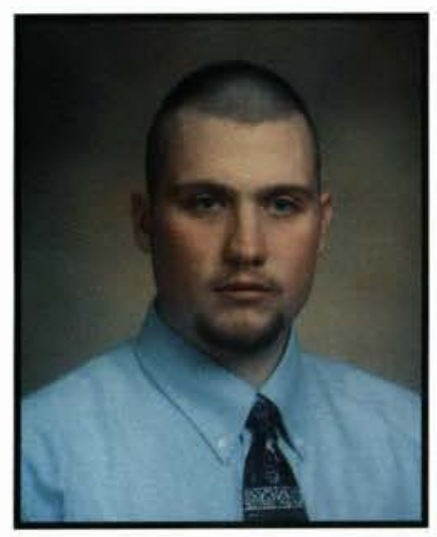

Tames Snottsuood

Criminal Justice

Orford, $\mathrm{NH}$

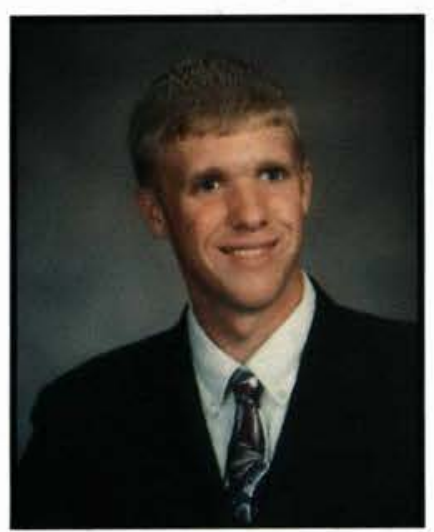

Eric F. Seenuyfo

Mechanical Engineering

Zeeland, MI

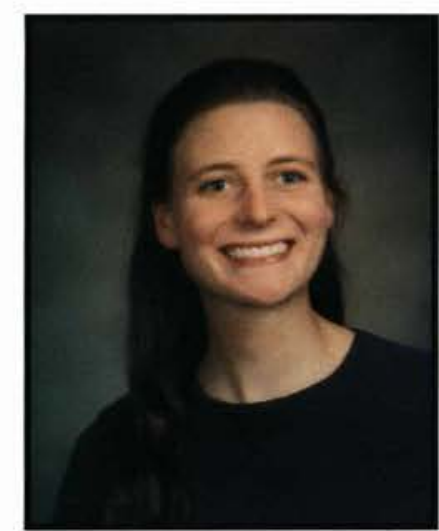

Presian R. Smyers:

Bible Comprehensive Uniontown, $\mathrm{OH}$

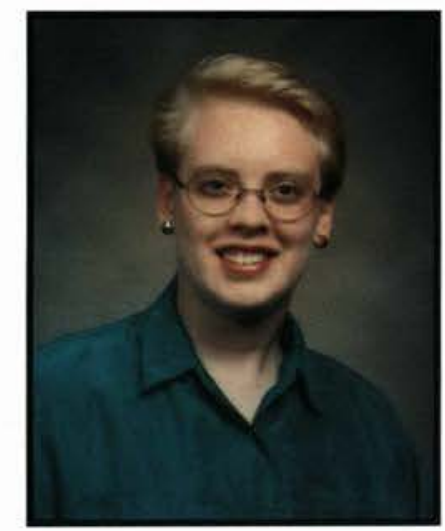

Bebelicate M. Sorenien Elementary Education

Hoffman Estates, IL

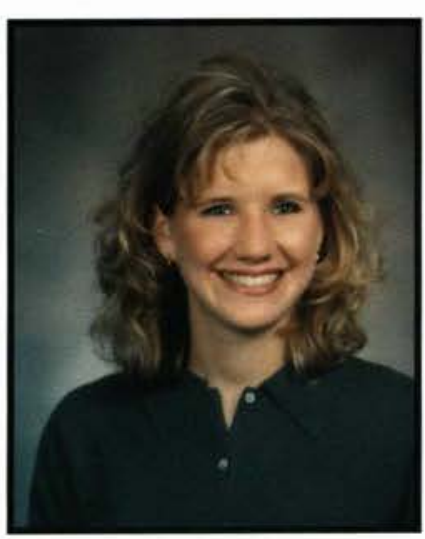

Amy L D. Spurling Marketing Jamesville, NY

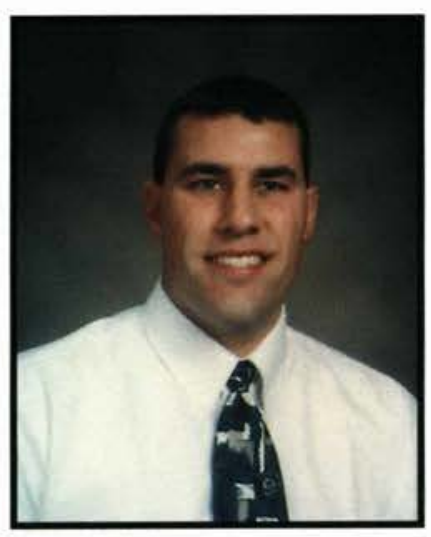

Kevin E. Stern

American Studies

Pleasant Hill, $\mathrm{OH}$

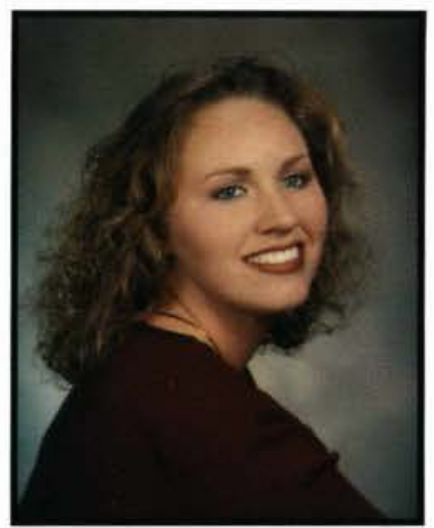

Shannon S. Show

English Education

Cambridge Springs, PA

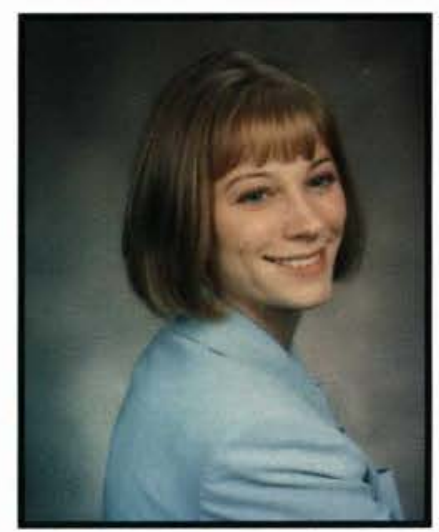

Bebecca G. Southuell

Physical Education

Etters, PA

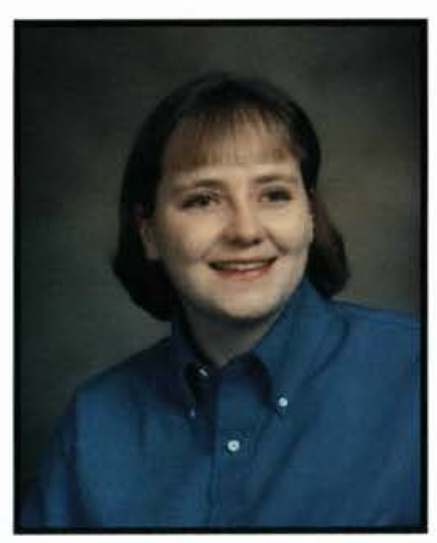

Fendra M. Slanton

Elementary Education

Pepperell, MA

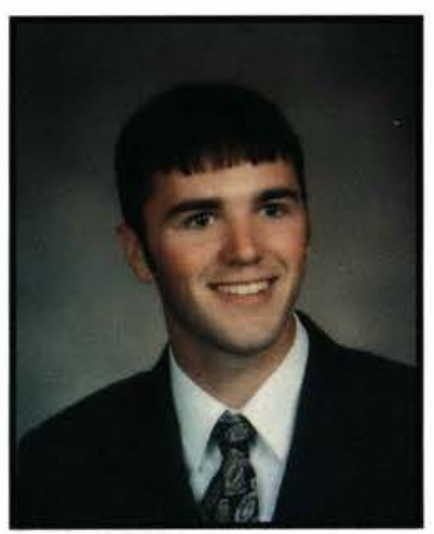

Darin P. Hevens

Bible Comprehensive

Hudsonville, MI

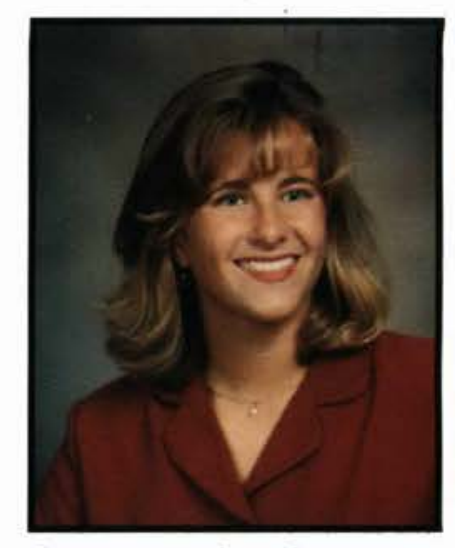

Bachel $\mathscr{L}$. Soderstrom Elementary Education Austin, MN

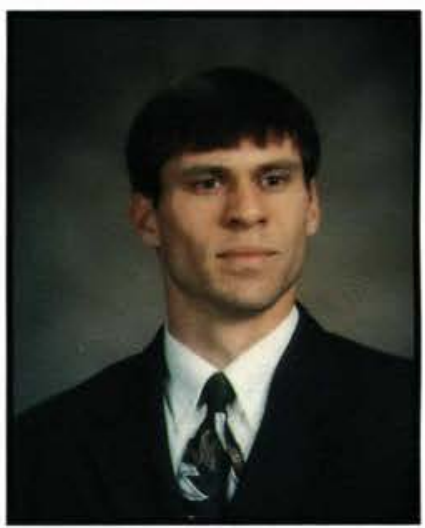

Todd E. Prangler

Management/Marketing

Vinton, VA

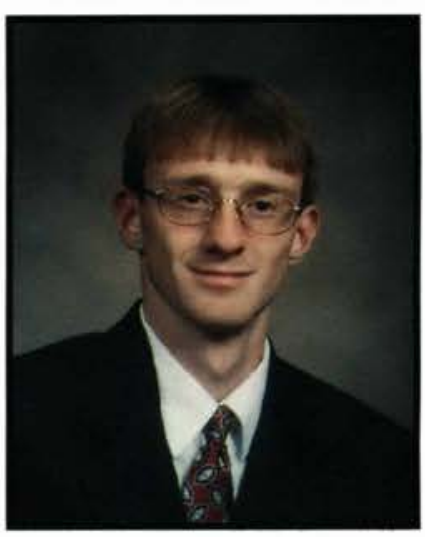

Neal. A. Slark

Marketing

Fallston, MD

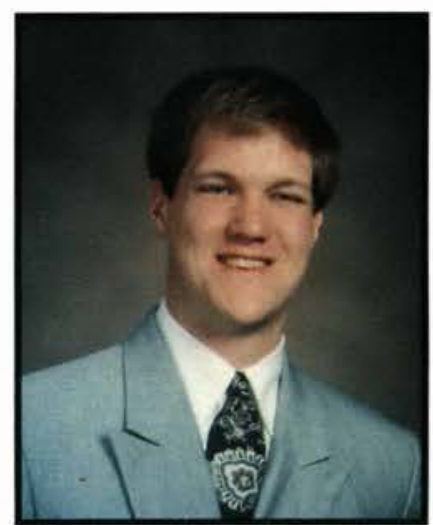

David T Heves Biology

Columbus, PA 


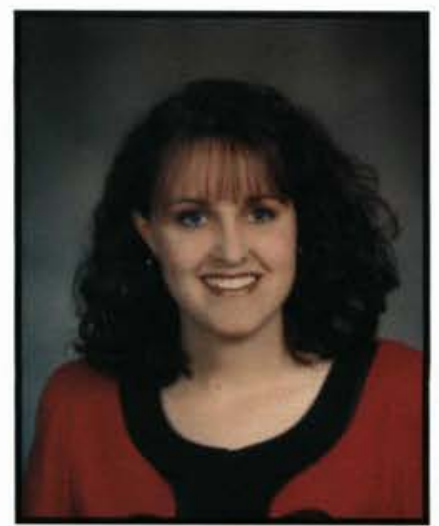

Elizabeth F. Slewart

Music Education

Cincinnati, $\mathrm{OH}$

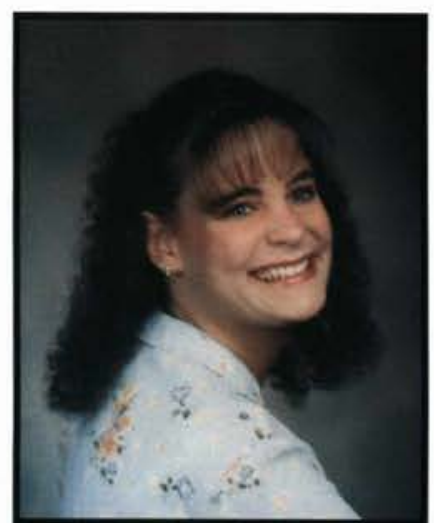

Aimee L. Slout

Elementary Education

Westerville, $\mathrm{OH}$

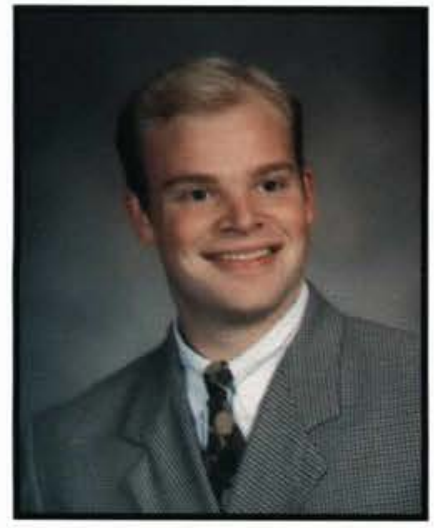

Bandall T. Hirong

Bible Comprehensive

Beech Grove, IN

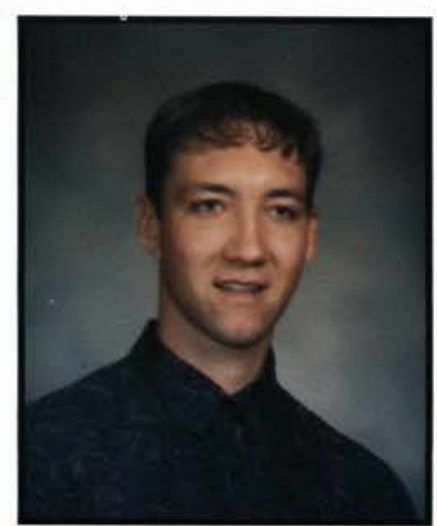

Benjamin O. Sulzman Biology

Keota, IA

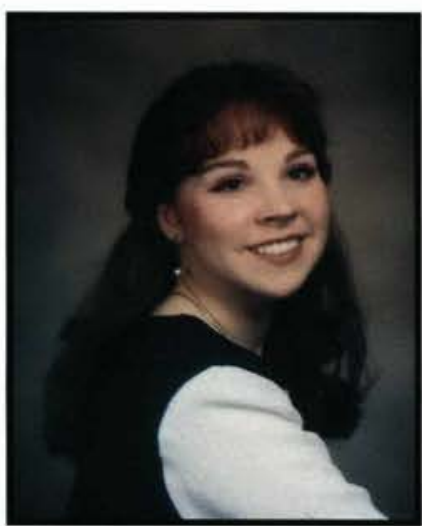

Michelle L. Slock

Broadcasting

Eaton Rapids, MI

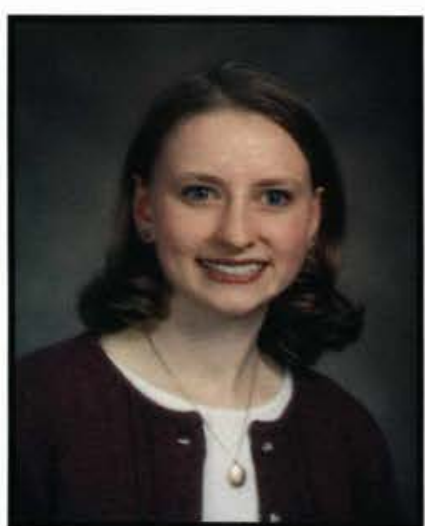

Tennifer OO. Slover

Elementary Education

Dayton, $\mathrm{OH}$

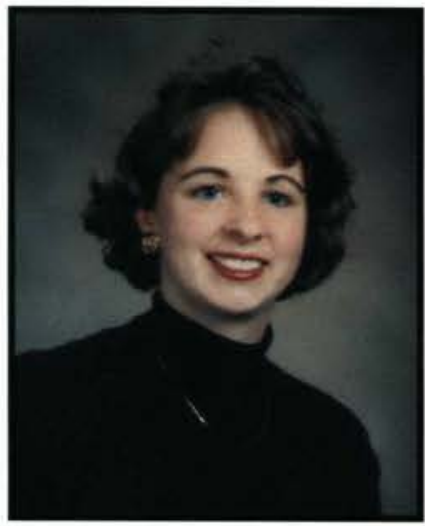

Abigail S. Siroven Biology

Grant, MI

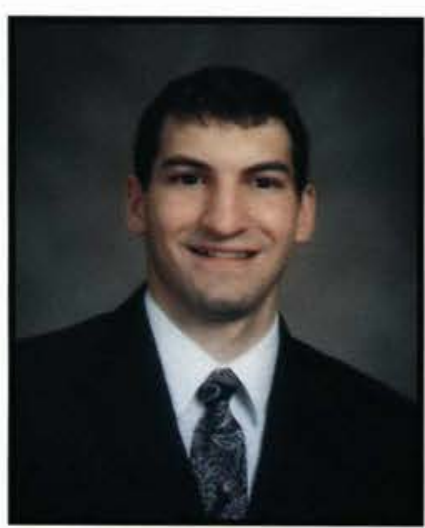

Mall Slutzman History

Twinsburg, $\mathrm{OH}$

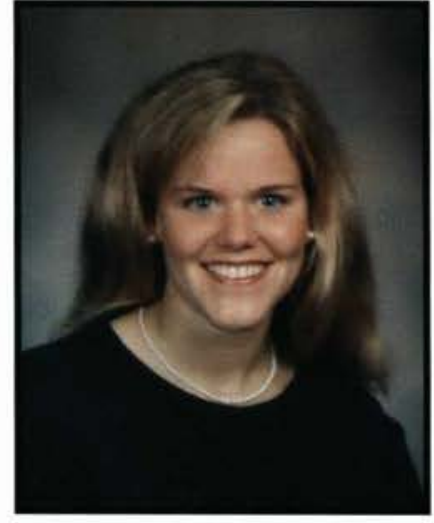

Glison F. Shone

Elementary Education

Byron Center, MI

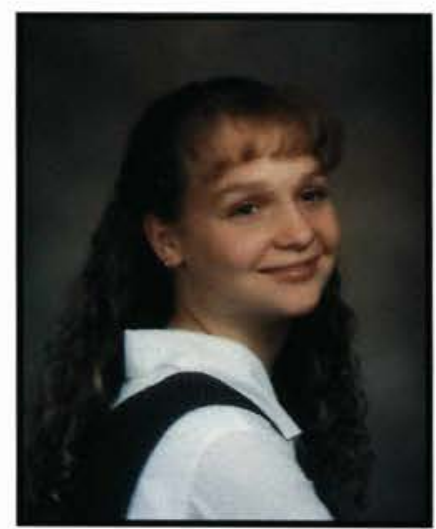

Stophanie Ab. Srreelman

Elementary Education

St. Clairsville, $\mathrm{OH}$

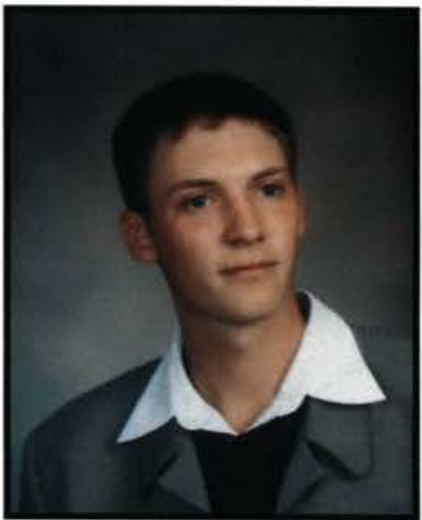

Ghristopher Mb. Aruchabili: Bible Comprehensive

$$
\text { Lebanon, IN }
$$

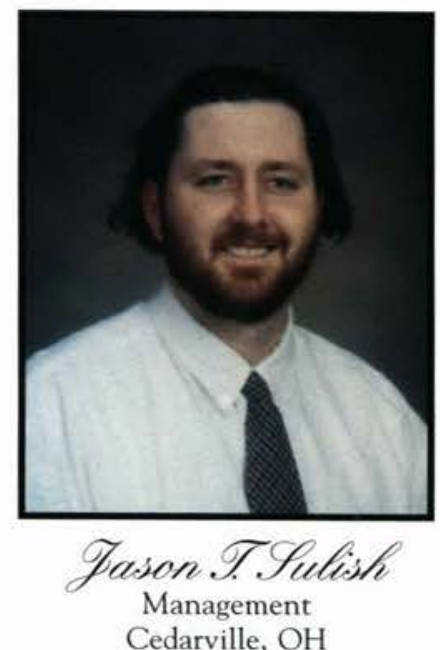

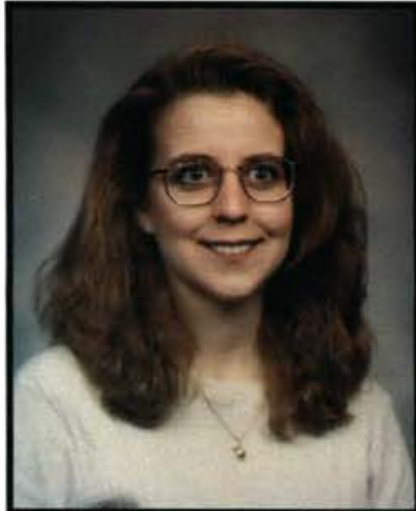

Elizabeth. Hone

Applied Psychology Poca, WV

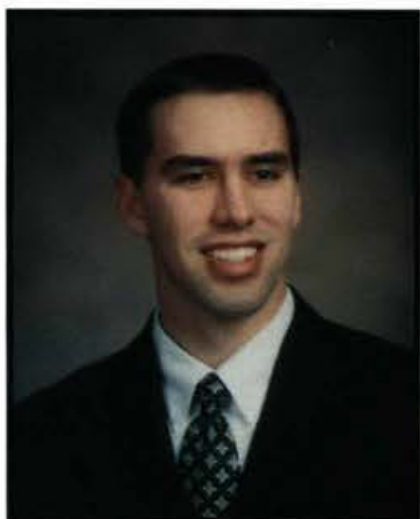

Teremy E. Strong

Athletic Training

Freeport, IL

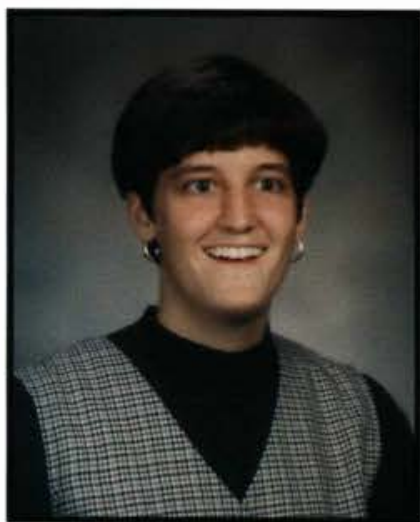

Tesisica A. Suenzi Nursing

West Salem, WI

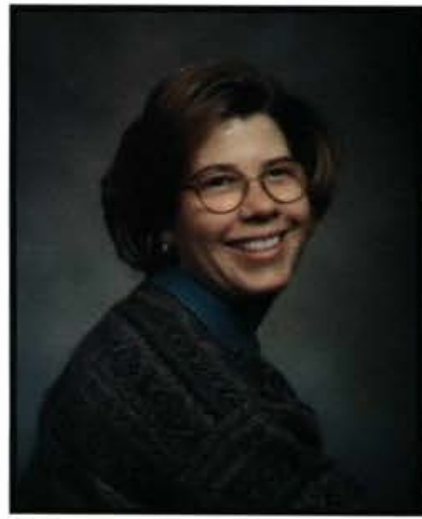

Shauna E. Summers

Applied Psychology Ft. Wayne, IN 


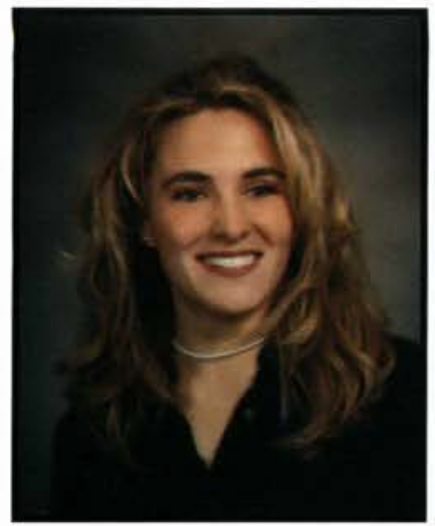

Susanne L. Sulter

Applied Psychology

Langhorne, PA

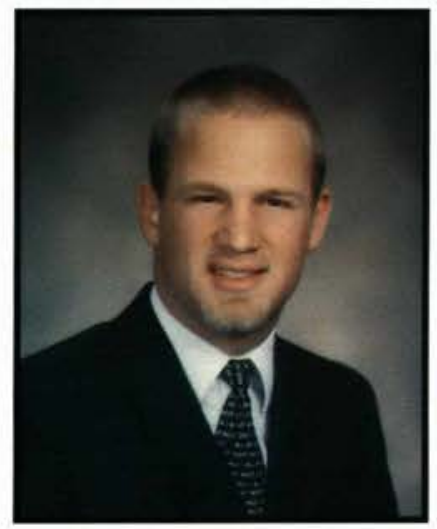

Daniel OF. Femmeifeld

Accounting

Kettering, $\mathrm{OH}$

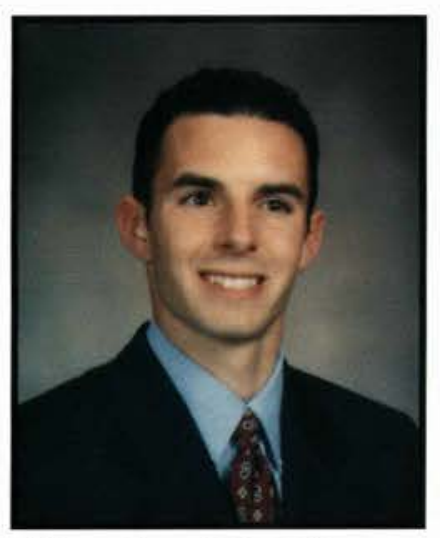

Matthew. S. Thompion

Management/Finance

New Palestine, IN

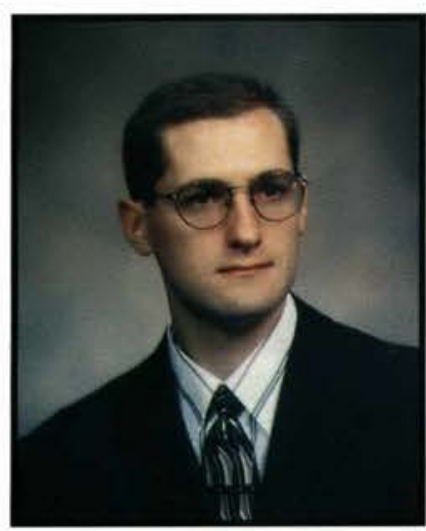

Prad C. Obmland

Finance/Accounting

Summerfield, FL

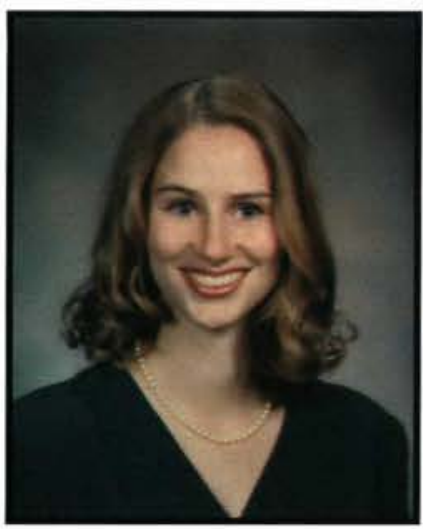

Brenda L. Tabberer

Professional Writing

Alto, MI

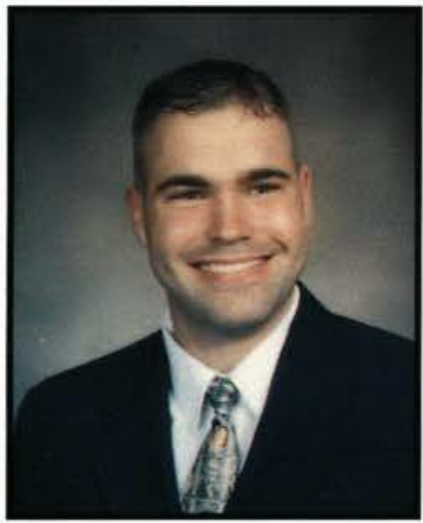

Benjamin O. Thirey

Wilmington, $\mathrm{OH}$

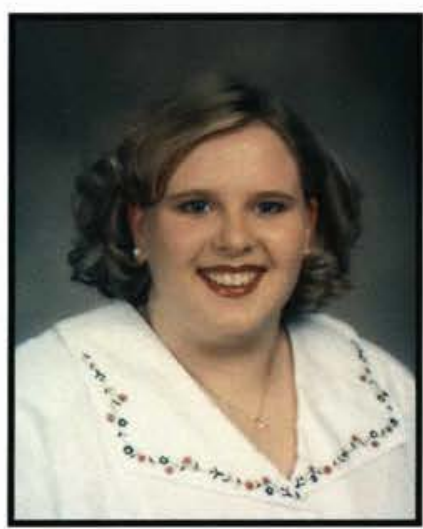

Sarah E. Fowniend

Communication Arts

Indianapolis, IN

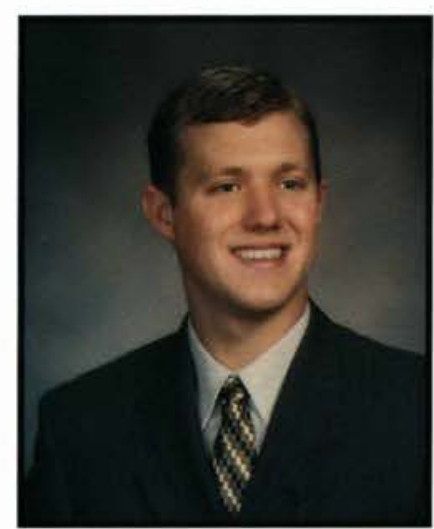

Toull QV. Tan boo Social Science

Bellville, $\mathrm{OH}$

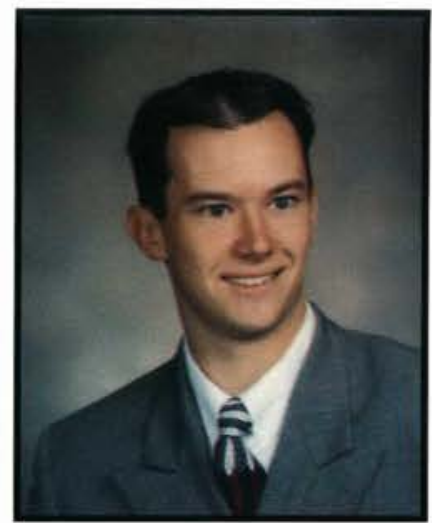

Brooke M. Faylor

Bible Comprehensive

$$
\mathrm{APO}, \mathrm{AE}
$$

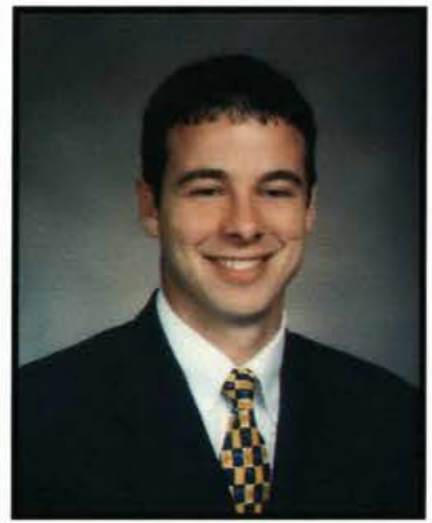

Pall P. Thoma;

Mechanical Engineering

Garrett, PA

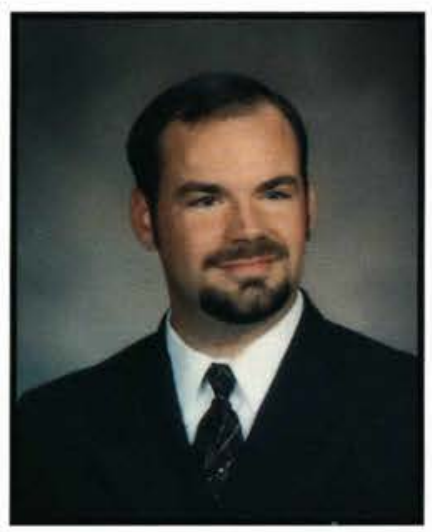

Teremy. T.Toyer

Bible Comprehensive

Haddon Heights, NJ

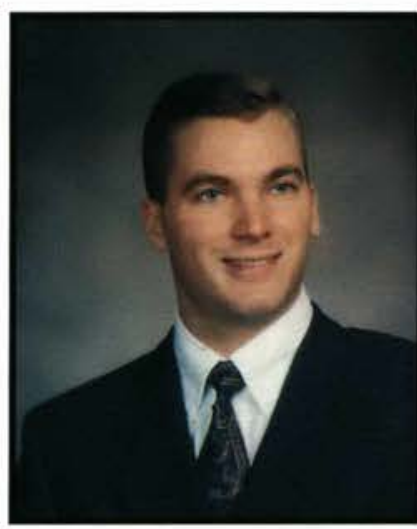

Scoll Ilb. Tandergrift Management

North Canton, $\mathrm{OH}$

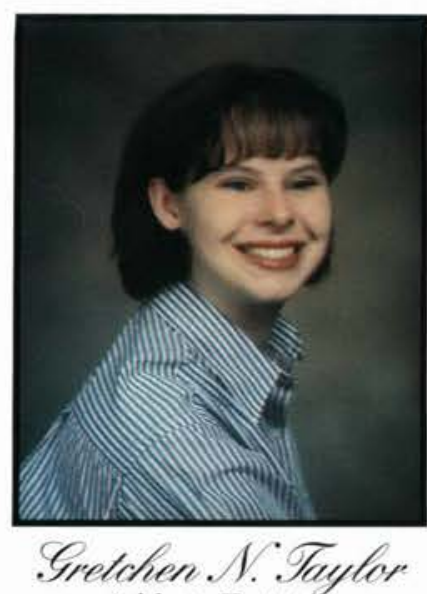

Athletic Training

Cedarville, $\mathrm{OH}$

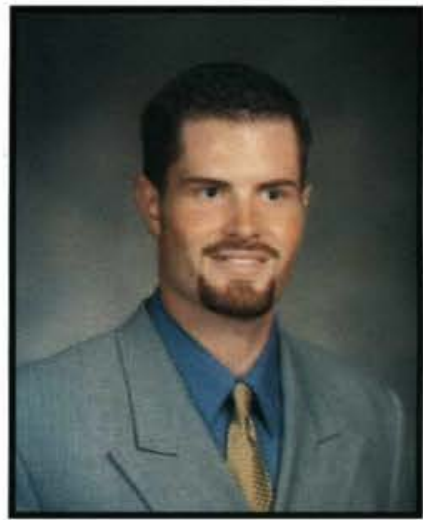

Sregory S. Thompion Marketing

Solon, $\mathrm{OH}$

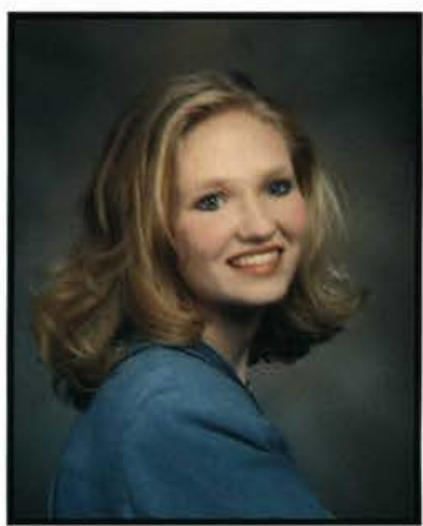

Trisha Ml Froil

Bible Comprehensive Lena, IL

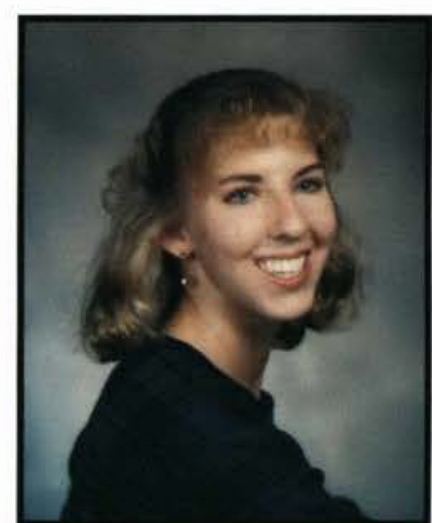

Fennifer. Il. Tander: Buise Communication Arts

Dowingtown, PA 


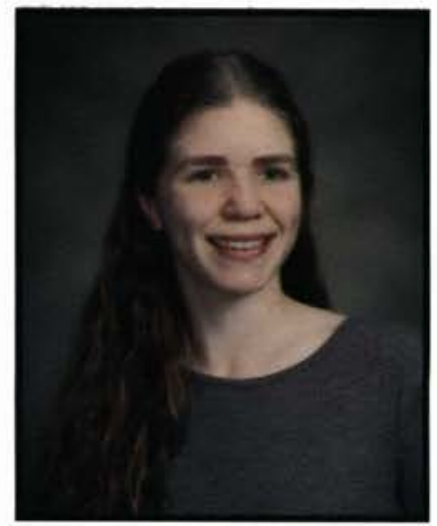

Bethany Taught English

Ketchikan, AK

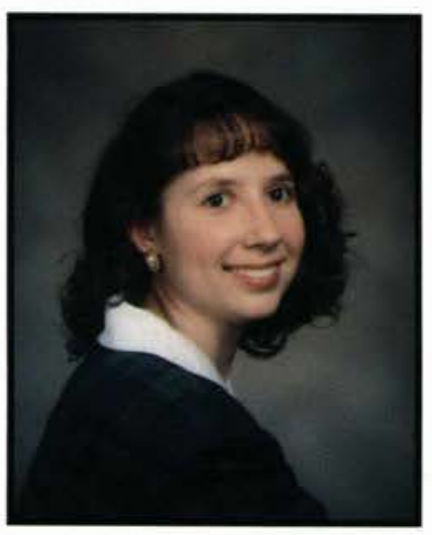

Amy E. Tolpe

Comprehensive Science

West Seneca, NY

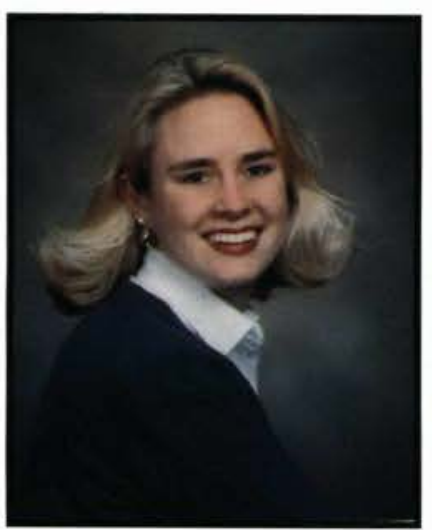

Dana Walter.

Elementary Education/Spanish Millersburg, PA

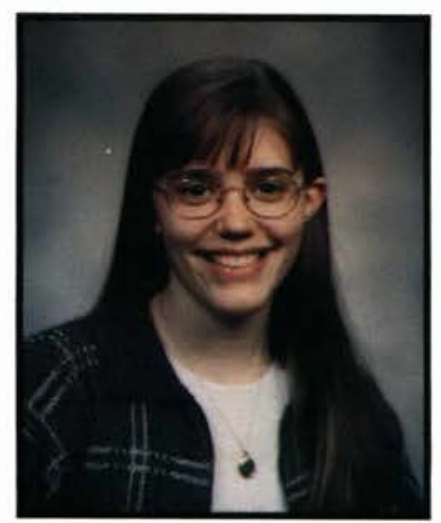

Kelly L. Warriner

Professional Writing

Wellsboro, PA

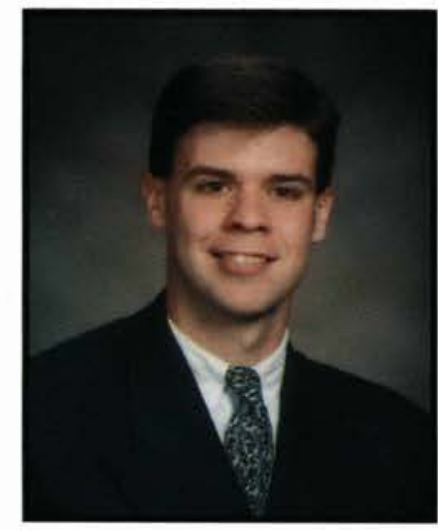

Reuben 2. Tauter

Music/Multimedia Technology

Brownsburg, IN

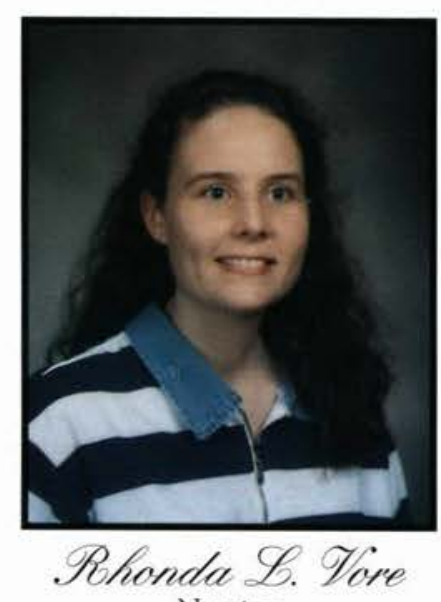

Cedarville, $\mathrm{OH}$

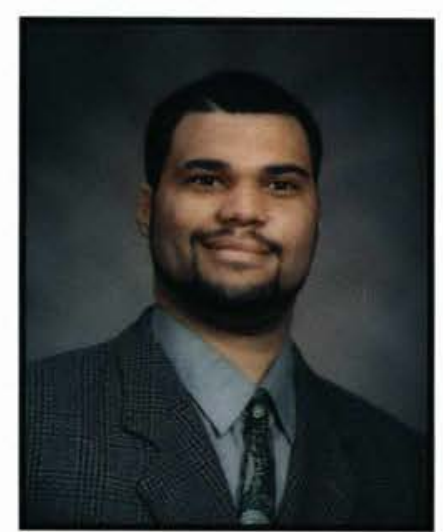

Fimathy C. Ware

History

Indianapolis, IN

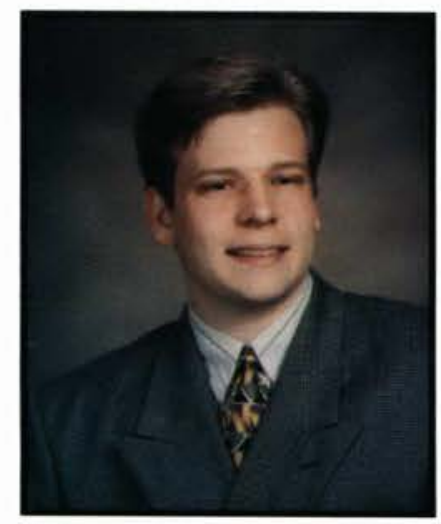

Benjamin D. Watson

Mechanical Engineering Milford, Ml

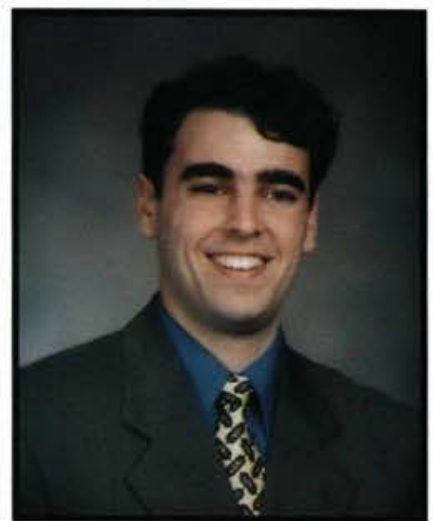

Ghristopher Tituretti

Communication Arts/Bible Comp. Livonia, MI

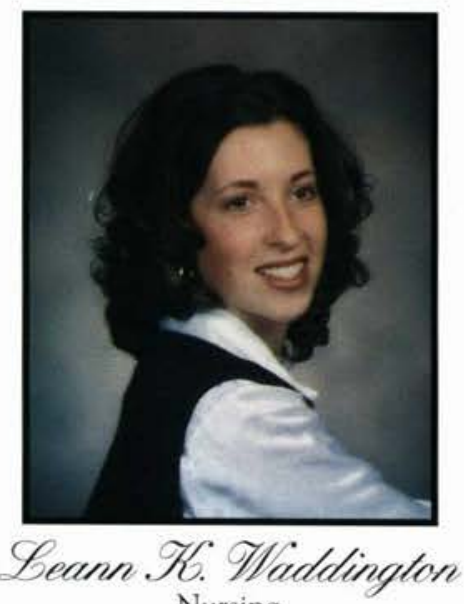

Nursing

Coleman, MI

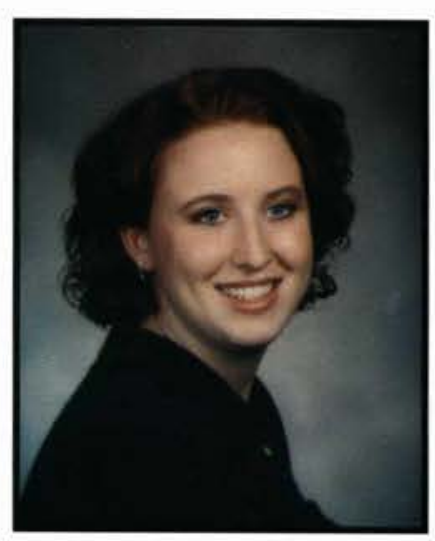

Lisa E. Tarren

Elementary Education Barberton, $\mathrm{OH}$

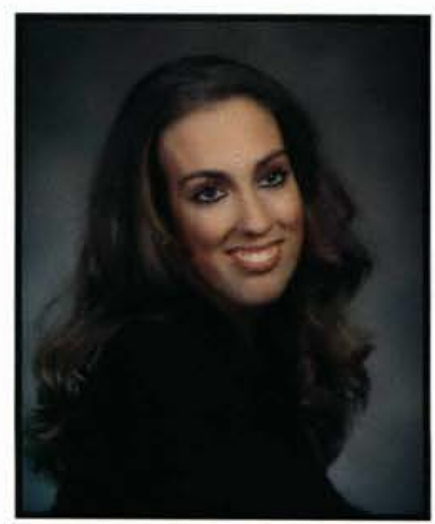

Laurie $\mathscr{L}$. Weber

Communication Arts/Bible Comp. Olympia, WA

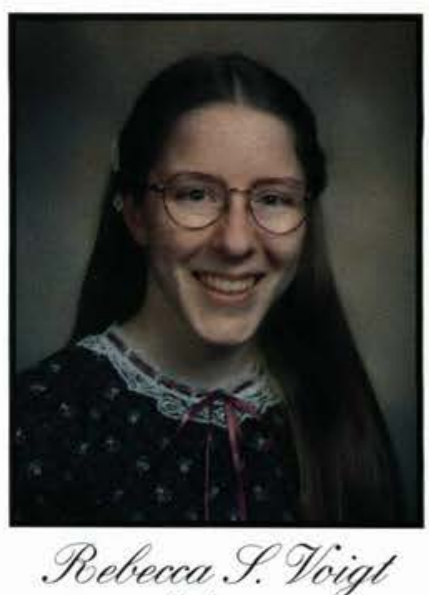

Biology

Midland, MI

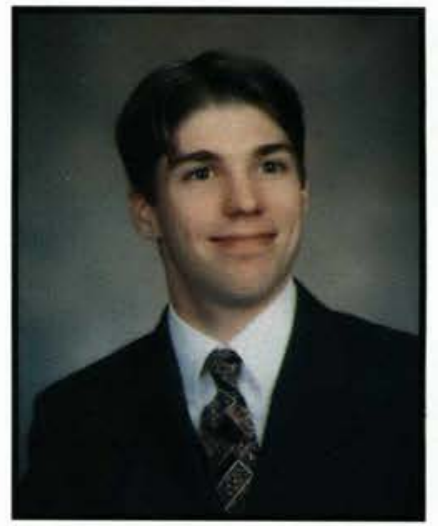

Philip Mb. Wallis

Broadcasting

Cedarville, $\mathrm{OH}$

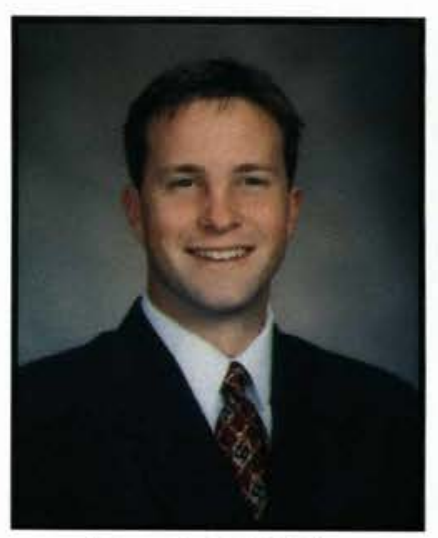

Maurf. F. Warren

Pre-Seminary

Cedarville, $\mathrm{OH}$

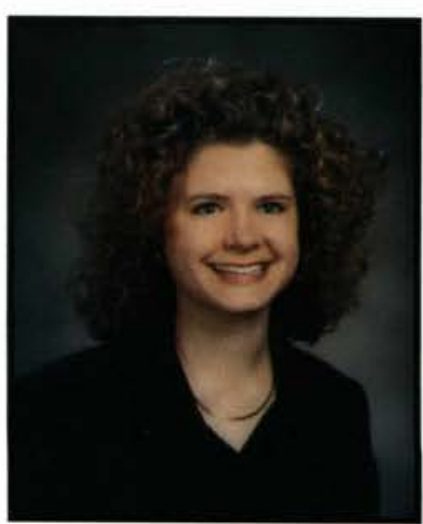

Rhonda R. Weber Elementary Education Owasso, OK 


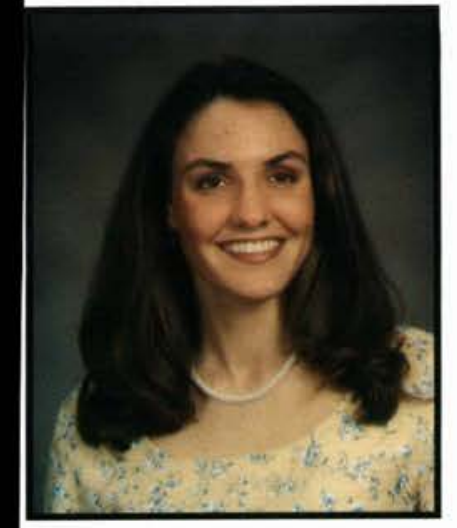

Tracy QD. Weber

Yorba Linda, CA

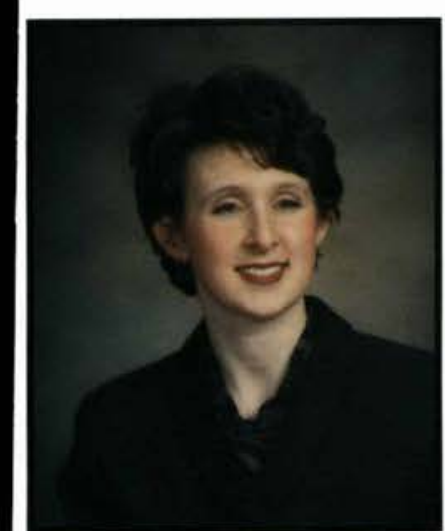

Susan E. West

Music

Temperance, MI

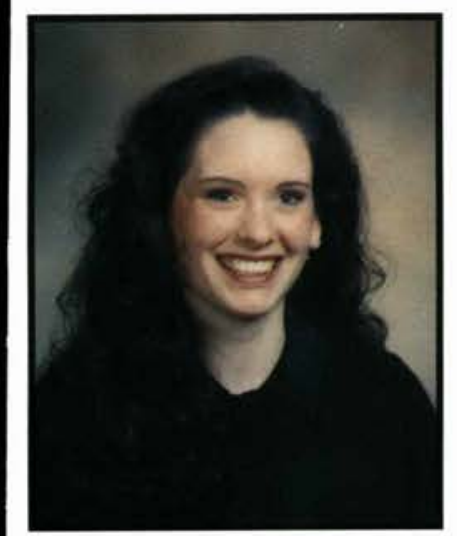

Alicisa Mb. Tllitten

Communication Arts

Romeo, MI

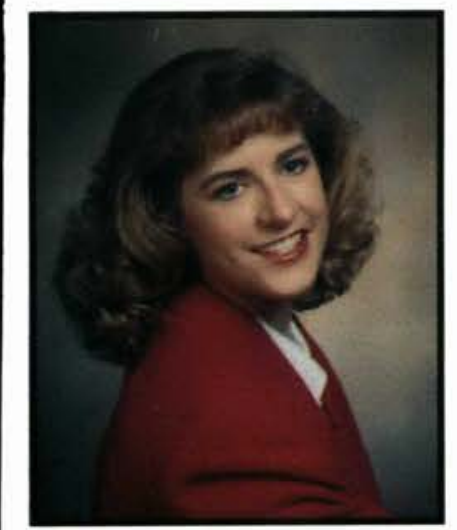

Emily H. Mifiamaa Communication Arts

Findlay, $\mathrm{OH}$

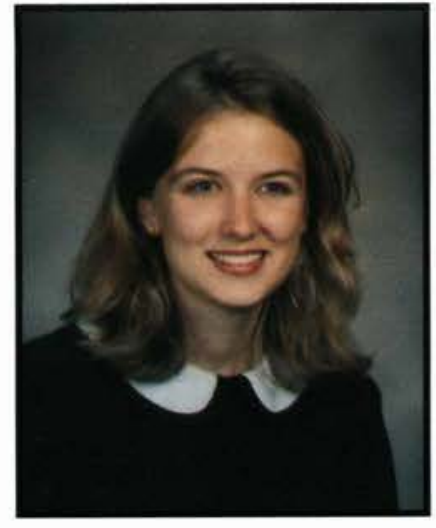

Foy L. Webster

Elementary Education

Pinellas Park, FL

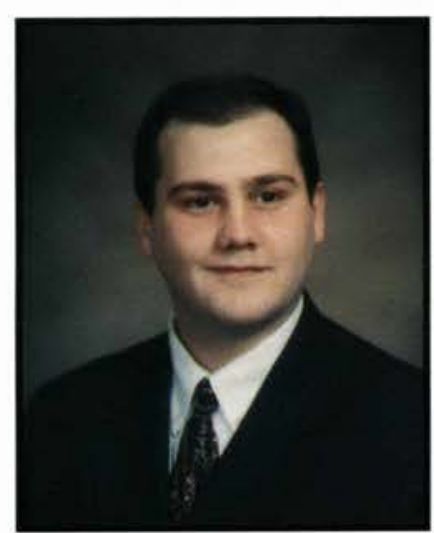

Gharlas: L. Theoler:

Bible Comprehensive Birch Run, MI

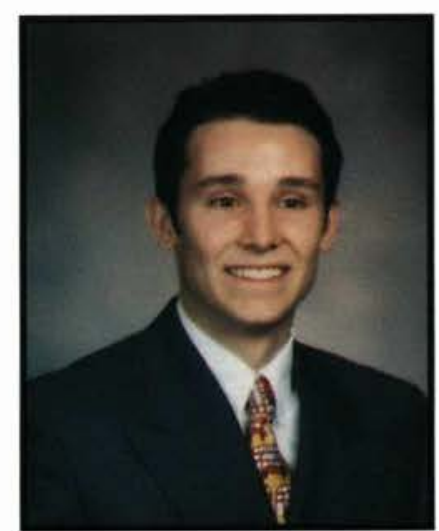

Fared A. Wich

Bible Comprehensive Glen Burnie, MD

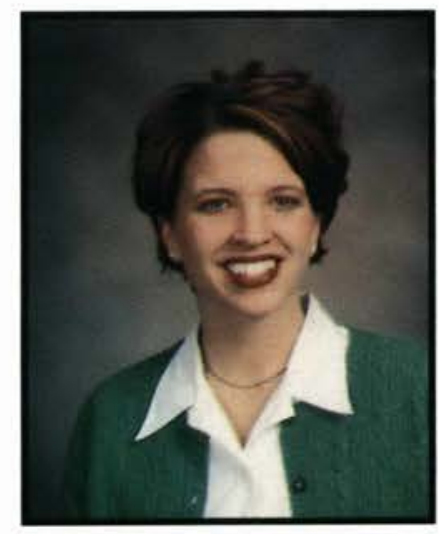

Tennifer Williamson

Elementray Education

Powell, $\mathrm{OH}$

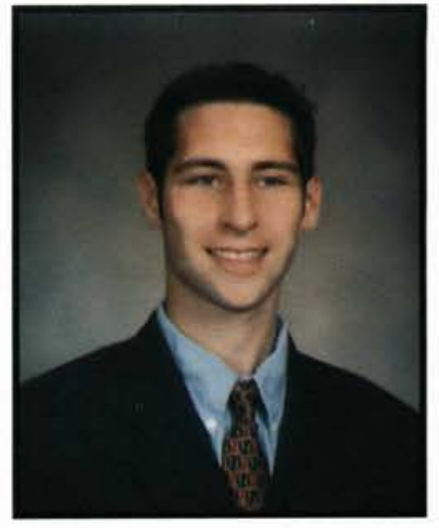

Robert S. Welner

Biology

Bath, ME

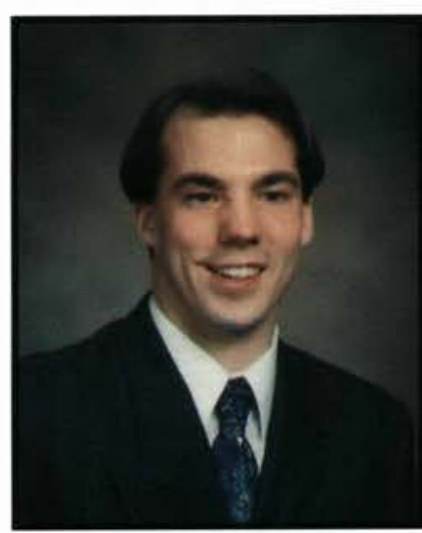

Goseph P. Whinnery

Electrical Engineering Columbus, $\mathrm{OH}$

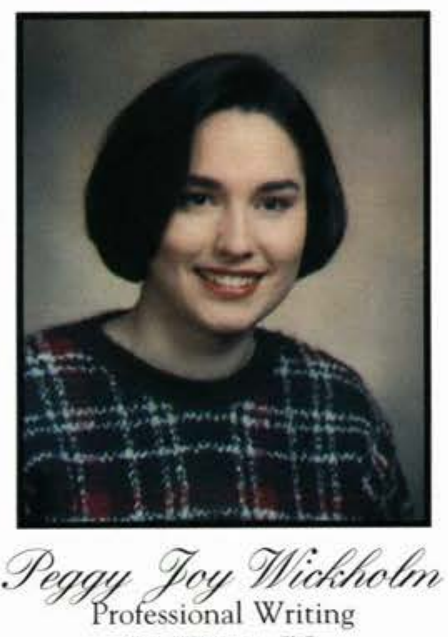

Ft. Wayne, IN

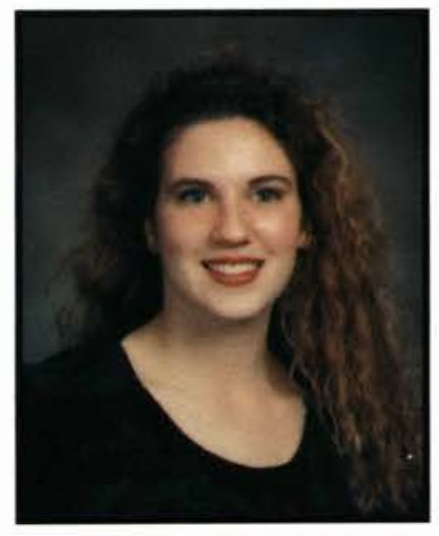

Tbolly $\underset{\text { Nursing }}{\text { Milson }}$

Mogadore, $\mathrm{OH}$

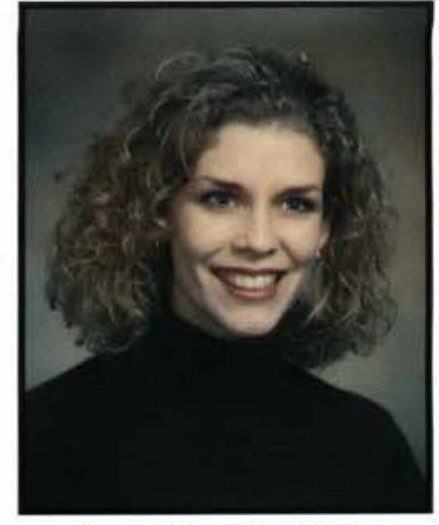

Angela L. Wenzel Communication Arts Papillion, NE

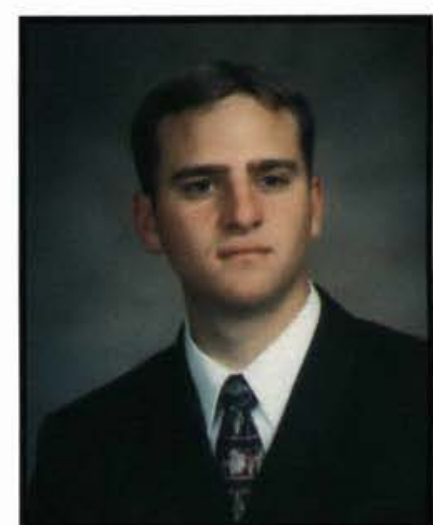

Gdum TYWhile

Marketing/Bible Comprehensive Decatur, IL

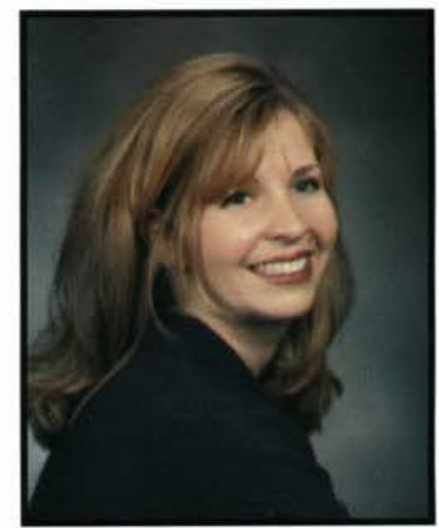

Amy L. Wilder Elementary Education

Centerville, $\mathrm{OH}$

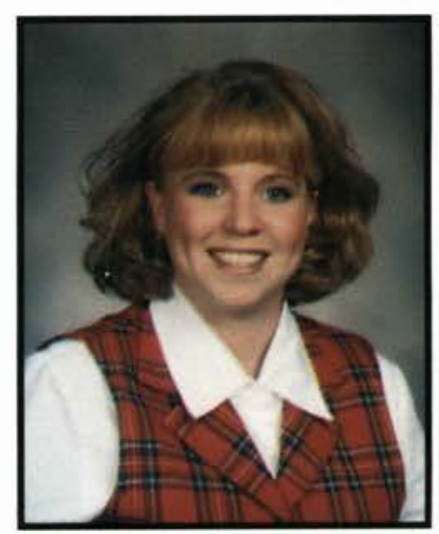

Sheri $\mathscr{K}$. Wilion

Elementary Education Batavia, $\mathrm{OH}$ 


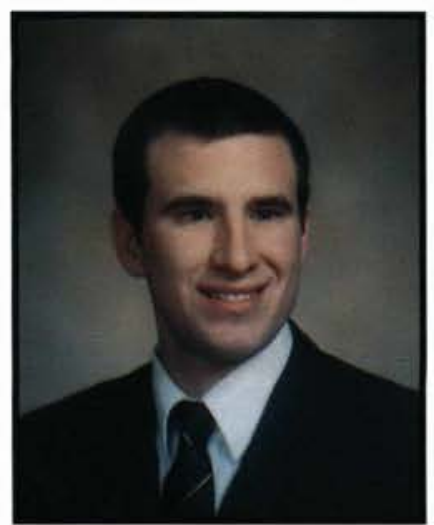

David L. Winn

Broadcasting

Morrisville, $\mathrm{PA}$

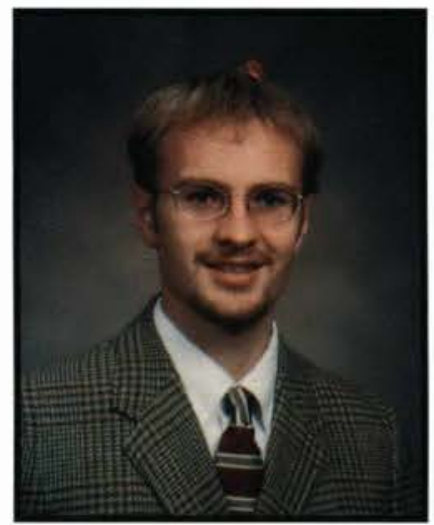

Gdam R. Witter:

International Studies

Cedarville, $\mathrm{OH}$

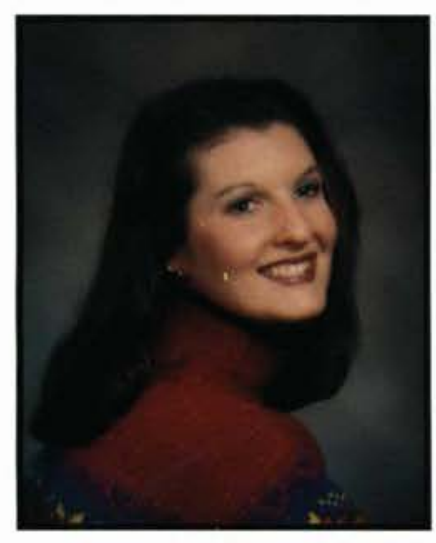

Sherri: Ko. Woodurd

Elementary Education

Onsted, MI

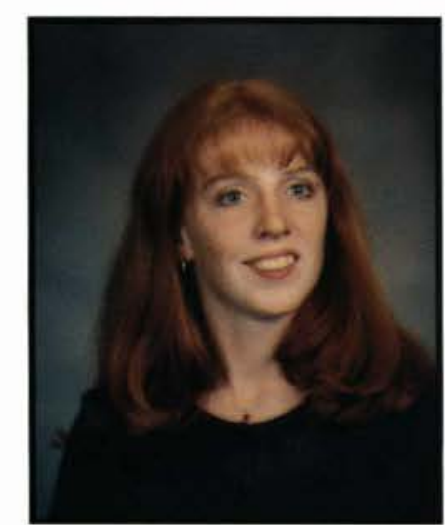

Elizabeth Wrigglesurorth Elementary Education

Cedarville, $\mathrm{OH}$

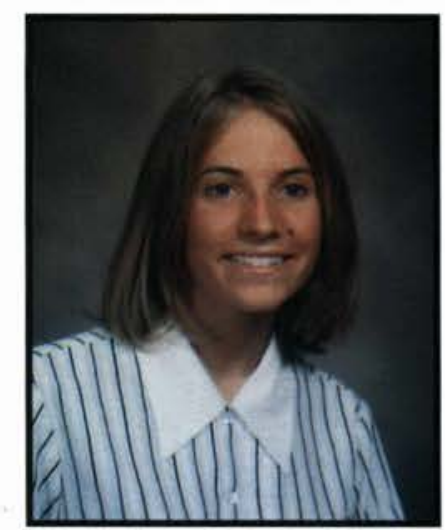

Tulie A. Wire:

English Education

North Bloomfield, $\mathrm{OH}$

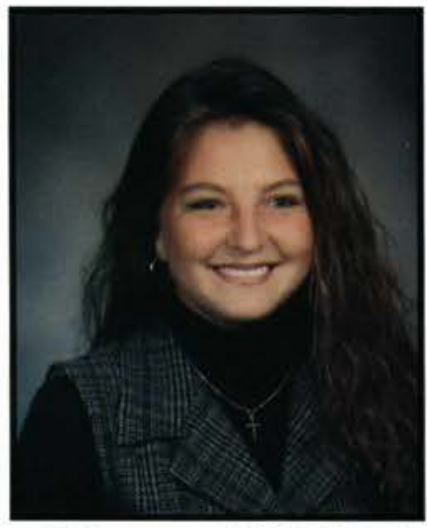

Tristin. T. Wohrle

Elementary Education

$$
\text { Grove City, OH }
$$

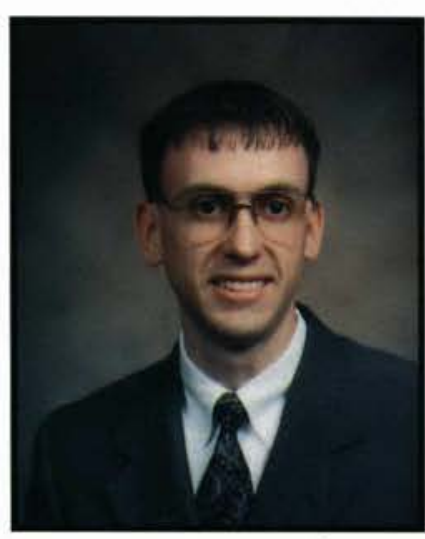

Andrew E. Toodman Computer Information Systems Grand Rapids, MI

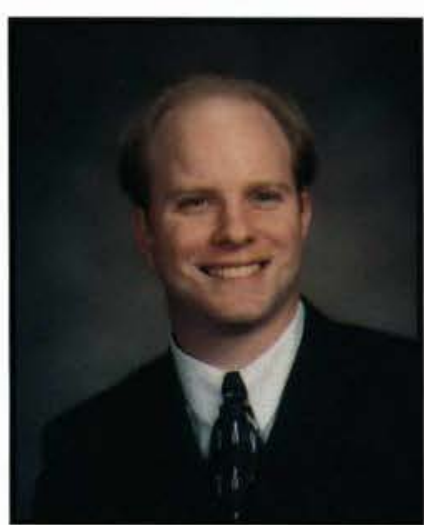

Scoll N. Trigglesworth Global Economics/International Business Cedarville, $\mathrm{OH}$

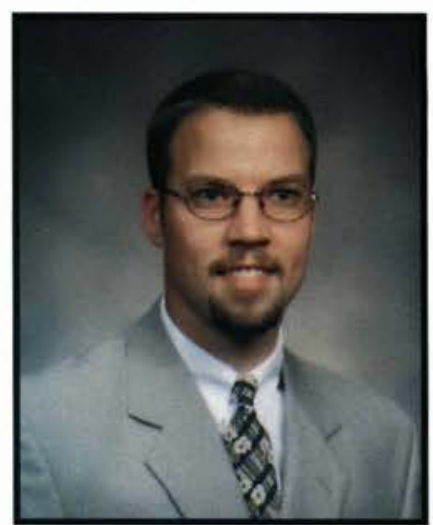

Gonathan Qf. Witmer

Bible Comprehensive

Millersburg, PA

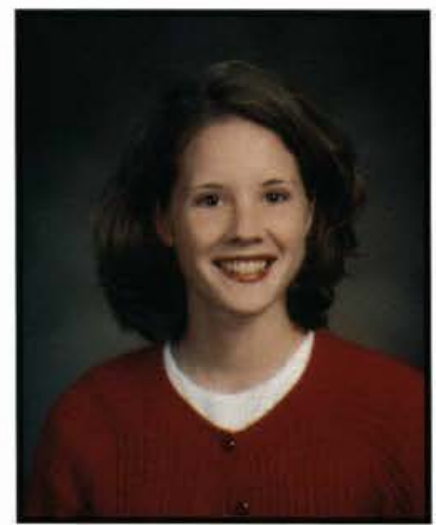

Mary E. Wolfe

Nursing

Ligonier, IN

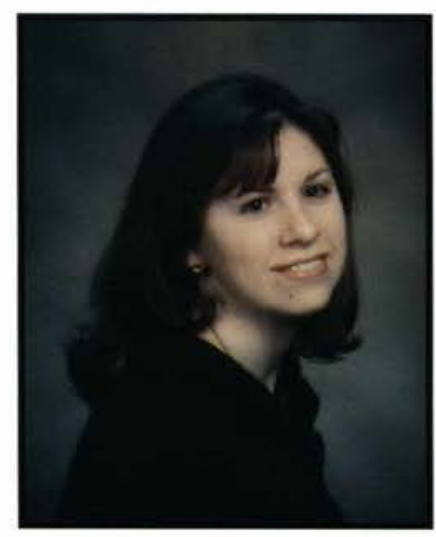

Deborah L. Woods

Elementary Education Delmar, NY

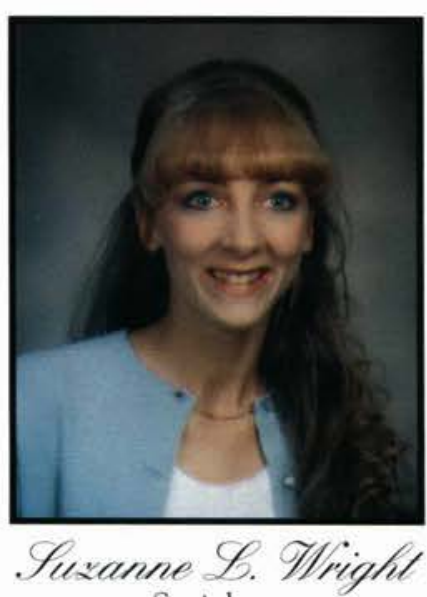
Sociology

Wadsworth, $\mathrm{OH}$

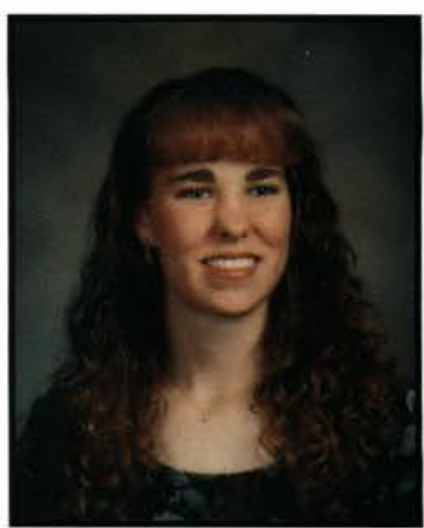

Gill. R. Witle

Nursing

Medford Lakes, N]

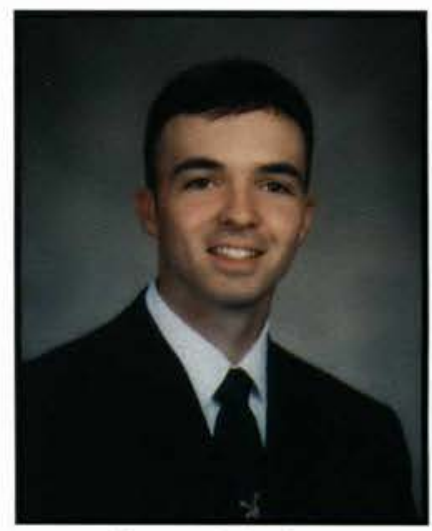

Mark E. Wood

Marketing

Clarkston, WA

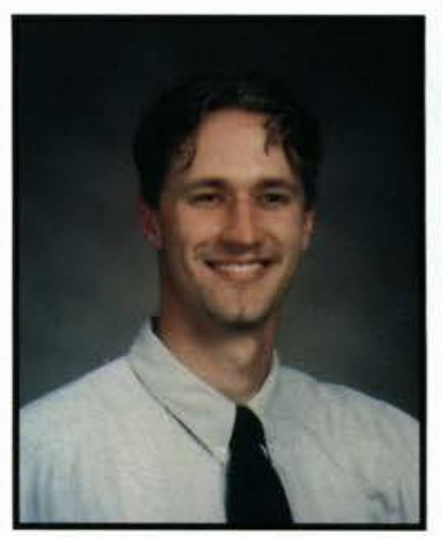

Tilliam E. Worfman

Bible Comprehensive Columbus, $\mathrm{OH}$

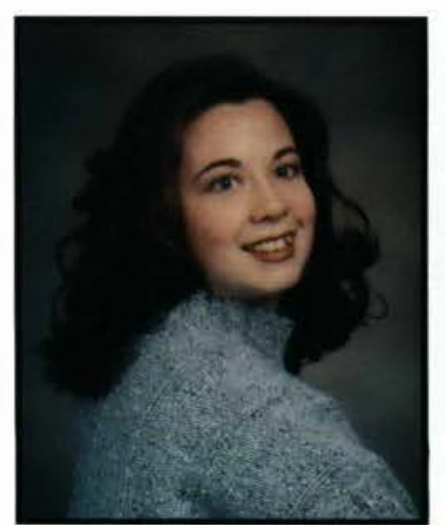

Tracie T. Wright

Nursing

Corunna, MI 


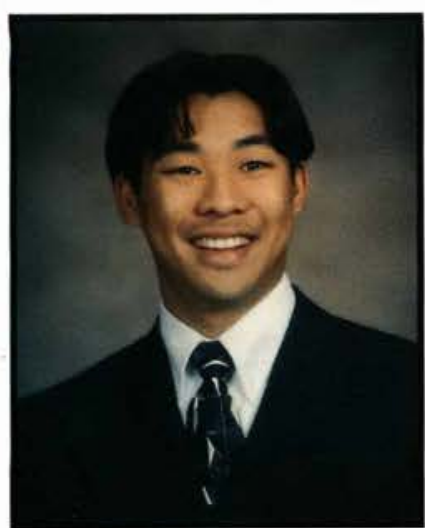

Tonathan G. Wie

Mechanical Engineering Apex, NC

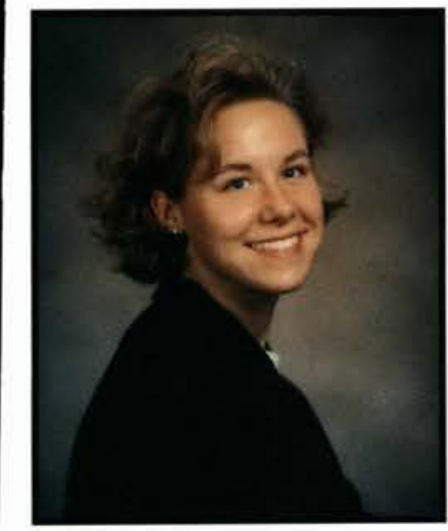
Tiffany. A. Eimmerman

Grayslake, IL

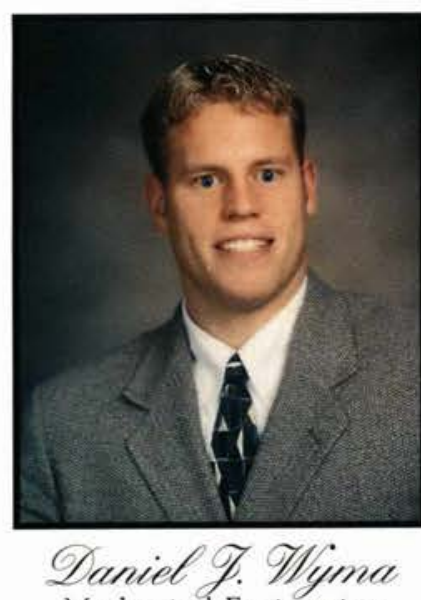

Mechanical Engineering Jenison, MI

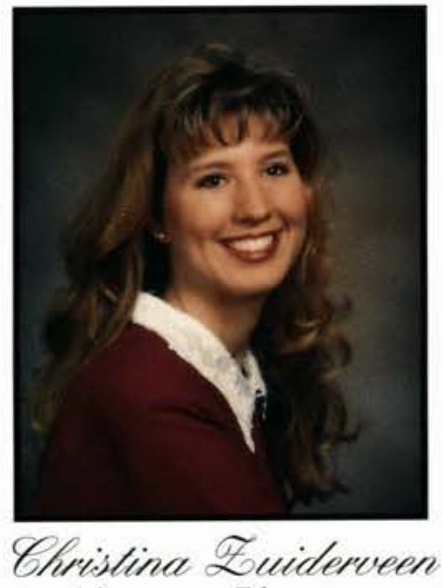

Elementary Education

Warsaw, IN

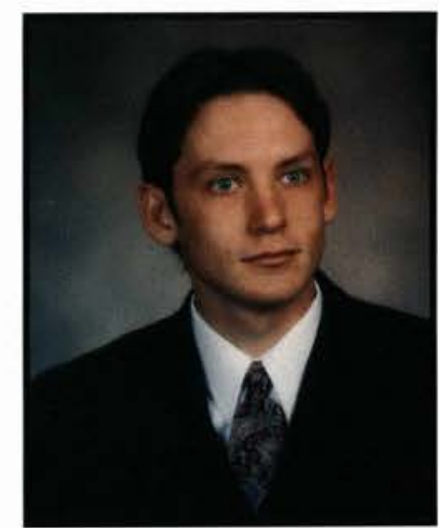

F. Nichael Yfoder Finance/Accounting Greenwood, DE

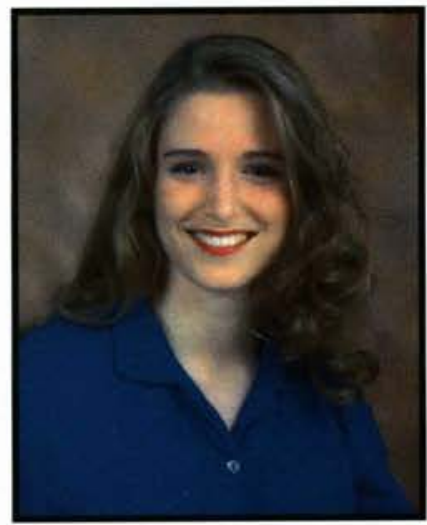
Gutie Paisithea

Eugene, ORE

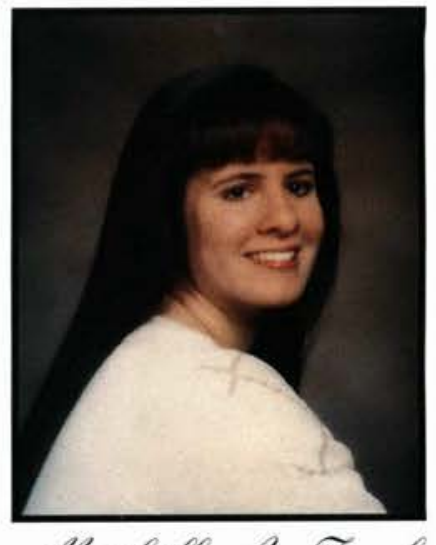

Michelle. A. Eeeb Elementary Education Belem Para 


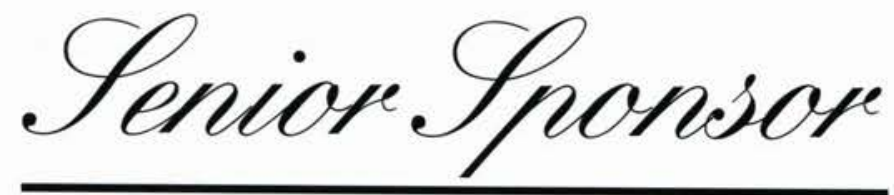

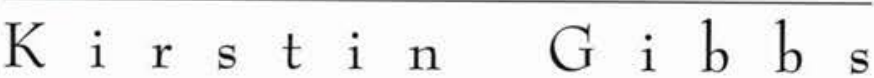

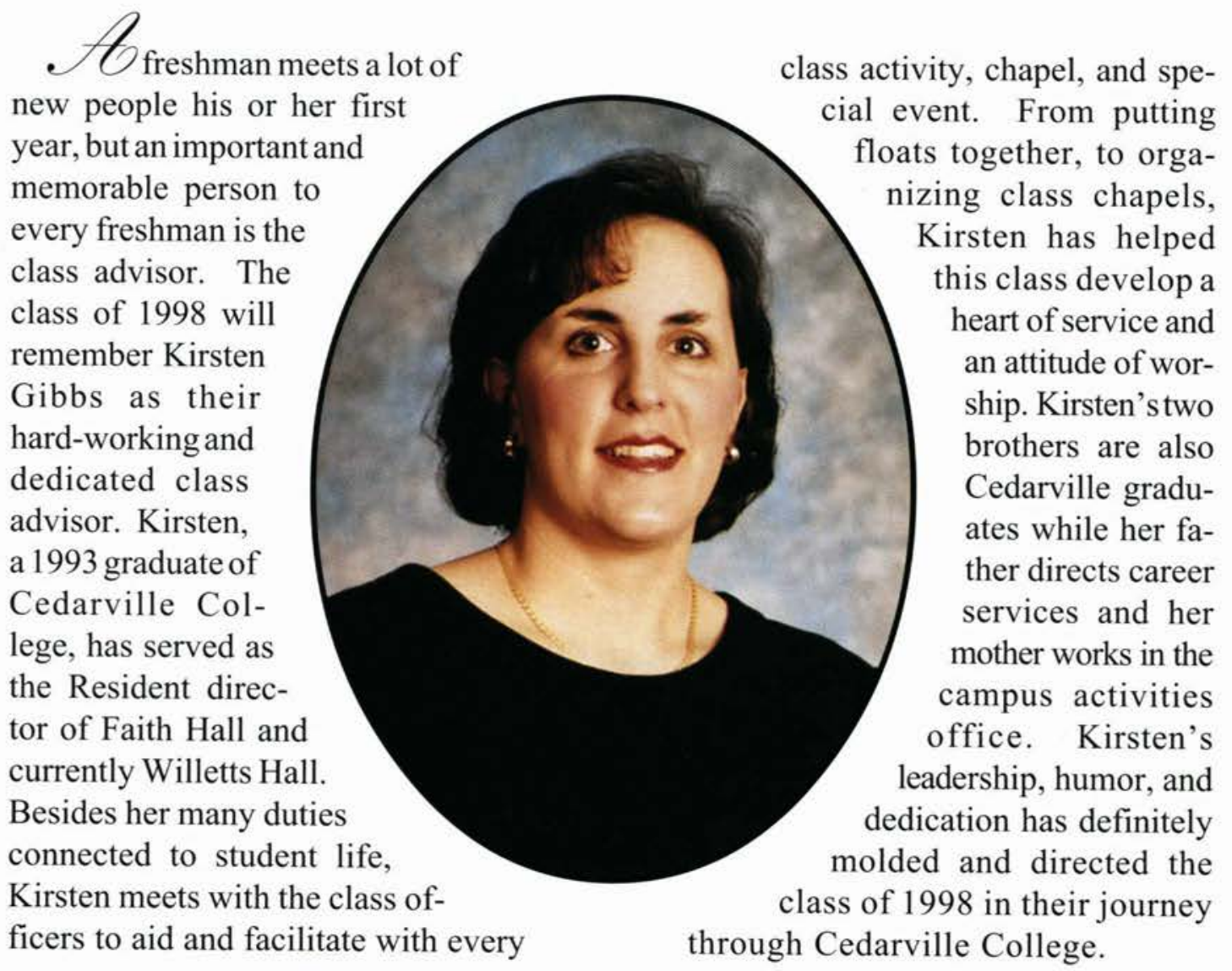

Tr the Summer of 1997, Kirsten led the South Africa MIS puppets team, which primarily ministered at ABWE churches around Durban, South Africa. Pictured right (1-r) are Jason Tovey, Chris Strychalski, Jennifer Howard, Allison Stone, Jill Barnes, Kirsten Gibbs, and Carrie Orme.

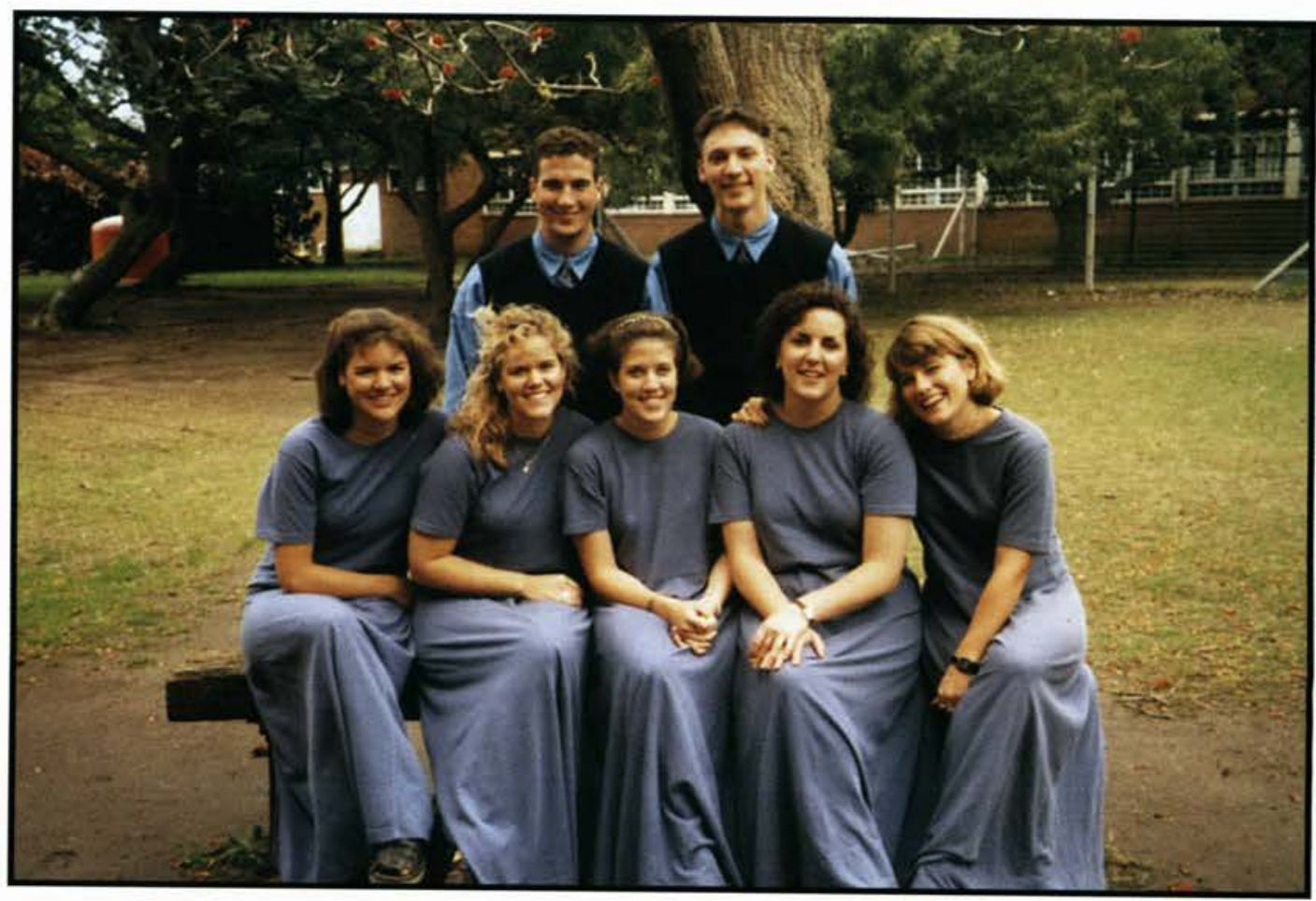




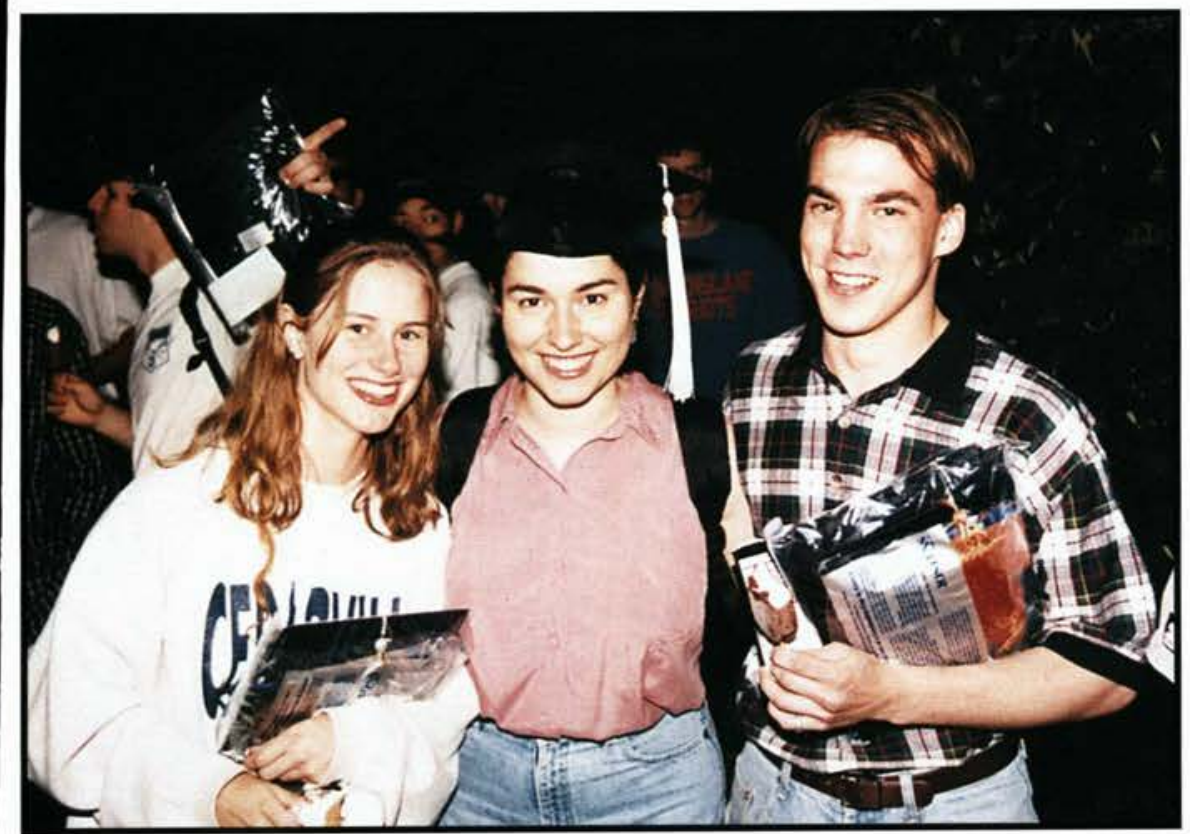

Prenda Tabberer, Joy Wickholm, and Joe Whinnery enjoy a time of fellowship at a senior gathering. (top)

OoHanna Byrer and Julie Ross show the binding tie amoung Cedarville studentsfriendship. (middle)

Kendra Stanton and Josh Haluko enjoy the events at a senior event. (bottom left)

Greg Dyson, in joyous anticipation of commencement day, eagerly recieves his graduation packet. (bottom right)
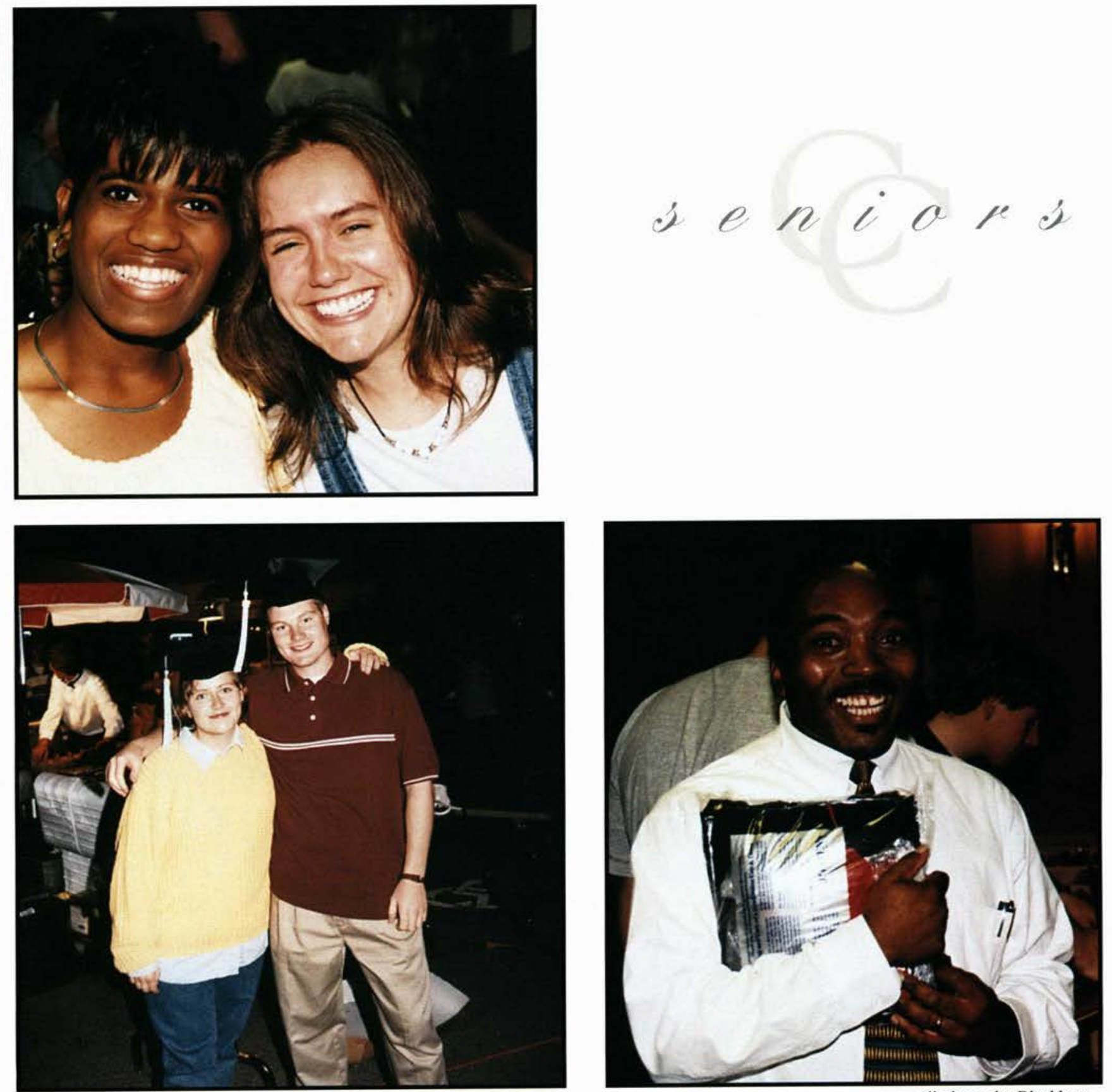

all photos by Blackburn 


\section{The}
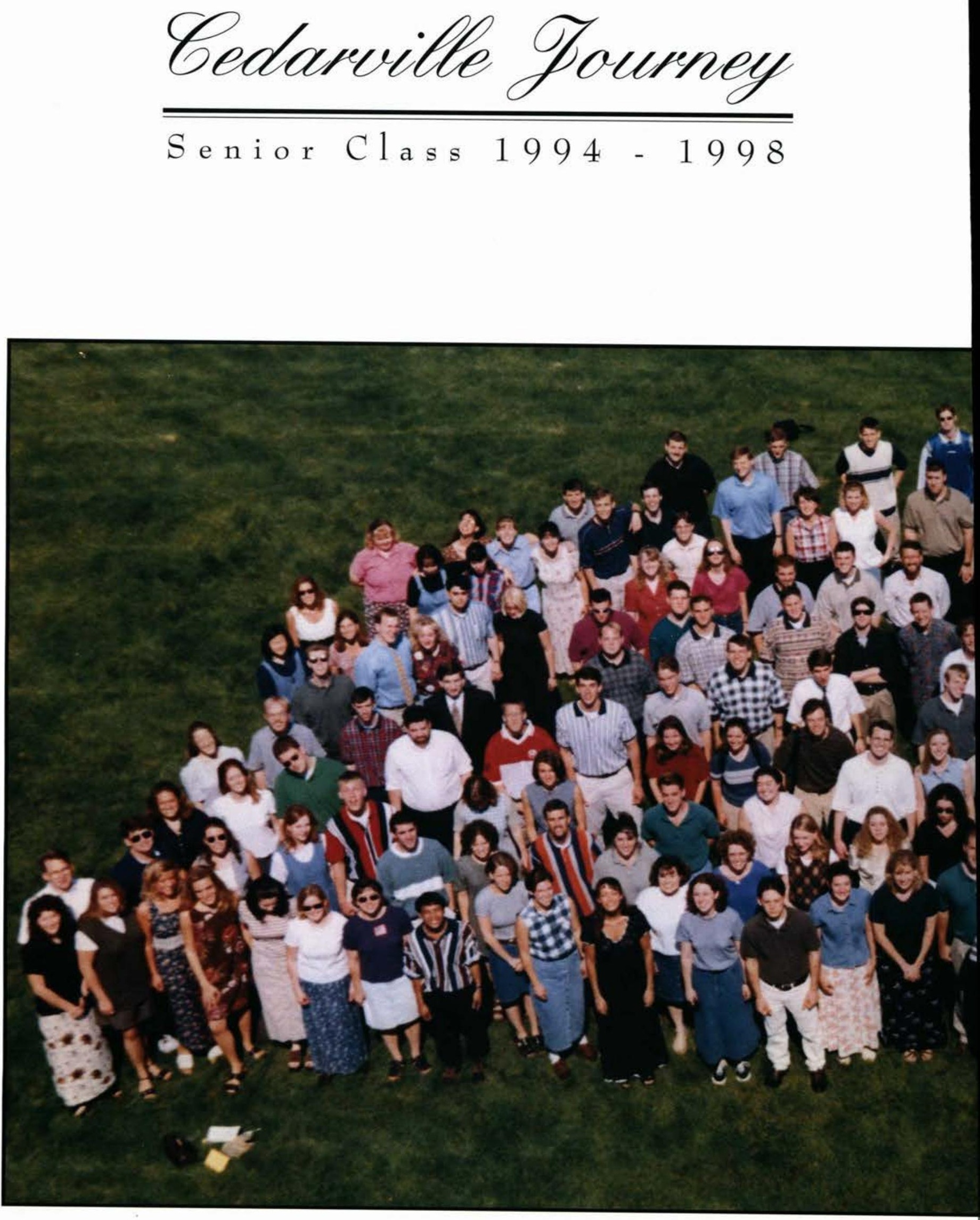


\section{by Ruthanne Pierson}

eptember 17, 1994, marked the warm fall day when 658 freshmen stepped onto the green grass of Cedarville lege, no longer high schoolers, yet barely college students. The day began as students pulled up to the Athletic Center ini vans carrying all their worldly belongings. They were immediately marauded by a bee and given a balloon. It was that their fun really began - they stood in lines. Lines would continue to mark their college experience, but every ney must have a starting point. In these early lines and in Getting Started groups, friendships formed as they desperately d to remember the myriad of names, faces, majors, hometowns, and abbreviations of buildings.

At their first fall Bible Conference, Warren Wiersbe spoke about "Abundant Living." The freshmen quickly realized if they wanted a seat on those harvest-gold pews, they would have to arrive early. Some were even sent to satellite tions where they watched chapel on the big screen.

Many were frustrated because they couldn't drive, and quickly familiarized themselves with any upperclassmen who wheels. After homecoming, many of the freshmen took their dates to Mom and Dad's Dairy Bar for dessert - where could you go? Those early days were spent lounging by the tennis courts, which used to be by the lake. If you were king for the action, that was found outside of Printy dorm. The unseasonably warm summer facilitated groups gregating on those famous Printy benches.

The class of 1998 has come a long way on their journey through their college experience, but the journey is not over It's only just begun.

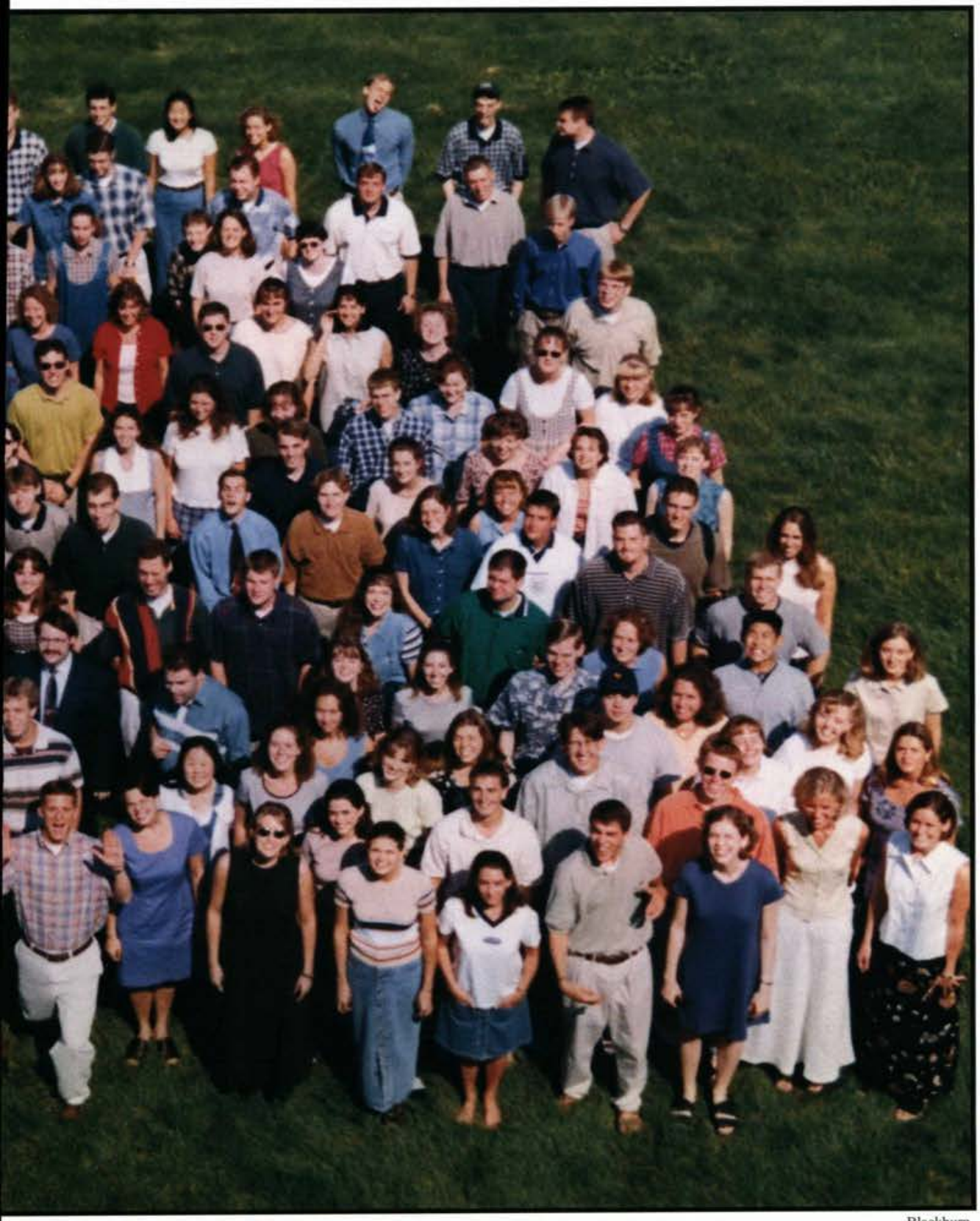

\author{
Cedarville's seniors \\ experience a reminder of \\ their freshman group pic. \\ Here they are pictured \\ after their last class chapel \\ as seniors.
}




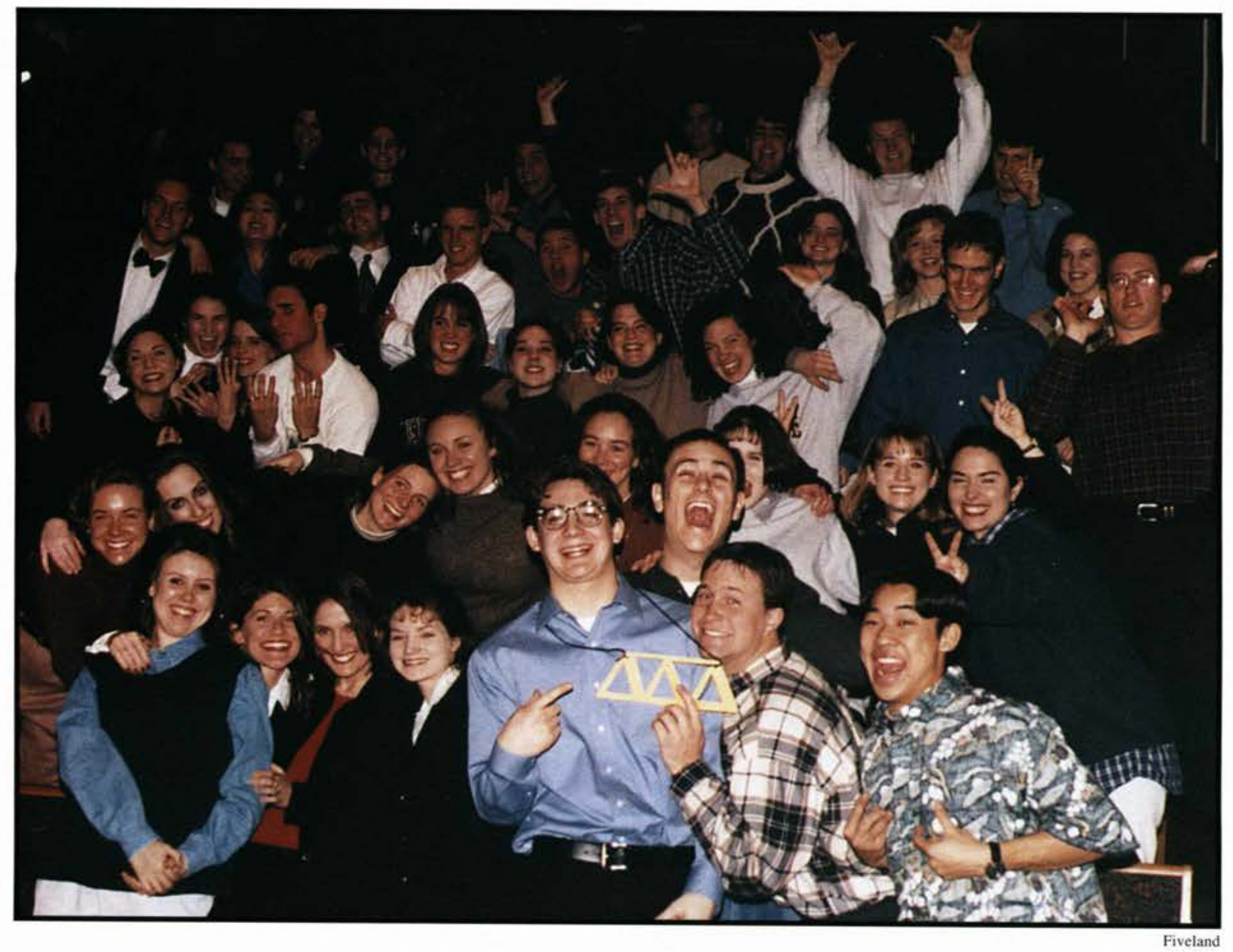

\section{Who's Who \\ among $\mathrm{a}$ merican Colleges and $\mathbf{u}$ niversities in 1998}

Mark Bruce Allen Joshua Edward Amos Jill Kathleen Barnes

Robert James Bouwens Gordon David Boyd

Lisa Sue Branon

Ryan Andrew Burkhard Ernest Panton Clark, Jr. Christina Lynn Farris Timothy Blaine Flowers Laura Lynn Foeldvari Heather Dawn Fourman Jason Allan Grahame Sara Alden Gromko
Jodie Diane Hager Tiffany Ann Hamilton Miles Anson Hanbury Nancy Jeanne Houck Rebecca Jo Jenks Erin Regina Johns Rebecca Lynn Lakes Joel Kirk LeBlanc Sarah Marie Lightly Jennifer Joy Lutz Aaron Michael Lynn Jason Andrew Malone Angela Ann Meredith

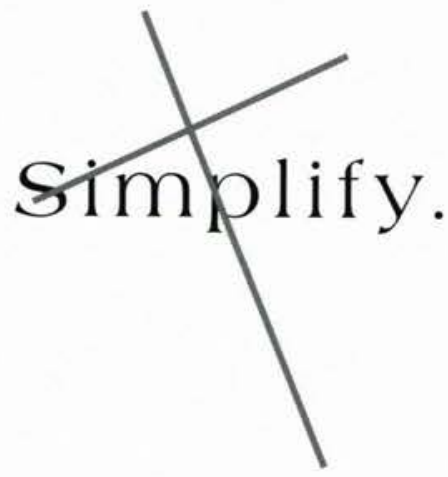

Brent David Miller Heidi Christine Neumann Patricia Lynne Noble Nathan McGuire Payne Ruthanne S. Pierson Laura Marie Refior Matthew Charles Rexford Charity Hope Rizer Micah Ethan Roberts Sara Marie Romang Carla Marie Salvaggio Stacey Marie Saville Dana Leigh Scott
Tamara Joy See Presian Renee Smyers Shannon SuAnn Snow Michelle Lindsay Stock Scott Matthew Vandegrift Christopher J. Vitarelli

Philip Mark Wallis

Mark Frederick Warren

Laurie Lynn Weber

Peggy Joy Wickholm

Lisa Marie Wood

Jonathan Gene Wu

Tiffany Ann Zimmerman

opposite page:

Ruthanne Pierson and Ernest Clark hosted this year's Who's Who as television personalities Connie Chung and Dan Rather (top).

Laura Refior showed us how a life of overcommitment can crowd out that which is most important: our relationship with God (center).

Those dreaded group projects! Charity Rizer, Becky Lakes, Anson Hanbury, Jon Wu, Dana Scott, and Laura Refior reminded the college family that people are not always what they seem (bottom). 


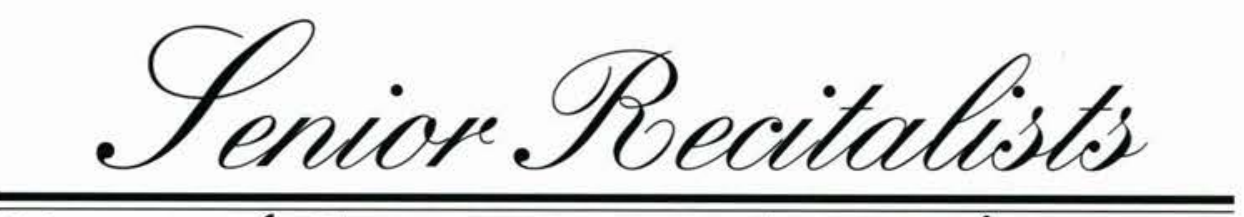

Music and Communication Arts Performances

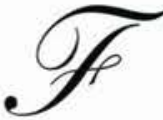

or Senior music and communication arts majors, the year culminates as they present their senior recital. The recitals serve as a four-year climax of training at Cedarville. Some seniors were very creative this year with some performing very unique concerts.

Steve Weber, senior music major with an emphasis in keyboard pedagogy, invited his own piano students to the recital. After he played piano music from the baroque period to the present, featuring works from Bach, Mozart, Chopin and others, Weber taught the students who attended how to perform a selection of his featured works.

Rebecca Lakes, senior music performance and music education double major, performed an elegant flute and piccolo recital. She was accompanied by a guitarist and a pianist for the majority of her recital.

Jody Hovis, senior music performance major, presented a voice recital including art songs and romantic period vocal pieces. She also sang her own miniopera for this dramatic vocal concert.

Anson Hanbury, senior communication arts major, presented a speech recital featuring Jekyll \& Hyde, an original compilation of material taken from the Robert Louis Stevenson short story, the play, and the Broadway musical, "Jekyll and Hyde."

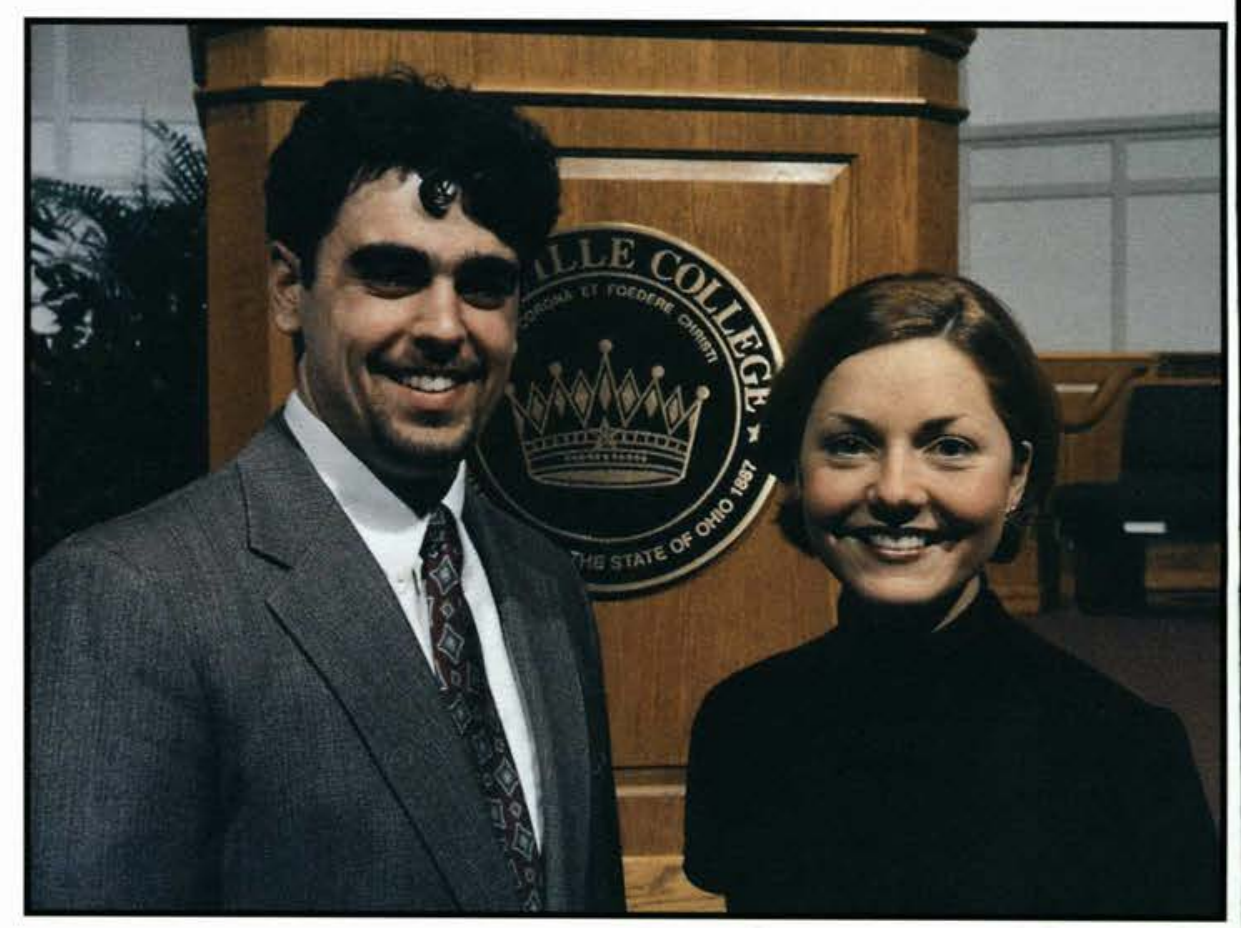

all photos by Huck

Ousic majors Scott Shaw, Ben Vawter, Rebecca Lakes, Lea Anne Churgovitch, Sarah Lightly, Steve Weber, Lisa Branon, Jodi Hovis, Erica Chung, Jim Dyer, and Beth Stewart completed their degrees with performances. Not pictured: Matt Rexford, Brian Rowley, Amanda Bruckner, Lisa Cook, Michael Frazier, and Sara Lightly. (top)

Communications majors Chris Vitarelli, Stacey Saville, Anson Hanbury (not pictured), Sarah Romang (not pictured), and Angela Wetzel (not pictured) each performed a dramatic speech recital to complete their degree. (bottom) 


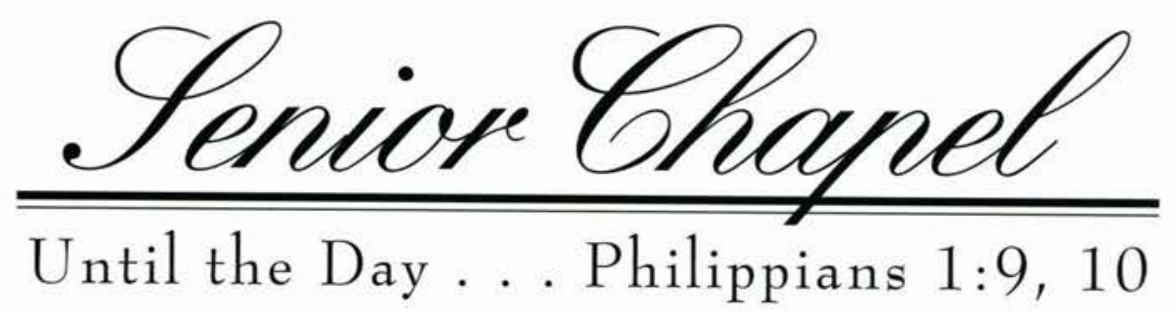

Otime chapels of the year. Recounting their last four years at Cedarville, this year's senior class presented a video, designed by Shelly Stock; several skits; and a number of personal testimonies. One of the personal testimonies was that of Christ Vitarelli. During his testimony, he attested of the Lord's leading and direction in his life. Vitarelli said that he, once a timid freshman who was afraid to sacrifice for Christ, is a senior who will someday look for a church in which to minister fulltime.

The senior class concluded their chapel with an original composition by Mark Warren, based on the class verses Philippians 1:9-10, entitled Until the Day. The class gathered together on stage as a collage of pictures from their past four years appeared on the big screens. At the end of the slide show, Mark Warren, Jodi Hovis, Sarah Lightly, and Anson Hanebury lead the seniors in their class song.

"This is probably the best senior class we've ever had," Dr. Dixon said as he walked up to the stage at the end of the song. Looking around Dr. Dixon began to cry and then lead the student body in prayer for the seniors, who would leave Cedarville to become salt and light in this contemporary culture - moreso than they have ever been before. The senior chapel was a true reminder of the journey the seniors have made together as well as the journey that lies ahead of them.

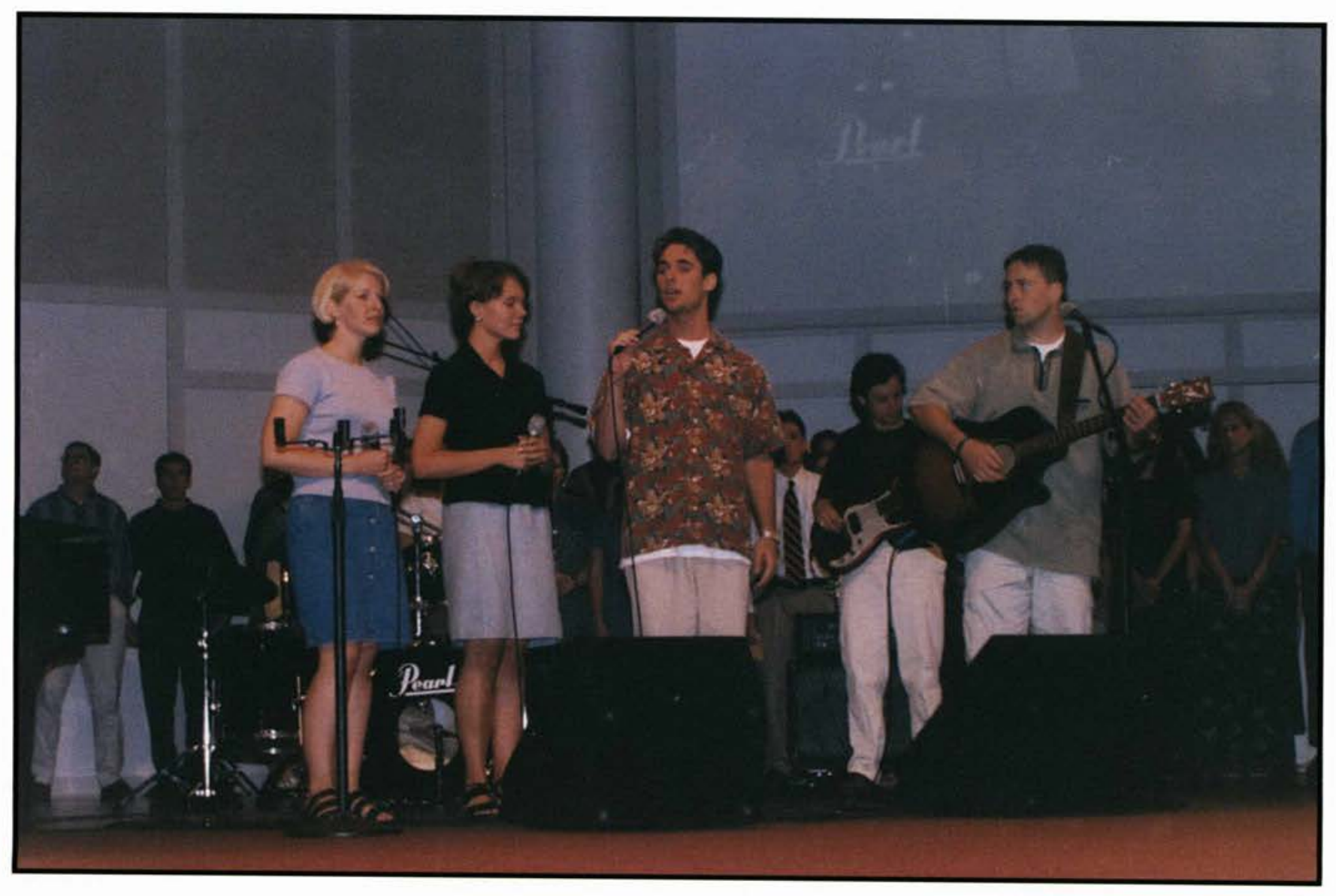

Oody Hovis, Sarah Lightly, Anson Hanebury, and Mark Warren lead the seniors in their class song, Until the Day, an original composition by Mark Warren. 
Engineering major Jon Wu was one of the several seniors who shared a testimony during the senior chapel. (top)
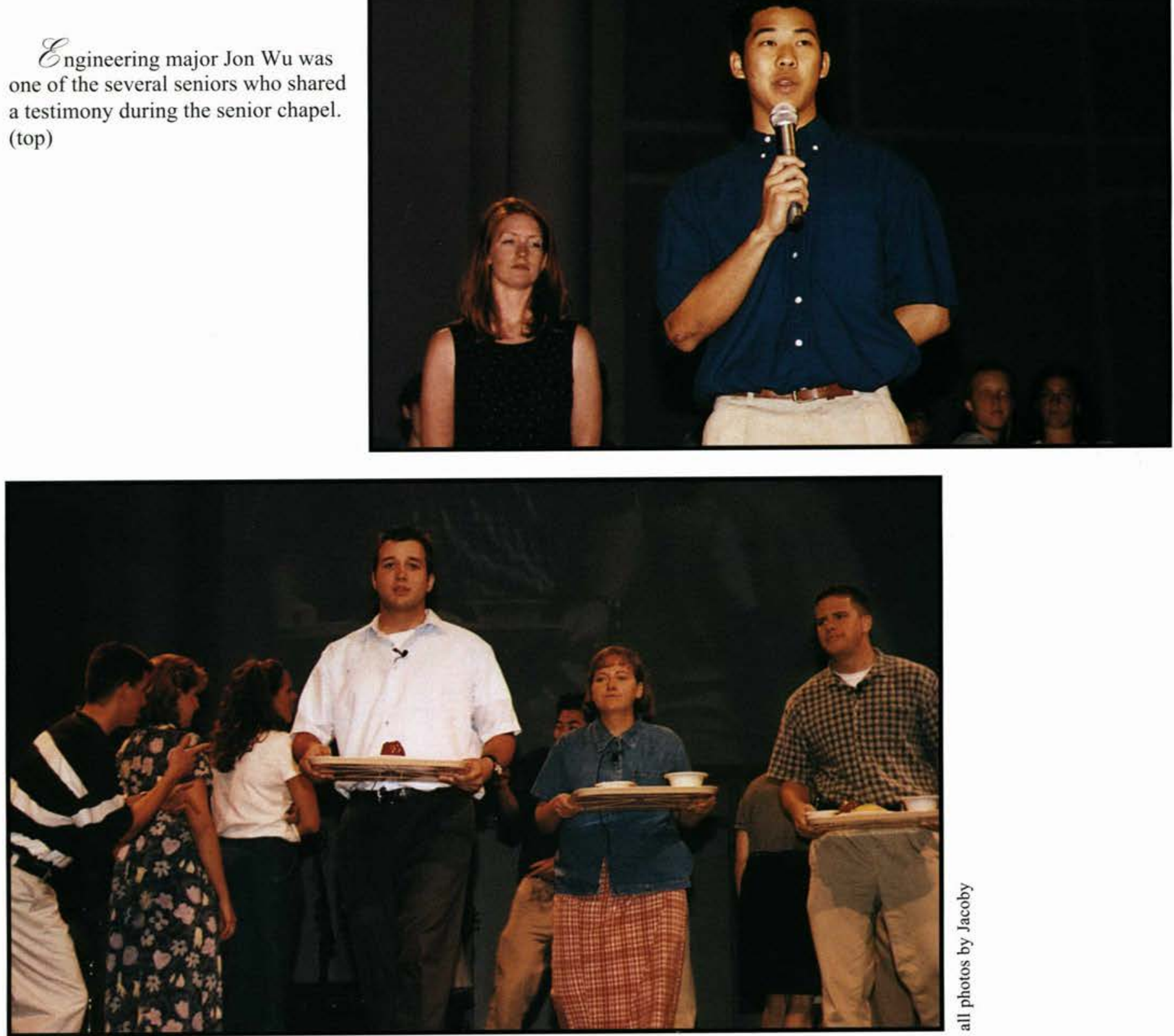

Wave Burke, Martha Failor, and Jay Kandel act out a skit based on their meals at Chuck's. (middle)

A lonely Steve Garcia, or at least in the senior skits, continues attempting to make friends. (bottom) 
$\mathscr{T}$ he Dixon's welcom the seniors to their beautiful two story home in the country. (right)
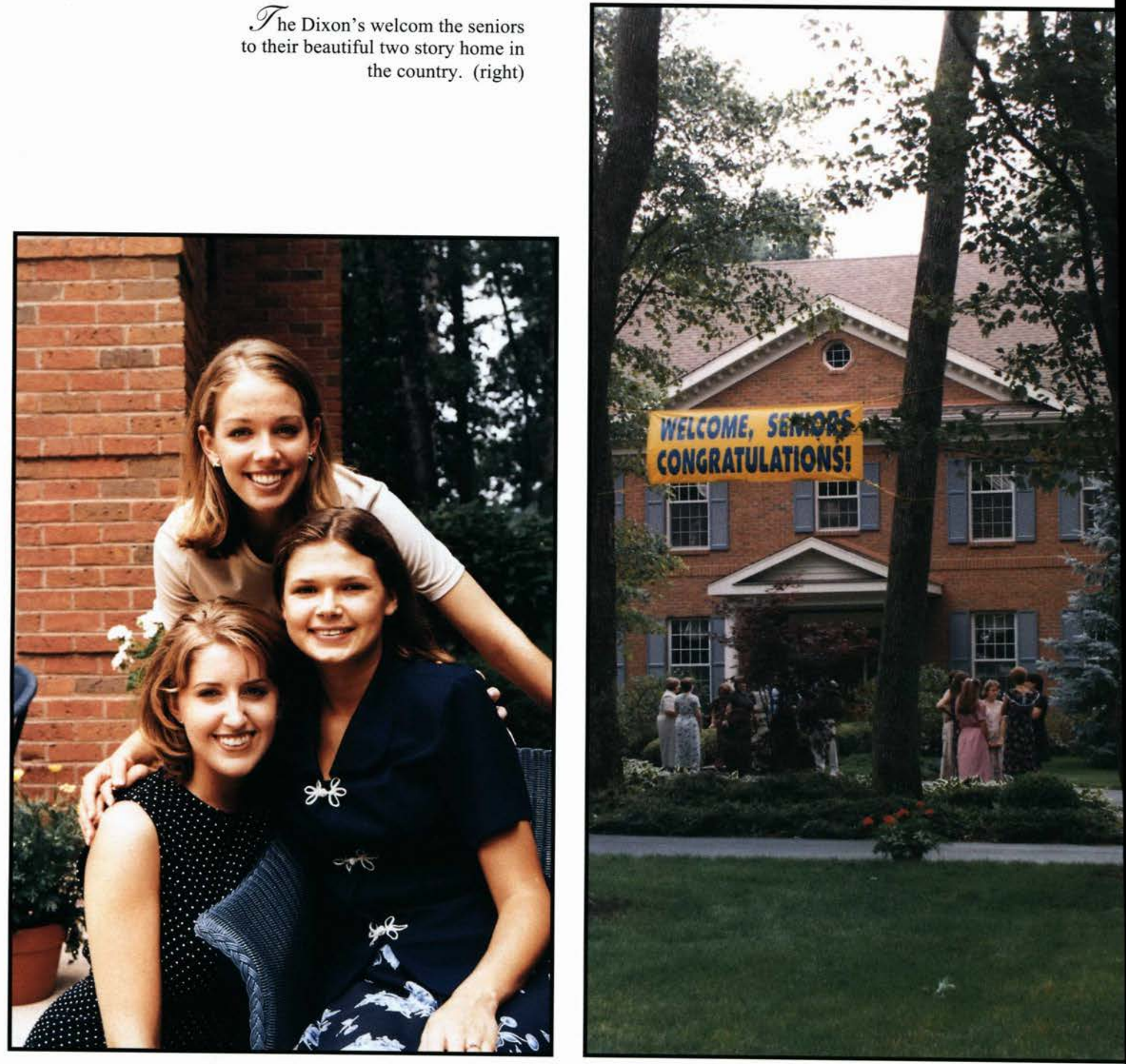

$\mathscr{N}_{\text {oel Mc Dermitt, Courtenay }}$ Shoaff, Chrystie Ruba share a memorable picture at the Dixon's reception. (above)

Toarisa Linafelter, Sheri Wilson, and Joey Decker enjoy their afternoon at the Dixon's. (right)

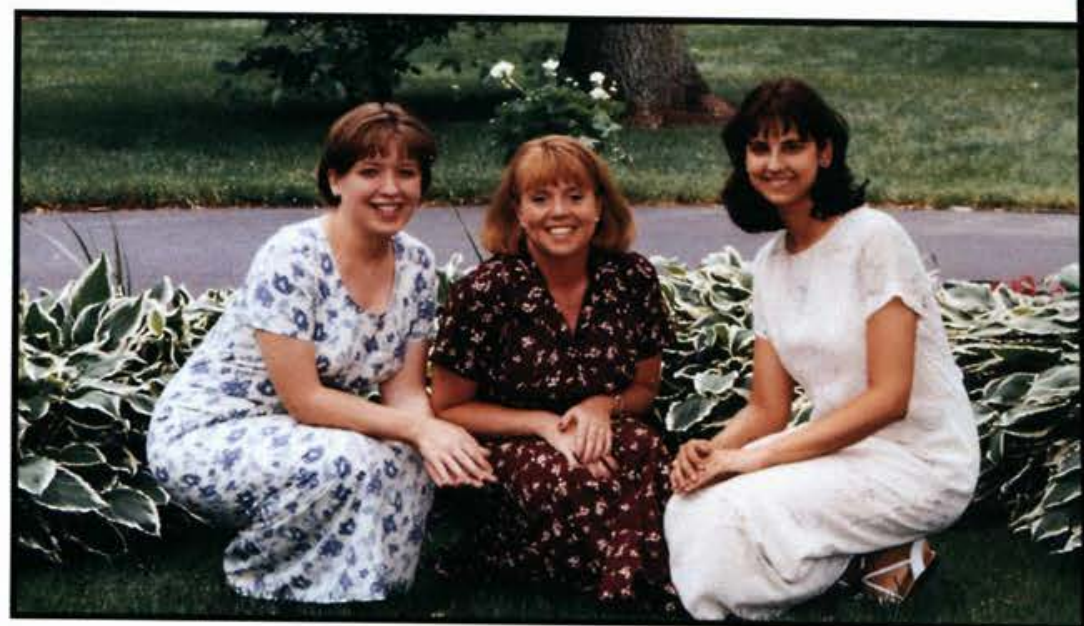


by Ruthanne Pierson

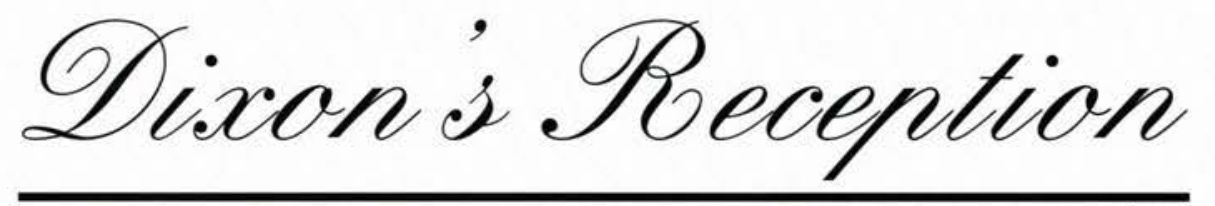

Senior Reception at the Dixon's

OPith

ith the grass freshly cut and dandelion free, the Dixon's welcomed the graduating senior class of 1998 to their home. Shifts of vans shuttled the seniors to the Dixon's home where they had the opportunity to visit with the Dr. and Mrs. Dixon, enjoy refreshments provided as always by Pioneer Food Service, and spend one last time saying good-bye to friends.

Students could mingle outside and enjoy the warm, humid afternoon, or peruse inside the Dixon's spacious house. For many, it was the first time in the president's home. Pictures where taken by the famous hammock, with Dr. and Mrs. Dixon, and with special friends. Mostly, it was a relaxing time to enjoy friends and say good-bye and thank to Dr. and Mrs. Dixon for all their leadership and investment in the lives of the seniors. As usual, Dr. and Mrs. Dixon were exceptional hosts and the students left one step closer to graduation.

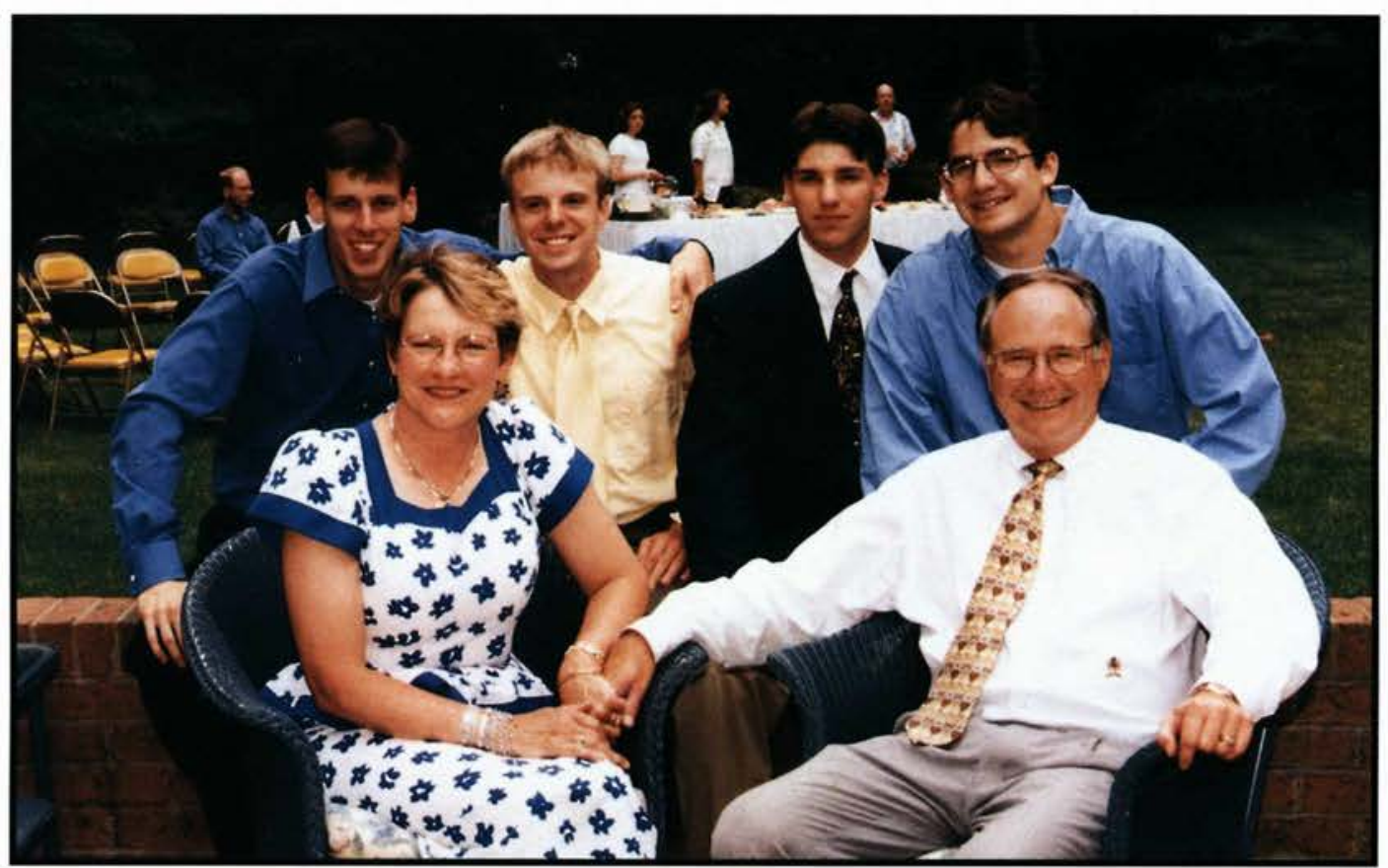

Dr. and Mrs. Dixon enjoy their afternoon with the seniors. Here they are pictured with Jason Malone, Scott Shaw, Phil Wallis, and Matt Rexford. 

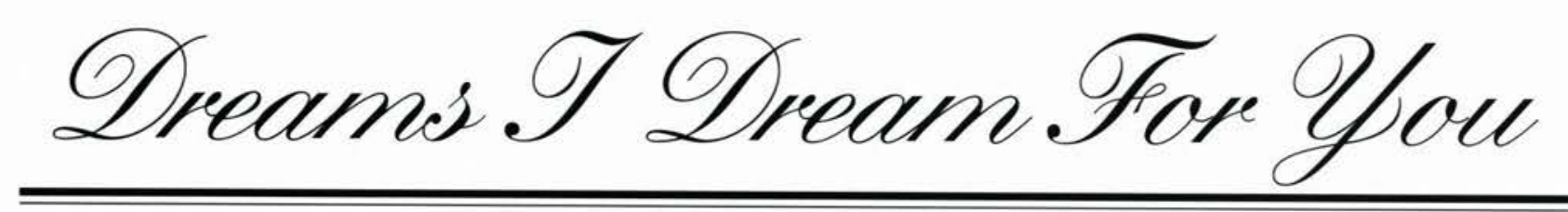

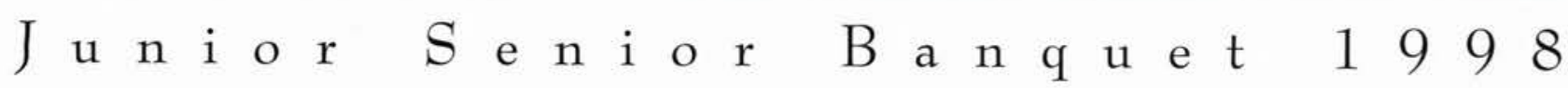

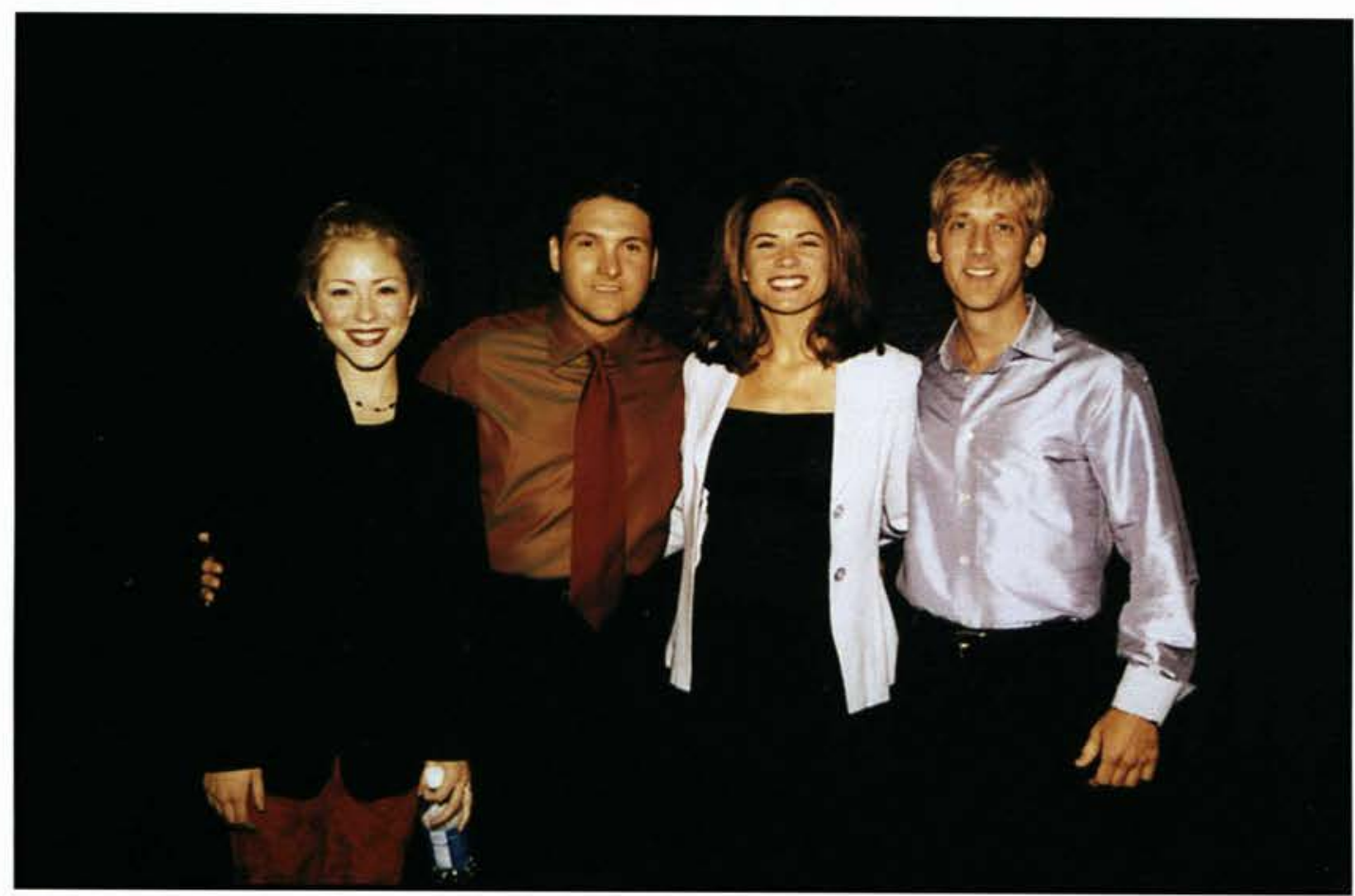

Huck

Performing at the 1998 Cedarville College Junior/Senior, Avalon, the 1998 Dove New Artist of the Year, lead the students in worship and entertained the students as well.

tiful hotel lobby. The students continued to enjoy each others company as well as dinner was served at approximately 7:00 p.m.

Dinner started with a delicious caesar salad along with fresh baked rolls. The main course followed, consisting of sirloin of beef, accompanied by a baked potato, and a vegetable medley. The crowd then enjoyed an intermission to mingle and take more pictures before returning to enjoy a rich dessert of white chocolate mousse cake.

Shortly after dessert, the banquet committee was asked to stand, consisting of Becky Crosson, Heidi Jo Dean, Paul DiCuirci, Tim Walker, and chairperson, Meaghan Lemke. After due recognition was given, the evening reached its peak as the entertainment of the evening, Avalon, came onto the stage. The popular Christian singing group proceeded to lead the enthusiastic group through a perfect combination of their upbeat hits along with some of their more worshipful slow songs.

After the concert, a slide show was shown that captured some of the great moments the seniors of Cedarville College have spent together over the years. It was a time for all Cedarville students present to reminisce and realize just how special their time at Cedarville has been.

The banquet concluded with Avalon coming back to the stage and singing the theme song for the night, "Dreams I Dream For You." The song was a reminder to everyone present that the dreams and plans Christ Jesus has for His children are greater than the dreams they dream for themselves. It made for a beautiful ending to a beautiful evening. 
Dr. and Mrs. Dixon, Dr. and Mrs. Wood, Pastor and Mrs. Rohm, and Mr. and Mrs. Rickard enjoy their time with each other and the Cedarville College students. (right)
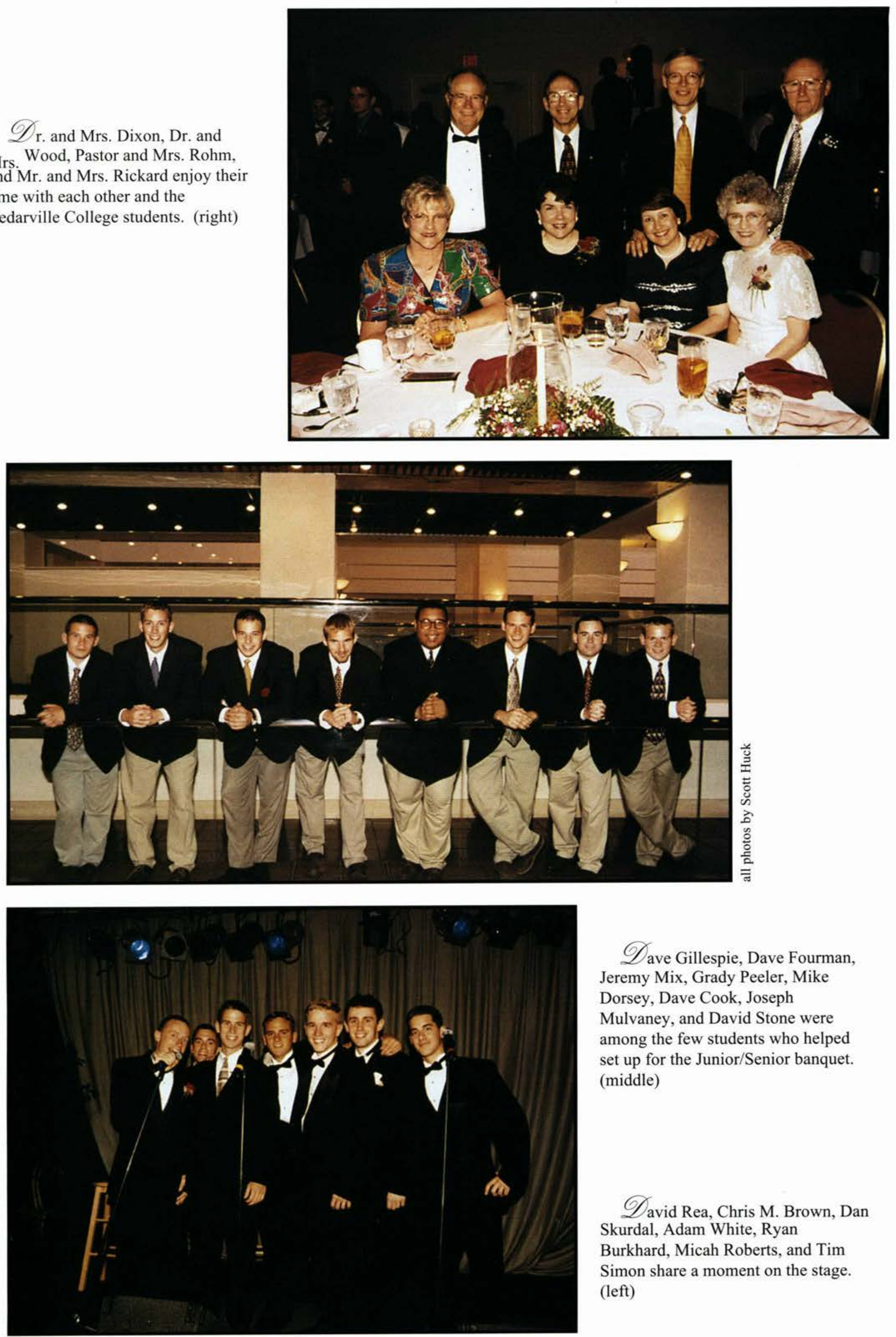

Dave Gillespie, Dave Fourman, Jeremy Mix, Grady Peeler, Mike Dorsey, Dave Cook, Joseph Mulvaney, and David Stone were among the few students who helped set up for the Junior/Senior banquet. (middle)

David Rea, Chris M. Brown, Dan Skurdal, Adam White, Ryan

Burkhard, Micah Roberts, and Tim Simon share a moment on the stage. (left) 


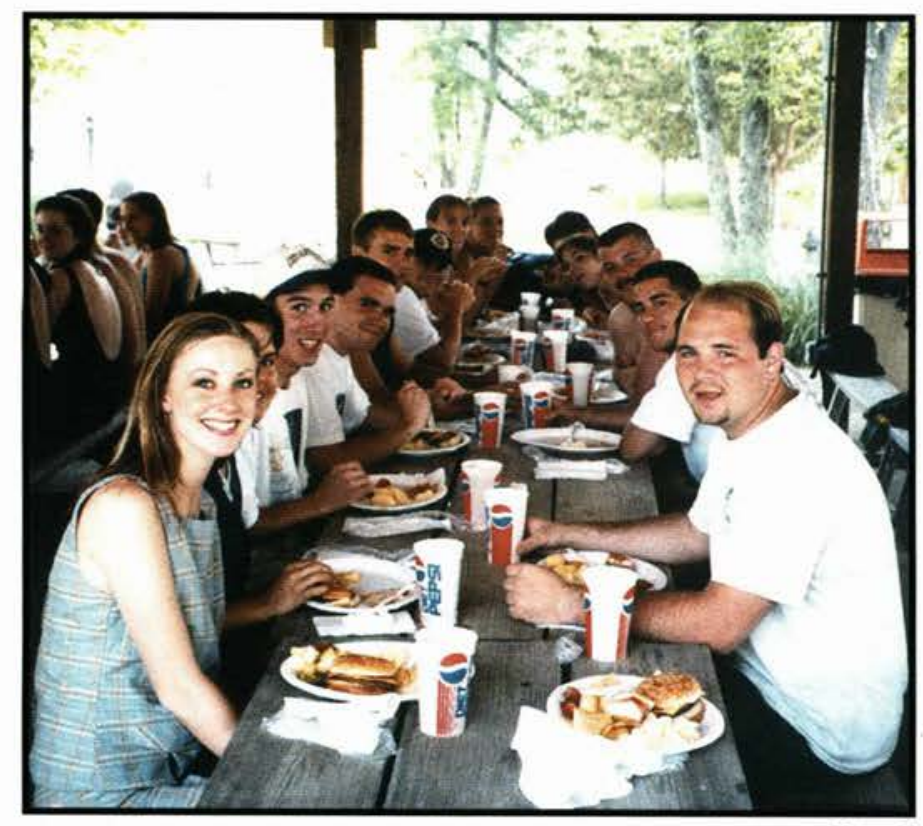

$\mathscr{T}$ he Beach was the first stop for seniors during Senior Day. Sharing lunch at the water park are (left) Jen Hangosky, Suzy King, Matt Murphy, Gabe Custer, Adam White, Josh Overholt, Heidi Neuman (right) Geoff Hillman, Tim Simon, Mike Harsh, and Shelly Stock.

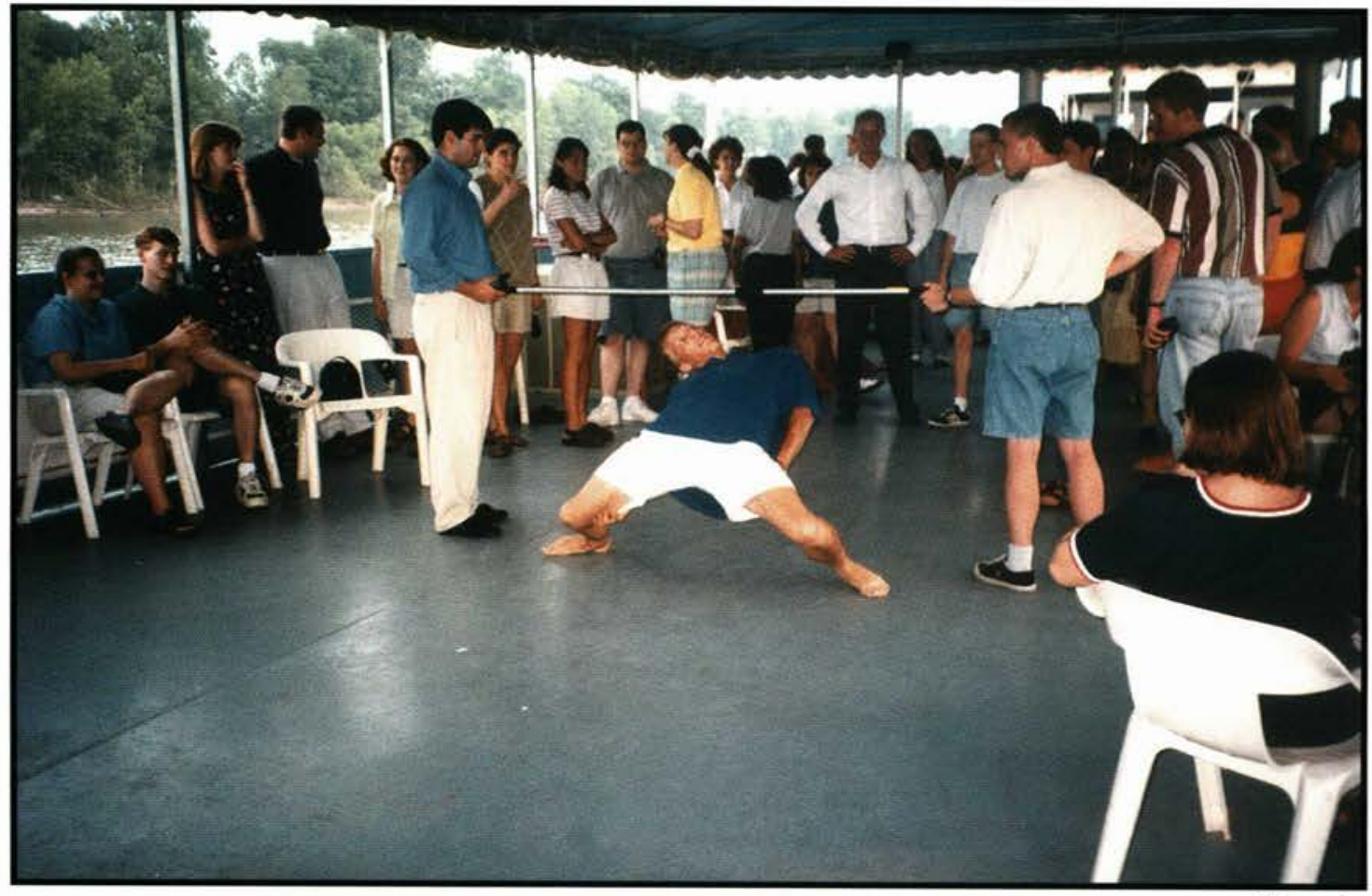

Andy Cooper displays his limbo skills aboard the Queen City Clipper. (middle)

James DeWald, Josh Haluko, Chris Vitarelli, Jodi Hovis, and Mr. and Mrs. Clay Davis. (bottom)

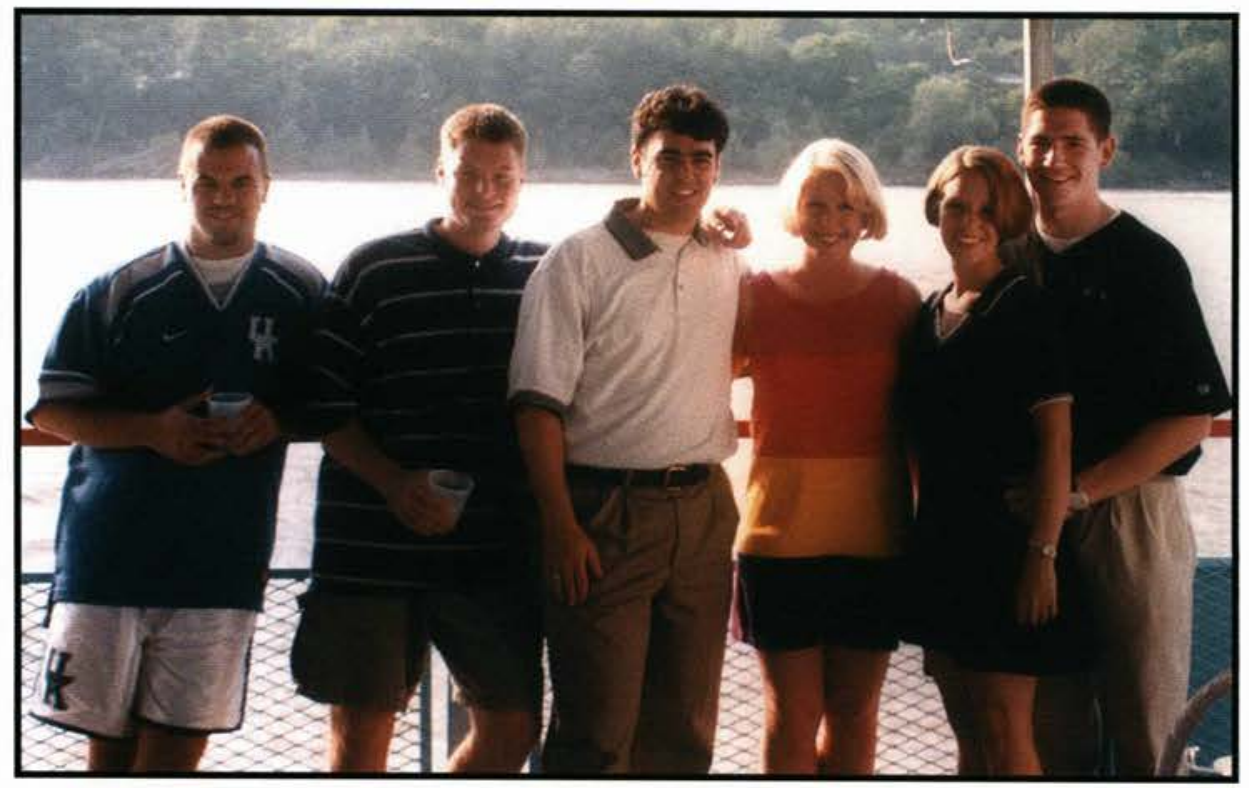


n June 6, 1998, Cedarville College conferred the associate's and bachelor's degree upon 534 members of its graduating senior $\mathrm{cl}$ The processional began as family, friends, and college family members proudly recognized the graduates filing into the packed Jame Jeremiah Chapel. Dr. Bill Rudd, chairman of the board of trustees, opened the ceremony in prayer; the choral and brass choir then fi the sanctuary with music and praise.

The president, Dr. Dixon, addressed the students and challenged them directly from their class verse, Philippians 1:9,10. His theme "Excellence in Love" and he addressed three areas where the graduates could demonstrate this theme in their lives. The class song, wri by graduating senior Mark Warren, "Until the Day" again reiterated the theme of loving Christ until the day of His glorious return.

Matt Murphy, the senior class president, presented Dr. Dixon with the senior class gift-a clock that will be displayed in the Technology Learning Center. The clock commemorates the theme for the academic year- "Timeless Truth for Contemporary Cultu The clock is meant to serve as a reminder to students to live every hour for Christ, faithfully serving Him.

The highlight, the conferral of degrees, was concluded with the last graduating senior leading the class in the changing of the tassel. honorary doctorate of divinity degree was also conferred to Pastor Eddie L. Hawkins, a prominent African American pastor in Clevela The Cedarville College Medal of Honor, presented by the board of trustees to distinguished servants and friends of the college who sensitive to the vision and dedication to the advancing of the college, was presented to Gene and Betty Miller. Student acades achievement was also recognized as five graduating seniors, Heather Fourman, Erin Johns, Heidi Neumann, Laurie Weber, and Lisa W received scholastic recognition for achieving a cumulative grade point average of 4.0 all four years. The president's trophy award also presented to Ruthanne Pierson and Jason Malone.

Kirsten Gibbs, the senior class advisor, led the senior class, parents, and college family in prayer for the graduates as the ceremony clo with the singing of the alma mater and chancellor James T. Jeremiah's benediction. The graduates left swelling with pride and filled $\mathrm{y}$ a sense of accomplishment, gratitude, and eagerness to embrace their culture for Christ and apply all that they have learned during th years at Cedarville College.

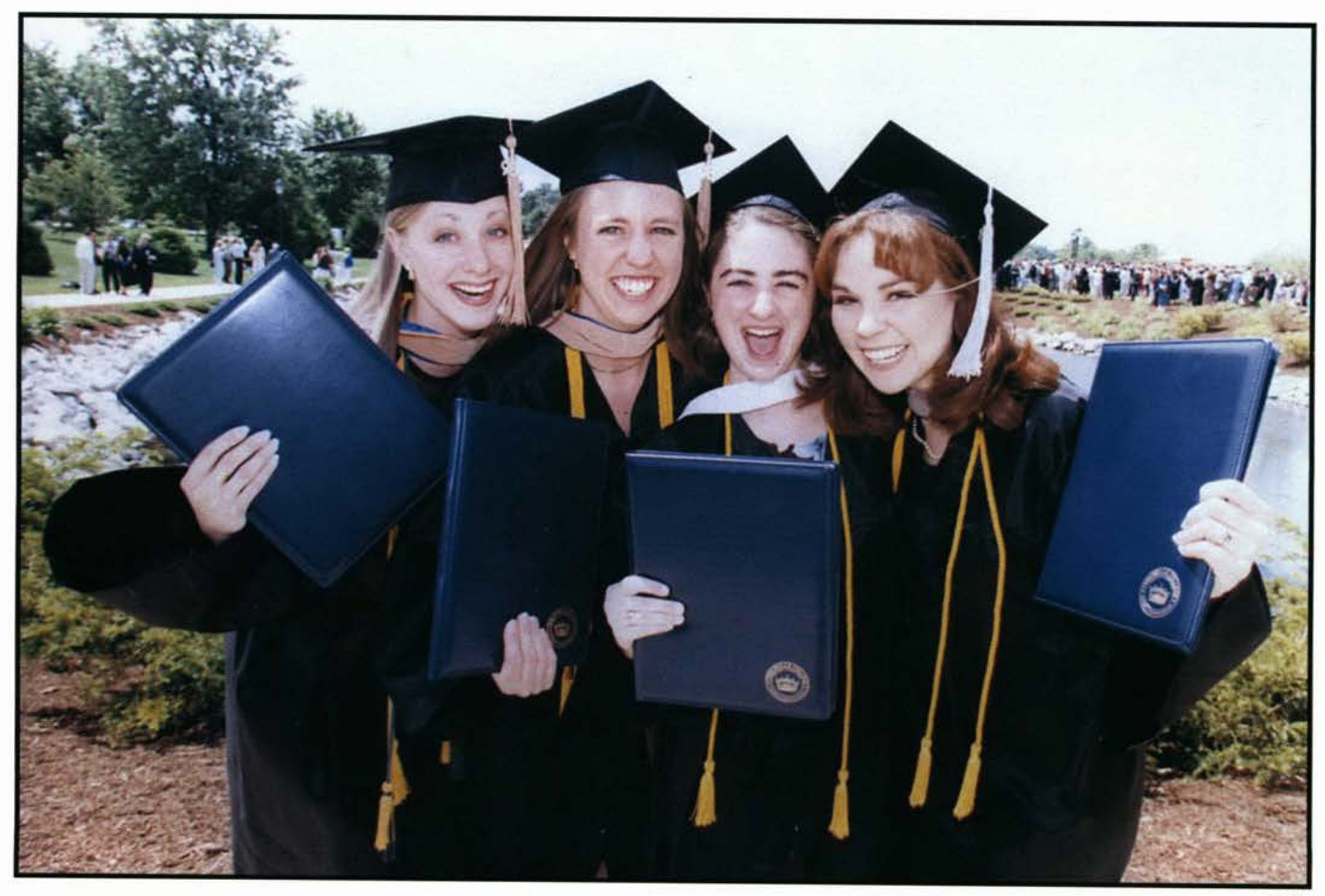

Oen Hangosky, Heidi Neuman, Anna Lankhurst, and Shelly Stock celebrate their four years together of friendship and dedicated work at Cedarville College. 
- $\mathrm{n}$ honorary doctorate is conferred upon Pastor Eddie L. Hawkins, both Trustee and friend of Cedarville College. (right)
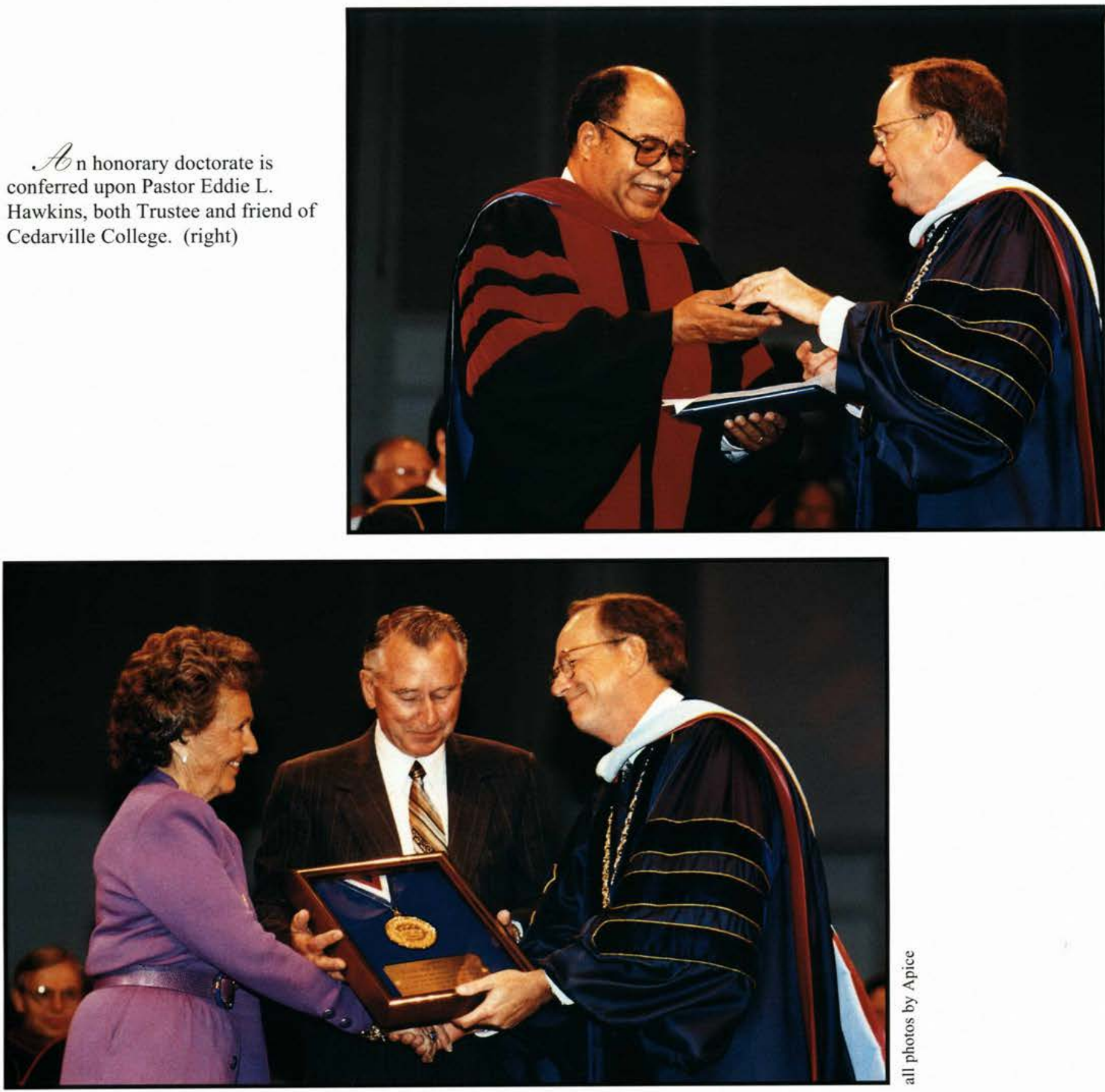

2 r. Dixon presents Gene and

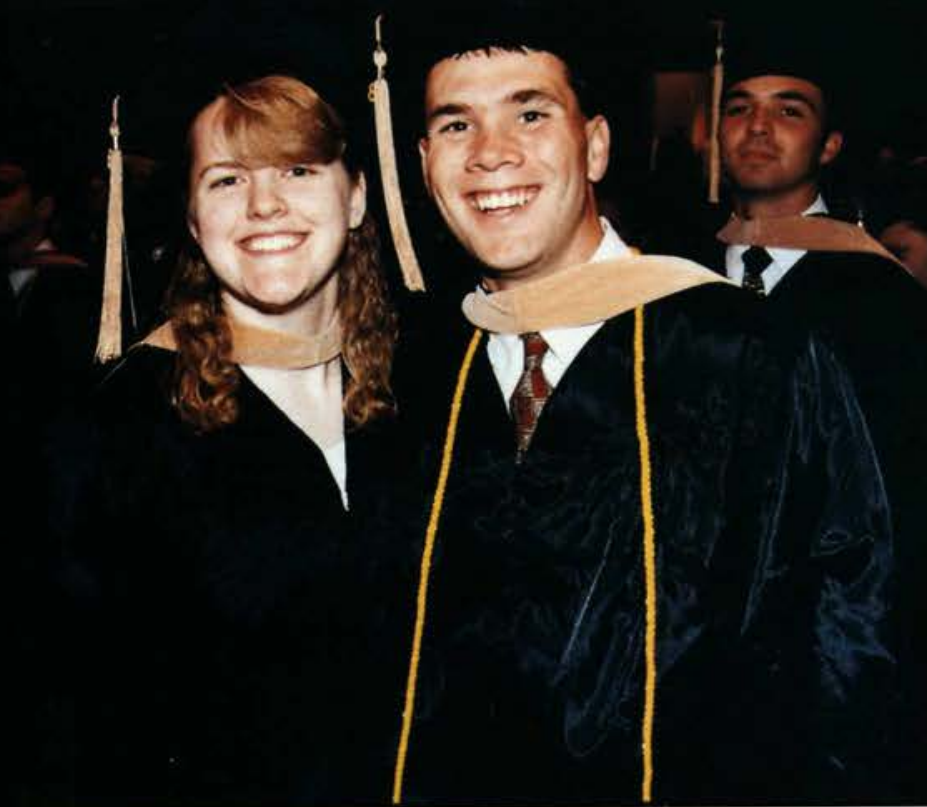
Betty Miller the Cedarville College Medal Of Honor, an award which distinguishes the Millers as servants who are sensative to the vision of the college. (above)

Caura Shultz, Rachel Sharp, Andrew Shaw, and Mark Wood await the 102nd Cedarville College commencement. (left) 


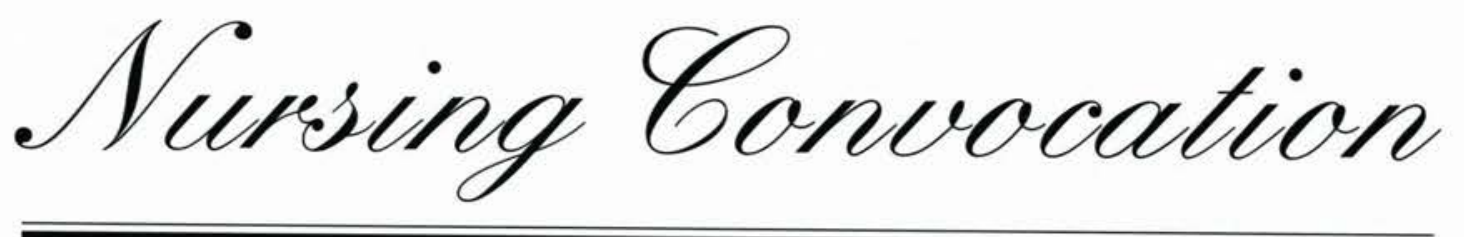

The Nursing Class of 1998

Glenda Akershoek

Janette Baker

Sara Bathrick

Stacey Billing

Michael Bonner

Stacy Brewer

Joseph Brinkley

Catherine Clagg

Bethany Comer

Brandi Covert

Thomas Culberson

Rachel Davis

Jennifer Decker

Stephanie Dickerson

Jamie Dodson
Jody Elliot

Lisa Faulkner

Gary Flick

Renee Francis

Kristen Frederick

Sara Gromko

Sarah Gross

Kim Guyn

Jodie Hager

Anna Harlan

Michelle Higgins

Alicia Hill

Melissa Hintz

Nancy Houck

Erica Hunter
Amy Hurst

Brenda Inion

Ann Kobiela

Gena Lamoreaux

Jaime Larson

Jodi Leinbach

Sarah Luke

Emily Meeks

Stephanie Moody

Catherine Nelson

Nathan Payne

Brett Pfeiffer

Dorothy Piovesan

Samantha Polgardy

Rebecca Ribeiro
Patrica Rice

Heather Scheffel

Dana Scott

Lesley Shover

Kathy Sohn

Jessica Stuenzi

Leann Waddington

Tracy Weber

Holly Wilson

Jill Witte

Mary Wolfe

Tracie Wright

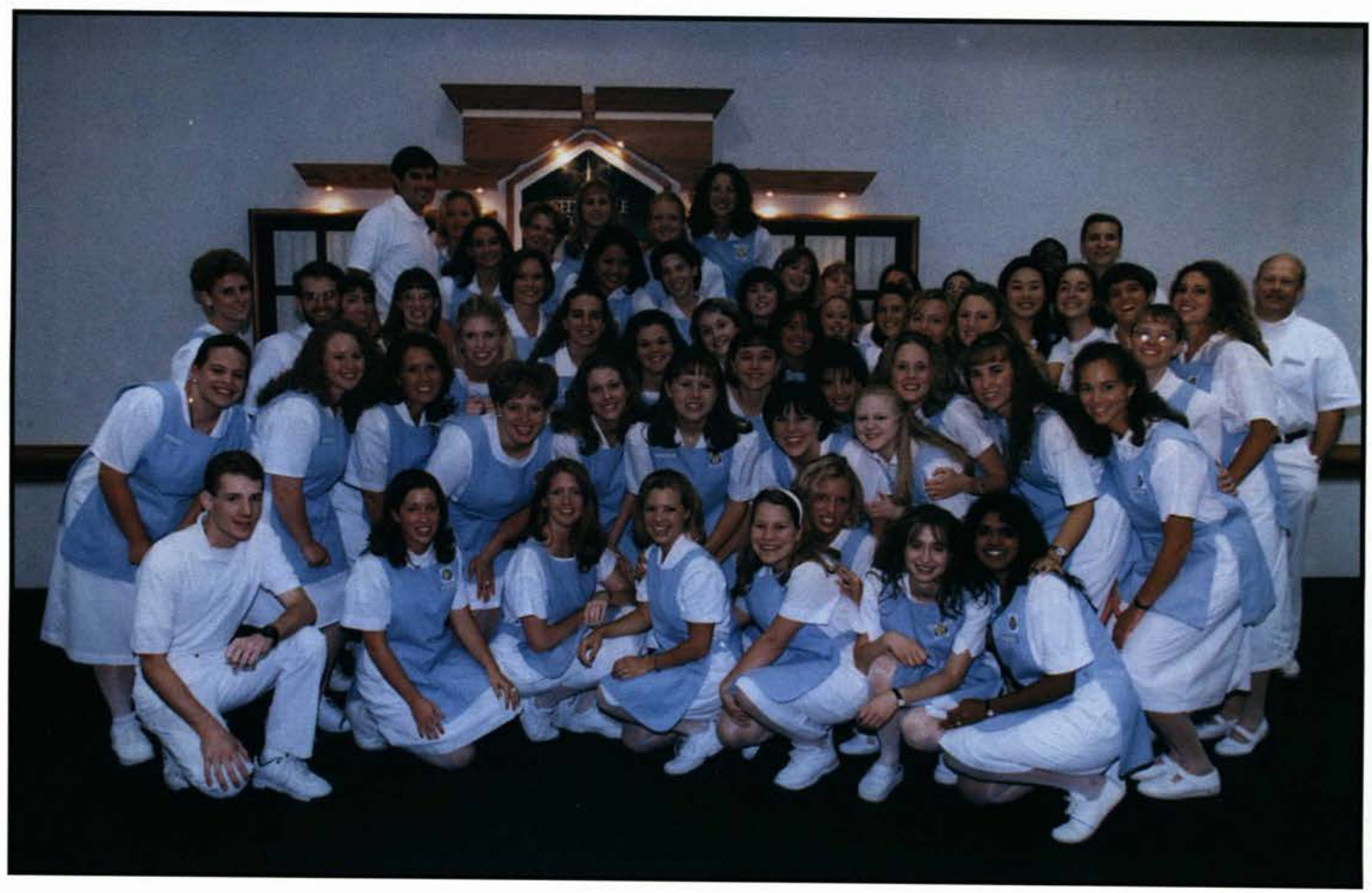




\section{Engineering Gonvocation}

The Engineering Class of 1998

Julie A. Armour

Eric D. Bedillion

Jeff G. Boddy

Robert J. Bouwens

Ryan A. Burkhard

David L. Carl

Joel R. Foerch

Daniel V. Grazier

Nathan P. Hart

Daniel W. Hicks

Nathan A. Houk

Scott M. Koziol

Adam W. Krampe
Michael S. Mann

Jacob D. Porter

David M. Rea

Micah E. Roberts

Benjamin Z. Ruffin

Daniel A. Skurdal

Eric J. Steenwyk

Scott B. Thomas

Benjamin D. Watson

Joseph P. Whinnery

Jonathan G. Wu

Daniel J. Wyma
Engineering Faculty

Charles W. Allport, Associate Professor of Mechanical Engineering Robert Chasnov, Associate Professor of Mechanical Engineering Timothy Dewhurst, Associate Professor of Mechanical Engineering Keith Francis, Associate Professor of Electrical Engineering Harwood Hegna, Associate Professor of Mechanical Engineering Clinton Kohl, Assistant Professor of Electrical Engineering Robert Laramore, Associate Professor of Electrical Engineering Sam Sangregory, Assistant Professor of Electrical Engineering D. Jeffrey Shortt, Assistant Professor of Electrical Engineering Thomas Thompson, Assistant Professor of Mechanical Engineering Tom Wailes, Associate Professor of Electrical Engineering Larry Zavodney, Professor of Mechanical Engineering

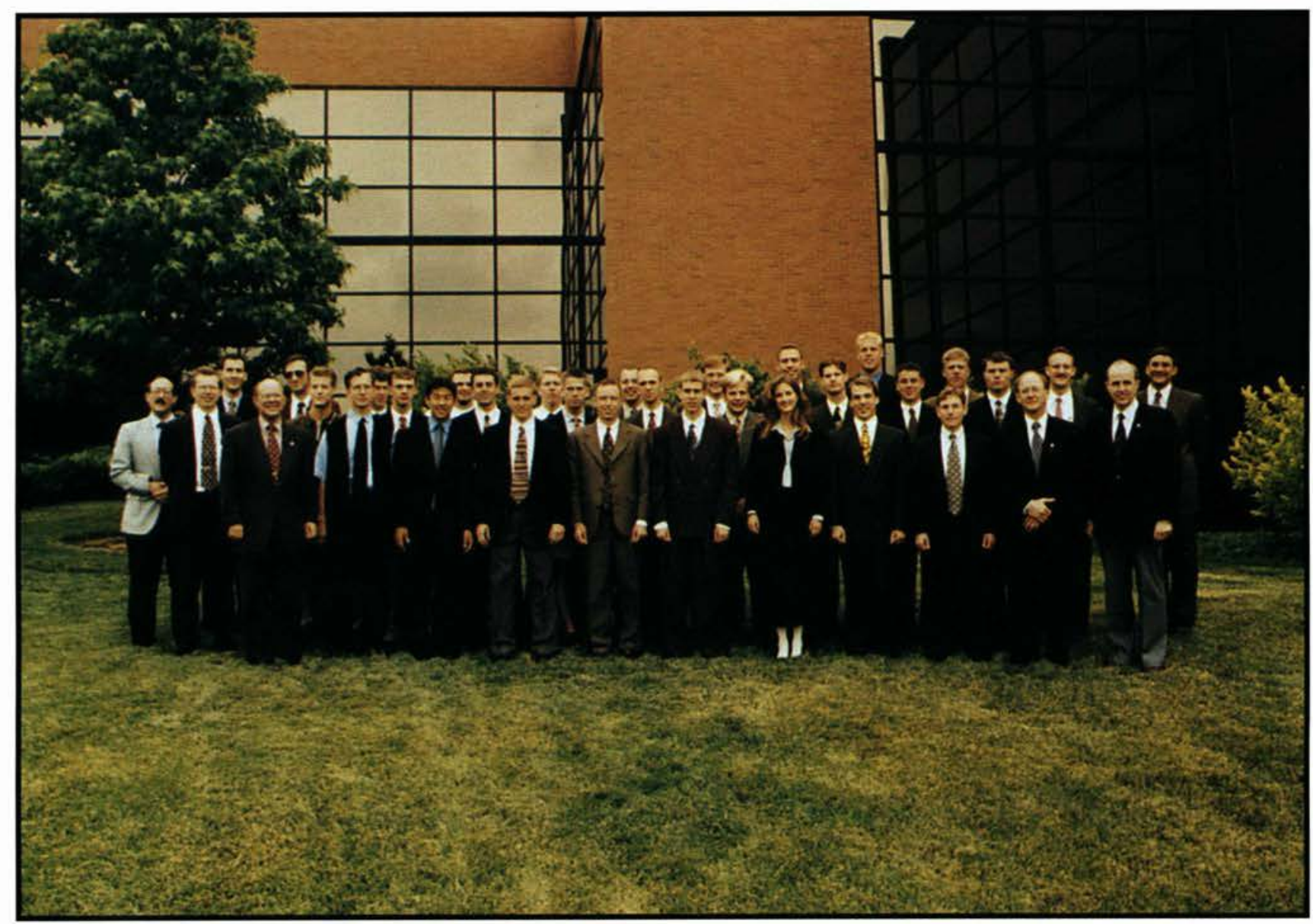

Cedarville College Public Relations photo 

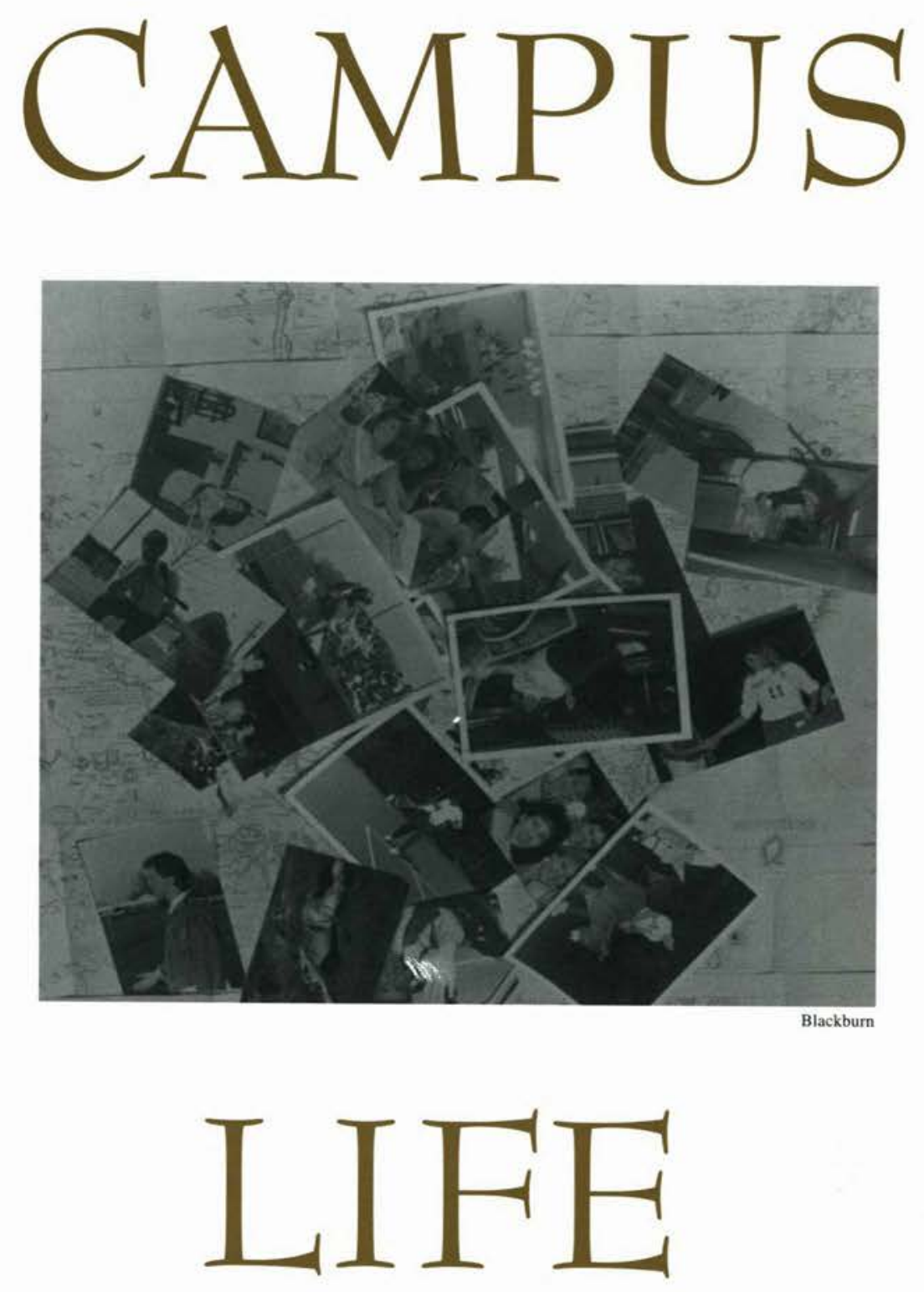


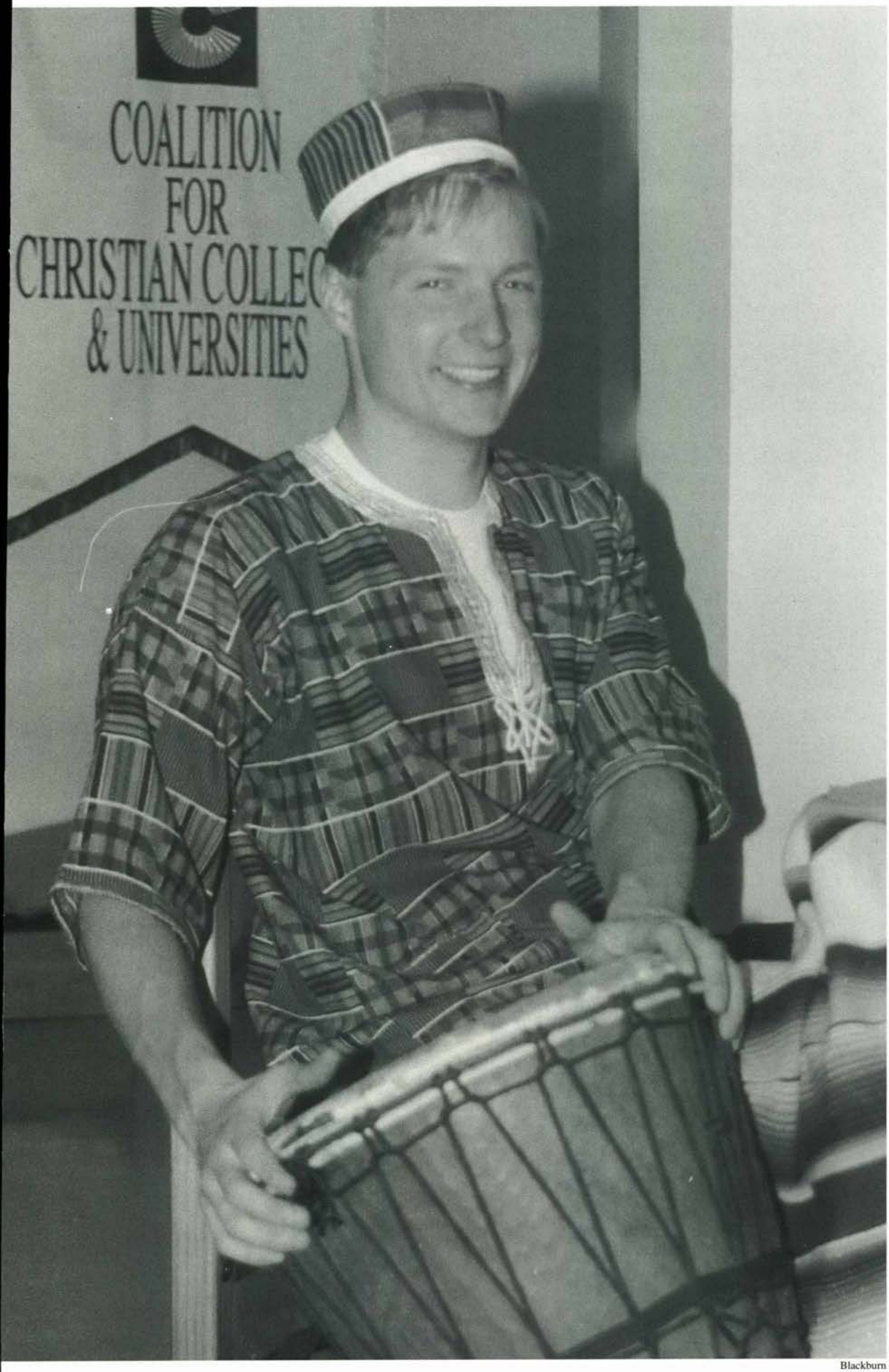

Rob Bouwens joins other students in sharing world-wide experiences at the annual cultural fair. 


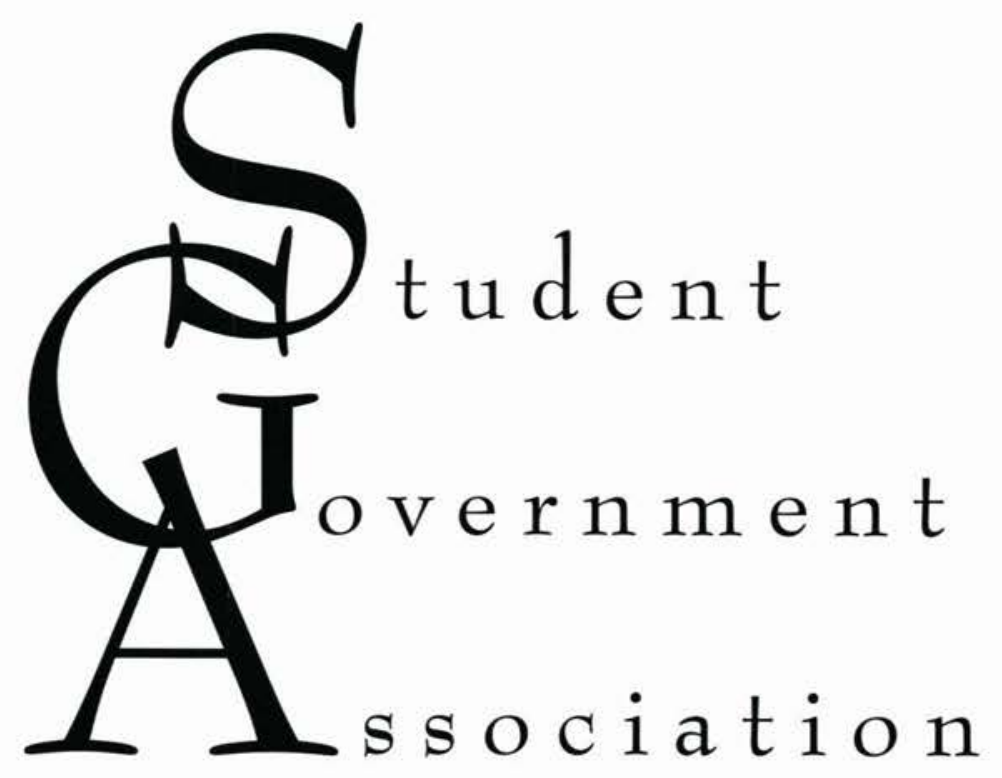

by Jennifer West

F For the Student Government Association, this was an eventful year characterized by change. Throughout the year, a team of four officers, various committees, and appointed class representatives, worked to fulfill all of their normal responsibilities while also restructuring the SGA.

Scott Van Loo, SGA president, was responsible for all the restructuring, as he directed the committee that prepared everything for next year. With the growth of the student body, it was time for a new system, and the changes that they made will guide the Student Government officers for years to come.

Angie Wenzel, SGA vice-president, was the woman in charge of homecoming. She also organized Hoopla '98, which was the kick-off for the new SGA, designed to take the appearance of a government party convention. Angie said that the purpose of the SGA is to get students to become involved in politics.

Dean Rickard was the advisor for the SGA, Jeff Beste a close assistant. Along with Scott and Angie, Christy Farris, Alissa Whitten, Scott Vandegrift, Tim Walker, Josh Amos, and Jeff Motter helped restructure SGA.

Jamie Dato, SGA treasurer, kept the soda machines and change machines filled. His role in the SGA was to take care of money issues. The SGA also helped campus organizations with funds and also awarded two scholarships.

Jason Malone led the SGA chapels, which took place on

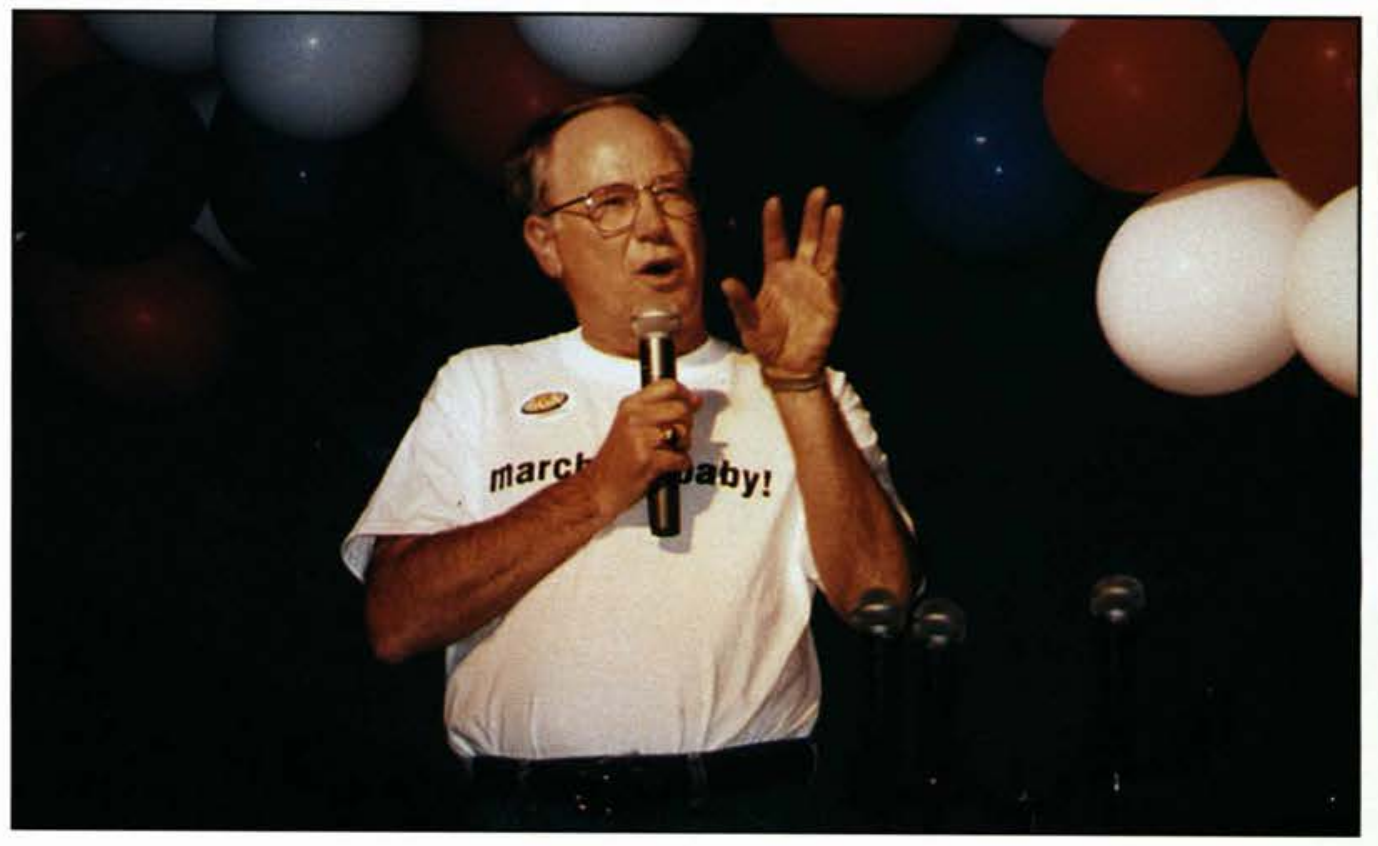

Dr. Dixon sees the vision of the New SGA and encourages the student body to take part in Hoopla ' 98.

Friday mornings. As chaplain, it was his responsibility to address the student body. Throughout the year he addressed desire, discipline, getting back to basics, and the armor of God. Senior Matt Rexford helped him by integrating worship into the chapels.

Altogether, the SGAorganized homecoming, the new SGA, and chapels, along with many other campus events. They ran the Special Olympics held at the college; they helped to promote cultural awareness throughout the year; and they led the efforts of Homeless Awareness Week. The SGA administrates every organization on campus, and they also organize elections for each class.

The people involved in the SGA this year did a fantastic job of offering support to the student body and reminding them why the SGA exists. They helped to get students involved, from homecoming to Hoopla. Hopefully their leadership will cause Cedarville students to make political activity part of their future. 


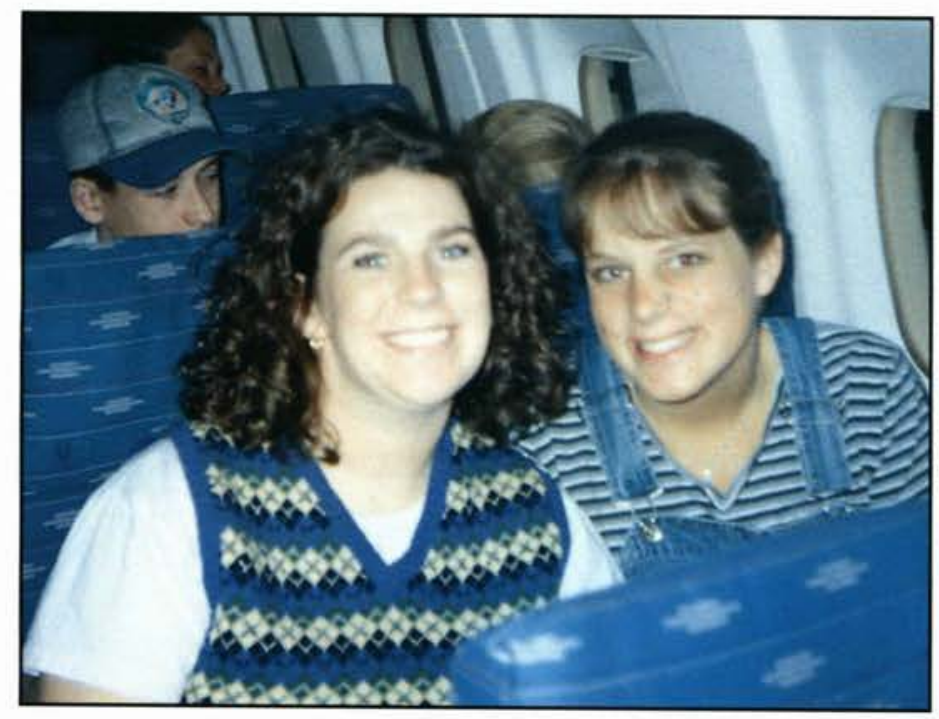

Diana Christensen and Roxanne England share fellowship during a C.A.B. trip (left).

Emily Alt, Laura Reifior, Josh Amos, and Matt Hamer show off their smiles, which come from developing close friendships during the time spent as a C.A.B. member (right).

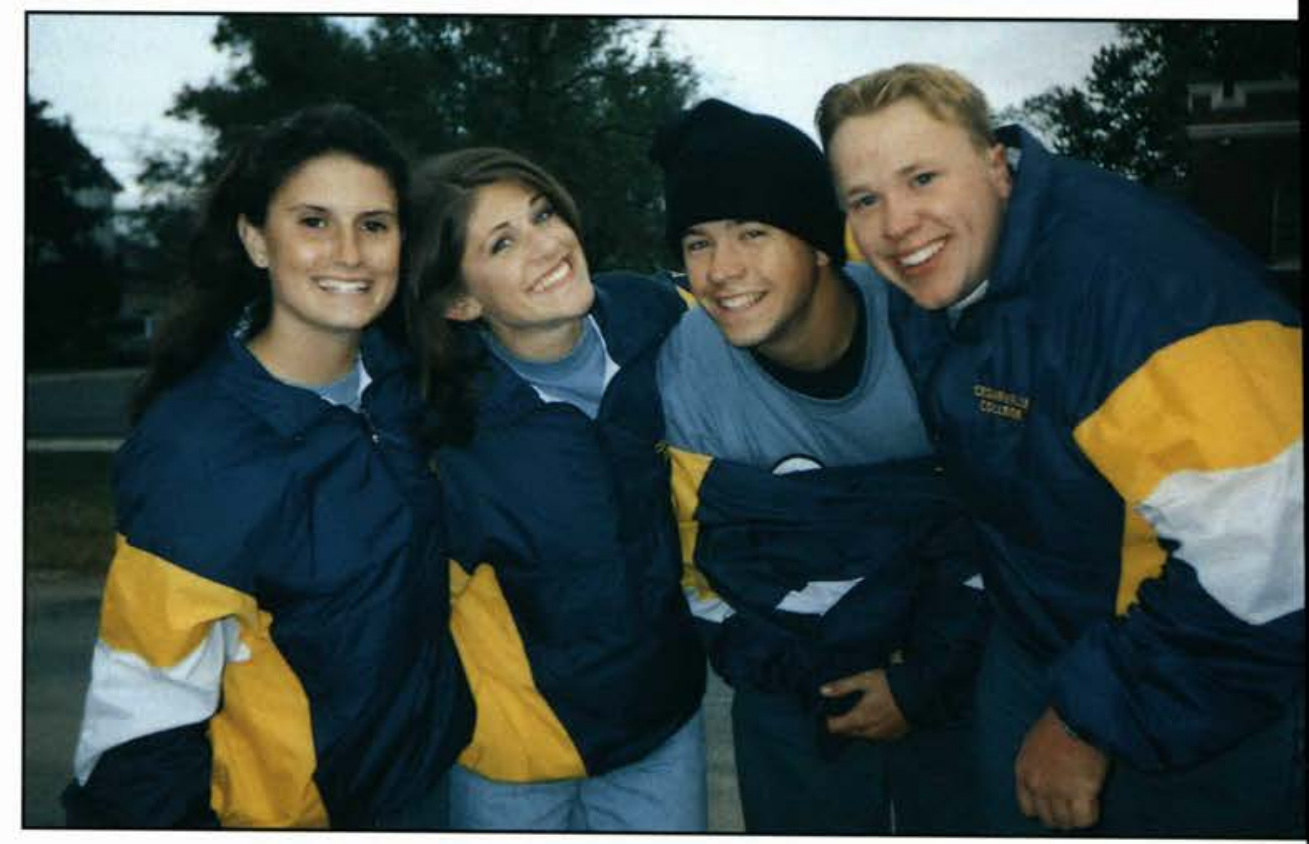

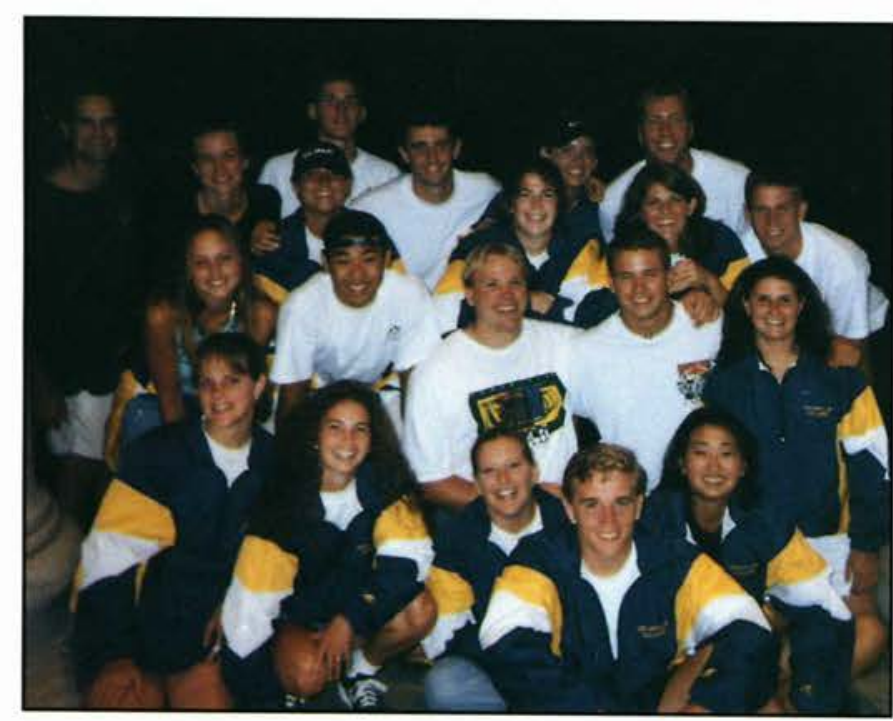

One of the many of fun activies, which the C.A.B. shared throughout the year, was a trip to Washington D.C. Here they are pictured at the Lincoln Memorial (above).
C.A.B. members portrayed Snow White and the Seven Dwarfs at Homecoming '97 (below).

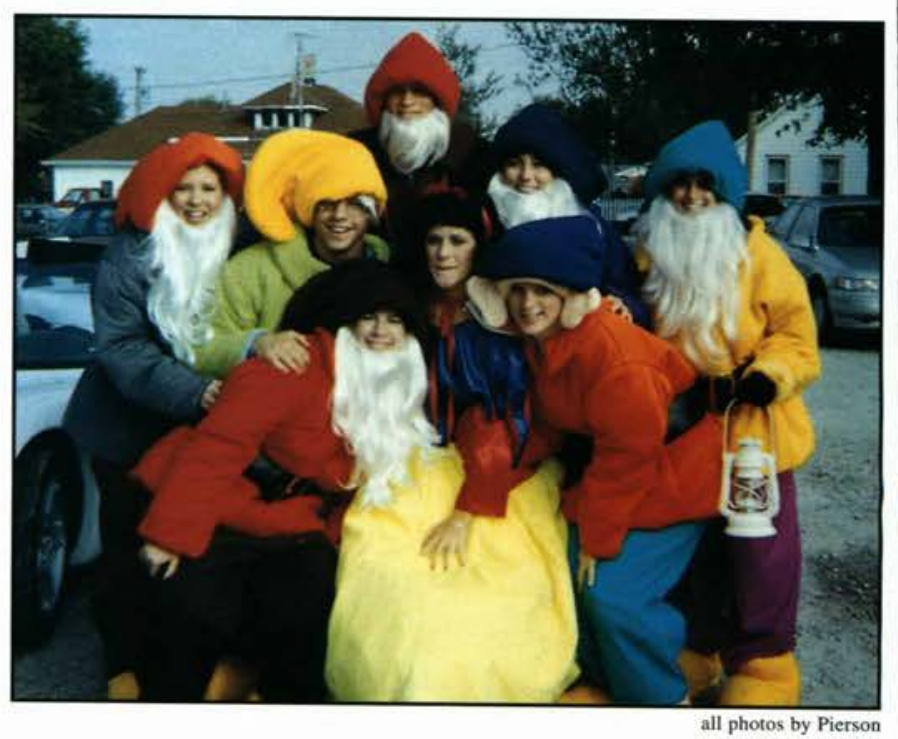




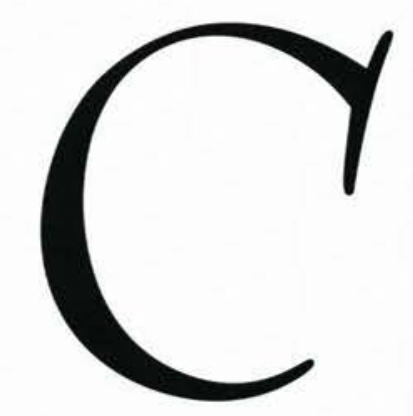

Campus Activities Board

\section{by Ruthanne Pierson}

$\prod_{h}$ his year twenty-one juniors and seniors comprised the Campus Activities Board. The Office of Campus Activities, headed by Dick Walker and his hardworking staff, selected these students the previous year based on campus involvement, service, student and faculty recommendations, and leadership. The teeshirt laden students perform tasks ranging from pulling Li'l Sibs activities together, to handing out hot cocoa to students on the way to class during cold mornings. You might find them shoveling snow in front of community homes, picking up trash along highway 72 , or helping guests find their seats at concerts. Whatever the task, their purpose is to serve and assist the Campus Activities office with any activities or special events.

The group arrived early on campus September $10^{\text {th }}$, and promptly departed on the "Possum" (a large overnight bus) for their annual "Trip." The "Trip," this year began with a lesson at the Annapolis Sailing School. After a few beginner basics, the group headed out to sea on the Chesapeake Bay to try out their newly discovered skills. From Annapolis, they road-biked to Washington D.C. and ended the two-day, 90-mile bike excursion in Leesburg, VA-tired and extremely sore. Cedarville graduate and Grand Rapids Seminary student, Jeff Burr ('93), led the group in a message series entitled "Seizing the Opportunities of the Storm." The purpose of the "Trip" is to develop team building and a sense of team unity, which is crucial to the success of any leadership team, early in the year.

Senior CAB member Charity Rizer explained, "The CAB provides the oppor-

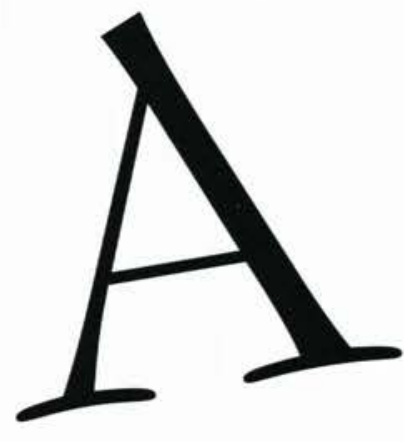
tunity to serve and have a lot of fun doing it." Yet, fun is always tempered with the humility of service. Bible professor, Dr. Drullinger, shared with the team, in their weekly meetings, a series entitled, "The Sacred Order of the Towel," highlighting the servant aspects of leadership. Service in leadership is truly what 


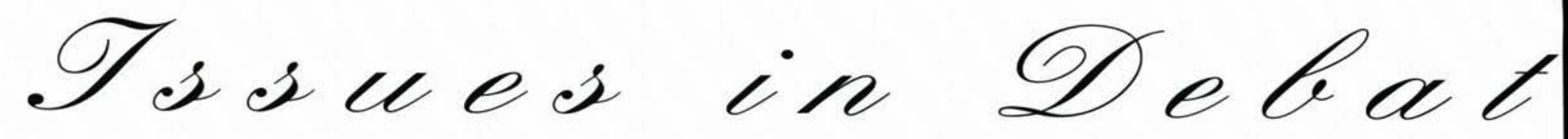

Tre. teams enjoyed successful seasons in 1997-98. The two intercollegiate speech teams competed against colleges across the nation. Team members spent hours each week researching and writing speeches, then sacrificing their weekends to travel to tournaments. While the rest of the campus goes out on Friday nights and sleeps late on Saturday mornings, these dedicated students traveled across the country, competing late into the night on Fridays and rising early

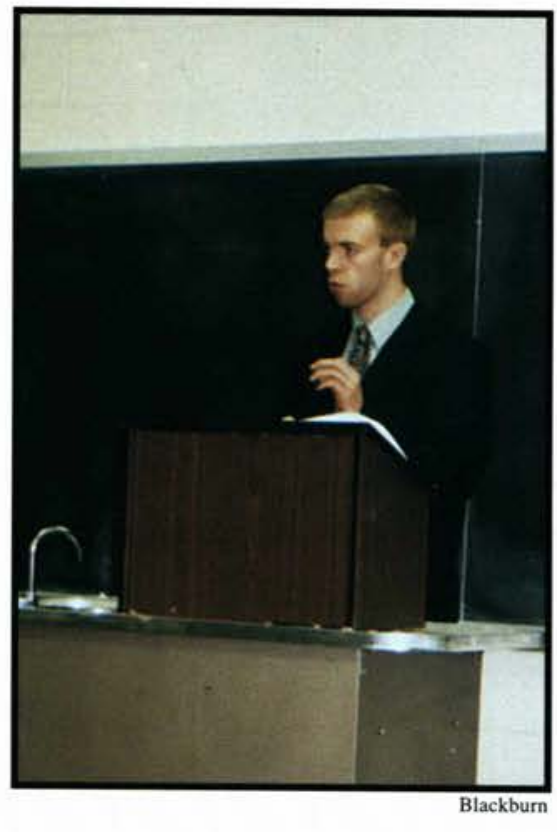
on Saturdays.

Debaters prepared cases to address each semester's topic. This fall they debated the resolution, "Casino gambling is detrimental to U.S. society." The winter topic was "Resolved: that the United States should abolish the use of peer jurors." The debate teams placed among the top eight teams in each division and won top speaker awards at every tournament. They won the novice division at the Western Illinois University tournament, one novice team broke semifinals against open division debaters, and teams nearly swept a tournament at Anderson, taking second, third, and fourth places. They competed at the national debate tournament in Illinios during the 1998 Spring Break.

Forensics teams competed in several types of events, including public address, oral interpretation, limited preparation events, and Lincoln-Douglas debate. The season began early in the fall and culminates in the Ohio state novice and varsity tournaments. The novice team had the most successful state tournament ever, taking home 21 out of 63 total trophies. The varsity team placed second in individual events behind The Ohio State University. by Joy Wickholm

Dusty Hansen makes eye contact during a debate (above).
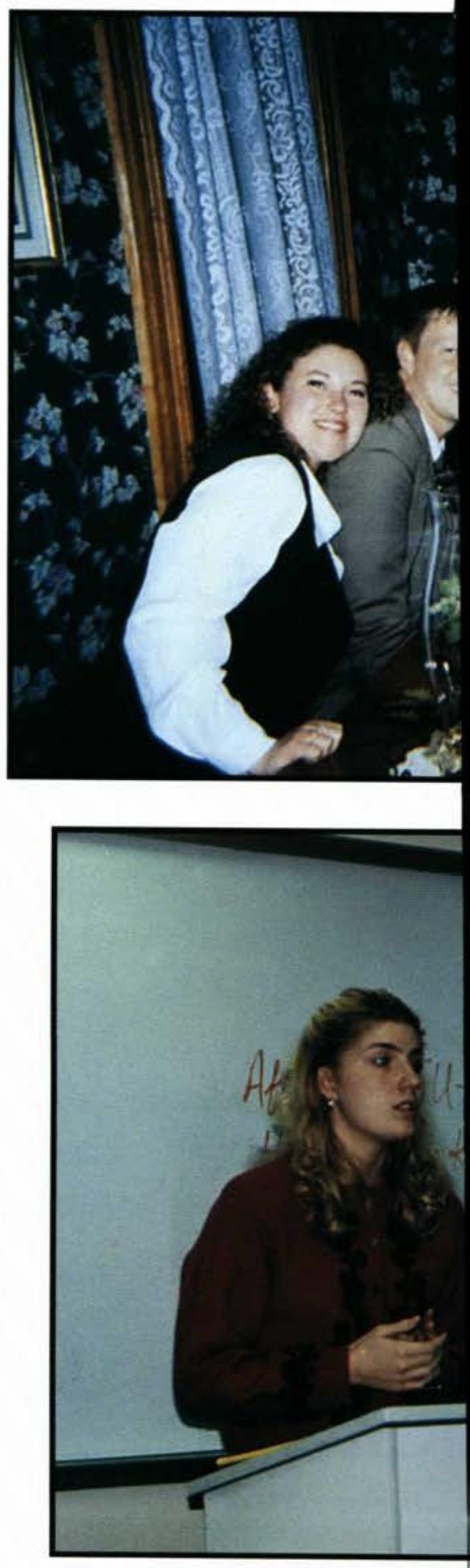


\section{wnd . Pareendici}
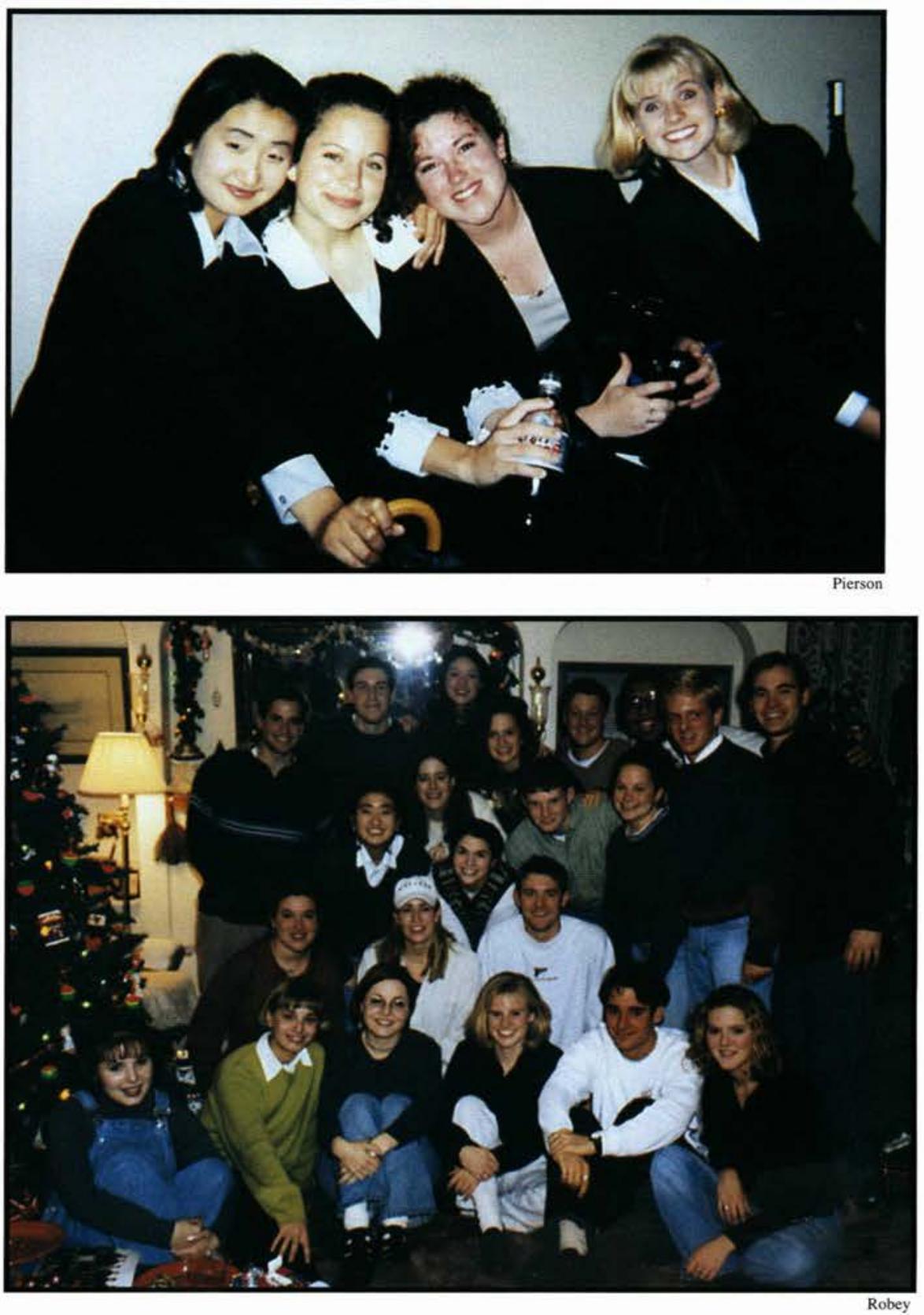

Andrea Endicott, Andy Hedges, Mike Dorsey, Chris Pierre, Ashley Barnes, and James Metsger (1 to r) enjoy an evening at Dr. Robey's (top left).

Ginger Butler pauses to emphaize a point (bottom left).

Ruthanne Pierson, Kelsey Perkins, Andrea Endicott, and Julie Forstrom enjoy one another's company at competitions (top right).

Rapport was built between team members and their coach: Annual Chistmas party held at Dr. and Mrs. Roby's home (below). 


\section{Goncert Ghorale}
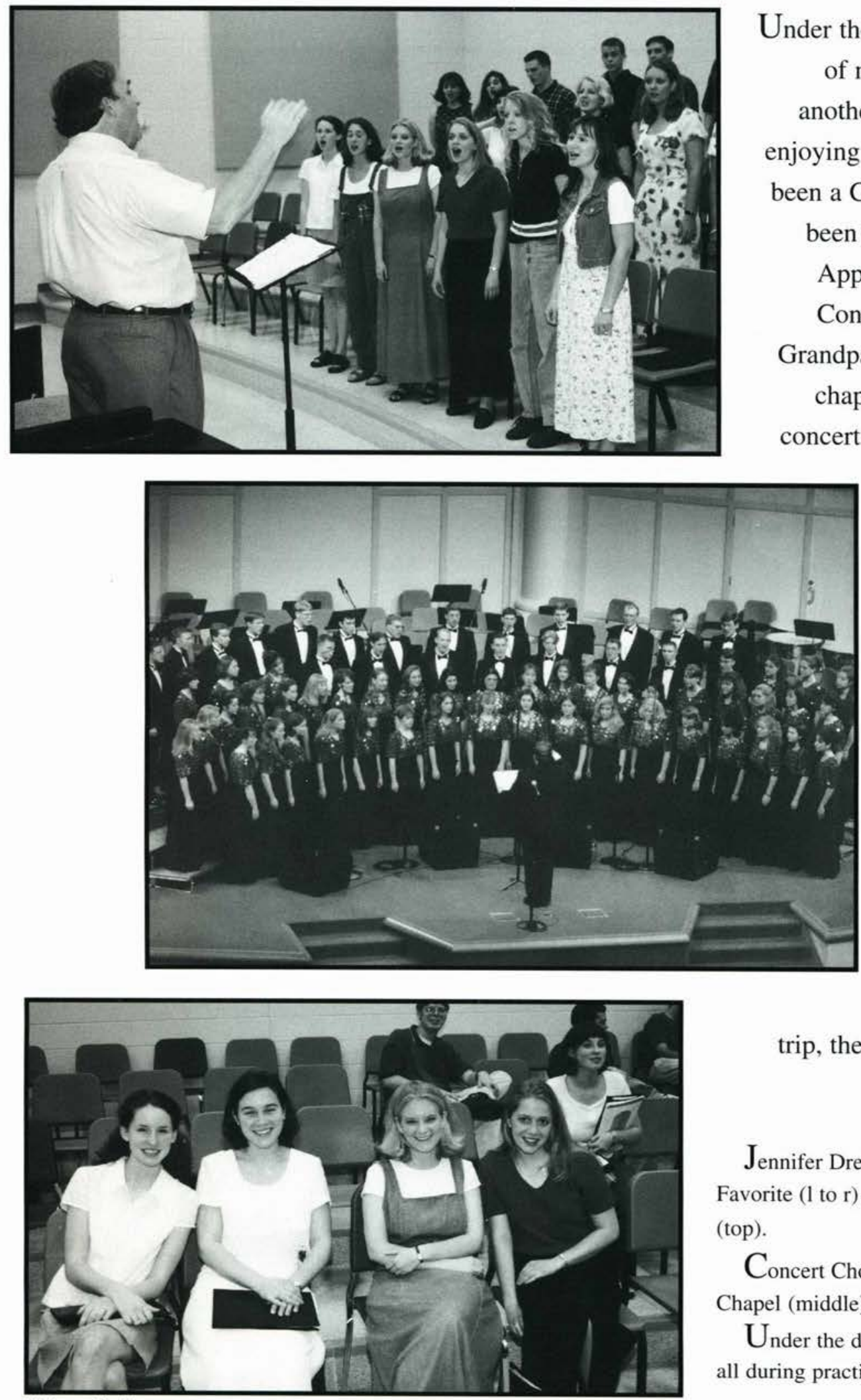

All photos: Blackburn
Under the direction of Lyle Anderson, professor of music, the Concert Chorale experienced another year of ministering through song and enjoying fellowship together. Dr. Anderson has been a Cedarville professor since 1970, and has

been the only director in this choir's history. Approximately ninety students made up the Concert Chorale this year. They sang in the Grandparent's Day chapel, in the annual praise chapel, at graduation, and in a special miniconcert in the recital hall along with the Men's

Glee Club.

The chorale focused on ministry, and Dr. Anderson encouraged this

by making prayer a priority and providing the group with ministry opportunities. Each year, the Concert Chorale has the opportunity to go on a small singing tour to spread the gospel. This Easter Break they were able to tour England, where they sang in small and large churches, and they also performed a few impromptu concerts. Although ministry was the first priority of the trip, the chorale also had the opportunity to see London and Oxford.

Jennifer Drexel, Erin Troike, Jenny Armour, Holly Favorite (1 to r) enjoy fellowship during a break from practice (top).

Concert Chorale ministers in the James T. Jeremiah Chapel (middle).

$\mathrm{U}_{\text {nder the direction of Dr. Anderson, members give their }}$ all during practice (bottom). 


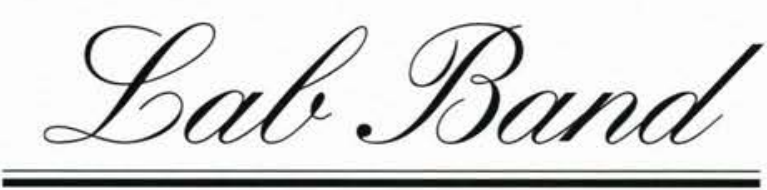

On several occasions this year, the Cedarville College Lab Band dazzled audiences through jazzy tunes, swing, and pop music. Playing classic melodies from various decades, the 22member group displayed its diversity by selecting tunes from the swing of the 1920 s to the pop of the 1990s. Their repertoire includes songs such as "Midnight Passage," "Soon and Very Soon," "Caravan," "Bugle Boogie Blues," and many other favorites. The Lab Band kept a very active concert schedule this year. They presented several great concerts to the Cedarville family and surrounding communities, including a swing concert at the opera house featuring guest soloist Jody Hovis. Another exciting concert by the lab band was held during Lil' Sibs weekend.

The Lab Band has been together for nine years, sharing their musical abilities with thousands. Mr. DiCuirci, the band's director, commented that this group is "highly committed and talented." He added, "this year has been a banner year for the band.'

Mark Wyse looks to the audience as he plays his ms (top).

Michael Di Curici pauses before he speaks to the ience with his deep voice (middle).

John Grapentine takes front stage during a perforance by the Lab Band (bottom).

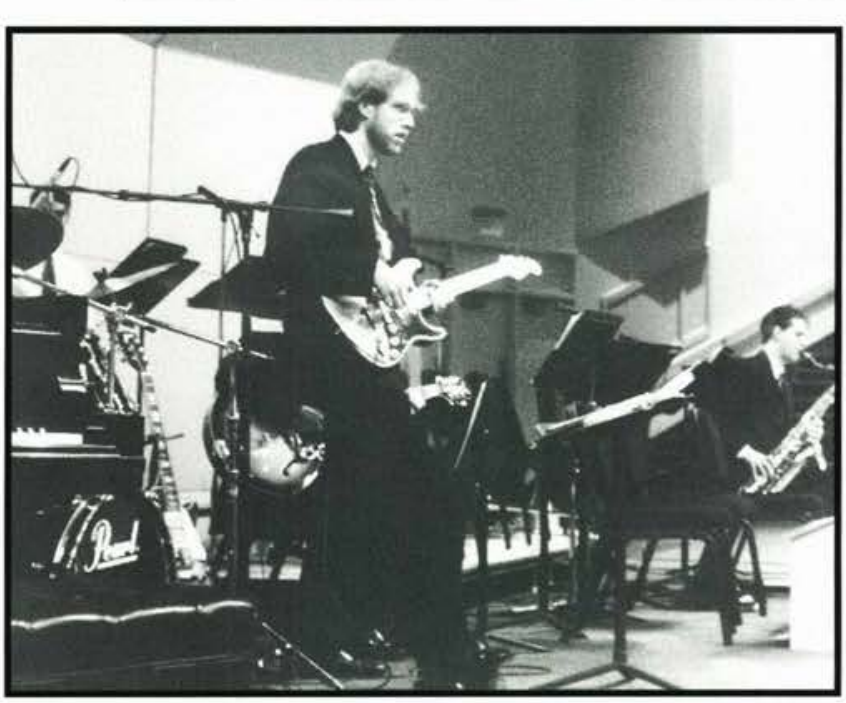

Blackburn 


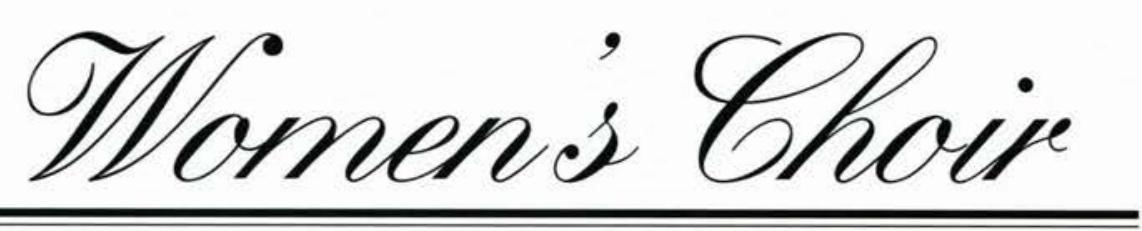

\begin{abstract}
Wone
omen's Choir is one of Cedarville's unique ministries. Under the direction of first- year faculty Mrs. Beth Porter, the Women's Choir provides a singing opportunity for women who are looking for a musical outlet. The Choir is open to any female student who is interested, and it requires an audition. The repertoire ranges from classical sacred music to popular Broadway tunes.
\end{abstract}

This year, the group has performed at the Winter Showcase concert, Chapel, and several local churches. Porter has enjoyed working with this group because she, "loves working with individual voices and making them sound like a solid group. It is so fun for me to share my musical wants and desires with the girls, have them respond and make music together."

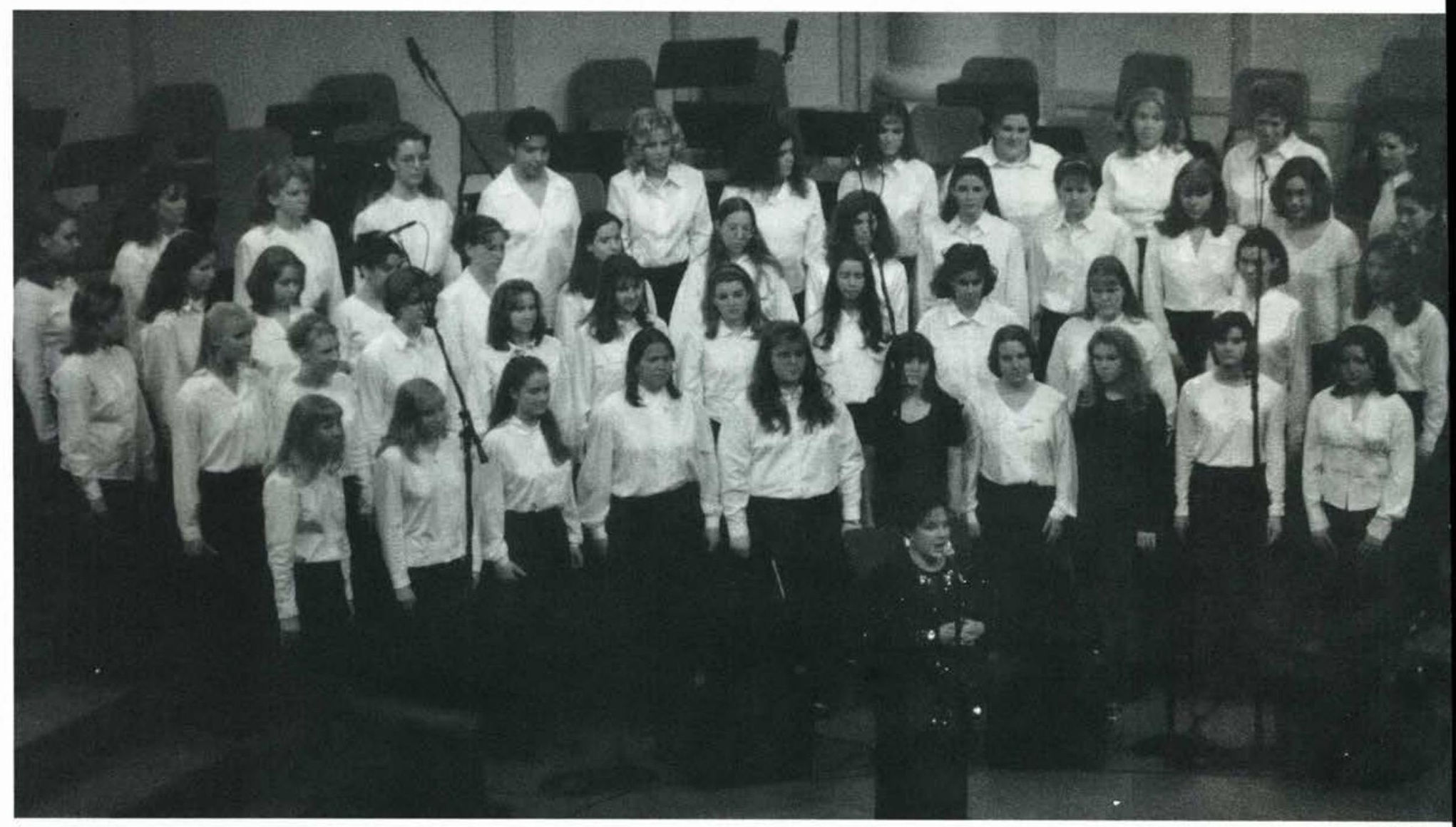

Blackbur

Women's Choir: Jennifer Abas, Jennifer Abbey, Dawn Albertson, Melanie barker, Karen Belding, Diane Bielo, Kim Boesch, Joyce Boggs, Jennife Brayer, Aimee Copeland, Angela DeSantis, Melissa Dove, Christina Gain, Elizabeth Bosztyla, Carol Guerette, Julie Henderson, Angela Howe, Eric Jenkins, Sarah Lightly, Courtney Ludema, Jessica Mathias, Amanda McLaughlin, Michelle Moore, Kristin Neuman, Joanna Overholt, Jennife Penna, Miriam Perez, Emily Poling, Errin Prentis, AMy Reno, Kimberly Scott, Jennifer Secor, Elizabeth Smith, Susanna Steeg, Risha Stockton, Ji Strychalski, Rebekah Thompson, Erin Tuinstra, Rebecca Vitarelli, Melanie Wadlington, Jennifer Weaver, Erica White, and Lissa Young (captio does not correspond with the arrangement in the photo) 


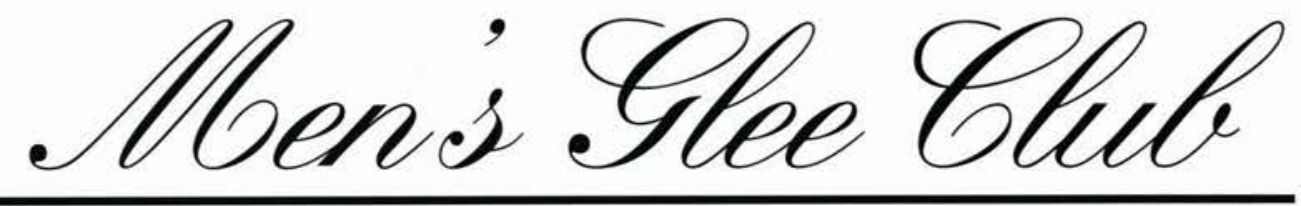

The Men's Glee Club was established in 1992 by Dr. Lyle Anderson and "exists to provide meaningful, enjoyable musical experiences for men as they sing God-honoring sacred and secular music." Men's Glee Clubs have existed for over 100 years in many different colleges and universities. They started out with male voices singing sentimental songs known as "glees" and have now diversified their repertoire from classical to contemporary popular music. Cedarville's Glee club consists of men from all majors and academic classes. This year, the 50 -member group has been able to minister in chapel, in the annual POP's concert, on their tour to Alabama, and singing the National Anthem for the Dayton Bombers hockey team and the Columbus Crew's soccer team.

Anderson says, "My role as the Men's Glee Club director has been very gratifying because of the high caliber of young men who constitute the group. Coming from many academic majors, the members manifest a 'one-for-all, all-for-one' attitude spiritually, musically, and socially."

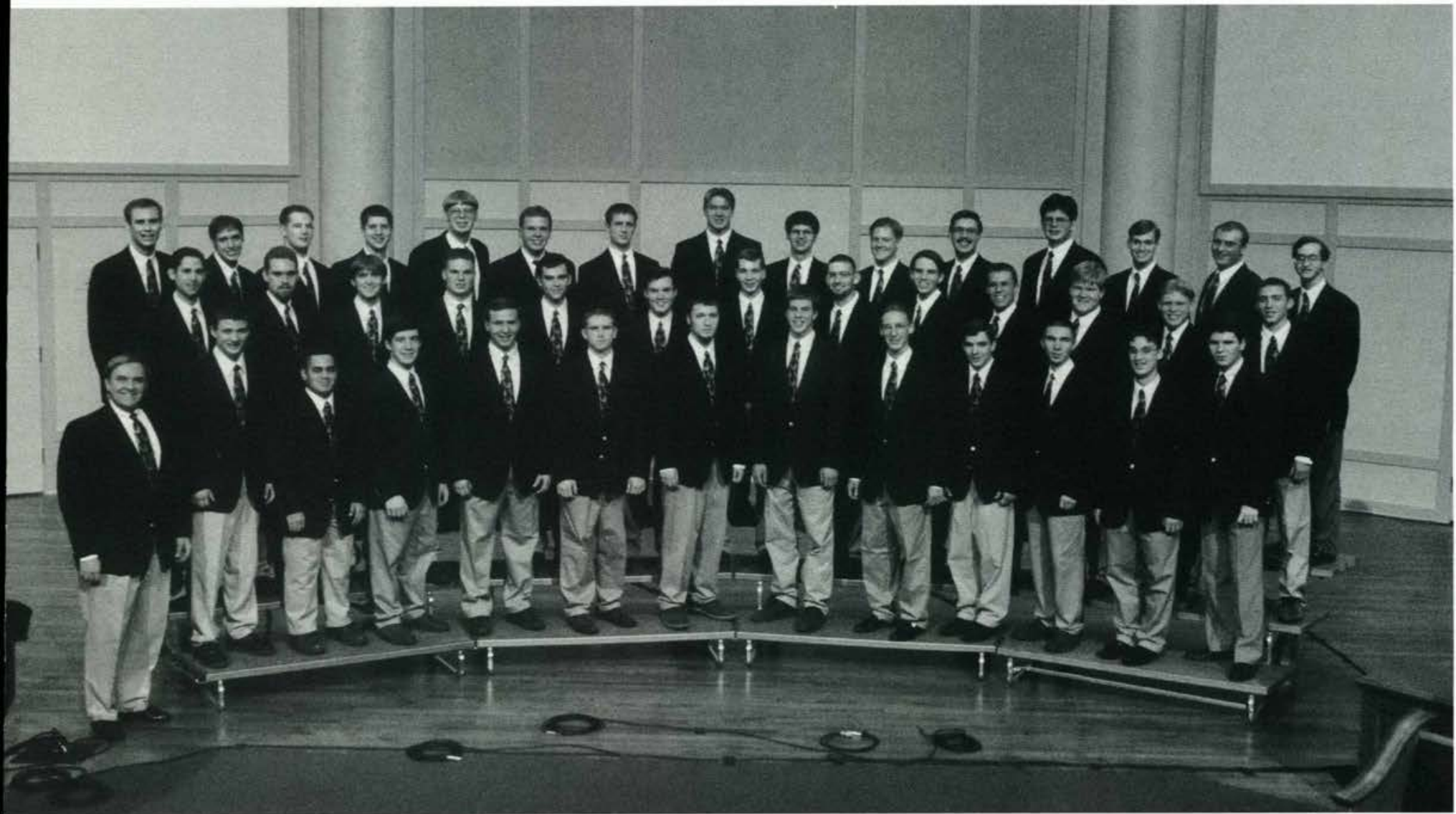

Blackburn

Men's Glee Club: Mark Armstrong, Kevin Boblitt, Jason Boggs, Dave Boyd, Matt Boyd, Ryan Einfeldt, Ryan Freed, Kyle Gantz, Andy Gingrich, ustin Goodrich, Timothy Hardin, Andy Hedges, Dave Hewitt, Karl Hjembo, Chad Jensen, James Johnson, Jerry King, Jon Kleis, Stephen Mattick, ohn Metcalf, Jason Naill, Matt Noll, Jason Overturf, Drew Peters, Daniel Rainsberger, Zach Rhodes, Andy Rodriquez, Brian Rosseau, Tom Sanderson, Curt Scott, Will Steward, Chris Straits, Paul Tocknell, Ken Waldock, Will Woods, and Jason Zaugg (caption does not correspond with he arrangement in the photo) 


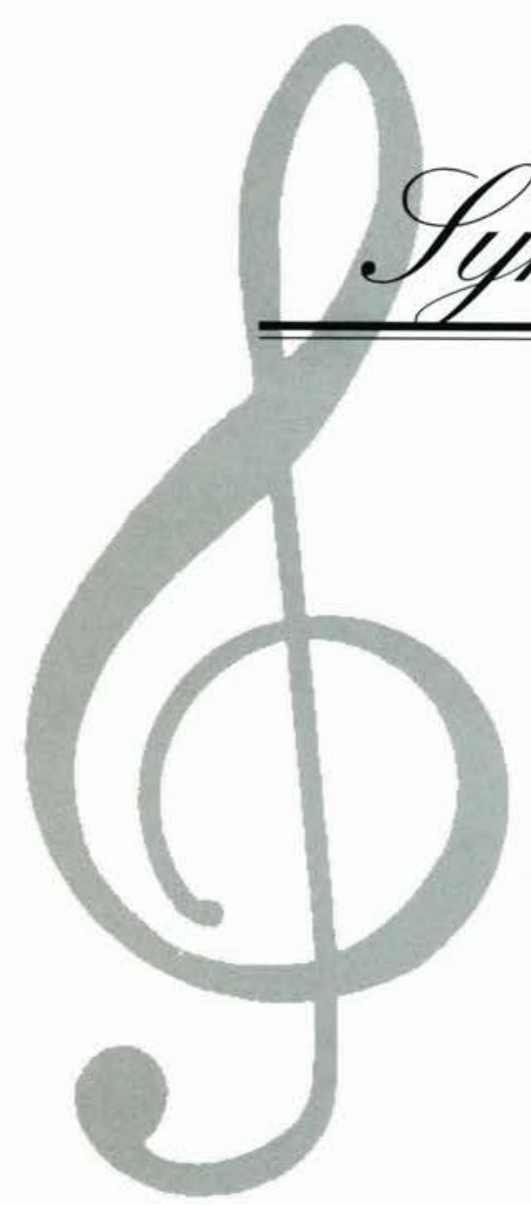

by Erica Chung

mphonic. Band

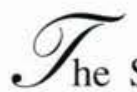

Symphonic Band had another very successful year. The band played at a variety of different concerts, ranging from the Homecoming Concert to the Newt Gingrich Rally. They also participated in a Brass Conference, a Pops Concert, the Winter Enrichment Conference, and the Music Showcase Concert.

Michael DiCuirci, professor of music, leads the Symphonic Band. DiCuirci has led many other excellent bands at Cedarville. "This has been a great band to work with. I sense a professional spirit coupled with a lot of talent. This version of the Symphonic Band reads quite well, and to date, their concerts have been fabulous," according to DiCuirci.

The future of the Cedarville Symphonic Band looks quite bright. DiCuirci's goals for the band are "more great concerts, guest artists, and even a better product into the 21 st century."

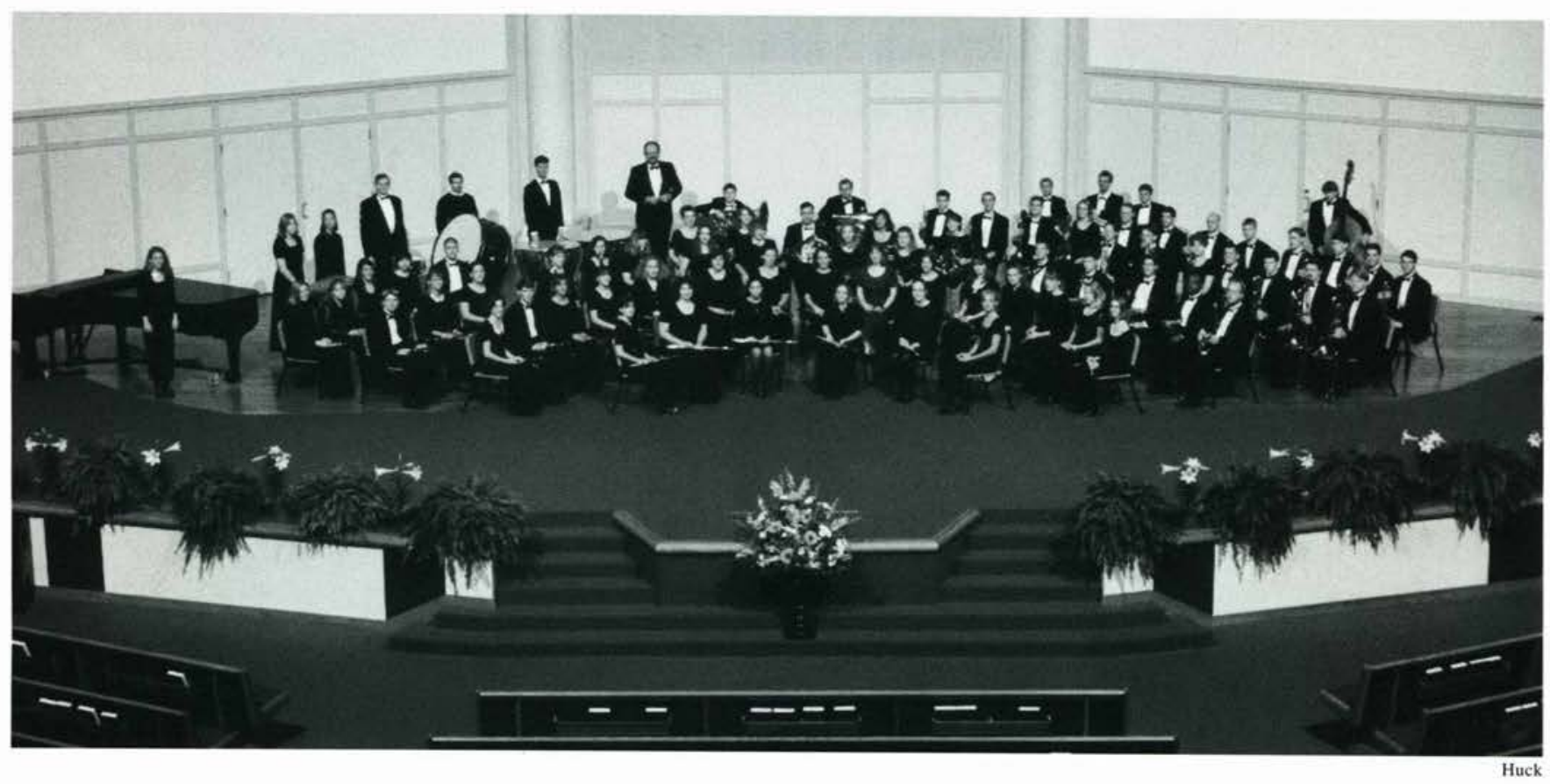

fymphonic Band Members: Piccolo:Lezley Bath. Flute: Becky Lakes, Faith Buchanan, Tammy McComb, Stephanie Croch, Dawn Driesbach, Sarah Mayer, Kelly Montague, Amy Morse, Kelly Tyson, Ruth Jackson, Chandra Lewis, Sabrina Springer, Becky Shellenbarger, Kelly McKay, Christinna Wheatley. Oboe:Elizabeth McDonald, Gretchen Dorman, Leanne Heath. Adrienne Hoghe, Cynthia Potter. Bassoon:Karen Leininger, Sarah McDonald, Christine Brittin. Bass Clarinet: Rachel Schafter, Amanda Bruckner, Kristin Small. Percussion: Ben Vawter, Carol Marks, Erica Chung, Tim Ropp, Brandon Ross, Jill Strychalski. Clarinet:Cindy Lawry, Rachel Soderstrom, Angela DeSantis, Karisa Linafelter, Heather Smith, Joshua Hesse, Ken Borror, Rebecca Kniowski, Nathan Lewis, Nathan Hart, Michelle Edwards, Ann Weeks, Holly Waechter, Sarah Hamrick, Suzanna Creps, Andrea Weber, Alicia Good, Joshua Eckburg. Saxophone: Jim Dyer, Tim Sutton, Allister Baldwin, Robbie Beat. Tenor Saxophone:Shawn Conley. Baritone Saxophone:Paul Sheldon. Trumpet: Israel Barr, Jamie Scheid, Brian Shook, Stephen Hand, John Filson, Jeff Brown, Andrew Nyveldt, Brian Gornick, Jared Voigt, Heather VanGorp, Phil Tate, Chris Smith, Ryan Einfelft. French Horn:Eileen McCoskey, Amy Bohn, Julie Saucier, Daniel Kwast, Tami Wortman, Summer Schafer, Adrienne Eads, Melody Brickel. Trombone:Tom Mullins, Kyle Harrison, Nick Grisco, Jil Townsend, David Jouwstra, Jonathan Grissom, Kevin Armstrong, Matt Snyder, Michael Mclain. Tuba: Chris M. Brown, Chris Grigson, Beth Frank, Virginia Miller, Michael P. DiCuirci, Jr., Derrick Doherty. String Bass: Kenneth Heale 


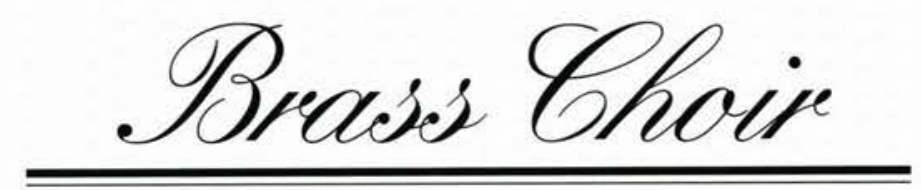

hey met twice a week to practice everything from classical to contem porary music in order to perform in chapels and special concerts throughout the year. Their concert schedule included three major performances in the Homecoming Praise concert, the annual Brass Players Conference, and Music Showcase.

The Brass Choir was made up of a talented group of students who had to audition to be involved, and went through a very selective process. Nineteen students were able to display and develop their talents this year on french horn, trumpet, trombone, baritone, tuba, and percussion.

Brass Choir was a great opportunity for the instrumentalists. The music was more intense than symphonic band music, and the small number of people allowed them to learn to work well together and to receive one-on-one instruction with their director, Mr. Charles Pagnard.

Mr. Pagnard is the principle trumpet player for the Dayton Philharmonic Orchestra, so his professional experience added even more to the one-on-one instruction he gave the players.

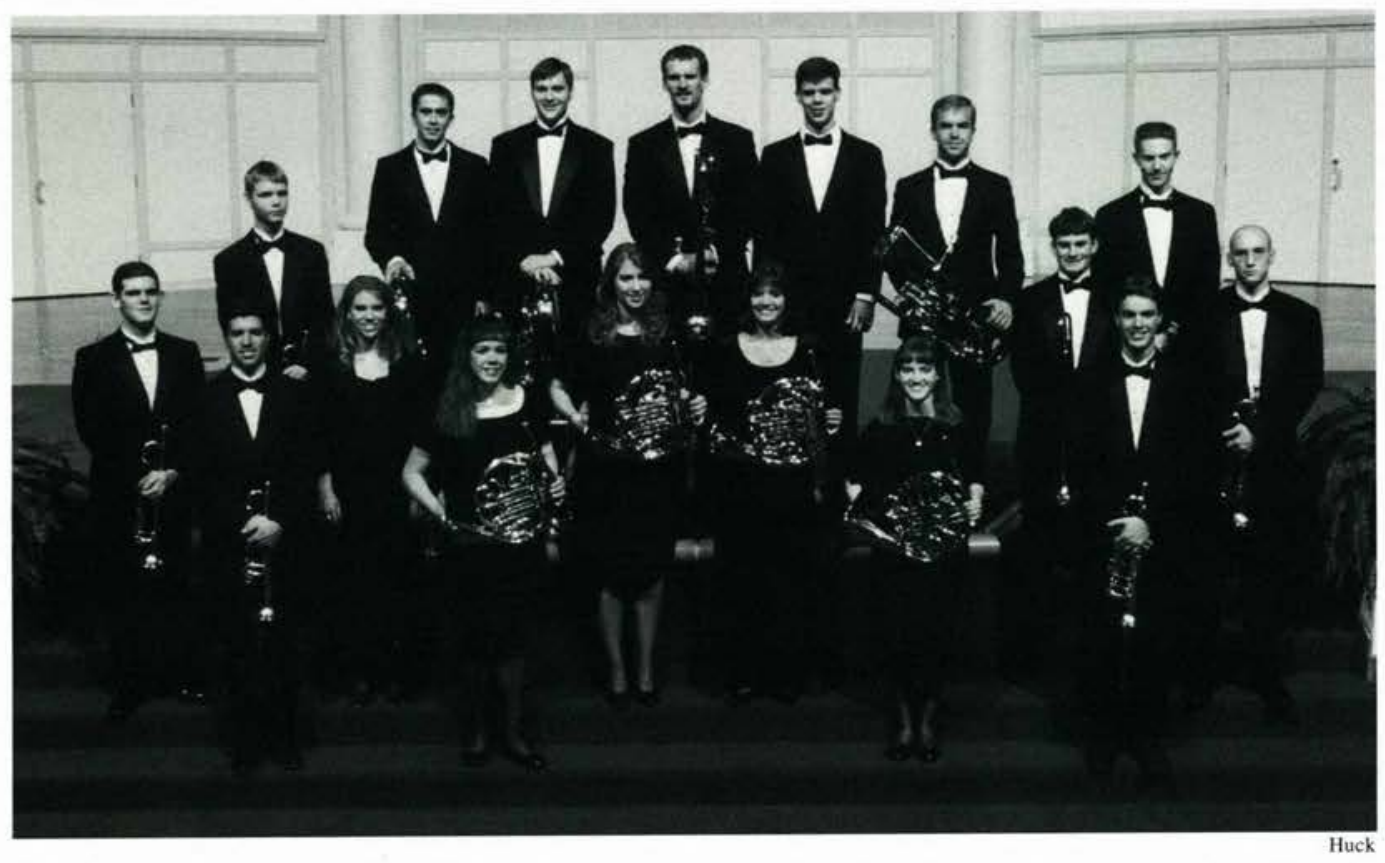

Prass Choir Members: Trumpet: Michael Eaton, Brian Gornick, Stephen Hand, Jamie Scheid, Brian Shook, Phil Tate. French Horn: Amy Bohn, Eileen McCoskey, Summer Schafer. Trombones: Paul DiCuirci, Kyle Harrison, Phil Thorsen. Baritone Horn: John McCaw. Tuba: Chris Brown, Chris Grigson. Percussion: Ben Vawter, Jill Strychalski. 


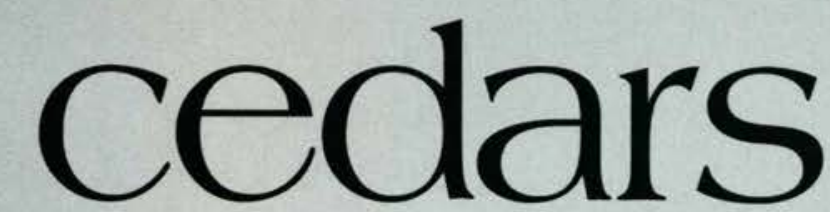

by Peter Bednarek

\section{A CEDARVILLE COLLEGE STUDENT PUBLICATION}

$\mathrm{P}_{\mathrm{r}=0}$ of the byproducts involved with journalism. The Cedars editorial staff is all too familiar with these and more like them. Senior news editor, Joy Wickholm said, "Cedars really taught me to be flexible and ingenious with my time - especially when you work from three in the afternoon until three in the morning a few nights in a row." Cedars is a biweekly publication and every other week its staff spends all afternoon and most of the night editing stories, cutting headlines, and doing other related tasks to have the paper ready for the printers by Thursday morning.

Cedars is the only Cedarville College news source of its kind, printing everything from past campus events to fashion columns. Within the confines of a single issue one can find music reviews, the latest Yellow Jacket Sports scores, and even information on where to take a date.

The editorial staff consists of the four people with the addition of a business manager and photographer. These four have individual responsibilities for each issue, but they work in conjunction to bring the final product together the week the paper is issued. Cedars utilizes a larger base of anywhere from 10-15 writers to follow stories and submit them as assigned.

The Cedars base of operations is located as high as one can go in the old Fine Arts Building in a tiny, but cozy attic office that becomes the sight of the biweekly, late-night ritual. The cramped quarters and stressful catastrophes have brought the staff together in a unique way. Wickholm concluded, "We've had a great time getting to know one and another while under the influence of caffeine and sugar, and while enduring power outages and ice storms. These are lasting friends and I will miss them." 


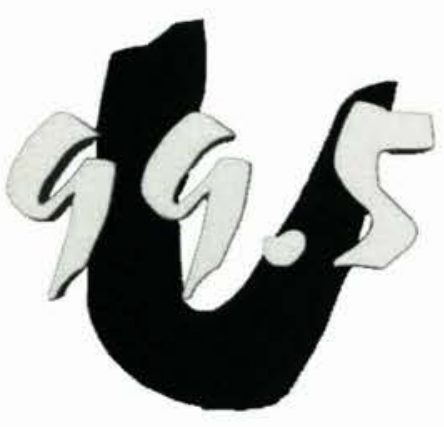

Department Heads:

Faculty Advisor: James

Leightenheimer

Station Manager: Craig Magrum

Program Director: Mark Allen

Information Director: Michael

Koerbel

Sales Manager: Paul Lykowski

Music Director: John Ward

Promotions Director: Josh Snyder

Production Director: Kevin Young

\section{The Student Radio Station of Cedarville College}

\section{DJ Listing and Schedule:}

\section{AM - 9AM}

Sunday: Ryan Coverdale w/ Jessica Acker Monday, Wednesday, and Friday: Ryan

Freed and Krista Warder

Tuesday and Thursday: Shelley Stock and Mandy Prusha

\section{PM - 10PM}

Sunday: Chris Fonte

Monday: "Primetime" John Ward and Shannon Boynton

Tuesday: "Christian Music Weekly" Michael Koerbel and Steve Guenther Wednesday: Eric Svendsen
Thursday: Amanda Prusha

Friday: Craig Magrum

Saturday: Mark Allen

10PM - 1AM

Sunday: Ben Stutzman

Monday: "Sportsville" Josh

Strychalski and Mark Allen with Pete McLeod

Tuesday: Sara Miller

Wednesday: Kevin Young

Thursday: Sarah Carr

Friday: Josh Gunderson

Saturday: Dave Cook

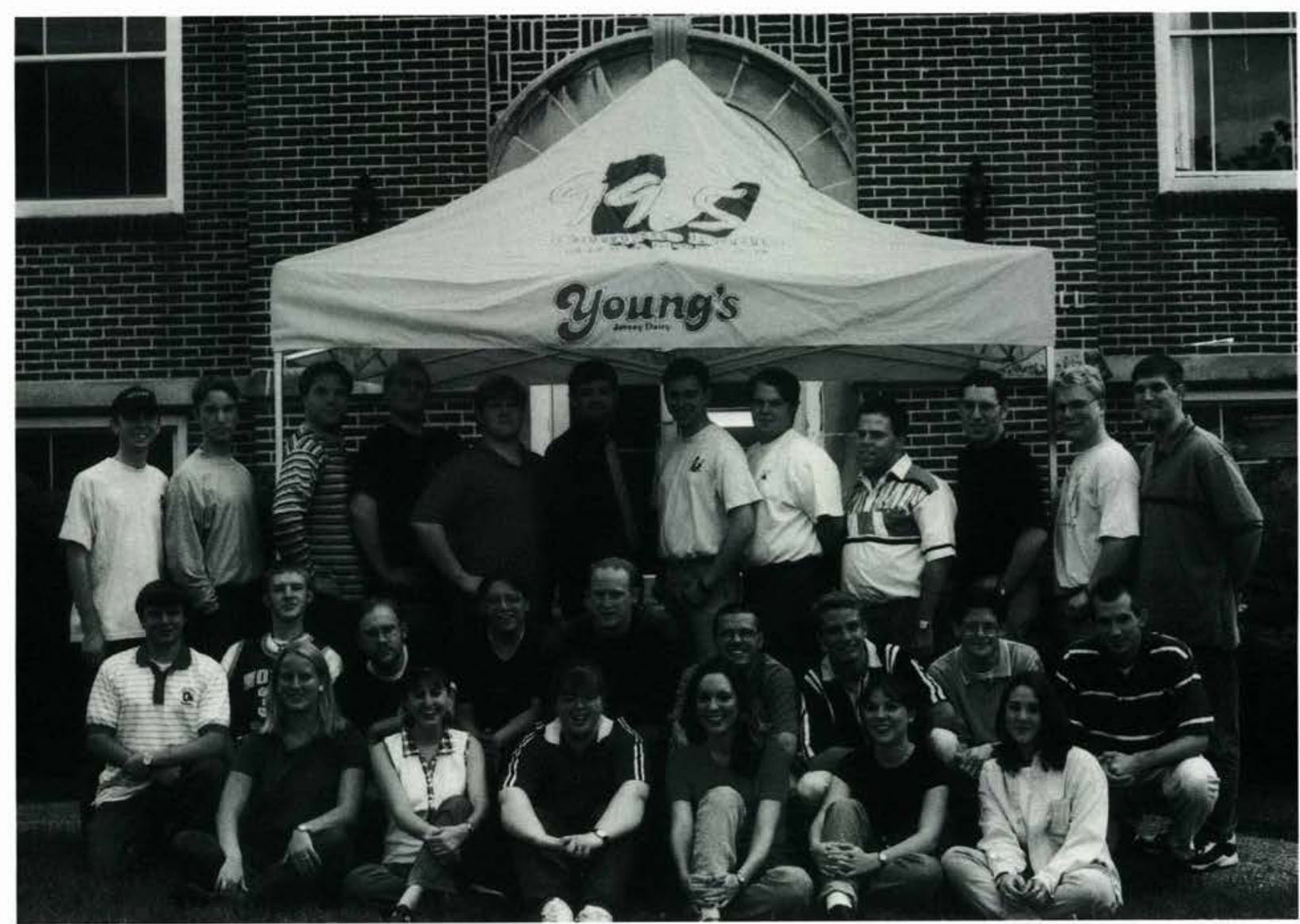

Leightenheimer

U99.5 Staff: (back, l-r) Josh Snyder, Mark Allen, Andy Bergman, Ryan Vogel, Ryan Freed, Steve Goldsworth, Craig Magrum, Josh Bean, Ryan Coverdale, Kevin Young, John Dearie, Ben Stutzmen (middle) John Ward, Josh Strychalski, Steve Guenther, Jeff Nafzinger, Paul Lykowski, Chris Fonte, Joel Peterson, Mike Korbel, Caleb Smith (front) Lindsay Kaiser, Diane Bielo, Amanda Lawrence, Krista Warder, Shelly Stock, and Jessica Acker 


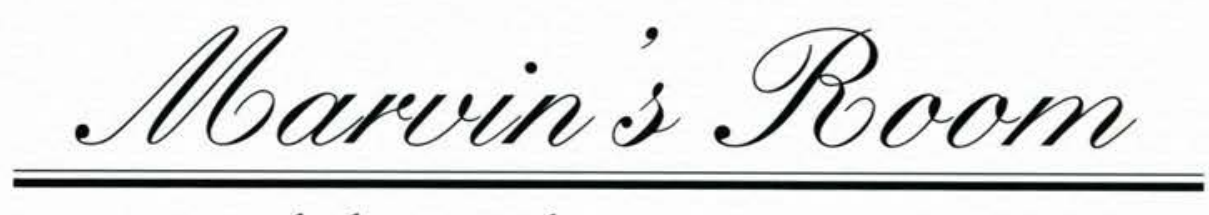

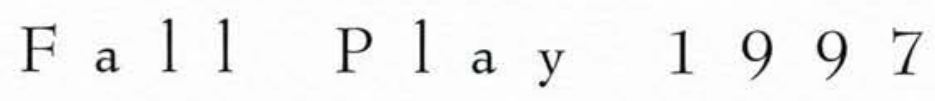

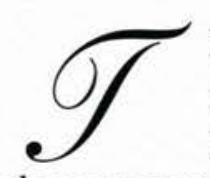

he Department of Communication Arts and Director David H. Robey presented Scott McPherson's play, Marvin's Room, on November 13-15, 1997, in Alford Auditorium. The theme of the play was hope in the midst of despair.

Marvin's Room gave us a realistic account of one family's struggle through a terminal illness. The play took place in various locations of Florida and Ohio in the 1980's. Featured in the play are Bessie and Lee, two sisters who have not seen or heard from one another for quite some time. Bessie is a single woman who has spent the past 20 years caring for her dying father, Marvin, and her crippled Aunt Ruth. Lee is a single parent with two troubled sons.

The crisis began when a doctor diagnosed Bessie with leukemia. Because she

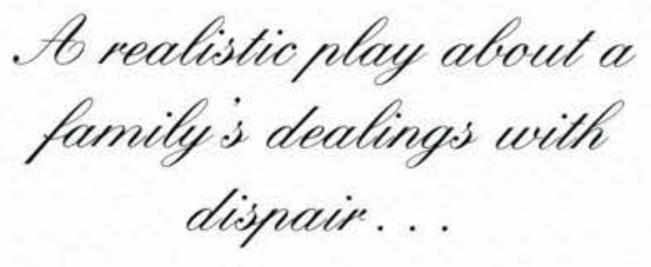

needed a bone marrow transplant, her sister and nephews had their bone marrow tested. The situation caused the family to grow closer in hope that one of their bone marrow types would match Bessie's In the end, they found that nothing matched. Despite Bessie's circum. stances, she remained content with he life.

The play presented the many obstacles this family had to overcome af ter Bessie's diagnosis, as well as the lifestyle contrasts between the two sisters. Love and selflessness contributed to Bessie's happiness throughout her life while Lee's selfishness destroyed many of her years.

Marvin's Room also aroused emotions; tears were intertwined with laughter. It was a play that showed some of the harder issues of life: parenting, aging, and the reality of death.

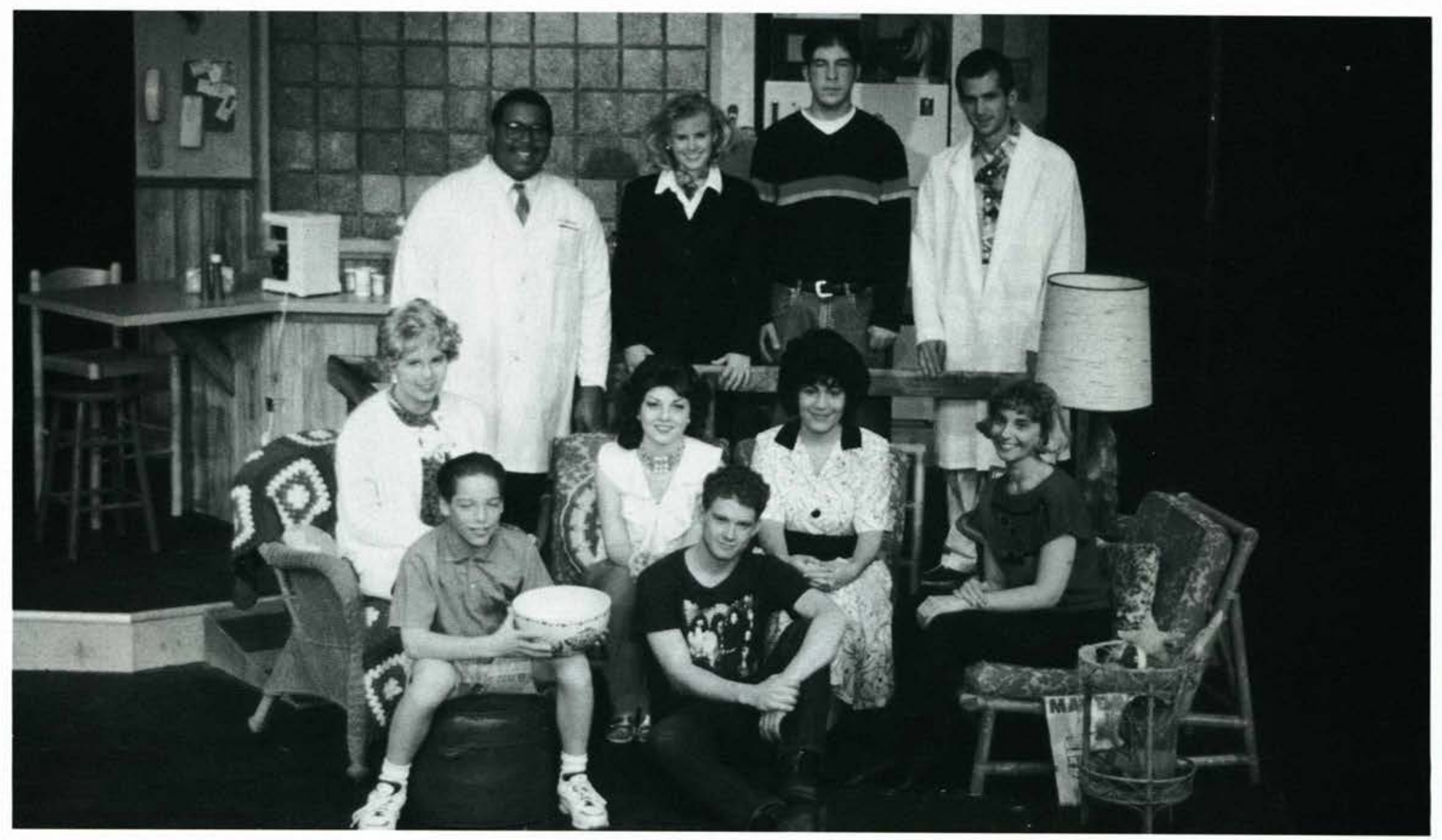

The cast of Marvin's Room-Front Row (L-R): C. Brandon Palmer, Jeremy Ryan Brown, Heidi Jo Dean; Middle Row: Sara Marie Romang, Stacy Marie Saville, Joanna L. Robinson; Back Row: Michael Leon Dorsey, Julie Forstrom, Jeremy Pierre, and Caleb J. Smith. 
$W_{\text {innie-the-Pooh, played by Jeremy }}$ Pierre, comforts Lee.
Gail and Wiredor

$\begin{array}{ll}\text { Bessie } & \text { JoannaL. Robinson } \\ \text { Dr.Wally } & \text { MichaelLeon Dorsey } \\ \text { Ruth } & \text { Sara Marie Romang* } \\ \text { Bob } & \text { Caleb J.Smith } \\ \text { Lee } & \text { Stacy Marie Saville* } \\ \text { Dr. Charlotte } & \text { Heidi Jo Dean* } \\ \text { Hank } & \text { Jeremy Ryan Brown } \\ \text { Charlie } & \text { C. Brandon Palmer } \\ \text { Nursing HomeDirector } & \text { JulieForstrom } \\ \begin{array}{l}\text { Marvin } \\ \text { Director }\end{array} & \text { Jeremy Pierre } \\ & \text { DavidH. Robey } \\ \text { * Denotes member of Alpha Beta Phi, Cedarville College } \\ \text { chapter of the national theatre honorary society, Alpha Psi } \\ \text { Omega theatre organization. }\end{array}$

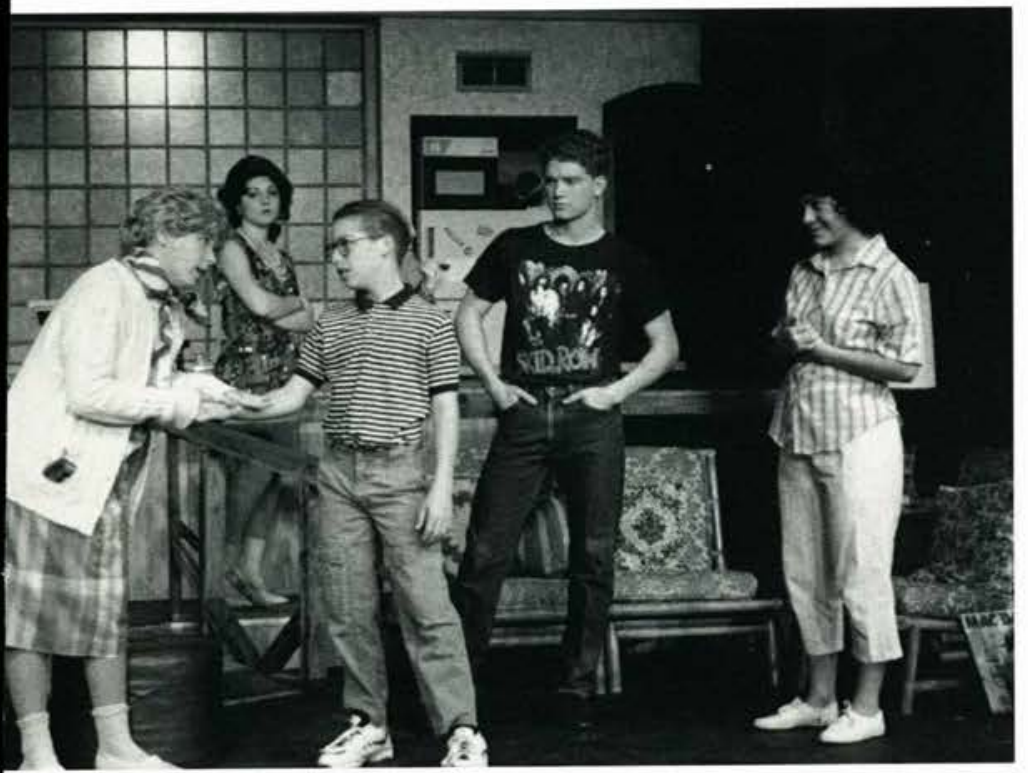

A scene from Marvin's Room (above).

All attention is focused on Ruth as she opens the canister (right).
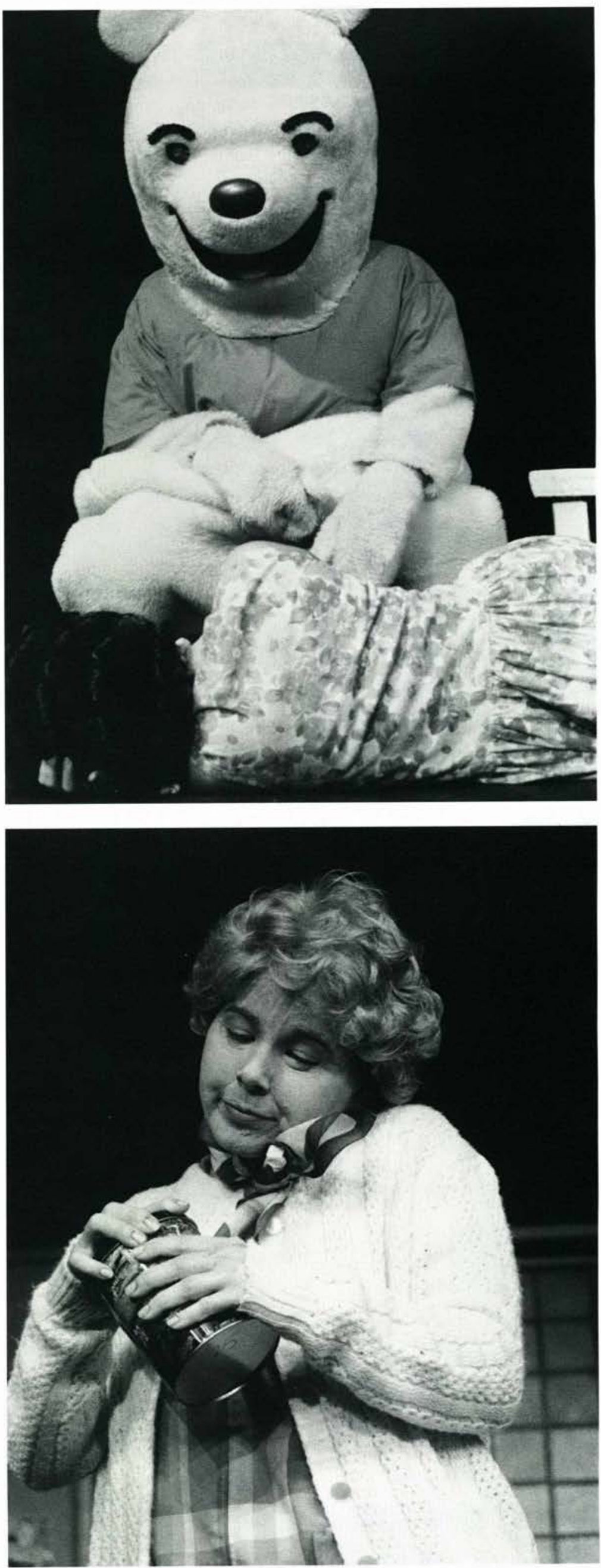

fall play-Marvin's Room 151 
Chris Vitarelli, as Sam Posner, presents flowers and a gift-wrapped package to Hannah Mandelbaum (Heidi Jo Dean) as Idaela Kantor (Martha Failor) looks on in exasperation (right).
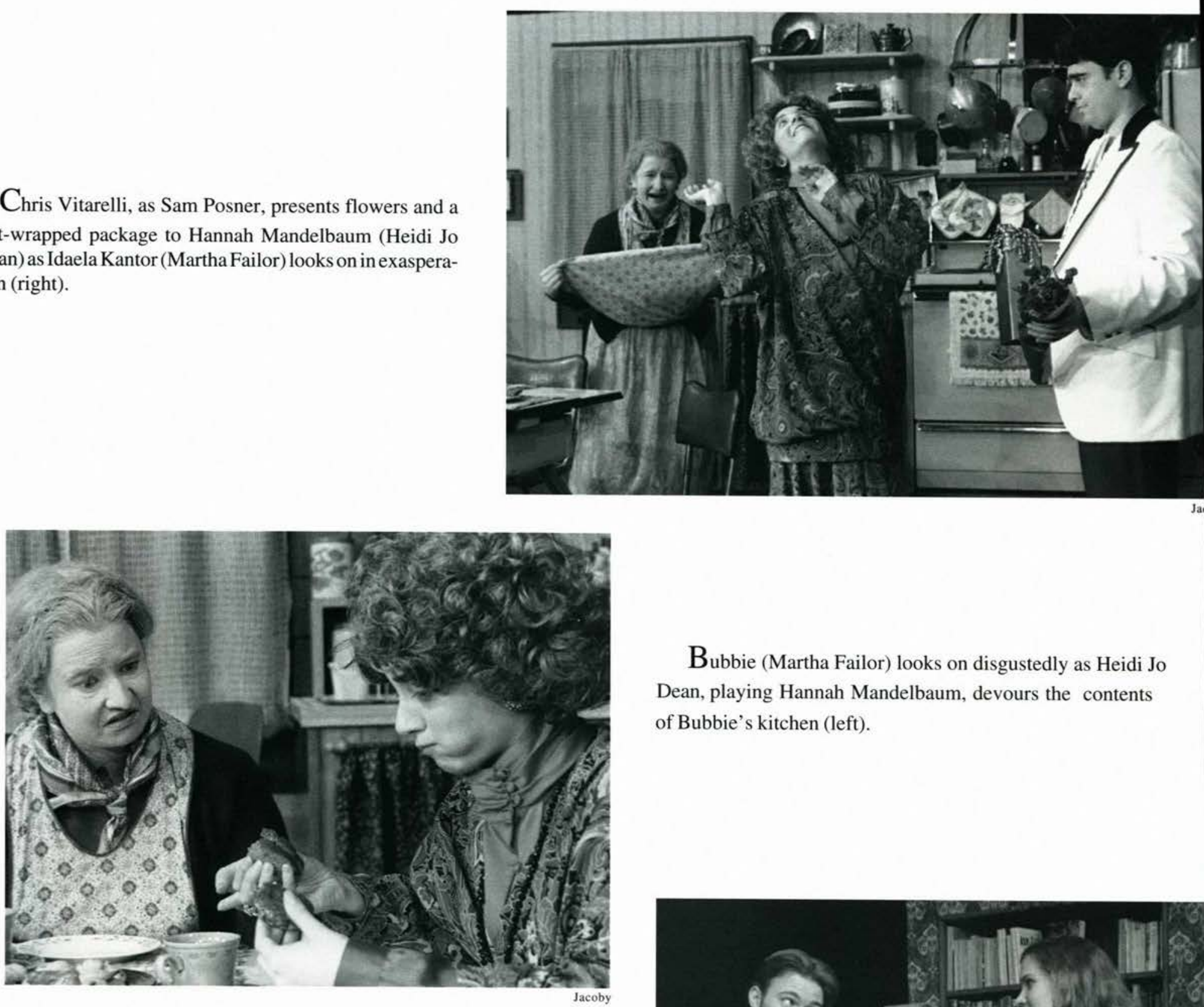

\section{Gait and Direotar}

$\begin{array}{ll}\text { IsabelleGrossman } & \text { Jessica Wagner } \\ \text { Idaela Kantor(Bubbie) } & \text { MarthaFailor } \\ \text { HannahMandelbaum } & \text { Heidi JoDean* } \\ \text { TylerMoss } & \text { DanielChristian Scott* } \\ \text { Sam Posner } & \text { Christopher J.Vitarelli* } \\ \text { EastsideDelivery Man } & \text { Caleb J.Smith* } \\ \text { Director } & \text { MischelleL.McIntosh* }\end{array}$

* Denotes member of Alpha Beta Phi Cedarville College chapter of the national theatre honorary society; Alpha Psi Omega theatre organization.

Bubbie (Martha Failor) looks on disgustedly as Heidi Jo Dean, playing Hannah Mandelbaum, devours the contents of Bubbie's kitchen (left).

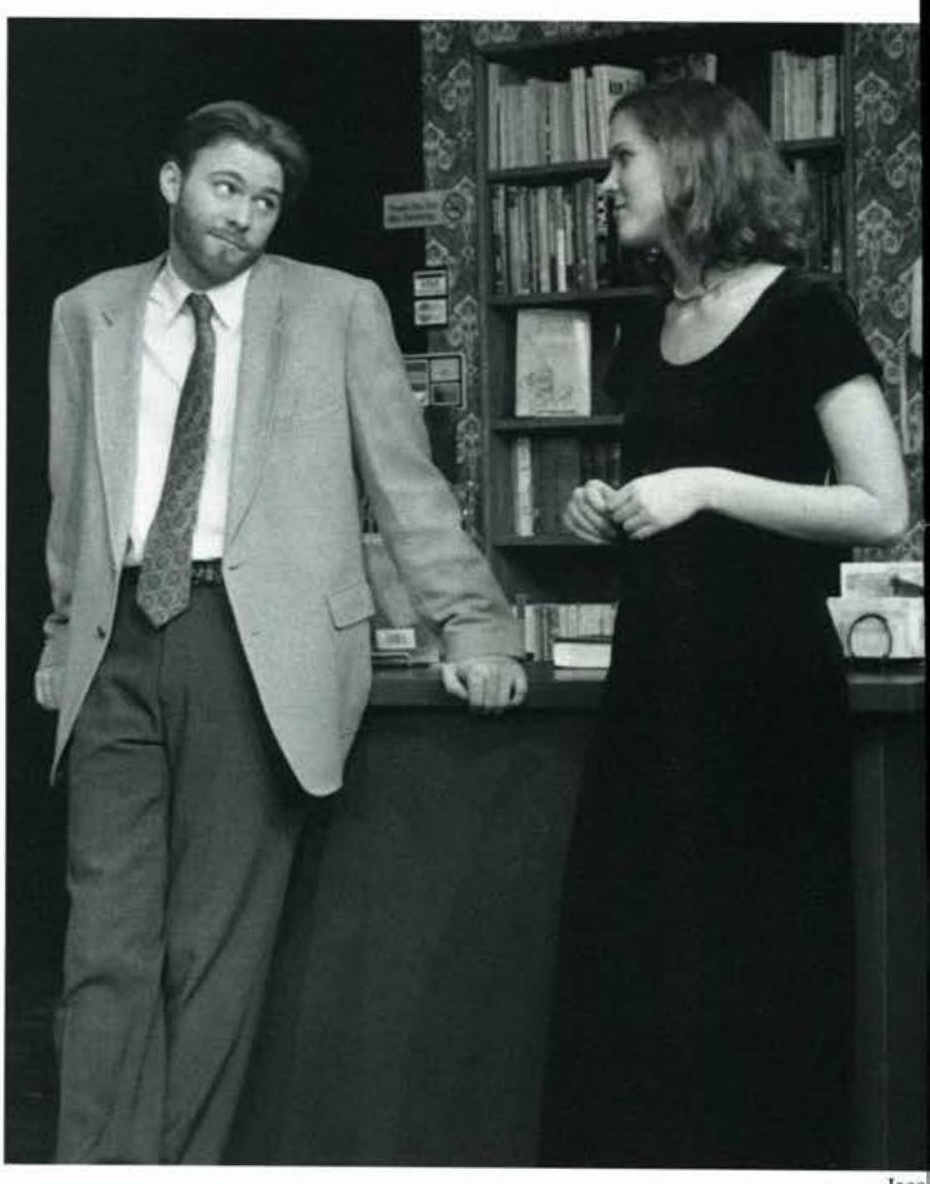

Isabelle Grossman (Jessica Wagner) shares an intimate conversation with Tyler Moss (Daniel Scott) in the bookstore (right). 


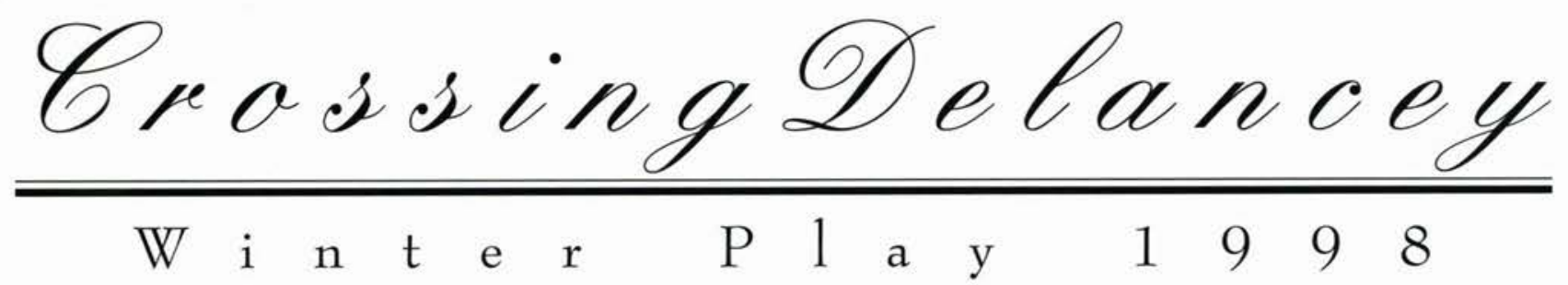

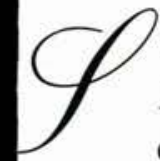
usan Sandler's Crossing Delancey, a play dealing with conflicts between modern love and traditional ways, was just in time for Nalentine's Day and Li'l Sibs weekend. Underthedirection of Mrs.MischelleMcInosh, anadjunctprofessorof communication arts, thecastandcrew of CrossingDelancey spent between 10 and 12 hours a week preparingfor 4 performances.

Senior speecheducation and communications major Sara Romang, the stage manager, explained the basic story line of the play. She said, "Izzy, a bookish dreamer, must choose to be loved or be in love. In choosing one, she can have both, butherfear of tradition and theold ways of
herbelovedBubbie(hergrandmother) cause hertobehesitant. Inreality, itisherBubbie's conception of love that is the truest, as demonstrated when she fondly reminisces

$$
\begin{aligned}
& \text {... to love or ta be loved... } \\
& \text { that is the question! }
\end{aligned}
$$

aboutherhusband, 'When someonewanted me so much he was ready to make a fool of himself, it waseasy to see he would be good to me."' The play had a definite Yiddish flavortoit-all but one of the charactersare Jewish. One of these characters, Sam
Posner, marked the end of senior Chris Vitarelli's seven role career at Cedarville.

McIntosh chose Crossing Delancey as the winterplay because she likes the story and the characters. She enjoys directing because it enables her to work closely with students and be creative. In the past, McIntosh has directed Cedarville productions including The Diary of Anne Frank (1994) and A Christmas Carol (1995). Her most recent project was directing The Best Christmas Pageant Ever over the holidays. In addition to earning a Master of Arts in Dramatic Productions and directing high school and college plays since 1977, McIntosh acted with a traveling Christian drama group.

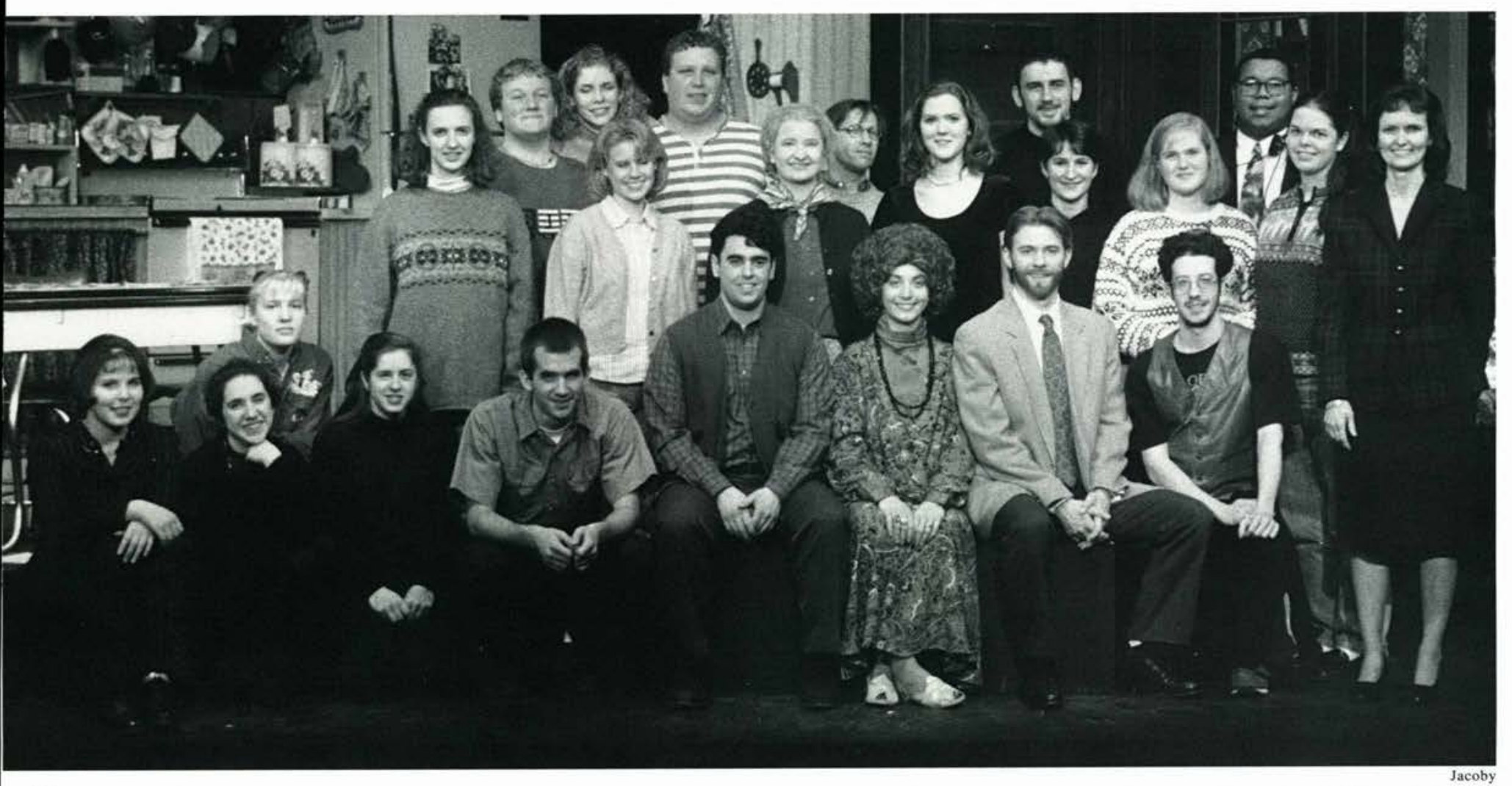

Front Row: (1 - r): Sara Romang, Ghena Marchetti, Patricia Hershberger, Caleb Smith, Christopher Vitarelli, Heidi Jo Dean, Daniel Scott, Todd Musser. Middle Row: (1 - r): Kristin Neumann, Clarissa Band, Julie Forstrom, Martha Failor, Jessica Wagner, Amy Hutchinson, Margarete Jenista, Vanessa Baker, Mischelle McIntosh. Back Row: (1 - r): Greg Davis, Angela Wenzel, Eric Bickel, D. N. C. Jones, Jason Pierson, Michael Dorsey. 


\section{The Hbeireis \\ S p ring P 1 a y 1998}

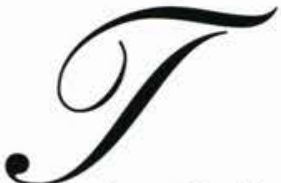

he spring play, The Heiress, under the direction of $\mathrm{Mr}$. Gary W. Barker, Associate Professor of Communications Arts, graced the stage of Cedarville College for two weeks. This moving and intriguing tale of love, control, and power presented a technical challenge for the nine cast members.

The Heiress is based on Henry James' novel Washington Square (recently made into a film of the same name), and adapted by Ruth and Augusta Goetz. This play was last produced on Broadway in 1995, to huge critical acclaim. Set in mid-1800 New York City, The Heiress tells the story of Catherine Sloper (Joanna
Robinson). Catherine is a shy and plain young woman who falls desperately in love with a delightful young fortune hunter (Jeremy Brown). Catherine's father (Brenon Christofer), a successful doctor,

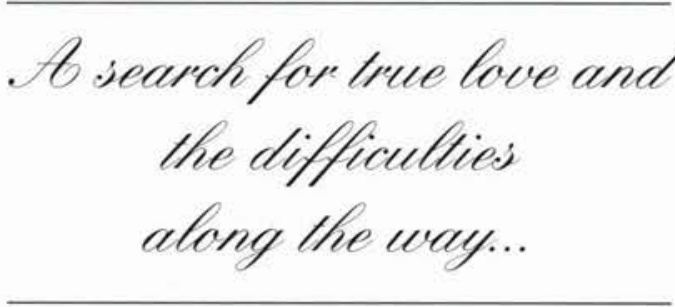

disapproves of the match and forbids their marriage. Catherine must decided whether she will allow her father to rule her, or follow her heart into marriage with a many who may not be worthy of her love.
Cast member Kelsey Perkins re called that she found the play chal lenging, requiring audience member to stick with the plot. Perkins ex plained, "The play does not give neatly wrapped ending yet I think caused a lot of people to think abou issues and relationships in their lives. Junior Jeremy Brown concluded tha this was one of his most challenging roles. His past characters have re quired more physical acting and exte rior emphasis, while the character o Morris Townsend concentrated on in ternalization of text and meaning.

Overall, the play received a generous turnout. The story evoked many emotion: yet successfully delivered a meaningfu. message wrapped in artistic talentandability

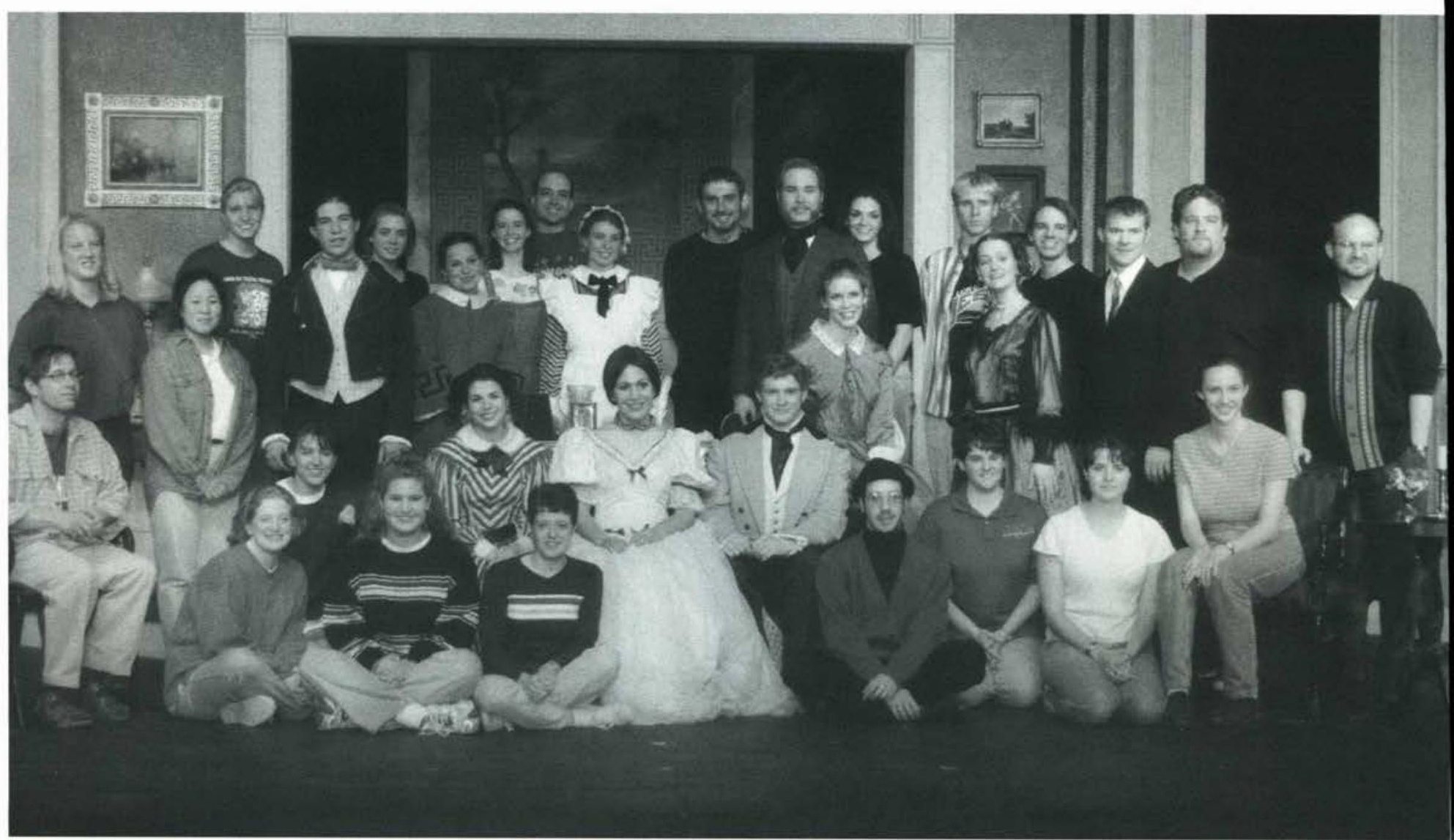

The cast and crew of The Heiress: Clarissa Band, Jeremy Ryan Brown, Mark Button, Karen Campbell, Shannah Campbell, Nicole Carpenter Cara Carver, Brenon Christofer, Naomi Cooper, Damon Douridas, Heather Fourman, Katie Futrell, Kelly Grady, Jennifer Groff, Hill Hand, Timothy Hardin, Matthew Hermiz, Krista Holmes, Casey Huebner, Shawn Hurne, D.N.C. Jones, Michelle Labor, Maren Meyers, Todd Musser, Kristin Neumann, Atsuko Ohtake, Erika Olin, Kelsey Perkins, Jeremy Pierre, Jason Pierson, Amy Reno, Joanna Robinson, Stacey Romeyn, Stacy Marie Seville, Daniel Christian Scott, Jennifer Vander Bush, Angie Wenzel. 
Catherine (Robinson) listens attentively as Morris (Brown) explains his plan for their elopement.

\section{Gail and Director}

\section{Catherine Sloper}

Dr. Austin Sloper

Morris Townsend

Lavinia Penniman

Elizabeth Almond

Marian Almond

Arthur Townsend

Mrs. Montgomery

Moira

Director
Joanna L. Robinson

Brenon Christofer

Jeremy Ryan Brown Jennifer Groff

Angie Wenzel*

Kelly Grady

Jeremy Pierre

Kelsey Perkins

Erika Olin

Gary W. Barker
* Denotes member of Alpha Beta Phi, Cedarville College chapter of the national theatre honorary society, Alpha Psi

Omega theatre organization.

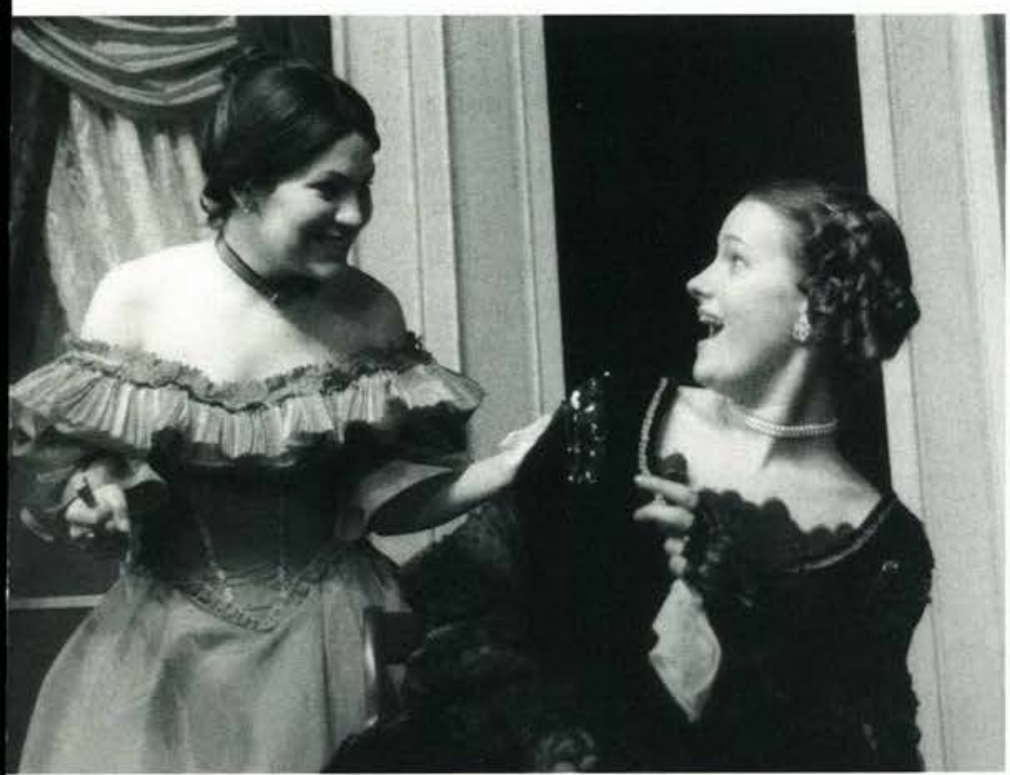

Catherine (Robinson) and Lavinia (Groff) share a few fun moments alone without Catherine's father.

Dr. Sloper (Christofer) remarks about the irony between Townsend's (Brown) fine leather gloves and his empty bank account.
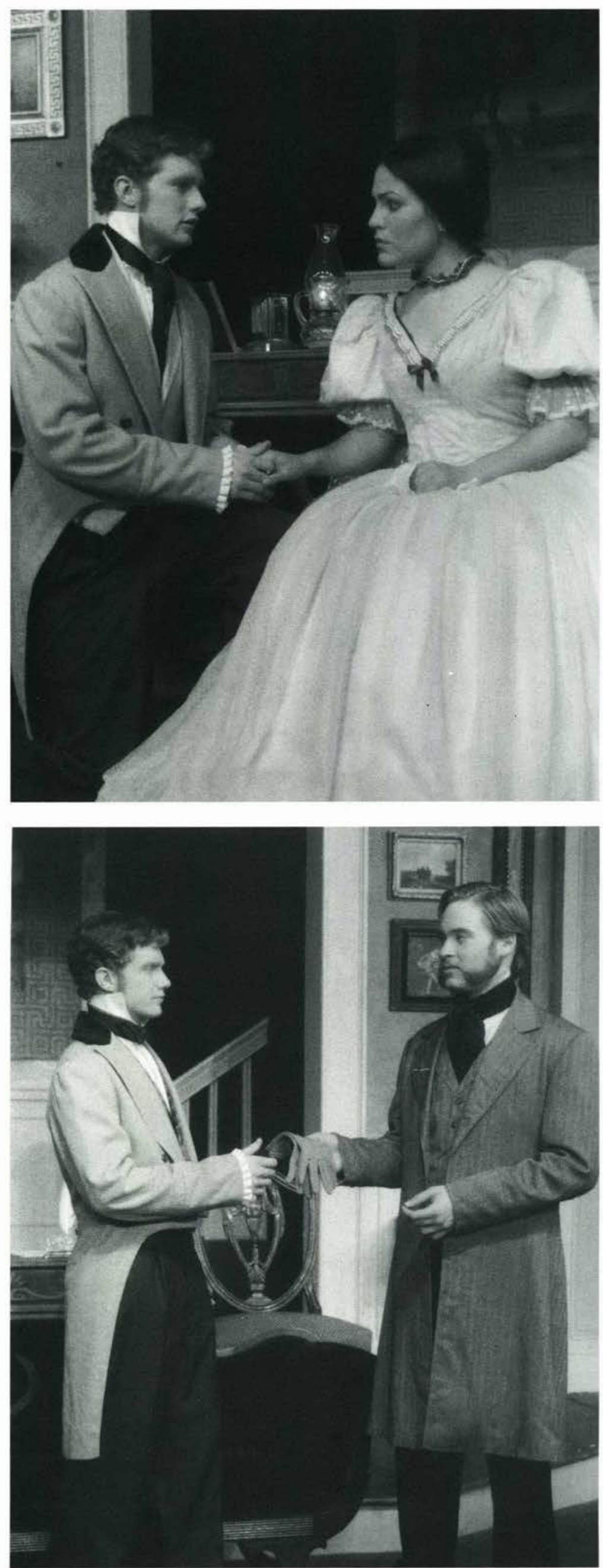

spring play-the heiress 155 

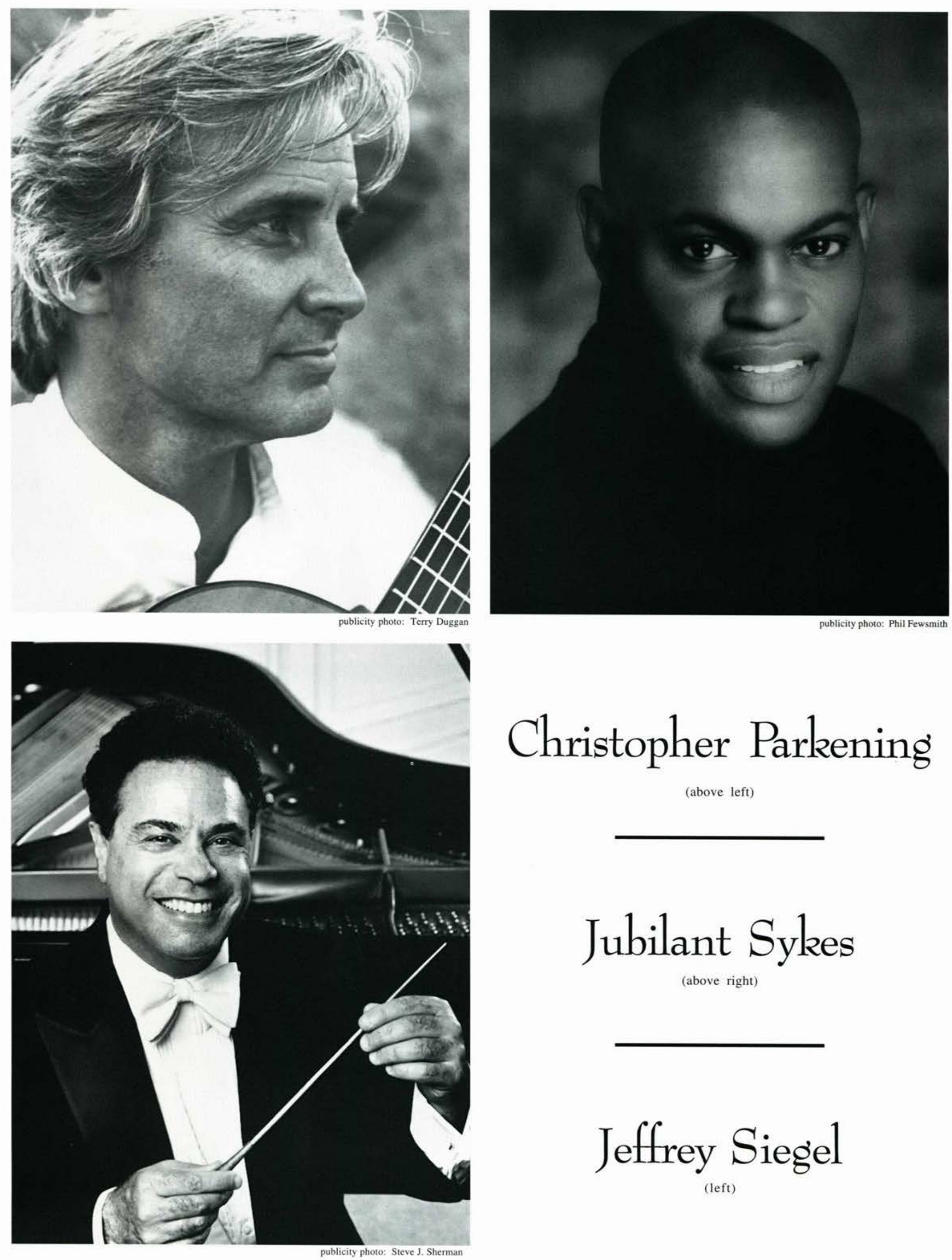

Christopher Parkening (above left)

\section{Jubilant Sykes}

(above right)

Jeffrey Siegel 


\section{Gullurat.

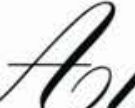 \\ C u l t u ra l F e s t 19968}

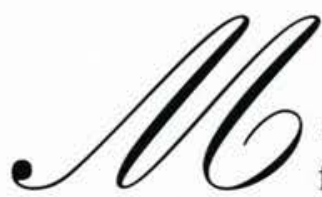
$\begin{array}{lll}a & y\end{array}$ Cedarville students come from small towns and have little intercultural experience. Known to some as "The Bubble", Cedarville would insulate students even further against cultural awareness if it were not for the cultural organizations that have been started around campus. These organizations are Beta Rho Delta, Iota ChiPhi, Mu Kappa, and the Spanish Club.

In some way, all of these organizations promote cultural awareness here at Cedarville. Beta Rho Delta (the German Club) focuses on the German culture. The Spanish Club helps make students aware of Spanish cultures. Iota Chi Phi promotes general cultural awareness. Finally, Mu Kappa focuses on serving the needs of international students and missionary kids (MKs).

Most Cedarville students know at least one other student who was raised as an MK. One of these MKs is Ben Nordaas, a senior elementary education major. Nordaas was raised on the mission field in Brazil. Preparing to come to Cedarville, he attended an MK school. After living in Brazil most of his life, Nordaas said, "I thoroughly enjoyed it. I call Brazil my home - after 17 years of the same place, I think anyone would. It wasn't all too dissimilar to [the United States] with some exceptions of the culture, but mostly the language. I know English well enough but enjoy speaking Portuguese, too." Nordaas continued to say that many Cedarville students have at least some interest in cultural awareness, whether it is the desire to hear stories about the mission field or the pursuit of learning about other cultures.

Cedarville's cultural organizations seek to address the needs of international students and MKs, as well as students who seek to learn more about other cultures. We are fortunate tohaveorganizations such as these to bring a new perspective to the Cedarville bubble.

\section{Kenneth Waldock} attends the Indian booth at Cedarville's annual Culture Fest.
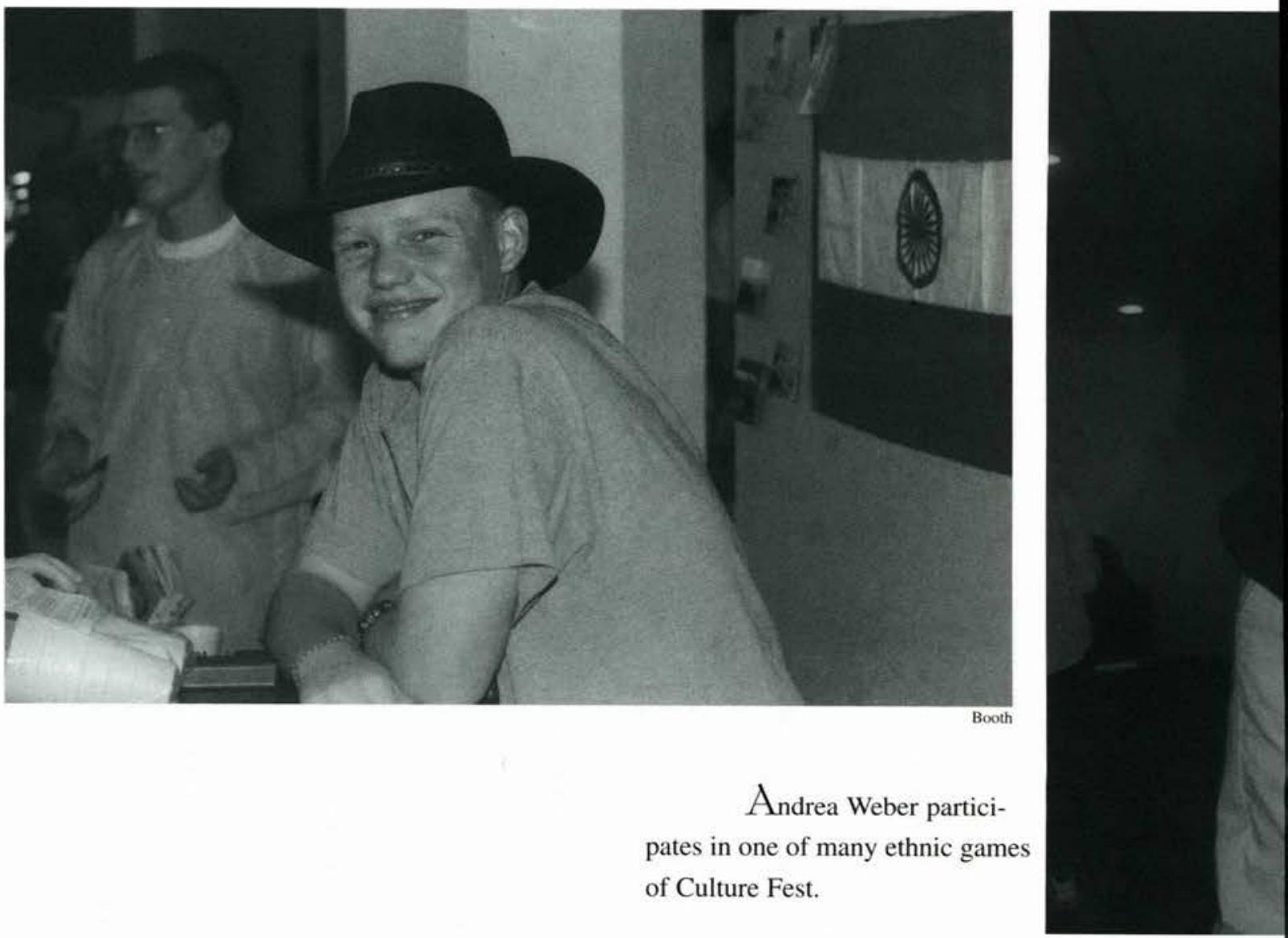


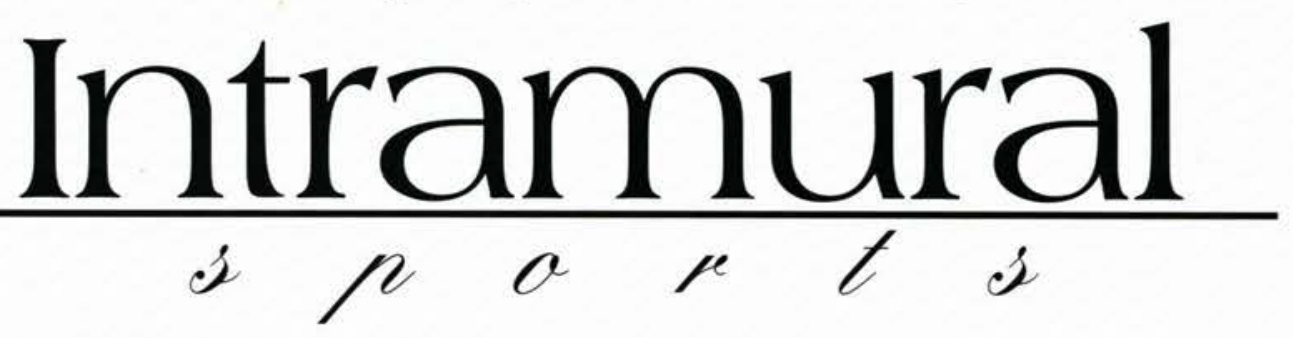

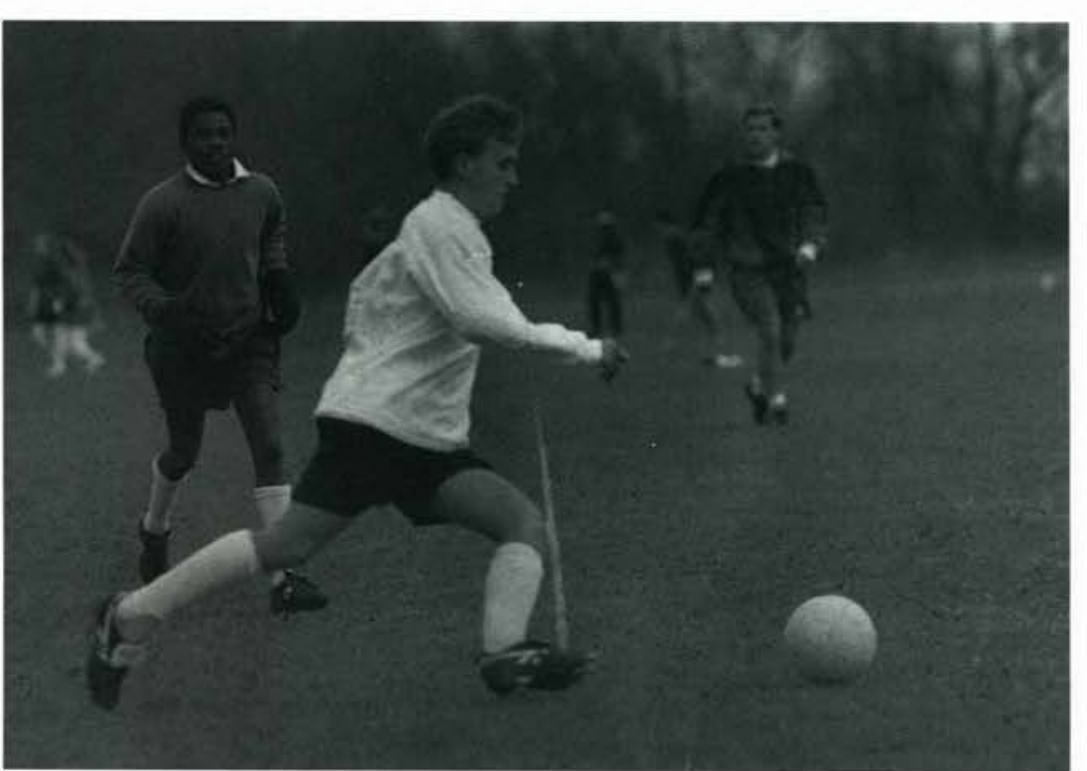

Blackburn

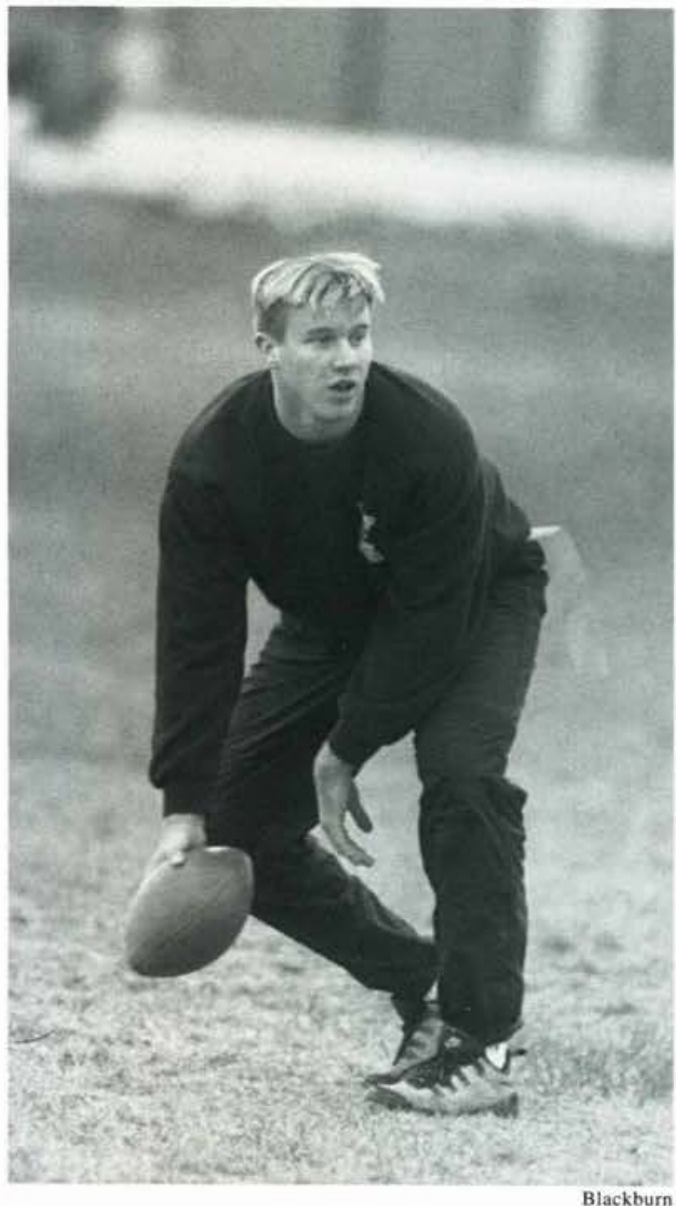
(left). intermural football game (above).
$M$ program this year through the Campus Activities O fice. He encouraged good sportsmanship and enjoy ment for all students, faculty, and staff who participate in sports teams because God has called us to "do all the glory of God," even when we play and recreate. most sports, teams compete for the champion awan and the sportsmanship award and win prizes in eac category.

This year, several new sports were added to offe even more variety. Along with wallyball, racquetbal volleyball, softball, basketball, flag football, socce sand volleyball, tennis, and ski trips, the college famil could participate in orienteering, group exercise classe the class clash, and th home run derby.

A very popula event, orienteering was great opportunity for red reation which combine navigational skills wit speedandagility. The goa was to complete a desig nated course as quickl as possible. Tw orienteering events wer heldforthe collegefamil this year, both on campu and at Possum Cree Reserve in Dayton.

Ryan Burkhart goes for the goal in intermural soccer (top left).

Sophomore Justin Goodrich concentrates on the opposing team during an intense moment in a intermural football game

Quarterback Amanda Poff recieves the ball during a female 


\section{Standing in the Gap}

$\mathrm{O}_{n}$ October, 1997 , thumpers of thousands of men met on the Mall in WashingtonD.C. toworship, pray, andconfess their sins before the Lord. Several men fromCedarvillewereamongthemanyPromise Keepers gathered at the capital to stand in the Gap between God and theirnation.

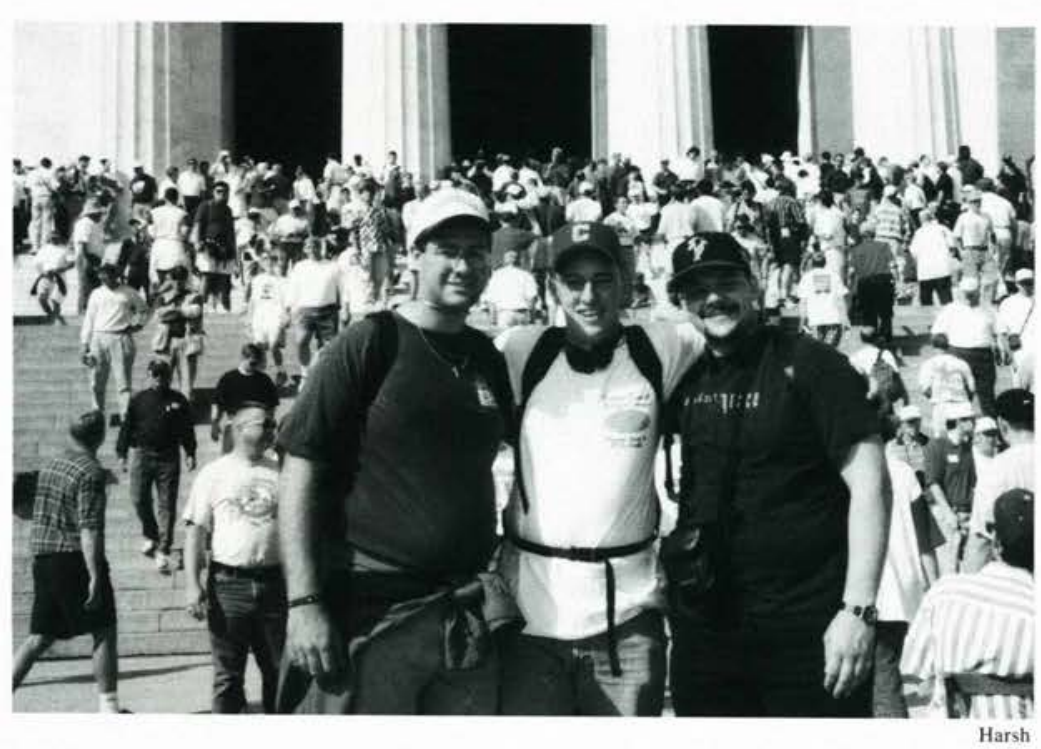

Jon Basner, Tom Leightenheimer, and Mike Harsh "stand in the gap" at our nation's capitol.

The foundations of the organization are "The Seven Promises of a Promise Keeper." These statements affirm a man's commitment to Christ, God's Word, purity, marriage and family, local churches, racial and denominational reconciliation, and the Great Commission. At the conferences, most of which are two-day affairs, men focus on these commitments through song, testimony, confession, and prayer. In 1997 alone, the organization hosted events in 19 different cities.

At each of the 1997 conferences, men were challenged to consider making a pilgrimage to the United States capital, not for the purpose of making a political statement, but rather to make a spiritual confession. These men came from around the continent, and Ohio men were no exception. On Friday afternoon, Oct. 3rd, Interstate 70 was jammed with vehicles streaming to D.C.

The stage sat in front of the Capitol, facing the Washington Monument. Men filled the entire Mall past the obelisk to the Reflecting Pool. An estimated 25,000 men spilled over onto the Ellipse in front of the White House. Twelve Sony Jumbo-Trons and speakers were positioned in the crowds so that those standing blocks away could see and hear what was happening on stage.

Dr. David Warren, was one of severalfacultymembers who attended Stand in the Gap. "My initial reaction was to be blown away by thevolumeofpeople. It was an exhilaratingfeeling tobethere with all these men who love the Lord.

There was an instant sense of camaraderie, closeness, and friendship," he said.

The first segment began when a speaker asked the men to acknowledge God. From the start of the six-hour assembly, it was evident that God had brought these men together. The speakers' names were intentionally not announced. All those who spoke to the crowd were dressed alike. Besides McCartney, the most recognizable speakers were veterans of Cedarville Bible Conferences. Joe Stowell's message early in the conference challenged those gathered toconsider their personal sanctification.

Tony Evans took the platform later in the day, during a segment that focused on reconciliation. "Tony Evans spoke on male leadership in the family," said senior Bible major Jason Malone. "He said that Promise Keepers weren't a threat to all the women who were upset, but that the husband had to be a helpmate to his wife." Malone said he sa few of those women protesting at the ra but considered their presence insignific when compared to the overall experienc attending Standing in the Gap.

Sophomore communications ma Michael Dorsey said that Stand in the $C$ was the fifth Promise Keepers event he his fatherhave been able to attend togeth Each conference has touched on the the of racial reconciliation. "Ilook around see you've got Blacks, Hispanics, Asia American Indians and think, that's what kingdom of heaven is going to be lik Dorsey said. The men were asked to int act and pray together. Dorsey, who is bla has not had a problem with racial issues, knows that other people have. At the ra in D.C., men came up to Dorsey and fatherin tears, apologizing for their attituc towards people of other races.

Speakersalsodealtwithsectarianism.Fr thestage,MaxLucadoasked thementosh their denomination. The response was a cophony. Then he asked who was theirLc and Savior. They answered in perfect u. son, "Jesus Christ is Lord." Senior Chr tian education/youth major, Jonath Basner was impressed with this segme "The biggest thing I took away from it $\mathrm{w}$ that even though I didn't agree with even thing everybody there held to doctrinally came away... realizing that the Kingdom God was bigger than Iever thought it cou be."

Upon departure from the conferen the speakers challenged the men to mai tain accountability among Christian $m$ in their churches and communities.

"We're going to take two years, ar we're going to sweep this nation founder McCartney told the crowd Washington. At the end of this time, January 1 of the year 2000 , men w gather on the steps of their state capito to reaffirm the Promises of a Promi Keeper. 


\section{by Rebecca Ritzel \\ Newt Gingrich}

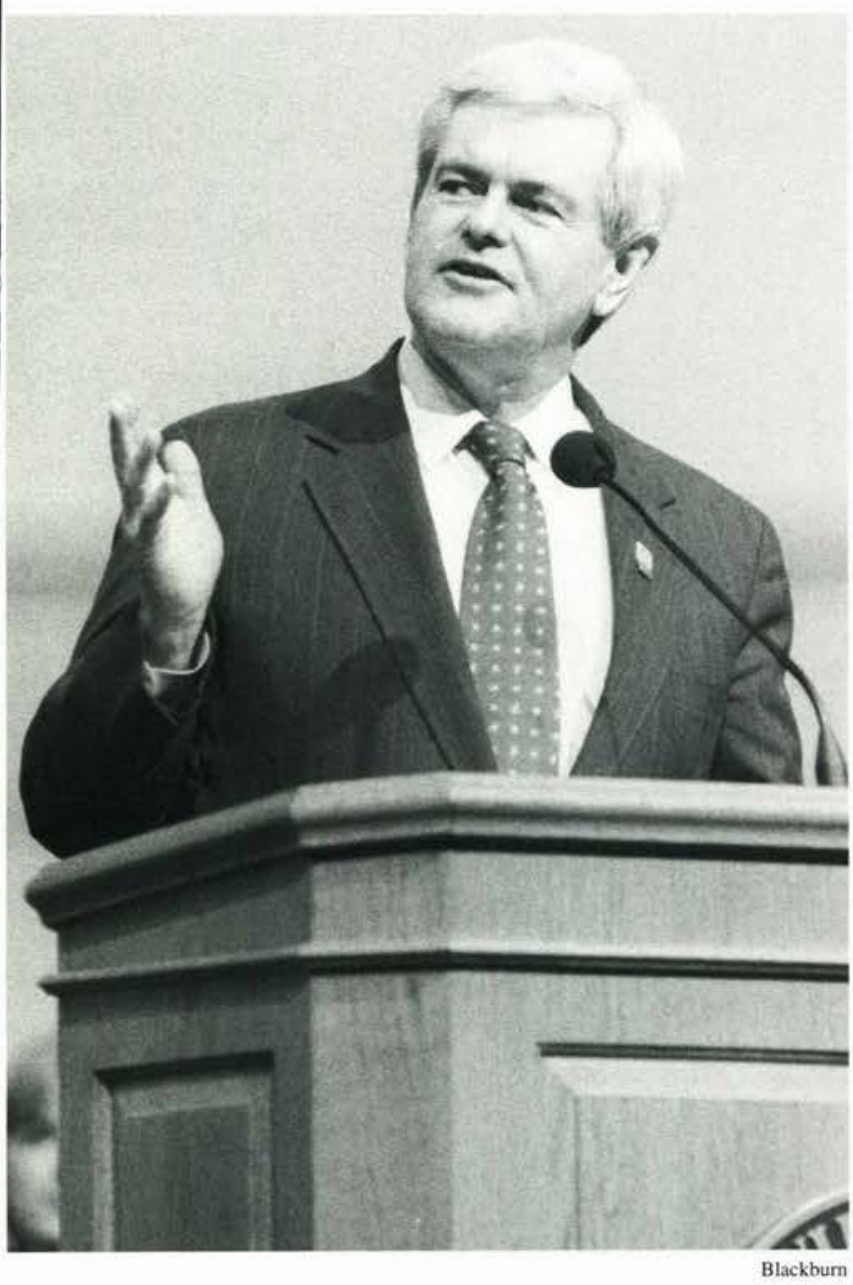

Speaker of the House, Newt Gingrich, addresses an audience of students, faculty, and townsmen from Cedarville.
T he average rural Midwestern county is not high on the list of national political priorities. Greene County, Ohio, however, can boast of electing a Republican Party member to every office, plus being home to a sitting Senator and Representative. When Congressman David Hopson went looking for a speaker for his county's annual Lincoln Day dinner, he went straight to the top of the GOP.

Speaker of the House Newt Gingrich spoke before a crowd of around 2,000 people on Friday, February 6 in Green County's largest auditorium, the Jeremiah Chapel. The Greene County Central Committee for the Republican Party played host to the event and solicited use of the building. As the college administration frequently emphasized, Cedarville merely provided the facilities.

Education professor Dr. Dwayne Frank has been a member of the county Republican committee for fiveyears. "The evening went very well. When you don't get that kind of a national person too often, you can'tlose," said Frank. This is his first year he has sponsored the Cedarville Young Republicans Club. Under the direction of president Kirk LeBlanc, the club organized 180 students to volunteer as security guards, hostesses, and parking attendants.

Approximately three fourths of the crowd at the rally were from the collegefamily. "I'd like to think that the averageCedarville student went out of intellectual curiosity... If Teddy Kennedy were here, I'd like to think we'd have the same response," Frank said.

Senior communications and political science major Jonathan Hammond, while not a personal fan of Gingrich, was glad the rally gave Cedarville students a chance to be politically active. "Anytime anyone gets a chance to attend a political rally, they should go, regardless of whether or not they like the speaker. You need to hear them out whether you agree with them or not. Until you've given them that time, you're not in a position to agree or disagree," Hammond said.

Mr. Gingrich's speech was preceded by the Symphonic Band's rendition of the "Battle Hymn of the Republic" and a concert version of the "Star Spangled Banner" performed by music professor Beth Porter. As is decorum at most political gatherings, a serious of introductions preceded the speaker. Dr. Dixon introduced Cedarville College to the crowd and introduced his "neighbor," Senator Michael DeWine. DeWine welcomed his colleague from the House of Representatives, Mr. David Hopson. Hopson expained the process of getting Gingrich to Greene County, including the Speaker declining a dinner invitation with Saddam Hussein for that very night.

Gingrich directed his speech at the local residents. He spoke of PTA meetings and writing letters to the school board. In an atmosphere like that of a one-sided town meeting, Gingrich proposed initiatives that must be encouraged at the local level.

A large show of hands went up when Gingrich asked the college students how many believed that with the present system, they would get nothing back from what the were paying in to Social Security. The Speaker did not blame them. "More people probably believe in UFO's than believe that they'll get Social Security," he said. Gingrich then proposed a new program that would issue each American a personal social security account and offered figures that showed its significant increase in savings from the present system.

Overall, attendees had a positive reaction to the event. Frank can recall hearing political speeches as far back as Truman. "I've heard a lot of political speeches in my life. The Newt speech was the best delivered and had the best substance of any speech I've heard," he said. 

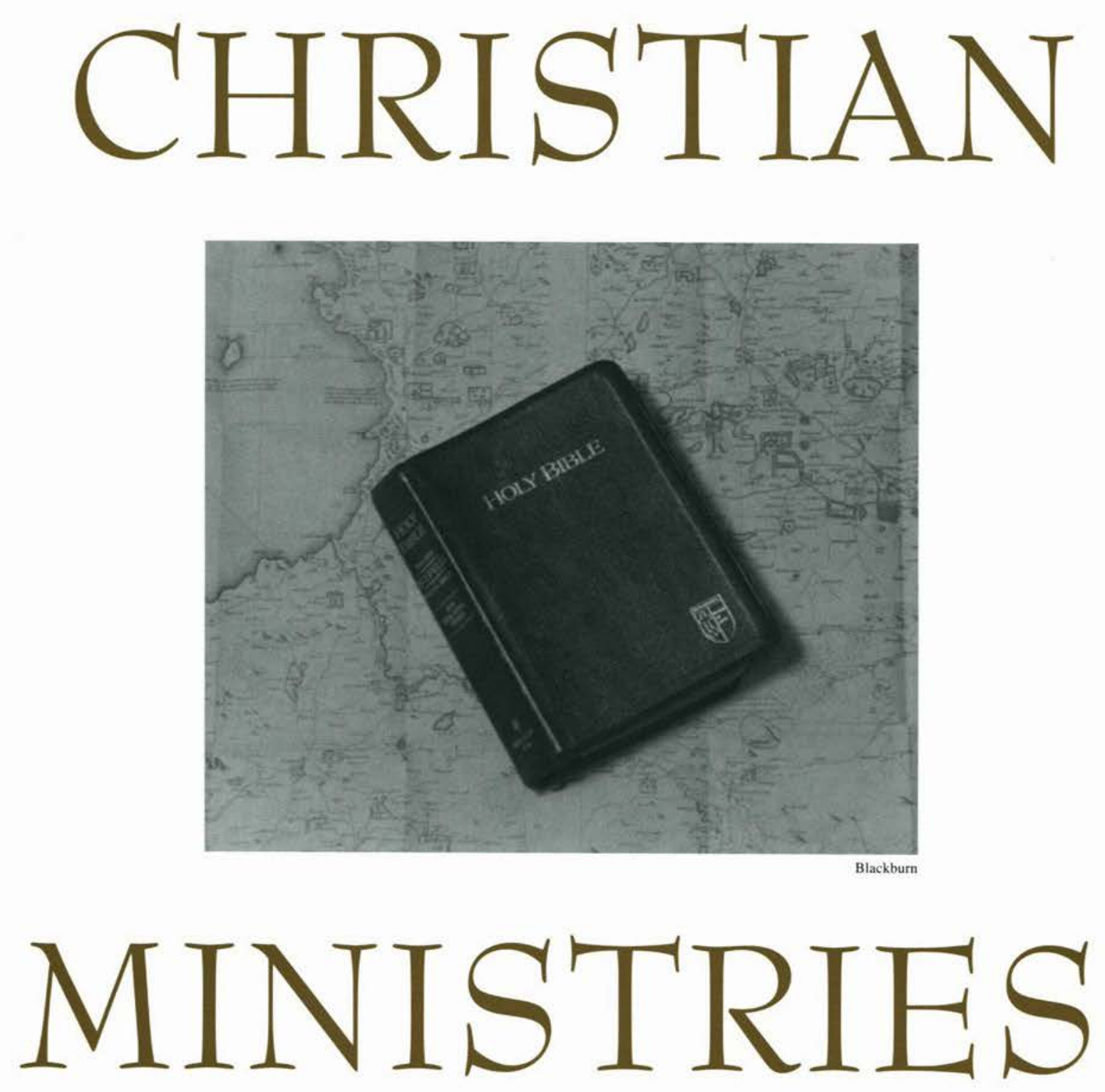


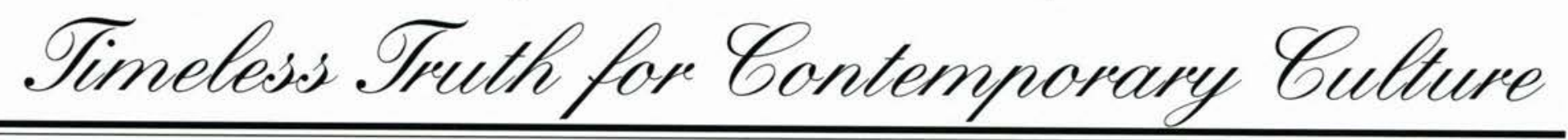

$$
\text { Bible Conferences } 1998
$$

very Bible Conference is a new challenge, a challenge to look at our lives spiritually and examine who we are and what we are doing for Christ. At this year's Fall Bible Conference, Dr. Warren Wiersbe helped the Cedarville family do just that. Dr. Wiersbe has pastored at Calvary Baptist Church in Covington, Kentucky, and at Moody Memorial Church in Chicago, Illinois. $\mathrm{He}$ has authored over one hundred books, and has spoken all across the United States.

Throughout the fall conference, Wiersbe addressed the importance of unity within the body of Christ. Using John 17 as his foundational text, Wiersbe directed the Cedarville family to look at Christ's prayer in John 17 and challenged the family to flow Christ's example. Wiersbe said, "If Jesus Christ prayed while He was here on earth, with all of His Purity and all of His power, where does that leave us?" Wiersbe also made special note of the life of Ezra. According to Wiersbe, Ezra had five things that we need to have: a divine call, a prepared heart, a studious mind, an obedient will, and a serving spirit.

Speaking and leading worship at the Winter Bible Conference was Dr. Richard Allen Farmer. Farmer grew up in the Upper Bronx and attended Trinity Baptist Church--a church with deep roots extending to the late 1890 s. Dr. Farmer is no stranger to Cedarville, as he led worship at the 1997 Missions Conference.

For the Winter Conference, Dr. Farmer adapted his series to Cedarville's theme for the year: Timeless Truth for Contemporary Culture. "Nick at Nite," "Who's the Boss?," and "The Guiding Light" were a few of the themes for his mes- sages. In his messages he focused Matt. 5:13-16 and I Thess. 5, as wel many other Scripture passages.

The Missions Conference, the conc sion of the year's Bible conferences, an event that few other conferences valed. "This was the greatest Missi Conference we've ever had," asser Dr. Dixon. More than 500 students w forward to pray during the invitat Thursday night.

Each morning a new speaker took platform to share about their minist their lives, and the people they ha reached for Christ. Speaking at evening services was the keynote speak Rev. George Murray, the general dire tor of TEAM. To begin the eveni services, Rev. Murray presented $\mathrm{m}$ sages explaining the sovereignty of $\mathrm{G}$ and he concluded by presenting the is portance of logical evangelism.

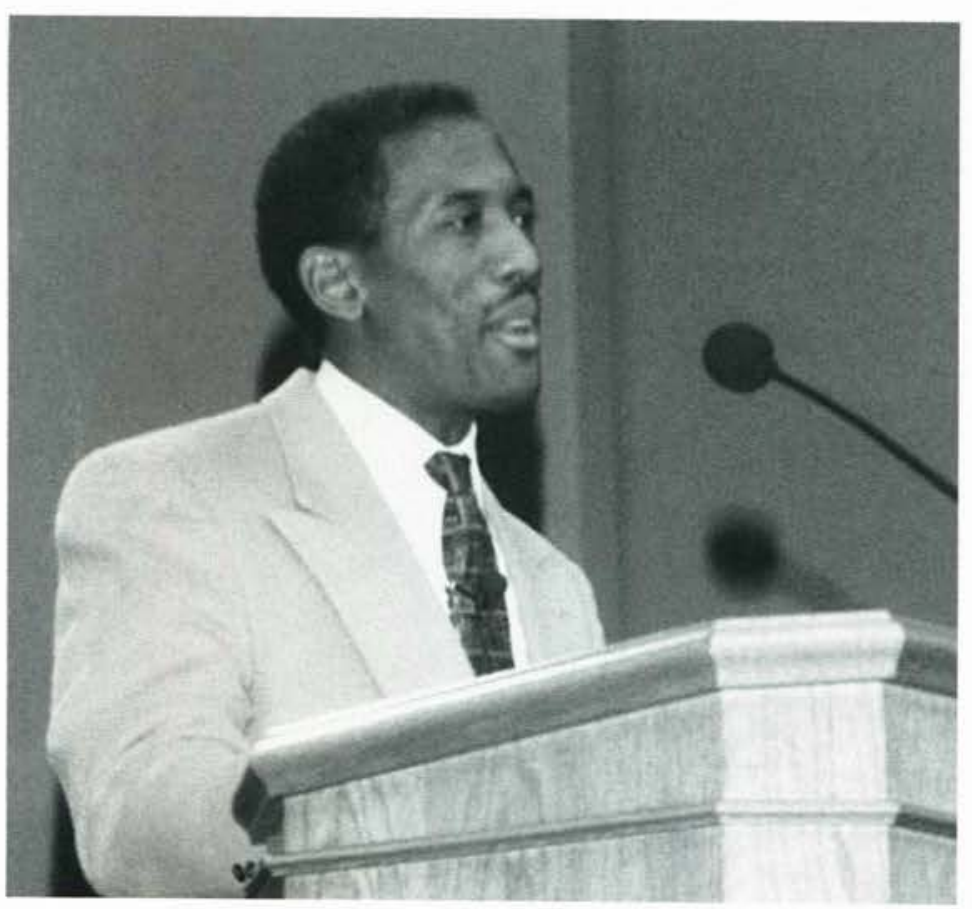

Peaking and leading worship at the Winter Bible Conference, Dr. Richard Allen Farmer addresses Timeless Truth for Contemporary Culture.

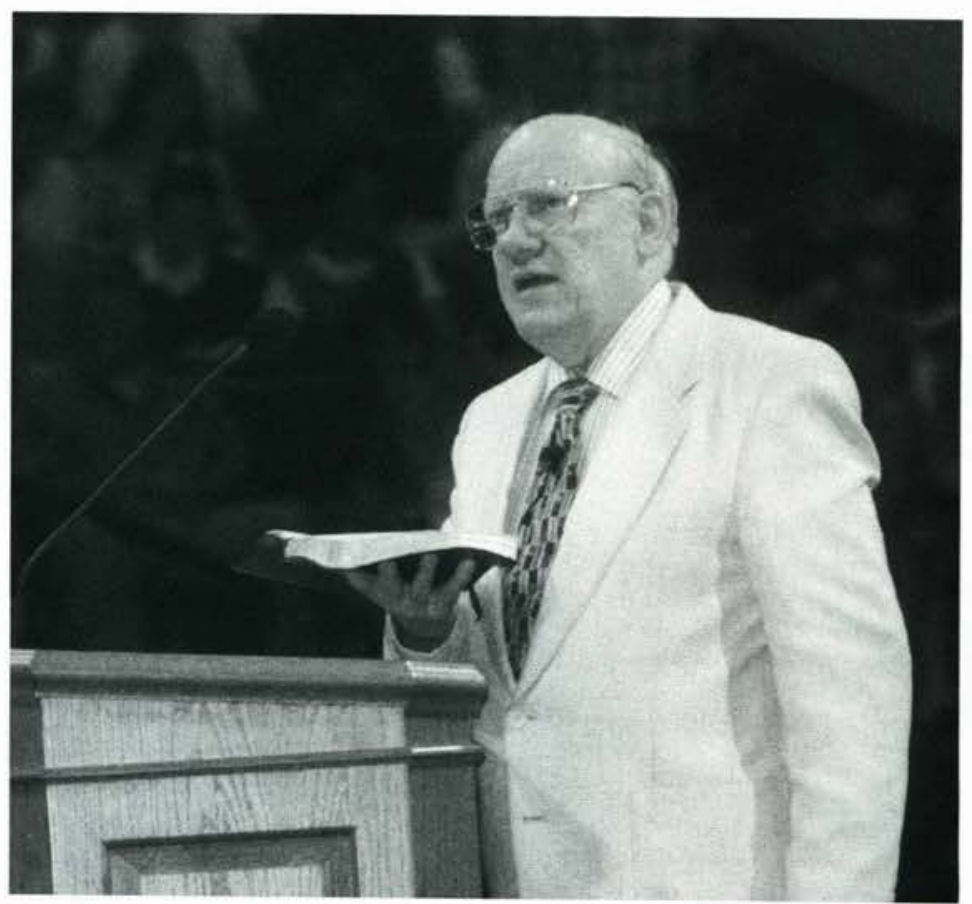

Tl. arren Wiersbe, well-known pastor, author, and teacher speaks at the Fall Bible Conference. 


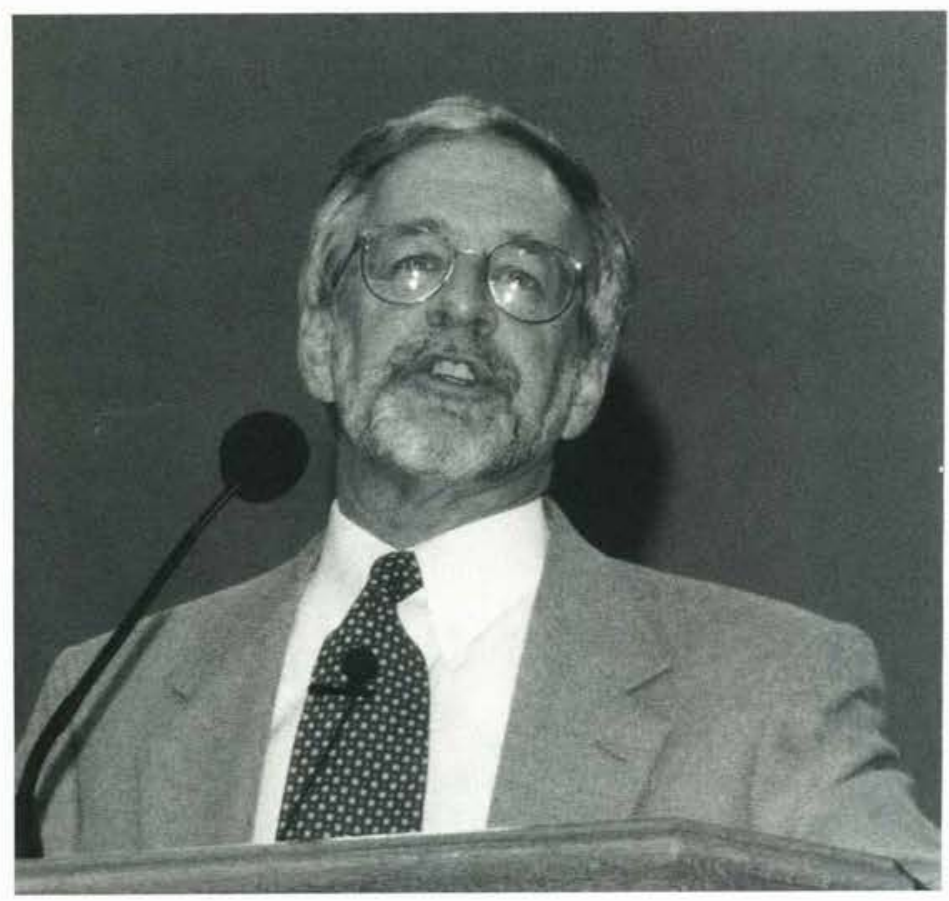

Pev. George Murray, the general director of TEAM, was the keynote speaker for the Missions Conference. (left)

$\mathscr{E}$ d Lewis, representative for TEAM and friend of many students, speaks to Cedarville students at hall meetings and group outings,

including the one pictured below.

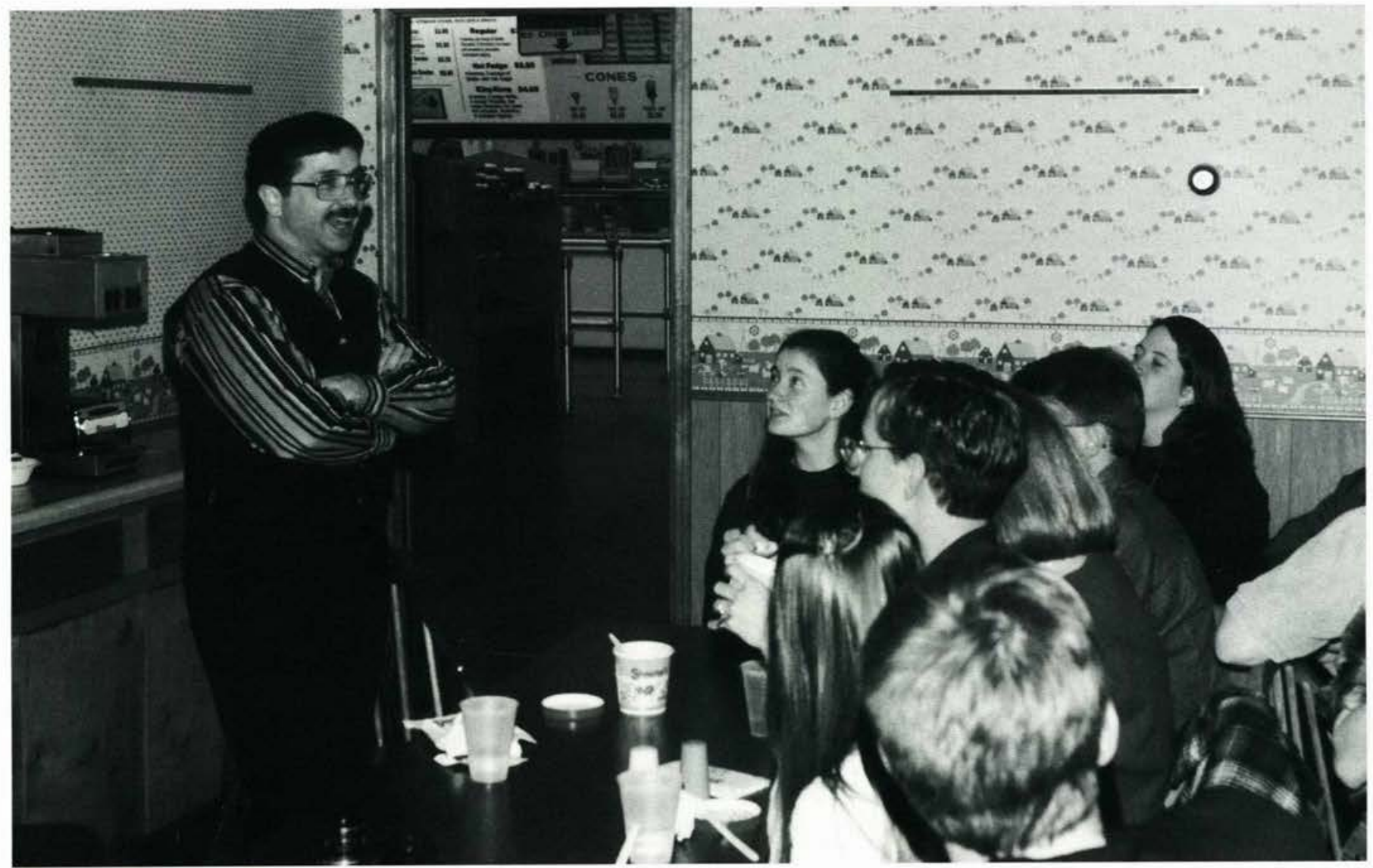

Every Bible Conference is a new challenge, a challenge to look at our lives spiritually and examine who we are and what we are doing for Christ. 


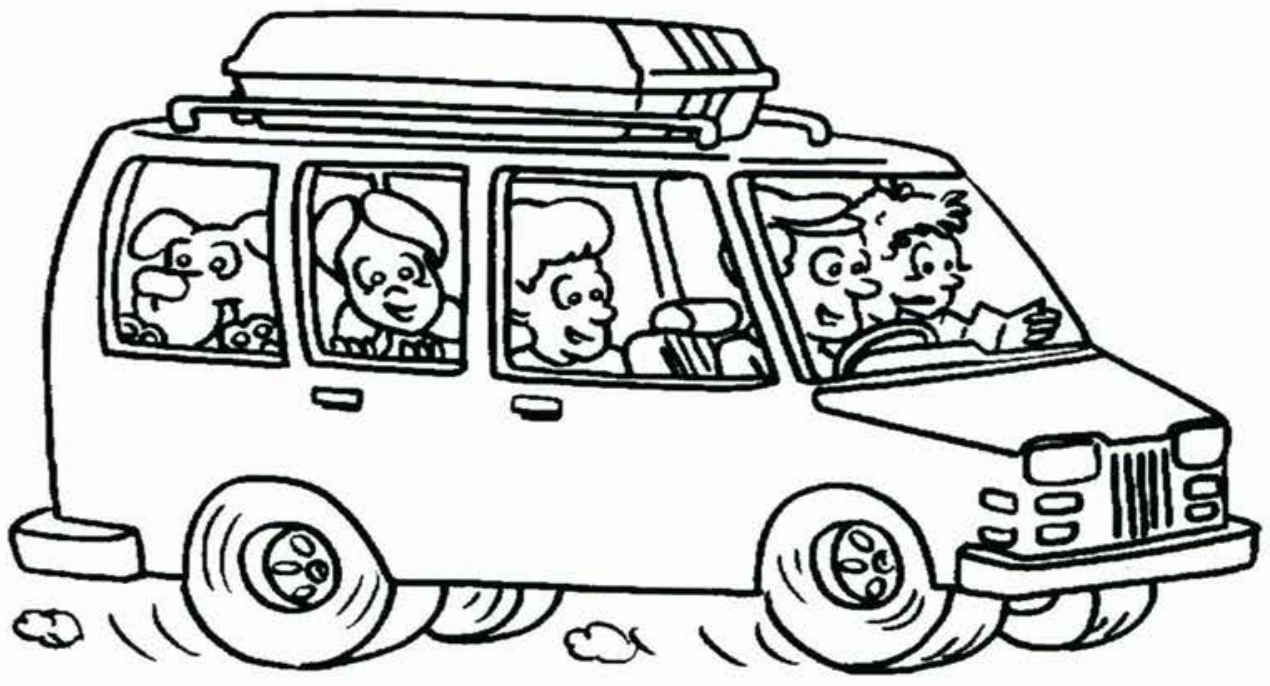

by Ruthanne Pierson

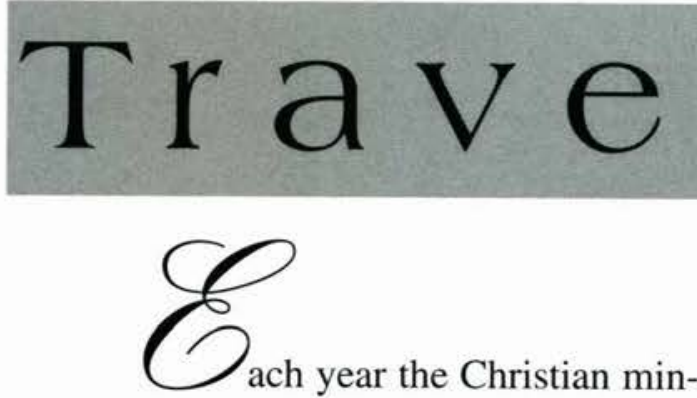

istries department commissions six touring teams to represent the college through music and drama. These groups act as vital links to local churches, schools, and community homes, providing exposure for the college, but most importantly, ministering to people. These teams strive to move beyond a Sundaychurch experience, but rather, integrate biblical Christianity by demonstrating a servant's heart in all areas of life. Although the formal ministry occurs through the performance, the teams have ample opportunities to minister to each other, the hosting families, and the people with whom they come in contact.

According to Brandon Waltz, director of the drama teams, "Drama and music are merely tools-ministry is the goal-therefore, those who are involved must be more than good actors, good musicians, or good puppeteers; they must have a heart and love for people."

This year, the students demonstrated their heart and love for people as they traveled nine weeks during the school year, and they anticipate eight more weeks this summer. During the spring and fall quarters, the team covered as much as a 250 mile radius, usually performing three times a weekend. When they are not traveling, they are usually rehearsing about six hours a week. With such busy schedules, the students have committed themselves to discipline and focus, yet are able to convey a balance of energy and enthusiasm that truly reaches people.

The response to this year's team has been encouraging and rewarding. The Lifeline players have had opportunities to perform at youth rallies numbering $600-800$ teens. There have been many decisions for Christ and some churches have even reported doubled attendance on the days that the teams perform. Church youth groups, local church bodies, and families have all commented on the demonstrated sincerity and servant's attitude of these students.

Such ministry occurs only after careful thought, prayer, and commitment. Each year, the teams travel to Brownsburg, Indiana to plan and prepare for the year. Here they quickly learn programs, pull together skits, develop themes, and form friendships for life. This year's team members have demonstrated again excellence in music and drama that God can effectively use when combined with a humble and willing heart. 


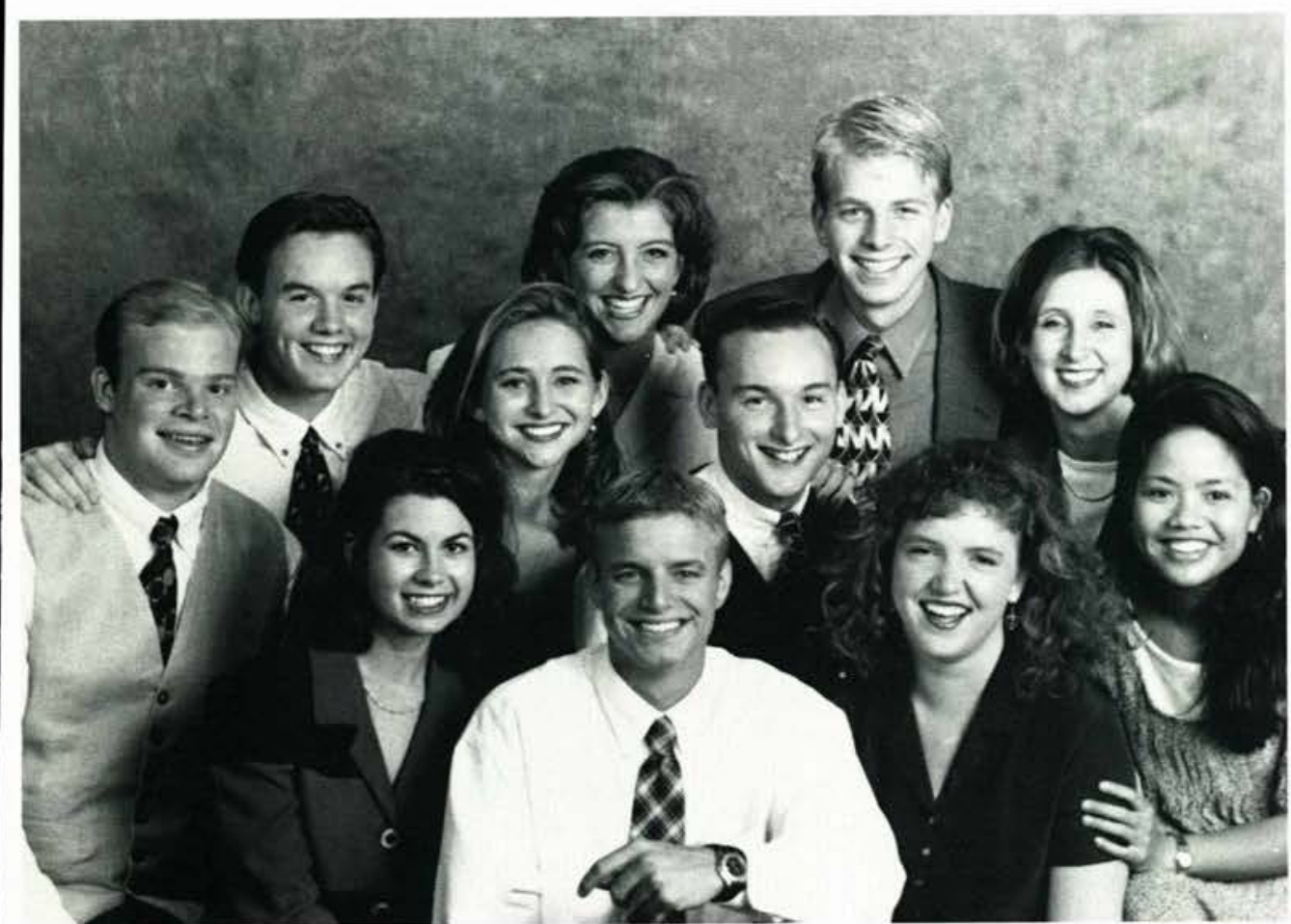

Members included: Top row - Randall Strong, Justin Dyer, Amber George, Mindi Pickell, Ryan Dyer (leader), Steve Handel, Susan West. Bottom row - Rebecca Upham, Andy Ziegenfuss, Lori Kenny, Brenda Inion

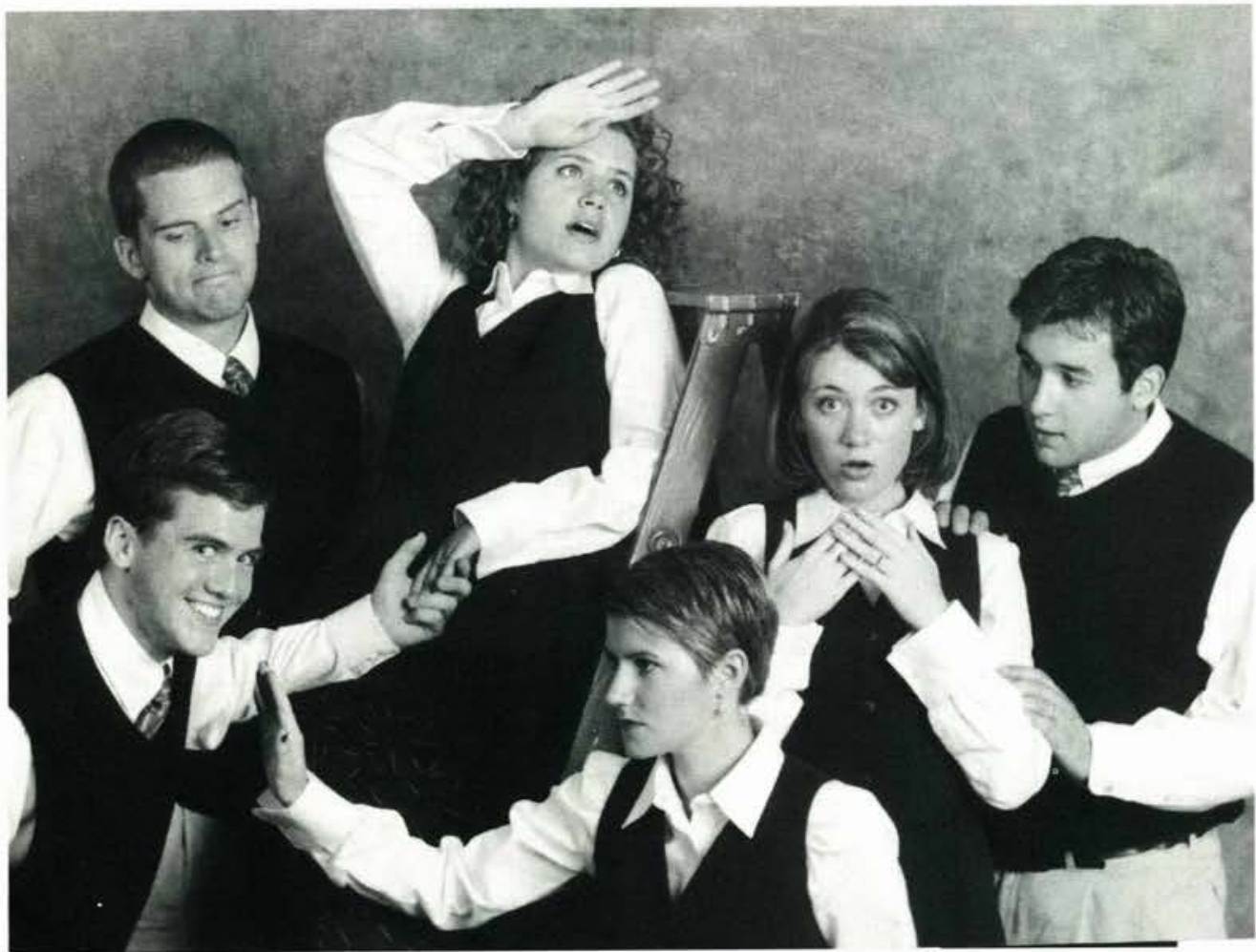

Members included: Top row - Jason Kandel (leader), Rhonda Weber, Sara Eleveld, David Burke. Bottom row: David Beary, Becky Crosson.

\section{Abundant Life Singers}

This team ministered with music and testimony during the summer, traveling throughout the southeastern states to churches and camps.

\section{Lifeline Players}

This six member team ministered through drama to youth groups and in church services throughout the year. During the summer, they toured the East Coast. 


\section{Kingsmen Quartet}

This men's quartet, ministering in testimony and song, traveled to Michigan during spring break and to California during the summer months.

\section{Swordbearers}

This singing team traveled throughout Georgia and Florida for spring break and throughout northwest Ohio and Michigan during the summer.

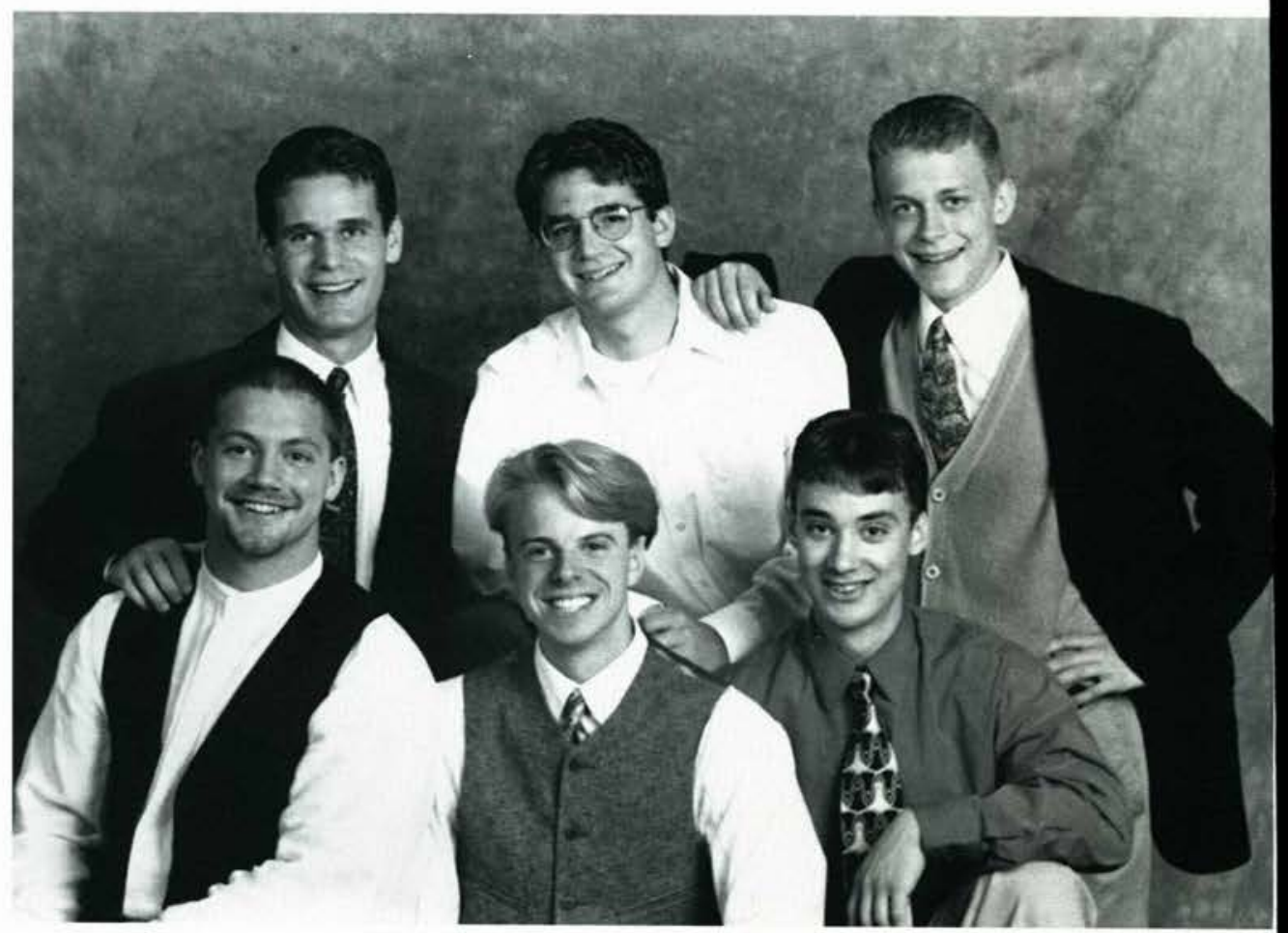

Members included: Top row - Michael Shepherd, Matt Rexford (leader), Jonathan Winn. Bottom row - Dan Forness, Scott Shaw, Jerry King.

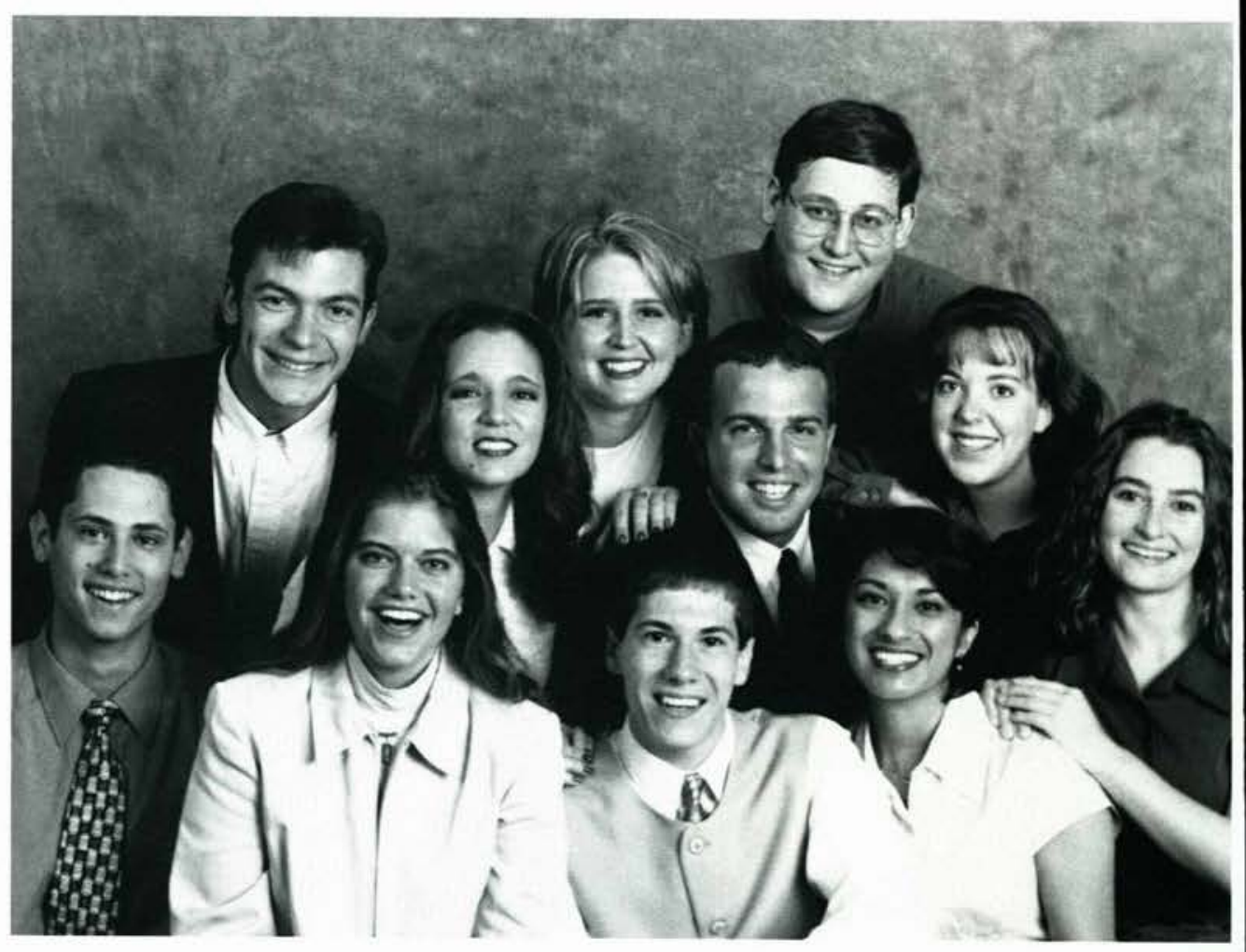

Members included: Top row: Josh Fronduti, Alisa Whitt, Salli Cowell, Tim Walker (leader), Scott Moodie, Jana Glessner. Bottom row - Andrew Rodriguez, Nikki Thomas, Josh Berrus, Rachel Puckett, Dana Scott. 


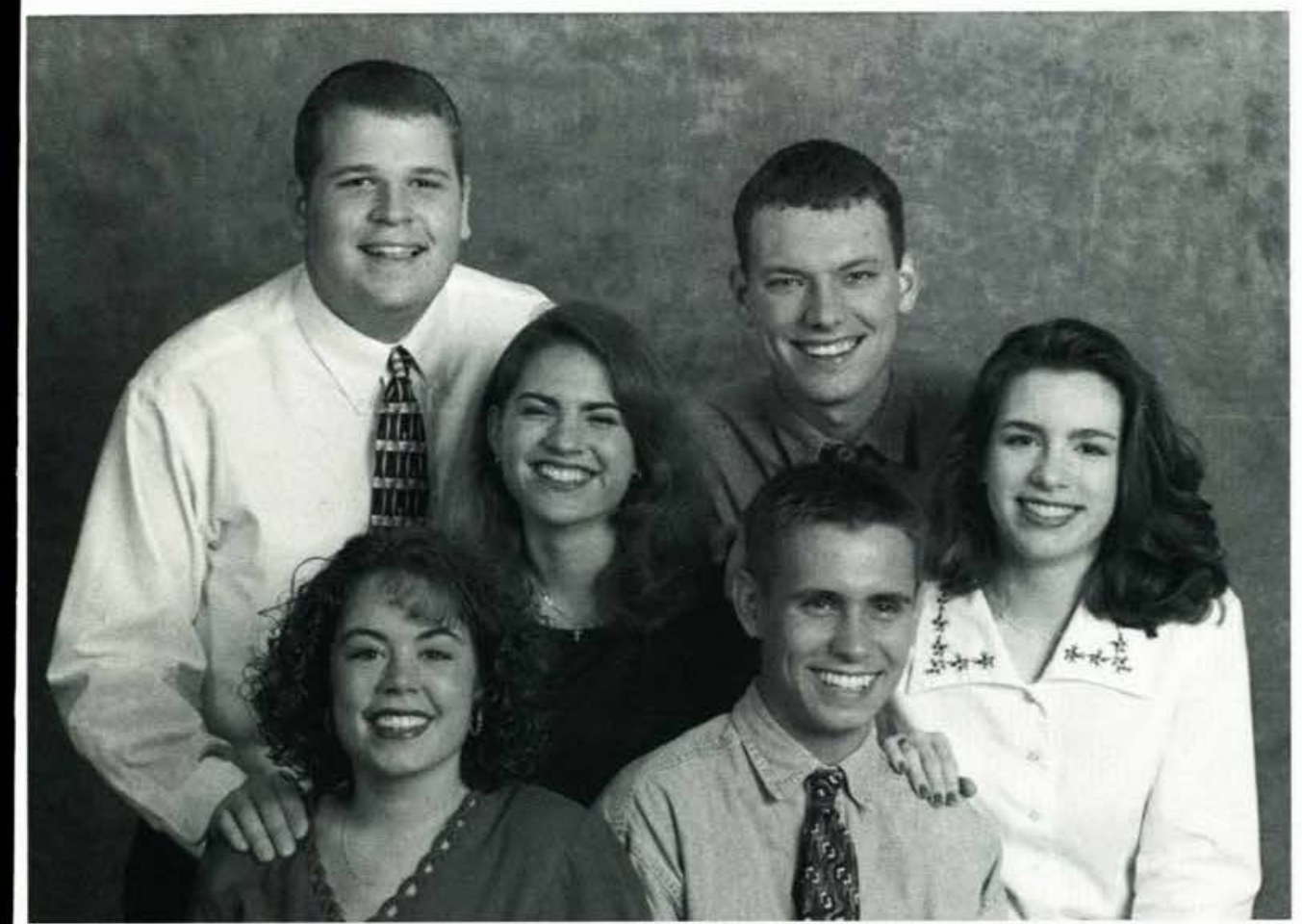

Members included: Top row - Aaron Borton, Jennifer Paulik, Chris Moles (leader), Elizabeth Abe. Bottom row - Carla Clark, Dan Price.

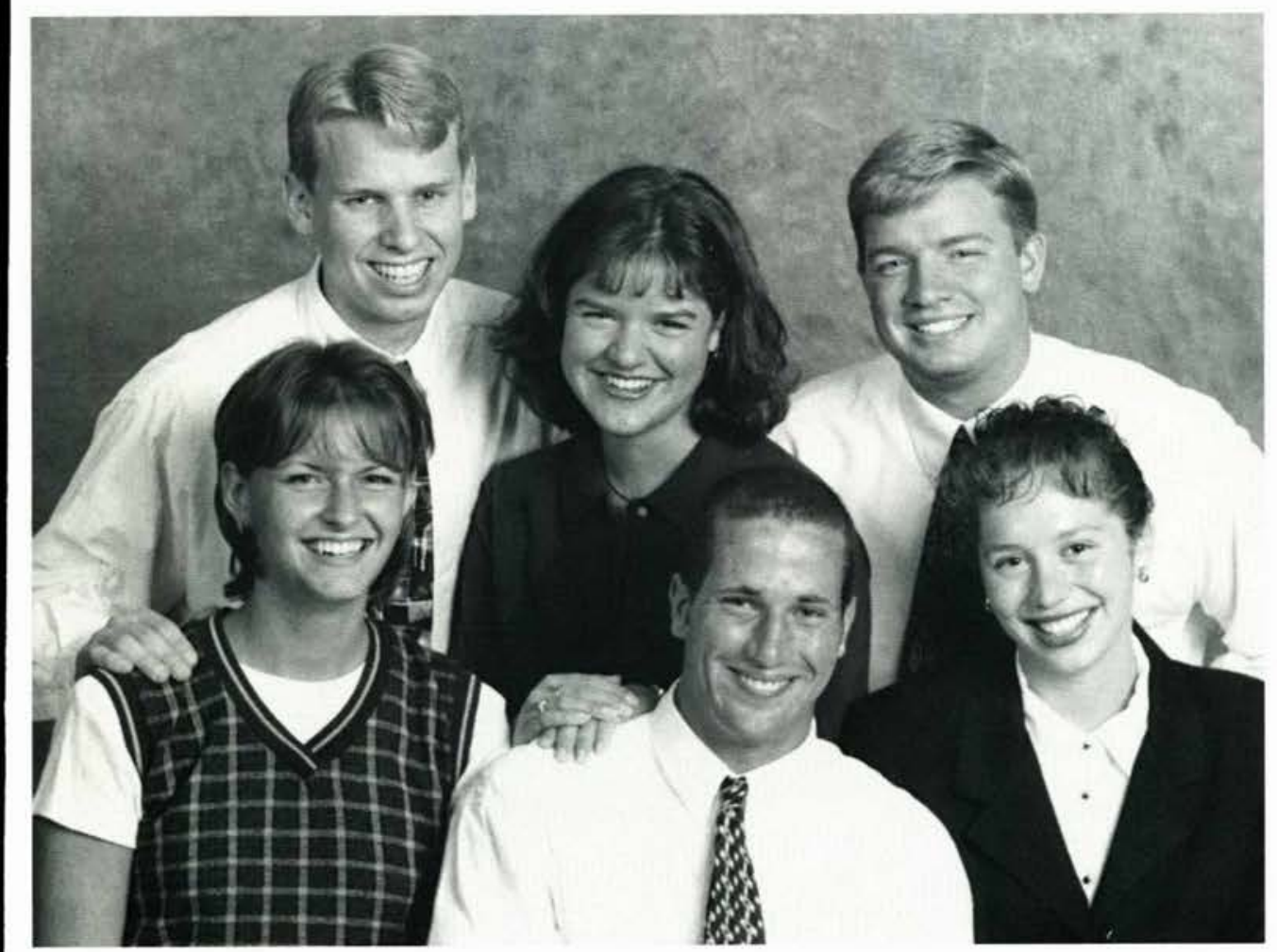

Members included: Top row - Mike Crawford, Jennifer Howard, Jim Amstutz. Bottom row Suzanne Eaton, Jason Tovey (leader), Amy Clutz.

\section{Master's Puppets 1}

Ministering with puppets, this team traveled throughout the school year and spring break and also toured the Midwest during the summer.

\section{Master's Puppets 2}

This team toured Washington state during the summer months, ministering to churches and Bible schools through puppets. 

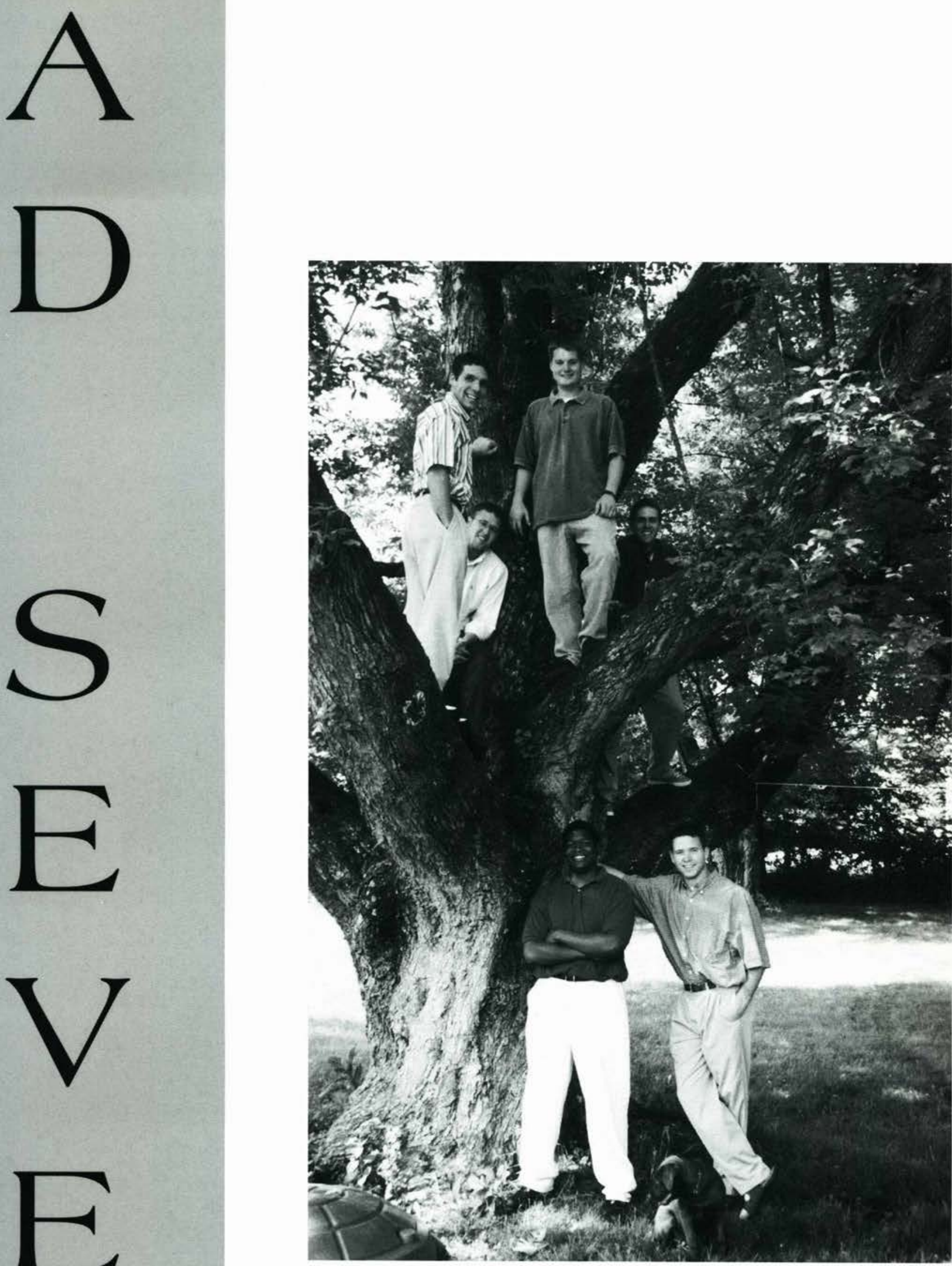

Blackburn

The Advisory Seven is a the group of student nominated and elected fellowship directors, which Pastor Rohm counsels as they lead the Sunday and Wednesday evening fellowship services for the student body. Many have come to know the Ad Seven as the spiritual leaders on campus. The 1997-98 Ad Seven consisted of (top) Jason Grahame, Jake Deister, Josh Haluko, Wade Harris (below) Nate Payne, and Josh Amos (not pictured: Josh Berrus). 


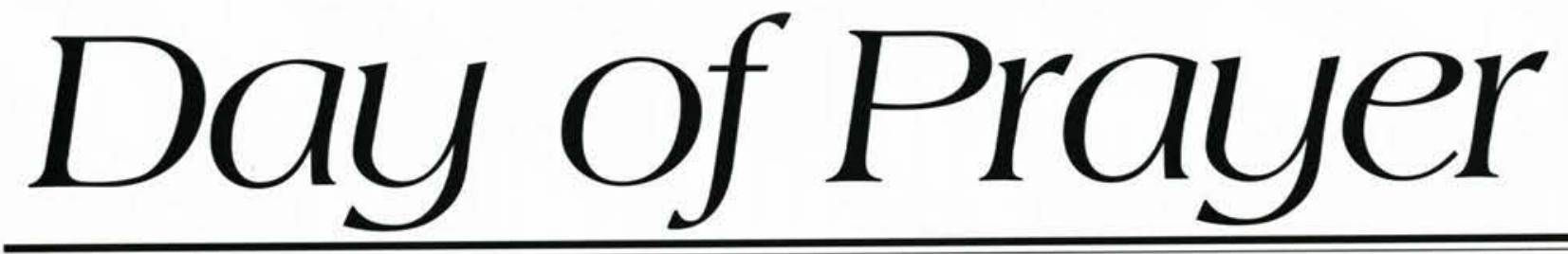

by Ruthanne Pierson

$\mathrm{H}_{\mathrm{a}}$

ands firmly clasped, huddled groups, and bent knees once more marked the National Day of Prayer. This year Cedarville commemorated this nationally recognized day of prayer by cancelling morning classes and dedicating a special hour and half long chapel to the topic and action of prayer.

The morning began at 8:00 am with refreshments and at $8: 30$, groups met all over campus to pray for the nation, missions, and unsaved parents. Since all classes were cancelled until 1:00 $\mathrm{pm}$, students and faculty were free to attend the focus group and fellowship in the fervent activity of prayer. This year has been a time of trial and tribulation for many of the students and college faculty and staff. The death toll numbered twenty-eight-many included parents of students, staff, and faculty members.

Yet, this was a time of hope in the midst of suffering. Dr. Dixon invited Danielle Parker and Dr. Lois Baker to share their personal stories of survival from serious car accidents-two living examples of the power of prayer. Reverend Ware, a prominent African-American pastor in Indianapolis, spoke on

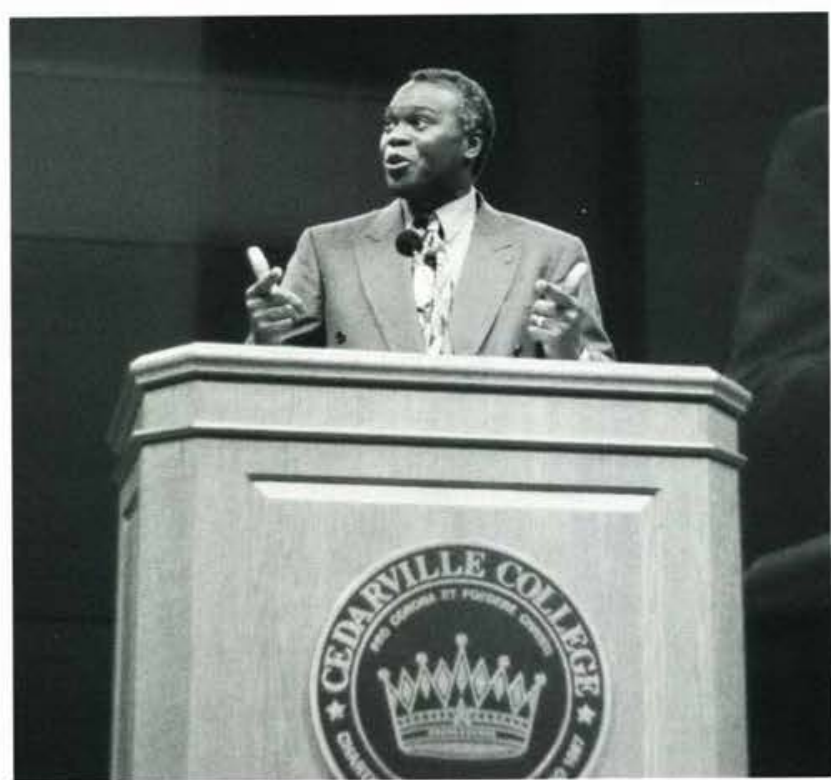

Reverend Ware, a prominent African American pastor, speaks at Cedarville's day of Prayer. racial reconciliation and shared his own story of provision and grace that God has extended to his family as his son remains paralyzed after a high school basketball injury. Annual prayer emphasis was again given to unsaved parents and grandparents as well as graduating seniors. Although only a day of prayer, Cedarville has purposed to honor and commemorate an activity that on this campus is a year-round event.
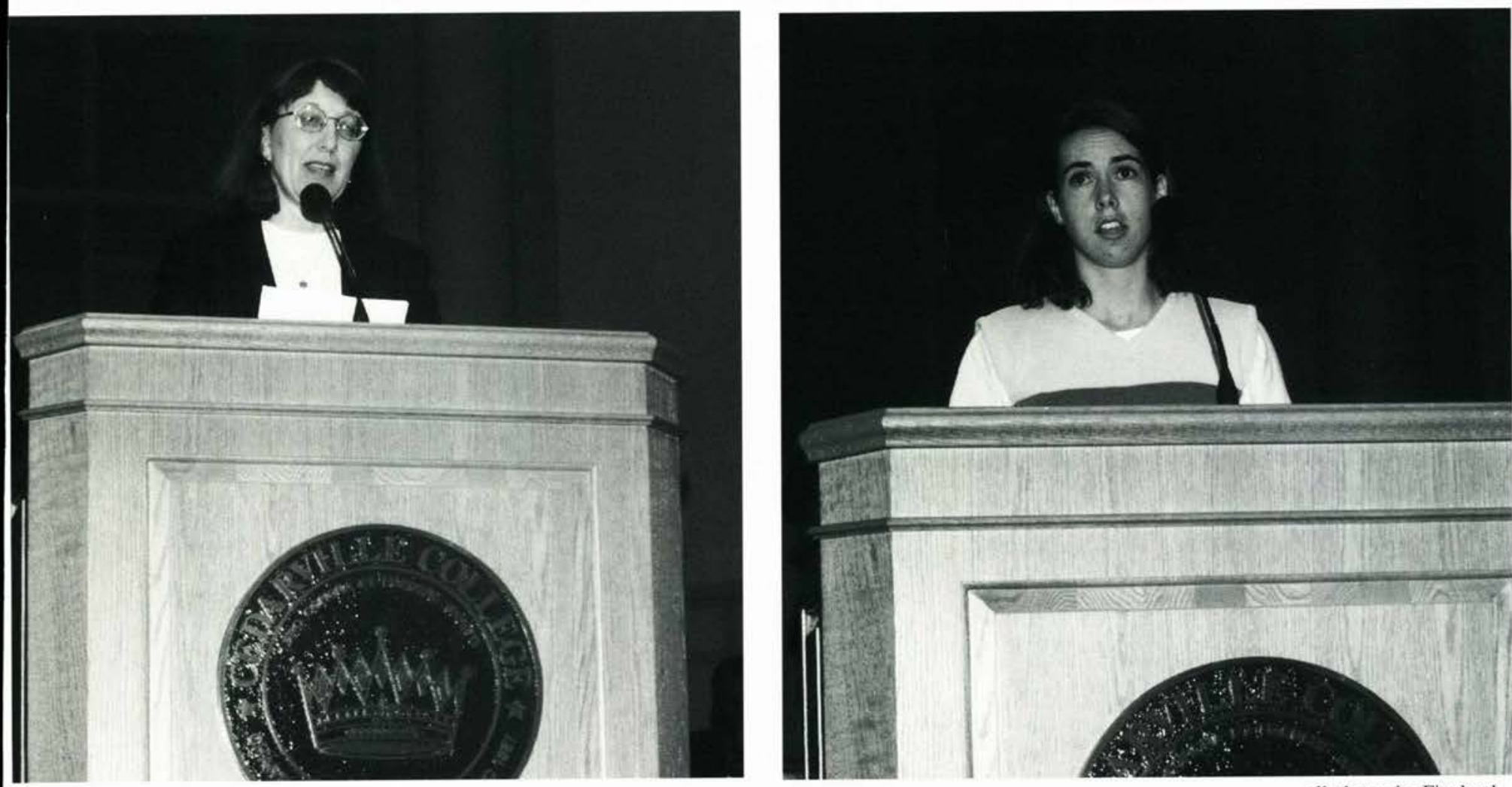

all photos by Fiveland

During the Day of Prayer Chapel Service, Dr. Dixon invited Professor Dr. Lois Baker (above left), and student Danielle Parker (above right) to share their personal testimonies of survival from serious car accidents-two living examples of the power of prayer. 


\section{L o c a 1 Church}

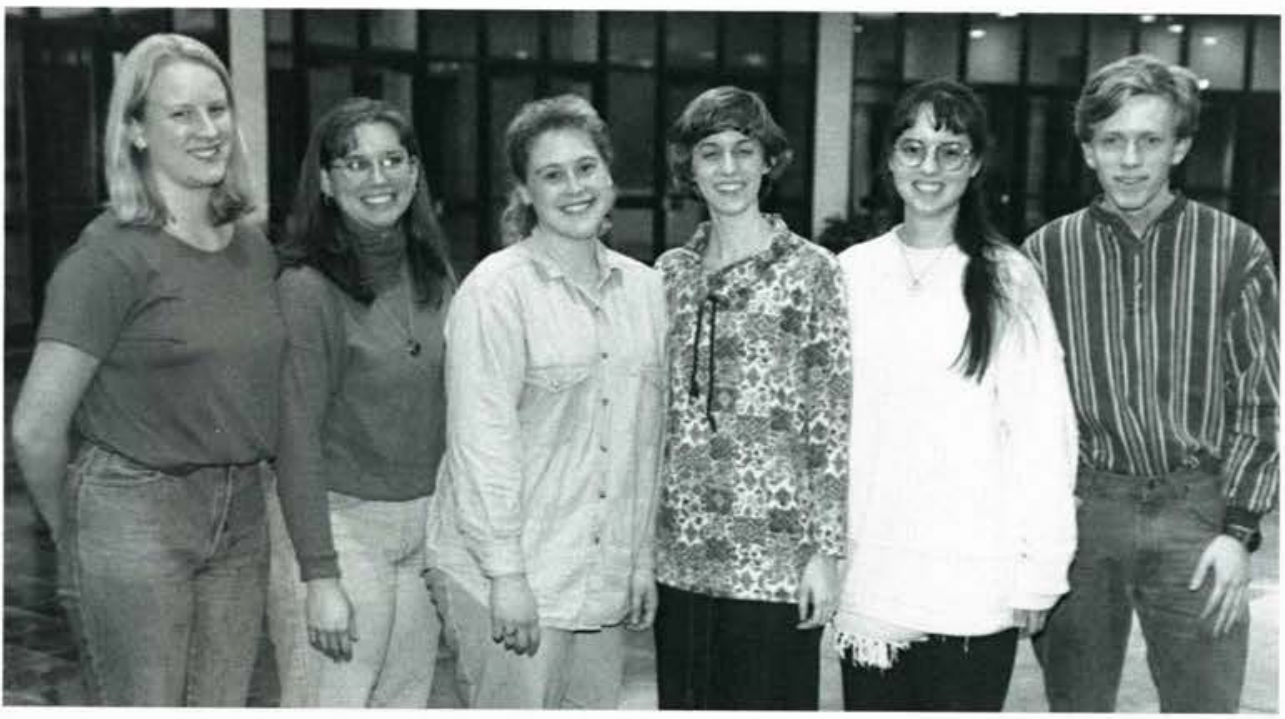

\section{Airway Baptist}

Description:Children's Church and AWANA

Nicole Carpenter, Dawn Albertson, Heidi Kinniburgh, Kristen Bollmeier, Bethany Walker, Ross Walker
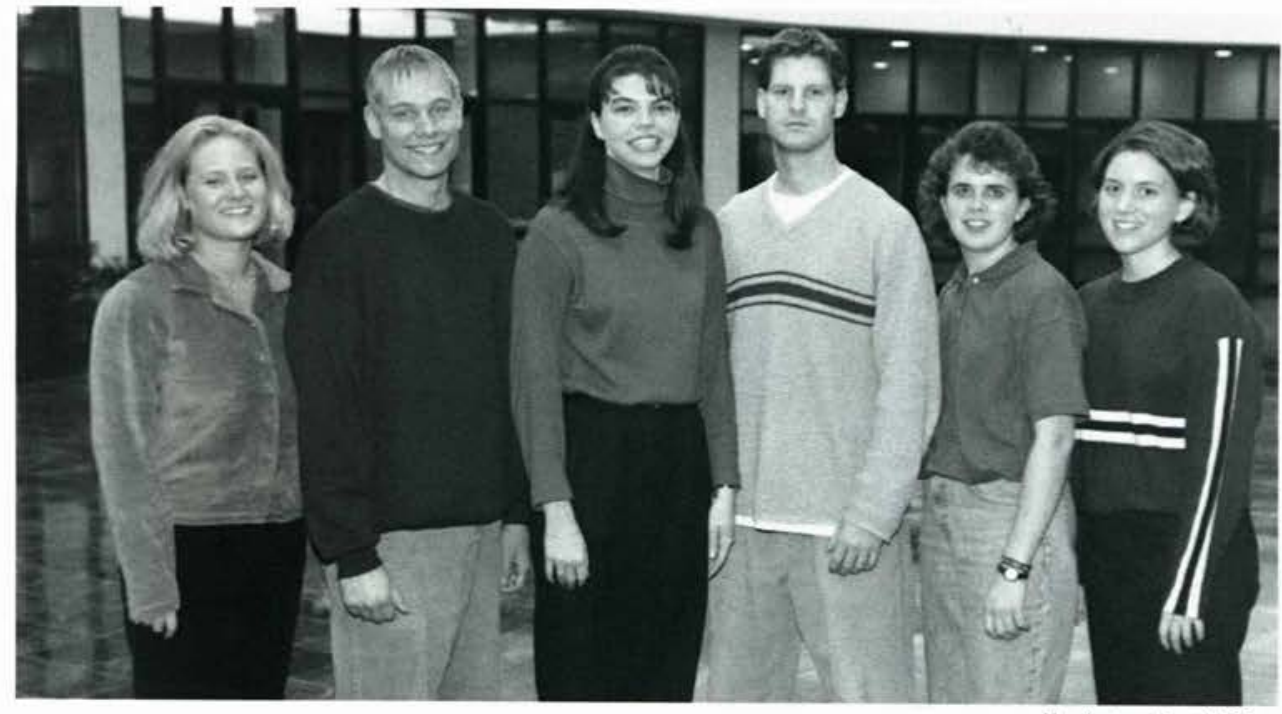

all photos by DaVor

\section{Beavercreek Baptist}

Description:AWANA Ministry

Leah Caldwell, Dave Shaffer, Ranee Baker, Eric Bedillion, Michelle Boehm, Jennifer

Burton

Not Pictured: Julie Henderson
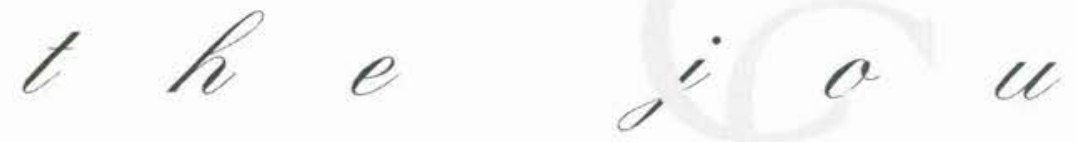

$$
\mu
$$$$
\text { n }
$$$$
\text { e }
$$ 
M in istries

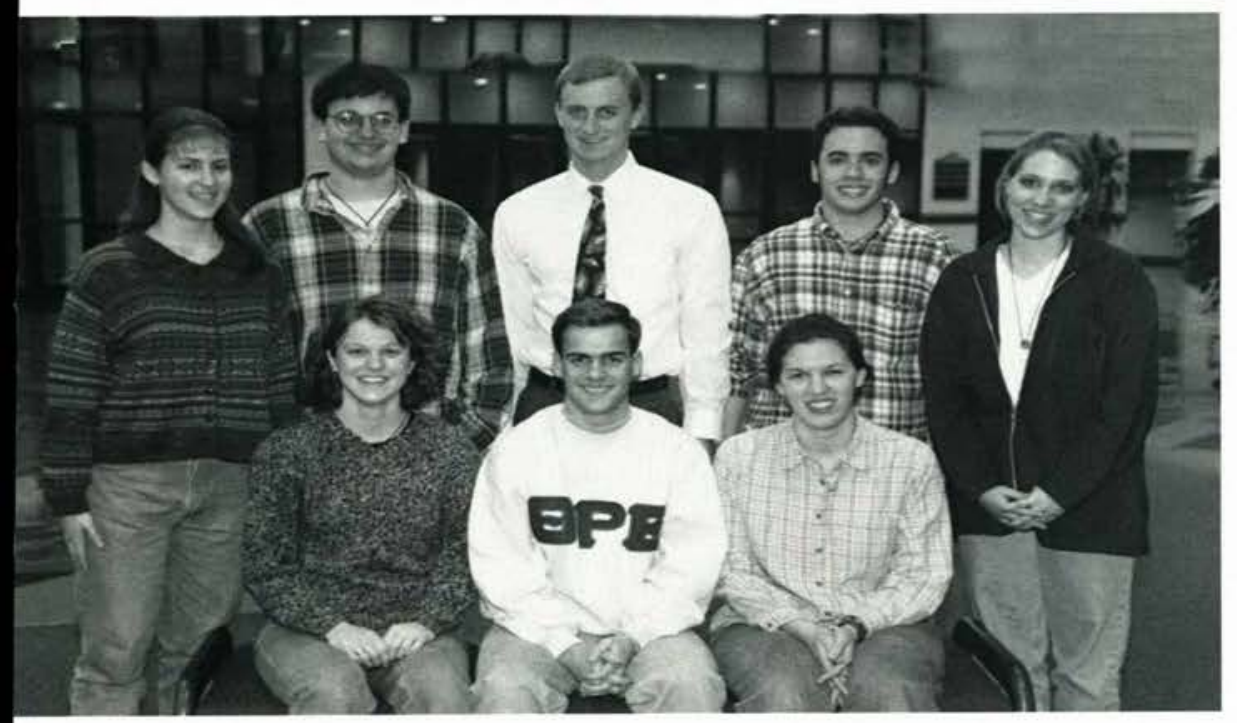

\section{Berea Bible}

Description:AWANA Ministry

F: Christina Fullerton, Joshua Ausfahl, Leanne Heath

B: Krista Morris, Jared Aldridge, Paul Numar De Kruyter, Bradford Barnard, Stacie Weinert

\section{Bethel Baptist}

Description:Nursery work and Children's Church

Lisa Smith. Tiffany Brooks, Erin Lee, Jami Broman.

Not Pictured: Amanda Bruckner, Tom Mullins

\section{Calvary Baptist}

Description: Children's Church, Sunday School, and Music

F: Susanna Workman,

Sarah Schlicher

B: RobertBouwens, JamesMurdock, Matthew D. Cook, Tracy Friesen Not Pictured: Jill Townsend, Danny Greco 


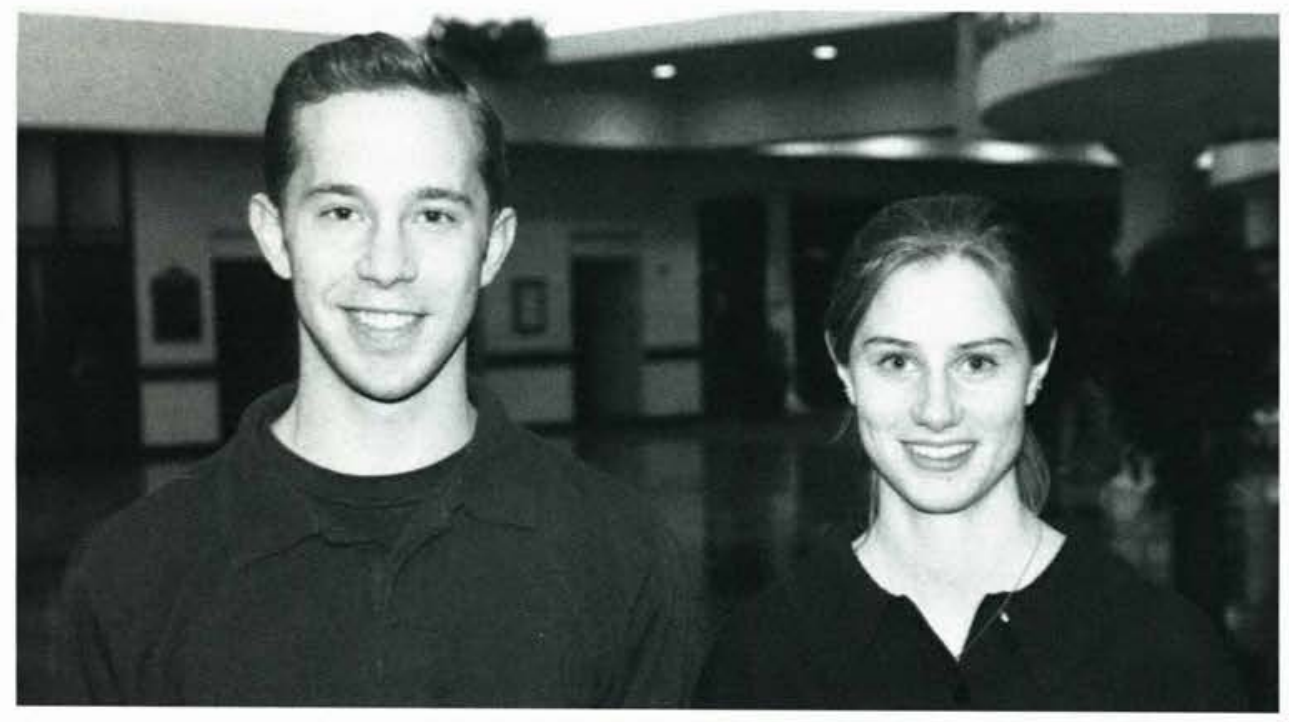

Calvary Grace Brethren - Dayton

Description:Childrens Church Sunday School and Music

Christopher Robin. Brenda Lynn Tabberer
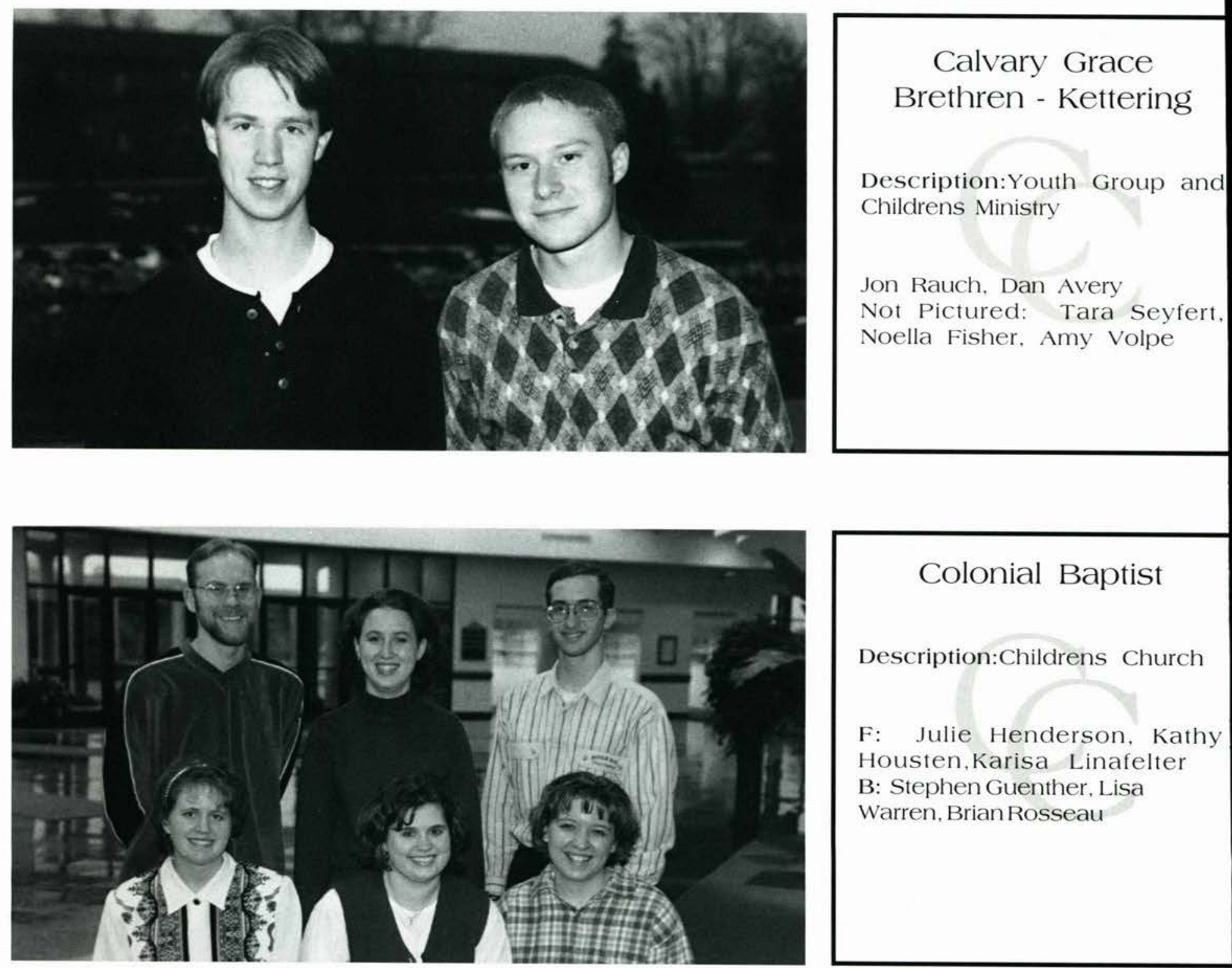

\section{Colonial Baptist}

Description:Childrens Church

F: Julie Henderson, Kathy Housten, Karisa Linafelter B: Stephen Guenther, Lisa warren, Brian Rosseau 


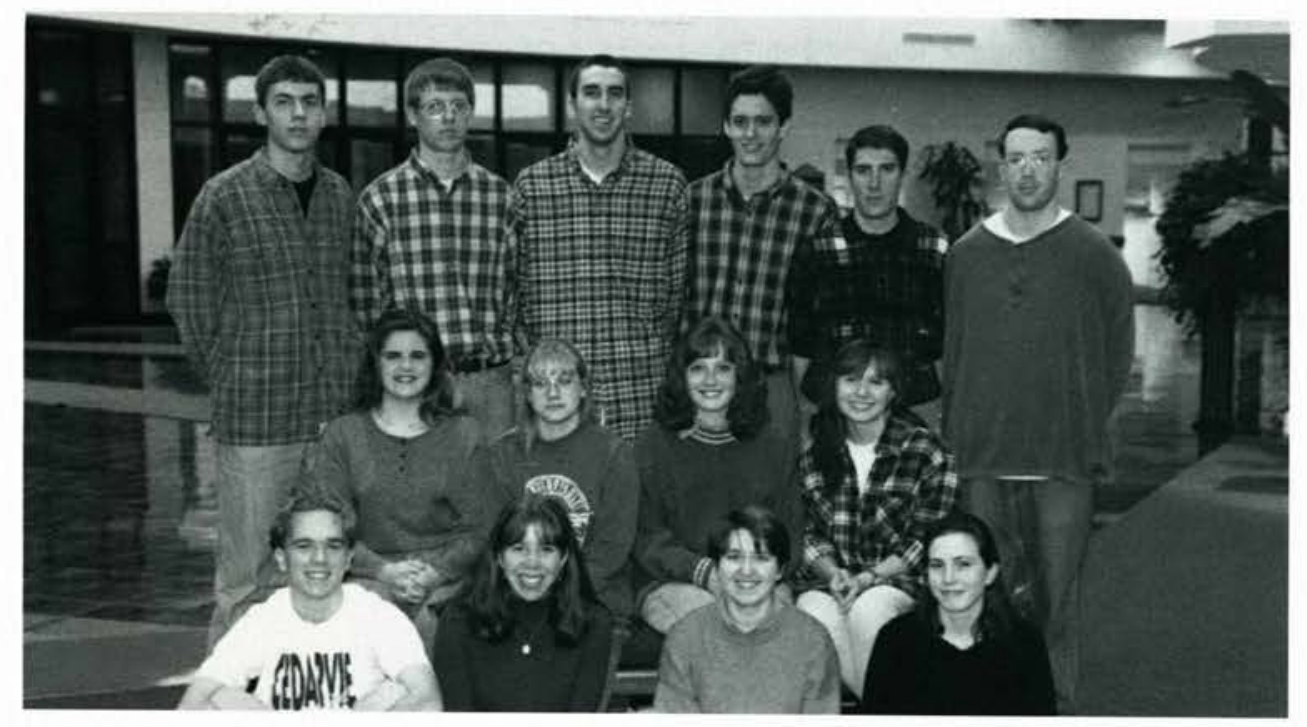

\section{Emmanuel Baptist}

Description:AWANA Ministry

F: Jeremy Frank, Mandy M Laughlin, Jeanne Carlton Erika Helfrick

M: Jenny Ploeg, Melody Brickel Sarah Flenar, Kris Boyes

B: Andy Kempe, Josh Michael Bryan Miller, Ian Duncan Mathew Murphy, Mark Treadwel

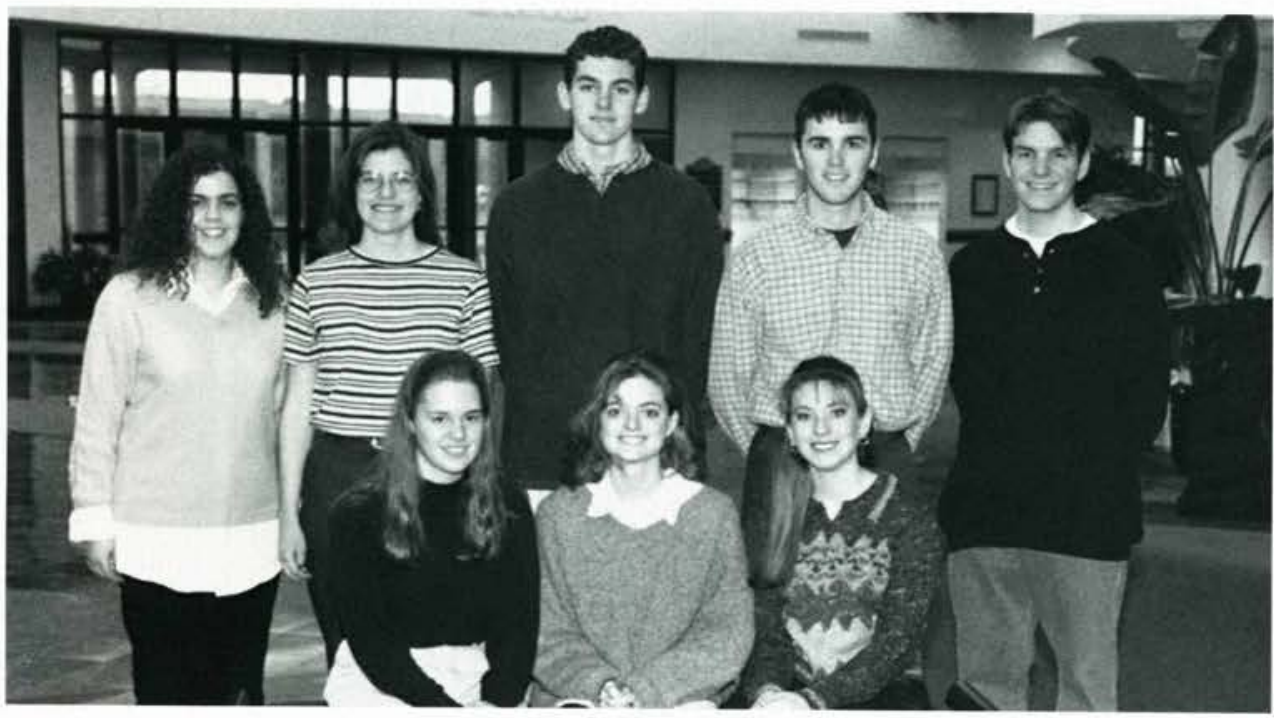

Fairhaven Church

Description:Children's Club

F: Becky Shellinbarger, Patty Noble, De Ann Christian

B: Rebecca Vitarelli, Julie Jouwstra, Rob Bayley, Darin Stevens, Dana Anglund

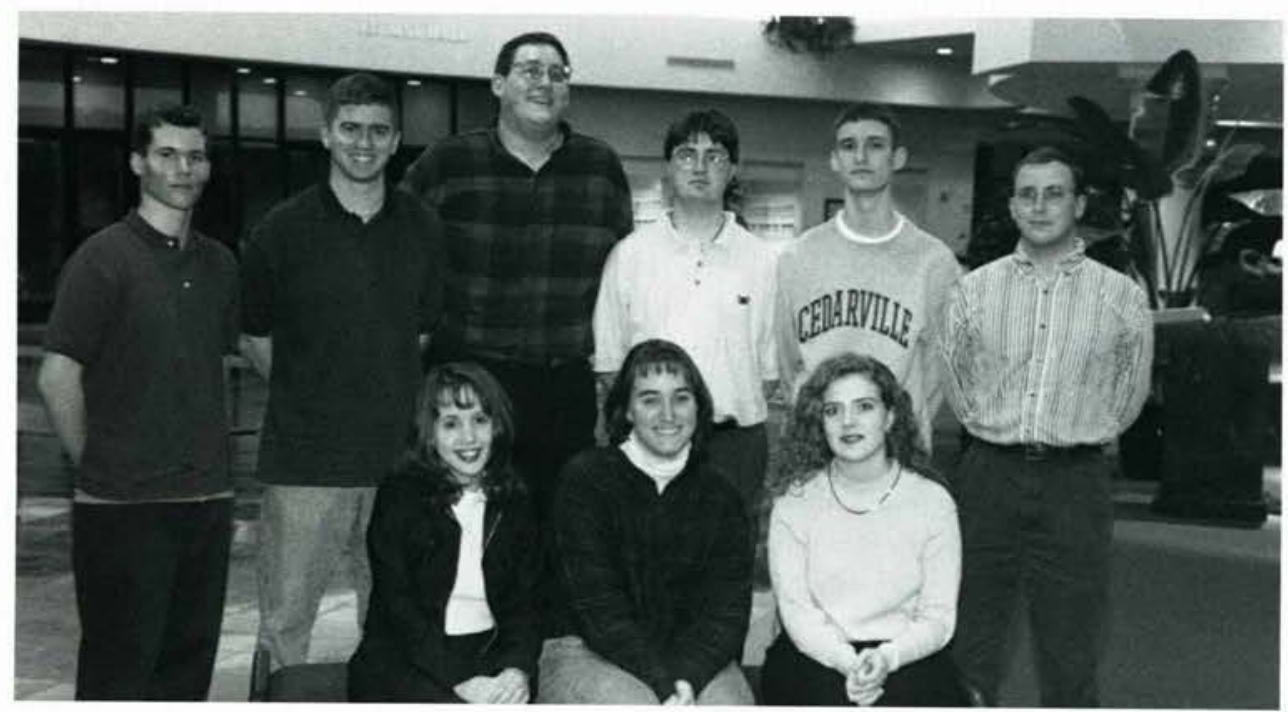

all photos by $\mathrm{DaVor}$

Description:Children's Church, Sunday School and Music

F: Kellie Forbes, Laura Schulz, Annmarie Reynolds

B: Matthew Nihiser, PJ Puryear, Scott Moodie, Chris Robertson, Adam Ballah, John Moodie

Not Pictured: Ryan Elam 


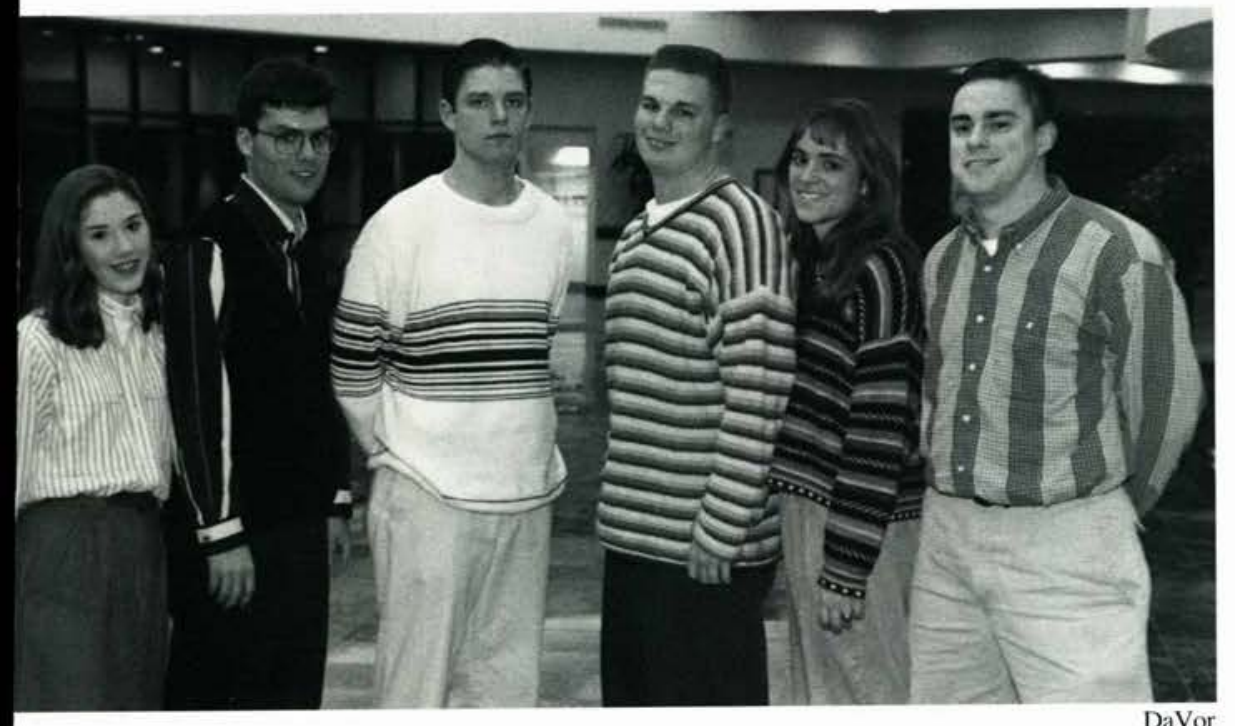

Far Hills

Description:Children's Church

Charisa Ripma, James Stitzel, Cliff Reynolds, Dave Hewitt, Joanna Overholt, Josh Overholt

Joyce Bontrager enjoys spending time with her Sparkies during AWANA. Bontrager is involved with the AWANA ministry at Friendship Baptist

\section{First Baptist - Enon}

Description:AWANA Ministry

F: Nicole Smith, Valerie Smith, Julie Forstom, Laura Brdlik B: Joe Beyer, Raymond Dewar III, David W. Jones, Jim Amstutz 


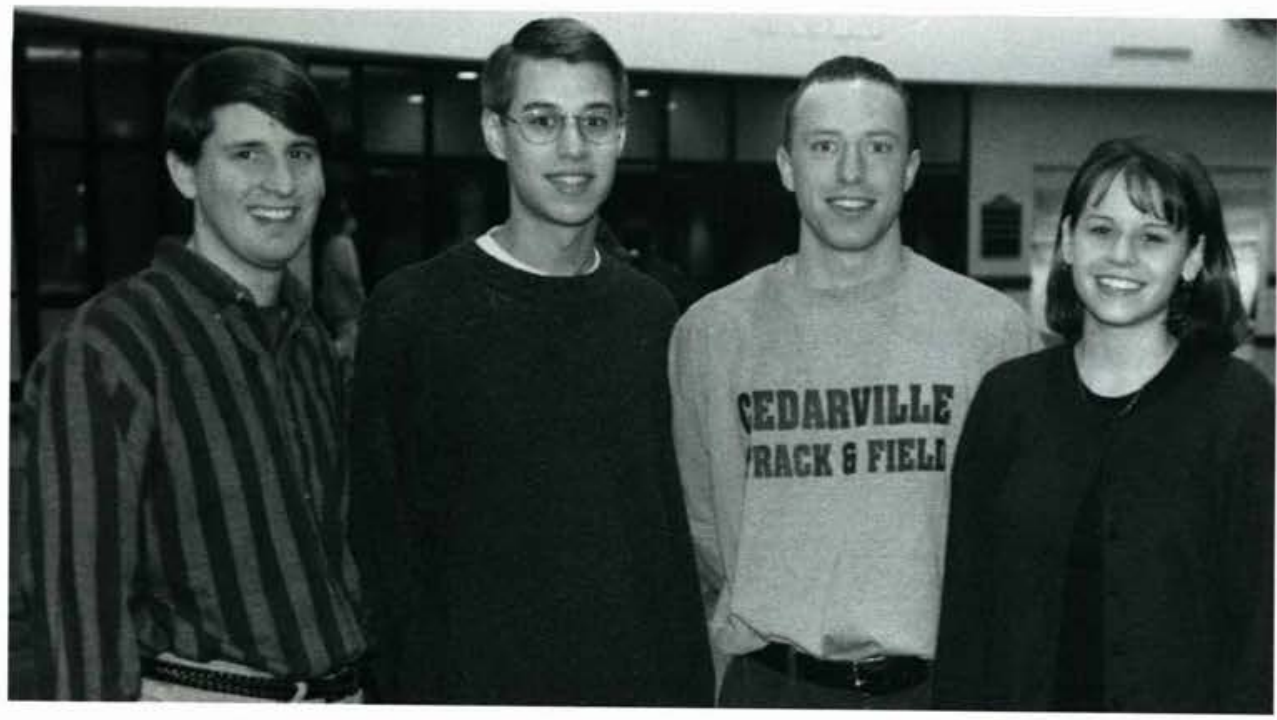

\section{First Baptist - Tipp City}

Description:Children's Churc and Sunday School

F: Tim Flowers, Mike Lewis David Rea, Nikki Luckmann

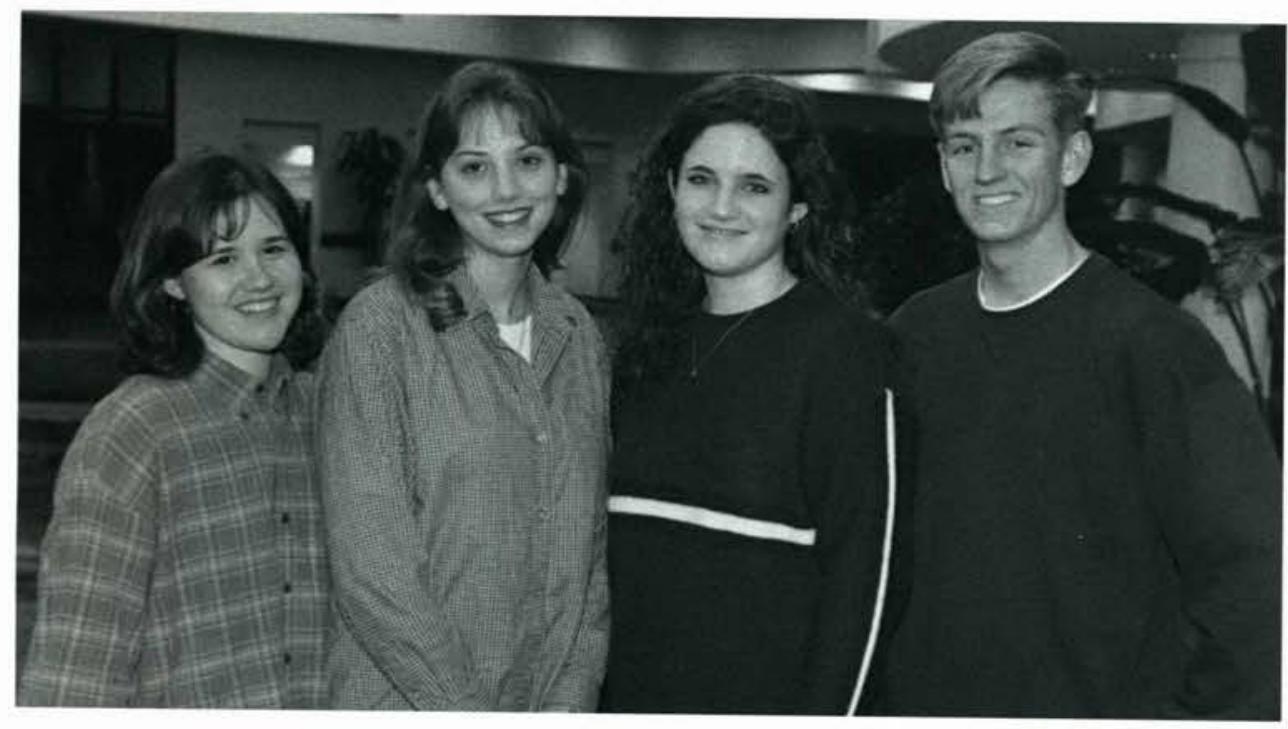

First Baptist -

Wilmington

Description:Children's Church, Junior High youth, and Music

Mary Beth Powell, Rachel Dyer, Michelle Moore, Christopher Recktenwald

First Reformed

Description:Children's Church

Laura Waddell 


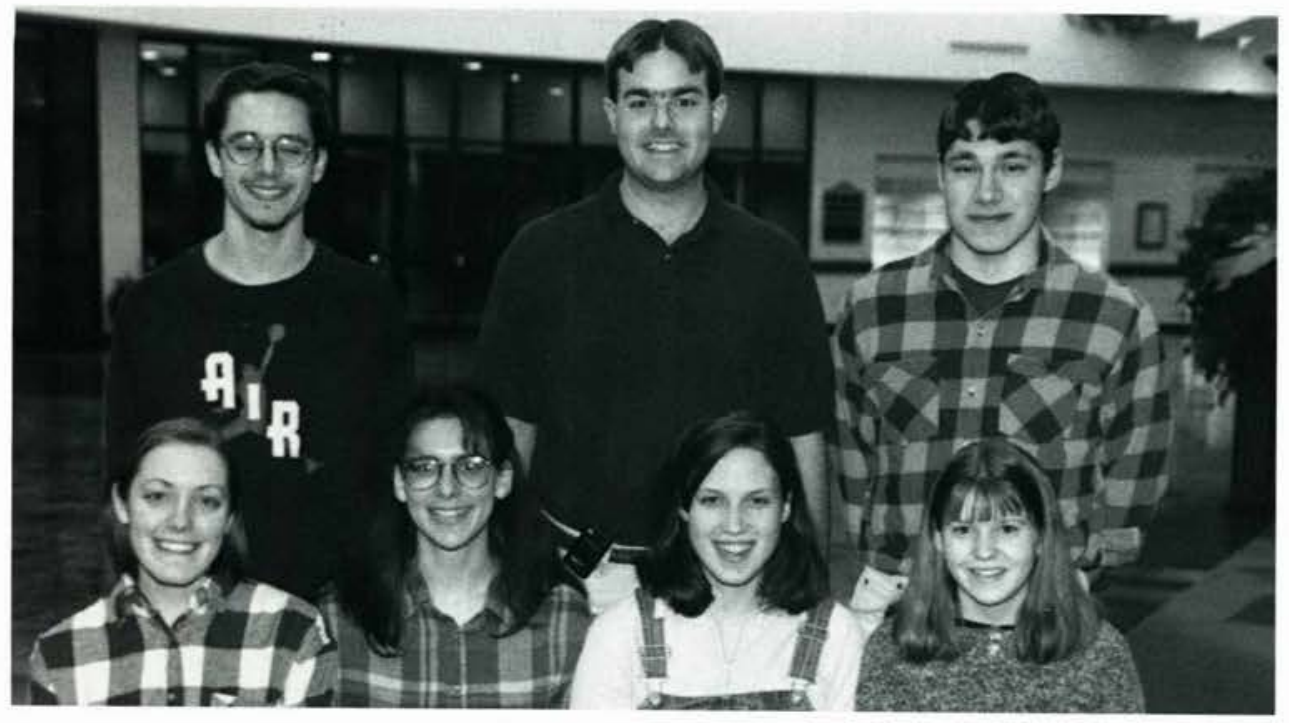

Friendship Baptist AWANA

Description:AWANA Ministry

F: Amy Herb, Michel Schafer, Joyce Bontrage Amy Hamilton

B: Mike wade, Chris Pool, Jeff Olson

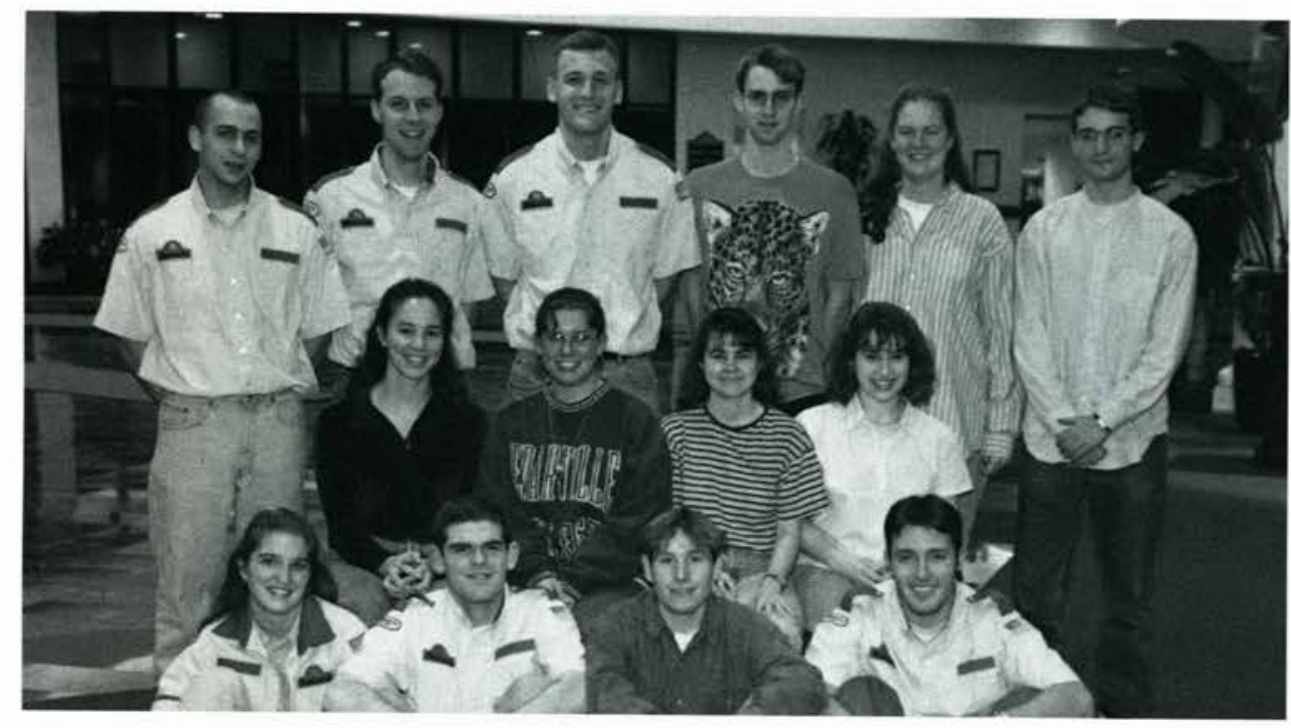

Grand Heights Baptist

Description:Children's Church and Nursery

F: Kristin Hoovler, Philip Tate, Scott Koziol, Greg Flory M: Nancy Houck, Dawr Albertson, Emily Watkins, Sarah Rittgers

B: Eric Pauling, Brian Gault Andy Litteral, Shawn Lundvall Erin Reagan, Aaron Mercer

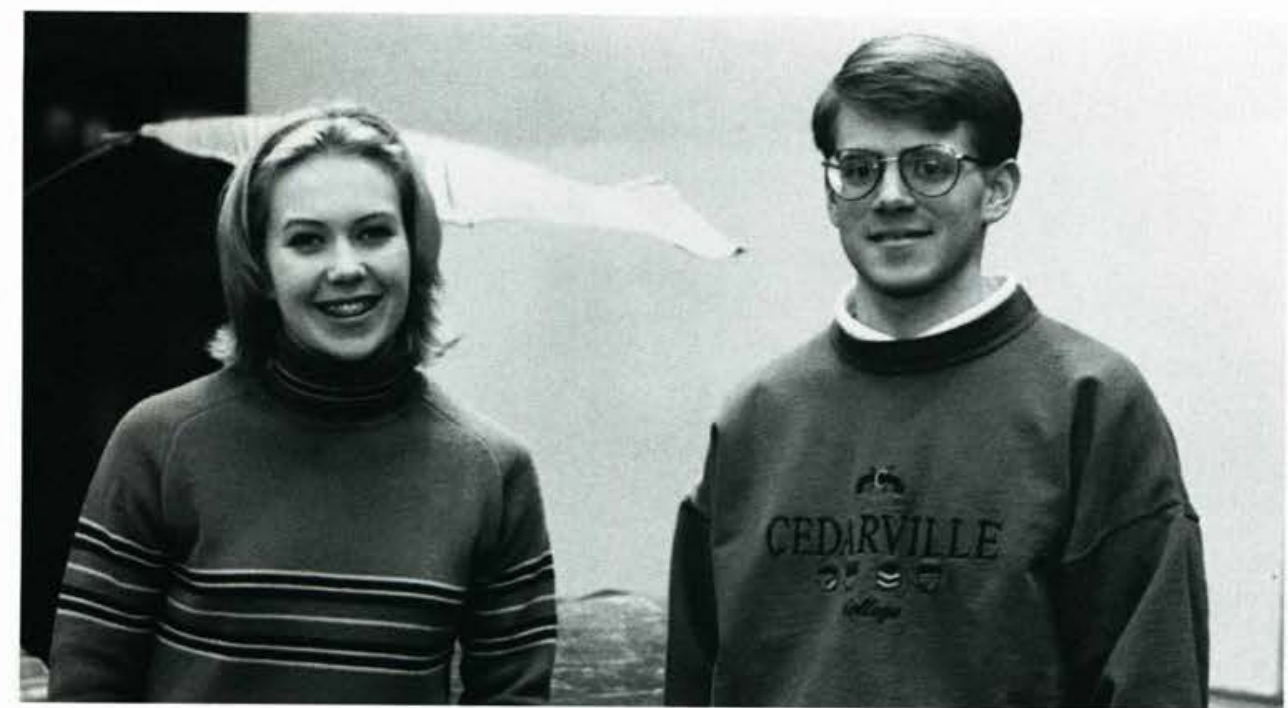

Heritage Fellowship

Description: Youth Group

Holly Dahlin, Joel Landis 

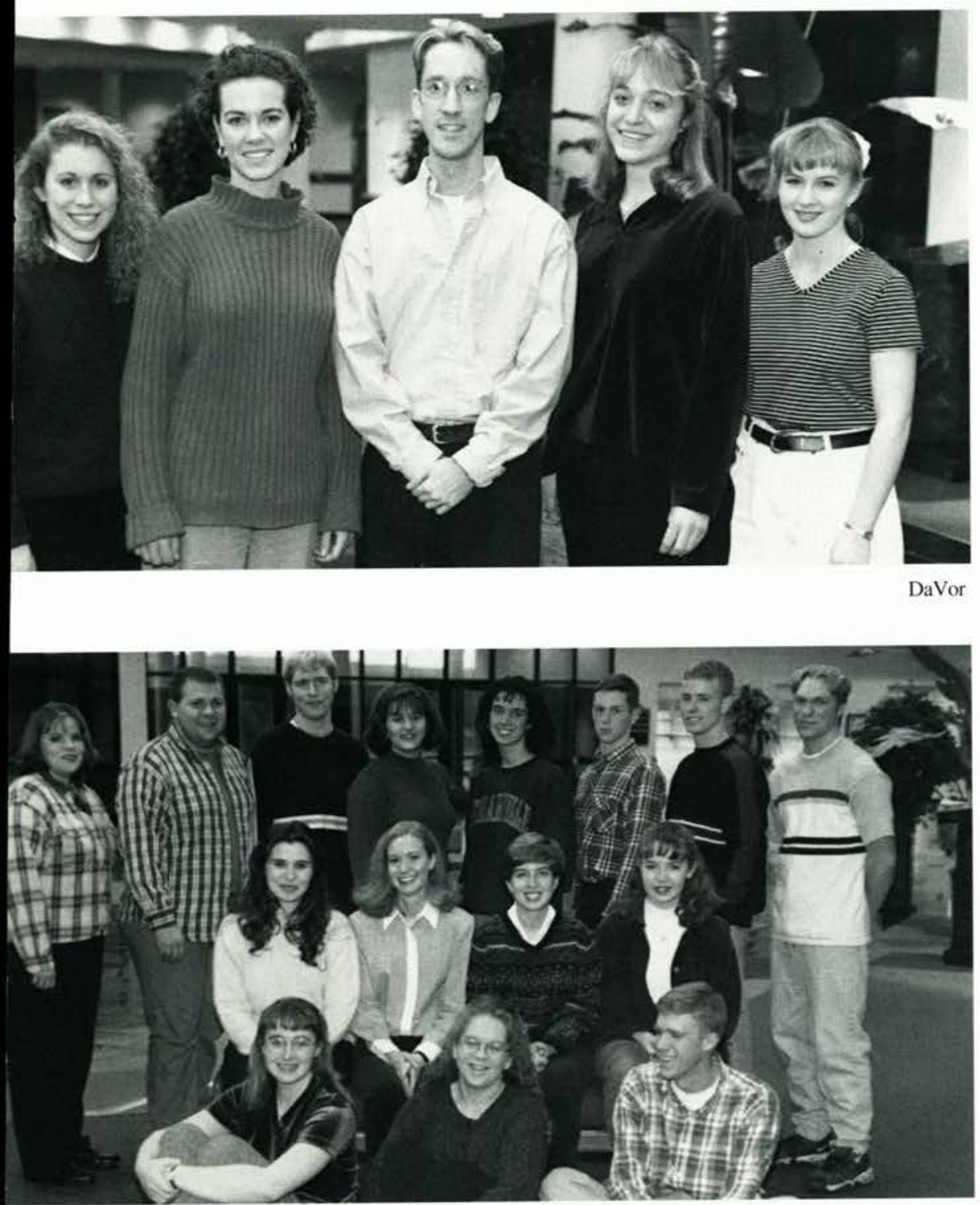

DaVor

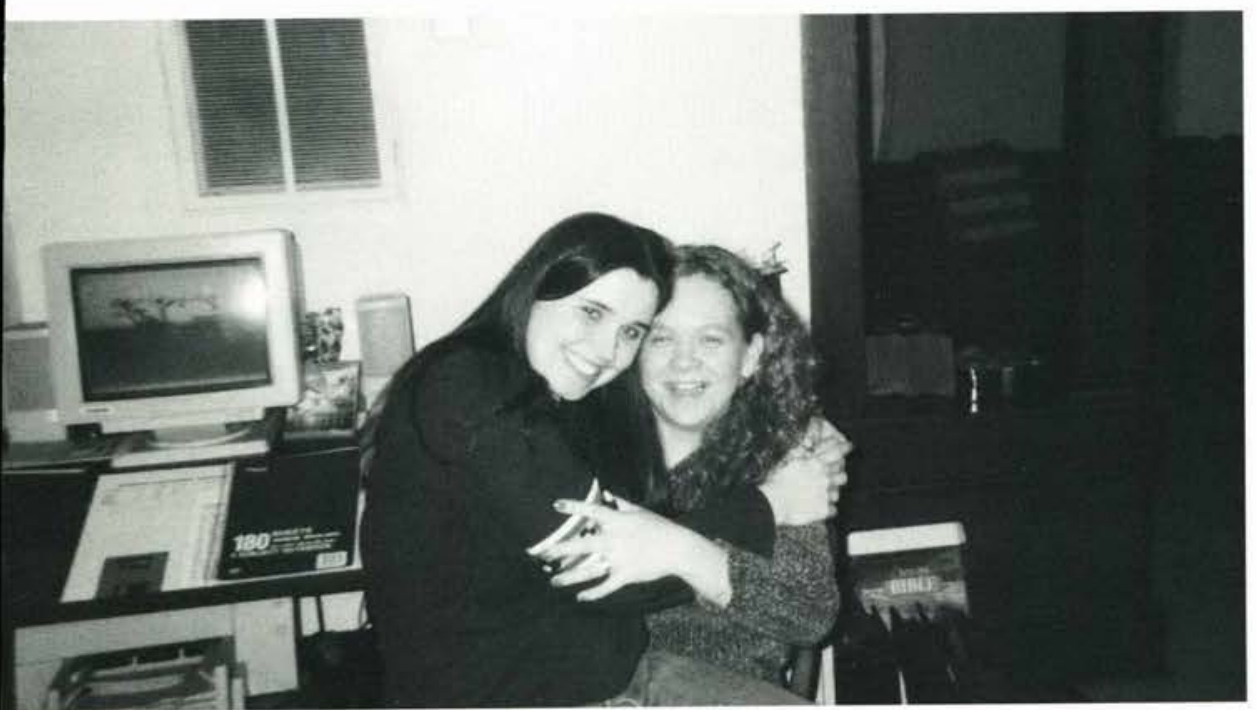

submitted by Summer Fielder

\section{Hope Chapel}

Description:Children's Churchand Youth Ministry

F: Amy Stowers, Erica White, Nathan Stephens, Hillary Doot, Jennifer Larson

Not Pictured: Dave Mc Grew

\section{Northside Baptist}

Description:Children's Church and AWANAMinistry

F:Shelly Yahara, Summer Fielder, Eric Steenwyk

M: Maranatha Ruberg, Jenna Hoffman, Pam Claus, Amy Morse B: Hannah Dager, Dave Anderson, Ryan Cook, Jennifer Cook, Jeanne Moynihan, Shawn Conley, Chad Foerch. Nick Grisco

Summer Fielder and Maranatha Rueberg express their friendship for the other. Fielder and Rueberg are both involved at Northside Baptist. 


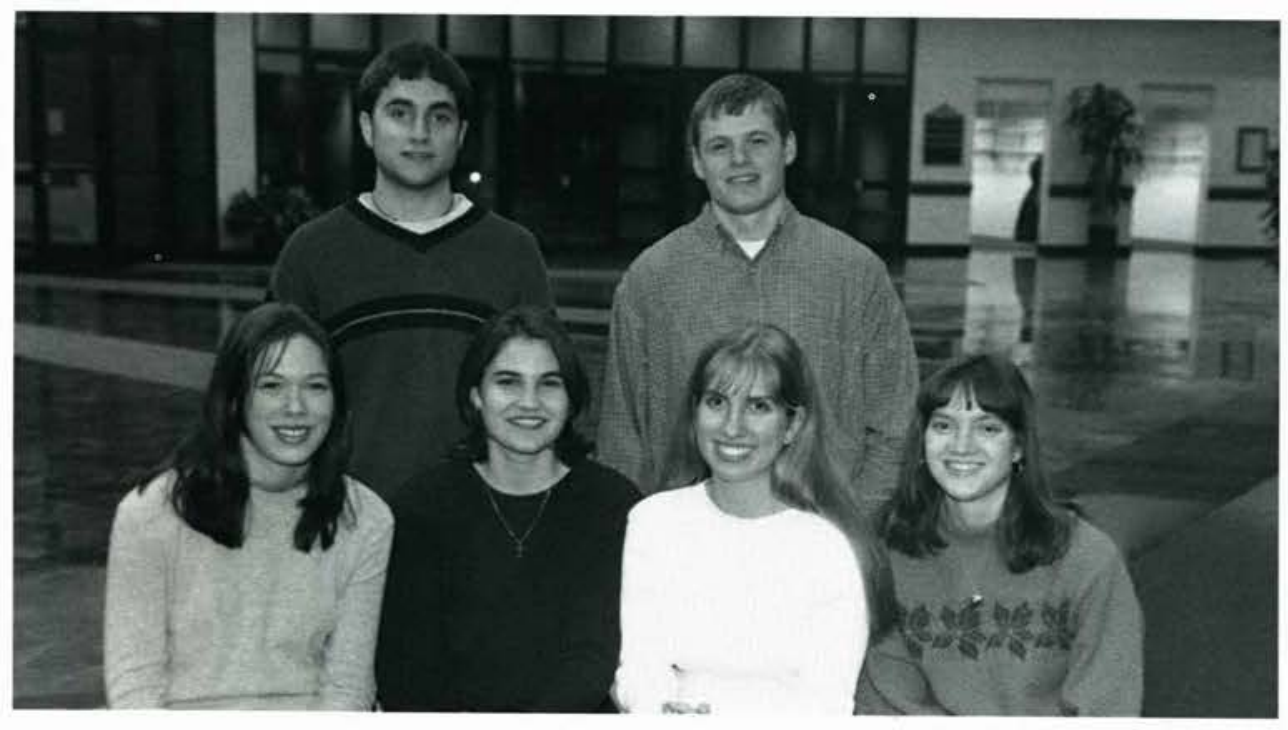

\section{Petre Road}

Description:Children's Church Nursery and Youth

F: Jenny Stryker, Karen King, Kathryn Johnson, Eileen MC Coskey

B: Mark Clark, Ty Waardenburg

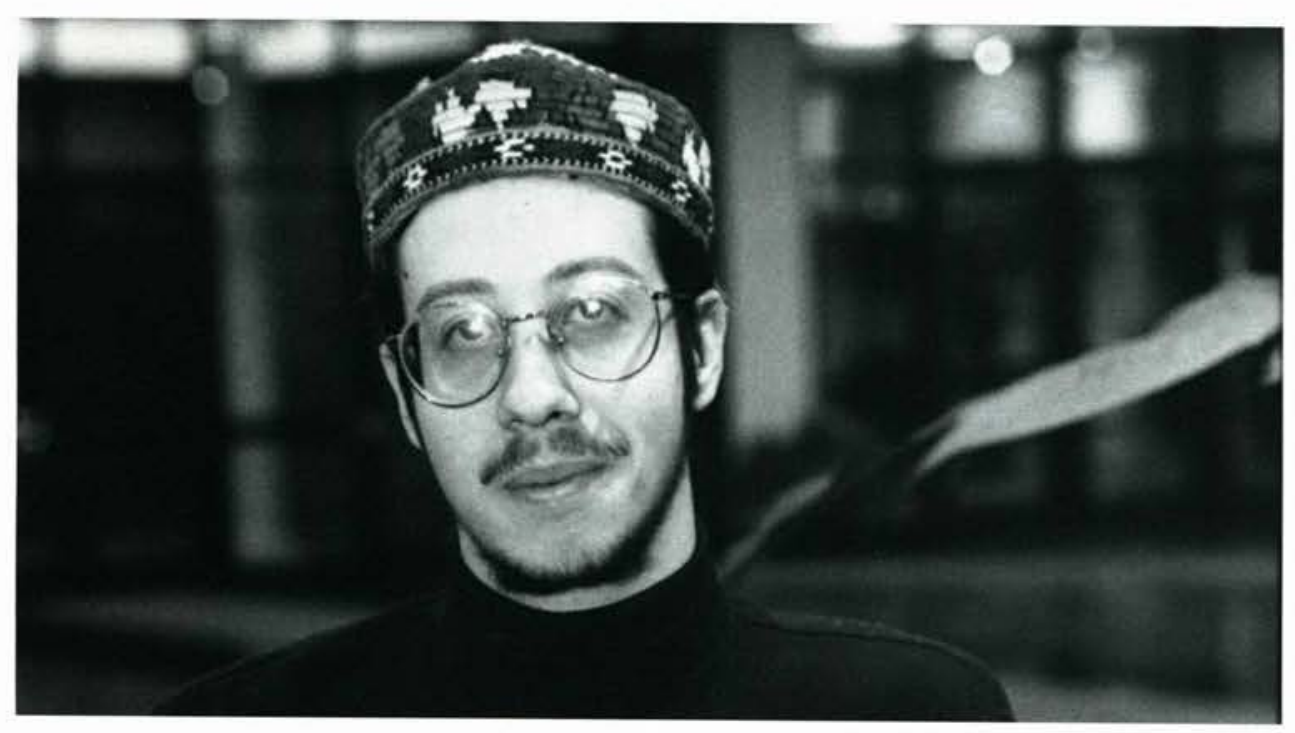

Prince of Peace United Brethren

Description:Children's Church and Music

Todd Musser

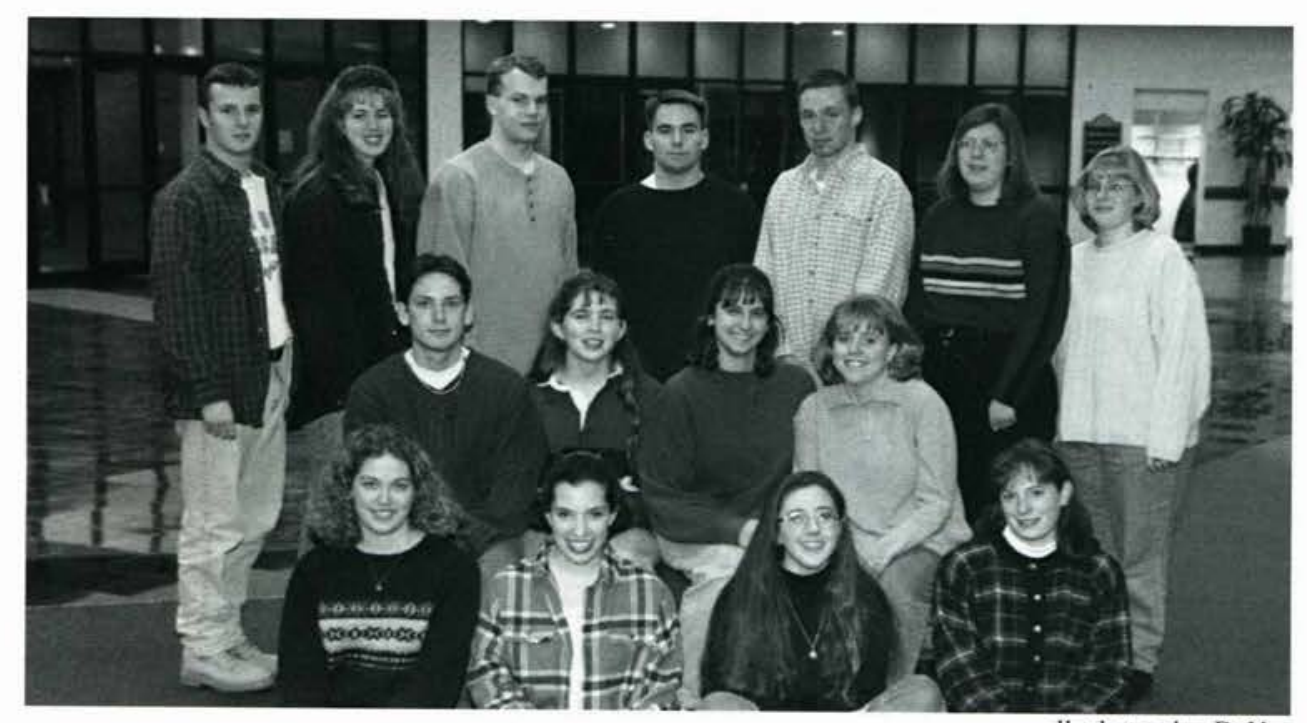

all photos by DaVor

\section{Southgate Baptist}

Description: AWANA Ministry

F: Gudrum Olson, Andrea King, Laura Kroner, Dawn Geib

M: J. Michael Yoder, Lori Hamilton, Joey Decker, Sheri Wilson

B: Troy Page, Julie Gregory, Kim Koeman, Joe Mulvaney, Bryan Falk, Sara Campbell, AmberRumphol 


\section{Outreach and Youtl}

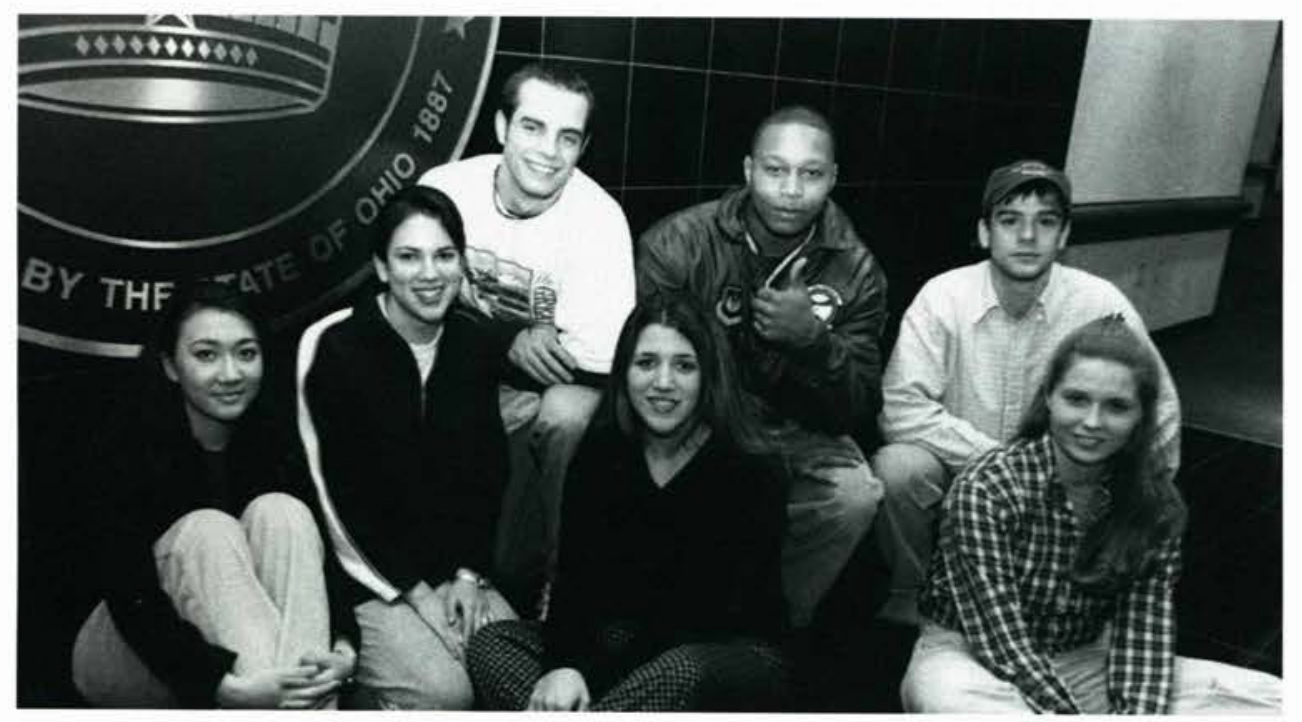

Wright Patterson Air Force Base

Description:Children's Church Youth Sunday School and Bible Study

F: Lina Ponder, Daphne Kiaz, Kandace Kenyon, Roberta Roe B: Rober W. Randall, Bobby Ray Johnson II, Jason O'Neal

Not Pictured: Ehrin Arimura Jeff Connors, Jackie Williams

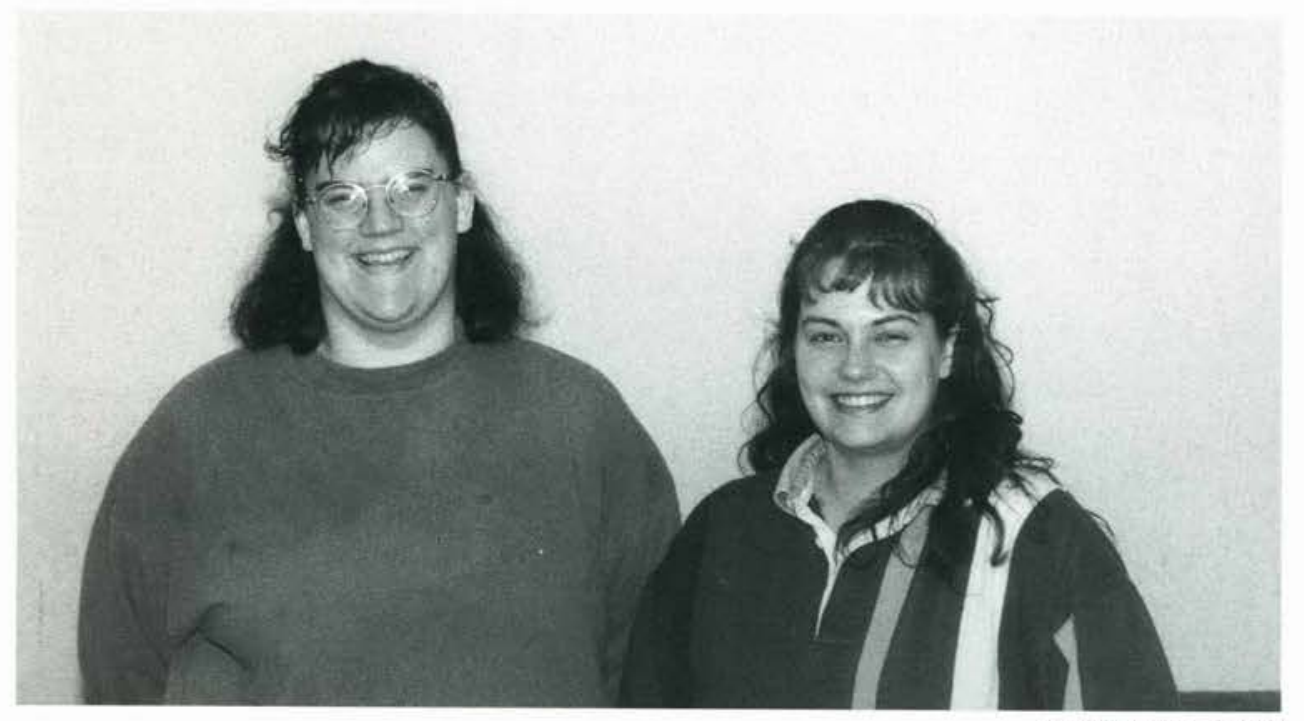

Adult Literacy

Description: Ministry by helping adults obtain their high school diploma

F: Brooke Higgins, Karin Shilling

all photos by $\mathrm{DaVor}$

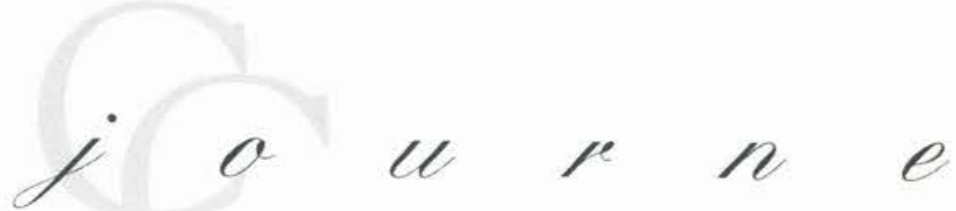




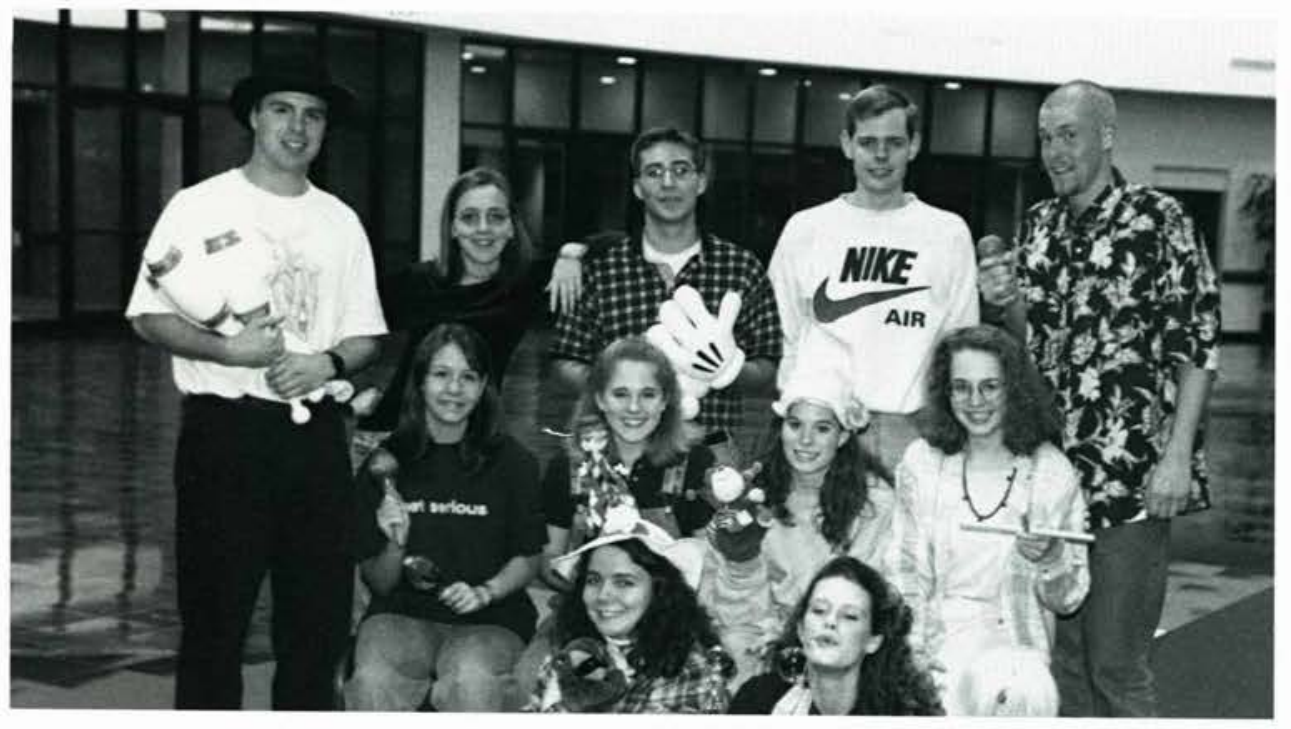

\section{Clowns For Christ}

Description: Ministering to young and old alike in a way that reinforces Bible knowledge and aids other ministries

F: Betsy Linnell, Julie Lamborn M: Britney Jones, Rachel Cassel, Angela Howe, Sandy Bennett B: John Myers, Melissa Roesch, Jordan Culp, Nathan Radford, Jeremy Couture

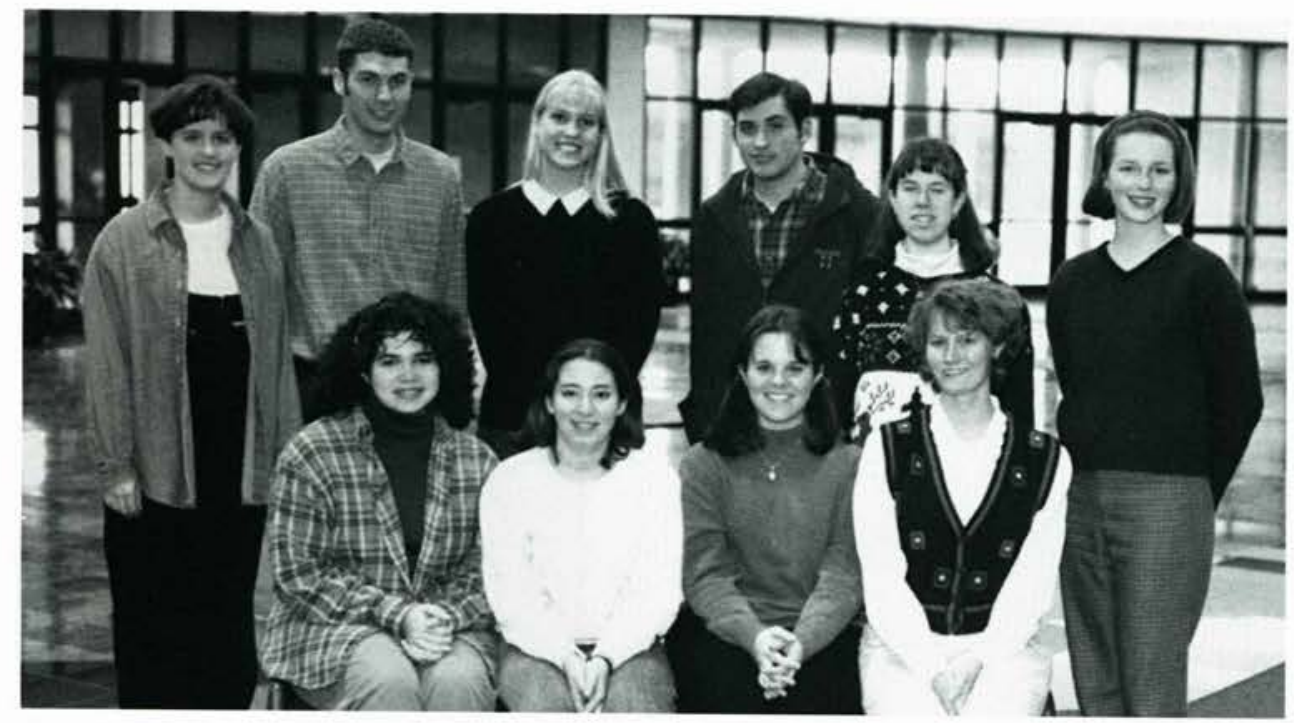

\section{College Partners}

Description: Big Brother/Big Sister ministry to Cedar Cliff school system children

F: Tammy Mc Comb, SarahSilvieus, Kelly Gleason, Christina Riley B: Julie Opperman, Jodi du Monceaux, Alan Bradly Cotter. Julie Trout, John Botkin, Kristin Neumann, Christine Howe

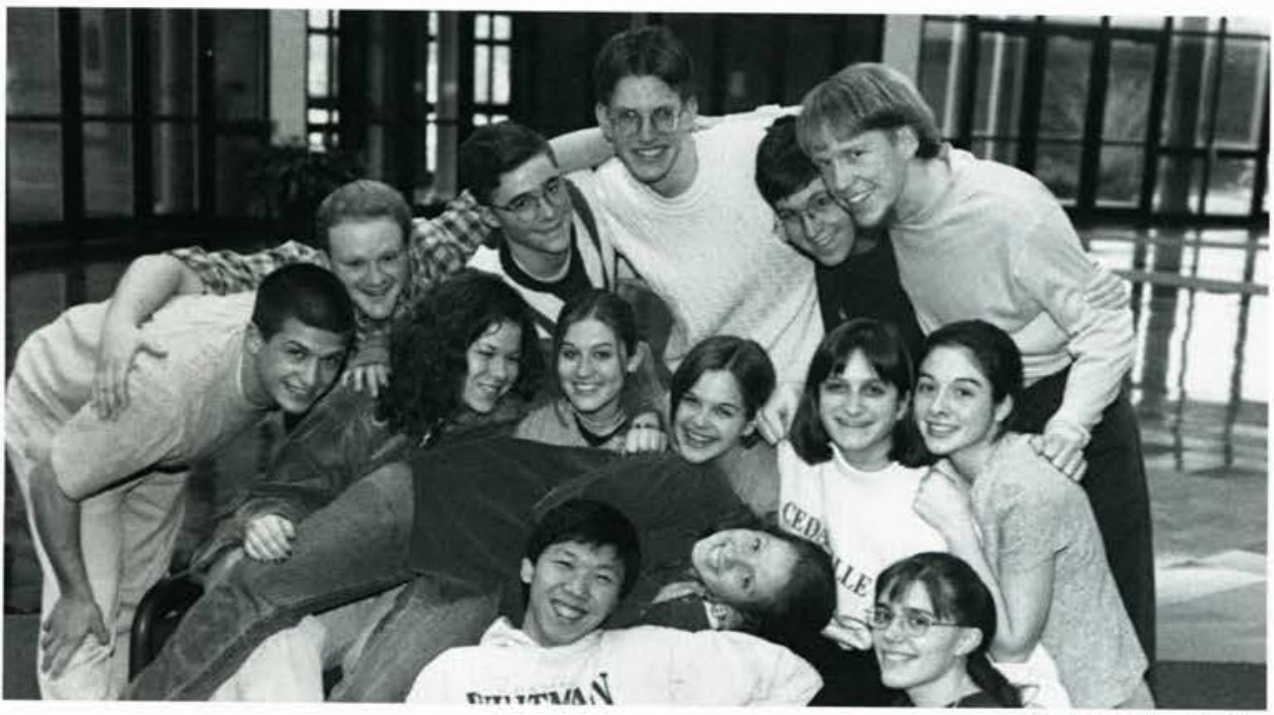

Dayton Gospel Mission

Description: Serving food, preparing services, general maintenance and more

F: Joseph Natalino, Jean Estes, John Stedge, Kelly Warriner, Cheri Vigeant

M: Sundi Myers, Jami Myers, Kelly Mc Kay, Jordan Natalino B: Joe Mellish, Scott Cameron, Dave Jouwstra, Gregory Rheam. Darrin Smith 


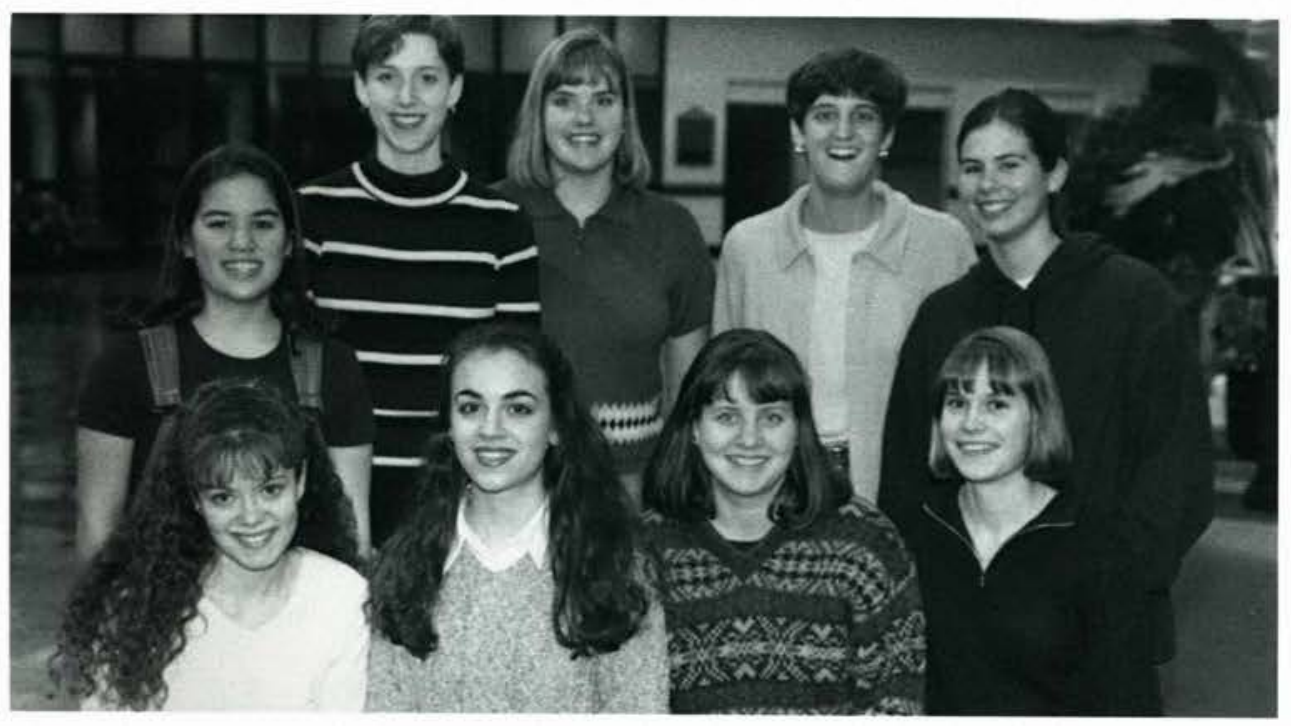

\section{Miami Valley CPC}

Description: Counseling women in crisis pregnancies on the sanctity of human life.

F: Jessica Pennington, Jennifer Griffith, Elizabeth Johnson, Emily Bishop

B: Keiko Noble, Summer Friend, Sarah Gilehrist, Jessica Stuenzi, Amy Mead

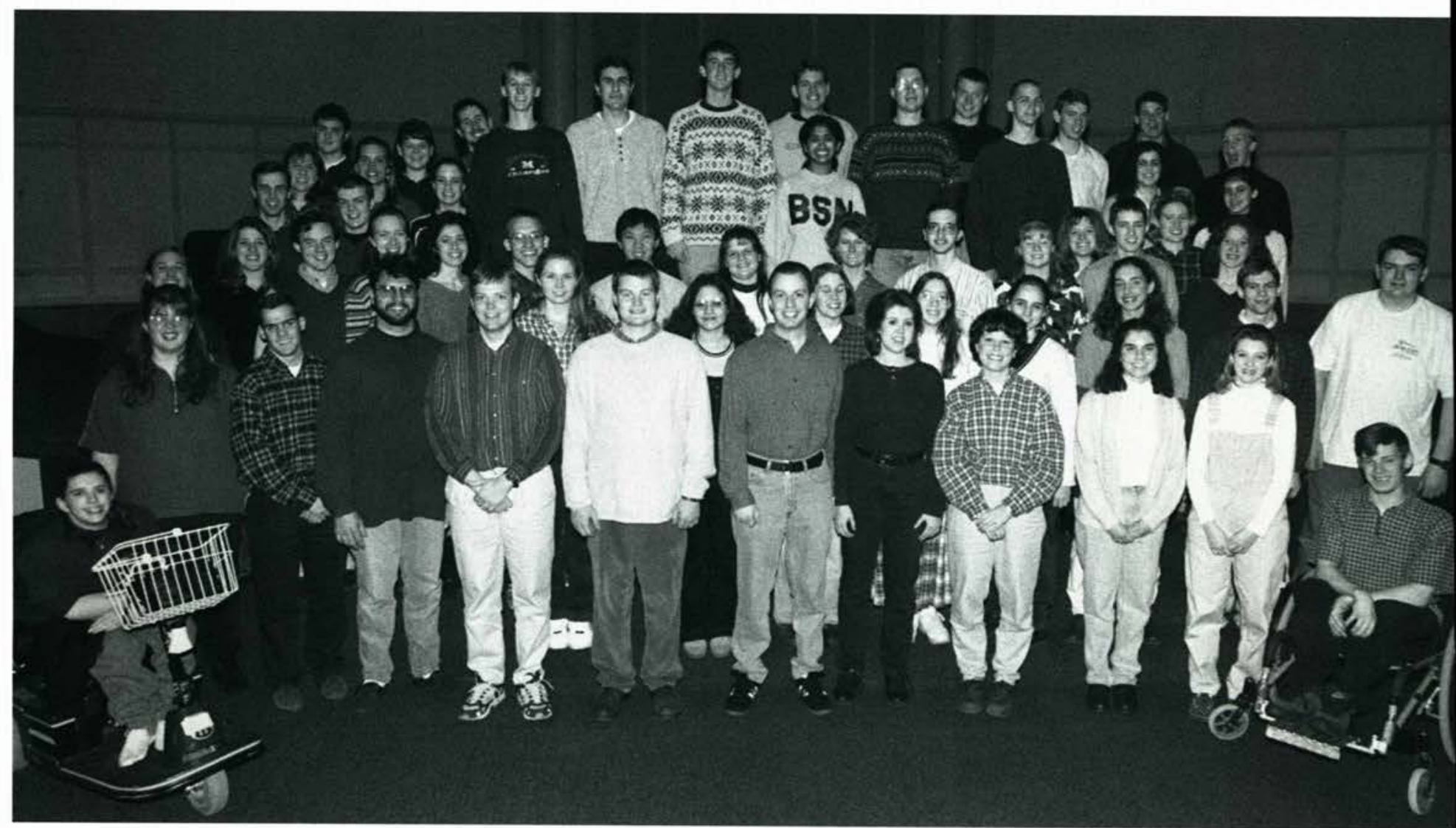

all photos by $\mathrm{DaV}$

Open Heirs

Description: Sharing the Gospel in downtown Cincinnati, Columbus and Dayton.

Front: Deborah Clingman, Melissa Dove, Josh Ausfahl, Rob Kocher, Dan Johansen, Josh Haluko. Dan Hicks, Erin Johns, Susie Dunham, Steve Lamp, Rachel Ryan, Matt Lamb, Amy Wooten, Jason Harding. Michelle Horne, Joel Hollins, John Stedge. Roberta Roe, Marlena Proper, Christina Riley, Brian Rosseau, Jessica Mathias, Jen Secor, Jodi Stone. Eddie Weniger, Carrie Miller, Stephen Kline, Matt Pederson

Back: Brooke Kessler, Stephanie Newman, Angie Tyson, Matt Edwards, Ryan Stern, Tim Abbott, Dan Bryne, Kyle Kickbusch Jared Skillings, Jaya Phillip, Brett Cooley, Rob Bouwens, Sam Jolman 


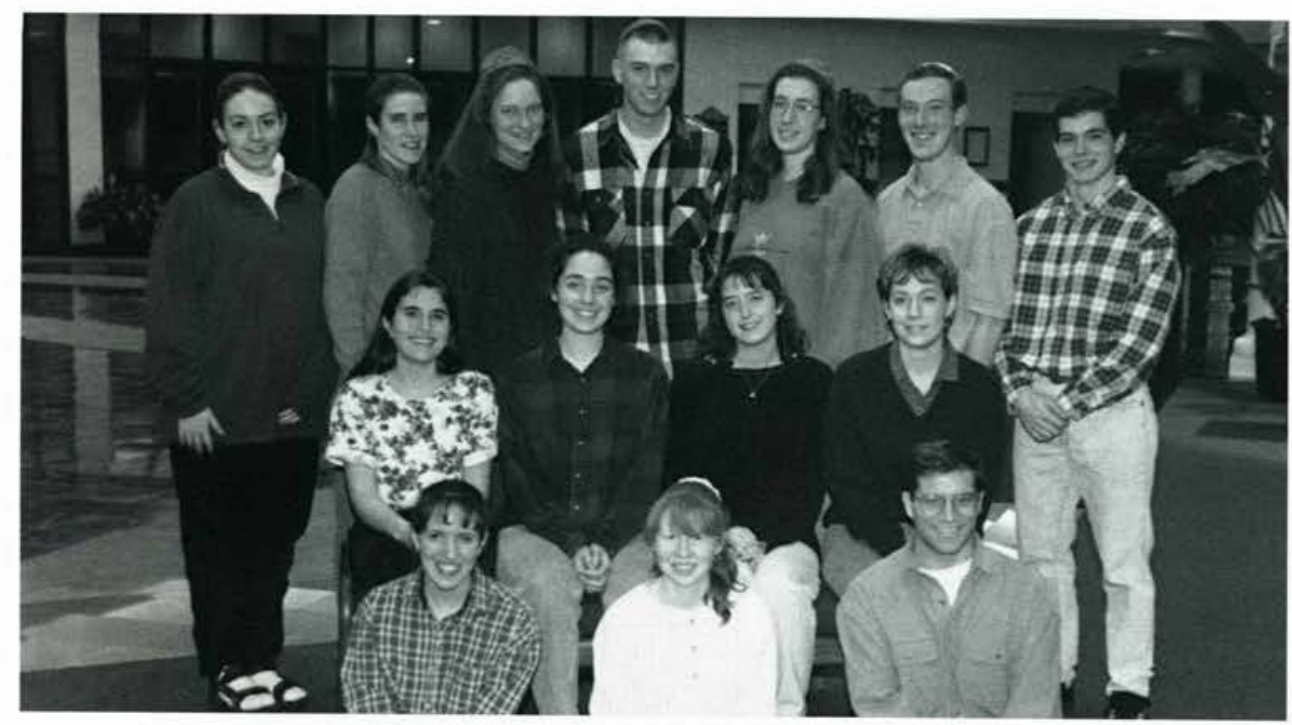

\section{Zion's Light Tutoring}

Description: Witness through tutoring Jewish immigrants.

F: RebekahPugno, RachelBrenge Andy Malone

M: Becky Foster, Patricia Rice AlielCunningham, HeatherFourmar B: Adaline Shultis, Michelle Bridges, Rachel Morris, Dale Sorensen, Ann Weeks, Nathar Lewis, Matthew Brown

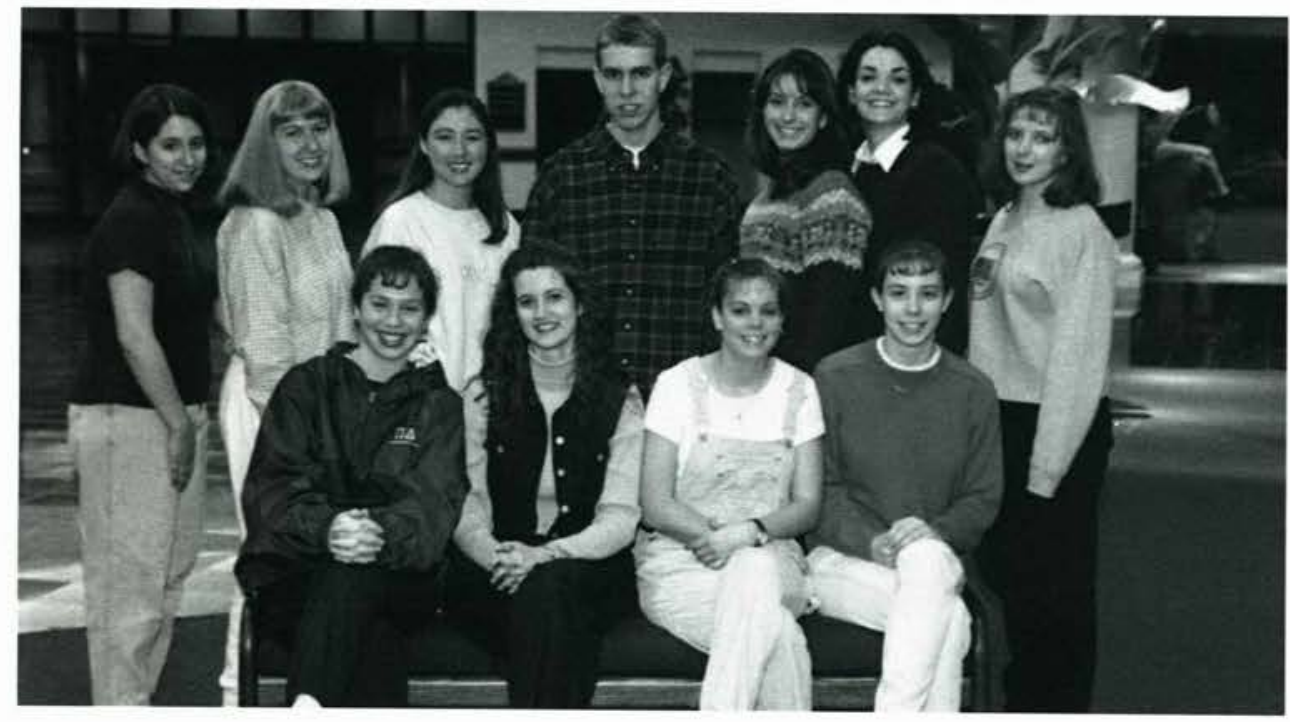

\section{Bristol House}

Description: Caring for elderly by having worship services and providing one-onone conversation.

F: Amy Clutz, Julie Armour, Susie Stout, Julie Lawitzen

B: Dayna Calise, Jennifer Davis, Jasmine Robinson, Nathan Harz Shawn Stephens, Maren Meyers. Katia Kochetova

Not Pictured: Heather Nicol, Debbie Meitzler, Laura Dolph, Karen Guikema, Andy Krum, Jennifer Willis, Christine Wiesert

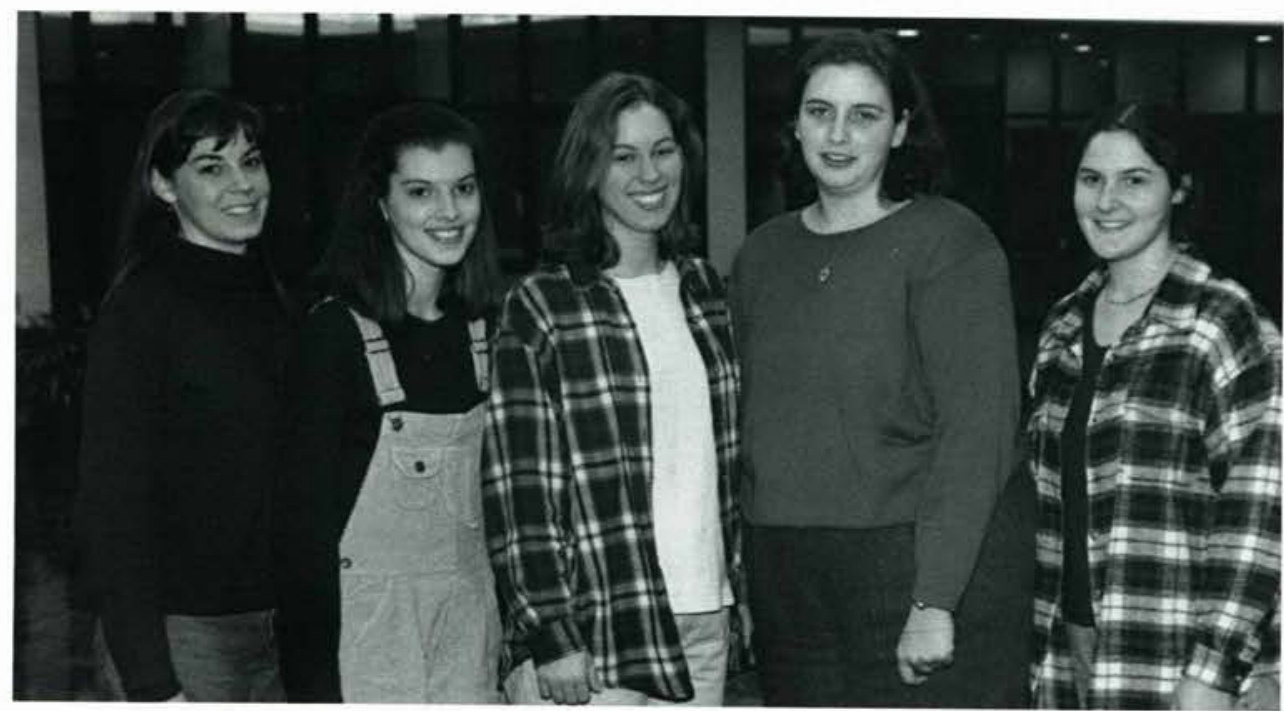

\section{CedarCliff Elderly Apartments}

Description: Caring for elderly through conversation and encouragement.

Jennifer Ferguson, Kristy Jackson, Erin Steelman, Anastasin Mobley, Sarah Ducka 


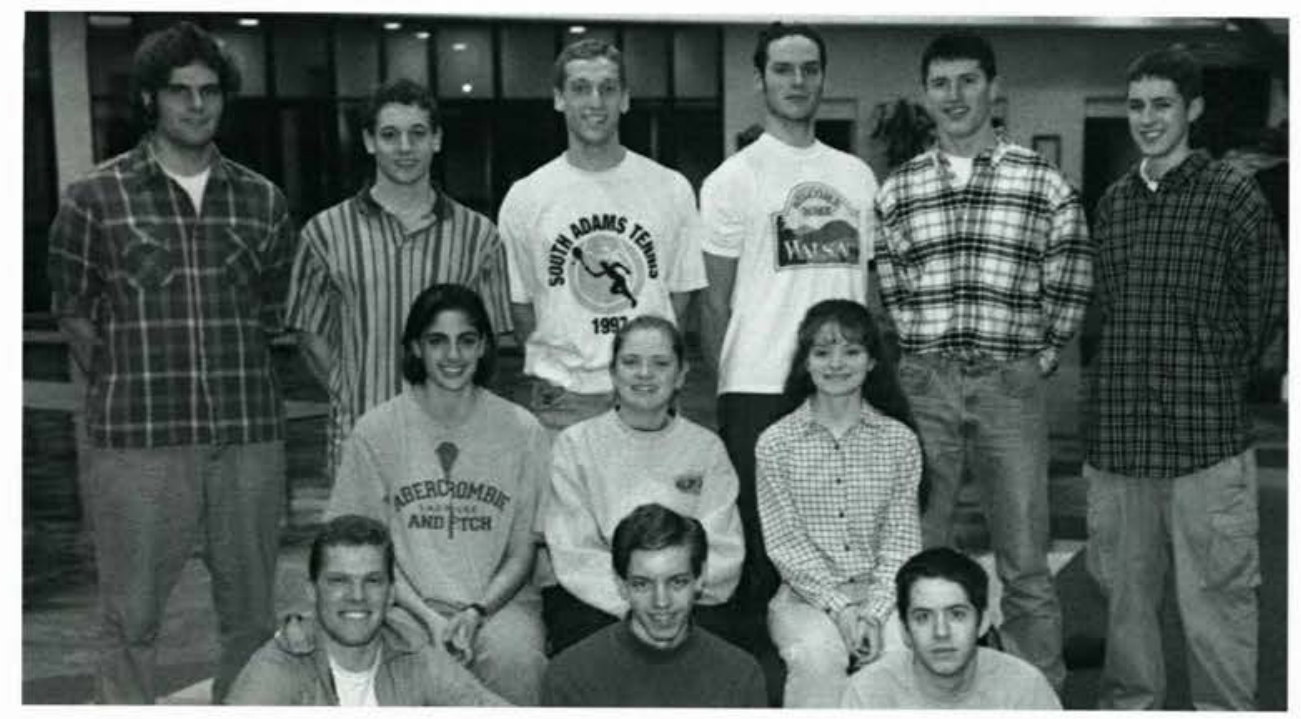

\section{Greene County Jail}

Description: Reaching out to adult and teen inmates through counseling and Bible study.

F: David Hofrt, Adam Rorex, Erid Sheldon

M: Gillian Gombis, Melliss Wabeke, Angela Meredith B: Jason Isaacs, Chris Smith Michael Wenger, David Cook Jason Alexander, Ed Weniger David Harrison

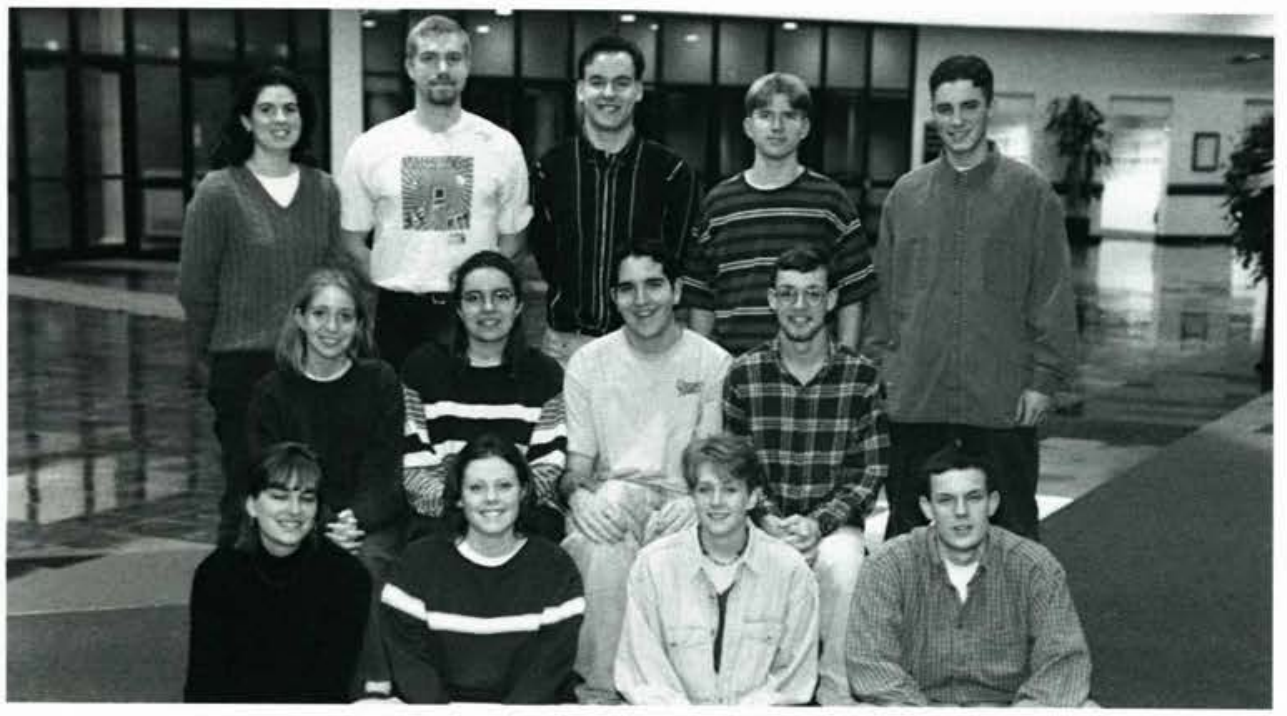

\section{Greene County Juvenile Detention}

Description: Ministering to teen inmates through counseling and Bible study.

F: Karen Jacobsen, Jenni Kerr Carrie Jones, James Klind M: Jill Breckenfeld, Lindsey Milne, Paul Gwilt, Phil Ausfahl B: Joyce Boggs, Micah Thirey, Ryan Stevens, Ken Borror, Sam Logan

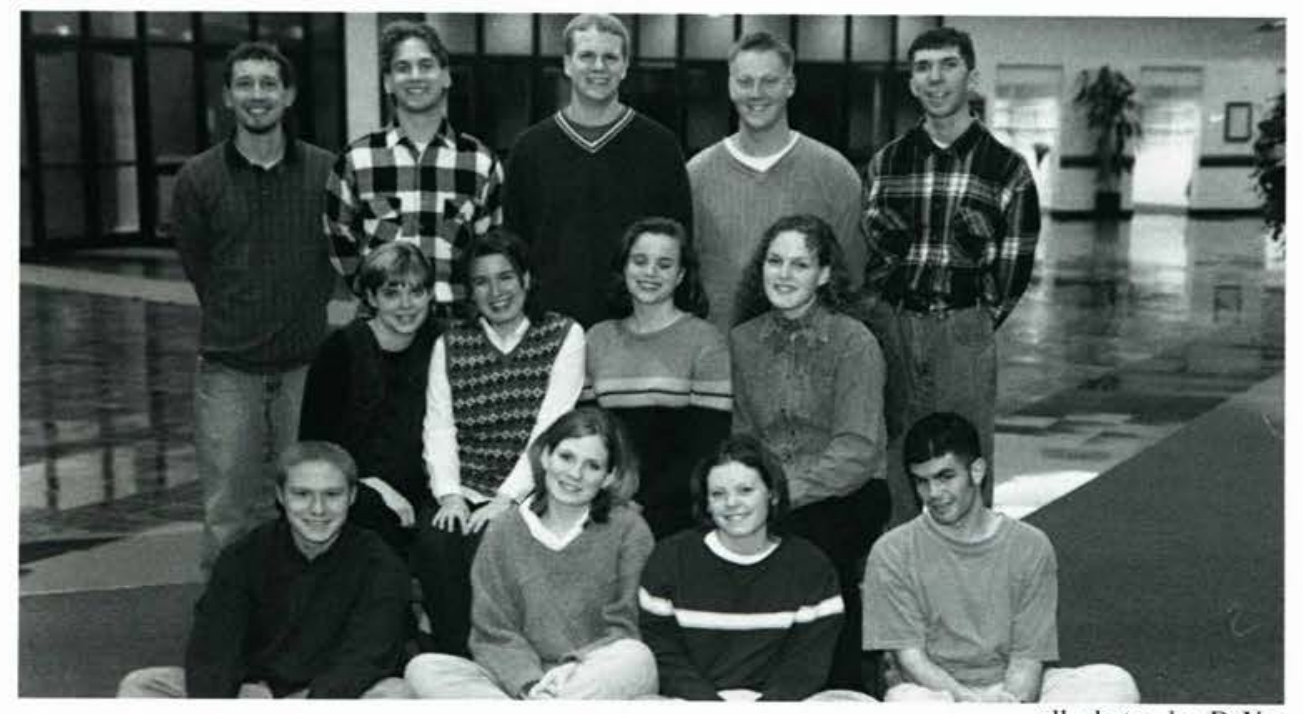

\section{Greene County Resi- dential Treatment \\ Center}

Description: Trying to rehabilitate teens through big brother/big sister ministry.

F: Jon Rauch, Haylee Biggs, Jenni Kerr, Dave Wilson

M: Marlena Bantle, Gina Doerr, Debbie Ellison, Elizabeth Barker B: Jon Schultz, Brad Neese. Michael F. Boehm, Andrew A. Hedges, Troy Pfeiffer 


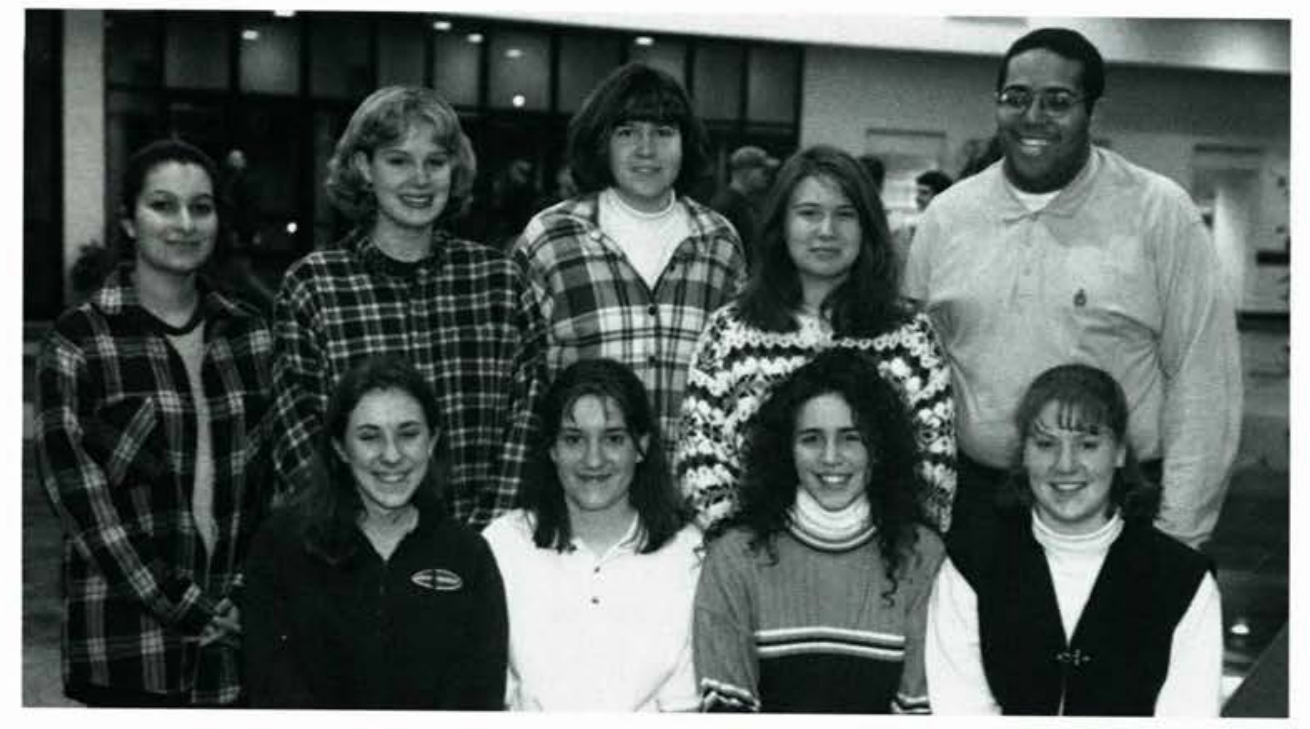

\section{Heathergreene II}

Description: Caring for elderly in a nursing home situation through conversation and encouragement

F: Sonya Foster, Sarah Martin, Geneva Roberts, Amie

Bockstahler

B: Ahlam Boland, Kathleen Pugh, Deanna Brower,

Stephanie Mace, Hugo Lopez Not Pictured: Stephanie

Newman

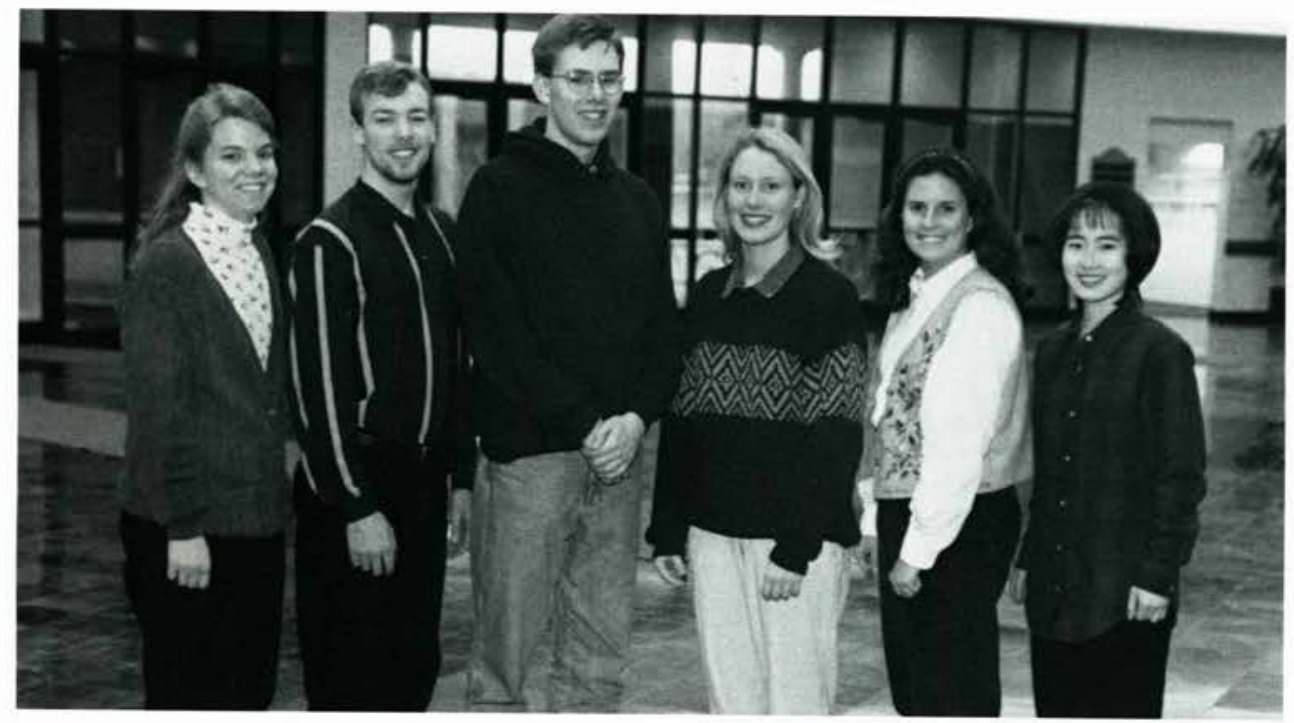

\section{Hillside Retirement Home}

Description: Caring for elderly in a nursing home situation through conversation and encouragement

Erin Tuinstra, Jim Leonard, Jonathan Neu, Holly Sorensen, Emily Alt, Cary Mesnard

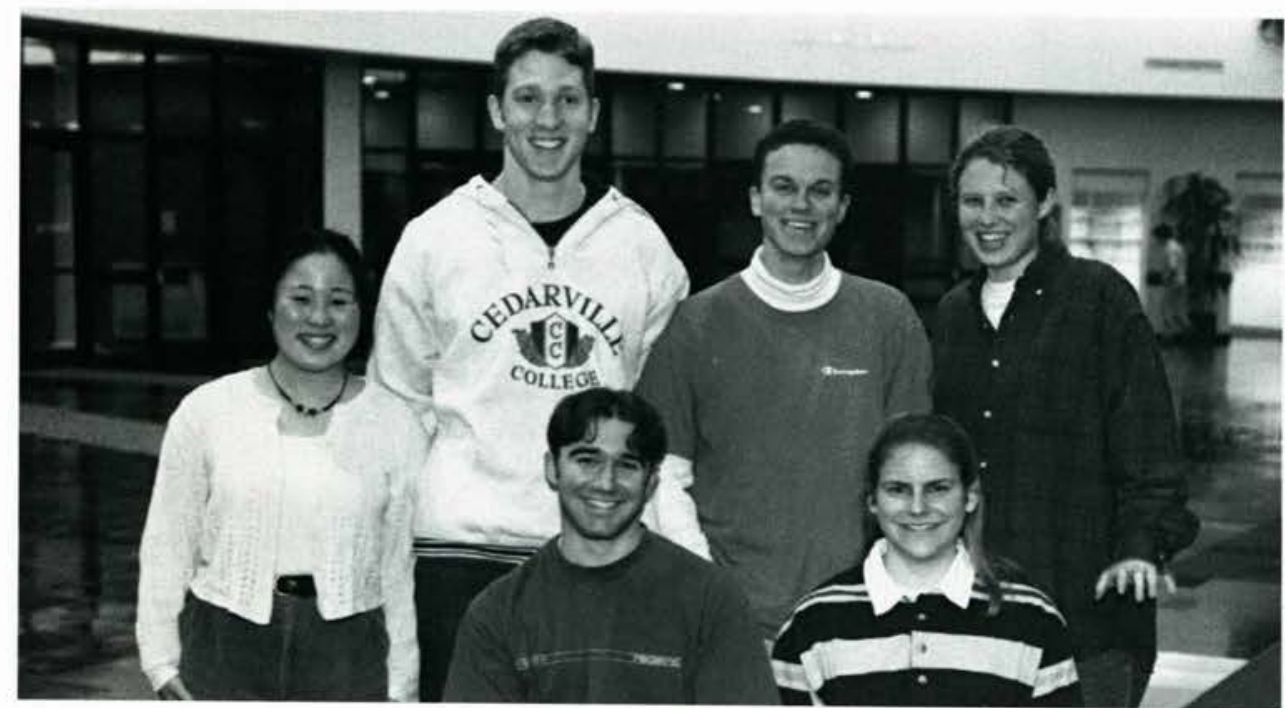

\section{IOOF}

Description: Caring for elderly in a nursing home situation through conversation and encouragement

F: Matt Huss, Kelly Reitz B: Atsuko Ohtake, J. Michael Perkins, Jason Cirone, Myra Luther

all photos by $\mathrm{DaVor}$ 


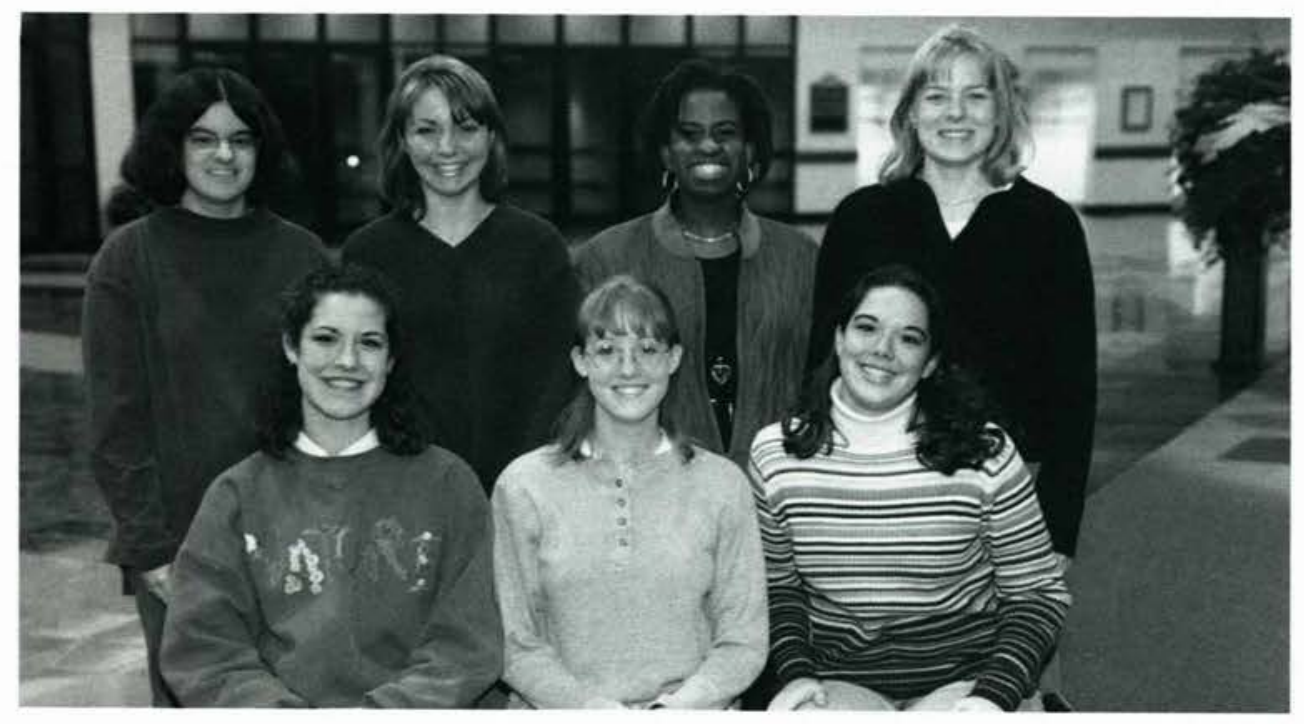

\section{Ridgewood Nursing} Center

Description: Caring for elderly in a nursing home situation through conversation andencouragement.

F: Katie Matson, Tracy Valiknac Janelle Rocke

B: Brenda Mick, Kristen Barnes, Sherri Ross, Kim Leverson Not Pictured: Jen Ament, Andrew Hedges

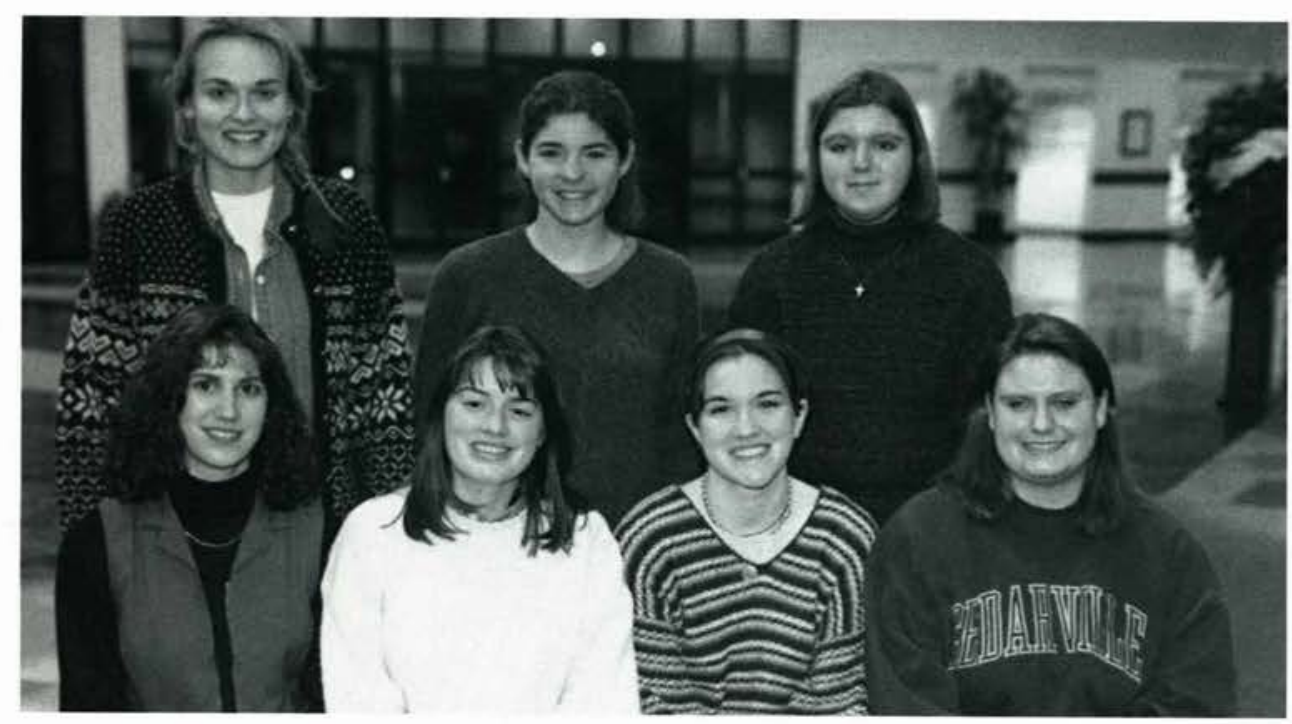

Ronald Mc Donald House

Description: Serving as host or hostess to families whose children are in the Dayton Children's Hospital.

F: Lisa Pendergrass, Ann Marie Swartz, Jackie Schaafsma, Melinda Gates B: Kim Kleiman, Sarah Pollock, Nicole Land

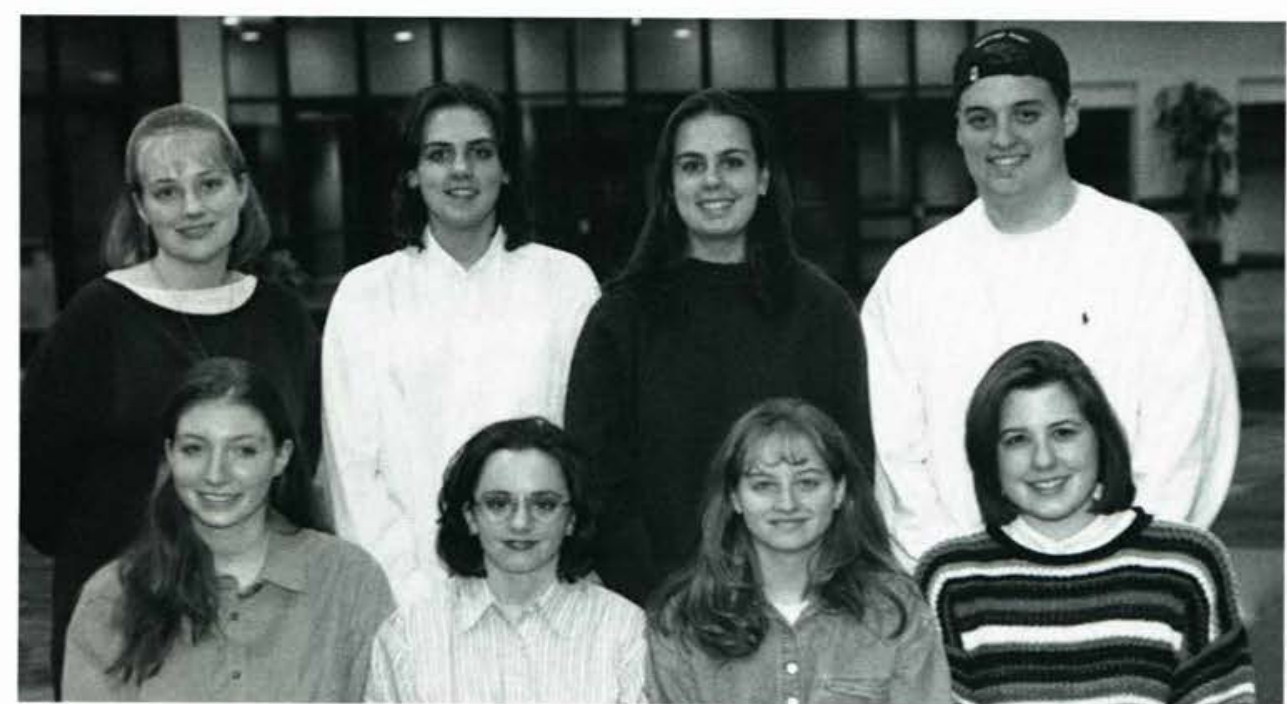

all photos by $\mathrm{DaVor}$

\section{Yellow Springs Riding Center}

Description: Using horseback riding to provide both therapy and entertainment to developmentally handicapped individuals.

F: Julie Bartlett, Michelle Miller, Beth Mills, Meredith Gross

B: Tiffany Burgett, Michele High, Kristi High, Kevin Deichert 


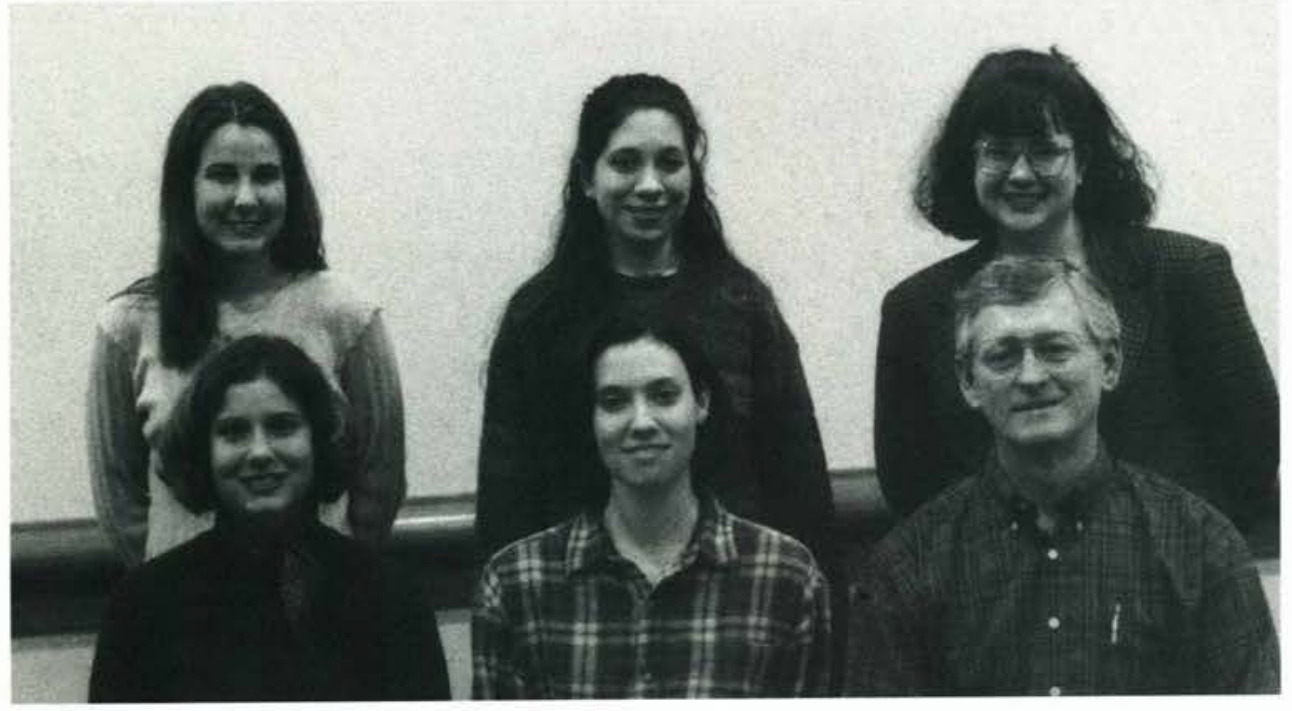

\section{Hungary Team (TESL)}

Description: Team members went to different Hungarian cities where they spent 4-6hours teaching English classes for 4-6 weeks creating contacts for a Baptist church.

F: Christy Taylor, Erica Jenkins, Dr. Merlin Ager

B: Rachelle Elder, Stephanie Crouch, Christy Cleaver

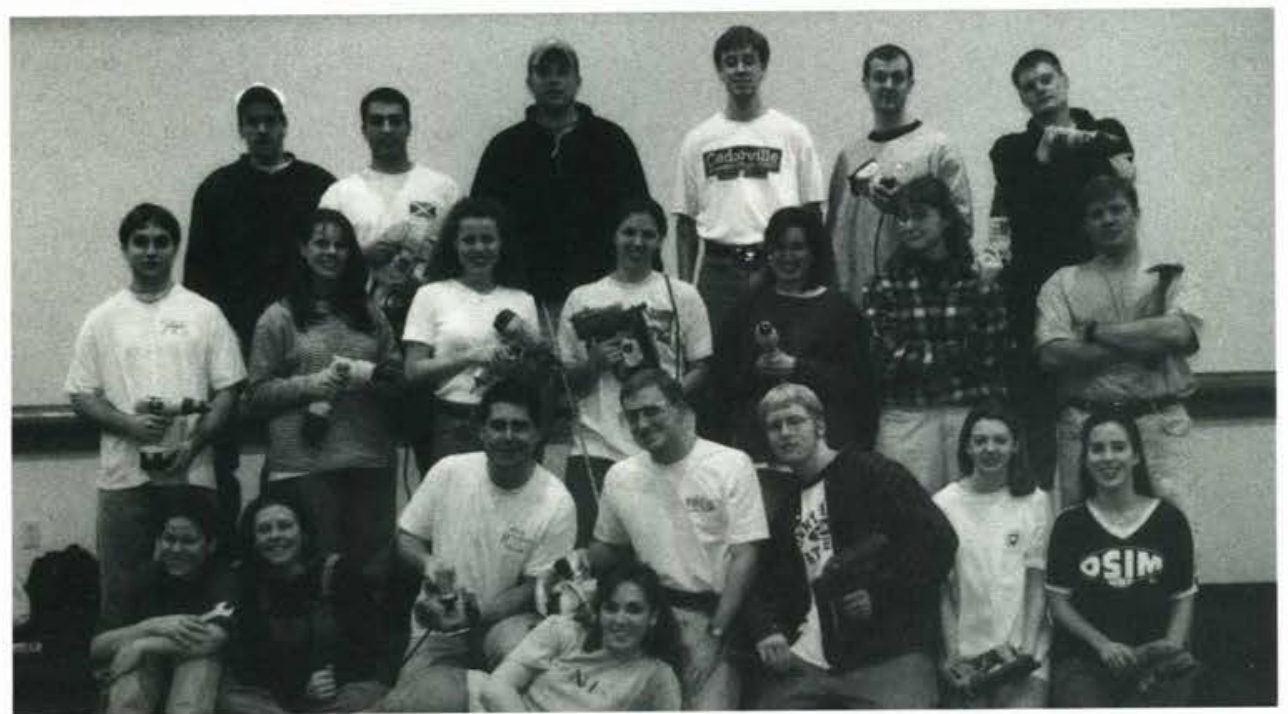

\section{Jamaica- Spring Break}

Description: Teammembersspent 10 days at the Christian Centre for the Deaf constructing a new dorm for up to 100 new students.

F:Sundi Myers, Jenni Kerr, Jeff Beste, Paul DeKruyter, Ryan Cook, Amy Wooten, Aimee Copeland M:Mark Clark, Kristi Gleason, Elisabeth Morris, Leanne Heath. Gina Doerr, Shelly Yahara, Jim Amstutz B:RobScott.Scott Lehr, Paul Rutila, Ben Forshee, John wambold, Josh Halulko

In front: Rachel E. Stewart

\section{Togo Nursing Team-} Spring Break

Description: This five-member team spent five weeks at an ABWE missions hospital in Togo. West Africa.

F: Holly Wilson, Tabitha Sheen, Renee Francis

B: Nathan Payne, Chris Brinkley 


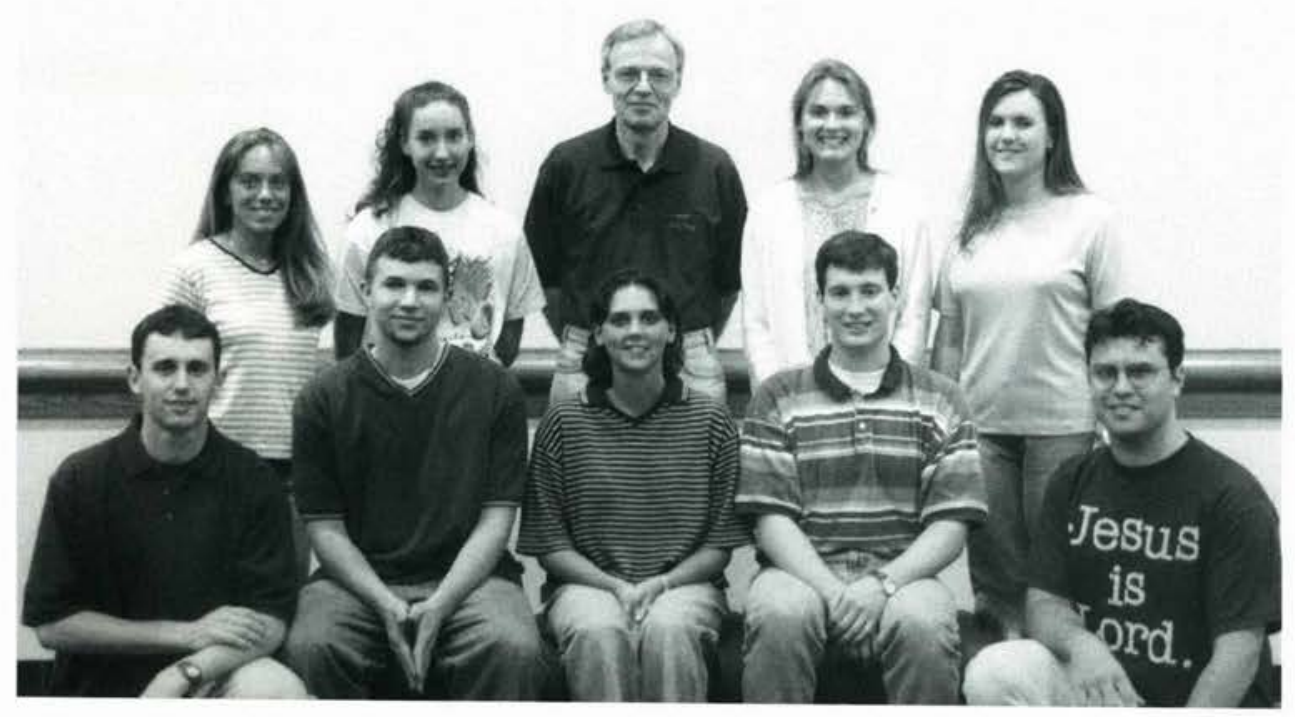

\section{Amazon}

F: Micah Roberts, Tim George, Michele High, Richard Porter, Rob Kocher

B: Dena Assid, Rachel Ryan, Pastor Rohm, Kim Kleiman, Jayme Brower

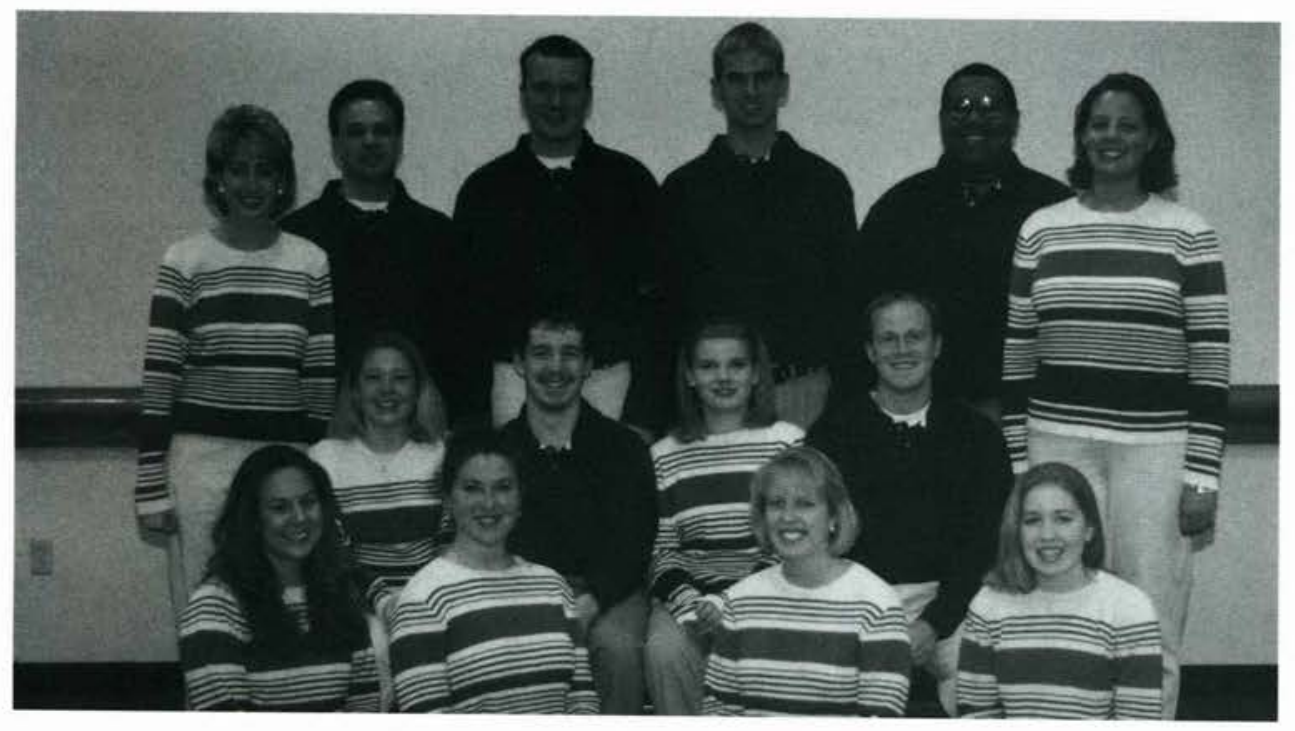

\section{Australia}

F: Kristina Bilodeau. Andrea Endicott, Becca Blackburn, Julie Finnigan

M: Carrie Fabian, Zach Rhodes, Jessica Meissner, Rick DeWalk

B: Lori Sutherland, Bob Sutherland, Greg Larson. Grady Peeler, Michael Dorsey, Mandy Hlad

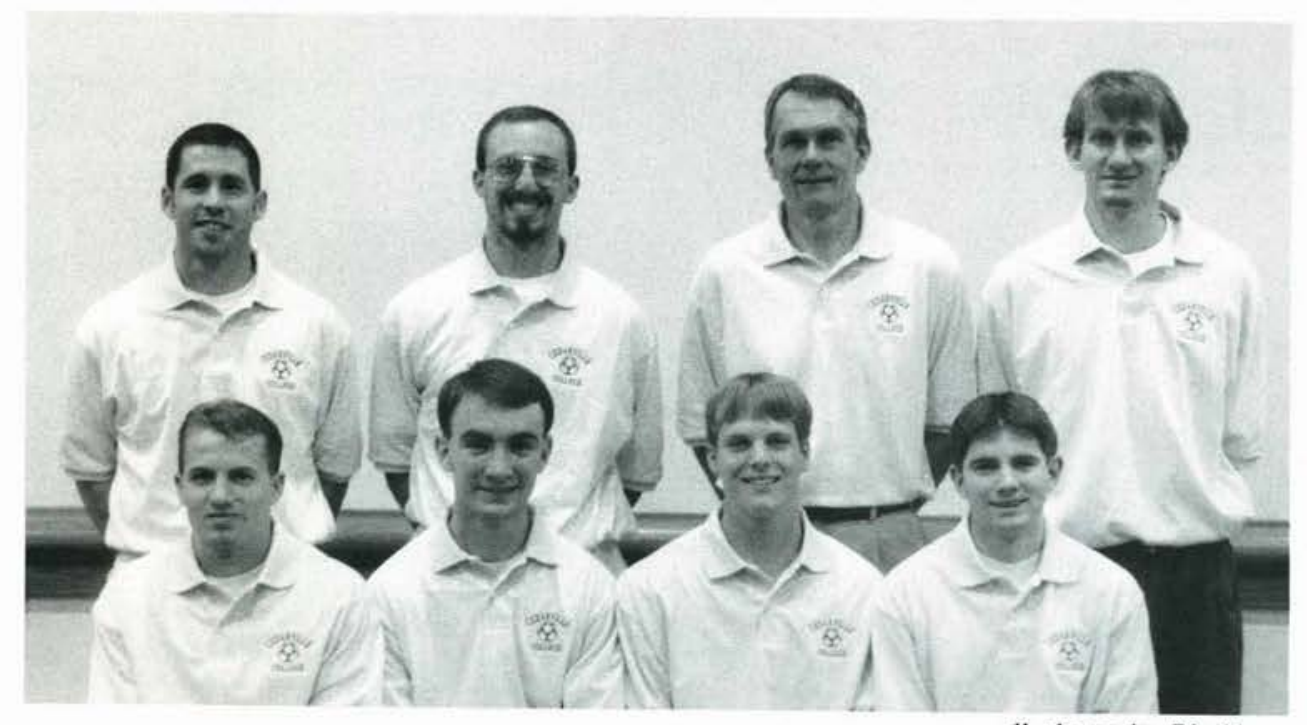

\section{Bangladesh}

F: Duane Hammond, Will Scotten, Christopher Brock, Russell Pound

B: Roger Swigart, BJ Bechtel, John McGillivray, Chad Deakyne

Not pictured: Jim Hunter, George weber. Peter Warinsee 


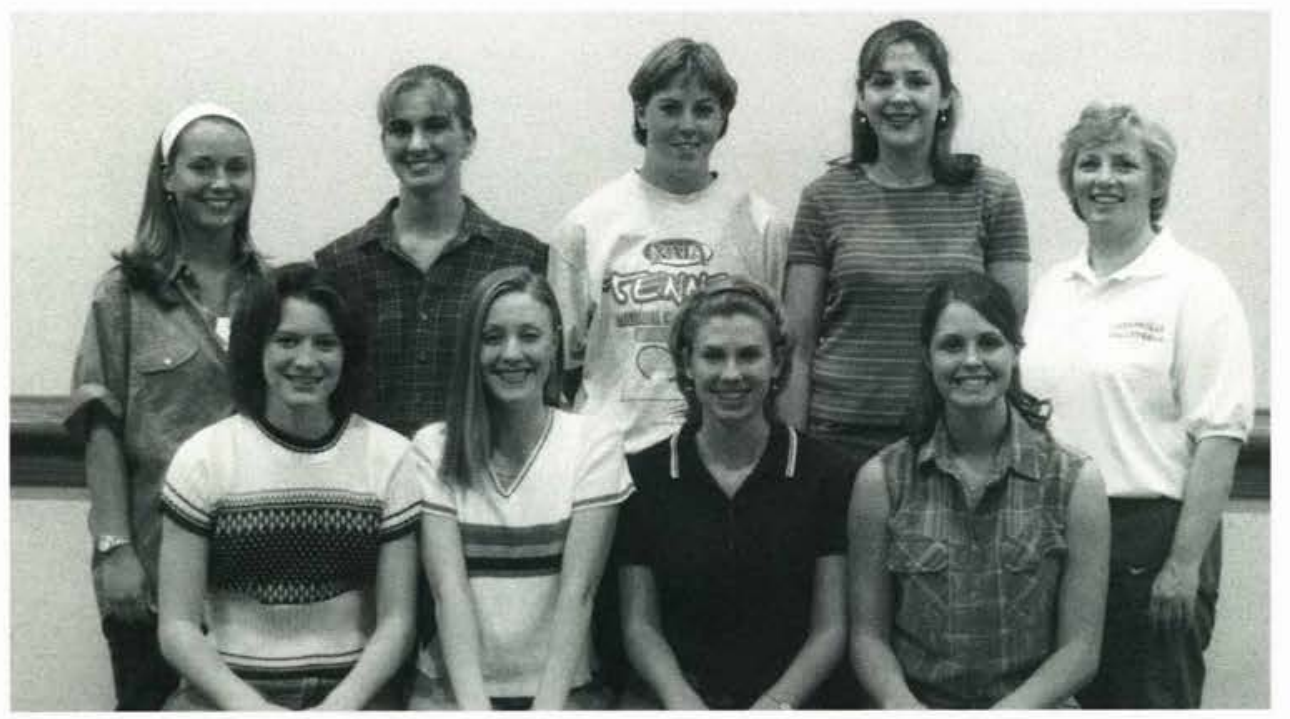

\section{Dominican Republic}

F: Jessica Stevenson.

Jennifer Hangosky, Pam Huls, Lori Bunger

B: Amber Corbin, Robyn Heffner, Casey Ruffin, Kathy Johnson, Coach Teresa Clark

Not pictured: Suzanne Lehman
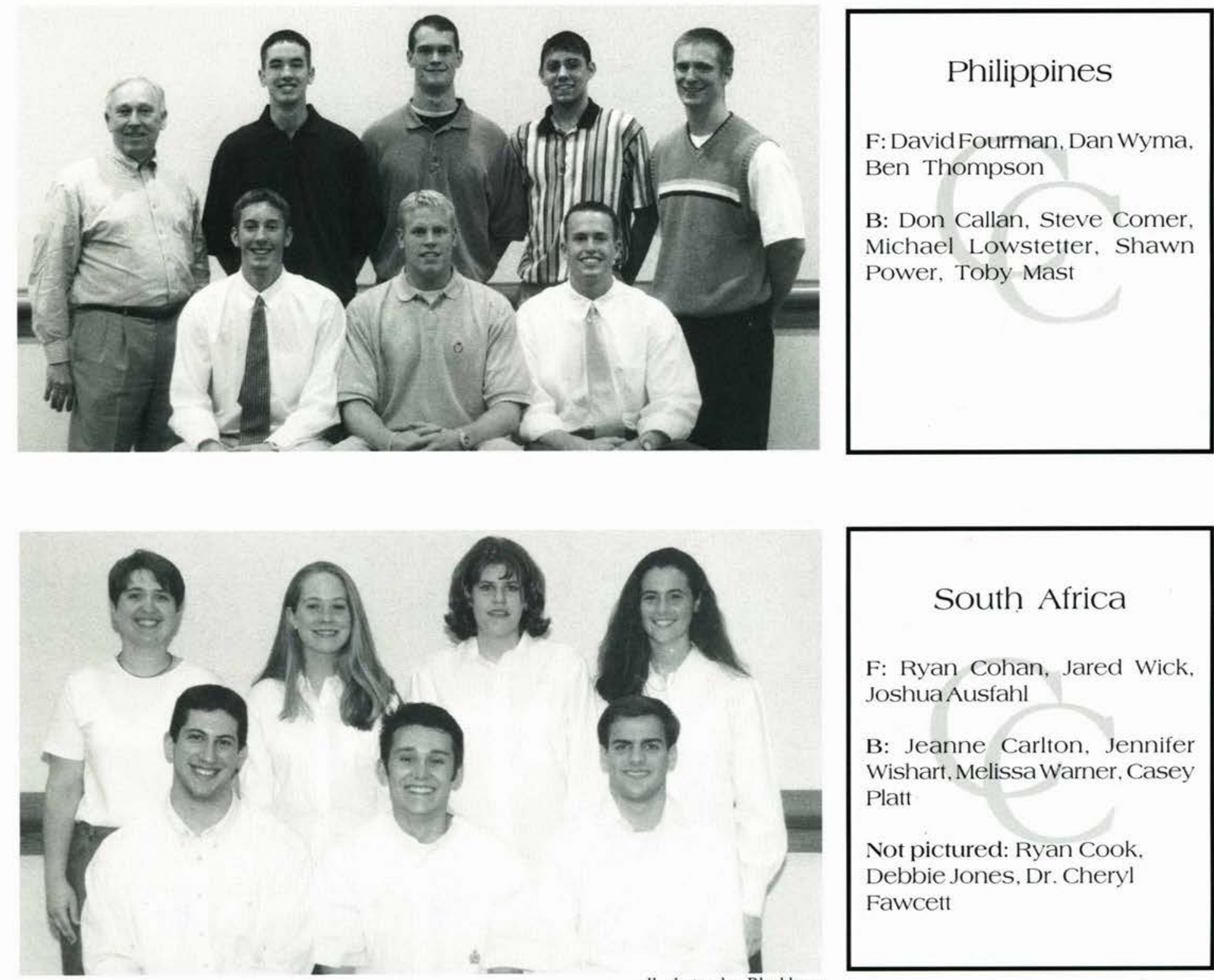

\section{South Africa}

F: Ryan Cohan, Jared Wick, Joshua Ausfahl

B: Jeanne Carlton, Jennifer Wishart, Melissa Warner, Casey Platt

Not pictured: Ryan Cook. Debbie Jones, Dr. Cheryl Fawcett 


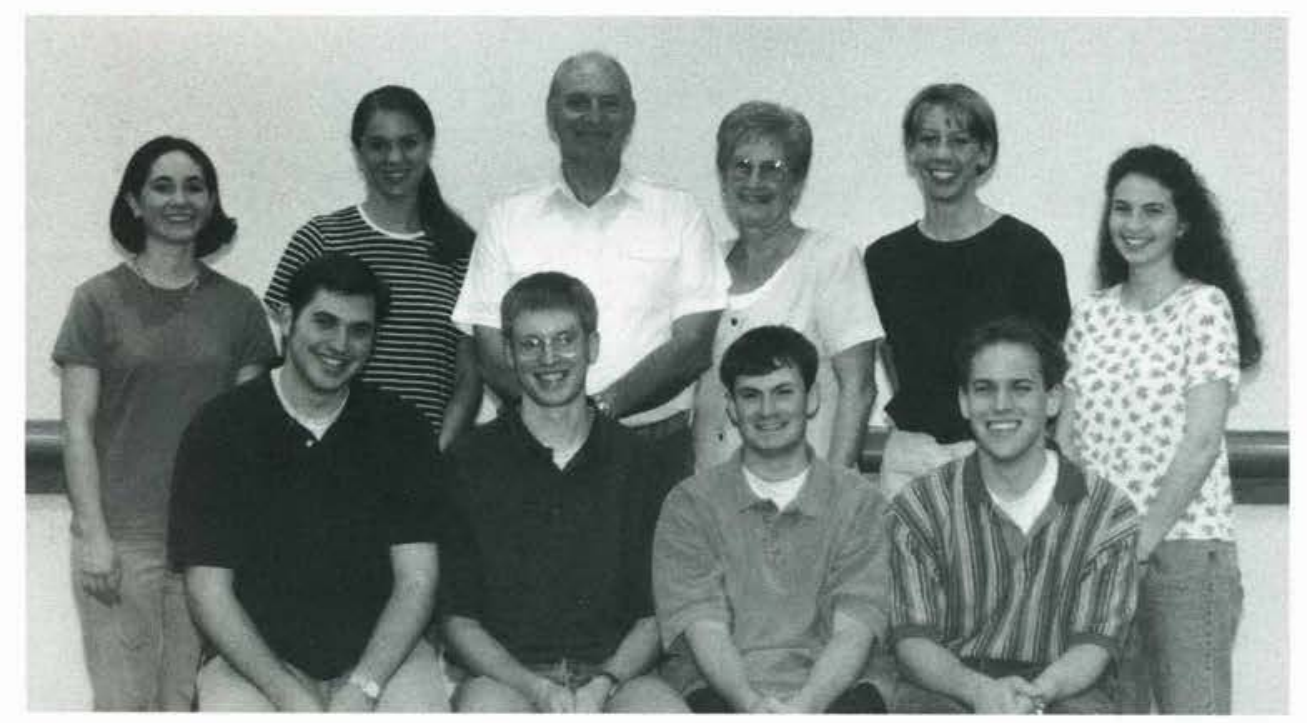

\section{Russia (Far East)}

F: John Botkin, Josh Michael, Philip Thorsen, Bill Fischer

B: Pamela Bower, Sarah High, Doc Lancaster, Joan Lancaster, Jennifer Howell. Charity Rizer

Not pictured: Bob Johnson, Aaron Berning, Karl Feucht

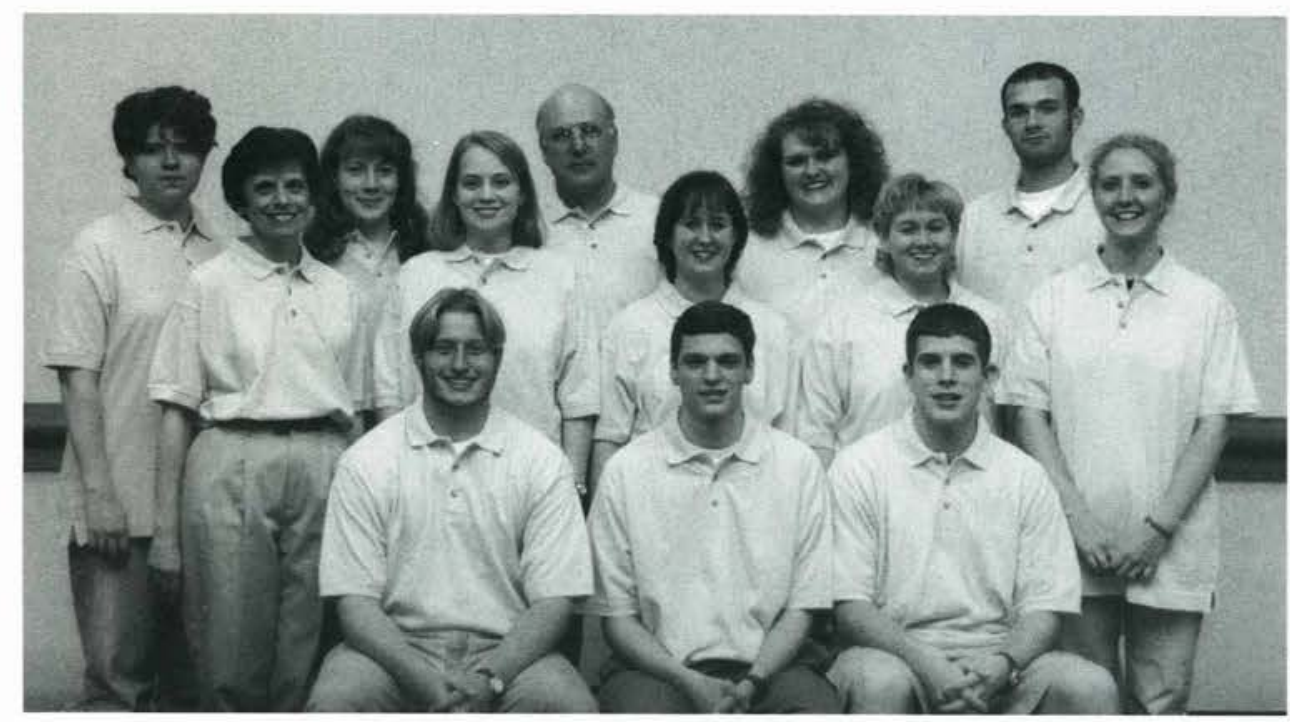

\section{Germany}

F: Todd Mitchell, Jonathan Fuge, Karl Feucht

M: Becky walker, Tiffany Burgett, Megan Schier, Alissa Williams, Beth Vencill

B: Jill Townsend, Rebecca Ritzel, Ron walker, Heather Murdoch, Scott Walker

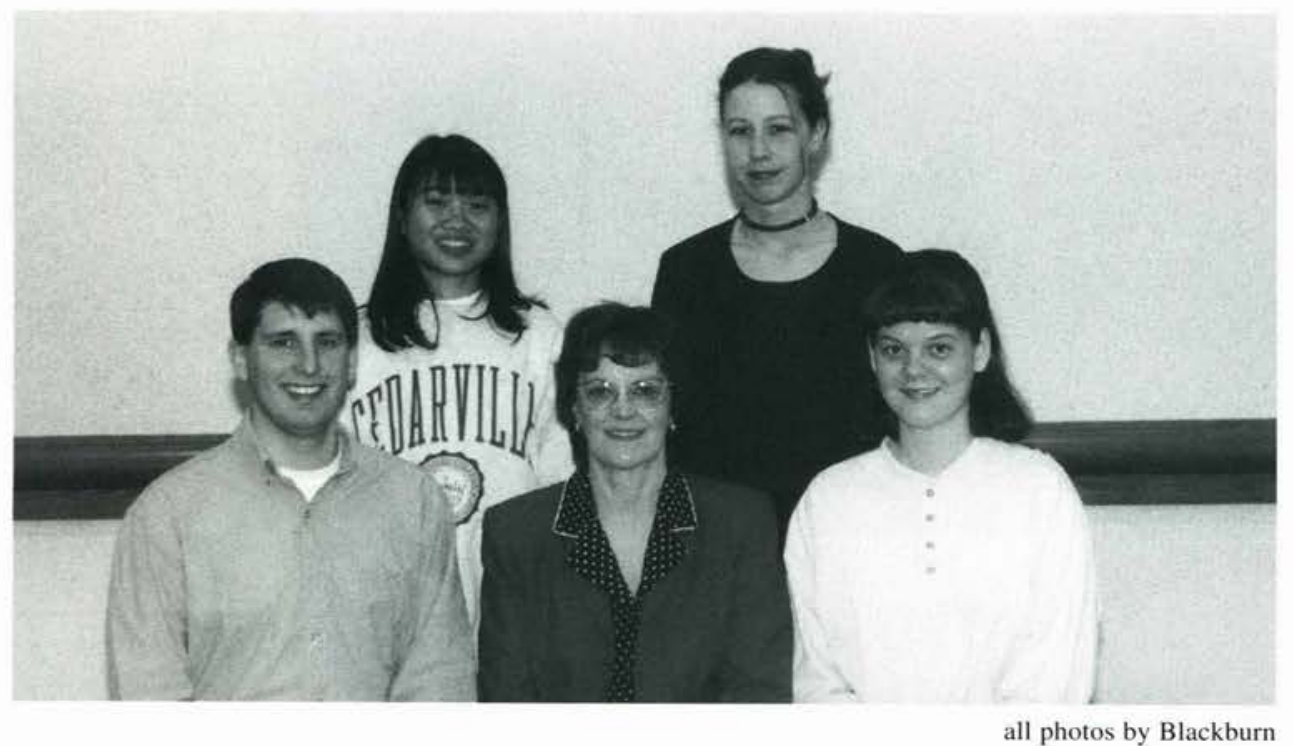

\section{China}

F: Tim Flowers, Beverly Monroe, Alicia Baisley

B: Esther Loh, Melisa J. Haynes

Not pictured: Kelly Ford, Lesley Grow, Melissa Hively, Kristin Rosner, Amy Hutchison, Ben watson, Jonathan wu 


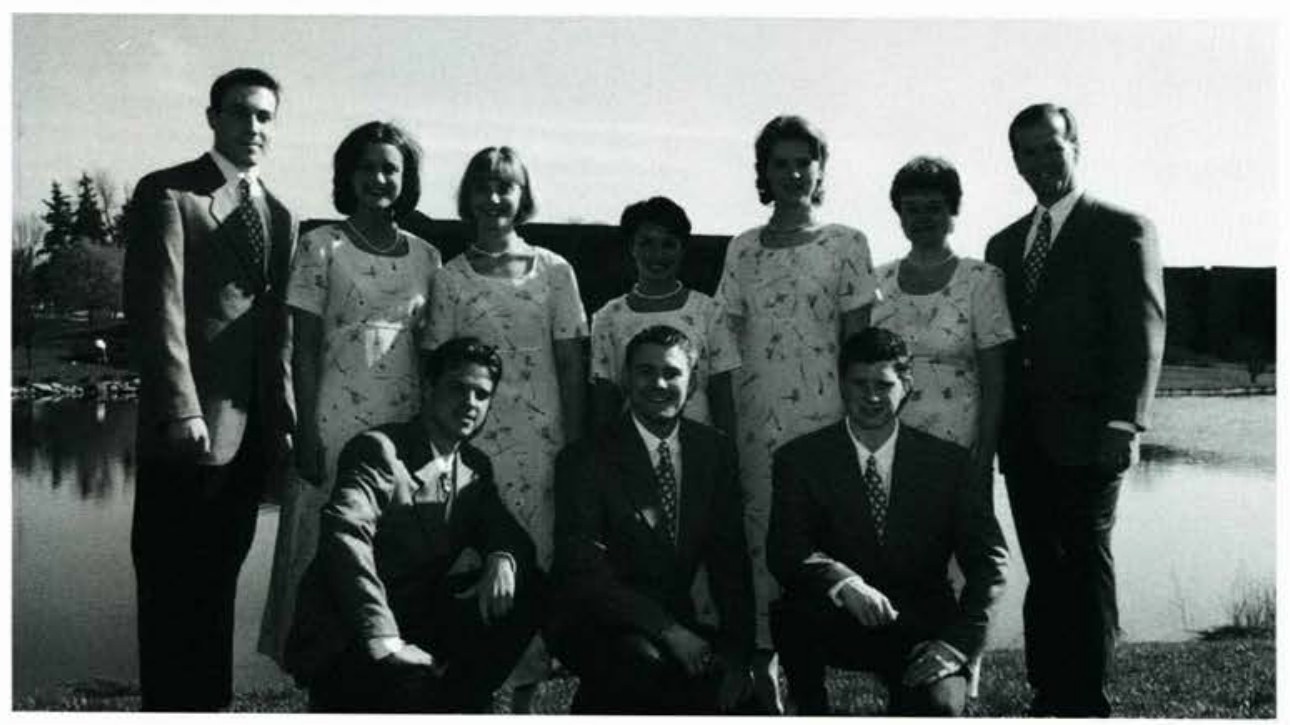

\section{England}

Standing (l-r) - Chris Pierre, Lori Brown, Heidi Jo Dean, Joanna Houck, Jessica Wagner, Mrs. Robey, and Dr. Robey (team leader)

Kneeling - Dave Henderson, Daniel Scott, and Jeremy Brown

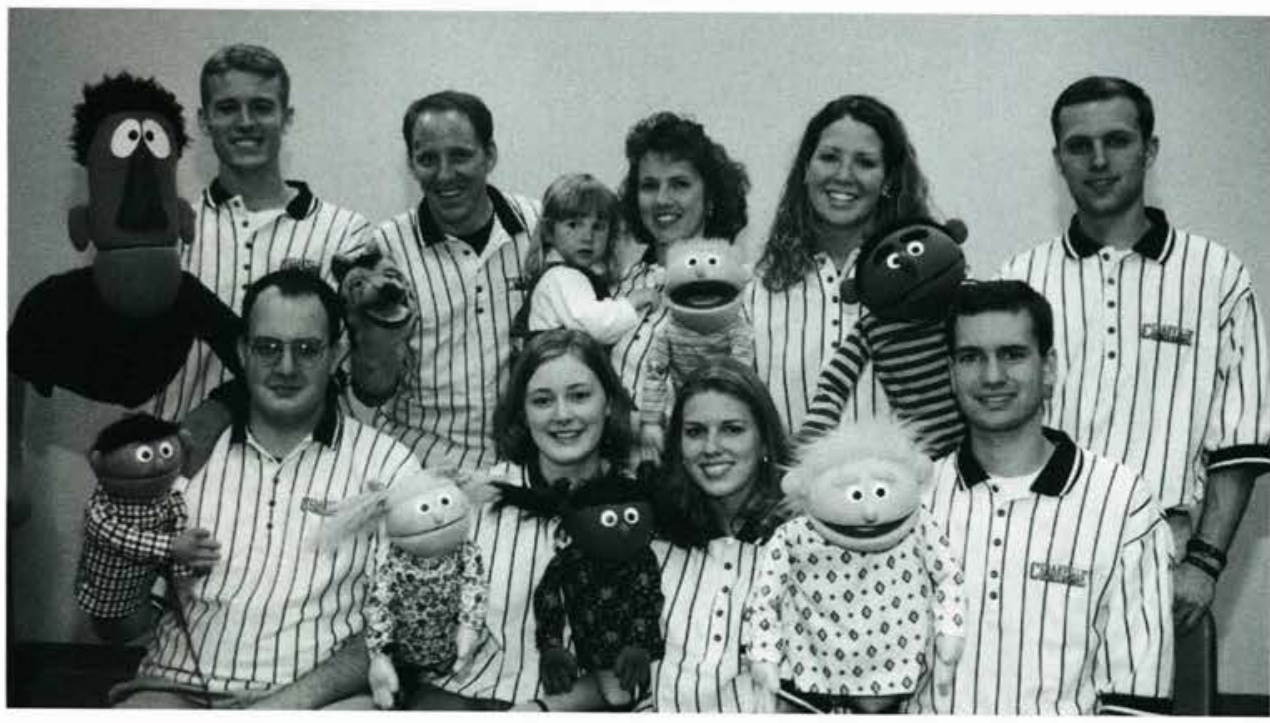

\section{Italy}

Standing - Chad Foerch, Scott Huck, Roxy Huck holding Abigail Huck, Becky Shuring, Kyle Miller

Sitting - Eric Brock, Melissa Anderson, Kristie Miller, Jordan Patrick

all photos by Huck
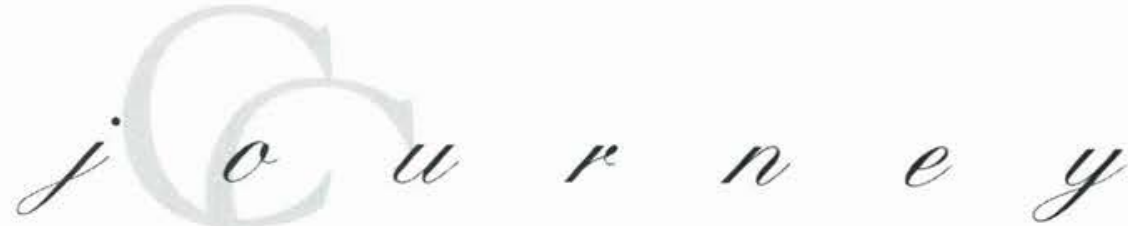
Magdalene and the other Mary went to look at the tomb. There was a violent earthquake, for an angel of the Lord came down from heaven and, going to the tomb, rolled back the stone and sat on it. His appearance was like lightning, and his clothes were white as snow. The guards were so afraid of him that they shook and became like dead men. The angel said to the women, "Do not be afraid, for I know that you are looking for Jesus, who was crucified. He is not here; he has risen, just as he said. Come and see the place where he lay. Then go quickly and tell his disciples: 'He has

risen from the dead ahead of you into you will see him.' you." So the women from the tomb, afraid and ran to tell his denly Jesus met ings," he said. They clasped his feet and Then Jesus said to afraid. Go and tell to Galilee; there they While the women way, some of the and is going Galilee. There Now I have told hurried away yet filled with joy, disciples. Sudthem. "Greetcame to him, worshiped him. them, "Do not be my brothers to go will see me." were on their guards went into the city and reported to the chief priests everything that had happened. When the chief priests had met with the elders and devised a plan, they gave the soldiers a large sum of money, telling them, "You are to say, 'His disciples came during the night and stole him away while we were asleep.' If this report gets to the governor, we will satisfy him and keep you out of trouble." So the soldiers took the money and did as they were instructed. And this story has been widely circulated among the Jews to this very day. Then the eleven disciples went to Galilee, to the mountain where Jesus had told them to go. When they saw him, they worshiped him; but some doubted. Then Jesus came to them and said, "All authority in heaven and on earth has been given to me. Therefore go and make disciples of all nations, baptizing them in the name of the Father and of the Son and of the Holy Spirit, and teaching them to obey everything I have commanded you. And surely I am with you always, to the very end of the age."

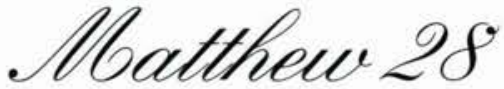




\section{Ministry Through Missions}

\section{$\mathrm{T}_{\mathrm{H}}$} missions exposure that presents a life changing experience. This year, a record 245 students traveled overseas representing Cedarville in missions involvement.

No matter the major, discipline, or talent--MIS has a place for almost every student. The unique opportunities range from paddling through the Amazon, singing in Australia, pouring concrete in Jamaica, and performing with puppets in Italy.

This summer, twenty Cedarville teams will span roughly thirty countries, not counting the individual students heading out with independent missions organizations.

The purpose of MIS is to expose students to a missions experience which will change their concept of missions, whether or not their decision is for full-time involvement. Students are trained and sent to assist the missionaries who have extended an invitation for a particular type of ministry.

Years of experience for some team leaders, as well as mission hosts, help teams develop and become a valuable asset to the established work.

Because of the college's keen interest in the development of Christian service, they maintain a full-time director for overseas missions, and in the fall, the College will add a full-time assistant director.

While everyone is excited about the number of students desiring to go on an MIS trip, each applicant is required to wait approximately two weeks for their involvement to be approved. This process is tedious, yet the department takes every measure to ensure each representative displays a servant's heart and maintains academic discipline.

The student is an ambassador for Christ and for Cedarville College, as well as for those who cannot go. The opportunity affords the challenge of letting the Lord navigate through our uncertainty. Yet, the uncertainty is worth the joy of the harvest reaped through student missions involvement.
Brian Nester (left), Director of MIS, and Ed Lewis (right), Representative for TEAM Mission, both share the desire and understand the importance of preparing students for the mission field.

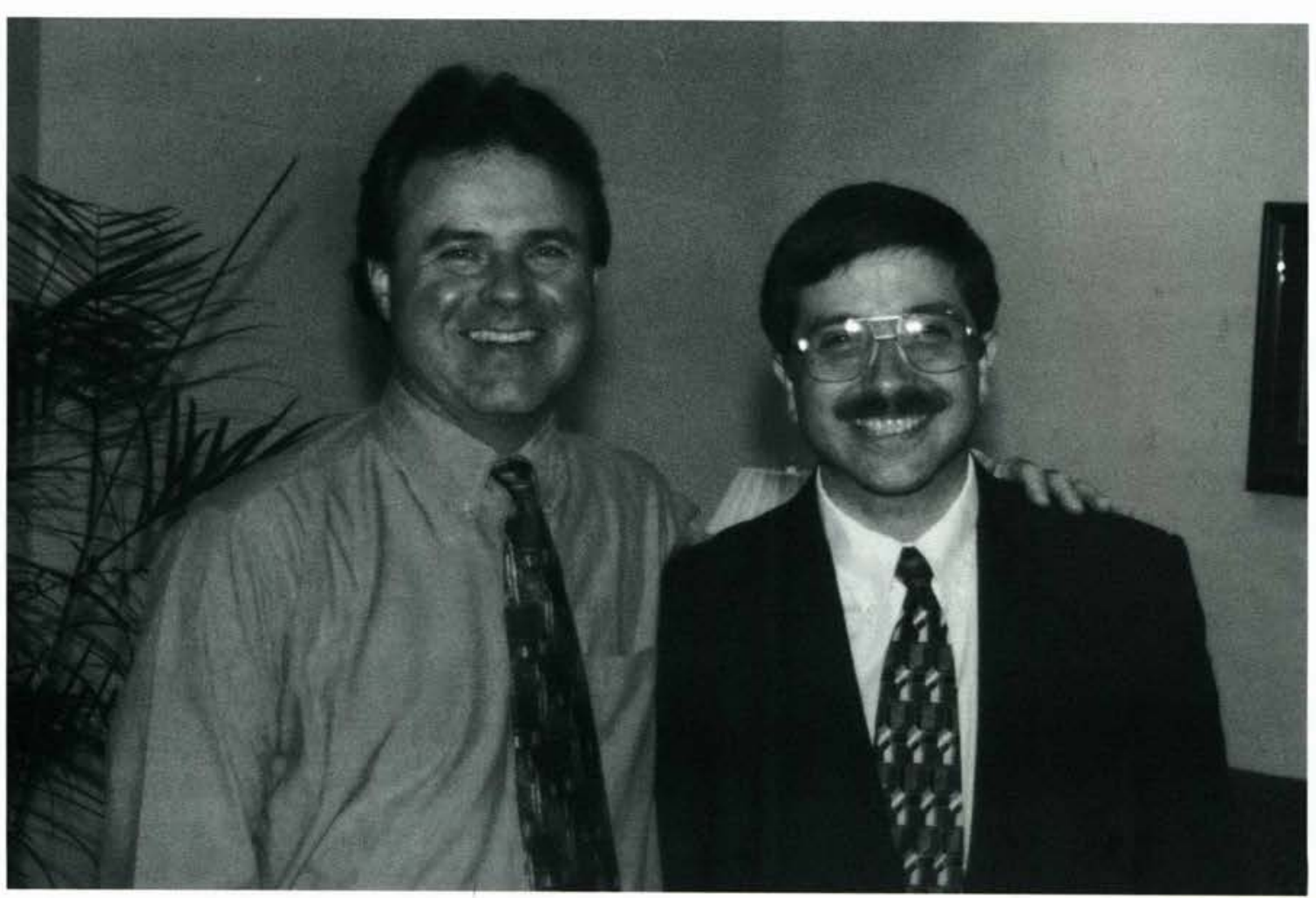




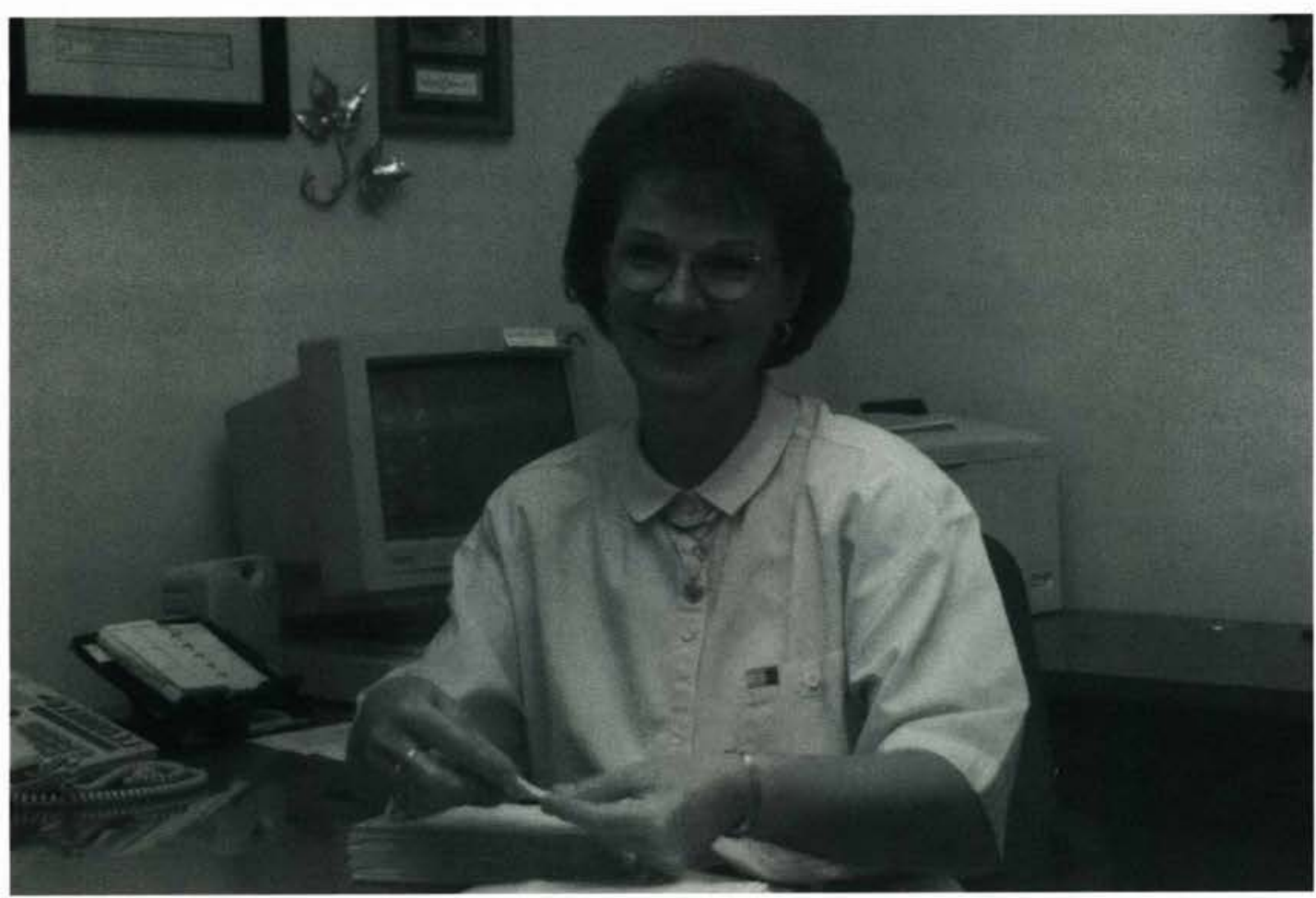

Shirley Johnson, MIS secretary, assists Brian Nester, processing Missions donations and helping organize passport photos, along with many other vital MIS duties.

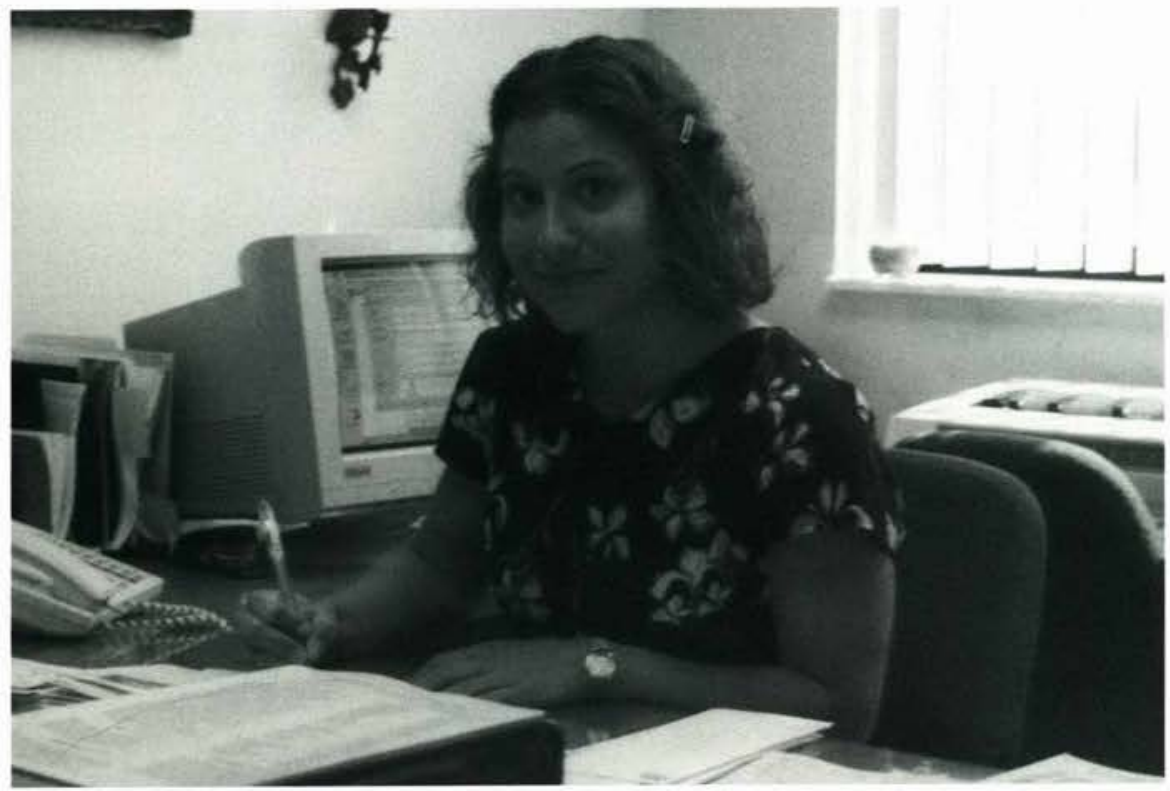

Christy Taylor, Junior MIS studentassistant, works to forward the cause of Christ through the MIS program.

This year, a record 245 students traveled overseas representing Jesus Christ and Cedarville in missions involvement. 


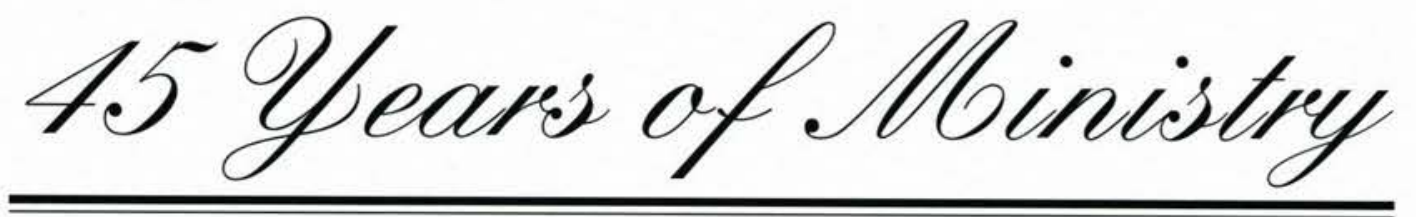

Dr. James T. Jeremiah Recognition Chapel

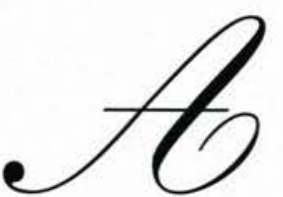

vice president for Bob Evans Farms, Inc., humorously awarded the chancellor a special Bob Evans tie and the Gentleman Farmer Award for Dr. Jeremiah's faithful patronage of his favorite restaurant. The award entitled Dr. Jeremiah to one square foot of the Dan Evans Farm in Rio Grande, Ohio. SGA president, Scott Van Loo, also awarded Dr. Jeremiah a Thomas Nelson New King James Version Bible. The Bible represents Dr. Jeremiah's work and contribution toward the development of the version.

Mr. W. Thomas Younger, former chairman of the board of trustees and current trustee of Cedarville, spoke to the audience highlighting some of the areas of Dr. Jeremiah's influential ministry. Additional honors included the an-

\section{Faithfulness to the Word of Sod and Cedarville College}

nouncement of a new scholarship bearing the chancellor's name. The scholarship will be an annual award given to a graduating senior entering seminary who intends to pursue the pastorate. This year's first recipient was senior Brian Bell who plans to attend either Dallas Theological Seminary in Texas, on Master's Seminary in California.

In April, the trustees voted to give Dr. Jeremiah his choice of condominiums in California, which will allow him to spend three months of the year with family. This announcement was made during the chapel, as well as the presentation of a box of letters from various college family members expressing their gratitude and appreciation to the chancellor. A commemorative painting displaying the various aspects of Dr. Jeremiah's 45 years of ministry at Cedarville College was the final presentation and gift.

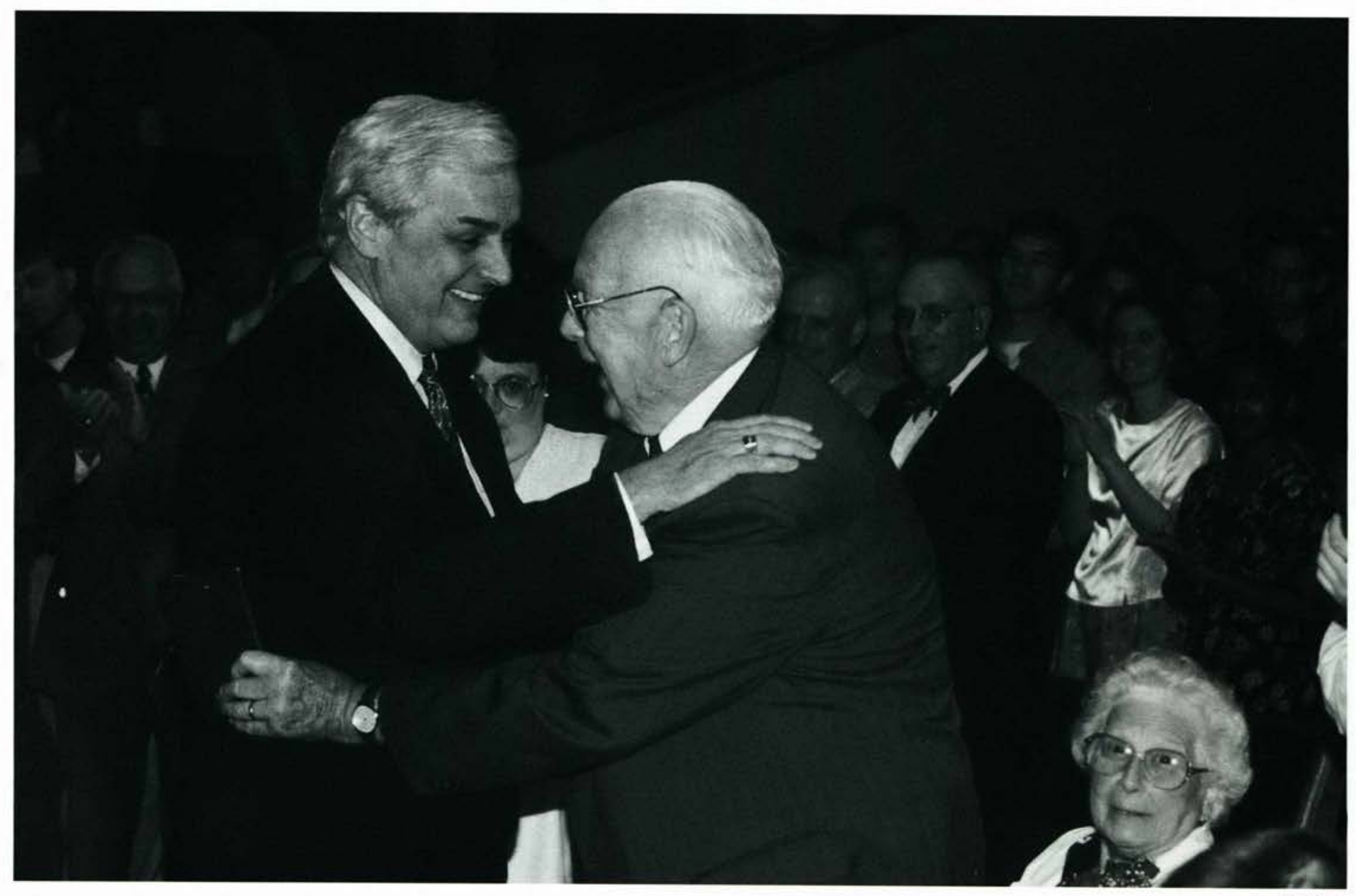

O) r. Jeremiah (right) and his son, Dr. David Jeremiah (left), Perkins family and friends recognize their efforts. 
Dr. Jeremiah is humorously awarded a special Bob Evans tie and the Gentleman Farmer Award for his faithful patronage of his favorite restaurant. (left)
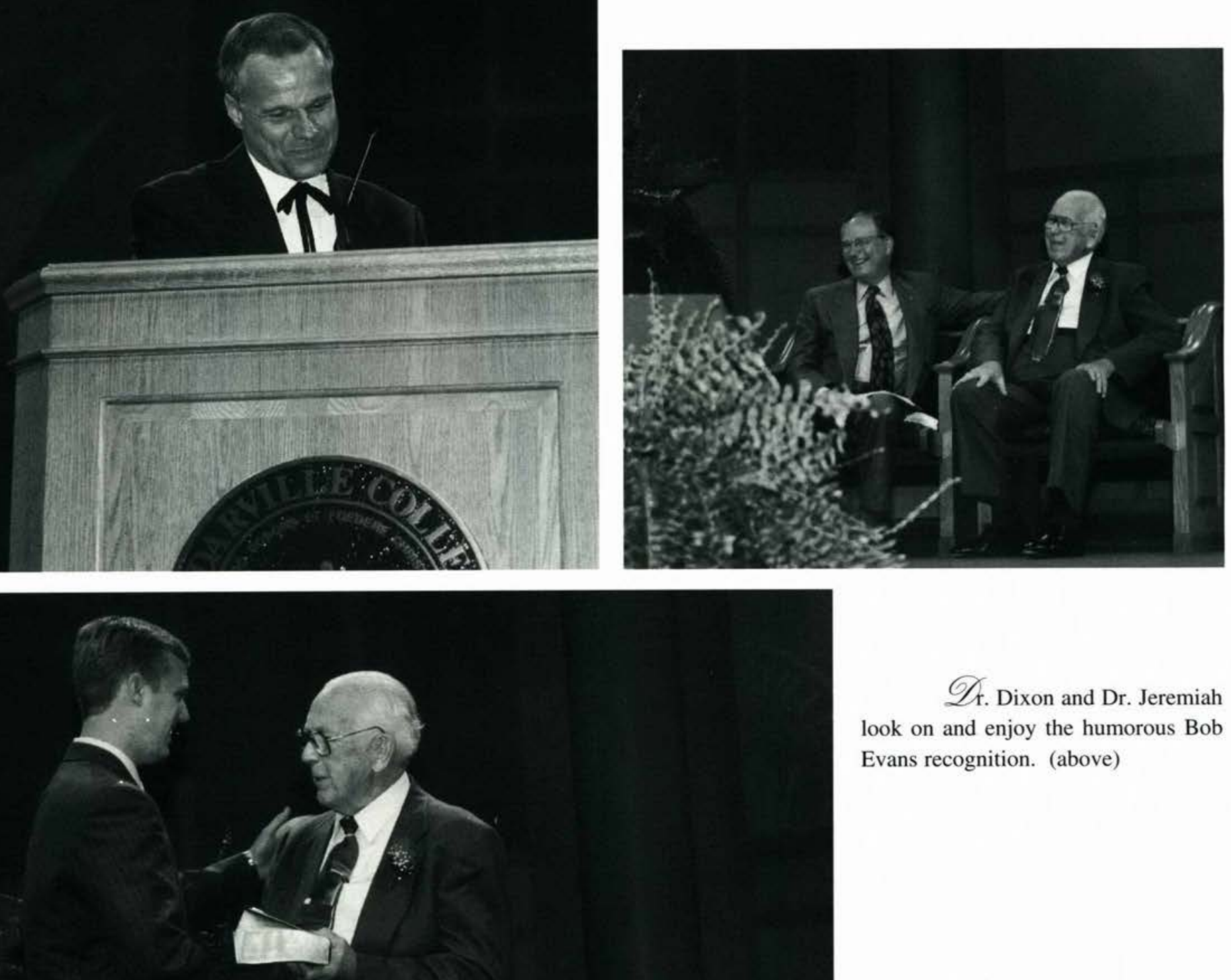

Qr. Dixon and Dr. Jeremiah look on and enjoy the humorous Bob Evans recognition. (above)

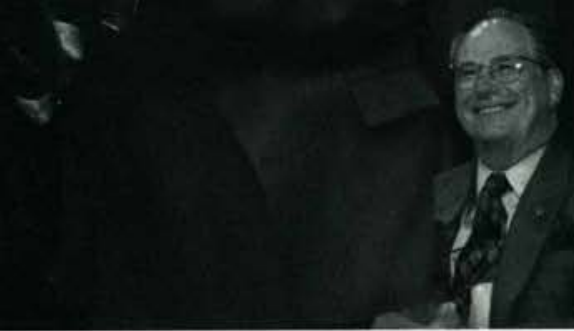

S. G.A. President, Scott Van Loo recognizes Dr. Jeremiah's valiant effort as he contributed to the publication of the New King James Bible. (left)

\section{A special thank you to Dr. James T. Jeremiah for 45 years of dedicated ministry for Jesus Christ.}


CAMPUS

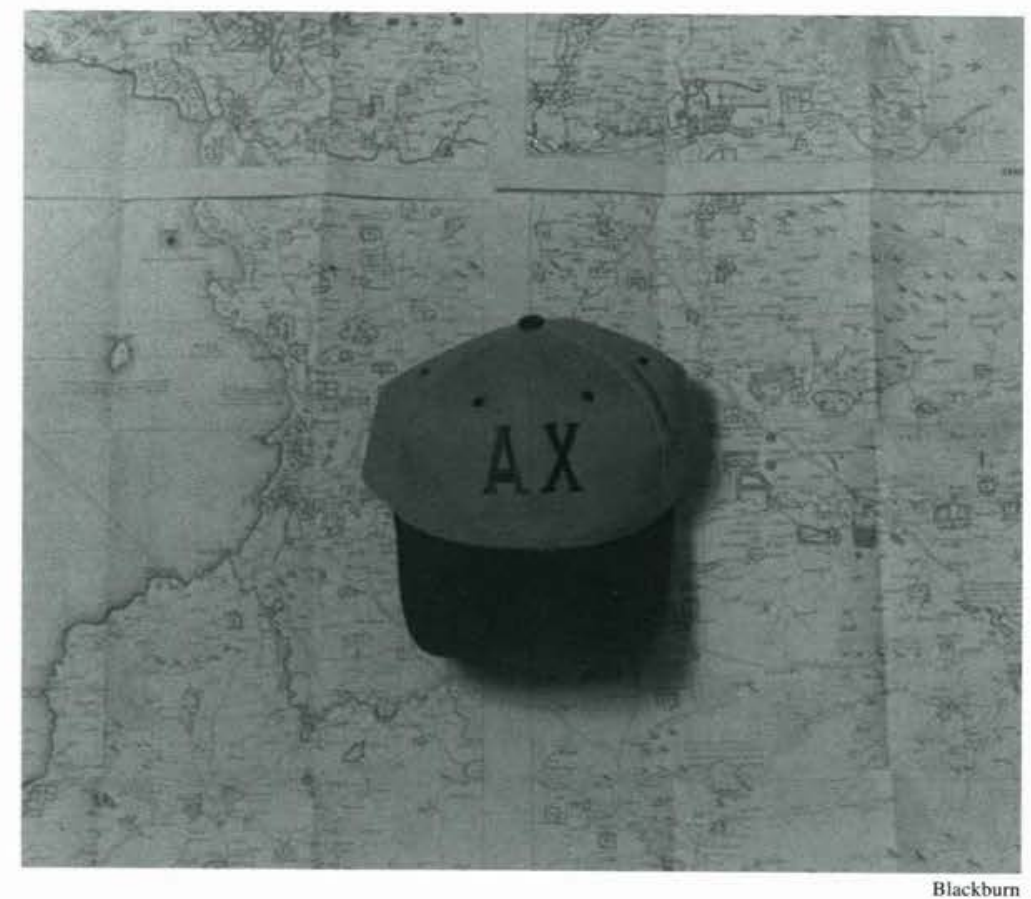

ORGANIZATIONS 



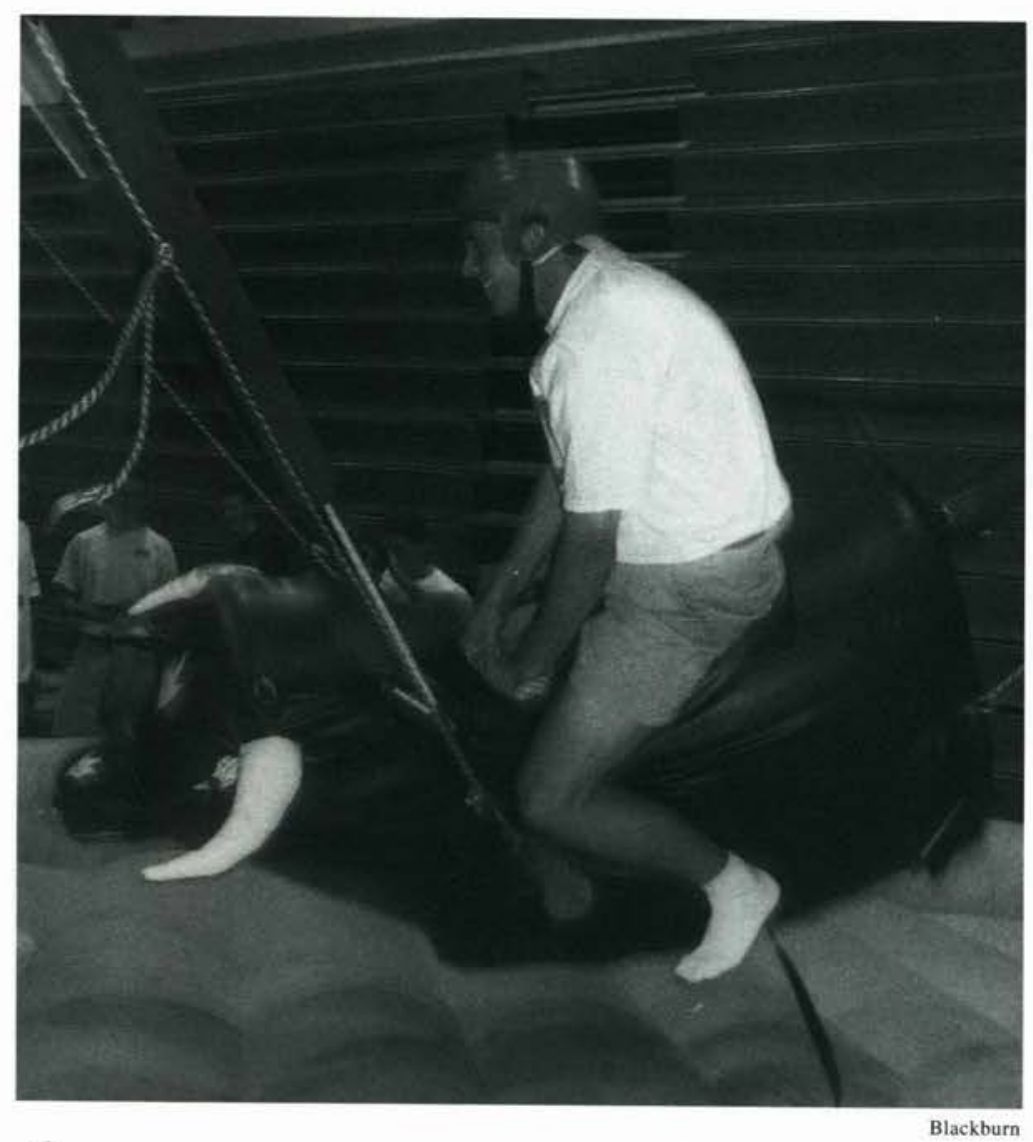

Senior Micah Roberts rides "Bungy Bull” provided by CAB (above).

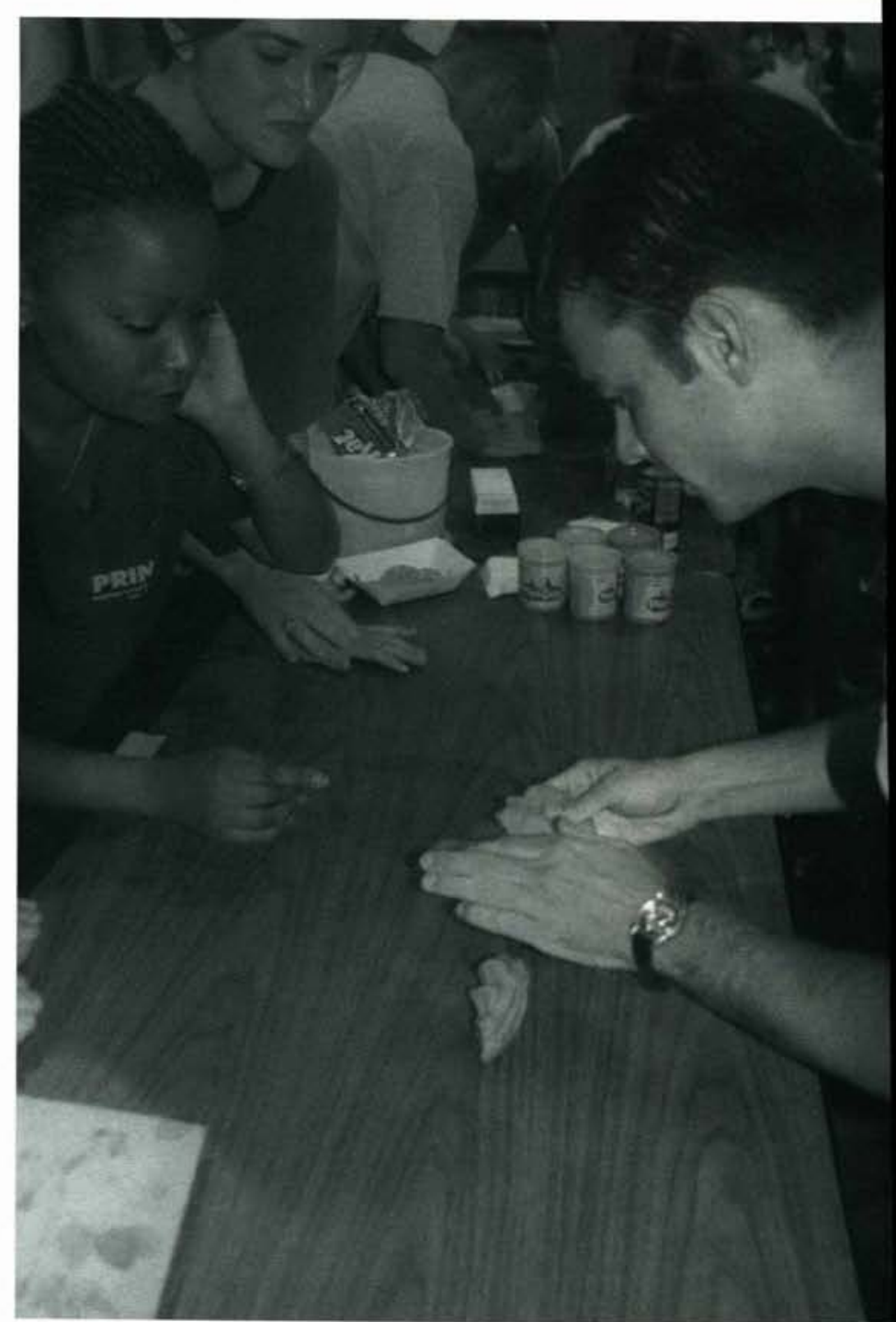

Bill Stuart plays Pictionary Playdough sponsored by Chi Delta Nu while Mandy Senior looks on (right).

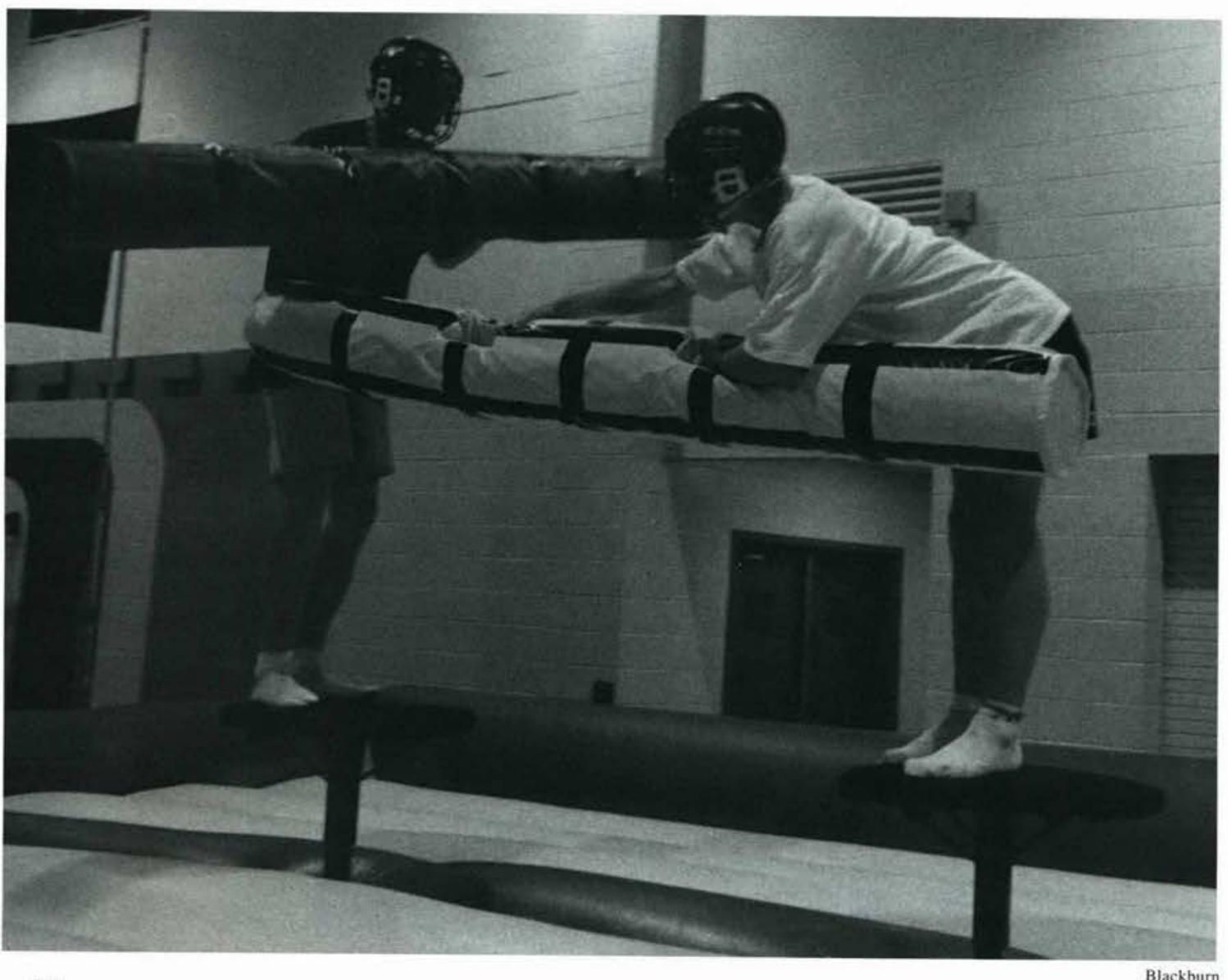

John Norris uses his creativity to sketch a caricature of freshman Jared Coleman (right top).

Dwight Bejek and Jamin Reda ride the barrels in a race provided by $\mathrm{CAB}$ (right middle

Two students contest with each other in the jousting tournament provided by Delta Omega Epsilon. 


\section{by $\quad$ Nancy Houck \\ Organizational Fair}

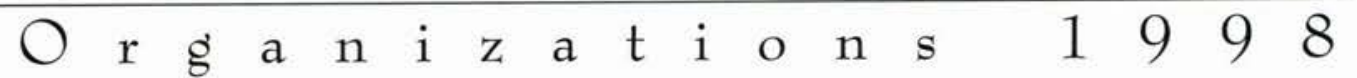

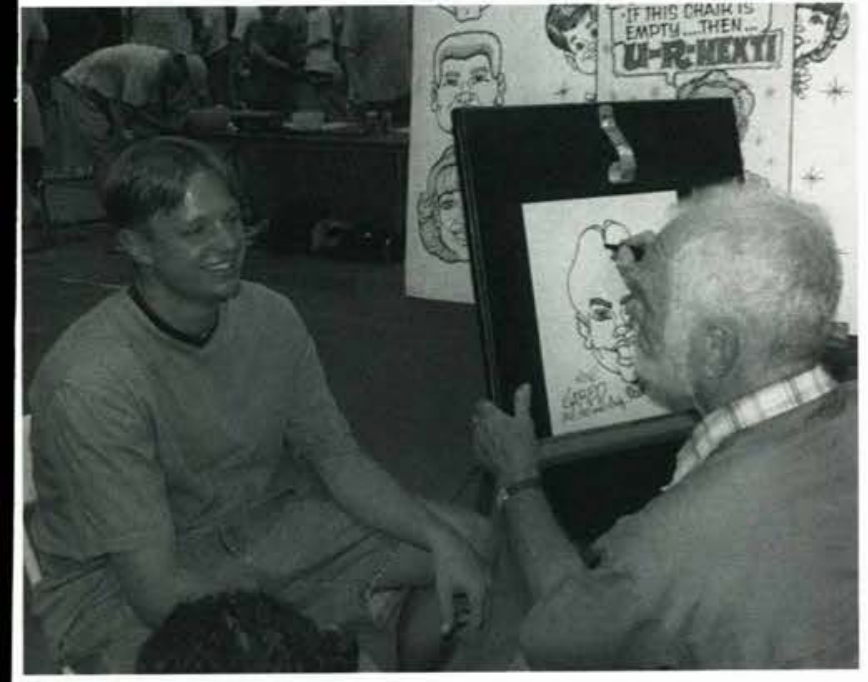

Blackburn

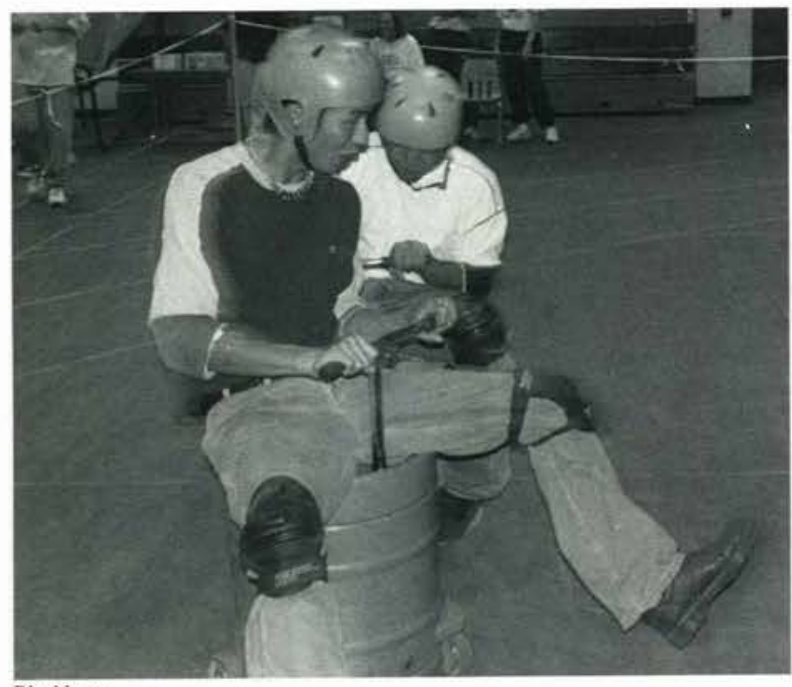

Blackburn

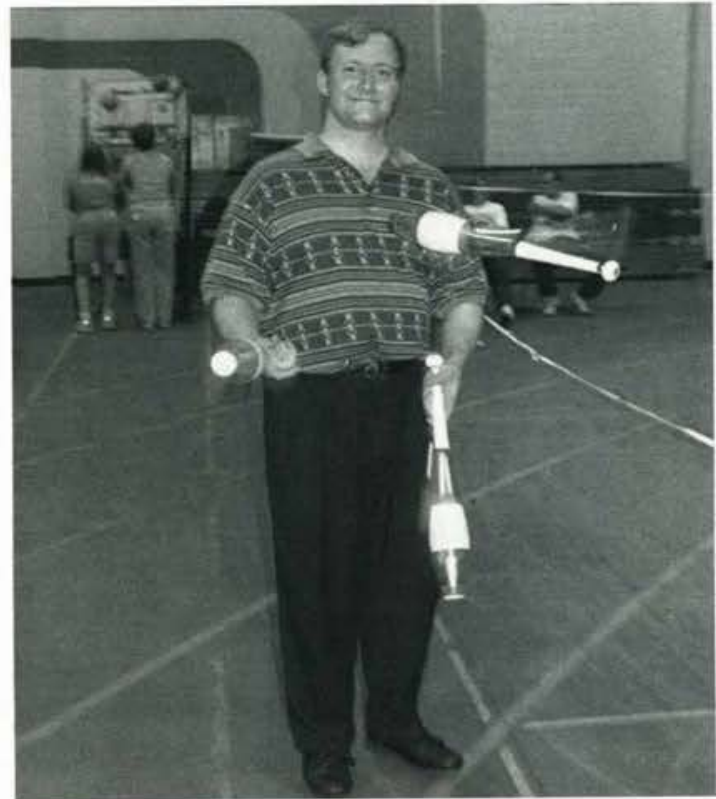

Blackburn
October 4, 1997 marked the annual Organizational Fair featuring numerous Cedarville clubs and organizations. Students flocked to the Athletic Center for plenty of food, folks, and fun.

The Campus Activities Board (CAB) sponsored the majority of the exciting events. CAB operated the Bungy Bull, Human Foosball, Barrel Racing, and Volley Bounce. In addition to these, they caricatured attendees and entertained them with a juggler.

Along with the entertainment provided by $\mathrm{CAB}$, the organizations offered a wide variety of foods fitting to their groups. Students could sip

Mu Kappa's tea, chomp Alpha Psi Omega's nachos and cheese, let

Kappa Epsilon Alpha's cotton candy melt in their mouths, slurp Alpha

Delta Omega's ice cream floats, or crunch the Student Government Association's snow cones. They could also drop by Colonial's and

Giovanni's booths and eat some pizza for the festivities. Heard throughout the AC were the sounds of U99.5 with frequent interruptions of karyoke. "Brady Bunch," "Happy Days,"

"Loveboat," and "Achy, Breaky Heart" were just a few of the numbers performed by Cedarville's songsters. Sports lovers enjoyed Delta Omega Epsilon's jousting contest, Alpha Chi's soccer challenge, Kappa Epsilon Alpha's speed pitch, and Varsity C's double shot. They took part in the Undergraduate Alumni Association's tractor pull, the Music Educator National Conference's shooting gallery and miniature golf hole. Participants could win goldfish at Theta Roe Epsilon's goldfish races and play Twister at Phi Epsilon Beta's corner after they decorated its members with sundae and hot dog toppings. Students also took turns striking the piñatas of candy at the Spanish

Club's booth.

Some organizations allowed students to show their creativity and intellect. At the Earth Stewardship table, students planted their own flowers.

They made spin art at Phi Gamma Psi's booth. They were entertained by Pictionary Playdough at Chi Delta Nu's table, and got their faces painted or hair colored by Epsilon Alpha Pi. Chi Delta Epsilon created tie-dyed apparel. Mu Kappa gave students a chance to experience foreign culture and have their pictures taken while wearing native clothing. The Christian Nurse's Association photographed students in an ER setting. The Cedarville CollegeEmergency

Medical Services collected students' funny stories, and the best writer received a cash prize. Tau Delta Kai awarded a cash prize to its trivia contest winner.

Commuter Crossroads surrounded a car with maintenance tips.

The fair allowed freshman and transfer students to get to know a little more about the clubs and organizations available on campus as well as to meet new people. The event was fun for all who attended as it successfully informed Cedarville students about the organizations. 

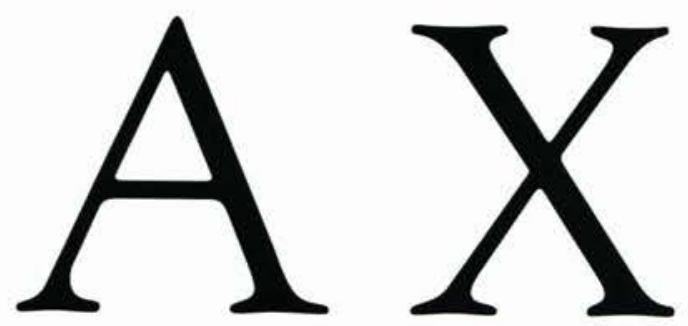

\section{$2 \cos 2 \cos 28$}

A l p h a C h i

by Christine Wiesert

Alpha Chi sponsored its 31st annual talent show on February 21, 1998. Jon and Donna Purple conducted the ceremony, encouraging audience involvement and providing humorous entertainment between talent acts.

Studentsdemonstratedmusical ability, both vocally and instrumentally. The Caylor Sis-

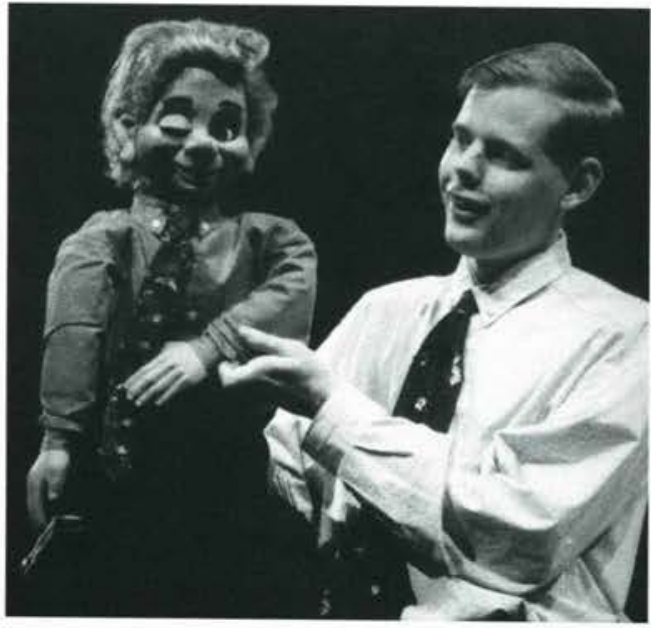
ters performed twooriginal songs. Theirgreat ability to harmonize and to play guitars impressed the audience. Tim Phillips performed a "musical comedy" with men from his unit on the Hill. They parodied a Veggie Tales song and generated laughs from the audience because of their witty rewrite.

Nathan Radford, an annual Alpha Chi Talent Show participant, brought more variety to the show with ventriloquism. He brought the audience to life with his exceptional talent. He presented his well-known "Auction Song" with his dummy, and then ventured toperform human ventriloquism with an audience volunteer.

BethAnne Kapansky captivated the crowd with her tap-dancing routine and gymnastic abilities. The Purples told students that Dr. Dixon added wood to the back section of the stage specifically for her routine in the talent show. While this was not the case, it did come in useful for Kapansky's act. Another returning participant, Jess Gamiere, amazed the crowd with illusionary card tricks. He also caught female students' attention by incorporating Celine Dion's "My Heart Will Go On" into his act.

Nathan Radford and the Caylor Sisters placed first, for non-musical and musical talents, respectively. Jess Gamiere placed second, while The TimPhillips Groupcame inthird.

Jess Gamiere dazzles the crowd with his magical talents (top right).

Nathan Radford and his talkative friend entertain the crowd (top left).

The Caylor Sisters perform an original song (center).

Tim Phillips and crew sing of their days at Cedarville(below).

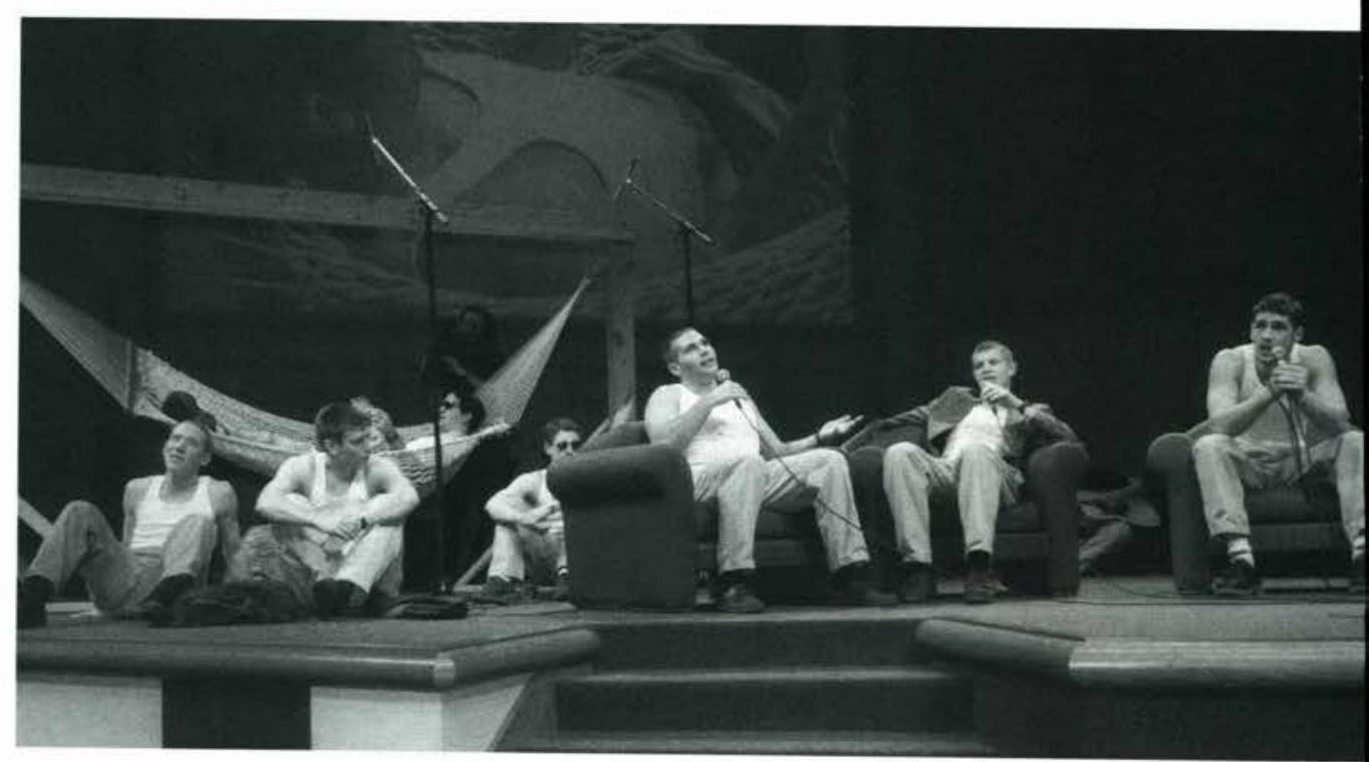




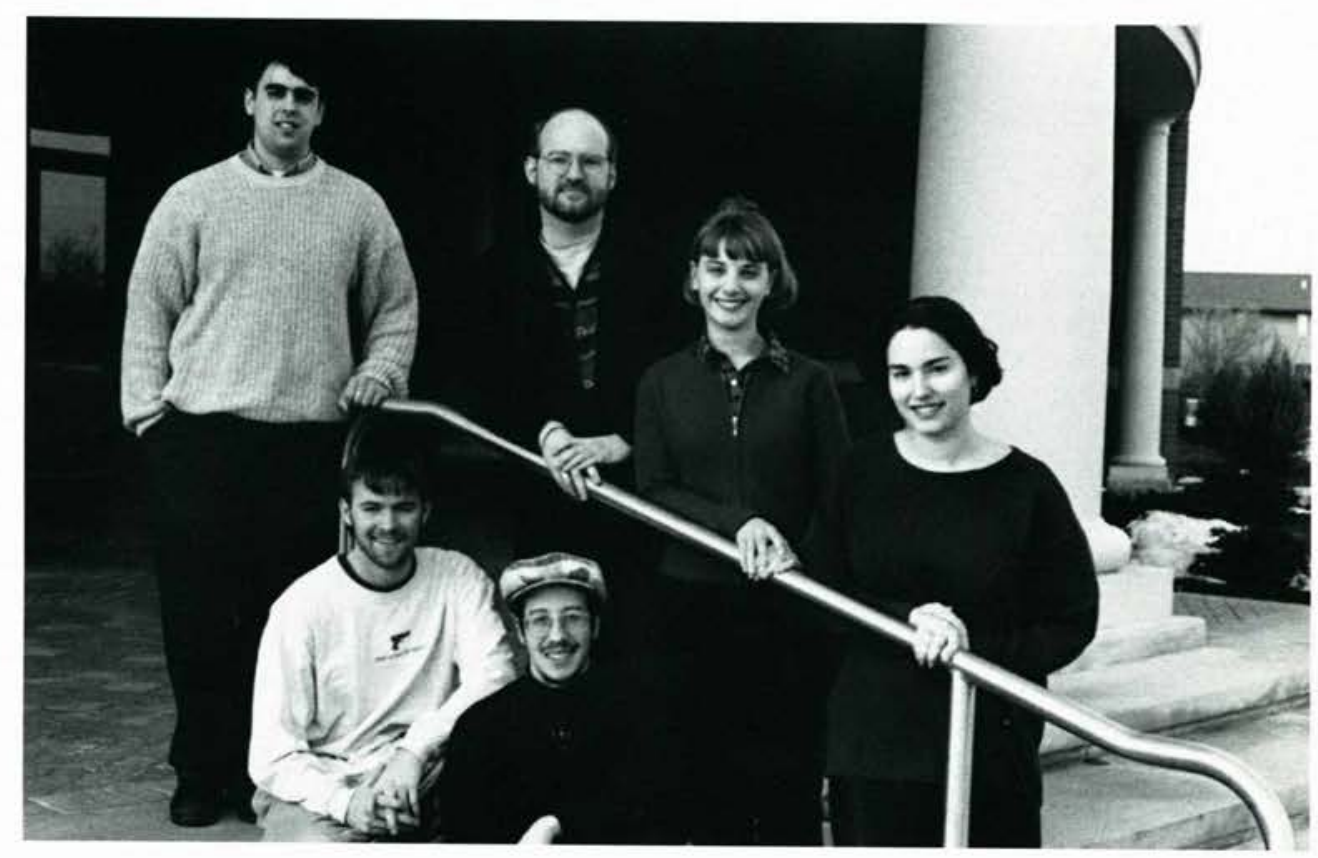

Alpha Beta Phi

F: Dan Scott, Todd Musser

B: Chris Vitarelli, Gary Barker-Advisor, Heidi Jo Dean, Joy Wickholm

Not Pictured: Sara Romang, Stacy Saville, Anson Hanbury, Angie Wenzel, Michelle Labor

Organizations

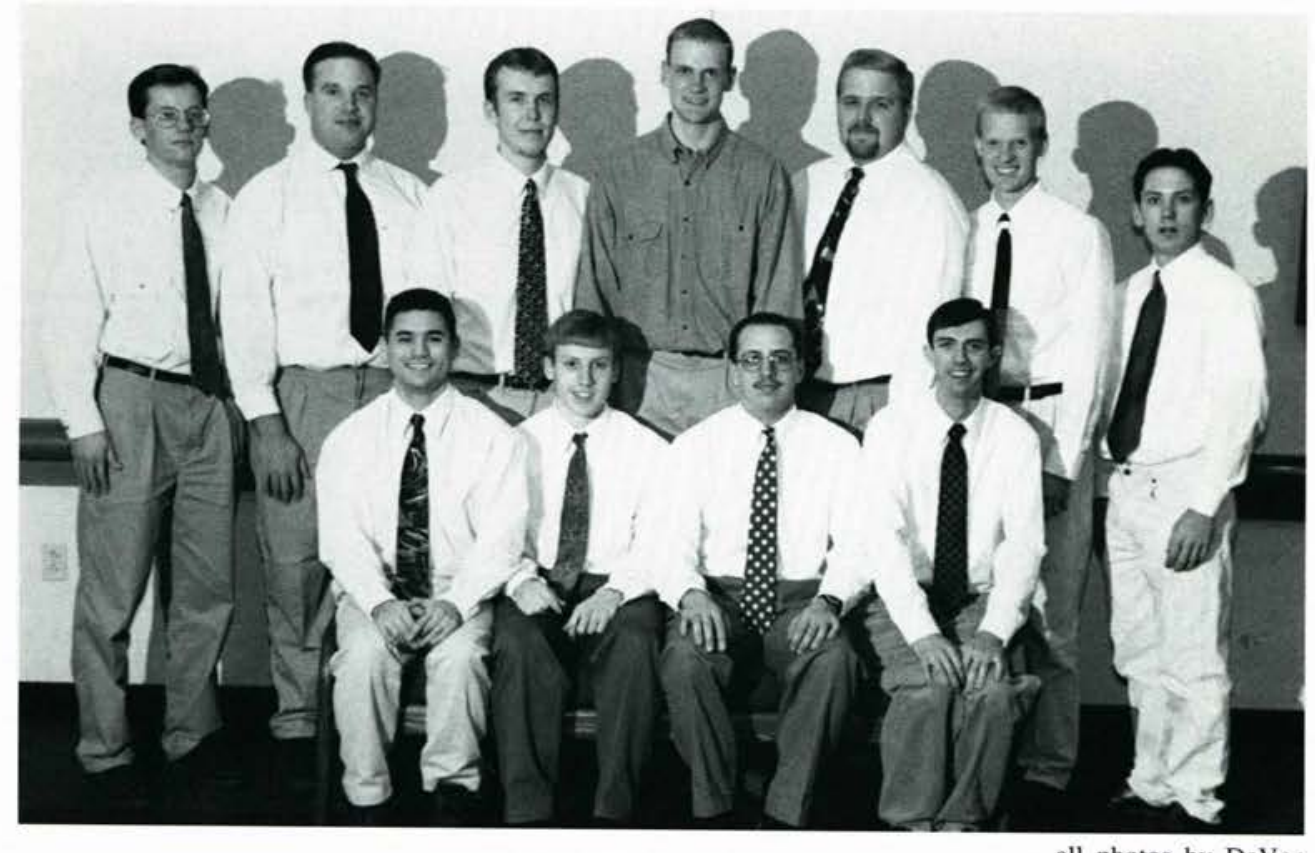

AlphaChi

all photos by DaVor

F: Nick Chou, Andrew Krum, Joel Misirian, Joe Lloyd

B: Luke Postema, Andrew Bergman, Chet Cromer, Brandon Luke, Eric Boothe, Derek Luke, J. Michael Yoder 

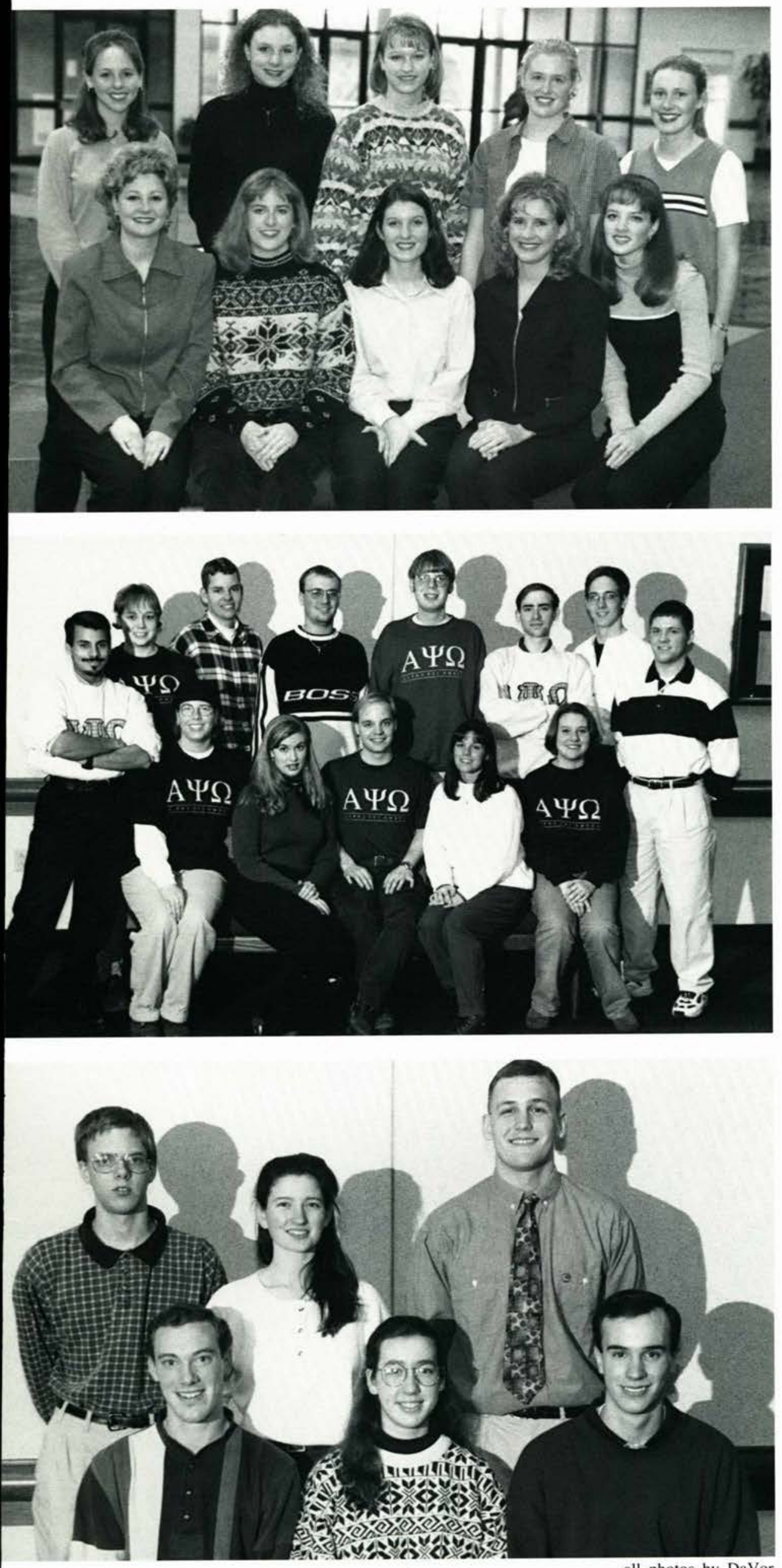

all photos by DaVor

\section{AlphaDelta Omega}

F: Hilary Pifer, Emily Wiljamaa, Sherri Woodard, Amy Spurling, Kim McKenzie

B: Rachel English, Allison Ramsey, Shari Kregel, Amy Kuyper, Holly Sorensen

\section{AlphaPsi Omega}

F: Shauna Summers, Jessica Seeley, Ben Bookie, Heidi Mc Kelvey, Elizabeth Smith

B: Paul Chevere, Jana Wright, Jared Skillings, Chad Jensen, Kevin Boblitt, Dave Hassenzahl, Matt Carr, Justin Wood

\section{ASME}

American Society of Mechanical Engineers F: Nathan Lewis, Ann Weeks, Andy Heyd

B: Brian Tojdowski, Deborah Pittman, Andy Litteral 


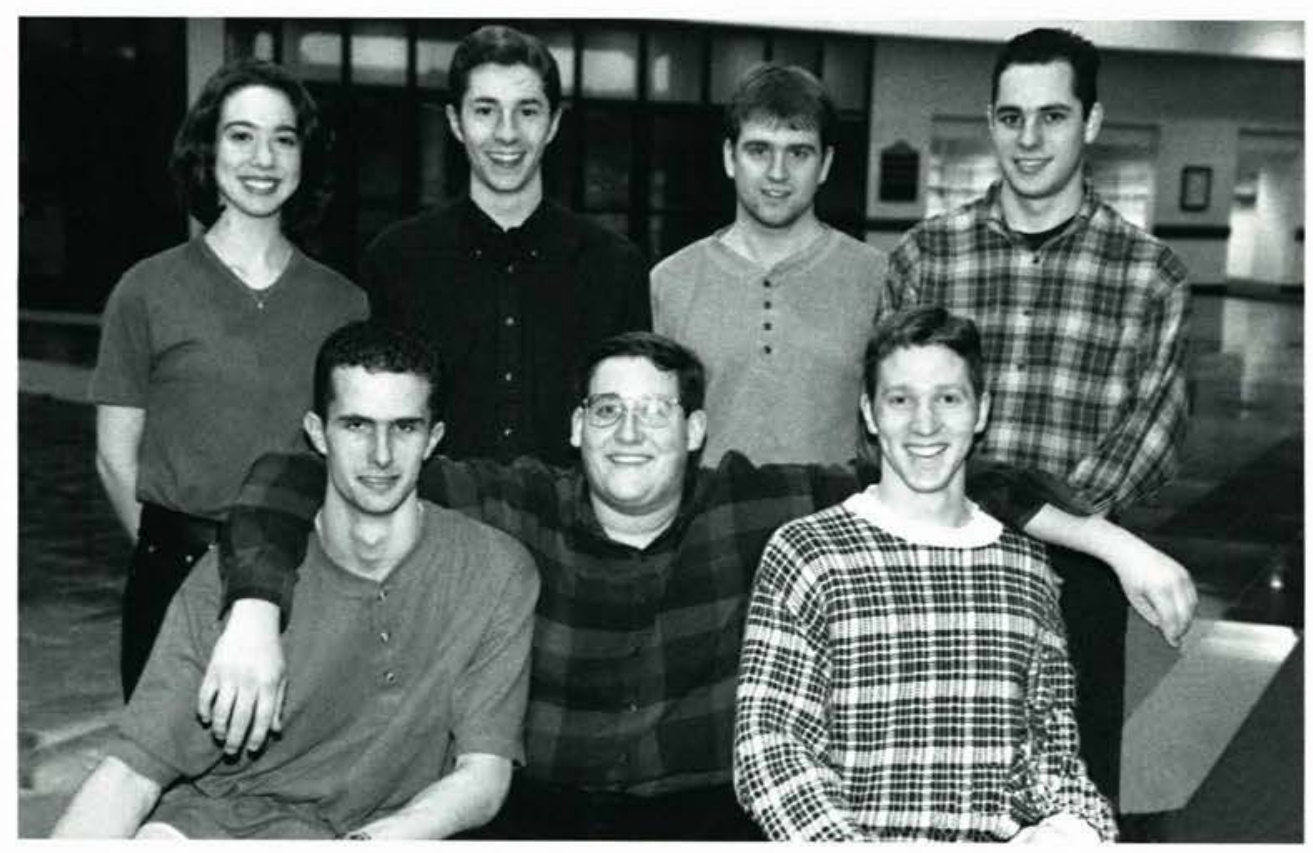

AITP

Association Of Information Technology Professionals

F: Brad Voumard, Scott Moodie, J. Michael Perkins, Chris J. Pool

B: Charis Perez, Andy Clary, Dan Freeman, Mark Milec

\section{A $\begin{array}{lllllllll} & \pi & \Omega & \phi & \Sigma & \Lambda & \Phi & \chi & \Psi\end{array}$}

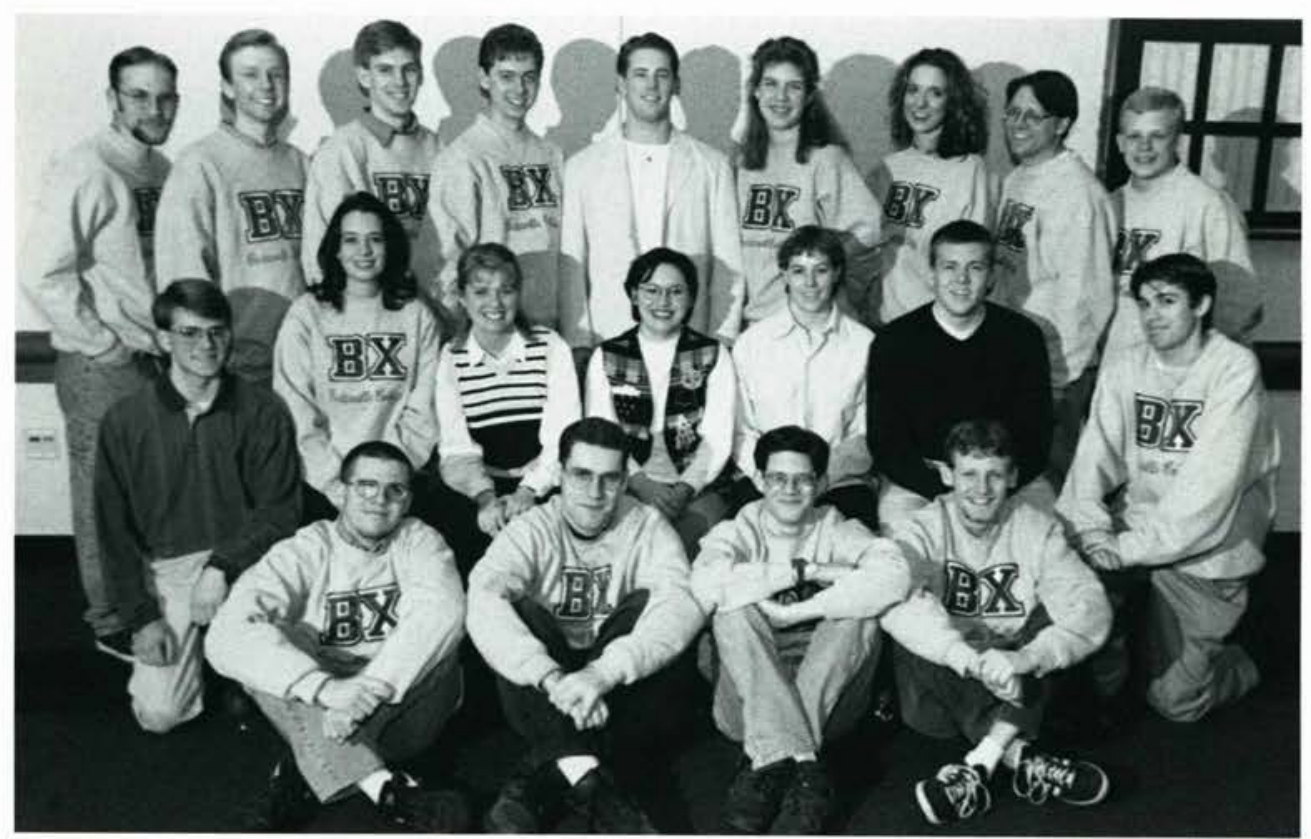

BetaChi

all photos by DaVor

F: Chris Fonte, Kevin M. Young, Michael Koerbel, Jeff Elliott

M: Joel Landis, Shannon R. Boynton, Sarah Carr, Jaime Wyntzen, Casey Ruffin, Don Chapin, Philip Wallis

B: Stephen Guether, Josh Snyder, Aaron Darr, Craig Magrum, Tom Sanderson, Sara Miller, Krista Warder, Jeff Nafzeger, Pete Mc Leod 


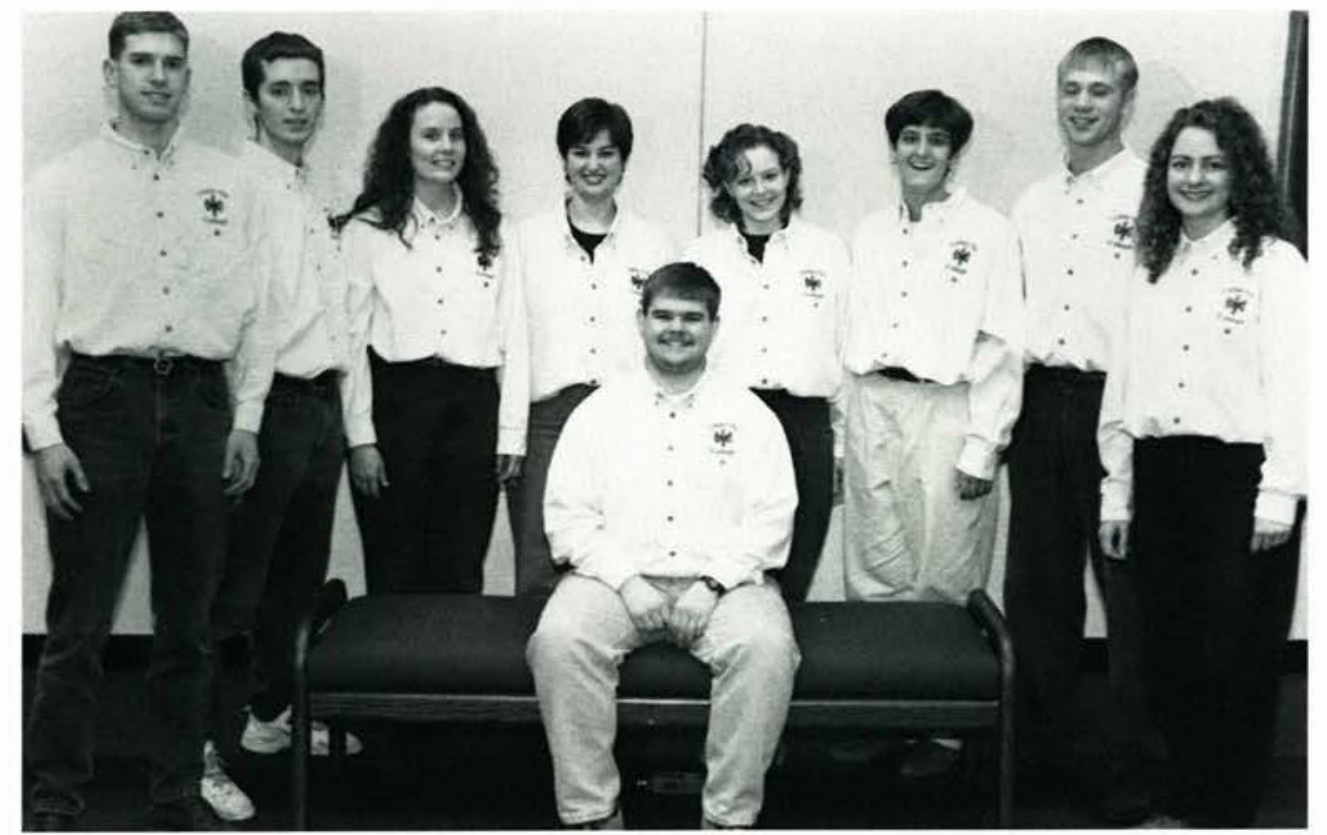

\section{CEMS}

Cedarville College Emergency Medical Service

\section{F: Donnie Woodyard}

B: David McPherson, Mark Collins, Rhonda Vore, Kara Doden, Robyn Bamford, Jessica Stuenzi, Joshua Tromp, Stephanie Bushholtz
A
$\pi$
$\Omega$
$\phi$
$\Sigma$
$\Lambda$
$\Phi$
$\chi$
$\Psi$
$\Delta$

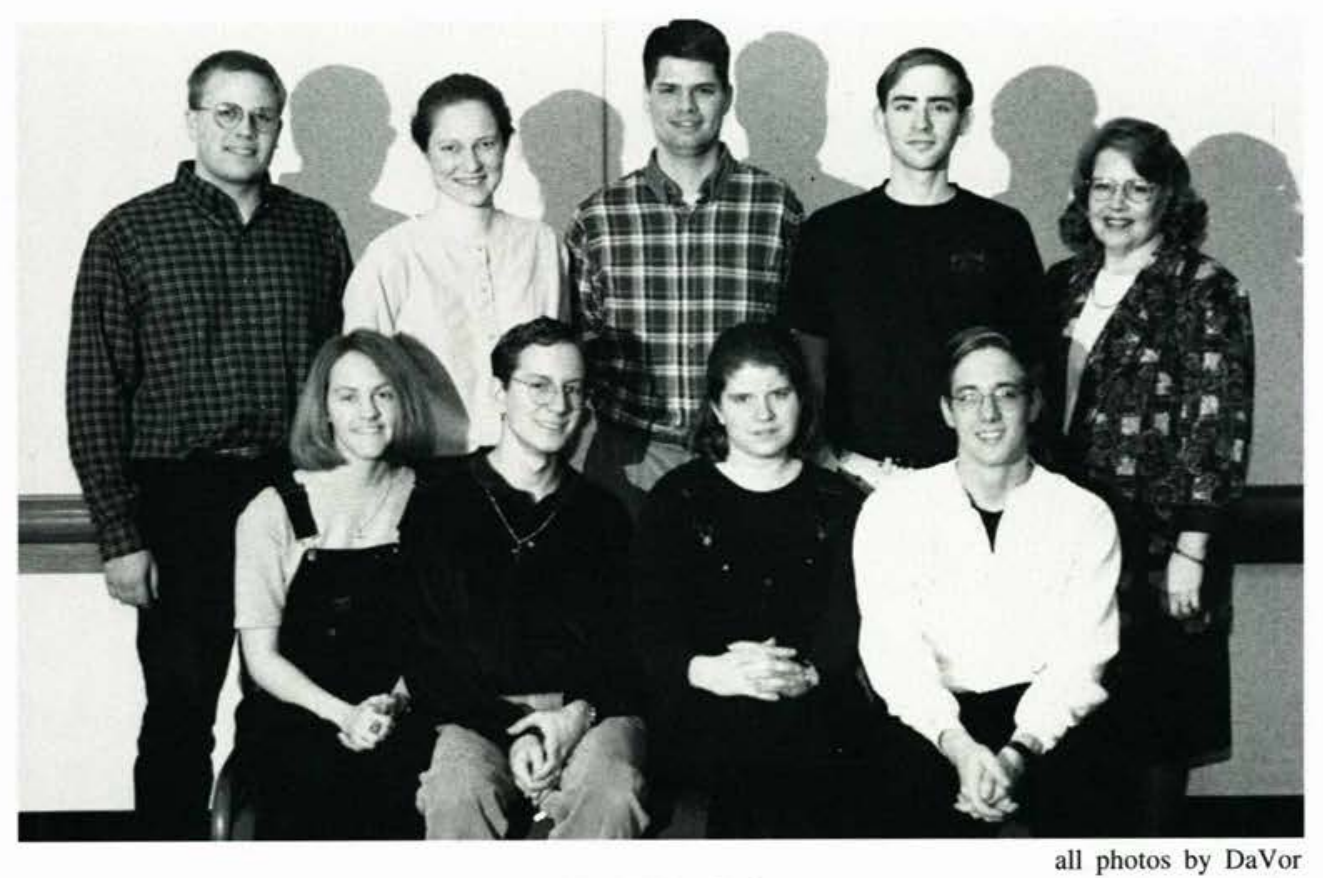

BetaRhoDelta

F: Jessica Gerber, David Carl, Jill Townsend, Matt Carr

B: Deborah Pittman, Jan-Harm Wolters, Rachel Morris, Andrew Marshall, Dave Hassenzahl, Carolyn Simons-Advisor 


\section{ChiDeltaEpsilon}

F : Andrea Dieringer, Juile Trout, Carrie Fabian, Danielle Coler, Joy Griffith, Tanya Gardner

M: Ester Twigg, Rhonda Culp, Leanne Heath, Sarah Crawford, Angela Howe

B : Jessica Estepp, Kerry Keane, Michelle Bolt, Erin Reagan, Abigail Variage, Brian Dye, Mark Price, Kelly Borick, Michelle Clark, Hooly Sorensen, Kriste Miller, Chris Olbrich

\section{Chi Delta Nu}

F : Doreen Fuhr, Betsy Linnell, Casey Platt, Roxanne England, Rachel Bontrager, Darin Stevens, James Dewald, Bill Stewart, Nate Childers

M: Sheri Wilson, Joy Carl, Joey Decker, Diana Christensen, Steve Merchange, Yvette Pieano, Tim Hotchkiss, Kathy Housten, Amanda Senior, Angie Tyson

B : Matt Palombo, Matt Noll, Ryan Cook, Dave Hewitt, Jason Isaals, Jordan Patrick, Jon Basner, Jeremy Troyer, Tom Leightenheimer, Bryan Miller, Scott Walker, Kristin Jacoby, Melissa Warner, Andy Gingrich, Todd Romin, Laura Cook, Aaron J. Cook

\section{ChiSigmaLota}

F: Brandi Leeds, Jennifer Cobb, Emily Watkins, Hannah Sherwood

B: Kristy Jackson, Kristi Gleason, Lindsay Schneider, Karen Guikema, Lissa Young, Dawn Geib, Kelly Reitz
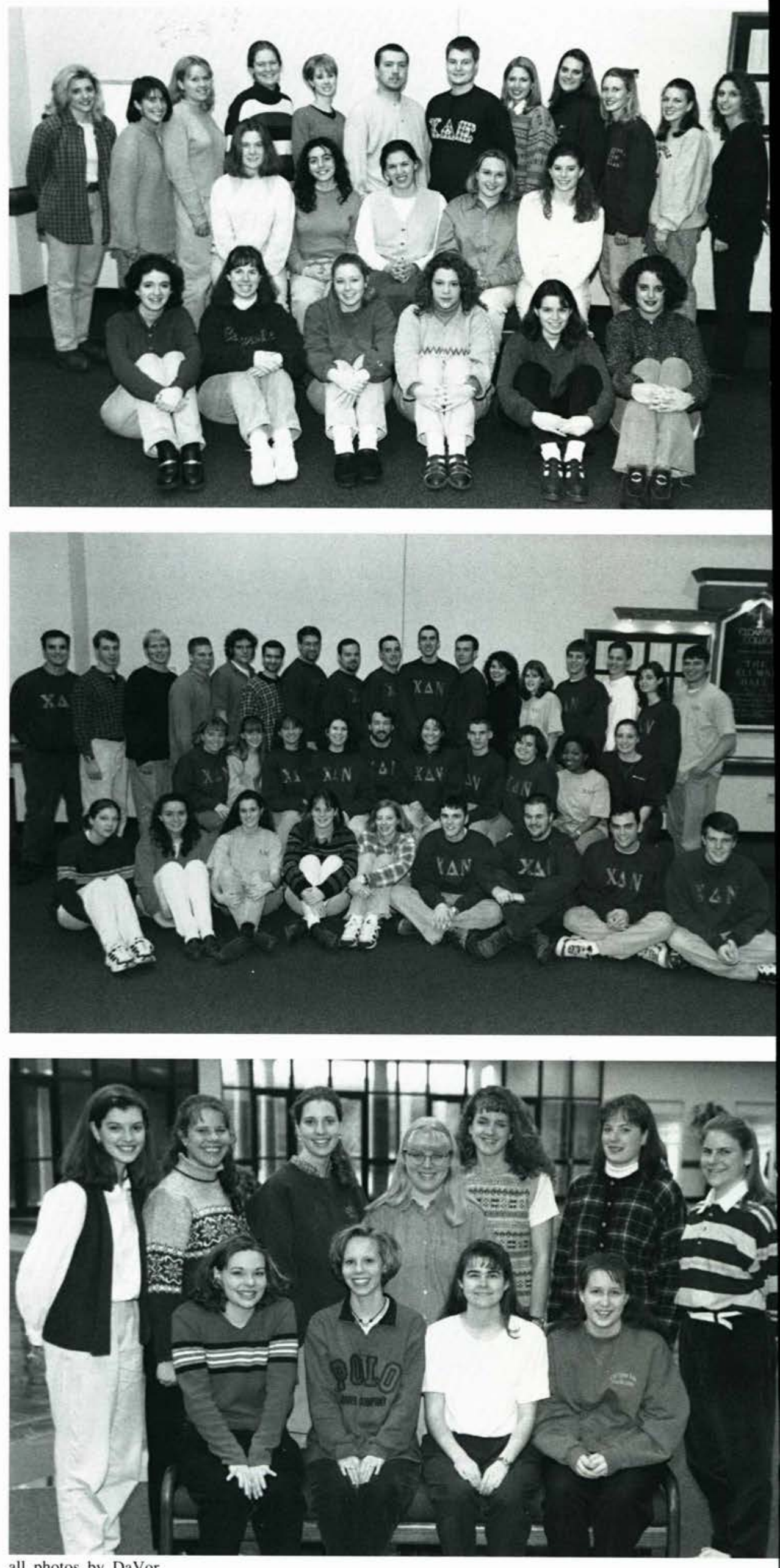

all photos by DaVor 


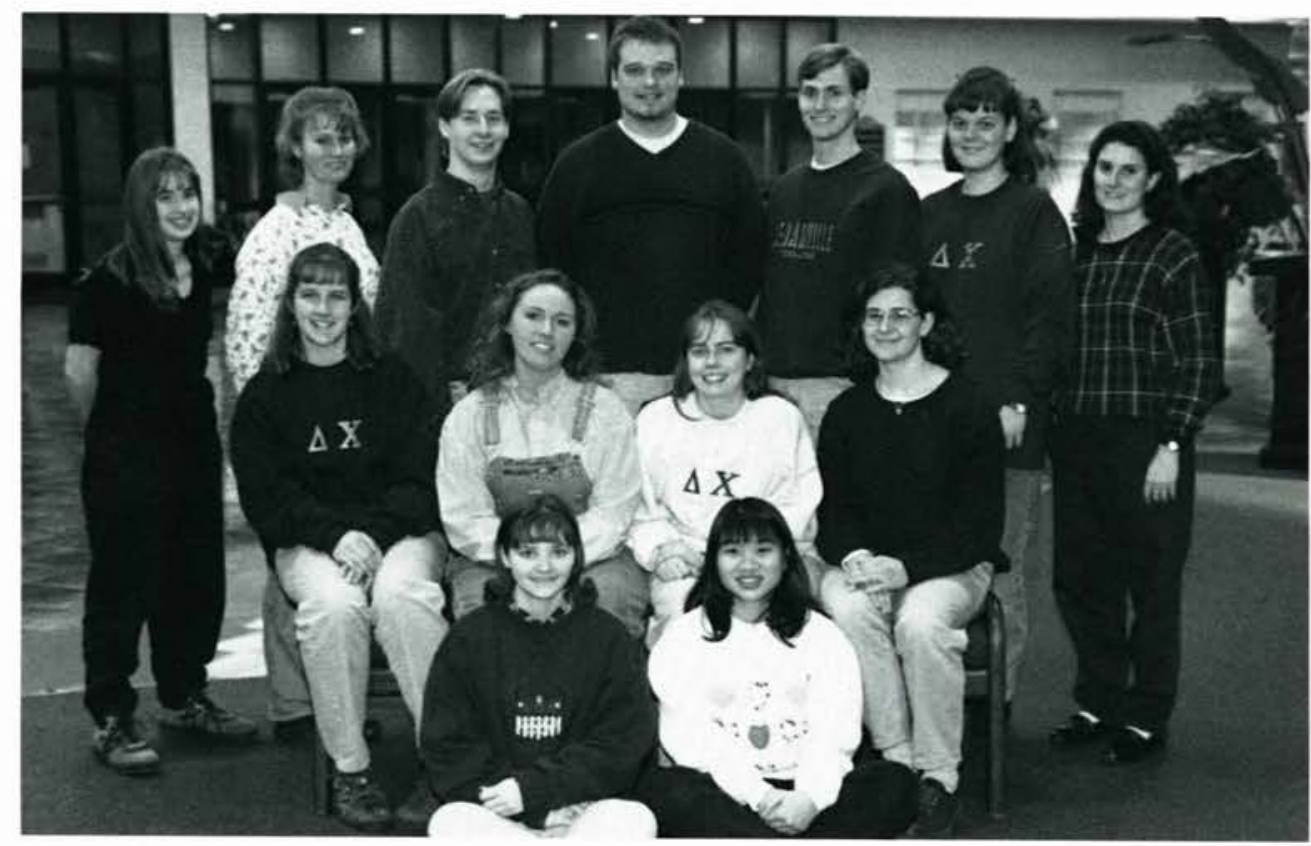

\section{Delta Chi}

F: Karen Belknap, Esther Loh

M: Sarah Walkey, Shannon Snow, Evelyn Brown, Emily Weber

B: Christina Powley, Christina Riley, Aaron Ponzanit, Steve Ryan, Rich Porter, Alicia Baisley, Jen Alt

\section{$\mathrm{A} \quad \pi \quad \Omega \quad \phi \quad \Sigma \quad \Lambda \quad \Phi \quad \chi \quad \Psi \quad \Delta$}

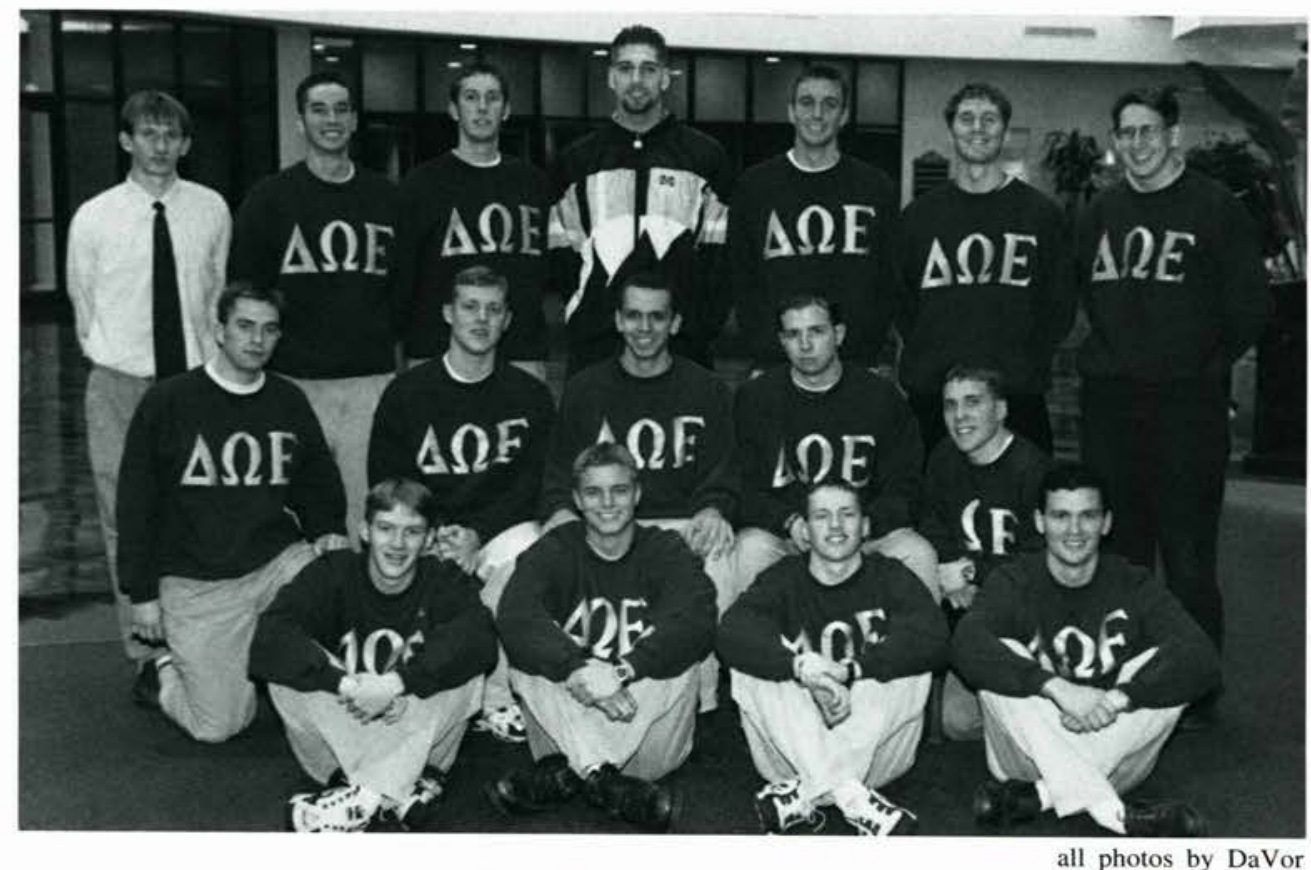

\section{Delta Omega Epsilon}

F: Josh Strychalski, Andy Ziegenfuss, Gabe Schlappi, Todd Johnson

M: Sweet Lou Brown, Scott Van Loo, Darin Rosenvold, Josh Lunney, Jay Clark

B: Chad Deakyne, Stephen Comer, David Fourman, Ted Forrest, John Krueger, David Rutledge, Yasir Haffey 


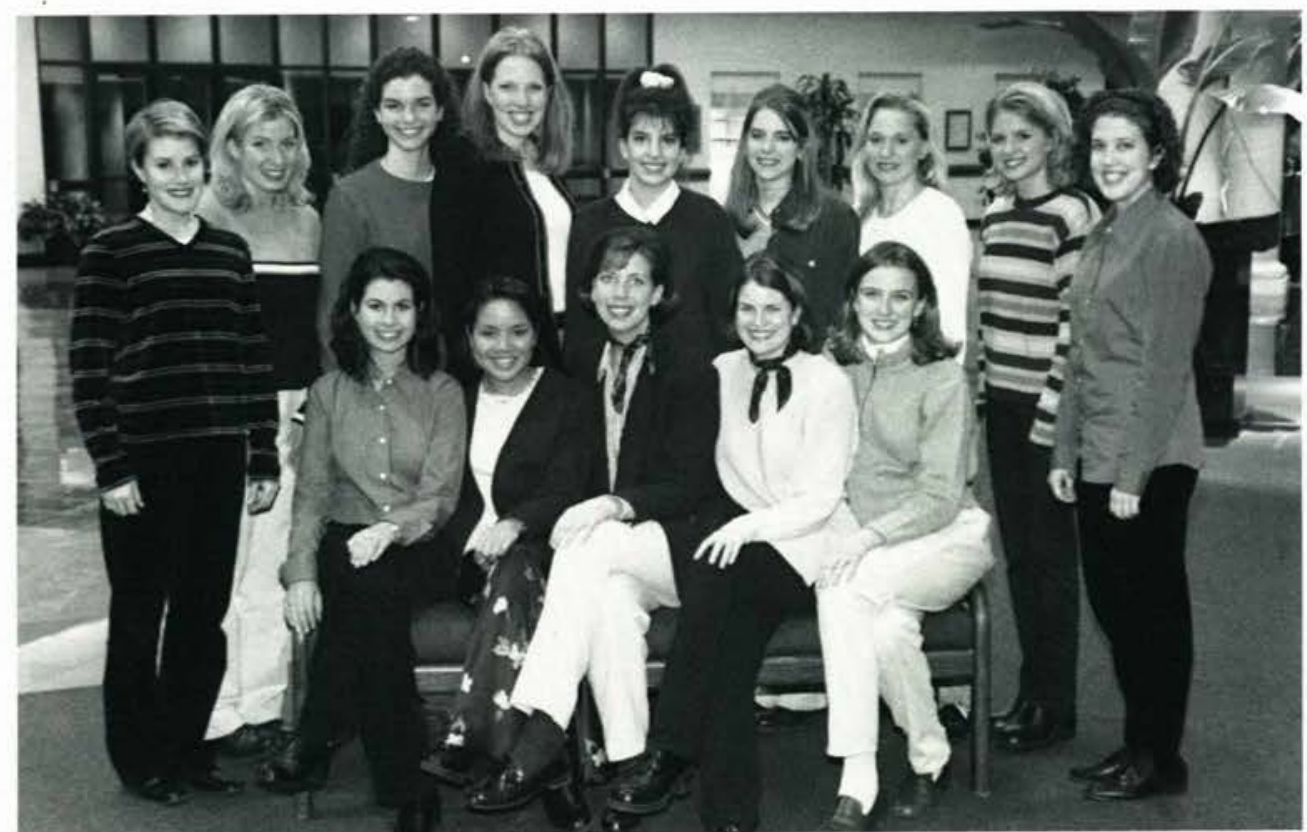

Delta Pi Sigma

F: Rebecca Upham, Brenda Inion, Bethany Gaffner, Jessica Angelone, Joy Webster

B: Becky Crosson, Amiee Nash, Kimberly Schweickart, Lindsay Peterson, Sarah Gross, Becky Lakes, Amy Hurst, Shana Lenhart, Jill Barnes

$\mathrm{A} \quad \begin{array}{llllllllll}\pi & \Omega & \phi & \Sigma & \Lambda & \Phi & \chi & \Psi & \Delta\end{array}$

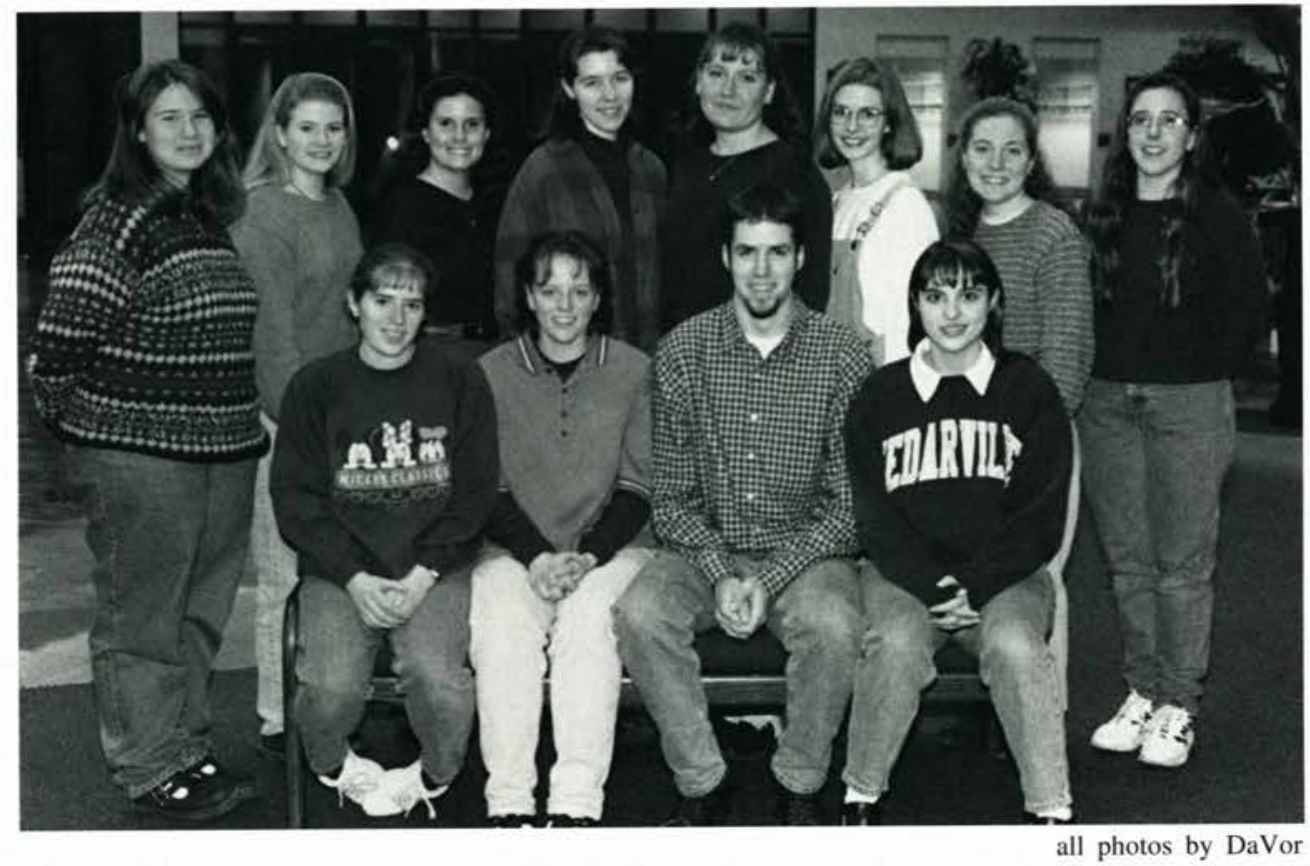

EarthStewardship

F: Jeanette Irish, Amber Wilson, Jared Mitchell, Heidi Mountz

B: Stephanie Mace, Wendy Harney, Emily Alt, Meredith Heckrote, Jamie Cartwright, Kelly Montague, Melanie Lehman, Laura Kroner 


\section{Epsilon Alpha Pi}

F : Faith Buchanan, Dave Wilson, Matthew Taylor, RebeccaComfort

M: Cheri Douglas, JoHanna Byrer, Melinda Schwartz, Jamie Michael, Jill Rynerson

B : Michelle High, Jennifer Bear, Naomi Cooper, Anastasia Mobley, Beth Cooper, Myra Luter, Rachel Dyer

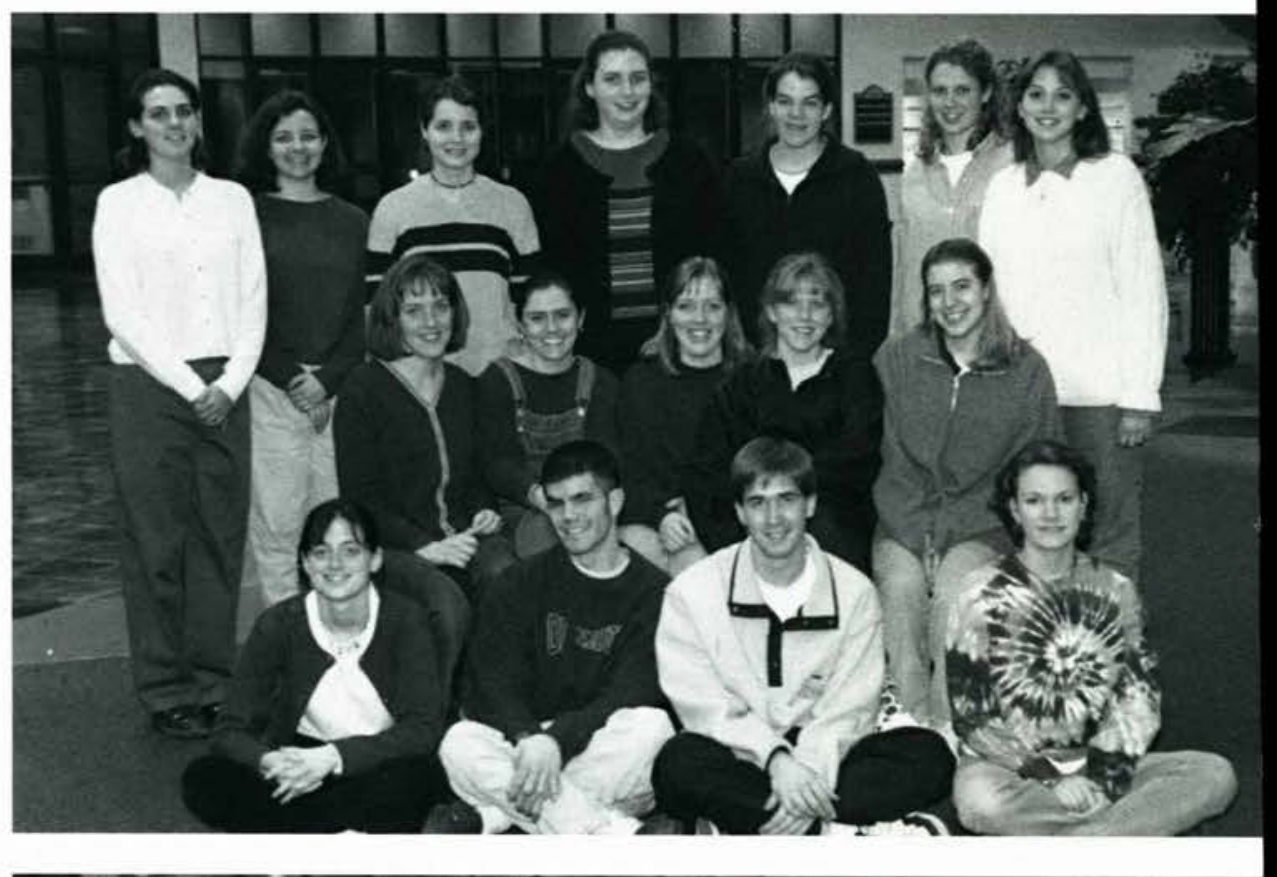

\section{Epslion Omega}

Rebecca Comfort, Jill Rynerson, Rebecca Johnson, JoHanna Byrer

I E E E

Institute of Electrical Engineers

Tim Mohler, Ken Shierman, Stacie Bennett, Ryan Wiseman, David Carl
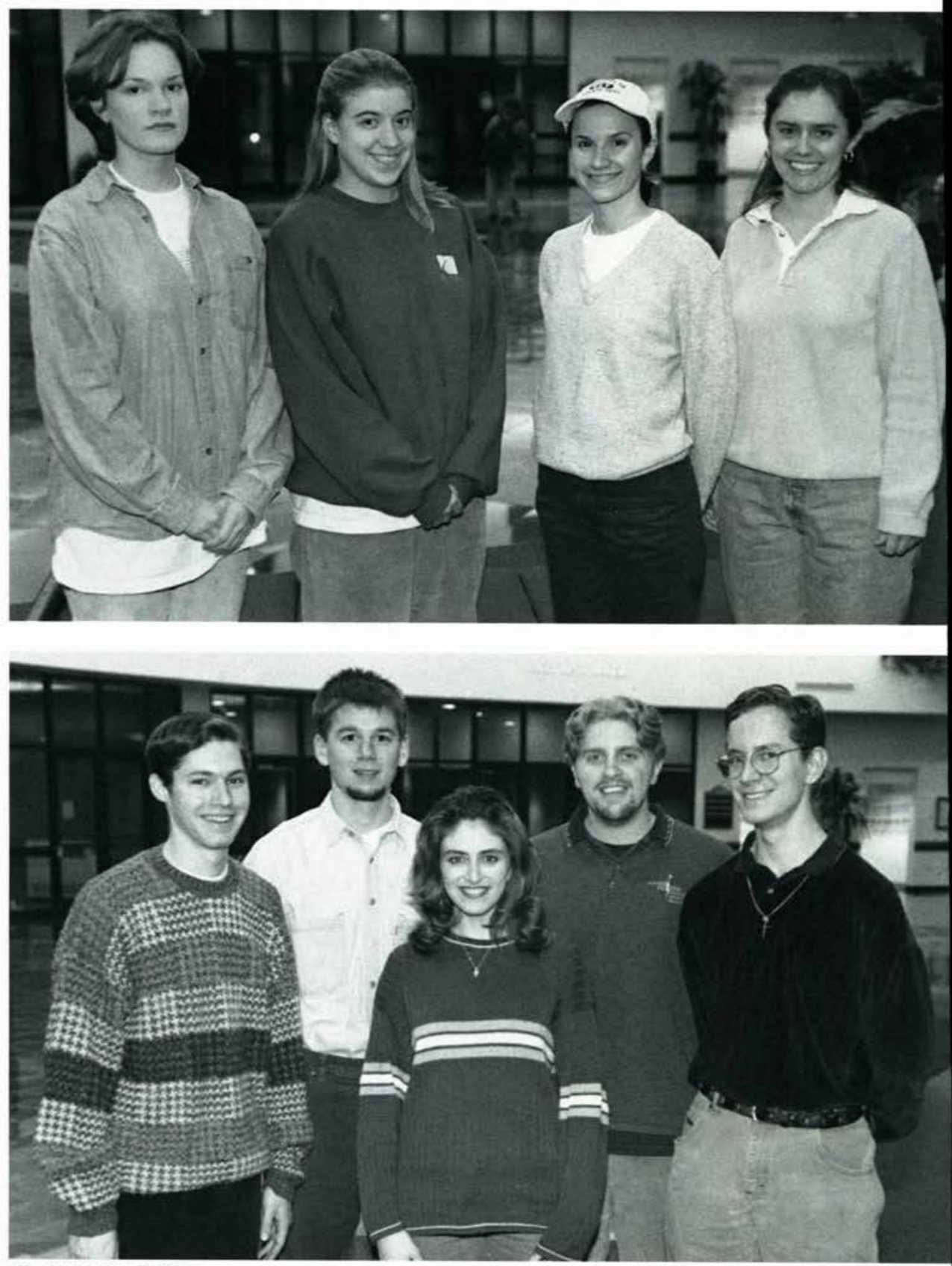

all photos by DaVor 


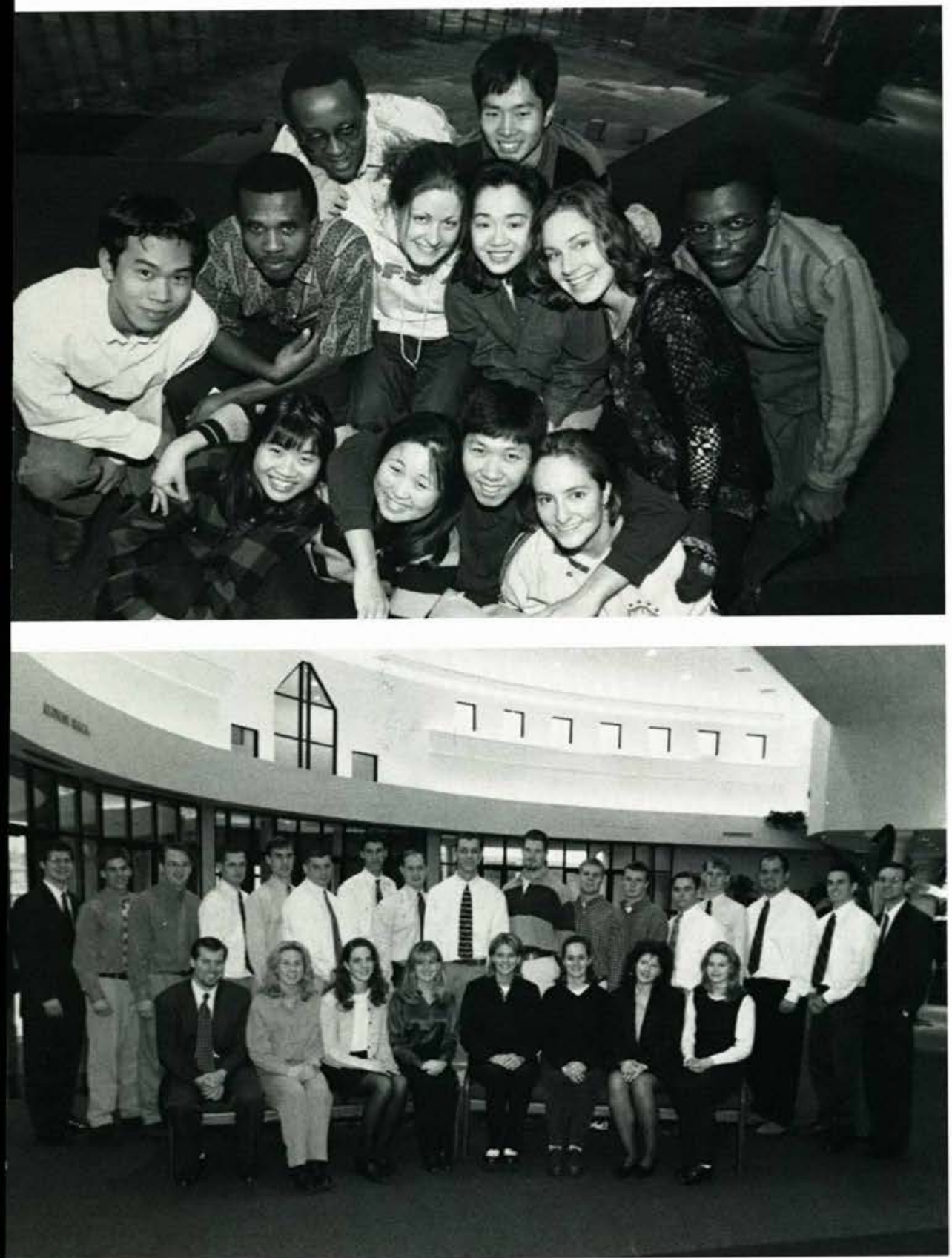

\section{International Student Organization}

F : Eshter Loh, Atsuko Ohtake, John Stedge,

Fernanda Fernandes

M: Pete Warinsee, John Abban Hanson, Sandy

Swales, Sonwoo Lee, Melanie Barker, Edwin Bett

B : Roy Ndiang'ui, Kouichi Ikeda

\section{KEA}

$K a p p a \quad E p s i l l o n \quad A l p h a$

F : David A. Jones, Kelly Cordts, Sarah Whitney,

Rebecca Fissel, Lesley Grow, Erin Barker, Jocelyn Endsley, Kristen Prince

B : Bill Woods, Kirk LeBlanc, Rob Mulvaney, Brad Umland, Carl Weise, Jeff Valdes, Dan Castellini, McArthur Hill, Nick Gapinski, Greg Thompson, Dan Parlin, Troy Page, Joe Mulvaney, Kyle Kickbusch, Dan Bosworth, Matt Thompson, Ryan Anderson

\section{MENC}

Music Educators National Conference

F: Katie Fatrell, Nicole Sparling, Leah Caldwell, Esther Twigg, Shelly Yahara

M: Lucinda Congdon, Lisa Branon, Amy Clutz, Angela DeSantis, Nikki Thomas, Beth Stewart, Eileen Mc Coskey, Cynthia Lowry

B : Jami Broman, Jennifer Abas, Jenni Weaver, Denelda Foltz, Tammy Mc Comb, Ryan Einfeldt, Andrew Nyveldt, Zach Rhodes, Becky Lakes, Stephanie Crouch, Kristen Joy Small, Hannah Rives 


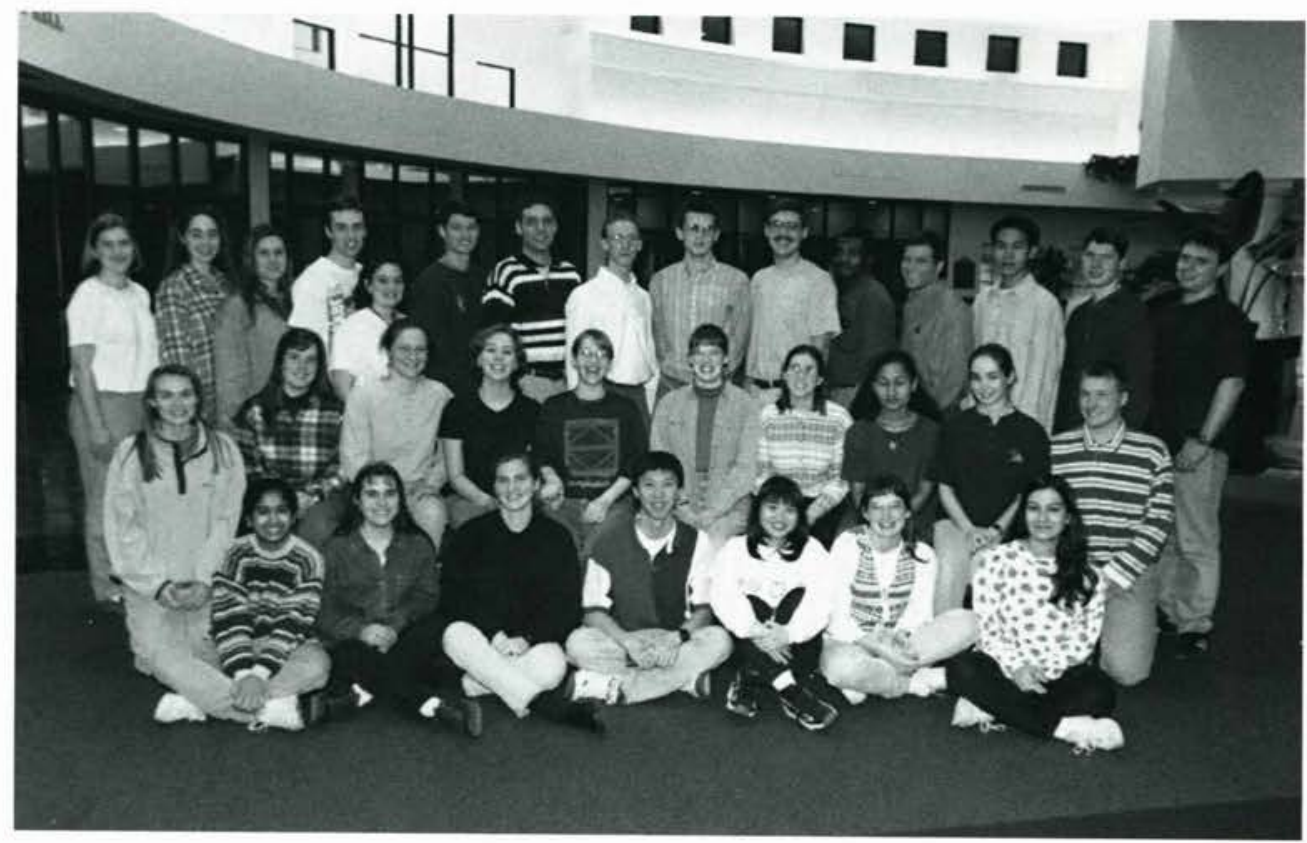

\section{MuKappa}

F: Jaya Philip, Becky Foster, Kimberly Ketterer, John Stedge Esther Loh, Janelle Baker, Ahlam Boland M: Kim Kleiman, Tiffany Linden, Rachel Morris, Tammy Stark Tami Weber, Janette Baker,

Stacy Stauffer, Rebecca Tharngan, Hannah Allen, Rob Bouwens

B: Emily Davis, Patricia Rice, Jayme Brower, Stefan Cliene, Juila Fawcett, Ben Nordaas, Jason Grahame, Ryan Einfeldt, Paul DeHart,

Nathan Waldock, John Abban Hanson, Andy Malone, Pete Warinsee, Jeff Schumacher, Bob Hirschelman

\section{A \\ $\pi$ \\ $\Omega$ \\ $\phi$ \\ $\Sigma$ \\ $\Lambda$ \\ $\Phi$ \\ $\chi$ \\ $\Psi$

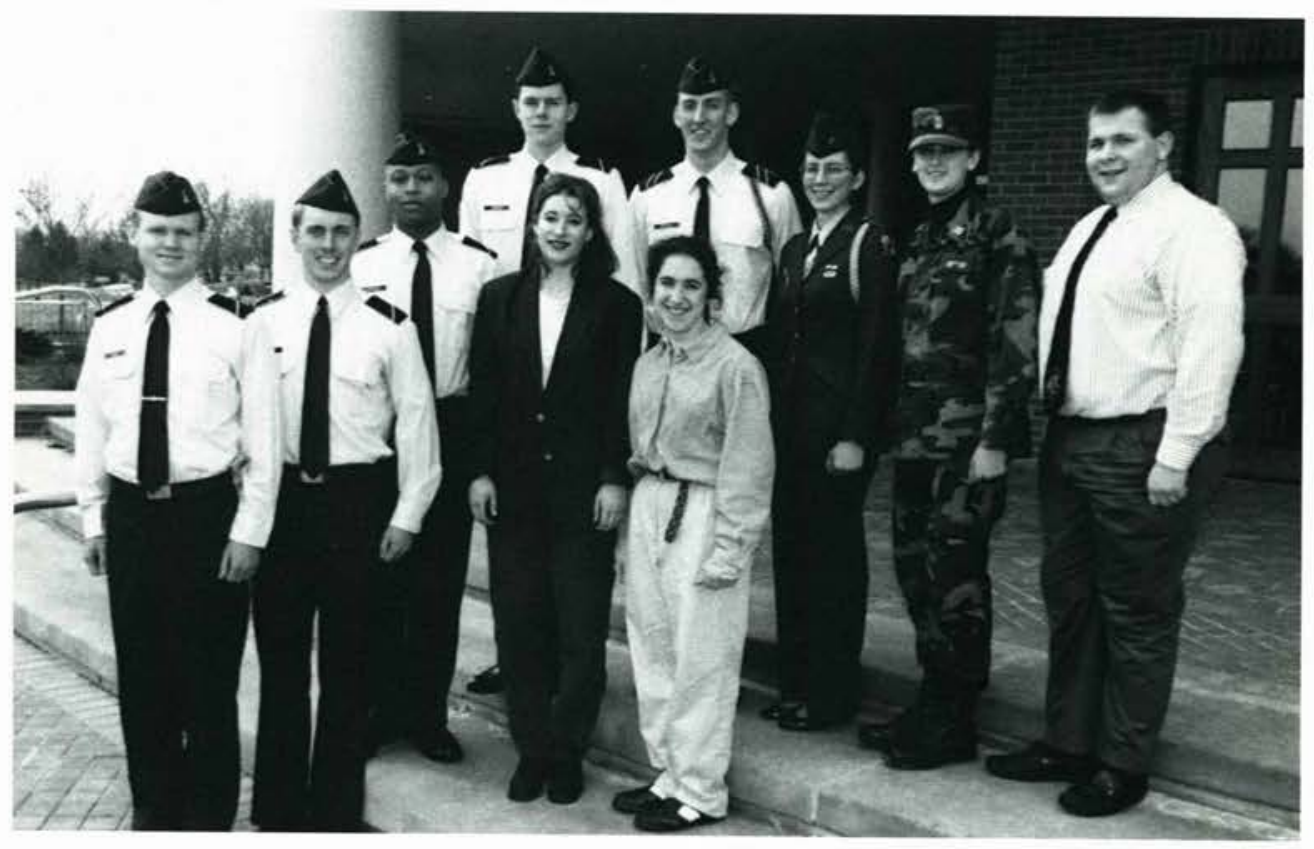

Officers Christian Fellowship

all photos by DaVor

F: Emily Weidler, Ghena Marchetti

B: Brandon Dow, Tim Sutton, Bobby Ray Johnson II, Matt Snyder, Jon Burson, Joanna Cormany, Catherine Clagg, Richard D. Anderson 


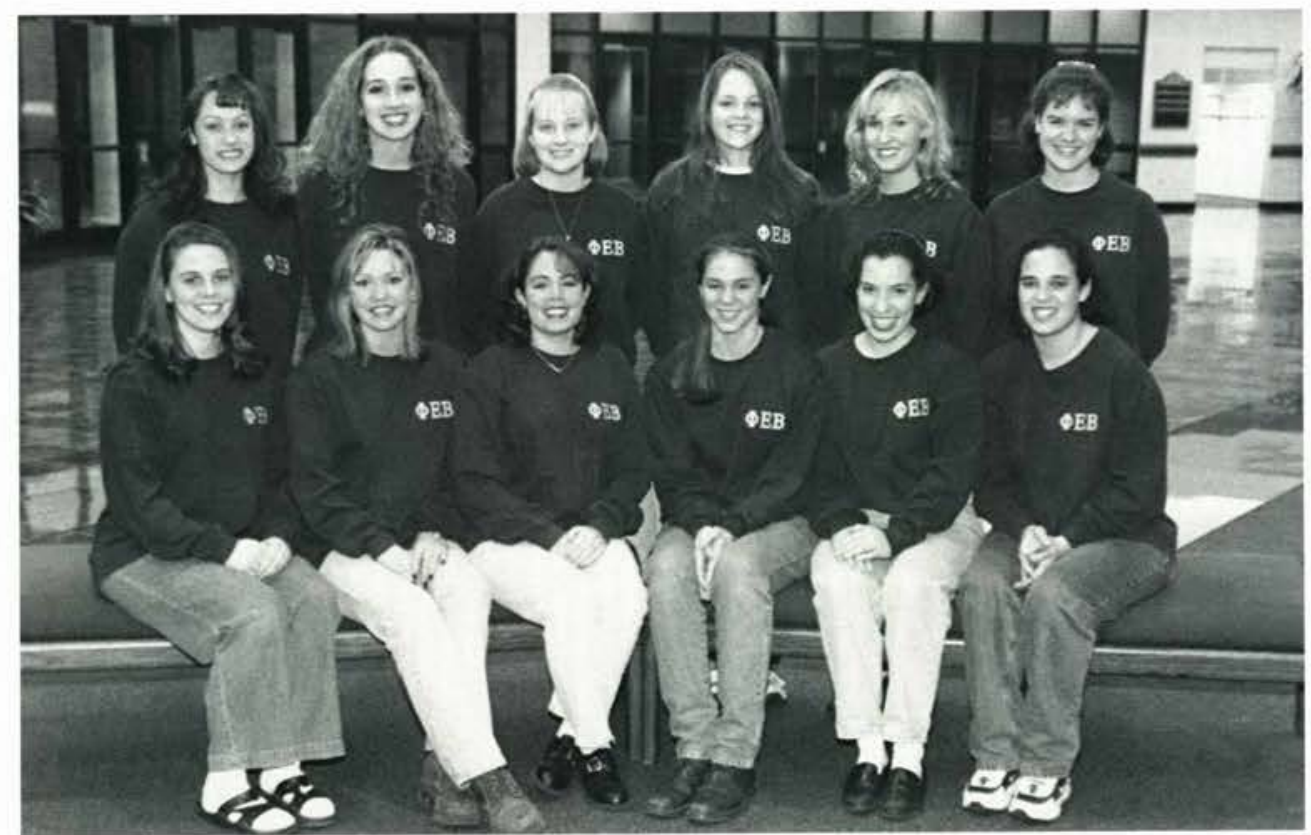

Phi Epsilon Beta

F: Sarah Hennis, Many Mc Guire, Clara Clark, Sarah High, Andrea King, Noella Fisher B: Lori Brown, Krista Byler, Tiffany Burgett, Melissa Powell, Karen Hayes, Jennifer Howard Not Pictured: Lisa Warren, Bekah Blackwood, Beth Vencill, Joy Hasty

\section{A \\ $\pi$ \\ $\Omega$ \\ $\phi \quad \Sigma$ \\ $\Lambda$ \\ $\Phi$ \\ $\chi$ \\ $\Psi$ \\ $\Delta$}

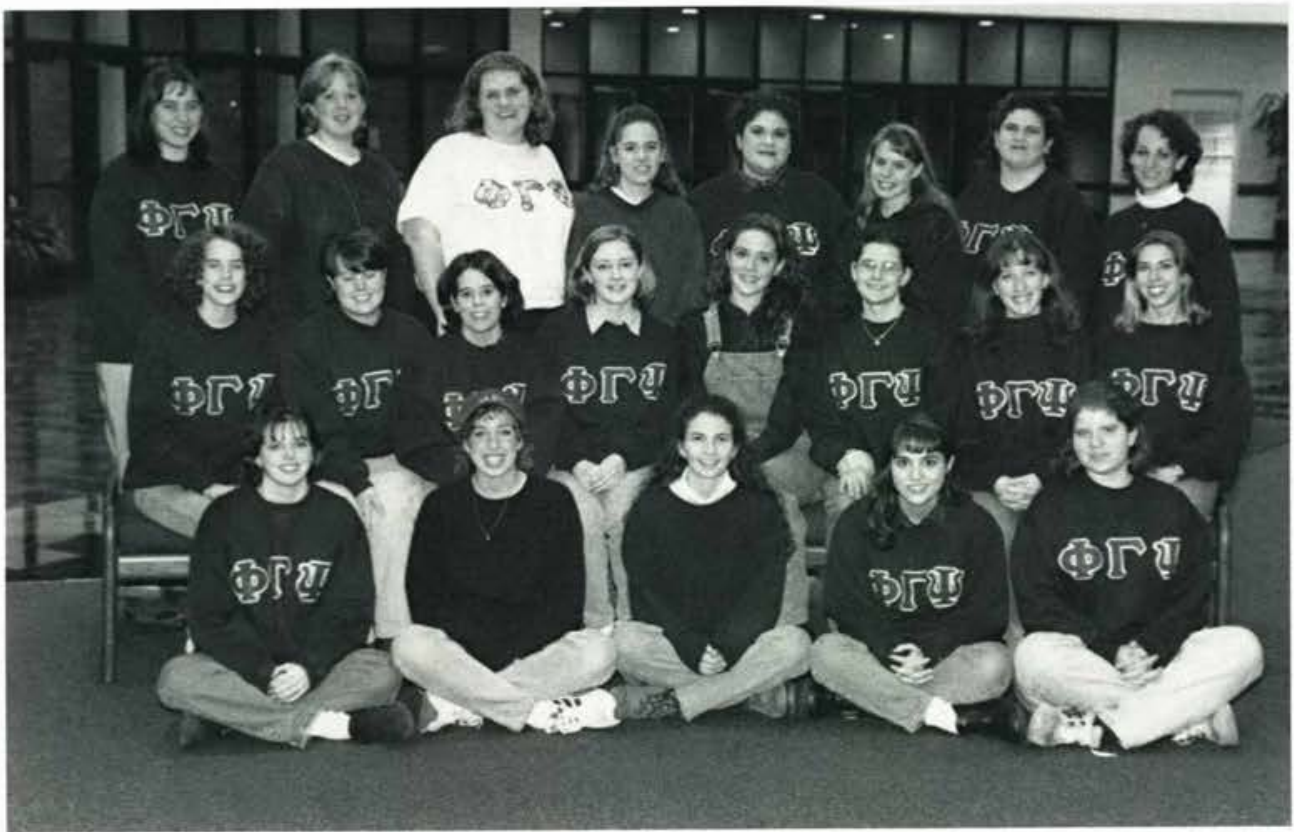

\section{Phi Gamma Psi}

all photos by DaVor

F: Juile Horne, Molly Heaton, Charity Rizer, Heidi Mountz, Jill Townsend, Ryan Anderson

M: Jennifer Tegtmeier, Cara Harju, Stephanie Jones, Melissa Crawford, Summer Bennington, Emily Weber, Amanda Mullen, Jen Vander Bush B: Erin Jopson, Jill Shearer, Heather Murdoch, Kyra Gray, Jocelyn Jones, Jenn Dolby, Heather Jackson, Gretchen Dorman

Not Pictured: Rene Rosencrantz, Heather Brode, Michelle Olson 


\section{PiDelta}

F: Jamie Cartwright, Joy Wickholm, Erika Olin, Amy Bohn, Kara Doden, Patty Noble, Andrea Endicott, Courtenay Shoaff, Amy Clutz

M: Rob Mulvaney, Summer Schafer, Lori Brown, Kendra Stanton, Holly Sorensen, Karen Hayes, Jennifer Paulik, Emily Davis, Karisa Linafelter, Erin Barker, Rebecca Leatherman

B : Elizabeth Johnson, Mike Crawford, Ryan Anderson, David Boyd, Jason Atwell, Heather Murdoch, Tim Flowers, Andrew Marshall, Kevin Boblitt, Jonathan Murphy, Joseph Qussar, Ross Meyers, Alicia Baisley, Jason Grahame, Joshua Rupp

\section{Republican Club}

Officers: David Meckley, Andrea Butz, Kirk LeBlanc

\section{ROTC}

F : Nathan Houck, Joanna Cormany, Ann Kobiela, Jeremy Preston, Adam Rizer

M: Emily Weidler, Paul Best, Nick Chou, Rachel Turkis

B : Brett Frey, Tim Sutton, Bobby Ray Johnson II, Matt Synder, Kevin Leverson, Catherine Clagg, Jon Burson, P.J. Puryear, Jeremy Mix, Brandon Dow, Pam Clause
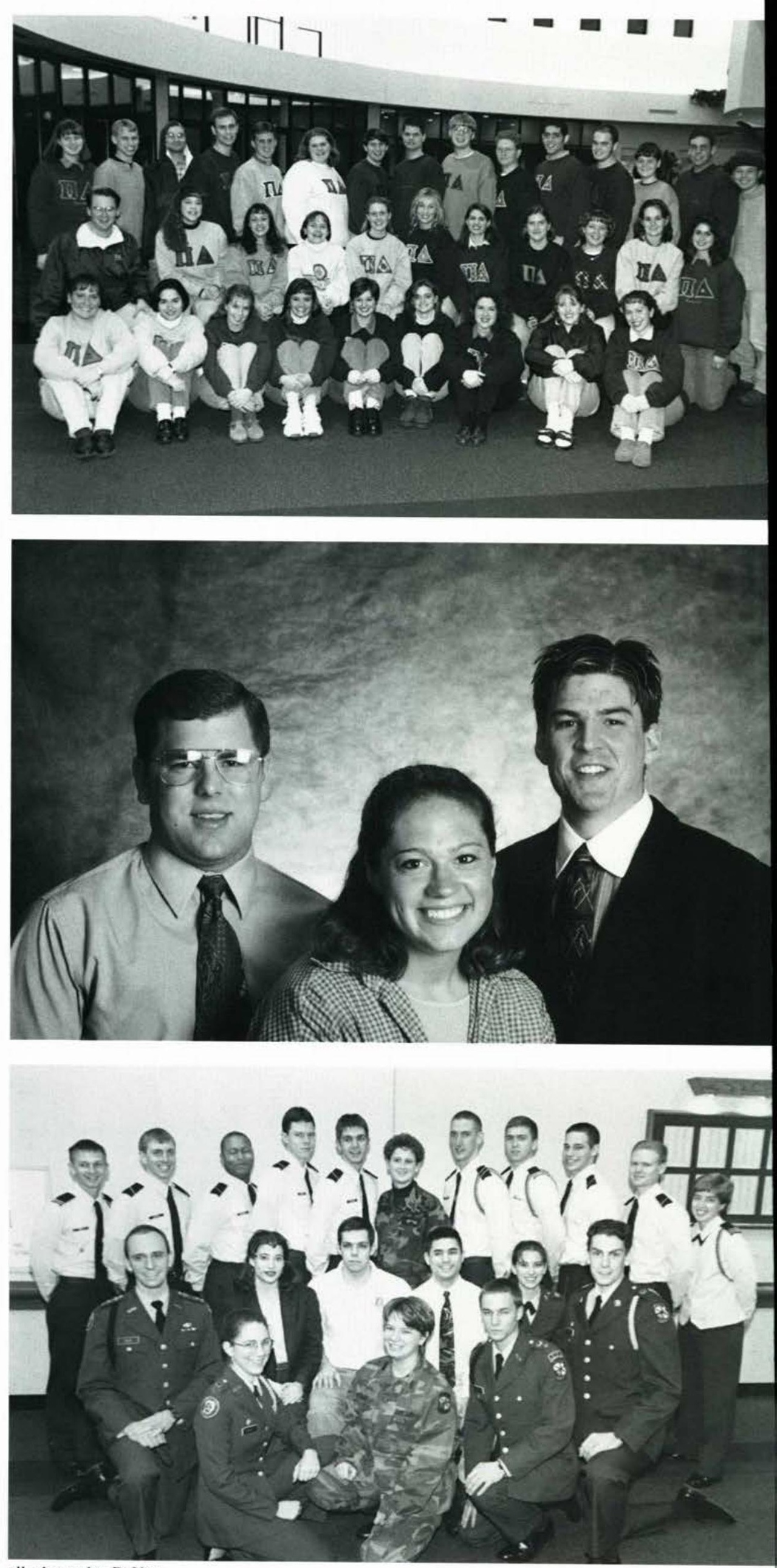

all photos by DaVor 


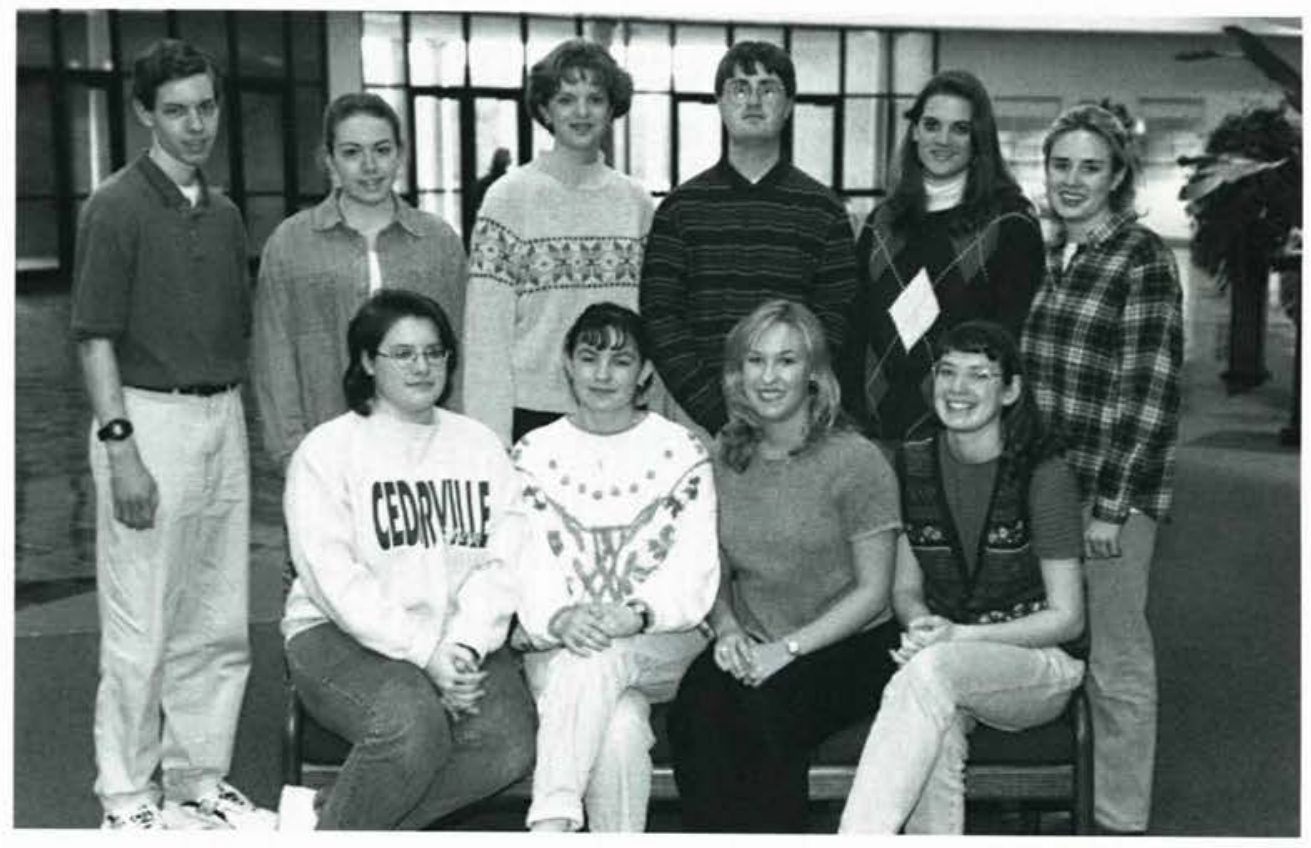

Spanish Club

F: Nicole Sweet, Edith Granillo, Karen Hayes, Janette Baker

B: Adam Rorex, Adaline Shultis, Jennifer Willis, Chris Robertson, Michelle Clane, Dana Walter

A $\quad \begin{array}{llllllllllll} & \Omega & \phi & \Sigma & \Lambda & \Phi & \chi & \Psi & \Delta\end{array}$

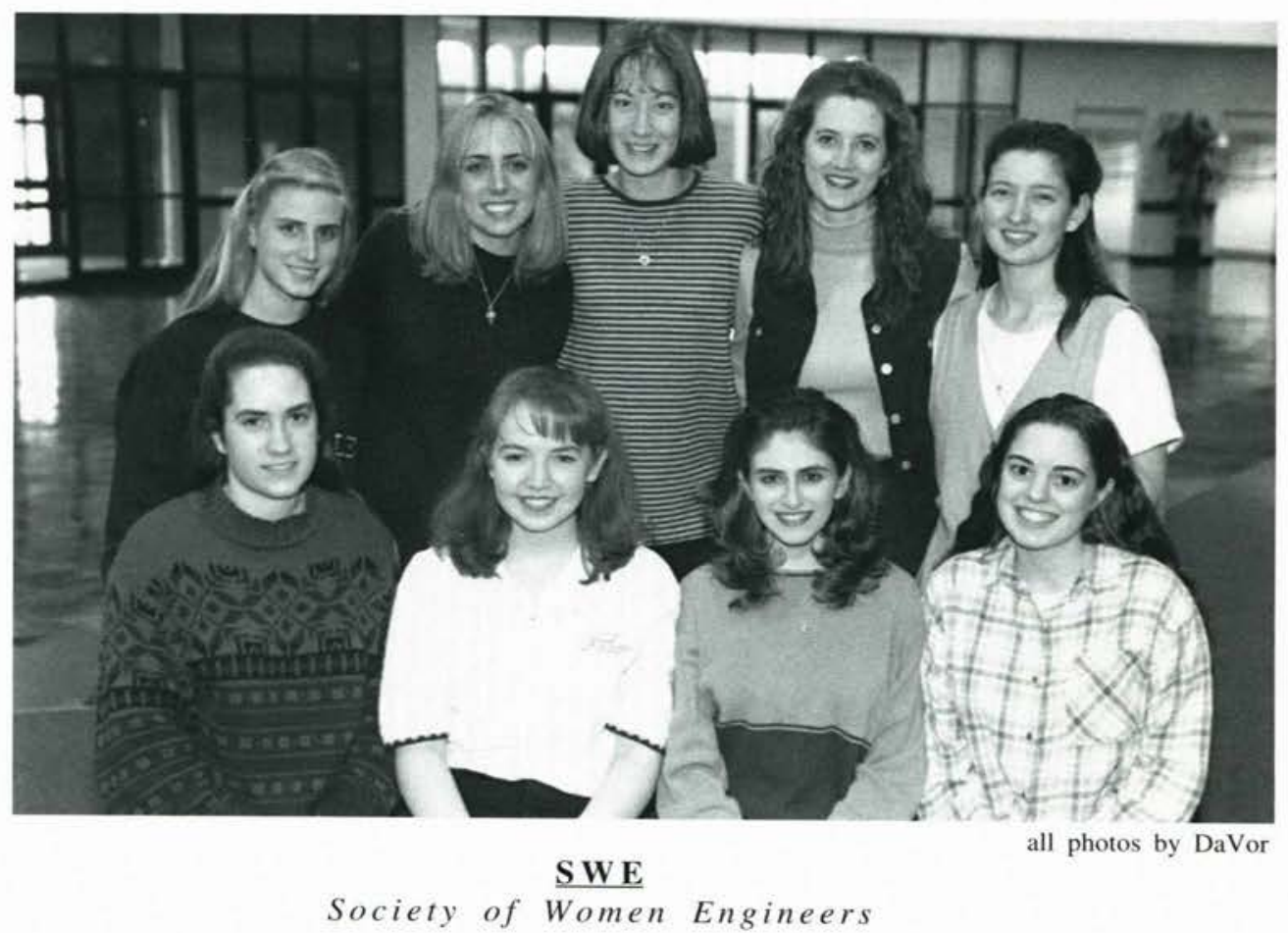

F: Krista Wood, Amy Morse, Stacie Bennett, Amy Carpenter

B: Heather Maybury, Robyn Dressler, Jenny Elliott, Juile Armour, Deborah Pittman 


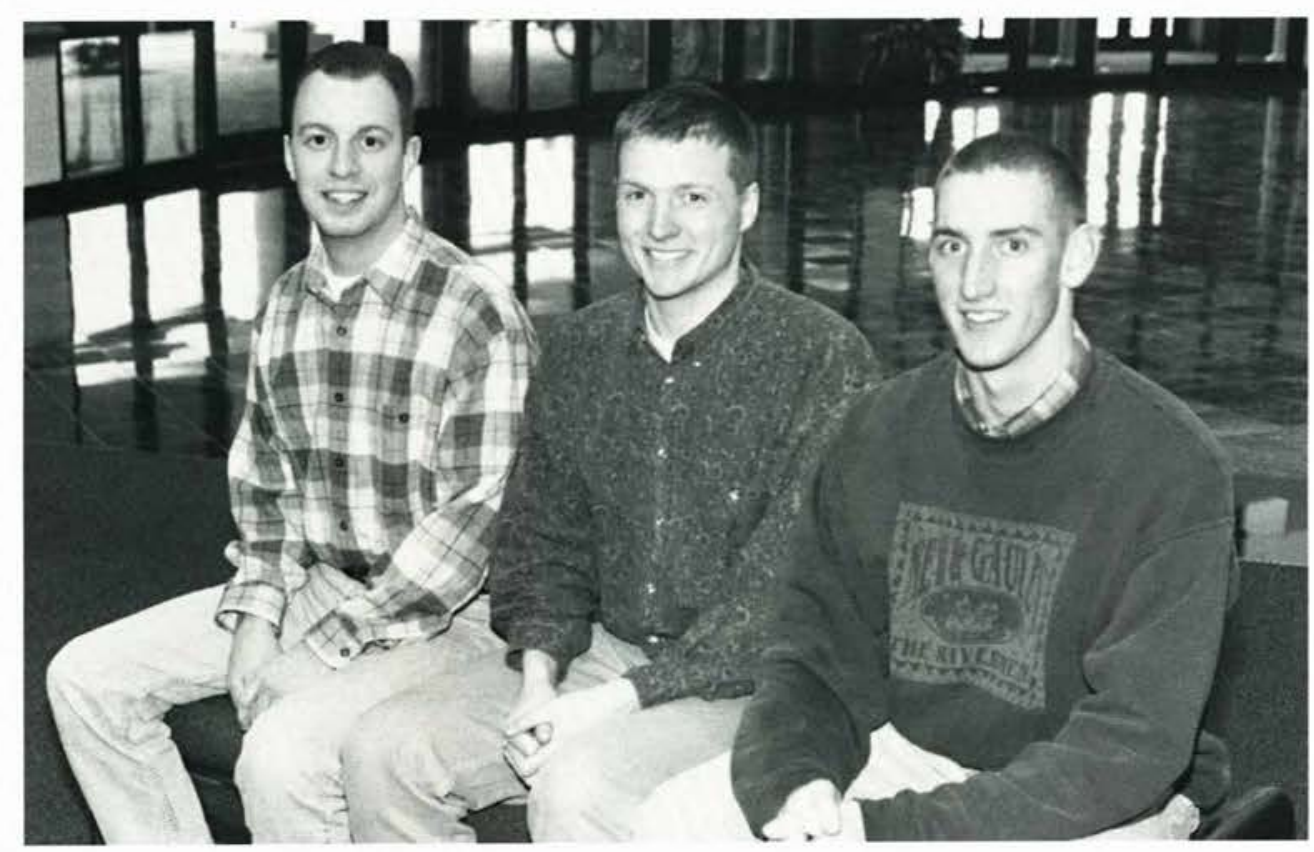

Tau BetaAlpha

Daniel Hicks, Rob Bouwens, Jon Burson

Not Pictured: Ryan Burkhard, David Carl

$\mathrm{A} \quad \pi \quad \begin{array}{lllllllll}\pi & & \boldsymbol{1} & \Lambda & \Phi & \chi & \Psi & \Delta\end{array}$

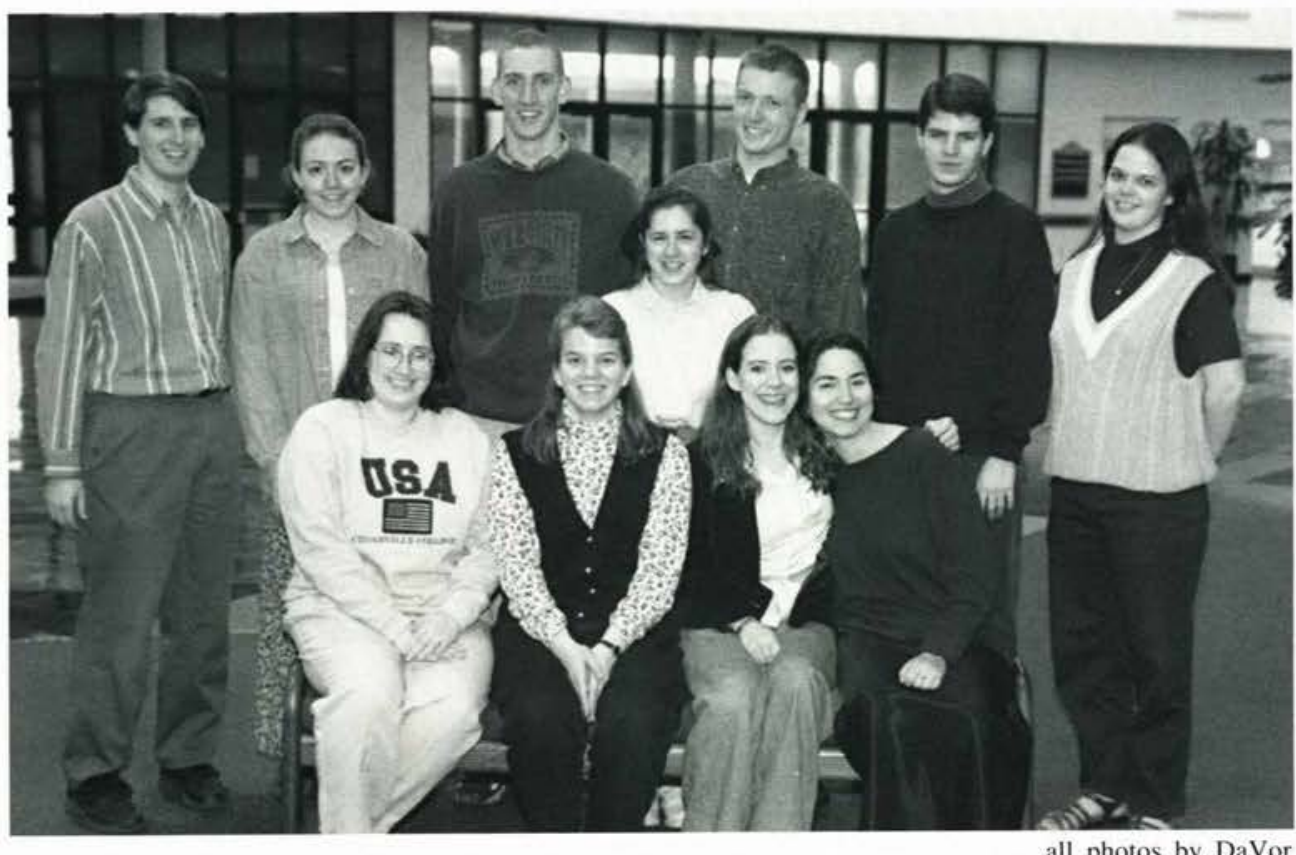

TauDeltaKappa

F: Kelly Burggraf, Erin Tuinstra, Lisa Walker, Joy Wickholm

B: Tim Flowers, Adaline Shultis, Jon Burson, Patricia Hershberger, Rob Bouwens, John Metcalf, Vanessa Baker 


\section{Theta RhoEpsilon}

F : Mark Clark, Roger Randall, Jon Wu, Tim Simon

M: Jim Amstutx, Jim Johnson, Steve Light, Tim Amstutz, Joshua Ausfahl, Jeremy Toyer

B : Andy Kempe, Shawn Shipp, John Mac Aurthor, Chris Moles, Jeff Beste - Advisor, Jeff Neuman,

Tom Leightenheimer, Jon Basner, Ernest Clark Jr., Brad Neese

Not pictured: Chris Vitarelli, Michael Dorsey, Paul DeKruyter

\section{U99.5FM}

F : Sarah Carr, Josh Gunderson, Sara Miller, Leah Caldwell, Josh Snyder, Rob Kirby, Craig Magrum, Eric Svendsen

M: Don Chapin, Jessica Acker, Ahlam Boland, Jamie Wyrtzen, Shelley Stock, John Ward, Mark Allen, Patty Noble, Jeff Nafziger, Paul Lykowski

B : Krista Warder, Timothy Hilgeman, David Cook, Jenny Maass, Ryan L. Freed, Joshua Bean, Jordan Culp, Brenon Christopher, John Dearie, Ben H. Stutzman, Joel Peterson
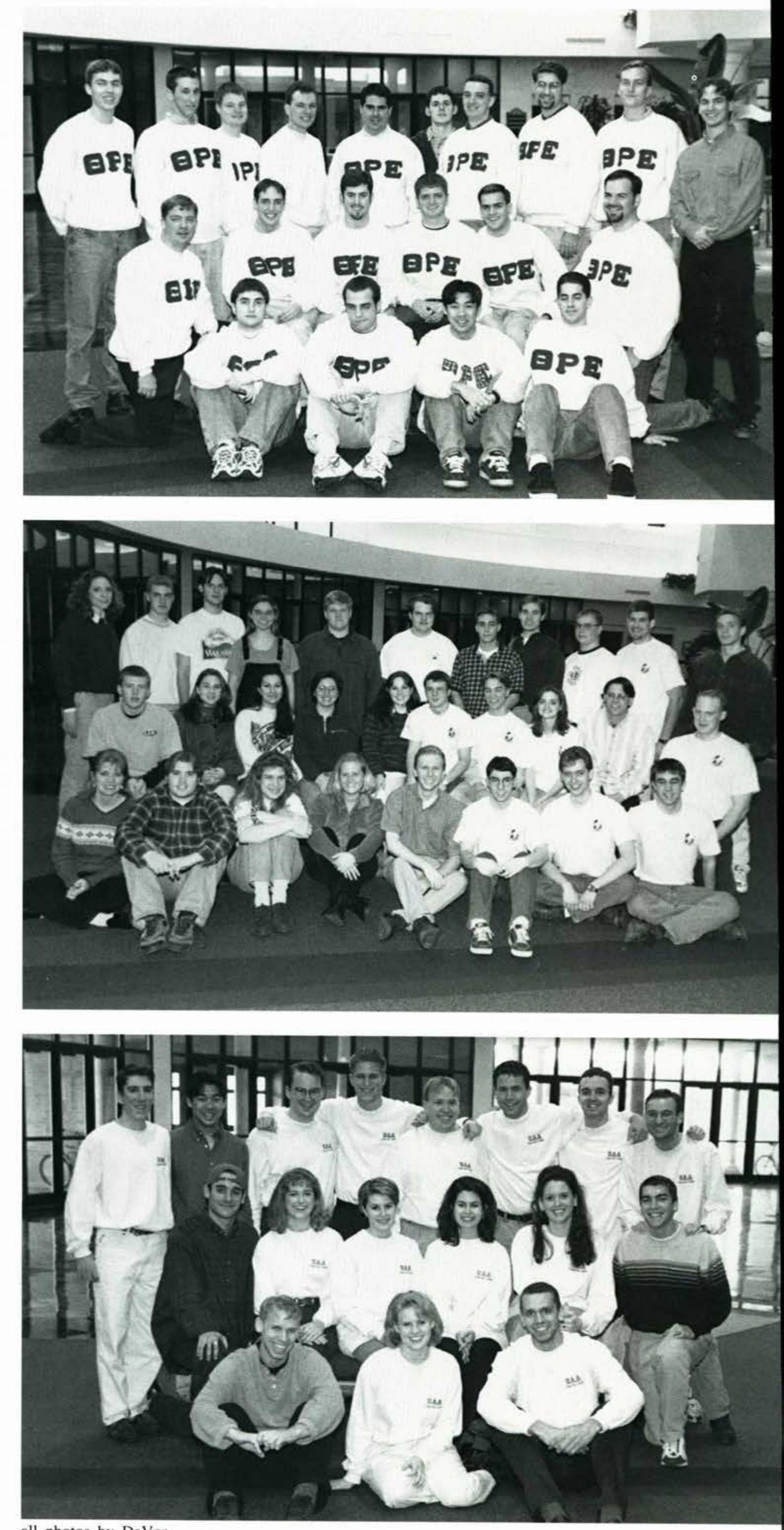

all photos by DaVor
UAA

Undergraduate Alumni Association

\section{F : Mike Crawford, Julie Forstrom, Darin Rosenvold}

M: Anson Hanbury, Emily Wilijamaa, Becky Crosson, Rebecca Uphan, Alissa Whitten, Ryan Coverdell

B : Matt Murphy, Jon Wu, Rob Mulvaney, Dave Rooke, Matt Hamer, Josh Amos, Mark Wood, Ryan Anderson 
ATHLETIC
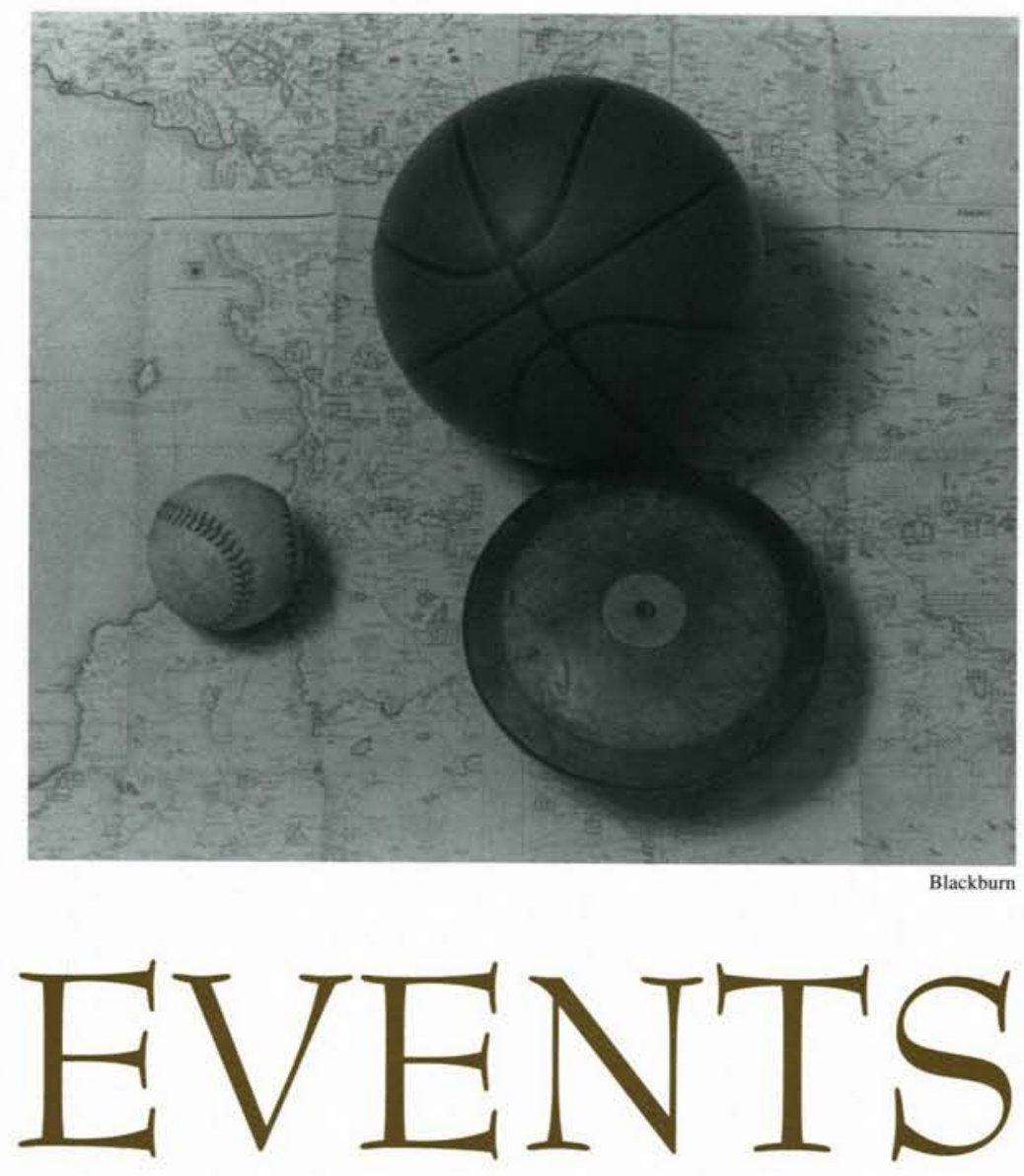

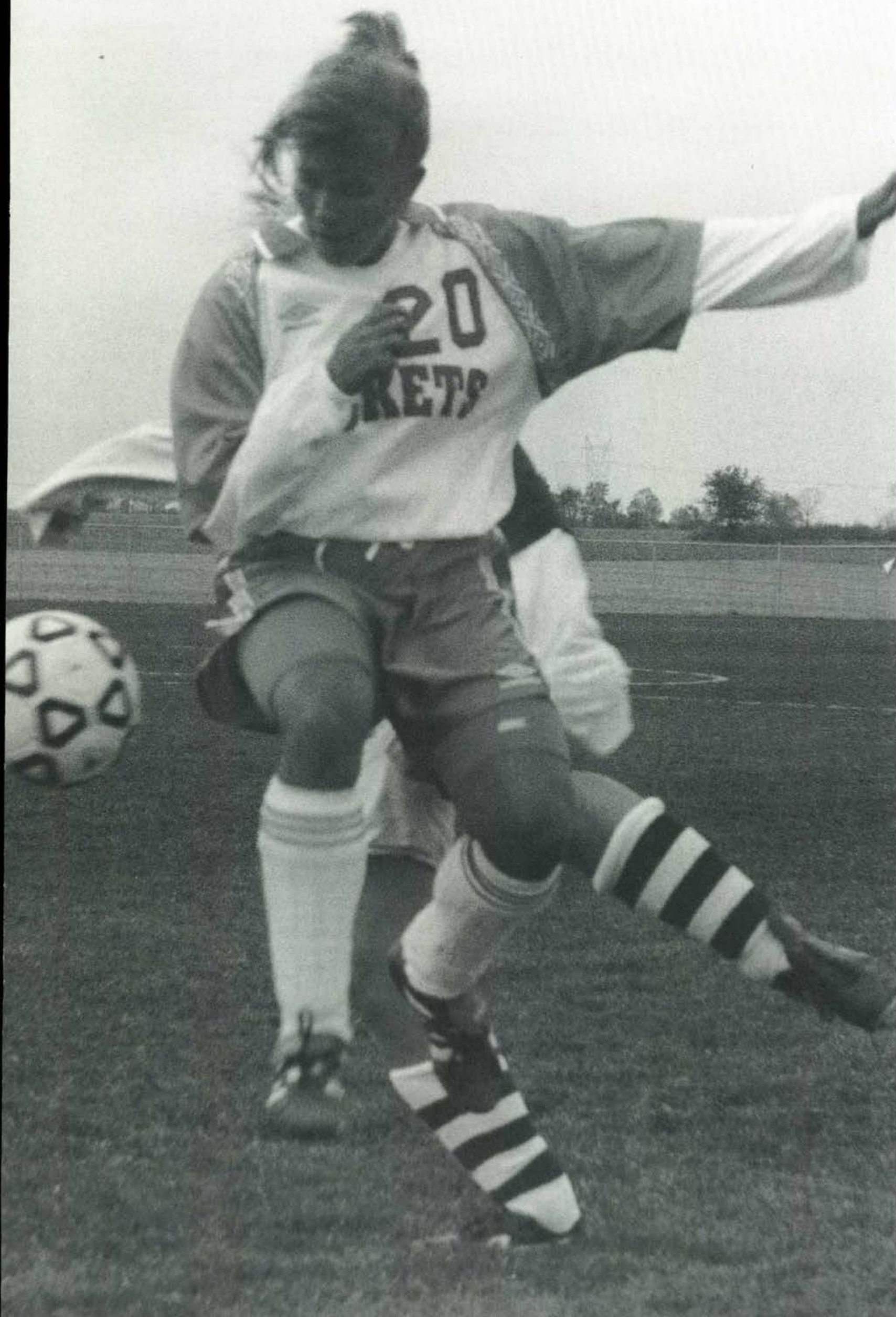

Cedarville women's soccer proves to be a winning addition to the lineup of Varsity sports at CC. Rachel Soderstrom shows determination as she fights her opponent for the ball. 


\section{Jackets Reach for Victory}

\section{The women's volleyball team rolled to a 30-}

\section{2 overall record for their third straight 30-win season.}

The Lady Jacket volleyball team rolled to a $30-12$ overall record for their third straight 30 win season. The spikers finished thirdin the Mid-OhioConference at 11-5, won two invitational tournaments, and again qualified for the MOC Tournament under second-year head coach Teresa Clark.

Juniorhitter Julie Opperman became only the fourth playerin school history to surpass 1,000 career kills as she raised her total to 1,386 . She led the MOC in attack percentage (.371) and ranked second in kills per game (4.11). Opperman was voted to the All-MOC First Team and the All-NCCAA Midwest Region squad. Classmate Julie Barkhaus joined Opperman on both of those all-star teams with herall-around performance. She rated first for Cedarville in assists and was second in kills and digs. Suzanne Lehman, another junior, was voted to the AllMOC Second Team after leading the squad in digs. Setter Lori Bunger earned a spot on the All-MOCFreshmen Team. Senior all-around performer Lisa Wood racked up numerous academic honors and graduated with a 4.0 grade point average. She was recognized for NAIA and NCCAA AllAmerica Scholar-Athlete accolades for the second straight year. Additionally, she was named to the GTE Academic All-America Third Team. On the court, she committed just eight service errors in 823 attempts for a .990 accuracy and finished second on Cedarville's all-time serve percentage list. The Lady Jackets notched tournament championships at Olivet and Indiana Wesleyan. They placed second in the 10 th Annual Cedarville Invitational.

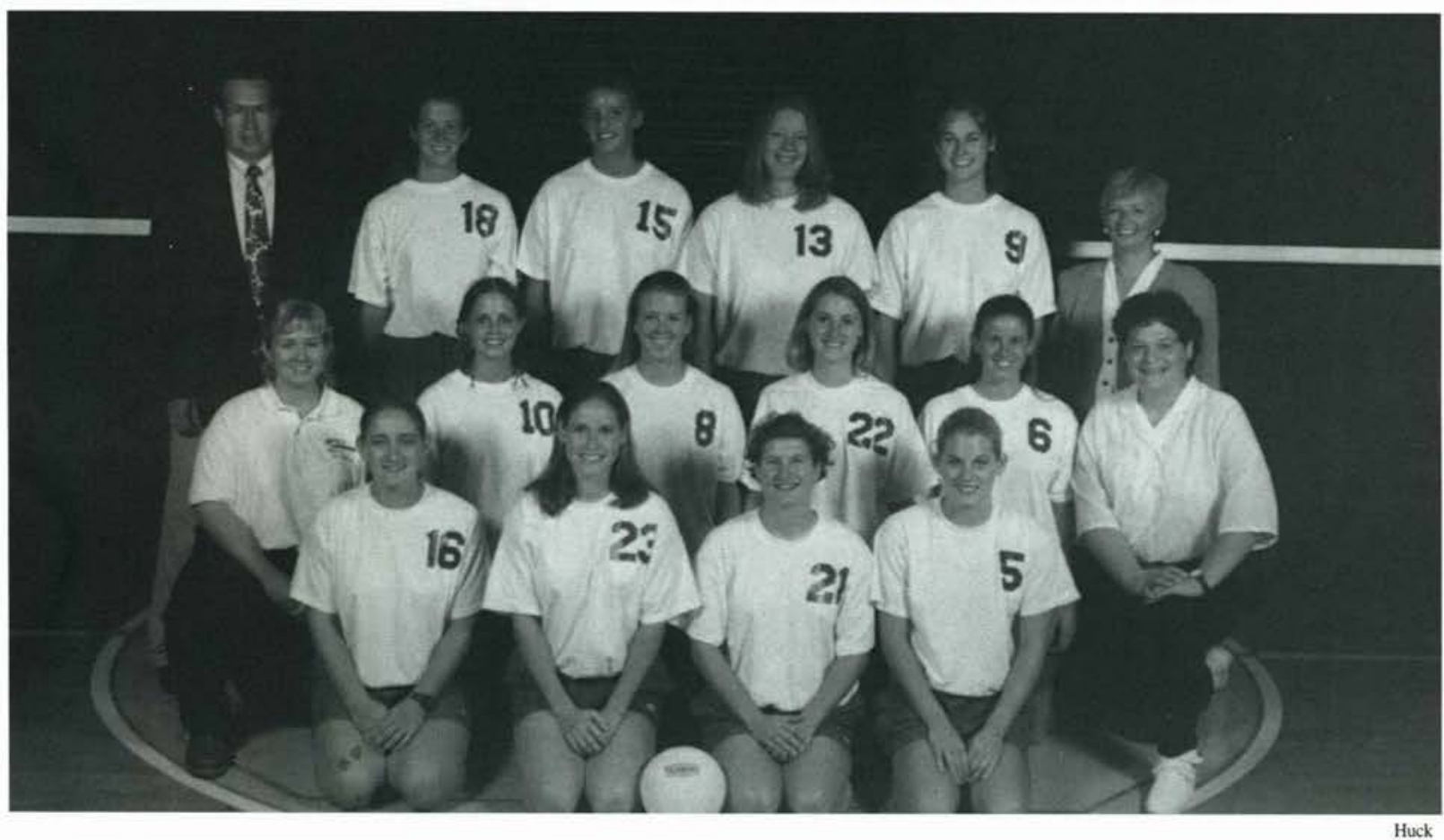

Women's Volleyball Team: Row 1:(1-r) Suzanne Lehman, Bethany Comer, Rachel Tilton, Julie Barkhaus. Row 2: Student-Trainer Alissa Williams, Lori Bunger, Karen Eccleston, Heather Scheffel, Amanda Johns, Team Chaplain Cheryl Fawcett. Row 3: Assistant Coach Jim Clark, Lisa Wood, Leah Ziegenfuss, Julie Opperman, Miranda Woller, Head Coach Teresa Clark. 


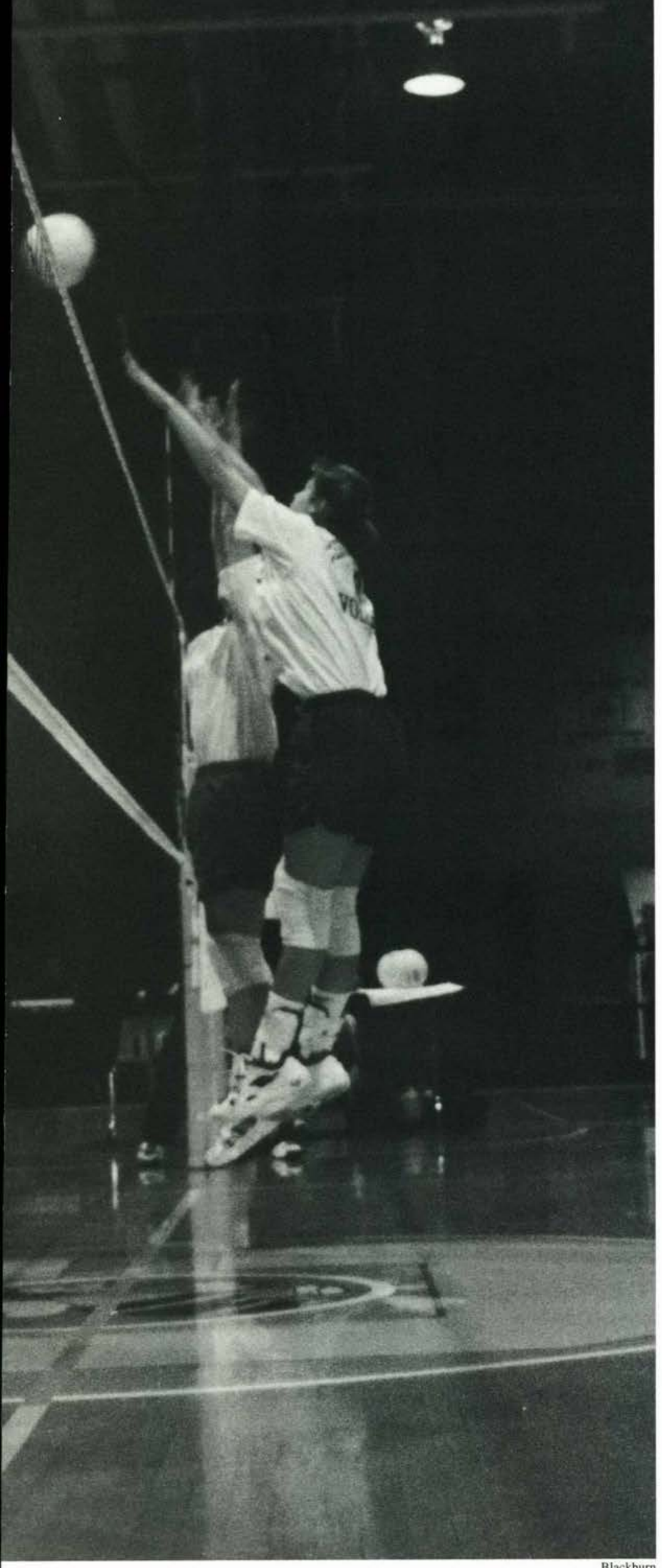

\begin{tabular}{llll|}
\hline & & \\
Northwood (Fla) & Won & Wilmington & Won \\
Shawnee State & Won & Ohio Dominican & Won \\
Grace & Lost & Shawnee State & Won \\
Urbana & Won & Mt. Vernon Nazarene & Lost \\
Indiana Wesleyan & Won & IUPU-Indianapolis & Won \\
Findlay & Won & Indiana Wesleyan & Won \\
Indianapolis & Won & Tri-State & Lost \\
St. Francis & Won & Trinity International & Won \\
Kenyon & Won & Rio Grande & Won \\
Mt. Vernon Nazarene & Lost & Tiffin & Won \\
Olivet & Won & Cumberland (Ky.) & Won \\
Barat & Won & Urbana & Won \\
Manchester & Lost & Concordia & Won \\
Olivet & Lost & Indiana Wesleyan & Won \\
Manchester & Won & Grace & Lost \\
Taylor & Won & Mount St. Joseph & Lost \\
Walsh & Lost & Ohio Dominican & Won \\
Malone & Won & Walsh & Lost \\
Urbana & Won & Malone & Won \\
Tiffin & Won & Rio Grande & Won \\
Heidelberg (at Tiffin) & Won & Tiffin & Lost \\
& & & \\
\hline
\end{tabular}

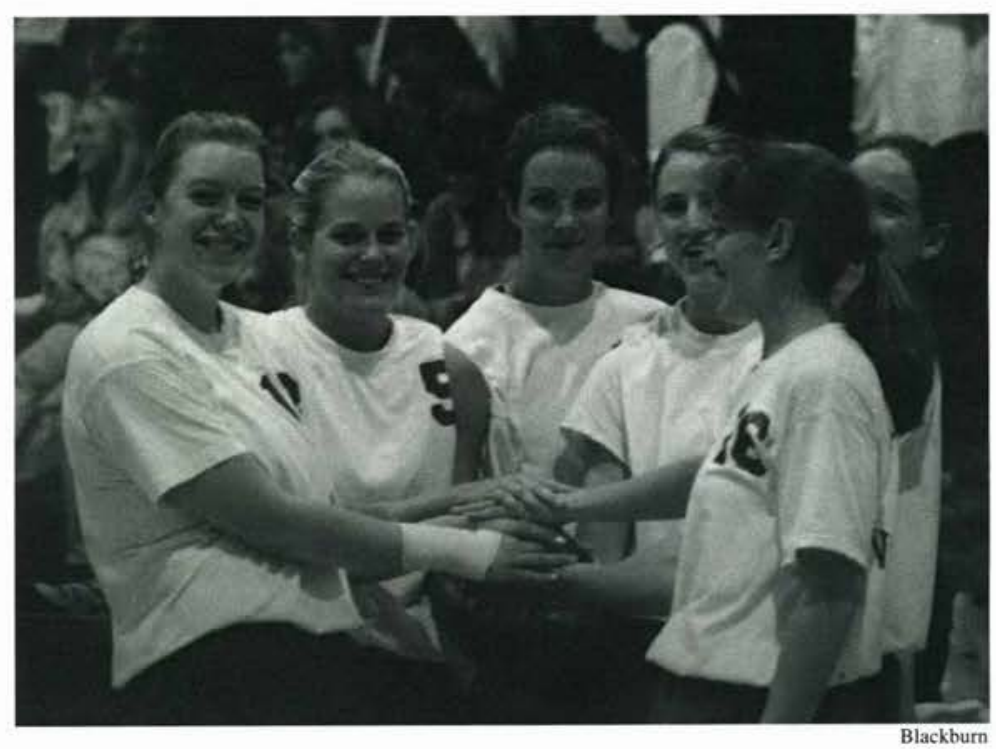

Two of the Lady Jackets team up to

block an opponent's shot during a match (left).

Julie Opperman, Julie Barkhaus, Lisa

Wood, Heather Scheffel, Suzanne Lehman, and Bethany Comer show that teamwork is the key to success (above). 

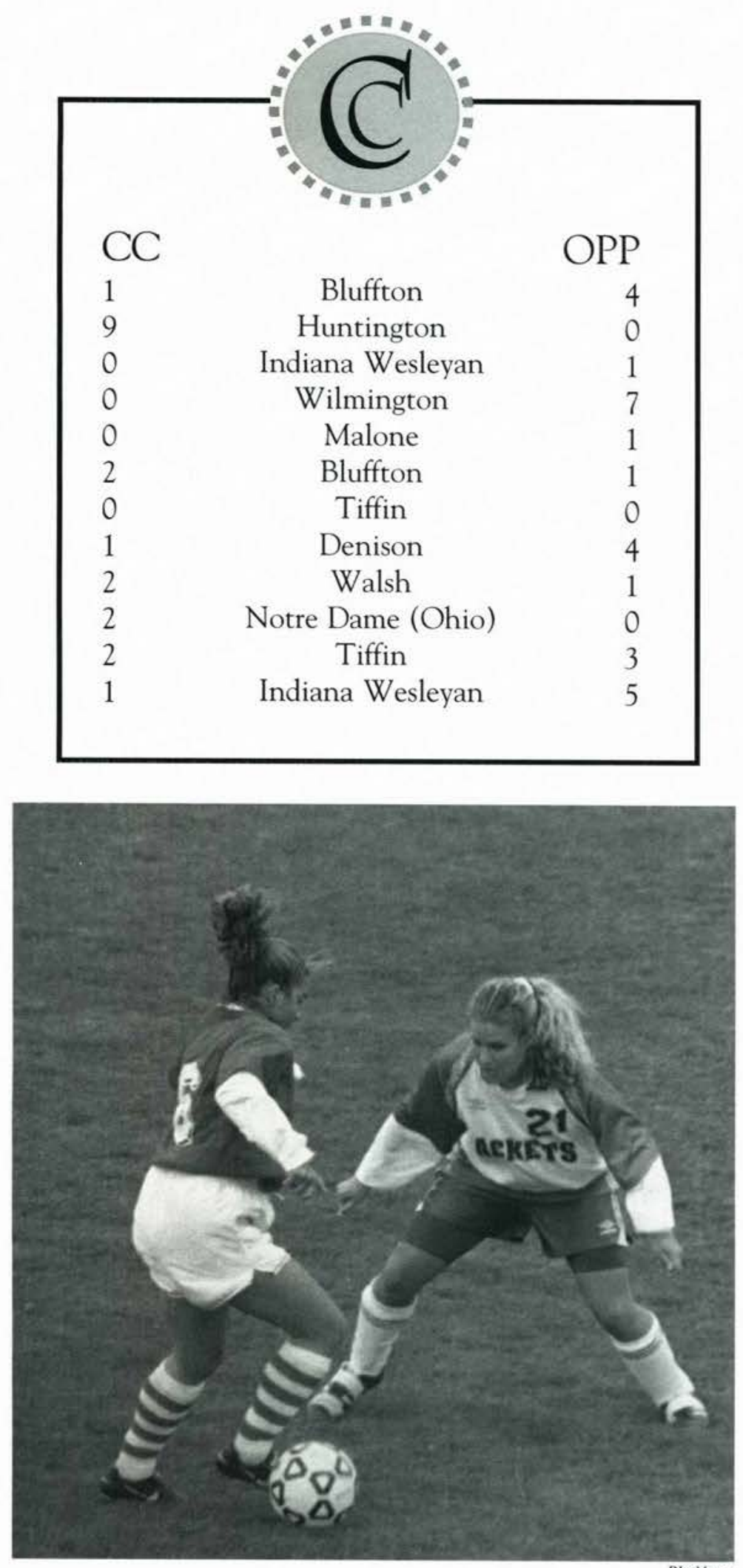

Freshman Amanda Yoder works to defend an opponent. Yoder was a tremendous asset during the Lady Jackets first season.

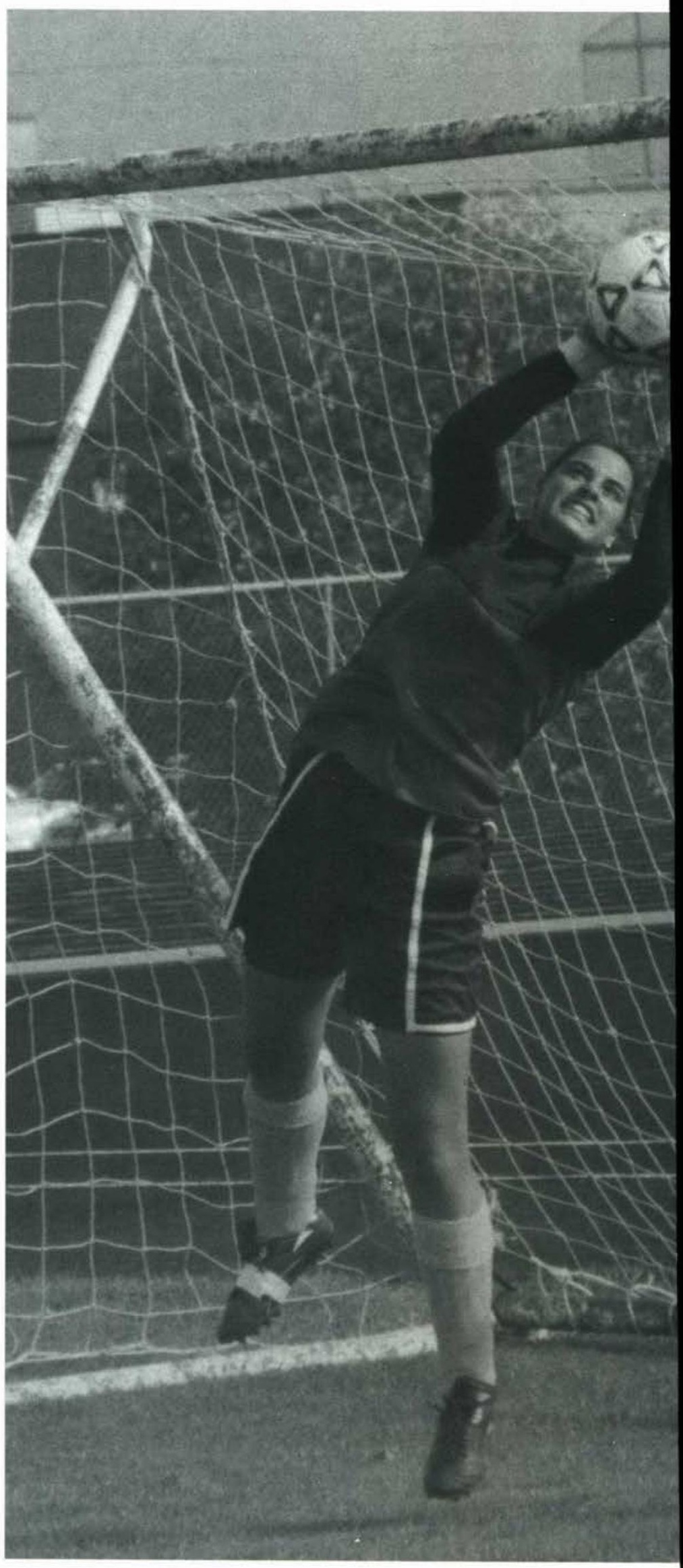

Sophmore Katie Mummau makes a tremendous save for the Jackets. Mummau lead the team in saves with 138 . 


\section{Lady Jackets Shoot to Win}

The new varsity sport on campus in 1997 was women's soccer and the Lady Jackets had a lot of positive things to talk about following a 4-7-1 season under head coach Dave Dillon. Cedarville qualified for two postseason tournaments and even hosted one game, had two players earn All-America honors, and had three members garner All-America ScholarAthlete recognition. The historic first match in school history resulted in a 4-1 setback at Bluffton. Freshman Allison Hume netted the program's first goal. It didn't take long for the women to record their first win as they blew past host Huntington, 9-0. Rookie forward Kristen DeVinney scored four goals in the match and Rachel Soderstrom was credited with Cedarville's first-ever assist.

\section{Women's
lishes itse
sity sport.}

Following three shutout losses, two by 1- 0 scores, the Jackets played their home opener against Bluffton. This time they turned the tables on the Beavers, 2-1, with DeVinney getting both goals. The biggest win of the season came in a 2-1 upset of Walsh, who entered the match ranked No. 6 in the NAIA Great Lakes Region. Stephanie Aittama scored the gamewinner with only 12 minutes left. Afterending the regular season with a 2-0 win at Notre Dame College, the Jackets dropped a four overtime marathon at home to Tiffin, 3-2, in a Mid-
Ohio Conference playoff match that was decided on penalty kicks. Cedarville's initial season finally ended in the NCCAA playoffs to eventual national champion Indiana Wesleyan. Junior back Lisa Thomson was voted the team's MVP and along with DeVinney, wholed the team in scoring with 10 goals and one assist for 21 points, were NCCAA All-America Second Team performers. Freshman goalkeeper Katie Mummau was voted to the All-NAIA Great Lakes Region First Team. Thomson as well as seniors Meredith Allgrim and Rachel Soderstrom were rec-

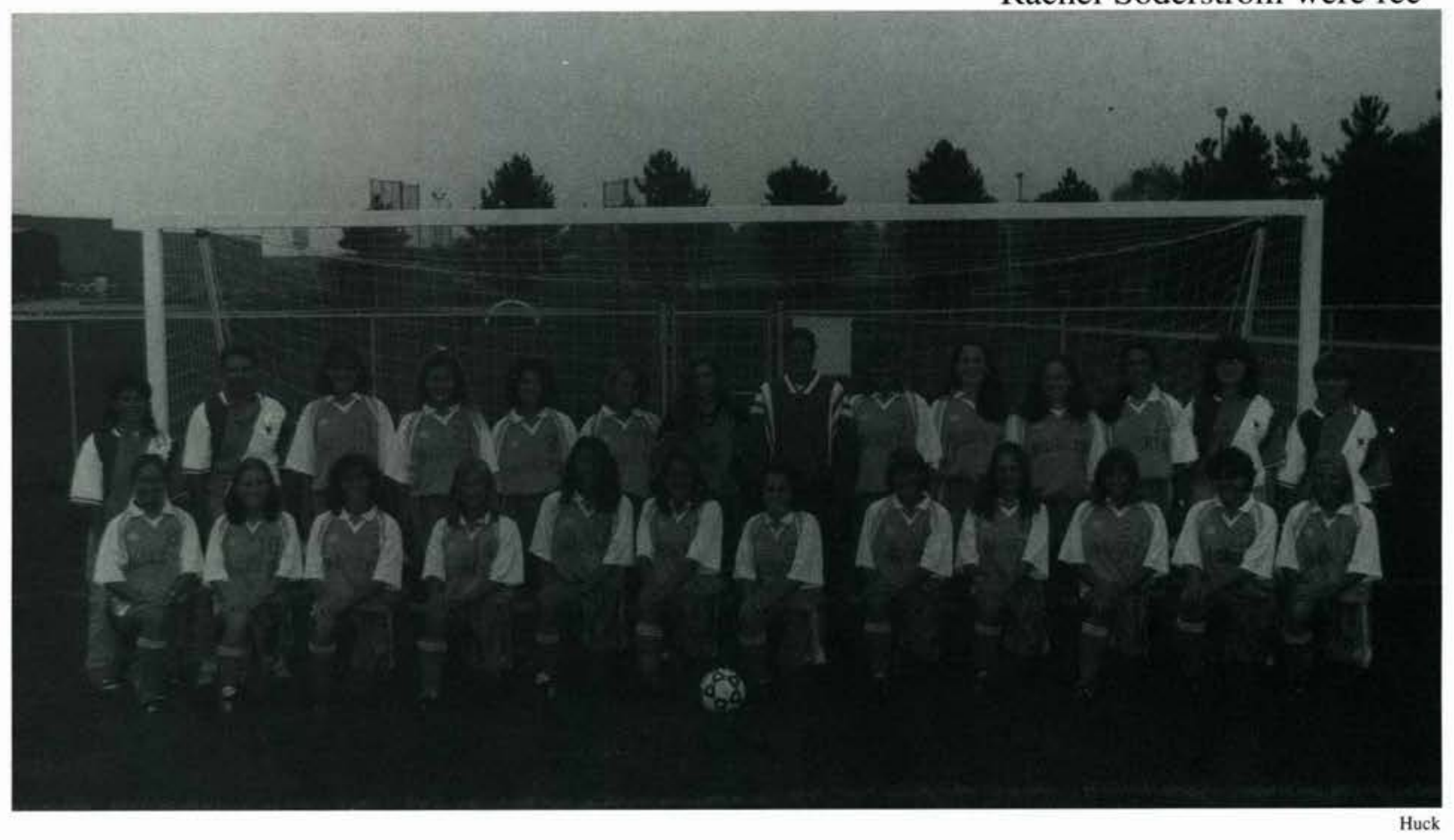

Women's Soccer Team: Row 1:(kneeling 1-r)Ann Ruegsegger, Andrea Creamer, Kristen DeVinney, Karen Hayes, Meredith Allgrim, Lisa Thompson, Michelle Miller, Carrie Orme, Rachel English, Rachel Soderstrom, Rachelle Paquin, Sheryl Buckley. Row 2:(standing 1-r) Assistant Coach Dawn Wambold, Head Coach Dave Dillon, Allison Hume, Amanda Yoder, Bethany Barch, Hannah Bryant, Siobhan Fagan, Katie Mummau, Rebecca Ashley, Christy Abbs, Amy Nyhuis, Melody Gbur, Manager Sarah Hills, Student Trainer Sheri Phipps. 


\section{Jackets Kick Way to Victory}

\section{Men's Soccer team uses new talent to achievesuccess on the field}

The Cedarville College men's soccer team finished the 1997 campaign with a 6-9-1 record overall and 2-4-1 in the MidOhio Conference under John McGillivray, who wrapped up his 24th year as head coach. The Yellow Jackets began and ended the season with impressive victories to go along with anotherHomecoming win. The kickers opened with an exciting 3-2 home victory over MidOhio Conference power Tiffin University. The Dragons entered the match having won 10 of the previous 13 league titles along with anine-game winning streak over Cedarville. However, once Dave Rutledge scored the season's first goal
11:30 into the match, the home teamnevertrailed. Rookiegoalkeeper Matt Powers made his collegiate debut with 16 saves. The Jackets later became the only regular season opponent to win at Mt. Vernon Nazarene. David Rooke scored the winner in the 2-1 decision and Matt Powers stopped a penalty kick. Cedarville edged Philadelphia College of Bible by a 2-1 count intheannualHomecomingmatch. The two teams played a scoreless first half before Dave Rutledge scored for the "Ville. After the Eagles tied it, Michael Hidalgo netted the game winner withDavidRookeassisting. The remaining highlight came in the season finale where seven Yel- low Jacket seniors bid farewell with a 4-1 home victory over longtime rival Asbury College. It was fitting that a senior figured in every Cedarville goal. Rooke paced the team in scoring with six goals and two assists for 14 points. He was named to the NCCAA All-America Second Team, the All-MOC Second Team, and was selected team MVP. Rutledge, who tied Hidalgoforsecondinteam scoring with five goals and three assists (for 13 points each), was again voted to the All-MOCFirst Team. He joined Rooke on the All-NCCAA Midwest Region First Team. Rockwood was tabbed to the All-NCCAAMidwestRegionSecond Team while Powers was an All-MOC Second Team choice. Seniors Andy Shaw and Ben Haffey were NCCAA All-America ScholarAthletes.

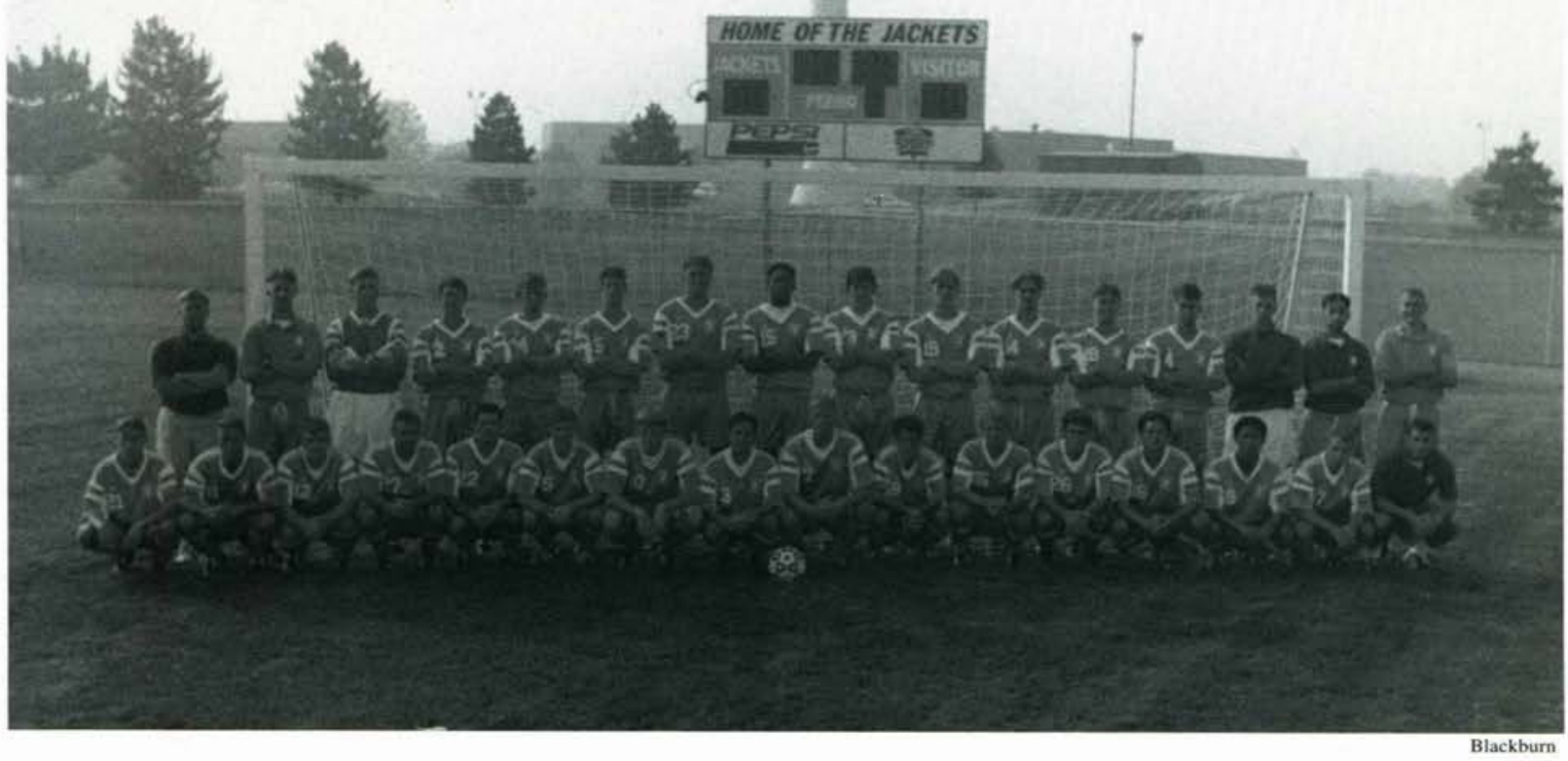

Men's Soccer Team: Row 1:(kneeling 1-r) Brett Carmichael, Jason Tovey, Tim Amstutz, Michael Tharp,Andy Shaw, Russ Pound, Reade Faulkner, Jeff Rockwood, David Rooke, Michael Hidalgo, Chris Brock, Tim Prusha, Aaron Cook, Pete Warinsee, Duane Hammond, Assistant Coach Roger Swigart. Row 2:(standing 1-r) Student Trainer Jim Amstutz, Manager Bill Workman, Jon Faulkner, Ben Nordaas, Chad Deakyne, Mike Moran, Nick Spaulding, Roddy Willis, Ben Haffey, Tim Rickert, Dave Rutledge, Josh Tackett, Derek Chandler, Matt Powers, Assistant Coach Jim Hunter, Head Coach John McGillivray. 


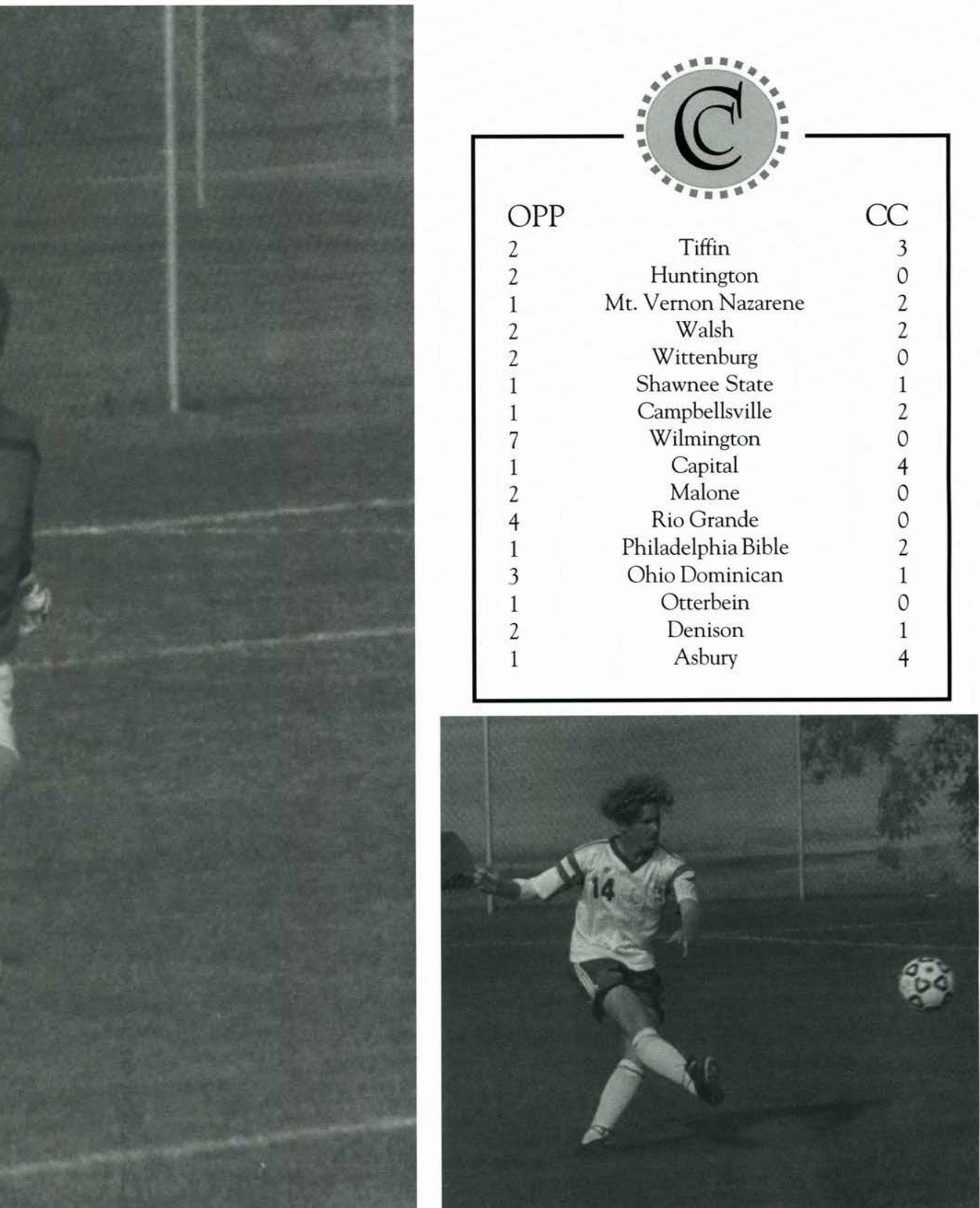

Junior Dave Rutledge focuses intently on his soccer game. Rutledge was second this year in goals with five for the season (above).

Freshman Matt Powers assists the Yellow Jackets as goalie. Powers led the team with 52 saves this season (left). 

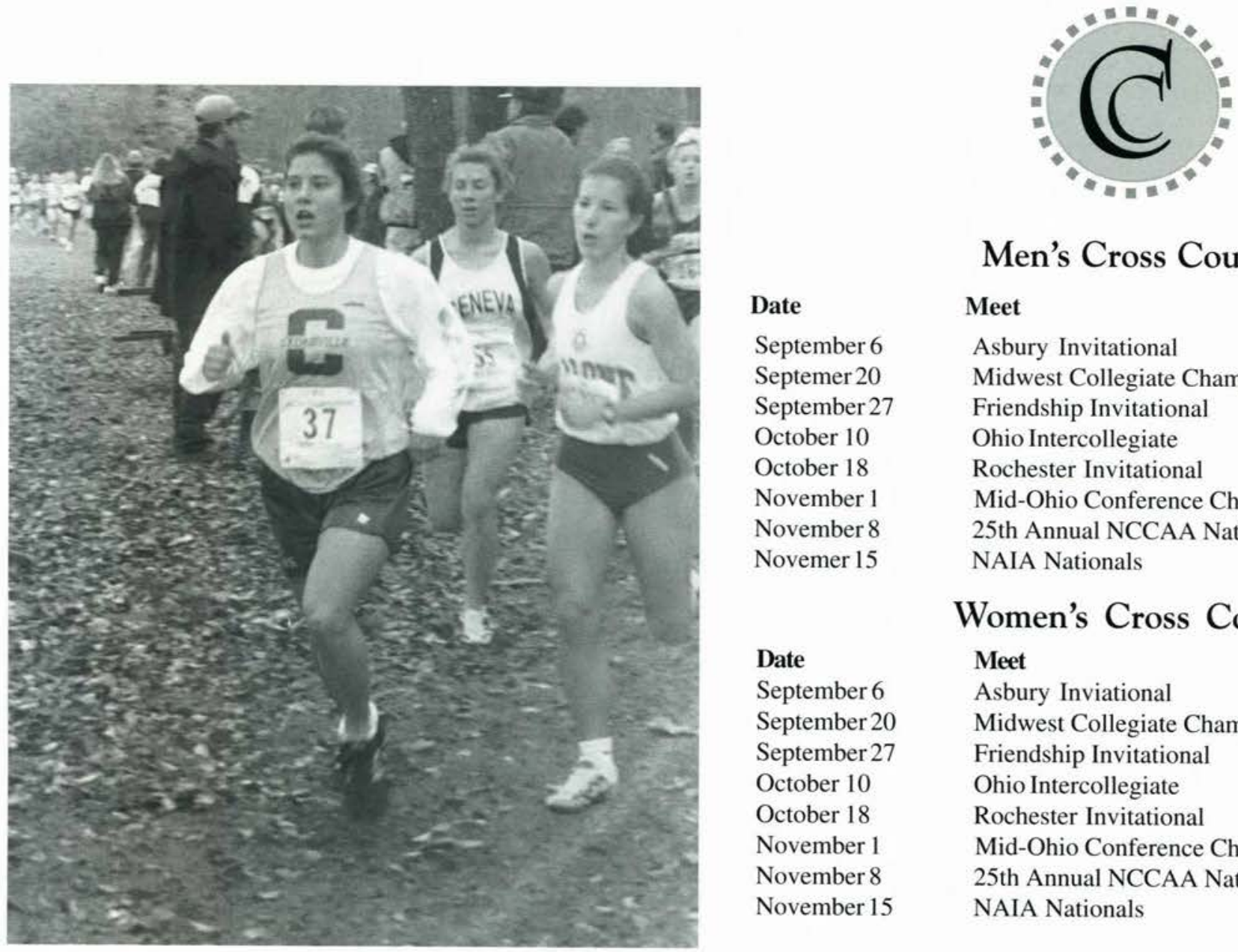

Date

September 6

Septemer 20

September 27

October 10

October 18

November 1

November 8

Novemer 15

Date

September 6

September 20

September 27

October 10

October 18

November 1

November 8

November 15

\section{Men's Cross Country}

\section{Meet}

Asbury Invitational

Midwest Collegiate Championships

Friendship Invitational

Ohio Intercollegiate

Rochester Invitational

Mid-Ohio Conference Championships

25th Annual NCCAA Nationals

NAIA Nationals

\section{Women's Cross Country}

\section{Meet}

Asbury Inviational

Midwest Collegiate Championships

Friendship Invitational

Ohio Intercollegiate

Rochester Invitational

Mid-Ohio Conference Championships

25th Annual NCCAA Nationals

NAIA Nationals
Result

2nd of

12 th of 2

1 st of

15 th of

1st of

2nd of

4 th of 2

12 th of 3

Result

2nd of

17 th of 3

2nd of 1

8 th of 3

3 rd of

3 rd of 5

2nd of $2 d$

19 th of 35

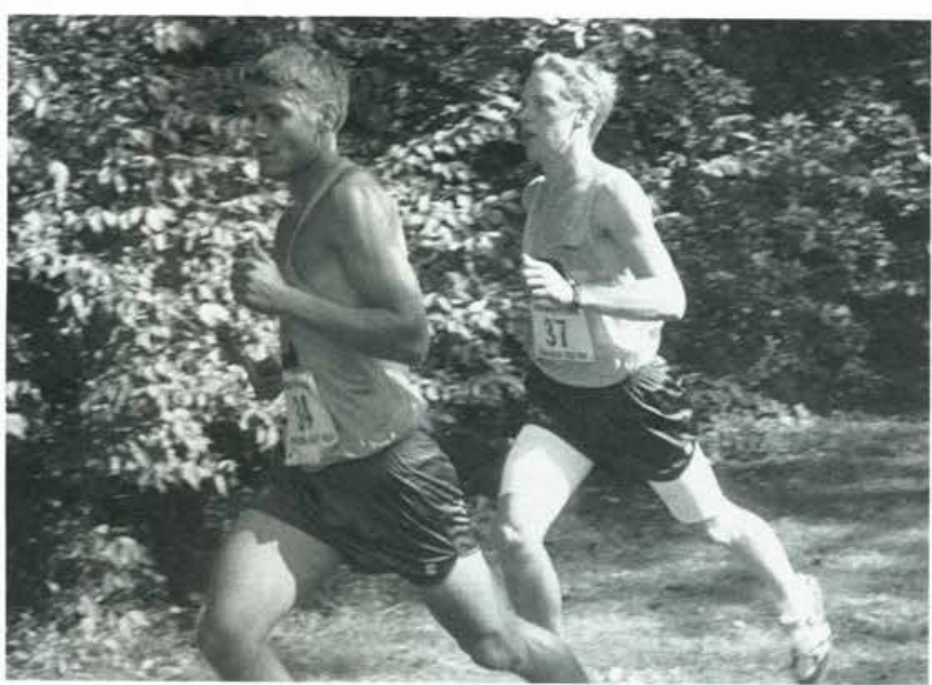

Christy Taylor leads the pack through a turn at a cross country meet. (top right)

Rachelle Elder and Becky Jordan encourage fellowship among the cross country teams. (middle right)

Scott Ruhlman focuses on the journey ahead. (middle left)

Ed Letts, Ben Thompson, and Joel Peterson hold their place in the race with determination. (bottom left)
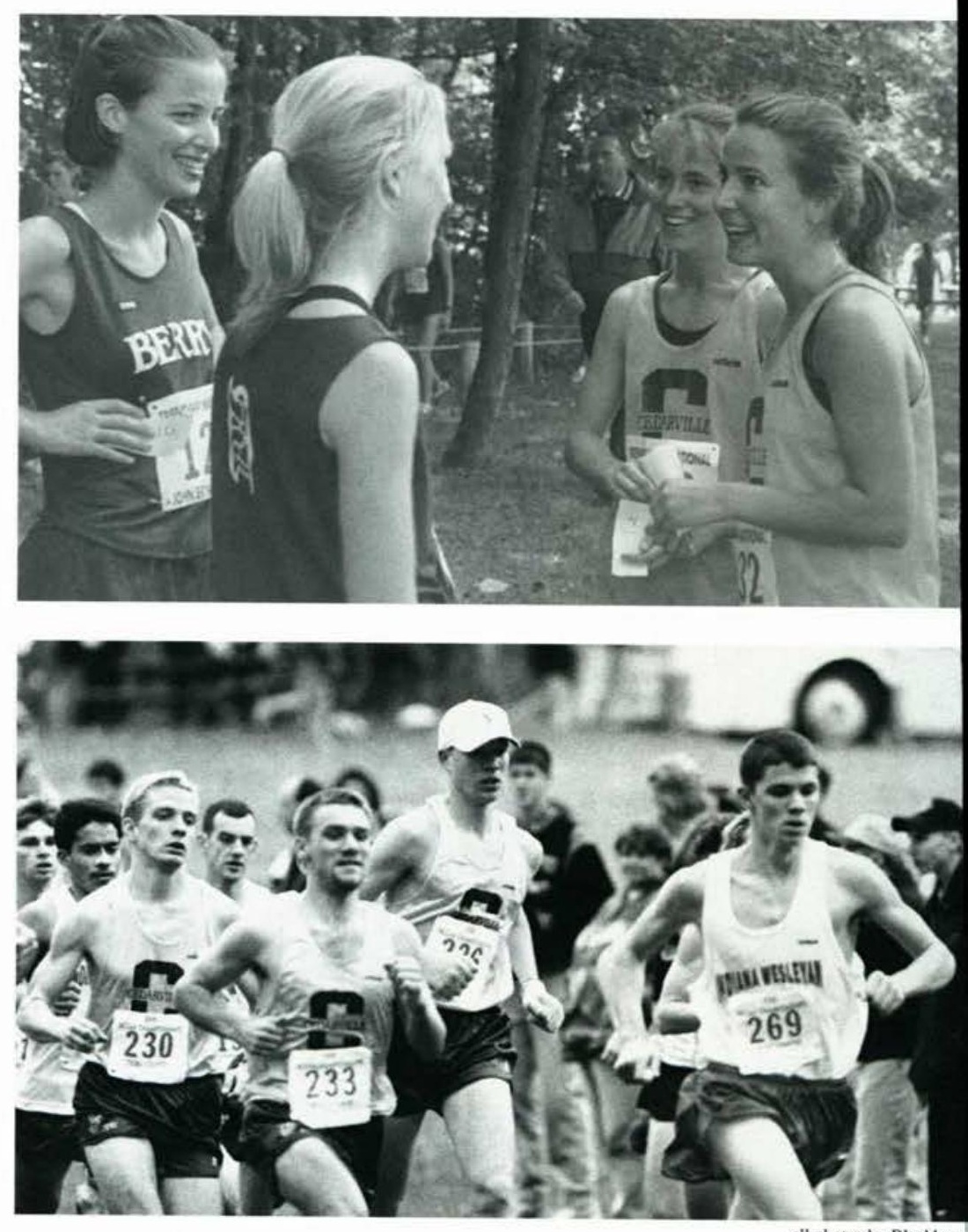

All photos by Backibun 


\section{A Race For The Finish}

\section{Cedarville men's and women's}

\section{ross country cross country teams return o the NAIA Championships.}

The Cedarville College en'scross country team made move back to the national ene by returning to the NAIA hampionships, while the omen's team maintained its psition as one of the top NAIA omen's cross country prorams in the country for 1997. he Lady Jackets were rated high as 14th in the nation efore placing 19th at the naonal meet for their fifth raight Top 20 finish. The omen placed second in their wn Friendship Invitational, iird in the MOC, andeighth in the All-Ohio Championships. Head coach Elvin King watched as they were also the NCCAArunner-up. Themen's 12th-place showing culminated an outstanding season in which they were also fourth in the NCCAA, first in their own Friendship Invitational and the Rochester Invitational, and second in the Mid-Ohio Conference. The Jackets were ranked as high as 17 th prior to moving up five slots on the national championshipcourse.

More importantly, the women were as successful in the classroom as on the field of competition. Cedarville was presented the NAIA TeamScholar Award for having the highest combined GPA (3.67) of any team at the national meet.

Finishing at the top in five of the eight meets, Junior Ben Thompson progressed to the number one position on the men's team. Thompson was an NCCAA All-American (top 30 finishers) upon placing eighth of 142 runners in the national meet. He was fourth in the MOC and was 36 th out of 336 runners at the NAIA Nationals.

Freshman Ed Letts made his presence felt as Cedarville's number two performer, joining Thompson on the All-America unit. The rookie was eighth in the MOC and 37 th at the NAIA. Senior Eric Crawford, closing out his career in the third spot for the men, was the team's lone NAIA All-America Scholar-Athlete and MOC Scholar-Athlete. Seniors Chris Leverette and Steve McGillivray joined him on the NCCAA All-America Scholar-Athlete team.

Junior Becky Jordan moved up to the ladies' numberone position and garnered NAIA All-America honors for the third straight year by placing 25th for the 5,000 meters. Jordan also picked up NCCAA All-America honors and finished third in the Mid-Ohio Conference. She was the team's top finisher in seven of the eight meets and she broke the 20:00 barrier five times during the season.

Women's Cross Country: (kneeling 1-r) Kathy Swartzentruber, ori Forward, Jill Breckenfeld, Christy Taylor, Rachelle Elder, Megan Hill, ecky Jordan, Laura Hammond (standing 1-r) Head Coach Elvin King, Sarah ollock, Jenny Heidenreich, Nikki Luckmann, JeriAnn Goodbar, Corrie irigorenko, Team Chaplains Dave and Pat Warren (right).
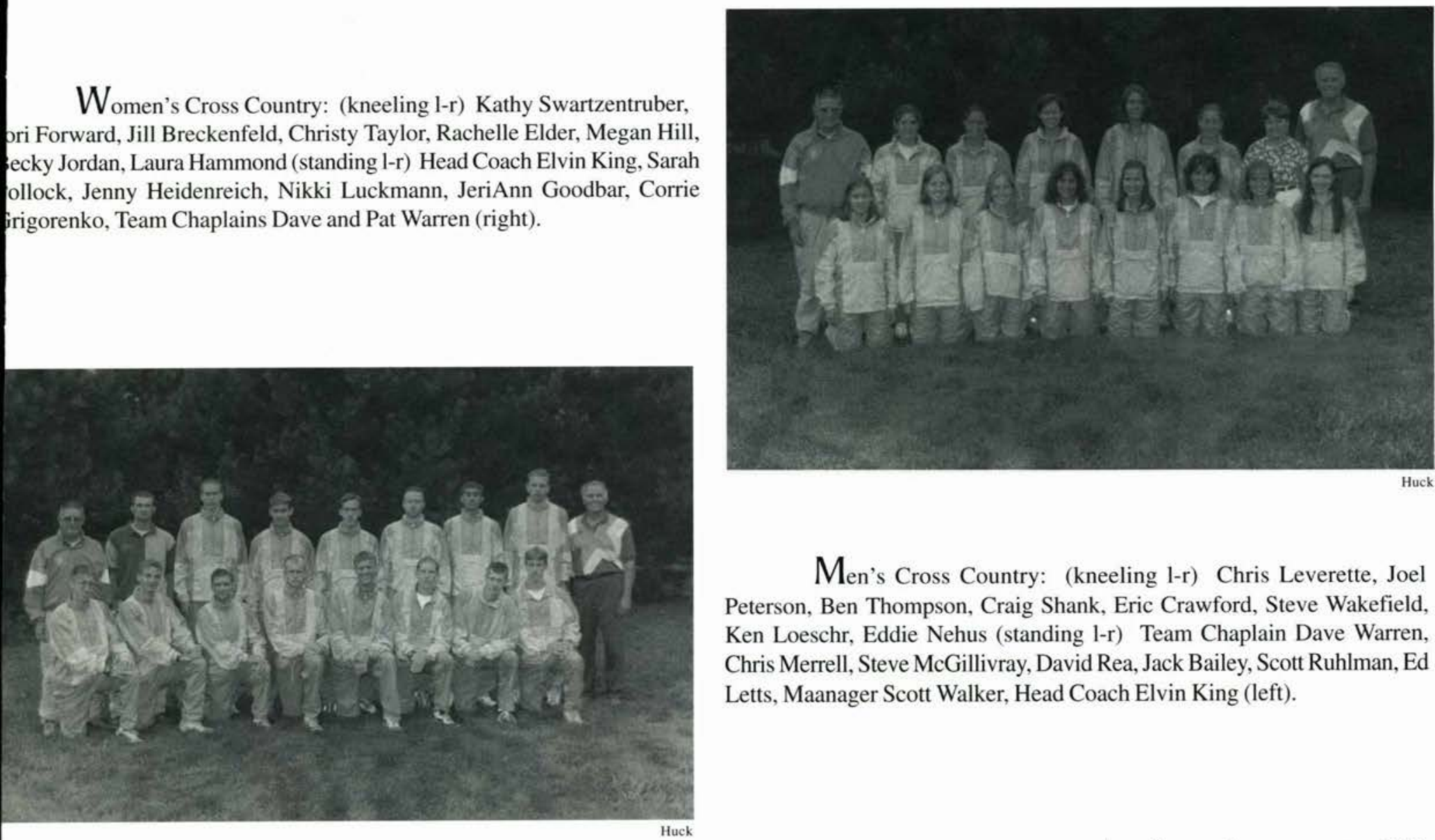

Men's Cross Country: (kneeling 1-r) Chris Leverette, Joel Peterson, Ben Thompson, Craig Shank, Eric Crawford, Steve Wakefield, Ken Loeschr, Eddie Nehus (standing 1-r) Team Chaplain Dave Warren, Chris Merrell, Steve McGillivray, David Rea, Jack Bailey, Scott Ruhlman, Ed Letts, Maanager Scott Walker, Head Coach Elvin King (left). 


\section{Lady Jacket's Perservere in MOC}

\section{Freshmen add talent and depth to the 97-98 Jacket's Team}

It was another year of rebuilding for the CedarvilleCollege women's basketball team with nine of the twelve players on the roster being freshmen or sophomores. The Lady Jackets finished 9-20 overall and 4-12 in the tough Mid-Ohio Conference.

"We had a lot of young players who matured throughout the season," said head coach Kathy Freese. "We're optimistic about the future if we can keep this group together."

Three rookies ended up in the starting lineup led by six-footcenterJulie Nourse. Her 12.6 points and 8.0 rebounds paced the squad in shooting accuracy at 58.4 percent from the field and 77.9 percent at the free throw line.

Women's Basketball Team: Row 1: (sitting 1 - r) Loree Beth Fraley, Gillian Gombis, Summer Bennington, Heather French, Charity Cole.

Row 2: (standing1-r) Joy Williams, Gretchen Taylor, Robin Duff, Amy Egolf, Tammy Matula, Beth Callinan, Kathy Freese.

Row 3: (standing 1-r) Tara Swaney, Stephanie Schanher, Julie Nourse, Jennifer Jones, Amanda Porter, Cassandra Goralski, Jodi Quint. pergame were team highs. She
Nourse earned the bulk of postseasonhonorsincluding being tabbed the Mid-OhioConference Freshman of the Year. She was named to the NCCAA All-America Second Team, the All-MOC First Team, the Section First Team, and the All-NCCAA Midwest Region First Team.

"We really couldn't ask foranythingmorefromJulieasan incoming freshman,"Freesecommented. "She ended up doing morethanatypicalfirst-yearplayer and really had a good season."

SummerBennington, the lonesenior,servedasteamcaptain andrankedsecondinbothscoring (10.9) andrebounding (7.5). She finishedwith955pointsduringher three-year Cedarville career and was voted to the All-NCCAA All-NAIADivisionIGreatLakes
Midwest Region Second Team. Junior guard Heather French averaged 8.3 points with a team-high 91 assists and joined Bennington on the NCCAAMidwest Second Team. Rookie guard Amanda Porter added 9.8 points and was All-MOC honorablemention.

French and junior forwardGillian Gombis were NAIA and NCCAA All-American Scholar-Athletes. They were also recognized as MOC Scholar-Athletes.

Their schedule was highly demanding. The MOC included NAIA Division II national champion Walsh as well as three-time defending regular season league champion Shawnee State. Central State and Findlay both qualified for the NAIA Division INationals, and Liberty was one of only two unbeaten NCAA Division I teams in the country.

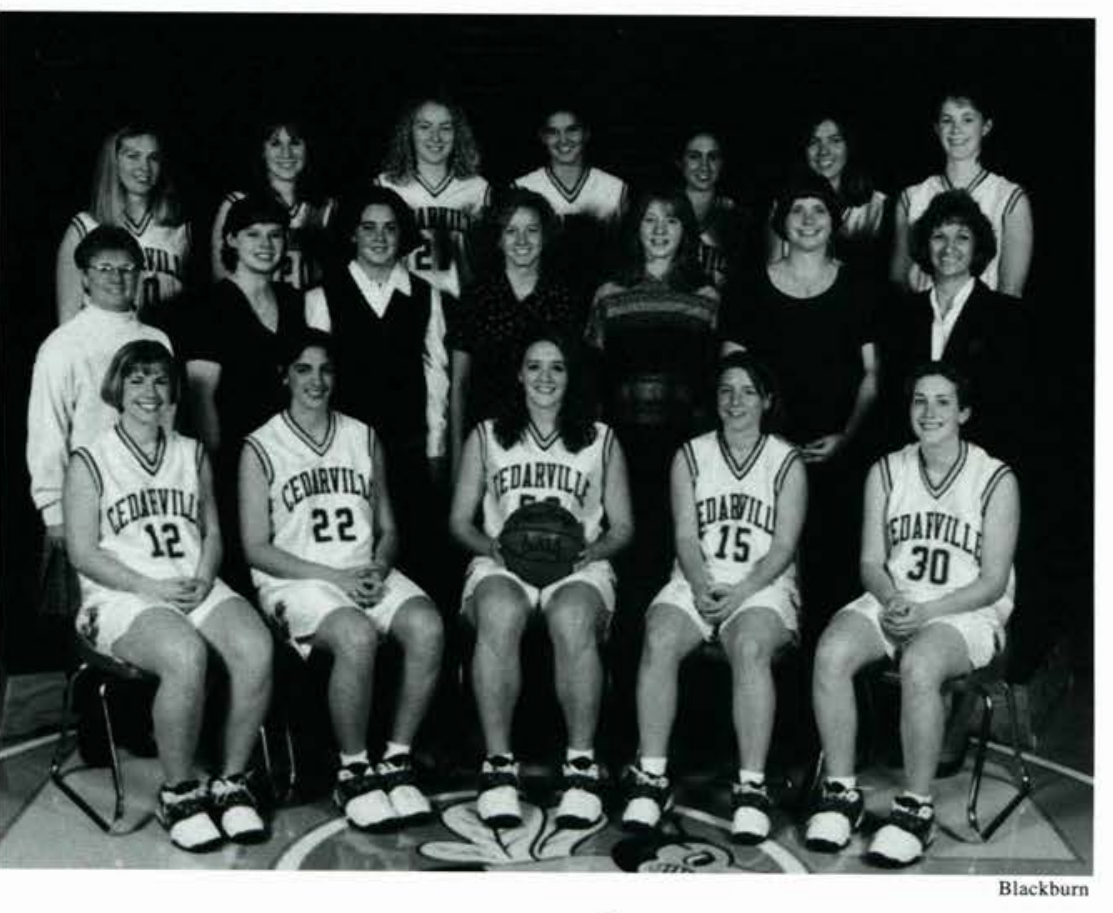

Junior Gillian Gombis shoots over the defender for two points (right).

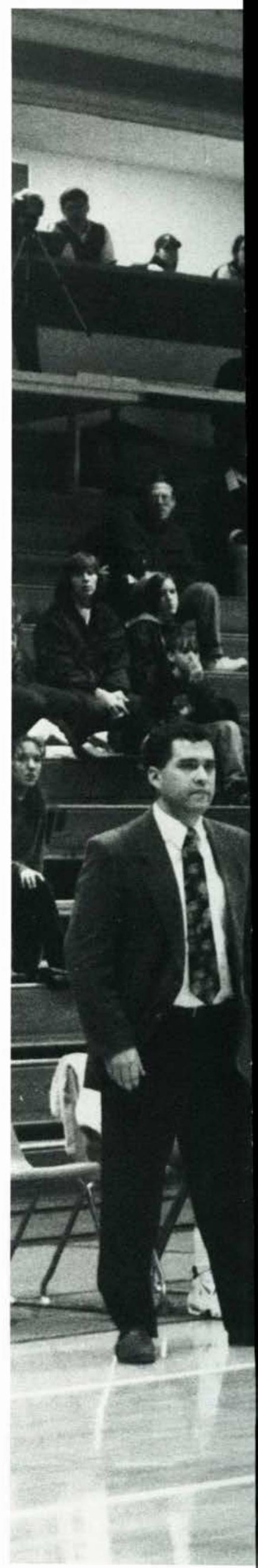




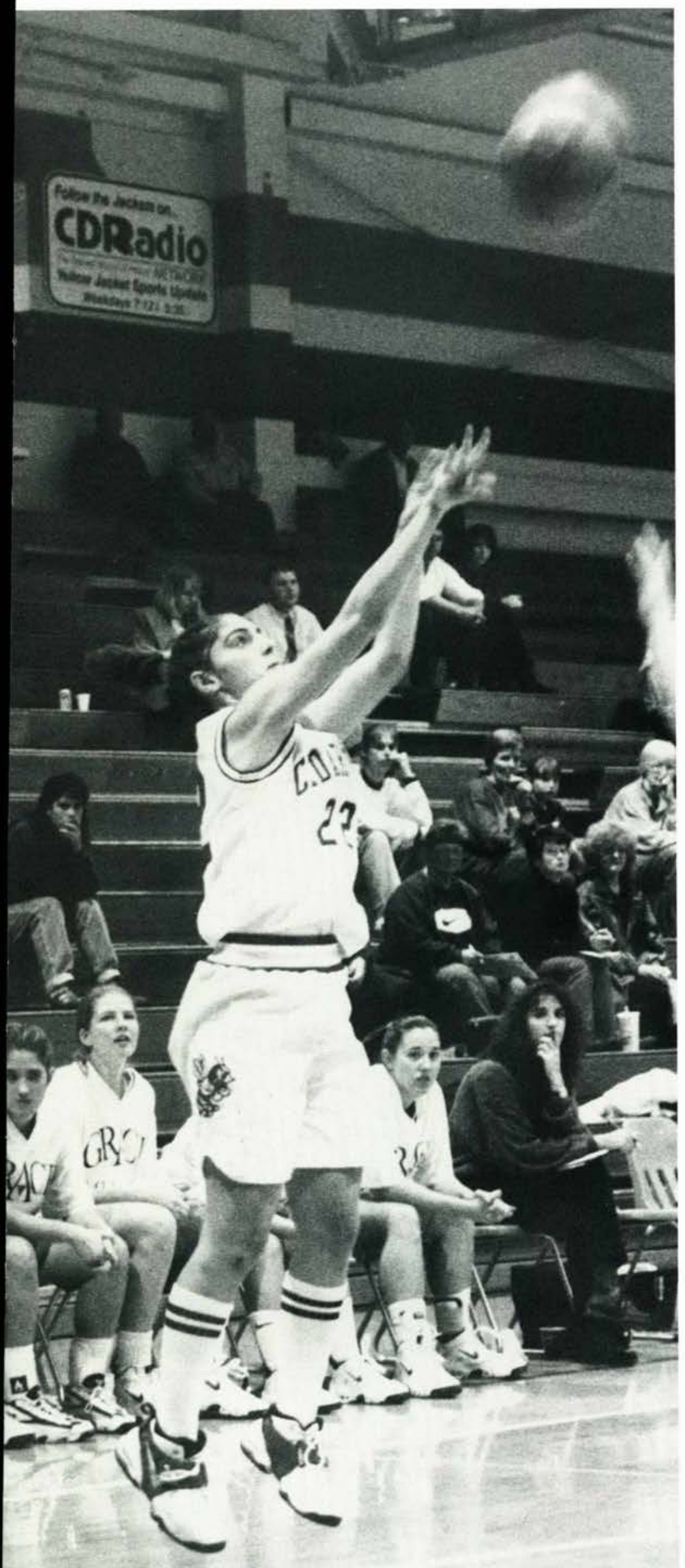

\begin{tabular}{|c|c|c|}
\hline $\mathrm{CC}$ & & OPP \\
\hline 75 & Davis \& Elkins & 70 \\
\hline 46 & Glenville State & 56 \\
\hline 62 & Taylor & 57 \\
\hline 65 & Grace & 59 \\
\hline 52 & Central State & 76 \\
\hline 86 & Mount St. Joseph & 53 \\
\hline 60 & Bluffton & 73 \\
\hline 70 & Malone & 62 \\
\hline 84 & Rio Grande & 96 \\
\hline 75 & Wilberforce & 68 \\
\hline 61 & Liberty & 103 \\
\hline 59 & Shawnee State & 73 \\
\hline 72 & Tiffin & 67 \\
\hline 95 & Ohio Dominican & 80 \\
\hline 65 & Mt. Vernon Nazarene & 77 \\
\hline 59 & Walsh & 82 \\
\hline 66 & Urbana & 86 \\
\hline 87 & Rio Grande & 91 \\
\hline 63 & Wilmington & 82 \\
\hline 91 & Malone & 61 \\
\hline 75 & Shawnee State & 77 \\
\hline 66 & Ohio Dominican & 86 \\
\hline 66 & Mt. Vernon Nazarene & 79 \\
\hline 62 & Walsh & 83 \\
\hline 63 & Urbana & 75 \\
\hline 63 & Tiffin & 70 \\
\hline 52 & Findlay & 77 \\
\hline 63 & Transylvania & 89 \\
\hline 83 & Concordia & 89 \\
\hline
\end{tabular}

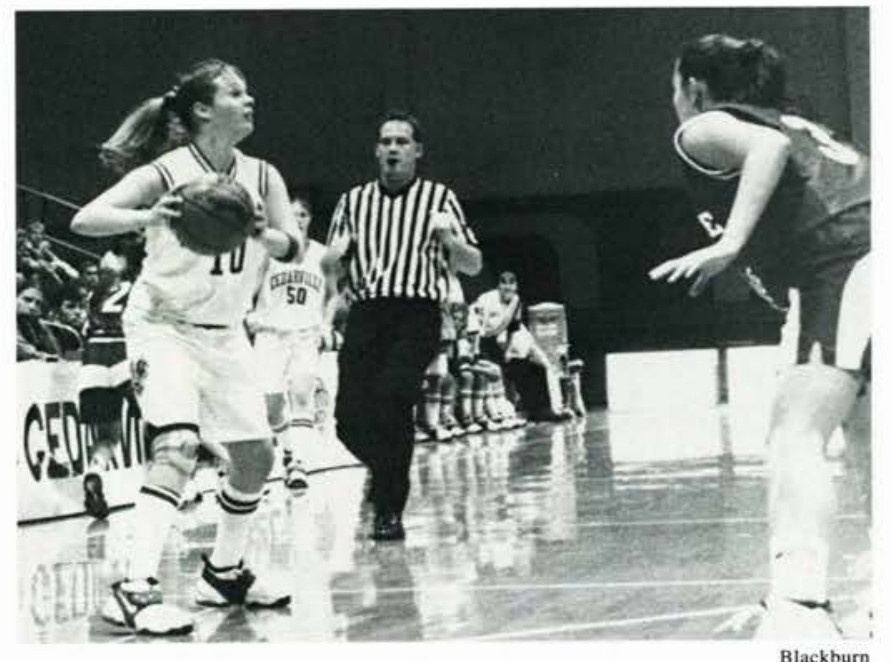

Sophomore Tara Swaney looks for a pass to a Jacket teammate (above). 


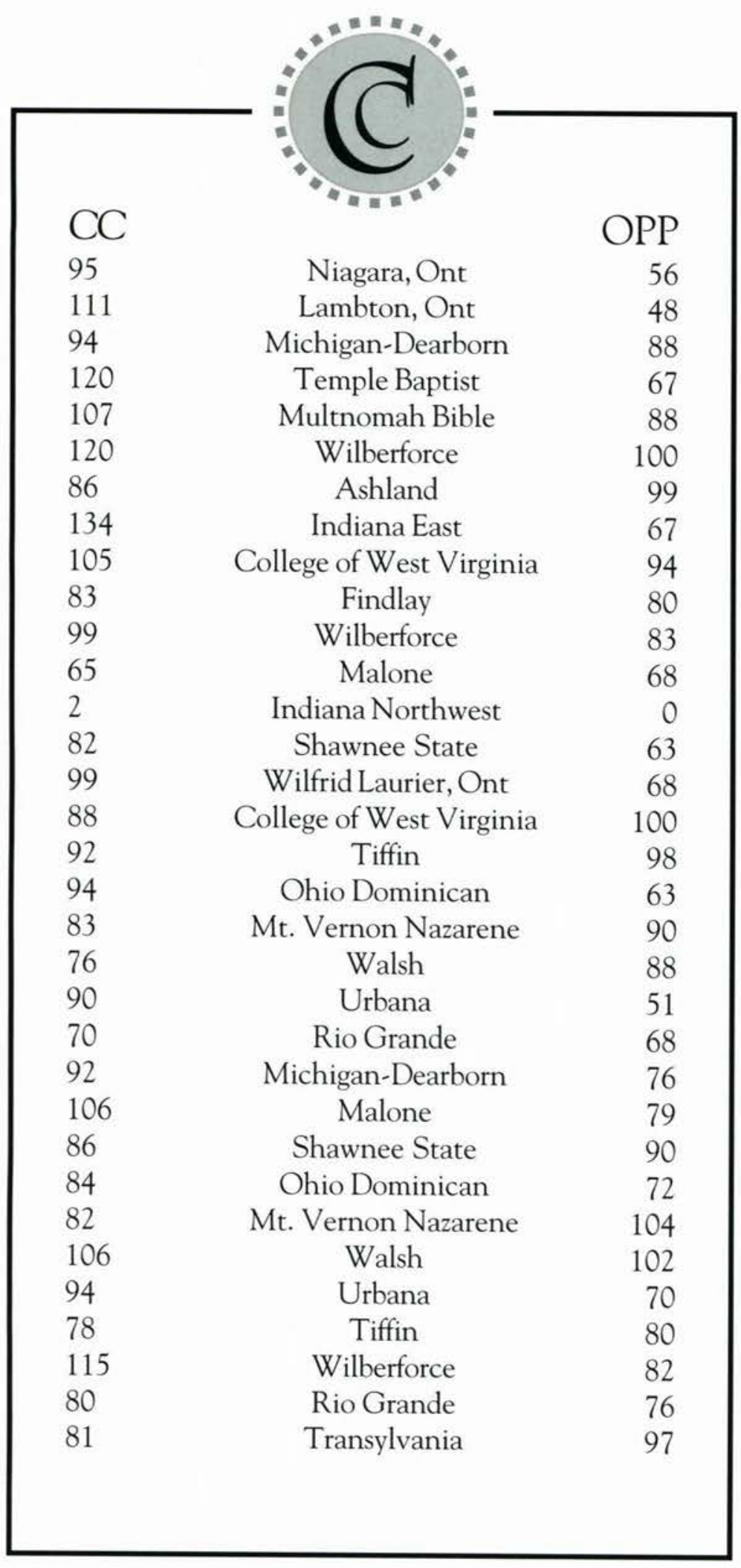

Senior Tim Ware looks to improve the Jackets' score by three points.

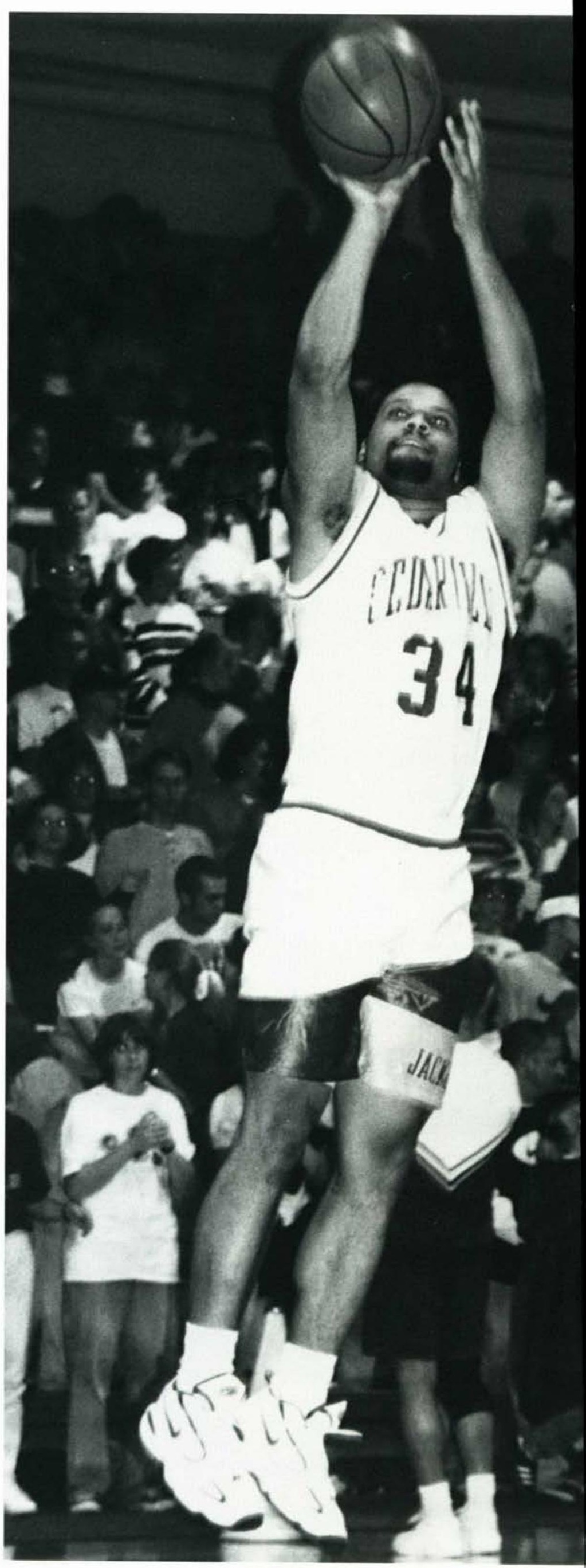




\title{
Jackets Start Off With A Bang
}

\author{
Jackets win first six games to cruise to a \\ 23-10 season
}

Cedarville College got back toplaying winning basketball in the men's program. The Yellow Jackets finished 23-10 overall for their first 20-win season in threeyears. Their 9-7 Mid-Ohio Conference record tied for fifth placeinthenine-teamleague. "We felt like it was a good seasonfor us considering the new players weincorporated into the system," mentioned head coach Jeff Reep. "It's something we can continue to build on."

Junior forward John Krueger averaged 22.4 points to lead the Mid-Ohio
Conference and the NAIA Division I Great Lakes Section. He has piled up 1,778 career points during his first three seasons and ranks ninth on Cedarville's all-time scoring list. Krueger was named an NCCAA Second Team AllAmerican and was voted to the All-NAIA Division I Great Lakes First Team, the All-MOC First Team, and to the AllNCCAA Midwest Region First Team. He was selected MVP of the 20th Annual Cedarville Invitational after scoring a career-high 41 points in the final game and was also MVP of the Jackets' Thanksgiving Classic.
Mid-Ohio Conference Freshman of the Year Jesse Deister scored more points (580) than any Yellow Jacket rookie in history which computed to an average of 18.1 points pergame. He was one of the top free throw shooters in the country at 87.9 percent and also paced the squad in field goal accuracy at 55.8 percent.

Deister was named to the All-NAIA Division I Great Lakes Section Second Team and the All-MOC Second Team. Hejoined Krueger on thefive-playerNCCAAMidwest Region First Team.

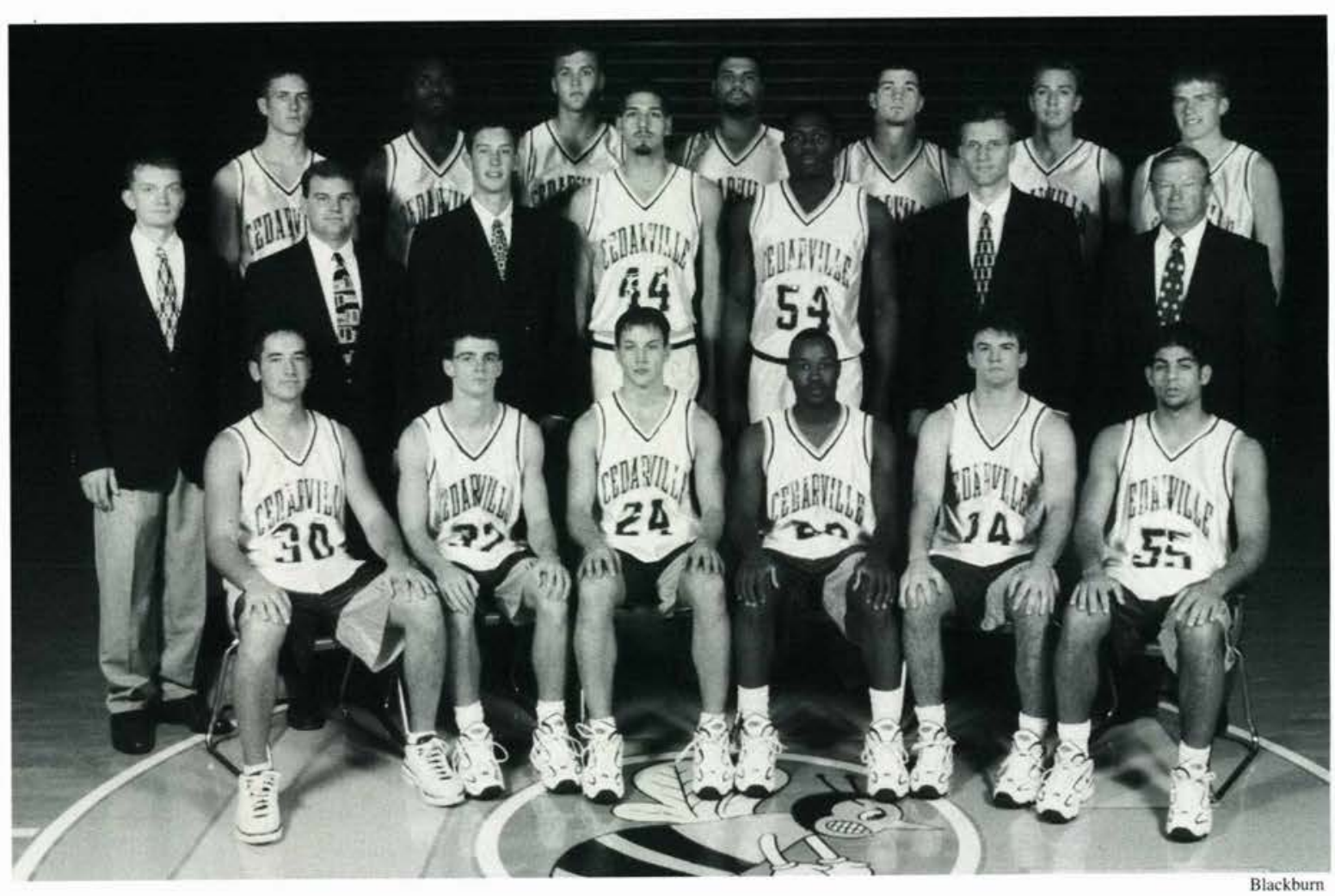

Men's Basketball Team: Row 1: (1-r) Steve Comer, Mike Lampton, Kyle Mraz, Jackie Williams, Clint Hayes, Dave Anthony. Row 2: D. A. Nichols, Gary Carter, David Fourman, Ted Forrest, Perry Mattis, Jeff Reep, Pete Reese. Row 3: Brent Miller, Linton Ellis, Aaron Stumpf, Tim Ware, Shay Richardson, John Krueger, Jesse Deister. 
Clint Hayes agressively eyes the ball and leads the Jacket's defensive attack. (right)

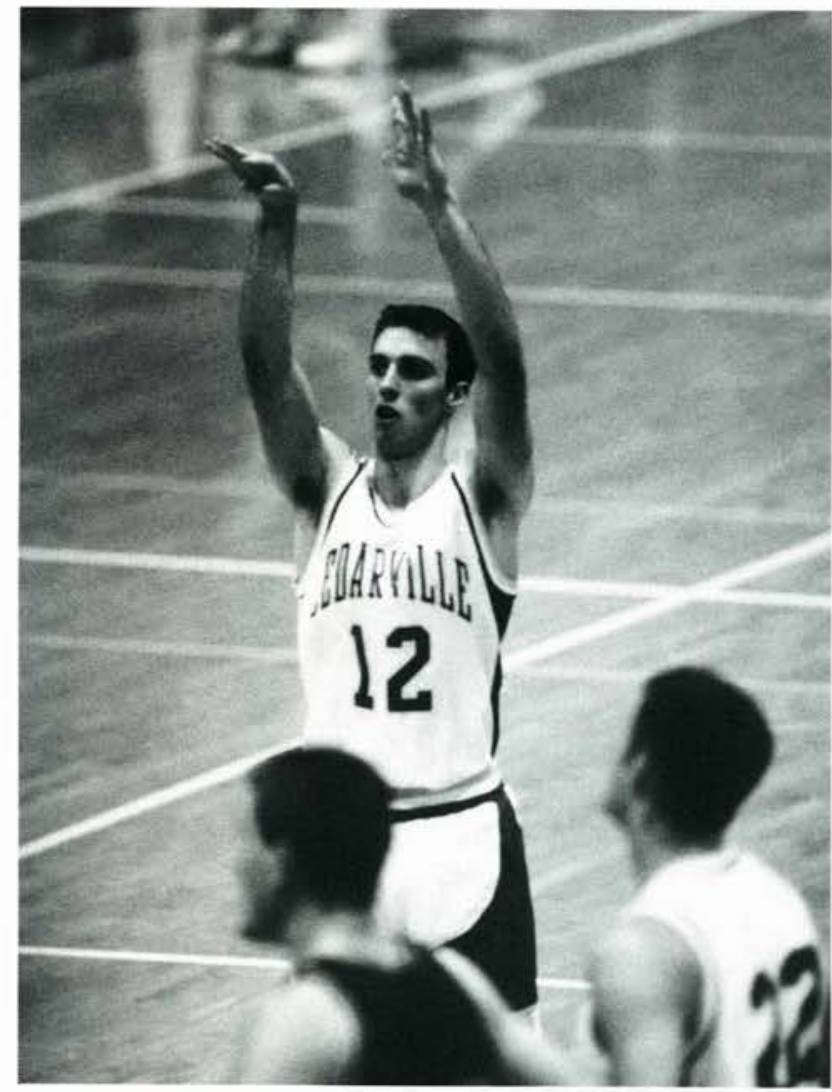

Shooting guard and power forward John Krueger makes another free throw. (above)

Rob Bouwens carries the flag while the pep band plays on. (right)
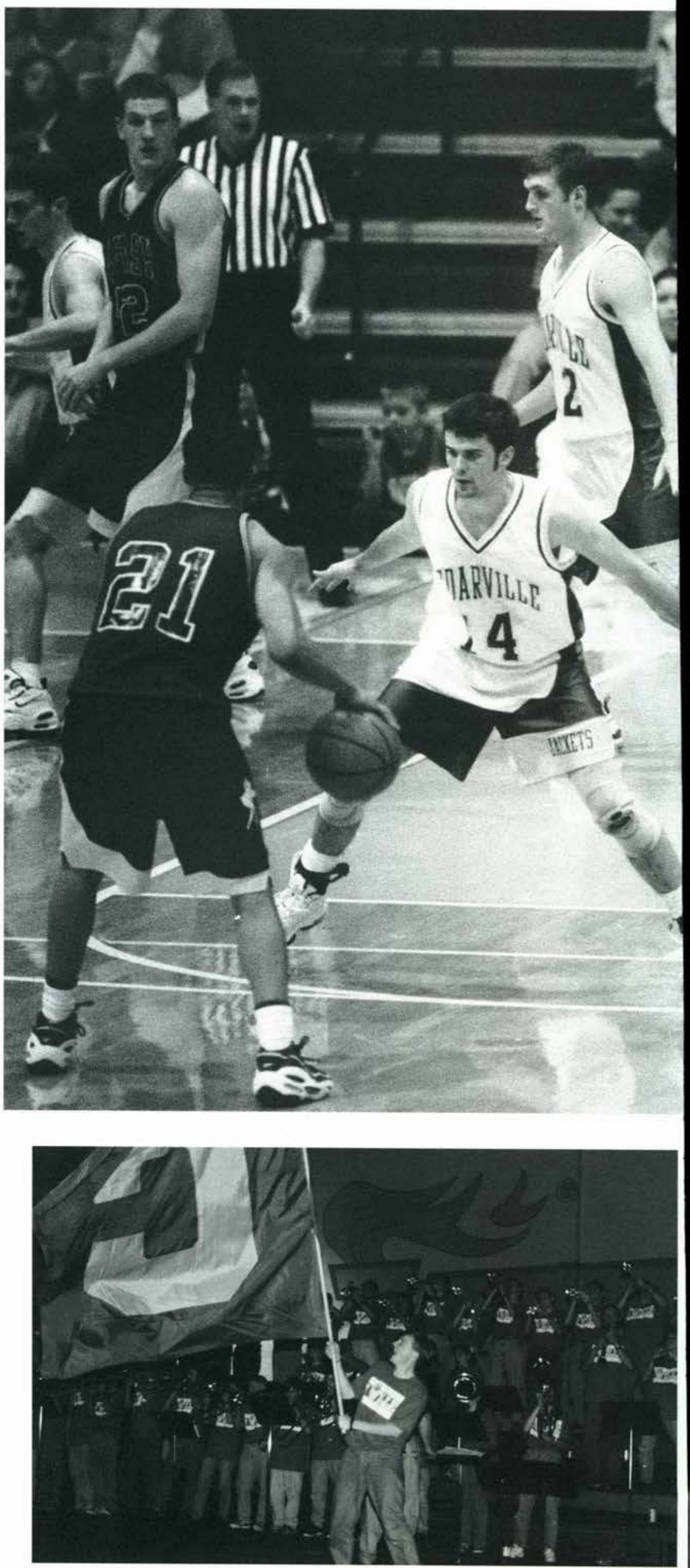

all photos by Blackburn 


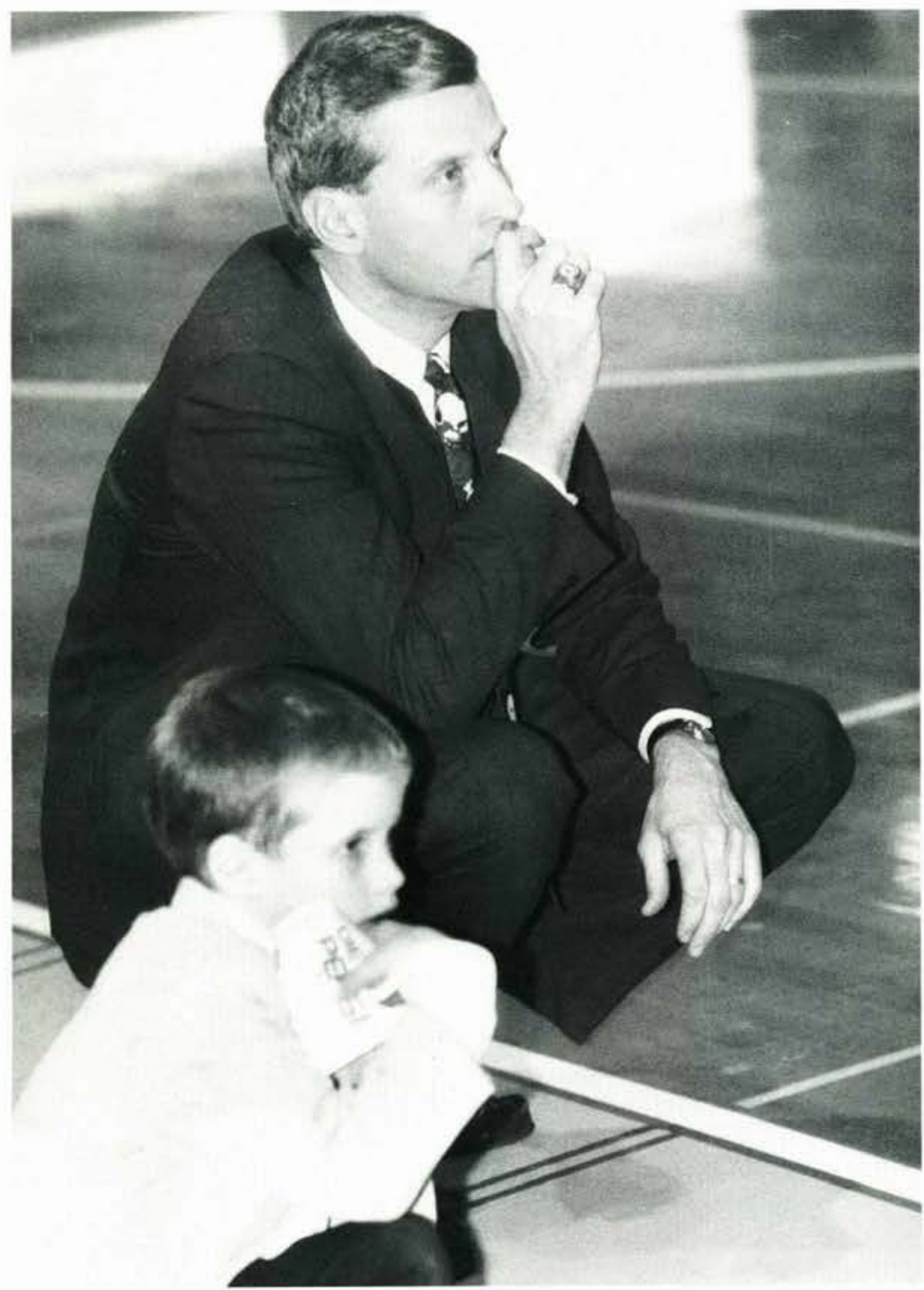

Coach Jeff Reep, along with his son, analyze a Jacket play from the sidelines. (left)

\author{
Jacket fans display their love \\ for mens' basketball. (below)
}

by Ruthanne S. Pierson

\section{Athletic Trainers}

\section{Special Thanks and Recognition}

Collegiate sports provide an opportunity for students to display their discipline, dedication, and Godgiven talent. Yet, behind the scenes, a team of students has spent countless hours helping these athletes reach their peak performance through their own discipline, dedication, and God-given talents. These students study their discipline in the classroom and then practically apply it through 1500 required hours in the training room-they are the athletic trainers.

Athletic training is the care, prevention, and rehabilitation of injuries within the athletic population. Athletic trainers provide care when an immediate injury occurs. These students assess and provide immediate treatment. Prevention occurs when the trainer tapes, braces, and/or stabilizes an already existing injury or joint. Finally, the trainer engages in rehabilitation, the main components including strength, endurance, proprioception, and functional return to activity.

Senior Jason Grahame explained that he chose the athletic training program because he loves sports, had a positive relationship with a high school athletic trainer, and enjoyed the sciences. Athletic training combined all three of these elements together. When asked what an athletic trainer's greatest satisfaction is, he responded, "helping other people." And helping others is exactly what athletic trainers do. 


\section{Women's Tennis}

The Lady Jacket tennis program enjoyed another successful season despite having the youngest team in Pam Johnson's 22 years as head coach. The 13-player roster consisted of just one junior, six sophomores, and six freshmen, but the youth movement produced a $10-2$ overall record and a runner-up showing in the Mid-Ohio Conference.

Cedarville was impressive in rolling to eight 9-0 victories, a noteworthy 43 win at Ohio Wesleyan, and a 7-2 decision at Mount St. Joseph. It took a good team to beat the Jackets. They lost 5-4 at Transylvania University without the services of one of their top players. They were also nipped 5-4 at four-time defending MOC champion Walsh University.

"Our team matured a lot during the season," recalled Johnson. "We used four sophomores and two freshmen as our main lineup and many times we faced experienced opponents. We have every reason to be optimistic about the future."

Number one player Casey Ruffin posted a 10-3 record during her sophomore season. She was named to the All-MOC Team in singles after running her career record to 20-5.

Freshman Katie Koeppen, who played in the second position, and sophomore Ginger Butler, who held down the third spot, earned All-MOC honors in both singles and doubles. They had a 11-2 mark as the squad's top doubles pairing. In singles, Butler had a teambest 12-1 record for the second straight year and Koeppen was 9-3. Freshman Jenny Brayer (12-2 record) and sophomores Beth Wolfe (10-2) and Julie Gregory (9-5) rounded out the top six singles spots. As a team overall, the Lady Jackets had a 66-18 record in singles and a dominant 37-5 mark in doubles.

In the MOC Tournament, Walsh won the event with 43 points and was followed by Cedarville (37), Malone (26.5), Tiffin (15.5), and Shawnee State (13). The Yellow Jackets had players in all six singles finals and in two of the three doubles finals.

Butler was the No. 3 Flight singles champion and did not lose a set in the process. Wolfe and Brayer rolled to the doubles title in the No. 3 Flight and finished the year with a 9-1 record.

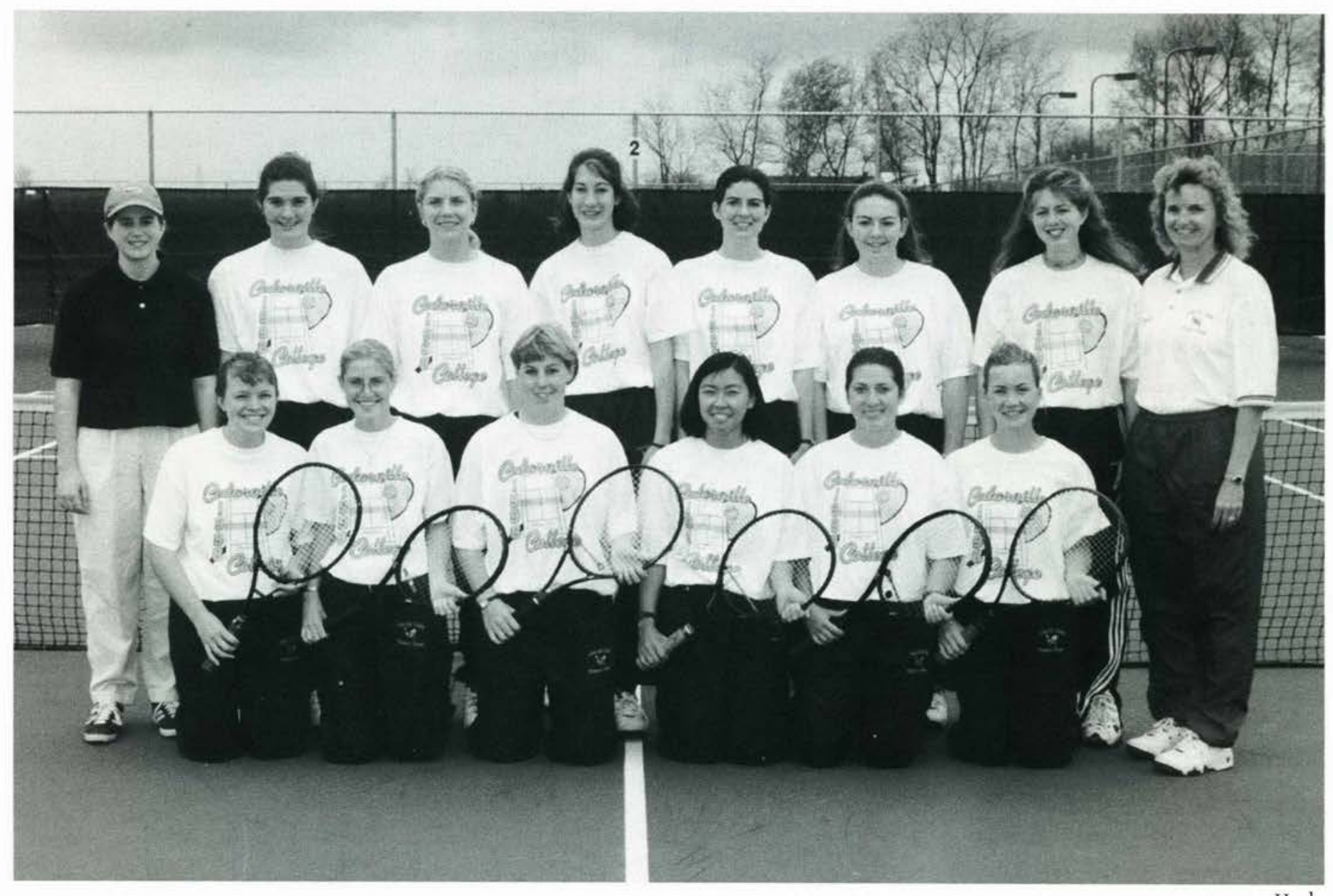

Women's Tennis: Row 1: (kneeling 1-r) Beth Moore, Katie Koeppen, Casey Ruffin, Angela Mast, Jenny Brayer, Beth Wolfe. Row 2: (standing 1-r) Student-Trainer Siobhan Fagan,Tammy Dosey, Ginger Butler, Jennifer Elliott, Joyce Boggs, Adaline Shultix, Julie Gregory, Head Coach Pam Johnson 


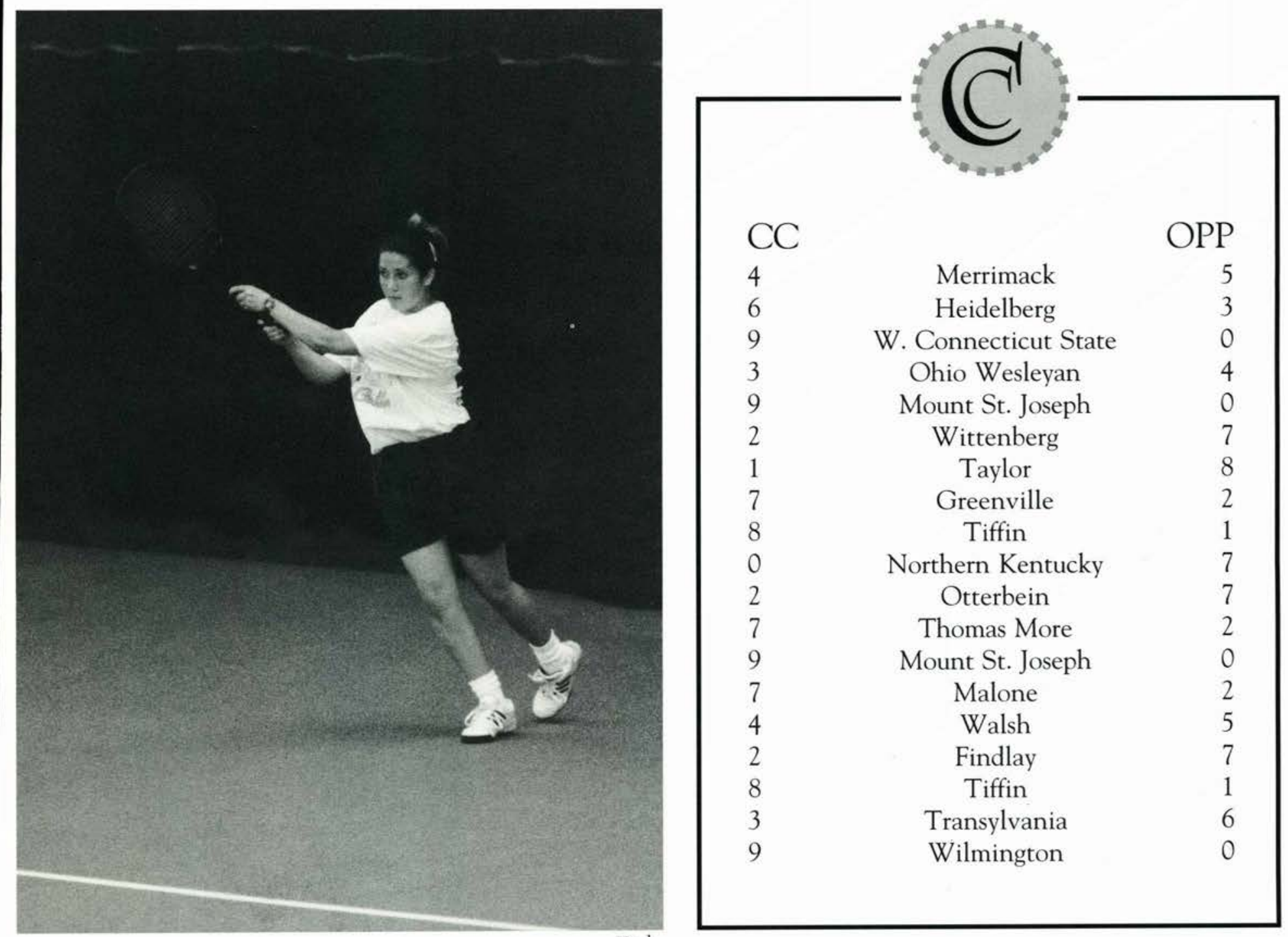

Huck

Freshman Jenny Brayer posted a 12-2 record (above left), while the team overall posted a $66-18$ record in singles and a dominant 37-5 mark in doubles.

Second singles player Ginger Butler, earned All-MOC honors in both singles and doubles. 


\begin{tabular}{|c|c|c|}
\hline $\mathrm{CC}$ & & OPP \\
\hline 4 & Merrimack & 5 \\
\hline 6 & Heidelberg & 3 \\
\hline 9 & W. Connecticut State & 0 \\
\hline 3 & Ohio Wesleyan & 4 \\
\hline 9 & Mount St. Joseph & 0 \\
\hline 2 & Wittenberg & 7 \\
\hline 1 & Taylor & 8 \\
\hline 7 & Greenville & 2 \\
\hline 8 & Tiffin & 1 \\
\hline 0 & Northern Kentucky & 7 \\
\hline 2 & Otterbein & 7 \\
\hline 7 & Thomas More & 2 \\
\hline 9 & Mount St. Joseph & 0 \\
\hline 7 & Malone & 2 \\
\hline 4 & Walsh & 5 \\
\hline 2 & Findlay & 7 \\
\hline 8 & Tiffin & 1 \\
\hline 3 & Transylvania & 6 \\
\hline 9 & Wilmington & 0 \\
\hline
\end{tabular}

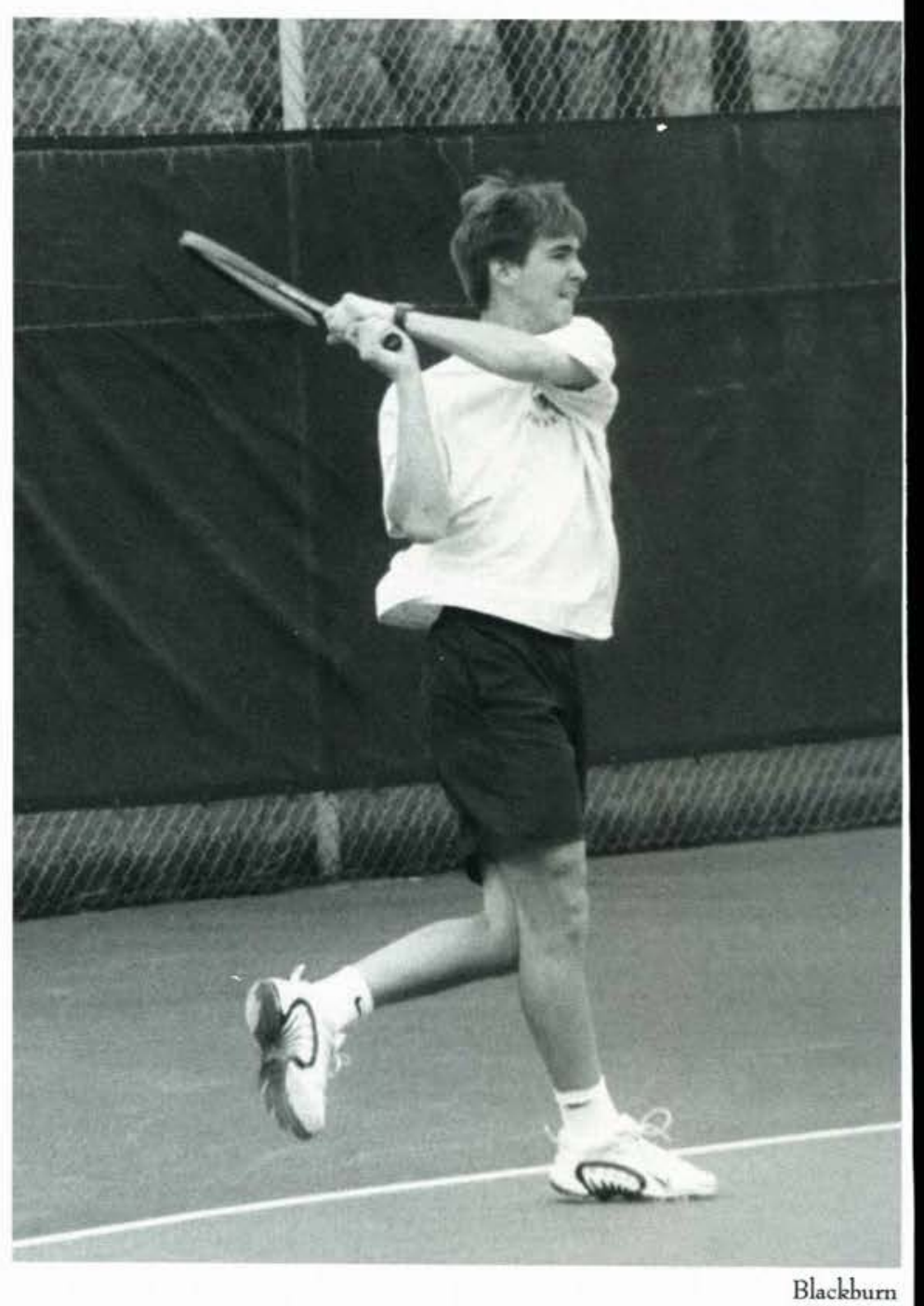

Matt Taylor, who ended the season with a 13-10 slate, returns a volley. (above right)

Junior Brian Wilbur completed his second year in the program and held down the team's number one singles spot. (below right)

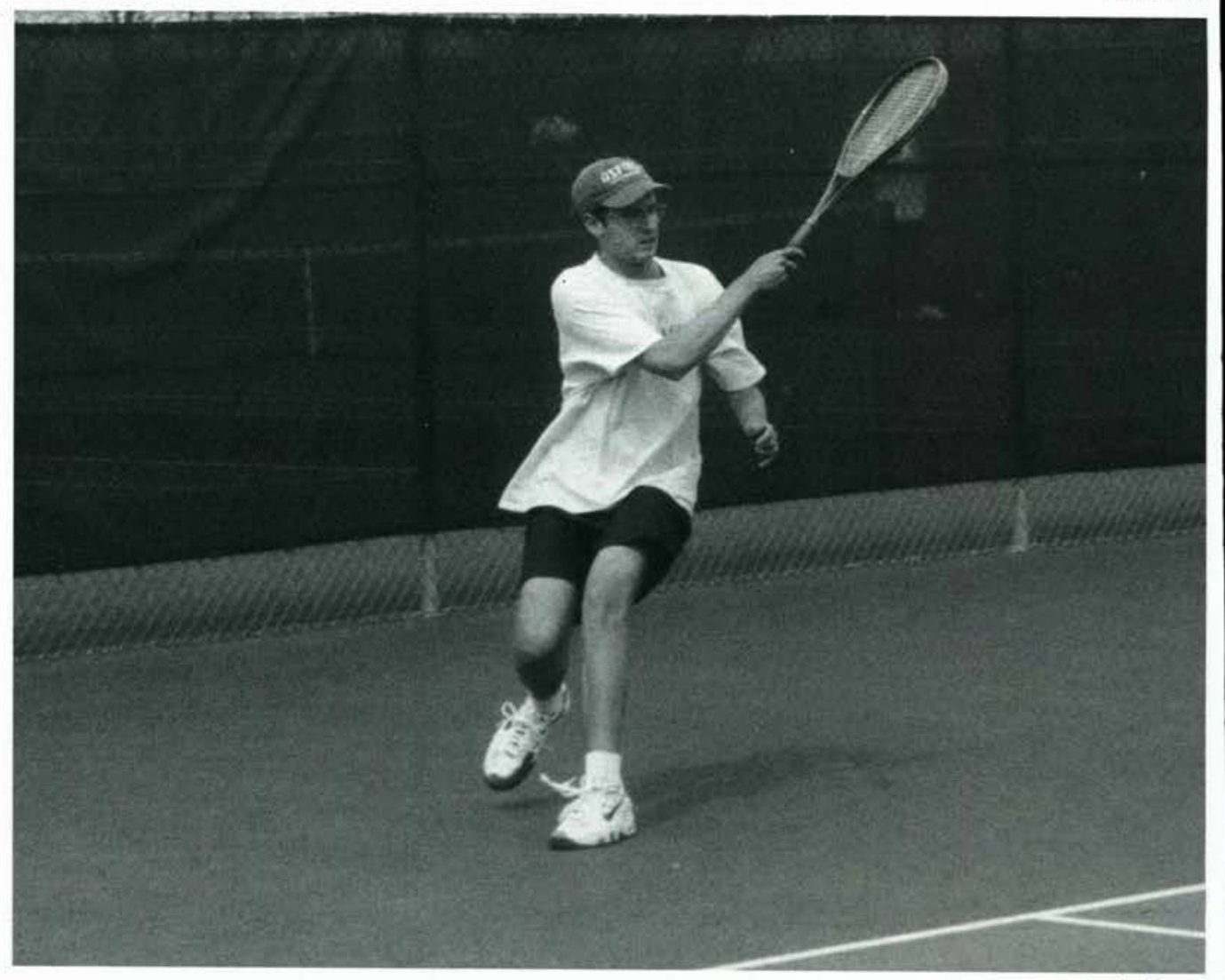




\section{Men's Tennis}

The Cedarville College men's tennis team posted a 12 10 dual match record during the 1998 season. Like the women, the Yellow Jackets put together their winning season without the benefit of having a senior on the roster.

Coach Alan Edlund's team could have easily finished with a more impressive record. The netters dropped all four onepoint matches that they were involved in.

"We're quite satisfied with our season," remarked Edlund, who completed his fourth season at the helm. "We didn't have the experience to win those close matches, but that will come as the players mature. This year was a big stepping stone for us to consistently get back to playing winning tennis."

One of the 5-4 setbacks occurred against Olivet Nazarene in the National Christian College Athletic Association Invitational which Cedarville hosted. The Jackets won two out of three matches to finish as the tournament runner-up. Cedarville also finished second in the Mid-Ohio Conference race and was fourth in the NAIA Great Lakes Sectional.

Brian Wilbur, a junior completing his second year in the program, held down the team's number one singles spot. He had a 10-14 record against the opposition's top player and is $21-22$ for his career.
The rest of the lineup had winning records for the season. In order of singles position, Carl Weise was $12-11$, Eric McVey was a teambest 18-6, James Metsger was 147, Matt Taylor had a 13-10 slate, and Reuben Duncan recorded a 117 mark.

Cedarville was $85-55$ as a team in singles with an overall doubles record of 40-28. Duncan and Metsger had a 11-6 record in doubles while McVey and Jason Hall were 4-1.

Wilbur, Weise, and Duncan were named to the NAIA AllAmerica Scholar-Athlete squad. The elite team recognizes juniors and seniors who maintain a minimum 3.50 cumulative grade point average.

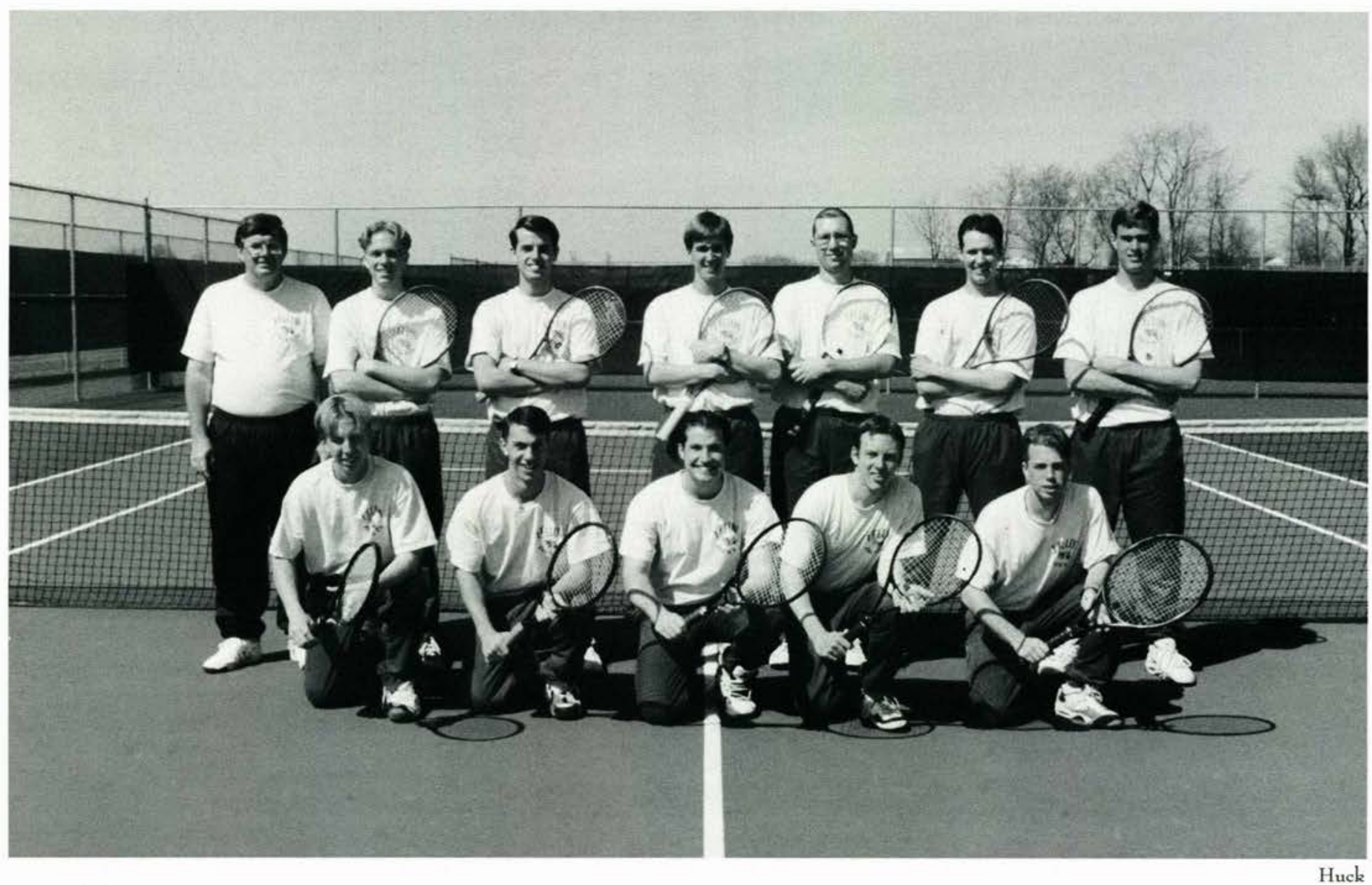

Men's Tennis: Row 1: (kneeling 1 - r) Eric McVey, Adam Beres, James Metsger, Jason Hall, Reuben Duncan. Row 2: (standing 1 - r) Head Coach Alan Edlund, Jeremy Frank, Robert Lutz, Matt Taylor, Brett Cooley, Brian Wilbur, Carl Weise. 
Senior Steve Burchett, here putting to the green, was named to the All-MOC Scholar-Athlete

Team, which include juniors and seniors who maintain a minimum 3.50 grade point average.

(right)

Matt Dunn, pictured below in a follow-through stance, was one of the three freshman newcomers who helped the team tremendously throughout the year. (below)

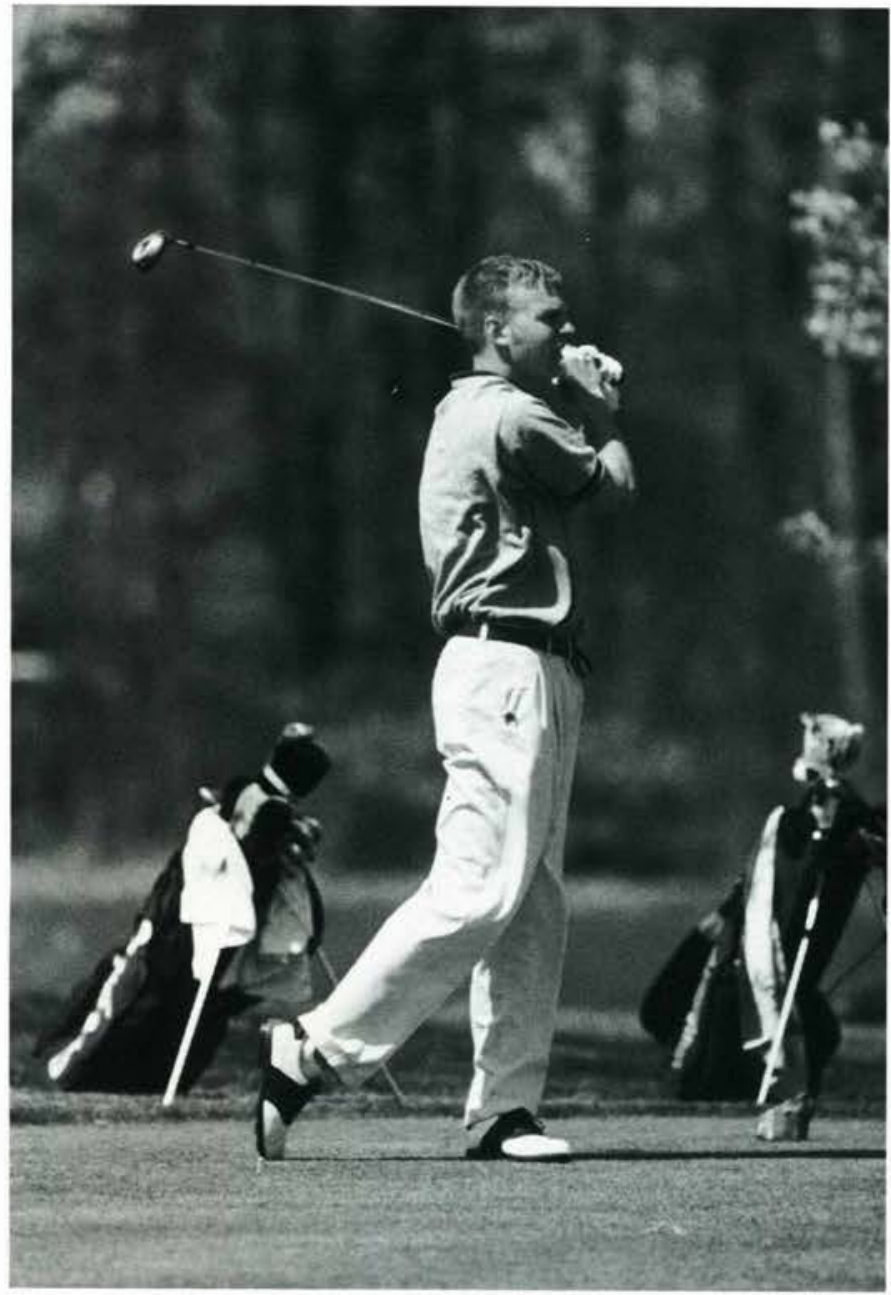

Blackburn

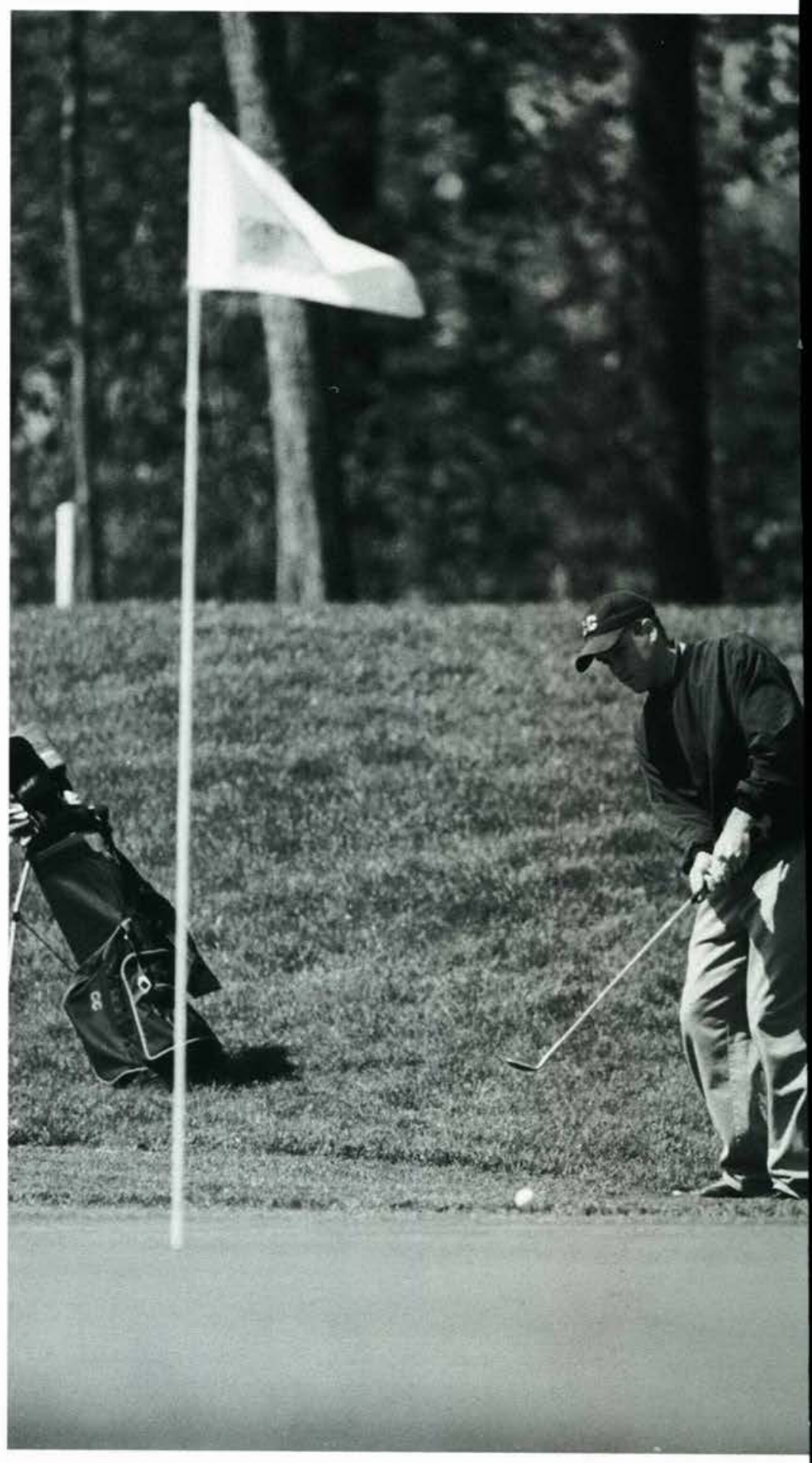

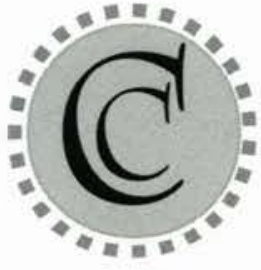

April 2

April 6

April 13

April 20,

April 24-5

April 29

May 7-8 at Urbana Invitatioinal (Urbana, OH)

at Shawnee State Invit. (Portsmouth, $\mathrm{OH}$ )

at Heidelberg/Tiffin Classic (Tiffin, $\mathrm{OH}$ )

at Walsh Invitational (North Canton, OH)

at Mt. Vernon Nazarene Invit.(Mt. Vernon, OH)

17th Annual Cedarville Invit. (Beavercreek, $\mathrm{OH}$ )

Mid-Ohio Conference Champ. (Mt.Vernon, $\mathrm{OH}$ )
5 th of 13

7 th of 10

9th of 12

tied 6th of 11

7 th of 9

5 th of 6

tied 6 th of 7 


\section{br Matat Wenenat Jackets' Trio Offers a Bright Future The freshmen newcomers give coach Jim Kragel a good foundation on which to build}

The Cedarville College men's golf team proved to be noticeably more competitive in 1998 with the addition of a trio of freshmen who took over the top three spots on the squad. The Yellow Jackets still have some work to do before joining the elite opponents on the schedule, but the newcomers certainly give head coach Jim Kragel a good foundation upon to which to build.

Russ Toms ended up with the lowest average on the team at 81.1 strokes per 18 holes. Six of his seven rounds were 82 or lower including a season-best 77 that he fired at the 11-team Walsh Invitational which placed him in a fifth-place tie individually. $\mathrm{He}$ also carded a 78 at the Heidelberg/Tiffin Classic and paced the linksters in the MidOhio Conference Championships with rounds of 82,80 , and 82 .

Toms' freshman classmate Matt Dunn averaged 81.3 with two scores in the 70's and it could have been more. He turned in an 80 in five of his ten rounds. One of those was the 17th Annual Cedarville Invitational at Beavercreek's Country Club of the North which was won by Mt. Vernon Nazarene. His 247 total in the MOC was secondbest on the team.

Dunn's season-opening 77 at the Urbana Invitational placed him third individually in the tournament and the score matched Toms for low round of the year. The Jackets ended up fifth out of 13 schools at Urbana which was their highest finish of the season.

Joe Mulvaney, the third newcomer, averaged 85.1 strokes. His low score was a 79 in the sec- ond round of the Mt. Vernon Nazarene Invitational.

Senior Troy Page carded an 81 in the Cedarville Invitational and averaged 85.8 for the season. Classmate Steve Burchett carried an 86.2 average, but his rounds of 83-83-82 in the MOC were third on the team. Additionally, Burchett was named to the All-MOC Scholar-Athlete Team which includes juniors and seniors who maintain a minimum 3.50 cumulative grade point average.

Kragel summarized the campaign by saying, "We're heading in the right direction. I appreciated the leadership of our seniors and the young players gained valuable experience at the varsity level. We are not far away from having the overall talent to challenge for some tournament titles."

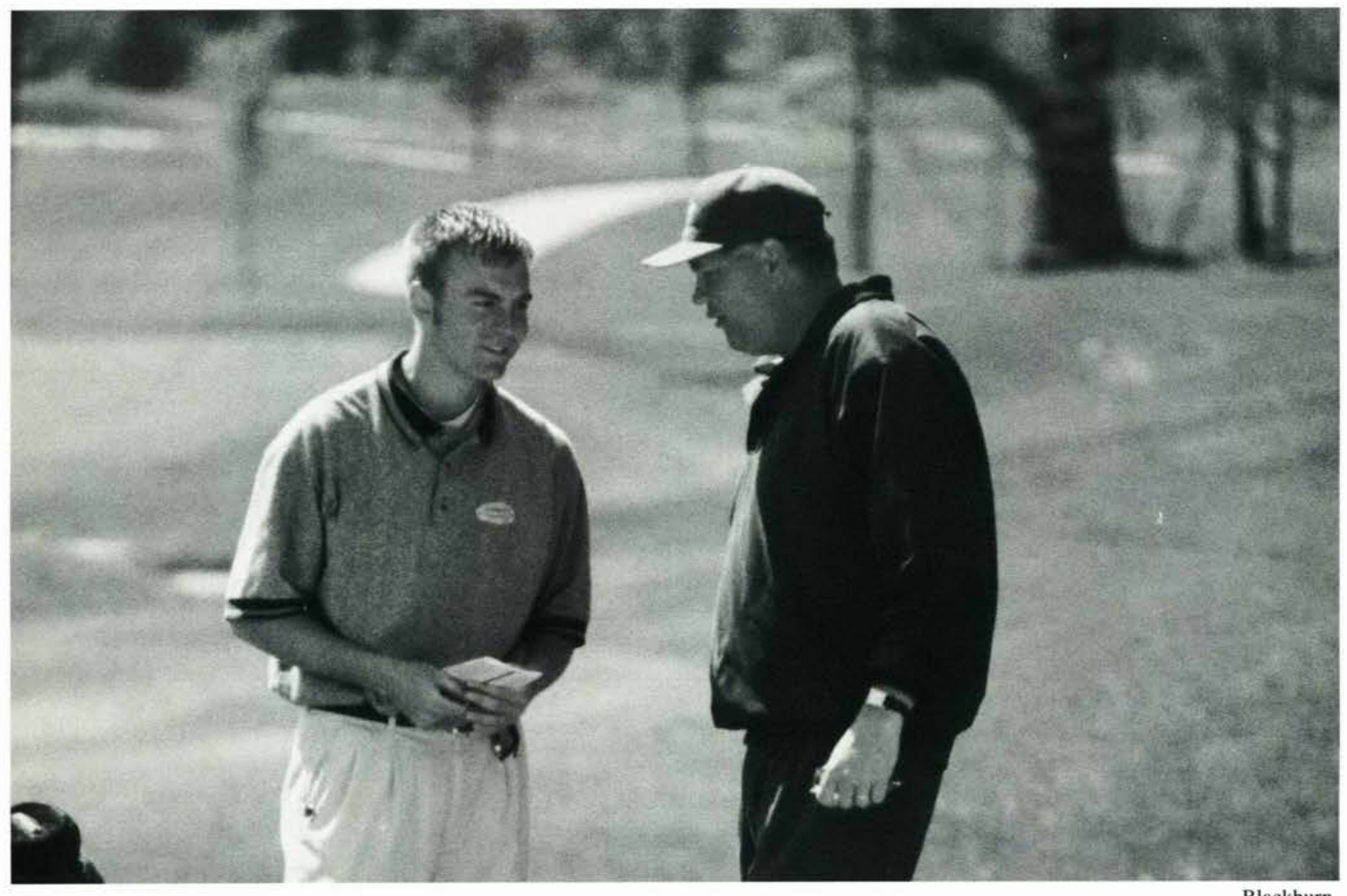

Coach Kragel (right) congratulates Matt Dunn (left) on his season-best 77 at the Walsh Invitational. 


\begin{tabular}{|c|c|c|}
\hline $\mathrm{CC}$ & 00 & OPP \\
\hline 1 & & 5 \\
\hline 0 & Mobile & 9 \\
\hline 0 & Houston Baptist & 11 \\
\hline 3 & Southern Wesleyan & 5 \\
\hline 7 & Ohio Dominican & 27 \\
\hline 5 & Ohio Dominican & 6 \\
\hline 2 & Mt. Vernon Nazarene & 5 \\
\hline 7 & Mt. Vernon Nazarene & 5 \\
\hline 0 & Walsh & 5 \\
\hline 5 & Walsh & 10 \\
\hline 2 & Tiffin & 3 \\
\hline 0 & Tiffin & 2 \\
\hline 2 & Urbana & 10 \\
\hline 3 & Urbana & 9 \\
\hline 1 & Malone & 3 \\
\hline 3 & Malone & 6 \\
\hline 1 & Shawnee State & 6 \\
\hline 1 & Shawnee State & 12 \\
\hline 1 & Urbana & 10 \\
\hline 8 & Urbana & 2 \\
\hline 2 & Taylor & 5 \\
\hline 1 & Rio Grande & 4 \\
\hline 3 & Rio Grande & 5 \\
\hline 4 & Wittenberg & 0 \\
\hline 6 & Wittenberg & 2 \\
\hline
\end{tabular}

Bonnie Schaefer puts all of her effort into the pitch. A diverse player, she pitched 127 1/3 innings while batting .297 . (top)

Yellow Jacket infielders Becky Summers, Beth Weaver, Elissa Morrison, Bonnie Schaefer, Andrea Butz, and Julie Schaefer motivate each other to excel before each inning. (bottom)
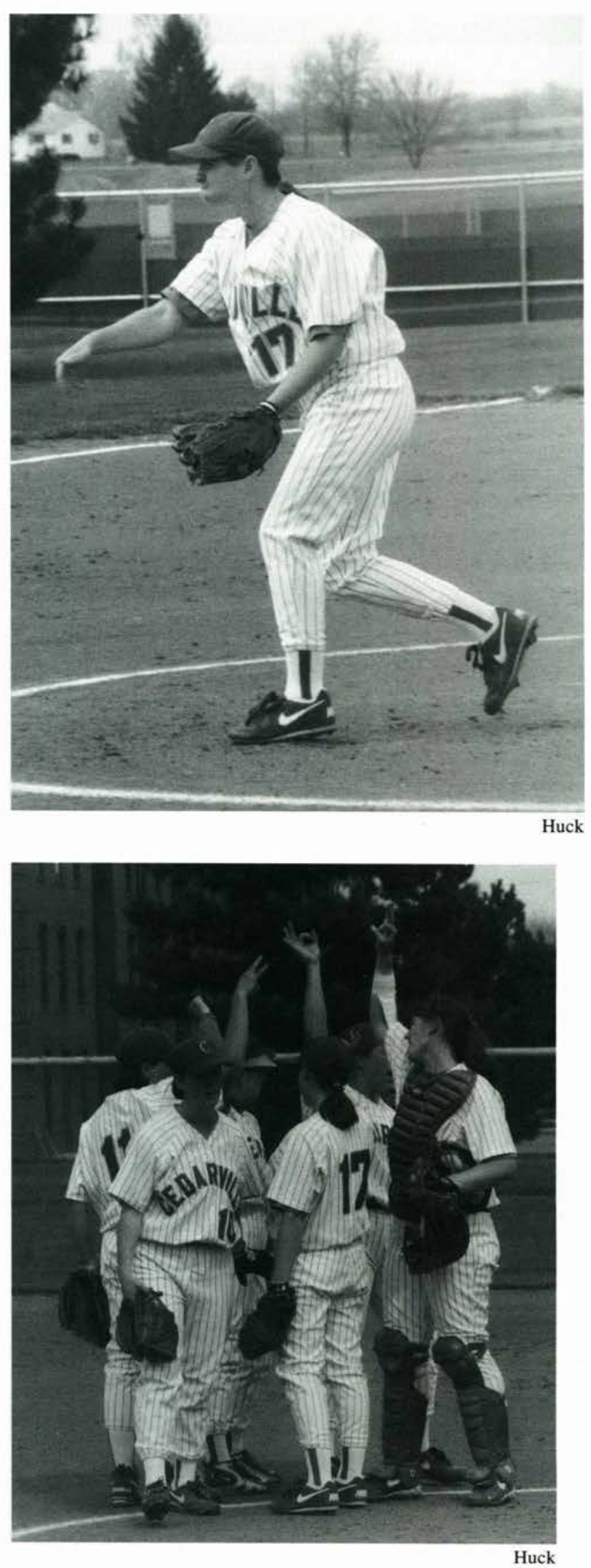


\section{Women's Softball}

The Cedarville College women's softball team labored to a 4-21 record overall and a 1-15 mark in Mid-Ohio Conference play during the 1998 season. Only ten players dotted the roster and eight of those started all 25 games.

Freshman outfielder Maria Lattanzio posted a .413 batting average to rank among the Mid-Ohio Conference leaders. She became only the sixth player in school history to hit .400 or better in a single season.

Lattanzio was first on the team in at bats (75), hits (31), runs scored (13), doubles (5), triples (2), home runs (1), and slugging percentage (.573). She was an honorable mention pick in the MOC.
Bonnie Schaefer, a junior, was the team's number two hitter with a .297 average which included a team-low two strikeouts in 64 at bats. The righthander was forced to pitch $1271 / 3$ innings out of a total of 157 due to injuries to the rest of the pitching staff. She had 19 complete games with a respectable 4.01 earned run average.

Behind the plate for every inning as catcher was Bonnie's older sister, Julie, who batted .246 during her senior season. The Schaefers were All-America Scholar-Athletes as well as MOC Scholar-Athletes which includes juniors and seniors with a minimum 3.50 cumulative grade point average.

The other senior on the team was first baseman Andrea Butz. She handled 165 fielding chances with a .970 accuracy and was even pressed into pitching three times. She hurled an 8-2 victory against an Urbana team that eventually qualified for postseason play.

Junior outfielder Beth

Weaver had a team-high 13 runs batted in while recording a .278 average. Sophomore leadoff hitter Becky Summers scored 12 times and had 15 walks which were the most on the club.

"I was pleased with the effort put forth by the women," remarked second-year head coach Dave Gaffner. "Bonnie was pressed into a difficult and tiring position as our primary pitcher, yet she responded well along with the rest of her teammates."

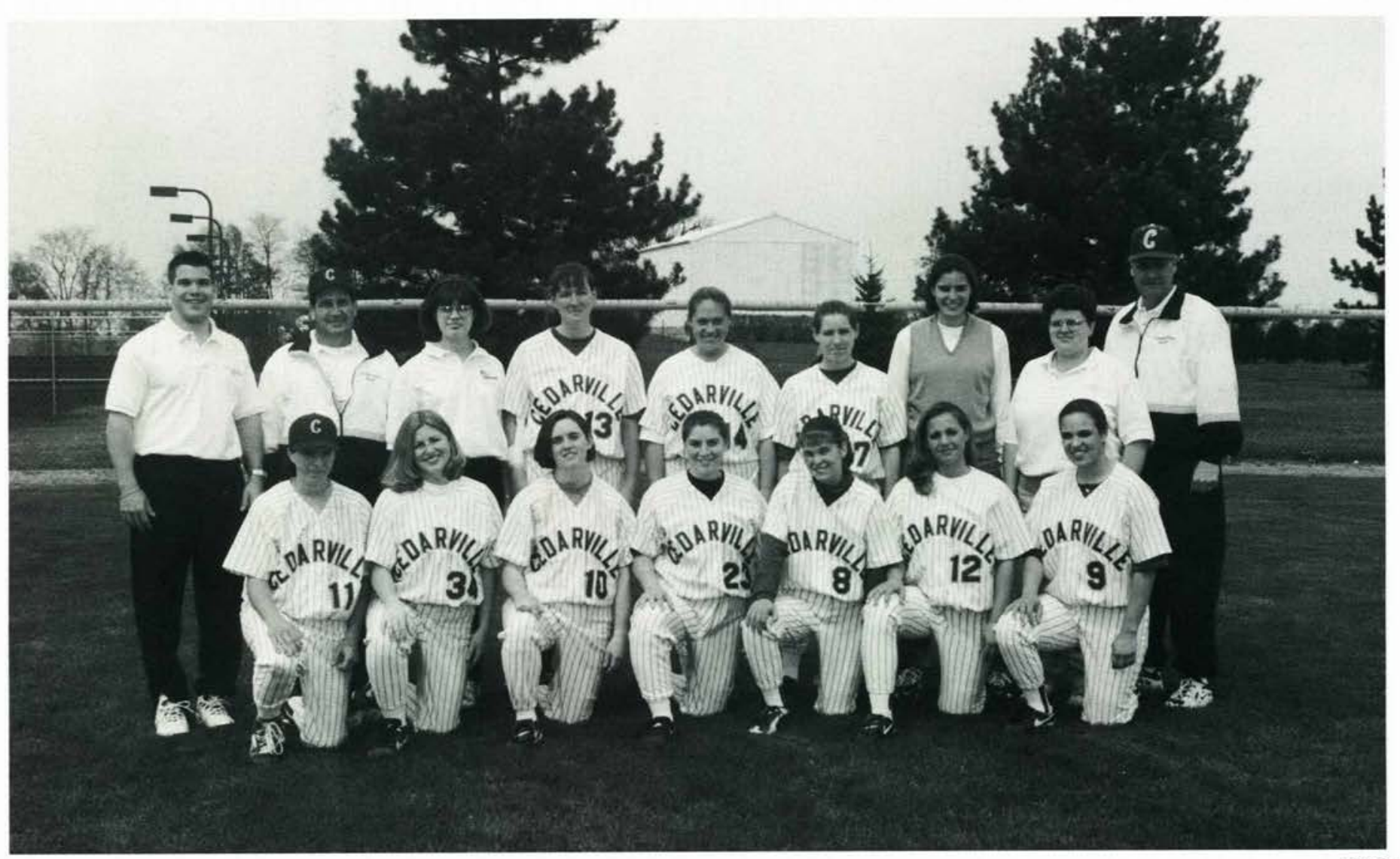

Huck

(kneeling 1-r) Becky Summers, Angela Fraley, Beth Weaver, Sarah Bishop, Elissa Morrison, Maria Lattanzio, Noella Fisher (standing) Assistant Coach Casey Wood, Assistant Coach Woody Herron, Student Manager Sarah Hills, Julie Schaefer, Andrea Butz, Bonnie Schaefer, Student-Trainer Katie Mummau, Student Assistant Annie Miller, Head Coach Dave Gaffner 


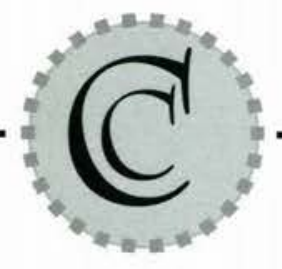

Opponet

Tennesse Temple

Rhode Island College

Webber

Warner Southern

Marietta

Wittenberg

Mt. Vernon Nazarene

Tiffin

Rio Grande

Urbana

Walsh

Malone

Shawnee State

Wilmington

Ohio Dominican

Bluffton

Concordia

Lincoln Christian

Spring Arbor

Scores reflect Cedarville - Opponent

Sophomore Dustin Crider calculates his swing as the ball quickly approaches the plate.

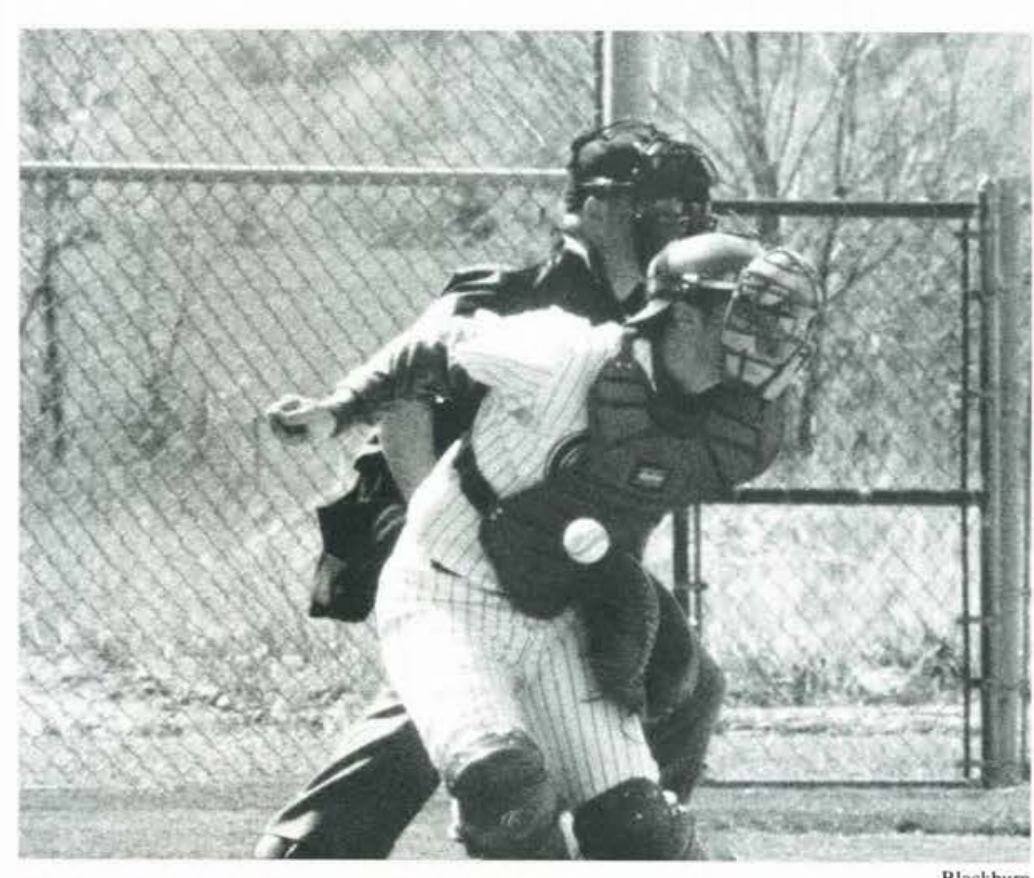

Freshman Steve Norris slides over to stop a wild pitch.
Score

$3-4,6-3$

3-4

$0-8,7-14$

$3-15,2-21$

2-25

3-19

$1-6,0-8$

$5-8,2-11$

$3-6,2-3$

$0-8,2-4$

$7-10,6-5$

$6-5,1-7$

$1-10,2-20$

4-12

$1-9,2-12$

$1-7,2-15$

2-9

13-4

$0-11$
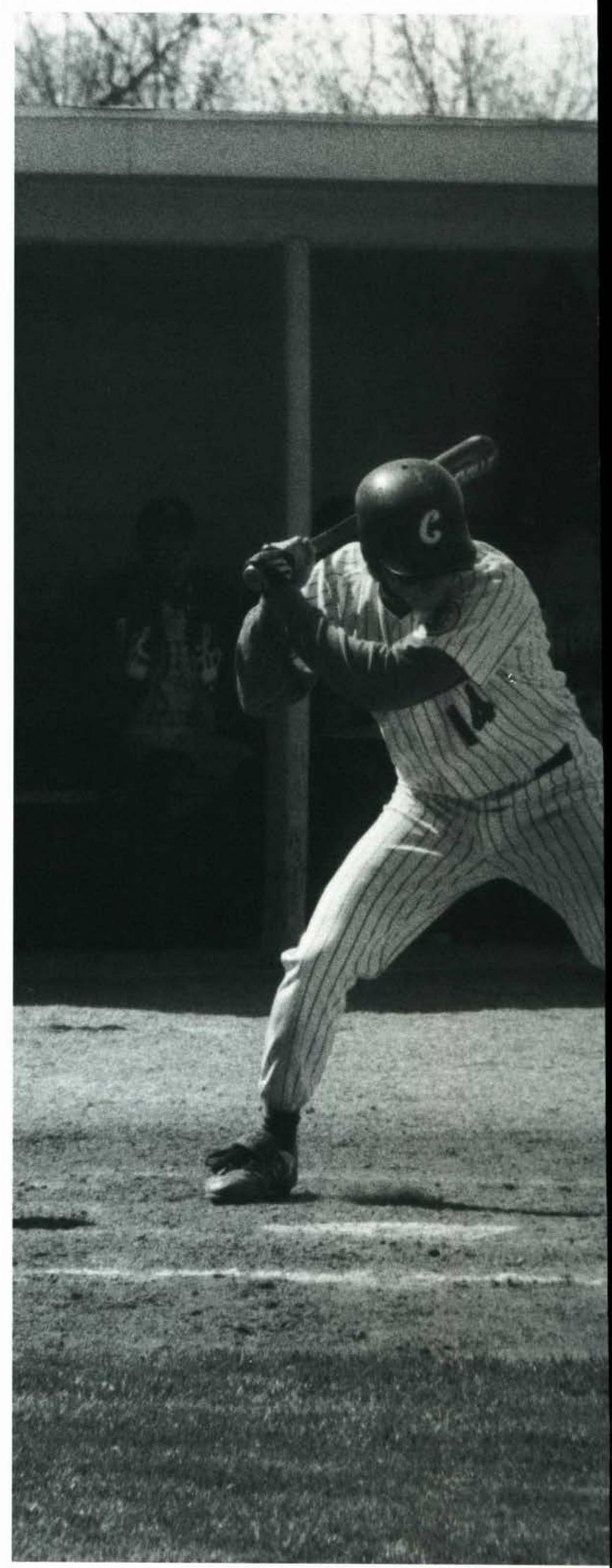


\section{Jackets Swing into Action}

\section{Jackets gain strength and momentum as season draws to a close.}

The 1998 version of Yellow Jacket baseball was no different from many of the other Cedarville spring sports teams in that they were extremely lean on experience. No less than 13 of the 16 players were either freshmen or sophomores and 11 of them were newcomers to the program. The result was a 4-27 record overall and 2-14 slate in the Mid-Ohio Conference.

Senior co-captain Josh Lunney batted a team-high .354 and was voted to the AllMid-Ohio Conference Second Team at third base. $\mathrm{He}$ was also named to the AllNCCAA Midwest Region squad.

Lunney paced Cedarville in nearly every offensive sta- tistical category. He was tops in hits (29), runs scored (18), doubles (6), triples (2), home runs (3), slugging percentage (.585), walks (13), and stolen bases (13) for the season.

The other senior co-captain was infielder Mark Wood, who was an honorable mention selection within the NCCAA Midwest Region. He was the only player to start all 31 games during the season. Freshman infielder Ryan Creeden hit .319 to rank second on the squad at the plate. Twin brother Trevor batted .277 and struck out just three times in 55 plate appearances.

Sophomore outfielder Gabe Schlappi joined Lunney on the All-NCCAA Midwest Region Team. He started all
30 games in which he played with a .272 batting average, 13 runs scored, four doubles, and 12 walks.

The Yellow Jackets fashioned a 6-3 victory at Tennessee Temple in the opening doubleheader of the season. They later surprised Walsh, 6-5, at home and the Cavs eventually qualified for the MOC Tournament. Cedarville followed that decision with a win at Malone in their very next game by the same 6- 5 count.

The Jackets experienced their best offensive contest in the next to last game of the season. In the NCCAA Midwest Regional, they drilled Lincoln Christian, 13-4, by hammering a season-high 16 hits.

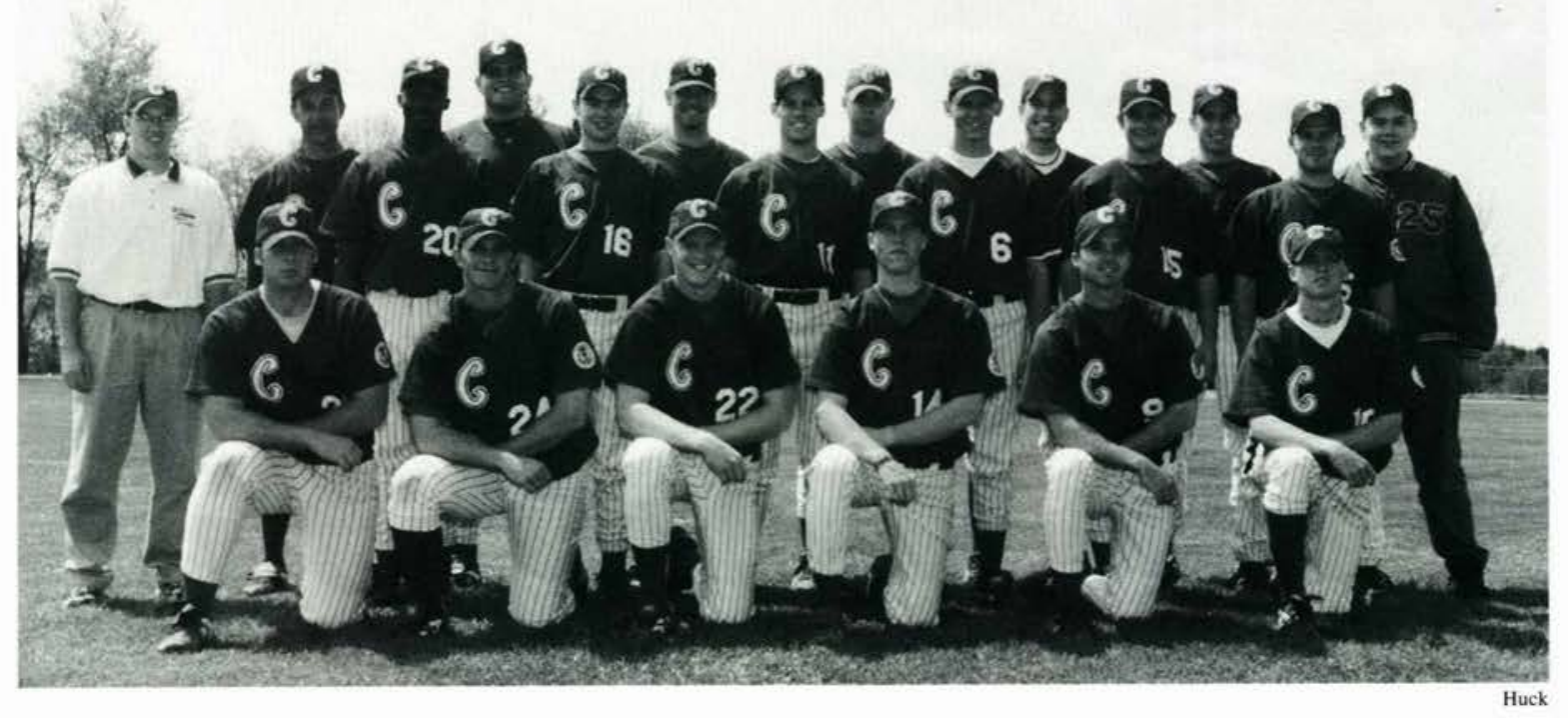

Men's Baseball Team: (kneeling 1-r) Greg Pauling, Johnny Freese, Nathan Verwys, Dustin Crider, Mark Wood, Gabe Schlappi. (standing l-r) Student-Trainer Matt Loose, Head Coach Norris Smith, Micah Hutchins, Assistant Coach Brandon Locks, Matt Johnson, Jim Tompkins, Rob Beat, Josh Lunney, Phil Hamilton, Ryan Creeden, Steve Norris, Trevor Creeden, Tim Sastic, Scorekeeper Brent Krumdiak. 


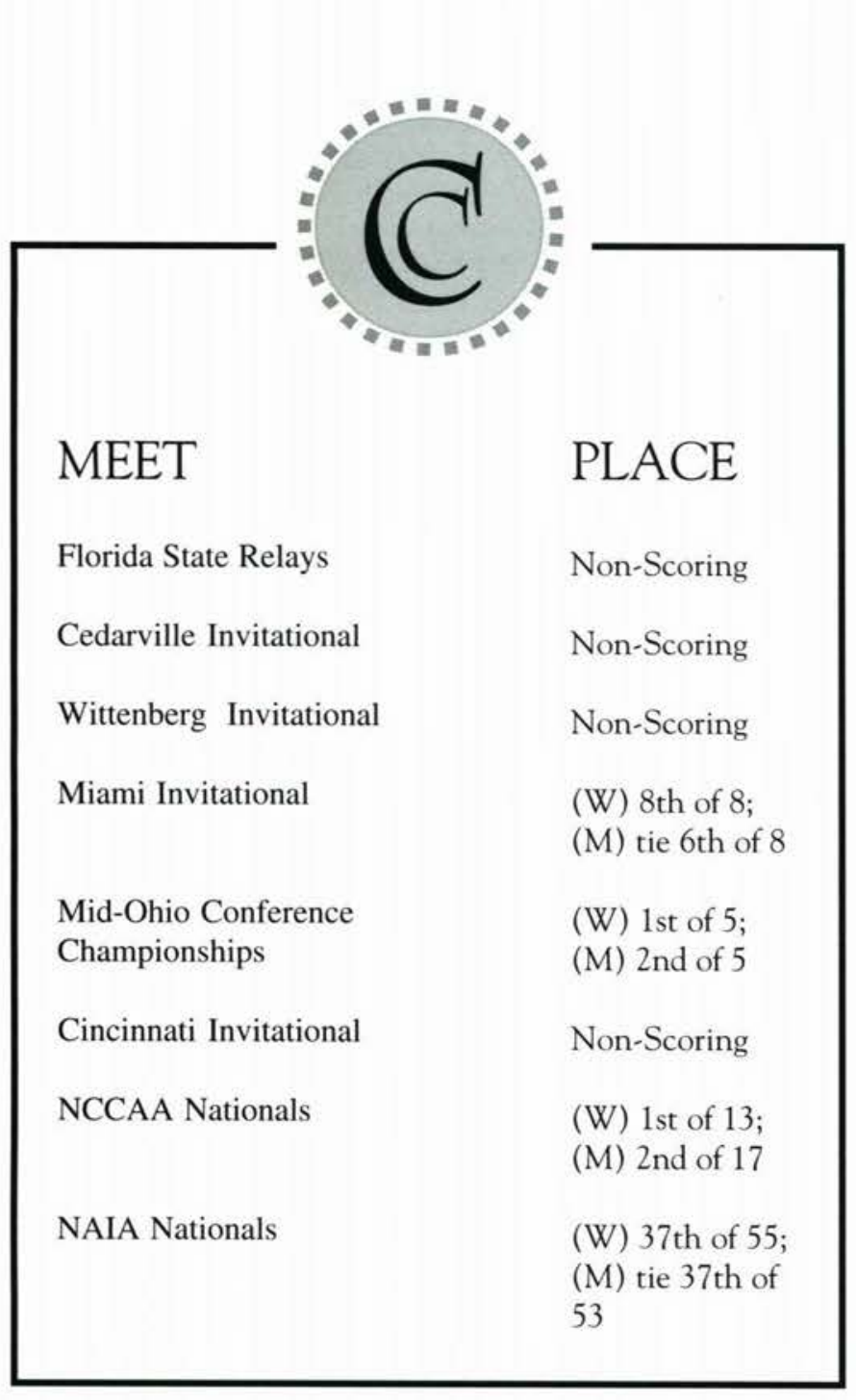

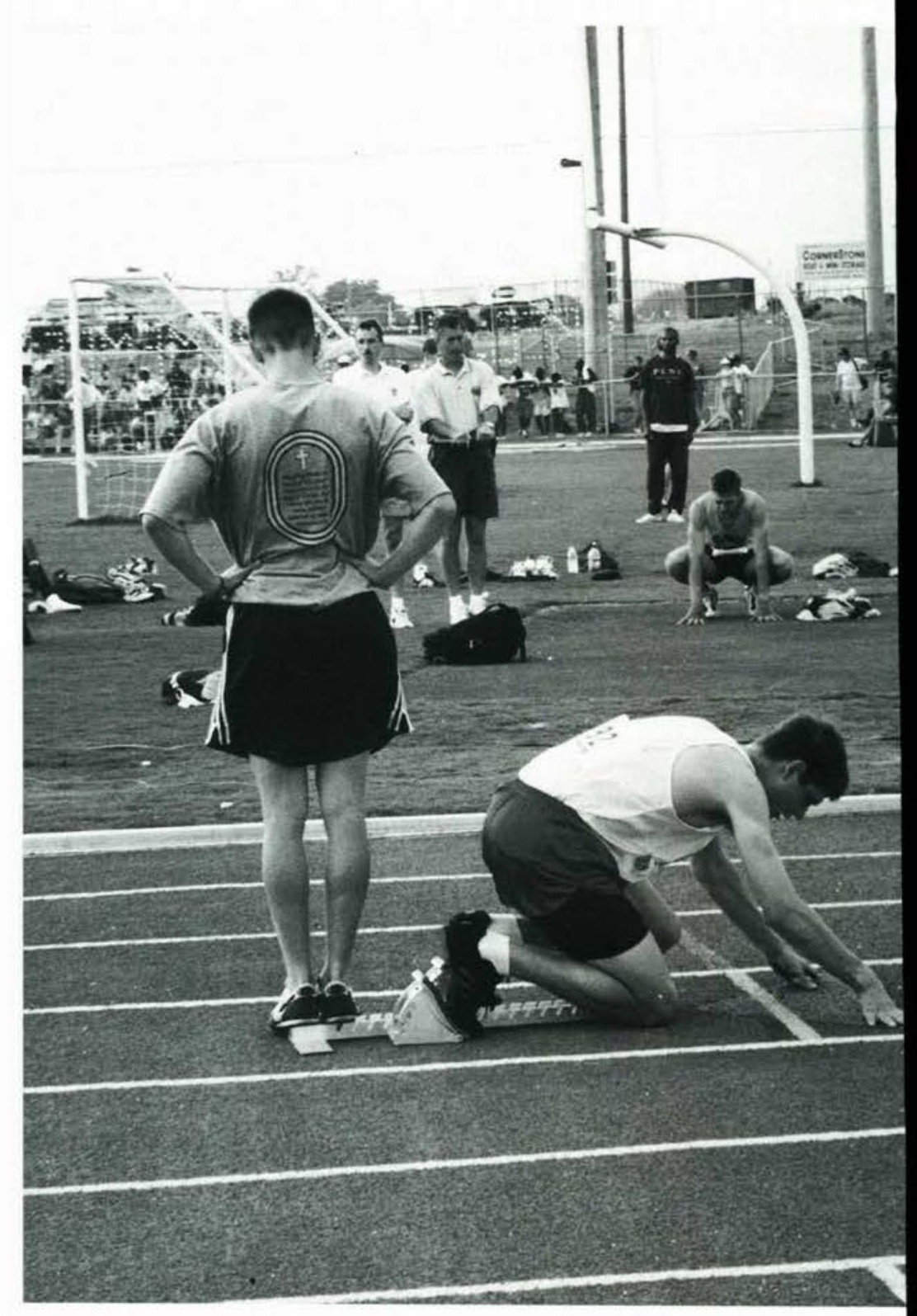

$E_{d \text { Letts focuses before }}$ competing. (above right)

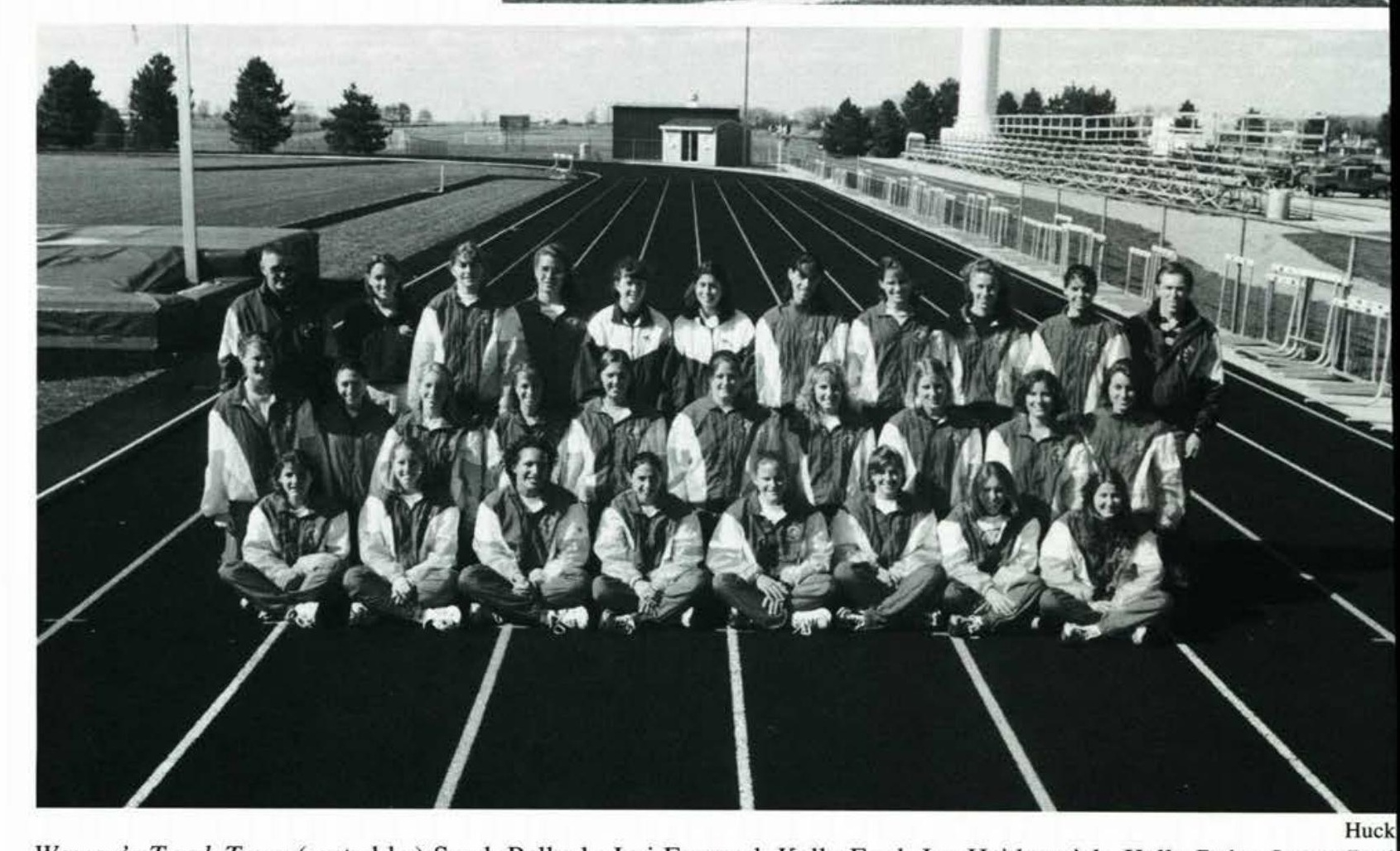

Women's Track Team (seated 1-r) Sarah Pollock, Jori Forward, Kelly Ford, Jen Heidenreich, Kelly Reitz, Loree Beth Fraley, Corrie Grigorenko, Rachelle Elder. (kneeling 1-r) Jodi Quint, Laura Hammond, Jill Breckenfeld, Becky Jordan JeriAnn Goodbar, Sandy Swales, Jody Thompson, Kristen Nichols, Christy Taylor, Meredith Allgrim. (standing 1-r) Assistant Coach Elvin King, Student-Trainer Sarah Thomas, Lindsey Mitchell, Alison Huizinga, Megan Hill, Studen Manager Janelle Forward, Jill Bruin, Allison Hume, Amy Crunelle, Rebecca Jenks, Head Coach Paul Orchard. 


\section{Jackets Take Ist and 2nd Overall}

The Yellow Jacket men's track and field program challenged for the NCCAA and Mid-Ohio Conference titles once again, and finished second in the NCCAA for the sixth time in seven years. The women's team won the NCCAA banner for an unprecedented fifth straight time and regained the Mid-OhioConference championship in 1998. Paul Orchard was voted the NCCAA and MOC Coach of the Year.

Nate Freeman's performance was the highlight of the season. The oldest men's record entering the outdoor season was the high jump mark of All-American Bud Davis at 6-feet 9-inches set in 1965. Freeman quickly erased that and twice cleared 6-10 3/4. At the NAIA Nationals he earned All-America honors by finishing fourth, and claimed the NCCAA and MOC high jump titles.

Senior thrower Dan Hudson scored the most points for the

\section{The women's team won the}

NCCAA banner and the men finished second in the NCCAA for the sixth time in the last seven years

Cedarville men in the 1998 outdoor season. He was the NCCAA and MOC discus champion and the MOC javelin champion. Hudson and distance runner Eric Crawford, who won the MOC 10,000 meter run, were NAIA and NCCAA All-America Scholar-Athletes.

Leverette was named an NCCAA All-America ScholarAthlete and Jon McGinnis won sixth place in the pole vault at the NAIA Indoor Nationals for AllAmerica recognition. Linton Ellis won the MOC 100 and 200 meter dashes, and Jason Alexander won the pole vault.

Junior distance runner Becky Jordan paced the women's team during the outdoor season with the most points scored in compe- tition. She finished as an NAIA All-American and placed sixth in the 5,000 meter run. AnNAIA All-American indoors in the 5,000 , she set outdoor school meter runs and the 3,000 meter steeplechase. She won the NCCAA 5,000 meter run and was an NAIA and NCCAA AllAmericaScholar-Athlete. Sandy Swales took first in the hammer throw with a heave of 139 -feet 4-inches.

At the NCCAA Nationals, the women piled up 113 points to edge fellow MOC member Malone College, who finished with 105.5. The Lady Jackets won just two events total and placed second in only two others, but won the team title. records in the 3,000 and 5,000

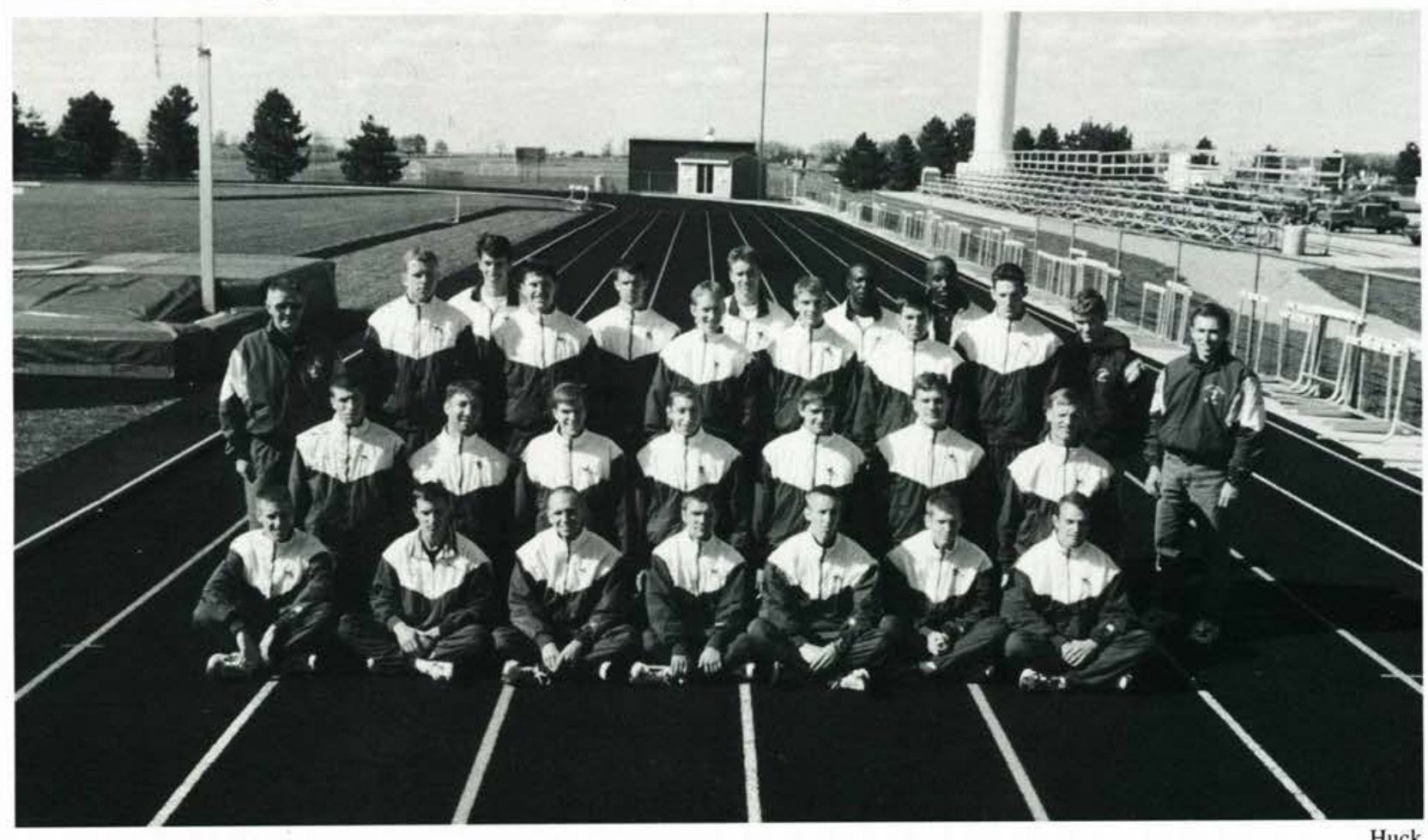

Men's Track Team (seated l-r) Eddie Nehus, Brian Hilty, Nathan Houk, Ben Thompson, Chris Leverette, Ken Loescher, Nate Jenkins. (kneeling 1-r) Pete Bednarek, Ben Stutzman, Dan Foster, Mark Hayner, Cliff Reynolds, Shawn Graves, Eric Crawford. (standing 1-r) Assistant Coach Elvin King, Chris Merrell, Dan Hudson, Jason Alexander, Greg Havens, Steve Wakefield, Ed Letts, Joel Peterson, Bamidele Ajayi, Todd Hintz, Linton Ellis, Nate Freeman, Scott Ruhlman, Head Coach Paul Orchard. 


\section{The 19.98}

Bedarville Bollege - Pbiracle 

Special Thanks to

Mr. Jack Simons, Advisor

Scott Huck Photographer

Ruthanne Pierson, Copy Editor

Rachel Acton, Assistant to Editorial Staff

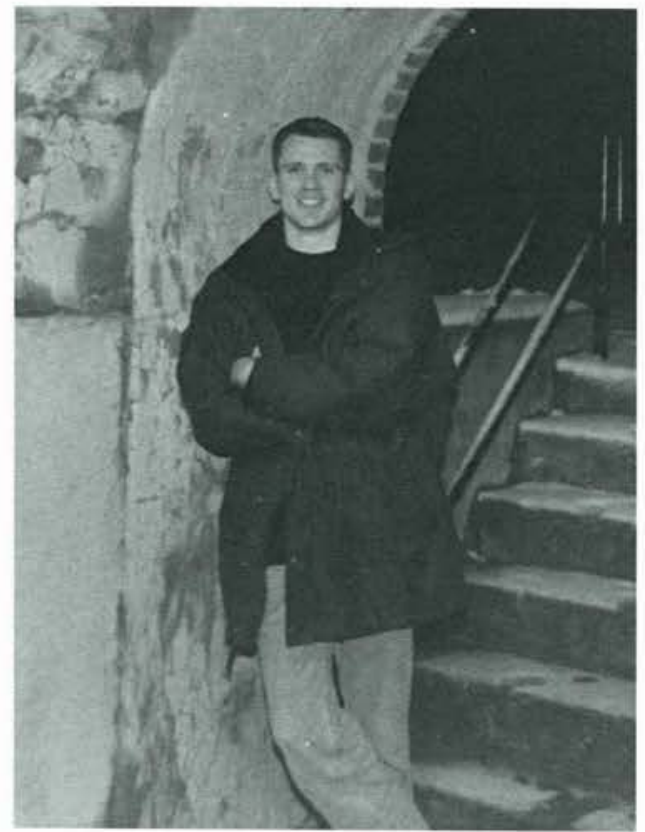

Chris Ashcraft Editor-in-Chief

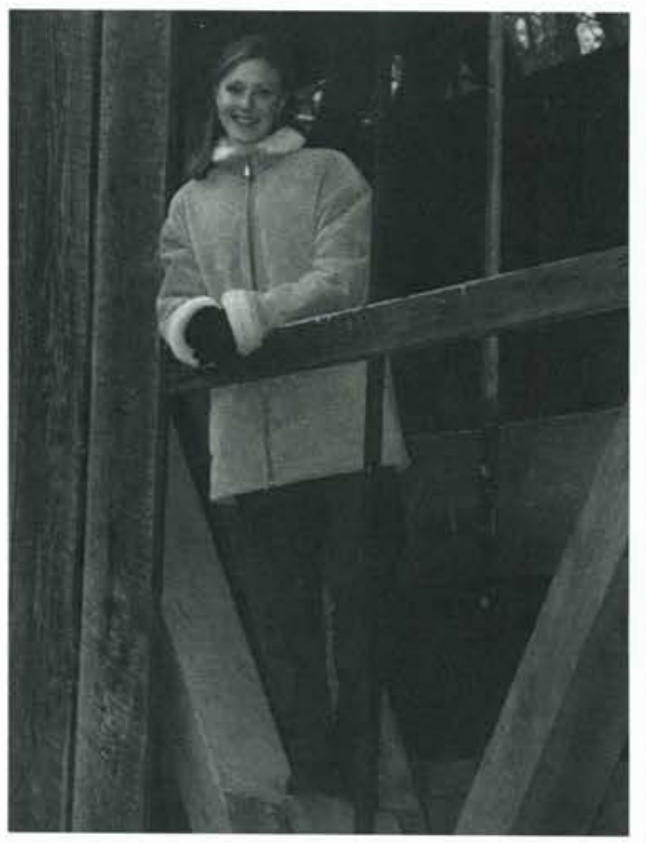

Jennifer Hangosky Business Manager

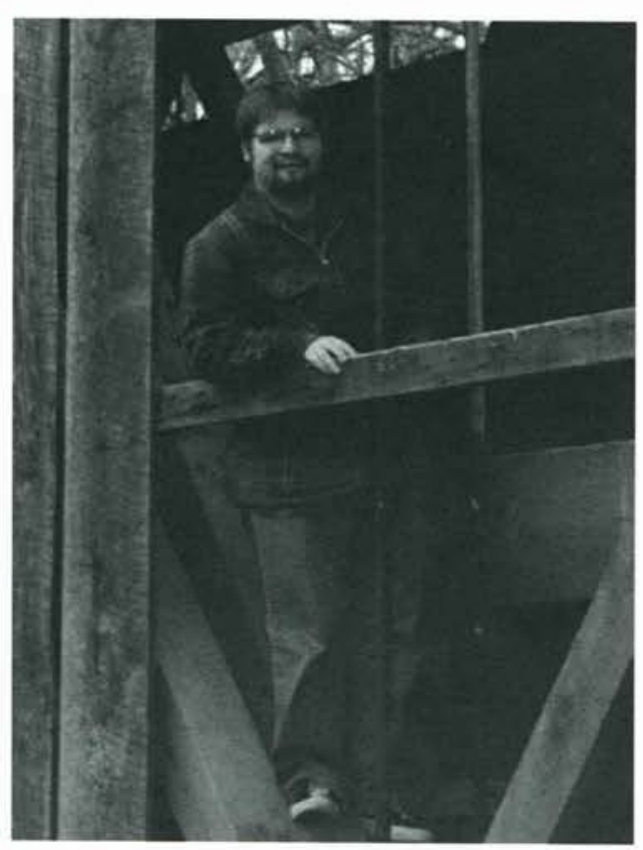

David Perry

Copy Editor

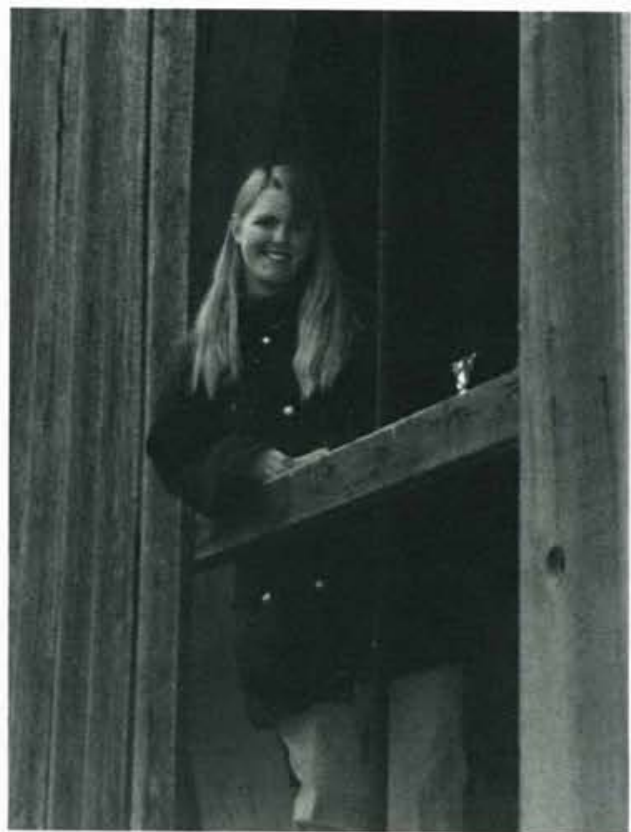

Rachel Sharp

Secretary 


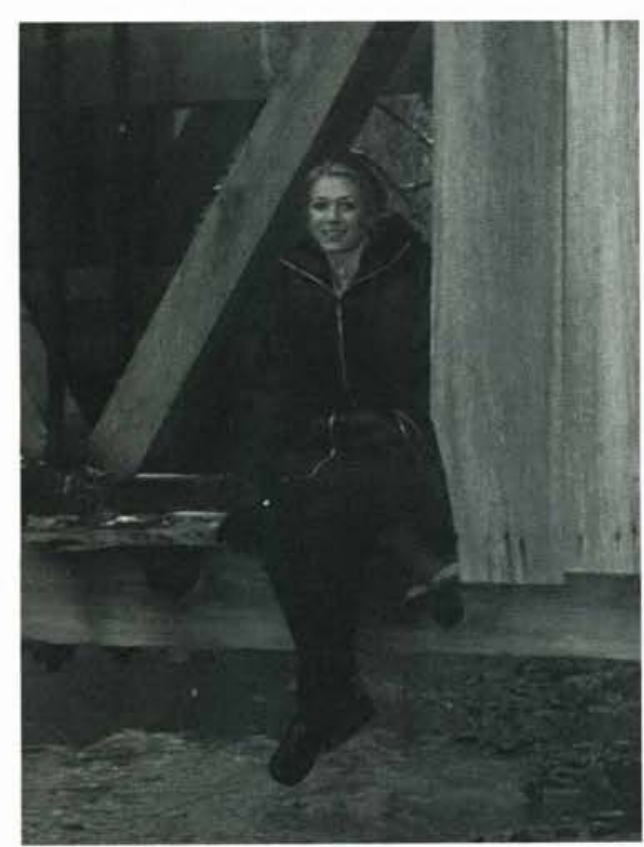

Angela Lenhart

Copy Editor

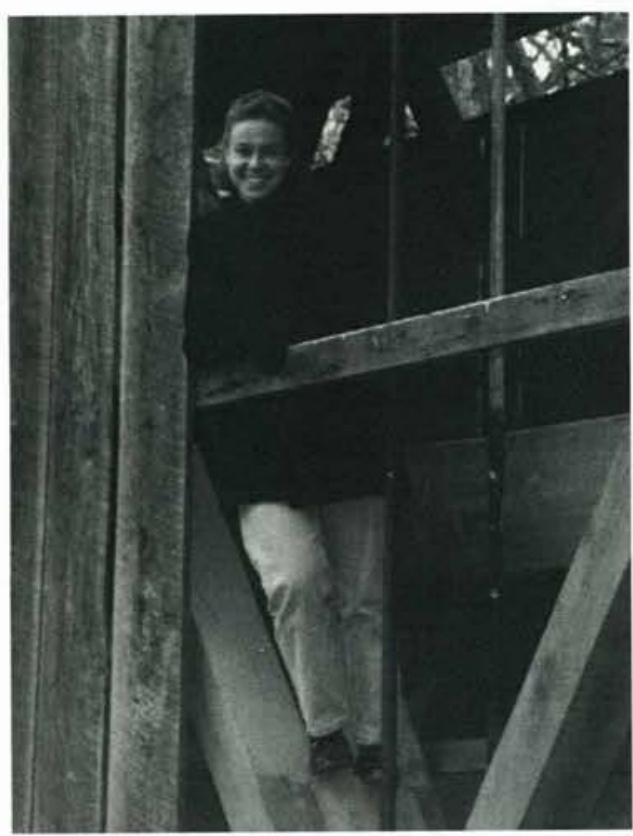

Tiffany Zimmerman

Layout Editor
Copy Staff

Brad Bartlett

Pete Bednarek

Ken Borror

Jeanne Carlton

Pete Chevere

Erica Chung

Beth Gaffner

Andrew Gingrich

Jonathan Head

Bethany Hoff

Tim Hotchkiss

Nancy Houck

Phillip Lee

Tricia Lott

Charis Perez

Christina Riley

Becky Shelford

Rachel J. Stewart

Kathy Tanis

Amy Volpe

Jennifer Wallace

Jennifer West

Christine Wiesert

\section{Photography Staff}

Eric Fiveland

Scott Huck

Kristin Jacoby

Bethany Vaught

\section{Layout Staff}

Emily Bohl

Ryan Cook

Gabe Custer

Summer Fielder

Sarah Lightly

Jenny Price

Chris Robertson

Elizabeth Smith

Rachel Soderstrom

Kendra Stanton

Brad Voumard

Aaron Warriner

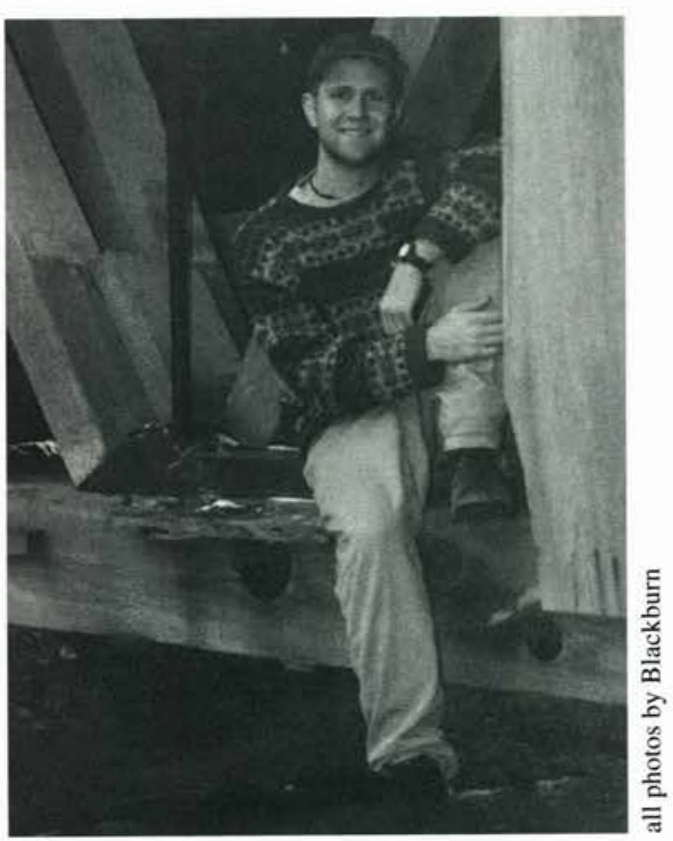

David Blackburn

Photography Editor 


\section{Ghumch Patrons}

Berean Baptist Church

Brunswick, ME

Calvary Baptist Church

Byesville, $\mathrm{OH}$

Cedar Hill Baptist Church

Cleveland Heights, $\mathrm{OH}$

Centerville Community Church

Centerville, $\mathrm{OH}$

Central Christian Church

Springfield, $\mathrm{OH}$
Emmanuel Baptist Church

Dayton, $\mathrm{OH}$

Emmanuel Baptist Church

Toledo, $\mathrm{OH}$

Faircreek Church

Fairborn, $\mathrm{OH}$

Grace Baptist Church of Western PA

Monroeville, PA

Grace Baptist Church

Westlake, $\mathrm{OH}$
Independent Bible Church

Wellsboro, PA

Kipton Community Church

Kipton, $\mathrm{OH}$

Ortonville Baptist Church

Ortonville, MI

Pike Grace Brethren Church

Johnstown, PA

Shortsville Baptist Church

Middleburg Center, PA

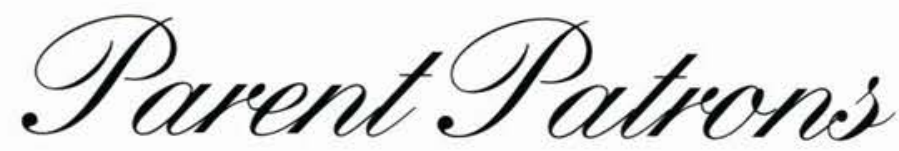

David and Lynn Allen

Jamestown, NY

Mr. and Mrs. W. Robert Ament

Murrysville, PA

Dr. and Mrs. Gene Amour

Rochester, NY

Trudy Anderson

Chino Valley, AZ

Mr. and Mrs. Roger E. Ashley

Lakewood, NY

Mr. and Mrs. Richard E. Band

Londonderry, $\mathrm{NH}$

Mr. and Mrs. Terry Barrons

Caro, MI

James Beckley

Londonderry, $\mathrm{NH}$
Virginia G. Bedillion

Lansdale, PA

Mr. and Mrs. Vernon Berning

Des Moines, IA

Mr. and Mrs. Henry P. Bilodeau

Littleton, $\mathrm{CO}$

Mr. and Mrs. Randy Bouwens

Wayland, MI

Mr. and Mrs. B. Richard Bowersox

Dayton, $\mathrm{OH}$

John W. Boyes, Jr.

Cleveland Heights, $\mathrm{OH}$

Robert and Debroah Breckenfeld

Milford, MI

Jenenne Burgett and family

Fredericktown, $\mathrm{OH}$
Bill and Donna Carl

Lakewood, NJ

Robert and Jessie Carr

Newton, PA

Mr. and Mrs. James Cartwright Indianapolis, IN

Mr. and Mrs. Bill Clark

Perry, IA

Gale Clark

Greenville, $\mathrm{OH}$

Mr. and Mrs. John A. Clutz, Jr.

Westerville, $\mathrm{OH}$

Dr. and Mrs. Alan Cochrane

Barboursville, WV

Glenn and Gayle Cook

Fort Lupton, CO 
Philip and Debbie Cormany

Rockville, MD

Graham and Elisabeth Cousens

Warrington, PA

Darrell and Loretta Coverdell

Bigfork, MT

Mr. and Mrs. D. Lance Dager

Shamong, NJ

James M. Dake

Grand Rapids, MI

Donald and Janet Davis

Columbus, $\mathrm{OH}$

Dr. and Mrs. Chris Deister

Beavercreek, $\mathrm{OH}$

Daryle Doden

Auburn, IN

Alfred and Linda Dodson

Danville, IN

Bill and Karen Dunn

West Chester, OH

Robert and Mary Fischer

Northridge, CA

William and Susan Flowers

Newport News, VA

Edda Frank

Lynchburg, $\mathrm{OH}$

Tom and Claudia Frazee

Ironton, $\mathrm{OH}$

Mike and Kathy Freese

West Liberty, $\mathrm{OH}$

Ken Gamiere

Mentor, $\mathrm{OH}$

Mr. and Mrs. F.L. Garcia

Roselle, NJ
Tom and Linda George

West Chester, $\mathrm{OH}$

Mr. and Mrs. L. P. German

Louisville, KY

Mr. and Mrs. Dave Gosman

Madison, IN

Mr. and Mrs. Edward Gray

Waldwick, NJ

Jerry and Linda Grow

Whitehall, MI

Mr. and Mrs. Allen M. Grubert

Pleasantville, NY

Rick and Linda Grunderson

Greenville, MI

Lew and Bev Guyn

Anaheim, CA

David and Linda Hangosky

Chesterland, $\mathrm{OH}$

Jim and Sharon Hannon

Vernon, CT

W. R. Harsh

Lakehead, CA

BJ Hetherington

Springfield, MO

Dr. and Mrs. McArthur O. Hill

Wheat Ridge, CO

Bob and Jae Hotchkiss

Sagamore Hills, $\mathrm{OH}$

Kenneth and Loretta Hovis

Goodrich, MI

Mr. and Mrs. Steven R. Howard

Springfield, IL

John and Jill Hurlow

Mansfield, $\mathrm{OH}$
John and Donna Hutchins

Cedartown, GA

Mr. and Mrs. Charles A. Jacoby

Camphill, PA

Frank and Barbara Jenista

Vienna, VA

Mark and Glennie Justice

Indianapolis, IN

Steve and Joyce Kaiser

Milford, IN

Gerold and Gloria Keller

Eaton Rapids, MI

Edward and Ruth Kipp

Beloit, WI

Michael and Wendy Koeppen

Galesburg, IL

George J. and Sharon T. Kopp

Clarks Summit, PA

John and Esther Lacy

Farmington Hills, MI

Brian and Judy Land

Tipp City, OH

Charles and Sara Jane Landis

Lancaster, PA

John and Jeanie LeBlanc

Bidwell, $\mathrm{OH}$

Geoff and Joanne Lofthouse

Rochester, NY

Michael and Bonnie Luck

Fort Washington, MD

Bill and Jacki Luke

Kearney, NE

Thomas and Helen Luther

Randolph, VT 
William and Candy Lyons

Palo Cedro, CA

Nicholas A. and Michele L. Mariano

Oregon, $\mathrm{OH}$

Clarence and Edna Mast

Tunkhannock, PA

Mr. and Mrs. Daniel R. McLarty

Burlington, CT

Rick and Cindy McVey

Decatur, IL

Thomas and Patricia Miller

Monroeville, $\mathrm{OH}$

Robert and Ann Moll

Schaumburg, IL

Mr. and Mrs. Jack Mountz

Redlands, CA

David K. and Florence E. Mowrey

Daleville, IN

Jeffery and Sharon Mraz

Akron, $\mathrm{OH}$

Mark and Diann Murphy

Burdett, NY

Gary and Nancy Nealis

Traverse City, MI

Gary and Julie Olin

Indianapolis IN

Gail Pedersen

Sidney, $\mathrm{OH}$

Frank and Joyce Pereira

Hagerstown, MD

William and Judy Perry

Sheffield, MA

Rich and Jan Pettersen

Texarkana, TX
Mr. and Mrs. James Pfeiffer

Parkton, MD

Harold and Patti Ploeg

Grand Rapids, MI

Linda M. Pool

Vienna, VA

William and Connie Powell

Franklin, $\mathrm{OH}$

Dr. and Mrs. Ronald W. Reed

Reading, PA

Mr. and Mrs. David Reisenbigler

Erie, IL

Robert and Suzanne Rice

Rockville, MD

Larry Richardson

Middletown, $\mathrm{OH}$

Ken Robertson

Warminster, PA

Mr. and Mrs. Charles Robertson

Bay Village, $\mathrm{OH}$

Donald Robin

King Ferry, NY

John Robinson

Verona, PA

Gerald and Bonnie Roe

Troy, NY

Mr. and Mrs. Charles Ross

East Providence, RI

Donald R. Ruegsegger, Jr.

West Carrollton, Ohio

Gary Rutledge

Rochester Hills, MI

Icilin Senior

Mohwah, NJ
Lawrence and Rebecca Sharp

Aurora, $\mathrm{OH}$

Ray and Linda Shoaff

Leesburg, VA

Ralph and Karen Skillings

Chillicothe, $\mathrm{OH}$

Jerry and Sue Smith

Elmer, NJ

Michael D. Smith

Salem, NJ

George and Claudia Stanton

Pepperell, MA

Bill and Annette Sutter

Langhorne, PA

Keith and Nancy Svendsen

Algonquin, IL

Mr. and Mrs. Keith Tatum

Hartville, $\mathrm{OH}$

Jim and Ruby Toms

Marion, IN

Raymond and Peggy Trout

Colesville, MD

Mr. and Mrs. Rollin G. Umland

Summerfield, FL

Ed and Kathi Vanderbush

Downingtown, PA

Leroy and Rosemary Vandergrift

North Canton, $\mathrm{OH}$

Daniel and Sheila Van Loo

Bellbille, $\mathrm{OH}$

Mr. and Mrs. Tom Waardenburg

Nashua, $\mathrm{NH}$

Mr. and Mrs. J. Bruce Walter

Millersburg, PA 
P. M. Warriner

Wellsboro, PA

Mr. and Mrs. John D. Weber

Olympia, WA

Dave and Cheryl Whitten

Romeo, MI

Dr. and Mrs. Ken Wiesert

Indianapolis, IN

Michael and Melanie Wiljamaa

Findlay, $\mathrm{OH}$
Jerry and Shirley Wilson

Batavia, $\mathrm{OH}$

Mr. and Mrs. Cliff Winburn

Tulsa, OK

Mr. and Mrs. Robert Winn

Yardley, PA

James and Lynda Wishart

Canton, MI

H. Wolters

Belmont, WI
Mr. and Mrs. Charles E. Workman Medina, $\mathrm{OH}$

Richard and Patricia Wyma Jenison, MI

David and Eva Young

Lancaser, PA

John and Kathy Zimmerman Grayslake, IL

Ralph and Pam Zimmerman

Adelphi, MD

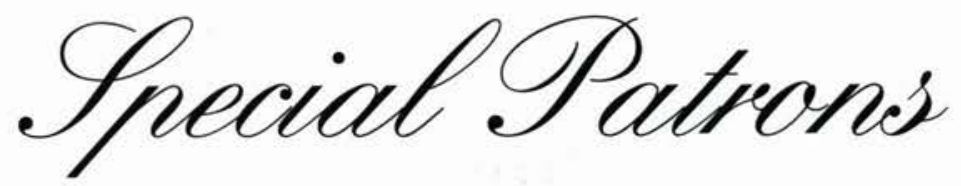

Antiques Plus

30 S. Detroit St.

Xenia, $\mathrm{OH}$

(513) 376-0622

\section{Cedarville College Bookstore}

Located in the center of the Cedarville

College campus

(937) 766-7894 


\section{$\mathscr{P}$}

Abas, Jennifer 63, 225

Abbas, Robert 40

Abbey, Jennifer 46, 185

Abbott, Timothy 46, 190

Abbs, Christy 239

Abe, Elisabeth 55

Abe, Elizabeth 171

Abel, Melanie 82,187

Abney, Corey 82

Acker, Jessica 46, 76, 232

Ackerman, Michelle 46

Acton, Caleb 55

Adam, Melissa 55, 195

Adamowich, Elizabeth 46

Adams, Daniel 63

Adams, Shannon 46

Ager, Merlin 36, 72, 199

Ager, Ruth 42

Aittama, Stephanie 46, 193

Ajayi, Bamidele 261

Akershoek, Glenda 82 ,

132

Albertson, Dawn 63, 174,

182

Aldridge, Jared 55, 175

Alexander, Jason 63,194 ,

261

Allen, Clayton 82

Allen, Danette 55

Allen, Deborah 82

Allen, Hannah 55, 226

Allen, Jennifer 55

Allen, Lukeus 55

Allen, Mark 77, 82, 118,

232

Allen, Rebecca 46

Allen, Sara 46

Allen, Shawn 46

Alley, Jewel 46

Alley, Leah 55

Allgrim, Meredith 82,

239, 260

Allport, Charles 37

Alt, Emily 138, 196, 223

Alt, Jennifer 63, 222

Alt, Melissa 46

Alyn, Irene 36

Ament, Jennifer 63

Ament, Robert 82, 137

Amos, Joshua 82, 118,

138,232

Amstutz, James 82, 171,

179, 199, 232, 240

Amstutz, Timothy 55,

232, 240

Amundson, Heather 82

Anderson, Alan 63

Anderson, Cara 46

Anderson, Dave 183

Anderson, Lyle 39

Anderson, Richard 55,

226

Anderson, Ryan 82, 225, $227,228,232,233$

Anderson, S. Nikki 82
Andrews, Adina 32,46

Andrews, Frances 42

Andrews, Marjorie 42

Angelone, Daniel 46

Angelone, Jessica 82, 223

Anglea, John 9

Anglund, Dana 55, 178

Anna, Laurie 82,129

Anthony, Dave 247

Appel, Becci 63

Apple, Eugene 8

Applegate, Jared 46

Archibald, Charles 55

Armour, Jenny 55, 142

Armour, Julie 19, 82, 133,

192, 229, 230

Armstrong, Kevin 83,

146, 187

Armstrong, Mark 63, 181

Arnold, Wayne 63

Ashcraft, Chris 17, 18, 83,

129, 187, 229, 264

Ashley, Rebecca 63, 195, 239

Assid, Dena 83, 159, 200

Atwell, Jason 83, 228

Augustus, Elizabeth 55

Ausfahl, Joshua 83, 137,

175, 190, 201, 232

Ausfahl, Philip 55, 194

Avery, Daniel 55, 176

Ayette, Jacqueline 46

Ayres, Rachael 63

\section{$\mathscr{B}$}

Baab, Stephen 55

Back, Ruth 46

Bader, Michal 42

Bader, Ronald 42

Baer, Allison 83

Bahn, Jennie 63

Bailey, Jack 46, 243

Bailey, Mellie 221

Baise, Barbara 42

Baise, Louann 42

Baisley, Alicia 63, 193,

202, 221, 222, 228

Baker, Jamie 55, 191

Baker, Janelle 46, 226

Baker, Janette 83,132 ,

226, 230

Baker, Ranee 55, 174

Baker, Sue 38

Baker, Vanessa 55, 153,

231

Balding, Ryan 46

Baldwin, Allister 63, 146

Baldwin, Christel 63

Baldwin, Martha 42

Baldwin, Matthew 55

Baldwin, Richard 37

Ballah, Adam 26, 178

Ballard, Stanley 36

Bamford, Robyn 219

Band, Clarissa 63, 137,

$153,154,191$

Banks, Benita 46
Bantle, Marlena 194

Barber, Rebecca 63, 203

Barch, Bethany 55, 239

Barger, Bekcy 221

Barker, Elizabeth 54,83 , 194

Barker, Erin 83, 225, 228

Barker, Gary 216

Barker, Melanie 55, 225

Barkhaus, Julie 236, 237

Barnard, Bradford 55, 175

Barnard, Jaclene 55

Barnes, Ashley 141

Barnes, Jill 83, 114, 118 , 223

Barnes, Kristen 198

Barnett, Holly 83

Barr, Israel 83, 146

Barron, Kelly 46, 177

Barrons, Jeffrey 63,197

Bartholomew, Ray 36

Bartlett, Bradley 83, 229

Bartlett, Julie 46, 198

Basner, Jonathan 83, 162 ,

220, 232

Bassett, Philip 38

Bath, Lezley 63, 146

Bathrick, Sara 14, 83, 132

Batt, Trevor 233

Baumann, Eddie 38

Bayley, Robert 63,178

Beach, John 63

Bean, Christopher 46

Bean, Joshua 46, 185,

187, 232

Bear, Jennifer 63, 224

Beary, David 63, 169

Beat, Robbie 46, 146, 259

Bechtel, William 63, 200

Bechtol, Heather 55

Beck, Abigail 46

Beck, Deborah 46

Beck, Matthew 83

Becker, Ronald 55

Beckley, Matthew 63

Bedford, Jaime 84, 221

Bedillion, Eric 77, 84,

133, 174

Bednarek, Pete 261

Bednarek, Peter 55

Beery, Carrie 55

Begley, Amanda 46

Bejek, Dwight 212

Belding, Karen 63

Belknap, Karen 46, 222

Bell, Bryan 29, 63

Belliveau, Patricia 42

Bender, Eric 46

Bennett, David 46

Bennett, Sandra 55, 189

Bennett, Stacie 55, 224,

229, 230

Bennington, Summer 84 ,

227, 244

Beres, Adam 46, 253

Bergman, Andrew 12, 63 , 216

Bernhard, William 8
Berning, Aaron 84

Berrus, Joshua 63, 170

Berry, Sabrina 55

Best, Paul 63, 228

Beste, Jeffery 42,199 , 232

Bett, Edwin 225

Beyer, Joseph 63, 179

Bickel, Eric 84, 153

Bielek, Robert 42

Bielo, Allyson 84,181

Bielo, Diane 46, 181

Bieniek, Michael 42

Bigelow, Ryan 84

Biggs, Haylee 194

Billing, Stacey 84,132

Billock, Jim 165, 195

Bills, Nycole 46

Bilodeau, Kristina 46 , 193, 200

Bischoff, Robert 46

Bishop, Emily 190

Bishop, Sarah 46, 257

Bjornstad, James 37

Bjornstad, Karen 191

Black, Jessica 63

Black, Stephen 46

Blackburn, Becca 200

Blackburn, David 265

Blackburn, Rebecca 55

Blair, Brian 42

Blair, Daniel 46

Blakemore, Darcie 63 ,

181

Blanton, Cynthia 63

Blaquiere, Elizabeth 46

Bliss, Carol 42

Blodgett, Andrew 55, 195

Blodgett, John 8

Blore, Melissa 63, 191, 221

Blosser, Daniel 46

Blumenstock, Helen 42

Blumenstock, Richard 37

Blupker, Sarah 221

Blythe, Jeremy 63

Boblitt, Kevin 23, 84,

197, 217, 228

Bockstahler, Amie 55,

196, 221

Boddy, Jeff 84, 133

Boddy, Judith 39

Boehm, Michael 55, 194

Boehm, Michelle 84, 174

Boertje, Julia 84

Boesch, Kimberly 63

Boggs, Jason 46

Boggs, Joyce 55, 194, 250

Bohl, Emily 55

Bohn, Amy 63, 146, 147, 228

Boland, Ahlam 46, 196, 226, 232

Bollman, Jill 84

Bollmeier, Kristen 63 ,

174

Bolt, Michelle 63, 191, 220

Bolthouse, William 8

Bonenberger, Omer 38

Bonn, Bradley 46

Bonner, Michael 84, 132

Bontrager, Joyce 55,179

182

Bontrager, Rachel 55, 22

Bookie, Benjamin 84, 21

Boothe, Eric 216

Border, Rebecca 63

Borick, Kelly 220

Borland, Lindsey 55

Borror, Kenneth 46, 146. 194

Borsos, Angela 46

Borton, Aaron 55, 171

Bosma, Janice 39

Bosworth, Daniel 63, 225 233 
man, Jami 46, 175, 225

mer, Pamela 42

boks, Bethany 46, 54

boks, Erin 63, 221

boks, Tiffany 175

bughton, Nikki 85

bwer, Deanna 63, 196

pwer, Jayme 63,200 ,

1, 226

bwn, Aaron 85

bwn, Charity 63

own, Christopher 63,

$7,146,147,215$

own, Evelyn 85, 222

own, Heather 46

own, Jason 85

own, Jeff 146

own, Jeremy 19,55 ,

$0,154,155$

own, Julie 46

own, Laura 64

own, Lori $72,85,227$,

wn, Matthew 55, 192

owning, Kelsey 55

uckner, Amanda 85,

6

uckner, Jessica 47

ueckner, Gilbert 8

uin, Jill $\quad 64,260$

yant, Hannah 55, 239

ryant, Patty 47

ryne, Dan 190

ryson, Amanda 85, 193

ubolz, Emilie 55

uchanan, David 55

uchanan, Faith 64, 146,

24

uchholtz, Stephanie 55

uck, Deborah 64, 181

ucklew, Elizabeth 42

uckley, Sheryl 64, 203,

39

uckman, Amy 47

udrew, Seth 55

ulthuis, Deanne 47

umgarner, Jamie 47

unger, Lori 47, 201, 236

urak, Aaron 64, 195

urchett, Steven 85

urgess, Margaret 86

urgett, Brooke 47

urgett, Tiffany 64,198 ,

02,227

urggraf, Kelly 64, 231

3urke, Dave 123

Burke, David 86, 169

Burkhard, Ryan 86, 118,

$27,133,233$

Burkhardt, Erin 47

Burkhart, Ryan 160

Burkholder, Patience 47

Burks, Sandra 55

Burrichter, Margaret 42

Burson, Jon 226, 228, 231

Burton, Jennifer 47,174

Bushholtz, Stephanie 219

Butler, Ginger 64, 233,
250

Butler, Jennifer 86

Button, Mark 154

Butz, Andrea 86, 228,

233, 256, 257

Byler, Krista 64, 227

Bylsma, Raenell 64

Byrd, Amanda 47, 54, 221

Byrd, Matthew 47

Byrer, JoHanna 86,115 ,

224

Byrne, Daniel 64

\section{6}

Cagwin, Deborah 42

Cain, David 212

Caldwell, Brian 64

Caldwell, Leah 56, 174, 225, 232

Calise, Dayna 47, 192

Call, Kirsten 56

Call, Michael 47

Callan, Donald 36, 201

Callinan, Beth 244

Cameron, Scott 47,189

Campbell, Debbie 29

Campbell, Fran 42

Campbell, Jack 42

Campbell, Karen 47, 154

Campbell, Sara 47, 184

Campbell, Shannah 64,

154

Cannon, Robyn 56

Cantor, Joseph 86, 221

Carboneau, Justin 56

Carl, David 86, 133, 219 ,

224

Carl, Joy 47, 220

Carlson, Carolyn 39

Carlson, Nicole 64

Carlton, Jeanne 178, 201

Carlton, Katie 56

Carmichael, Brett 47, 240

Carpenter, Amy 64, 229,

230

Carpenter, Benjamin 47,

193

Carpenter, Nicole 47, 154,

174

Carr, Alberta 42

Carr, Joanna 47, 187

Carr, John 64

Carr, Matthew 47, 217,

219

Carr, Sarah 64, 218, 232

Carraher, James 8

Carter, April 86

Carter, Catherine 56

Carter, Christopher 47,

233

Carter, Gary 42, 247

Carter, Kristyn 86

Cartwright, Jamie 64, 203,

223, 228

Carver, Cara 56, 154

Cassel, Rachel 56, 189

Castellini, Daniel 64, 195,
225

Castle, Sally 38

Cato, James 42

Cato, Melody 42

Caudill, Medford 56

Caylor, Allison 64, 214

Caylor, Andrea 64, 214

Chakalis, Nicole 64

Chamberlain, Terry 39

Chamberlin, Kristine 86

Chandler, David 47

Chandler, Derek 64, 240

Chapin, Donald 64, 218,

232

Chapman, Robert 64

Chasnov, Robert 38

Cheatwood, Jerami 64

Cheney, Andrew 47

Chesnes, John 64

Chevere, Paul 217

Chevere, Peter 64

Chiarelli, Michelle 56

Childres, Nathan 56, 220

Chmura, Emma 64

Choate, Heather 56

Chou, Nicholas 22, 64,

216, 228

Chouinard, Andrew 56

Christensen, Diana 64,

138,220

Christian, DeAnn 56, 178

Christiansen, Corrie 47,

195, 221

Christiansen, Sherry 47, 54

Christman, Heidi 64, 229

Christofer, Brenon 56,

154, 155, 232

Chundler, David 221

Chung, Erica 86,120 ,

121, 146

Churgovich, Lea Anne 86,

120, 121

Cirone, Jason 86,196

Clagg, Catherine 86,132 ,

221, 226, 228

Clane, Michelle 230

Clark, Carla 171

Clark, Clarla 56, 227

Clark, Elizabeth 64

Clark, Ernest 86, 118,

$119,177,232$

Clark, James 42

Clark, Jay 222

Clark, Mark 56, 184, 199,

229, 232

Clark, Martin 9

Clark, Michelle 64, 191,

220

Clark, Teresa 38, 201, 236

Clary, Andrew 64, 181, 218

Claus, Pamela 64, 183, 228

Clawson, Nancy 64

Cleaver, Christy 87,199

Clevenger, Charles 39

Click, Paul 87, 197
Cliene, Stefan 226

Cline, Jack 8

Clingman, Deborah 47, 190

Clutz, Amy $64,171,192$, 225, 228

Coates, Gregory 64

Cobb, Jennifer 56, 220

Coble, Jenny 64

Cochrane, Daniel 64, 229

Cochrell, Kelly 64, 187

Cody, Christopher 47

Cohan, Ryan 56, 201

Cole, Charity 193, 244

Cole, Lisa 42

Coleman, Jared 47, 212

Coler, Danielle 87, 220

Collins, Jonathan 47

Collins, Mark 219

Collins, Nick 47

Colman, James 36

Comer, Bethany 87,132 ,

236, 237

Comer, Stephen 201, 222, 247

Comfort, Rebecca 87, 224

Commons, William 8

Compton, Christine 56

Conant, Johannah 64

Congdon, Lucinda 56 ,

225

Conger, Kevin 47

Conley, Mandy 56

Conley, Shawn 56, 146, 183

Connors, Jeffrey 64

Conway, Janet 39

Cook, Aaron 47, 64, 220,

240

Cook, Christine 47

Cook, David 56, 127, 194,

232

Cook, Jennifer 56, 183

Cook, Laura 64, 220

Cook, Lisa 87

Cook, Matthew 64, 175

Cook, Ryan 47, 183, 199 , 220

Cook, Shauna 56, 221

Cooley, Brett 56, 190, 253

Coon, Tina 56, 197, 221

Cooper, Andrew 87, 128, 129

Cooper, Elizabeth 87,224

Cooper, Lonny 64

Cooper, Naomi 64, 154,

181, 224

Cope, Tiffiny $19,56,187$

Copeland, Aimee 64, 197 ,

199

Copher, Heather 47

Corbin, Amber 56, 201

Cordts, Kelly 64, 193, 225

Corey, Timothy 47

Cormany, Joanna 64, 226,

228

Cormany, Joel 47

Corson, Michael 39

Cotter, Alan 47, 189

Cousens, Andrew 87

Couser, Gregory 37

Couture, Jeremy 64,189

Coverdell, Ryan 87, 232

Covert, Brandi 132

Covill, Jason 56

Cowell, Salli 170

Cowell, Sallisha 56

Cox, Kimberly 56

Coy, Ronald 42

Crain, Nathan 64

Cramer, Kathleen 64, 203, 221

Crawford, Eric 243, 261

Crawford, James 56

Crawford, Melissa 64,

227

Crawford, Michael 87 ,

$171,228,232$ 
Davis, Greg 153

Davis, Jennifer 47, 192

Davis, Jerred 47

Davis, Matthew 47

Davis, Rachel 88, 132 , 221

De Boer, Elizabeth 56

De Conto, Jessie 18

De Graw, Bethany 137

De Haan, Carolyn 56

De Hart, Nathan 56

De Hart, Paul 47, 226

De Kock, Carole 88

De Kruyter, Paul 88,175 , 199

De Shetler, Shawn 65

De Vinney, Kristen 56, 239

De Witt, Sherri 47

Deakyne, Chad 65, 200,

222, 240

Dean, Heidi $65,150,152$,

153, 216

Dean, Joel 65

Deardorff, Donald 39

Deardorff, Julie 39

Deardorff, Melissa 56

Dearie, John 56, 232

Deaton, James 65, 229

Decker, Jennifer 88,132

Decker, Joey 88,124 ,

184, 220

Dehnke-Hirschelman,

Robert 58, 226

Deichert, Kevin 65, 198

Deister, Jesse 47, 247

Dellert, Nancy 47, 221

Denen, Travis 47

Denlinger, David 42

Dennison, Paul 56

Denton, Rachelle 47

Deranek, Norma 43

Dermitt, Noel Mc 124

Derstine, Disa 47

DeSantis, Angela 65,146 , 225

DeVries, James 8

Dewald, James 88, 128, 220

Dewalk, Richard 65, 200

Dewar, Raymond 65, 179

Deweese, Mary 56

Diaz, Daphne 65

Dickerson, Stephanie 88 ,

132, 221

Dickey, Ian 47, 233

Dickey, LaVerne 43

Dickinson, Joshua 47

DiCuirci, Michael 39,

143, 146

DiCuirci, Paul $13,65,147$

Dieringer, Andrea 65, 220

Diggle, John 65

Diller, Benjamin 88

Dillon, Dave 239

Dillon, Margaret 43

Divan, Linda 43

Dixon, Dr. Paul 30, 72,
125,131

Dixon, Dr. Paul 9, 19,

127, 136

Dixon, Pat 125,127

Dizer, Emily 65

Doden, Daryle 8

Doden, Kara 56, 219, 228

Dodge, Candace 56

Dodson, Jamie 88, 132

Doerr, Gina $65,194,199$

Doese, Jason 65

Doherty, Derrick 47, 146

Dolby, Jennifer 56, 227

Dolph, Laura 65

Doot, Hillary 47, 183

Dorman, Gretchen 56,

146, 227

Dorsey, Michael 56, 127,

$141,150,153,200$

Dosey, Tammy 47, 195, 250

Douglas, Cheri 88, 224

Douglas, Melissa 47

Douridas, Damon 65, 154

Dove, Melissa 47, 190,

191

Dow, Brandon 47, 226,

228

Dressler, Robyn 47, 230

Drexel, Jennifer 48, 142

Driesbach, Dawn 65, 146

Drullinger, David $6,7,37$

Drullinger, Helen 6,7

Du Four, Andrea 48

du Monceaux, Jodi 65 ,

189

Duda, Sarah 48, 192

Duff, Robyn 48, 244

Dunbar, James 48

Duncan, Ian 56, 178

Duncan, Reuben 65, 253

Dunham, J. Aaron 88

Dunham, Susan 65,190

Dunn, Matthew 48

Dunn, Sarah 48, 221

Dye, Brian 88,220

Dye, Daniel 56

Dyer, James 88, 120, 121,

146

Dyer, Justin 48, 169

Dyer, Rachel 65, 180, 224

Dyer, Ryan 169

Dyson, Gina 221

Dyson, Gregory 43,89, 115,121

Eaby, Joel 89

Eads, Adrianne 56, 146

Eaton, Michael 147

Eaton, Suzanne 171

Eccleston, Karen 65, 236

Eckburg, Joshua 48, 146

Eckstein, Sharon 43

Edem, Eric 65

Edem, Jason 48

Edgington, Codi 48
Edlund, Alan 253

Edwards, David 65

Edwards, Matthew 56,

190

Edwards, Melanie 56

Edwards, Michelle 56, 146

Egolf, Amy 89, 244

Ehrich, Andrew 195

Eimers, Leroy 40

Eimers, Sharon 38

Einfeldt, Ryan 56, 146,

225, 226

Elam, Ryan 48

Eldeen, Stacie 89

Elder, Rachelle 89, 199,

242, 243, 260

Eleveld, Sara 56, 169

Elliot, Jody 132

Elliott, Jeff 89, 193, 218

Elliott, Jennifer 57, 230,

250

Elliott, Jody 89,221

Ellis, Linton 247, 261

Ellison, Debra 89, 194

Elmore, Floyd 37

Elmore, Pamela 43

Emerson, Shawn 65

Emery, Jonathan 65, 193

Emery, Robert 89

Emery, Saranne 89

Endicott, Andrea 57, 141,

200, 228

Endsley, Jocelyn 89,225 ,

233

Engelmann, James 8

England, Roxanne 65,

138, 220

English, Rachel 217, 239

Entner, Sandra 37

Essington, Michael 57

Estepp, Jessica 65, 220

Estes, Carol 38

Estes, Daniel 37

Estes, Jean 89, 189

Estes, Kerry 43

Etheridge, Rutledge 65 , 193

Fabian, Carrie 57, 200,

220

Fagan, Joy 39

Fagan, Siobhan 57, 239,

250

Failor, Martha 89, 123,

152, 153

Falk, Bryan 89, 184

Farkus, Karyn 57, 187

Farlow, Joyce 43

Farlow, Julia 48

Farrell, Daniel 65

Farris, Christina 89,118

Fatrell, Katie 225

Faulkner, Jonathan 48,

233, 240

Faulkner, Lisa 132
Faulkner, Reade 240

Faulkner, Susan 43

Faulkner, Thomas 89

Favorite, Holly 48, 142,

221

Fawcett, Cheryl 37, 236

Fawcett, Clifford 37

Fawcett, Jeffrey 37

Fawcett, Julia 48, 226

Fenchak, Charles 233

Fenstermaker, Brian 65

Fenton, Tim 193, 229

Ferguson, Brent 65, 221

Ferguson, Jennifer 57,

192

Fernandes, Fernanda 48, 221, 225

Ferrigno, Michael 48

Feucht, Karl 48, 202

Fielder, Summer 57, 183

Filson, John 146

Finnigan, Julie 57, 200

Fischer, William 65, 202

Fisher, Eric 48

Fisher, Jennifer 90

Fisher, Noella 65,165 , 227, 257

Fissel, Nancy 43

Fissel, Rebecca 65, 225 , 233

Fiveland, Eric 65

Fleck, Carrie 48

Flenar, Sarah 48, 178

Flentge, Dennis 40

Flick, Gary 132

Flory, Gregory 22, 65,

182,229

Flory, Marisa 48, 221

Flowers, Timothy 90, 118,

$180,202,228,231$

Foeldvari, Laura 90, 118

Foerch, Chad 48, 183

Foerch, Joel 77, 90, 133

Folkmann, Noelle 65, 191

Foltz, Denelda 65, 225

Fonte, Christopher 48, 218

Foote, Amanda 90, 195

Foote, Brian 48

Foote, Melissa 48

Forbes, Kellie 48, 178

Ford, Kelly 90, 260

Forness, Dan 21, 215

Forness, Daniel 170

Forrest, Ted 222, 247

Forshee, Ben 199

Forstrom, Julie 65, 141,

$150,153,179,232$

Forward, Janelle 260

Forward, Jenelle 48

Forward, Jori 65, 243, 260

Foser, Lorraine 48

Foster, Becky 192, 226

Foster, Dan 261

Foster, Daniel 48, 191

Foster, Heather 65

Foster, Rebekah 48

Foster, Sonya 65, 196

Fountain, Kevin 90

Fourman, David 13, 57 ,

127, 201, 222, 247

Fourman, Heather 90,

118, 154, 192

Fourman, Jolie 65

Fourman, Matthew 90

Fox, Rebekah 57

Fox, Steven 57

Fraker, Heather 65

Fraley, Alison 57, 187

Fraley, Angela 257

Fraley, Anglea 48

Fraley, Dara 43

Fraley, Loree $57,244,2$

Francis, Keith 38

Francis, Renee 90, 132,

199, 221

Frank, Bethany 65,146 ,

195

Frank, Dwayne 38

Frank, Jeremy 57, 178, 253 
14

fantz, Kyle 57

japinski, Nicholas 65

japinski, Nickolas 225

jarber, Rebecca 48

Jarcia, Stephen 91

farcia, Steve 123

jardner, Miriam 48, 197

fardner, Tanya 65,220

farver, Brian 48

jates, Melinda 57, 198

Jathany, Paul 43

Gault, Brian 65,182

Jault, Kristen 91

Gauvin, Peter 65

sbur, Melody 91, 239

fedraitis, Sara 57

Geesaman, Belinda 48

Geib, Dawn 57, 184, 220

jeiger, Bethany 91

jeiger, Brandon 65

Genovia, Rebecca 91, 221

George, Amber 66, 169

jeorge, Carol 43

George, Timothy 66,200

Gerber, Jessica 57, 219

Gerber, Jillisa 91

Gerber, Steve 76

Gerrish, Janae 66

Gersema, Andrea 66

Getz, LaVonna 57

Gibbs, Kirsten 114

Gideon, Christina 48

Gilbert, Linda 91

Gilbert, Samuel 48, 193

Gilchrist, Sarah 57, 190

Gillespie, David 66, 127,

177

Gillett, Allison 57

Gillett, Shelly 66

Gilliam, Vanessa 48

Gingrich, Andrew 48,

187,220

Girth, Richard 48

Gleason, Kelly 48, 189

Gleason, Kristi 91, 199,

220

Gleason, Stephenie 57

Glessner, Jana 66, 170

Glick, John 91

Glupker, Christopher 91

Glupker, Sarah 66

Goble, Ryan 48

Godwin, Joseph 8

Goehring, Erin 66

Goehring, Justin 57

Goetz, Matthew 57

Goldsworth, Stephen 66

Gollmer, Steven 40

Gombis, Gillian 66, 194,

244,245

Gombis, Meredith 48

Good, Alicia 48, 146

Goodbar, JeriAnn 57,

$233,243,260$

Goodrich, Justin 57,160

Goodrow, Thomas 66

Goralski, Cassandra 244
Gordin, Amy 48

Gordon, Jennifer 48

Gornick, Brian 48, 146, 147

Gorp, Heather Van 62 ,

221

Gorsuch, Barry 66,137

Gorsuch, Berney 66, 137

Gosman, Anna 129

Gosman, Eric 91, 129

Gosztyla, Elizabeth 48

Gottwals, Dianne 43

Gottwals, Janna 91

Goulette, Blake 91, 229

Grady, Kelly 66, 154

Graff, Heather 48

Grafton, Philip 43

Graham, David 8

Grahame, Jason 66, 118 ,

226, 228

Granillo, Edith 66, 230

Grapentine, John 19, 143,

215

Grapentine, Sarah 66

Gras, Monique 66

Graves, Shawn 57, 187,

233, 261

Gray, Don 57

Gray, Kyra 48, 54, 227

Graybill, Michael 91

Graybill, Robert 48, 177

Grazier, Dan 77

Grazier, Daniel 91, 133

Greco, Daniel 57

Green, Harold 43

Green, Margaret 43

Green, Rebekah 48

Greenwood, Aimee 92

Greenwood, Janice 43

Greer, Kevin 66

Gregg, Michael 66

Gregory, Julie 57, 184,

250

Gribbin, Michael 92

Griffin, Rachel 66

Griffith, Jennifer 48, 51,

190

Griffith, Joy 57, 197, 220

Griffith, Kristy 43

Grigorenko, Corrie 48,

243, 260

Grigson, Christopher 57,

146, 147

Grindall, Kelly 57

Grisco, Nick 146, 183

Grissom, Jonathan 146

Groff, Jennifer 154, 155

Gromacki, Robert 37

Gromko, Sara 92, 118,

132

Gross, Meredith 57, 198

Gross, Sarah 92, 132, 223

Grow, Lesley 66, 225,

233

Grubbs, Michael 66

Grubert, Jennifer 48

Gruet, John 92

Gryn, Stephen 48

Guenin, Roy 8
Guenther, Stephen 57,

176

Guerette, Carolyn 92, 193

Guether, Stephen 218

Guikema, Karen 57, 203,

220

Gunderson, Josh 232

Guyn, Kim 132

Guyn, Kimberly 92

Guynik, Lara 233

Gwilt, Carrie 92, 221

Gwilt, Paul 66, 194

Gyurik, Lara 66

Gyurik, Tia 54

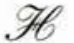

Haffey, Ben 240

Haffey, Deborah 74

Haffey, Esther 48

Haffey, Yasir 222

Hager, Jodie $17,92,118$,

132, 221

Hague, Keith 43

Hain, Kimberly 49, 181

Haisch, Kevin 66

Hall, James 57

Hall, Jason 57, 253

Hallsten, Jonathan 57

Halsey, Joseph 40

Haluko, Joshua 128

Halulko, Joshua 92, 115,

190, 199

Hamer, Matthew 66, 137,

138,232

Hamilton, Amy 57, 182

Hamilton, John 49

Hamilton, Lori 92, 184

Hamilton, Philip 49, 259

Hamilton, Tiffany 92, 118

Hammond, Duane 66,

200, 233, 240

Hammond, Jonathan 66

Hammond, Laura 243,

260

Hamrick, Sarah 49, 146

Hanbury, M. Anson 92,

$118,119,232$

Hancock, Jillianne 57, 195

Hand, Jill 49, 154

Hand, Stephen 51, 146, 147

Handel, Stephen 66, 169

Hanebury, M. Anson 122

Hangosky, Jennifer 17,

$18,92,128,129,130,201$, 264

Hansell, Timothy 43

Hansen, Dustin 66, 140

Hanson, John 225, 226

Hardin, Timothy 57,154

Harding, Jason 190

Harju, Cara 92, 227

Harkleroad, Lance 66

Harlan, Anna 92, 132

Harner, Sandra 39
Harney, Wendy 49, 195, 223

Harrell, Brooke 49

Harrison, David 49, 194

Harrison, Kyle 49, 146, 147

Harsh, Michael 19,93,

128,162

Hart, Nathan 93, 133, 146

Hart, Rachel 66

Harz, Nathan 192

Hassell, RoseAnn 57

Hassenzahl, David 66,

187, 217, 219

Hasty, Joy 93, 181, 233

Hauk, Nathan 197

Hauser, Michael 49

Havens, Greg 261

Hawkins, E. L. 131

Hawkins, E.L. 8

Hayes, Clint 247, 248

Hayes, Eric 49

Hayes, Karen 66, 227,

228, 230, 239

Hayley, Nathan 49, 229

Hayner, Mark 57, 261

Haynes, Jeffrey 66

Haynes, Melisa 202

Haynes, Melissa 49

Hazen, Marinus 36

Heale, Kenneth 49, 146

Heath, Leanne 57, 146,

$175,199,220$

Heatherington, Melissa 14

Heaton, Molly 57, 227

Heaton, Timothy 38

Heckrote, Meredith 49,

223

Hedges, Andrew 57, 141,

194

Heffner, Robyn 57, 201

Heflin, Christina 57

Hegna, Harwood 38

Heidenreich, Jen 260

Heidenreich, Jennifer 49 ,

243

Heineman, April 66

Heldreth, Karri 57

Helfrick, Erika 178

Helmick, Larry 40

Hellwig, Evan 38

Helmuth, Dale 43

Helton, David 93

Henderson, David 49

Henderson, Julie 49, 176

Henniger, Jared 66

Henning, Nelson 40

Hennis, Elizabeth 66

Hennis, Sarah 227, 233

Herb, Amy 58, 182

Herman, Christopher 58

Hermiz, Matthew 154

Herrmann, Jeffrey 49

Herrold, Kerri 49

Herron, Woody 257

Hershberger, Patricia 49,

$153,229,231$

Hess, Aubrey 58

Hesse, Joshua 49, 146

Hester, Joy $11,49,195$,

203

Hewitt, Dave 179, 220

Hewitt, Timothy 66

Heyd, Andrew 66, 217

Hickernell, Paul 58

Hicks, Daniel 93,

133, 190, 231

Hidalgo, Michael 93, 240

Higgins, Brooke 93, 186

Higgins, Michelle 93, 132

High, Kristi 49, 198

High, Michele 66, 198,

200, 224

High, Sarah 58, 202, 227

Hilgeman, Timothy 49 ,

232

Hill, Alicia 93, 132

Hill, Christa 66

Hill, Dustin 93

Hill, McArthur 66, 225 
House, Melissa 58

House, Shannon 66

Housten, Kathleen 94,

176, 220

Hovis, Jody $15,94,120$,

$121,122,128$

Howard, Jennifer 58,114 , 171, 227

Howard, Jeremy 66

Howard, Timothy 66

Howder, Scott 43

Howe, Abigail 94

Howe, Angela 66, 189,

220

Howe, Christine 49, 189

Howell, Jennifer 66, 202

Hubbard, Patricia 94

Huber, Patricia 43

Huck, Scott 43

Hudson, Dan 261

Hudson, Daniel 94

Huebner, Casey 58, 154

Huggler, Valerie 94

Hughes, Brent 66, 191

Hughes, Samuel 49

Huizinga, Alison 66, 260

Hulbert, James 58

Hulet, Ronald 49

Hull, Gary 43

Huls, Pamela 58, 201

Hume, Allison 49, 239 , 260

Hunt, Barbara 43

Hunt, Leigh 43, 75

Hunt, Robert 43

Hunter, Erica 94, 132, 221

Hunter, Jim 240

Hunter, Kristen 66

Hurlow, Jodi 49

Hurne, Shawn 49, 154

Hurst, Amy 94, 132, 223

Husak, Nathan 49

Husband, Scott 94

Huss, Matthew 66, 196

Hutchins, Micah 49, 259

Hutchinson, Amy 153

Hutchinson, Christopher 49, 193

Hutchison, Aaron 94

Hutchison, Amy 66

Hutchison, Thomas 37

Hutfless, Jennifer 58

J
Ikeda, Kouichi 159,225
Ingalls, Margaret 39
Inion, Brenda $14,16,94$,
$132,169,223$
Irish, Jeanette 66,223
Isaacs, Jason $67,191,194$,
220
Issler, Weston 49
Ivey, Becky 95

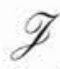

Jackson, Heather 58, 227

Jackson, Kristy 67, 192,
220

Jackson, Ruth 95, 146

Jacobs, Jack 8

Jacobsen, Karen 67, 137,

194

Jacobson, Jodie 67

Jacoby, Kristin 67, 193, 220

Jaskilka, Julie 113

Jenista, Margaret 49,153

Jenkins, Erica 58, 193,

199

Jenkins, Nate 261

Jenkins, Nathan 67, 233

Jenks, Rebecca 95, 118,

233, 260

Jenks, William 49

Jensen, Chad 67, 77, 217

Jeremiah, James 8

Jex, Stacy 95

Johansen, Daniel 67, 190

Johns, Amanda 58, 236

Johns, Erin 95, 118, 190

Johnson, April 95, 221

Johnson, Bobby 49, 186,

226, 228

Johnson, Brenda 95

Johnson, Clifford 37

Johnson, Elizabeth 67,

190, 228

Johnson, Gregory 58, 95

Johnson, Jaime 95

Johnson, James 58, 62,

232

Johnson, Julien 95

Johnson, Katherine 58

Johnson, Kathryn 58,

184, 201

Johnson, Martha 37

Johnson, Matthew 49,

259

Johnson, Pamela 38, 250

Johnson, Rebecca 95, 224

Johnson, Sharon 37

Johnson, Shirley 43, 207

Johnson, Timothy 43

Johnson, Todd 95, 222

Johnson, Trisha 67

Jolman, Samuel 49, 190

Jones, Britney 58, 189

Jones, Callie 49

Jones, Carrie 49, 194

Jones, D.N.C. 153,154

Jones, David A. 95, 225

Jones, David W. 67, 179

Jones, Jennifer 244

Jones, Jocelyn 58,227

Jones, Josalyn 26

Jones, Keith 58

Jones, Stephanie 67, 227

Jonson, Laura 67

Jopson, Erin 49, 54, 227

Jopson, Matthew 67

Jordan, Becky 260

Jordan, Jeffrey 58

Jordan, Rebecca 67, 242, 243
Jouwstra, David 49,71, 146, 189, 229

Jouwstra, Julie 95, 178

Judkins, Kevin 67

Junkins, Todd 67

Justice, Allison 67, 197

Justice, Angela 67

$\mathscr{K}$

Kaercher, Murtha 43

Kaiser, Lindsay 49

Kaminsky, Benjamin 49

Kammeyer, David 44

Kandel, Jason 169

Kandel, Jay 123

Kane, Mark 67, 187

Kanzeg, Sarah 49

Kapansky, Beth 67, 181

Katz, Lisa 58

Kaufman, Melissa 67

Kay, Kelly Mc 203

Kaynor, Daniel 95

Kayser, Rebecca 67

Keane, Kerry 187,220

Kear, Denise 58

Keary, Stephen 67

Keenan, James 67

Keirn, Lori 44

Keller, Elaine 44

Keller, Laura 49, 197, 221

Keller, Natalie 67

Kelly, Jeremy 67

Kemp, Heather 49

Kempe, Andrew 58, 178,

232

Kempton, Ruth 8

Kendall, Joanne 44

Kennelly, Heather 58, 181

Kenny, Lori 95, 169

Kenworthy, Lauren 49

Kenyon, Kandace 49, 186

Kerr, Jennifer 49, 96, 194,

199

Kerr, Rachel 49

Kerwin, Douglas 67

Kessler, Brooke 49, 190

Kester, Shalom 67, 193

Ketterer, Kimberly 58,

226

Kiaz, Daphne 186

Kick, Steven 49

Kickbusch, Kyle 58, 190 ,

225

Killian, Kelly 49

King, Andrea 58, 184,

221, 227

King, Elvin 38, 243, 260, 261

King, Jerry 170

King, Karen 58, 184

King, Scott 67

King, Suzanne $17,96,128$

King, Toi 44

Kinney, Naomi 49

Kinniburgh, Heidi 50,

174, 195, 221

Kinsey, Heidi 58

Kintner, Sarah 67
Kipp, Erika 50, 221

Kirby, Robert 58, 232

Klakring, Brian 77, 96

Kleiman, Kimberly 58 ,

198, 200, 226

Kleis, Jonathan 50, 193

Klimek, Mark 40

Klind, James 194

Kline, Andrea 67

Kline, James 67

Kline, Stephen 96, 190,

191

Knauff, Glenn 44

Knauff, Nancy 44

Knight, Rachel 96

Kniowski, Rebecca 67,

146

Kobiela, Ann 96, 132, 228

Koch, Phillip 50

Kocher, Robert 50,67,

190, 200

Kochetova, Ekaterina 50

Kochetova, Katia 192

Koeman, Kim 184

Koeppen, Katie 50, 250

Koerbel, Michael 58, 218

Koetsier, Jill 67

Koetsier, Lynn 50

Kohl, Clinton 38

Kooy, Coriann 67, 181

Kopp, Paul 96

Kordic, Mark 44

Kouba, Robert 96

Koy, Cariann 221

Koziol, Scott 96, 133, 182

Kragel, James 38

Krampe, Adam 96, 133

Kranenburg, Jennifer 50

Kregel, Shari 67, 217

Kreuder-Crowell, Vianna 58

Krick, Kendra 67

Kroner, Laura 67, 184,

221, 223

Krueger, John 67, 222,

247, 248

Krum, Andrew 58, 216

Krumdiack, Brent 50,

181, 259

Kuczynski, Kimberly 67

Kuhn, Kristin 58

Kuhns, Michael 67

Kunz, Gregory 44

Kurowicki, Stephanie 50,

197

Kuruvilla, Heather 40

Kuvshinikov, Barbi 58

Kuyper, Amy 58, 217

Kwast, Daniel 58, 146, 181

Kwast, Timothy 58,181

La Fleur, Mark 58

Laber, Ellen 50, 54

Labor, Michelle 96, 154

Lacy, Seth 50

Lakes, Becky 119, 121,

146, 223, 225

Lakes, Corinne 44

Lakes, Hannah 67

Lakes, Rebecca 96,118,

120

Lamb, Matt 190

Lamborn, Julie 58, 189,

191, 221

Lamoreaux, Gena 96, 132

Lamp, Steven 67, 190

Lampton, Michael 58, 24

Land, Nicole 198

Landis, Joel $67,182,218$

Lane, Deforia 8

Laning, Michael 67

Lankhorst, Anna 96

Lankhurst, Anna 130

Laramore, Robert 38

Larr, Chad 44, 96

Larson, Greg 200

Larson, Jaime 96, 132,

221

Larson, Jennifer 50,58 ,

183

Lasso, Nathan 50

Lattanzio, Maria 257

Lauritzen, Julie 67, 192, 221

Lawry, Cynthia 67, 146, 185,225

Lawson, Thomas 50, 221

Lay, Christina 233 
eukhardt, William 58 everette, Chris 261 leverette, Christopher 97, 43

everson, Kevin 228

everson, Kimberly 58 , 98

Lewis, Chandra 146

Lewis, Ed 167, 206

Lewis, Michael 67, 180

ewis, Nathan 67, 146,

$92,217,229$

Lewis, Nelson 50

Light, Stephen 58, 232

ightly, Sarah 97, 118,

20, 121, 122

Linafelter, Karisa 97, 124,

146, 176, 228

Linden, Tiffany 58,226

Linn, David 97

Linn, Faith 44

Linnell, Betsy 58,189 ,

\section{0}

Linton, Jennifer 58

Litteral, Andrew 67, 182,

217,229

Little, Katie 58

Lloyd, Joseph 97, 216

Loach, Barbara 39

Locks, Brandon 259

Loescher, Ken 261

Loescher, Kenneth 50

Loeschr, Kenneth 243

Logan, Samuel 50, 194

Loh, Esther 50, 202, 222,

225,226

Longo, Kimberly 44

Loose, Matthew 67, 259

Lopez, Hugo 196

Lopez, Michael 38

Lorinovich, Lindsey 195

Lorinovich, Melissa 97

Lottf, Tricia 50

Lowstetter, Michael 50,

201

Lucas, John 50, 221

Luck, Michael 59

Luckmann, Nicole 59,

180,243

Ludema, Courtney 50 ,

181

Luke, Brandon 59, 216

Luke, Derek 12, 97, 216

Luke, Sarah 97, 132, 221

Lundvall, Shawn 67, 182

Lunney, Joshua 97, 222,

259

Luo, Dali 40

Luo, Ling Lin 40

Lutes, Jennifer 50

Luther, Myra 196, 224

Lutz, Jennifer J. 97, 118

Lutz, Jennifer L. 137

Lutz, Jessica 59

Lutz, Robert 50, 253

Lykowski, Paul 67, 232

Lynn, Aaron 97, 118

Lyons, Marie 98, 185
Lyttle, Jonathan 50, 195, 221

221

Mazelin, Mark 44

Mc Auley, Christopher

68, 193

Maass, Jennifer 50, 232

Mac Aurthor, John 232

Mace, Stephanie 68, 196,

221, 223

MacPherson, Lisa 59

Madsen, Jennifer 50

Magrum, Craig 98, 218,

232

Mahl, Kelsey 59

Mallman, Joan 68, 191

Malone, Andrew 98, 192, 226

Malone, Jason 20, 21, 98,

118, 125, 137

Manchesky, Jason 59

Mann, Michael 98, 133

Mann, Rebekah 50

Mansfield, Carrie 33, 68,

159

Manson, Paul 50

Mantravadi, Samuel 68

Manwarren, Joel 50

Manwiller, Andrew 68

Marchetti, Ghena 68,153 ,

226

Margene, Aaron 59

Margene, Jeremy 59

Mariage, Abigail 68

Mariage, Amanda 50

Mariano, Nicholas 98

Marks, Carol 19, 59, 146

Marotta, Rosemarie 68

Marr, Chirsty 68

Marsh, Kelly 44

Marshall, Andrew 98,

219, 228

Marshall, Kristin 68, 221

Marshall, Matthew 50

Martens, Justin 59, 203

Martens, Wendy 221

Martin, Christine 98

Martin, Ruth 39

Martin, Sarah 68, 196

Mason, Jennifer 68

Massai, Neil 98

Massey, Jillian 59

Mast, Angela 59, 233, 250

Mast, Toby 201

Mathias, Jessica 50, 190

Matson, David 39

Matson, Katie 198

Matthews, Mark 44

Mattick, Stephen 50

Mattis, Perry 247

Matula, Tamara 98, 193,

244

Maurice, Michael 68

Maurizi, Janice 50

Maxie, Wayne 44

Maybury, Heather 68, 230

Mayer, Kathleen 68

Mayer, Sarah 59, 146

Maynard, Kimberly 98,

Mc Dermitt, Noel 98

146

Mc Donald, Sarah 59,

146, 193, 221

Mc Farland, Kathy 68

Mc Grew, David 59

227

Mc Kay, Amanda 67

189

Mc Kenzie, Dave 50

217

Mc Lain, Michael 146

Mc Larty, Erin 68

Mc Mahon, Emily 59

Mc Neal, Andrea 50

219

Mc Quillen, Stuart 19

Mc Quinn, Ethan 99

Mc Vey, Eric 59, 253

Mc Vey, Philip 68

McCain, Alan 44

McDole, Virginia 98

McDonald, Debra 44

McGillivray, John 38,

200, 240

178

McNeal, Kezia 44

McQuillen, Stuart 59

Mead, Amy 59, 190

177
228

Meckstroth, Melissa 50

Meeks, Emily 99, 132

Meissner, Jessica 59, 200

Meitzler, Deborah 50

Melcher, Amanda 68

Mellish, Joseph 68, 189

Mencarini, Kristina 68

Mercer, Aaron 59, 182

Merchant, Steven 99, 220

Meredith, Angela 99, 118,

194

Merrell, Chris 243, 261

Merritt, Fred 44

Merritt, Jason 68

Mesnard, Cary 50, 196

Metcalf, John 231

Metsger, James 59, 141,

253

Mc Donald, Elizabeth 68, Meyers, Angela 99

Mc Fadden, Cynthia 68

Mc Gahan, Meredith 68

Mc Gillivray, Steve 243

Mc Goldrick, James 40

Mc Guire, Amanda 59,

Mc Kay, Kelly 50, 146,

Mc Kelvey, Heidi 59, 217

Mc Kenzie, Kimberly 68 ,

Mc Kinney, Elizabeth 50

Mc Leod, Joel 59, 187

Mc Leod, Peter 99, 218

Mc Murray, Stephen 50

Mc Pherson, David 99,

McDole, Robert 98, 221

McIntosh, Michelle 153

McLaughlin, Amanda 59,

Meadows, Kevin 18, 161

Meadows, Kimberly 50 ,

Meckley, David 99, 203,

Meyers, Maren 27, 50,

154, 192

Meyers, Ross 68, 228

Michael, Jamie 224

Michael, Joshua 68,178 ,

202

Michaels, Tammy 99

Michaleski, Carin 99

Mick, Brenda 59, 198,

221

Mick, Jeffrey 99

Mick, Nellie Rae 99

Middleswart, Mindy 50

Milec, Mark 68, 218

Miller, Andrea 59

Miller, Annie 257

Miller, Brent 99, 118, 247

Miller, Bryan 99, 178,

220, 233

Miller, Carrie 68,190

Miller, Cheryl 44

Miller, Chris 37

Miller, Douglas 40

Miller, Eugene 8

Miller, Haley 50

Miller, Jeff 19,68

Miller, Kristie 68, 220

Miller, Kyle 99

Miller, Michelle 198, 233,

239

Miller, Nicholas 50

Miller, Sara $100,218,232$

Miller, Shawn 68

Miller, Timothy 23,50

Miller, Virginia 59, 146

Miller, William 59

Mills, David 37,59

Mills, Elizabeth 59, 198

Milne, Lindsey 68, 194

Minnick, Jill 59

Misirian, James 8

Misirian, Joel 100, 216

Mitchell, Diane 203

Mitchell, Jared 68, 223

Mitchell, Lindsey 68, 260

Mitchell, Paul 203

Mitchell, Todd 50, 202
Mix, Jeremy $50,127,137$, 228

Mjavatn, Jonas 59,187

Mobley, Anastasia 68,

192, 224

Modin, Kevin 59, 191

Modock, Alison 68

Mohler, Benjamin 51

Mohler, Tim 177, 224

Mohr, Stephen 59

Moles, Chris 68, 232

Moles, Christopher 171

Moll, Robert 59

Monroe, Allen 40

Monroe, Beverly 202

Montague, Kelly 68, 146, 223

Moodie, John 68, 178

Moodie, Scott 51, 170,

178, 218

Miller, Mindy 99

Moody, Scott 20

Moody, Stephanie 100,

132

Moon, Katie 100

Moore, Beth 51, 250

Moore, Kathryn 100

Moore, Michelle 51, 180,

197, 221

Moran, Michael 68, 240

Moreland, Kurt 38

Morgan, Kelley 68

Morris, Elisabeth 59, 199

Morris, Krista 51, 175

Morris, Phyllis 44

Morris, Rachel 68, 192, 
Murphy, Matthew 128, 129, 232

Murray, Brad 100

Murray, Michaela 100

Musgrave, Angie 59

Musselman, Lavern 44

Musser, Todd 68,153 ,

154, 184, 216

Myczka, Cynthia 51

Myers, Daniel 51

Myers, Jami 51, 189

Myers, Jennifer 68

Myers, John 59, 189

Myers, Sundi 68, 189,

199

1

Nafziger, Jeffrey 68,218 , 232

Naill, Jason 68

Nash, Aimee 17, 59, 223

Natalino, Jordan 51, 189

Natalino, Joseph 51, 189

Ndiang'ui, Roy 59, 225

Nealis, Matthew 51

Neeley, Sandra 100

Neer, Jud 51

Neese, Brad 59, 194, 232

Nehus, Eddie 261

Nehus, Edward 51, 243

Neises, Brian 51, 191

Nelson, Benjamin 51

Nelson, Beth 68

Nelson, Catherine 100 ,

132, 221

Nester, Brian 44, 206

Neu, Jonathan 59, 196

Neuman, Heidi 128,129 , 130

Neuman, Jeffrey 100, 232

Neumann, Heidi 100, 118

Neumann, Kristin 51, 153, 154, 189

New-Day, Tiffany 51

Newell, Heidi 51

Newfeld, Meredith 68

Newman, Stephanie 190

Nicholas, Luann 44

Nichols, Amy 100

Nichols, Bethany 59, 197

Nichols, D. A. 247

Nichols, Kristen 51, 260

Nicol, Heather 51

Nielsen, Lynsa 51

Nihiser, Matthew 178

Noble, Keiko 59, 190

Noble, Patricia 101, 118, 178, 228, 232

Noftz, Isaiah 59

Noftz, Jacob 51

Noll, Matthew 51, 62 ,

185,220

Nolt, Christopher 68

Nolt, Lonnie 59

Nordaas, Benjamin 101, $159,226,240$

Norris, John 212

Norris, Steven 51, 258,

259

Nourse, Julie 244

Nyhuis, Amy 51, 239

Nyveldt, Andrew 68, 146, 225

O'Neal, Jason 59, 186

Ober, Sara 101, 233

Ohtake, Atsuko 101, 154, 196, 225

Olander, Jason 59

Olbrich, Christine 59,

220, 233

Olin, Erika 69, 154, 228

Olson, Gudrun 59, 184

Olson, Jeffrey 69,182

Olson, Michelle 69

Opperman, Julie 69,189 ,

233, 236, 237

Orchard, Paul 39, 260,

261

Orlowski, Alicia 51

Orme, Betty 37

Orme, Carrie $69,114,239$

Ormsbee, David 9

Orr, Kelly 59

Osborne, Christine 51

Osterc, Andrea 101

Osterc, Kerri 69

Overdorf, Timothy 101

Overholt, Joanna 179

Overholt, Joshua 101,

128,179

Overmyer, Joshua 51

Overturf, Jason 69

Oxford, Evan 69

Packard, Jovon 51

Page, Troy 101, 184, 225

Pagnard, Charles 39

Painter, Bonita 59

Palmer, C. Brandon 150

Palmer, Julie 101

Palombo, Matt 69, 161, 220

Paquin, Rachelle 60, 239

Parker, Danielle 60

Parlin, D. Daniel 101, 225

Parr, Katherine 44

Parr, Kristina 60, 203

Parr, Robert 40

Passineau, Wendy 101

Patrick, Jordan 60, 220

Patten, Randy 8

Patten, Rebecca 101

Patterson, Andrea 51, 181

Patterson, Nathan 51

Patton, Jessica 69

Paulik, Jennifer 69,171 ,

228

Pauling, Eric 60, 182

Pauling, Greg 259

Payne, Nathan 101, 118,

132, 199

Payne, Rose 44
Peary, Lisa 101

Pedersen, Matthew 60, 190

Peeler, Grady 60,127 , 161, 200

Peirson, Loren 18

Pel, Mitona 69

Pellowe, Melissa 51

Pendergrass, Lisa 51, 198

Pennell, Melissa 51, 76

Pennington, Jessica 60,

190

Pereira, Janene 51

Perez, Charis 101, 218

Perez, Miriam 60, 197

Perkins, Brandon 69, 161

Perkins, J. Michael 69,

193, 196, 218

Perkins, Kelsey 69, 141, 154

Perlow, David 69

Perry, Christopher 101

Perry, David 102, 264

Perry, Susan 102

Peter, Leah 69

Peterman, Jessica 102

Peters, LaChelle 51

Peterson 76

Peterson, Amy 60, 197

Peterson, Ben 69

Peterson, Holly 102

Peterson, Joel 232, 242,

243, 261

Peterson, Lani 52

Peterson, Lindsay 215, 223

Peterson, Tiffany 60

Petterson, Aaron 195

Pfeiffer, Brett 102,132

Pfeiffer, Jason 52

Pfeiffer, Troy 60, 194

Phelps, Spencer 52, 229

Philip, Jaya 60, 190, 226

Phillips, Douglas 44

Phillips, Edmond 44

Phillips, J. Chris 193

Phillips, Tim 214

Philyaw, Amber 52

Phipps, James 25, 36

Phipps, Sheri 239

Phipps, Terry 40

Pickell, Melinda 102, 169

Pieano, Yvette 220

Pierce, Krista 60

Pierre, Christopher 69, 141, 195

Pierre, Jeremy 22, 52,

$150,151,154$

Pierson, Jason 52, 153 , 154, 191

Pierson, Loren 35, 69

Pierson, Michael 181

Pierson, Ruthanne 18 ,

$102,118,119,141,229$

Pifer, Hilary 102, 217

Pinkley, Dale 69

Piovesan, Dorothy 102, 132
Pitstick, Amy 60

Pittenturf, Christopher

102

Pittman, Deborah 69, 217, 219, 229, 230

Pizano, Yvette 102

Plaatje, Matthew 60

Platt, Casey 60, 201, 220

Ploeg, Jennifer 52, 178

Plummer, Susan 60

Pochop, Wendy 69, 229

Poe, Justin 102

Poelman, Amie 52, 195,

221

Poff, Amanda 69, 160

Pohlman, Lindsay 52

Polgardy, Samantha 102,

132, 221

Policani, Vanessa 52

Poling, Emily 52, 195

Pollard, Amy 60

Pollock, Sarah 52, 198,

243, 260

Pomerleau, Sarah 52

Ponder, Lina 60, 186

Ponzani, Aaron 102, 222

Pool, Christopher 69, 182, 218

Porter, Amanda 52, 244

Porter, Jacob 102, 133

Porter, Phil 69

Porter, Richard 69,102, 200, 222

Postema, Luke 216, 229

Potter, Cynthia 103, 146

Potter, Daniel 52

Potter, John 44

Potter, Karie 52

Pound, Russell 69,200, 240

Powell, Mary 103,180

Powell, Melissa 69, 227

Powell, Nicholas 52, 195

Power, Shawn 201

Powers, Matthew 52, 240,

241

Powley, Christina 52, 222

Prado, Michelle 60

Pratt, Sandra 40

Prentis, Erin 69

Pressdee, Jennifer 52

Preston, Christa 60

Preston, Jeremy 69, 228

Preston, Joseph 103

Price, Daniel 171

Price, Mark 220

Price, Mary 103

Price, Ruth 52

Primo, Angela 60

Prince, Kristen 52, 225

Proper, Marlena 60, 190

Prugh, Ruth 44

Prusha, Timothy 52, 240

Puckett, Rachel 60, 170

Pugh, Kathleen 69, 196

Pugno, Rebekah 52, 192

Pulley, Lewis 69

Purdy, Kelly 103

Purple, Donna 44

Purple, Jonathan 37

Puryear, P.J. 178, 228,

229

Puterbaugh, Jennifer 69

Quint, Jodi 60, 244, 260

Qussar, Joseph 228

Qussar, Naseem 69

\section{$\mathscr{R}$}

Racine, Jesse 60

Radford, Nathan 103, 189 214

Ragle, William 37

Rahilly, Sharon 40

Raines, Scott 69

Rains, Patricia 103

Rainsberger, Daniel 60

Rambo, Jacob 103

Ramsey, Allison 60, 195,

217

Randall, Roger 69,186 ,

232 
ee, Clinton 45

ce, Patrica 132

ce, Patricia 103, 192,

chards, Ginger 141

chardson, Michael 69

chardson, Shay 247

ckard, Donald 9, 127,

ckert, Timothy 52,240

deout, Kimberly 69

gg, Amy 104

ggs, Jack 36

ggs, Joyce 39

ley, Christina 60,189 ,

0,222

naldi, James 45

ngler, Amanda 69

pma, Charisa 52, 179

sing, Christina 104

ttgers, Sarah 60, 182,

tzel, Rebecca 69,202

tzer, Jamie 60

ves, Hannah 60, 193,

25

izer, Adam 60, 228

izer, Charity 104,118 , 19, 202, 227

oberts, Geneva 14,60 , 96

oberts, Micah 104, 118 , 27, 133, 200, 212

oberts, Misty 52

oberts, Shawna 104

obertson, Christopher

$9,178,230$

obertson, Mark 69

obey, Beverly 45

obey, David 38

obin, Christopher 69,

76,197

obinson, Charles 104,

61

obinson, Jasmine 52 ,

92

Robinson, Joanna 52, 150,

54,155

Robinson, Mindy 60

Rocke, Janelle 52, 198

Rockwood, Jeffrey 104 ,

40

Rodriguez, Andrew 170

Roe, Roberta 52, 186, 190

Roesch, Melissa 52, 189

Rogers, Lynn 8

Rohm, Lynn 45, 127

Rohm, Robert 9, 127, 200

Roley, Paul 69

Romang, Sara 104, 118, 150,153

Romeyn, Stacey 60, 154

Romin, Todd 60, 220

Ronczkowski, Sarah 52,

193

Rooke, David 104, 232,

233,240

Ropp, Timothy 52, 146
Rorex, Adam 60, 194, 230

Rose, Joel 60

Rosencrantz, Rene 54,

104

Rosenvold, Darin 104, 222, 232

Rosner, Kristin 69

Ross, Brandon 52, 146

Ross, Erin 69, 229

Ross, Julie 104, 115

Ross, Sherri 52, 198

Rosseau, Brian 60, 176,

190

Rossignol, James 54

Rotman, David 37

Rotman, Douglas 69

Rouse, Wendi 69

Rowe, Tabitha 52

Ruba, Chrystie 104, 124

Ruberg, Maranatha 60 ,

183

Ruby, Carl 37

Rudd, William 8

Ruegsegger, Ann 104,

239

Ruffin, B. Zach 104,133

Ruffin, Casey 60, 201,

218, 250, 251

Ruhlman, Scott 60,242 ,

243, 261

Rummel, Paula 69

Rumphol, Amber 52, 184

Runnion-Gray, Jason 104

Ruoss, Megan 60, 195,

221

Rupp, Joshua 105, 228

Russell, Jayne 45

Russell, Ted 105

Rutila, Paul 199

Rutledge, David 69,222,

240, 241

Ryan, Rachel 60, 190,

191, 200, 221

Ryan, Stephen 69, 222

Rynerson, Jill 105, 224

Sage, Alan 52

Sage, Amanda 52

Salvaggio, Carla 19, 105,

118,233

Salyer, Melissa 69

Sampsel, Brian 52, 187

Samuels, Tina 52

Sanderson, Kimberly 60

Sanderson, Thomas 69,

218

SanGregory, Samuel 38

Sastic, Timothy 52, 259

Saucier, Julie 69,146

Sava, Daniel 69

Savage, Gretchen 60

Saville, Stacy 105, 118,

$120,150,154$

Schaafsma, Jaclyn $\quad 52,198$

Schaefer, Bonnie 70, 233,

256,257
Schaefer, Julie 233,256 , 257

Schafer, Michele 105,182

Schafer, Rachel 70, 146

Schafer, Summer 105,

$146,147,191,228$

Schanher, Stephanie 52,

244

Scharnberg, Lorne 8

Scheffel, Heather 132 ,

236, 237

Scheid, James 70, 146, 147

Schenk, Joel 60

Schield, Christina 60

Schier, Megan 105, 202

Schierloh, Kristin 52

Schlappi, Gabe 222, 259

Schlesener, Brady 52

Schlicher, Sarah 52, 175

Schloegel, Bethany 105

Schmidt, Christine 60,

203

Schmuck, Amanda 52

Schneider, Lindsay 70 , 220

Schuck, Emily 52

Schuler, Dean 70

Schuler, Heather 105

Schulman, Crystal 60

Schultz, Jonathan 105,

194

Schulz, Laura 105, 178

Schumacher, Jeffrey 70 , 226

Schumacher, Robert 40

Schuring, Rebekah 60

Schwartz, Constance 70

Schwartz, Melinda 224

Schweickart, Kimberly

223

Schwinn, Lana 105

Scott, Brett 52

Scott, Christopher 70

Scott, Curt 52

Scott, Dana 105, 118,

$119,132,170$

Scott, Daniel 19, 152,

153, 154, 216

Scott, Dawn 45

Scott, Kimberly 70

Scott, Lisa 60

Scott, Nicole 52

Scott, Rob 199

Scotten, Will 200

Secor, Jennifer 52, 190

See, Tamara 105, 118

Seeley, Jessica 70, 217

Seely, Denver 105, 233

Seigneur, Tim 187

Selin, Stephanie 60

Sell, Jamie 70

Sellers, James 40

Senior, Amanda 106, 212, 220

Sevo, Shane 229

Seyfang, Bethany 70

Seyfert, Tara 70, 221
Shaffer, David 52, 174

Shank, Craig 70, 243

Shank, Joel 137

Shank, Merilee 45

Sharp, Rachel 106, 131,

264

Shaw, Aaron 60

Shaw, Andrew 106, 131, 240

Shaw, Scott 106, 120,

$121,125,170$

Shearer, Jill 61, 227

Sheen, Tabitha 199

Sheldon, Eric 52, 194

Sheldon, Paul 70, 146

Shelford, Rebecca 70, 229

Shellenbarger, Rebecca

52, 146, 178

Shepherd, Michael 61, 170

Sherwood, Abigail 52

Sherwood, Hannah 70,

220

Sherwood, Joshua 61

Shierman, Kenneth 61,

191, 224, 229

Shilling, Karin 106, 186

Shipp, Shawn 106, 232

Shoaff, Courtenay 106,

124,228

Shook, Brian 52, 146, 147

Shortt, Jeffrey 38

Shover, Lesley 106, 132

Shrader, Tamara 221

Shrier, Jeanette 53, 195

Shriver, Melissa 53

Shrubsole, Jon 106

Shrubsole, Judith 40

Shrubsole, Sara 53

Shultis, Adaline 61, 192,

230, 231, 250

Shultz, Laura 131

Shumaker, Erick 70

Shupp, Michael 106

Sicard, Christian 61

Silaghi, Rozalia 45

Silvieus, Sarah 53, 189

Silvius, John 40

Simon, Timothy 106,127 ,

128,232

Simons, Carolyn 39, 219

Simons, Jack 39

Simons, Scott 53

Simons, Steve 19

Sims, Kevin 40

Skamanich, Crystal 53,

195

Skillings, Jared 70, 190,

217

Skillman, Jon 203

Skillman, Katy 203

Skillman, Sylvia 45

Skurdal, Daniel 106, 127,

133

Slates, Stephen 106

Slone, Tammy 45

Small, Kristen 51, 53,

146, 225

Smith, Allyson 106, 229

Smith, Benjamin 45

Smith, Bill 8

Smith, Brittany 61

Smith, Caleb 53, 150, 153

Smith, Chris $61,146,194$, 229

Smith, Darrin 106, 189

Smith, Elizabeth 106,

197, 217

Smith, Galen 37

Smith, Heather 107,146 ,

191

Smith, Jaclyn 61

Smith, Jane 45

Smith, Jedediah 70

Smith, Kristie 61

Smith, Lisa 53, 175

Smith, Michelle 70

Smith, Nathan 53

Smith, Nicole 61,179

Smith, Norris 45, 259

Smith, Sarah 37

Smith, Stephen 61 
Stark, Michael 70, 187

Stark, Neal 107

Stark, Tammy 61,226

Staufer, Timothy 53

Stauffer, Stacy 61, 191, 226

Stedge, John $53,189,190$, 221, 225, 226

Steeg, Susanna 61

Steelman, Erin 70, 192

Steenwyk, Eric 28, 107,

133, 183

Steinmetz, Samuel 61

Stephens, Nathan 61, 183

Stephens, Shawn 53, 192

Stern, Kevin 107

Stern, Ryan 53, 190, 197

Stevens, Albert 8

Stevens, Darin 107, 178, 220

Stevens, Ryan 61, 194

Stevenson, Jessica 201

Steves, David 107, 221

Steves, Deborah 53

Stewart, Beth 120, 121, 195, 225

Stewart, Bill 220

Stewart, Elizabeth 108

Stewart, Rachel E. 61,

199, 221

Stewart, Rachel J. 61

Stewart, William 61

Stiegelmeier, Adam 53

Stitzel, James 53, 179

Stock, Michelle 108, 118

Stock, Shelley 232

Stock, Shelly 128, 129,

130

Stockton, Risha 53

Stone, Alison 15, 108,

114

Stone, David 127

Stone, Deana 45

Stone, Elizabeth 108

Stone, Jodi 61,190

Stone, Stephen 45

Stormont, Rebekah 53

Stout, Aimee 108

Stout, Susan 54, 192

Stover, Jennifer 108

Stowers, Amy 61, 183

Stowers, Rebecca 53, 181

Straits, Christopher 53,

181

Streetman, Stephanie 108

Strong, Brian 53

Strong, Daniel 61

Strong, Jeremy 108

Strong, Randall 108, 169

Strong, Steven 70

Stroven, Abigail 19, 108, 181

Strubhar, Heidi 53

Strunk, Jennifer 61

Struz, Dawn 53

Strychalski, Christopher

108, 114

Strychalski, Jill 53, 146,
147

Strychalski, Joshua 70 ,

222

Stryker, Jenny $\quad 61,184$

Stuart, Bill 212

Stuenzi, Erin 70

Stuenzi, Jessica 108, 132, 190, 219

Stumbo, Melissa 70

Stumpf, Aaron 247

Stutes, Patty 45

Stutzman, Ben 261

Stutzman, Ben H. 61, 232

Stutzman, Benjamin C.

108

Stutzman, Beth 195

Stutzman, Matt 108

Sulish, Jason 108

Summers, Becky 256, 257

Summers, Rebecca 61, 233

Summers, Shauna 108,

217

Sutherland, Bob 200

Sutherland, Lori 200

Sutter, Suzanne 109

Sutter-Tkel, Cynthia 40

Sutton, Timothy 53, 146, 226, 228

Svendsen, Eric 61, 232

Swales, Sandra 61, 225,

233

Swales, Sandy 260

Swaney, Tara 61, 244,

245

Swartz, Ann 61, 198

Swartz, Janelle 61

Swartzentruber, Kathy 53, 243

Sweeney, Lauren 53, 177

Sweet, Nicole 230

Sweetser, Wesley 38

Swenson, Paul 61

Swigart, Roger 200, 240

Swiger, Tonya 61

Swota, Juliene 53

Synder, Matt 228

\section{T}

Tabberer, Brenda 109 , 115, 176, 229

Tackett, Joshua 70, 240

Tait, Douglas 61

Talladay, Jay 70

Tallarita, Teresa 61

Tapp, Letitia 53

Tate, Philip 146, 147, 182

Tatum, Scott 61

Taylo, Christy 260

Taylor, Brooke 109

Taylor, Christy 70, 199,

207, 221, 233, 242, 243

Taylor, Gretchen 109, 244

Taylor, Joel 53

Taylor, Matthew 224,

233, 252, 253

Taylor, Stacy 61,187
Tegtmeier, Jennifer 70 , 227

Tehan, David 53

Temmesfeld, Daniel 109

Terkelsen, Susan 45

Thaman, Patrick 53

Tharngan, Rebecca 61, 193, 226

Tharp, Michael 53, 240

Thayer, Katrina 61

Thirey, Benjamin 109

Thirey, Micah 61, 194

Thomas, Nicole 70, 170, 225

Thomas, Sarah 61, 260

Thomas, Scott 109, 133

Thompson, Adam 70

Thompson, Becky 181

Thompson, Ben 261

Thompson, Benjamin $\mathrm{H}$.

70, 233

Thompson, Benjamin M.

$61,201,242,243$

Thompson, Elaine 53

Thompson, Gregory 109, 225

Thompson, Jody 61, 233, 260

Thompson, Lisa 239

Thompson, Matthew 109,

203, 225, 233

Thompson, Patricia 61

Thompson, Rebekah 53

Thompson, Thomas 38

Thomson, Brian 61

Thomson, Lisa 70

Thorsen, Philip 53, 147, 202

Throop, Deanna 40

Tidwell, Jonathan 53

Tiel, Jennifer 70

Tilton, Rachel 236

Timco, Erin 70

Tocknell, John 45

Tocknell, Paul 53

Tojdowski, Brian 217,

229

Tomkinson, Sara 53

Tompkins, Jim 259

Toms, Russell 53, 233

Tong, Jennifer 53

Tovey, Jason 61, 114,

171,240

Townsend, Jill 26, 70,71, 146, 202, 219, 227

Townsend, Sarah 109

Townsend, Timothy 61

Toyer, Jeremy 109, 232

Toyer, Lee Anne 61

Treadwell, Mark 61, 178

Trimble, James 61

Troike, Erin 61, 142

Tromp, Joshua 61,219

Trost, Trisha 109, 181

Troupos, Christopher 70

Trout, Julie 61, 189, 220

Troyer, Jennifer 53

Troyer, Jeremy 220

Troyer, Marv 221
Trylick, Aaron 61

Tucholski, Nicholas 53

Tucker, Amber 53

Tuinstra, Erin 61, 196, 231

Turkis, Rachel 61, 228

Turner, Cooley 45

Turner, Jonathan 70

Twigg, Esther 62, 220, 225

Tyler, Donald 8

Tyson, Angela 62, 190, 220

Tyson, Carrie 70

Tyson, Heather 62, 187

Tyson, Kelly 146

Umland, Brad 109, 225, 233

\section{Q6}

Upham, Rebecca 70, 169,

223,232

Urban, Jennifer 53

Urbassik, Ryan 70, 197

$\mathscr{V}$

Valade, Megan 62

Valdes, Jeff 225

Valiknac, Tracy 62, 198

Vallowe, Erin 53, 195

Van Gorp, Heather 146

Van Hooser, Krista 53

Van Loo, Scott 109, 137, 222

Vandegrift, Scott 109 ,

118,137

Vander Bush, Jennifer

$109,154,227$

Vanderground, Rebecca 70

Vanlier, Michele 62, 203,

233

Variage, Abigail 220

Vaughan, Ryan 53

Vaught, Bethany 110

Vawter, Ben 120,121,

146, 147

Vawter, Reuben 110

Venable, Ruth 53

Vencill, Beth 70, 185, 202

Verwys, Nathan 259

Vigeant, Cheri 189

Vine, Kitty 45

Vitali, Neil 62

Vitarelli, Christopher 110 , $118,120,128,152,153$,

216

Vitarelli, Rebecca 53, 178

Voigt, Jared 70, 146, 177

Voigt, Rebecca 110

Volpe, Amy 110

Volpe, Rachel 62

Vore, Rhonda 110,219

Voumard, Bradley 70 ,

218

Waardenburg, Ty 62,18

Wabeke, Melissa 70, 19

Waddell, Laura 70, 180

Waddington, Leann 110

132

Wade, Michael 62, 182,

229

Wadlington, Melanie 6 195, 221

Waechter, Holly 70,146

Wagner, Jessica 62,152

153

Wagner, Lindsay 62

Wagner, Trudee 45

Wakefield, Steve 243, 2

Walberg, Karissa 53, 76

Walcott, Catherine 70

Waldock, Kenneth 53, 158

Waldock, Nathan 226

Walker, Becky 202

Walker, Bethany 70, 174

Walker, Lisa 70, 229, 23 
eaver, Jenni 187,195 ,

ber, Andrea 54, 146, 9,193

eber, Emily 71, 191, 2, 227

eber, Jason 71

eber, Laurie 110,118

eber, Rhonda 110, 169

eber, Steve 120,121

eber, Tami 71, 226

eber, Tracy 111, 132, 1

ebster, Joy 111, 223

eeks, Ann 71, 146,

2, 217, 229

eidler, Emily 62,226 , 28

einert, Stacie 54, 175, 21

eise, Carl 71, 195, 225,

53

Veisert, Christine 229

Velner, Robert 111

endler, Kristil 54

Venger, Michael 71, 194

Veniger, Edward 190,

94

Ventz, Eric 54, 177

Venzel, Angela 111,

$37,153,154$

Vest, Jennifer 62,197

Vest, Linda 45

Vest, Nellie 45

Vest, Susan 111, 169

Vetzel, Angie 15

Netzel, Daniel 36

Vetzel, Phyllis 45

Neygand, Nathan 54

Whaley, Jeremy 215
Whaley, Vernon 39

Wheatley, Christina 54, 146

Wheeler, Amanda 54

Wheeler, Charles 111

Wheeler, Lorraine 62

Whinnery, Joseph 111 , 115,133

White, Adam 111, 127, 128

White, Carrie 71

White, Erica 183

Whitely, Lisa 54

Whitlock, Heather 54

Whitmore, John 40

Whitney, Sarah 14, 71,

225

Whitson, Kendra 71

Whitt, Alisa 71, 170

Whitten, Alissa 111, 232

Whygle, Danielle 62

Wick, Jared 111, 201

Wickholm, P. Joy 111, 115, 118, 216, 228, 229, 231

Wickholm, Sharon 62

Wiersma, Sara 62,177

Wiesert, Christine 71

Wiggins, Robert 40

Wilbur, Brian 252, 253

Wilder, Amy 111, 181

Wilder, Justin 71

Wiljamaa, Emily 111,

$197,217,232$

Wilkins, Julie 54

Wilkins, Nicole 197

Williams, Alissa 71, 202,

236

Williams, Amy 54

Williams, Jackie 62,247
Williams, Joshua 54

Williams, Joy 45,244

Williamson, Jennifer 111

Williamson, Mark 62

Willis, Jennifer 54, 230

Willis, Roddy 240

Willis, Roderick 54

Wilmer, Loring 62

Wilson, Amber 223

Wilson, David 62, 194,

224

Wilson, Holly 111,132 ,

199

Wilson, Sheri 111,124 ,

184,220

Wilson, Stephanie 71

Winar, Julie 54, 197, 221

Winburn, Megan 54

Wing, Jason 71

Wingert, Braden 71

Winkels, Margueritte 62

Winn, David 112

Winn, Jonathan 170

Wires, Julie 112

Wiseman, Ryan 224

Wishart, Jamie 62

Wishart, Jennifer 62,201

Wita, Adrienne 54

Witherell, Neil 62

Withers, Bethany 62

Witmer, Jonathan 112

Witte, Jill 112, 132, 221

Witters, Adam 112

Wohrle, Kristin 112

Wolf, David 54

Wolf, Katherine 71

Wolfe, Aaron 71

Wolfe, Beth 250

Wolfe, Elizabeth 62, 195, 203
Wolfe, Mary 112, 132

Woller, Miranda 62, 236

Wolters, Jan-Harm 28,

219

Womack, Glenda 45

Womack, Jay 45

Womack, Mark 45

Wood, Casey 257

Wood, Duane 9,127

Wood, Justin 217

Wood, Krista 229, 230

Wood, Lisa 118, 236, 237

Wood, Mark 40, 112, 131,

232, 233, 259

Wood, Sharon 45, 127

Wood, Terra 54

Woodard, Sherri 112, 217

Woodman, Andrew 112

Woods, Deborah 112

Woods, William 71, 225

Woodyard, Donnie 219

Wooten, Amy 54, 190, 199

Word, Krista 62, 203

Worhle, Kristin 19

Workman, Susanna 62,

175,187

Workman, William 112,

240

Wortman, Tami 54, 146

Wren, Cindy 71

Wrigglesworth, Elizabeth

112

Wrigglesworth, Scott 112

Wright, Jana 71, 193, 217

Wright, Nathan 71

Wright, Suzanne 112

Wright, Thomas 71

Wright, Tomas 193

Wright, Tracie $81,112,132$

Wu, Jonathan 113,118 ,
$119,123,133,232$

Wyma, Daniel 113, 133,

201

Wyrtzen, Jaime 54, 218,

232

Wyse, Mark 62, 143

If

Yahara, Shelley 54, 183, 199, 225

Yankovich, Kevin 71

Yinger, Randy 71

Yingling, Laurie 71

Yoder, Amanda 238, 239

Yoder, J. Michael 113,

184, 216, 233

Yoder, Kenneth 54

Yoder, Michael 71

Young, Kevin 71, 218

Young, Kristy 71

Young, Lissa 54, 185, 187,220

\&

Zaugg, Jason 54

Zavodney, Lawrence 36

Zeeb, Michelle 113

Zehr, Jamie 71

Ziegenfuss, Andy 169,

215,222

Ziegenfuss, Leah 236

Ziel, Troy 54

Zimmerman, Tiffany 19 , 113, 118, 265

Zimmermann, Amy 221

Zinz, Angela 71

Zirke, Tiffany 71

Zuiderveen, Christina 113

Zwar, Katie 62,185

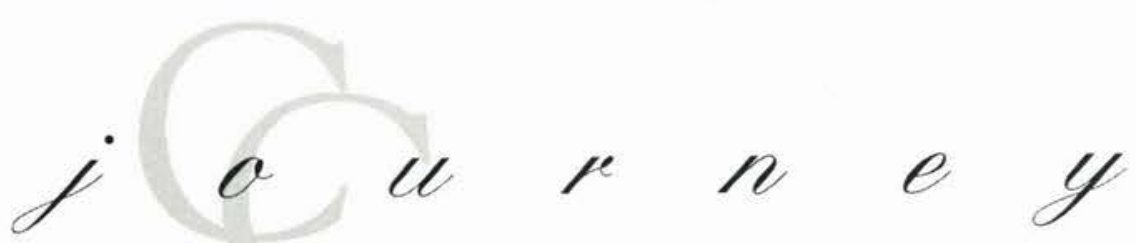


JOSTENS 




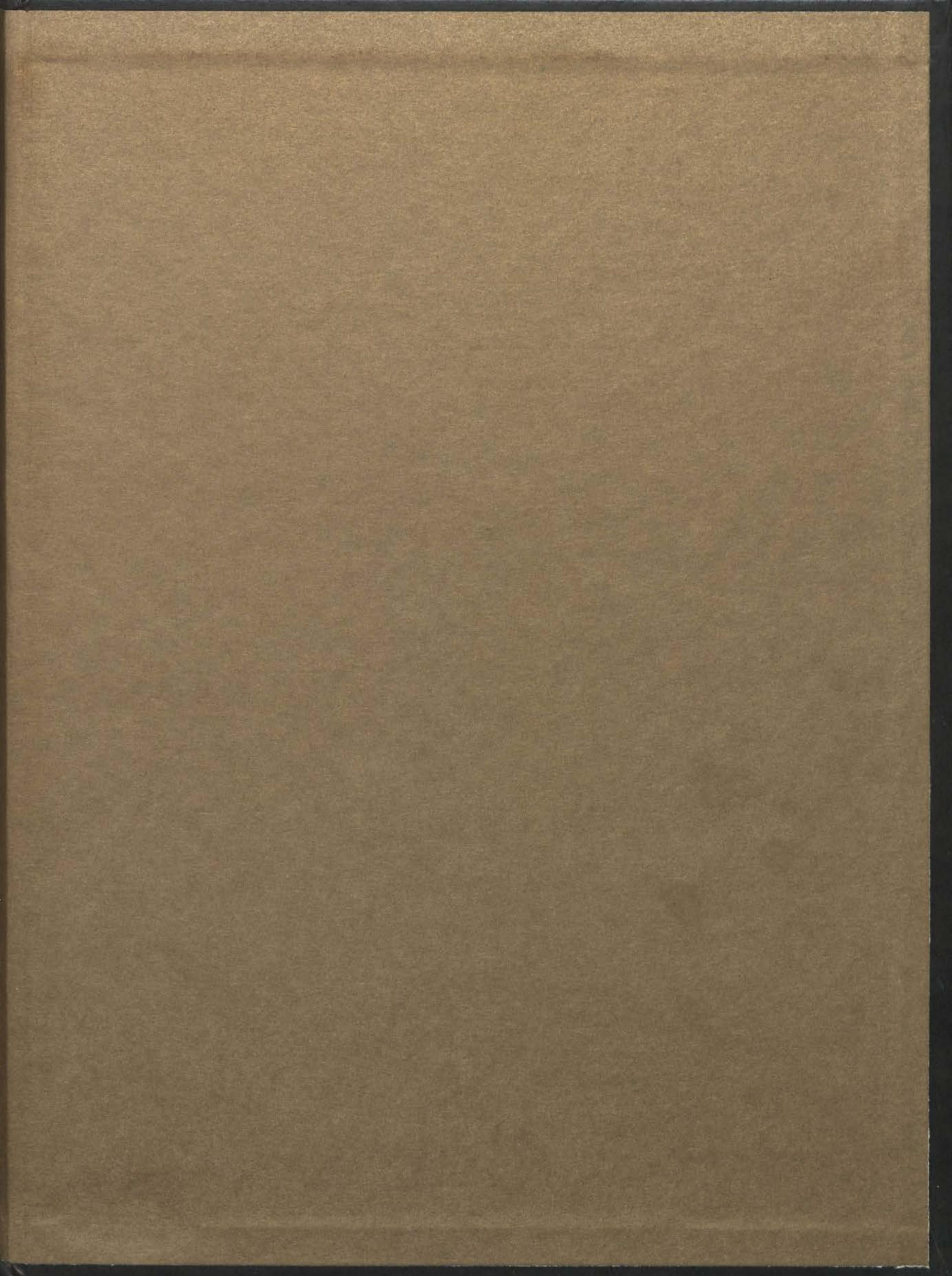


